Historic, Archive Document

Do not assume content reflects current scientific knowledge, policies, or practices. 

ftr?

United States

Agriculture

Forest Service

Intermountain

Research Station

General Technical

Report INT-227

\section{Gross Characteristics \\ of Lodgepole \\ Pine Trees}

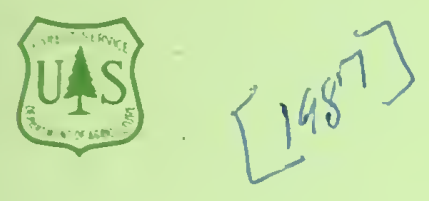

\section{in North America}

ic Peter Koch,

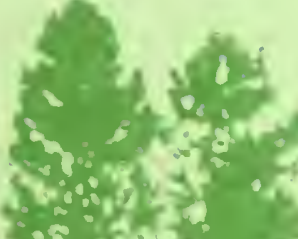

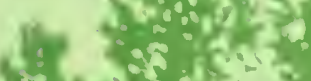

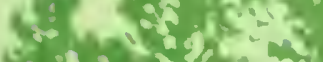

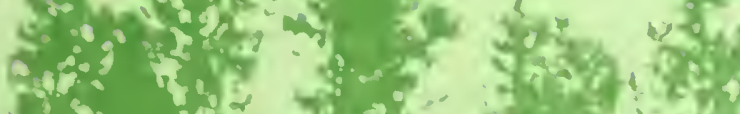

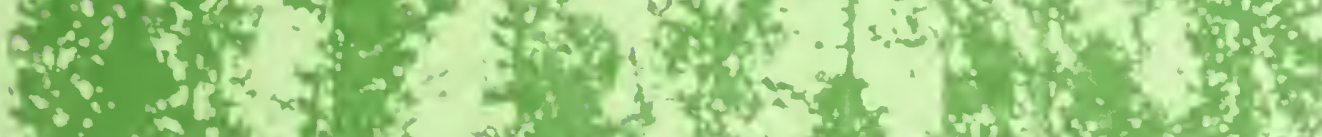

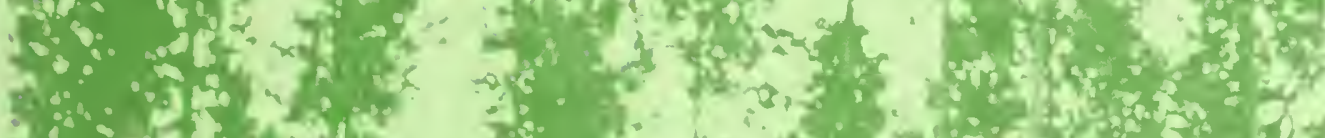
$\because$ ats.

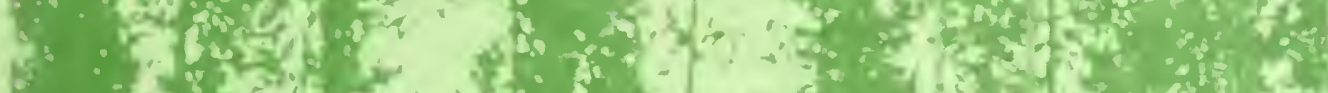

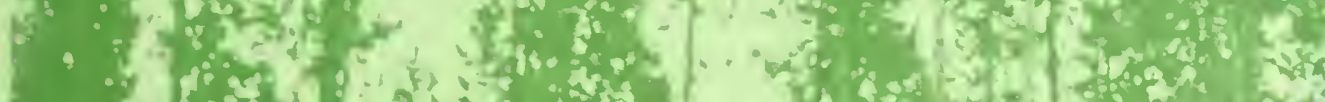

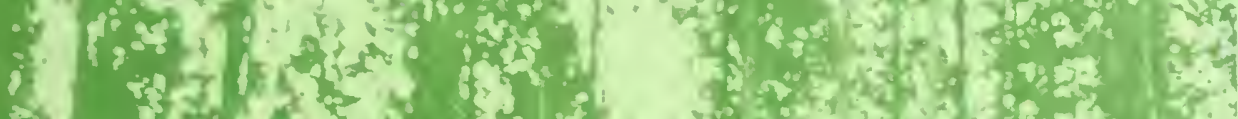
a of t.

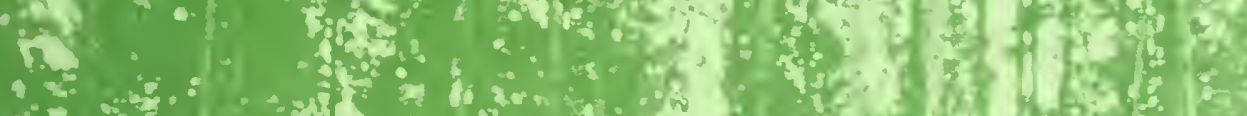

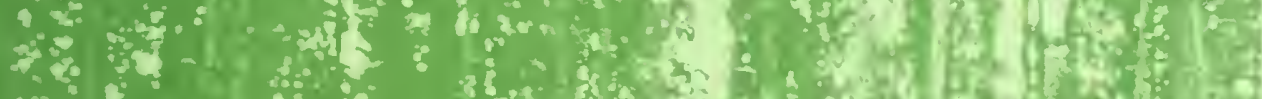

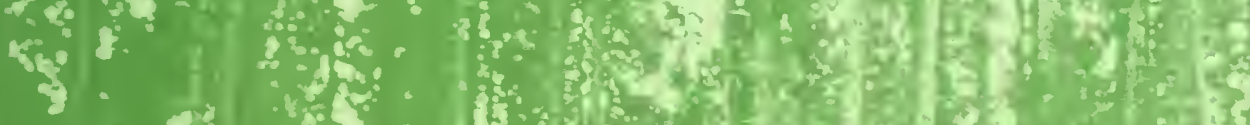

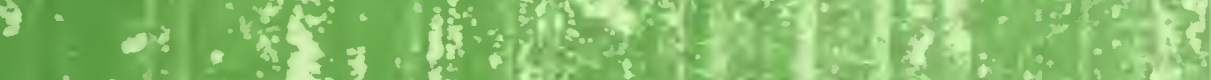
$\therefore$ a 3 (t)

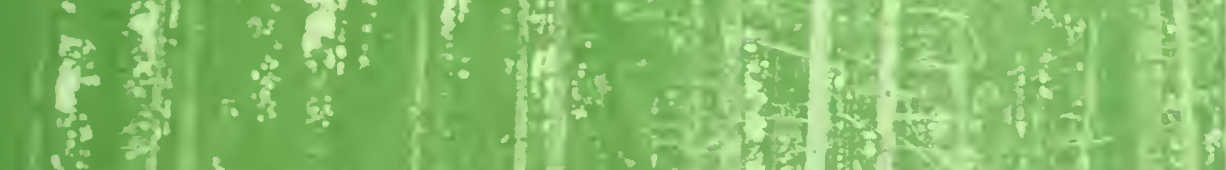
$1: 71$,

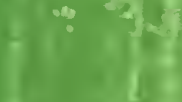
$f=\frac{1}{1}$ $f=1$ 10 . 글

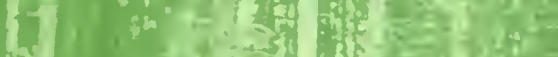
is (1)

$d^{2}$ $x^{2}$

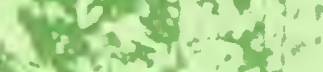

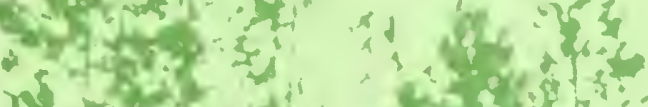
if 4 osom वit sto 


\section{THE AUTHOR}

PETER KOCH is currently president, Wood Science Laboratory, Inc., Corvallis, MT 59828. At the time the specimen collection was made he was chief wood scientist with the Intermountain Research Station, Forest Service, U.S. Department of Agriculture, Ogden, UT, stationed at the Forestry Sciences Laboratory, Missoula, MT.

\section{ACKNOWLEDGMENTS}

This report was written under contract with the University of Montana, Missoula. The author appreciatively acknowledges the work of Joyce Schlieter, who made the needed statistical analyses and produced the computerplotted charts.

\section{CONTENTS}

Chapter 1: Tree Characteristics, Dimensions, and

Cubic Volumes ..................... 1

Chapter 2: Moisture Content of Tree Components....................... 76

Chapter 3: Stem Taper . . . . . . . . . . . . . . . . 116

Chapter 4: Specific Gravities and Weights of Tree Components..................... 132

Chapter 5: Distribution, Moisture Content, Weight, and Specific Gravity of Heartwood and Sapwood

AD-8s Bookplate

$(1-\infty)$

NATIONAT

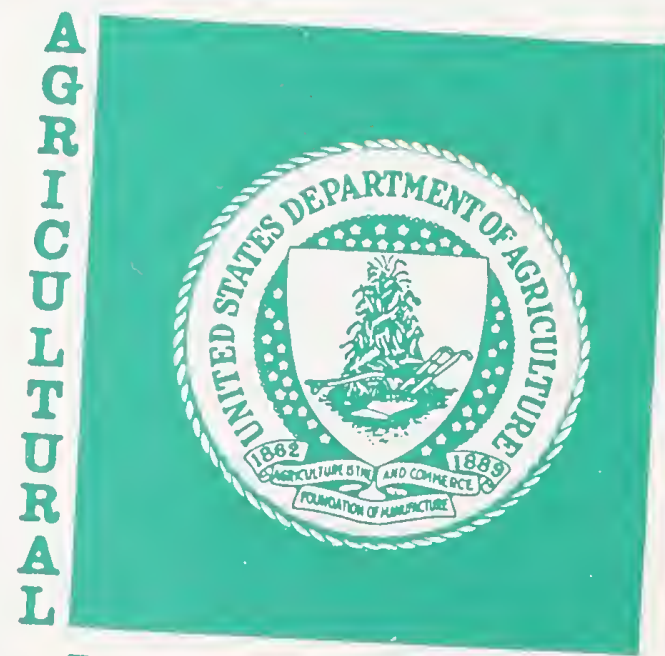

LIBRARY

August 1987

Intermountain Research Station

324 25th Street

Ogden, UT 84401 


\section{METRIC CONVERSION FACTORS}

\begin{tabular}{|c|c|c|c|c|c|}
\hline \multicolumn{3}{|c|}{ English units to metric } & \multicolumn{3}{|c|}{ Metric units to English } \\
\hline \multicolumn{6}{|c|}{ LENGTH } \\
\hline 1 in & $=$ & $25.4 \mathrm{~mm}$ (exactly) & $1 \mathrm{~mm}$ & $=$ & $0.0393701 \mathrm{in}$ \\
\hline 1 in & $=$ & $2.54 \mathrm{~cm}$ (exactly) & $1 \mathrm{~cm}$ & $=$ & $0.393701 \mathrm{in}$ \\
\hline $1 \mathrm{ft}$ & $=$ & 0.3048 m (exactly) & $1 \mathrm{~m}$ & $=$ & $3.28084 \mathrm{ft}$ \\
\hline $1 \mathrm{yd}$ & $=$ & 0.9144 m (exactly) & $1 \mathrm{~m}$ & $=$ & $1.09361 \mathrm{yd}$ \\
\hline 1 chain (22 yd) & $=$ & 20.1168 m (exactly) & $1 \mathrm{~m}$ & $=$ & 0.0497097 chain \\
\hline $1 \mathrm{mi}$ & $=$ & $1.60934 \mathrm{~km}$ & $1 \mathrm{~km}$ & $=$ & $0.621371 \mathrm{mi}$ \\
\hline \multicolumn{6}{|c|}{ AREA } \\
\hline $1 \mathrm{in}^{2}$ & $=$ & $645.16 \mathrm{~mm}^{2}$ (exactly) & $1 \mathrm{~mm}^{2}$ & $=$ & $0.0015500 \mathrm{in}^{2}$ \\
\hline $1 \mathrm{in}^{2}$ & $=$ & $6.4516 \mathrm{~cm}^{2}$ (exactly) & $1 \mathrm{~cm}^{2}$ & $=$ & $0.15500 \mathrm{in}^{2}$ \\
\hline $1 \mathrm{ft}^{2}$ & $=$ & $0.0929030 \mathrm{~m}^{2}$ & $1 \mathrm{~m}^{2}$ & $=$ & $10.7639 \mathrm{in}^{2}$ \\
\hline $1 \mathrm{yd}^{2}$ & $=$ & $0.836127 \mathrm{~m}^{2}$ & $1 \mathrm{~m}^{2}$ & $=$ & $1.19599 \mathrm{yd}^{2}$ \\
\hline 1 mil-acre & $=$ & $4.04686 \mathrm{~m}^{2}$ & $1 \mathrm{~m}^{2}$ & $=$ & 0.247105 mil-acre \\
\hline 1 acre & $=$ & 0.404686 ha & $1 \mathrm{ha}$ & $=$ & 2.47105 acres \\
\hline $1 \mathrm{mi}^{2}$ & $=$ & $2.58999 \mathrm{~km}^{2}$ & $1 \mathrm{~km}^{2}$ & $=$ & $0.386102 \mathrm{mi}^{2}$ \\
\hline \multicolumn{6}{|c|}{ VOLUME OR CAPACITY } \\
\hline $1 \mathrm{in}^{3}$ & $=$ & $16,387.064 \mathrm{~mm}^{3}$ & $1 \mathrm{~mm}^{3}$ & $=$ & $0.000061024 \mathrm{in}^{3}$ \\
\hline $1 \mathrm{in}^{3}$ & $=$ & $16.38706 \mathrm{~cm}^{3}$ & $1 \mathrm{~cm}^{3}$ & $=$ & $0.061024 \mathrm{in}^{3}$ \\
\hline $1 \mathrm{ft}^{3}$ & $=$ & $0.0283168 \mathrm{~m}^{3}$ & $1 \mathrm{~m}^{3}$ & $=$ & $35.3147 \mathrm{ft}^{3}$ \\
\hline $1 \mathrm{yd}^{3}$ & $=$ & $0.764555 \mathrm{~m}^{3}$ & $1 \mathrm{~m}^{3}$ & $=$ & $1.30795 \mathrm{yd}^{3}$ \\
\hline 1 cunit $\left(100 \mathrm{ft}^{3}\right.$ & & & & & \\
\hline of solid wood) & $=$ & $2.83168 \mathrm{~m}^{3}$ & $1 \mathrm{~m}^{3}$ & $=$ & 0.353147 cunit \\
\hline 1 cord $(128$ & & & & & \\
\hline stacked $\mathrm{ft}^{3}$ ) & $=$ & $3.62456 \mathrm{~m}^{3}$ (stacked) & $1 \mathrm{~m}^{3}$ (stacked) & $=$ & 0.275896 cord \\
\hline $1 \mathrm{bd} \mathrm{ft}$ & $=$ & $0.002359738 \mathrm{~m}^{3}$ & $1 \mathrm{~m}^{3}$ & $=$ & $423.7759 \mathrm{bd} \mathrm{ft}$ \\
\hline 1 gal (US) & $=$ & $3.785412 \mathrm{~L}$ & $1 \mathrm{~L}$ & $=$ & 0.264172 gal (US) \\
\hline \multicolumn{6}{|c|}{ MASS OR WEIGHT } \\
\hline 1 grain & $=$ & $0.064799 \mathrm{~g}$ & $1 \mathrm{~g}$ & $=$ & 15.4324 grains \\
\hline $1 \mathrm{oz}$ & $=$ & $28.3495 \mathrm{~g}$ & $1 \mathrm{~g}$ & $=$ & $0.0352740 \mathrm{oz}$ \\
\hline $1 \mathrm{lb}$ & $=$ & $0.453592 \mathrm{~kg}$ & $1 \mathrm{~kg}$ & $=$ & $2.20462 \mathrm{lb}$ \\
\hline 1 ton (short) & $=$ & $907.1847 \mathrm{~kg}$ & $1 \mathrm{~kg}$ & $=$ & $\begin{array}{l}0.0011023 \text { ton } \\
\text { (short) }\end{array}$ \\
\hline 1 ton (short) & $=$ & $0.907185 \mathrm{t}$ & $1 \mathrm{t}$ & $=$ & $\begin{array}{l}1.10231 \text { tons } \\
\text { (short) }\end{array}$ \\
\hline 1 ton (long) & $=$ & $1.01605 t$ & $1 \mathrm{t}$ & $=$ & 0.98420 ton (long) \\
\hline \multicolumn{6}{|c|}{ RATIOS } \\
\hline $1 \mathrm{ft}^{2} /$ acre & $=$ & $0.229568 \mathrm{~m}^{2} / \mathrm{ha}$ & $1 \mathrm{~m}^{2} / \mathrm{ha}$ & $=$ & $4.35600 \mathrm{ft}^{2} / \mathrm{acre}$ \\
\hline $1 \mathrm{ft}^{3} /$ acre & $=$ & $0.0699725 \mathrm{~m}^{3} / \mathrm{ha}$ & $1 \mathrm{~m}^{3} / \mathrm{ha}$ & $=$ & $14.2913 \mathrm{ft}^{3} /$ acre \\
\hline 1 cord/acre & $=$ & $\begin{array}{l}8.95647 \mathrm{~m}^{3} \\
\text { (stacked)/ha }\end{array}$ & $\begin{array}{l}1 \mathrm{~m}^{3} \\
\text { (stacked)/ha }\end{array}$ & $=$ & $0.111651 \mathrm{cord} / \mathrm{acre}$ \\
\hline $1 \mathrm{lb} / \mathrm{ft}^{3}$ & $=$ & $16.0185 \mathrm{~kg} / \mathrm{m}^{3}$ & $1 \mathrm{~kg} / \mathrm{m}^{3}$ & $=$ & $0.0624280 \mathrm{lb} / \mathrm{ft}^{3}$ \\
\hline 1 ton (short)/acre & $=$ & $2.24170 \mathrm{t} / \mathrm{ha}$ & $1 \mathrm{t} / \mathrm{ha}$ & $=$ & $\begin{array}{l}0.446090 \text { ton } \\
\text { (short)/acre }\end{array}$ \\
\hline $1 \mathrm{mi} / \mathrm{gal}$ (US) & $=$ & $0.425143 \mathrm{~km} / \mathrm{L}$ & $1 \mathrm{~km} / \mathrm{L}$ & $=$ & $2.35215 \mathrm{mi} / \mathrm{gal}$ (US) \\
\hline
\end{tabular}




\section{RESEARCH SUMMARY}

In the primary study three replications of disease- and insect-free specimens of 76-, 152-, and 228-mm diameter at breast height (d.b.h.) Pinus contorta var. latifolia Engelm. were collected in low-, medium-, and highelevation zones (for the latitudinal zone) from nine equally spaced north latitudes (40 through 60 degrees) across 10 degrees of longitude in such a way as to encompass the major range of latifolia. Latitudinal and elevational-but not longitudinal-effects on tree characteristics were pronounced.

In a secondary study to examine variations in murrayana characteristics, three replications of 76-, 152-, and 228-mm Pinus contorta var. murrayana (Grev. \& Balf.) Engelm. were collected at medium elevation at four latitudes (37.5, $40,42.5$, and 45 degrees) in California and Oregon at a single longitude per latitude. Also, varietal differences between latifolia and murrayana were studied in the three latitudes common to the two (40,42.5, and 45 degrees).

\section{Tree Characteristics, Dimensions, and Cubic Volumes}

Because stemwood characteristics of var. latifolia are of primary interest to those who process lodgepole pine, averages for a few of the basic characteristics of this variety are shown in the following tabulation; readers are cautioned, however, that values for these characteristics vary significantly with latitude and elevational zone, as well as diameter.

\begin{tabular}{|c|c|c|c|}
\hline \multirow{2}{*}{$\begin{array}{l}\text { Stemwood } \\
\text { characteristic }\end{array}$} & \multicolumn{3}{|c|}{ Diameter at breast height } \\
\hline & $76 \mathrm{~mm}$ & $152 \mathrm{~mm}$ & $228 \mathrm{~mm}$ \\
\hline $\begin{array}{l}\text { Age at stump height, } \\
\text { years }\end{array}$ & 71 & 91 & 107 \\
\hline $\begin{array}{l}\text { Ring width at stump } \\
\text { height, millimeters }\end{array}$ & 0.67 & 1.01 & 1.33 \\
\hline $\begin{array}{l}\text { Moisture content, } \\
\text { percent }\end{array}$ & $-\ldots$ & $\ldots 99--$ & $\ldots .$. \\
\hline $\begin{array}{l}\text { Specific gravity, } \\
\text { stemwood average }\end{array}$ & 0.43 & 0.42 & 0.41 \\
\hline Tree height, meters & 9.3 & 15.6 & 19.1 \\
\hline $\begin{array}{l}\text { Stem length below } \\
\text { crown, meters }\end{array}$ & 5.0 & 8.8 & 10.9 \\
\hline $\begin{array}{l}\text { Stem taper inside bark, } \\
\text { below crown, } \\
\text { millimeters per meter }\end{array}$ & 6.3 & 7.8 & 10.5 \\
\hline $\begin{array}{l}\text { Stem taper inside bark, } \\
\text { within crown, millimeters } \\
\text { per meter }\end{array}$ & 13.1 & 15.9 & 18.5 \\
\hline
\end{tabular}

Of all the tree characteristics measured, d.b.h. and stump-root system dimensions were most closely correlated with other tree characteristics. Latifolia trees 76-, 152-, and 228-mm d.b.h. averaged 71, 91, and 107 years old, respectively, at stump height of $152 \mathrm{~mm}$. The mediumelevation zone for latifolia decreased from about 2,700 m at latitude 40 degrees to about $750 \mathrm{~m}$ at 60 degrees. The three diameter classes averaged 9.3,15.6, and $19.1 \mathrm{~m}$ in height; trees were tallest in latitudes 50 through 55 degrees. Crown ratio was unrelated to d.b.h., and averaged 0.46 for the 243 latifolia trees sampled. Stem length below crown averaged $5.0,8.8$, and $10.9 \mathrm{~m}$ for the three diameter classes.

Stem crook (sweep) between 10 and 70 percent of tree height was unrelated to d.b.h. and averaged $43 \mathrm{~mm}$. The number of live branches per tree averaged 64,108 , and 133 for trees 76-, 152-, and 228-mm d.b.h.; mean branch diameters were 9,13 , and $19 \mathrm{~mm}$, respectively, with branch angles averaging 85,79 , and 77 degrees. The number of dead branches per tree averaged 57, 100, and 119. Stem diameter at the base of the live crown averaged 52,100 , and $148 \mathrm{~mm}$ for the three diameter classes. Only 191 of the 243 trees had cones on the tip $305 \mathrm{~mm}$ of the top 25 branches. Southern latitudes had more open-coned trees than northern latitudes. The proportion of completetree wood volume comprised of wood from each tree portion averaged as follows: stem to apical tip, 82 percent; live branches, 4 percent; dead branches, 2 percent; and stump-root system to $305 \mathrm{~mm}$ radius from stump pith, 12 percent. The bark percentage of gross (wood plus bark) volume of each tree portion averaged as follows (diameter data pooled): stem to apical tip, 11.3 percent; live branches, 37.8 percent; and stump-root system, 14.0 percent.

Varietal differences between latifolia and murrayana in the latitudes common to the two ( 40 to 45 degrees) were not major, except that latifolia bore significantly more cones than murrayana. All of the murrayana trees were classified as open-coned, whereas 15 to 50 percent of the latifolia trees at these latitudes were classified as closedconed. Live branch diameter averaged $2 \mathrm{~mm}$ less, and branch angle several degrees larger, in murrayana trees than in latifolia. Live branchbark percentage of gross live branch volume was greater in murrayana than in latifolia.

\section{Moisture Content of Tree Components}

The moisture contents of components of lodgepole pine trees of varieties latifolia and murrayana are strongly related to latitude and diameter, but less related to elevational zone. Longitudinal zone was studied only for latifolia, but no effects were discernible.

Differences between the moisture contents of tree components of latifolia and murrayana were minor-most related to bark moisture contents; in latitudes $40,42.5$, and 45 degrees latifolia bark moisture content tended to be positively correlated with latitude, whereas bark moisture of murrayana was negatively correlated with latitude.

Throughout the full range of latitude (40 to 60 degrees) in which latifolia moisture contents were studied, however, there was a pronounced decrease in latifolia treecomponent moisture content from south to north. Maximum moisture contents usually occurred at latitude 42.5 or 45 degrees, and minimums were observed between 52.5 and 60 degrees. For example, stemwood moisture content (diameter data pooled) averaged 124 percent at 42.5 degrees and only 83 percent at 60 degrees. Similarly, stembark moisture content averaged 131 percent at 45 degrees but only 80 percent at 52.5 degrees. 
Moisture contents of the following components were inversely correlated with d.b.h. (that is, moisture contents were higher in trees $76 \mathrm{~mm}$ in d.b.h. than in trees of larger diameter): complete trees (with or without foliage), foliage, stembark, heartwood, and wood and bark of the stumproot system. Sapwood, however, had higher moisture content in trees of large diameter than in those of small diameter.

The moisture content of both wood and bark increased sharply from stump height to upper stem; the increase was greater in bark (72 to 165 percent) than in wood (90 to 130 percent).

Moisture contents of tree components were most closely and most frequently correlated with specific gravity of wood and bark of components, heartwood percentage of stemwood volume, sapwood thickness at stump height, and with crown ratio.

Tree average moisture contents (all latifolia data pooled) for tree components were generally in the range from 90 to 110 percent of ovendry weight, with exceptions as follows: cones (26 percent), dead branchwood (18 percent), sapwood (119 percent), heartwood (43 percent), and bark of lateral roots (121 percent).

Significant variations related to latitude, d.b.h., elevational zone, and height in tree are so large, however, that variety-wide generalizations about average moisture contents of tree components should be made with caution.

\section{Stem Taper}

Stems of large-diameter latifolia and murrayana trees flared more in the butt section than those of smaller diameter-both inside and outside bark. Below-crown average stemwood taper averaged $8.2 \mathrm{~mm} / \mathrm{m}$ (3.6 standard deviation) for latifolia and $9.5 \mathrm{~mm} / \mathrm{m}$ (4.7) for murrayana; in both, this taper was positively correlated with d.b.h. Latifolia trees $228 \mathrm{~mm}$ in d.b.h. from high elevational zones had more below-crown stemwood taper than those from medium or low zones. Latifolia trees in Canadian latitudes had less below-crown stemwood taper than those in United States latitudes. Least below-crown taper was found in small-diameter, slow-grown trees with little foliage, small branches, narrow crowns, thin bark, and small central stump-root systems.

Within-crown stemwood taper was also positively correlated with d.b.h., but was much greater than below-crown taper; it averaged $15.8 \mathrm{~mm} / \mathrm{m}$ (4.1) for latifolia and 15.7 (4.8) for murrayana. Trees from high-elevation zones had more within-crown stemwood taper than those from low and medium zones. Within-crown stemwood taper in latifolia averaged least in the middle latitudes (45 to 50 degrees). For all latifolia it was least in small trees with small branches, narrow crowns with few cones, high crown ratios, low heartwood content, and small central stumproot systems.

For both varieties stem diameter inside bark at the base of the live crown was proportional to d.b.h.; it averaged $52 \mathrm{~mm}$ (11), $100 \mathrm{~mm}(18)$, and $148 \mathrm{~mm}$ (23) for latifolia and $58 \mathrm{~mm}(12), 108 \mathrm{~mm}$ (17), and $169 \mathrm{~mm}$ (21) for murrayana in trees 76, 152, and $228 \mathrm{~mm}$ in d.b.h. Stem diameter inside bark at the base of the live crown was least in small, thin-barked trees with little heartwood, small stump-root systems, and short, narrow crowns with small branches. In latifolia trees, stem diameter at the base of the live crown tended to be larger in southern latitudes than in northern.

Stemwood volume within crown, as a percentage of total stemwood volume, averaged 16.0 percent (12.1) for latifolia and 26.5 percent (13.8) for murrayana. This proportion was unrelated to elevational zone or d.b.h. Latifolia in Canadian latitudes had only 12.2 percent within-crown stemwood, whereas trees of this variety in the United States averaged 20.8 percent. Within-crown stemwood had the least proportion of total stemwood volume in tall but short-crowned older trees having low moisture content, high heartwood content, high specific gravity of bark and sapwood, and thin stembark.

Longitudinal effects on taper characteristics were absent or minor.

\section{Specific Gravities and Weights of Tree Components}

The most important finding of this research is that stemwood specific gravity of latifolia trees 76, 152, and $228 \mathrm{~mm}$ in d.b.h.- in a spectrum of ages-decreased with increasing d.b.h., and increased with increasing latitude. With diameter, latitudinal, and elevational data pooled, latifolia stemwood specific gravity averaged 0.418 (sapwood averaged 0.414 and heartwood 0.434 ) based on unextracted ovendry weight and green volume. As noted above, latifolia stemwood specific gravity was negatively correlated with d.b.h., averaging $0.427,0.419$, and 0.407 for trees 76,152 , and $228 \mathrm{~mm}$ in d.b.h. Trees in the three diameter classes averaged 71, 91, and 107 years old, respectively, with growth-ring width at $152 \mathrm{~mm}$ stump height averaging $0.67,1.01$, and $1.33 \mathrm{~mm}$.

Stemwood specific gravity diminished with increasing height in tree up to the base of the live crown, above which it remained constant or increased slightly at values between 0.39 and 0.40 . At all percentages of heights in the stems, small-diameter trees had higher stemwood specific gravity than large trees. For all diameters, stemwood specific gravity could be closely estimated from stemwood specific gravity at 20 percent of tree height. Stemwood specific gravity was unrelated to elevational zone within latitudinal sampling zone, but was positively correlated with latitude, averaging minimum (0.390) at 42.5 degrees and maximum (0.435) at 55 degrees. This specific gravity trend was inverse to stemwood moisture content trend with latitude, and aligned with the trend of heartwood percent of stemwood weight.

Wood of latifolia live branches had higher average specific gravity $(0.487)$ than that of the stump-root system $(0.469)$ or stem $(0.418)$. Specific gravity of bark of live branches, stump-root system, and stem averaged 0.411 , 0.415 , and 0.369 , respectively.

Complete latifolia trees 76, 152, and $228 \mathrm{~mm}$ in d.b.h. had average ovendry weights of 28,170 , and $440 \mathrm{~kg}$, including foliage and stump-root systems to a lateral-root radius of $305 \mathrm{~mm}$ from stump pith. Trees from high elevational zones weighed less than those from low. With diameter and elevational data pooled, trees weighed least in the three southernmost latitudes (40 through 45 degrees) and most in latitudes 47.5 through 55 degrees. 
Latifolia tree component proportions varied significantly with d.b.h., latitude, and elevation; but with all data pooled, component weight percentages (ovendry) averaged $6.8,1.0,5.9,2.0,72.8$, and 11.5 percent for technical foliage, cones, live branches, dead branches, stem, and stump-root system. Small trees had a greater proportion of foliage and stump-root system, and a lesser proportion of cones, live branches, and stem weight than large trees.

The weight of latifolia green wood plus bark of the three major tree components required to provide $1 \mathrm{~m}^{3}$ of barkfree wood was greater for small trees than large, and varied with latitude and elevation. With all data pooled, average requirements for foliage-free branches, stem (152 mm stump height to apical tip), and stump-root system were $1,448,920$, and $1,046 \mathrm{~kg}$, respectively.

Bark ovendry-weight proportions of tree components were greater in small trees than large, and varied with latitude and elevational zone. With all latifolia data pooled, however, averages were 11.6, 10.1, 33.8, and 12.5 percent for complete foliage-free tree, stem, live branches, and stump-root system, respectively.

Variations related to longitudinal zones across latitudinal sampling zones were minor, except that individual latifolia cones from trees on the east end of sampling zones weighed more than those on trees from the west end.

At the three latitudes the two varieties had in common (40, 42.5, and 45 degrees), murrayana had higher specific gravity for most tree components than latifolia; for example, stemwood of murrayana averaged 0.451 vs. 0.401 for latifolia, and specific gravity of bark of complete trees averaged 0.387 for murrayana vs. 0.363 for latifolia (basis of ovendry weight and green volume).

Latifolia had more weight of foliage per tree, and a higher foliage-weight proportion ( 7.3 percent vs. 5.3 percent, ovendry basis).

With diameter data pooled, $1,025 \mathrm{~kg}$ of murrayana stems (wood plus bark, green) is required to yield $1 \mathrm{~m}^{3}$ of barkfree wood, whereas only $926 \mathrm{~kg}$ of latifolia will yield this volume of wood.

\section{Distribution, Moisture Content, Weight, and Specific Gravity of Heartwood and Sapwood}

In latifolia the age of the lowest tree disk where heartwood did not occur averaged 21,11 , and 10 years in trees 76,152 , and $228 \mathrm{~mm}$ in d.b.h.; this age was also negatively correlated with latitude. The height of this lowest heartwood-free disk averaged 76,89 , and 93 percent in trees of the three diameters, and was positively correlated with latitude.

The height (above a stump height of $152 \mathrm{~mm}$ ) in latifolia at which maximum heartwood diameter occurred averaged $0.80,0.53$, and $0.44 \mathrm{~m}$ for trees 76,152 , and $228 \mathrm{~mm}$ in d.b.h.; this height was also negatively correlated with latitude. Heartwood percentage of stem diameter at height of maximum heartwood diameter was positively correlated with latitude, and averaged 48, 54, and 59 percent for trees of the three diameter classes.

In latifolia, minimum sapwood thickness where heartwood was present averaged 16, 24, and $29 \mathrm{~mm}$ for trees
76,152 , and $228 \mathrm{~mm}$ in d.b.h.; trees in northern latitudes and middle to upper elevational zones (within latitudinal zones) had thinnest sapwood. This minimum sapwood thickness occurred at 51,60 , and 70 percent of height in trees of the three diameter classes; the percentage of height was positively correlated with latitude. Sapwood thickness was maximum near ground level, diminished rapidly up to about 10 percent of tree height, then remained more or less constant to about 70 percent of tree height, and finally diminished with approach to the apical tip. Sapwood was thinnest in northern latitudes.

Heartwood volume as a percentage of entire stemwood volume in latifolia averaged 22,28 , and 34 percent in trees 76, 152, and $228 \mathrm{~mm}$ in d.b.h.; heartwood volume percentages were positively correlated with latitude.

Sapwood moisture content in latifolia averaged 119 percent, with moisture contents of 110,122 , and 126 percent in trees 76, 152, and $228 \mathrm{~mm}$ in d.b.h.; it was negatively correlated with latitude. Sapwood moisture content was minimum in the lowest 10 percent of the stems (110 percent), increased more or less linearly to a maximum (136 percent) at about 80 percent of tree height, and then diminished slightly toward the apical tip.

Heartwood moisture content in latifolia averaged 43 percent, with moisture contents of 47,42 , and 41 percent in trees 76, 152, and $228 \mathrm{~mm}$ in d.b.h. Heartwood moisture content averaged minimum (42 percent) at stump height of $152 \mathrm{~mm}$, and increased curvilinearly to a maximum (52 percent) at 90 percent of tree height.

Heartwood percentage of ovendry weight of entire latifolia stemwood averaged 23, 29, and 35 percent for trees 76,152 , and $228 \mathrm{~mm}$ in d.b.h.; these percentages were positively correlated with latitude.

Specific gravity of sapwood in entire stems (based on green volume and unextracted ovendry weight) averaged 0.414 , and was maximum at middle latitudes; it was 0.423 , 0.415 , and 0.405 in trees 76,152 , and $228 \mathrm{~mm}$ in d.b.h. Sapwood specific gravity averaged 0.449 at stump height, decreased to a minimum of 0.387 at 70 percent of tree height, and then increased to 0.399 at 90 percent of tree height.

Specific gravity of heartwood of entire latifolia stemwood averaged 0.434 ; it was $0.459,0.430$, and 0.412 in trees 76,152 , and $228 \mathrm{~mm}$ in d.b.h. With diameter data pooled, heartwood had average specific gravity of 0.482 at stump height of $152 \mathrm{~mm}$, decreased sharply to a minimum of 0.412 at 30 percent of tree height, and then increased to a near maximum $(0.478)$ at 90 percent.

In the three latitudinal sampling zones common to the two varieties (40,42.5, and 45 degrees), some significant differences were observed between latifolia and murrayana in heartwood and sapwood characteristics. In latifolia maximum heartwood diameter occurred at an average of 8.5 percent of tree height ( $1.01 \mathrm{~m}$ above stump top); it averaged lower in murrayana $(6.3$ percent and $0.81 \mathrm{~m})$. Specific gravity of entire sapwood averaged significantly higher in murrayana (0.444) than in latifolia (0.397); at all heights in trees, murrayana had greater sapwood specific gravity than latifolia. Specific gravity of heartwood also averaged significantly higher in murrayana $(0.500)$ than in latifolia (0.427); this relationship applied to all latitudes, diameters, and heights in trees. 


\title{
Gross Characteristics of Lodgepole Pine Trees in North America
}

\author{
Peter Koch
}

\section{CHAPTER 1: TREE CHARACTERISTICS, DIMENSIONS, AND CUBIC VOLUMES}

\section{CONTENTS}

1-1 The Lodgepole Pine Resource in North

Page

America ....................... 4

1-2 General Study Plan and Objectives ........ 5

1-3 Limitations of the Study ............. 6

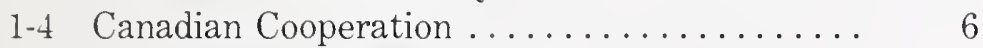

1-5 Past Work on Characterization .......... 6

1-6 General Study Procedures............... 8

Locating and Selecting the 243 Latifolia

Trees ......................

Locating and Selecting the 36 Murrayana

Trees ........................

Field and Laboratory Work ...........

General Field Procedure .............

Central Stump-Root System Procedure .....

Cones Procedure ..................

Dead Branches Procedure ............

Foliage Procedure.................

Live Branches Procedure..............

Stem Procedure................... 10

Statistical Analyses ................ 10

1-7 Tree Characteristics, Dimensions, and Cubic

Volumes....................... 10

1-8 Introduction . . . . . . . . . . . . . ... 10

$1-9$ Objective and Scope................ 11

1-10 Literature Review .................. 11

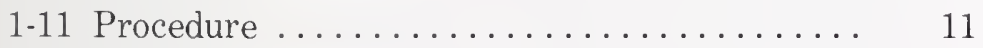

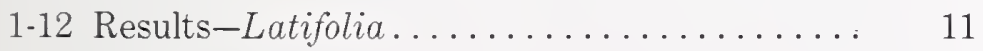

Tree Age ..................... 12

Tree Height to Apical Tip.............. 13

Tree Height to 25-mm Top Diameter

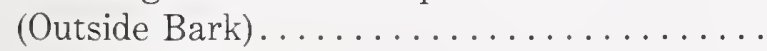

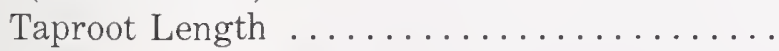

Width of Live Crown ...............

Length of Live Crown ...............

Length of Stem Below Crown ...........

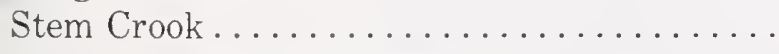

Number of Live Branches .............

Average Diameter of Live Branches

(50 mm From Stem). . . . . . . . ..... 17

Average Live Branch Angle . . . . . . . . . . . 18

Number of Dead Branches ............. 19
Stem Diameter (Bark-Free) at Base of Live

Page

Crown ...................... 20

Crown Ratio ................... 20

Average Growth-Ring Width at $152-\mathrm{mm}$

Stump Height ................ 20

Number of Cones on the Tip $305 \mathrm{~mm}$ of the

Top 25 Branches ................ 22

Total Number of Cones per Tree

(Calculated).

Cone Serotiny

Branchbark Thickness

(Measured With a Scale) .............. 23

Central Rootbark Thickness

(Measured With a Scale) ............. 23

Lateral Rootbark Thickness

(Measured With a Scale) .............

Stumpbark Thickness

(Measured With a Scale) ............. 25

Stembark Thickness

(Measured With a Diameter Tape)........ 26

Total Volume of Dead Branches

(Thousand $\mathrm{cm}^{3}$ ) ................ 27

Volume of Live Branches, Wood Plus Bark

(Thousand $\mathrm{cm}^{3}$ )

Volume of Live Branchwood

(Thousand $\mathrm{cm}^{3}$ ) .

Volume of Live Branchbark

(Thousand $\mathrm{cm}^{3}$ ) .

Volume of Stump-Root System, Wood Plus

Bark (Thousand $\mathrm{cm}^{3}$ ) ...............

Volume of Stump, Wood Plus Bark

(Thousand $\mathrm{cm}^{3}$ ) .................

Volume of Lateral Roots, Wood Plus Bark

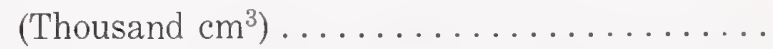

Volume of Central Root Mass, Wood Plus

Bark (Thousand $\mathrm{cm}^{3}$ ) ...............

Volume of Stump-Root System, Wood Only

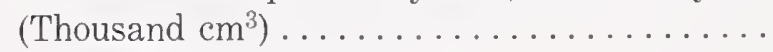

Volume of Stump, Wood Only

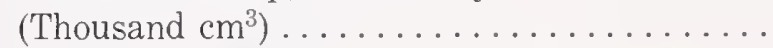

Volume of Lateral Roots, Wood Only

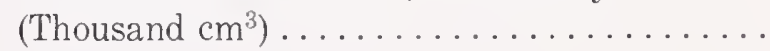


Volume of Central Root Mass, Wood Only

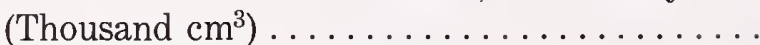

Volume of Stump-Root System, Bark Only

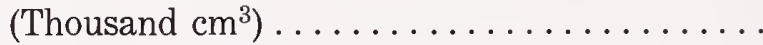

Volume of Stump, Bark Only

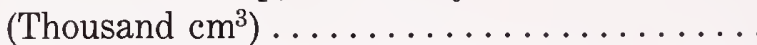

Volume of Lateral Roots, Bark Only

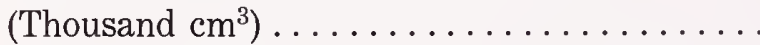

Volume of Central Root Mass, Bark Only

(Thousand $\mathrm{cm}^{3}$ ) ..................

Stem Volume to Apical Tip, Wood Plus Bark

(Thousand $\mathrm{cm}^{3}$ ) ..................

Stemwood Volume to the Apical Tip

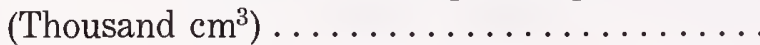

Stembark Volume to Apical Tip

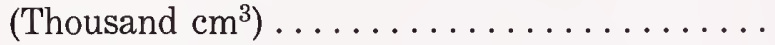

Complete-Tree Volume, Wood Plus Bark

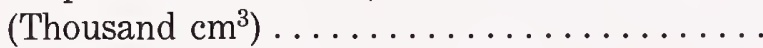

Complete-Tree Volume, Wood Only

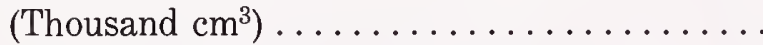

Complete-Tree Volume, Bark Only

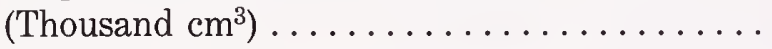

Stembark as Percentage of Gross Stem

Volume by Height in Tree ............

Stembark as Percentage of Gross Stem

Volume.........................

Stump-Rootbark as Percentage of Gross

Stump-Root System Volume............

Live Branchbark as Percentage of Gross Live

Branch Volume .....................

Bark of Complete Tree as Percentage of

Complete-Tree Volume ... . . . . . . . . . .

Stemwood as Percentage of Complete-Tree

Wood Volume ......................

Live Branchwood as Percentage of Complete-

Tree Wood Volume ...................

Dead Branchwood as Percentage of Complete-

Tree Wood Volume ...................

Stumpwood as Percentage of Complete-Tree

Wood Volume ....................

Stump-Root System Wood as Percentage of

Complete-Tree Wood Volume .............

1-13 Results-Murrayana ...............

Tree Age .....................

Tree Height to Apical Tip...............

Tree Height to 25-mm Top Diameter

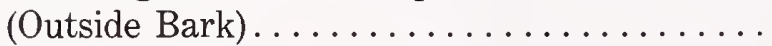

Taproot Length ...................

Width of Live Crown ...............

Length of Live Crown ..............

Length of Stem Below Crown ...........

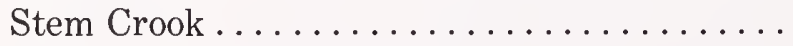

Number of Live Branches . . . . . . . . . . . .

Average Diameter of Live Branches ........

Average Live Branch Angle ..............

Number of Dead Branches ..............

Stem Diameter (Bark-Free) at Base of Live

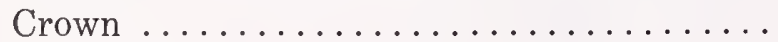

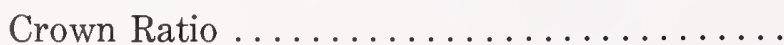

Page
Average Growth-Ring Width at 152-mm

Page

Stump Height ...................

Number of Cones on Tip $305 \mathrm{~mm}$ of the Top

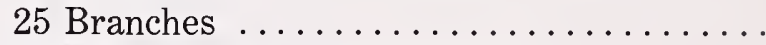

Total Number of Cones per Tree

(Calculated) . .

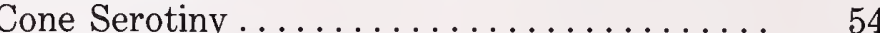

Branchbark Thickness

(Measured With a Scale) ..............

Central Rootbark Thickness

(Measured With a Scale) ................ 54

Lateral Rootbark Thickness

(Measured With a Scale) ..............

Stumpbark Thickness

(Measured With a Scale) ...............

Stembark Thickness

(Measured With a Diameter Tape)........

Total Volume of Dead Branches

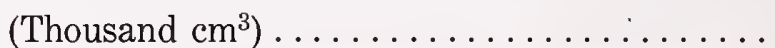

Volume of Live Branches, Wood Plus Bark

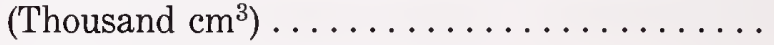

Volume of Live Branchwood

(Thousand $\mathrm{cm}^{3}$ ) ................ 56

Volume of Live Branchbark

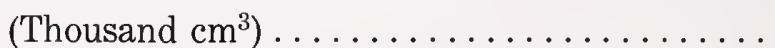

Volume of Stump-Root System, Wood Plus

Bark (Thousand $\mathrm{cm}^{3}$ ) ..............

Volume of Stump, Wood Plus Bark

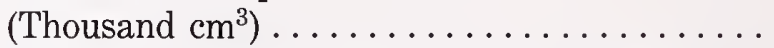

Volume of Lateral Roots, Wood Plus Bark

(Thousand $\mathrm{cm}^{3}$ ) ..................

Volume of Central Root Mass, Wood Plus

Bark (Thousand $\mathrm{cm}^{3}$ ) . . . . . . . . . . .

Volume of Stump-Root System, Wood Only

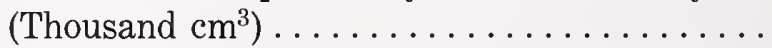

Volume of Stump, Wood Only

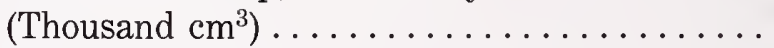

Volume of Lateral Roots, Wood Only

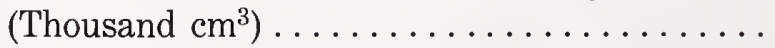

Volume of Central Root Mass, Wood Only

(Thousand $\mathrm{cm}^{3}$ ) ..................

Volume of Stump-Root System, Bark Only

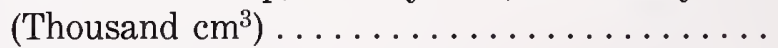

Volume of Stump, Bark Only

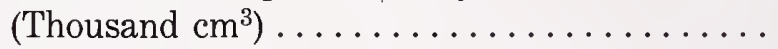

Volume of Lateral Roots, Bark Only

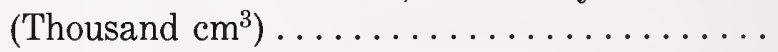

Volume of Central Root Mass, Bark Only

(Thousand $\mathrm{cm}^{3}$ ) ..................

Stem Volume to Apical Tip, Wood Plus Bark

(Thousand $\mathrm{cm}^{3}$ ) .................

Stemwood Volume to Apical Tip

(Thousand $\mathrm{cm}^{3}$ ) .................

Stembark Volume to Apical Tip

(Thousand $\mathrm{cm}^{3}$ ) ..................

Complete-Tree Volume, Wood Plus Bark

(Thousand $\mathrm{cm}^{3}$ ) .................

Complete-Tree Volume, Wood Only

(Thousand $\mathrm{cm}^{3}$ ) . 
Complete-Tree Volume, Bark Only

(Thousand $\mathrm{cm}^{3}$ )

Stembark as Percentage of Gross Stem

Volume by Height in Tree .............

Stembark as Percentage of Gross Stem

Volume.

Stump-Root Bark as Percentage of Gross

Stump-Root System Volume.............

Live Branchbark as Percentage of Gross Live

Branch Volume....................

Bark of Complete Tree as Percentage of

Complete-Tree Volume ...............

Stemwood as Percentage of Complete-Tree

Wood Volume ......................

Live Branchwood as Percentage of Complete-

Tree Wood Volume ...................

Dead Branchwood as Percentage of Complete-

Tree Wood Volume ..................

Stumpwood as Percentage of Complete-Tree

Wood Volume ....................

Stump-Root System Wood as Percentage of

Complete-Tree Wood Volume...........

1-14 Results-Latifolia Compared to

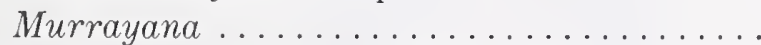

Tree Age .....................

Average Diameter of Live Branches $(50 \mathrm{~mm}$

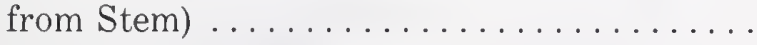

Average Live Branch Angle ............

Average Growth-Ring Width at 152-mm

Stump Height . . . . . . . . . . . . . . . .

Number of Cones on Tip $305 \mathrm{~mm}$ of the Top

25 Branches
Page
Total Number of Cones per Tree

(Calculated) . . . . . . . . . . . . . . . 63

Cone Serotiny . . . . . . . . . . . . . . . . . 63

Central Rootbark Thickness

(Measured With a Scale) . . . . . . . . . . . 63

Lateral Rootbark Thickness

(Measured With a Scale)

Stumpbark Thickness

(Measured With a Scale) ..............

Stembark Thickness

(Measured With a Diameter Tape)........

Volume of Stump, Wood Plus Bark

(Thousand $\mathrm{cm}^{3}$ ) .................

Volume of Central Root Mass, Wood Plus

Bark (Thousand $\mathrm{cm}^{3}$ ) . . . . . . . . . . . . .

Volume of Stump, Wood Only

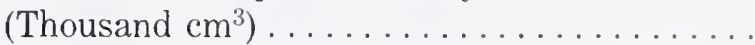

Volume of Central Root Mass, Wood Only

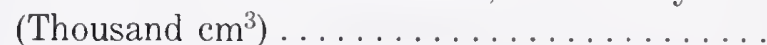

Volume of Stump, Bark Only

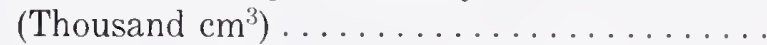

Stembark as Percentage of Gross Stem

Volume by Height in Tree .............

Live Branchbark as Percentage of Gross Live

Branch Volume....................

Stump-Root System Wood as Percentage of

Complete-Tree Wood Volume............

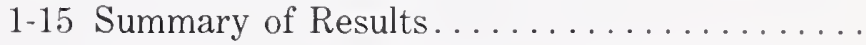

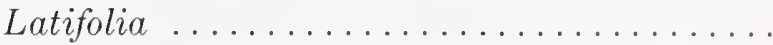

Latifolia Compared to Murrayana .........

1-16 References.....................
Page 


\section{1-1 THE LODGEPOLE PINE RESOURCE IN NORTH AMERICA}

Lodgepole pine (Pinus contorta Dougl. ex Loud.) occupies about 5.25 million ha of commercial forest land in the United States (containing 748 million $\mathrm{m}^{3}$ of lodgepole growing stock and over 71 billion bd ft of lodgepole timber, mostly in Montana, Idaho, Wyoming, Colorado, and Oregon), and is the fourth most extensive timber type west of the Mississippi River. On these 5.25 million ha, a significant proportion of the trees are dead, having been killed by insects. In the Northern Region alone, a 1979 survey reported 540,862 ha severely infested with mountain pine beetle. The most recent survey data for Idaho indicate that insects and disease have killed about 1 percent of the lodgepole pine trees. Canada has a greater acreage of lodgepole pine forest type (20 million ha, comprising 22 percent of the total forest land in western Canada) than the United States.

Most of the North American lodgepole pine resource is of the variety latifolia (Pinus contorta var. latifolia Engelm.) centered along the Rocky Mountains from 40 to 60 degrees north latitude, with Sierra lodgepole pine (Pinus contorta var. murrayana [Grev. \& Balf.] Engelm.), and shore pine (Pinus contorta Dougl. ex Loud. var. contorta) comprising significantly lesser volumes on Sierra and coastal areas (fig. 1-1). A fourth variety (bolanderi [Parl.] Vasey) is a shrub confined to Mendocino County, CA.

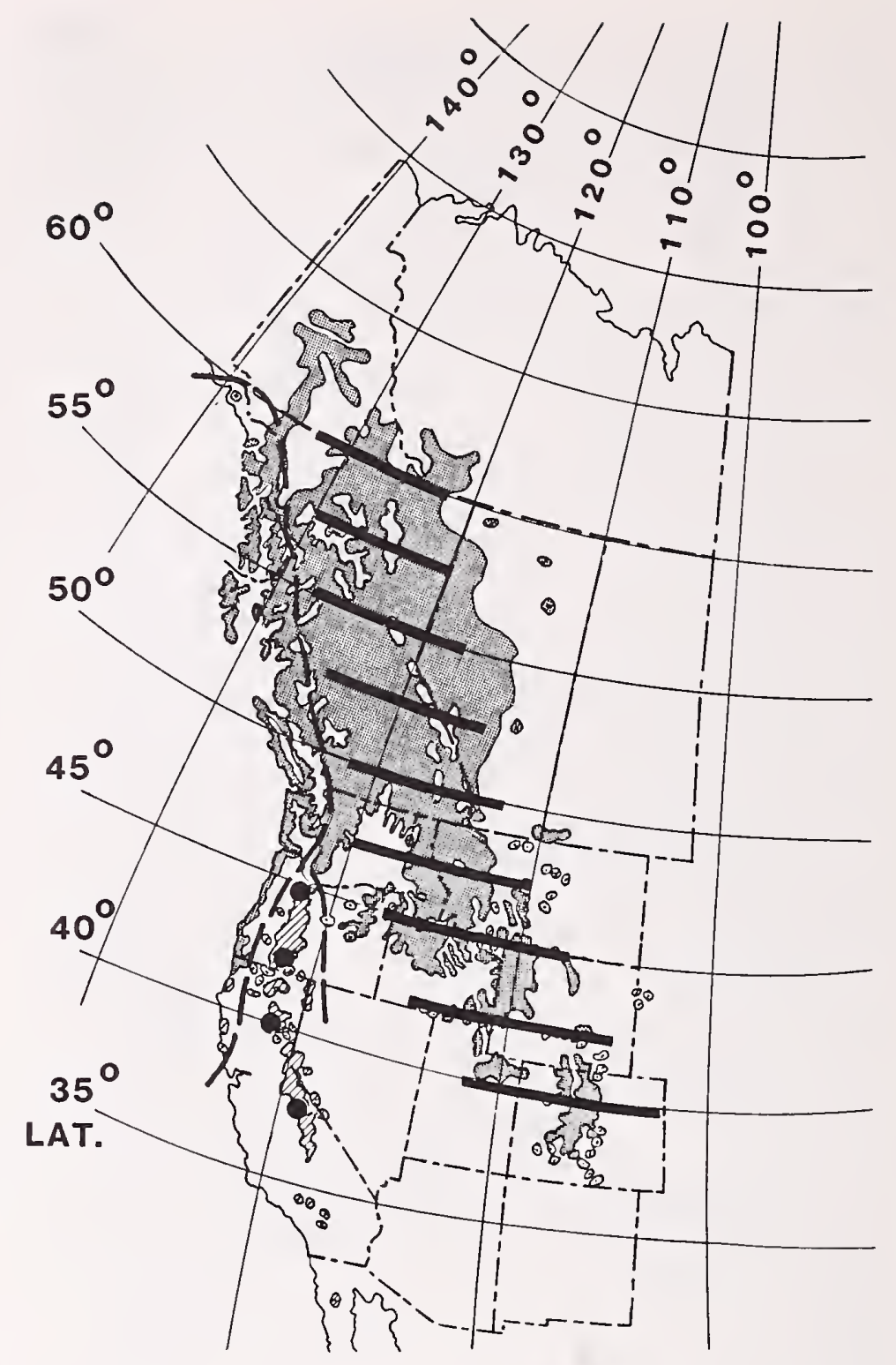

Figure 1-1-Sampling zones superimposed on Little's (1971) range map of lodgepole pine in North America. Variety latifolia is mapped to the right of the dashed lines, murrayana between them, and contorta to the left of them. Variety contorta was not studied because of its small potential for commercial use. 
In both Canada and the United States, much of the lodgepole resource is in older (60 to 200 years), virtually stagnated stands in which growth rate is very low and mortality very high (fig. 1-2). Typically, trees are small in diameter. Slightly more than one-third of the volume (ovendry weight basis) is in trees less than $175 \mathrm{~mm}$ in diameter measured at breast height outside bark (Van Hooser and Chojnacky 1983); such a diameter might be considered the lower limit for lumber manufacture.

Silvicultural treatments (thinning or removal and regeneration to managed stand with controlled stocking) are so expensive, and stumpage revenue so little, much of the acreage has received no treatment to accelerate growth and slow mortality.

\section{1-2 GENERAL STUDY PLAN AND OBJECTIVES}

This General Technical Report, presenting gross characteristics of lodgepole pine trees in North America, comprises five chapters, as follows:

Chapter 1: Tree Characteristics, Dimensions, and Cubic Volumes

Chapter 2: Moisture Content of Tree Components

Chapter 3: Stem Taper

Chapter 4: Specific Gravities and Weights of Tree Components

Chapter 5: Distribution, Moisture Content, Weight, and Specific Gravity of Heartwood and Sapwood.

These five chapters are part of the initial output of a decade-long (1983-93) research program intended to improve utilization of lodgepole pine forests of the 21st century in North America. Details of this program can be found in Koch (1985).

Further reports-beyond this initial five-chapter General Technical Report on gross tree characteristics-will provide data on anatomical, chemical, mechanical, and additional physical characterization of tree components as industrial raw materials; most should be complete by 1990 .

The entire characterization effort is confined to varieties latifolia and murrayana, with emphasis on the former. Tree data will primarily be correlated with diameter at breast height outside bark (d.b.h.), and with elevational, latitudinal, and longitudinal zones. Also, within-tree variation in properties with height and radial position will be determined. Properties of variety latifolia and those of murrayana will be compared for trees in latitudinal zones common to both varieties.

The primary objective during tree collection was to obtain disease- and insect-free specimens of 76-, 152-, and

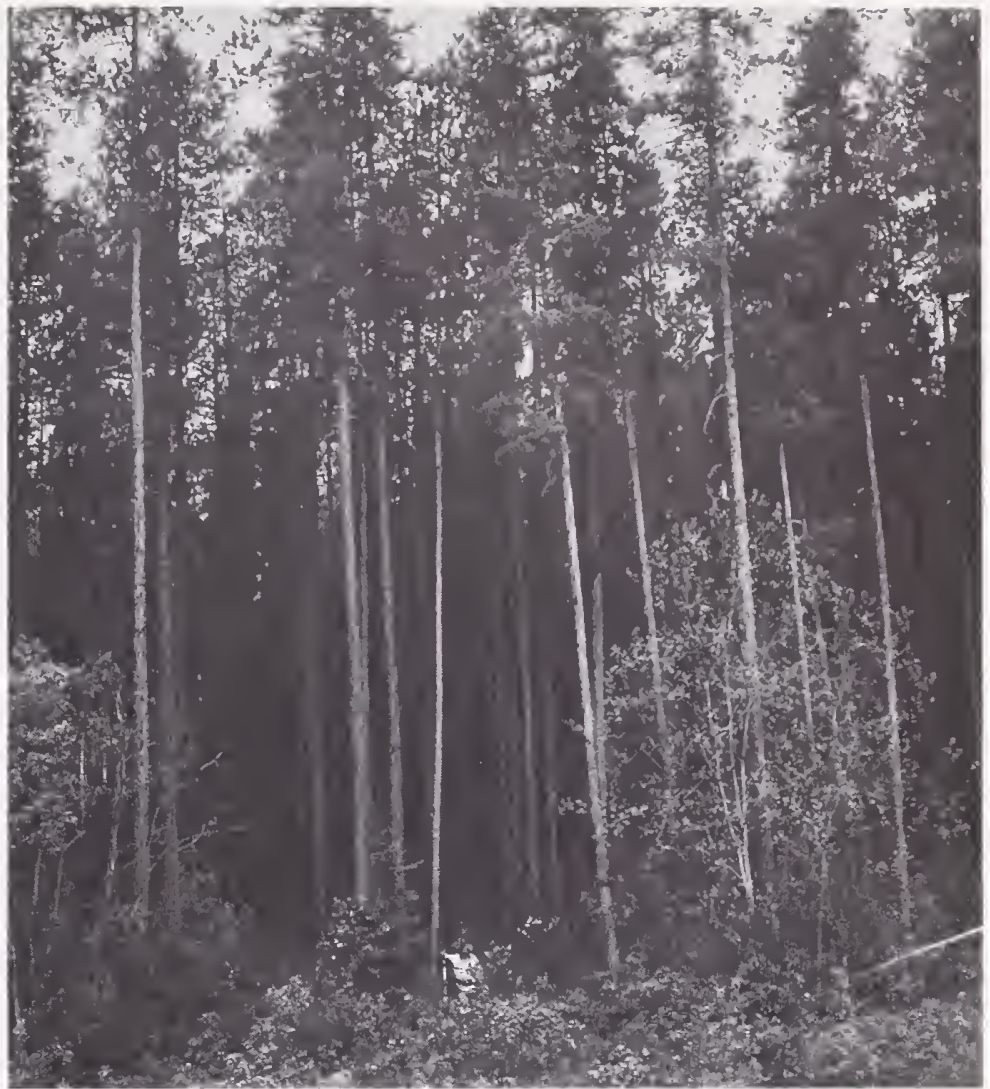

Figure 1-2-Natural unthinned lodgepole pine stand (var. latifolia) in low-elevation zone $(716 \mathrm{~m})$ at 55 degrees latitude $12 \mathrm{~km}$ north of Fort St. James, BC. The tree sampled here, next to the stadia rod, measured $155 \mathrm{~mm}$ d.b.h., $19.1 \mathrm{~m}$ high from stump top to apical tip, and was 163 years old.

228-mm lodgepole pine (var. latifolia) at low, medium, and high elevations from nine equally spaced north latitudinal zones (40 to 60 degrees) across 10 degrees of longitude, in such a way as to encompass the major range of this variety (fig. 1-1).

A secondary objective was to sample these same three diameter classes of var. murrayana at midelevation at four north latitudes $(37.5,40,42.5$, and 45 degrees) in California and southern Oregon at a single longitude per latitude (fig. 1-1).

The trees of both varieties were sampled in such a way that between-variety comparisons could be made for midelevation trees from latitudes $40,42.5$, and 45 degrees. The collection totaled 243 latifolia trees and 36 murrayana trees.

Chapter 1 presents results of analyses of gross tree characteristics, dimensions, and cubic volumes. 


\section{1-3 LIMITATIONS OF THE STUDY}

A work of this scope, broadly describing trees of a species with great latitudinal, longitudinal, and elevational range, cannot meet the needs of readers of all disciplines. Recognizing this reality, the work was written principally for use by industrialists, scientists, process engineers, and students who need a description of gross species characteristics and some appreciation of their variations within North America.

Because the sampling plan calls for a specimen collection stratified by d.b.h., latitude, and elevational zone-without sampling intensity adjusted for volume distribution within these stratifications-it does not permit computation of species-average values valid rangewide.

Moreover, the sampling plan does not permit evaluation of effects of site quality, age, and stand density-even though it is well known that these three parameters significantly affect many, perhaps most, of the characteristics evaluated. This shortcoming in experimental design was thoroughly discussed before study initiation.

Because resources available for this study of lodgepole pine as an industrial raw material were not only finite, but modest, the study objectives were limited to determination of broad material characteristics variations related to tree d.b.h. and spatial location (latitude, longitude, and elevational zone). The study was not designed to deal with the very complex relationships involving site quality, tree age, or stand density; as a result, the sampling plan does not permit such analyses.

The elevational range of lodgepole pine (latifolia) is considerably greater in southern latitudes than in northern (fig. 1-3); and therefore site quality and stand densities probably vary less in northern than in southern latitudes.

\section{1-4 CANADIAN COOPERATION}

The Canadian Forestry Service, working through the University of British Columbia, was able to accomplish collection of the 135 trees along the five latitudes in that nation during the summers of 1983 and 1984; the collection was made under the direction of Dr. Robert Kennedy, Dean of Faculty of Forestry, University of British Columbia. This substantial contribution to the overall effort is appreciatively acknowledged. Extending the collection from near the southern limit to near the northern limit of the species range greatly enhanced its value.

\section{1-5 PAST WORK ON CHARACTERIZATION}

Simultaneously with our characterization effort, an exhaustive review of the world literature on lodgepole pine has been accomplished. It is evident from the approximately 4,000 publications comprising this body of literature on lodgepole pine, that research efforts have been largely

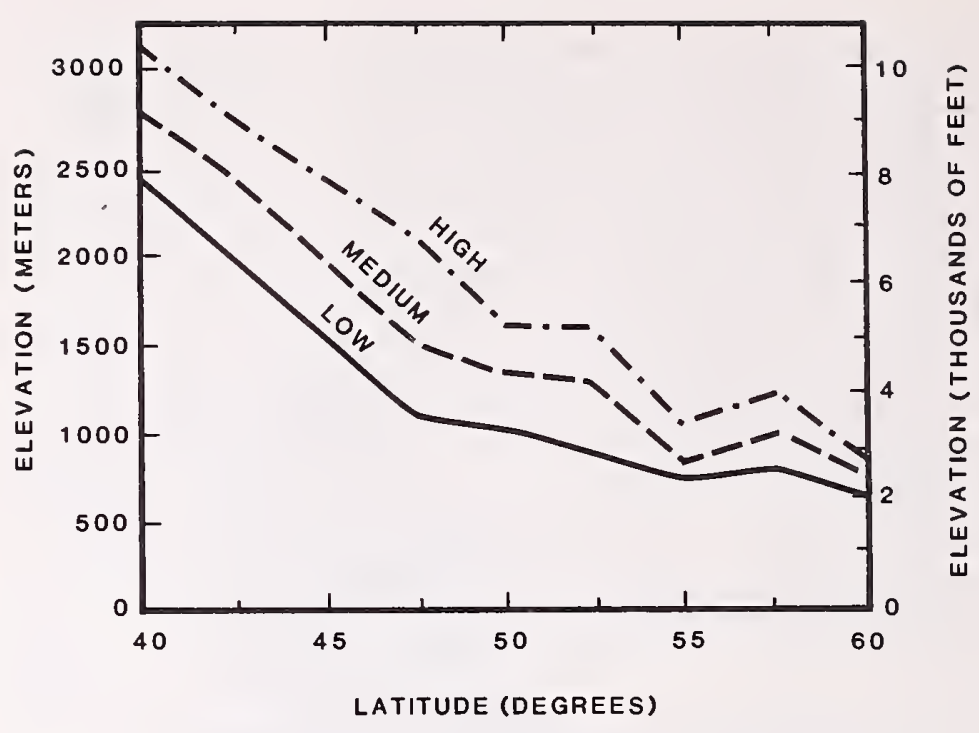

Figure 1-3-Elevational trends in the three zones (low, medium, and high) where lodgepole pine (var. latifolia) was sampled along nine latitudes. Each plotted point is the average for nine trees; that is, three diameters by three replications.

devoted to provenance trials, regeneration technology, silviculture, growth and yield, physiology and ecology, watershed and wildlife management, fire management, and insect and disease problems-particularly problems related to the mountain pine bark beetle. Probably less than 3 percent of the literature deals directly with utilization of the species.

There are essentially no data in the literature that provide an integrated overview of the anatomical, physical, chemical, and mechanical properties of varieties latifolia and murrayana related to latitude, elevational zone, diameter class, and longitudinal zone spanning the major range of these trees in North America. Because of this lack of characterization overview, literature related to the first chapter-which deals with a very large number of diverse characteristics-is not abstracted. Instead, table 1-1 lists references peripherally pertinent to introducing all five chapters (for example, those references concerned with species, botanical descriptions, and keys) and those regionally pertinent to the subject matter of chapter 1 . This tabulation should be useful to readers wishing to study listed topics in greater depth.

In chapters 2 through 5 , which individually deal with a narrower range of topics, a thorough summarization of the pertinent world literature is provided. 
Table 1.1-References pertinent on a regional and local basis to the subject matter of this paper, and to subjects peripherally pertinent to the series of papers

\section{Subject}

\section{References}

Bark thickness

\section{Bark volume}

Branch characteristics Branch volume Cone serotiny

Cone yield

Crown

dimensions

Crown ratio

Elevational effects Spalt and Reifsnyder (1962) Snell and Max (1982)

\section{Faurot (1977)} (1970), Tower (1909) Thompson (1978) Lowery (1967)
(Citations marked with an "relate to attack by mountain pine beetle or other insect) Amman $\left(1969^{*}, 1972^{*}\right)$, Amman and Pace (1976*). Berryman (1976*, 1978*), Blyth (1955), Cabrera (1978), Cerezke (1973*), Cole (D.M. 1973*), Cole (D.M.) and Jensen (1980), Cole (W.E. 1973*), Cole (W.E.) and Amman (1980 ), Cole (W.E.) and Cahill (1976*), Faurot (1977), Hawksworth and others (1983*), Kozak and Yang (1981), Lange (1971), Myers (1964a), Parker (1950), Shrimpton and Thomson (1983*). Smith and Kozak (1971), Smithers (1961), Spada (1960),

Drake (1983), Faurot (1977), Hakkila and Panhelainen (1970), Kozak and Yang (1981),

Franklin (1954), Franklin and Callaham (1970)

Armit $(1964,1966)$, Bates (1917,1930), Brown (1975), Cooper and others (1959), Critchfield (1980), Crossley (1955,1956a, 19560), Harl (1979), Hellum and Barker $(1980,1981)$. Hellum and Pelchat (1979), Kamra (1982), Knapp and Anderson (1980), Kovalchik and Blake (1972), Linhart (1978), Lotan (1963, $1964,1957,1968,1970,1975 a, 19750,1976)$ : Lotan and Jensen (1970), Lotan and Perry (1983), Macaulay (1976), Moore (19816), Mowat (1960), Muir (1982), Muir and Lotan Iin press]. Perry and Lotan (1979), Sutherland and others (1982), Tackle (1959), Teich

Lotan (1963,1975a.19750), Lotan and Jensen (1970), Moore (1981a,1981b), Smithers (1961),

Alexander (1974), Alexander and others (1967), Bonnor (1964), Brown (1976,1978), Chapman and others (1982), Cole (1983), Cole and Jensen (1983), Darms (1966, 1971a), Eis and others (1982), Fannestock (1960), Gary $(1974,1976,1978)$, Kimes and others (1979), Mattnews (1953), Moeur (1981), Mogren (1967), Muler (1971), Smith and Bailey (1964), Smithers (1961), Wel ner and

Brown (1978), Cole and Jensen (1983)

Amman (1973), Amman and others (1973.1977). Bannan (1954), Benecke and Morris (1978), Clausen (1955), Cole (D.M.) and Stage (1972), Cole (W.E.1973), Cole (W.E.) and Amman (1980), Cunn ngham and Roberts (1970), Forestry Research West (1983), Hagner (1980a.1980b). Hawksworn (1956), Hobbs and Partridge (1979), Illingworth (1971), Krajina (1970), Larson (1978), Lindgren and others (1976). Loten and Perry (1983), Moore (1981a), Neustein (1966),

Table 1.1-Con.

\section{Subject}

The

\section{Geographic} variation

Height-diamete:
cata
Latitudinal
effects

Root form (Excluding $s=e d$ ings)

Soecies descriotions: general; mostly cf var. latifolia

Species descriotions: bolanderi literature Species descriptions: shore pine literature
References

Rehfeld: (1980.1983), Rehield and Wyroti (1981), Safranyik (1978), Scoti (1970). Shepperd and Alexander (198.3), Smithers (1961)

Birot (1978), Crichíld (1957). Deiricrson (1970), Forrest (1977a.19770.1979,1981). Hagner (1980a, 19800), Henderson and Petty (1972). Ilingworth (1969.1971,1976), Jefters and 8 ack (1953), Knowes (i980). Knowes and Grani [in press]. Maschning (1971), M.:0. (1954a.19540), Woore (1981a, 19810), Wowa (i960). Newman and Jancey (1981). Nisson (1981), Nyland (1980), Perry (1975), Pery and Lotan (1978), Smith (R.H.1983), Wheeler and Guries (1982a,19820), Yeh and Lavon (1979). Ying and oiners (1985)

Cole (D.M.) and Ecminste' (193z), L'ye's (1966)

Alcen and ZEsaca (1983). Amman and cthers (1977), Christie anc L nes (1979), Hagner (1980a,19800), Illingworth (1971), Jorsson ano others (i:8i), Krajina ( $\$ 90)$, Linogren and oiners (1976), Hoore (:981a.19sib), Sairanyi (1978), Teylo: and ctiners (:९82)

Bernd: and Gibbons (1958), Bisnco (1932) Boggie (1972), Gail and Long (1935), Horon (1958), Nielsen (1982), Pieife: (i982), Smith (J.H.G. 1964), Smitners (1961), van Eercen and Kinghom (1978)

Anderson and Tiecemann (1970), Baretu and oiners (1983), Setts (1945), Daries (1930). Dietrichson (1970), Edvarcs (1954,1955).

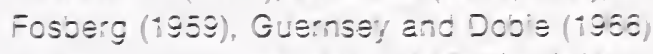
Hosie (i973), Illingworth (1976), Kotok (1971), Laing (1955), La Roi anc Hratilk (1980). Loooe (197i): Lotan and $A$ Exance' (i973). Loian and Critchileld [in press], Loian and Perry (1983), WacDonalc anc Woos (1957) MicDougal (1975), Ministry di Technology (1965), Mrov (1054a,19540), :'00re (i9810) Moss (1955), Nyland (1980). O'Driscol (1978,1980), Paul (1962), Pister anc Daubenmire (1975), Pfister and oiners (1977) Polge (1963), Red, Collins inu series. Lic. (1983), Roche (1966), Saiterlund (1975). Schmidt (1981), Smithers (1961), Tackle (1959), Trappe and Harris (195z). U.S. Depermeni oi Agriculture Forest Serrice (1973), van den Driessche (1956-1957), Welner (1975), Wheeler and Crichilelo (1985), Whesler and Guries ( $1982 a, i 9820$ ). Wikstrom (1957)

Hanan (1963), Jenny and oirers (1959)

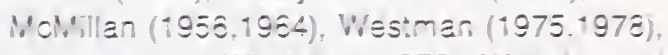
Westmen and Whitarer (1975), Whee er and Critchfisld (1985)

Crichifec (1965), Davicsonia (1979), Davies (1980). Dunsworn and others ( 982 ), Kumle' (1989). Hoss (1971), Peane (1952), Pecerick (1980), Peterson and Haref (i976), Rocne (1963), Smith (R.B. i97i), Swan (H.S.D. 


\begin{tabular}{ll}
\hline Subject & \multicolumn{1}{c}{ References } \\
\hline & 1972), Thiers (1973), U.S. Department of \\
& Agriculture (1964), van den Driessche \\
& (1956-1957), Wass (1976), Wheeler and \\
& Critchfield (1985)
\end{tabular}

Species descriptions: Sierra lodgepole literature

Species descriptions: Keys to species

\section{Species}

descriptions:

Keys to

varieties

Species descriptions: Keys to geographic origin

Stem crook (sweep)

Stem volume and volume tables

\section{Stump volume}

Root volume (cubic)
Agee (1983), Clausen (1965), Dykstra (1974), Griffin and Critchfield (1972), Gunther (1929), Harris (1973), Laing (1955), Little (1966), Manning and Hemmingson (1975), McMillan (1964), Righter and Stockwell (1949), Shirling (1946), Smith (F.W. 1981), Stock and others (1978), Struble $(1967,1968)$, U.S. Department of Agriculture (1964), Went (1973), Wheeler and Critchfield (1985), Wheeler and Guries (1982b)

Bagnell (1975; pollen key), Barton (1975; extractives key), Bates (1925; seedling key), Gilbertson and others (1961; root key), Hansen and Cushing (1973; pollen key), Kellogg and others (1982; wood anatomy key), Laing (1955; botanical key), Longyear (1908; botanical key), Mack (1971; pollen key), Mayer and Fox (1981; LANDSAT digital classification key), Swan (E.P.) (1966; chemical key to wood), Weir and Thurston (1977; pollen key)

Fosberg (1959; botanical key)

Forrest (1977a,1977b,1979,1981; chemical key), McMullan and Colangeli (1982; chemical key)

Dobie and Middleton (1980), Fitzsimons (1982), Hornibrook (1950), Kotok (1967), Lines and Booth (1972), Lines and others (1971), Malcolm (1968), Moss (1971), Pfeifer (1982), Schroeder and Phillips (1984), Sterba (1980)

Alemdag $(1973,1976)$, Allen and others (1976), Berry (1981), Blyth (1955), Bonnor (1966), British Columbia Forest Service (1936), Chapman and others (1982), Cole (D.M. 1971,1979,1983), Cole (D.M.) and Edminster (1985), Dahms (1964,1971b,1975), Dominion Forest Service (1944), Duff $(1956,1966)$, Duffy and Meyer (1962), Edminster (1978), Eis and others (1982), Eriksson (1973), Faurot (1977), Hamilton and Christie (1971), Hanzlik (1916), Heger (1965), Honer (1967), Hornibrook (1948), Jeffers and Spragg (1966), Johnson $(1952,1955)$, Johnstone $(1975,1976)$, MacLean and Berger (1976), Massie and others (1983), Moessner (1957), Myers (1964b,1967,1969), Oregon State Board of Forestry (n.d.), Plank and Cahill (1984), Quintus (1951), Smith (J.H.G.) and Ker (1957), Smithers (1961), Upson (1914), Ziegler (1907)

\section{Raile (1982)}

No literature found

\section{1-6 GENERAL STUDY PROCEDURES}

\section{Locating and Selecting the 243 Latifolia Trees}

The sample area spanned from 40 to 60 degrees (inclusive) at 2.5-degree intervals; the width of the sample area was 10 degrees of longitude, with sample area shifting 2.5 degrees west for each 2.5 degrees shift north in latitude (fig. 1-1). Sample band width was 0.5 degree of latitude on each side of the nominal latitude line; that is, each latitude band was 1 degree deep in the north-south direction (60 nautical miles), and 10 degrees of longitude wide in the east-west direction.

Within each of these nine latitudinal sampling bands, natural unthinned stands were identified, with the following constraints: adjacent to road traversable by pickup truck; within boundaries of National or Provincial Forests; and containing some more-or-less level benches or flats.

It was found that at least nine such stands could be identified within each sampling band. The identified stands were ranked by elevation, and then the three highest, the three most intermediate, and the three lowest were selected for sampling. These elevational zones were highest in the south and lowest in the north; elevational zone width was broadest at midlatitude (fig. 1-3).

On a bench or flat typical of each of these selected stands, single trees 76,152 , and $228 \mathrm{~mm}$ in d.b.h. and free of insects and diseases were taken that in the collector's view typified within-stand trees of these diameters on that bench or flat. Thus, 27 latifolia trees were taken from each of the nine latitudes -3 diameters $\times 3$ elevations $\times 3$ replications, for a total of 243 trees.

It is important to note that this sampling scheme resulted in selection of 76-, 152-, and 228-mm trees that were of approximately the same age, because most of the stands were of fire origin. Thus, most of the smalldiameter trees were suppressed, while the larger trees were the fast growers.

\section{Locating and Selecting the 36 Murrayana Trees}

The sample areas extended from 37.5 to 45 degrees latitude at 2.5-degree intervals; that is, trees were sampled at $37.5,40,42.5$, and 45 degrees-but only at one longitude per latitude (fig. 1-1).

The same three constraints on location applied to latifolia also applied to murrayana, but murrayana was sampled only from midelevation, as follows:

\begin{tabular}{ccc} 
Latitude & \multicolumn{2}{c}{ Elevation } \\
Degrees & Meters & Feet \\
37.5 & 2,402 & 7,880 \\
40 & 1,676 & 5,499 \\
42.5 & 2,006 & 6,581 \\
45 & 1,148 & 3,766
\end{tabular}

Thus, nine murrayana trees were taken from each of the four latitudes -3 diameters $\times 1$ elevation $\times 3$ replications, for a total of 36 trees. 


\section{Field and Laboratory Work}

General Field Procedure-All fieldwork was completed during the summer months of 1983 and 1984. After selection of each tree a photograph was taken of it (with its identifying code number), a note made regarding the soil type, and a record made of the following data: latitude, longitude, elevation, diameter at breast height, and date. The tree was trenched as though the lateral roots were severed by a tube $0.9 \mathrm{~m}$ in diameter centered on the tree pith. The tree was uprooted and the root brushed free of dirt; an effort was made to extract whatever taproot there was to a diameter of 1 inch. Total tree height was measured from the top of a 152-mm-high stump to the apical tip, and also to a $25.4-\mathrm{mm}$ stem diameter measured outside bark.

Length of stump-root system was measured from stump top to the bottom of whatever taproot there was. Length and width of the live crown were measured. The lateral root system was pruned back to a $305-\mathrm{mm}$ radius, and the complete tree with attached stump-root system and intact foliage weighed.

Following all the field procedures described in subsequent paragraphs, selected tree parts were trucked to the Forestry Sciences Laboratory of the Intermountain Research Station in Missoula, MT, for prompt ( $<3$ weeks) analysis.
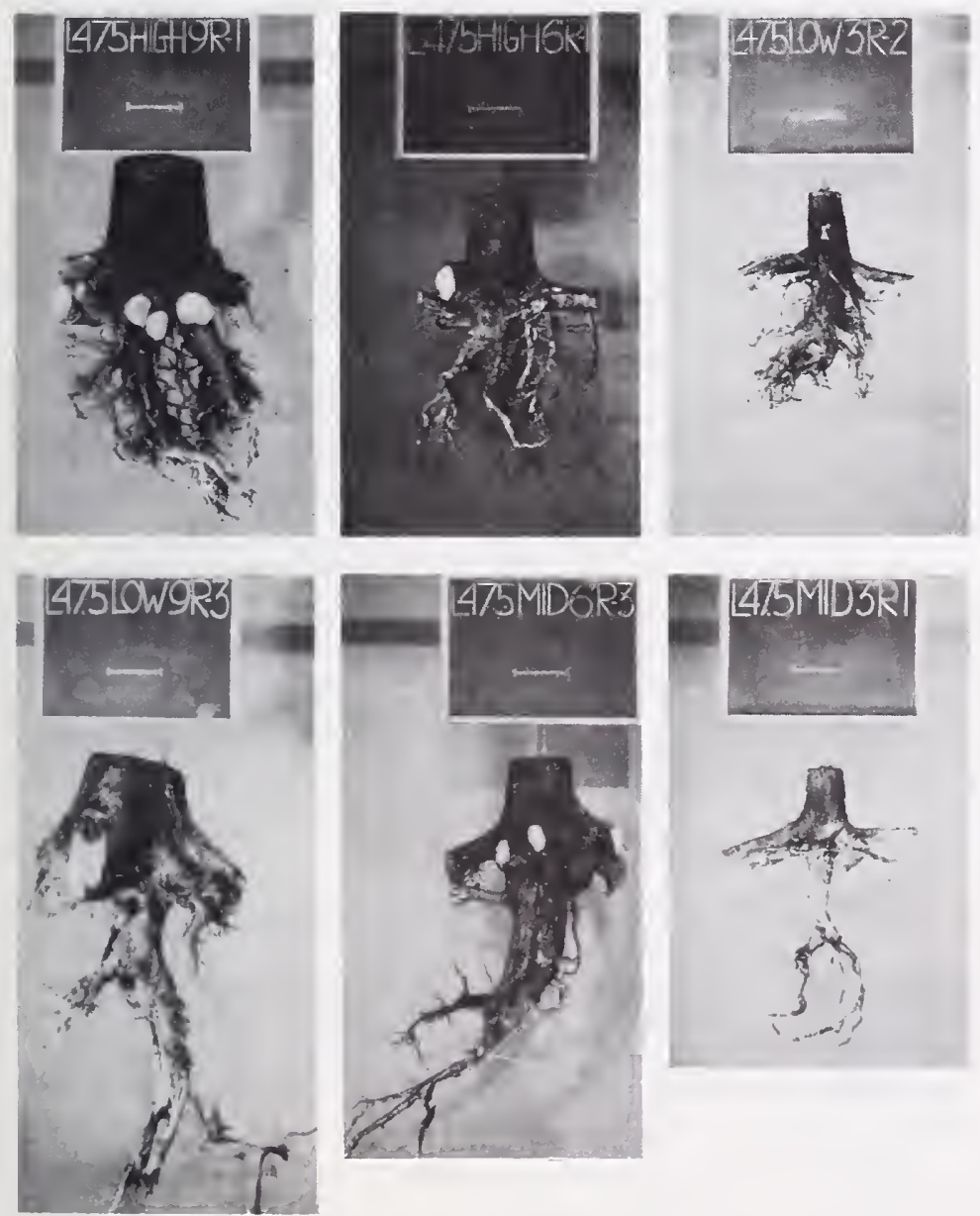

Figure 1-4-Variation in root form of trees measuring $228 \mathrm{~mm}$ (left), $152 \mathrm{~mm}$ (center), and $76 \mathrm{~mm}$ (right) in d.b.h. sampled at latitude 47.5 degrees from three elevational zones. The scale marks on the chalkboards indicate $152 \mathrm{~mm}$.
Central Stump-Root System Procedure-In the field, the stump-root system was severed at $152 \mathrm{~mm}$ stump height, weighed, and sealed in a polyethylene bag. At the Missoula laboratory, the root system was further cleaned and all roots smaller than $6 \mathrm{~mm}$ in diameter were trimmed; the stump-root system was then weighed and photographed. Typically, the stump-root systems were characterized by a stout taproot, with length positively correlated $(r=0.625)$ with tree d.b.h.; great variation in root form was observed (fig. 1-4). The system was then segmented into three portions (stump top to root collar, lateral roots, and central root mass including the root collar and taproot), and each portion weighed while green and the volume measured by water immersion. Bark thickness of each portion was measured. The bark was then removed from each portion, the bark-free weight and volume recorded, and the bark of each portion ovendried and weighed. Wood from each portion of the stump root was sampled and ovendried to determine moisture content. All three portions were retained in specimen storage.

Cones Procedure-In the field, all cones on the first lineal $305 \mathrm{~mm}$ of the top 25 live branches (excluding the apical tip) were counted, clipped, and the number of closed cones in this sample recorded. A subsample of a few cones was sealed in polyethylene for later determination of moisture content. The remainder of the clipped cones were bagged in muslin (with additions from the first $305 \mathrm{~mm}$ of live branches 26 through 50 , if necessary to obtain a sufficient supply) for analyses of anatomy and heat of combustion. In the laboratory the green weight and moisture content of the cones were determined, the muslin-bagged cones air dried and stored, and by Lotan and Jensen's (1970) formula the total number of cones on the tree calculated.

Dead Branches Procedure-In the field, the number of dead branches was counted; after the complete tree was weighed, all dead branches were clipped entire (flush with the stem) and weighed. From the total population of dead branches, ten 152-mm-long lengths from branch midlength were randomly sampled and sealed in a polyethylene bag for laboratory determination of moisture content and specific gravity.

Foliage Procedure-In the field, foliage from the four live branch whorls nearest $60,70,80$, and 90 percent stem height was clipped and put in a polyethylene bag for laboratory determination of moisture content; additional foliage from the same branches was collected for air drying and laboratory determination of properties. This foliage, together with all of the other technical foliage (all needles and needle-bearing twigs up to $6 \mathrm{~mm}$ diameter outside bark) on the tree were weighed in aggregate.

Live Branches Procedure-On the three branches nearest the $60,70,80$, and 90 percent stem level (12 branches in all per tree) each branch diameter was measured $50 \mathrm{~mm}$ from the stem, outside bark; also, branch angle was measured at point of entry to the stem (ascending branches have angles less than 90 degrees, while drooping branches have angles more than 90 degrees). From each of these branches a 203-mm length was taken at midlength and bagged in polyethylene for laboratory determination of moisture content and specific gravity. 
From adjacent branches similar lengths were taken for air drying and laboratory determination of other properties. In the field, these subsamples plus the branch ends and butts and all of the other foliage-free branches on the tree were weighed to get an aggregate live-branch weight.

In the laboratory, the moisture-content lengths were weighed green, and their volume measured by water immersion. The average thickness of the bark on each length was recorded, the bark removed, and the weight and volume of the bark-free length recorded. The ovendry weight of each bark-free length was then recorded, and also the ovendry weight of the bark from each length.

Stem Procedure-In the field, the stem was shorn of branches so that it was complete from 152-mm-high stump to apical tip. By stretching a taut string between the 10and 70-percent stem levels, the maximum crook was measured and recorded together with the stem level at which it occurred.

From the $0,10,20,30,40,50,60,70,80,90$ percent, and apical-tip level of the stem, a pair of disks was removed-one $50 \mathrm{~mm}$ thick and bagged in polyethylene for laboratory determination of moisture content and specific gravity, the other $75 \mathrm{~mm}$ thick and air dried for laboratory determination of additional properties.

Also transported from field to laboratory were two stem sections with bark in place-the first between stem levels 10 and 20 percent, and the second between 20 and 30 percent. In the laboratory these two stem sections were debarked and both wood and bark air dried and stored.

In the laboratory the number of annual rings at stump height was recorded, and the characterization disks air dried and stored. Each moisture disk was weighed green, its volume measured by water immersion, and its bark thickness (as measured by diameter tape before and after debarking) recorded. The debarked disk was weighed and its volume recorded. Heartwood was indicated by application of ferric chloride solution ( $10 \mathrm{~g} \mathrm{FeCl}$ in $90 \mathrm{~g}$ water) and split away from the sapwood, heartwood diameter was measured, and heartwood weight and volume recorded. The ovendry weights of bark, sapwood, and heartwood of each disk were then recorded.

\section{Statistical Analyses}

Analyses of variance were made in three groupings (table 1-2): latifolia throughout its principal latitudinal range of 40 through 60 degrees; murrayana through its primary latitudinal range of 37.5 through 45 degrees; and latifolia compared to murrayana at the three common latitudes of $40,42.5$, and 45 degrees.

For each of the two varieties, standard deviations for tree characteristics are noted in the text (in parentheses following average values); such notations are made only by diameter class, with all other factors pooled.

Correlations of interest observed in latifolia between tree characteristics are also noted in each discussion in the results section of the report.

\section{1-7 TREE CHARACTERISTICS, DIMENSIONS, AND CUBIC VOLUMES}

Previous sections provide a general introduction to this entire work. Subsequent sections in this chapter focus on tree characteristics, dimensions, and cubic volumes.

\section{1-8 INTRODUCTION}

Industrial managers concerned with the utilization of lodgepole pine need an understanding of general tree characteristics, dimensions, and cubic volumes. In partial satisfaction of such needs, this first chapter provides data on: taproot length, width of live crown, tree age, tree height to apical tip, tree height to 25-mm top diameter outside bark, length of live crown, length of stem below crown, stem crook, number of live branches, average diameter of live branches, average live branch angle, number of dead branches, crown ratio, average growthring width, total number of cones per tree, degree of cone serotiny, thickness of bark on stem and branches and roots, and volume and volume percentages of tree components-including both wood and bark of complete tree, live and dead branches, stem, stumps, and roots.

Table 1-2-Analyses of variance format

\begin{tabular}{|c|c|c|c|c|c|}
\hline Source & $\begin{array}{l}\text { Degrees } \\
\text { of } \\
\text { freedom }\end{array}$ & Source & $\begin{array}{l}\text { Degrees } \\
\text { of } \\
\text { freedom }\end{array}$ & Source & $\begin{array}{c}\text { Degrees } \\
\text { of } \\
\text { freedom }\end{array}$ \\
\hline \multicolumn{2}{|c|}{ Latifolia } & \multicolumn{2}{|c|}{ Murrayana } & \multicolumn{2}{|c|}{$\begin{array}{l}\text { Latifolia compared } \\
\text { to Murrayana }\end{array}$} \\
\hline Latitude (L) & 8 & Latitude & 3 & Variety (V) & 1 \\
\hline Elevation (E) & 2 & Diameter & 2 & Latitude & 2 \\
\hline Diameter (D) & 2 & $L \times D$ & 6 & Diameter & 2 \\
\hline$L \times E$ & 16 & Error & 24 & $V \times L$ & 2 \\
\hline$L \times D$ & 16 & & - & $V \times D$ & 2 \\
\hline$E \times D$ & 4 & Total & 35 & $L \times D$ & 4 \\
\hline$L \times E \times D$ & 32 & & & $V \times L \times D$ & 4 \\
\hline Error & 162 & & & Error & 36 \\
\hline Total & 242 & & & Total & 53 \\
\hline
\end{tabular}




\section{1-9 OBJECTIVE AND SCOPE}

As previously noted, this characterization effort is confined to two varieties of lodgepole pine: Pinus contorta var. latifolia Engelm., and Pinus contorta var. murrayana (Grev. \& Balf.) Engelm., with emphasis on the former. The primary objective during tree collection was to obtain three replications of disease- and insect-free specimens of var. latifolia measuring 76,152 , and $228 \mathrm{~mm}$ in diameter at breast height (d.b.h.) at low, medium, and high elevations from nine equally spaced north latitudinal zones (40 to 60 degrees) across 10 degrees of longitude in such a way as to encompass the major range of this variety (fig. 1-1).

A secondary objective was to sample three replications of these same three diameter classes of var. murrayana at midelevation at four north latitudes $(37.5,40,42.5$, and 45 degrees) in California and Oregon at a single longitude per latitude (fig. 1-1).

The trees of both varieties were sampled in such a way that between-variety comparisons could be made for midelevation trees at latitudes $40,42.5$, and 45 degrees. The sampling plan does not permit computation of speciesaverage values. The collection totaled 243 latifolia and 36 murrayana trees.

In this chapter variations in tree characteristics, dimensions, and cubic volumes are discussed. No attempt is made to construct equations for prediction of these properties. Instead, graphs are presented of data aggregated in various significant ways that permit readers to obtain information directly from the observed study data.

Explanations of statistical analyses procedures and a table of analyses of variance formats, with degrees of freedom indicated, are shown in table 1-2. In the results portion of this chapter standard deviations are noted in the text in parentheses following average values.

\section{1-10 LITERATURE REVIEW}

As previously noted, the literature lacks an overview of tree characteristics, dimensions, and cubic volumes related to latitude, elevational zone, diameter class, and longitudinal zone spanning the major range of lodgepole pine in North America. Because of this lack of characterization overview, literature related to this first chapter-which deals with a very large number of diverse characteristicsis not abstracted. Instead, table 1-1 lists peripherally pertinent references.

\section{1-11 PROCEDURE}

Procedural details of the study are given in section 1-6, and will not be repeated here except to note that the elevational zones of low, medium, and high are relative.
Medium refers to an elevation that is medium for the variety at the latitude at which sampled; similarly, low and high refer to lower and upper elevational zones in which the variety occurs at the latitude sampled. Latifolia elevational zones were highest in the south $(2,481,2,711$, and $3,144 \mathrm{~m}$ at 40 degrees) and progressively lower with each more northerly latitude $(604,739$, and $879 \mathrm{~m}$ at 60 degrees). Murrayana was sampled at elevations in the range from 1,148 to $2,402 \mathrm{~m}$.

Trees were uprooted (with central taproot intact and with lateral roots severed at a radius of $305 \mathrm{~mm}$ from tree pith) from level benches in natural unthinned stands within National or Provincial Forests. The sampling scheme resulted in selection of 76-, 152-, and 228-mm trees averaging 71,91 , and 107 years of age, respectively, for latifolia, and 67, 84, and 91 years for murrayana. Most of the small-diameter trees were suppressed, while the larger trees were the fast growers.

Readers of these results should keep in mind that the three diameter classes $(76 \mathrm{~mm}$ with standard deviation of $1.96 \mathrm{~mm} ; 152 \mathrm{~mm}$ with standard deviation of $2.49 \mathrm{~mm}$; and $228 \mathrm{~mm}$ with standard deviation of $2.97 \mathrm{~mm}$ ) were selected in such a manner that trees were usually sampled in groups of three (one from each diameter class) from each bench sampled, and that frequently the stands were of fire origin and therefore somewhat uniform in age. Thus, the $76-\mathrm{mm}$ trees averaged 71 years of age at stump height, the $152-\mathrm{mm}$ trees 91 years, and the 228-mm trees 107 years of age. This age distribution suggests that the 76-mm class represents somewhat suppressed trees, while the $228-\mathrm{mm}$ trees were relatively fast growers in the stands selected.

Additionally, readers should remember that the sample extended from almost the extreme southern end of the range to almost the extreme northern end of the rangemidpoint of the samples was 50 degrees (fig. 1-1). Elevational zones were much higher in the south (near $3,000 \mathrm{~m}$ ) than in the north where they were less than $1,000 \mathrm{~m}$ (fig. 1-3).

Longitudinal effects on latifolia were confounded with latitudinal effects (the northern latitudinal zones were further west than the southern latitudinal zones). When each latitudinal zone was divided into 10 longitudinal zones, each a degree of longitude wide, and expressed by a number from 1 to 10 going from east to west, no significant longitudinal effects were found for any characteristic.

\section{1-12 RESULTS-LATIFOLIA}

In the paragraphs that follow, only those main effects and interactions shown statistically significant (5 percent level) by analyses of variance are discussed, tabulated, and graphed. 


\section{Tree Age}

As noted above, the three diameter classes averaged (with standard deviations in parentheses following) 71 (27), 91 (31), and 107 (39) years of age measured at $152 \mathrm{~mm}$ stump height. Trees averaged oldest at high elevation (103 years) and youngest at low elevation (75 years); at medium elevation average age was intermediate at 91 years, but variations in this trend were evident by latitude (fig. 1-5). Tree age throughout all latitudes averaged 90 years but was greatest at the two latitudinal extremes-94 years at 40 degrees and 116 years at 60 degrees; it was minimum (78 years) at 45 degrees.
LATIFOLIA
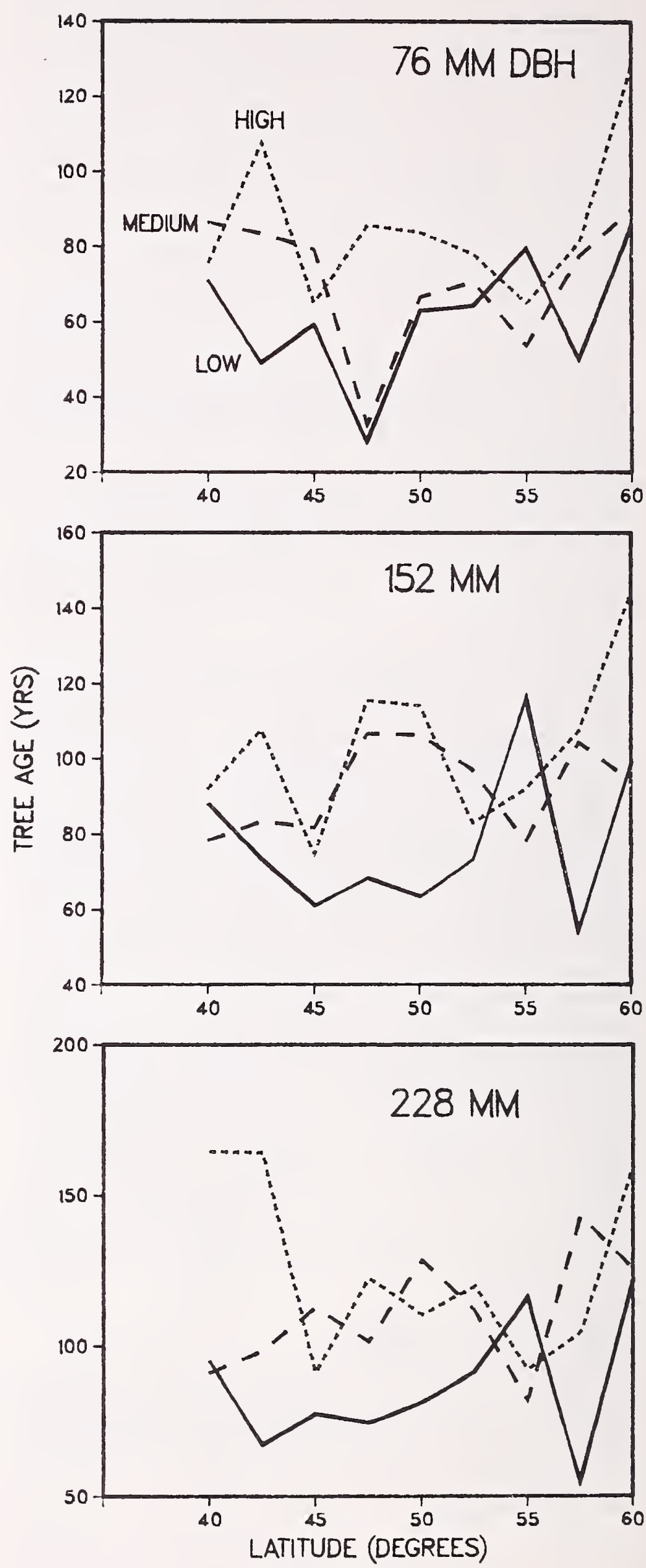

Figure 1-5-Tree age at 152-mm-high stump level related to elevational zone and latitude for latifolia trees of three diameters. 


\section{Tree Height to Apical Tip}

The three diameter classes averaged $9.3(2.0), 15.6(2.5)$, and 19.1 (3.0) $\mathrm{m}$ in height from 152-mm-high stump to apical tip; this height varied significantly with both latitude and elevation; trees were tallest at latitudes 50 , 52.5 , and 55 degrees (fig. 1-6). Except in the middiameter class, trees were tallest at low elevation and shortest at high elevation, as follows:

\begin{tabular}{|c|c|c|c|}
\hline \multirow[b]{2}{*}{ D.b.h. } & \multicolumn{3}{|c|}{ Elevation zone } \\
\hline & Low & Medium & High \\
\hline $\mathrm{mm}$ & $\cdots$ & $m$ & \\
\hline 76 & 9.7 & 9.4 & 8.7 \\
\hline 152 & 15.7 & 15.9 & 15.1 \\
\hline 228 & 20.0 & 19.1 & 18.2 \\
\hline Average & 15.1 & 14.8 & 14.0 \\
\hline
\end{tabular}

Tree height to apical tip was positively correlated with taproot length (0.60), number of live branches (0.63), average branch angle (0.60), and volume of wood plus bark in the stump-root system ( 0.81$)$; it was negatively correlated with the stembark percentage of gross stem volume $(-0.81)$, and treebark percentage of gross tree volume $(-0.83)$.

\section{Tree Height to 25-mm Top Diameter (Outside Bark)}

Tree height from 152-mm-high stump to a diameter outside bark of $25 \mathrm{~mm}$ is of interest to roundwood products producers. This height averaged 8.0 (1.9), 14.7 (2.5), and $18.3(2.9) \mathrm{m}$ for the three diameter classes, but varied significantly with both latitude and elevation class. Trees were generally tallest to the $25-\mathrm{mm}$ dimension in latitude zones 50, 52.5, and 55 degrees (fig. 1-7). Except for the $152-\mathrm{mm}$ trees, trees were tallest in low-elevation and shortest in high-elevation zones, as follows:

\begin{tabular}{rrrr} 
& \multicolumn{3}{c}{ Elevation zone } \\
\cline { 2 - 4 } D.b.h. & Low & Medium & High \\
$m m$ & $-\ldots \ldots$ & $m$ & $\ldots$ \\
76 & 8.3 & 8.2 & 7.6 \\
152 & 14.7 & 15.1 & 14.3 \\
228 & 19.1 & 18.4 & 17.5
\end{tabular}

Tree height to $25-\mathrm{mm}$ top diameter was positively correlated with taproot length $(0.60)$, number of live branches (0.63), live branch angle (0.61), and volume of wood plus bark in the stump-root system $(0.80)$; it was negatively correlated with stembark percentage of gross stem volume $(-0.81)$, and with bark percentage of gross tree volume $(-0.83)$.

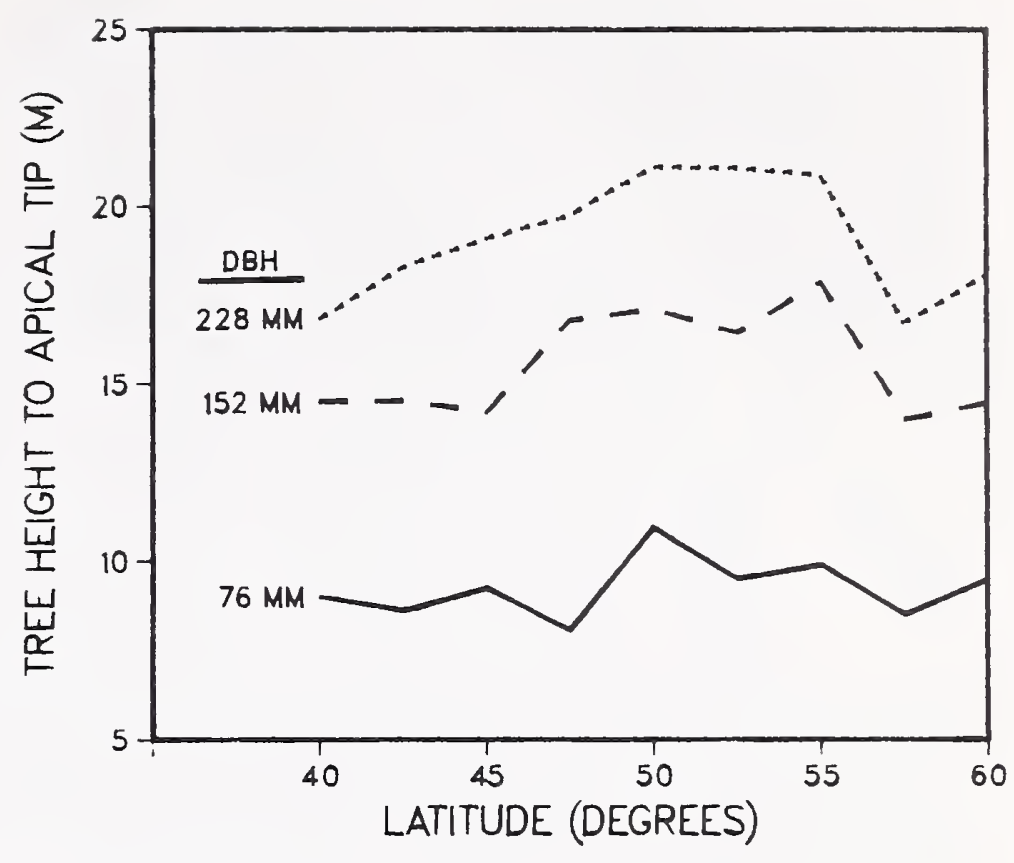

Figure 1-6-Tree height from 152-mm-high stump top to apical tip related to latitude for latifolia trees of three diameters.
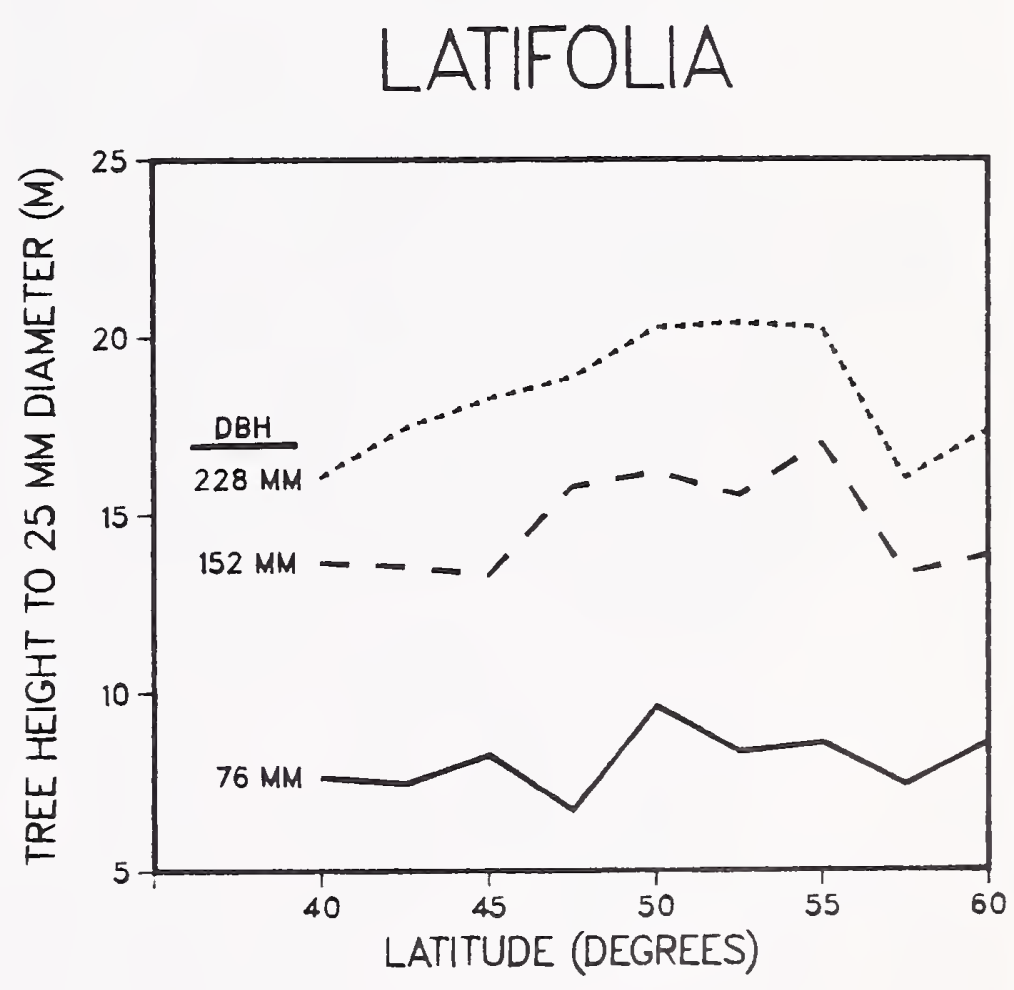

Figure 1-7-Tree height from stump top to 25-mm top diameter (measured outside bark) for latifolia trees of three diameters. 


\section{Taproot Length}

Taproot length, measured from stump top to the end of the portion of taproot the field crews were successful in extracting (fig. 1-4), was positively correlated with d.b.h., and averaged $55.4(16.7), 77.8(20.5)$, and $94.2(21.6) \mathrm{cm}$ for the three diameter classes. Taproot lengths were generally longer in southern latitudes, with maximum lengths occurring near 47.5 degrees (fig. 1-8). Except for the $76-\mathrm{mm}$ trees, taproots were longest in low-elevation and shortest in high-elevation zones, as follows:

\begin{tabular}{|c|c|c|c|}
\hline \multirow[b]{2}{*}{ D.b.h. } & \multicolumn{3}{|c|}{ Elevation zone } \\
\hline & Low & Medium & High \\
\hline $\mathrm{mm}$ & $\cdots$ & $-m-$ & $\cdots$ \\
\hline 76 & 53.3 & 60.2 & 52.6 \\
\hline 152 & 83.7 & 76.4 & 73.3 \\
\hline 228 & 103.7 & 98.3 & 80.6 \\
\hline
\end{tabular}

Taproot length was positively correlated with both height to apical tip and to 25-mm top diameter (both 0.60 ), growth-ring width at stump height (0.53), and wood volume of complete tree (0.62).
LATIFOLIA

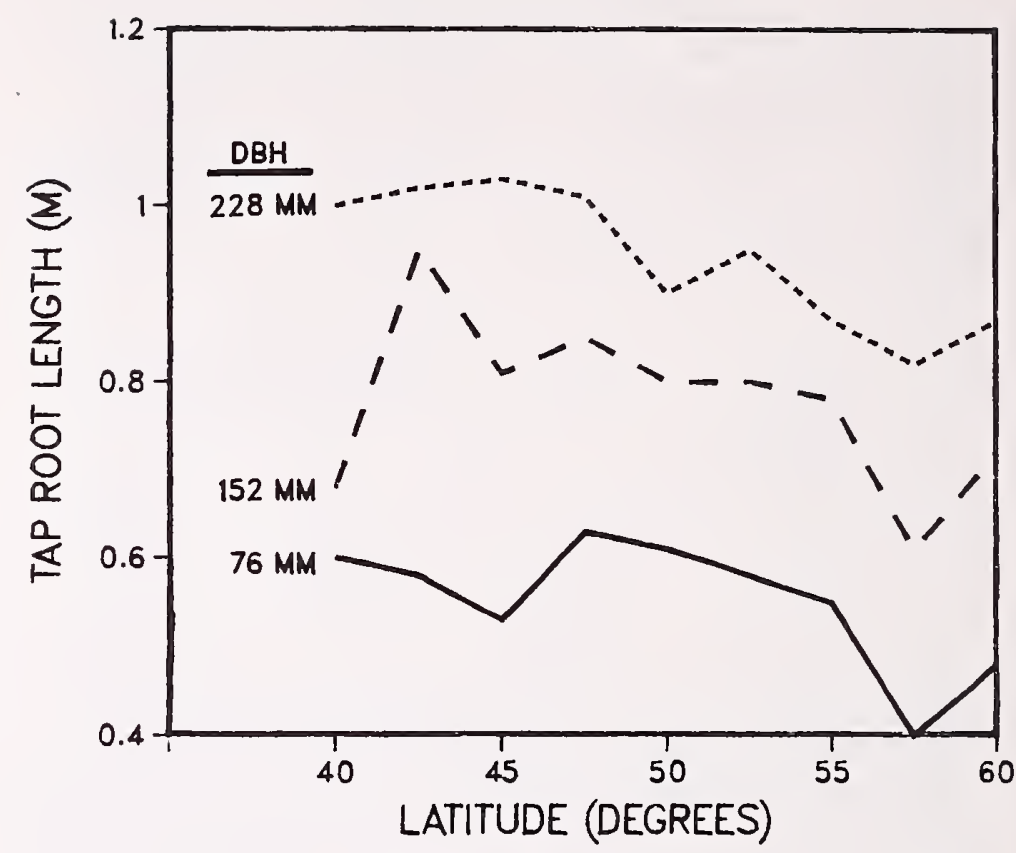

Figure 1-8-Taproot length from stump top to the bottom end of that portion of the taproot field crews were successful in extracting related to latitude for latifolia trees of three diameters. 


\section{Width of Live Crown}

Crown width was unrelated to latitude, but was positively correlated with d.b.h.-averaging $1.16(0.32), 1.81$ $(0.36)$, and $2.85(0.74) \mathrm{m}$ for the three diameter classes, and negatively correlated wth elevation zones, as follows:

\begin{tabular}{|c|c|c|c|}
\hline \multirow[b]{2}{*}{ D.b.h. } & \multicolumn{3}{|c|}{ Elevation zone } \\
\hline & Low & Medium & High \\
\hline$m m$ & $\cdots$ & $\cdots m-$ & $\cdots$ \\
\hline 76 & 1.22 & 1.15 & 1.12 \\
\hline 152 & 1.93 & 1.83 & 1.68 \\
\hline 228 & 2.95 & 3.00 & 2.60 \\
\hline Average & 2.03 & 1.99 & 1.80 \\
\hline
\end{tabular}

Crown width was positively correlated with tree height $(0.58)$, taproot length (0.54), average diameter of live branches (0.73), average ring width at stump height (0.52), stembark thickness at 50 percent of tree height (0.71), total live branch volume (0.87), gross volume of the stumproot system ( 0.81$)$, stemwood volume (0.77), and live branchwood percentage of wood volume in the complete tree (0.64). It was negatively correlated with live branchbark percentage of gross live branch volume $(-0.69)$.

\section{Length of Live Crown}

Crown length was positively correlated with d.b.h., averaging 4.21 (1.57), 6.73 (2.48), and 8.24 (2.59) $\mathrm{m}$ for the three diameter classes. Elevational effects varied with latitude, with no clear trend evident. For the two smaller diameter classes, crowns were shorter in northern latitudes than in southern (fig. 1-9).

Length of live crown was also positively correlated with taproot length (0.53), number of live branches (0.63), average ring width at stump height $(0.55)$, gross volume of live branches (0.56), stemwood volume (0.53), and bark volume of the complete tree $(0.58)$. It was poorly correlated with branch diameter $(0.38)$ or branch angle $(-0.27)$.
LATIFOLIA
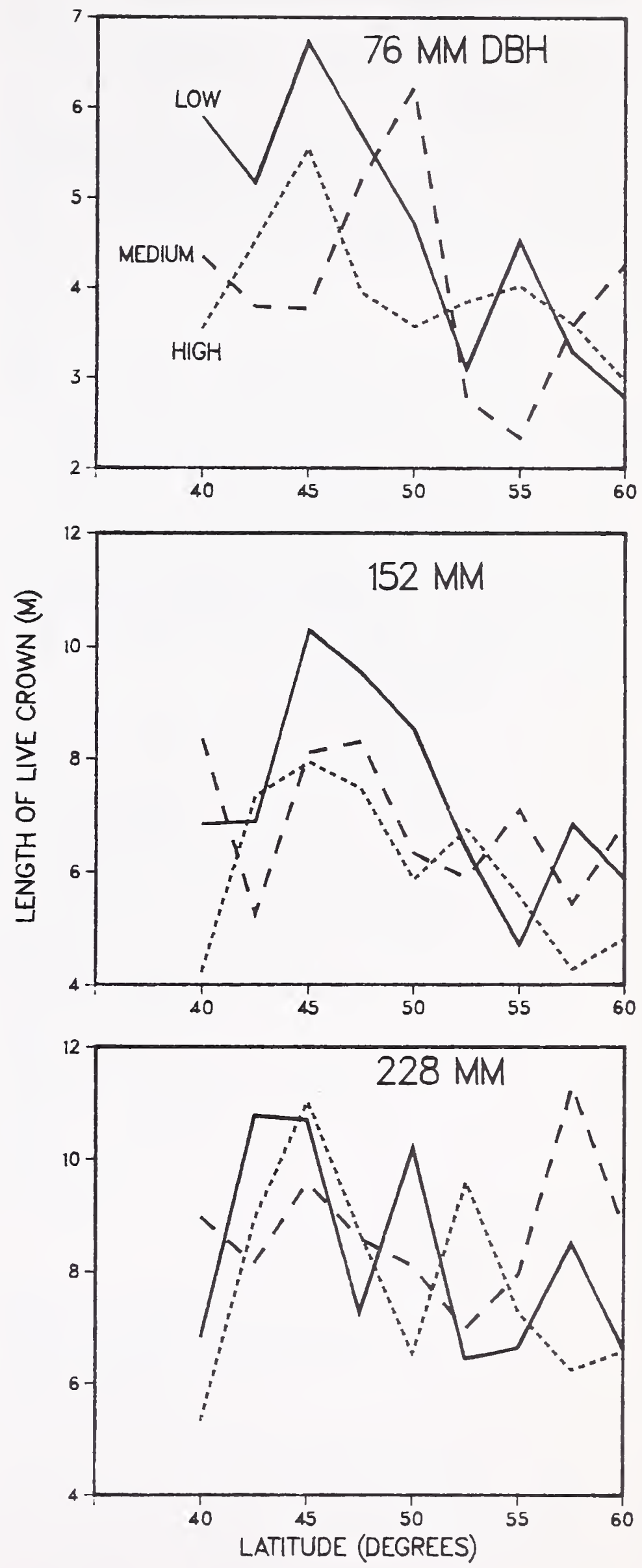

Figure 1-9-Length of live crown related to elevational zone and latitude for latifolia trees of three diameters. 


\section{Length of Stem Below Crown}

Stem length below crown was positively correlated with tree diameter, averaging 5.03 (2.53), 8.82 (3.43), and 10.85 (3.83) $\mathrm{m}$ for the three diameter classes. Latitudes $50,52.5$, and 55 degrees had trees with the longest stem lengths below crowns (fig. 1-10).

Length of stem below crown was negatively correlated with stembark percent of gross stem volume $(-0.67)$ and crown ratio $(-0.69)$. It was positively correlated with wood-plus-bark volume of the stump-root system $(0.56)$ and with stemwood volume (0.68).

\section{Stem Crook}

Stem crook between 10 and 70 percent of tree height averaged $43 \mathrm{~mm}$, with standard deviation of $24.5 \mathrm{~mm}$, and was unrelated to tree diameter or elevational zone. Trees within latitude zones 47.5 through 55 degrees averaged only $38 \mathrm{~mm}$ of stem crook, while the other five latitudinal zones averaged $48 \mathrm{~mm}$ stem crook (fig. 1-11). We measured the percentage of tree height where maximum stem crook occurred, but found its location was unrelated to any of the factors in the study; the average location was at 40 percent of tree height from stump top to apical tip.

Stem crook had a significant, but slight, positive correlation with tree age (0.21).
LATIFOLIA

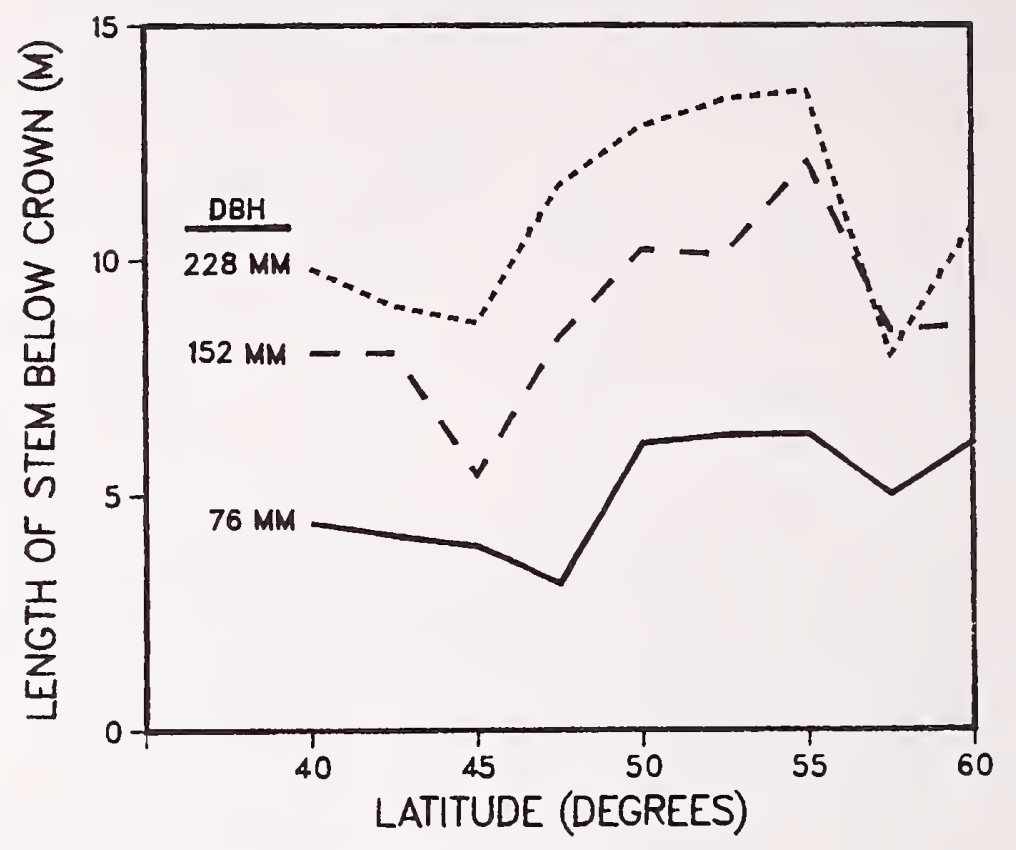

Figure 1-10-Length of stem below crown related to latitude for latifolia trees of three diameters.

\section{LATIFOLIA}

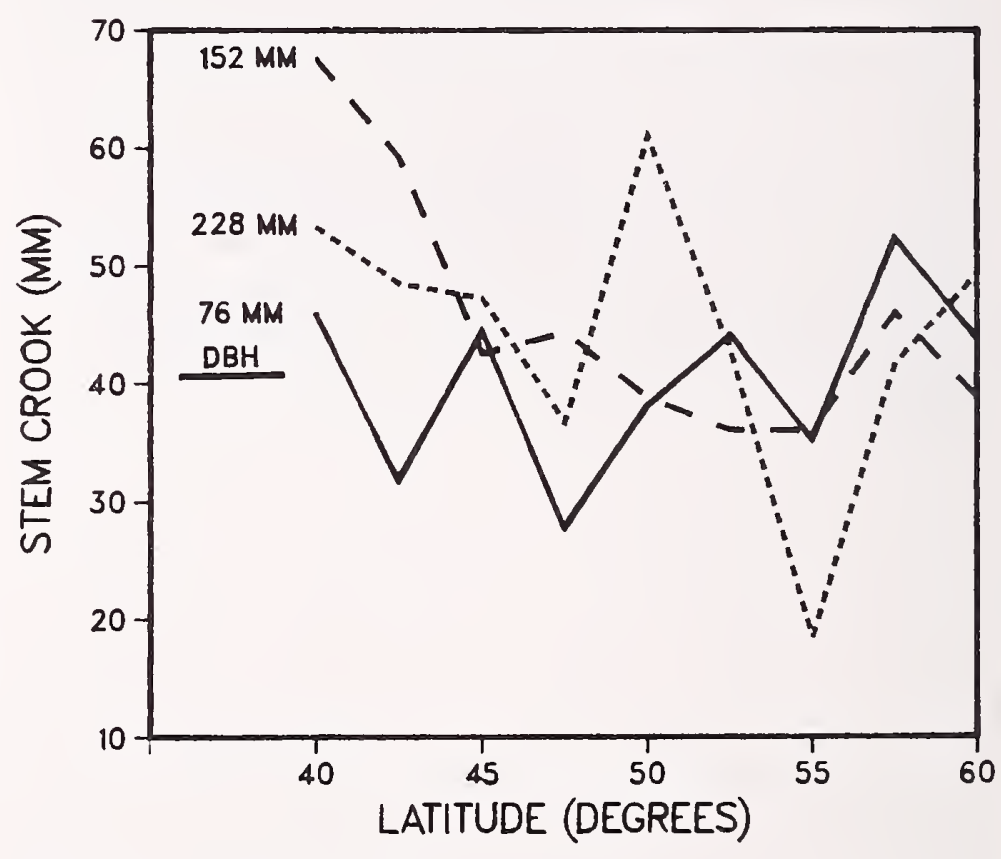

Figure 1-11-Maximum stem crook (sweep), measured perpendicular to a taut string placed against stem periphery at 10 percent of tree height and stretched to 70 percent of tree height related to latitude for latifolia trees of three diameters. 


\section{Number of Live Branches}

The number of live branches per tree was positively correlated with d.b.h., averaging 64 (27), 108 (36), and 133

(36) for the three diameter classes. Trees at latitudes 47.5 and 60 degrees had fewer live branches than those at the other seven latitudes; those at 50 degrees had most live branches (fig. 1-12).

The number of live branches was also positively correlated with tree height $(0.63)$, crown length $(0.63)$, and wood-plus-bark volume of the stump-root system (0.62), and with wood and bark volume of the complete tree (0.65).

\section{Average Diameter of Live Branches (50 mm From Stem)}

Mean branch diameter outside bark was unrelated to elevational zone but was positively correlated with d.b.h., averaging 9 (2.0), 13 (2.9), and 19 (4.0) $\mathrm{mm}$ for the three tree diameter classes. Trees at 50 degrees latitude averaged smallest branches $(12 \mathrm{~mm})$, while those at 60 degrees had the largest, averaging $16 \mathrm{~mm}$ (fig. 1-13).

Average diameter of live branches was negatively correlated with live branchbark percent of gross live branch volume $(-0.82)$ and with branch angle $(-0.29)$. It was positively correlated with tree height $(0.59)$, crown width $(0.72)$, number of cones on the top 25 branches $(0.52)$, branchbark thickness (0.59), stembark thickness at 50 percent of tree height $(0.71)$, total volume of live branchwood $(0.78)$, volume of wood plus bark in the stump-root system $(0.81)$, and volume of wood plus bark in the stem $(0.77)$.

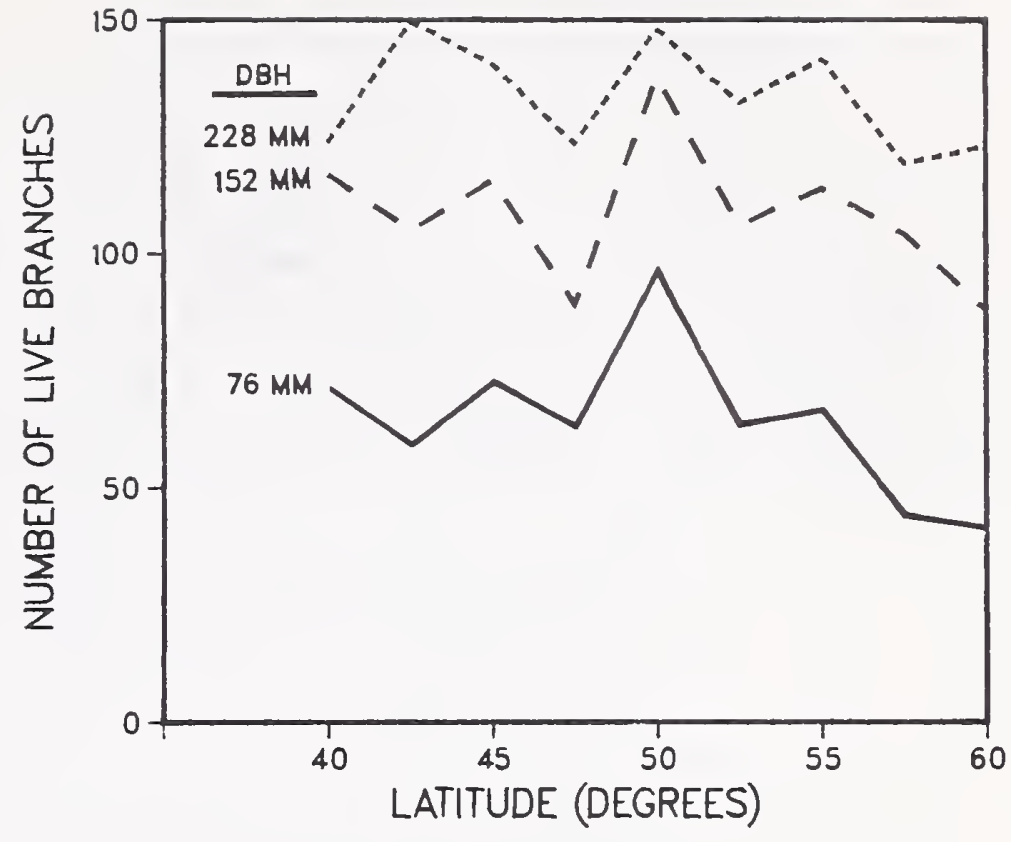

Figure 1-12-Number of live branches on latifolia trees related to latitude and d.b.h.

\section{LATIFOLIA}

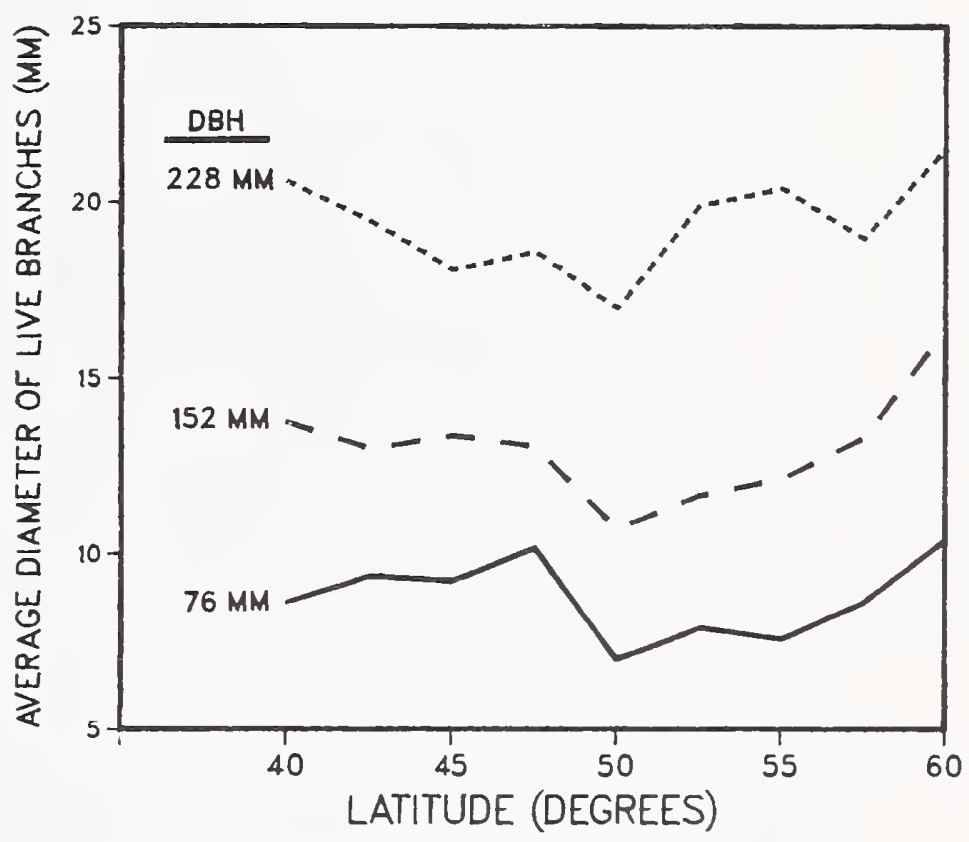

Figure 1-13-Average diameter of live branches, measured outside bark and $50 \mathrm{~mm}$ from stem surface, related to latitude for latifolia trees of three diameters. 


\section{Average Live Branch Angle}

The average angle between live branches and stem (upward-pointing branches had angles less than 90 degrees; those with drooping branches more than 90 degrees) was larger in small trees than large, and averaged 85 (12.5), 79 (10.0), and 77 (10.5) degrees for the three diameter classes. In latitude zones 50 and 52.5 degrees, trees in the high-elevation zone had larger branch angles than those in the low-elevation zone, while at 45 degrees the reverse was true (fig. 1-14).

Average live branch angle was negatively correlated with branch diameter $(-0.29)$ and average ring width at stump height $(-0.41)$.
LATIFOLIA
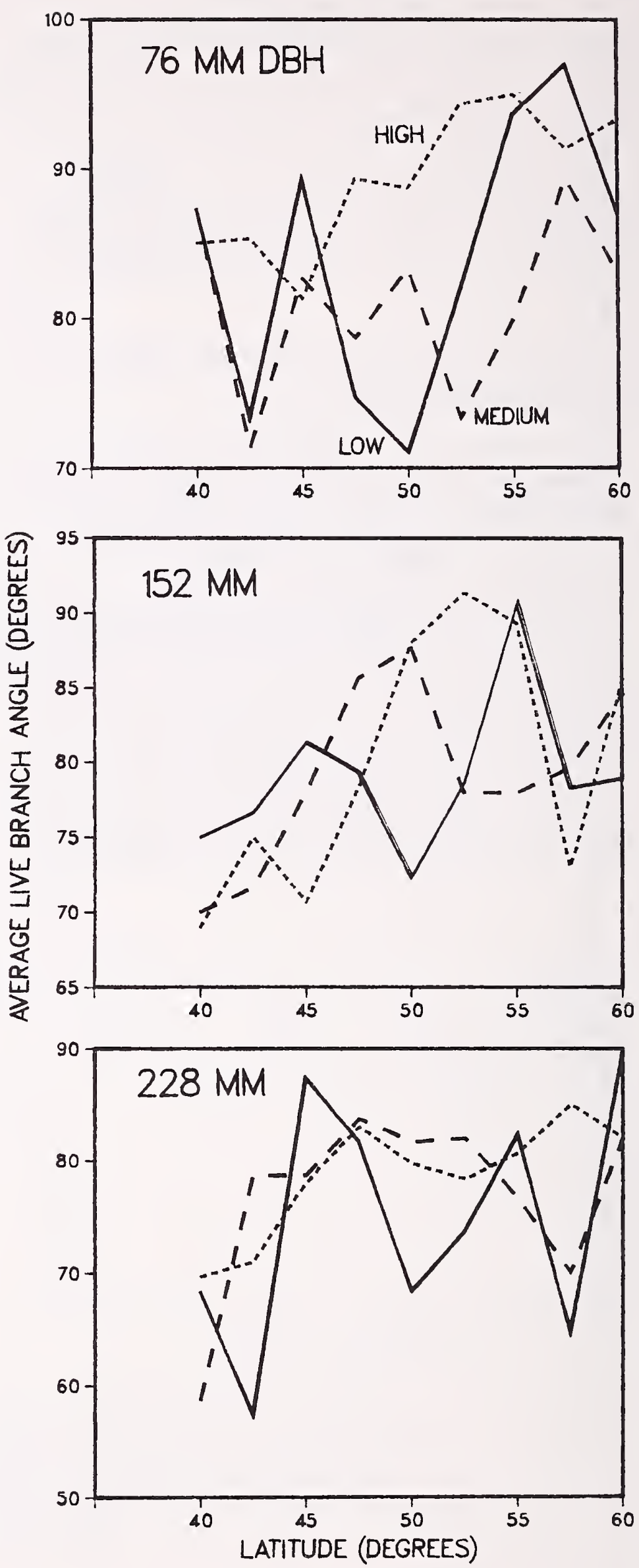

Figure 1-14-Average live branch angle, measured between stem surface above branch and branch upper surface at point of entry to stem, related to elevational zone and latitude for latifolia trees of three diameters. 


\section{Number of Dead Branches}

The number of dead branches per tree was unrelated to elevational zone, but was positively correlated with d.b.h., averaging 57 (36), 100 (43), and 119 (53) for the three diameter classes. Fewest were observed in latitudes 42.5 through 47.5 degrees (average 72), and most in latitudes 50 through 57.5 degrees, where trees averaged 106 dead branches per tree (fig. 1-15).

The number of dead branches was also positively correlated with tree height $(0.53)$, stem length below crown $(0.57)$, and with wood-plus-bark volume of the stump-root system (0.49). It was negatively correlated with treebark percentage of gross tree volume $(-0.55)$.
LATIFOLIA

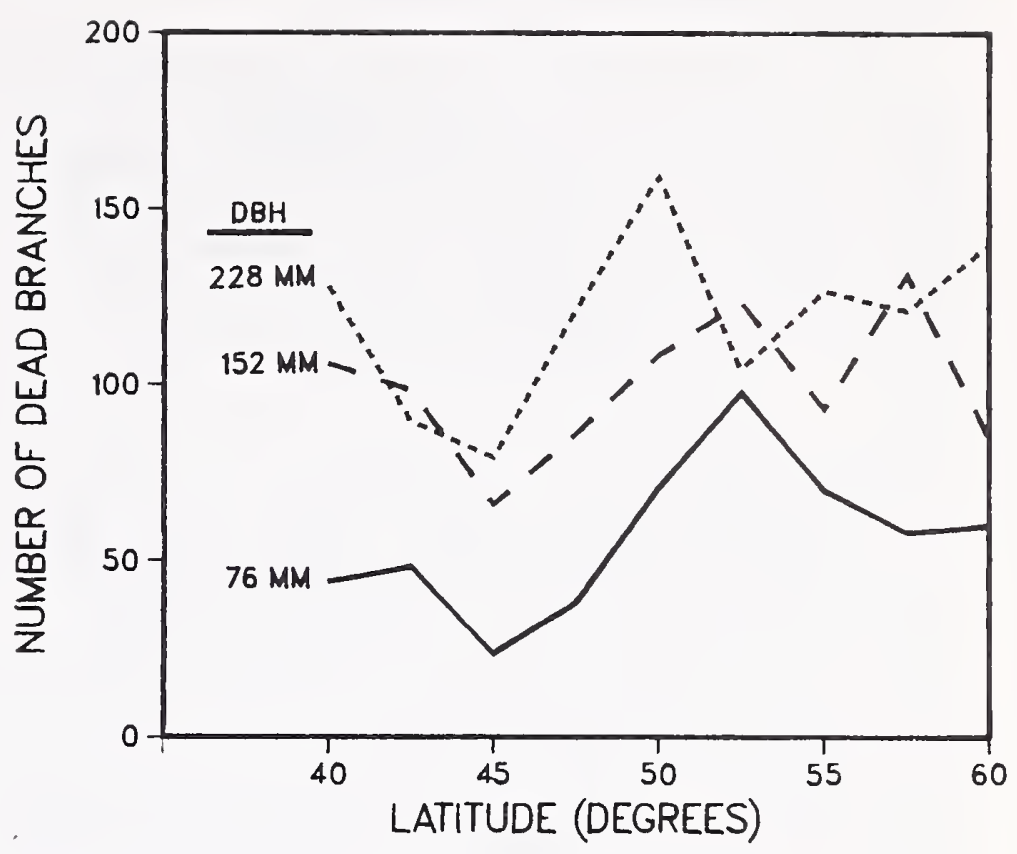

Figure 1-15-Number of dead branches on latifolia trees related to latitude and d.b.h. 


\section{Stem Diameter (Bark-Free) at Base of Live Crown}

Stem diameter at the base of the live crown was proportional to d.b.h., averaging 52 (11.4), 100 (18.5), and 148 (23.1) $\mathrm{mm}$ for the three diameter classes. This belowcrown diameter tended to be larger in southern latitudes than northern-particularly in the two smaller d.b.h. classes (fig. 1-16)-probably because crown ratios in the south were larger than in the north (fig. 1-17).

\section{Crown Ratio}

Crown ratio, the ratio of crown length to tree height from stump top to apical tip, is of primary interest to tree physiologists while stem ratio (1.0 - crown ratio) is of interest to those who convert trees to products. Because stem ratio is easily calculated from crown ratio, only data on the latter are reported here.

Crown ratio was unrelated to tree diameter, averaging 0.456 for all latifolia trees, with standard deviation of 0.168 . It was inversely related to elevational zone, with averages of $0.470,0.453$, and 0.446 for low, medium, and high zones, but the effect varied with latitude (fig. 1-17). Averages for latitudinal zones were lowest at 52.5 and 55 degrees, and highest at 40 through 47.5 degrees, as follows:

$\begin{array}{cr}\text { Latitudinal zone } & \text { Crown rati } \\ \text { Degrees } & \\ 40 & 0.474 \\ 42.5 & .499 \\ 45 & .576 \\ 47.5 & .527 \\ 50 & .431 \\ 52.5 & .368 \\ 55 & .376 \\ 57.5 & .446 \\ 60 & .410\end{array}$

Crown ratio was positively correlated with crown length (0.49) and negatively correlated with stem length below crown $(-0.69)$.

\section{Average Growth-Ring Width at 152-mm Stump Height}

As expected, because the small trees were suppressed and the large trees were the fast growers in most stands selected, growth-ring width was positively related to d.b.h., averaging $0.67(0.35), 1.01(0.35)$, and $1.33(0.46)$ $\mathrm{mm}$ for the three diameter classes. Ring width varied inversely with elevational zone and averaged $1.19,0.96$, and $0.86 \mathrm{~mm}$ for low, medium, and high zones-but the relationship differed with latitude (fig. 1-18). Ring width averaged widest at 47.5 degrees $(1.23 \mathrm{~mm})$ and least at 60 degrees $(0.72 \mathrm{~mm})$.

Average growth-ring width at stump height was positively correlated with taproot length (0.53), crown length $(0.55)$, dead branch volume (0.53), total live branch volume (0.52), volume of wood plus bark in the stump-root system (0.57), and volume of wood plus bark in the stem (0.53).
LATIFOLIA
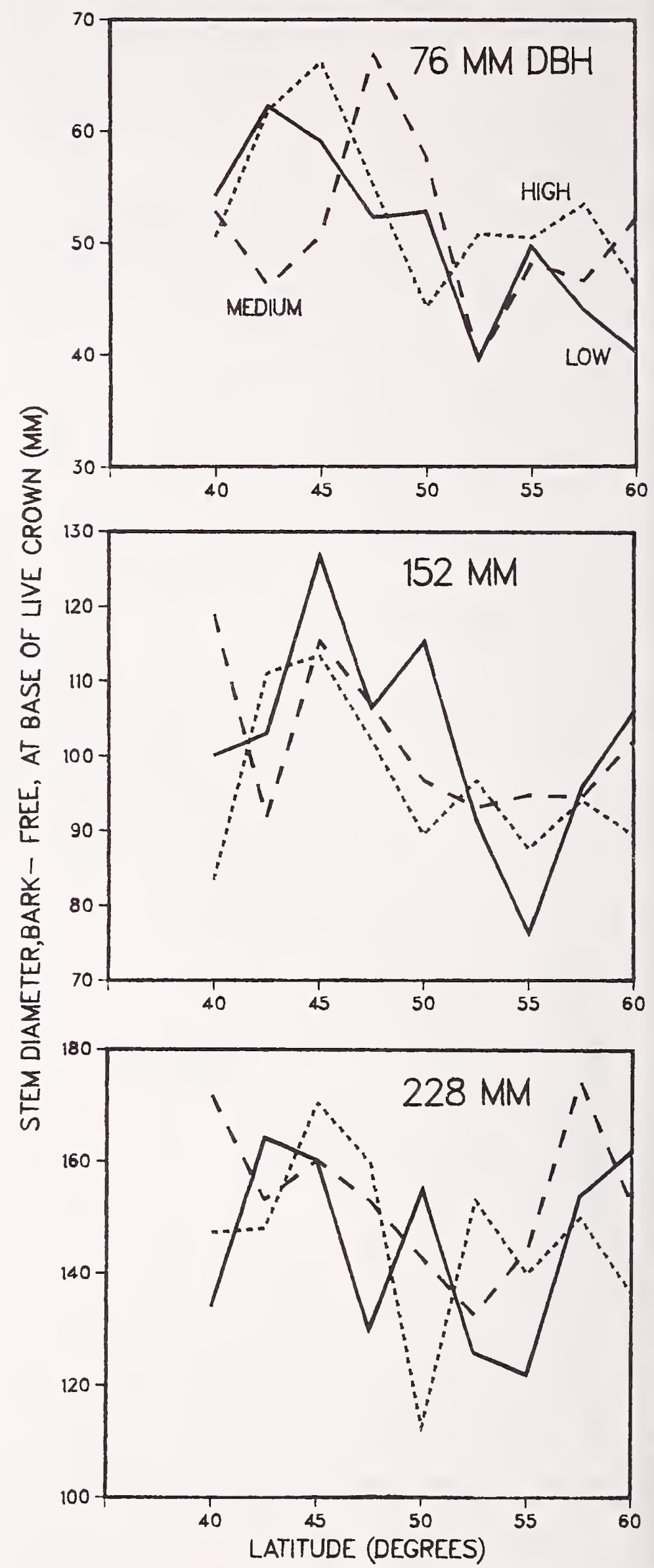

Figure 1-16-Stem diameter, measured inside bark at base of live crown, related to elevational zone and latitude for latifolia trees of three d.b.h. classes. 


\section{LATIFOLIA}
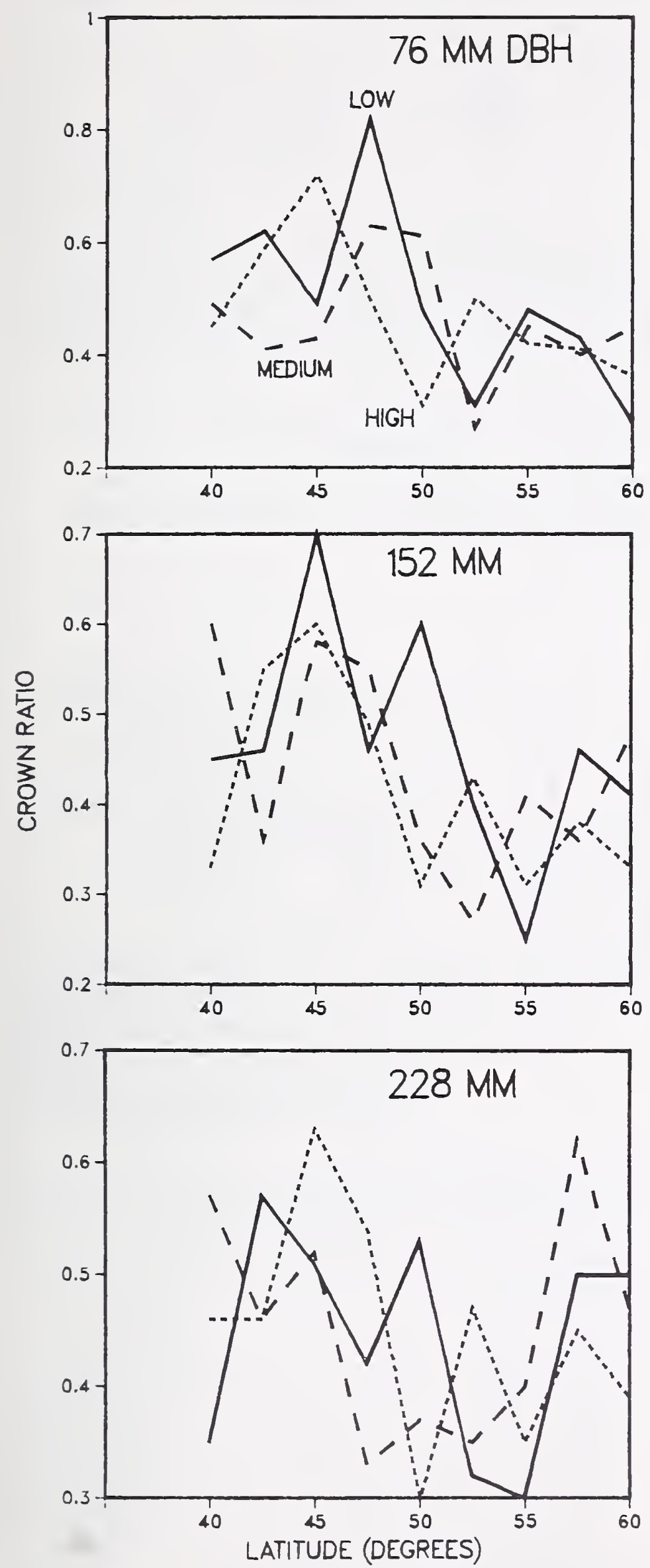

Figure 1-17-Crown ratio (crown length/tree height) related to elevational zone and latitude for latifolia trees of three diameters.
LATIFOLIA

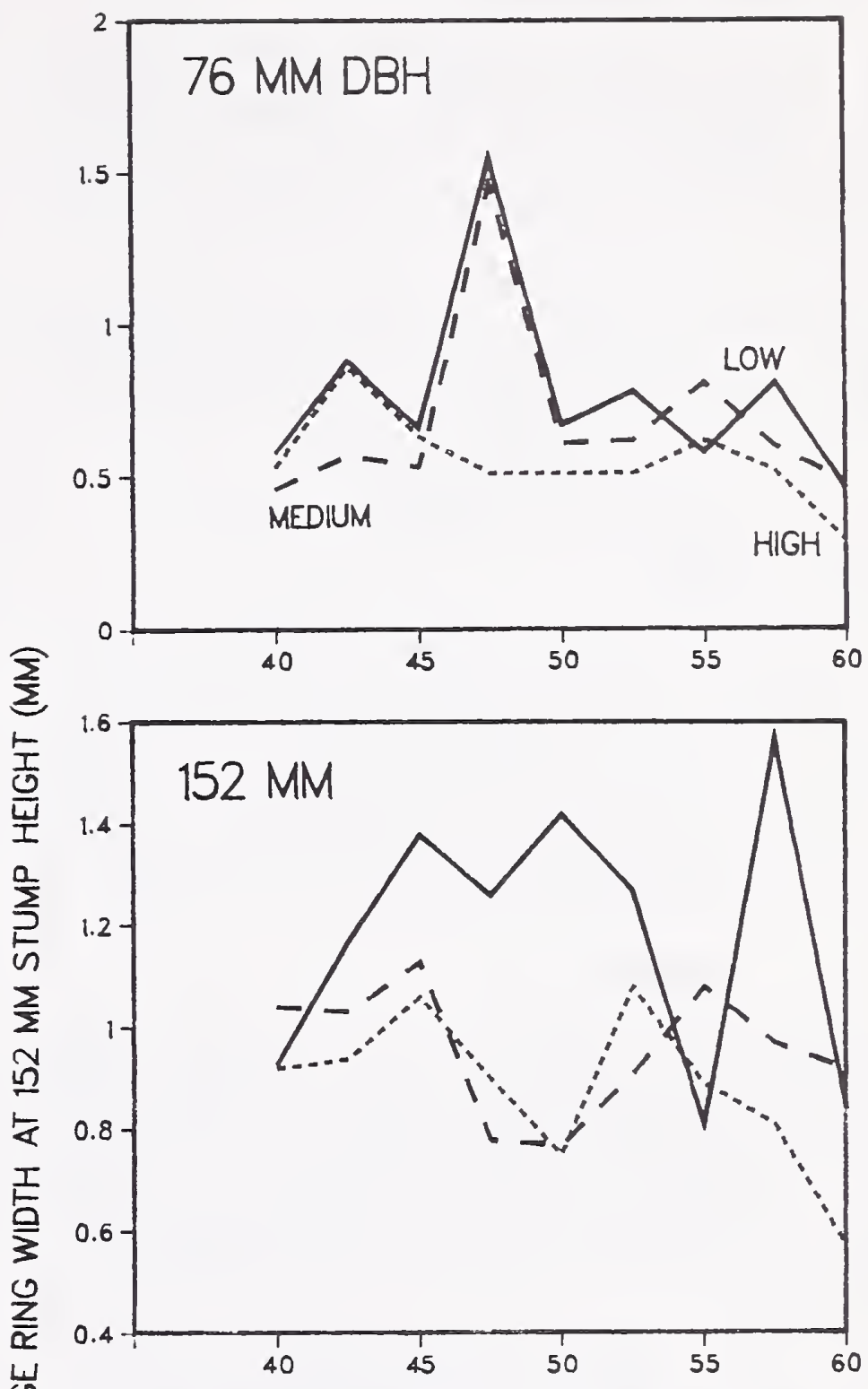

造

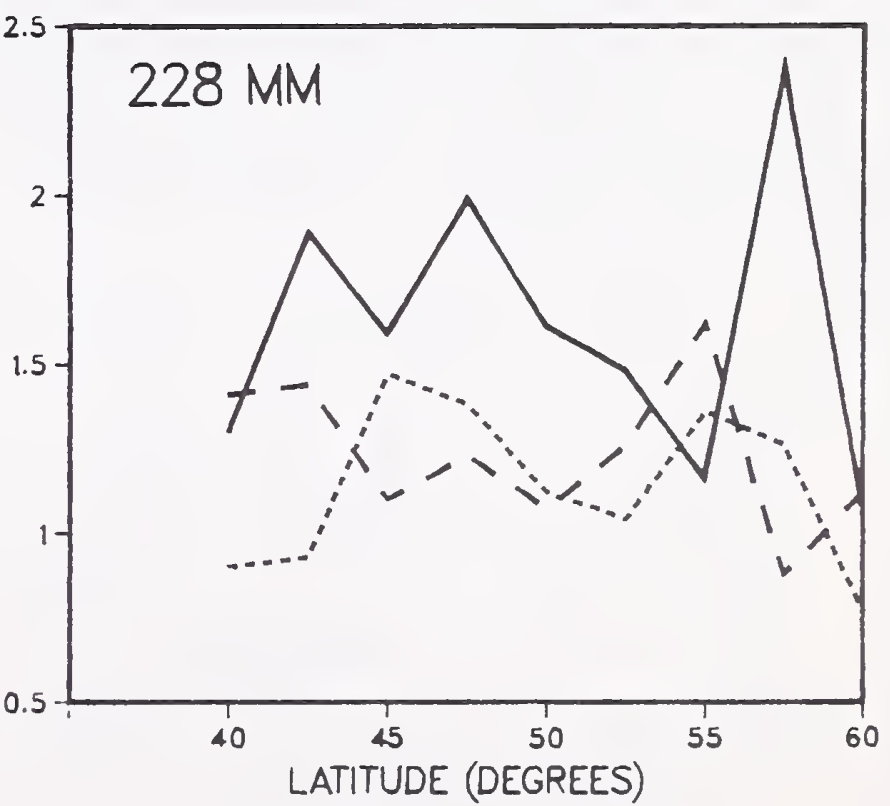

Figure 1-18-Average width of growth rings,

measured at stump height, related to elevational zone and latitude for latifolia of three diameters. 


\section{Number of Cones on the Tip $305 \mathrm{~mm}$ of the Top 25 Branches}

Only 191 of the 243 trees had cones on the tip $305 \mathrm{~mm}$ of the top 25 branches. Aggregate cone numbers on these 25 branches were unrelated to latitudinal or elevational zone, but were positively correlated with d.b.h., averaging 6 (19), 35 (32), and 78 (62) cones for the three diameter classes.

Number of cones on the tip $305 \mathrm{~mm}$ of the top 25 branches was positively correlated with the wood-plus-bark volume of the stump-root system $(0.55)$, average branch diameter (0.52), total live branch volume $(0.46)$, and the wood-plus-bark volume of the stem $(0.58)$.

\section{Total Number of Cones per Tree (Calculated)}

The calculated number of cones per tree was unrelated to latitudinal or elevational zones, but was positively correlated with d.b.h., averaging 32 (86), 160 (154), and 555 (587) cones per tree for the three diameter classes. These averages are low because they reflect the fact that not all of the 243 trees had cones on the tip $305 \mathrm{~mm}$ of the top 25 branches-the basis for computation of tree totals.

\section{Cone Serotiny}

The number of trees with cones on the top 25 branches was positively correlated with d.b.h., numbering 37,74 , and 80 for the three diameter classes-for a total of 191 out of the total 243 latifolia trees. The number of conebearing trees was unrelated to elevational zone, and averaged 21 trees out of 27 per latitude, varying from a minimum of 16 at 47.5 degrees to a maximum of 26 at 60 degrees.

Of these 191 trees with cones, 62.3 percent had predominantly serotinous (closed) cones and 25.7 percent had predominantly open cones; the remaining 12 percent was intermediate. A greater percentage of cone-bearing trees in lower elevational zones had serotinous cones, and a lesser percentage had open cones, than trees in highelevation zones, as follows:

$\begin{array}{ccc}\begin{array}{c}\text { Elevational } \\ \text { zone }\end{array} & \text { Serotinous } & \text { Open } \\ & \ldots \ldots \text { - Percent } & -\ldots \\ \text { Low } & 67.1 & 20.2 \\ \text { Medium } & 65.8 & 21.3 \\ \text { High } & 57.3 & 34.9\end{array}$

A greater percentage of cone-bearing trees of small d.b.h. had serotinous cones than trees of large d.b.h.; percentage of open-coned trees was unrelated to d.b.h., however, as follows:

$\begin{array}{rcc}\begin{array}{c}\text { D.b.h. } \\ \text { class }\end{array} & \text { Serotinous } & \text { Open } \\ m m & -\ldots \text { - Percent } & \ldots \\ 76 & 65.3 & 25.4 \\ 152 & 60.7 & 27.1 \\ 228 & 59.9 & 23.8\end{array}$

At all latitudes the proportion of cone-bearing trees with intermediate cones (neither predominantly open nor predominantly closed) was more or less constant in the range from 10 to 20 percent. The percentage of trees with serotinous cones exceeded the percentage with open cones at all latitudes except 42.5 and 45 degrees, but the proportion of trees with predominantly serotinous cones increased with increasing latitude; at latitudes of 52.5 through 60 degrees, virtually all cone-bearing trees had serotinous cones (fig. 1-19).

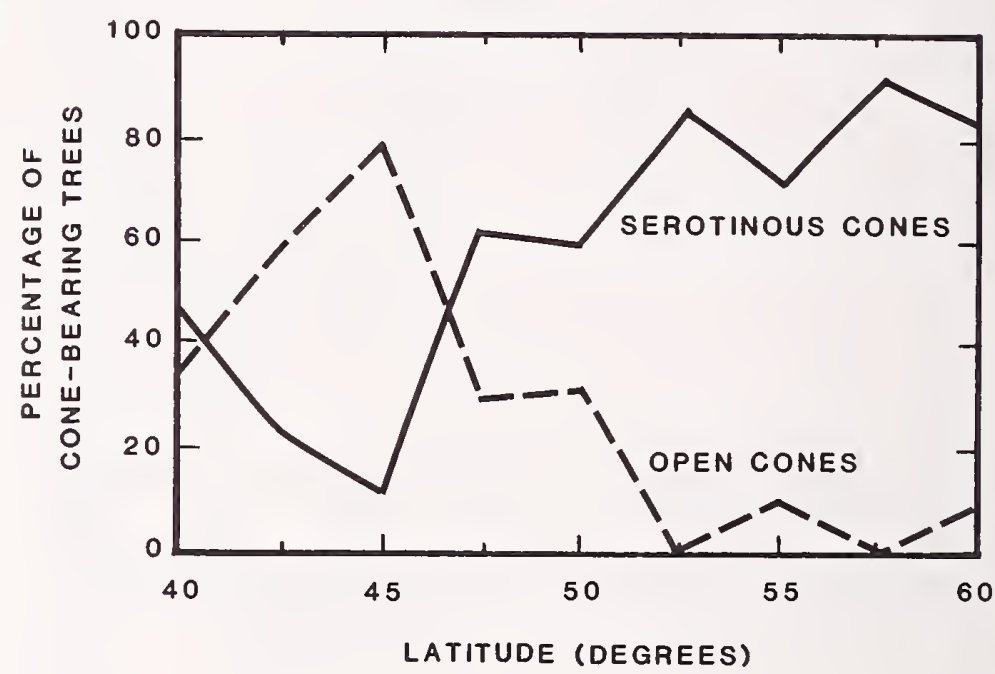

Figuro 1-19-Latitudinal zone related to percentage of cone-bearing latifolia trees having predominantly serotinous (closed) cones and predominantly open cones. Remaining trees (10 to 20 percent) carried a mixture of serotinous and open cones. 


\section{Lateral Rootbark Thickness (Measured With a Scale)}

Bark thickness of the lateral roots within a few inches of the root collar was unrelated to elevational zone, but was positively correlated with d.b.h., averaging $2.2(0.60), 3.3$ (1.01), and $4.6(1.32) \mathrm{mm}$ for the three diameter classes. Bark was thinnest (average $3.2 \mathrm{~mm}$ ) in the five southern latitudinal zones and thickest $(3.6 \mathrm{~mm})$ in the four northernmost zones (fig. 1-22).

Lateral rootbark thickness was negatively correlated with live branchbark percentage of gross live branch volume $(-0.50)$. It was positively correlated with tree height (0.47), crown width (0.59), live branch diameter (0.59), branchbark thickness (0.43), bark thickness of central root $(0.71)$, stumpbark thickness $(0.72)$, stembark thickness at 50 percent of tree height (0.66), total live branch volume (0.65), wood-plus-bark volume of stump-root system (0.65), and bark volume of the stump-root system $(0.70)$.
LATIFOLIA

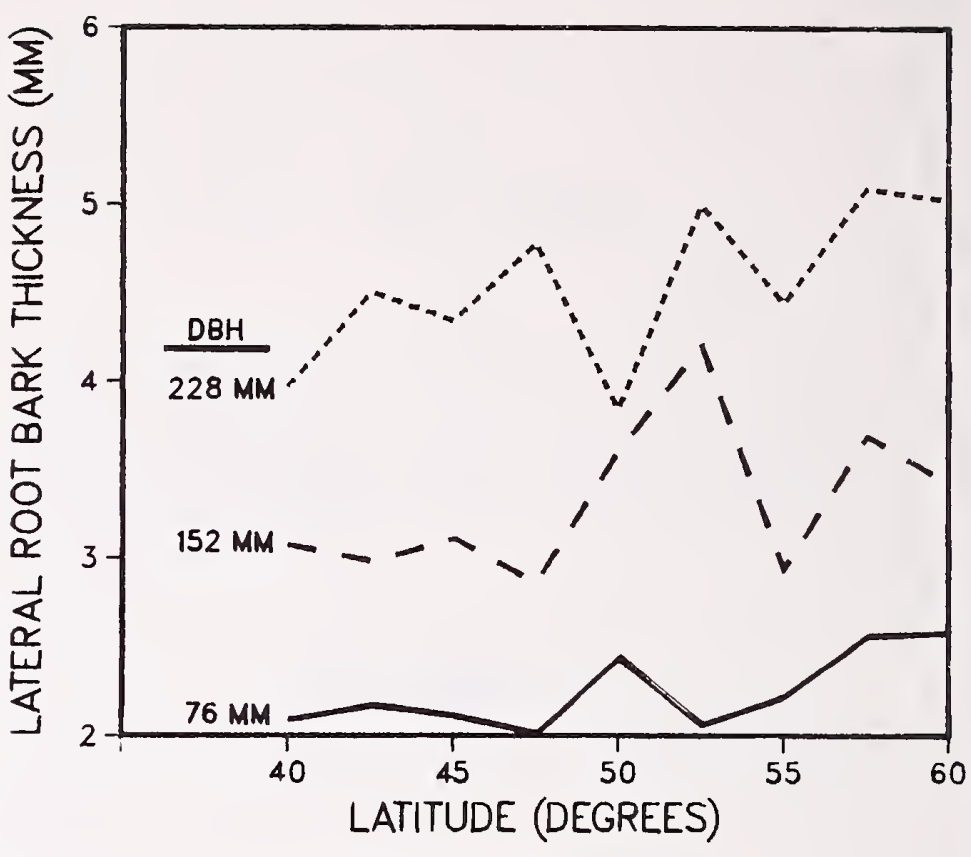

Figure 1-22-Lateral rootbark thickness related to latitude for latifolia trees of three diameters. 


\section{Stumpbark Thickness (Measured With a Scale)}

Bark thickness of the stump between groundline and 152-mm stump height was positively correlated with d.b.h., averaging 4.2 (1.20), 6.8 (2.83), and $8.6(2.79) \mathrm{mm}$ for the three diameter classes. Bark averaged thickest in low-elevation zones $(7.0 \mathrm{~mm})$ and in midlatitude zones $(7.6 \mathrm{~mm})$; it averaged thinnest in high-elevation zones $(6.2 \mathrm{~mm})$ and in the three southern or three northern latitudinal zones $(6.0 \mathrm{~mm})$. Interactions between elevational and latitudinal zones were complex, however (fig. 1-23).

Stumpbark thickness was also positively correlated with crown width (0.55), thickness of central rootbark (0.70), thickness of lateral rootbark (0.72), thickness of stembark at 50 percent of tree height (0.57), total live branch volume (0.55), and wood-plus-bark volume of the stumproot system (0.57). It was only weakly correlated with branchbark thickness $(0.27)$.
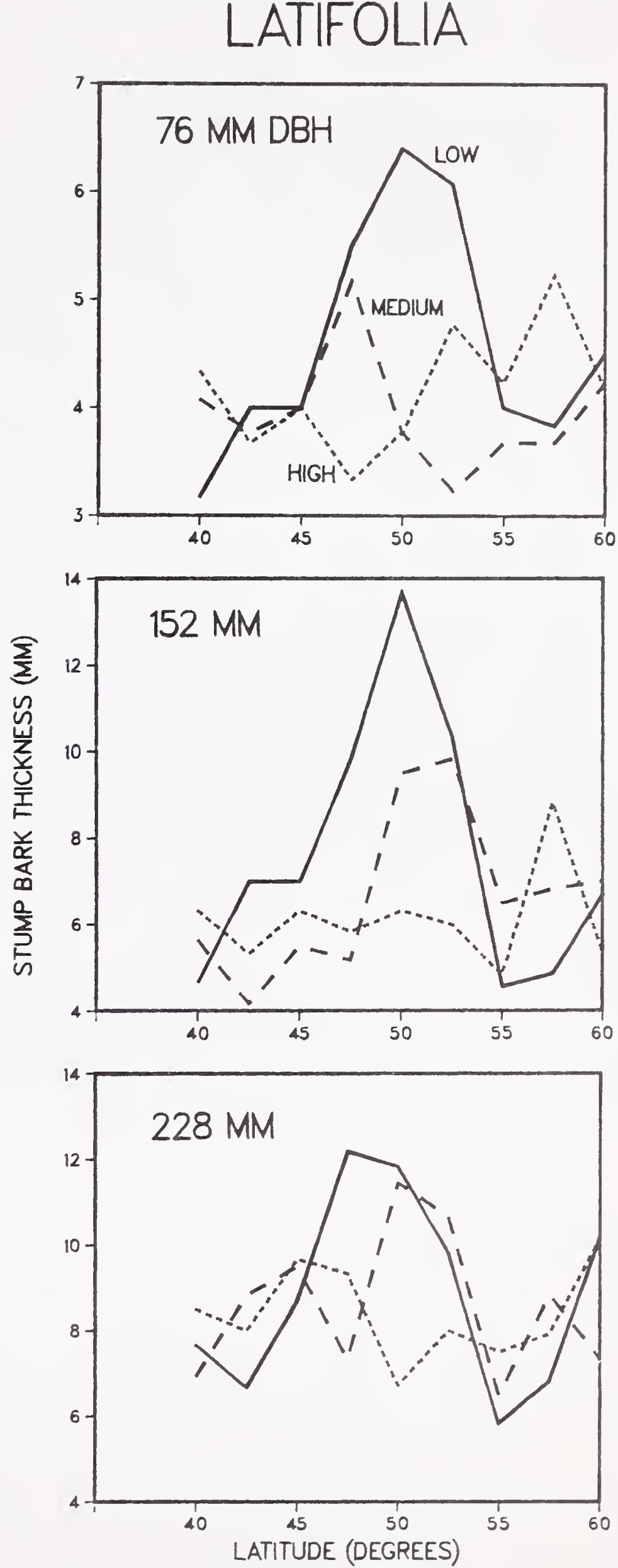

Figure 1-23-Stumpbark thickness, averaged from groundline to $152-\mathrm{mm}$-high stump top, related to elevational zone and latitude for latifolia trees of three diameters. 


\section{Stembark Thickness (Measured With a Diameter Tape)}

Stembark thickness was measured from stump level ( 0 percent tree height) to 90 percent of height to apical tip, at 10-percent intervals. Tree d.b.h. and height in stem were the dominant variables related to stembark thickness; bark was thickest at stump level and diminished in ogee pattern with increased height in tree, and with tree d.b.h. (fig. 1-24). Pooling all elevation, latitude, and heightin-tree classes, stembark thickness averaged 2.4, 3.7, and $4.9 \mathrm{~mm}$ for the three diameter classes.

Only at stump height was stembark thickness inversely related to elevation class; i.e., with all other factors pooled, bark at stump height was $7.5 \mathrm{~mm}$ thick at low, $6.3 \mathrm{~mm}$ at medium, and $6.1 \mathrm{~mm}$ thick at high elevation. At all higher levels in the stem, stembark thickness was about equal at medium and high elevation, but was consistently 0.1 or $0.2 \mathrm{~mm}$ thinner at low elevation than in the other two elevation classes.

With stembark thickness averaged for all heights in the stem, latitudinal effects were minor (fig. 1-25).

Stembark thickness at 50 percent of tree height was positively correlated with height to $25 \mathrm{~mm}$ top diameter $(0.58)$, crown width $(0.70)$, crown length $(0.47)$, number of live branches $(0.53)$, live branch diameter $(0.71)$, growthring width at stump height (0.43), number of cones on the top 25 branches (0.52), branchbark thickness (0.57), central rootbark thickness $(0.60)$, lateral rootbark thickness $(0.66)$, stumpbark thickness (0.57), total live branch volume (0.76), total stump-root system volume (0.78), and stembark volume (0.82).
LATIFOLIA

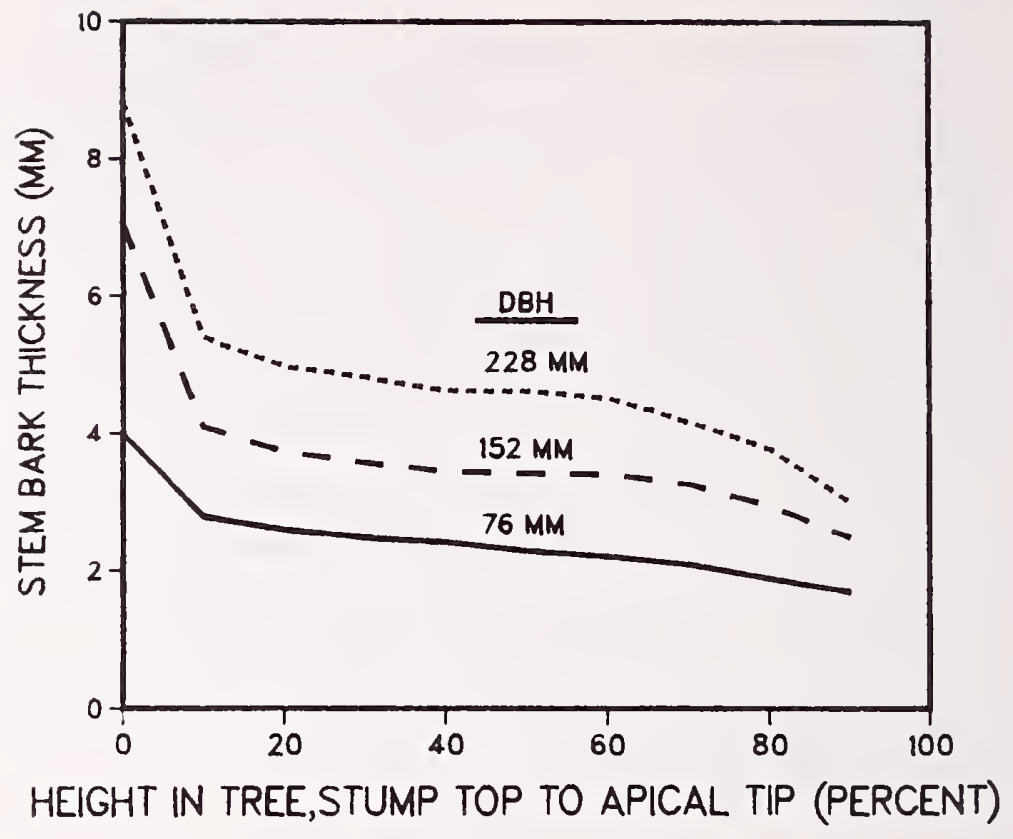

Figure 1-24-Stembark thickness related to height in latifolia trees of three diameters.
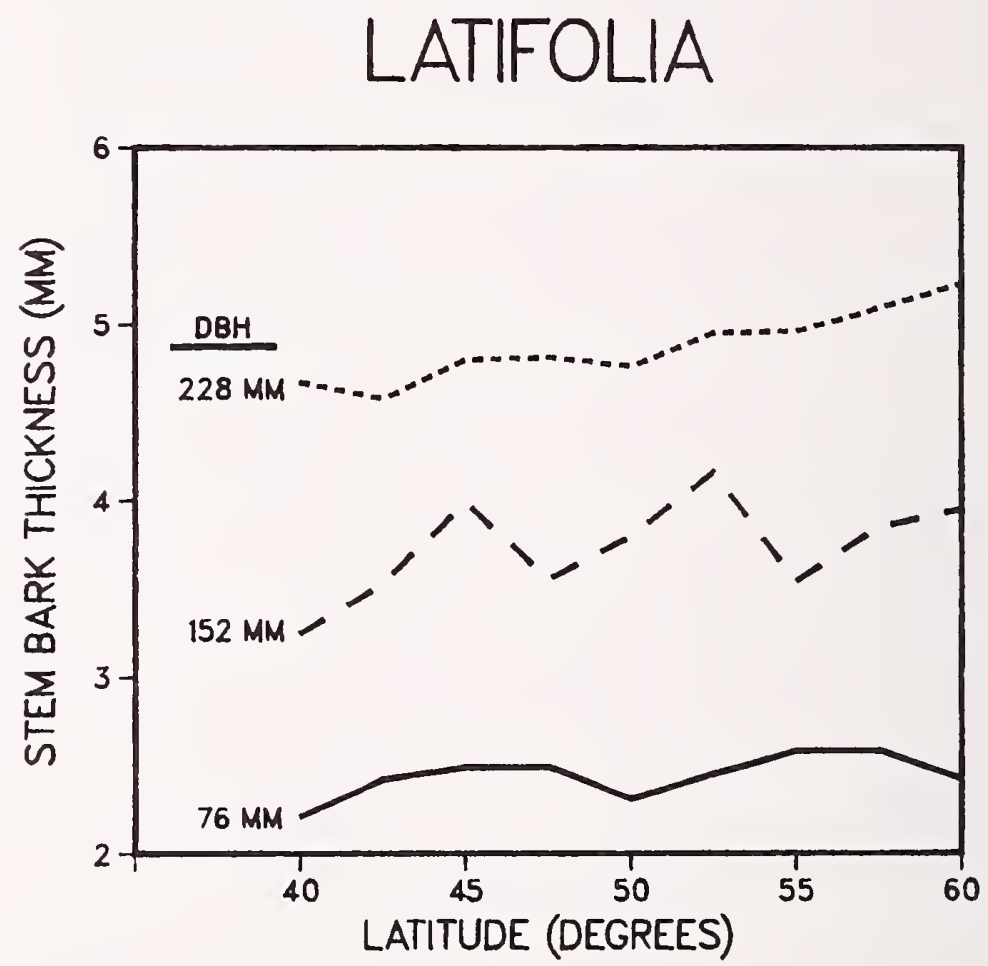

Figure 1-25-Stembark thickness, averaged from stump height to 90 percent of tree height, related to latitude for latifolia trees of three diameters. 


\section{Total Volume of Dead Branches (Thousand $\mathrm{cm}^{3}$ )}

Volume of dead branches was positively correlated with d.b.h., averaging $0.5(0.40), 3.4$ (2.87), and 10.2 (9.40) for the three diameter classes. High-elevation trees had less volume of dead branches than low-elevation trees, as follows:

\begin{tabular}{cccc} 
& \multicolumn{3}{c}{ Elevation class } \\
\cline { 2 - 4 } D.b.h. & Low & Medium & High \\
$\mathrm{mm}$ & $\ldots \ldots$ & Thousand $\mathrm{cm}^{3}$ & $\ldots$ \\
76 & 0.7 & 0.5 & 0.4 \\
152 & 4.5 & 3.1 & 2.7 \\
228 & 13.9 & 9.9 & 6.7 \\
Average & 6.4 & 4.5 & 3.3
\end{tabular}

The effect of latitude varied with diameter and elevation class (fig. 1-26). At 57.5 degrees, all $152-\mathrm{mm}$ trees had average dead-branch volume of 7.15 ; at the other eight latitudes, dead-branch volume for this diameter class (elevations pooled) averaged much less-in the range from 2.2 to 3.7 .

Dead-branch volume was positively correlated with crown width $(0.50)$, average ring width at stump height (0.53), total live branch volume $(0.59)$, total root system volume (0.58), and total stem volume $(0.54)$.

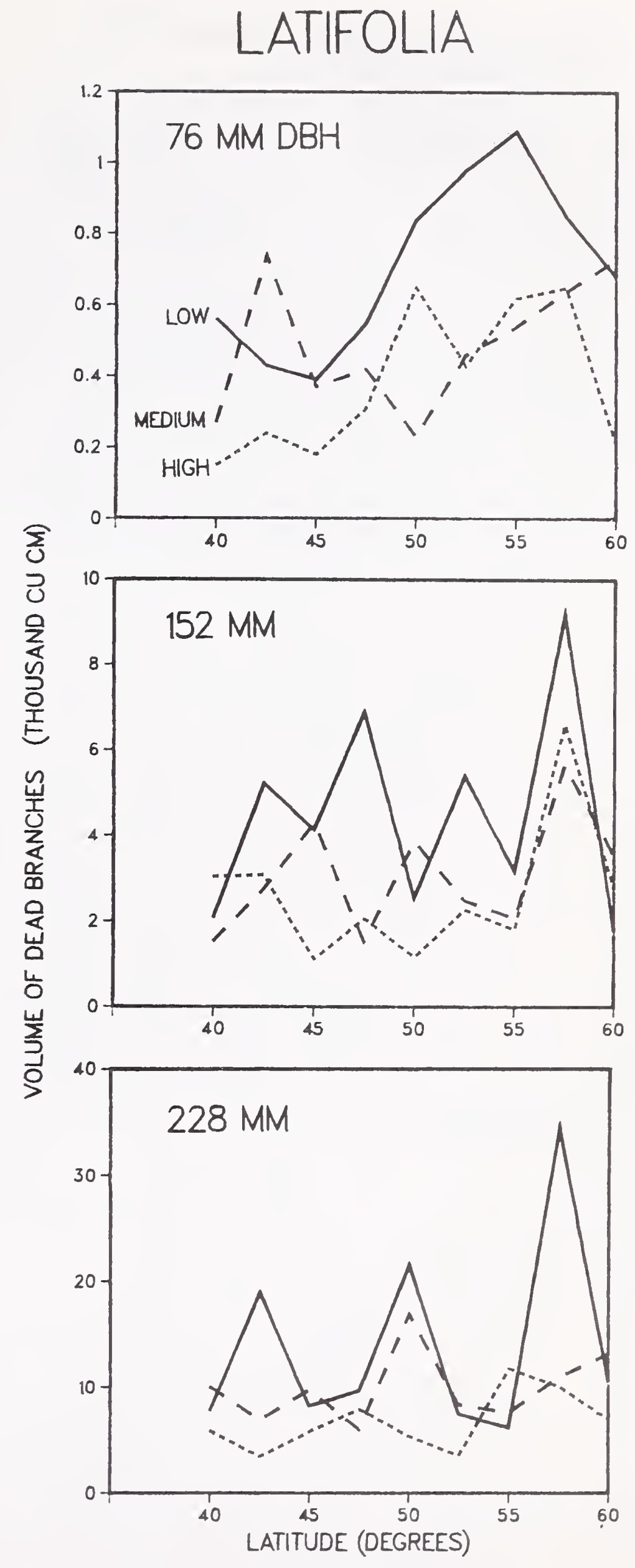

Figure 1-26-Volume of dead branches of latifolia trees of three diameters related to elevational zone and latitude. 


\section{Volume of Live Branches, Wood Plus Bark (Thousand $\mathrm{cm}^{3}$ )}

Total volume was positively correlated with d.b.h., averaging 1.5 (0.81), $10.2(4.37)$, and 35.9 (15.15) for the three diameter classes. Volume varied inversely with elevation, averaging (with all latitudes and diameters pooled) 17.6, 16.3, and 13.6 for low-, medium-, and high-elevation classes; for the $76-\mathrm{mm}$ diameter class, latitude interacted with elevation, however (fig. 1-27).

Total live branch volume was also negatively correlated with live branchbark percentage of gross live branch volume $(-0.66)$. It was positively correlated with tree height (0.56), length of taproot (0.52), width of crown (0.87), length of crown (0.50), number of live branches $(0.50)$, live branch diameter (0.77), average growth-ring width at stump height (0.52), branchbark thickness $(0.55)$, lateral rootbark thickness $(0.65)$, stembark thickness at 50 percent of tree height $(0.76)$, dead branch volume $(0.60)$, total stump-root system volume (0.84), and total stem volume (0.77).
LATIFOLIA
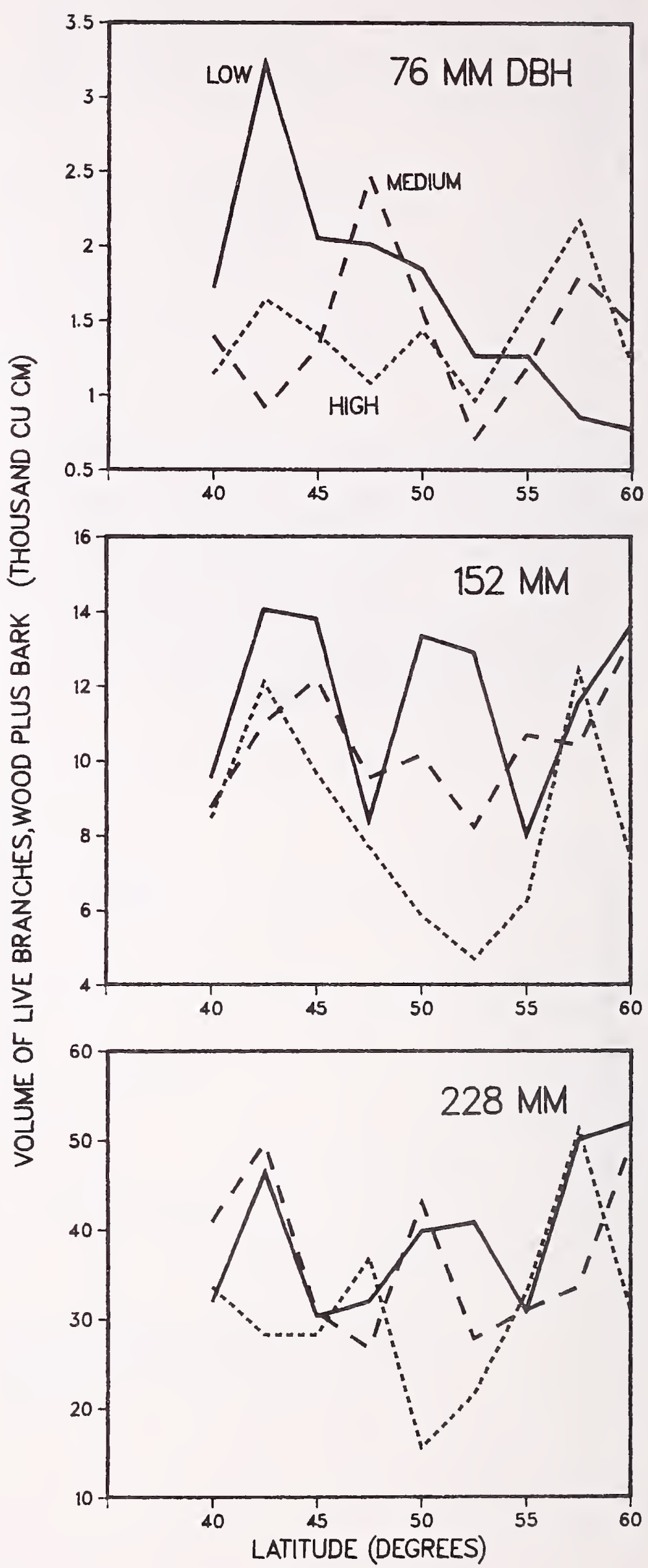

Figure 1-27-Live-branch volume, wood plus bark, of latifolia trees of three diameters related to elevational zone and latitude. 


\section{Volume of Live Branchwood (Thousand $\mathrm{cm}^{3}$ )}

Live branchwood volume was positively correlated with d.b.h., averaging $0.8(0.45), 6.4$ (2.81), and 25.5 (11.27) for the three diameter classes. Volume tended to vary inversely with elevation, particularly for the 152 -mm trees; with all diameter and latitude values pooled, averages were 12.2, 11.3, and 9.2 for low-, medium-, and high-elevation classes. Latitude interacted with elevation in the $76-\mathrm{mm}$ diameter class, elevation was the main effect in the $152-\mathrm{mm}$ class, but the $228-\mathrm{mm}$ diameter class showed no branchwood volume relation to either latitude or elevation (fig. 1-28),

Live branchwood volume was also positively correlated with crown width $(0.86)$, average live branch diameter (0.78), stembark thickness at 50 percent of tree height (0.73), total volume of stump-root system (0.84), and total stem volume $(0.77)$.

\section{Volume of Live Branchbark (Thousand $\mathrm{cm}^{3}$ )}

Live branchbark volume was positively correlated with d.b.h., averaging 0.7 (0.39), 3.8 (1.74), and 10.4 (4.43) for the three diameter classes. It was unrelated to latitude, but was inversely correlated with elevation class, particularly in 152-mm trees, as follows:

\begin{tabular}{cccc} 
& \multicolumn{3}{c}{ Elevation class } \\
\cline { 2 - 4 } D.b.h. & Low & Medium & High \\
$\mathrm{mm}$ & $-\ldots$. & Thousand $\mathrm{cm}^{3}$ & $\ldots$ \\
76 & 0.8 & 0.7 & 0.7 \\
152 & 4.3 & 3.8 & 3.1 \\
228 & 11.1 & 10.6 & 9.5 \\
Average & 5.4 & 5.0 & 4.4
\end{tabular}

Volume of live branchbark was also positively correlated with crown width $(0.84)$, crown length $(0.56)$, average live branch diameter $(0.70)$, average ring width at stump height (0.57), lateral rootbark thickness (0.65), stembark thickness at 50 percent of stem height (0.79), total stumproot system volume $(0.82)$, and total stem volume $(0.74)$.

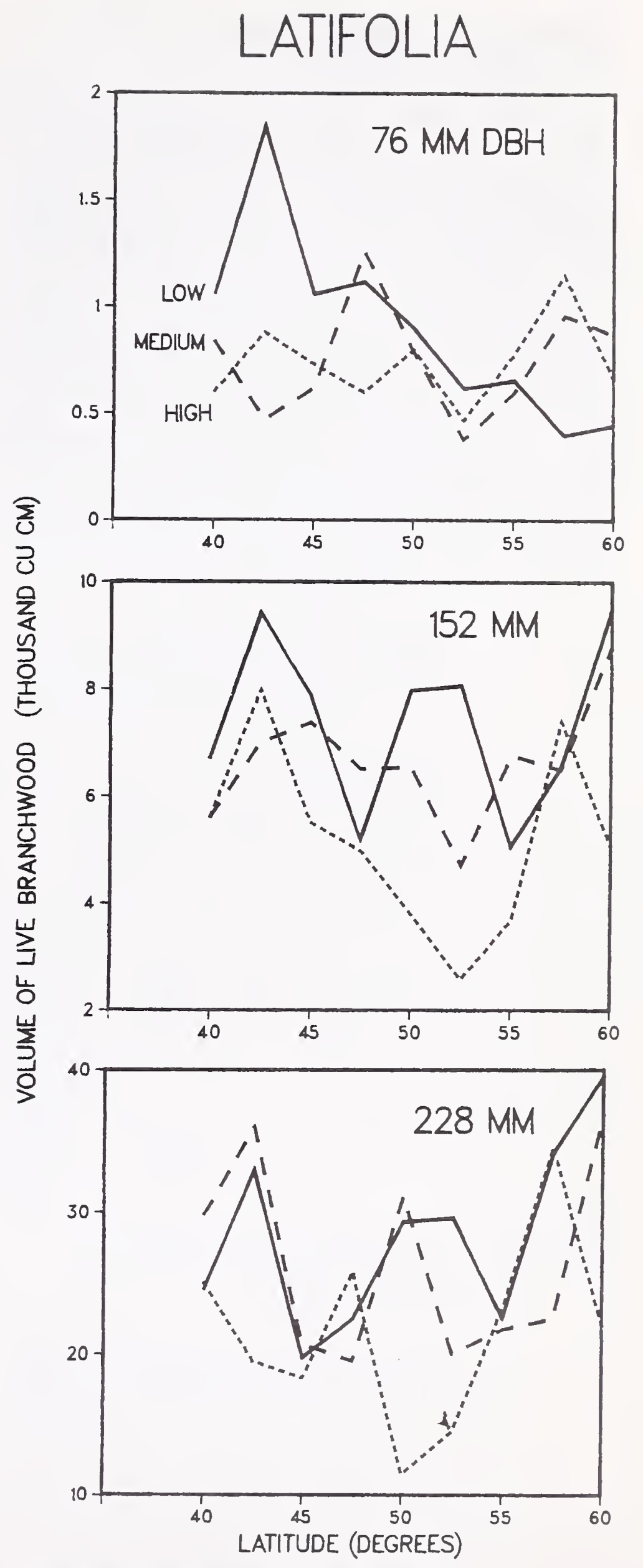

Figure 1-28-Live branchwood volume related to elevational zone and latitude for latifolia trees of three diameters. 


\section{Volume of Stump-Root System, Wood Plus Bark (Thousand $\mathrm{cm}^{3}$ )}

Stump-root system volume was positively correlated with tree d.b.h., averaging $4.2(0.95), 20.9$ (3.30), and 49.3 (7.17) for the three diameter classes. For $76-\mathrm{mm}$ trees, system volume was greater in northern than in southern latitudes, and for 228-mm trees, system volumes in southern latitudes were less in lower elevation classes than in higher-except at latitude 57.5 degrees (fig. 1-29).

Volume of the stump-root system including wood and bark was negatively correlated with stembark volume percentage of gross stem volume $(-0.71)$. It was positively correlated with tree height to 25 -mm top diameter $(0.82)$, crown width (0.81), number of live branches (0.62), average live branch diameter (0.81), average growth-ring width at stump height (0.57), number of cones on top 25 branches $(0.62)$, stembark thickness at 50 percent of tree height (0.78), total live branch volume (0.84), stem volume including wood and bark (0.95), and complete-tree volume (0.97).

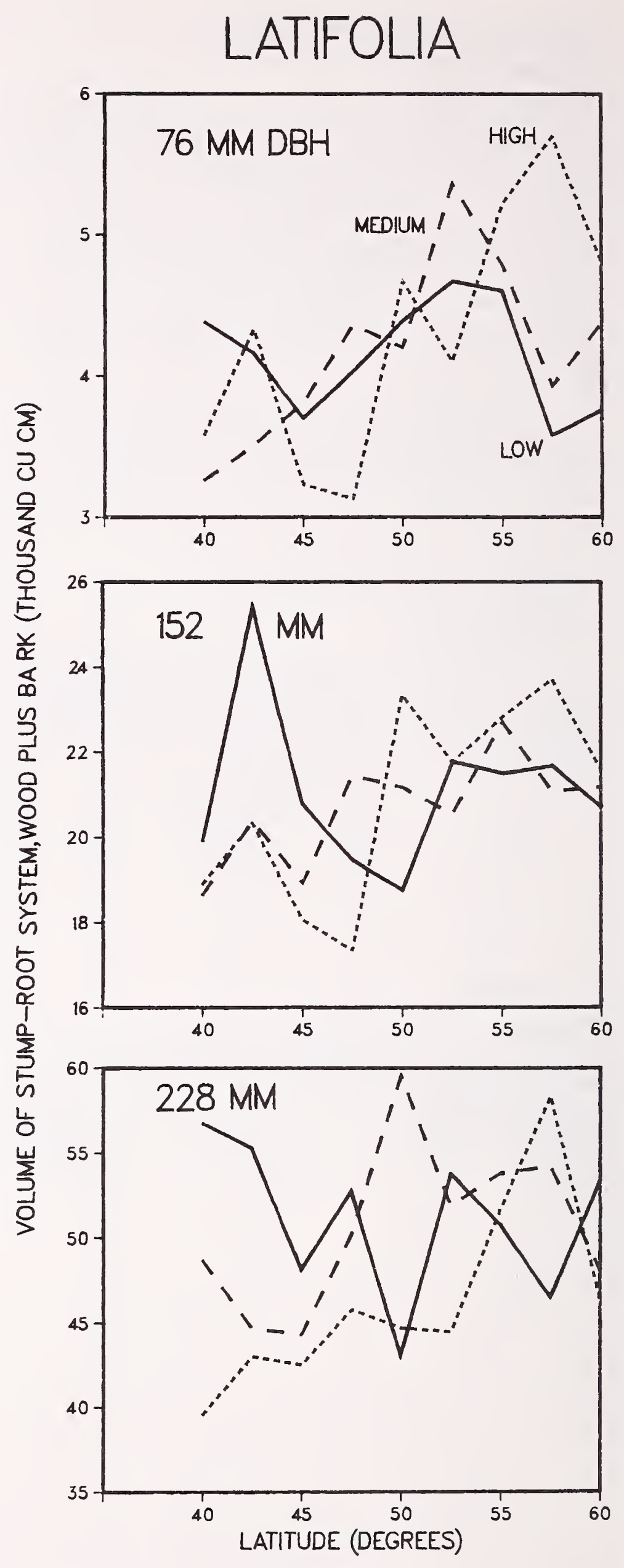

Figure 1-29-Stump-root system volume, wood plus bark, of latifolia trees of three diameters related to elevational zone and latitude. 


\section{Volume of Stump, Wood Plus Bark (Thousand $\mathrm{cm}^{3}$ )}

Stump volume (groundline to 152 -mm-high stump top) was unrelated to elevational zone, but was positively correlated with tree d.b.h., averaging $1.3(0.30), 4.2$ (1.17), and 8.4 (2.60) for the three diameter classes. Stump volumes were largest in latitudinal zones 40 and 42.5 degrees and smallest between latitudes 52.5 and 60 degrees, depending on d.b.h. (fig. 1-30).

\section{Volume of Lateral Roots, Wood Plus Bark (Thousand $\mathrm{cm}^{3}$ )}

Lateral root volume (root collar to a radius $305 \mathrm{~mm}$ from stump pith) was unrelated to elevational zone, but was positively correlated with tree d.b.h., averaging 1.2 (0.61). 7.5 (2.13), and 17.2 (5.34) for the three diameter classes. Lateral root volumes were smallest or nearly so at latitude 40 degrees and largest at 57.5 or 60 degrees, depending on diameter (fig. 1-31).

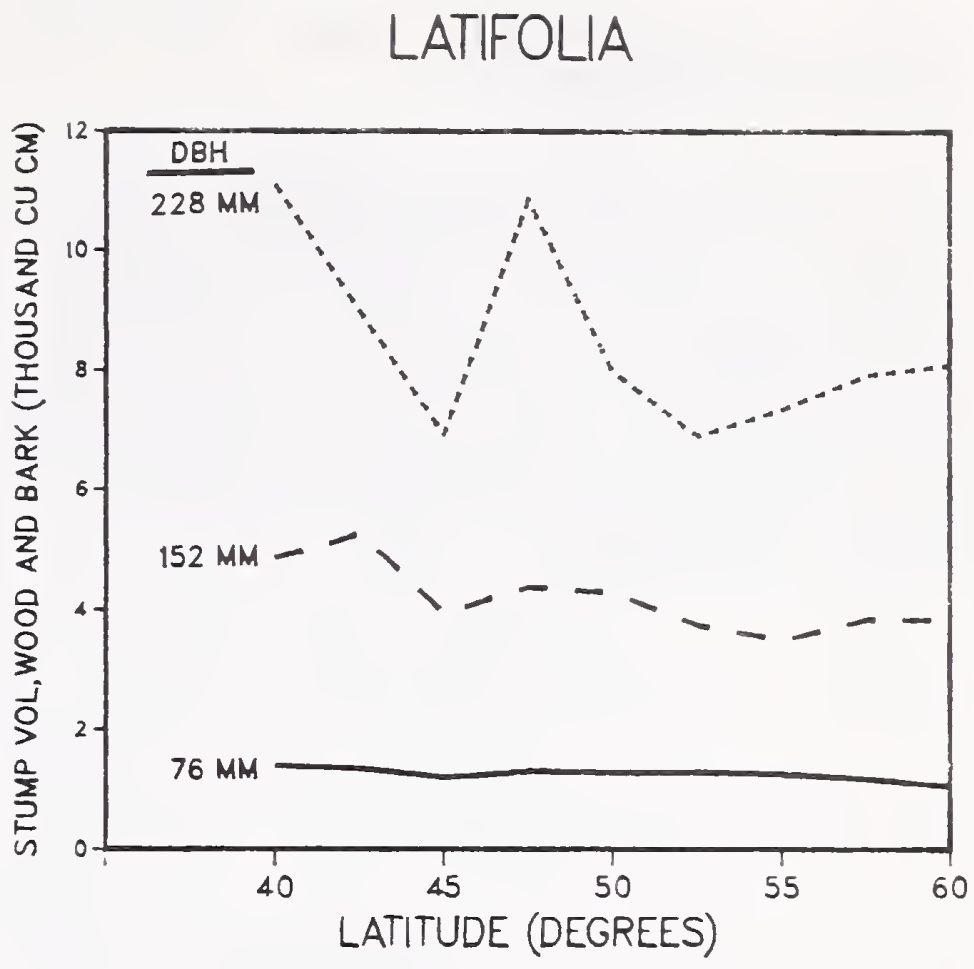

Figure 1-30-Stump volume from groundline to stump top, wood plus bark, related to latitude for latifolia trees of three diameters.
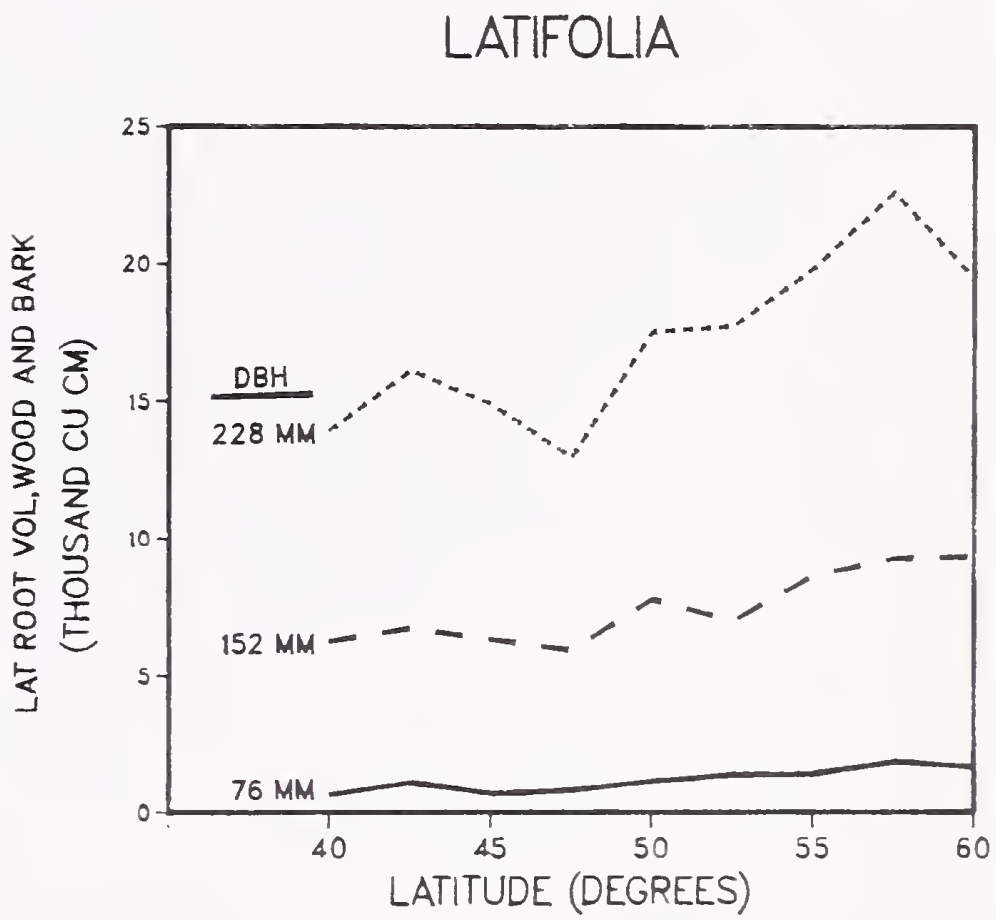

Figure 1-31-Lateral root volume, wood plus bark, related to latitude for latifolia trees of three diameters. 


\section{Volume of Central Root Mass, Wood Plus Bark (Thousand $\mathrm{cm}^{3}$ )}

The central root mass shorn of laterals and stump, but with that portion of the taproot recovered by the field crews, had volume positively correlated with tree d.b.h., averaging $1.8(0.55), 9.3(2.57)$, and 23.4 (5.75) for the three diameter classes. For $76-\mathrm{mm}$ trees, volumes were largest in latitudes 50 through 55 degrees and smallest in latitude 57.5 degrees; $152-\mathrm{mm}$ trees had central root mass volume unrelated to either latitude or elevational zone; 228-mm trees had a complex interaction of latitude with elevational zone (fig. 1-32).
LATIFOLIA

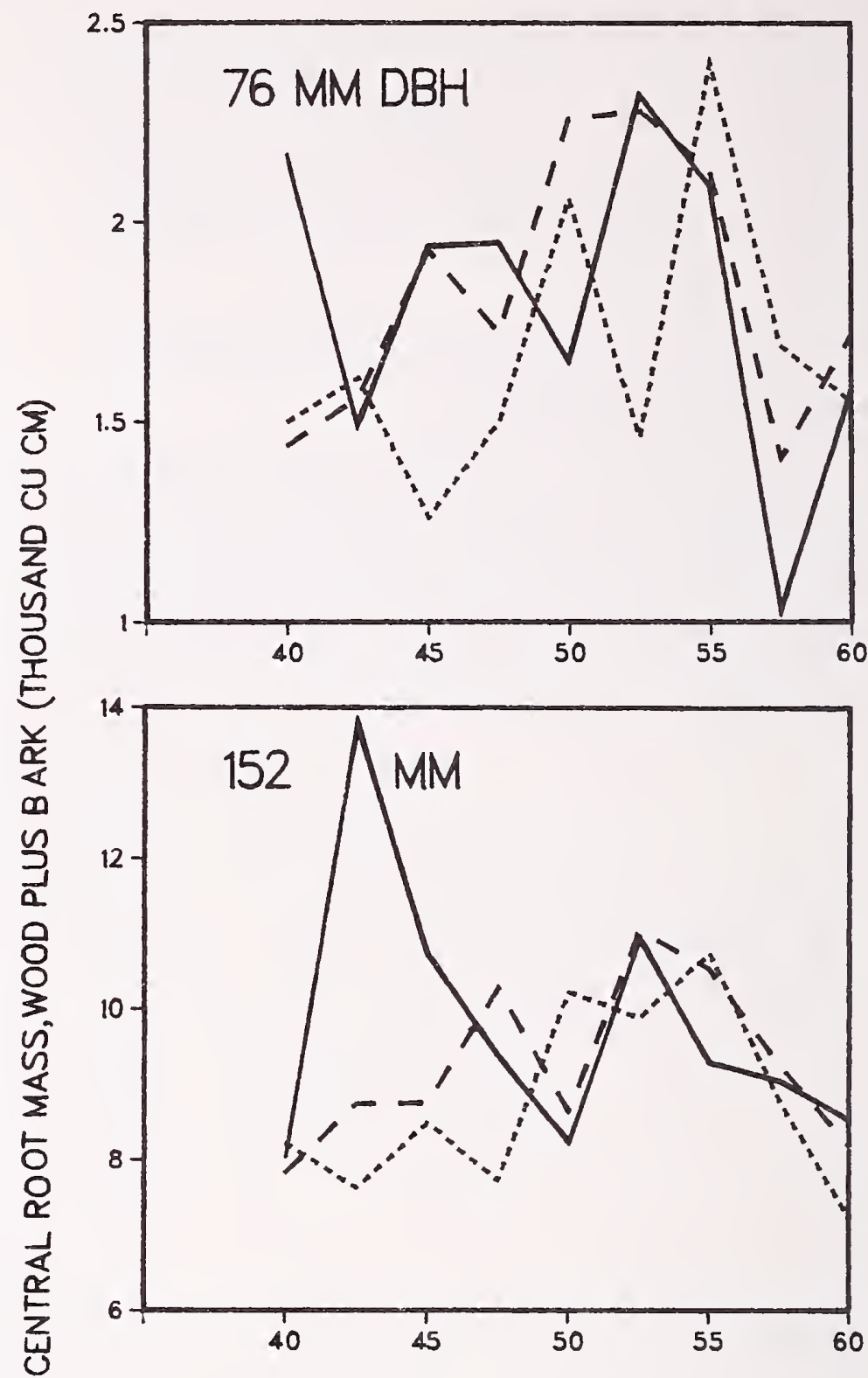

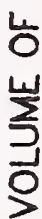

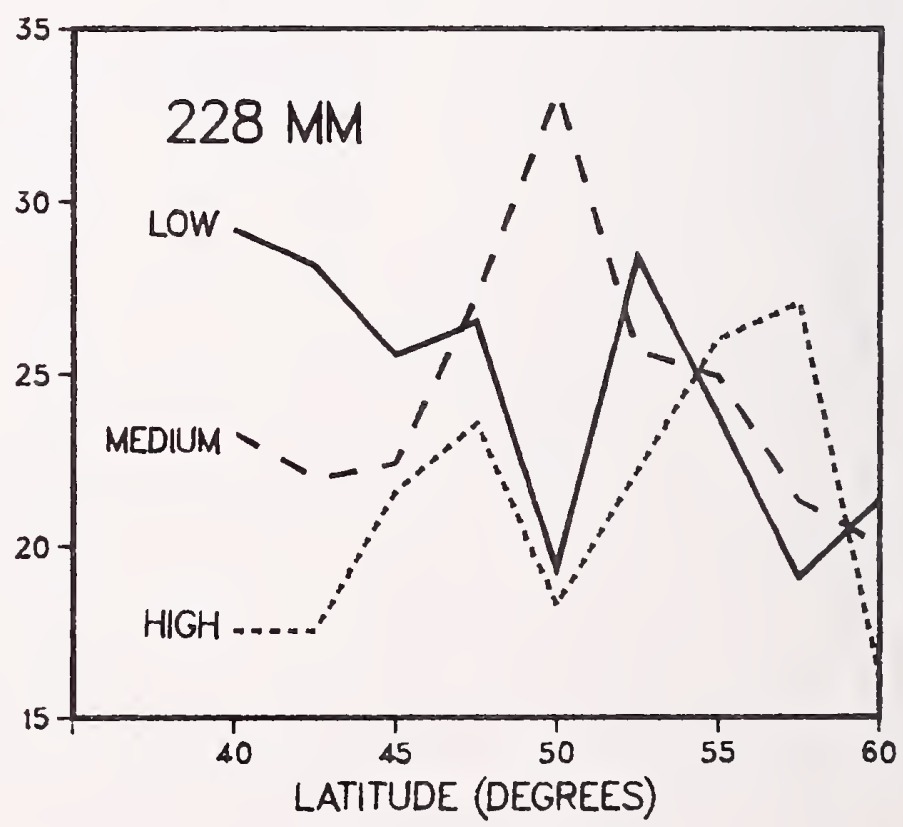

Figure 1-32-Volume of wood plus bark in central root mass including taproot, but shorn of laterals and stump, related to elevational zone and latitude for latifolia trees of three diameters. 


\section{Volume of Stump-Root System, Wood Only (Thousand $\mathrm{cm}^{3}$ )}

The stump-root system wood volume was positively correlated with d.b.h., averaging $3.5(0.79), 18.1$ (3.03), and 44.1 (6.52) for the three diameter classes. For $76-\mathrm{mm}$ trees, wood volumes in root systems were larger in northern latitudes than in southern; elevational trends were absent or complex (fig. 1-33).

The volume of wood in the stump-root system was also positively and closely correlated with total stem volume $(0.95)$ and total tree volume $(0.97)$.

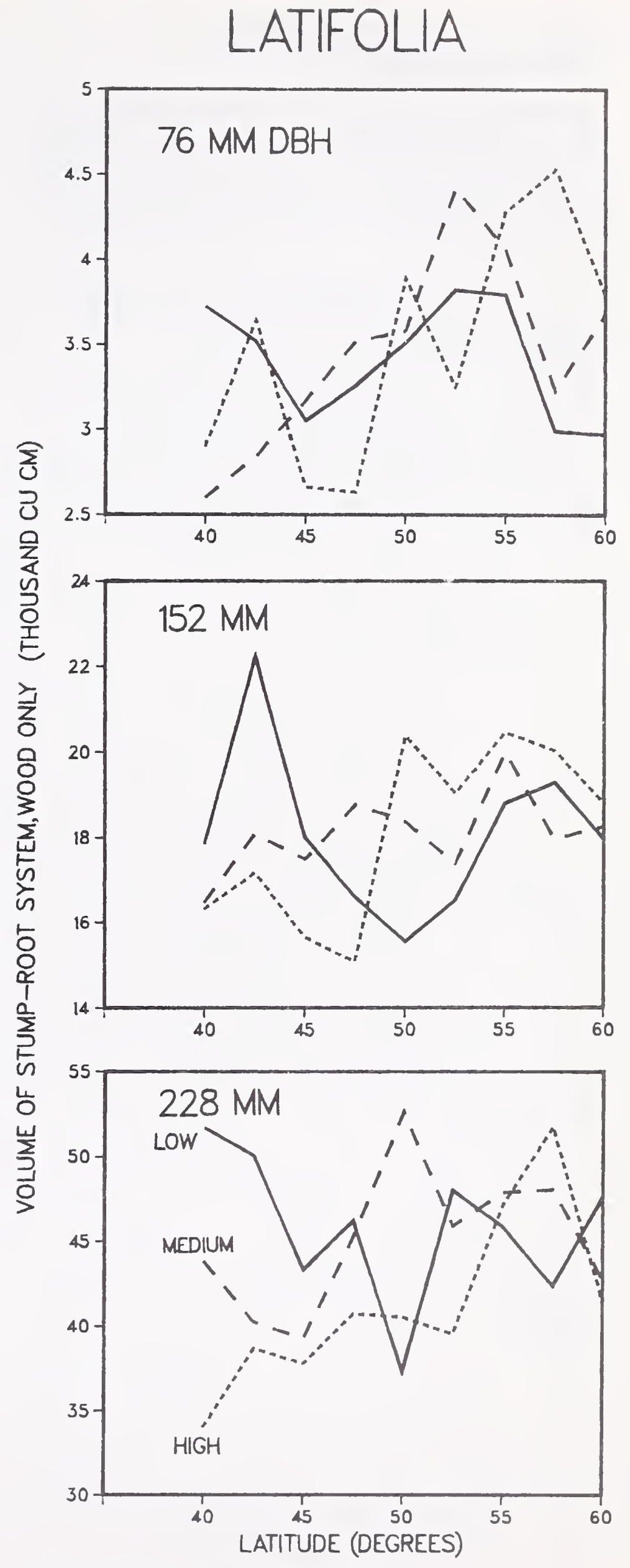

Figure 1-33-Wood volume in stump-root system of latifolia trees of three diameters related to elevational zone and latitude. 


\section{Volume of Stump, Wood Only (Thousand $\mathrm{cm}^{3}$ )}

Stumpwood volume was unrelated to elevational zone, but was positively correlated with tree d.b.h., averaging $1.0(0.26), 3.6(1.02)$, and $7.6(2.50)$ for the three diameter classes. Trees 152 and $228 \mathrm{~mm}$ in d.b.h. had the largest stumpwood volumes in latitudes 40 and 42.5 degrees (fig. 1-34).

\section{Volume of Lateral Roots, Wood Only (Thousand $\mathrm{cm}^{3}$ )}

Wood volume of lateral roots was unrelated to elevational zone, but was positively correlated with d.b.h., averaging $0.9(0.50), 6.3(1.84)$, and $15.1(4.50)$ for the three diameter classes. Volumes were maximum for all three d.b.h. classes in latitudes 57.5 and 60 degrees (fig. 1-35).

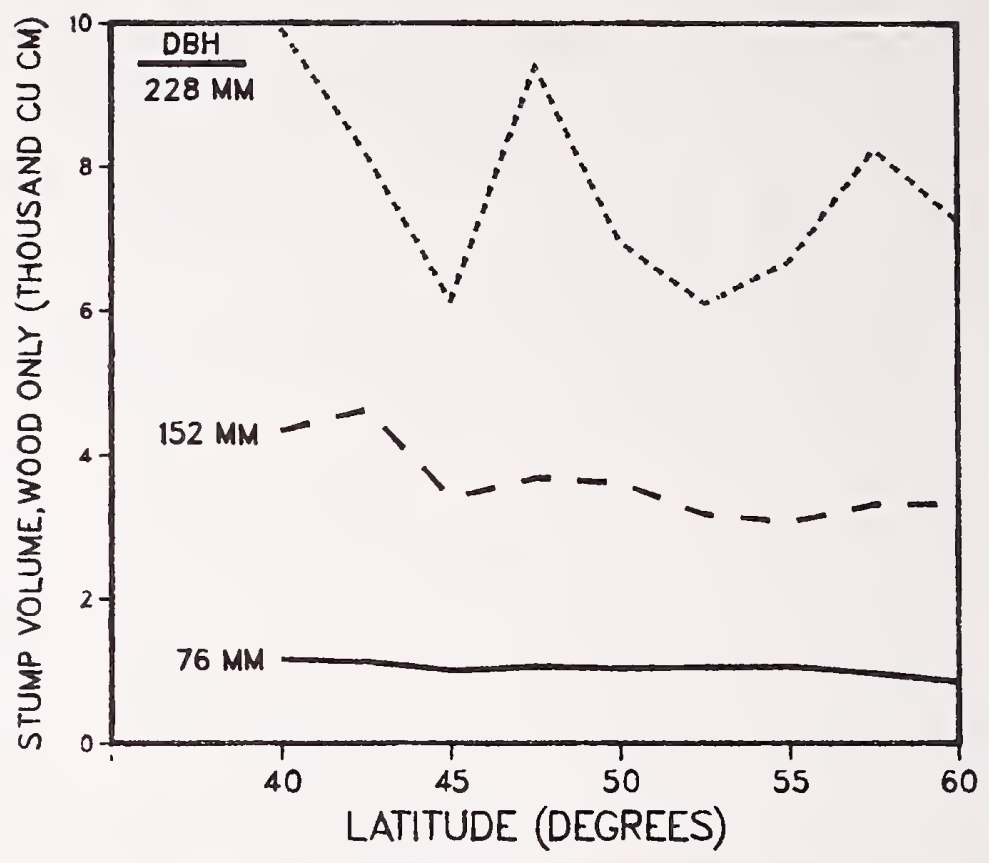

Figure 1-34-Wood volume in stump, groundline to stump top, related to latitude for latifolia trees of three diameters.

\section{LATIFOLIA}

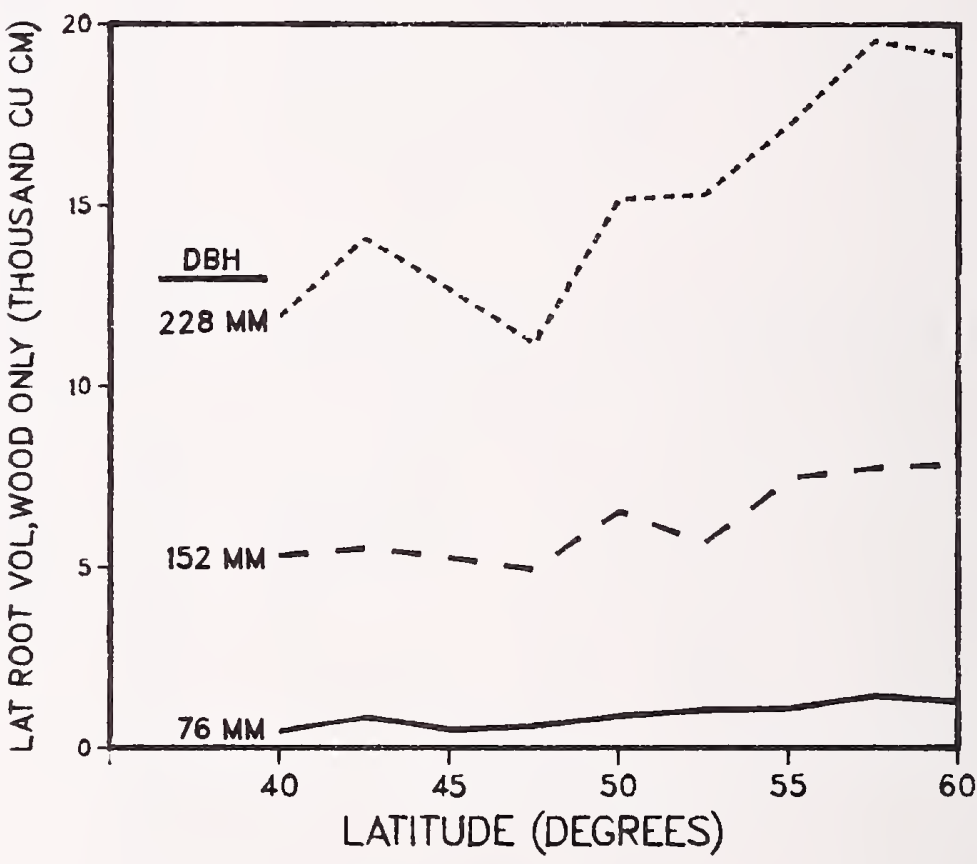

Figure 1-35-Wood volume in lateral roots, root collar to $305-\mathrm{mm}$ radius from tree pith, related to latitude for latifolia trees of three diameters. 


\section{Volume of Central Root Mass, Wood Only (Thousand $\mathrm{cm}^{3}$ )}

Wood volume of the central root mass shorn of stump and laterals, but including taproot, was positively correlated with d.b.h., averaging $1.5(0.48), 8.3(2.28)$, and 21.4 (5.23) for the three diameter classes. For $76-\mathrm{mm}$ trees, volumes were greatest at latitudes 50 through 55 degrees, but were unrelated to elevational zone. Central root mass wood volumes of $152-\mathrm{mm}$ trees were not correlated with elevational zone or latitude. In $228-\mathrm{mm}$ trees at all latitudes except 55 and 57.5 degrees, wood volumes were greater in low- and medium-elevation zones than in high zones (fig. 1-36).
LATIFOLIA
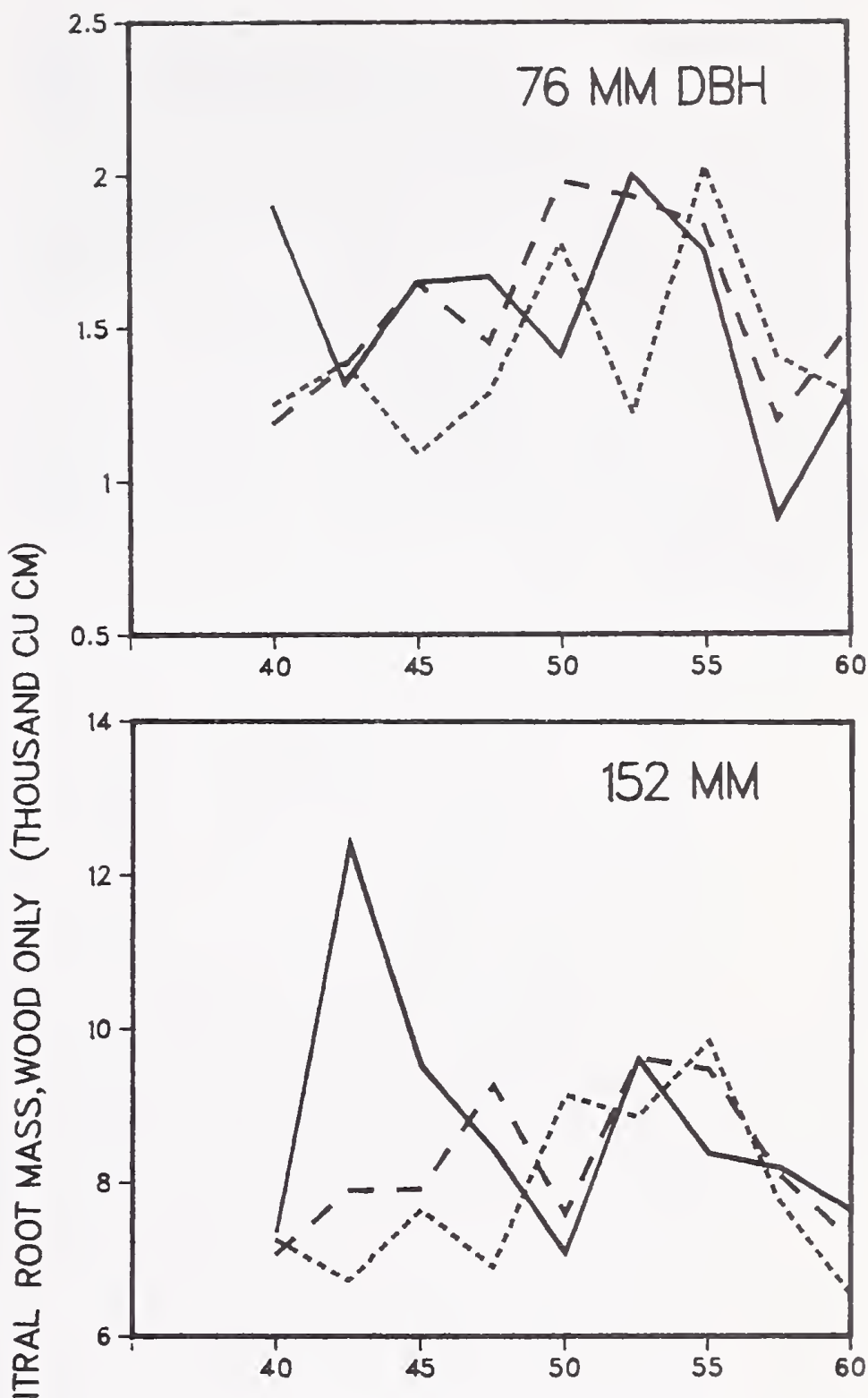

殅

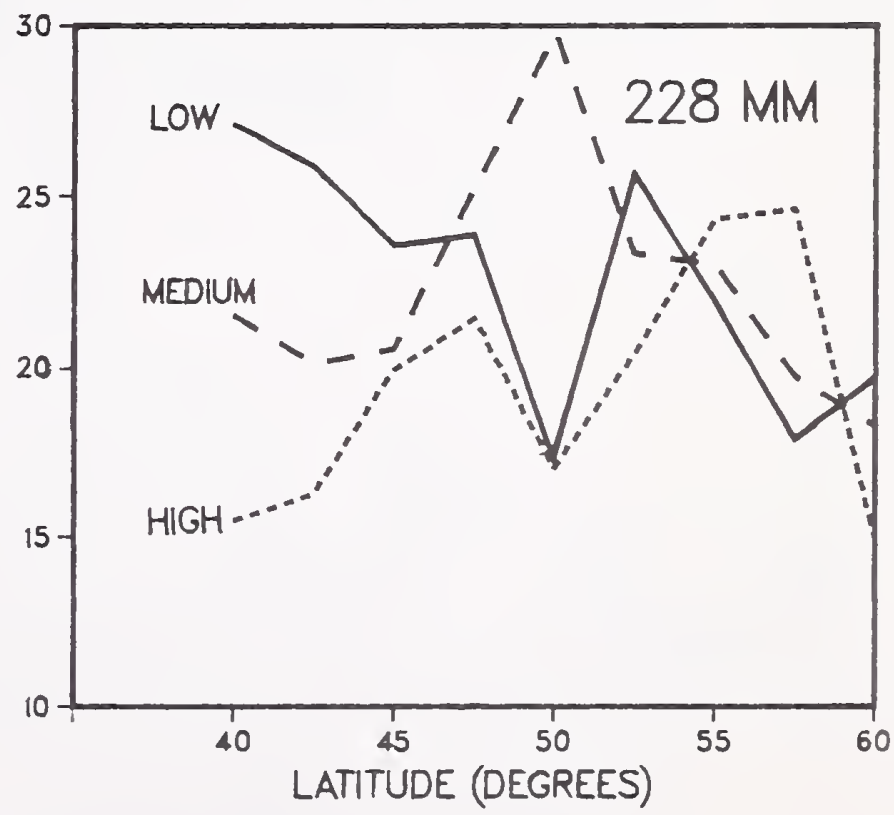

Figure 1-36-Wood volume in central root mass and taproot related to elevational zone and latitude in latifolia trees of three diameters. 


\section{Volume of Stump-Root System, Bark Only (Thousand $\mathrm{cm}^{3}$ )}

Bark volume of the stump-root system was positively correlated with tree d.b.h., averaging $0.8(0.21), 2.8(0.68)$, and 5.3 (1.14) for the three diameter classes. For $76-\mathrm{mm}$ trees, bark volume averaged somewhat more in the five northernmost latitudes than in the four southern latitudes; in the three northernmost latitudes, trees in high-elevation zones had more bark volume than those in low or medium zones (fig. 1-37). For the 152- and 228-mm trees, no elevational or latitudinal trends were discernible.

The volume of bark in the stump-root system was positively correlated with the volume of live branchwood $(0.80)$ and bark $(0.79)$, with the volume of stemwood $(0.87)$ and bark (0.91), and with the volume of treewood $(0.89)$ and bark (0.93).
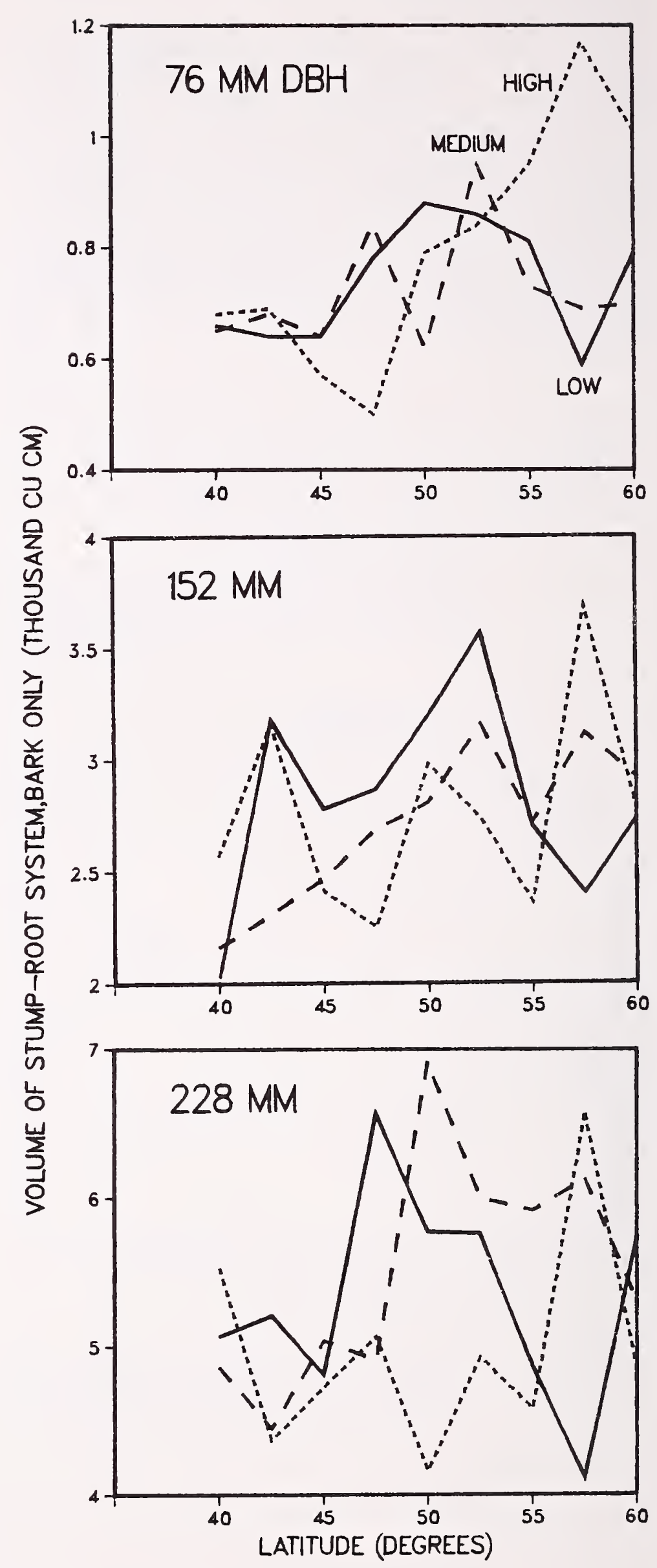

Figure 1-37-Bark volume in stump-root system related to elevational zone and latitude for latifolia trees of three diameters. 
Volume of Stump, Bark Only (Thousand $\mathrm{cm}^{3}$ )

Bark volume from stump top to ground level was positively correlated with d.b.h., averaging $0.21(0.08)$, $0.56(0.26)$, and $0.92(0.42)$ for the three diameter classes. For 76-mm trees, bark volume was greatest at 47.5 degrees latitude in low-elevation trees; in 152-mm trees latitude and elevational classes were unrelated to stumpbark volume; in 228-mm trees, however, volume of stumpbark diminished from 40 through 45 degrees latitude, showed a sharp increase at 47.5 degrees, and then diminished in more northerly latitudes (fig. 1-38).
LATIFOLIA
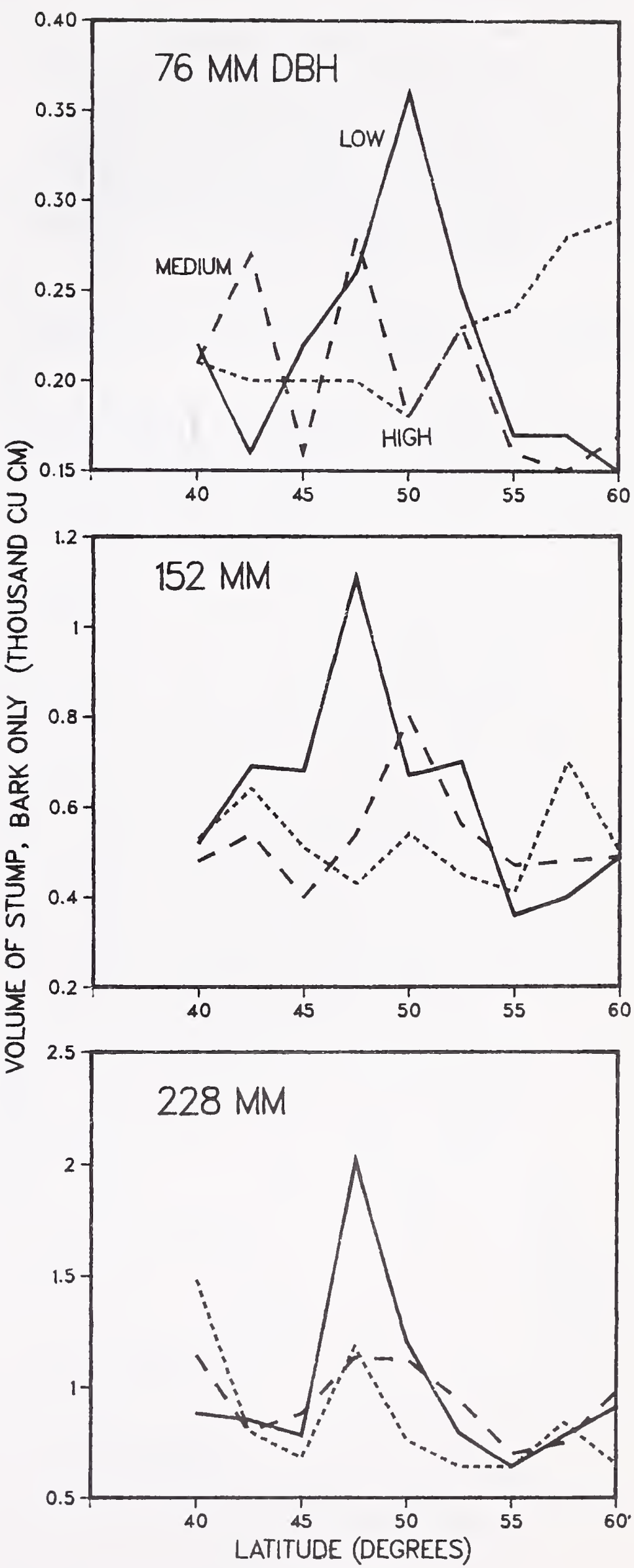

Figure 1-38-Bark volume of stump related to elevational zone and latitude for latifolia trees of three diameters. 


\section{Volume of Lateral Roots, Bark Only (Thousand $\mathrm{cm}^{3}$ )}

Bark volume of lateral roots from root collar to a radius of $305 \mathrm{~mm}$ from stump pith was positively correlated with d.b.h., averaging $0.28(0.13), 1.22(0.39)$, and $2.37(0.83)$ for the three diameter classes. In all three diameter classes, volume of lateral rootbark generally increased with increasing latitude, but the relationship of elevation class to volume was more complex (fig. 1-39). The average for the four southern latitudes was 1.08; that for the five northern latitudes was 1.45 .

\section{Volume of Central Root Mass, Bark Only (Thousand $\mathrm{cm}^{3}$ )}

Volume of bark on the central root mass, including taproot, was unrelated to elevational or latitudinal zones, but was positively correlated with d.b.h., averaging 0.26 (0.93), $0.99(0.38)$, and $2.00(0.79)$ for the three diameter classes.
LATIFOLIA
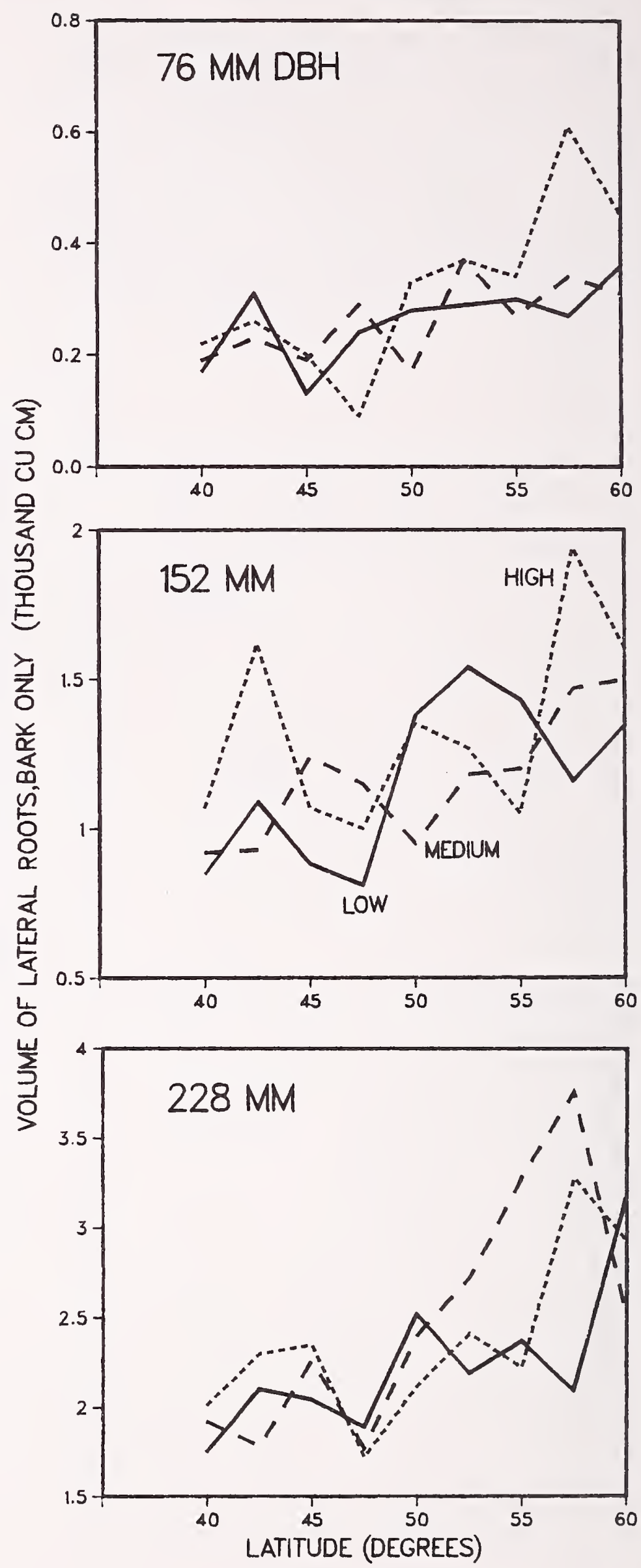

Figure 1-39-Bark volume of lateral roots related to elevational zone and latitude for latifolia trees of three diameters. 


\section{Stem Volume to Apical Tip, Wood Plus Bark (Thousand $\mathrm{cm}^{3}$ )}

Total stem volume averaged 24.8 (5.5), 156.6 (31.4), and 413.9 (76.1) for the three diameter classes. Trees in highelevation zones had less stem volume than those in lower zones, as follows:

\begin{tabular}{cccr} 
& \multicolumn{3}{c}{ Elevation zone } \\
\cline { 2 - 4 } D.b.h. & Low & Medium & High \\
$m m$ & $\ldots \ldots$ & Thousand $\mathrm{cm}^{3}$ & $\ldots$ \\
76 & 25.1 & 25.1 & 24.2 \\
152 & 155.3 & 163.2 & 151.2 \\
228 & 432.1 & 418.4 & 391.2 \\
Average & 204.2 & 202.3 & 188.9
\end{tabular}

Northern-latitude $76-\mathrm{mm}$ trees averaged more total volume than southern. Trees $152 \mathrm{~mm}$ had the largest volumes in latitude zones 50 through 55 degrees and smallest volumes in the three southernmost latitudes. Trees in the 228-mm class also had largest volumes in latitude zones 50 through 55 degrees, but had smallest volumes in the 40- and 57.5-degree latitudinal zones (fig. 1-40).

Stem volume to apical tip, including wood and bark, was positively correlated with d.b.h. (0.94), tree height (0.89), length of taproot $(0.61)$, crown width $(0.74)$, average live branch diameter $(0.77)$, stembark thickness at 50 percent of tree height $(0.74)$, total live branch volume $(0.77)$, and total volume of stump-root system $(0.95)$.

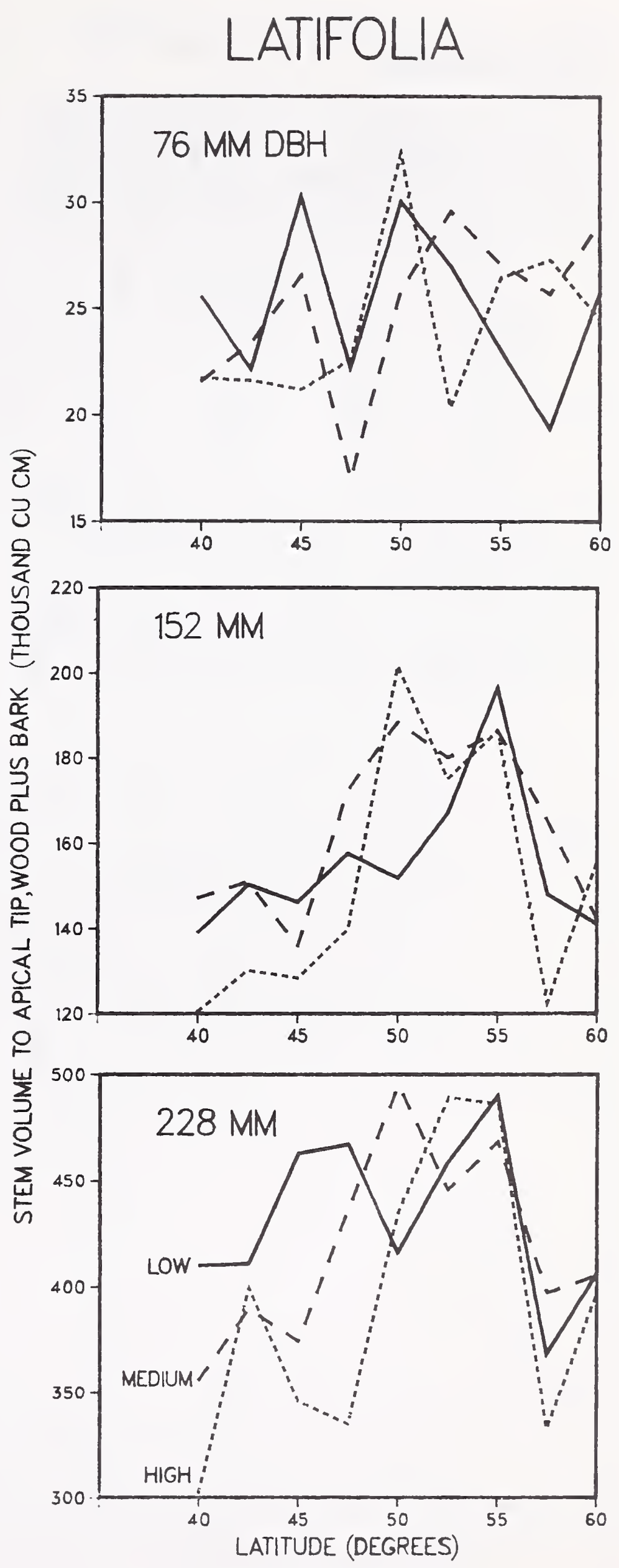

Figure 1-40-Stem volume from stump top to apical tip, wood plus bark, related to elevational zone and latitude for latifolia trees of three diameters. 


\section{Stemwood Volume to the Apical Tip (Thousand $\mathrm{cm}^{3}$ )}

Stemwood volume to the apical tip for the three diameter classes averaged $21.2(5.0), 140.3$ (29.2), and 377.4 (71.2). Except for medium-elevation 76- and 152-mm trees, stemwood volume to apical tip was negatively correlated with elevation zone, as follows:

\begin{tabular}{cccr} 
& \multicolumn{3}{c}{ Elevation zone } \\
\cline { 2 - 4 } D.b.h. & \multicolumn{1}{c}{ Low } & Medium & High \\
$m m$ & $\ldots \ldots$ & Thousand $\mathrm{cm}^{3}$ & $\ldots$ \\
76 & 21.5 & 21.6 & 20.6 \\
152 & 138.4 & 146.4 & 136.2 \\
228 & 394.3 & 380.9 & 357.0 \\
Average & 184.8 & 183.0 & 171.3
\end{tabular}

Stemwood volume was least or nearly so at 40 degrees (for $76-\mathrm{mm}$ trees the least was at 47.5 degrees), and averaged most at 50 degrees for $76-\mathrm{mm}$ trees and 55 degrees for the two larger diameter classes (fig. 1-41).

Stemwood volume was positively and equally correlated to the same factors as noted for total stem volume; it was also closely correlated to stembark volume $(0.96)$.
LATIFOLIA
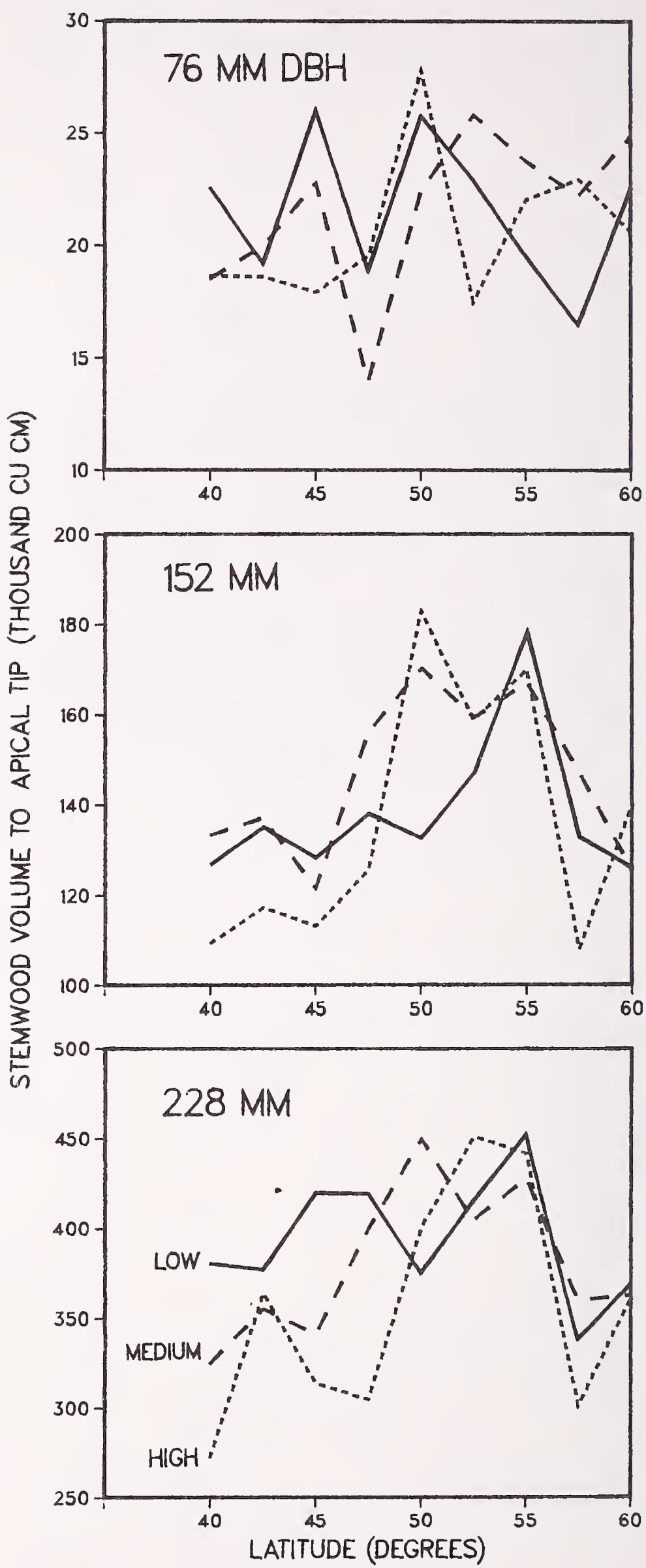

Figure 1-41-Stemwood volume from stump top to apical tip in latifolia trees of three diameters related to elevational zone and latitude. 


\section{Stembark Volume to Apical Tip (Thousand $\mathrm{cm}^{3}$ )}

Stembark volume to apical tip for the three diameter classes averaged $3.6(0.70), 16.3(0.44)$, and 36.5 (7.31). In the six southern latitudinal zones stembark volume averaged less in high-elevation than in low-elevation zones, but in the three northernmost zones the reverse was true. For all diameter classes, stembark volume was lowest at 40 degrees latitude; highest averages or nearly so were in latitudinal zones 50 through 55 degrees (fig. 1-42).

Stembark volume was positively and about equally correlated to the same factors as noted for total stem volume. Stembark thickness at 50 percent of tree height is a better measurable indicator of stembark volume $(r=0.82)$ than stumpbark thickness $(r=0.64)$.

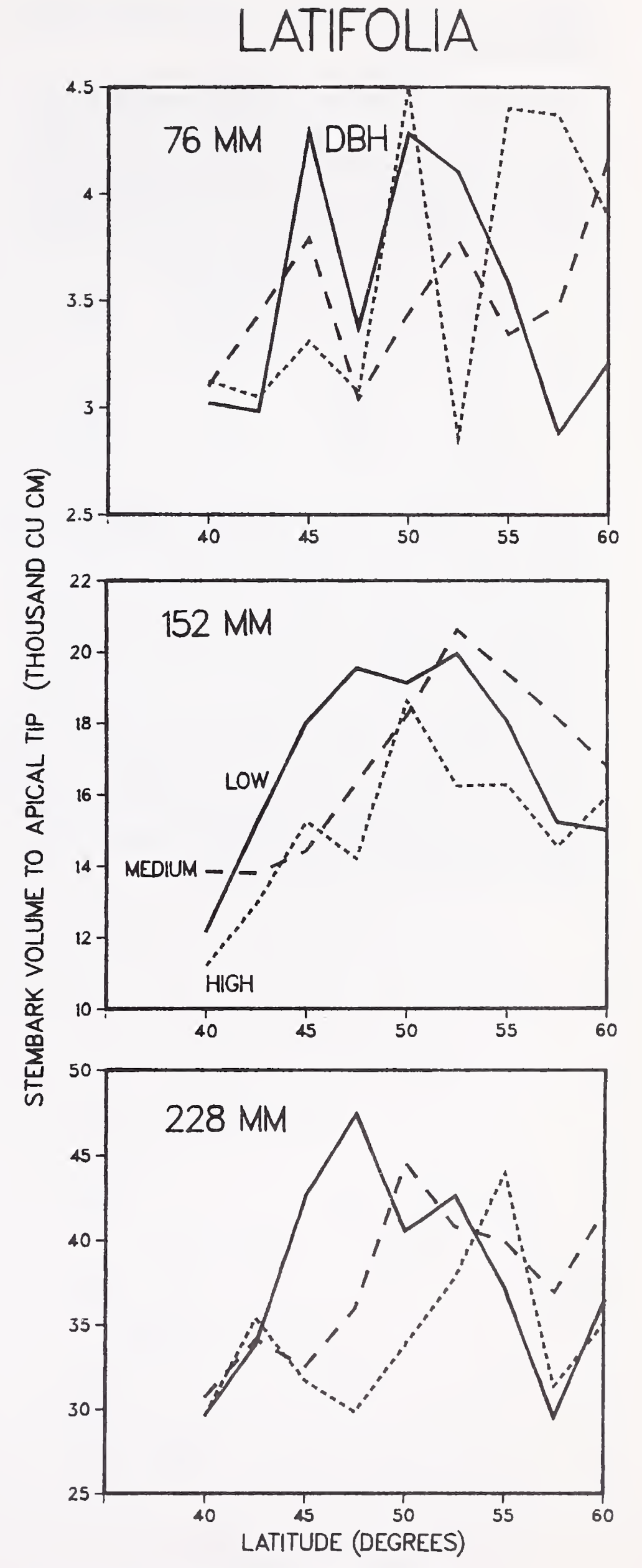

Figure 1-42-Stembark volume from stump top to apical tip in latifolia trees of three diameters related to elevational zone and latitude. 


\section{Complete-Tree Volume, Wood Plus Bark (Thousand $\mathrm{cm}^{3}$ )}

Complete-tree volume of wood plus bark (stump-root system, stem, live and dead branches-but not foliage) averaged 31.0 (5.6), 191.1 (32.1), and 509.0 (75.6) for the three diameter classes. Complete trees in high-elevation zones had least volume and, except for 152-mm trees, those in low-elevation zones had most volume, as follows:

\begin{tabular}{cccr} 
& \multicolumn{3}{c}{ Elevation zone } \\
\cline { 2 - 4 } D.b.h. & Low & Medium & High \\
$m m$ & $\ldots \ldots$ & Thousand $\mathrm{cm}^{3}$ & $\ldots$ \\
76 & 31.6 & 31.2 & 30.3 \\
152 & 192.6 & 197.6 & 183.0 \\
228 & 535.6 & 516.0 & 475.3 \\
Average & 253.3 & 248.3 & 229.6
\end{tabular}

Average complete-tree volumes were lowest at 40 degrees for 152 - and $228-\mathrm{mm}$ trees, and nearly so for $76-\mathrm{mm}$ trees; largest average volumes were at 50 degrees for $76-\mathrm{mm}$ trees and at 55 degrees for trees of the two larger diameter classes. In general, complete-tree volume averages were largest in latitude zones 50 through 55 degrees (fig. 1-43).

Complete-tree volume, including wood and bark, was closely correlated with d.b.h. (0.96) and total volume of the stump-root system (0.97). It was also positively correlated with tree height (0.87), live branch volume $(0.82)$, average diameter of live branches (0.79), crown width $(0.78)$, and stembark thickness at 50 percent of stem height (0.76). Crown length had weaker correlation (0.54).
LATIFOLIA

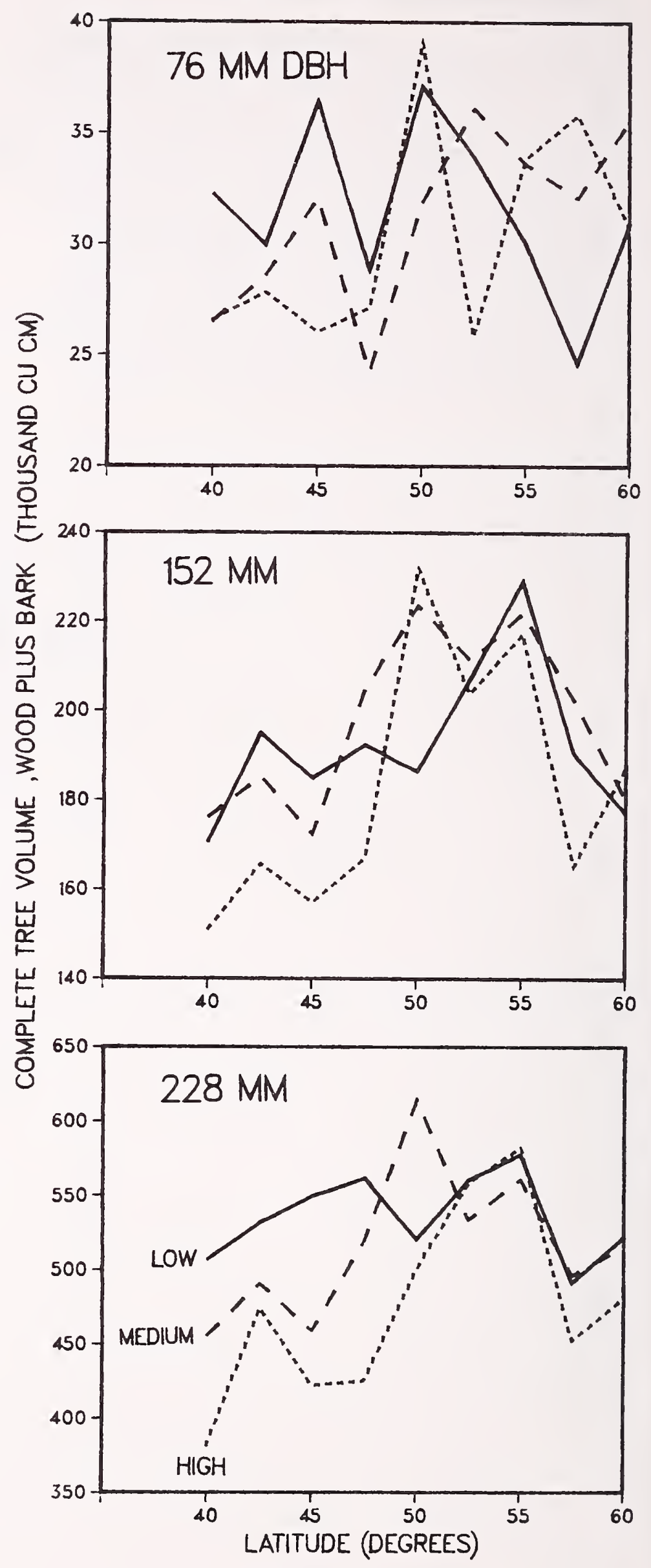

Figure 1-43-Complete-tree volume, wood plus bark, in latifolia trees of three diameters related to elevational zone and latitude. 


\section{Complete-Tree Volume, Wood Only (Thousand $\mathrm{cm}^{3}$ )}

Complete-tree volume of wood averaged 26.0 (5.1), 168.5 (30.6), and 456.8 (71.4) for the three diameter classes.

Trees from high-elevation zones had least wood volume and, with the exception of the 152-mm trees, those from low zones had the most wood volume, as follows:

\begin{tabular}{cccr} 
& \multicolumn{3}{c}{ Elevation zone } \\
\cline { 2 - 4 } D.b.h. & Low & Medium & High \\
$m m$ & $\ldots \ldots$ & Thousand $\mathrm{cm}^{3} \ldots \ldots$ \\
76 & 26.6 & 26.3 & 25.2 \\
152 & 169.3 & 174.2 & 162.1 \\
228 & 481.4 & 462.4 & 426.6 \\
Average & 225.8 & 221.0 & 204.5
\end{tabular}

Complete-tree wood volume averaged maximum for all three diameter classes in latitude zones 50 through 55 degrees and minimum for 152 - and $228-\mathrm{mm}$ trees in the 40-degree zone; $76-\mathrm{mm}$ trees had minimum wood volume at 47.5 degrees (fig. 1-44).

Complete-tree wood volume was positively and equally correlated with the same characteristics noted for woodplus-bark complete-tree volume.
LATIFOLIA
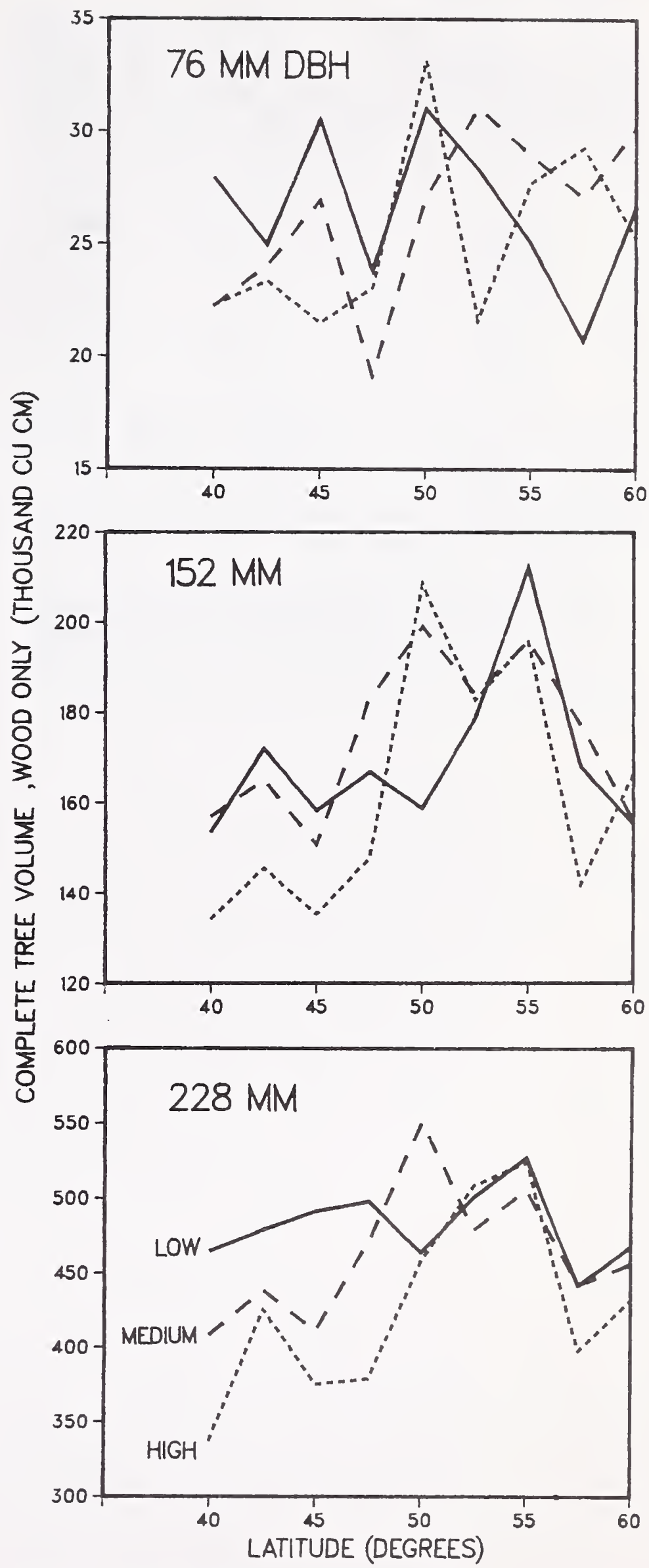

Figure 1-44-Complete-tree volume of wood only in latifolia trees of three diameters related to elevational zone and latitude. 


\section{Complete-Tree Volume, Bark Only (Thousand $\mathrm{cm}^{3}$ )}

Bark volume of complete trees averaged 5.0 (0.91), 22.8 (4.22), and 52.2 (9.01) for the three diameter classes. For 152- and 228-mm trees, complete-tree bark volume varied inversely with elevational zone; bark volume on $76-\mathrm{mm}$ trees was unrelated to elevational zone, as follows:

\begin{tabular}{|c|c|c|c|}
\hline \multirow[b]{2}{*}{ D.b.h. } & \multicolumn{3}{|c|}{ Elevation zone } \\
\hline & Low & Medium & High \\
\hline$m m$ & \multicolumn{3}{|c|}{..... Thousand $\mathrm{cm}^{s} \ldots .}$. \\
\hline 76 & 5.0 & 4.9 & 5.1 \\
\hline 152 & 24.1 & 23.4 & 20.9 \\
\hline 228 & 54.2 & 53.6 & 48.7 \\
\hline Average & 27.8 & 27.3 & 24.9 \\
\hline
\end{tabular}

Complete-tree bark volume averages for all three diameter classes were smallest in the 40-degree latitude zone. Trees $76 \mathrm{~mm}$ had highest bark volume at 50 degrees (5.6), $152 \mathrm{~mm}$ at 52.5 degrees (25.6), and $228 \mathrm{~mm}$ at 52.5 and 55 degrees (54.7) (fig. 1-45).

Complete-tree bark volume was positively and equally correlated with the same characteristics noted for woodplus-bark complete-tree volume, except that correlations were closer with stembark thickness at 50 percent of tree height (0.85) and with total live branch volume (0.88).
LATIFOLIA
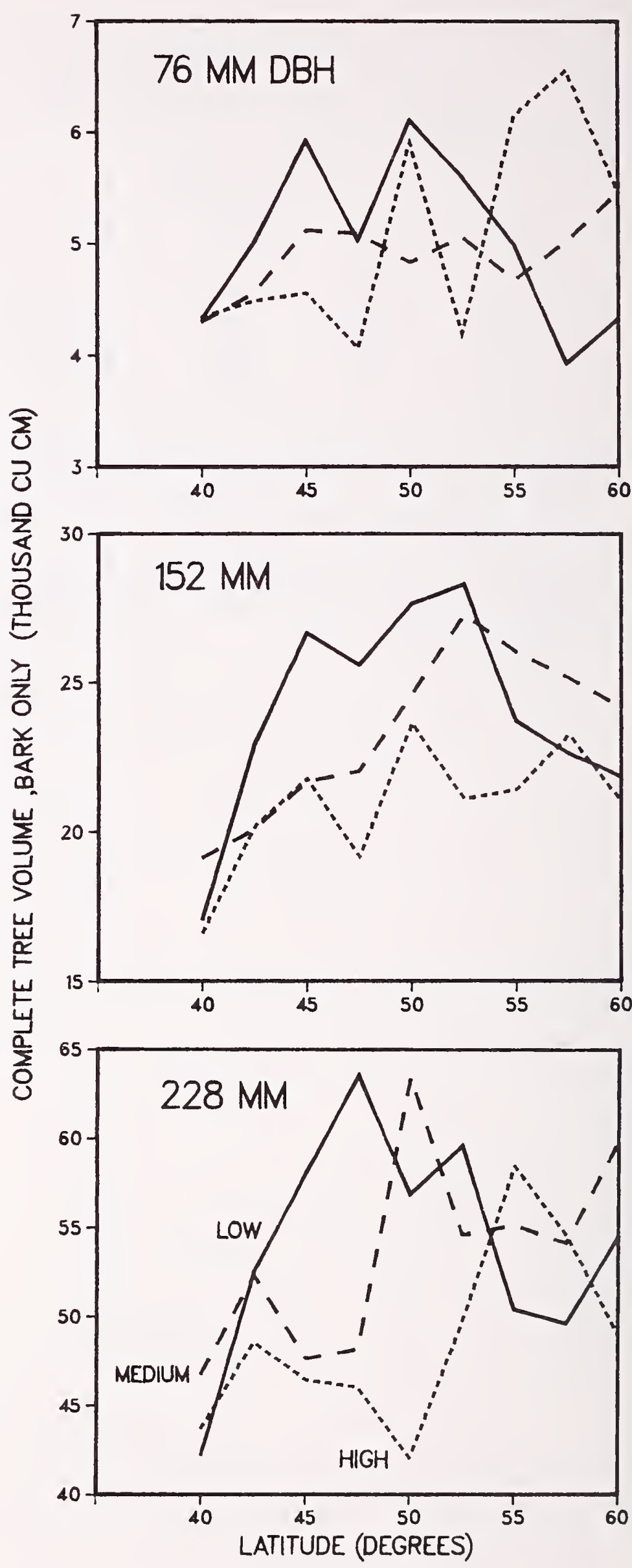

Figure 1-45-Complete-tree volume of bark only in latifolia trees of three diameters related to elevational zone and latitude. 


\section{Stembark as Percentage of Gross Stem Volume by Height in Tree}

Stembark percentage at various heights in the trees was unrelated to elevational zone, except at stump height. Low-elevation-zone trees at latitudes $45,47.5,50$, and 52.5 degrees had bark percentages significantly above the 12.1 percent mean for stump height, averaging 13.4, 19.2, 18.1, and 15.9 percent, respectively.

Bark percentage was related to latitude only at 50,60, and 90 percent of tree height, where-at 45 degrees latitude only-bark volume percentage was one to two percentage points above the means for these heights.

The dominant factors were tree d.b.h. and height in tree. In all three diameter classes, bark percentage was relatively large at stump height, diminished from stump height to 10 or 20 percent of tree height, and then was positively correlated with height in tree (fig. 1-46).
LATIFOLIA

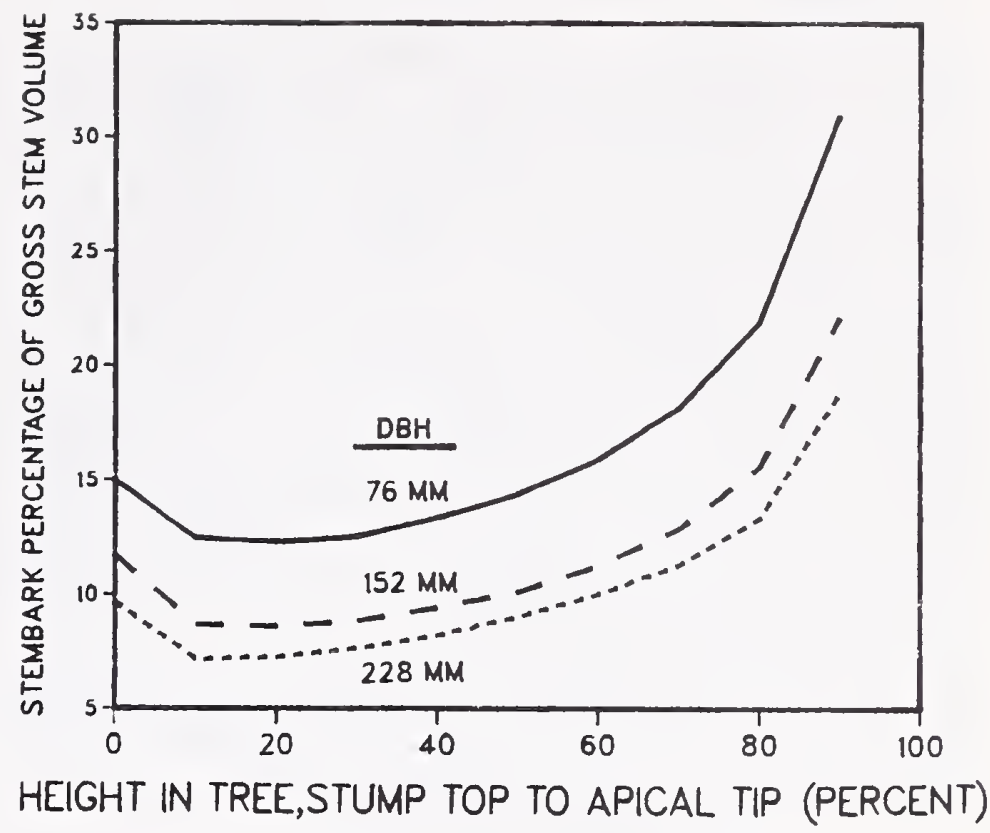

Figure 1-46-Stembark percentage of gross stem volume related to height in latifolia trees of three diameters; latitudinal and elevational data pooled. 


\section{Stembark as Percentage of Gross Stem Volume}

Stembark volume as a percentage of gross volume of stem from stump top to apical tip was inversely correlated with d.b.h., averaging 14.6 (2.2), 10.5 (1.8), and 8.9 (1.3) percent for the three diameter classes; that is, small trees have a higher percentage of stembark than large trees. Low-elevation zones had trees with greatest stembark percentages in latitudinal zones 47.5 and 50 degrees, with minimum percentage in the 40 -degree zone. Mediumelevation zones had trees with greatest stembark percentages at the northernmost latitude, and least at latitudes 50 and 55 degrees. High-elevation zones had trees with greatest stembark percentages at 57.5 degrees and least at 50 degrees. For all diameter classes, latitude interacted with elevational zone (fig. 1-47).

Stembark percentage of total stem volume to apical tip was most closely correlated-negatively-with tree height $(-0.81)$, d.b.h. $(-0.77)$, and length of stem below crown $(-0.67)$.
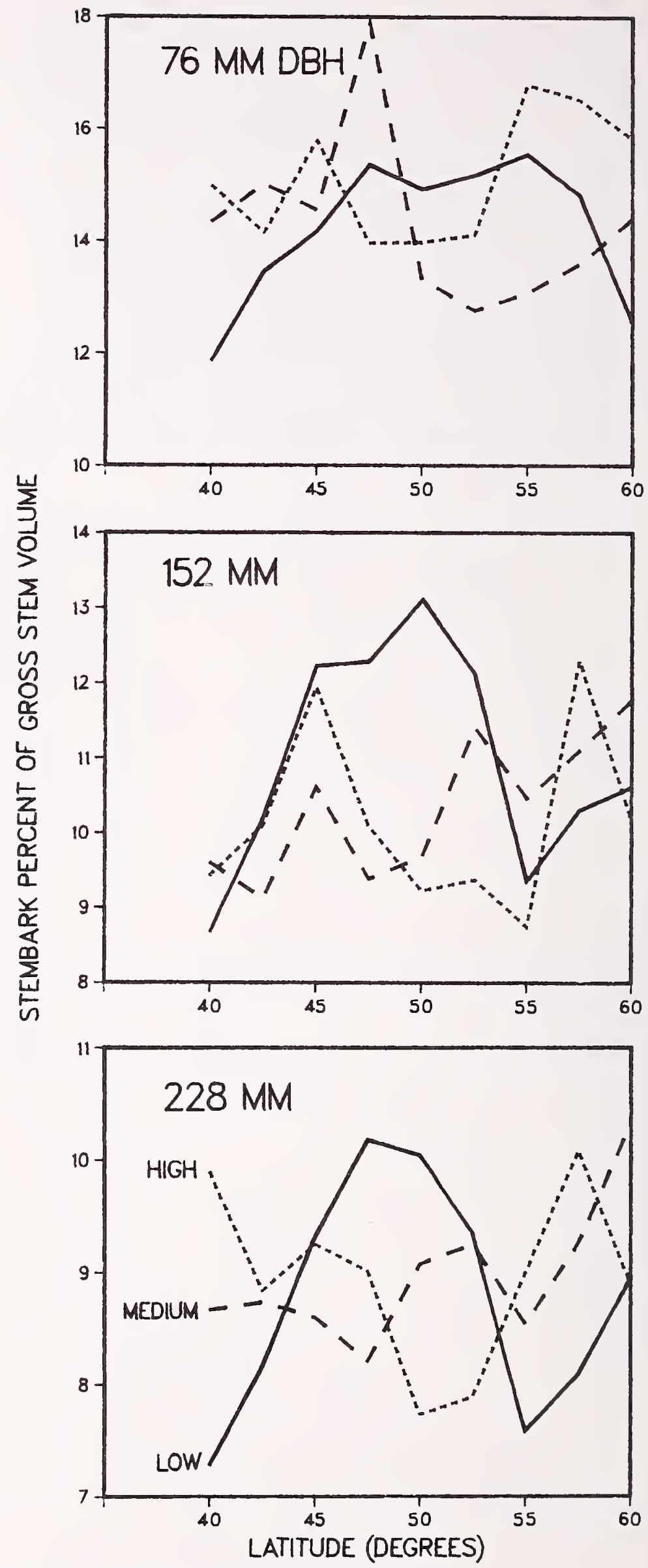

Figure 1-47-Stembark percentage of gross stem volume related to elevational zone and latitude for latifolia trees of three diameters. 


\section{Stump-Rootbark as Percentage of Gross Stump-Root System Volume}

Stump-rootbark volume as a percentage of gross volume of stump-root system was unrelated to elevation, but, as in stems, was inversely correlated with tree d.b.h., averaging 17.9 (3.3), $13.3(2.6)$, and $10.7(1.9)$ percent bark for 76-, $152-$, and $228-\mathrm{mm}$ diameter classes, respectively.

Bark volume percentage in the stump-root system was unrelated to latitude except for the 152-mm diameter class where percentage of bark volume was greatest in latitudinal zones 50 and 52.5 degrees and least at latitude 40 degrees (fig. 1-48).

Stump-rootbark volume percentage of total stump-root system volume was most closely correlated-negativelywith d.b.h. and tree height ( $r=-0.74$ for each).

\section{Live Branchbark as Percentage of Gross Live Branch Volume}

Branchbark volume percentage of gross live branch volume was unrelated to elevational zone, but was inversely correlated with tree d.b.h., averaging 46.8 (5.9), 37.1

(5.5), and 29.4 (5.3) percent for the 76-, 152-, and 228-mm diameter classes.

Latitude was related to branchbark volume percentage in all three tree diameter classes (fig. 1-49); this percentage was least in the most southerly and in the most northerly zones-40 and 60 degrees-and maximum in intermediate zones. For $76-\mathrm{mm}$ trees, branchbark volume percentage was greatest in latitudinal zones 52.5 and 55 degrees; for 152- and 228-mm trees, at 47.5 degrees.

Live branchbark percentage of total live branch volume was negatively correlated with average branch diameter $(-0.82)$, d.b.h. $(-0.79)$, total volume of stump-root system $(-0.77)$, total stem volume $(-0.75)$, tree height $(-0.69)$, and crown width $(-0.69)$.
LATIFOLIA

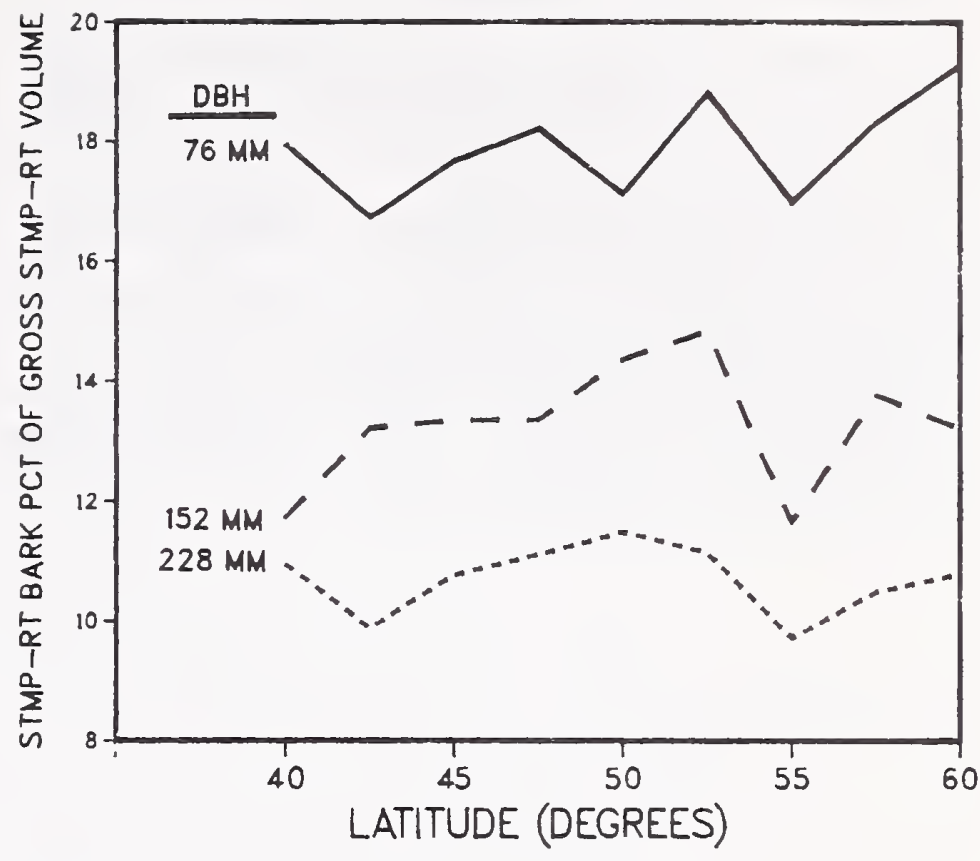

Figure 1-48-Bark volume of stump-root system as a percentage of gross stump-root system volume related to latitude for latifolia trees of three diameters.

\section{LATIFOLIA}

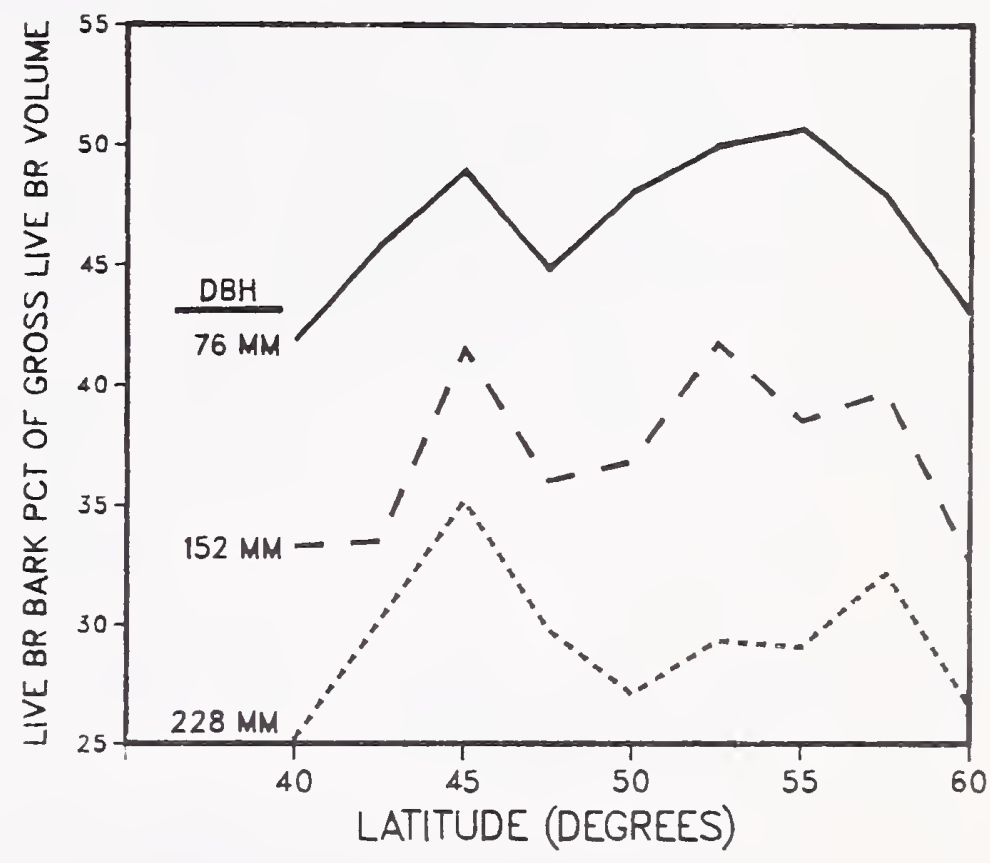

Figure 1-49-Bark volume of live branches as a percentage of gross live branch volume related to latitude for latifolia trees of three diameters. 


\section{Bark of Complete Tree as Percentage of Complete-Tree Volume}

Complete-tree bark volume as a percentage of completetree volume was inversely correlated with d.b.h., averaging 16.3 (2.7), 12.1 (2.1), and 10.4 (1.7) percent for 76-, $152-$, and $228-\mathrm{mm}$ trees.

The latitude-elevation interaction was complex, permitting no generalization (fig. 1-50).

Bark volume percentage of complete-tree volume was positively correlated with stembark percentage of the wood-plus-bark volume at 50 percent of tree height (0.93) and negatively correlated with tree height $(-0.83)$, d.b.h. $(-0.73)$, and total stump-root system volume $(-0.68)$.
LATIFOLIA

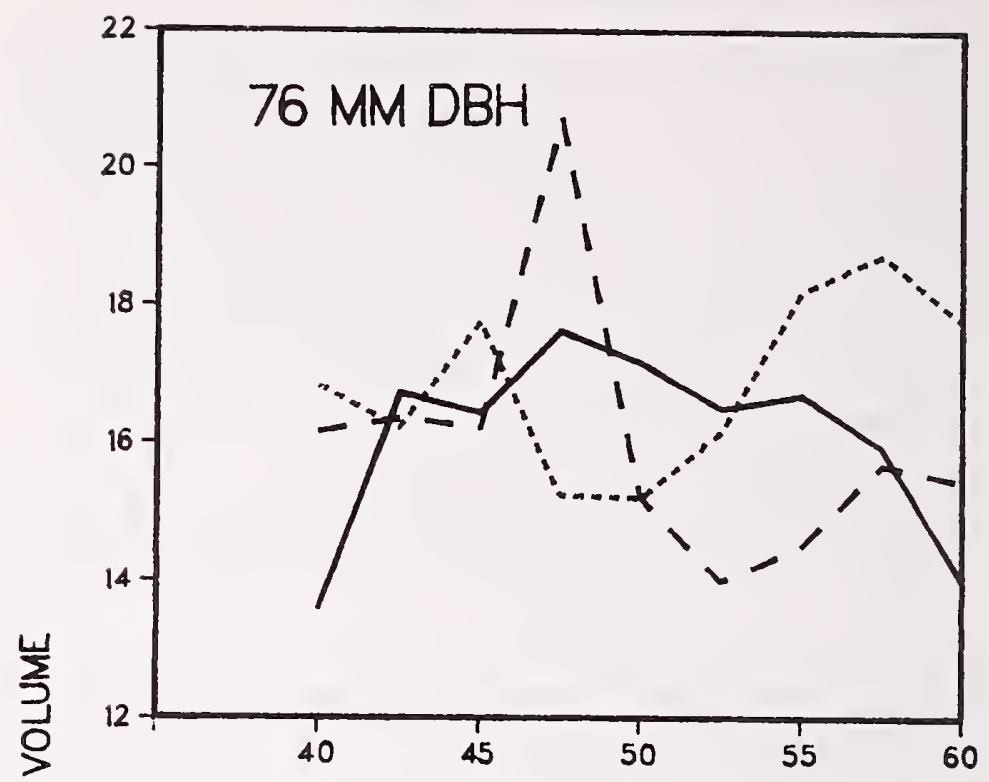

넘

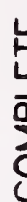

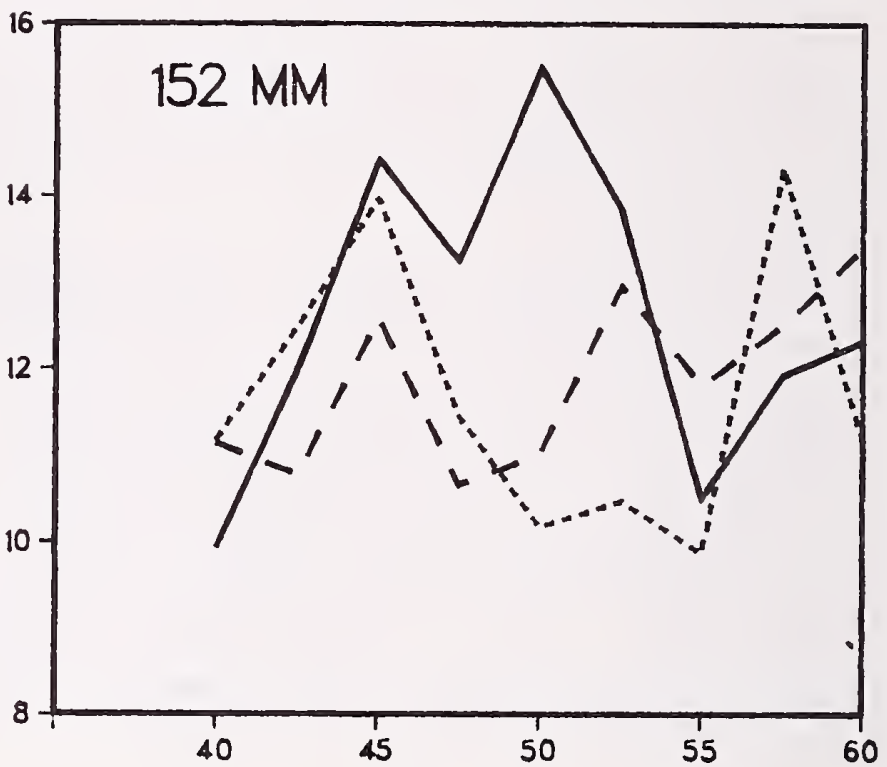

㞾

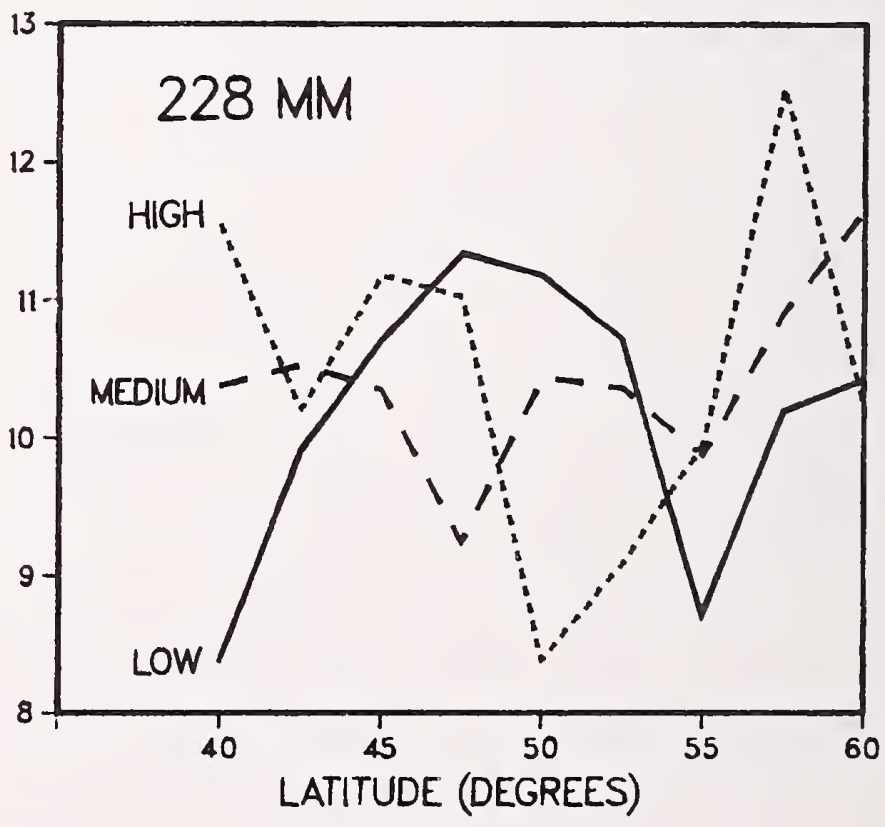

Figure 1-50-Bark volume of complete tree as a percentage of gross volume of complete tree related to elevational zone and latitude for latifolia trees of three diameters. 


\section{Stemwood as Percentage of Complete- Tree Wood Volume}

Stemwood volume averaged 82.1 percent of completetree wood volume; this percentage was unrelated to elevational zone; however, it varied slightly - but significantlywith d.b.h., averaging 81.1 (4.9), 82.9 (4.1), and 82.3 (4.8) percent for 76-, 152-, and 228-mm trees.

Volume of stemwood as a percentage of treewood also varied significantly with latitude; it averaged largest at 52.5 degrees (84.0 percent) and smallest at 57.5 degrees, where it was 78.7 percent (fig. 1-51).

Volume of stemwood as a percentage of complete-tree wood volume was poorly correlated with the characteristics measured; it had closest correlation-positive-with tree height $(0.46)$ and length of stem below crown $(0.54)$.

\section{Live Branchwood as Percentage of Complete-Tree Wood Volume}

Live branchwood averaged 4.3 percent of complete-tree wood volume; as with stemwood, this percentage was unrelated to elevational zone but did vary significantly with d.b.h., averaging 3.2 (2.03), 4.0 (1.95), and 5.7 (2.81) percent for $76-, 152-$, and $228-\mathrm{mm}$ trees.

Live branchwood as a percentage of treewood volume also varied significantly with latitude; with diameter data pooled averages were lowest at 52.5 degrees ( 3.0 percent) and highest (4.8 to 5.4 percent) in the two southernmost and two northernmost latitudinal zones (fig. 1-52).

Live branchwood as a percentage of complete-tree volume was positively correlated with crown width (0.64), average live branch diameter $(0.52)$, and crown ratio (0.42).
LATIFOLIA

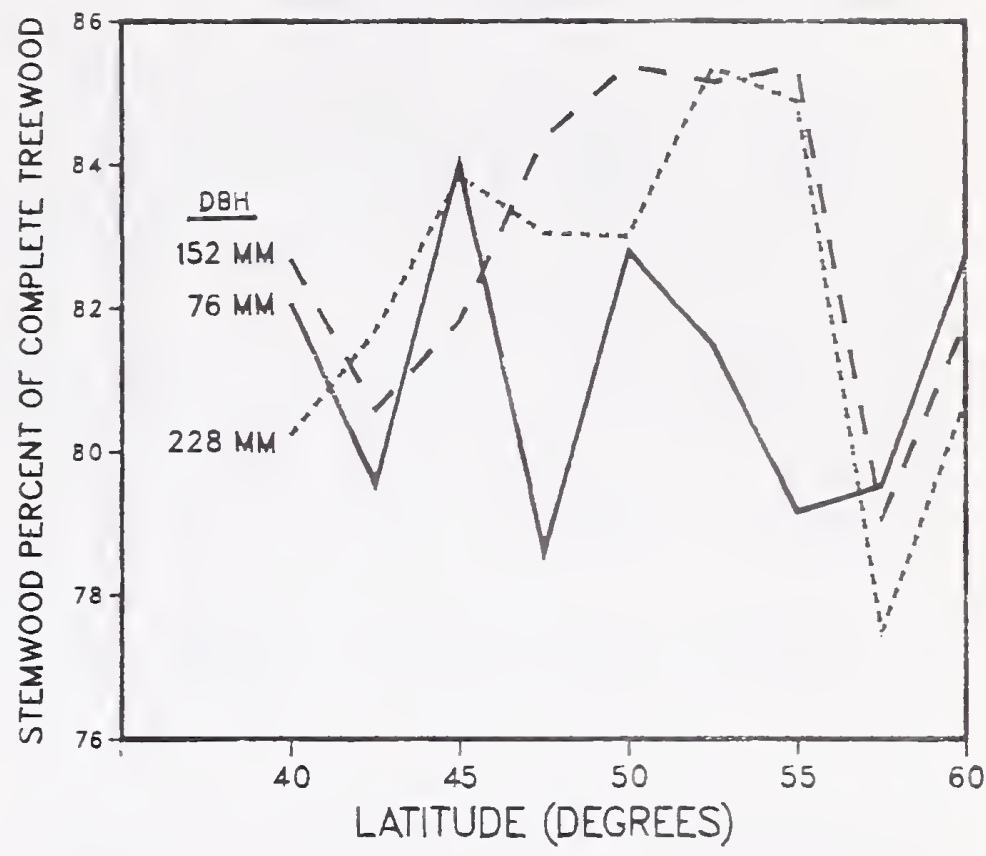

Figure 1.51-Stemwood as a percentage of complete-tree wood volume related to latitude for latifolia trees of three diameters.
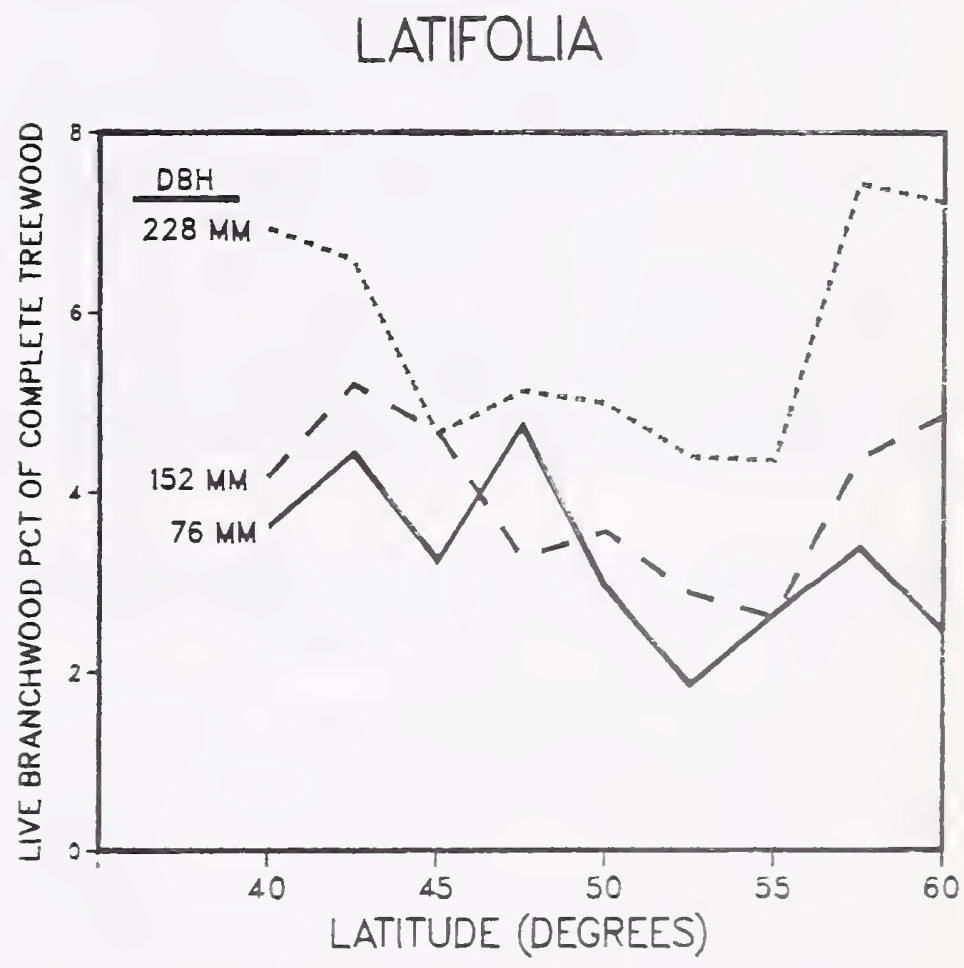

Figure 1-52-Live branchwood as a percentage of complete-tree wood volume related to latitude for latifolia trees of three diameters. 


\section{Dead Branchwood as Percentage of Complete-Tree Wood Volume}

Dead branchwood volume averaged 2.1 percent of complete-tree wood volume, with standard deviation of 1.82; unlike live branchwood, this percentage was unrelated to d.b.h., but did vary inversely with elevational zone, averaging $2.8,2.0$, and 1.7 percent for low, medium, and high zones, respectively.

Dead branchwood percentage of tree volume also varied significantly with latitude; with diameter data pooled averages were lowest (1.6 percent) at 40 degrees and, for reasons not clear, averages more than doubled (4.0 percent) in the 57.5 percent latitudinal zone (fig. 1-53).

Dead branchwood volume percentage of complete-tree wood was poorly correlated with tree characteristics, except for negative correlation with stemwood percentage of treewood volume $(-0.52)$ and positive correlation with dead branchwood volume (0.66).

\section{Stumpwood as Percentage of Complete- Tree Wood Volume}

From groundline to stump top, stumpwood averaged 2.7 percent of complete-tree volume; this percentage was unrelated to elevational zone but varied inversely with d.b.h., averaging 4.1 (1.27), $2.2(0.74)$, and $1.7(0.71)$ percent for 76-, 152-, and 228-mm trees, respectively.

Stumpwood percentage of treewood volume also varied significantly with latitude for all three diameter classes (fig. 1-54); with diameter data pooled, stumpwood percentage of treewood volume averaged 3.3 percent for the two most southerly latitudes and 2.5 percent for the seven northern latitudes.

Stumpwood volume percentage of complete-tree wood was negatively correlated with tree height $(-0.80)$, d.b.h. $(-0.70)$, total stem volume $(-0.69)$, and stem length below crown $(-0.68)$.

\section{Stump-Root System Wood as Percentage of Complete-Tree Wood Volume}

Total stump-root system wood (stump, central root collar and taproot, and laterals to $305 \mathrm{~mm}$ radius from stump pith) averaged 11.5 percent of complete-tree wood volume. The percentage was unrelated to elevational or latitudinal zone, but was inversely correlated with d.b.h., averaging 13.6 (3.25), $10.9(1.84)$, and 9.8 (1.73) percent for 76-, 152-, and $228-\mathrm{mm}$ trees, respectively.

Stump-root system wood volume as a percentage of complete-tree wood volume was positively correlated with stembark percentage of gross stem volume $(0.65)$ and negatively correlated with tree height $(-0.73)$, stem length below crown $(-0.66)$, and, as noted above, with d.b.h. $(-0.54)$.
LATIFOLIA

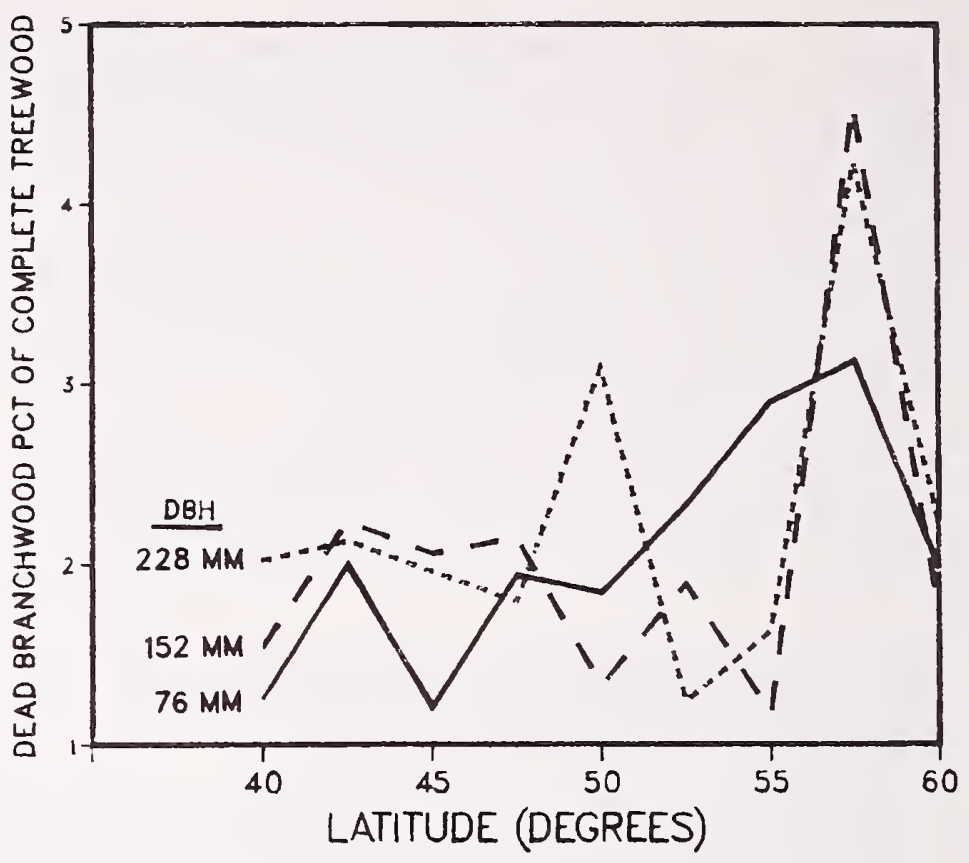

Figure 1-53-Dead branchwood as a percentage of complete-tree wood volume related to latitude for latifolia trees of three diameters.
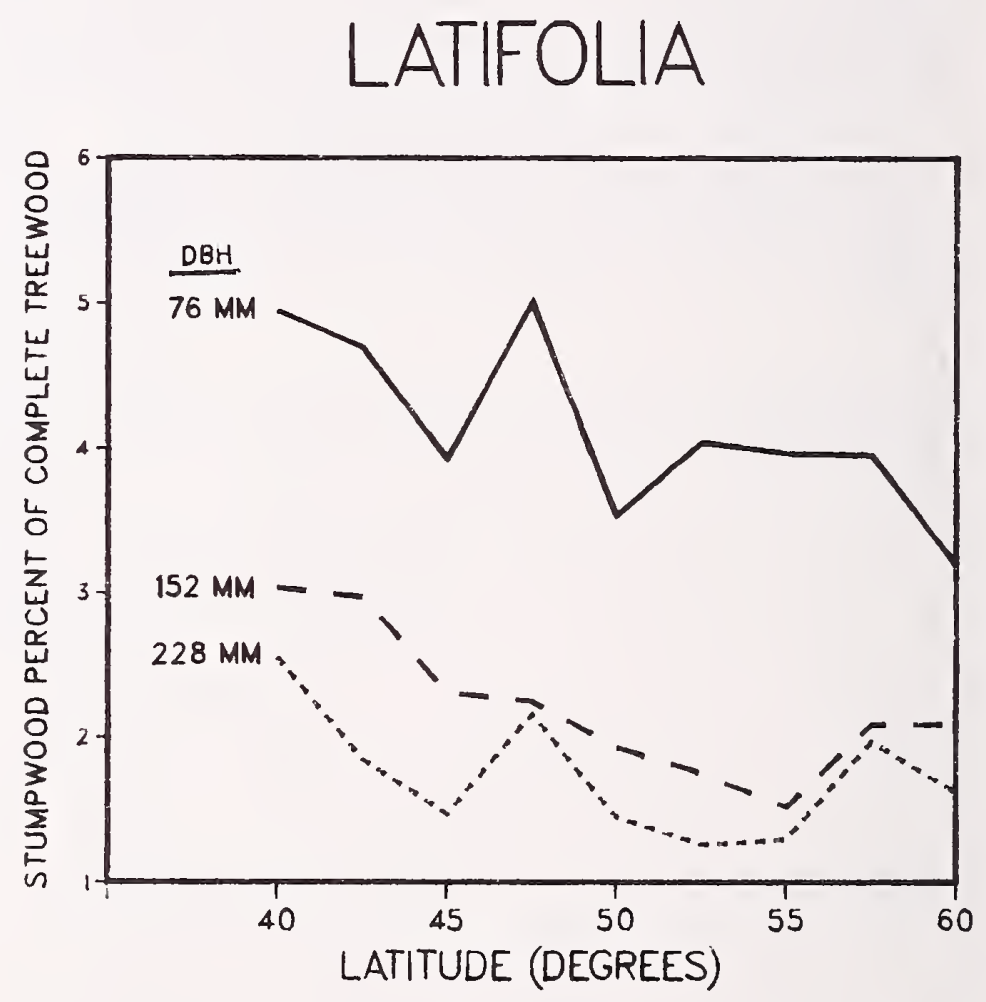

Figure 1-54-Stumpwood as a percentage of complete-tree wood volume related to latitude for latifolia trees of three diameters. 


\section{1-13 RESULTS-MURRAYANA}

For the murrayana trees, the three d.b.h. classes averaged $76 \mathrm{~mm}$, with standard deviation of $1.8 \mathrm{~mm}$; $151 \mathrm{~mm}$, with standard deviation of $2.9 \mathrm{~mm}$; and $229 \mathrm{~mm}$, with standard deviation of $3.9 \mathrm{~mm}$. All were selected at medium elevation, which for the four latitudes averaged as follows:

\begin{tabular}{|c|c|c|}
\hline Latitude & Elevation & General location \\
\hline Degrees & Meters & \\
\hline 37.5 & 2,402 & $\begin{array}{l}\text { Just east of Yosemite National } \\
\text { Park }\end{array}$ \\
\hline 40 & 1,676 & Vicinity of Quincy, CA \\
\hline 42.5 & 2,006 & Southwest of Paisley, OR \\
\hline 45 & 1,148 & North of Breitenbush, OR \\
\hline Average & 1,808 & \\
\hline
\end{tabular}

Because the entire murrayana sample totaled but 36 trees, correlations among tree characteristics are not noted in the detail provided for the 243 latifolia trees. Standard deviations for diameter-class data are noted in parentheses following their average values, as they were in the latifolia results section.

Even with this small sample (nine trees per latitude), numerous latitudinal differences were observed. Only those statistically significant are graphed or tabulated. It seems likely from studying the data, however, that had more trees been sampled, statistically significant differences between the two southern latitudes and the two northern latitudes would have been found in many moreperhaps most-of the characteristics measured.

\section{Tree Age}

The three diameter classes averaged 67 (25), 84 (34), and 91 (37) years of age measured at $152 \mathrm{~mm}$ stump height, but the trees from 42.5 degrees averaged nearly twice the age of those from the other three latitudes (fig. 1-55).
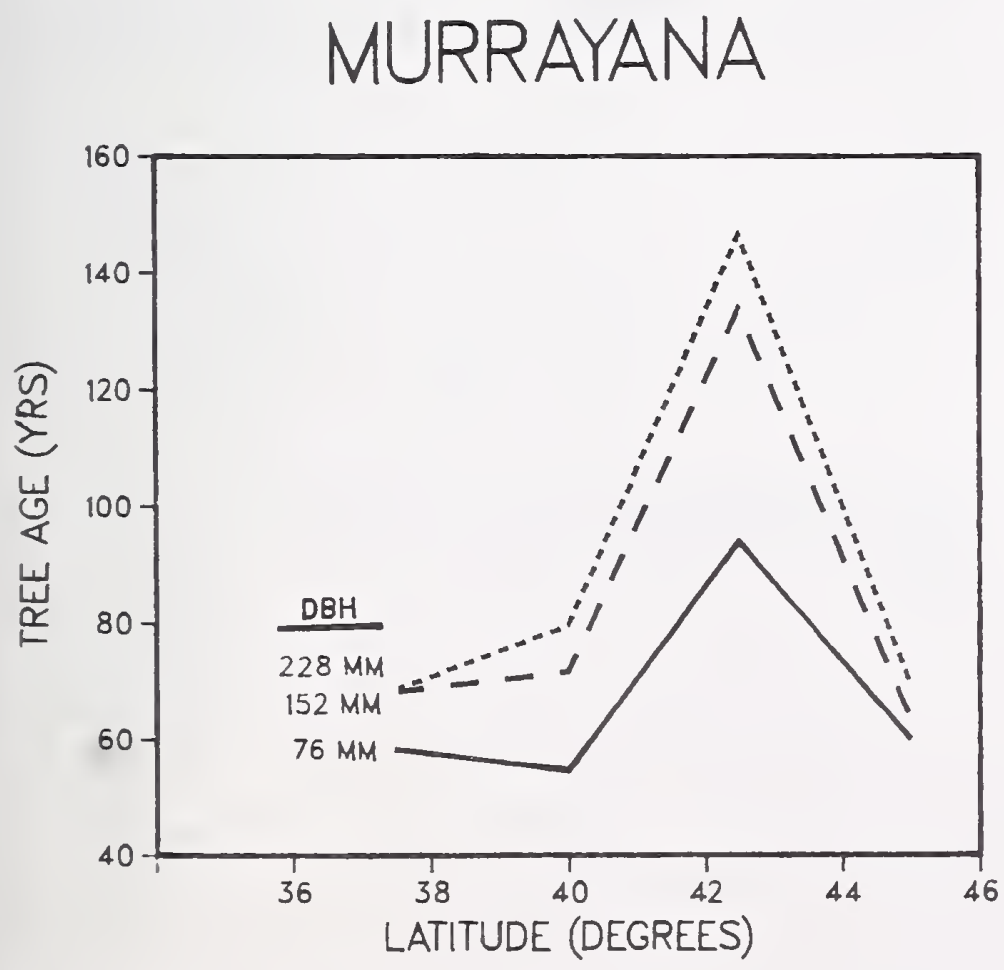

\section{Tree Height to Apical Tip}

Tree height was significantly related to d.b.h., but not to latitude; average values were as follows:

\begin{tabular}{cccc} 
& \multicolumn{3}{c}{ D.b.h. class } \\
\cline { 2 - 4 } Latitude & $\mathbf{7 6} \mathrm{mm}$ & $152 \mathrm{~mm}$ & $228 \mathrm{~mm}$ \\
Degrees & $\ldots \ldots$ & Meters & $\ldots \ldots .$. \\
37.5 & 6.1 & 10.6 & 15.2 \\
40 & 6.8 & 12.3 & 19.5 \\
42.5 & 7.8 & 16.4 & 20.3 \\
45 & 8.9 & 15.6 & 19.6 \\
Average & 7.4 & 13.7 & 18.7 \\
& $(2.0)$ & $(3.8)$ & $(4.5)$
\end{tabular}

\section{Tree Height to 25-mm Top Diameter (Outside Bark)}

Tree height to a $25-\mathrm{mm}$ top diameter was positively correlated with d.b.h., averaging $6.2(1.9), 12.8(3.8)$, and 17.8 (4.5) $\mathrm{m}$ for the three diameter classes. Trees were significantly higher at the two northernmost latitudes than at the southern latitudes (fig. 1-56).

\section{Taproot Length}

Taproot length, measured from stump top to the end of the portion of the taproot that the field crews were able to extract, was unrelated to latitude but was positively correlated with d.b.h., averaging 58 (14), 91 (13), and 97 (25) $\mathrm{cm}$ for the three diameter classes.
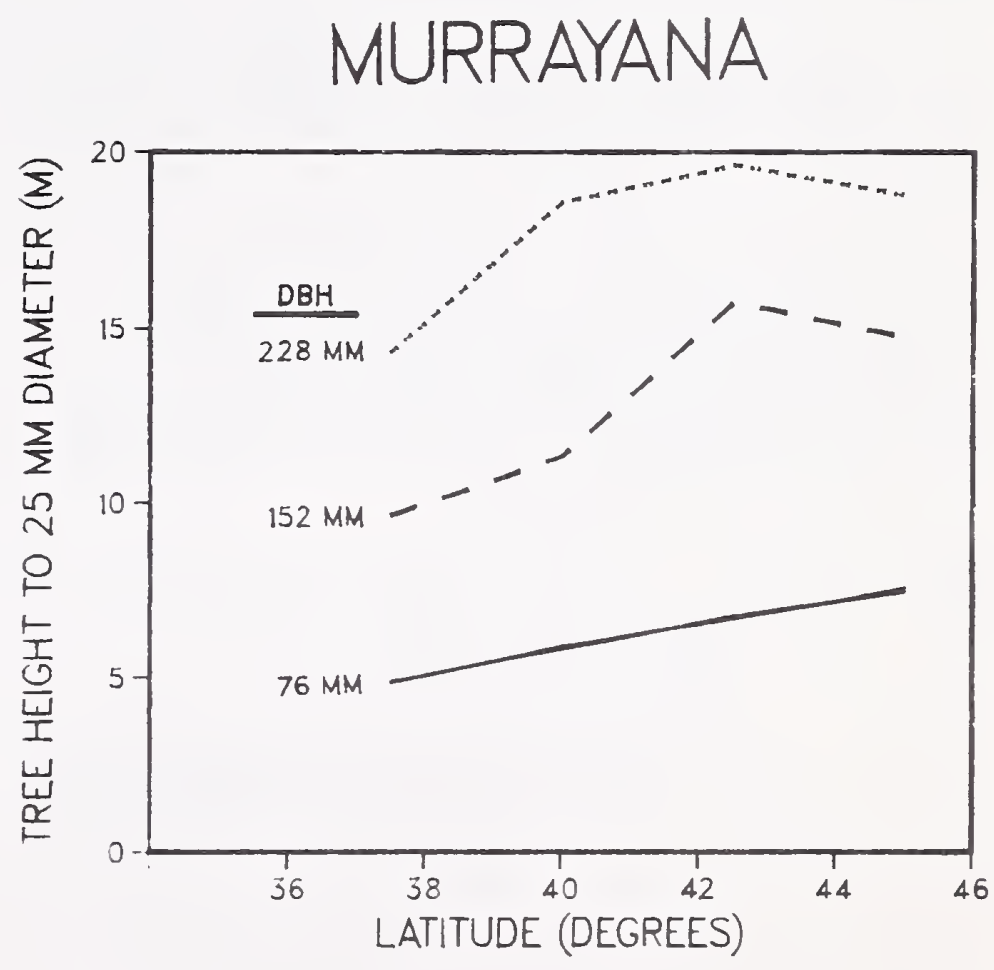

Figure 1-56-Height from stump top to 25-mm stem diameter (measured outside bark) related to latitude for murrayana trees of three diameters.

Figure 1-55-Age measured at $152 \mathrm{~mm}$ stump height related to latitude for murrayana trees of three diameters. 


\section{Width of Live Crown}

Crown width was positively correlated with d.b.h., averaging $1.30(0.23), 1.83(0.23)$, and $2.64(0.53) \mathrm{m}$ for the three diameter classes. It differed with latitudinal zone, averaging widest at 37.5 degrees and narrowest at 42.5 degrees (fig. 1-57).

\section{Length of Live Crown}

Crown length was unrelated to latitude but was positively correlated with d.b.h., averaging 4.4 (1.6), 7.2 (2.2), and 10.7 (2.3) $\mathrm{m}$ for the three diameter classes.

\section{Length of Stem Below Crown}

Stem length below crown was positively correlated with d.b.h., averaging 2.98 (1.53), 6.50 (3.67), and 7.99 (3.81) m for the three diameter classes. The southern latitudes averaged shorter in this dimension than the northern latitudes (fig. 1-58).

\section{Stem Crook}

Stem crook between 10 and 70 percent of tree height averaged $55 \mathrm{~mm}$, with standard deviation of $37 \mathrm{~mm}$; it was unrelated to either d.b.h. or latitudinal class. We measured the percentage of tree height where maximum crook occurred, but found its location not significantly related to either latitude or diameter class; the average location was at 37 percent of tree height.

\section{Number of Live Branches}

The number of live branches per tree was unrelated to latitude, but was positively correlated with d.b.h., averaging 72 (18), 127 (34), and 146 (45) for the three diameter classes.

\section{Average Diameter of Live Branches}

Similarly, average diameter of the live branches was unrelated to latitude but was positively correlated with d.b.h., averaging 7.4 (1.6), 11.9 (2.8), and 18.4 (3.6) $\mathrm{mm}$ for the three diameter classes.
MURRAYANA

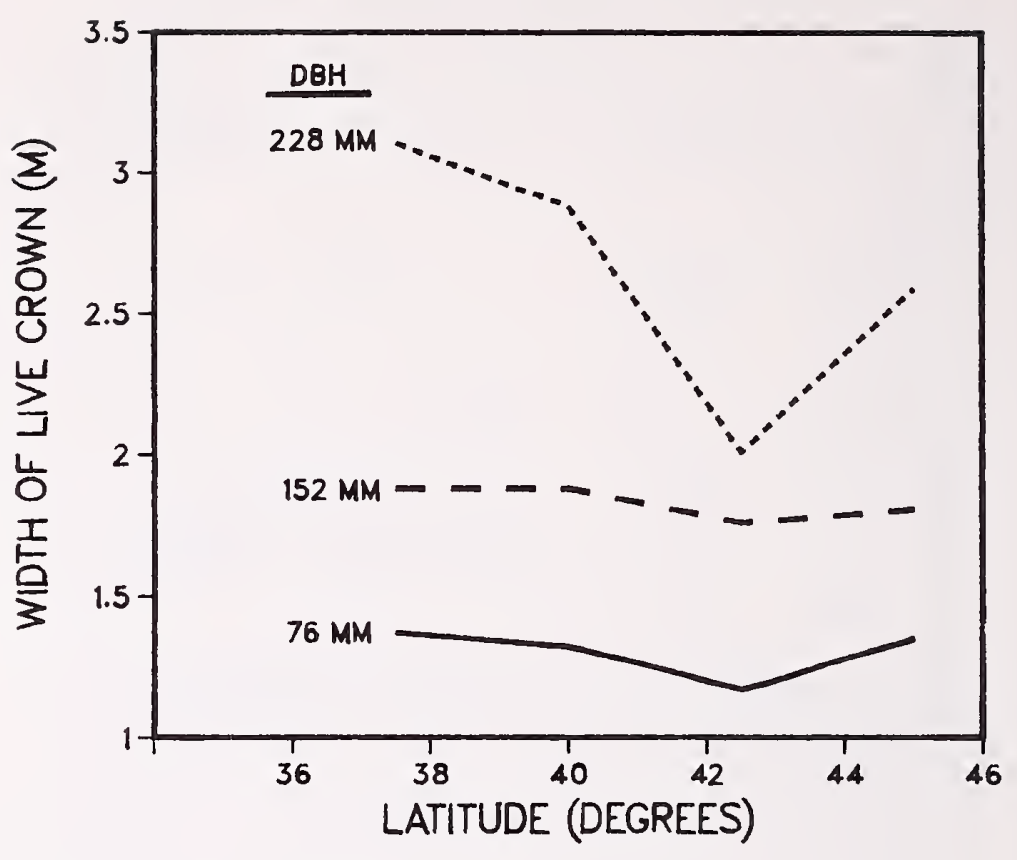

Figure 1-57-Width of live crown of murrayana trees of three diameters related to latitude.
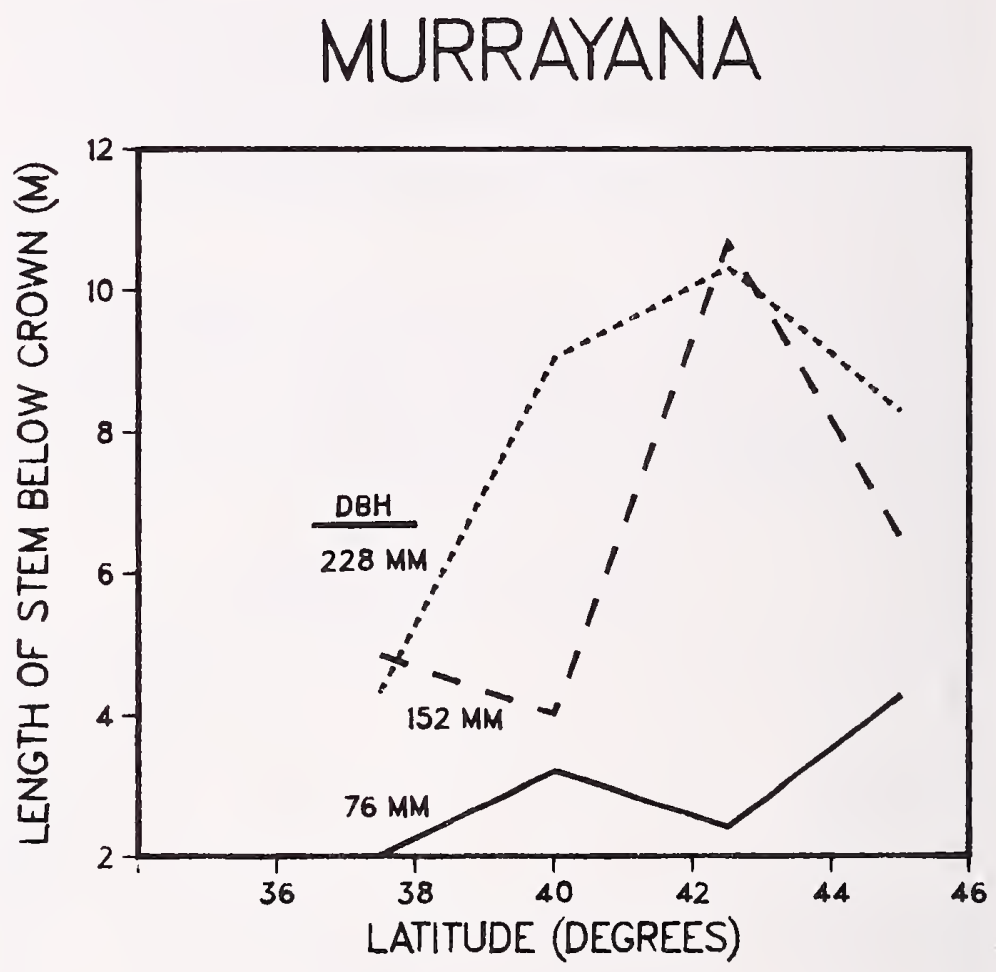

Figure 1-58-Length of stem below live crown of murrayana trees of three diameters related to latitude. 


\section{Average Live Branch Angle}

The average angle between live branches and stem (upward-pointing branches have angles less than 90 degrees; those with drooping branches more than 90 degrees) was greater in small trees than in large, and averaged 88 (9.6), 83 (9.2), and 78 (13.1) degrees for the three diameter classes. Trees in the southern two latitudinal zones averaged 88 degrees, while those in the north averaged 77 degrees (fig. 1-59).

\section{Number of Dead Branches}

Number of dead branches was not significantly related to latitude but was positively correlated with d.b.h., averaging 34 (23), 79 (34), and 94 (34) per tree for the three diameter classes.

\section{Stem Diameter (Bark-Free) at Base of Live Crown}

Stem diameter at the base of the live crown was not significantly related to latitude but was positively correlated with d.b.h., averaging 58 (12), 108 (17), and 169 (21) $\mathrm{mm}$ for the three diameter classes.

\section{Crown Ratio}

Crown ratio averaged 0.58 , with standard deviation of 0.15 . It was unrelated to either diameter class or latitudinal zone.

\section{Average Growth-Ring Width at $152-\mathrm{mm}$ Stump Height}

Ring width was positively correlated with d.b.h., averaging $0.7(0.30), 1.1(0.42)$, and $1.6(0.58) \mathrm{mm}$ for the three diameter classes. Growth rings were significantly narrower in trees from 42.5 degrees latitude (fig. 1-60).
MURRAYANA

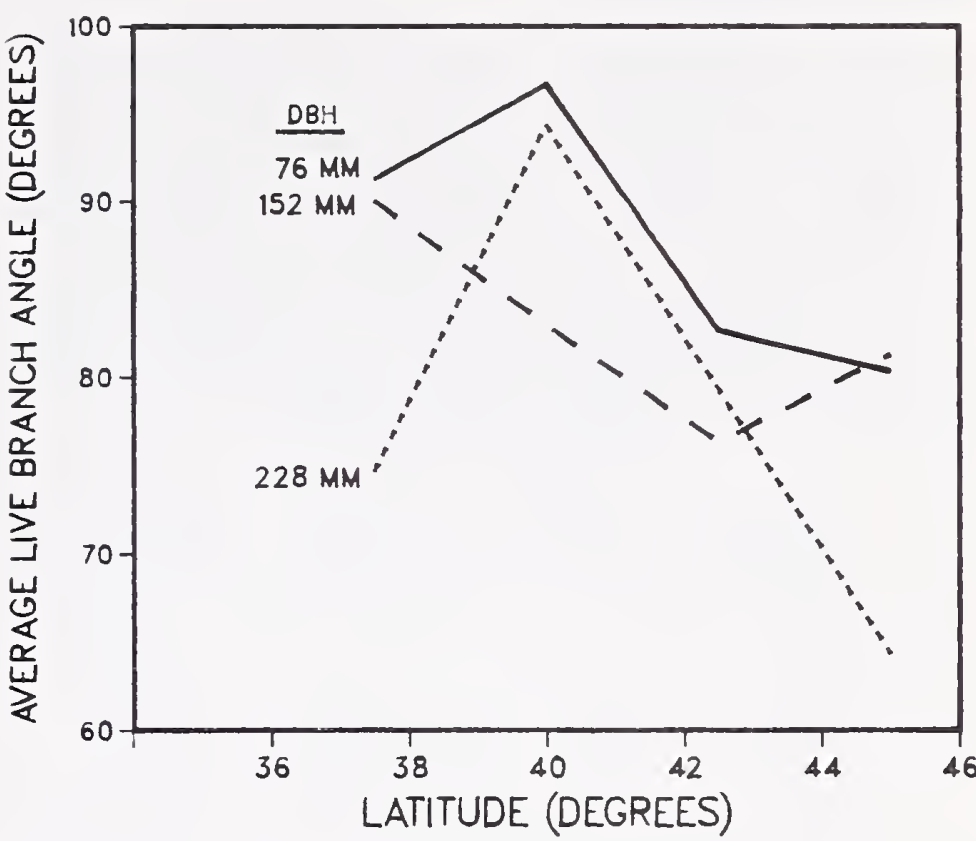

Figure 1-59-Average live branch angle, measured between stem surface above branch and branch top surface adjacent to its entry into stem, related to latitude for murrayana trees of three diameters.

\section{MURRAYANA}

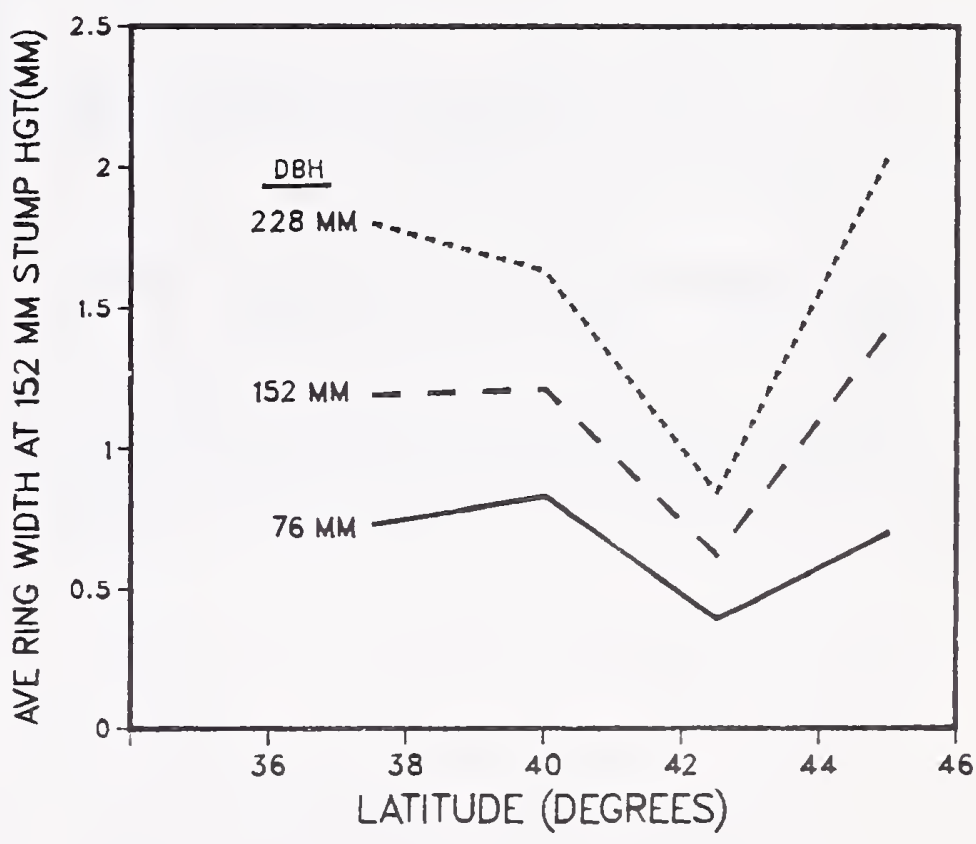

Figure 1-60-Average growth ring width at $152 \mathrm{~mm}$ stump height related to latitude for murrayana trees of three diameters. 


\section{Number of Cones on Tip $305 \mathrm{~mm}$ of the Top 25 Branches}

Of the 12 trees in each d.b.h. class, 10 of the $76-\mathrm{mm}$ trees, two of the $152-\mathrm{mm}$ trees, and two of the $228-\mathrm{mm}$ trees had no cones on the tip $305 \mathrm{~mm}$ of the top 25 branches. The aggregate number of cones on this portion of the top 25 branches was positively correlated with d.b.h., averaging 1.3 (3.7), 7.4 (8.9), and 18.4 (19.7) cones per tree for the three diameter classes. Trees from latitude 42.5 degrees had most cones on these branch sections and trees from 40 degrees least, as follows:

\begin{tabular}{cccc} 
& \multicolumn{3}{c}{ D.b.h. class } \\
\cline { 2 - 4 } Latitude & $\mathbf{7 6} \mathbf{~ m m}$ & $\mathbf{1 5 2} \mathbf{~} \mathbf{m}$ & $\mathbf{2 2 8} \mathbf{~ m m}$ \\
Degrees & $\ldots$ & Number of cones & $\ldots$ \\
37.5 & 0 & 7.0 & 12.3 \\
40 & 0 & 1.7 & 4.0 \\
42.5 & 0 & 16.3 & 40.7 \\
45 & 5 & 4.7 & 16.7
\end{tabular}

\section{Total Number of Cones per Tree (Calculated)}

The calculated total number of cones per tree was unrelated to latitude but was positively correlated with d.b.h., averaging 10 (25), 48 (42), and 165 (100) for the three diameter classes.

\section{Cone Serotiny}

All of the trees bearing cones were classified as openconed; that is, more than 80 percent of the cones were open on each tree that had cones.

\section{Branchbark Thickness (Measured With a Scale)}

Branchbark thickness was unrelated to latitude but was positively correlated with d.b.h., averaging $1.1(0.20), 1.2$ (0.25), and $1.3(0.33) \mathrm{mm}$ for the three diameter classes.

\section{Central Rootbark Thickness (Measured With a Scale)}

Central rootbark thickness was unrelated to latitude but was positively correlated with d.b.h., averaging $2.8(0.74)$, 3.8 (1.11), and $5.4(1.82) \mathrm{mm}$ for the three diameter classes.

\section{Lateral Rootbark Thickness (Measured With a Scale)}

Bark thickness of the lateral roots was positively correlated with d.b.h., averaging $2.2(0.45), 2.8(0.75)$, and 3.4 (0.94) $\mathrm{mm}$ for the three diameter classes. Thickest bark (3.4 $\mathrm{mm}$ average for nine trees) was observed in the southernmost latitude, while the three more northerly latitudes averaged $2.6 \mathrm{~mm}$ (fig. 1-61).

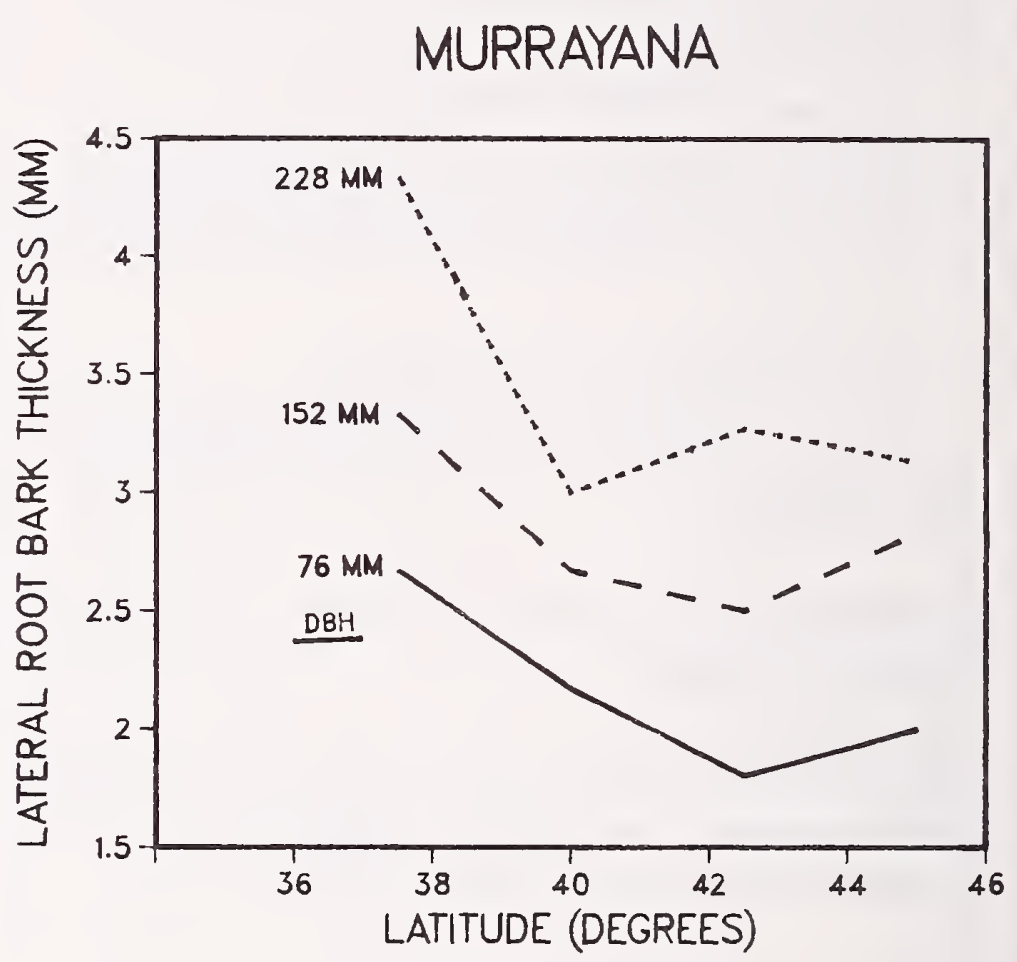

Figure 1-61-Lateral rootbark thickness related to latitude for murrayana trees of three diameters. 
Stumpbark Thickness (Measured With a Scale)

Bark thickness of the stump between groundline and $152-\mathrm{mm}$ stump height was unrelated to latitude but was positively correlated with d.b.h., averaging 3.6 (0.85), 5.4 (1.70), and $7.2(1.25) \mathrm{mm}$ for the three diameter classes.

\section{Stembark Thickness (Measured With a Diameter Tape)}

Stembark thickness was positively correlated with d.b.h., averaging 2.3, 3.7, and $4.7 \mathrm{~mm}$ for the three diameter classes (data for all 10 heights in each tree pooled); it was maximum at stump height and diminished in ogee-curve form with height in tree (fig. 1-62).

Trees in latitudinal zones 37.5 and 40 degrees had thicker bark than those in zones of 42.5 and 45 degrees (fig. 1-63).
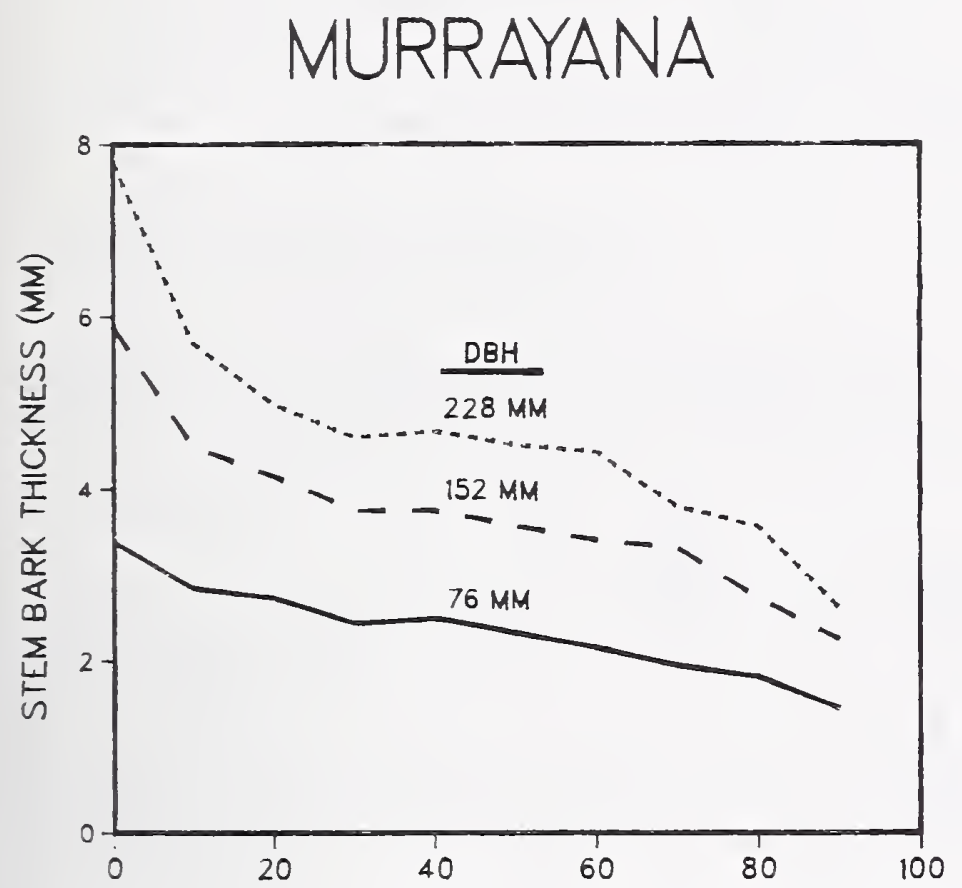

HEIGHT IN TREE,STUMP TOP TO APICAL TIP (PERCENT)

Figure 1-62-Stembark thickness related to height in tree for murrayana trees of three diameters; latitudinal data pooled.
MURRAYANA
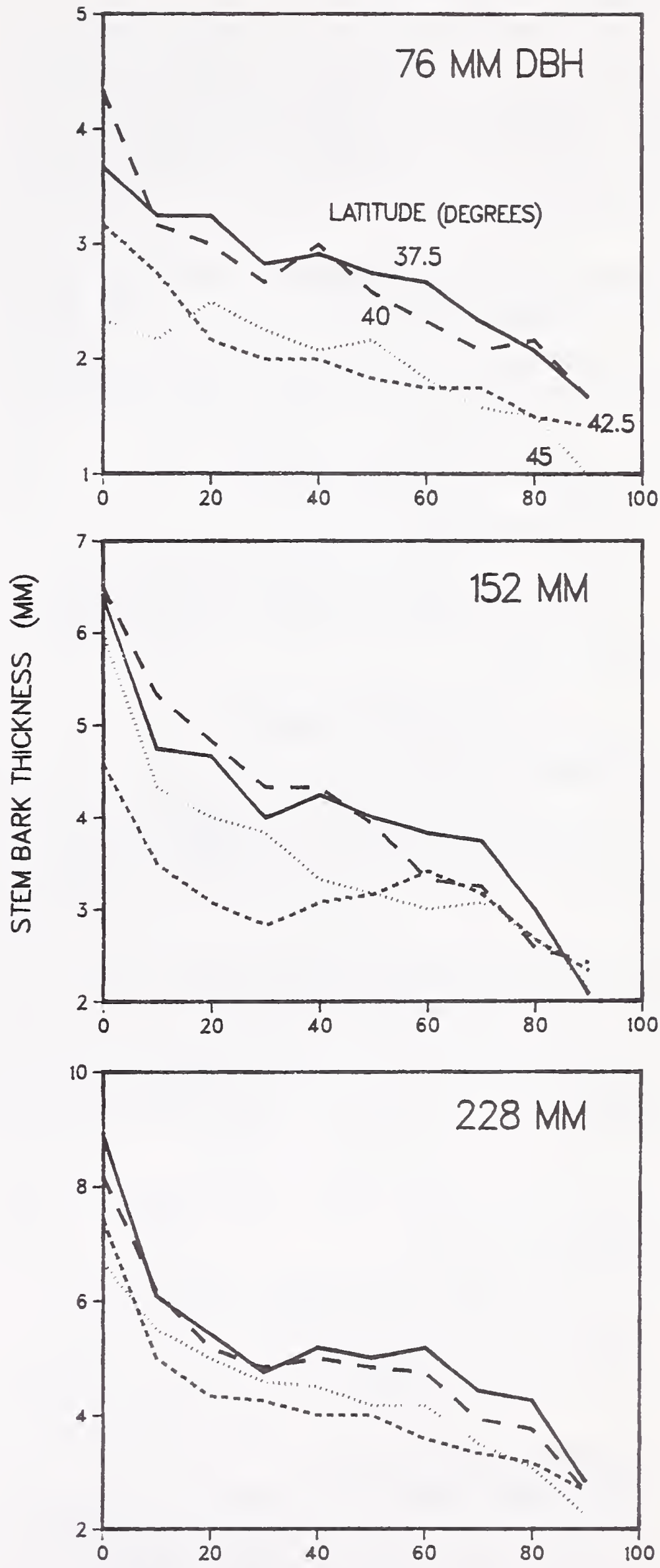

HEIGHT IN TREE,STUMP TOP TO APICAL TIP (PERCENT)

Figure 1-63-Stembark thickness related to latitude and height in stem for murrayana trees of three diameters. 


\section{Total Volume of Dead Branches (Thousand $\mathrm{cm}^{3}$ )}

Volume of dead branches on each tree was positively correlated with d.b.h., averaging $0.4(0.30), 1.7(1.10)$, and 8.8 (2.46) for the three diameter classes. Trees $76 \mathrm{~mm}$ in d.b.h. had dead-branch volume positively correlated with latitude (fig. 1-64). In the 40-degree zone trees of all diameters averaged twice the dead-branch volume of those in more southerly zones.

\section{Volume of Live Branches, Wood Plus Bark (Thousand $\mathrm{cm}^{3}$ )}

Total volume was unrelated to latitude but was positively correlated with d.b.h., averaging 1.4 (0.59), 8.9 (3.24), and 30.9 (14.46) for the three diameter classes.

\section{Volume of Live Branchwood (Thousand $\mathrm{cm}^{3}$ )}

Similarly, live branchwood volume was unrelated to latitude but was positively correlated with d.b.h., averaging $0.7(0.30), 5.1(1.76)$, and $19.6(7.80)$ for the three diameter classes.

\section{Volume of Live Branchbark (Thousand $\mathrm{cm}^{3}$ )}

Live branchbark volume also was unrelated to latitude but was positively correlated with d.b.h., averaging 0.7 $(0.30), 3.8(1.60)$, and 11.3 (6.97) for the three diameter classes.

\section{Volume of Stump-Root System, Wood Plus Bark (Thousand $\mathrm{cm}^{3}$ )}

Stump-root system volume, including both wood and bark, was unrelated to latitude but was positively correlated with d.b.h., averaging 3.9 (1.09), 21.0 (5.31), and 45.7 (6.52) for the three diameter classes.

\section{Volume of Stump, Wood Plus Bark (Thousand $\mathrm{cm}^{3}$ )}

Total stump volume (groundline to $152 \mathrm{~mm}$ stump top) was unrelated to latitude but was positively correlated with d.b.h., averaging $1.2(0.36), 4.6$ (1.55), and 7.1 (1.71) for the three diameter classes.

\section{Volume of Lateral Roots, Wood Plus Bark (Thousand $\mathrm{cm}^{3}$ )}

Lateral root volume (root collar to a radius $305 \mathrm{~mm}$ from stump pith) was positively correlated with tree d.b.h., averaging $0.7(0.29), 6.5$ (2.55), and $16.1(0.94)$ for the three diameter classes. Trees 152 and $228 \mathrm{~mm}$ in d.b.h. had maximum lateral root volume at 40 degrees of latitude; volumes were lowest or nearly so at 45 degrees (fig. 1-65).

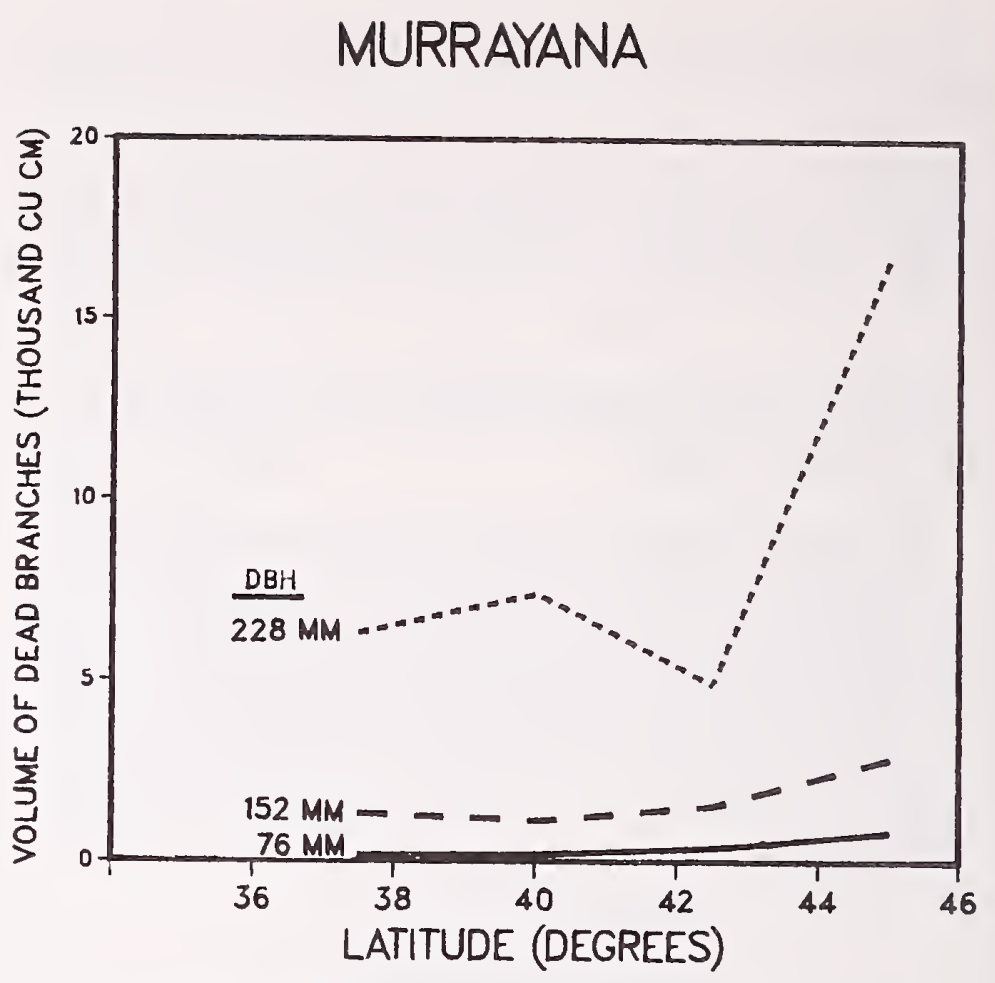

Figure 1-64-Dead-branch volume related to latitude for murrayana trees of three diameters.
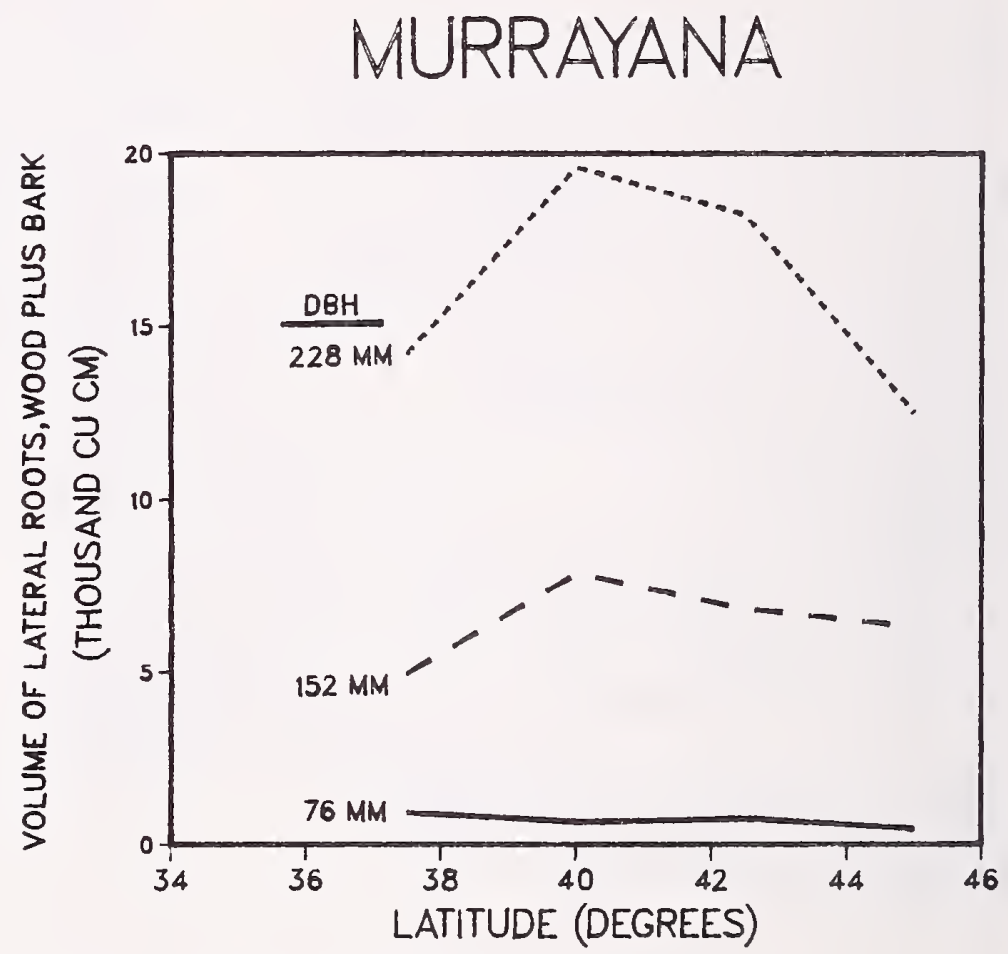

Figure 1-65-Lateral root volume, wood plus bark, related to latitude for murrayana trees of three diameters.

\section{Volume of Central Root Mass, Wood Plus Bark (Thousand $\mathrm{cm}^{3}$ )}

The central root mass shorn of laterals and stump, but with that portion of the taproot recovered by the field crews, had volume unrelated to latitude, but positively correlated with tree d.b.h., averaging $2.0(0.71), 10.0$ (2.61), and $22.4(5.00)$ for the three diameter classes. 
Volume of Stump-Root System, Wood Only (Thousand $\mathrm{cm}^{3}$ )

The stump-root system wood volume was positively correlated with d.b.h., averaging $3.2(0.91), 17.0(6.42)$, and 41.3 (5.71) for the three diameter classes. Wood volume was greatest at 40 degrees and least in the 45 -degree latitudinal zone (fig. 1-66).

\section{Volume of Stump, Wood Only} (Thousand $\mathrm{cm}^{3}$ )

Stumpwood volume was unrelated to latitude but was positively correlated with d.b.h., averaging $1.1(0.30), 4.5$ (1.58), and $6.4(1.54)$ for the three diameter classes.

\section{Volume of Lateral Roots, Wood Only (Thousand $\mathrm{cm}^{3}$ )}

Wood volume of lateral roots was unrelated to latitude but was positively correlated with d.b.h., averaging 0.5 (0.23), 5.6 (2.37), and 14.1 (3.45) for the three diameter classes.

\section{Volume of Central Root Mass, Wood Only (Thousand $\mathrm{cm}^{3}$ )}

Wood volume of the central root mass shorn of stump and laterals, but including taproot, was unrelated to latitude but was positively correlated with d.b.h., averaging 1.5 (0.69), 8.3 (2.96), and 20.7 (4.54) for the three diameter classes.

\section{Volume of Stump-Root System, Bark Only (Thousand $\mathrm{cm}^{3}$ )}

Bark volume of the stump-root system was unrelated to latitude but was positively correlated with d.b.h., averaging $0.6(0.19), 2.6(0.91)$, and 4.4 (1.11) for the three diameter classes.

\section{Volume of Stump, Bark Only (Thousand $\mathrm{cm}^{3}$ )}

Bark volume from stump top to ground level was positively correlated with d.b.h., averaging $0.18(0.06)$, $0.51(0.17)$, and $0.67(0.22)$ for the three diameter classes. Stumpbark volume was usually least at 45 degrees and greatest in the southern latitudes (fig. 1-67).

\section{Volume of Lateral Roots, Bark Only (Thousand $\mathrm{cm}^{3}$ )}

Bark volume of lateral roots from root collar to a radius of $305 \mathrm{~mm}$ from stump pith was unrelated to latitude but positively correlated with d.b.h., averaging $0.2(0.07), 1.0$ $(0.58)$, and $2.0(0.76)$ for the three diameter classes.

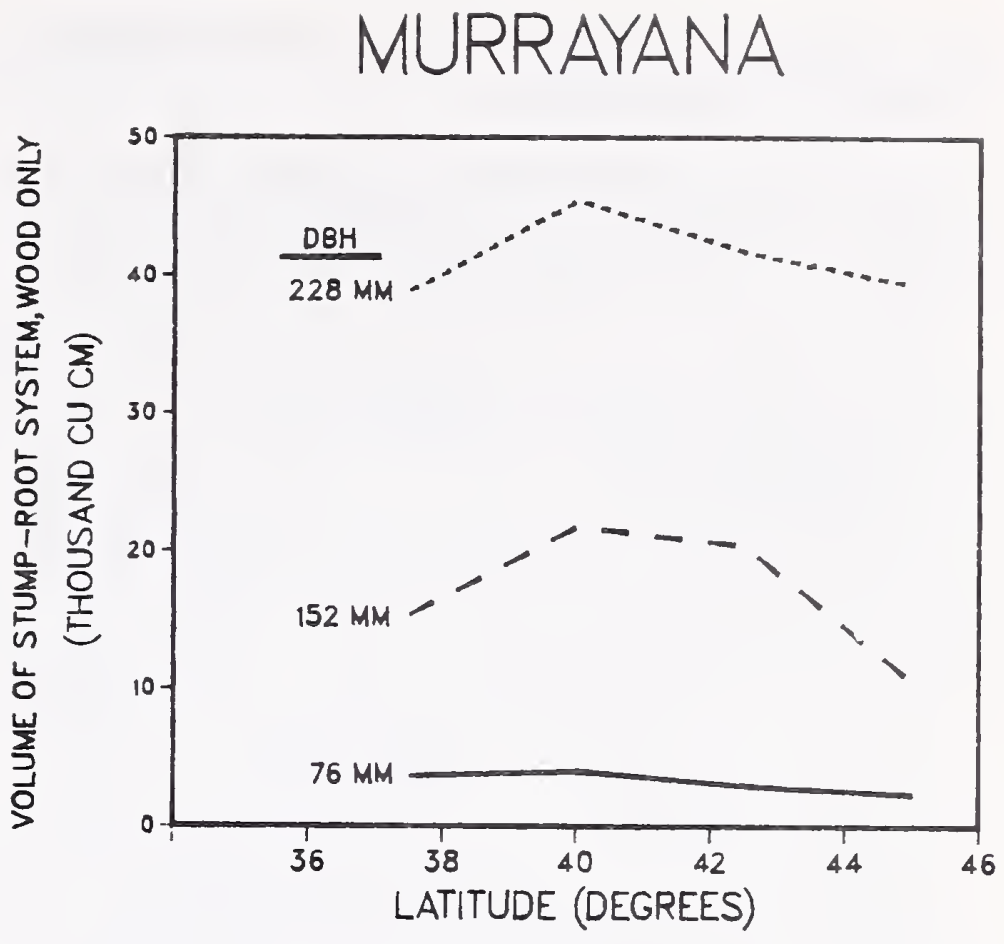

Figure 1-66-Wood volume in stump-root system of murrayana trees of three diameters related to latitude.
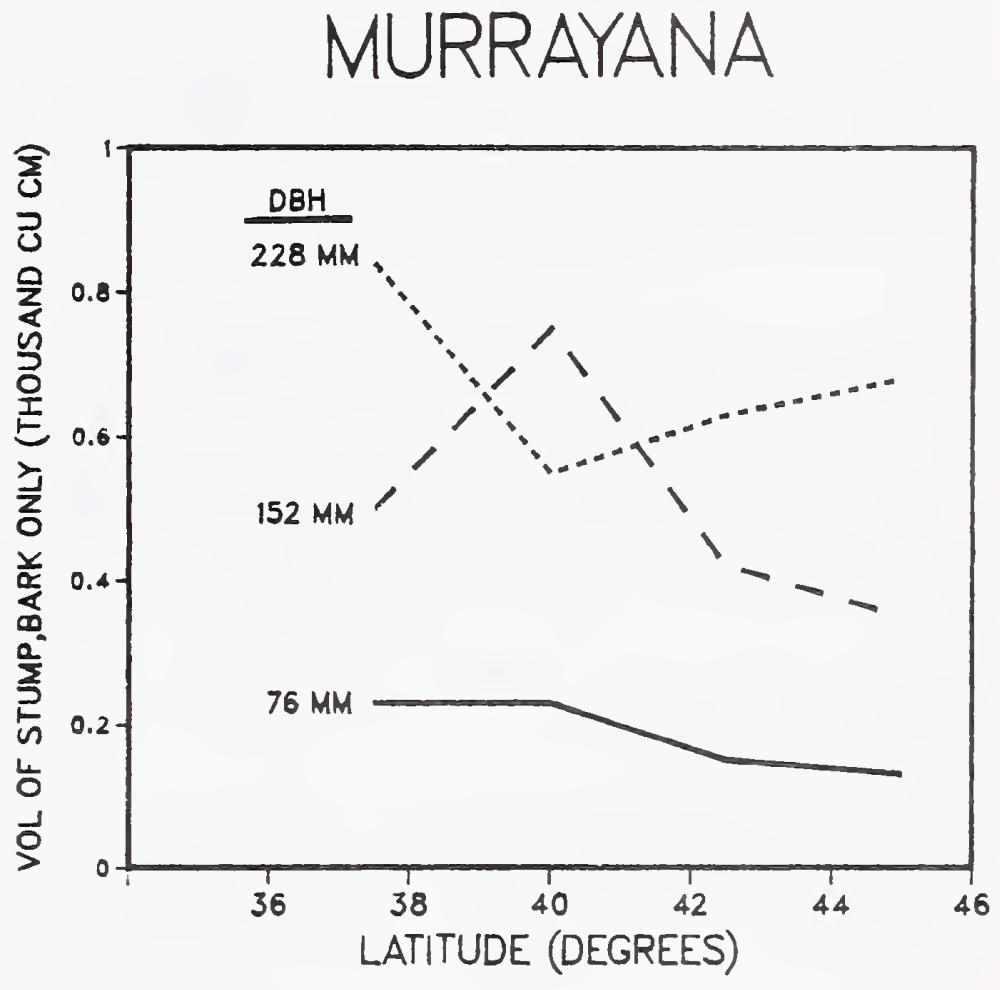

Figure 1-67-Bark volume in stump of murrayana trees of three diameters related to latitude.

\section{Volume of Central Root Mass, Bark Only (Thousand $\mathrm{cm}^{3}$ )}

Volume of bark on the central root mass, including taproot, was unrelated to latitude but was positively correlated with d.b.h., averaging $0.3(0.11), 1.0(0.37)$, and 1.7 $(0.56)$ for the three diameter classes. 


\section{Stem Volume to Apical Tip, Wood Plus Bark (Thousand $\mathrm{cm}^{3}$ )}

Total stem volume was unrelated to latitude but was positively correlated with d.b.h., averaging 18.5 (4.5), 124.2 (39.4), and $367.4(105.0)$ for the three diameter classes.

\section{Stemwood Volume to Apical Tip (Thousand $\mathrm{cm}^{3}$ )}

Similarly, stemwood volume to the apical tip was unrelated to latitude but was positively correlated with d.b.h., averaging 15.8 (4.1), 111.1 (6.6), and 336.1 (98.5) for the three diameter classes.

\section{Stembark Volume to Apical Tip (Thousand $\mathrm{cm}^{3}$ )}

Stembark volume to the apical tip was unrelated to latitude; for the three diameter classes it averaged 2.7 (0.50), 13.2 (3.24), and 31.3 (6.79).

\section{Complete-Tree Volume, Wood Plus Bark (Thousand $\mathrm{cm}^{3}$ )}

Complete-tree volume of wood plus bark (stump-root system, stem, live and dead branches-but not foliage) was unrelated to latitude but positively correlated with d.b.h., averaging 24.2 (4.72), 156.0 (38.7), and 452.7 (97.14) for the three diameter classes.

\section{Complete-Tree Volume, Wood Only (Thousand $\mathrm{cm}^{3}$ )}

Complete-tree volume of wood was unrelated to latitude but was positively correlated with d.b.h., averaging 20.2 (0.3), 136.4 (36.8), and $405.8(95.5)$.

\section{Complete-Tree Volume, Bark Only (Thousand $\mathrm{cm}^{3}$ )}

Bark volume of complete trees was unrelated to latitude but was positively correlated with d.b.h., averaging 4.1 (0.73), $19.6(2.83)$, and $46.9(6.71)$ for the three diameter classes.
MURRAYANA

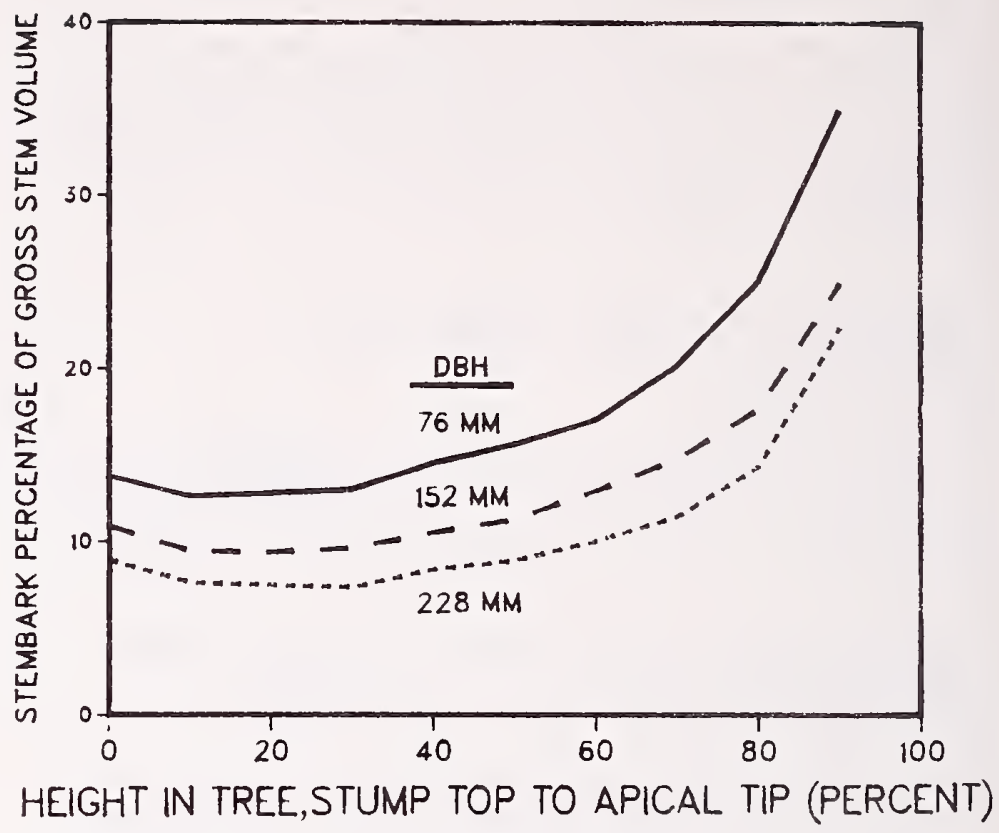

Figure 1-68-Stembark percentage of gross stem volume at 10 heights in murrayana trees of three diameters; latitudinal data pooled.

\section{Stembark as Percentage of Gross Stem Volume by Height in Tree}

In all diameter classes, bark percentage was relatively large at stump height, decreased from stump height to 20 percent of tree height, and then was positively correlated with height in tree (fig. 1-68); large-diameter trees had less percentage of stembark volume at all stem heights than small-diameter trees.

Trees in latitudinal zones 37.5 and 40 degrees had a greater percentage of stembark at all heights than those from latitudes 42.5 and 45 degrees; the 42.5 -degree zone had trees with least percentage of stembark volume (fig. 1-69). 
MURRAYANA
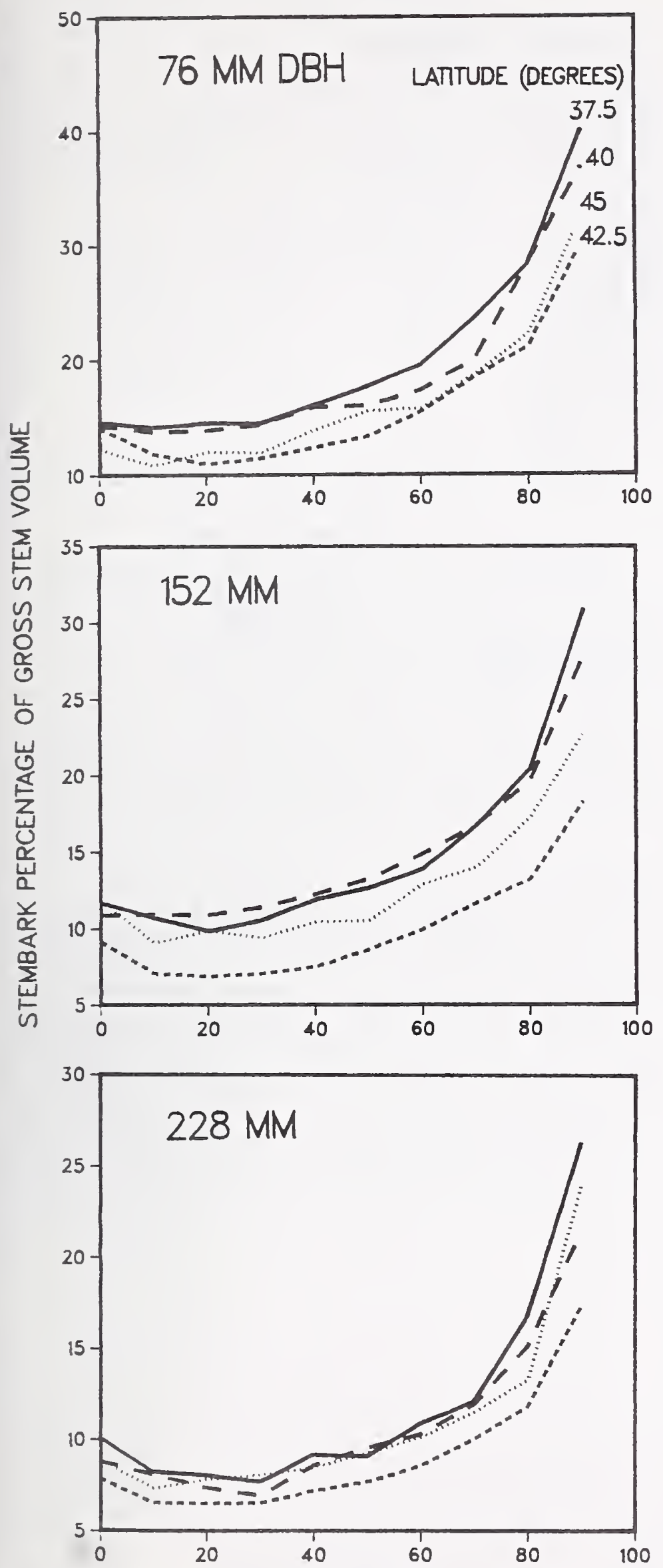

HEIGHT IN TREE,STUMP TOP TO APICAL TIP (PERCENT)

Figure 1-69-Stembark percentage of gross stem volume related to latitude and height in tree for murrayana trees of three diameters.

\section{Stembark as Percentage of Gross Stem Volume}

Stembark volume as a percentage of gross volume of stem from stump top to apical tip was negatively correlated with d.b.h., averaging $14.8(2.0), 11.0(1.7)$, and 8.7 (1.0) percent for the three diameter classes; that is, small trees had a greater percentage of stembark than large trees.

Trees in the southernmost latitudinal zone had the greatest percentage of stembark volume, averaging 12.6 percent; those at 42.5 degrees least, averaging 10.0 percent (fig. 1-70).

\section{Stump-Root Bark as Percentage of Gross Stump-Root System Volume}

Stump-root bark volume as a percentage of gross volume of stump-root system was unrelated to latitude, but, as in stems, was inversely correlated with d.b.h., averaging $16.7(1.6), 12.3(2.0)$, and 9.5 (1.6) percent for 76-, 152-, and 228-mm trees, respectively.

\section{Live Branchbark as Percentage of Gross Live Branch Volume}

Percentage of branchbark in gross live branch volume was unrelated to latitude but was inversely correlated with tree d.b.h., averaging 52.3 (4.4), 42.0 (4.9), and 34.7 (7.0) percent for 76-, 152-, and 228-mm trees, respectively.

\section{MURRAYANA}

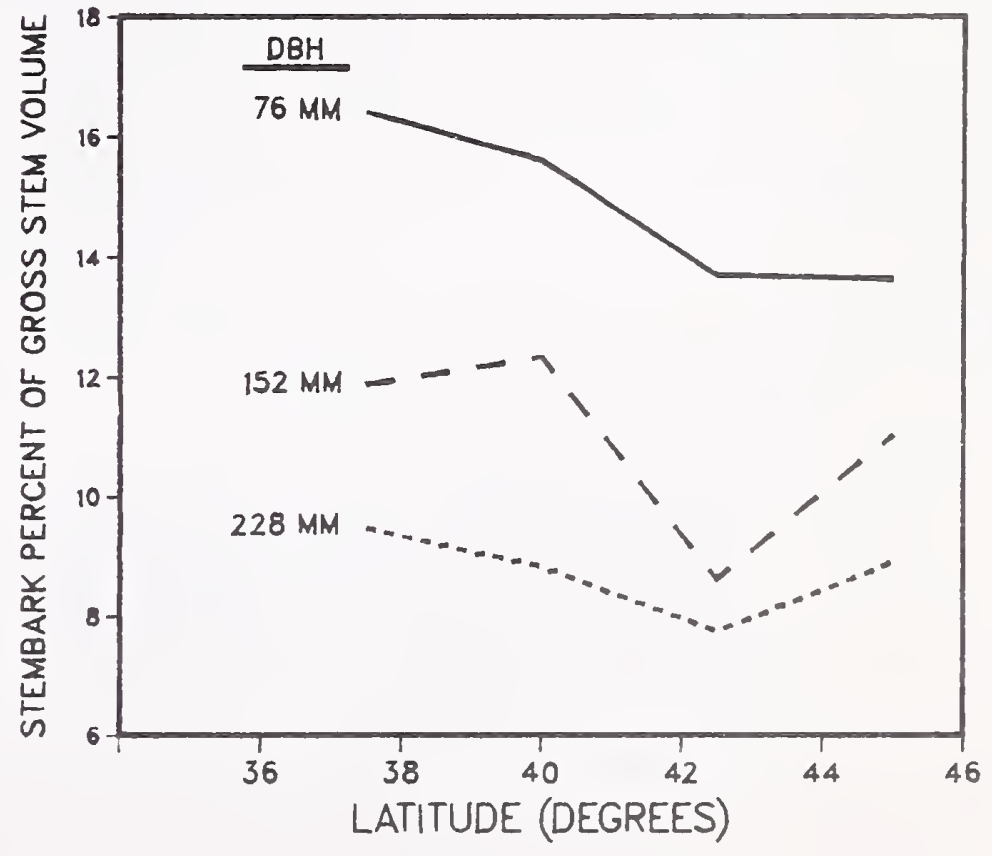

Figure 1-70-Stembark percentage of gross stem volume (stump top to apical tip) related to latitude for murrayana trees of three diameters. 


\section{Bark of Complete Tree as Percentage of Complete-Tree Volume}

Complete-tree bark as a percentage of complete-tree volume was inversely correlated with d.b.h., averaging $17.1(2.8), 13.0(2.5)$, and 10.8 (3.0) percent for 76-, 152-, and $228-\mathrm{mm}$ trees.

In the southernmost latitudinal zone (37.5 degrees) percentage of complete-tree bark was highest (15.9 percent with diameter data pooled); it was lowest at 42.5 degrees, where it averaged only 11.4 percent (fig. 1-71).

\section{Stemwood as Percentage of Complete- Tree Wood Volume}

Stemwood volume averaged 79.8 (6.66) percent of complete-tree volume and was unrelated to tree diameter. It was least in the southern latitudes and most in the northern latitudes, averaging 75.1, 77.6, 83.9, and 82.6 percent for latitudes $37.5,40,42.5$, and 45 degrees, respectively.

\section{Live Branchwood as Percentage of Complete-Tree Wood Volume}

Live branchwood as a percentage of complete-tree wood volume was unrelated to latitude but was positively correlated with d.b.h., averaging 3.6 (1.90), 4.3 (2.58), and 5.5 (3.81) for 76-, 152-, and 228-mm trees.

\section{MURRAYANA}

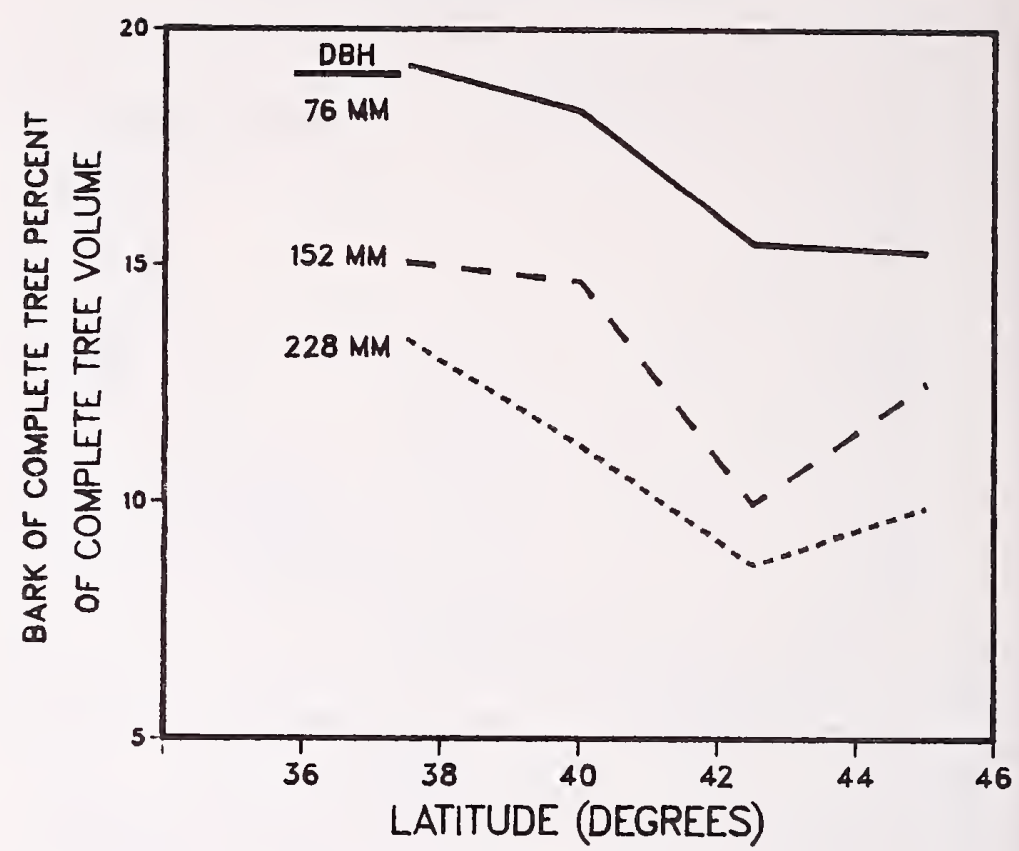

Figure 1-71-Bark volume of complete tree as a percentage of volume of complete tree, wood plus bark, related to latitude for murrayana trees of three diameters. 


\section{Dead Branchwood as Percentage of Complete-Tree Wood Volume}

Dead branchwood volume averaged 1.9 (1.49) percent of complete-tree volume and was unrelated to tree diameter. Percentage of dead branchwood was greatest in the most northerly latitudinal zone where it averaged 3.4 percent; for $76-\mathrm{mm}$ trees only, it was positively correlated with latitude, as follows:

\begin{tabular}{|c|c|c|c|}
\hline \multirow[b]{2}{*}{ Latitude } & \multicolumn{3}{|c|}{ D.b.h. class } \\
\hline & $76 \mathrm{~mm}$ & $152 \mathrm{~mm}$ & $228 \mathrm{~mm}$ \\
\hline Degrees & \multicolumn{3}{|c|}{$\ldots \ldots$ Percent $\ldots \ldots \ldots$} \\
\hline 37.5 & 0.92 & 1.40 & 1.80 \\
\hline 40 & 1.05 & 1.09 & 1.81 \\
\hline 42.5 & 2.03 & .91 & 1.06 \\
\hline 45 & 4.01 & 1.97 & 4.19 \\
\hline \multirow[t]{2}{*}{ Average } & 2.00 & 1.34 & 2.22 \\
\hline & $(1.49)$ & $(.83)$ & $(1.92)$ \\
\hline
\end{tabular}

\section{Stumpwood as Percentage of Complete- Tree Wood Volume}

From groundline to 152-mm-high stump top, stumpwood as a percentage of complete-tree wood varied inversely with d.b.h., averaging $5.4(1.74), 3.6(1.68)$, and $1.7(0.56)$ percent for 76-, 152-, and 228-mm trees. With diameters pooled, this percentage averaged greatest ( 4.5 percent) at 40 degrees latitude and least (2.7 percent) at 45 degrees (fig. 1-72).

\section{Stump-Root System Wood as Percentage of Complete-Tree Wood Volume}

Total stump-root system wood (stump, central root collar and taproot, and laterals to $305 \mathrm{~mm}$ radius from stump pith) as a percentage of complete-tree wood volume was inversely correlated with d.b.h., averaging 16.5 (5.2), 13.3 (6.2), and 10.7 (2.7) percent for 76-, 152-, and 228-mm trees. Stump-root wood volume percentage averages were smallest (9.0) in the northernmost latitudinal zone and highest (16.5) in the two southernmost zones (fig. 1-73).

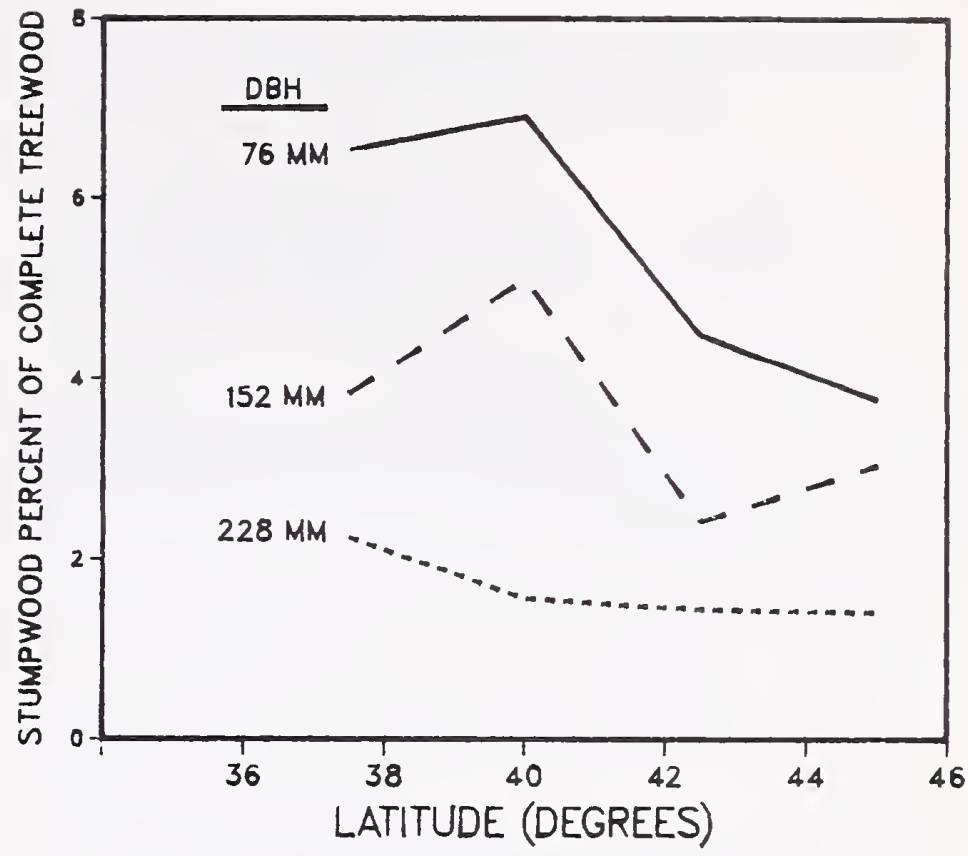

Figure 1-72-Stumpwood percentage of complete-tree wood volume related to latitude for murrayana trees of three diameters.

\section{MURRAYANA}

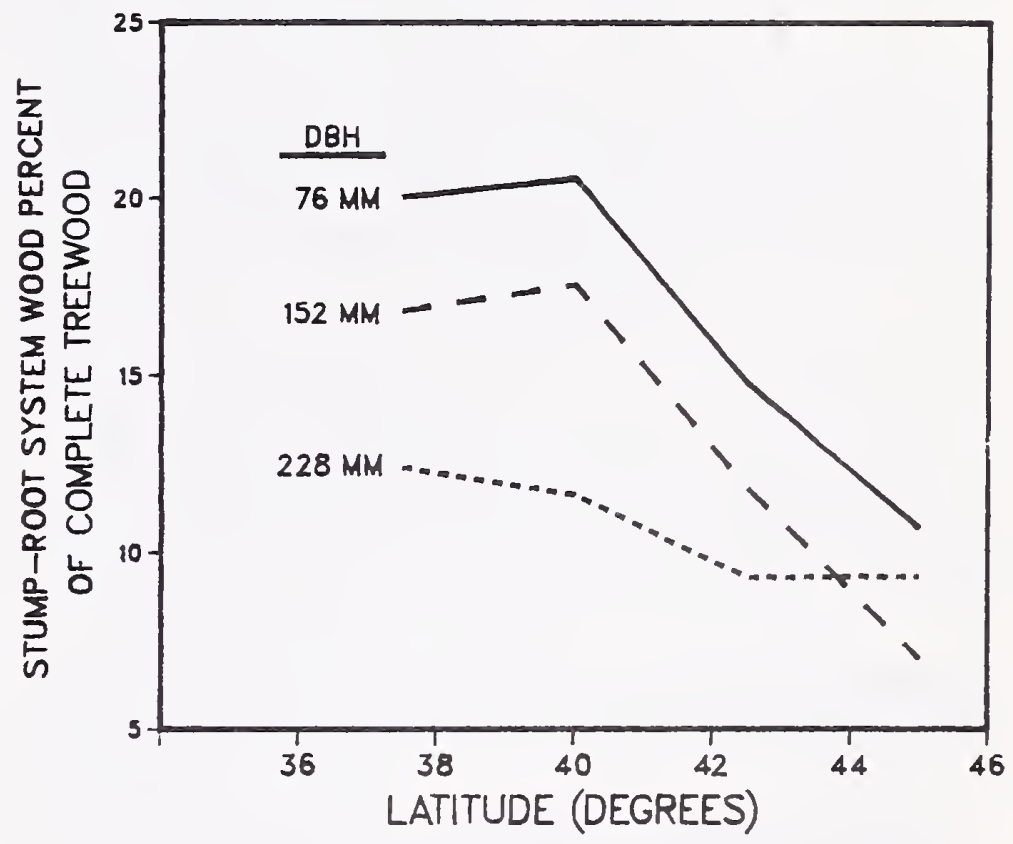

Figure 1-73-Wood volume of the stump-root system as a percentage of complete-tree wood volume related to latitude for murrayana trees of three diameters. 


\section{1-14 RESULTS-LATIFOLIA COMPARED TO MURRAYANA}

The experimental design permitted an orthogonal comparison between the two varieties at three latitudes, as follows:
Varieties:
(2) latifolia and murrayana
D.b.h. classes:
(3) 76,152 , and $228 \mathrm{~mm}$
Latitudinal zones:
(3) $40,42.5$, and 45 degrees
Elevational zones:
(1) medium
Replications:

Sample size for this comparison therefore totaled 54 trees, 27 of each variety. Sample locations and average elevations were as follows:

\begin{tabular}{|c|c|c|}
\hline $\begin{array}{l}\text { Variety } \\
\text { and } \\
\text { latitude }\end{array}$ & Elevation & General location \\
\hline Degrees & Meters & \\
\hline \multicolumn{3}{|c|}{ murrayana } \\
\hline 40 & 1,676 & Vicinity of Quincy, CA \\
\hline 42.5 & 2,006 & Southwest of Paisley, OR \\
\hline 45 & 1,148 & North of Breitenbush, OR \\
\hline \multicolumn{3}{|l|}{ latifolia } \\
\hline 40 & 2,711 & $\begin{array}{l}\text { Between Boulder, CO, and } \\
\text { Meeker, UT }\end{array}$ \\
\hline 42.5 & 2,376 & $\begin{array}{l}\text { Between Lander, WY, and Soda } \\
\text { Springs, UT }\end{array}$ \\
\hline 45 & 1,930 & $\begin{array}{l}\text { Between the Gallatin River, MT, } \\
\text { and north of John Day, OR }\end{array}$ \\
\hline
\end{tabular}

In the discussions that follow, only significant relationships associated with varietal differences are explained; the other effects are more completely described in the previous two results sections.

\section{Tree Age}

At 42.5 degrees, murrayana trees (diameters pooled) averaged 125 years old vs. only 89 for latifolia; but at 40 and 45 degrees, murrayana trees averaged younger than latifolia-67 vs. 88 years.

\section{Average Diameter of Live Branches (50 $\mathrm{mm}$ from Stem)}

Live branch diameter was about $2 \mathrm{~mm}$ less on murrayana trees than on latifolia.

\section{Average Live Branch Angle}

In latitudinal zones 40 and 42.5 degrees, live branch angle averaged greater on murrayana than on latifolia trees-85 vs. 75 degrees; at 45 degrees of latitude differences varied with tree d.b.h. (fig. 1-74).

\section{COMPARISON}
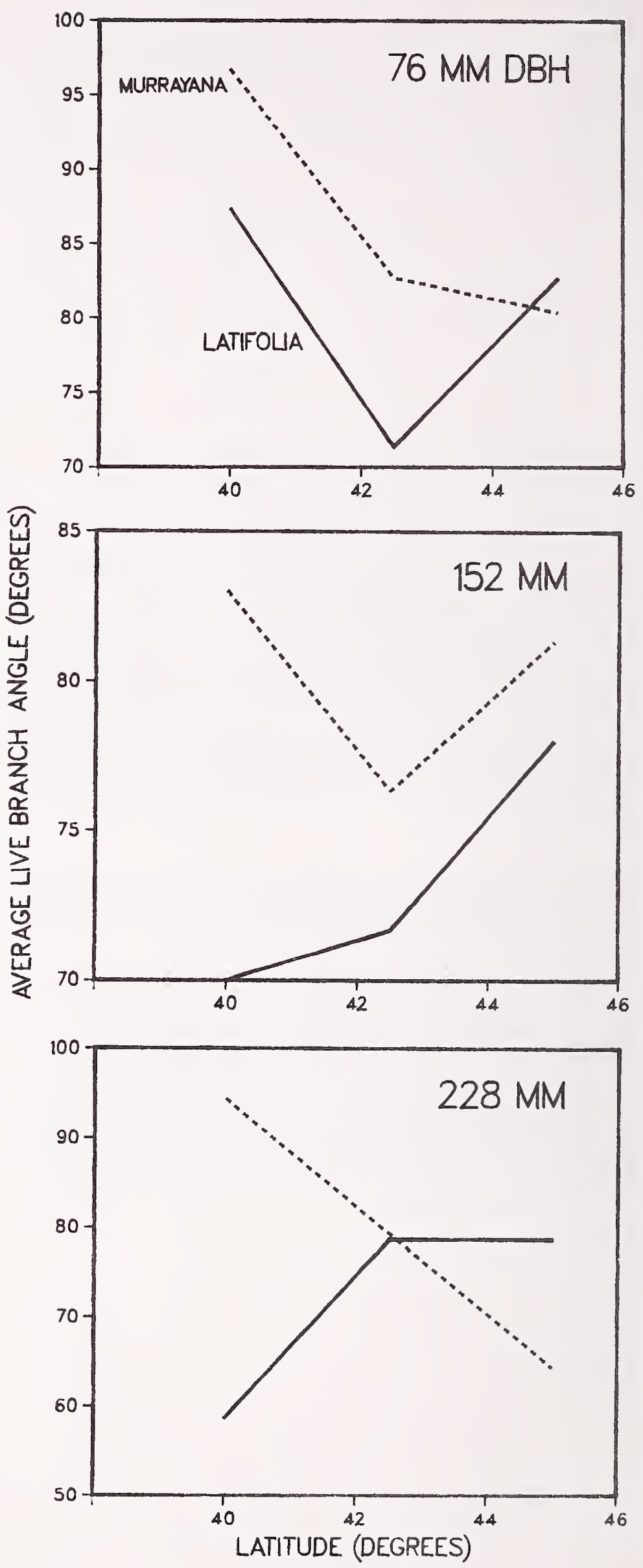

Figure 1-74-Average live branch angles of murrayana trees of three diameters compared with those of latifolia related to latitude. 
Average Growth-Ring Width at $152-\mathrm{mm}$ Stump Height

At 42.5 degrees latitude, murrayana had average ring width of only $0.6 \mathrm{~mm}$, whereas latifolia ring width averaged $1.0 \mathrm{~mm}$. At the other two latitudes, however, murrayana rings averaged wider than those of latifolia$1.3 \mathrm{~mm}$ vs. $0.9 \mathrm{~mm}$.

\section{Number of Cones on Tip $305 \mathrm{~mm}$ of the Top 25 Branches}

Latifolia trees had almost four times more cones on the tip $305 \mathrm{~mm}$ of the top 25 branches than murrayana, as follows:

$\begin{array}{ccc}\text { Latitude } & \text { Latifolia } & \text { Murrayana } \\ \text { Degrees } & \ldots . . & \text { Number } \\ 40 & 25 & 2 \\ 42.5 & 70 & 19 \\ 45 & 16 & 9 \\ \text { Average } & 37 & 10\end{array}$

\section{Total Number of Cones per Tree (Calculated)}

With diameters and latitudes pooled, calculated total number of cones per latifolia tree was more than three times that per murrayana tree-279 vs. 80 .

\section{Cone Serotiny}

Murrayana trees were all classified as open-coned trees, whereas the degree of serotiny of latifolia trees depended on latitudinal zone. Latifolia trees in northern latitudes were mostly classified as closed-coned; those in the southern latitudes were mostly open-coned (fig. 1-19).

\section{Central Rootbark Thickness (Measured With a Scale)}

At latitudes 42.5 and 45 degrees, central rootbark was thicker on latifolia than on murrayana trees-averaging $4.3 \mathrm{~mm}$ vs. $3.6 \mathrm{~mm}$; at 40 degrees, however, murrayana bark was the thickest $-4.3 \mathrm{~mm}$ vs. $3.5 \mathrm{~mm}$ for latifolia.

\section{Lateral Rootbark Thickness (Measured With a Scale)}

On lateral roots, latifolia bark was thicker than that of murrayana at all latitudes, averaging for all diameters and latitudes $3.1 \mathrm{~mm}$ vs. $2.6 \mathrm{~mm}$.

\section{Stumpbark Thickness (Measured With a Scale)}

Similarly, average thickness of stumpbark was greater for latifolia than for murrayana-5.8 mm vs. $5.1 \mathrm{~mm}$, with all diameters and latitudes pooled.

\section{Stembark Thickness (Measured With a Diameter Tape)}

From stump top through 40 percent of tree height, murrayana stembark (diameter and latitudinal data pooled) was slightly thicker than that of latifolia-4.1 $\mathrm{mm}$ vs. $4.0 \mathrm{~mm}$. At 50 percent of tree height both varieties had equal bark thickness-3.3 mm. From 60 to 90 percent of tree height, latifolia had slightly thicker stembark than murrayana-2.9 $\mathrm{mm}$ vs. $2.7 \mathrm{~mm}$.

\section{Volume of Stump, Wood Plus Bark (Thousand $\mathrm{cm}^{3}$ )}

In 152-mm trees at 40 degrees, the average stump volume of wood plus bark was greater in murrayana (6.7) than in latifolia (4.7). The overall averages for all diameters and latitudes indicated that stumps of murrayana had less gross volume (4.3) than latifolia (4.8), however.

\section{Volume of Central Root Mass, Wood Plus Bark (Thousand $\mathrm{cm}^{3}$ )}

The gross central root volume was not greatly different for the two varieties except at 40 degrees latitude, where 152- and 228-mm latifolia trees had much greater volume (23 and 73) than murrayana (11 and 24).

\section{Volume of Stump, Wood Only (Thousand $\mathrm{cm}^{3}$ )}

In $76-\mathrm{mm}$ trees the two varieties had equal volumes of wood in the stump (1.0). The 152-mm murrayana trees averaged more stumpwood volume than latifolia (4.8 vs. 4.1); in 228-mm trees, however, the murrayana trees had less stumpwood volume (6.3 vs. 7.8).

\section{Volume of Central Root Mass, Wood Only (Thousand $\mathrm{cm}^{3}$ )}

Wood volume in the central root mass was not greatly different in the two varieties, except that 76-mm murrayana trees at 40 degrees had much greater wood volume than latifolia (2.3 vs. 1.2). 


\section{Volume of Stump, Bark Only (Thousand $\mathrm{cm}^{3}$ )}

Except for 76- and 152-mm trees at 40 degrees latitude, bark volume in the stump from groundline to $152-\mathrm{mm}$-high stump top was greater in latifolia than in murrayana trees (fig. 1-75).

\section{Stembark as Percentage of Gross Stem Volume by Height in Tree}

At latitude 40 degrees, murrayana had-at each height sampled-about 2 percentage points more bark volume as a percentage of gross stem volume than latifolia.

At latitude 42.5 degrees, however, latifolia had-at each height sampled-about 1 percentage point more bark volume as a percentage of gross stem volume than murrayana.

At latitude 45 degrees, bark volume percentages at all heights sampled were about equal for the two varieties.

The overall latitudinal comparison is shown by the following tabulation for stembark percentage of entire gross stem volume (diameter data pooled):

$\begin{array}{ccc}\text { Latitude } & \text { Latifolia } & \text { Murrayana } \\ \text { Degrees } & \ldots . . . . \text {. Percent } & \ldots . . . \\ 40 & 10.9 & 12.3 \\ 42.5 & 11.0 & 10.0 \\ 45 & 11.3 & 11.2\end{array}$

\section{Live Branchbark as Percentage of Gross Live Branch Volume}

With diameter data pooled, murrayana averaged more live branchbark as a percentage of live branch gross volume than latifolia, as follows:

$\begin{array}{ccc}\text { Latitude } & \text { Latifolia } & \text { Murrayana } \\ \text { Degrees } & \ldots \ldots . . \text {. Percent } & \ldots . . . \\ 40 & 34.5 & 46.5 \\ 42.5 & 38.1 & 39.2 \\ 45 & 41.5 & 42.2 \\ \text { Average } & 38.0 & 42.6\end{array}$

\section{Stump-Root System Wood as Percentage of Complete-Tree Wood Volume}

With diameter data pooled, murrayana averaged more stump-root system wood as a percentage of complete-tree wood volume than latifolia in the two southern latitudinal zones, as follows:

$\begin{array}{ccc}\text { Latitude } & \text { Latifolia } & \text { Murrayana } \\ \text { Degrees } & \ldots \ldots . . \text {. Percent } & \ldots . . . \\ 40 & 11.3 & 12.5 \\ 42.5 & 10.8 & 12.0 \\ 45 & 11.1 & 9.0 \\ \text { Average } & 11.1 & 12.5\end{array}$
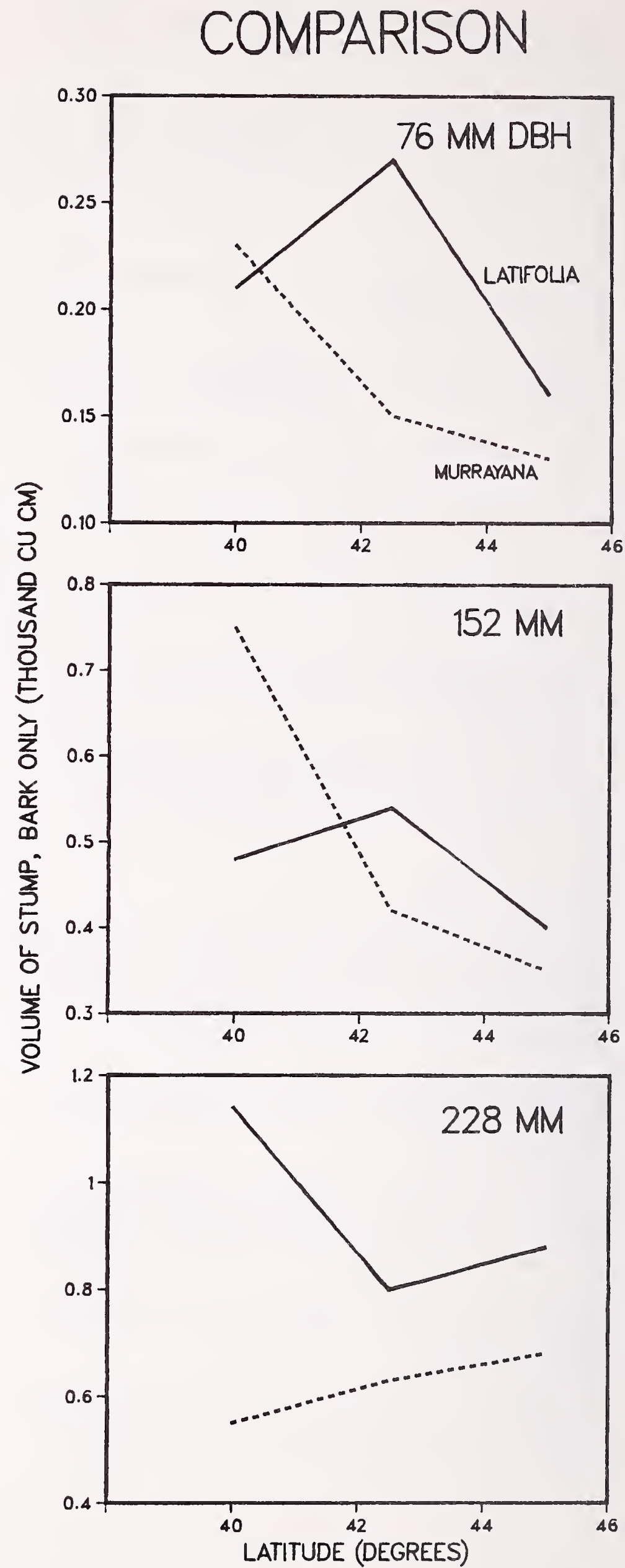

Figure 1-75-Volume of bark in stumps of murrayana trees of three diameters compared with volume in latifolia related to latitude. 


\section{1-15 SUMMARY OF RESULTS}

\section{Latifolia}

Throughout the latitudinal range sampled (40 through 60 degrees), trees 76-, 152-, and 228-mm d.b.h. averaged 71, 91, and 107 years of age, respectively; trees of equal diameter were older if taken from high elevation than low. The medium-elevation zone for latifolia decreased from about $2,700 \mathrm{~m}$ at latitude 40 degrees to about $750 \mathrm{~m}$ at 60 degrees.

The three diameter classes averaged 9.3, 15.6, and $19.1 \mathrm{~m}$ in height; trees were tallest at latitudes 50 through 55 degrees, and-except in the middiameter class-were tallest at low elevation and shortest at high elevation.

Of all the tree characteristics measured, root system dimensions and volumes were most closely correlated with other major tree characteristics. Taproot length was positively correlated with d.b.h., averaging 554,778 , and $942 \mathrm{~mm}$ for the three diameter classes.

Crown width was more closely correlated with other tree characteristics than crown length. Crown ratio was unrelated to d.b.h., and averaged 0.46 for the 243 trees sampled.

Stem length below crown was positively correlated with d.b.h., and averaged 5.0, 8.8, and $10.9 \mathrm{~m}$ for the three diameter classes; latitudes 50 through 55 degrees had trees with the longest stem length below crown.

Stem crook (sweep) between 10 and 70 percent of tree height averaged $43 \mathrm{~mm}$ and was unrelated to d.b.h. or elevational zone; midlatitude trees had less stem crook than those in the south or the north of the range.

The number of live branches per tree averaged 64, 108, and 133 for trees 76-, 152-, and 228-mm d.b.h.; mean branch diameter for these trees was 9,13 , and $19 \mathrm{~mm}$, respectively, with branch angles averaging 85,79 , and 77 degrees.

The number of dead branches per tree was unrelated to elevational zone, and averaged 57, 100, and 119 for the three diameter classes; fewest were observed in latitudes 42.5 through 47.5 degrees, most in latitudes 50 through 57.5 degrees.

Stem diameter at the base of the live crown was proportional to d.b.h., averaging 52, 100 , and $148 \mathrm{~mm}$ for the three diameter classes.

Growth-ring width measured at 152 -mm stump height was positively correlated with d.b.h., averaging $0.67,1.01$, and $1.33 \mathrm{~mm}$ for the three diameter classes.

Only 191 of the 243 trees had cones on the tip $305 \mathrm{~mm}$ of the top 25 branches; their number-and the total number of cones on each tree-was positively correlated with d.b.h. Southern latitudes had more open-coned trees than those in northern latitudes; at 52.5 degrees and farther north virtually all of the trees were classified as closed-coned (fig. 1-19).
Complete-tree volume of wood plus bark (stump-root system, stem, live and dead branches-but not foliage) averaged $31.0,191.1$, and 509.0 thousand $\mathrm{cm}^{3}$ for the three diameter classes. Trees at high elevation had least volume. Complete-tree volumes averaged minimum at 40 degrees; they averaged maximum in latitudinal zones 50 through 55 degrees.

The proportion of complete-tree wood volumes comprised of wood from each of the tree portions averaged as follows:

\begin{tabular}{|c|c|c|c|}
\hline \multirow[b]{2}{*}{ Tree portion } & \multicolumn{3}{|c|}{ Tree d.b.h.. mm } \\
\hline & 76 & 152 & 228 \\
\hline & \multicolumn{3}{|c|}{$\ldots$ Percent... } \\
\hline Stem to apical tip & 81 & 83 & 82 \\
\hline Live branches & 3 & 4 & 6 \\
\hline Dead branches & 2 & 2 & 2 \\
\hline $\begin{array}{l}\text { Stump-root system to } 305 \mathrm{~mm} \\
\text { radius from stump pith }\end{array}$ & 14 & 11 & 10 \\
\hline Total & 100 & 100 & 100 \\
\hline
\end{tabular}

The bark percentage of gross (wood-plus-bark) volume of each tree component averaged as follows:

\begin{tabular}{|c|c|c|c|}
\hline \multirow[b]{2}{*}{ Tree component } & \multicolumn{3}{|c|}{ Tree d.b.h., mm } \\
\hline & 76 & 152 & 228 \\
\hline & $\cdots$ & ercen & $\cdots$ \\
\hline Stem to apical tip & 14.6 & 10.5 & 8.9 \\
\hline Live branches & 46.8 & 37.1 & 29.4 \\
\hline Stump-root system & 17.9 & 13.3 & 10.7 \\
\hline
\end{tabular}

\section{Latifolia Compared to Murrayana}

Varietal differences in the characteristics reported here were not major, except as noted in the following paragraphs.

In the latitudes common to the two varieties $(40,42.5$, and 45 degrees), branch diameter averaged $2 \mathrm{~mm}$ less in murrayana trees than in latifolia; at latitudes 40 and 42.5 degrees branch angle averaged 10 degrees larger on murrayana than on latifolia ( 85 vs. 75 degrees).

Latifolia bore significantly more cones than murrayana at all three latitudes. All of the murrayana trees were classified as open-coned, whereas 15 to 50 percent of the latifolia trees at these latitudes were classified as closedconed (fig. 1-19).

Latifolia had about 20 percent thicker lateral rootbark than murrayana, and stumpbark was about 15 percent thicker on latifolia than on murrayana.

With diameter data pooled, murrayana had more live branchbark as a percentage of gross live branch volume than latifolia-42.6 percent vs. 38.0 percent. 


\section{1-16 REFERENCES}

Agee, James K. Fuel weights of understory-grown conifers in southern Oregon. Canadian Journal of Forest

Research. 13(4): 648-656; 1983.

Alden, John N.; Zasada, John. Potential of lodgepole pine as a commercial forest tree species on an upland site in interior Alaska. In: Murray, Mayo, ed. Lodgepole pine: regeneration and management: Proceedings of a fourth international workshop; 1982 August 17-19; Hinton, AB, Canada. General Technical Report PNW-157. Portland, OR: U.S. Department of Agriculture, Forest Service, Pacific Northwest Forest and Range Experiment Station; 1983: 42-48.

Alemdag, I. S. Stand volume tables for white spruce and lodgepole pine in the upper Liard River area, Yukon Territory. Information Report FMR-X-54 (Study FM-95). Ottawa, ON: Department of the Environment, Canadian Forestry Service, Forest Management Institute; 1973. $6 \mathrm{p}$.

Alemdag, I. S. Metric site-index curves for white spruce and lodgepole pine in the upper Liard River area, Yukon Territory. Information Report FMR-X-33M. Ottawa, ON: Department of the Environment, Canadian Forestry Service, Forest Management Institute; 1976. 18 p.

Alexander, Robert R. Silviculture of subalpine forests in the Central and Southern Rocky Mountains: the status of our knowledge. Research Paper RM-121. Fort Collins, CO: U.S. Department of Agriculture, Forest Service, Rocky Mountain Forest and Range Experiment Station; 1974. $88 \mathrm{p}$.

Alexander, Robert R.; Tackle, David; Dahms, Walter G. Site indexes for lodgepole pine, with corrections for stand density: methodology. Research Paper RM-29. Fort Collins, CO: U.S. Department of Agriculture, Forest Service, Rocky Mountain Forest and Range Experiment Station; 1967. $18 \mathrm{p}$.

Allen, Gerald M.; Adams, David L.; Houck, Geoffrey L.; Hatch, Charles R. Volume tables for small trees in northern Idaho. Station Note 27. Moscow, ID: University of Idaho, College of Forestry, Wildlife and Range Sciences, Forest, Wildlife and Range Experiment Station; $1976.6 \mathrm{p}$.

Amman, Gene D. Mountain pine beetle emergence in relation to depth of lodgepole pine bark. Research Note INT-96. Ogden, UT: U.S. Department of Agriculture, Forest Service, Intermountain Forest and Range Experiment Station; 1969. 8 p.

Amman, Gene D. Mountain pine beetle brood production in relation to thickness of lodgepole pine phloem. Journal of Economic Entomology. 65(1): 138-140; 1972.

Amman, Gene D. Population changes of the mountain pine beetle in relation to elevation. Environmental Entomology. 2(4): 541-547; 1973.

Amman, Gene D.; Pace, Vincent E. Optimum egg gallery densities for the mountain pine beetle in relation to lodgepole pine phloem thickness. Research Note INT-209. Ogden, UT: U.S. Department of Agriculture, Forest Service, Intermountain Forest and Range Experiment Station; 1976. 8 p.

Amman, Gene D.; Baker, Bruce H.; Stipe, Lawrence E. Lodgepole pine losses to mountain pine beetle related to elevation. Research Note INT-171. Ogden, UT: U.S. Department of Agriculture, Forest Service, Intermountain Forest and Range Experiment Station; 1973. 8 p.

Amman, Gene D.; McGregor, Mark D.; Cahill, Donn B.; Klein, William H. Guidelines for reducing losses of lodgepole pine to the mountain pine beetle in unmanaged stands in the Rocky Mountains. General Technical Report INT-36. Ogden, UT: U.S. Department of Agriculture, Forest Service, Intermountain Forest and Range Experiment Station; 1977. 19 p.

Anderson, Tom D.; Tiedemann, Arthur R. Periodic variation in physical and chemical properties of two central Washington soils. Research Note PNW-125. Portland, OR: U.S. Department of Agriculture, Forest Service, Pacific Northwest Forest and Range Experiment Station; $1970.9 \mathrm{p}$.

Armit, D. Miscellaneous notes: cone habit of lodgepole pine. In: Forest research review year ended March 1964. Victoria, BC: British Columbia Forest Service; 1964: 56-57.

Armit, D. Silvics and silviculture of lodgepole pine in the north central interior of British Columbia. Research Note 40. Victoria, BC: Department of Lands, Forests, and Water Resources, British Columbia Forest Service; 1966. $50 \mathrm{p}$.

Bagnell, C. Robert, Jr. Species distinction among pollen grains of Abies, Picea, and Pinus in the Rocky Mountain area (a scanning electron microscope study). Review of Paleobotany and Palynology. 19(3): 203-220; 1975.

Bannan, M. W. Tracheid size and anticlinal divisions in the cambium of lodgepole pine. Canadian Journal of Botany. 42(9): 1105-1118; 1964.

Barrett, James W.; Martin, Robert E.; Wood, Donald C. Northwestern ponderosa pine and associated species. In: Burns, Russell M., compiler. Silvicultural systems for the major forest types of the United States. Agriculture Handbook 445. Washington, DC: U.S. Department of Agriculture, Forest Service; 1983: 16-18.

Barton, G. M. Western-conifer extractive chemistry aids the technologist. Information Report VP-X-142. Vancouver, BC: Department of the Environment, Canadian Forestry Service, Western Forest Products Laboratory; 1975. 18 p. Available from: Forintek Canada Corp., Vancouver, BC.

Bates, C. G. The production, extraction, and germination of lodgepole pine seed. Technical Bulletin 191. Washington, DC: U.S. Department of Agriculture; 1930. 92 p.

Bates, Carlos G. The biology of lodgepole pine as revealed by the behavior of its seed. Journal of Forestry. 15(4): 410-416; 1917.

Bates, Carlos G. A key to the identification of some coniferous seedlings. Journal of Forestry. 23: 278-281; 1925.

Benecke, U.; Morris, J. Y. Tree provenance trials. In: Orwin, Joanna, ed. Revegetation in the rehabilitation of mountain lands: symposium proceedings; 1974. F.R.I. Symposium. 16. Rotorua: New Zealand Forest Service, Forest Research Institute; 1978: 99-138.

Berndt, Herbert W.; Gibbons, Robert D. Root distribution of some native trees and understory plants growing on three sites within ponderosa pine watersheds in Colorado. Station Paper 37. Fort Collins, CO: U.S. Department of Agriculture, Forest Service, Rocky Mountain Forest and Range Experiment Station; 1958. 14 p. 
Berry, A. B. Metric form-class volume tables. Information Report PI-X-10. Chalk River, ON: Canadian Forestry Service, Petawawa National Forestry Institute; 1981. $24 \mathrm{p}$.

Berryman, Alan A. Theoretical explanation of mountain pine beetle dynamics in lodgepole pine forests. Environmental Entomology. 5(6): 1225-1233; 1976.

Berryman, Alan A. A synoptic model of the lodgepole pine/mountain pine beetle interaction and its potential application in forest management. In: Berryman, Alan A.; Amman, Gene D.; Stark, Ronald W., tech. eds., Kibbee, Darline L., publ. ed. The theory and practice of mountain pine beetle management in lodgepole pine forests: symposium proceedings; 1978 April 25-27; Pullman, WA. Moscow, ID: University of Idaho, Forest, Wildlife and Range Experiment Station; 1978: 98-105.

Betts, H. S. Lodgepole pine (Pinus contorta var. latifolia). American Woods. Washington, DC: U.S. Department of Agriculture, Forest Service; 1945.5 p.

Birot, Par Y. Variabilité géographique du poids de la graine de Pinus contorta: Geographic variation in seed weight in Pinus contorta. Silvae Genetica. 27(1): 32-40; 1978.

Bishop, Daniel M. Lodgepole pine rooting habits in the Blue Mountains of northeastern Oregon. Ecology. 43(1): 140-143; 1962.

Blyth, A. W. Standard volume tables for lodgepole pine in Alberta. Technical Note 9. Ottawa, ON: Canada Department of Northern Affairs and Natural Resources, Forestry Branch, Forest Research Division; 1955. 14 p.

Boggie, Robert. Effect of water-table height on root development of Pinus contorta on deep peat in Scotland. Acta Oecologica Scandinavica. 23(3): 304-312; 1972.

Bonnor, G. M. The influence of stand density on the correlation of stem diameter with crown width and height for lodgepole pine. Forestry Chronicle. 40(3): 347-349; 1964.

Bonnor, G. M. Aerial stand volume tables for ten forest types in Canada: Project S-1. Information Report FMR-X-1. Ottawa, ON: Department of Forestry Canada, Forest Management Research and Services Institute; 1966. [Pagination unknown.]

British Columbia Forest Service. Volume, yield, and stand tables for some of the principal timber species of British Columbia. Victoria, BC: British Columbia Forest Service, Lands Department, Research Division; 1936. 53 p.

Brown, James K. Fire cycles and community dynamics in lodgepole pine forests. In: Baumgartner, David M., ed. Management of lodgepole pine ecosystems: symposium proceedings; 1973 October 9-11; Pullman, WA. Pullman, WA: Washington State University, Cooperative Extension Service, College of Agriculture; 1975: 429-456. (vol. 1).

Brown, James K. Predicting crown weights for 11 Rocky Mountain conifers. In: Oslo biomass studies: IUFRO Congress; 1976 June: 103-115.

Brown, James K. Weight and density of crowns of Rocky Mountain conifers. Research Paper INT-197. Ogden, UT: U.S. Department of Agriculture, Forest Service, Intermountain Forest and Range Experiment Station; 1978. $56 \mathrm{p}$.
Cabrera, Homero. Phloem structure and development in lodgepole pine. In: Berryman, Alan A.; Amman, Gene D.; Stark, Ronald W., tech. eds., Kibbee, Darline L., publ. ed. The theory and practice of mountain pine beetle management in lodgepole pine forests: symposium proceedings; 1978 April 25-27; Pullman, WA. Moscow, ID: University of Idaho, Forest, Wildlife and Range Experiment Station; 1978: 54-63.

Cerezke, H. F. Bark thickness and bark resin cavities on young lodgepole pine in relation to Hylobius warreni Wood (Coleoptera:Curculionidae). Canadian Journal of Forest Research. 3(4): 599-601; 1973.

Chapman, R. C.; Baldwin, V. C.; Clausnitzer, R. R. Cubic foot volume, bole green weight and total above ground green weight of small diameter lodgepole pine, larch and ponderosa pine. Research Bulletin XB 0914. Pullman, WA: Washington State University, Agricultural Research Center; 1982. 7 p.

Christie, J. M.; Lines, R. A comparison of forest productivity in Britain and Europe in relation to climatic factors. Forest Ecology and Management. 2(2): 75-102; 1979.

Clausen, Jens. Population studies of alpine and subalpine races of conifers and willows in the California high Sierra Nevada. Evolution. 19(1): 56-68; 1965.

Cole, D. M.; Jensen, C. E. Estimating phloem thickness in lodgepole pine stands using electrical resistance measurements. Canadian Journal of Forest Research. 10(1): 102-106; 1980.

Cole, Dennis M. A cubic-foot stand volume equation for lodgepole pine in Montana and Idaho. Research Note INT-150. Ogden, UT: U.S. Department of Agriculture, Forest Service, Intermountain Forest and Range Experiment Station; 1971. 8 p.

Cole, Dennis M. Estimation of phloem thickness in lodgepole pine. Research Paper INT-148. Ogden, UT: U.S. Department of Agriculture, Forest Service, Intermountain Forest and Range Experiment Station; 1973. $10 \mathrm{p}$.

Cole, Dennis M. Merchantable cubic stand volume conversion factors for lodgepole pine in Montana and Idaho. Research Note INT-259. Ogden, UT: U.S. Department of Agriculture, Forest Service, Intermountain Forest and Range Experiment Station; 1979. 12 p.

Cole, Dennis M. Canopy development in lodgepole pine: implications for wildlife studies and multiple resource management. General Technical Report INT-139. Ogden, UT: U.S. Department of Agriculture, Forest Service, Intermountain Forest and Range Experiment Station; 1983. $13 \mathrm{p}$.

Cole, Dennis M.; Edminster, Carleton B. Growth and yield of lodgepole pine. In: Baumgartner, David M.; Krebill, Richard G.; Arnott, James T.; Weetman, Gordon F., eds. Lodgepole pine: the species and its management: symposium proceedings; 1984 May 8-10; Spokane, WA; 1984 May 14-16; Vancouver, BC. Pullman, WA: Office of Conferences and Institutes, Cooperative Extension; 1985: 263-290.

Cole, Dennis M.; Jensen, Chester E. Models for describing vertical crown development of lodgepole pine stands. Research Paper INT-292. Ogden, UT: U.S. Department 
of Agriculture, Forest Service, Intermountain Forest and Range Experiment Station; 1983. 10 p.

Cole, Dennis M.; Stage, Albert R. Estimating future diameters of lodgepole pine trees. Research Paper INT-131. Ogden, UT: U.S. Department of Agriculture, Forest Service, Intermountain Forest and Range Experiment Station; 1972. 20 p.

Cole, Walter $\mathrm{E}$. Interaction between mountain pine beetle and dynamics of lodgepole pine stands. Research Note INT-170. Ogden, UT: U.S. Department of Agriculture, Forest Service, Intermountain Forest and Range Experiment Station; 1973.6 p.

Cole, Walter E.; Amman, Gene D. Mountain pine beetle dynamics in lodgepole pine forests. Part 1: course of an infestation. General Technical Report INT-89. Ogden, UT: U.S. Department of Agriculture, Forest Service, Intermountain Forest and Range Experiment Station; $1980.56 \mathrm{p}$.

Cole, Walter E.; Cahill, Donn B. Cutting strategies can reduce probabilities of mountain pine beetle epidemics in lodgepole pine. Journal of Forestry. 74(5): 294-297; 1976.

Cooper, Robert W.; Schopmeyer, Clifford S.; McGregor, William H. Davis. Sand pine regeneration on the Ocala National Forest. Product Research Report 30. Washington, DC: U.S. Department of Agriculture, Forest Service; $1959.37 \mathrm{p}$.

Critchfield, W. B. A new hybrid Christmas tree. Southern Lumberman. 211(2632): 132-133; 1965.

Critchfield, William B. Geographic variation in Pinus contorta. Maria Moors Cabot Foundation Publication 3. Cambridge, MA: Harvard University; 1957. 118 p.

Critchfield, William B. The genetics of lodgepole pine. Research Paper WO-37. Washington, DC: U.S. Department of Agriculture, Forest Service; 1980. 57 p.

Crossley, D. I. The production and dispersal of lodgepole pine seed. Technical Note 25. Ottawa, ON: Canada Department of Northern Affairs and National Resources, Forestry Branch, Forest Research Division; 1955. 12 p.

Crossley, D. I. Effect of crown cover and slash density on the release of seed from slash-borne lodgepole pine cones. Forest Research Division Technical Note 41. Ottawa, ON: Forestry Branch, Department of Northern Affairs and National Resources; 1956a. 51 p.

Crossley, D. I. Fruiting habits of lodgepole pine. Technical Note 35. Ottawa, ON: Canada Department of Northern Affairs and National Resources, Forestry Branch, Forest Research Division; 1956b. 32 p.

Cunningham, A.; Roberts, Q. A provenance trial of Pinus contorta at $4,800 \mathrm{ft}$. in the Kaweka Range. New Zealand Journal of Forestry. 15(1): 79-87; 1970.

Dahms, Walter. Gross yield of central Oregon lodgepole pine. In: Baumgartner, David M., ed. Management of lodgepole pine ecosystems: symposium proceedings; 1973 October 9-11; Pullman, WA. Pullman, WA: Washington State University, Cooperative Extension Service, College of Agriculture; 1975: 208-232. (vol. 1).

Dahms, Walter G. Gross and net yield tables for lodgepole pine. Research Paper PNW-8. Portland, OR: U.S. Department of Agriculture, Forest Service, Pacific Northwest Forest and Range Experiment Station; 1964. $14 \mathrm{p}$.
Dahms, Walter G. Relationship of lodgepole pine volume increment to crown competition factor, basal area, and site index. Forest Science. 12(1): 74-82; 1966.

Dahms, Walter G. Growth and soil moisture in thinned lodgepole pine. Research Paper PNW-127. Portland, OR: U.S. Department of Agriculture, Forest Service, Pacific Northwest Forest and Range Experiment Station; 1971a. $32 \mathrm{p}$.

Dahms, Walter G. Fifty-five-year-old lodgepole pine responds to thinning. Research Note PNW-141. Portland, OR: U.S. Department of Agriculture, Forest Service, Pacific Northwest Forest and Range Experiment Station; 1971b. 13 p.

Davidsonia. Pinus contorta D. Douglas ex Loudon: shore pine, lodgepole pine. Davidsonia. 10(4): 75-83; 1979.

Davies, E. J. M. Useless? The case against contorta. Scottish Forestry. 34(2): 110-113; 1980.

Dietrichson, Jon. Geografisk variasjon hos Pinus contorta Dougl.: en unders $\phi$ kelse med sikte pa treslagets bruk i Norge: Geographic variation in Pinus contorta Dougl.: a study aiming at the use of the species in Norway. Norske Skogforsoksvesen. 28(2): 111-140; 1970.

Dobie, J.; Middleton, G. R. Lumber yields from sweepy lodgepole pine. Forestry Chronicle. 56(2): 66-67; 1980.

Dominion Forest Service. Interpolated volume tables (total volume) for use in compilation of sample plot data. Miscellaneous Series 3. Ottawa, ON: Dominion Forest Service; 1944. 20 p.

Drake, Erik. Undersökning av barkvolymen i södra och mellersta Sverige: A study of the bark volume in south and central Sweden. Report 149. Uppsala, Sweden: The Swedish University of Agricultural Sciences, Department of Forest Products; 1983. 61 p. plus appendixes.

Duff, G. Estimation of volume of forked trees in exotic coniferous stands in New Zealand. Forest Research Note 6. Wellington: Ministry of Forests, New Zealand Forest Service, Forest Research Institute; 1956.10 p.

Duff, G. Yield tables for unthinned stands of the "green" varieties of Pinus contorta in New Zealand. Technical Paper 50. Wellington: New Zealand Forest Service, Forest Research Institute; 1966. 37 p.

Duffy, Patrick J. B.; Meyer, Merle P. A preliminary study of aerial volume table construction for lodgepole pine in west-central Alberta. Forestry Chronicle. 38(2): 212-218; 1962.

Dunsworth, B. G.; Northway, S. M.; Packee, E. C. Shore pine and Douglas-fir height and volume development on low productivity sites. Canadian Journal of Forest Research. 12(2): 438-439; 1982.

Dykstra, Gary F. Drought resistance of lodgepole pine seedlings in relation to provenance and tree water potential. Research Note 62. Victoria, BC: British Columbia Forest Service, Research Division; 1974. 7 p.

Edminster, Carleton B. RMYLD: computation of yield tables for even-aged and two-storied stands. Research Paper RM-199. Fort Collins, CO: U.S. Department of Agriculture, Forest Service, Rocky Mountain Forest and Range Experiment Station; 1978. 26 p.

Edwards, M. V. A summary of information on Pinus contorta with special reference to its use in Europe. Part 1. Forestry Abstracts. 15(4): 389-396; 1954. 
Edwards, M. V. A summary of information on Pinus contorta with special reference to its use in Europe. Part II. Forestry Abstracts. 16(1): 3-13; 1955.

Eis, S.; Craigdallie, D.; Simmons, C. Growth of lodgepole pine and white spruce in the central interior of British Columbia. Canadian Journal of Forest Research. 12(3): 567-575; 1982.

Eriksson, Harry. Volymfunktioner for stainde trad av ask, asp, klibbal och contorta-tall: Tree volume functions for ash, aspen, alder and lodgepole pine in Sweden. (Fraxinus excelsior L., Populus tremula L., Alnus glutinosa (L.) Gartn., Pinus contorta Dougl. var. latifolia Engelm.). Research Note 26. Stockholm, Sweden: Royal College of Forestry; 1973. $26 \mathrm{p}$.

Fahnestock, George R. Logging slash flammability. Research Paper 58. Ogden, UT: U.S. Department of Agriculture, Forest Service, Intermountain Forest and Range Experiment Station; 1960. 67 p.

Faurot, James L. Estimating merchantable volume and stem residue in four timber species: ponderosa pine, lodgepole pine, western larch, Douglas-fir. Research Paper INT-196. Ogden, UT: U.S. Department of Agriculture, Forest Service, Intermountain Forest and Range Experiment Station; 1977. 55 p.

Fitzsimons, B. An investigation of the effects of poor stem form and sawmill recovery on coastal lodgepole pine. Irish Forestry. 39(1): 30-47; 1982.

Forestry Research West. Relative ecological position and extent of occurence of major species. Forestry Research West. [Fort Collins, CO]: U.S. Department of Agriculture, Forest Service; 1983 June. Cover illustration.

Forrest, G. I. Geographical variation in the monoterpenes of the resin of Pinus contorta. In: Seals, D. T., chairman, [and others]. EEC symposium on forest tree biochemistry: proceedings; 1977 January 25-27; Brussels. Luxembourg: Commission of the European Communities; 1977a: 55-71.

Forrest, G. I. Identification of unknown lodgepole pine origins. Research Information Note 30/77/GEN. Surrey, England: Forestry Commission Research and Development Division, Forestry Commission Research Station; 1977b. 4 p.

Forrest, G. I. Monoterpene variation in lodgepole pine (Pinus contorta) and Scots pine (Pinus sylvestris). In: Rudin, Dag, ed. Proceedings of the conference on biochemical genetics of forest trees; 1978; Umea, Sweden. Report 1. Umea, Sweden: Swedish University of Agricultural Sciences, Department of Forest Genetics and Plant Physiology; 1979: 136-150.

Forrest, G. Ian. Geographical variation in oleoresin monoterpene composition of Pinus contorta from natural stands and planted seed collections. Biochemical Systematics and Ecology 9(2/3): 97-103; 1981.

Fosberg, F. R. Pinus contorta and its variations. Baileya. $7(1): 7-10 ; 1959$.

Franklin, E. C.; Callaham, R. Z. Multinodality, branching and forking in lodgepole pine (Pinus contorta var. murrayana Engelm.). Silvae Genetica. 19(5/6): 180-184; 1970.

Franklin, Edward Carlyle. An analysis of branching and forking characteristics in families of lodgepole pine (Pinus contorta var. murrayana Engelm.). Berkeley, CA: University of California; 1964. 79 p. M.S. thesis.
Gail, Floyd W.; Long, E. M. A study of site, root development, and transpiration in relation to the distribution of Pinus contorta. Ecology. 16: 88-100; 1935.

Gary, Howard L. Canopy weight distribution affects windspeed and temperature in a lodgepole pine forest. Forest Science. 20(4): 369-371; 1974.

Gary, Howard L. Crown structure and distribution of biomass in a lodgepole pine stand. Research Paper RM-165. Fort Collins, CO: U.S. Department of Agriculture, Forest Service, Rocky Mountain Forest and Range Experiment Station; 1976. 20 p.

Gary, Howard L. The vertical distribution of needles and branchwood in thinned and unthinned 80-year-old lodgepole pine. Northwest Science. 52(4): 303-309; 1978.

Gilbertson, R. L.; Leaphart, C. D.; Johnson, F. D. Field identification of roots of conifers in the Inland Empire. Forest Science. 7(4): 352-356; 1961.

Griffin, James R.; Critchfield, William B. The distribution of forest trees in California. Research Paper PSW-82. Berkeley, CA: U.S. Department of Agriculture, Forest Service, Pacific Southwest Forest and Range Experiment Station; 1972 (reprinted with supplement 1976). $118 \mathrm{p}$.

Guernsey, F. W.; Dobie, J. Properties and utilization of lodgepole pine in western Canada. Department of Forestry Publication 1143. Ottawa, ON: Minister of Forestry, Canada Department of Forestry; 1966. 24 p.

Gunther, A. Everard. The twisting of the tamarac pine. Scottish Forestry Journal. 43(2): 81-94; 1929.

Hagner, Mats. Geographic variation in Pinus contorta and Picea mariana with respect to cone size, seedling growth rhythm and cotyledons. In: Pinus contorta as an exotic species: proceedings of the IUFRO working party meeting 1980 on Pinus contorta provenances (S2-02-06) in Norway and Sweden. Svergis Lantbruksuniversitet Research Note 30. Garpenberg, Sweden: Swedish University of Agricultural Sciences, Department of Forest Genetics; 1980a: 83-101.

Hagner, Mats. Geographical variation in seed quality of lodgepole pine (Pinus contorta Dougl.) between and within stands. In: Pinus contorta as an exotic species: proceedings of the IUFRO working party meeting 1980 on Pinus contorta provenances (S2-02-06) in Norway and Sweden. Svergis Lantbruksuniversitet Research Note 30. Garpenberg, Sweden: Swedish University of Agricultural Sciences, Department of Forest Genetics; 1980b: 275-286.

Hakkila, Pentti; Panhelainen, Arja. On the wood properties of Pinus contorta in Finland. Communicationes Instituti Forestalis Fenniae. 73(1); 1970. 43 p.

Hamilton, G. J.; Christie, J. M. Forest management tables (metric). Forestry Commission Booklet 34. London: Forestry Commission; 1971. 201 p.

Hanan, A. M. S. “Bolander's pine?" Irish Forestry. 20(1): 3-6; 1963.

Hansen, Barbara S.; Cushing, Edward J. Identification of pine pollen of late Quaternary age from the Chuska Mountains, New Mexico. Geological Society of America Bulletin. 84(4): 1181-1200; 1973.

Hanzlik, Edward J. A growth and volume study of lodgepole pine in the Ochoco Mountains. University of Washington Forestry Club Annual 4: 27-33; 1916. 
Harris, J. Maddern. Physical properties, resin content, and tracheid length of lodgepole pine grown in New Zealand. New Zealand Journal of Forest Science. 3(1): 91-109; 1973.

Hartl, Daniel L. Selection for serotiny in lodgepole pine: mathematical analysis of the model of Perry and Lotan. Evolution. 33(3): 969-972; 1979.

Hawksworth, Frank G. Upper altitudinal limits of lodgepole pine dwarfmistletoe in the Central Rocky Mountains. Phytopathology. 46(10): 561-562; 1956.

Hawksworth, Frank G.; Lister, C. Kendall; Cahill, Donn B. Phloem thickness in lodgepole pine: its relationship to dwarf mistletoe and mountain pine beetle (Coleoptera: Scolytidae). Environmental Entomology. 12(5): 1447-1448; 1983.

Heger, L. A trial of Hohenadl's method of stem form and stem volume estimation. Forestry Chronicle. 41(4): 466-475; 1965.

Hellum, A. K.; Barker, N. A. Cone moisture content influences seed release in lodgepole pine. Canadian Journal of Forest Research. 10(3): 239-244; 1980.

Hellum, A. K.; Barker, N. A. The relationship of lodgepole pine cone age and seed extractability. Forest Science. 27(1): 62-70; 1981.

Hellum, A. K.; Pelchat, M. Temperature and time affect the release and quality of seed from cones of lodgepole pine from Alberta. Canadian Journal of Forest Research. (2): 154-159; 1979.

Henderson, J.; Petty, J. A. A comparison of wood properties of coastal and interior provenances of lodgepole pine. Forestry. 45(1): 49-57; 1972.

Hobbs, Stephen D.; Partridge, Arthur D. Wood decays, root rots, and stand composition along an elevation gradient. Forest Science. 25(1): 31-42; 1979.

Honer, T. G. Standard volume tables and merchantable conversion factors for the commercial tree species of central and eastern Canada. Information Report FMR-X-5. Ottawa, ON: Canada Department of Forestry and Rural Development, Forestry Branch, Forest Management Research and Services Institute; 1967. [Pagination unknown.]

Hornibrook, E. M. Cubic-foot volume table for lodgepole pine. Research Note 4. Fort Collins, CO: U.S. Department of Agriculture, Forest Service, Rocky Mountain Forest and Range Experiment Station; 1948. 3 p.

Hornibrook, E. M. Estimating defect in mature and overmature stands of three Rocky Mountain conifers. Journal of Forestry. 48(9): 408-417; 1950.

Horton, K. W. Rooting habits of lodgepole pine. Technical Note 67. Ottawa, ON: Canada Department of Northern Affairs and National Resources, Forestry Branch, Forest Research Division; 1958. 26 p.

Hosie, R. C. Lodgepole pine. In: Native trees in Canada. [Ottawa]: Canadian Forestry Service, Department of the Environment; 1973: 52-53.

Illingworth, K. Variation in Pinus contorta with particular reference to British Columbia. In: Forest research review: year ended March, 1969. Victoria, BC: British Columbia Forest Service, Department of Lands, Forests, and Water Resources, Forest Research Division; 1969: 42-46.
Illingworth, K. Geographic variation in Pinus contorta. In: Proceedings 13th meeting on forest tree breeding in Canada; 1971: 107-112.

Illingworth, Keith. Natural variation within lodgepole pine in British Columbia. In: Meeting of IUFRO working party on Pinus contorta provenance; 1974 September; Edinburgh, Scotland. Research and Development Paper 114. United Kingdom: Forestry Commission of Great Britain; 1976: 40-43.

Jeffers, J. N. R.; Black, T. M. An analysis of variability in Pinus contorta. Forestry. 36(2): 199-218; 1963.

Jeffers, J. N. R.; Spragg, L. K. A volume table for lodgepole pine (Pinus contorta Loudon). Statistics Section Paper 127. London: Forestry Commission; 1966. $2 \mathrm{p}$.

Jenny, H.; Arkley, R. J.; Schultz, A. M. The pygmy forestpodsol ecosystem and its dune associates of the Mendocino coast. Madroño. 20(2): 60-74; 1969.

Johnson, Floyd. Volume tables for lodgepole pine in Oregon and Washington based on diameter, height and form. Portland, OR: U.S. Department of Agriculture, Forest Service, Pacific Northwest Forest and Range Experiment Station; 1952. 32 p.

Johnson, F. A., compiler. Volume tables for Pacific Northwest trees (a compilation). Agriculture Handbook 92. Washington, DC: U.S. Department of Agriculture, Forest Service; 1955. 112 p.

Johnstone, W. D. Variable stand density yields of natural lodgepole pine stands in Alberta. In: Baumgartner, David M., ed. Management of lodgepole pine ecosystems: symposium proceedings; 1973 October 9-11; Pullman, WA. Pullman, WA: Washington State University, Cooperative Extension Service, College of Agriculture; 1975: 186-207. (vol. 1).

Johnstone, W. D. Variable-density yield tables for natural stands of lodgepole pine in Alberta. Forestry Technical Report 20. Ottawa, ON: Department of Fisheries and the Environment, Canadian Forestry Service, Northern Forest Research Centre; 1976. 110 p.

Jonsson, Alena; Eriksson, Gösta; Dormling, Ingegerd; Ifver, Jan. Studies on frost hardiness of Pinus contorta Dougl. seedlings grown in climate chambers. Studia Forestalia Suecica 157. Uppsala, Sweden: Swedish University of Agricultural Sciences, College of Forestry; 1981. 47 p.

Kamra, S. K. Seed biology of lodgepole pine (Pinus contorta Dougl.). Report 3. Umea, Sweden: Swedish University of Agricultural Sciences, Department of Forest Genetics and Plant Physiology; 1982. 51 p.

Kellogg, R. M.; Rowe, S.; Koeppen, R. C.; Miller, R. B. Identification of the wood of the soft pines of western North America. IAWA Bulletin n.s. 3(2): 95-101; 1982.

Kimes, D. S.; Smith, J. A.; Berry, J. K. Extension of the optical diffraction analysis technique for estimating forest canopy geometry. Australian Journal of Botany. 27(5): 575-588; 1979.

Knapp, Allan K.; Anderson, Jay E. Effect of heat on germination of seeds from serotinous lodgepole pine cones. American Midland Naturalist. 104(2): 370-372; 1980.

Knowles, Margaret Helen. Genetic variation of lodgepole pine over time and microgeographical space. Dissertation Abstracts International. 41(4): 1206-B; 1980. Abstract. 
Knowles, Peggy; Grant, Michael C. Genetic variation of lodgepole pine over time and microgeographical space. Evolution; [in press]. $30 \mathrm{p}$.

Koch, Peter. Utilizing lodgepole pine forests of the 21st century-a research program. In: Baumgartner, David M.; Krebill, Richard G.; Arnott, James T.; Weetman, Gordon F., eds. Lodgepole pine: the species and its management: symposium proceedings; 1984 May 8-10; Spokane, WA; 1984 May 14-16; Vancouver, BC. Pullman, WA: Office of Conferences and Institutes, Cooperative Extension; 1985: 343-349.

Kotok, E. S. Tree characteristics influence $2 \times 4$ stud yield of lodgepole pine. Research Note INT-63. Ogden, UT: U.S. Department of Agriculture, Forest Service, Intermountain Forest and Range Experiment Station; 1967. 8 p.

Kotok, E. S. Lodgepole pine (Pinus contorta Dougl.). American Woods FS 253 (rev.). Washington, DC: U.S. Department of Agriculture, Forest Service; 1971. 7 p.

Kovalchik, Bernard; Blake, George. The effect of piling and burning versus chopping of logging residues on natural regeneration of serotinous lodgepole pine forests. Research Note 11. Missoula, MT: University of Montana, School of Forestry, Montana Forest and Conservation Experiment Station; 1972. 4 p.

Kozak, A.; Yang, R. C. Equations for estimating bark volumes and thickness of commercial trees in British Columbia. Forestry Chronicle. 57(3): 112-115; 1981.

Krajina, V. J. Ecology of forest trees in British Columbia. Ecology of Western North America. 2: 1-146; 1970.

Kumler, M. L. Plant succession on the sand dunes of the Oregon coast. Ecology. 50(4): 695-704; 1969.

Laing, E. V. Morphological variations in tree species. In: Report on forest research for the year ending March, 1954. London: Forestry Commission; 1955: 56-57.

Lange, Robert W. Bark thickness, $k$, factors for four Montana coniferous tree species. Research Note 9. Missoula, MT: University of Montana, School of Forestry, Montana Forest and Conservation Experiment Station; 1971. $2 \mathrm{p}$.

La Roi, George H.; Hnatiuk, Roger J. The Pinus contorta forests of Banff and Jasper National Parks: a study in comparative synecology and syntaxonomy. Ecological Monographs. 50(1): 1-29; 1980.

Larson, Larry L. Vegetative variability along a gradient from lodgepole pine-spruce-fir. Fort Collins, CO: Colorado State University; 1978. 101 p. Ph.D. dissertation. Available from: University Microfilms International, Ann Arbor, MI.

Lindgren, Dag; Krutzsch, Peter; Twetman, Jan; Kiellander, Carl Ludvig. Survival and early growth of Pinus contorta provenances in northern Sweden. Research Note 20. Stockholm: Royal College of Forestry, Department of Forest Genetics; 1976. 42 p.

Lines, R.; Mitchell, A. F.; Pearce, M. L. Provenance: lodgepole pine, Scots pine, Sitka spruce, silver firs, Douglas fir. In: Report on forest research for the year ended March 1971. London: Forestry Commission; 1971: 39-44.

Lines, Roger; Booth, T. C. Investigation of basal sweep of lodgepole and shore pines in Great Britain. Forestry (Great Britain). 45(1): 59-66; 1972.
Linhart, Yan B. Maintenance of variation in cone morphology in California closed-cone pines: the roles of fire, squirrels and seed output. Southwestern Naturalist. 23(1): 29-40; 1978.

Little, Elbert L., Jr. Eight pine species at Onion Valley, California. Leaflet Western Botany. 10(15): 289-292; 1966.

Little, Elbert L., Jr. Atlas of United States trees. Vol. 1. Conifers and important hardwoods. Miscellaneous Publication 1146. Washington, DC: U.S. Department of Agriculture, Forest Service; 1971.

Longyear, B. O. The evergreen trees of Colorado. Bulletin 130. Fort Collins, CO: Colorado Agricultural College, Agricultural Experiment Station; 1908. 32 p.

Loope, Lloyd L. Dynamics of forest communities in Grand Teton National Park. Naturalist. 22(1): 39-47; 1971.

Lotan, James E. Sampling serotinous cones in lodgepole pine. Proceedings Montana Academy of Science. 23: 20-24; 1963.

Lotan, James E. Regeneration of lodgepole pine: a study of slash disposal and cone opening. Research Note INT-16. Ogden, UT: U.S. Department of Agriculture, Forest Service, Intermountain Forest and Range Experiment Station; 1964. $4 \mathrm{p}$.

Lotan, James E. Cone serotiny of lodgepole pine near West Yellowstone, Montana. Forest Science. 13(1): 55-59; 1967.

Lotan, James E. Cone serotiny of lodgepole pine near Island Park, Idaho. Research Paper INT-52. Ogden, UT: U.S. Department of Agriculture, Forest Service, Intermountain Forest and Range Experiment Station; 1968. $6 \mathrm{p}$.

Lotan, James E. Regeneration of lodgepole pine forests in the Northern Rocky Mountains. In: Baumgartner, David M., ed. Management of lodgepole pine ecosystems: symposium proceedings; 1973 October 9-11; Pullman, WA. Pullman, WA: Washington State University, Cooperative Extension Service, College of Agriculture; 1975a: 516-535. (vol. 2).

Lotan, James E. The role of cone serotiny in lodgepole pine forests. In: Baumgartner, David M., ed. Management of lodgepole pine ecosystems: symposium proceedings; 1973 October 9-11; Pullman, WA. Pullman, WA: Washington State University, Cooperative Extension Service, College of Agriculture; 1975b: 471-495. (vol. 1).

Lotan, James E. Cone serotiny-fire relationships in lodgepole pine. In: Tall Timbers fire ecology conference 14 and Intermountain Fire Research Council fire and land management symposium: proceedings; 1974 October 8-10; Missoula, MT. Tallahassee, FL: Tall Timbers Research Station; 1976: 267-278.

Lotan, James E.; Alexander, Robert R. Lodgepole pine. In: Silvicultural systems for the major forest types of the United States. Agriculture Handbook 445. Washington, DC: U.S. Department of Agriculture, Forest Service, Division of Timber Management Research; 1973: 42-44.

Lotan, James E.; Critchfield, William B. Silvies of Pinus contorta. In: Silvics of North American species. Agriculture Handbook. Washington, DC: U.S. Department of Agriculture, Forest Service; [in press]. 
Lotan, James E.; Jensen, Chester E. Estimating seed stored in serotinous cones of lodgepole pine. Research Paper INT-83. Ogden, UT: U.S. Department of Agriculture, Forest Service, Intermountain Forest and Range Experiment Station; 1970. 10 p.

Lotan, James E.; Perry, David A. Ecology and regeneration of lodgepole pine. Agriculture Handbook 606 . Washington, DC: U.S. Department of Agriculture, Forest Service; 1983. 51 p.

Lotan, James Elmer. Cone serotiny in Pinus contorta. Ann Arbor, MI: University of Michigan; 1970. 94 p. Ph.D. dissertation.

Macaulay, James Donald. Mechanical seed extraction of lodgepole pine. Dissertation Abstracts International. 36(12, Part 1): 6278B-6279B; 1976. Abstract.

MacDonald, J.; Wood, R. F. Pinus contorta Loudon. In: MacDonald, James; Wood, R. F.; Edwards, M. V.; Aldhous, J. R., eds. Exotic forest trees in Great Britain. Forestry Commission Bulletin 30. London: Forestry Commission; 1957: 94-100.

Mack, Richard N. Pollen size variation in some western North American pines as related to fossil pollen identification. Northwest Science. 45(4): 257-269; 1971.

MacLean, Colin; Berger, John M. Softwood tree volume equations for major California species. Research Note PNW-266. Portland, OR: U.S. Department of Agriculture, Forest Service, Pacific Northwest Forest and Range Experiment Station; 1976. 34 p.

Malcolm, F. B. Sacrificing short butt log to chips may reduce lodgepole stud warping. Forest Industries. 95(5): 88-89; 1968.

Manning, T. D. R.; Hemmingson, J. A. Bark and oleoresin monoterpene hydrocarbons of Pinus contorta grown in New Zealand. New Zealand Journal of Science. 18: 115-118; 1975.

Maschning, E. [Variation of cotyledon number in some Pinus contorta provenances.] In German. Silvae Genetica. 20(1/2): 10-14; 1971.

Massie, M. R. C.; Manning, G. H.; McCloskey, K. R. Metric single-tree total volume tables for the Yukon Territory. Information Report BC-X-242. Victoria, BC: Environment Canada, Canadian Forestry Service, Pacific Forest Research Centre; 1983. 19 p.

Matthews, J. D. Some applications of genetics and physiology in thinning. Forestry (Great Britain). 36(2): $172-180 ; 1963$.

Mayer, Kenneth E.; Fox, Lawrence, III. Identification of conifer species groupings from Landsat digital classifications. Journal of the American Society of Photogrammetry. 48(11): 1607-1614; 1981.

McDougal, Fred W. The importance of lodgepole pine in Canada. In: Baumgartner, David M., ed. Management of lodgepole pine ecosystems: symposium proceedings; 1973 October 9-11; Pullman, WA. Pullman, WA: Washington State University, Cooperative Extension Service, College of Agriculture; 1975: 10-26. (vol. 1).

McMillan, Calvin. The edaphic restriction of Cupressus and Pinus in the coast ranges of central California.

Ecological Monographs. 26(3): 177-212; 1956.

McMillan, Calvin. Survival of transplanted Cupressus and Pinus after thirteen years in Mendocino County, California. Madroño. 17(8): 250-253; 1964.
McMullan, E. E.; Colangeli, A. Comparison of starch and polyacrylamide gel-electrophoresis and isoelectric focusing for isozyme analysis in two conifers. Silva Fennica. 16(2): 226-231; 1982.

Ministry of Technology. Wood structure: home-grown timber investigations: lodgepole pine. In: Forest Products Research 1964. London: Ministry of Technology; 1965: 9.

Mirov, N. T. Lodgepole pine discovered and misnamed. Madroño. 12: 156-157; 1954a.

Mirov, Nicholas T. Geography of the genus Pinus. Bulletin of the Geological Society of America. 65(12/2): 1397; 1954b. Abstract.

Moessner, Karl E. Preliminary aerial volume tables for conifer stands in the Rocky Mountains. Research Paper 41. Ogden, UT: U.S. Department of Agriculture, Forest Service, Intermountain Forest and Range Experiment Station; 1957. $17 \mathrm{p}$.

Moeur, Melinda. Crown width and foliage weight of Northern Rocky Mountain conifers. Research Paper INT-283. Ogden, UT: U.S. Department of Agriculture, Forest Service, Intermountain Forest and Range Experiment Station; 1981. $14 \mathrm{p}$.

Mogren, E. W. Height growth in relation to crown size in juvenile lodgepole pine. Research Note 17. Fort Collins, CO: Colorado State University, College of Forestry and Natural Resources; 1967. 2 p.

Moore, M. B. Seed source variation in lodgepole pine and 1st-year root development. Tree Planters' Notes. 32(4): 5-8; $1981 \mathrm{a}$.

Moore, Musser Beighley. Geographic variation in lodgepole pine in the Central Rocky Mountains. Fort Collins, CO: Colorado State University; 1981b. 188 p. Ph.D. dissertation. Available from: University Microfilms International, Ann Arbor, MI.

Moss, Alan. Lodgepole pine in the Okanagan Valley. Scottish Forestry. 9(2): 68-72, 67; 1955.

Moss, Alan. An investigation of basal sweep of lodgepole and shore pines in Britain. Forestry (Great Britain). 44(1): 43-65; 1971.

Mowat, Edwin L. No serotinous cones on central Oregon lodgepole pine. Journal of Forestry. 58: 118-119; 1960.

Muir, Patricia S. Final report: fire frequency and the life history of lodgepole pine (Pinus contorta var. latifolia). Madison, WI: University of Wisconsin, Department of Botany; 1982.33 p.

Muir, Patricia S.; Lotan, James E. Serotiny and life history of Pinus contorta var. latifolia. Canadian Journal of Botany. 63: 938-945; 1985.

Muller, Robert A. Transmission components of solar radiation in pine stands in relation to climatic and stand variables. Research Paper PSW-71. Berkeley, CA: U.S. Department of Agriculture, Forest Service, Pacific Southwest Forest and Range Experiment Station; 1971. $13 \mathrm{p}$.

Myers, Clifford A. Taper tables, bark thickness, and diameter relationships for lodgepole pines in Colorado and Wyoming. Research Note RM-31. Fort Collins, CO: U.S. Department of Agriculture, Forest Service, Rocky Mountain Forest and Range Experiment Station; 1964a. $6 \mathrm{p}$. 
Myers, Clifford A. Volume tables and point-sampling factors for lodgepole pine in Colorado and Wyoming. Research Paper RM-6. Fort Collins, CO: U.S. Department of Agriculture, Forest Service, Rocky Mountain Forest and Range Experiment Station; 1964b. 16 p.

Myers, Clifford A. Height-diameter curves for tree species subject to stagnation. Research Note RM-69. Fort Collins, CO: U.S. Department of Agriculture, Forest Service, Rocky Mountain Forest and Range Experiment Station; 1966. 2 p.

Myers, Clifford A. Yield tables for managed stands of lodgepole pine in Colorado and Wyoming. Research Paper RM-26. Fort Collins, CO: U.S. Department of Agriculture, Forest Service, Rocky Mountain Forest and Range Experiment Station; 1967. 20 p.

Myers, Clifford A. Board-foot volumes to a 6-inch top for lodgepole pines in Colorado and Wyoming. Research Note RM-157. Fort Collins, CO: U.S. Department of Agriculture, Forest Service, Rocky Mountain Forest and Range Experiment Station; 1969. 3 p.

Neustein, S. A. Trial plantations at high elevations. In: Report on forest research for the year ended March 1965. London: Forestry Commission; 1966: 169-172.

Newman, K. W.; Jancey, R. C. Sample size in studies of geographic variation. Canadian Journal of Botany. 59(11): 2158-2159; 1981.

Nielsen, Carl Christian Norgard. En stabilitetsunder s $\phi$ gelse i Pinus contorta ved hjaelp af en traekmålings metode: A stability study of Pinus contorta using a tensile force measurement method. Dansk Skovforenings Tidsskrift. 67(1): 1-41; 1982.

Nilsson, Jan-Erik. Flowering in Pinus contorta. Sveriges Lantbruksuniversitet Report 2. Umea, Sweden: Swedish University of Agricultural Sciences, Department of Forest Genetics and Plant Physiology; 1981. 128 p.

Nyland, Edo. Lodgepole pine in the Yukon. In: Pinus contorta as an exotic species: proceedings of the IUFRO working party meeting 1980 on Pinus contorta provenances (S2-02-06) in Norway and Sweden. Research Note 30. Garpenberg, Sweden: Swedish University of Agricultural Sciences, Department of Forest Genetics; 1980: 27-43.

O'Driscoll, J. Pinus contorta in Ireland. In: Proceedings of IUFRO joint meeting of working parties: lodgepole pine, Sitka spruce and Abies provenances [S2-02-06, S2-02-12 and S2-02-14]; 1978; Vancouver, Canada. Victoria, BC: British Columbia Ministry of Forests, Information Services Branch; 1978: 137-139. (vol. 2).

O'Driscoll, J. The importance of lodgepole pine in Irish forestry. Irish Forestry. 37(1): 7-22; 1980.

Oregon State Board of Forestry. Standard volume table for lodgepole pine on the Deschutes Plateau, Oregon. Salem, OR: Oregon State Board of Forestry; n.d. 1 p.

Parker, H. A. Bark thickness of lodgepole pine. Silviculture Leaflet 49. Ottawa, ON: Department of Resources and Development, Forestry Branch, Division of Forest Research; 1950 November. 2 p. [Replaces Silviculture Leaflet 49 issued 1950 September.]

Paul, Benson, H. Properties and uses of western pine. Wood Workers Digest. 64(1): 43-45; 1962.

Peattie, Donald Culross. Beach and lodgepole pine. Natural History. 61(8): 372-378; 1952.
Pederick, L. A. Provenance variation in Pinus contorta. In: Forestry Technical Paper 28. Melbourne, Australia: Forests Commission Victoria; 1980: 32-40.

Perry, David A.; Lotan, James E. Variation in lodgepole pine (Pinus contorta var. latifolia): greenhouse response of wind pollinated families from five populations to day length and temperature-soil. Canadian Journal of Forest Research. 8(1): 81-89; 1978.

Perry, David A.; Lotan, James E. A model of fire selection for serotiny in lodgepole pine. Evolution. 33(3): 958-968; 1979.

Perry, David Anthony. Ecotypic variation in Pinus contorta Dougl. var. latifolia Engelm. (lodgepole pine). Dissertation Abstracts International. 35(9): 4427-B; 1975. Abstract.

Peterson, Glenn W.; Harvey, George M. Dispersal of Scirrhia (Dothistroma) pini conidia and disease development in a shore pine plantation in western Oregon. Plant Disease Reporter. 60(9): 761-764; 1976.

Pfeifer, A. R. Factors that contribute to basal sweep in lodgepole pine. Irish Forestry. 39(1): 7-16; 1982.

Pfister, Robert D.; Daubenmire, R. Ecology of lodgepole pine (Pinus contorta Dougl.). In: Baumgartner, David M., ed. Management of lodgepole pine ecosystems: symposium proceedings; 1973 October 9-11; Pullman, WA. Pullman, WA: Washington State University, Cooperative Extension Service, College of Agriculture; 1975: 27-46. (vol. 1).

Pfister, Robert D.; Kovalchik, Bernard L.; Arno, Stephen F.; Presby, Richard C. Forest habitat types of Montana. General Technical Report INT-34. Ogden, UT: U.S. Department of Agriculture, Forest Service, Intermountain Forest and Range Experiment Station; 1977. $174 \mathrm{p}$.

Plank, Marlin E.; Cahill, James M. Estimating cubic volume of small diameter tree-length logs from ponderosa and lodgepole pine. Research Note PNW-417. Portland, OR: U.S. Department of Agriculture, Forest Service, Pacific Northwest Forest and Range Experiment Station; 1984. 7 p.

Polge, Hubert. [The quality of wood of the principal exotic conifers used in French plantations.] In French. Annales de L'Ecole Nattionale des Eaux et Forêts 20(3): 401-469; 1963.

Quintus, Dick. Board foot volume table for lodgepole pine. Bend, OR: Oregon State Board of Forestry; 1951. 2 p. Mimeographed.

Raile, Gerhard K. Estimating stump volume. Research Paper NC-224. St. Paul, MN: U.S. Department of Agriculture, Forest Service, North Central Forest Experiment Station; 1982. 4 p.

Rehfeldt, G. E. Adaptation of Pinus contorta populations to heterogeneous environments in northern Idaho. Canadian Journal of Forest Research. 13(3): 405-411; 1983.

Rehfeldt, G. E.; Wykoff, W. R. Periodicity in shoot elongation among populations of Pinus contorta from the Northern Rocky Mountains. Annals of Botany. 48: 371-377; 1981.

Rehfeldt, Gerald E. Cold acclimation in populations of Pinus contorta from the Northern Rocky Mountains. Botanical Gazette. 141(4): 458-463; 1980.

Reid, Collins Nurseries, Ltd. The management and silviculture of lodgepole pine in B.C. Occasional Paper 1. 
[Victoria, BC]: Forest Research Council of British Columbia; 1983. $64 \mathrm{p}$.

Righter, F. I.; Stockwell, Palmer. The fertile species hybrid, Pinus Murray-banksiana. Madroño. 10(3): 65-69; 1949.

Roche, L. Variation in lodgepole pine with reference to provenances planted in Great Britain and Ireland. Forestry. 39(1): 30-39; 1966.

Roche, Laurence. The shore variety of Pinus contorta. Baileya. 11(1): 11-14; 1963.

Safranyik, Les. Effects of climate and weather on mountain pine beetle populations. In: Berryman, Alan A.; Amman, Gene D.; Stark, Ronald W., tech. eds., Kibbee, Darline L., publ. ed. The theory and practice of mountain pine beetle management in lodgepole pine forests: symposium proceedings; 1978 April 25-27; Pullman, WA. Moscow, ID: University of Idaho, Forest, Wildlife and Range Experiment Station; 1978: 77-84.

Satterlund, Donald R. Climatic factors and lodgepole pine. In: Baumgartner, David M., ed. Management of lodgepole pine ecosystems: symposium proceedings; 1973 October 9-11; Pullman, WA. Pullman, WA: Washington State University, Cooperative Extension Service, College of Agriculture; 1975: 297-309. (vol. 1).

Schmidt, W. C. Forests of the Rocky Mountain west. In: Lotan, James E.; Alexander, Martin E.; Arno, Stephen F.; [and others]. Effects of fire on flora. General Technical Report WO-16. Washington, DC: U.S. Department of Agriculture, Forest Service; 1981: 11-16.

Schroeder, James G.; Phillips, Douglas R. Effect of sweep and crook on veneer yield. Forest Products Journal. 34(10): 45-47; 1984.

Scott, D. Comparison between lodgepole pine and mountain beech in establishment and $\mathrm{CO}_{2}$ exchange. New Zealand Journal of Botany. 8(3): 357-360; 1970.

Shepperd, Wayne D.; Alexander, Robert R. Overview to silvicultural systems in the Central Rocky Mountains. Fort rollins, CO: U.S. Department of Agriculture, Forest Service, Rocky Mountain Forest and Range Experiment Station; 1983. $31 \mathrm{p}$.

Shirling, A. E. The age of needle leaves. Transactions of the Kansas Academy of Science. 49(2): 161-166; 1946.

Shrimpton, D. M.; Thomson, A. J. Growth characteristics of lodgepole pine associated with the start of mountain pine beetle outbreaks. Canadian Journal of Forest Research. 13: 137-143; 1983.

Smith, Frederick Walter. Effects of competition for soil water on growth and water status of Pinus contorta on pumice soil. Seattle, WA: University of Washington; 1981. 142 p. Ph.D. dissertation. Available from: University Microfilms International, Ann Arbor, MI.

Smith, J. H. G.; Ker, J. W. Timber volume depends on $D^{2}$ H. British Columbia Lumberman. 41(9): 28-30; 1957.

Smith, J. H. G.; Kozak, A. Thickness, moisture content, and specific gravity of inner and outer bark of some Pacific Northwest trees. Forest Products Journal. 21(2): 38-40; 1971.

Smith, J. Harry G. Root spread can be estimated from crown width of Douglas fir, lodgepole pine, and other British Columbia tree species. Forestry Chronicle. 40(4): 456-473; 1964.
Smith, J. Harry G.; Bailey, Gordon R. Influence of stocking and stand density on crown widths of Douglas fir and lodgepole pine. Commonwealth Forestry Review. 43(3): 243-246; 1964.

Smith, R. B. Development of dwarf mistletoe (Arceuthobium) infections on western hemlock, shore pine, and western larch. Canadian Journal of Forest Research. 1(1): 35-42; 1971.

Smith, Richard H. Monoterpenes of lodgepole pine xylem resin: a regional study in Western United States. Forest Science. 29(2): 333-340; 1983.

Smithers, L. A. Lodgepole pine in Alberta. Bulletin 127. Ottawa, ON: Canada Department of Northern Affairs and National Resources, Department of Forestry; 1961. $153 \mathrm{p}$.

Snell, J. A. Kendall; Max, Timothy A. Bark-to-wood ratios for logging residue in Oregon, Washington, and Idaho. Administrative Report. Portland, OR: U.S. Department of Agriculture, Forest Service, Pacific Northwest Forest and Range Experiment Station; 1982. 9 p.

Spada, Benjamin. Estimating past diameters of several species in the ponderosa pine subregion of Oregon and Washington. Research Note 181. Portland, OR: U.S. Department of Agriculture, Forest Service, Pacific Northwest Forest and Range Experiment Station; 1960. $4 \mathrm{p}$.

Spalt, Karl W.; Reifsnyder, William E. Bark characteristics and fire resistance: a literature survey. Occasional Paper 193. New Orleans, LA: U.S. Department of Agriculture, Forest Service, Southern Forest Experiment Station; $1962.19 \mathrm{p}$.

Sterba, Hubert. Stem curves-a review of the literature. Forestry Abstracts. 41(4): 141-145; 1980.

Stock, Mary W.; Guenther, Jerry D.; Pitman, Gary B. Implications of genetic differences between mountain pine beetle populations to integrated pest management. In: Berryman, Alan A.; Amman, Gene D.; Stark, Ronald W., tech. eds., Kibbee, Darline L., publ. ed. The theory and practice of mountain pine beetle management in lodgepole pine forests: symposium proceedings; 1978 April 25-27; Pullman, WA. Moscow, ID: University of Idaho, Forest, Wildlife and Range Experiment Station; 1978: 197-201.

Struble, G. R. Insect enemies in the natural control of the lodgepole needle miner. Journal of Economic Entomology. 60(1): 225-228; 1967.

Struble, George R. Needle miner infestations in lodgepole pine east of the Sierra crest. Research Note PSW-177. Berkeley, CA: U.S. Department of Agriculture, Forest Service, Pacific Southwest Forest and Range Experiment Station; 1968. 2 p.

Sutherland, J. R.; Lock, W.; Woods, T. A. D.; Suttill, T. Sirococcus blight not seed-borne on serotinous lodgepole pine. Canadian Forestry Service Research Notes. 2(3): 20-22; 1982.

Swan, E. P. Chemical methods of differentiating the wood of several western conifers. Forest Products Journal. 16(1): 51-54; 1966.

Swan, H. S. D. Foliar nutrient concentrations in lodgepole pine as indicators of tree nutrient status and fertilizer requirement. Woodlands Report WR/42. Pointe Claire, PQ: Pulp and Paper Research Institute of Canada; 1972. $19 \mathrm{p}$. 
Tackle, David. Silvics of lodgepole pine. Miscellaneous Publication 12. Ogden, UT: U.S. Department of Agriculture, Forest Service, Intermountain Forest and Range Experiment Station; 1959. 24 p.

Taylor, Fred W.; Wang, Eugene I. C.; Micko, Michael M. Differences in the wood of lodgepole pine in Alberta. Wood and Fiber. 14(4): 296-309; 1982.

Teich, A. H. Cone serotiny and inbreeding in natural populations of Pinus banksiana and Pinus contorta. Canadian Journal of Botany. 48(10): 1805-1809; 1970.

Thiers, H. D.; Smith, A. H. A new species of Suillus. Mycologia. 65(6): 1375-1377; 1973.

Thompson, C. F. Drag scarification trials in lodgepole pine logging slash in the Nelson Forest District of British Columbia (E.P. 714). Research Note 82. Victoria, BC: Ministry of Forests, Forest Service Research Division; 1978. $13 \mathrm{p}$.

Tower, Gordon E. A study of the reproductive characteristics of lodgepole pine. Proceedings Society of American Foresters. 4(1): 84-106; 1909.

Trappe, James M.; Harris, Robert W. Lodgepole pine in the Blue Mountains of northeastern Oregon. Research Paper 30. Portland, OR: U.S. Department of Agriculture, Forest Service, Pacific Northwest Forest and Range Experiment Station; 1958. 22 p.

U.S. Department of Agriculture. Hybrid Christmas tree... for the 1970s. Agricultural Research. 13(6): 8-9; 1964.

U.S. Department of Agriculture, Forest Service. Silvicultural systems for the major forest types of the United States. Agriculture Handbook 445. Washington, DC: U.S. Department of Agriculture, Forest Service, Division of Timber Management Research; 1973. 124 p.

Upson, Arthur T. Volume table for lodgepole pine. Forestry Quarterly. 12: 319-329; 1914.

van den Driessche, R. J. Pinus contorta and its future prospect in this country. Y coedwigwr [The Forester]. 3(1): 5-7; 1956-1957.

van Eerden, E.; Kinghorn, J. M., eds. Proceedings of the root form of planted trees symposium; 1978 May 16-19; Victoria, BC. Joint Report 8. Victoria, BC: British Columbia Ministry of Forests and Canadian Forestry Service; 1978. $157 \mathrm{p}$.

Van Hooser, Dwane D.; Chojnacky, David C. Whole tree volume estimates for the Rocky Mountain States. Resource Bulletin INT-29. Ogden, UT: U.S. Department of Agriculture, Forest Service, Intermountain Forest and Range Experiment Station; 1983. 69 p.

Wass, E. F. Ecology of shore pine stands infested with dwarf mistletoe on southeastern Vancouver Island. [Information Report] BC-X-142. Victoria, BC: Environment Canada, Canadian Forestry Service, Pacific Forest Research Centre; 1976. 33 p.

Weir, G. H.; Thurston, E. L. Scanning electron microscopic identification of fossil Pinaceae pollen to species by surface morphology. Palynology. 1: 157-165; 1977.

Wellner, Charles A. The importance of lodgepole pine in the United States. In: Baumgartner, David M., ed.
Management of lodgepole pine ecosystems: symposium proceedings; 1973 October 9-11; Pullman, WA. Pullman, WA: Washington State University, Cooperative Extension Service, College of Agriculture; 1975: 1-9. (vol. 1).

Wellner, Charles A.; Lowery, David P. Spiral grain-a cause of pole twisting. Research Paper INT-38. Ogden, UT: U.S. Department of Agriculture, Forest Service, Intermountain Forest and Range Experiment Station; 1967. $17 \mathrm{p}$.

Went, F. W. Rhizomorphs in soil not connected with fungal fruiting bodies. American Journal of Botany. 60(2): 103-110; 1973.

Westman, Walter E. Edaphic climax pattern of the pygmy forest region of California. Ecological Monographs. 45(2): 109-135; 1975.

Westman, Walter E. Patterns of nutrient flow in the pygmy forest region of northern California. Vegetatio. 36(1): 1-15; 1978.

Westman, W. E.; Whittaker, R. H. The pygmy forest region of northern California: studies on biomass and primary productivity. Journal of Ecology. 63(2): 493-520; 1975.

Wheeler, Nicholas C.; Critchfield, William B. The distribution and botanical characteristics of lodgepole pine: biographical and management implications. In: Baumgartner, David M.; Krebill, Richard G.; Arnott, James T.; Weetman, Gordon F., eds. Lodgepole pine: the species and its management: symposium proceedings; 1984 May 8-10; Spokane, WA; 1984 May 14-16; Vancouver, BC. Pullman, WA: Office of Conferences and Institutes, Cooperative Extension; 1985: 1-13.

Wheeler, Nicholas C.; Guries, Raymond P. Biogeography of lodgepole pine. Canadian Journal of Botany. 60(9): 1805-1814; 1982a.

Wheeler, Nicholas C.; Guries, Raymond P. Population structure, genic diversity, and morphological variation in Pinus contorta Dougl. Canadian Journal of Forest Research. 12(3): 595-606; $1982 \mathrm{~b}$.

Wikstrom, John H. Lodgepole pine-a lumber species. Research Paper 46. Ogden, UT: U.S. Department of Agriculture, Forest Service, Intermountain Forest and Range Experiment Station; 1957. 15 p.

Yeh, F. C.; Layton, C. The organization of genetic variability in central and marginal populations of lodgepole pine Pinus contorta spp. latifolia. Canadian Journal of Genetics and Cytology. 21(4): 487-503; 1979.

Ying, Cheng C.; Illingworth, K.; Carlson, M. Geographic variations in lodgepole pine and its implications for tree improvement in British Columbia. In: Baumgartner, David M.; Krebill, Richard G.; Arnott, James T.; Weetman, Gordon F., eds. Lodgepole pine: the species and its management: symposium proceedings; 1984 May 8-10; Spokane, WA; 1984 May 14-16; Vancouver, BC. Pullman, WA: Office of Conferences and Institutes, Cooperative Extension; 1985: 45-53.

Ziegler, E. A., compiler. Forest tables-lodgepole pine. Circular 126. Washington, DC: U.S. Department of Agriculture, Forest Service; 1907. 24 p. 


\section{CHAPTER 2: MOISTURE CONTENT OF TREE COMPONENTS}

\section{CONTENTS}

$2-1$ Introduction $\ldots \ldots \ldots \ldots \ldots \ldots \ldots \ldots \ldots \ldots$

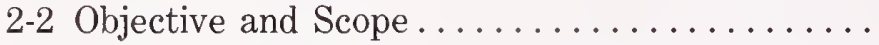

2-3 Literature Review .................

Yearly, Seasonal, and Daily Variation in

Moisture Content ..................

Live Branch Moisture Content . . . . . . . . . .

Bark Moisture Content ................

Stump-Root System Moisture Content .......

Foliage Moisture Content ..............

Stem Moisture Content ................

Dead-Tree Moisture Content ............

2-4 Procedure .......................

2-5 Results-Latifolia.................

Complete Tree With Cones and Foliage .......

Complete Tree Without Cones or Foliage......

Complete Tree, Wood Only..............

Complete Tree, Bark Only ............

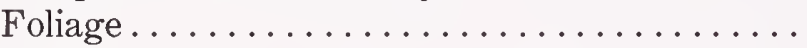

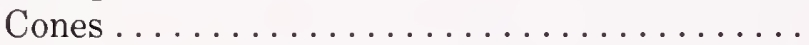

Dead Branchwood .................

Live Branches, Wood Plus Bark ..........

Live Branchwood ...................

Live Branchbark....................

Stem, Wood Plus Bark-Tree Average ........

Stem, Wood Plus Bark-Variation With

Height ......................

Stemwood-Tree Average ..............

Stemwood-Variation With Height ........

Stembark-Tree Average ...............

Stembark-Variation With Height .........

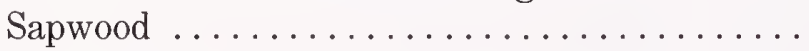

Heartwood ........................

Stump-Root System, Wood Plus Bark........

Stump-Root System, Wood Only ...........

Stump-Root System, Bark Only ...........

Stump, Wood Plus Bark ..............

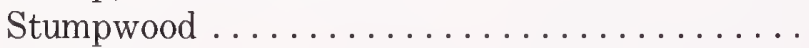

Stumpbark......................

Lateral Roots, Wood Plus Bark...........

Lateral Roots, Wood Only ..............

Lateral Roots, Bark Only ...............

Central Root Mass-Taproot, Wood Plus Bark ..

Central Root Mass-Taproot, Wood Only .......

Central Root Mass-Taproot, Bark Only ........
Page
2-6 Results-Murrayana ................ Complete Tree With Cones and Foliage ....... Complete Tree Without Cones or Foliage ..... Complete Tree, Wood Only............... Complete Tree, Bark Only ............. Foliage ....................... Cones .........................

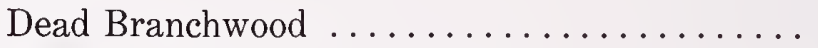

Live Branches, Wood Plus Bark ..........

Live Branchwood ..................

Live Branchbark...................

Stem, Wood Plus Bark-Tree Average ........

Stem, Wood Plus Bark-Variation With

Height ....................

Stemwood-Tree Average . . . . . . . . . . . . .

Stemwood-Variation With Height .........

Stembark-Tree Average ...............

Stembark-Variation With Height.........

Sapwood

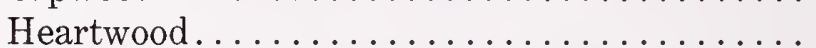

Stump-Root System, Wood Plus Bark........ Stump-Root System, Wood Only ...........

Stump-Root System, Bark Only ...........

Stump, Wood Plus Bark ..............

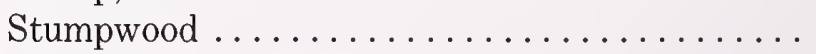

Stumpbark ......................

Lateral Roots, Wood Plus Bark...........

Lateral Roots, Wood Only .............

Lateral Roots, Bark Only ...............

Central Root Mass-Taproot, Wood Plus Bark ..

Central Root Mass-Taproot, Wood Only .......

Central Root Mass-Taproot, Bark Only ........

2-7 Results-Latifolia Compared to Murrayana ...

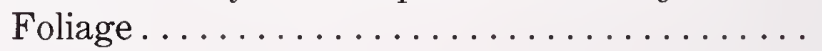

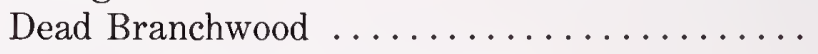

Live Branches, Wood Plus Bark ...........

Live Branchbark...................

Stump-Root System, Wood Plus Bark........

Stump-Root System, Bark Only ...........

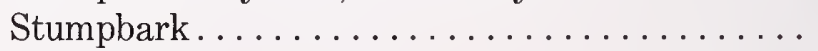

Lateral Roots, Bark Only ..............

Central Root Mass-Taproot, Bark Only........

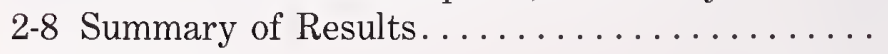

2-9 References.
Page

102

102

102

103

103

103

103

103

103

103

104

104

104

105

105

105

106

106

106

106

106

107

107

107

107

107

107

108

108

108

108

109

109

109

110

110

110

111

112

113

114

114

115 


\section{2-1 INTRODUCTION}

Foliage, bark, and wood of living lodgepole pines commonly contain about $1 \mathrm{~kg}$ of water for each kilogram of dry biomass, but the ratio varies significantly among and within trees. For use as fuel, bark and foliage serve best if dry. Wood in use generally serves best if most of the water is removed because many of the desirable properties of wood are negatively correlated with moisture content.

Some utilization processes require that water solutions be made to penetrate wood. For these reasons it is useful to know the location of water in trees and, while not within the scope of this chapter, the manner of its movement.

Moisture content is usually expressed as a percentage of ovendry weight of wood, bark, or foliage, as follows.

Percentage moisture content $=$

[(weight with moisture - ovendry weight)

lovendry weight] $\times 100$

The ovendry weight of wood, bark, and foliage is measured after drying it to constant weight in an oven held at 101 to $105{ }^{\circ} \mathrm{C}$.

\section{2-2 OBJECTIVE AND SCOPE}

As previously noted, this characterization effort is confined to two varieties of lodgepole pine: Pinus contorta var. latifolia Engelm., and Pinus contorta var. murrayana (Grev. \& Balf.) Engelm., with emphasis on the former. The primary objective during tree collection was to obtain three replications of disease- and insect-free specimens of var. latifolia measuring 76,152 , and $228 \mathrm{~mm}$ in diameter at breast height (d.b.h.) at low, medium, and high elevations from nine equally spaced north latitudinal zones (40 to 60 degrees) across 10 degrees of longitude in such a way as to encompass the major range of this variety (fig. 1-1).

A secondary objective was to sample three replications of these same three diameter classes of var. murrayana at midelevation at four north latitudes (37.5, 40, 42.5, and 45 degrees) in California and Oregon at a single longitude per latitude (fig. 1-1).

The trees of both varieties were sampled in such a way that between-variety comparisons could be made for midelevation trees at latitudes $40,42.5$, and 45 degrees. The sampling plan does not permit computation of speciesaverage values. The collection totaled 243 latifolia and 36 murrayana trees.

In this chapter variations in moisture contents of tree components are discussed. No attempt is made to construct equations for prediction of component moisture content. Instead, graphs are presented of data aggregated in various significant ways that permit readers to obtain moisture content information directly from the observed study data.

For latifolia some significant simple correlations are tabulated to aid subsequent students of the subject in developing predictive equations.

Explanations of statistical analyses procedures and a table of analyses of variance formats, with degrees of freedom indicated, are shown in table 1-2. In the results portion of this chapter standard deviations are noted in the text in parentheses following average values.

\section{2-3 LITERATURE REVIEW}

\section{Yearly, Seasonal, and Daily Variation in Moisture Content}

Because snow prevented access to upper elevations from early November to early June, tree collections were made during the months of June through October in 1983 and 1984. Interpretation of results reported here should be tempered with knowledge that some variation in tree component moisture content occurs with both year and season sampled. For example, Markstrom and Hann (1972) found that in five trees sampled each season near Fort Collins, CO, sapwood of 156- to 242-year-old latifolia had higher moisture content in 1967 than in 1968, and that moisture content was least in spring and most in fall and winter, as follows:

$\begin{array}{ccc}\text { Year and season } & \text { Sapwood } & \text { Heartwood } \\ \text { Outer Inner } & \text { Outer Inner } \\ \text { Percent of ovendry weight }\end{array}$

1967

$\begin{array}{lllll}\text { Spring growing } & 138 & 138 & 35 & 43 \\ \text { Summer } & 145 & 144 & 42 & 48 \\ \text { Fall dormancy } & 161 & 147 & 39 & 47 \\ \text { Winter } & 173 & 164 & 43 & 68 \\ 1968 & & & & \\ \quad \text { Spring growing } & 127 & 131 & 36 & 47 \\ \text { Summer } & 150 & 150 & 42 & 55\end{array}$

The foregoing data are based on increment cores removed at 0.91 and $1.22 \mathrm{~m}$ above ground level.

Reid (1961) found that the moisture content of outer sapwood and inner bark of latifolia trees in British Columbia was about 10 percentage points greater at 4 a.m. than at 4 to 8 p.m.; noontime moisture content was intermediate. His data indicated an outer sapwood moisture content of about 150 percent, with inner sapwood having a much lower moisture content-about 50 percent; he observed that outer heartwood had about 25 percent moisture content, and innermost heartwood about 40 percent.

\section{Live Branch Moisture Content}

Dobie and McIntosh (1976) found that latifolia branches (wood plus bark) on 83 trees freshly harvested in late July and early August near Hinton, $\mathrm{AB}$, had average moisture content of 74 percent of ovendry weight.

Fahnestock (1960) found that whole branches (wood plus bark) from fresh latifolia logging slash in northern Idaho had a moisture content of 82 percent (nine samples); branchwood (one sample) averaged 96 percent.

\section{Bark Moisture Content}

Smith and Kozak (1971) found that latifolia trees in British Columbia had inner bark and outer bark moisture contents of 128 and 42 percent, respectively (ovendryweight basis). They provided no data on average moisture content for whole bark.

From other observations in British Columbia, Reid (1961) found that moisture content of inner bark of 
latifolia stems was about 250 percent in May and June, but increased to 290 percent in July and August (ovendryweight basis).

\section{Stump-Root System Moisture Content}

No data specific to lodgepole pine stump-root systems were found in the literature.

\section{Foliage Moisture Content}

In late July and early August 1975, Dobie and McIntosh (1976) sampled 83 latifolia trees shortly after they were harvested near Hinton, $\mathrm{AB}$, and found that average foliage moisture content was 94 percent of ovendry weight.

Fahnestock (1960) found that foliage from fresh latifolia logging slash (one sample) in northern Idaho had a moisture content of 179 percent of ovendry weight.

Grouping data from a number of Rocky Mountain conifers (including latifolia), Brown (1978) observed that foliage moisture content was consistently greater than branchwood moisture content by about 24 percentage points. In dominant conifers, foliage moisture contents were highest in top portions of the crown and decreased downward through the crown; differences in foliage moisture content in crown sections of intermediates were much less than in dominants.

\section{Stem Moisture Content}

Dobie and McIntosh (1976) found that 83 latifolia stems (wood plus bark) sampled shortly after harvest in late July and early August near Hinton, AB, had average moisture content of 67 percent of ovendry weight.

In a study of latifolia trees in the Colorado Front Range, Dixon (1969) concluded that growth factors were unrelated to the moisture content of the wood in stems.

Similarly, from a study of stemwood of eighty-five 100-year-old latifolia trees growing near Hinton, AB, Johnstone (1970) found that tree-average stemwood moisture content was not closely correlated with other tree characteristics he measured; the best correlations were with dry needle weight per tree $(r=+0.37)$, tree height $(r=+0.32)$, and d.b.h. $(r=+0.30)$. Moisture content of disks taken at various heights in the tree had correlations with other characteristics, as follows:

\begin{tabular}{lr}
\multicolumn{1}{c}{ Characteristic } & $\boldsymbol{r}$ \\
Height above ground & 0.68 \\
Age of disk & -.67 \\
Average growth ring width & .43 \\
Disk diameter inside bark & -.39 \\
Disk specific gravity & -.38
\end{tabular}

From the 85 trees he examined a total of 713 disks; the moisture content of the 713 disks of stemwood averaged 85 percent of ovendry weight.

Johnstone found a curvilinear relationship between height in tree (feet) and percent moisture content of stemwood-ovendry-weight basis-as follows:

Percent moisture content $=0.697+0.000159 H^{2}$
For this equation, standard error of the estimate was 17.2 percentage points and $r^{2}$ was 0.49 .

Average values for stemwood were as follows:

$\begin{array}{lc}\text { Position in tree } & \begin{array}{c}\text { Percent moisture content } \\ \text { (and standard deviation) }\end{array} \\ \text { Within crown } & 99(23) \\ \text { At breast height } & 70(12) \\ \text { Tree average } & 79(14)\end{array}$

Tree averages for stemwood in these 100-year-old trees ranged from a low of 45 percent to a high of 109 percent.

In British Columbia, Reid (1961) observed that the moisture content of latifolia sapwood is normally in the range from 85 to 165 percent of ovendry weight; he found heartwood to have about 30 percent moisture content. Substantial radial variation in the moisture contents of both sapwood and heartwood was observed (fig. 2-1).

\section{Dead-Tree Moisture Content}

This experiment was concerned only with insect- and disease-free live trees. Because of widespread mortality of lodgepole pine caused by insect attack, loss of moisture in standing dead trees is also of interest (fig. 2-1). Readers needing information on dead-tree moisture content will find useful the following references: Fahey $(1980,1981)$, Ince (1982), Lieu and others (1979), Lowery (1978), Lowery and Hearst (1978), Lowery and others (1977), Reid (1961), and U.S. Department of Agriculture, Forest Service (1948).

Additionally, the Pacific Northwest Forest and Range Experiment Station of the U.S. Department of Agriculture, Forest Service, has manuscripts in press on the subject-as does the Western Laboratory of FORINTEK CANADA CORP. in Vancouver, BC.

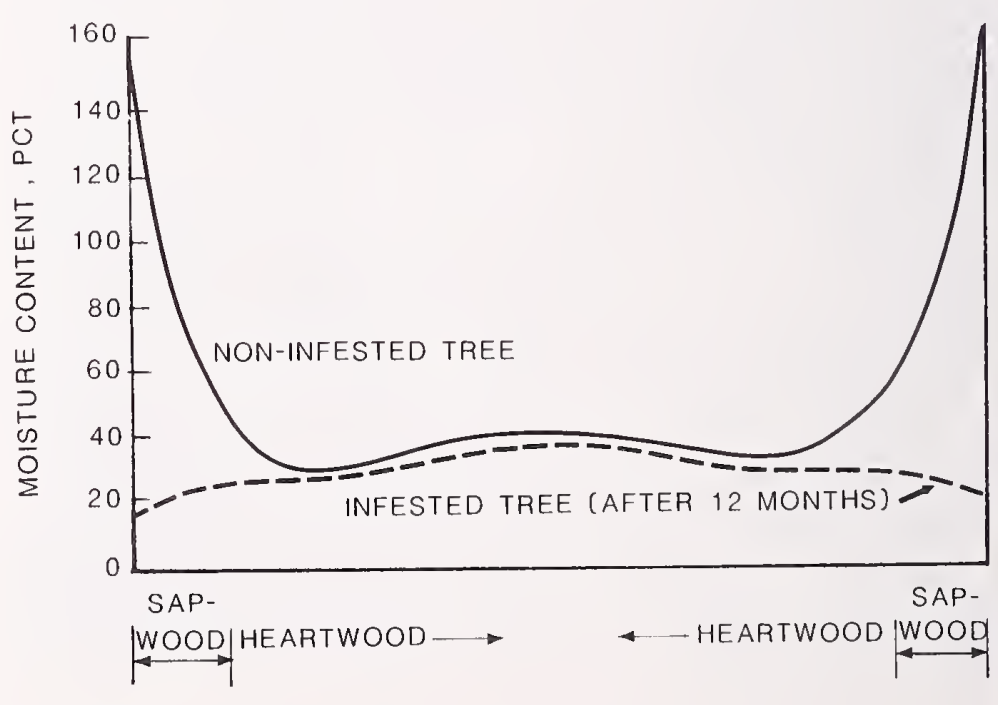

Figure 2-1-Radial variation of sapwood and heartwood moisture content (ovendry-weight basis) at $1.1-\mathrm{m}$ level in a healthy latifolia stem, and in a stem 12 months after attack and infestation by the mountain pine beetle. (Drawing after Reid 1961.) 


\section{2-4 PROCEDURE}

Procedural details of the study are given in chapter 1 , and will not be repeated here except to note that the elevational zones of low, medium, and high are relative. Medium refers to an elevation that is medium for the variety at the latitude at which sampled; similarly, low and high refer to lower and upper elevational zones in which the variety occurs at the latitude sampled. Latifolia elevational zones were highest in the south $(2,481,2,711$, and $3,144 \mathrm{~m}$ at 40 degrees) and progressively lower with each more northerly latitude $(604,739$, and $879 \mathrm{~m}$ at 60 degrees). Murrayana was sampled at elevations in the range from 1,148 to $2,402 \mathrm{~m}$.

Trees were uprooted (with central taproot intact and with lateral roots severed at a radius of $305 \mathrm{~mm}$ from tree pith) from level benches in natural unthinned stands within National or Provincial Forests. The sampling scheme resulted in selection of 76-, 152-, and 228-mm trees averaging 71, 91, and 107 years of age, respectively, for latifolia, and 67, 84, and 91 years for murrayana. Most of the small-diameter trees were suppressed, while the larger trees were the fast growers.

Table 2-1-Average moisture content of lodgepole pine tree components, with data from the 243 latifolia and the 36 murrayana trees pooled separately ${ }^{1}$

Variety

Tree component

Complete tree with cones and

foliage

Complete tree, wood only

Complete tree, bark only

Foliage

Cones (from first $305 \mathrm{~mm}$ of top 25

branches)

Dead branchwood

Live branches, wood plus bark

Live branchwood

Live branchbark

Stem, wood plus bark

Stemwood

Stembark

Sapwood

Heartwood

Stump-root system, wood plus bark

Stump-root system, wood only

Stump-root system, bark only

Stump, wood plus bark

Stumpwood

Stumpbark

Lateral roots, wood plus bark

Lateral roots, wood only

Lateral roots, bark only

Central root mass-taproot, wood

plus bark

Central root mass-taproot, wood

only

Central root mass-taproot, bark

only

'Because of the effects of d.b.h., latitude, and elevational zone, reference to appropriate figures and text discussion is required for interpretation of these data.

Percent of ovendry weight

$\begin{array}{rr}96.6 & 108.6 \\ 95.9 & 108.0 \\ 103.3 & 113.7 \\ 110.6 & 114.3 \\ & \\ 25.8 & 22.1 \\ 18.2 & 16.4 \\ 94.2 & 97.3 \\ 88.6 & 92.7 \\ 106.4 & 105.3 \\ 99.4 & 111.6 \\ 98.9 & 111.2 \\ 101.9 & 114.1 \\ 119.3 & 125.1 \\ 43.4 & 44.4 \\ 95.7 & 112.1 \\ 94.9 & 110.8 \\ 106.2 & 120.9 \\ 88.8 & 99.8 \\ 90.5 & 100.7 \\ 77.3 & 92.1 \\ 106.3 & 125.1 \\ 103.7 & 121.4 \\ 120.7 & 140.2 \\ & \\ 93.6 & 113.0 \\ 92.4 & 112.5 \\ & \\ 107.1 & 115.3\end{array}$

\section{2-5 RESULTS-LATIFOLIA}

Average moisture contents of tree components are summarized in table 2-1, but interpretation of these averages requires reference to the main effects and interactions attributable to d.b.h., latitude, and elevational zone-as discussed in the following paragraphs. Moisture contents throughout the paper are expressed as percentage of ovendry weight.

Latitudinal sampling areas spanned 10 degrees of longitude (fig. 1-1), but no significant moisture-content variations attributable to longitudinal location along these 10-degree-wide sampling areas were detected.

In the following paragraphs summarizing results, only those main effects and interactions shown statistically significant (5-percent level) by analyses of variance are discussed, tabulated, and graphed.

\section{Complete Tree With Cones and Foliage}

Moisture contents of the 76-, 152-, and 228-mm diameter classes averaged-with standard deviations in parentheses following-98.5 (27.8), 96.7 (19.4), and 94.6 (18.3) percent of ovendry weight. Low-elevation trees had less moisture content (94.7 percent) than those from medium- and highelevation zones (97.5 percent), but moisture varied with latitude. Trees at 40 through 45 degrees latitude had from 105 to 120 percent moisture content, while those from 50 through 60 degrees of latitude had only 73 to 96 percent moisture (fig. 2-2).

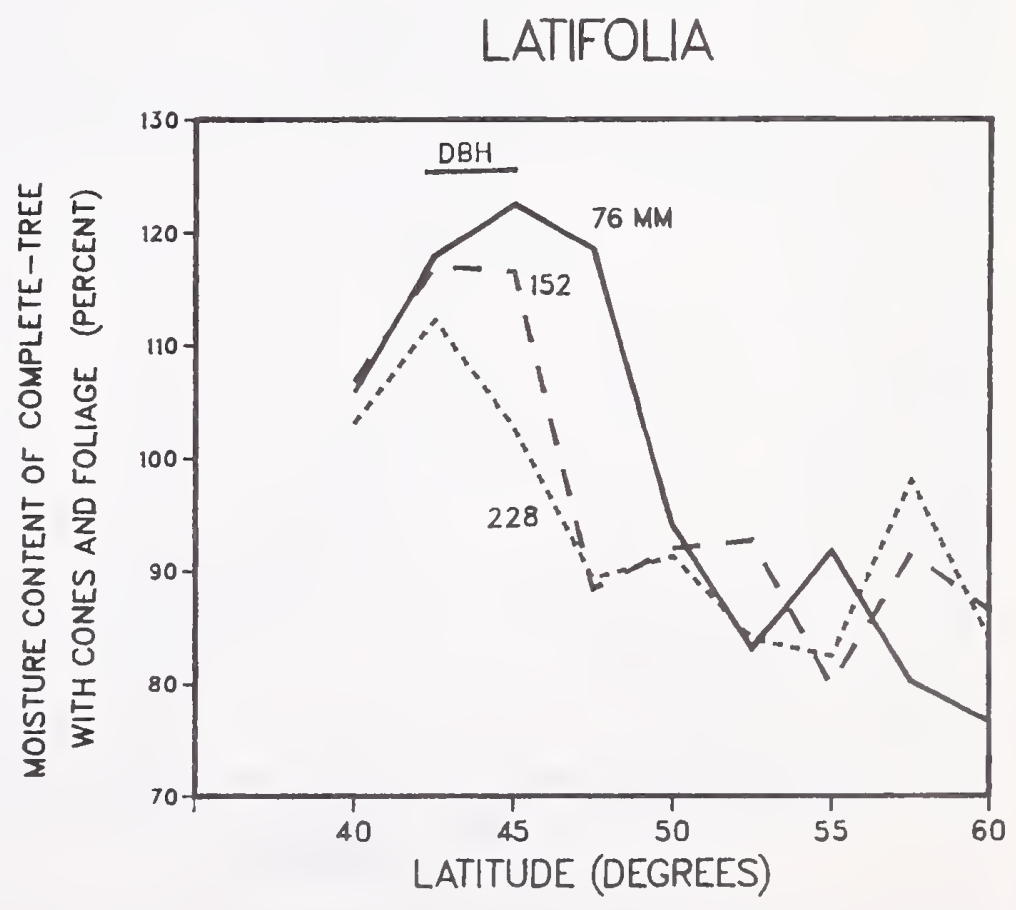

Figure 2-2-Moisture content of complete tree, with cones and foliage related to latitude for latifolia trees of three diameters. 
Correlations between moisture content of complete tree with cones and foliage and the following measured properties are of interest:

\section{Property}

$r$

Moisture content of stem, wood plus bark, at 20 percent of tree height

Moisture content of stemwood at $152 \mathrm{~mm}$ stump height

Moisture content of stump-root system, wood plus bark

Heartwood volume percent of stemwood volume

Moisture content of live branches, wood plus bark

Complete-tree bark specific gravity

$-.587$

Complete-tree wood specific gravity

Stemwood specific gravity

Sapwood specific gravity

$-.572$

$-.569$

$-.537$

Crown ratio

Heartwood diameter at $152 \mathrm{~mm}$ stump height

Sapwood thickness at $152 \mathrm{~mm}$ stump height

\section{Complete Tree Without Cones or Foliage}

Complete trees without cones or foliage, measuring 76 , 152 , and $228 \mathrm{~mm}$ in d.b.h., had average moisture contents of 98.5 (27.9), 96.7 (19.4), and 94.6 (18.3) percent. These moisture contents varied significantly with latitude, decreasing from 104 to 124 percent at 40 through 45 degrees, to 76 to 97 percent at 50 through 60 degrees (fig. 2-3).

\section{LATIFOLIA}

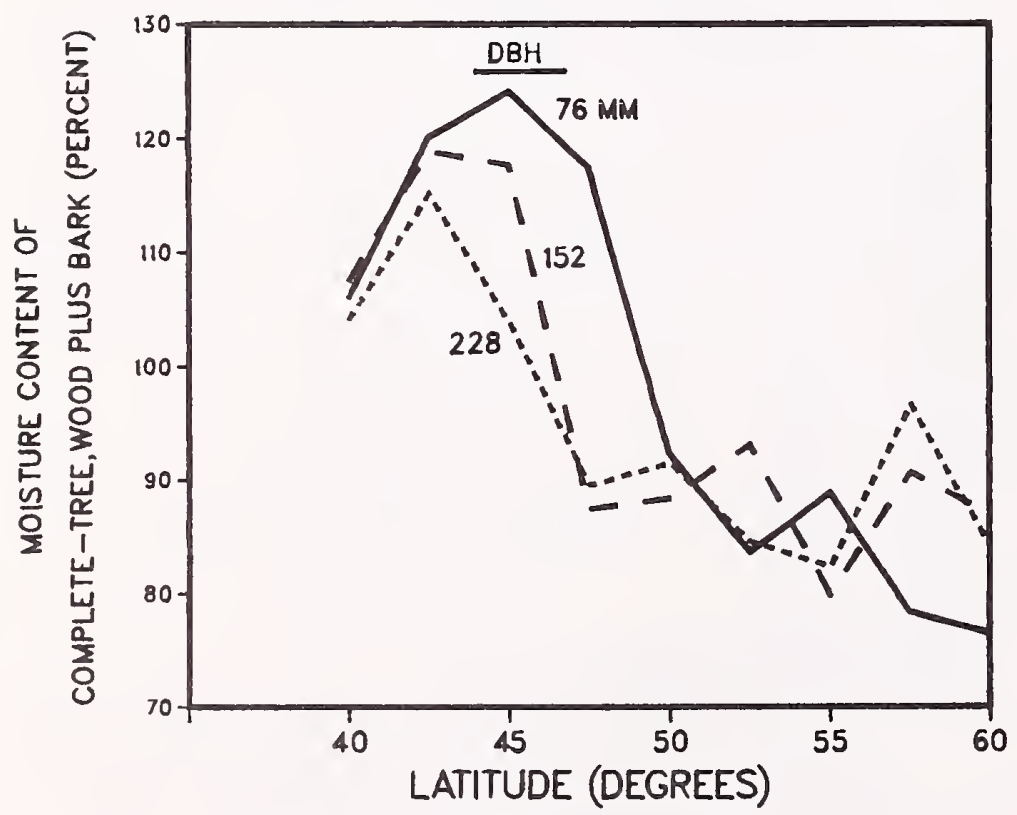

Figure 2-3-Moisture content of complete tree, wood plus bark-but without cones and foliage, related to latitude for latifolia trees of three diameters.
Correlations between moisture content of complete tree without cones or foliage and the following measured properties are of interest:

\section{Property}

$r$

Moisture content of stem, wood plus bark, at 20 percent of tree height

0.878

Moisture content of stemwood at $152 \mathrm{~mm}$ stump height

Moisture content of stump-root system, wood plus bark

Heartwood volume percent of stemwood volume

$-.745$

Moisture content of live branches, wood plus bark

Complete-tree wood specific gravity

$-.588$

Stemwood specific gravity

$-.586$

Complete-tree bark specific gravity $\quad-.577$

Sapwood specific gravity $\quad-.555$

Crown ratio $\quad .514$

Sapwood thickness at $152 \mathrm{~mm}$ stump height $\quad .440$

\section{Complete Tree, Wood Only}

Complete-tree wood in trees of the three diameter classes did not vary greatly in average moisture content; with latitudinal and elevational data pooled, complete-tree wood of the 76-, 152-, and 228-mm trees averaged 96.0 (28.9), 96.7 (20.5), and 95.0 (18.9) percent moisture content. Variation with latitude was substantial, however; at latitudes 40 through 45 degrees wood moisture contents were in the range from 103 to 121 percent, while at latitudes 50 through 60 degrees complete-tree wood moisture contents were much lower-72 to 96 percent (fig. 2-4). At low elevations, treewood averaged 94.7 percent moisture

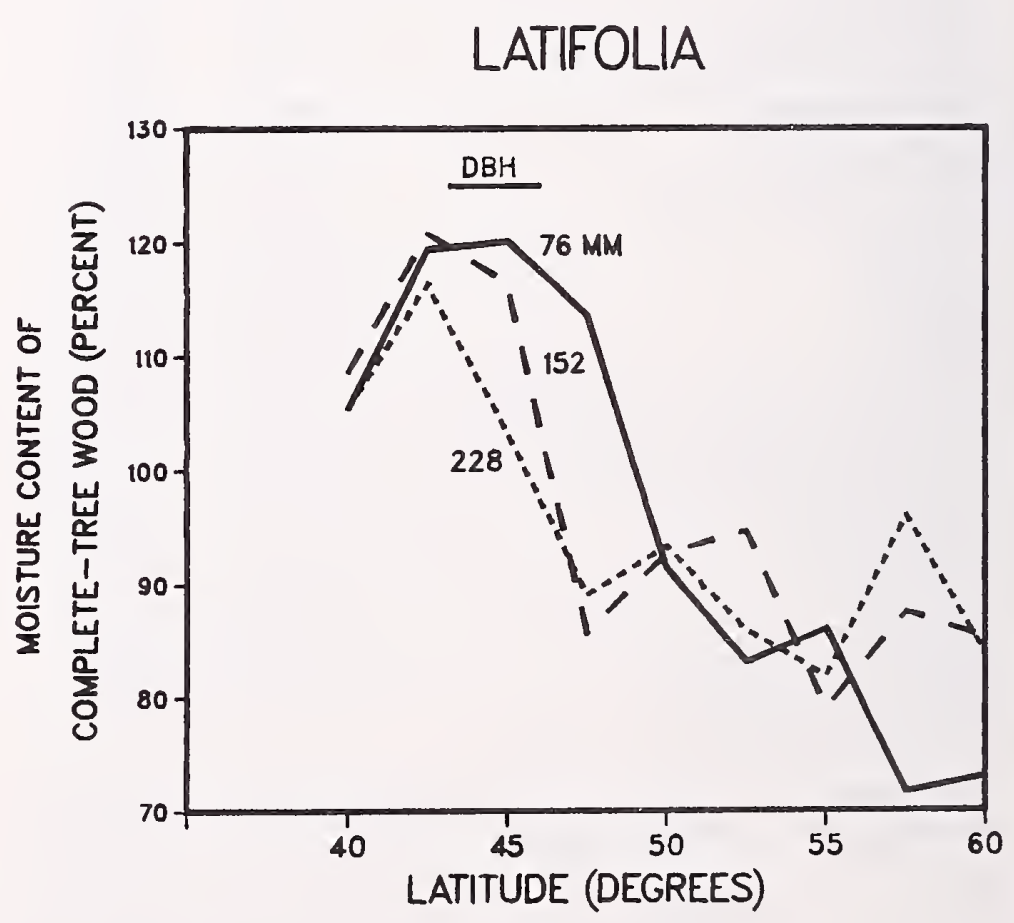

Figure 2-4-Moisture content of complete-tree wood related to latitude for latifolia trees of three diameters. 
content, while at medium and high elevation the average was 97.5 percent-a difference not significant at the 5 -percent level.

Correlations between moisture content of complete-tree wood and the following measured properties are of interest:

\section{Property}

Moisture content of stemwood at 20 percent of stem height

0.888

Moisture content of stemwood at $152 \mathrm{~mm}$ stump height

Moisture content of stump-root system, wood only

Moisture content of live branches, wood plus bark

Heartwood volume percentage of stemwood volume

Complete-tree wood specific gravity

Stemwood specific gravity

$-.604$

Sapwood specific gravity

Complete-tree bark specific gravity

Crown ratio

$-.566$

$-.501$

.492

Sapwood thickness at $152 \mathrm{~mm}$ stump height

\section{Complete Tree, Bark Only}

Moisture content of complete-tree bark (that of stem, stump-root, and branches) varied with latitude (fig. 2-5) and with elevational zone and diameter class, as follows:

\begin{tabular}{ccc}
$\begin{array}{c}\text { Elevational } \\
\text { zone }\end{array}$ & \multicolumn{2}{c}{$\begin{array}{c}\text { Average and } \\
\text { standard deviation }\end{array}$} \\
Low & $\ldots$ - Percent $\ldots .$. \\
Medium & 106.5 & $(26.2)$ \\
High & 104.9 & $(23.0)$ \\
& \multicolumn{2}{c}{ Average and } \\
D.b.h. & standard deviation \\
mm & $\ldots \ldots$ Percent - - \\
76 & 115.5 & $(28.0)$ \\
152 & 101.9 & $(22.2)$ \\
228 & 92.4 & $(19.7)$ \\
Average & 103.3 & $(25.3)$
\end{tabular}

Complete-tree bark moisture contents averaged highest at 45 degrees latitude (131 percent) and lowest at 52.5 degrees (81 percent) (fig. 2-5).
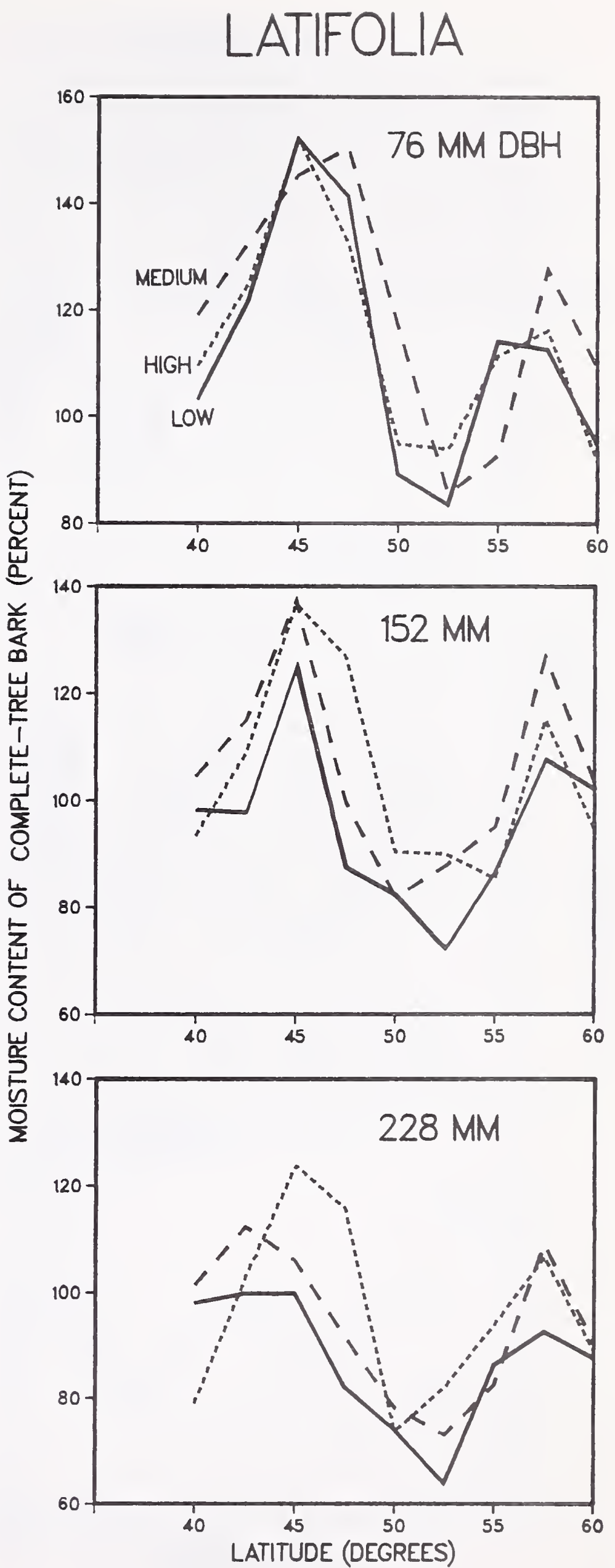

Figure 2-5-Moisture content of complete-tree bark related to elevational zone and latitude for latifolia trees of three diameters. 
LATIFOLIA
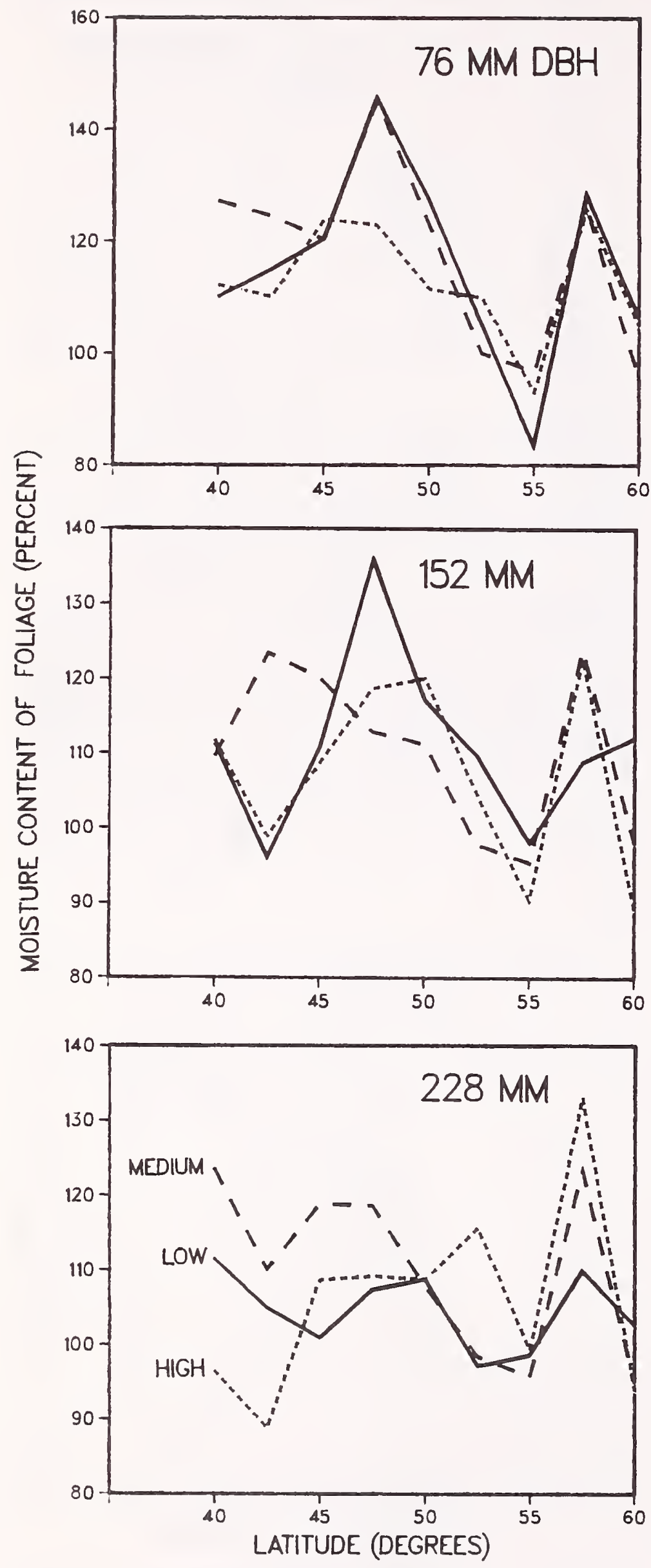

Correlations between moisture content of complete-tree bark and the following measured properties are of interest:

\section{Property $\quad r$}

Moisture content of stembark $\quad 0.977$

Complete-tree bark specific gravity $\quad-.832$

Moisture content of stembark at 20 percent of tree height

Moisture content of stembark at $152 \mathrm{~mm}$ stump height

Moisture content of live branchbark

.746

Moisture content of stump-root system, bark only

Heartwood volume percentage of stemwood volume

Heartwood diameter at $152 \mathrm{~mm}$ stump height

Crown ratio

Tree height

\section{Foliage}

Trees of small diameter had foliage with the highest moisture content, as follows:

\begin{tabular}{ccc} 
D.b.h. & \multicolumn{2}{c}{$\begin{array}{c}\text { Average moisture content } \\
\text { and standard deviation }\end{array}$} \\
$m m$ & 115.4 & $(17.5)$ \\
76 & 109.5 & $(14.9)$ \\
152 & 106.9 & $(15.1)$ \\
228 & 110.6 & $(16.2)$
\end{tabular}

Foliage from medium elevational zones averaged highest moisture content (average 112.7 percent), but elevational effects varied with latitude (fig. 2-6).

Correlations between foliage moisture content and measured properties were weak; those of interest follow:

\section{Property}

Moisture content of live branchbark

0.462

Moisture content of complete tree, bark only

.422

Specific gravity of complete-tree bark

$-.355$

Crown ratio

.310

Tree age

Tree height 


\section{Cones}

Cones from trees 76,152 , and $228 \mathrm{~mm}$ in d.b.h. had average moisture contents of 29.1 (27.8), 26.4 (20.0), and 23.7 (16.0) percent, but moisture content varied widely with latitude (fig. 2-7). With all data pooled, the average was 25.8 percent, with standard deviation of 20.4 percent.

Cone moisture content had little correlation with other measured tree properties; closest correlations are as follows:

\section{Property}

$r$

Moisture content of live branches, wood plus bark

Moisture content of dead

branchwood

Stump-root wood volume as percentage of treewood volume

\section{LATIFOLIA}

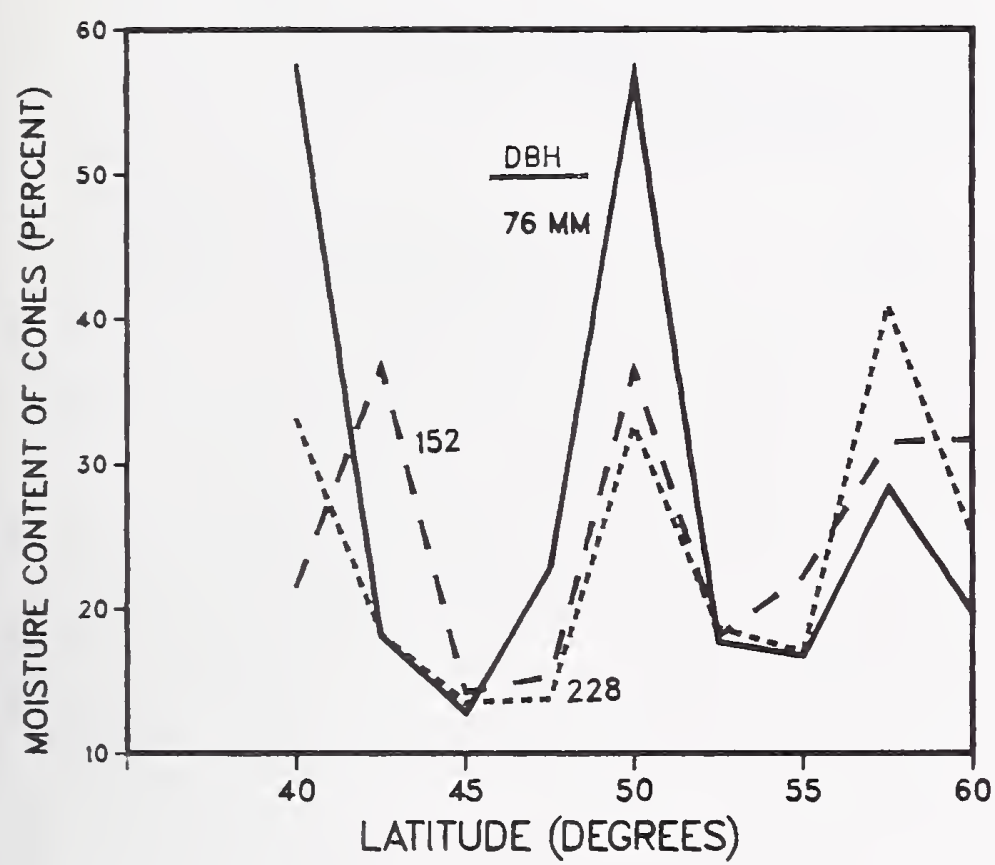

Figure 2-7-Moisture content of cones of latifolia trees of three diameter classes related to latitude.

\section{Dead Branchwood}

Moisture content of dead branchwood did not vary significantly with diameter but did vary with latitude (fig. 2-8); moisture content was lowest at 45 degrees latitude (14 percent) and highest at 57.5 degrees (28 percent). With all data pooled, dead branchwood averaged 18.2 percent moisture content, with standard deviation of 9.9 percent.

As with cones, moisture content of dead branchwood was poorly correlated with other measured tree properties; closest correlations were as follows:

\section{Property}

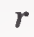

Moisture content of foliage

0.256

Moisture content of cones

Dead branchwood percent of completetree wood volume

\section{LATIFOLIA}

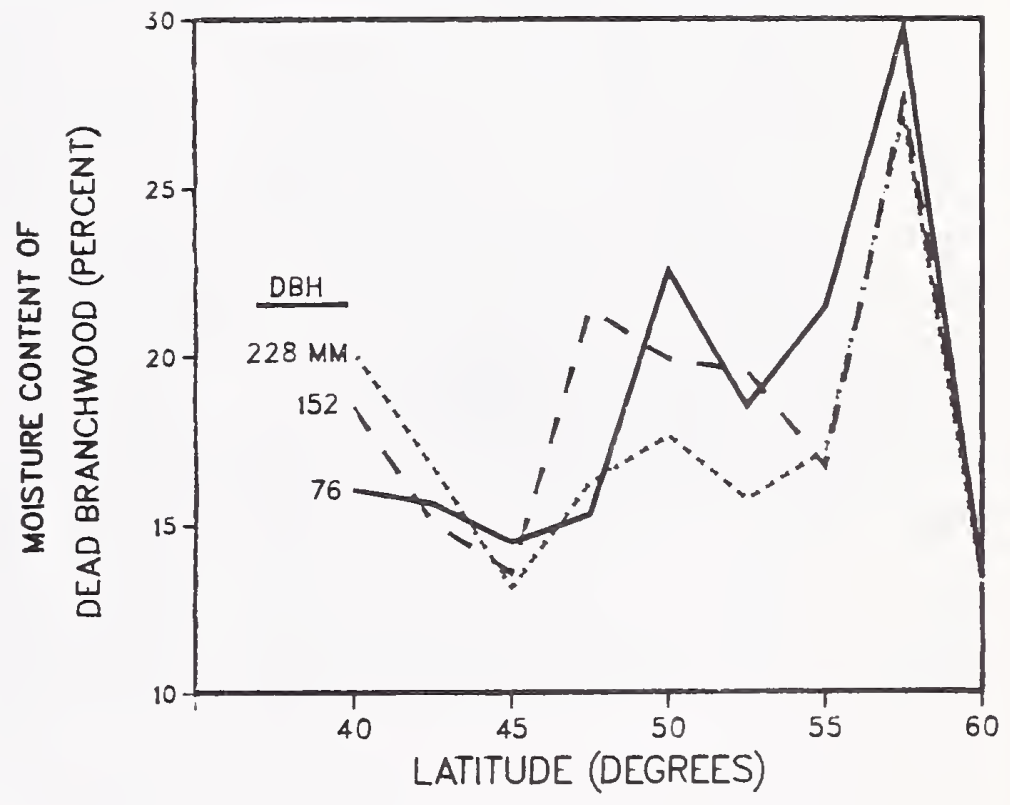

Figure 2-8-Moisture content of dead branchwood related to latitude for latifolia trees of three diameters. 


\section{Live Branches, Wood Plus Bark}

The moisture content of foliage-free live branches (wood plus bark) did not vary significantly with d.b.h. or with elevational zone but did vary with latitude (fig. 2-9); moisture contents were highest at latitude 42.5 degrees (106 percent) and lowest at 60 degrees (83 percent). With all data pooled, live branches (wood plus bark) had average moisture content of 94.2 percent, with standard deviation of 15.9 percent.

Correlations between moisture content of live branches (wood plus bark) and the following measured properties are of interest:

\section{Property}

Moisture content of complete tree with cones and foliage

0.733

Moisture content of branch-free stem, wood plus bark

Moisture content of stem, wood plus bark, at 50 percent of tree height

Moisture content of stem, wood plus bark, at $152 \mathrm{~mm}$ stump height

Moisture content of stump-root system, wood plus bark

Heartwood volume as percentage of stemwood volume

Specific gravity of live branchwood

Specific gravity of complete-tree wood

Specific gravity of stemwood

Specific gravity of complete-tree bark

Specific gravity of sapwood

Sapwood thickness at $152 \mathrm{~mm}$ stump height
$-.542$

$-.532$

$-.481$

$-.467$

$-.457$

$-.447$

.409
LATIFOLIA

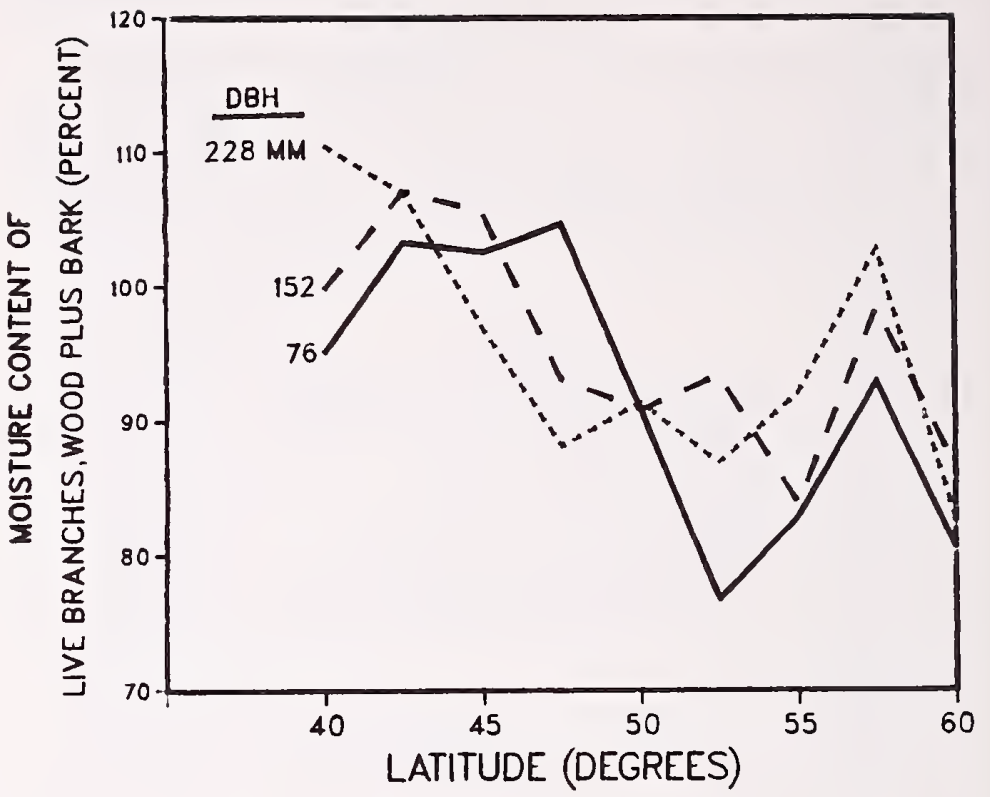

Figure 2-9-Moisture content of live branches, wood plus bark, related to latitude for latifolia trees of three diameters. 


\section{Live Branchwood}

Branchwood moisture content in trees of 76-, 152-, and 228-mm d.b.h. averaged 84.2 (17.9), 90.4 (17.1), and 91.1 (16.4) percent. In low-, medium-, and high-elevation zones branchwood averaged $90.5,88.9$, and 86.3 percent moisture content, but varied with latitude (fig. 2-10). Branchwood moisture content had highest moisture content at 42.5 degrees (104 percent) and lowest at 60 degrees (77 percent).

Correlations between moisture content of live branchwood and the following properties are of interest:

\section{Property}

Specific gravity of live branchwood

Moisture content of complete-tree wood

$-0.629$

Moisture content of sapwood

.599

.583

Moisture content of stemwood

.575

Moisture content of stemwood at 70 percent of tree height

Moisture content of stemwood at $152 \mathrm{~mm}$ stump height

Moisture content of lateral roots, wood only

Heartwood volume as percentage of stemwood volume

Specific gravity of complete-tree wood

Specific gravity of stemwood
LATIFOLIA
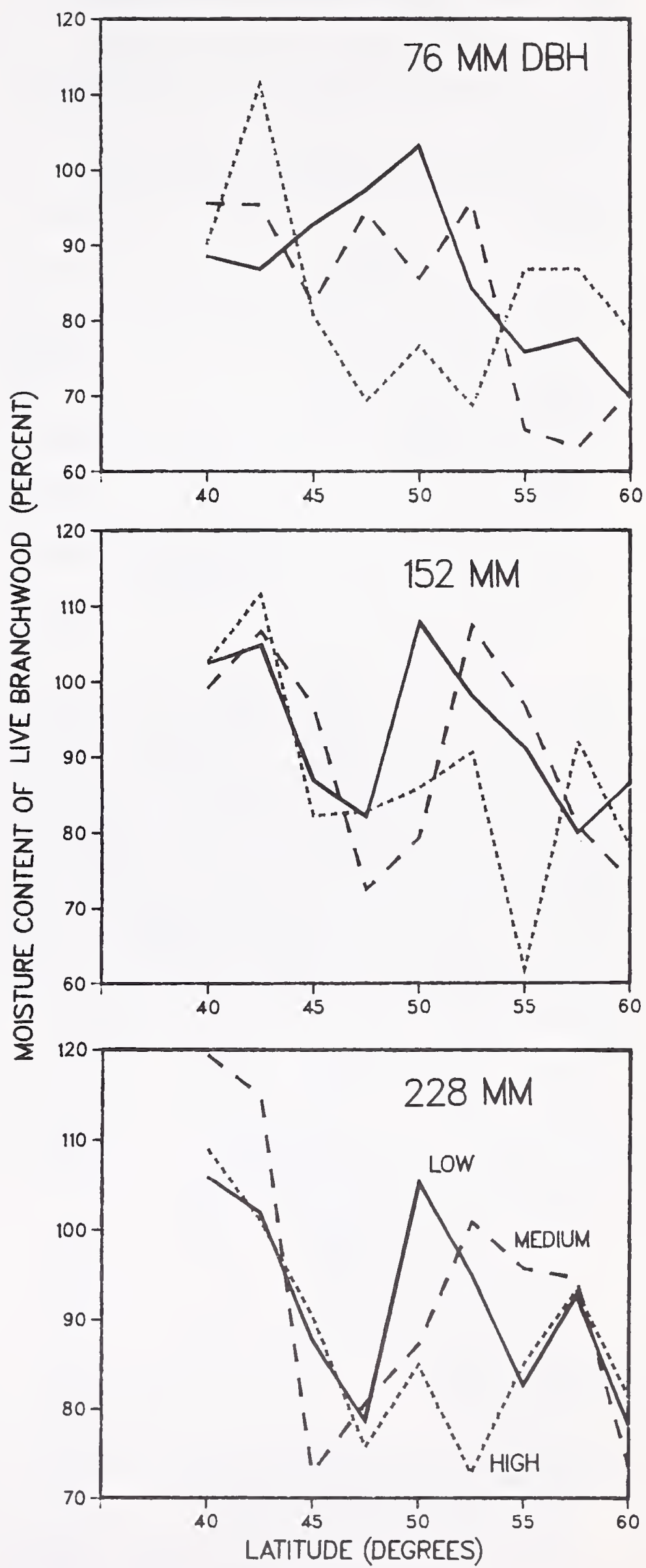

Figure 2-10-Moisture content of live branchwood related to latitude and to elevational zone for latifolia trees of three diameters. 


\section{Live Branchbark}

The moisture content of the bark of live branches averaged 106.4 percent, with standard deviation of 25.8 percent, and varied significantly only with latitude (fig. 2-11). Branchbark moisture content averaged highest at 45 degrees (132 percent) and lowest at 52.5 degrees (79 percent).

Correlations between moisture content of live branchbark and the following measured properties are of interest:

\section{Property}

Specific gravity of complete-tree bark $-0.679$

Moisture content of stembark at 50 percent of tree height

Moisture content of stembark

Moisture content of complete tree with cones and foliage

Moisture content of stump-root system, bark only

Moisture content of stemwood

Crown ratio

Heartwood volume percent of stemwood volume

\section{Stem, Wood Plus Bark-Tree Average}

The moisture content of branch-free stems, wood plus bark, averaged 99.4 percent, with standard deviation of 24.5 percent. Trees 76,152 , and $228 \mathrm{~mm}$ in d.b.h. averaged 100.9 (30.6), 100.1 (21.9), and 97.2 (19.9) percent moisture content, but varied with latitude (fig. 2-12).

Stems had highest moisture content at 42.5 degrees (122 percent) and lowest at 60 degrees (85 percent).

Correlations between tree-average moisture content of stem (wood plus bark) and the following measured properties are of interest:

\section{Property}

Moisture content of complete tree with cones and foliage

Moisture content of stem (wood plus bark)

at 20 percent of tree height

Moisture content of stem (wood plus bark) at $152 \mathrm{~mm}$ stump height

Moisture content of stump-root system, wood plus bark

Heartwood volume as percentage of stemwood volume

Moisture content of live branches, wood plus bark

Specific gravity of stemwood

Specific gravity of complete-tree wood

$-.574$

Specific gravity of complete-tree bark

$-.559$

Sapwood specific gravity

$-.551$

Crown ratio
LATIFOLIA

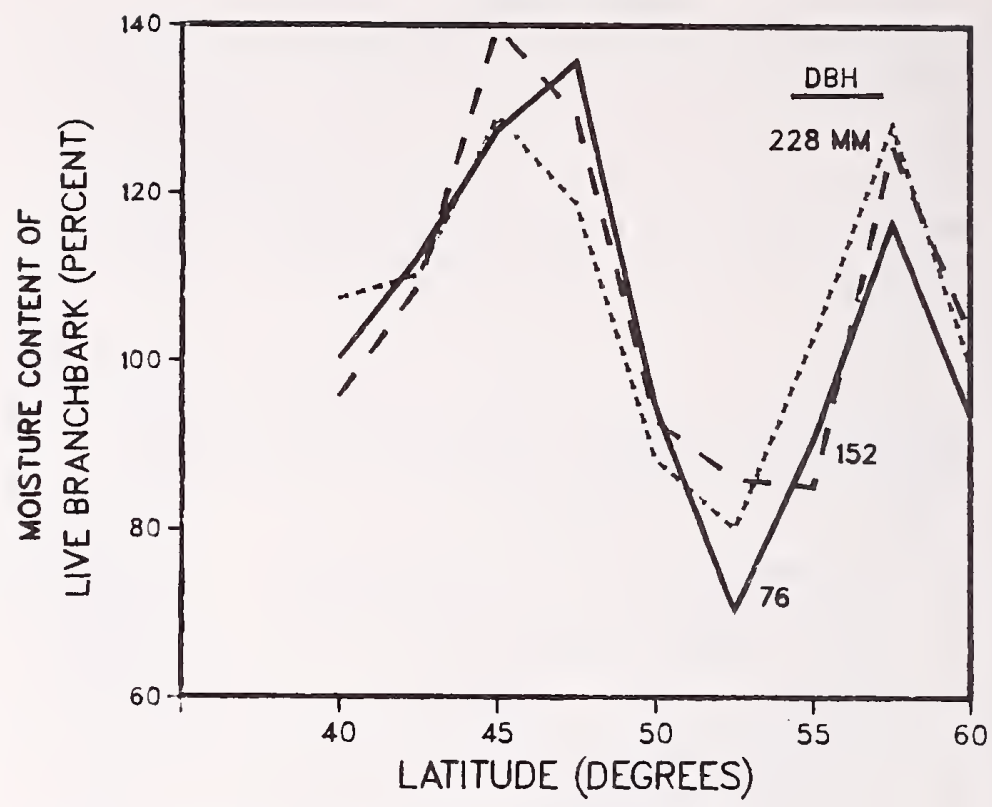

Figure 2-11-Moisture content of live branchbark related to latitude for latifolia trees of three diameters.

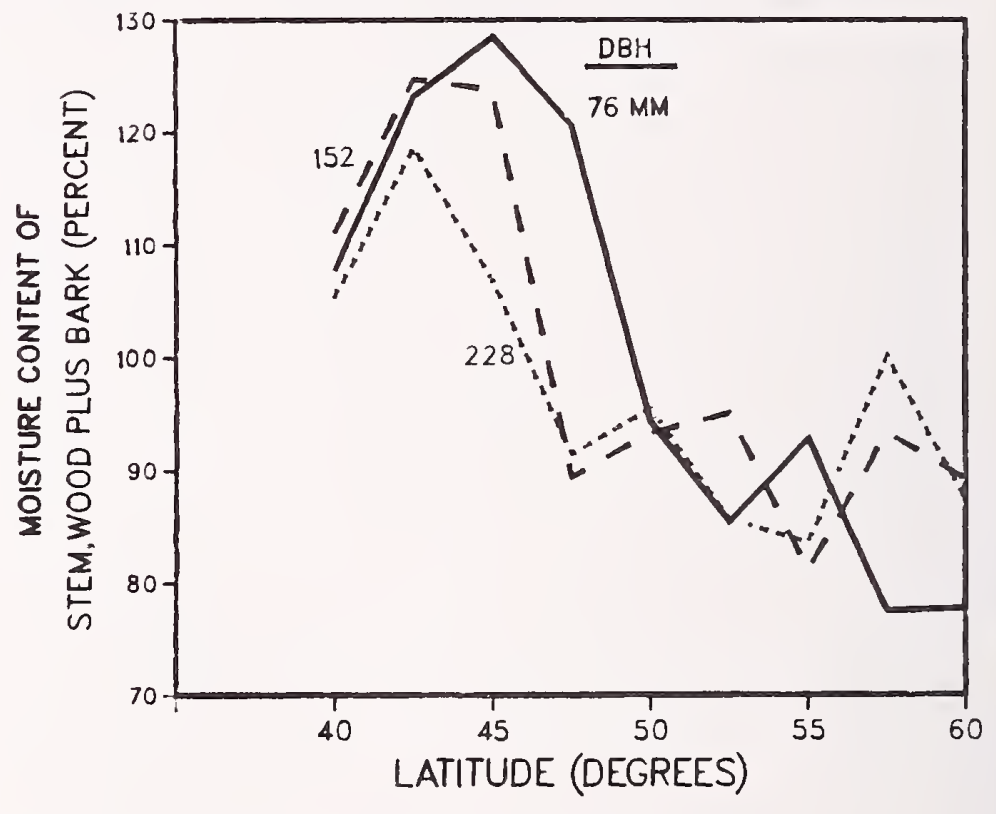

Figure 2-12-Moisture content of branch-free stem, wood plus bark, related to latitude for latifolia trees of three diameters. 


\section{Stem, Wood Plus Bark-Variation With Height}

Moisture content of stems, wood plus bark, was positively correlated with height in tree, with minimum of 89 percent at stump-top level, and increasing to 137 percent at 90 percent of tree height; at the apical tip tissues averaged 187 percent moisture content (fig. 2-13). Latitudinal effects on moisture content of the branch-free stem (wood plus bark) were similar at all heights in the trees

(fig. 2-14).

Of the tree heights for which correlations were analyzed $(0,20,50$, and 70 percent of tree height from stump top to apical tip), the moisture content at 20 percent height provided the closest correlations for most moisture contents of interest, as follows (except for live branch moisture content-which was best correlated with 50 percent height where $r=0.664$; and moisture content of wood and bark of the stump-root system-which were best correlated with 0 percent height where $r=0.752$ ):

\section{Property}

$r$
0.885
.878

.870
.783

Moisture contents of stem (wood plus bark) at 0,20 , and 50 percent heights were a little more closely correlated with heartwood volume as a percentage of stemwood volume $(-0.779,-0.774,-0.787)$ than the moisture content at 70 percent height $(r=-0.734)$.

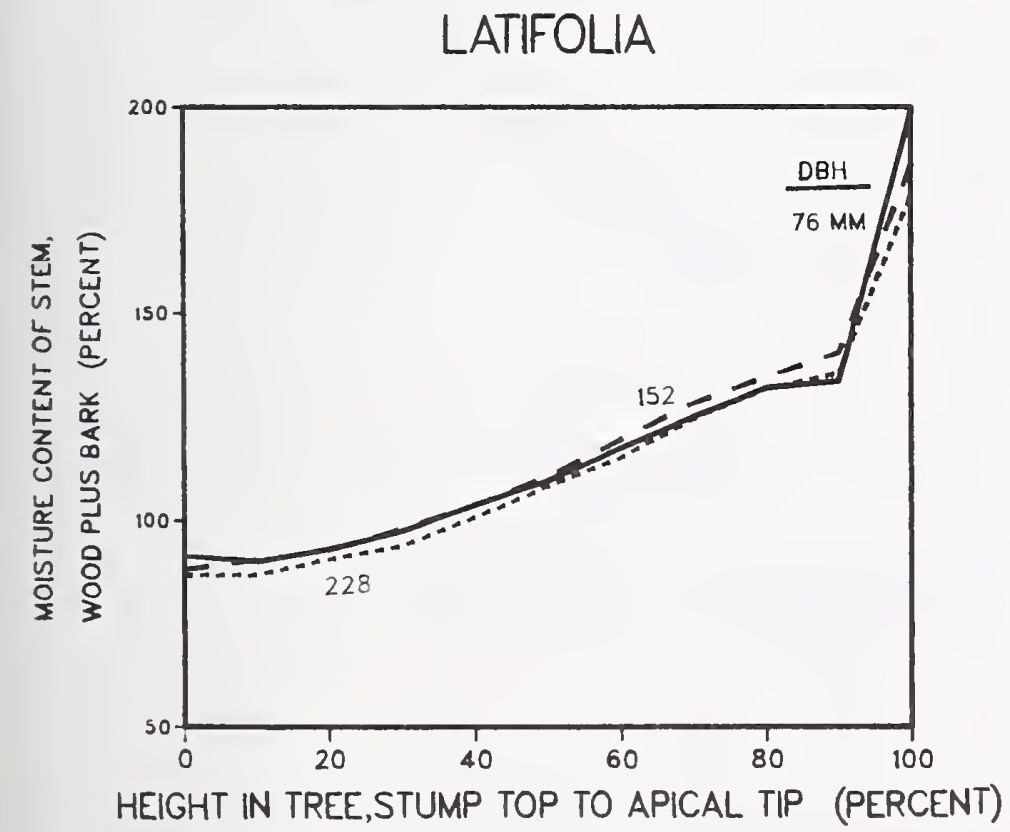

Figure 2-13-Moisture content of branch-free stem, wood plus bark, related to height in tree for latifolia trees of three diameters.
LATIFOLIA

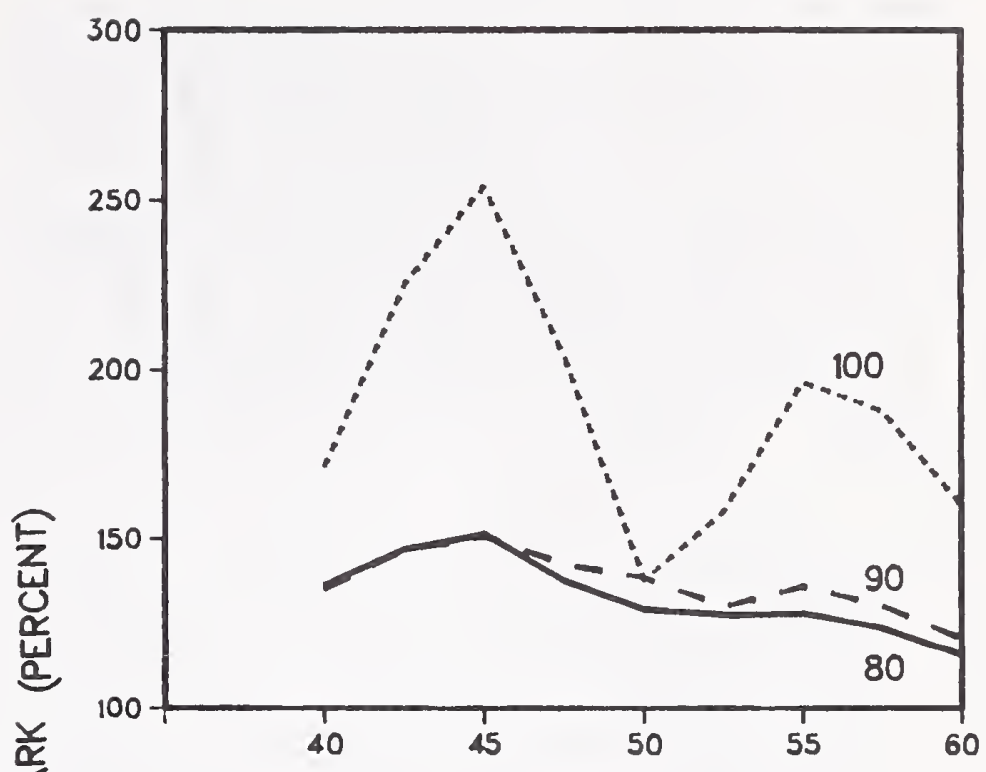

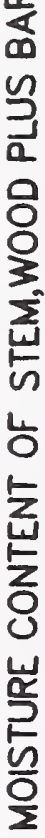
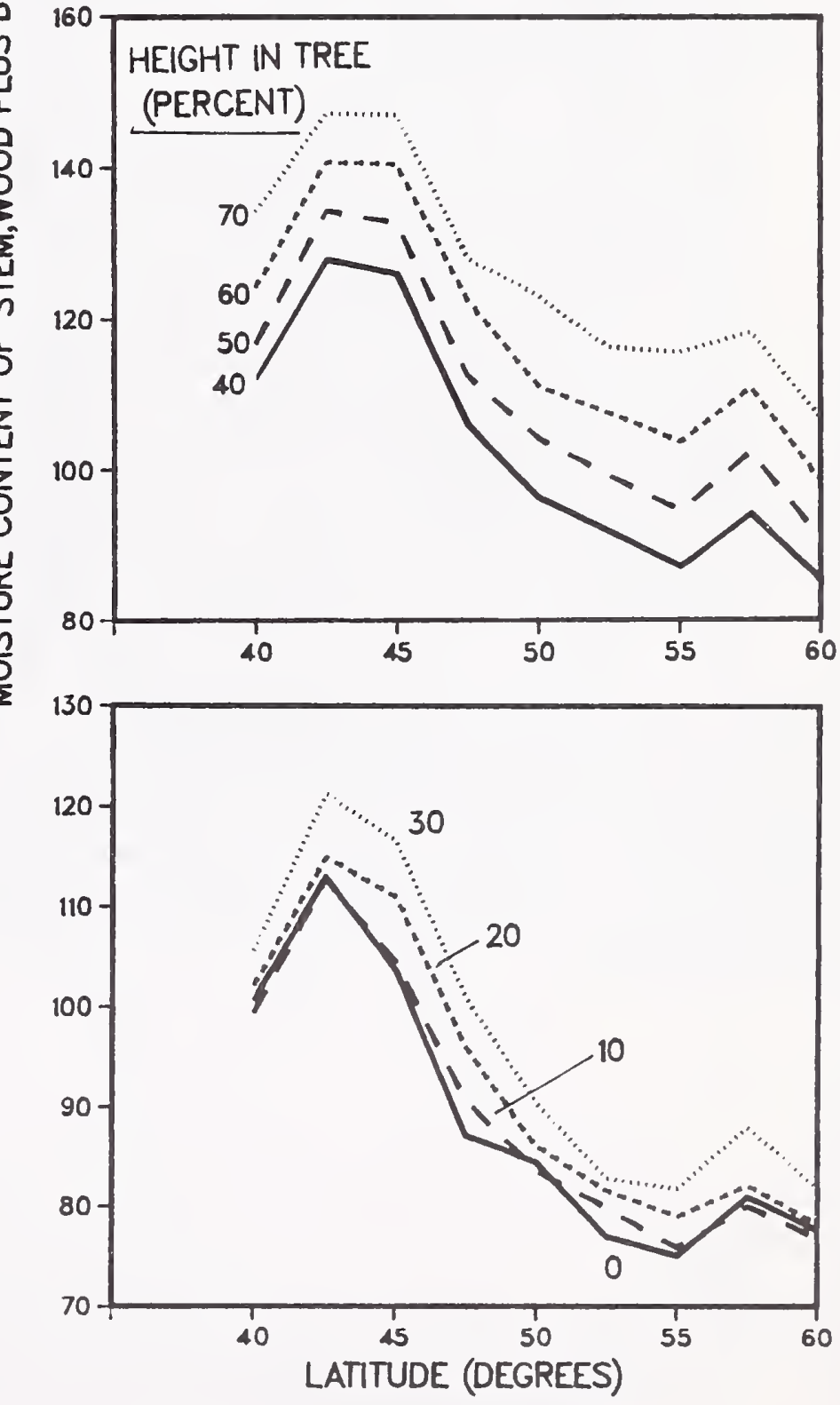

Figure 2-14-Moisture content of branch-free stem, wood plus bark, related to height in tree and to latitude, with data from the three diameter classes of latifolia trees pooled. 


\section{Stemwood-Tree Average}

Stemwood of the trees had average moisture content of 98.9 percent, with standard deviation of 25.4 percent. By d.b.h. the averages did not differ appreciably but did differ with latitude (fig. 2-15). In southern latitudes the 76-mm trees had high moisture content but in northern latitudes had lowest moisture content. With diameter data pooled, stemwood moisture content was highest at 42.5 degrees (124 percent) and lowest at 60 degrees (83 percent).

Correlations between tree-average moisture content of stemwood and the following measured properties are of interest:

\begin{tabular}{|c|c|}
\hline Property & $\boldsymbol{r}$ \\
\hline $\begin{array}{l}\text { Moisture content of complete tree without } \\
\text { cones or foliage }\end{array}$ & 0.992 \\
\hline $\begin{array}{l}\text { Moisture content of complete tree with } \\
\text { cones and foliage }\end{array}$ & .972 \\
\hline $\begin{array}{l}\text { Moisture content of stemwood at } 20 \text { percent } \\
\text { of tree height }\end{array}$ & .891 \\
\hline Moisture content of sapwood & .886 \\
\hline $\begin{array}{l}\text { Moisture content of stemwood at } 152 \mathrm{~mm} \\
\text { stump height }\end{array}$ & .859 \\
\hline $\begin{array}{l}\text { Moisture content of wood of stump-root } \\
\text { system }\end{array}$ & .794 \\
\hline $\begin{array}{l}\text { Heartwood volume as percentage of stem- } \\
\text { wood volume }\end{array}$ & -.722 \\
\hline $\begin{array}{l}\text { Moisture content of live branches, wood plus } \\
\text { bark }\end{array}$ & .695 \\
\hline Specific gravity of stemwood & -.600 \\
\hline Specific gravity of complete-tree wood & -.595 \\
\hline Specific gravity of sapwood & -.566 \\
\hline Specific gravity of complete-tree bark & -.498 \\
\hline Crown ratio & .492 \\
\hline Sapwood thickness at $152 \mathrm{~mm}$ stump height & .473 \\
\hline
\end{tabular}

\section{Stemwood-Variation With Height}

Stemwood moisture content was about 90 percent at stump height and at 10 percent of tree height; above these heights moisture content increased to 130 percent in the upper stem (fig. 2-16). The decrease in stemwood moisture content in northerly latitudes was evident at all heights in the stem (fig. 2-17).
LATIFOLIA

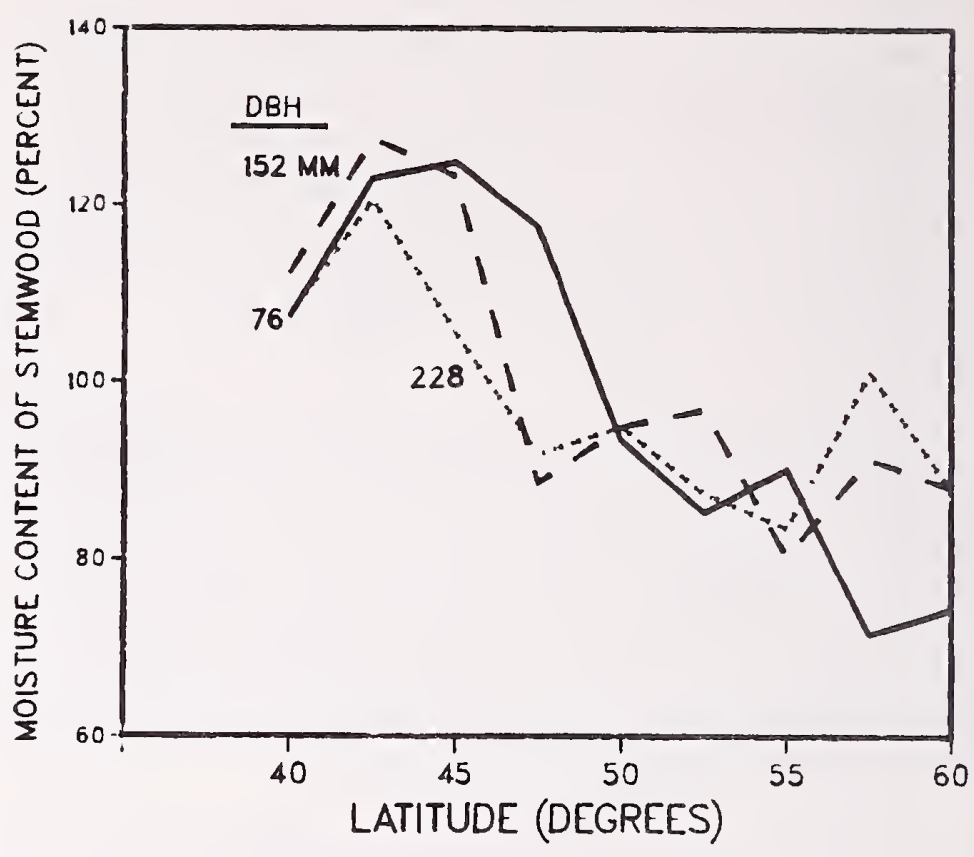

Figure 2-15-Moisture content of stemwood related to latitude for latifolia trees of three diameters.

\section{LATIFOLIA}

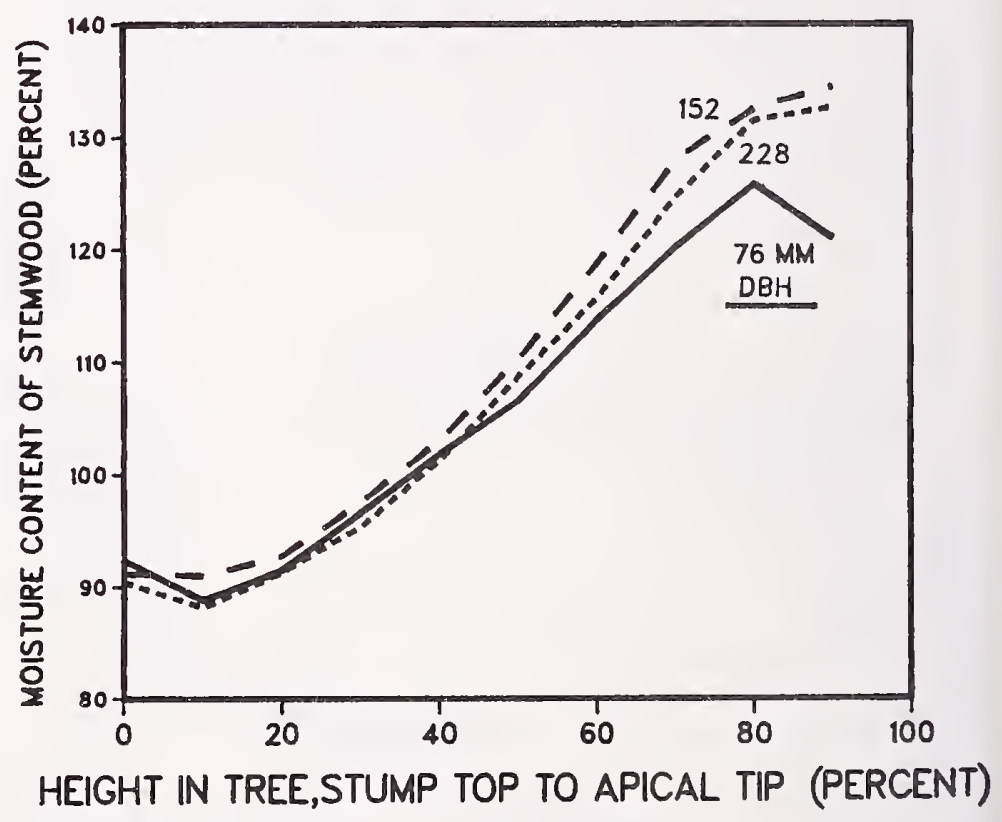

Figure 2-16-Moisture content of stemwood related to height in tree for latifolia trees of three diameters. 
The moisture content of wood of the stump-root system was best correlated with stemwood moisture content at $152 \mathrm{~mm}$ stump height ( $r=0.756$ ); that of live branchwood was best correlated with stemwood moisture content at 70 percent height ( $r=0.572$ ).

Stemwood moisture content at 20 percent of tree height was more closely correlated with moisture contents of entire stemwood $(r=0.891)$, complete-tree wood $(r=0.888)$, and sapwood ( $r=0.801)$ than stemwood moisture contents at 0,50 , or 70 percent of tree height.

Stemwood moisture content at $152 \mathrm{~mm}$ stump height was more closely correlated with stemwood specific gravity $(r=-0.643)$ and heartwood volume percent of stemwood volume $(r=-0.771)$ than stemwood moisture contents at 20,50 , or 70 percent of tree height.
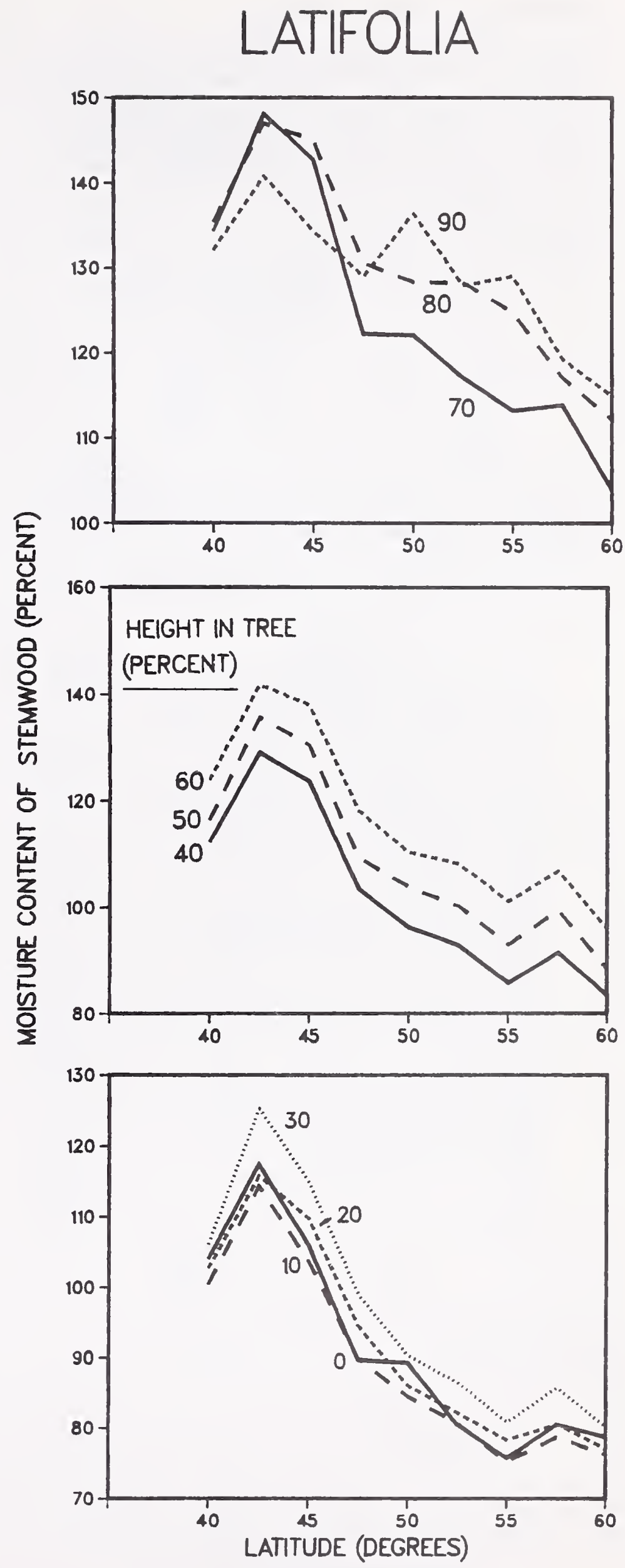

Figure 2-17-Moisture content of stemwood related to height in tree and to latitude, with data from the three diameter classes of latifolia trees pooled. 


\section{Stembark-Tree Average}

Stembark had slightly higher moisture content than stemwood, averaging 101.9 percent, with standard deviation of 28.6 percent. Stembark moisture content was inversely correlated with d.b.h., averaging 118.8 (31.2), 100.9 (23.6), and $86.2(20.1)$ percent for d.b.h. classes of 76,152 , and $228 \mathrm{~mm}$.

Stembark moisture content also varied significantly with elevational zone, as follows:

\begin{tabular}{lrr}
$\begin{array}{c}\text { Elevational } \\
\text { zone }\end{array}$ & $\begin{array}{c}\text { Average moisture content } \\
\text { and standard deviation }\end{array}$ \\
Low & \multicolumn{2}{c}{. - . Percent $\ldots$. . . } \\
Medium & 97.1 & $(29.9)$ \\
High & 105.1 & $(30.2)$ \\
& 103.1 & $(25.2)$
\end{tabular}

Stembark moisture content also varied with latitude (fig. 2-18); it was highest at 45 degrees (131 percent) and lowest at 52.5 degrees ( 80 percent).

Correlations between tree-average moisture content of stembark and the following measured properties are of interest:

\section{Property}

Moisture content of complete-tree bark

Moisture content of stembark at 20 percent of tree height

0.977

Specific gravity of complete-tree bark

Moisture content of stembark at $152 \mathrm{~mm}$ stump height

Moisture content of bark of stump-root system

Moisture content of live branchbark

Heartwood diameter at $152 \mathrm{~mm}$ stump height

Heartwood volume as percentage of stem wood volume

Tree height

$-.516$

Stem weight (wood plus bark), ovendry

Complete-tree bark as percentage of complete-tree volume

$-.493$

Weight of stump-root system, ovendry

D.b.h.

$-.471$

$-.469$

Crown ratio

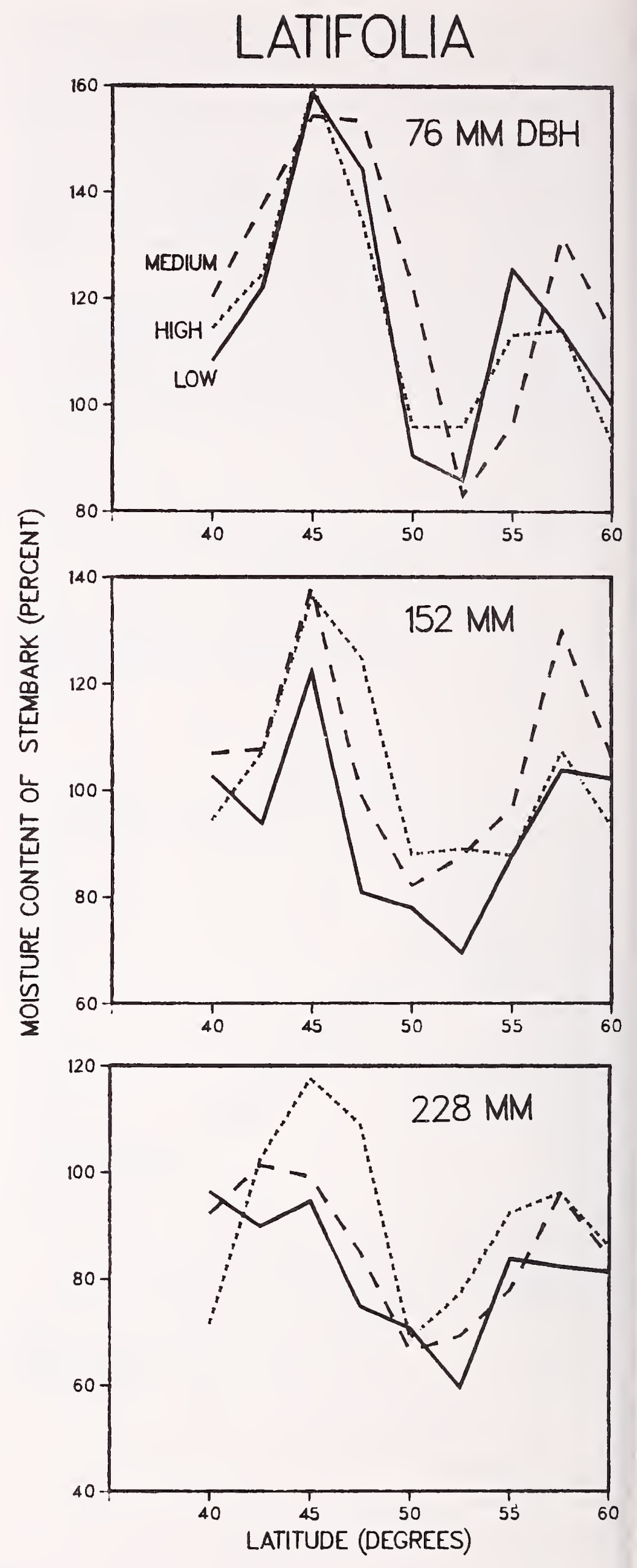

Figure 2-18-Moisture content of stembark related to latitude and to elevational zone for latifolia trees of three diameters. 


\section{Stembark-Variation With Height}

Stembark moisture content was lowest at stump height (72 percent average) and increased more or less linearly with height in tree to 165 percent average in the upper stem (fig. 2-19). Latitudinal trends were similar for all heights in the stem (fig. 2-20).

Of the heights analyzed $(0,20,50$, and 70 percent), moisture content of stembark at 20 percent of tree height was most closely correlated with the following properties of interest:

\section{Property}

$\boldsymbol{r}$

Moisture content of stembark, tree average

0.826

Specific gravity of complete-tree bark

$-.821$

Heartwood volume as percentage of stemwood volume

Moisture content of complete tree with cones and foliage

Moisture content of live branchbark was best correlated with stembark moisture content at 50 percent of tree height ( $r=0.639$ ). Moisture content of the stump-root system was best correlated with moisture content of the stembark at $152 \mathrm{~mm}$ stump height $(r=0.567)$.

\section{LATIFOLIA}

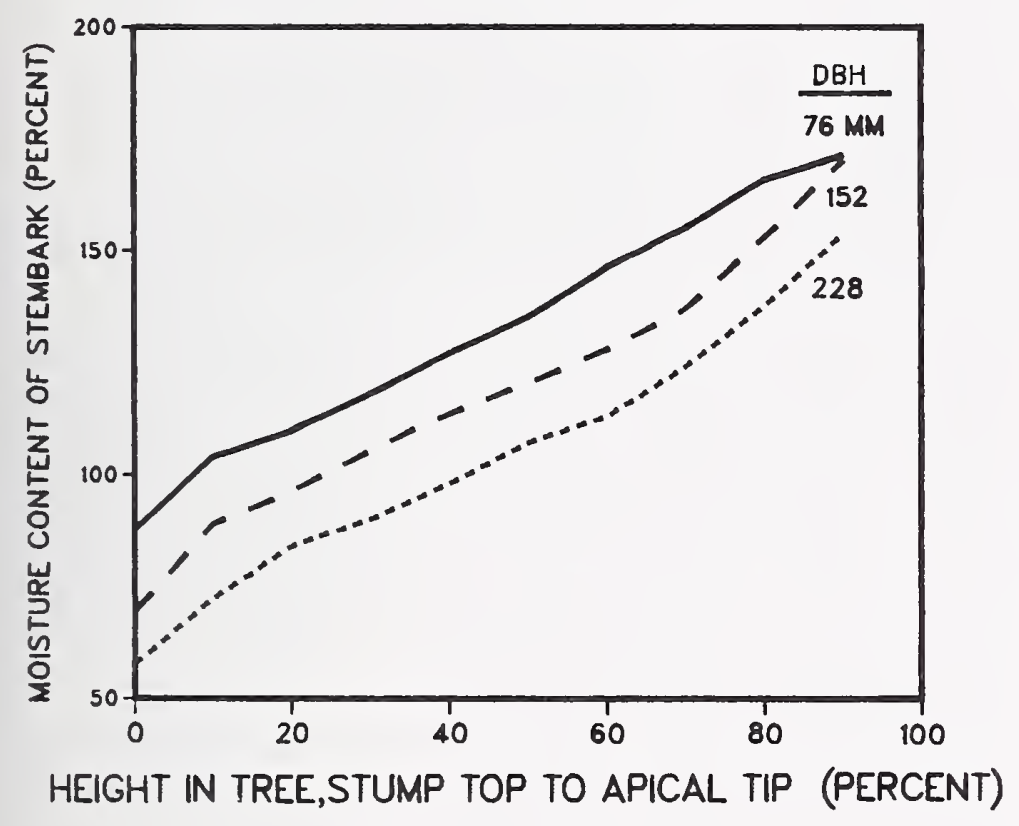

Figure 2-19-Moisture content of stembark related to height in tree for latifolia trees of three diameters.
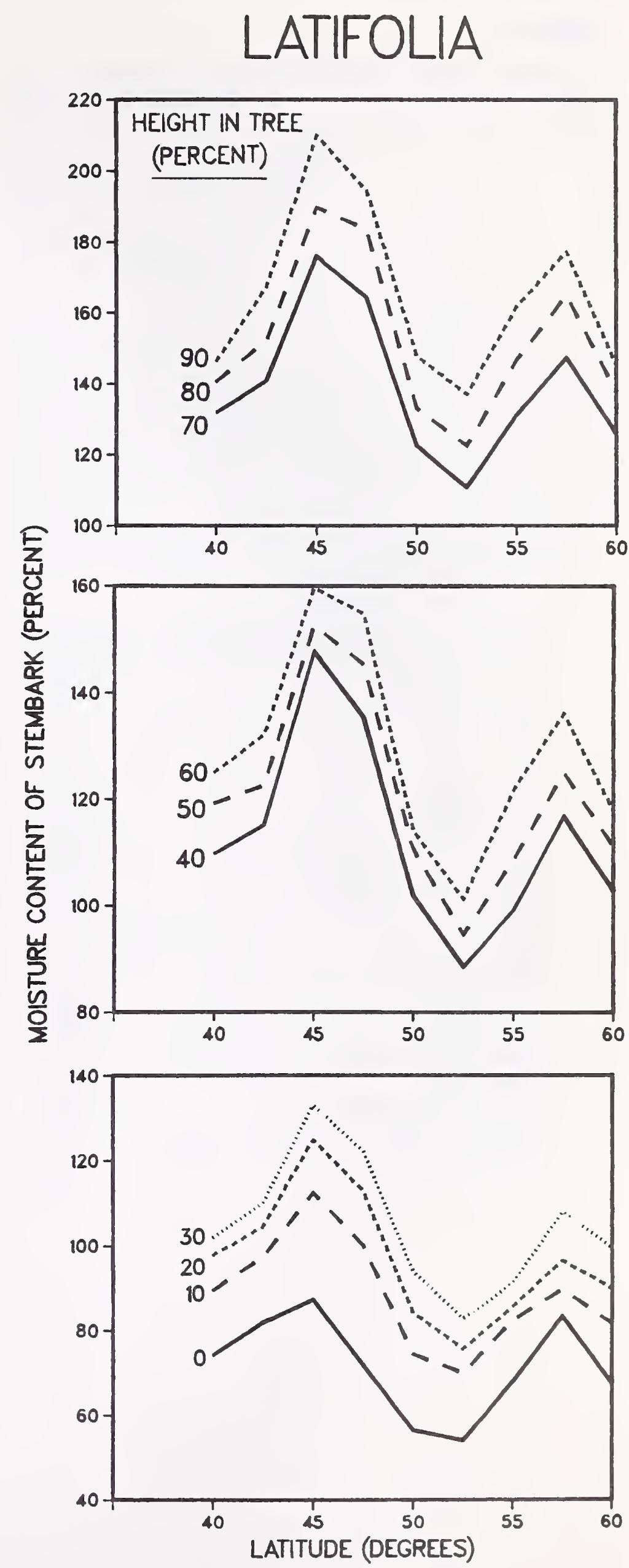

Figure 2-20-Moisture content of stembark related to height in tree and to latitude, with data from the three diameter classes of latifolia trees pooled. 


\section{Sapwood}

Sapwood moisture content averaged 119.3 percent, with standard deviation of 23.1 percent. The smallest trees had lowest sapwood moisture content, as follows:

\begin{tabular}{|c|c|c|}
\hline \multirow{2}{*}{$\begin{array}{c}\text { D.b.h. } \\
m m \\
76\end{array}$} & \multicolumn{2}{|c|}{$\begin{array}{c}\begin{array}{c}\text { Moisture content } \\
\text { and standard deviation }\end{array} \\
\ldots . . \text { - Percent } \ldots . . .\end{array}$} \\
\hline & 110.1 & (28.5) \\
\hline 15 & 121.7 & (18.6) \\
\hline 228 & 126.1 & $(17.7)$ \\
\hline
\end{tabular}

This relationship changed at 45 degrees latitude where trees of all three diameters had sapwood with the same moisture content, and at 47.5 degrees where sapwood moisture content was higher in $76-\mathrm{mm}$ trees than in 228-mm trees (fig. 2-21). Sapwood moisture content averaged highest at latitude 42.5 degrees (139 percent) and lowest at 55 degrees (108 percent).

Correlations between sapwood moisture content and the following measured properties are of interest:

\section{Property}

Moisture content of complete-tree wood

Moisture content of complete tree with cones and foliage

Moisture content of stemwood at 20 percent of tree height

Moisture content of stemwood at $152 \mathrm{~mm}$ stump height

Specific gravity of stemwood

Specific gravity of complete-tree wood

$-.689$

$-.679$

Specific gravity of sapwood

$-.678$

Moisture content of live branches, wood plus bark

Moisture content of stump-root system, wood plus bark

Sapwood thickness at $152 \mathrm{~mm}$ stump height

Heartwood volume as percentage of stemwood volume

Specific gravity of live branchwood

Live branchwood as percentage of completetree wood volume

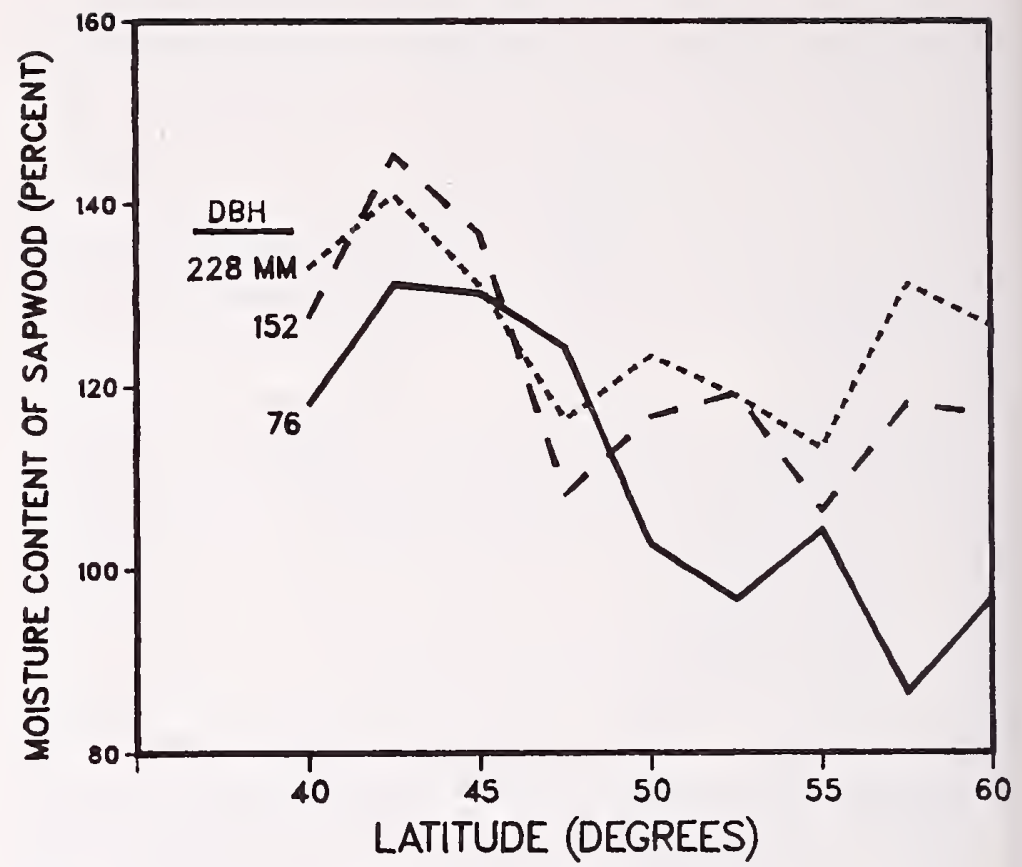

Figure 2-21-Moisture content of sapwood related to latitude for latifolia trees of three diameters. 


\section{Heartwood}

Heartwood moisture content was much less than that of sapwood; it averaged 43.4 percent, with standard deviation of 5.7 percent. Heartwood moisture content was inversely correlated with d.b.h., averaging 47.2 (6.9), 41.9 (3.8), and 40.9 (3.8) percent in trees 76,152 , and $228 \mathrm{~mm}$ in d.b.h.

In contrast to sapwood, the smallest trees had highest heartwood moisture content at all latitudes, and variation with latitude was less pronounced in heartwood than in sapwood-especially in larger trees (fig. 2-22).

Heartwood moisture content was poorly correlated with moisture contents of other tree portions; the closest correlations were with stem moisture contents at $152 \mathrm{~mm}$ stump height and at 70 percent of tree height ( $r$ for both $=0.341)$ and with moisture content of entire stembark $(r=0.396)$. Other correlations of interest are as follows:

\section{Property}

Tree height

Complete-tree bark as percentage of gross complete-tree volume

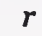

$-0.537$

Stembark as percentage of gross stem volume

Sapwood weight, ovendry

Stump-root wood volume as percentage of treewood volume

$-.449$

$-.447$

$-.441$

$-.440$

$-.434$

Stem weight, wood plus bark, ovendry

Specific gravity of complete-tree bark

Weight of stump-root system, ovendry

Heartwood diameter at $152 \mathrm{~mm}$ stump height

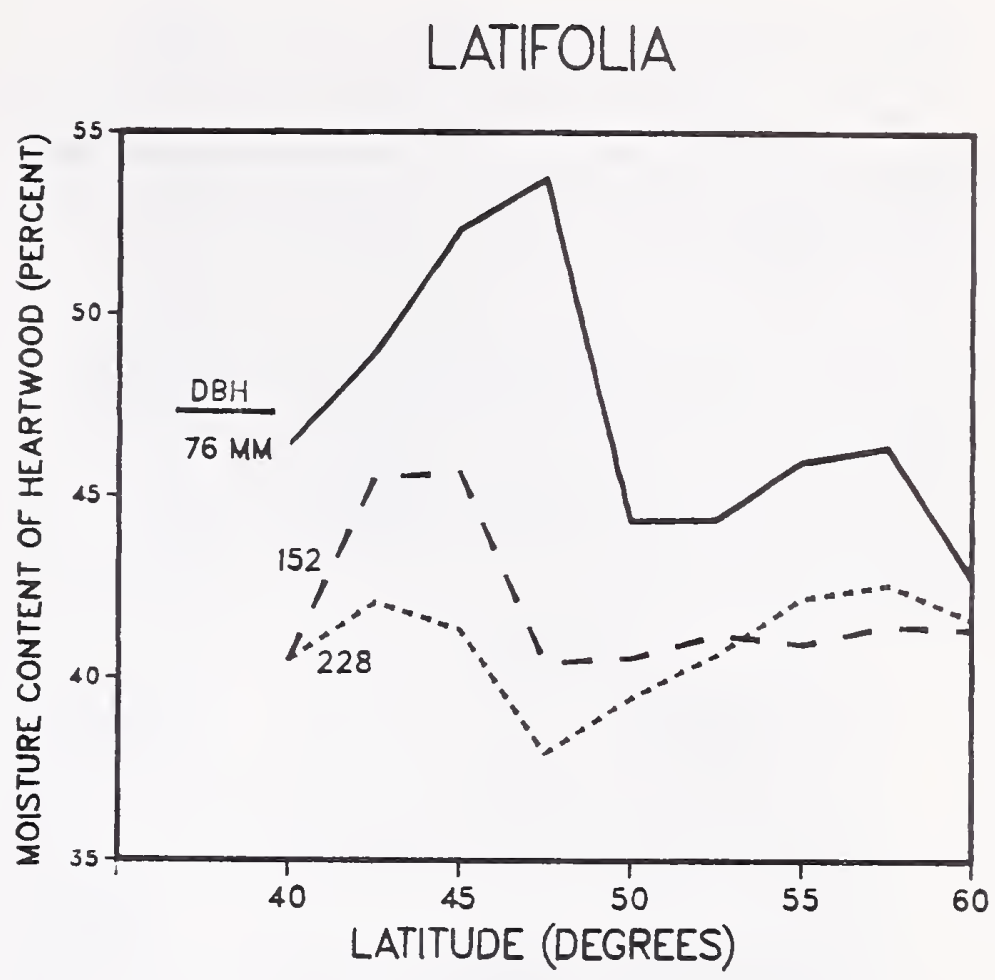

Figure 2-22-Moisture content of heartwood related to latitude for latifolia trees of three diameters. 


\section{Stump-Root System, Wood Plus Bark}

Wood plus bark of the stump-root systems had average moisture content of 95.7 percent, with standard deviation of 23.1 percent. Trees 76,152 , and $228 \mathrm{~mm}$ in d.b.h. had moisture contents of 101.3 (26.1), 93.0 (19.1), and 92.7 (22.7) percent.

Stump-root moisture contents in trees of all three diameters decreased significantly in northern latitudes (fig. 2-23); maximums were at 42.5 degrees (120 percent) and minimums at 60 degrees ( 80 percent).

Correlations between moisture content of the gross stump-root system and the following measured properties are of interest:

$$
\text { Property } r
$$

Moisture content of complete tree with cones and foliage

Moisture content of complete tree without cones or foliage

Moisture content of branch-free stem, wood plus bark

Moisture content of stemwood

Heartwood volume as percentage of stemwood volume

Moisture content of live branches, wood plus bark

Specific gravity of wood of stump-root system

Specific gravity of complete-tree wood

Specific gravity of stemwood

$-.538$

$-.507$

Crown ratio

Specific gravity of sapwood

$-.461$

\section{Stump-Root System, Wood Only}

Wood of the stump-root systems averaged 94.9 percent moisture content, with standard deviation of 23.7 percent. Wood of trees 76-, 152-, and 228-mm d.b.h. had moisture contents of 99.5 (27.7), 92.0 (20.1), and 93.1 (22.1) percent, but these percentages varied with latitude (fig. 2-24). Wood of the stump-root systems averaged highest moisture content at 42.5 degrees latitude (133 percent) and lowest at 60 degrees (90 percent).

Correlations between moisture content of the wood of the stump-root system and the following measured properties are of interest:

\section{Property}

Moisture content of complete tree with cones and foliage

0.842

Moisture content of complete tree without cones or foliage

Moisture content of branch-free stem, wood plus bark

Heartwood volume as percentage of stemwood volume

Specific gravity of wood of stump-root system

Moisture content of live branches, wood plus bark

Specific gravity of complete-tree wood $\quad-.564$

Specific gravity of stemwood
LATIFOLIA

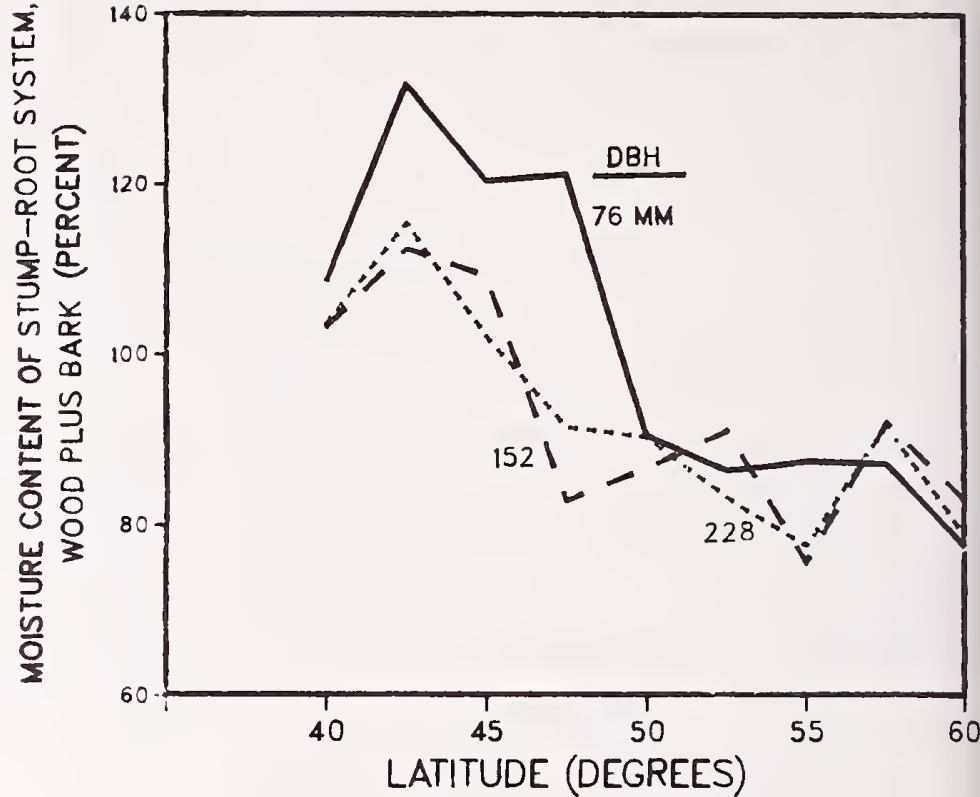

Figure 2-23-Moisture content of stump-root system, wood plus bark, related to latitude for latifolia trees of three diameters.

\section{LATIFOLIA}

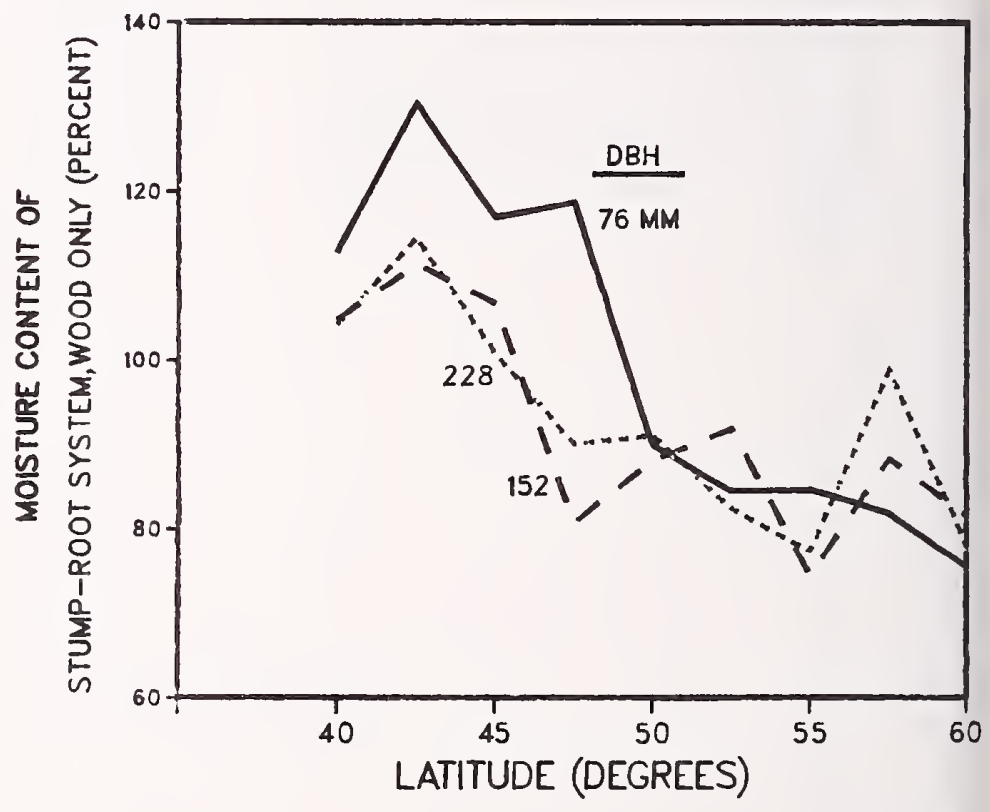

Figure 2-24-Moisture content of wood of the stump-root system related to latitude for latifolia trees of three diameters. 


\section{Stump-Root System, Bark Only}

Bark of the stump-root systems had average moisture content of 106.2 percent, with standard deviation of 26.5 percent. Bark moisture content was inversely correlated with d.b.h., averaging 116.1 (29.0), 102.0 (24.5), and 100.4 (23.2) for trees 76,152 , and $228 \mathrm{~mm}$ in diameter.

Bark moisture content varied with elevational zone, as follows:

$\begin{array}{ccc}\begin{array}{c}\text { Elevational } \\ \text { zone }\end{array} & \begin{array}{c}\text { Average moisture content } \\ \text { and standard deviation }\end{array} \\ \text { Low } & \ldots \ldots \ldots \text { - Percent } \ldots \ldots \\ \text { Medium } & 96.9 & (24.3) \\ \text { High } & 108.4 & (27.7) \\ & 113.3 & (25.0)\end{array}$

Bark of the stump-root systems had highest moisture content at 42.5 degrees latitude (133 percent) and lowest at 50 degrees (89 percent) (fig. 2-25).

Correlations between moisture content of the bark of the stump-root system and the following measured properties are of interest:

\section{Property}

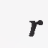

Moisture content of complete-tree bark

0.720

Moisture content of stembark

Specific gravity of complete-tree bark

Moisture content of complete tree with cones and foliage

Moisture content of complete tree without cones or foliage

Moisture content of stembark at $152 \mathrm{~mm}$ stump height

Moisture content of branch-free stem, wood plus bark

.533

Heartwood volume as percentage of stemwood volume

.436
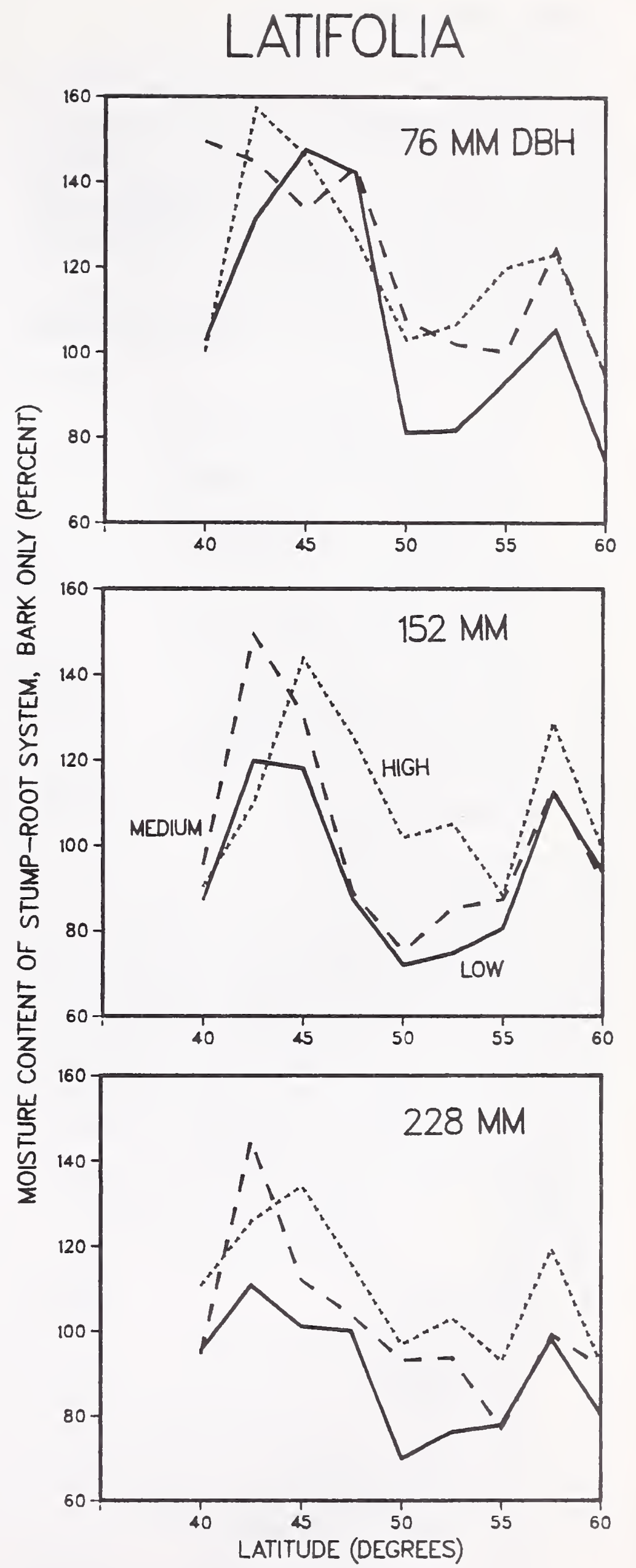

Figure 2-25-Moisture content of bark of the stump-root system related to latitude and to elevational zone for latifolia trees of three diameters. 


\section{Stump, Wood Plus Bark}

Wood plus bark in the stump from ground level to 152-mm-high stump top had average moisture content of 88.8 percent, with standard deviation of 25.3 percent. In trees of 76-, 152-, and 228-mm d.b.h., stumpwood plus bark had moisture contents of 94.2 (28.7), 85.8 (23.4), and 86.3 (22.7) percent, but varied significantly with latitude (fig. 2-26). Stumpwood plus bark moisture contents averaged highest at 42.5 degrees latitude (117 percent) and least at 55 degrees (72 percent).

Correlations between moisture content of the stump (wood plus bark) and the following measured properties are of interest:

\section{Property}

$r$

Moisture content of stem, wood plus bark, at $152 \mathrm{~mm}$ stump height

Moisture content of complete tree without cones or foliage

Moisture content of complete tree with cones and foliage

Moisture content of branch-free stem, wood plus bark

Heartwood volume as percentage of stemwood volume

Specific gravity of complete-tree bark

Specific gravity of complete-tree wood

Specific gravity of wood of stump-root system

Specific gravity of stemwood

\section{Stumpwood}

Stumpwood had average moisture content of 90.5 percent, with standard deviation of 27.3 percent, and had little correlation with d.b.h. In trees from low-elevation zones, stumpwood had higher moisture content (93.4 percent) than in those from medium-elevation zones (87.9 percent) or high zones (90.3 percent), but the relationship varied with latitude. Stumpwood had highest moisture content at 42.5 degrees latitude (119 percent) and lowest at 55 degrees (73 percent) (fig. 2-27).

Correlations between stumpwood moisture content and the following measured properties are of interest:

\section{Property}

$r$

Moisture content of stemwood at $152 \mathrm{~mm}$ stump height

Moisture content of complete-tree wood

Moisture content of complete tree with cones and foliage

Heartwood volume as percentage of stemwood volume

Moisture content of stemwood

Moisture content of sapwood

Moisture content of live branches, wood plus bark

Specific gravity of complete-tree wood

Specific gravity of stemwood

Specific gravity of complete-tree bark

Specific gravity of wood of stump-root system
LATIFOLIA

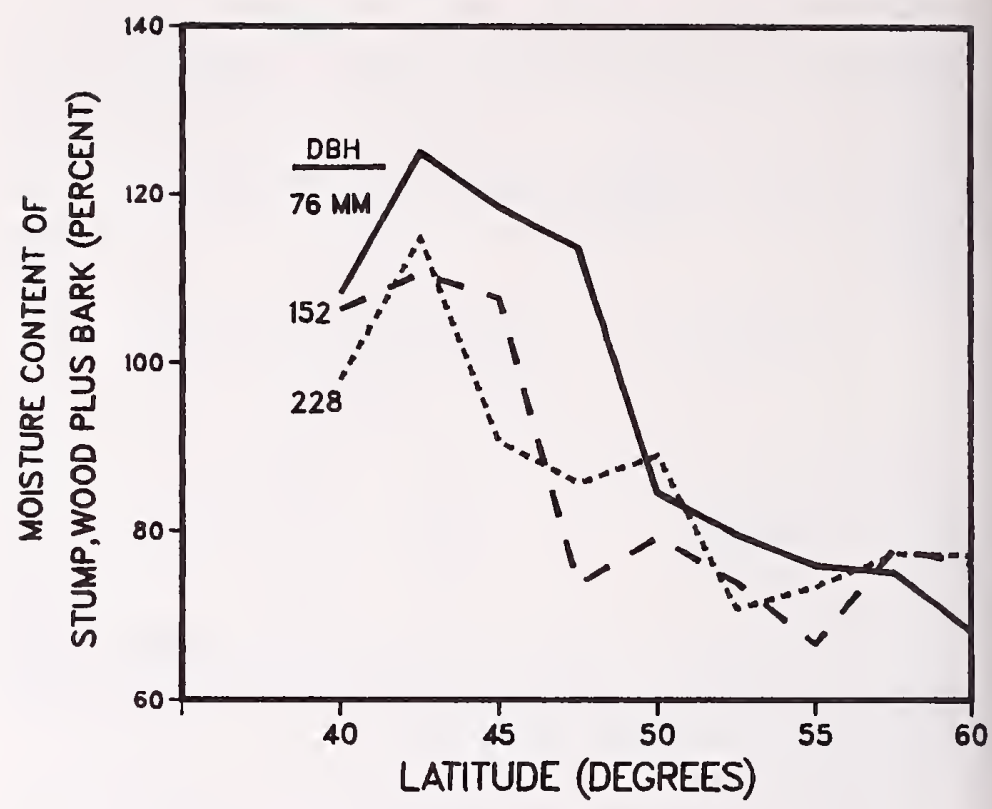

Figure 2-26-Moisture content of stump from groundline to stump top, wood plus bark, related to latitude for latifolia trees of three diameters.

\section{LATIFOLIA}

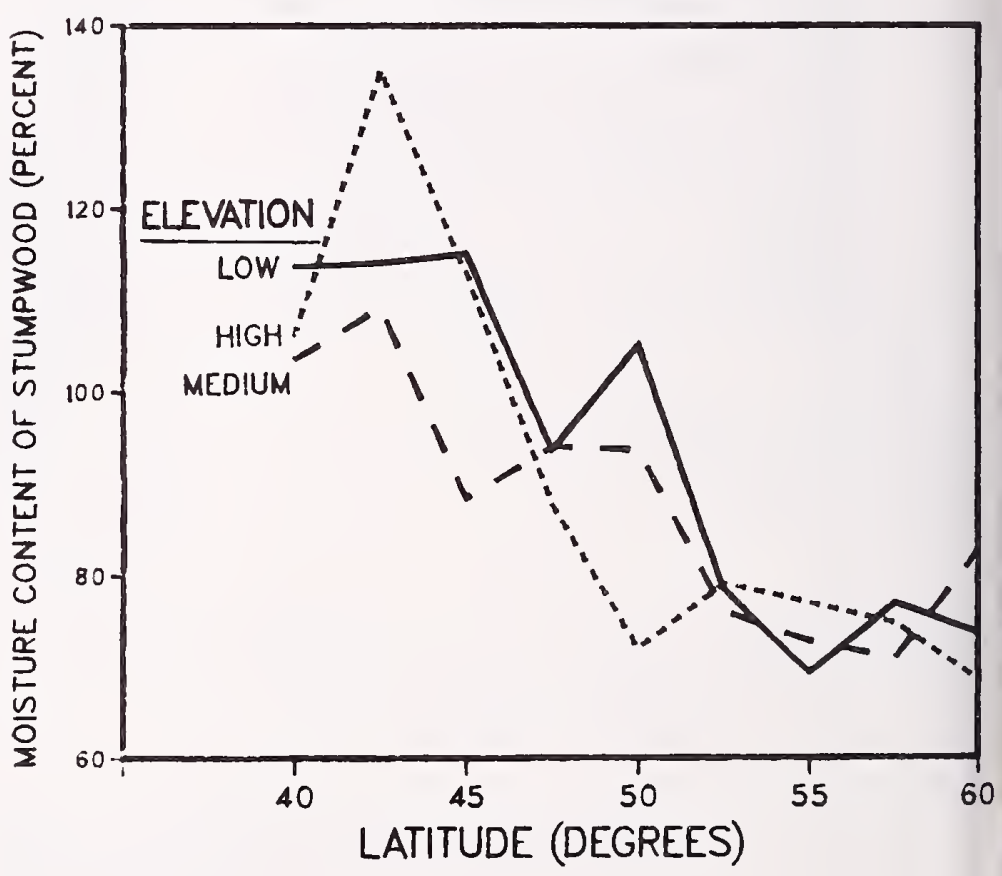

Figure 2-27-Moisture content of stumpwood (groundline to stump top) related to latitude for latifolia trees in three elevational zones. 


\section{Stumpbark}

Moisture content of stumpbark averaged 77.3 percent, with standard deviation of 27.6 percent; it was inversely correlated with d.b.h., averaging 93.6 (30.4), 73.6 (24.1), and 64.8 (18.9) percent for trees 76,152 , and $228 \mathrm{~mm}$ in diameter. It was positively correlated with elevational zone, as follows:

$\begin{array}{lcc}\begin{array}{c}\text { Elevational } \\ \text { zone }\end{array} & \begin{array}{c}\text { Average moisture content } \\ \text { and standard deviation }\end{array} \\ \text { Low } & \ldots \ldots \text {. . Percent } \ldots \ldots . . \\ \text { Medium } & 72.8 & (26.4) \\ \text { High } & 74.1 & (25.5) \\ & 85.1 & (29.3)\end{array}$

Stumpbark moisture content varied with latitude (fig. 2-28); it was highest at 42.5 degrees (98 percent) and lowest at 50 degrees (56 percent).

Correlations between stumpbark moisture content and the following measured properties are of interest:

\section{Property}

Moisture content of stump-root system, bark only

Specific gravity of complete-tree bark

Tree height

Heartwood diameter at $152 \mathrm{~mm}$ stump height

Complete-tree bark percentage of gross complete-tree volume

Stem weight, wood plus bark, ovendry

Heartwood volume as percentage of stemwood volume

Moisture content of branchbark

D.b.h.

$-.425$
LATIFOLIA

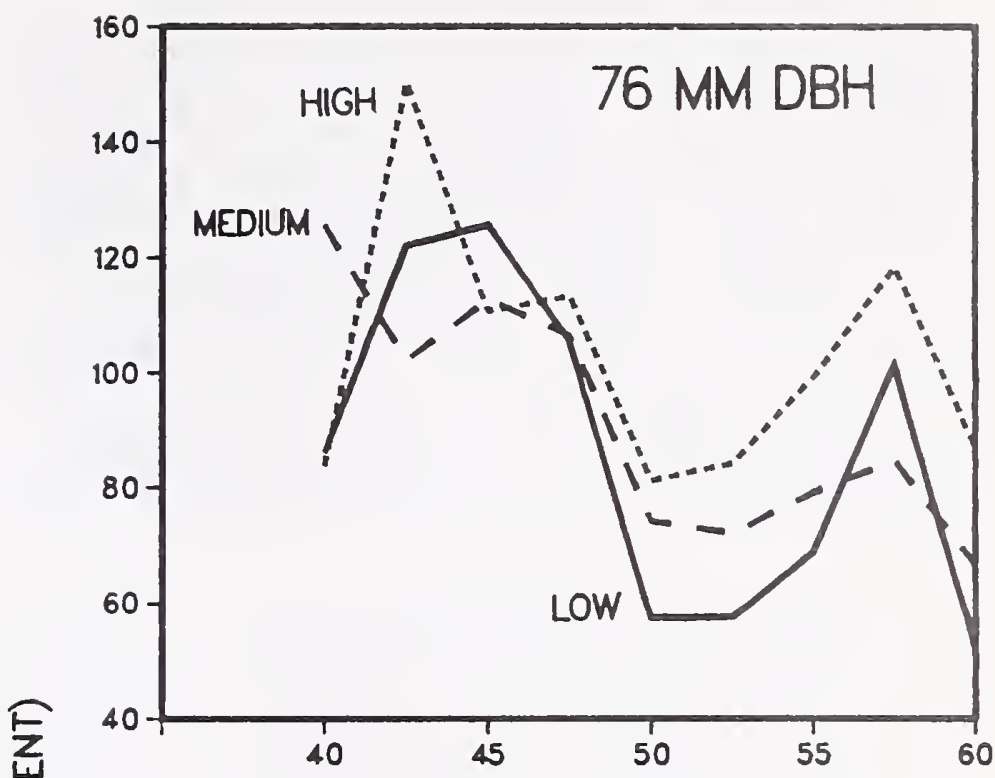

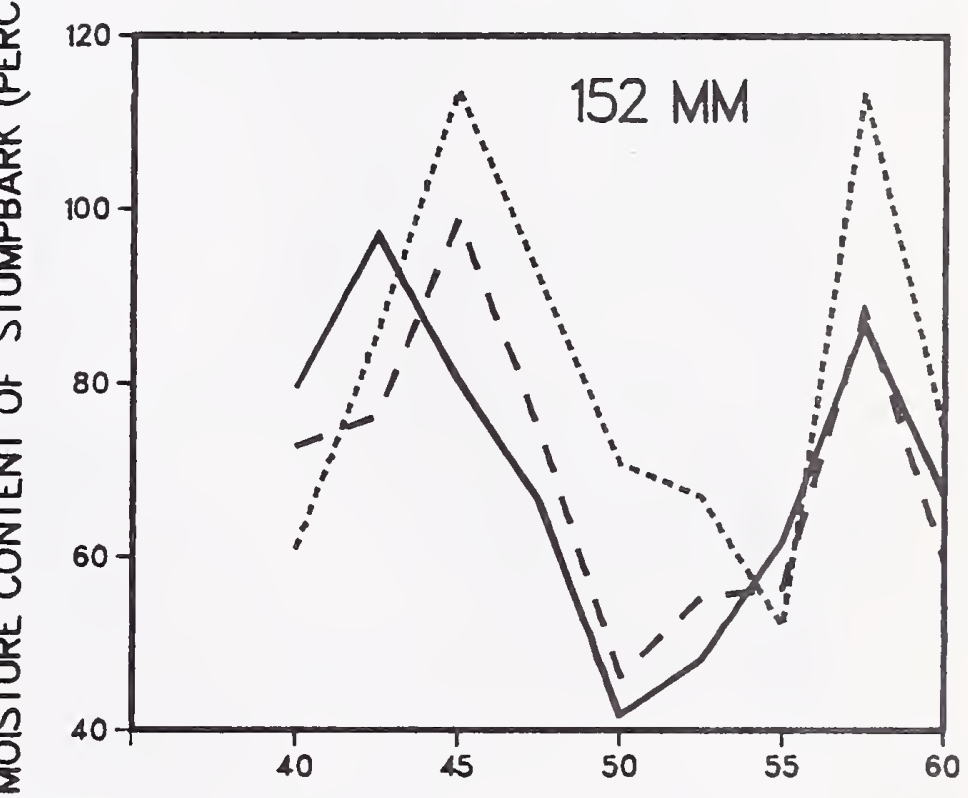

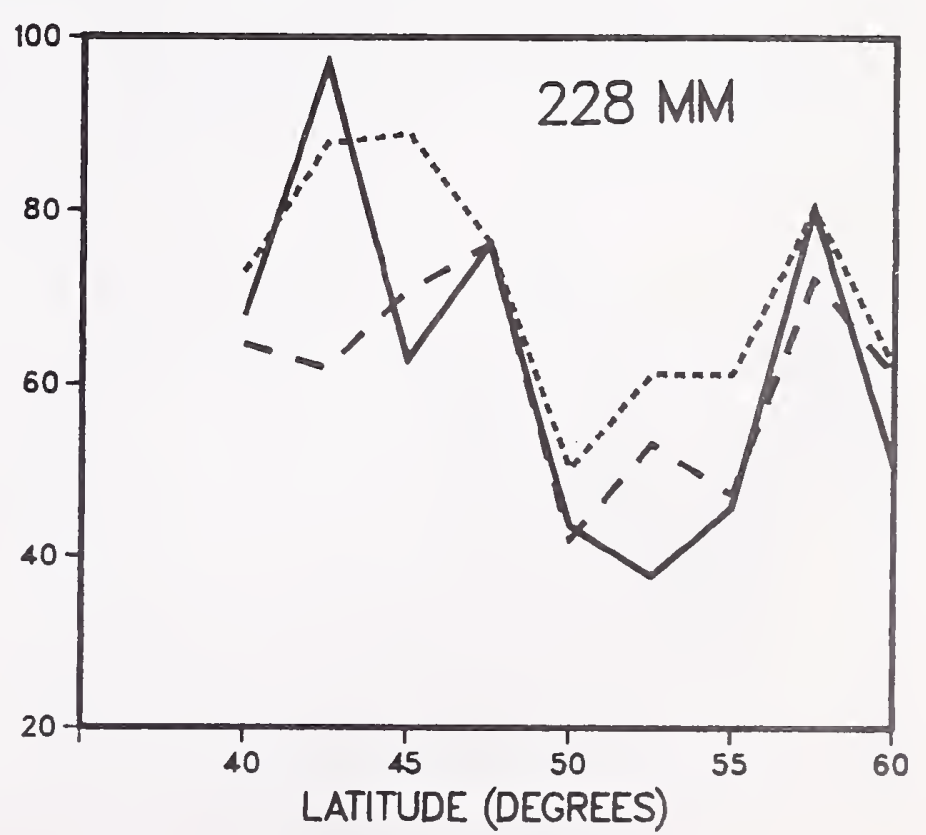

Figure 2-28-Moisture content of stumpbark (groundline to stump top) related to latitude and to elevational zone for latifolia trees of three diameters. 


\section{Lateral Roots, Wood Plus Bark}

Wood plus bark of lateral roots from root collar to $152 \mathrm{~mm}$ radius from tree pith averaged 106.3 percent moisture content, with standard deviation of 25.5 percentage points. Trees 76, 152, and $228 \mathrm{~mm}$ in d.b.h. had lateral root moisture contents of 113.0 (29.2), 104.0 (22.5), and 101.7 (23.3) percent, but these averages were significantly related to both latitudinal and elevational zones (fig. 2-29). Moisture contents averaged highest at 42.5 degrees latitude (131 percent) and least at 55 degrees (84 percent).

Correlations between the moisture content of lateral roots (wood plus bark) and the following measured properties are of interest:

\section{Property}

Moisture content of stem, wood plus bark, at $152 \mathrm{~mm}$ stump height

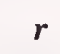

Moisture content of complete tree with cones and foliage

Moisture content of complete tree without cones or foliage

Heartwood volume as percentage of stemwood volume

Moisture content of stem, wood plus bark

Specific gravity of complete-tree bark

Specific gravity of wood of stump-root system

Moisture content of live branches, wood plus bark

Specific gravity of complete-tree wood

Specific gravity of stemwood

Specific gravity of sapwood

Crown ratio

Heartwood diameter at $152 \mathrm{~mm}$ stump height

.729

$-.596$

$-.577$

.572

$-.570$

$-.557$

$-.515$

.514

$-.501$
ATIFOLIA

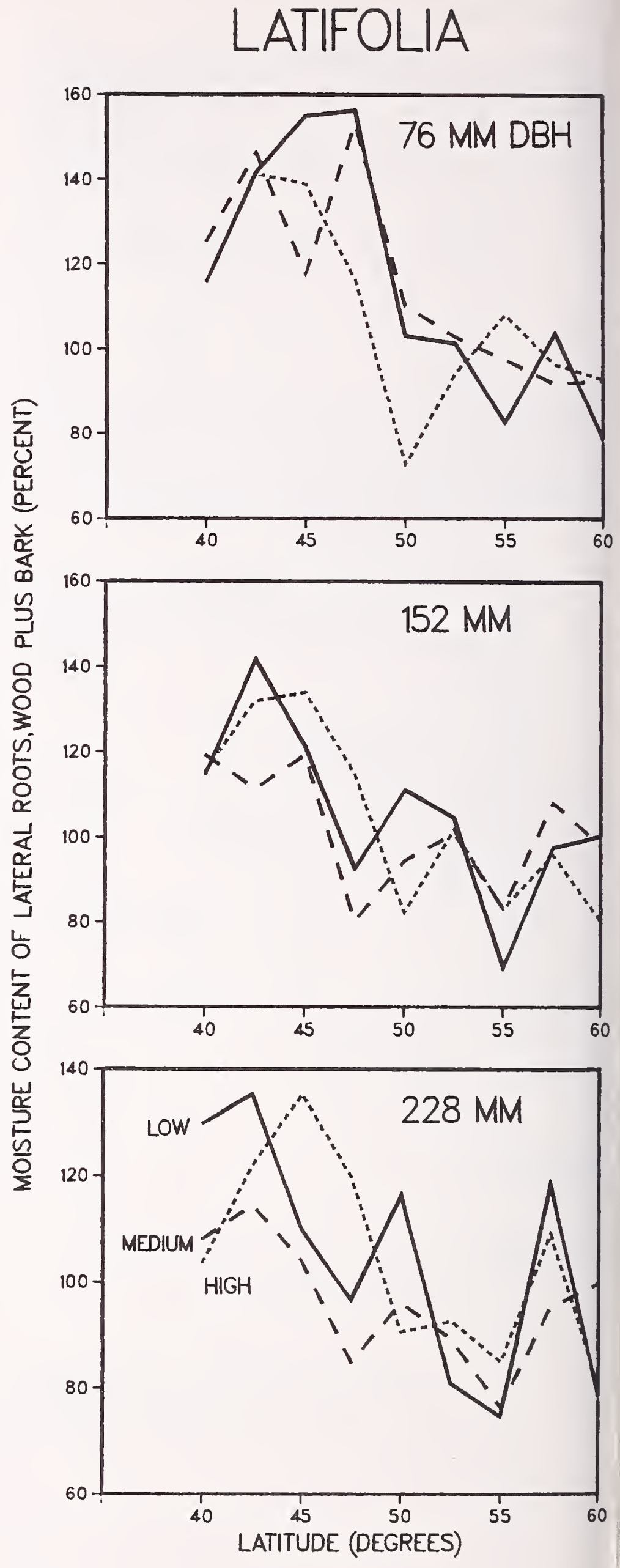

Figure 2-29-Moisture content of lateral roots from root collar to $305 \mathrm{~mm}$ radius from tree pith, wood plus bark, related to latitude and elevational zone for latifolia trees of three diameters. 


\section{Lateral Roots, Wood Only}

Moisture content of lateral root wood did not vary significantly with tree diameter; with diameter data pooled, moisture content averaged 103.7 percent, with standard deviation of 26.5 percentage points. Lateral root wood moisture content was, however, significantly related to both latitude and elevational zone (fig. 2-30), with trees from low-elevation zones having slightly higher moisture content (107 percent) than those from the other two zones (102 percent). Moisture contents averaged highest at 42.5 degrees latitude (130 percent) and lowest at 55 degrees (81 percent).

Correlation between the moisture content of lateral root wood and the following measured properties are of interest:

\section{Property}

Moisture content of stemwood at $152 \mathrm{~mm}$ stump height

Moisture content of complete tree with cones and foliage

Moisture content of complete tree without cones or foliage

Heartwood volume as percentage of stemwood volume

Moisture content of branch-free stem, wood plus bark

Specific gravity of complete-tree wood

Specific gravity of wood of stump-root system

$-.596$

$-.590$

Moisture content of live branches, wood plus bark

Specific gravity of stemwood

Moisture content of sapwood

$-.539$

Specific gravity of complete-tree bark

Specific gravity of sapwood

Crown ratio
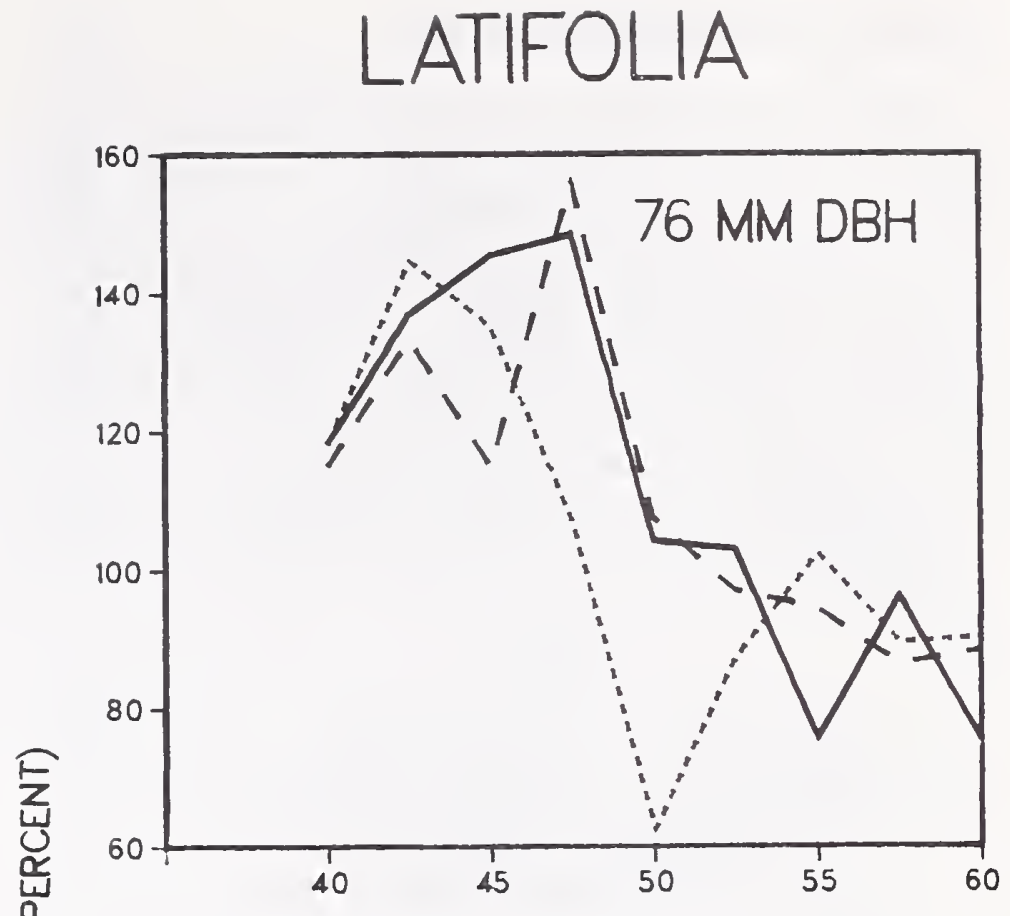

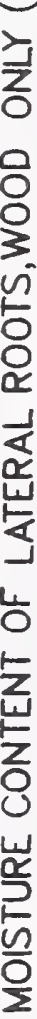
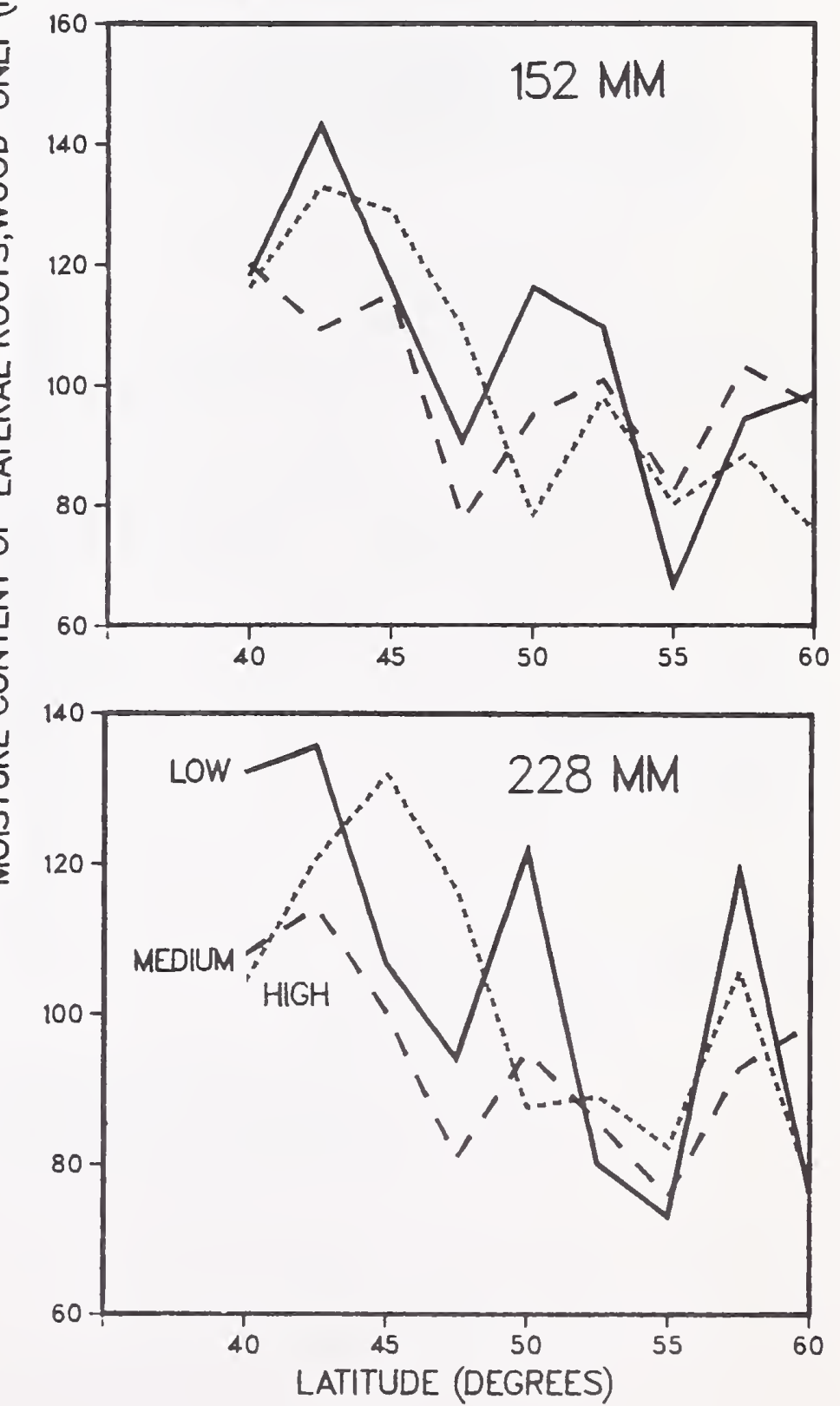

Figure 2-30-Moisture content of wood in lateral roots, from root collar to $305 \mathrm{~mm}$ radius from tree pith, related to latitude and elevational zone for latifolia trees of three diameters. 


\section{Lateral Roots, Bark Only}

Moisture content of bark of the lateral roots averaged 120.7 percent, with standard deviation of 31.7 percentage points. Trees 76,152 , and $228 \mathrm{~mm}$ in d.b.h. had bark moisture contents of 130.7 (37.5), 118.0 (29.0), and $113.3(25.3)$ percent. High-elevation trees had moister bark than lowparticularly those 152 and $228 \mathrm{~mm}$ in d.b.h. (fig. 2-31).

Bark of the lateral roots had highest moisture content at 45 degrees latitude (153 percent) and lowest moisture content at 55 degrees (101 percent).

Correlations between the moisture content of lateral rootbark and the following measured properties are of interest:

\section{Property}

0.625

Moisture content of complete-tree bark

Specific gravity of complete-tree bark

Moisture content of stembark at 20 percent of tree height

Moisture content of live branches, wood plus bark

Moisture content of complete tree with cones and foliage

Heartwood volume as percentage of stemwood volume
LATIFOLIA
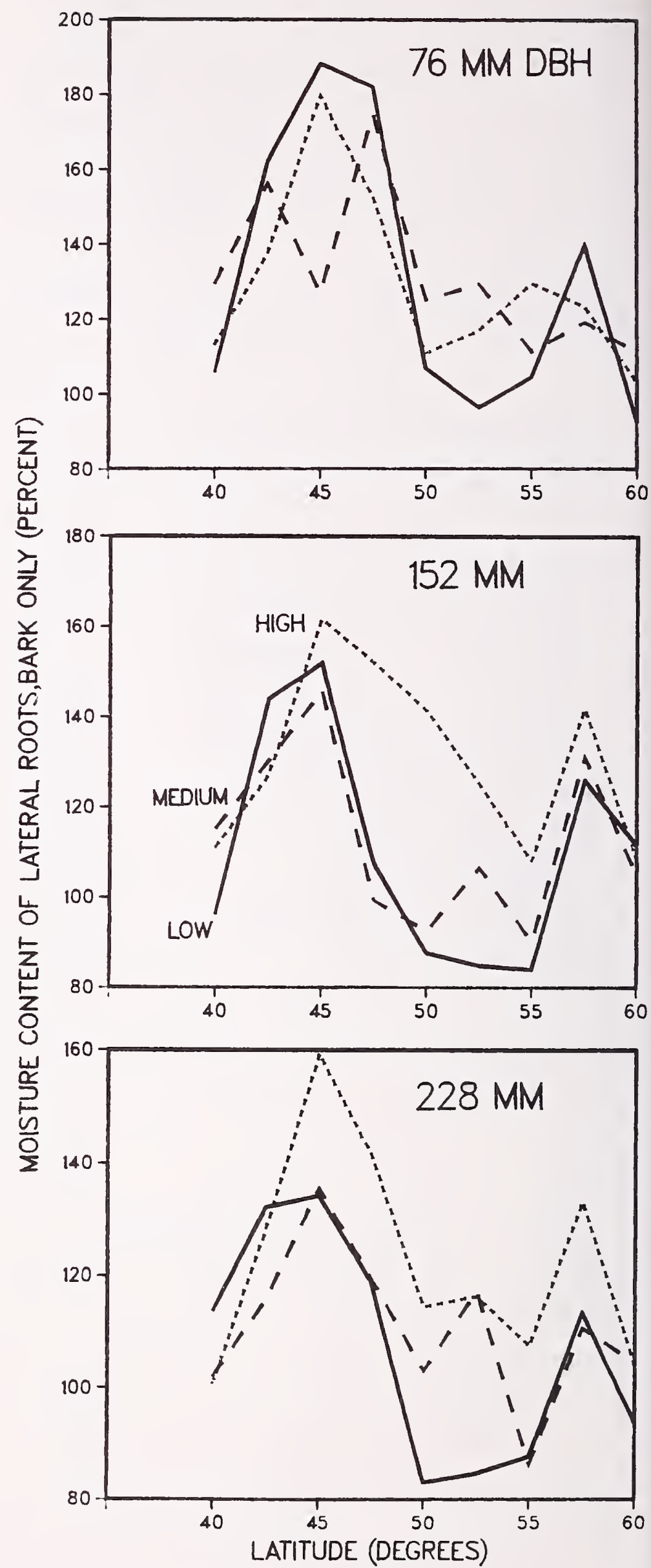

Figure 2-31-Moisture content of bark in lateral roots, from root collar to $305 \mathrm{~mm}$ radius from tree pith, related to latitude and to elevational zone for latifolia trees of three diameters. 


\section{Central Root Mass-Taproot, Wood Plus Bark}

Wood plus bark of the central root mass-taproot shorn of laterals and stump had average moisture content of 93.6 percent, with standard deviation of 25.0 percentage points. In southerly latitudes, $76-\mathrm{mm}$ trees had more moisture content than the two larger diameter classes (fig. 2-32). Moisture content of wood plus bark averaged highest at 42.5 degrees latitude (115.7 percent) and lowest at 60 degrees ( 73 percent).

Correlations between the moisture content of the wood plus bark of the central root mass-taproot and the following measured properties are of interest:

\section{Property}

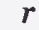

Moisture content of stem, wood plus bark,

at $152 \mathrm{~mm}$ stump height

Moisture content of complete tree with cones and foliage

Moisture content of complete tree without cones or foliage

Specific gravity of wood of the stump-root system

Heartwood volume as percentage of stemwood volume

Moisture content of branch-free stem, wood plus bark

Moisture content of live branches, wood plus bark

Specific gravity of complete-tree bark

$-.513$

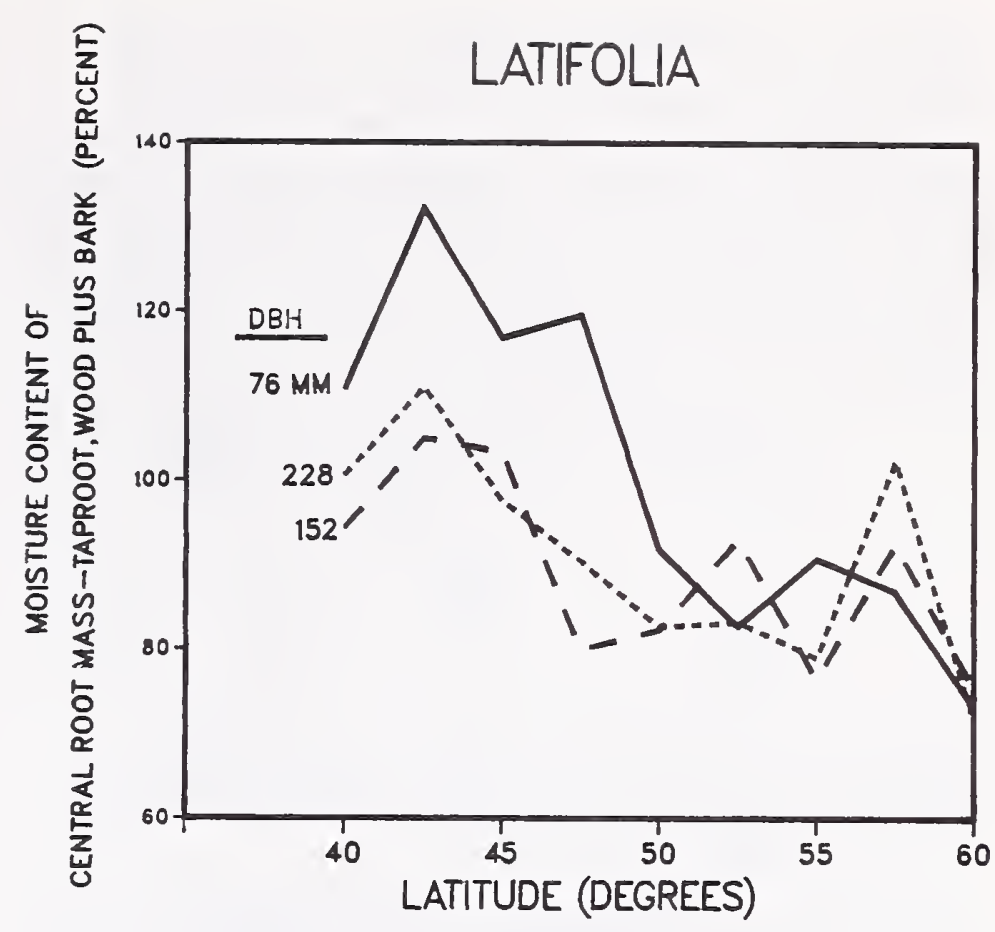

Figure 2-32-Moisture content of central root mass and taproot shorn of stump and laterals, wood plus bark, related to latitude for latifolia trees of three diameters.

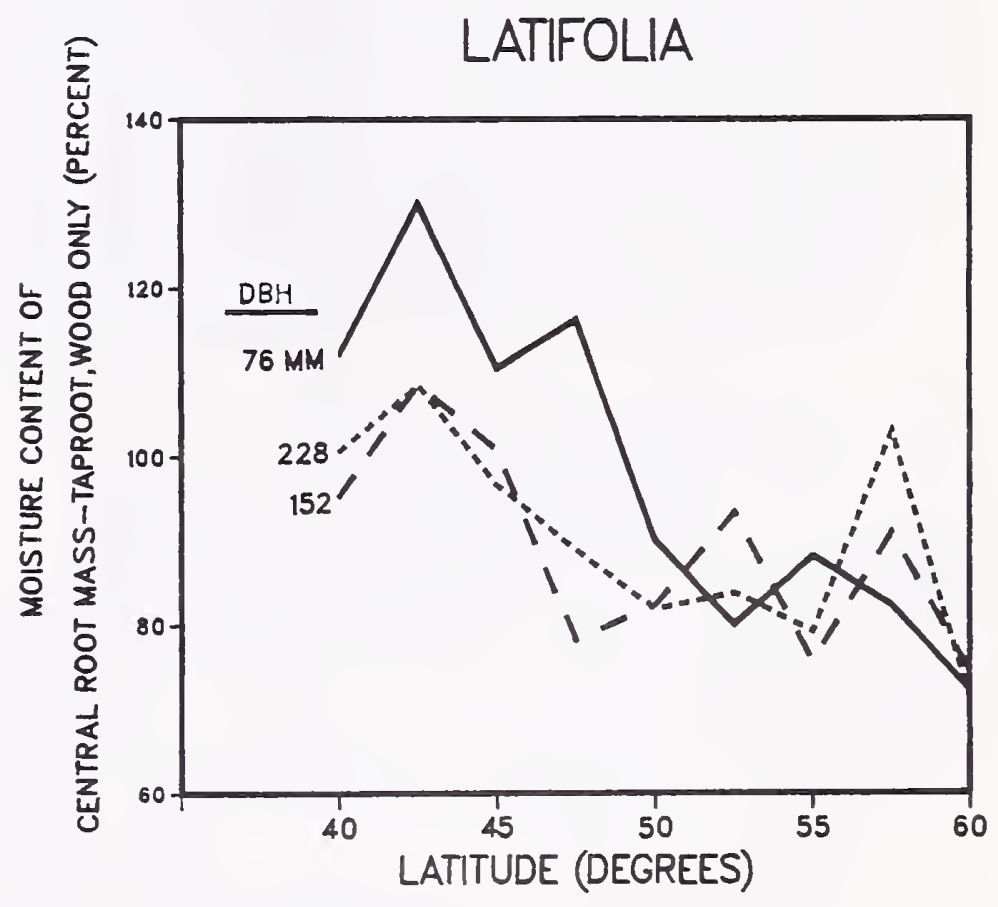

Figure 2-33-Moisture content of the wood in central root mass and taproot related to latitude for latifolia trees of three diameters.
Moisture content of complete tree with cones and foliage

Moisture content of complete-tree wood

Specific gravity of the wood of the stump. root system

Heartwood volume as percentage of stemwood volume

$-.683$

Moisture content of live branches, wood plus bark

Specific gravity of complete-tree wood

Specific gravity of complete-tree bark

$-.506$

Specific gravity of stemwood 


\section{Central Root Mass-Taproot, Bark Only}

Bark of the central root mass-taproot had average moisture content of 107.1 percent, with standard deviation of 31.5 percentage points. Bark moisture content varied significantly with d.b.h., elevational zone, and latitude. For trees 76,152 , and $228 \mathrm{~mm}$ in d.b.h., moisture contents were 121.0 (33.0), 101.6 (31.8), and 98.5 (24.5) percent. Variation with elevational zone was as follows:

\begin{tabular}{|c|c|c|}
\hline $\begin{array}{c}\text { Elevational } \\
\text { zone }\end{array}$ & $\begin{array}{c}\text { Average m } \\
\text { and stand } \\
\ldots \ldots \ldots P\end{array}$ & $\begin{array}{c}\text { ure content } \\
\text { deviation } \\
n t \ldots \ldots\end{array}$ \\
\hline Low & 101.0 & (33.3) \\
\hline Medium & 106.1 & $(29.2)$ \\
\hline High & 114.0 & $(31.0)$ \\
\hline
\end{tabular}

Average bark moisture was highest at 42.5 degrees latitude (145 percent) and lowest at 60 degrees (85 percent) (fig. 2-34).

Correlations between the moisture content of the bark of the central root mass-taproot and the following measured properties are of interest:

\section{Property}

Specific gravity of complete-tree bark

Moisture content of complete-tree bark

Moisture content of stembark at $152 \mathrm{~mm}$ stump height

Moisture content of complete tree with cones and foliage

Heartwood volume as percentage of stemwood volume

Moisture content of branch-free stem, wood plus bark

Heartwood diameter at $152 \mathrm{~mm}$ stump height

\section{2-6 RESULTS-MURRAYANA}

For the murrayana trees, the three d.b.h. classes averaged $76 \mathrm{~mm}$ with standard deviation of $1.8 \mathrm{~mm}$, $151 \mathrm{~mm}$ with standard deviation of $2.9 \mathrm{~mm}$, and $229 \mathrm{~mm}$ with standard deviation of $3.9 \mathrm{~mm}$. All were selected at medium elevation, which for the four latitudes averaged as follows (fig. 1-1):

$\begin{array}{ccc}\begin{array}{c}\text { Latitude } \\ \text { Degrees }\end{array} & \begin{array}{c}\text { Elevation } \\ \text { Meters }\end{array} & \text { General location } \\ 37.5 & 2,402 & \begin{array}{c}\text { Just east of Yosemite } \\ \text { National Park }\end{array} \\ 40 & 1,676 & \begin{array}{c}\text { Vicinity of Quincy, CA } \\ \text { Southwest of Paisley, OR }\end{array} \\ 42.5 & 2,006 & \begin{array}{l}\text { North of Breitenbush, OR } \\ 45\end{array} \\ \end{array}$

Because the entire murrayana sample totaled but 36 trees, correlations among tree characteristics are not noted in the detail provided for the 243 latifolia trees. Standard deviations for diameter-class data are noted in parentheses following their average values, as they were in the latifolia results section.

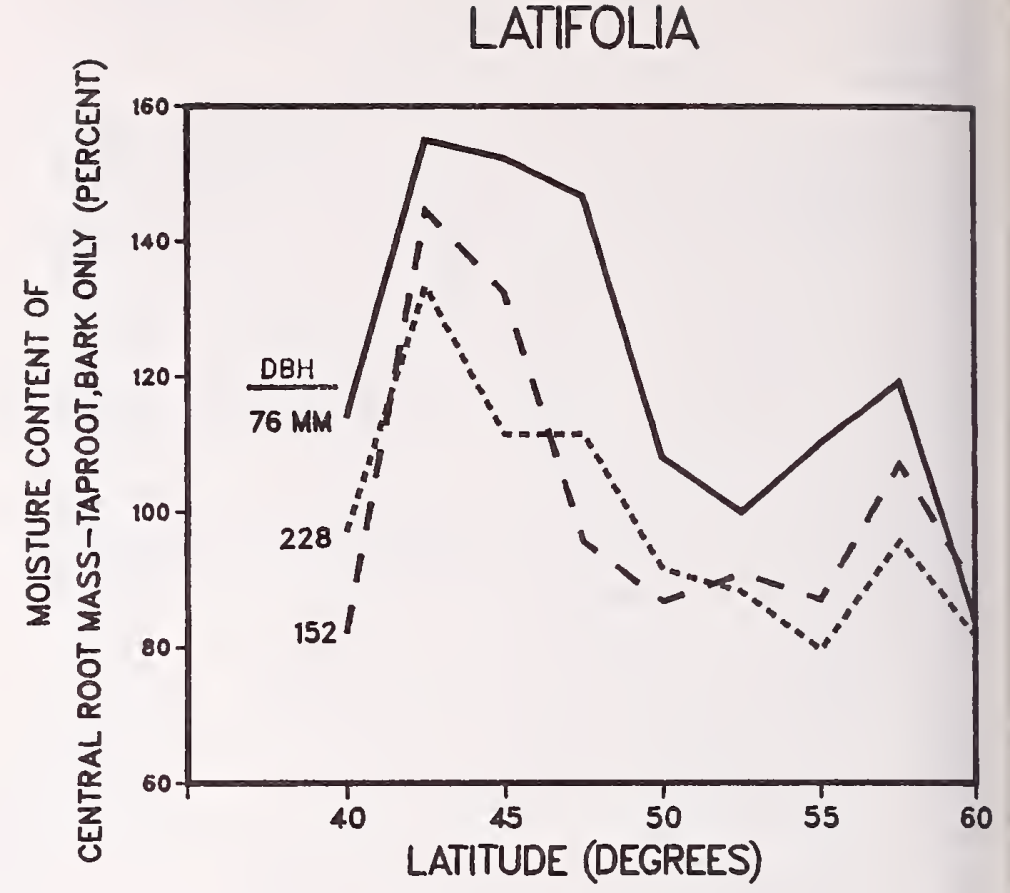

Figure 2-34-Moisture content of the bark of central root mass and taproot related to latitude for latifolia trees of three diameters.

Even with this small sample (nine trees per latitude), numerous latitudinal differences were observed. Only those statistically significant are graphed or tabulated. It seems likely from studying the data, however, that had more trees been sampled, statistically significant differences between the two southern latitudes and the two northern latitudes-as well as among diameter classeswould have been found in most of the moisture contents measured.

\section{Complete Tree With Cones and Foliage}

Moisture content of complete trees with cones and foliage did not vary significantly with diameter or latitude; the average was 108.6 percent, with standard deviation of 16.6 percent.

\section{Complete Tree Without Cones or Foliage}

Average moisture content of complete trees without cones or foliage averaged 108.8 percent, with standard deviation of 17.5 percent. This moisture content did not vary significantly with d.b.h., but was inversely correlated with latitude, as follows:

\begin{tabular}{lcr} 
Latitude & \multicolumn{2}{c}{$\begin{array}{c}\text { Average and } \\
\text { standard deviation }\end{array}$} \\
Degrees & - . - Percent . . . \\
37.5 & 120.5 & $(15.7)$ \\
40 & 111.7 & $(18.1)$ \\
42.5 & 103.4 & $(8.0)$ \\
45 & 99.5 & $(20.2)$
\end{tabular}




\section{Complete Tree, Wood Only}

Average moisture content of complete-tree wood averaged 108.0 percent, with standard deviation of 19.0 percent; it did not vary significantly with latitude, but was positively correlated with diameter; trees 76,152 , and $228 \mathrm{~mm}$ in d.b.h. had tree wood moisture contents of 97.1 (17.4), 111.1 (18.9), and 115.9 (16.6) percent.

\section{Complete Tree, Bark Only}

Bark of complete trees had average moisture content of 113.7 percent, with standard deviation of 19.5 percent, but varied significantly (inversely) with both d.b.h. and latitude (fig. 2-35). Treebark in d.b.h. classes of 76, 152, and $228 \mathrm{~mm}$ had moisture contents of 124.5 (23.5), 111.2 (14.4), and 105.3 (15.5) percent. Variation with latitude is summarized as follows:

\begin{tabular}{ccr} 
Latitude & \multicolumn{2}{c}{$\begin{array}{c}\text { Average and } \\
\text { standard deviation }\end{array}$} \\
Degrees & $\ldots$ - Percent & . . - \\
37.5 & 132.1 & $(17.6)$ \\
40 & 115.0 & $(13.8)$ \\
42.5 & 98.4 & $(10.9)$ \\
45 & 109.1 & $(19.4)$
\end{tabular}

\section{Foliage}

Moisture content of foliage averaged 114.3 percent, with standard deviation of 12.2 percent. It was not significantly related to d.b.h., but did vary significantly with latitude, as follows:

\begin{tabular}{ccr} 
Latitude & \multicolumn{2}{c}{$\begin{array}{c}\text { Average and } \\
\text { standard deviation }\end{array}$} \\
Degrees & $\ldots$. Percent & $\ldots$ \\
37.5 & 113.7 & $(13.6)$ \\
40 & 103.9 & $(10.3)$ \\
42.5 & 114.5 & $(2.5)$ \\
45 & 125.1 & $(9.8)$
\end{tabular}

\section{Cones}

Moisture content of cones averaged 22.1 percent, with standard deviation of 20.3 percentage points; neither d.b.h. nor latitude was significantly related to cone moisture content.

\section{Dead Branchwood}

As with cones, moisture content of dead branchwood was unrelated to d.b.h. or latitude. With all data pooled, the average moisture content was 16.4 percent, with standard deviation of 6.2 percentage points.

\section{Live Branches, Wood Plus Bark}

The moisture content of live branches, wood plus bark, averaged 97.3 percent, with standard deviation of 11.2 percentage points. It was unrelated to latitude, but was positively correlated with d.b.h. classes of 76,152 , and $228 \mathrm{~mm}$ as follows: $89.6(9.8), 98.6$ (11.3), and $103.5(8.2)$ percent.

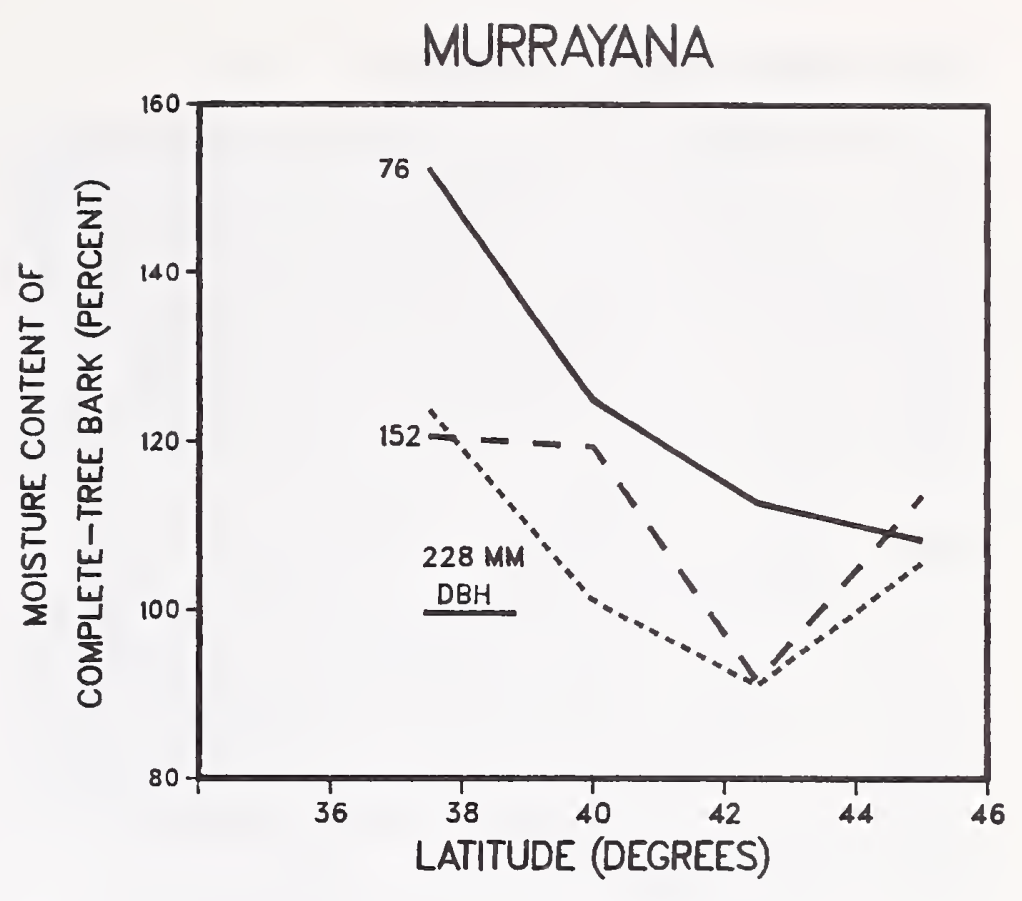

Figure 2-35-Moisture content of complete-tree bark related to latitude for murrayana trees of three diameters.

\section{Live Branchwood}

Live branchwood had average moisture content of 92.7 percent, with standard deviation of 12.9 percentage points. It was positively correlated with both d.b.h. and latitude (fig. 2-36). Branchwood moisture content of trees 76, 152, and $228 \mathrm{~mm}$ in d.b.h. averaged 82.7 (11.6), 96.5 (13.3), and 98.8 (7.5) percent. Moisture contents averaged least at 37.5 degrees latitude ( 85 percent) and highest at 42.5 degrees (99 percent).

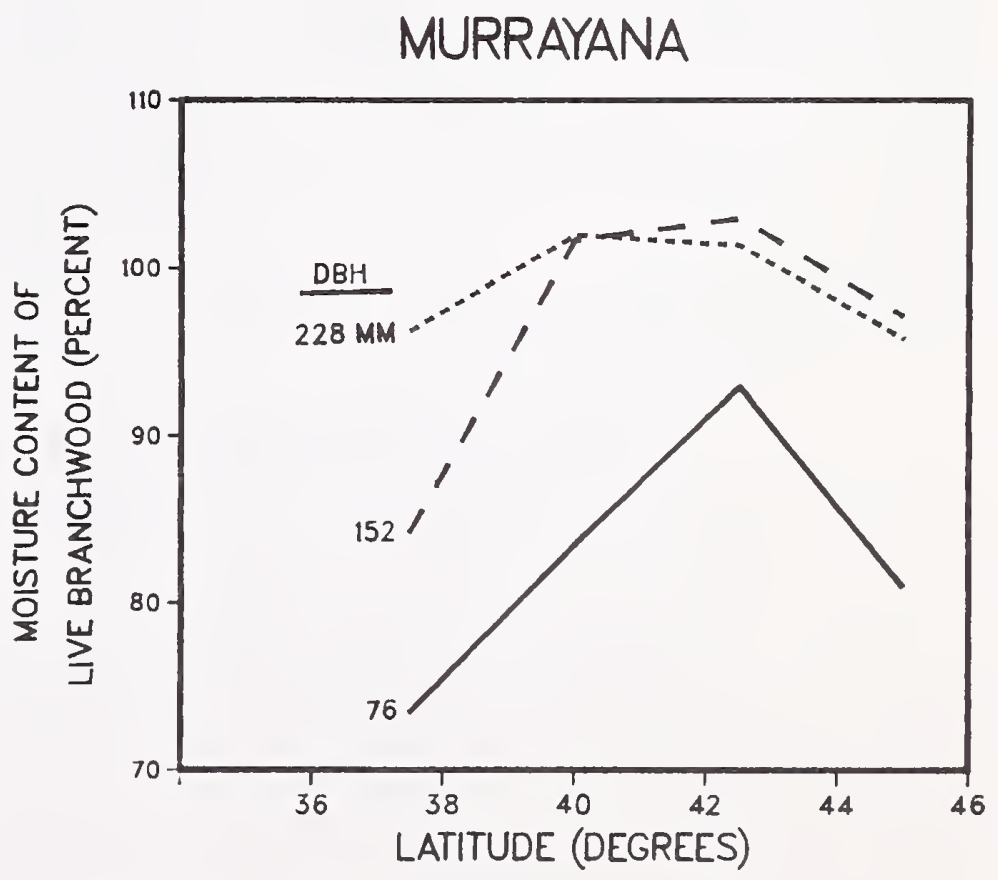

Figure 2-36-Moisture content of live branchwood related to latitude for murrayana trees of three diameters. 


\section{Live Branchbark}

Live branchbark had average moisture content of 105.3 percent, with standard deviation of 23.8 percentage points; it was positively correlated with d.b.h. and also significantly related to latitude (fig. 2-37). Moisture content of live branchbark from trees 76,152 , and $228 \mathrm{~mm}$ in d.b.h. averaged 99.8 (20.2), 101.8 (23.6), and 114.4 (26.5) percent.

Bark moisture content was highest at 37.5 degrees latitude (132 percent) and lowest at 42.5 degrees (80 percent).

\section{Stem, Wood Plus Bark-Tree Average}

Moisture content of the branch-free stem, wood plus bark, had average moisture content of 111.6 percent, with standard deviation of 19.2 percent. It was unrelated to latitude, but was positively correlated with d.b.h. classes of 76,152 , and $228 \mathrm{~mm}$ as follows: 101.8 (17.0), 113.6 (18.9), and 119.4 (18.6) percent.

\section{Stem, Wood Plus Bark-Variation With Height}

Moisture content of wood plus bark of branch-free stems increased with increasing height in trees; the three diameter classes had similar moisture content variations with height (fig. 2-38). At 152-mm stump height the average was 98 percent, while at 80 and 90 percent of tree height the average was about 143 percent.

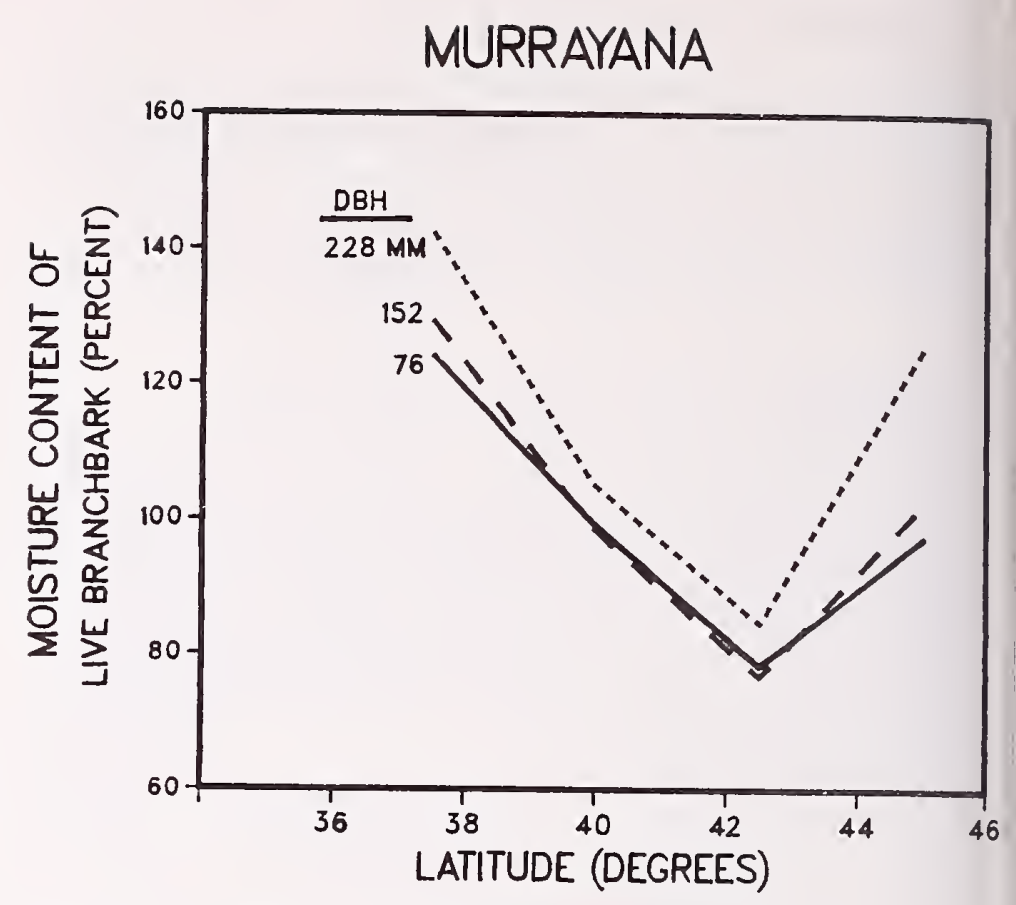

Figure 2-37-Moisture content of live branchbark related to latitude for murrayana trees of three diameters.

\section{MURRAYANA}

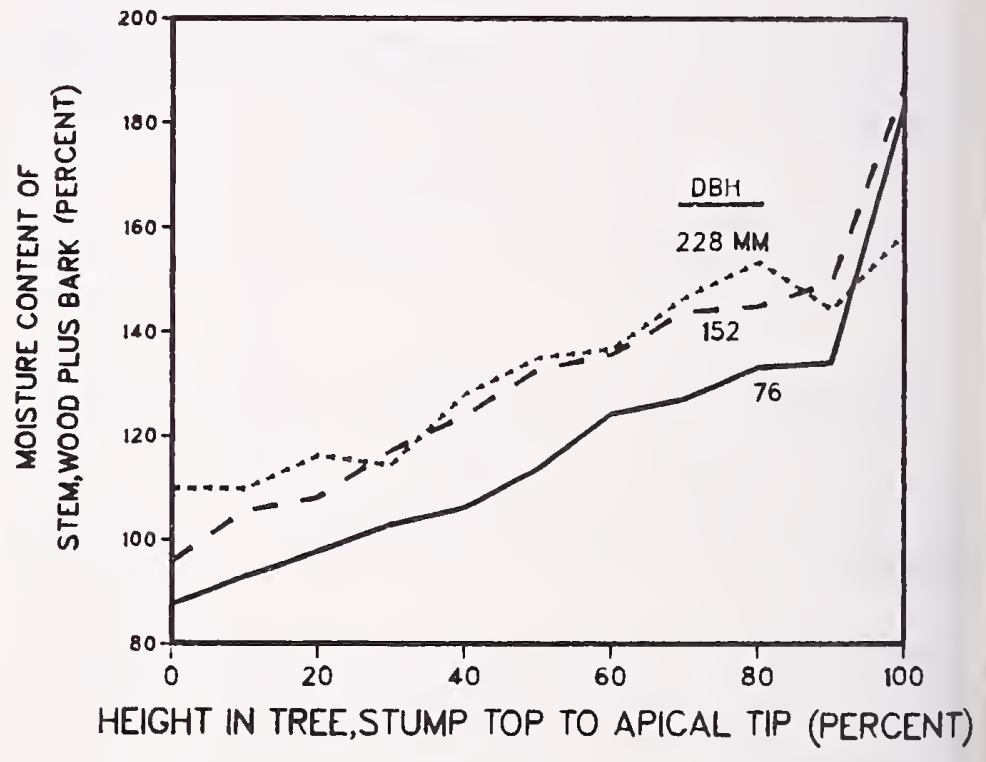

Figure 2-38-Moisture content of branch-free stem, wood plus bark, related to height in tree for murrayana trees of three diameters. 


\section{Stemwood-Tree Average}

Stemwood moisture content averaged 111.2 percent, with standard deviation of 20.9 percent. It was unrelated to latitude, but was positively correlated with d.b.h. classes of 76,152 , and $228 \mathrm{~mm}$ as follows: 98.4 (17.4), 113.8 (19.8), and 121.3 (19.8) percent.

\section{Stemwood-Variation With Height}

Moisture content of stemwood increased with increasing height in trees; the three d.b.h. classes had similar patterns of variation with height (fig. 2-39). At 152-mm stump height the average was 99 percent, while at 80 percent of tree height average stemwood moisture content was 139 percent.

\section{Stembark-Tree Average}

Stembark moisture content averaged 114.1 percent, with standard deviation of 22.6 percentage points. It varied significantly with latitude and also was inversely correlated with d.b.h. (fig. 2-40). Trees 76,152 , and $228 \mathrm{~mm}$ in d.b.h. had average stembark moisture contents of 129.3 (26.6), 113.2 (15.7), and 99.9 (14.1) percent. Stembark moisture contents averaged highest at 37.5 degrees latitude (131 percent) and lowest at 42.5 degrees (100 percent).
MURRAYANA

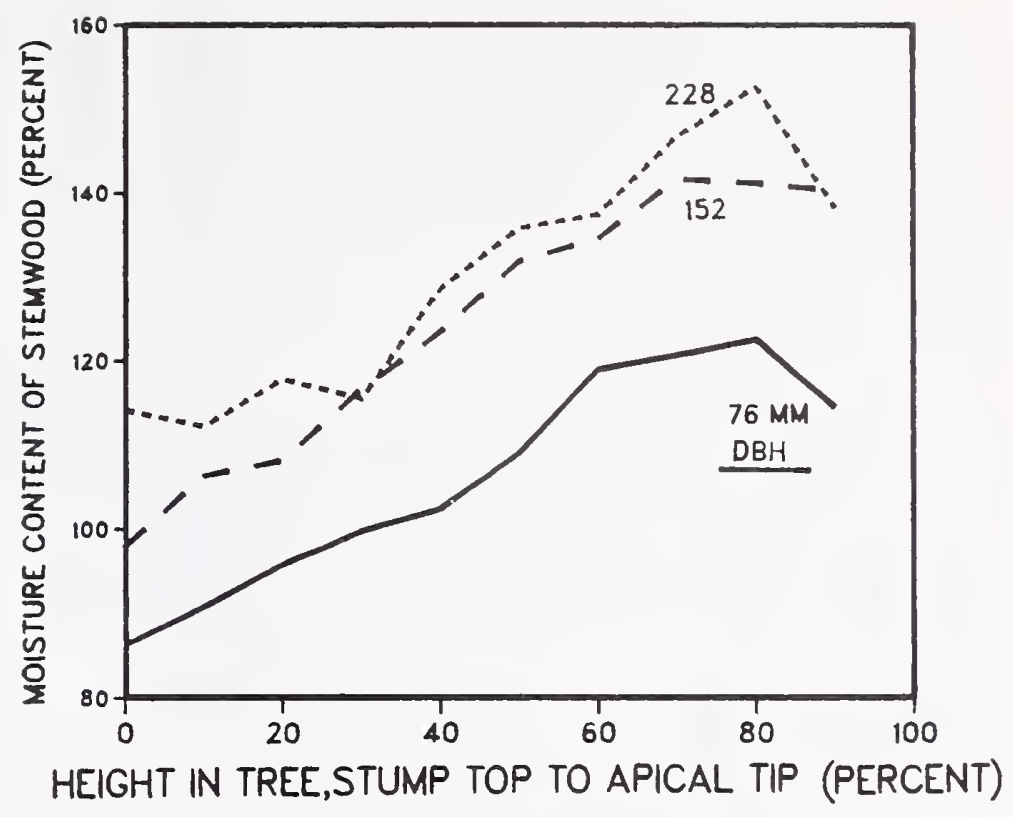

Figure 2-39-Moisture content of stemwood related to height in tree for murrayana trees of three diameters.

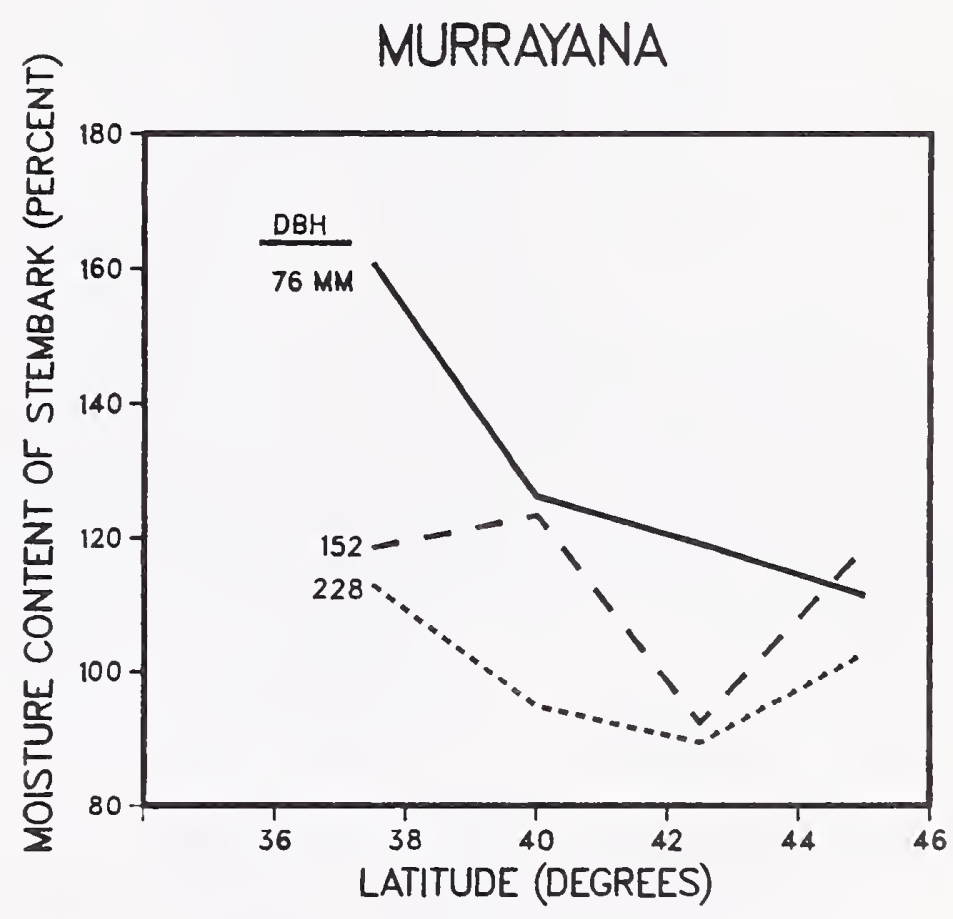

Figure 2-40-Moisture content of stembark related to latitude for murrayana trees of three diameters. 


\section{Stembark-Variation With Height}

Stembark moisture content increased from about 99 percent at stump height to about 131 percent at 90 percent of tree height; patterns of variation with height were similar for the three diameter classes (fig. 2-41). This trend in stembark variation with height in tree was found at all four latitudes studied (fig. 2-42).

\section{Sapwood}

Sapwood moisture content averaged 125.1 percent, with standard deviation of 21.2 percentage points. It was unrelated to latitude, but was positively correlated with d.b.h. Trees 76,152 , and $228 \mathrm{~mm}$ in diameter had average moisture contents of 104.5 (15.5), 128.5 (14.4), and 142.3 (13.3) percent.

\section{Heartwood}

Heartwood moisture content was much less than that of sapwood, averaging 44.4 percent, with standard deviation of 5.8 percentage points. It was unrelated to d.b.h., but varied inversely with latitude, as follows:

\begin{tabular}{ccc} 
Latitude & \multicolumn{2}{c}{$\begin{array}{c}\text { Average and } \\
\text { standard deviation }\end{array}$} \\
Degrees & . . - Percent - . . \\
37.5 & 49.0 & $(4.7)$ \\
40 & 44.3 & $(7.7)$ \\
42.5 & 43.4 & $(4.8)$ \\
45 & 41.1 & $(2.9)$
\end{tabular}

\section{Stump-Root System, Wood Plus Bark}

Wood plus bark of the stump-root system had average moisiure content of 112.1 percent, with standard deviation of 22.3 percent. Moisture content was unrelated to d.b.h., but varied inversely with latitude, as follows:

\begin{tabular}{lcr} 
Latitude & \multicolumn{2}{c}{$\begin{array}{c}\text { Average and } \\
\text { standard deviation }\end{array}$} \\
Degrees & - . - Percent - . . \\
37.5 & 126.5 & $(14.5)$ \\
40 & 119.9 & $(26.8)$ \\
42.5 & 98.9 & $(11.9)$ \\
45 & 103.1 & $(22.8)$
\end{tabular}

\section{Stump-Root System, Wood Only}

Moisture content of wood of the stump-root system was unrelated to either d.b.h. or latitude. It averaged 110.8 percent, with standard deviation of 24.3 percentage points.

\section{MURRAYANA}

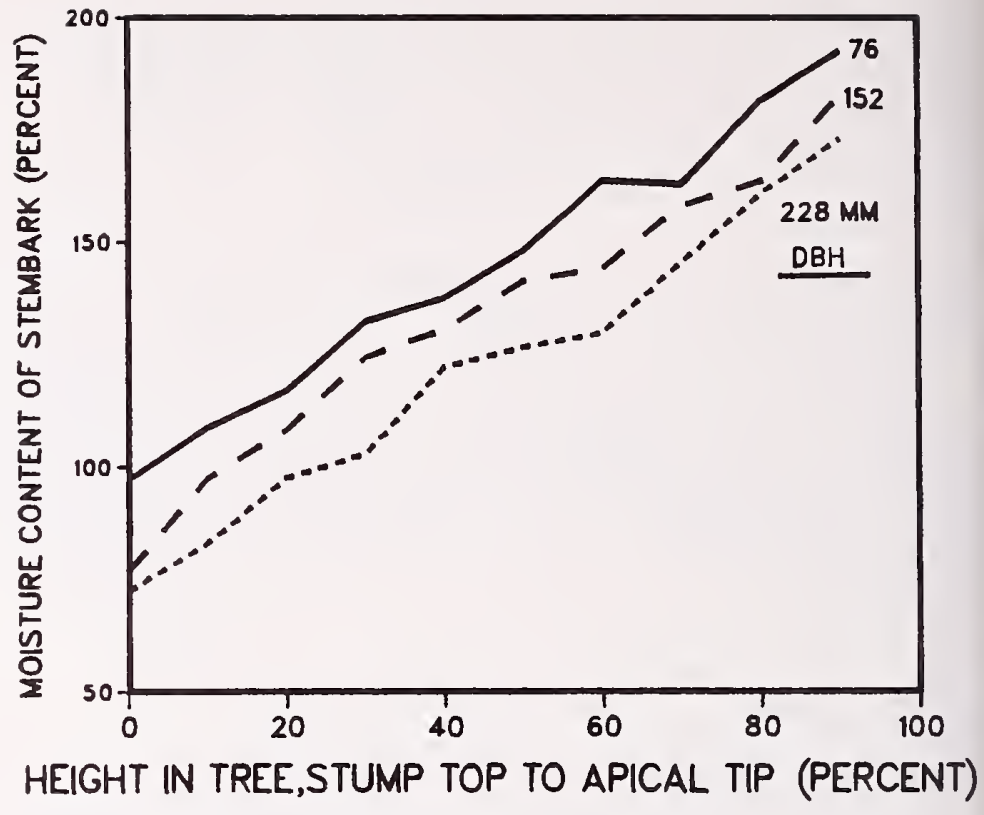

Figure 2-41-Moisture content of stembark related to height in tree for murrayana trees of three diameters.

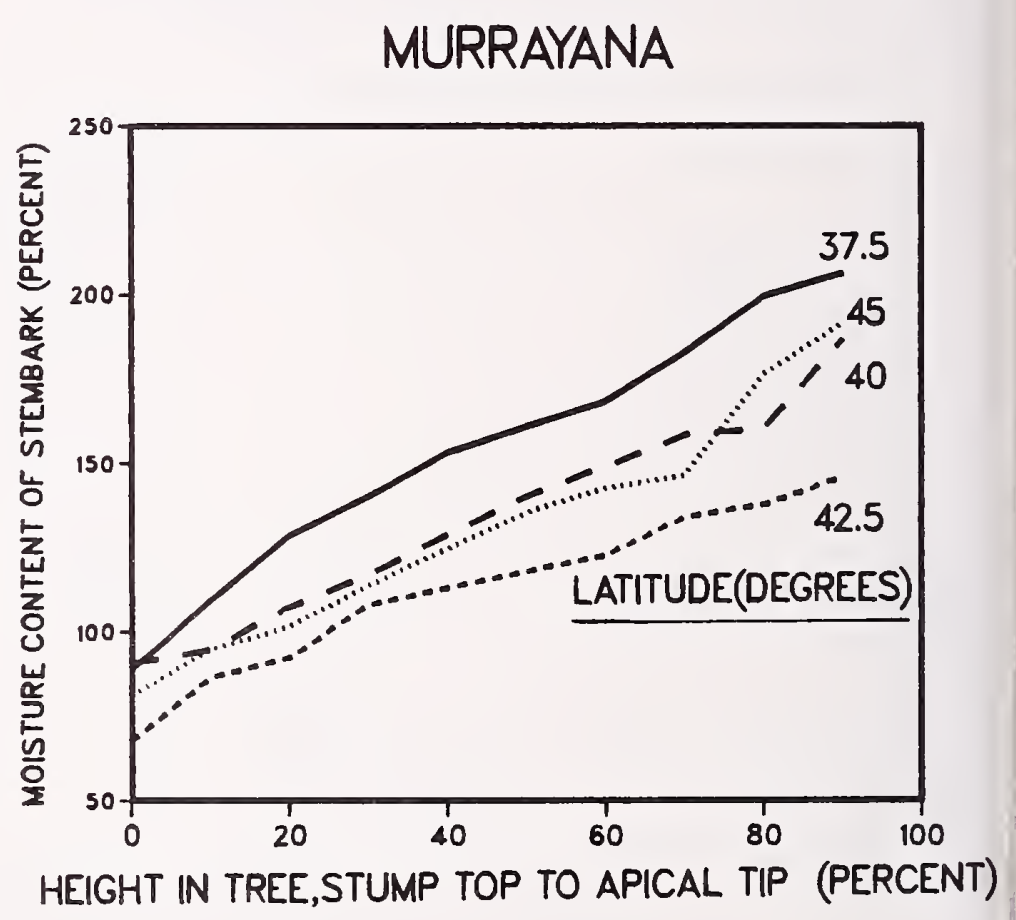

Figure 2-42-Moisture content of stembark related to height in tree and to latitude for murrayana trees, with data from the three diameter classes pooled. 


\section{Stump-Root System, Bark Only}

Bark of the stump-root system had average moisture content of 120.9 percent, with standard deviation of 25.4 percentage points. It varied significantly with both d.b.h. and latitude (fig. 2-43). Bark from 76-mm trees had highest moisture content, averaging 137.4 (28.4) percent; bark from the two larger diameter classes had moisture contents of 111.5 (16.9) and 113.9 (22.7) percent. Bark moisture content was highest at 40 degrees latitude (136 percent) and lowest at 45 degrees (101 percent).

\section{Stump, Wood Plus Bark}

Moisture content of wood plus bark of the stump-from groundline to $152 \mathrm{~mm}$ stump top-was unrelated to either d.b.h. or latitude. It averaged 99.8 percent, with standard deviation of 22.9 percent.

\section{Stumpwood}

Similarly, stumpwood moisture content was unrelated to latitude or d.b.h., averaging 100.7 percent, with standard deviation of 25.5 percentage points.

\section{Stumpbark}

Moisture content of stumpbark averaged 92.1 percent, with standard deviation of 29.1 percentage points. It was inversely correlated with both latitude and d.b.h.

(fig. 2-44). Trees 76,152 , and $228 \mathrm{~mm}$ in d.b.h. had average stumpbark moisture contents of 117.2 (30.3), 84.4 (17.9), and 74.9 (19.7) percent. Moisture content was highest at 37.5 degrees (108 percent) and lowest at 45 degrees (73 percent).

\section{Lateral Roots, Wood Plus Bark}

Moisture content of wood plus bark of lateral roots from root collar to $305 \mathrm{~mm}$ radius from tree pith averaged 125.1 percent, with standard deviation of 28.0 percentage points. It was unrelated to d.b.h., but varied significantly with latitude, as follows:

\begin{tabular}{|c|c|c|}
\hline Latitude & \multicolumn{2}{|c|}{$\begin{array}{c}\text { Average and } \\
\text { standard deviation }\end{array}$} \\
\hline Degrees & \multicolumn{2}{|c|}{ - . Percent ... } \\
\hline 37.5 & 142.4 & $(16.4)$ \\
\hline 40 & 136.9 & $(30.5)$ \\
\hline 42.5 & 110.9 & $(11.3)$ \\
\hline 45 & 110.1 & (33.7) \\
\hline
\end{tabular}

\section{Lateral Roots, Wood Only}

Moisture content of wood of the lateral roots was unrelated to either d.b.h. or latitude; it averaged 121.4 percent, with standard deviation of 30.5 percentage points.
MURRAYANA

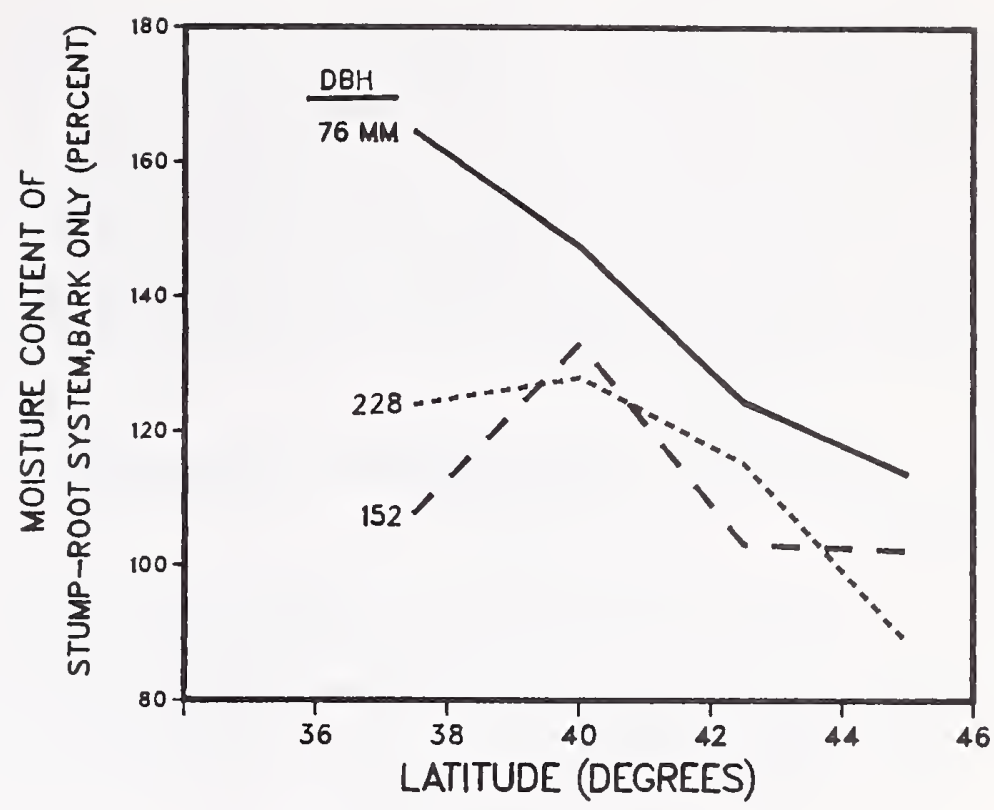

Figure 2-43-Moisture content of bark of the stump-root system related to latitude for murrayana trees of three diameters.

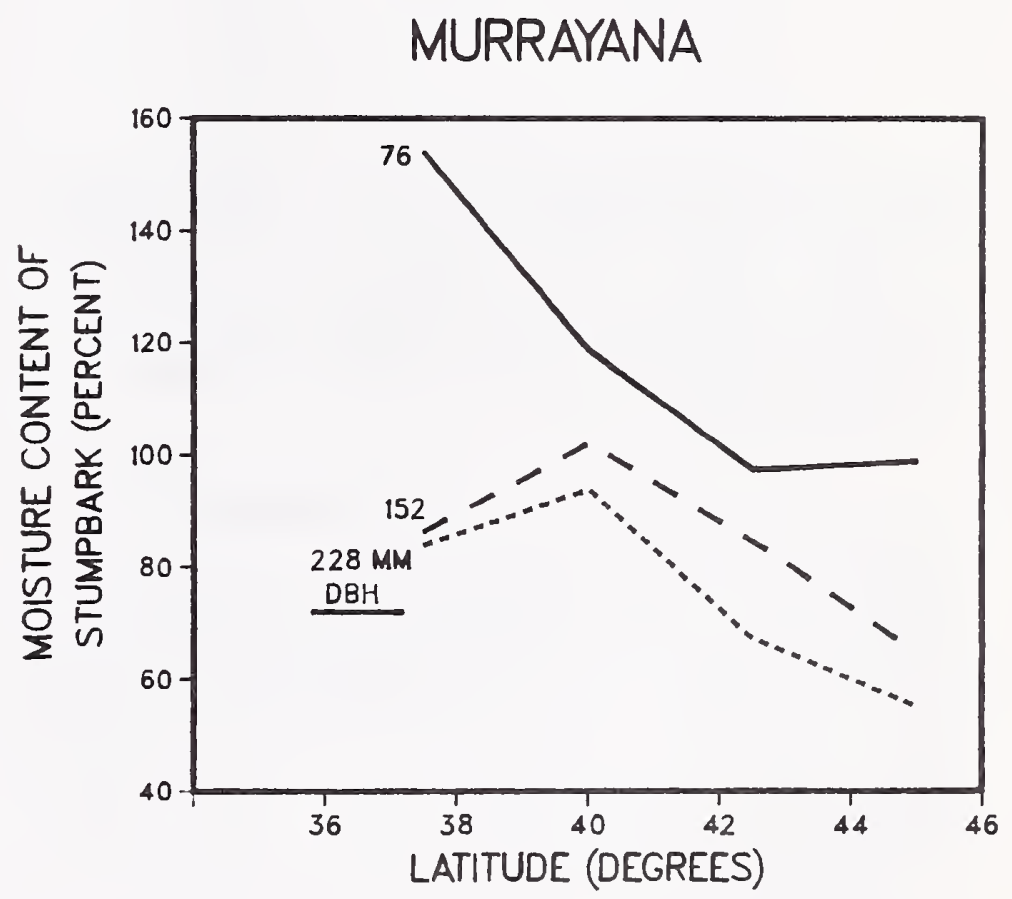

Figure 2-44-Moisture content of stumpbark, groundline to stump top, related to latitude for murrayana trees of three diameters. 


\section{Lateral Roots, Bark Only}

Bark of the lateral roots had moisture content averaging 140.2 percent, with standard deviation of 29.7 percent. It varied inversely with both d.b.h. and latitude (fig. 2-45). Trees $76 \mathrm{~mm}$ in d.b.h. had lateral rootbark with moisture content of 158.3 (33.6) percent, whereas those of the two larger diameter classes had moisture contents of 131.2 (23.7) and 131.2 (24.1) percent. Moisture content averaged highest at 40 degrees latitude (157 percent) and lowest at 45 degrees (123 percent).

\section{Central Root Mass-Taproot, Wood Plus Bark}

Wood plus bark of the central root mass-taproot-shorn of laterals and stump-had average moisture content of 113.0 percent, with standard deviation of 26.5 percentage points. It was unrelated to d.b.h., but varied significantly with latitude, as follows:

\begin{tabular}{ccr} 
Latitude & \multicolumn{2}{c}{$\begin{array}{c}\text { Average and } \\
\text { standard deviation } \\
\text { Degrees }\end{array}$} \\
37.5 & 126.5 & $(11.7)$ \\
40 & 124.7 & $(33.6)$ \\
42.5 & 94.4 & $(17.0)$ \\
45 & 106.5 & $(27.0)$
\end{tabular}

\section{Central Root Mass-Taproot, Wood Only}

Moisture content of wood of the central root masstaproot was unrelated to either d.b.h. or latitude; it averaged 112.5 percent, with standard deviation of 28.3 percentage points.

\section{Central Root Mass-Taproot, Bark Only}

Bark of the central root mass-taproot had moisture content averaging 115.3 percent, with standard deviation of 34.2 percentage points. It varied significantly with both d.b.h. and latitude (fig. 2-46). Trees $76 \mathrm{~mm}$ in d.b.h. had moisture contents averaging 137.6 (30.9) percent, whereas those of the two larger diameter classes averaged 95.6 (34.9) and $112.7(24.0)$ percent.

Taproot bark moisture content was highest at 40 degrees latitude (135 percent) and lowest at 45 degrees (98 percent).

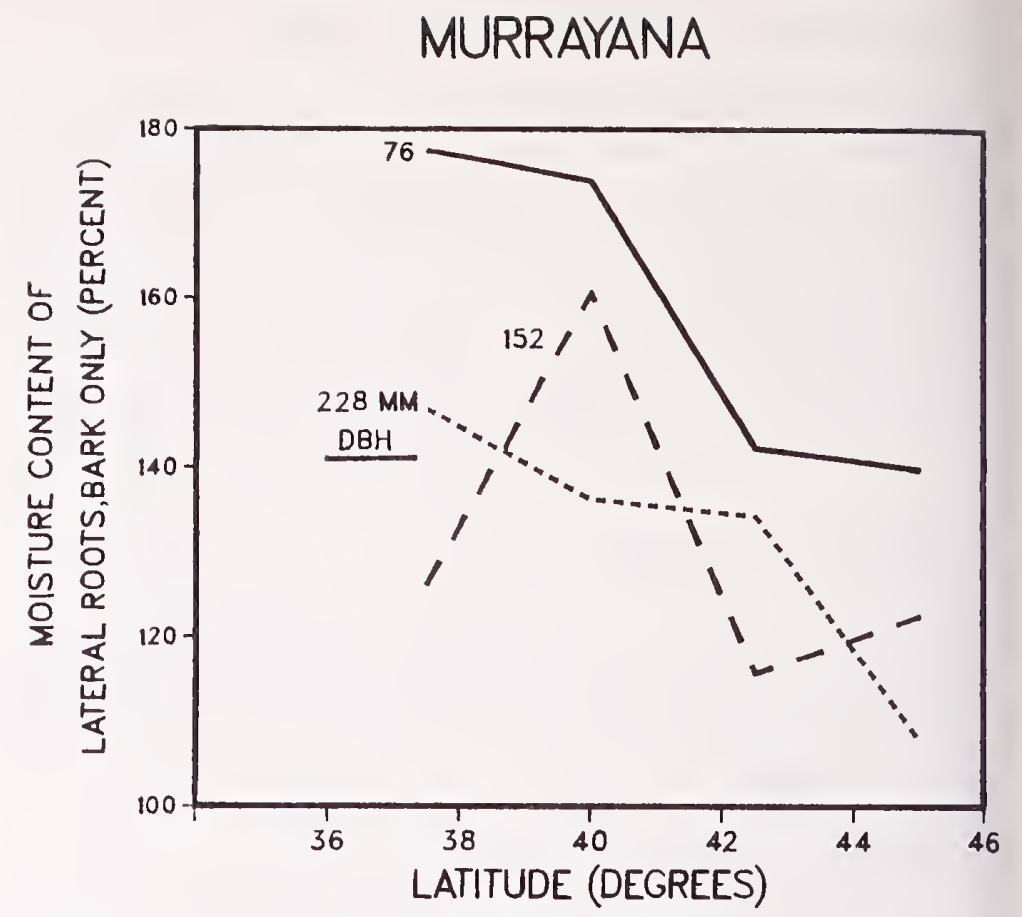

Figure 2-45-Moisture content of bark of lateral roots, root collar to $305 \mathrm{~mm}$ radius from tree pith, related to latitude for murrayana trees of three diameters.

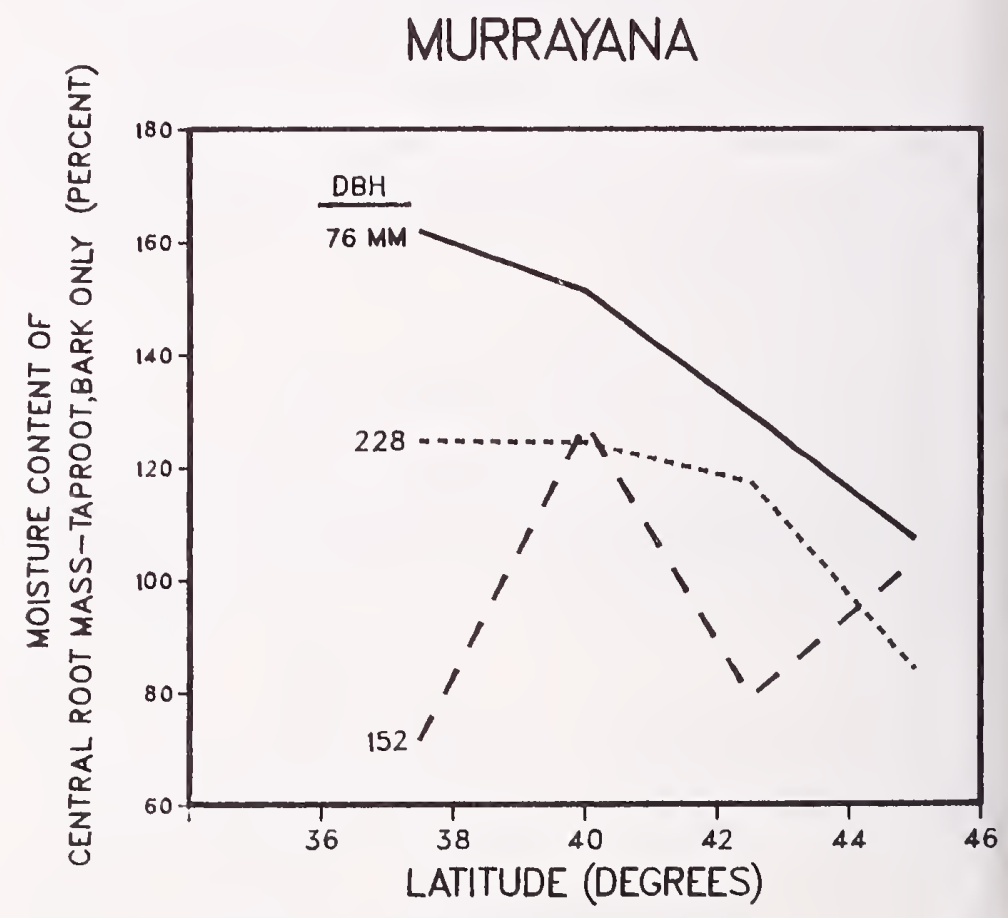

Figure 2-46-Moisture content of bark of central root mass and taproot, shorn of laterals and stump, related to latitude for murrayana trees of three diameters. 


\section{2-7 RESULTS-LATIFOLIA COMPARED TO MURRAYANA}

The experimental design permitted an orthogonal comparison between the two varieties at three latitudes as follows:
Varieties:
(2) latifolia and murrayana
D.b.h. classes:
(3) 76,152 , and $228 \mathrm{~mm}$
Latitudinal zones:
(3) $40,42.5$, and 45 degrees
Elevational zones:
(1) medium $(1,148$ to $2,711 \mathrm{~m})$
Replications:

Sample size for this comparison therefore totaled 54 trees, 27 of each variety. In the discussions that follow, only significant relationships associated with varietal differences are explained; the other effects are more completely described in the previous two results sections.

No statistically significant varietal differences were observed in moisture contents of the following components:

Complete tree with cones and foliage

Complete tree without cones or foliage

Complete tree, wood only

Cones

Live branchwood

Stem, wood plus bark-tree average

Stem, wood plus bark-variation with height

Stemwood-tree average

Stemwood-variation with height

Stembark - tree average

Stembark-variation with height

Sapwood

Heartwood

Stump-root system, wood only

Stump, wood plus bark

Stumpwood

Lateral roots, wood plus bark

Lateral roots, wood only

Central root mass-taproot, wood plus bark

Central root mass-taproot, wood only

Most of the significant varietal differences observed were related to bark and foliage rather than wood moisture content, as discussed in the following paragraphs; dead branchwood was the exception to this generalization.

\section{Foliage}

At 40 and 42.5 degrees, latifolia had higher foliage moisture contents than murrayana; the reverse was true at 45 degrees, as follows:
COMPARISON

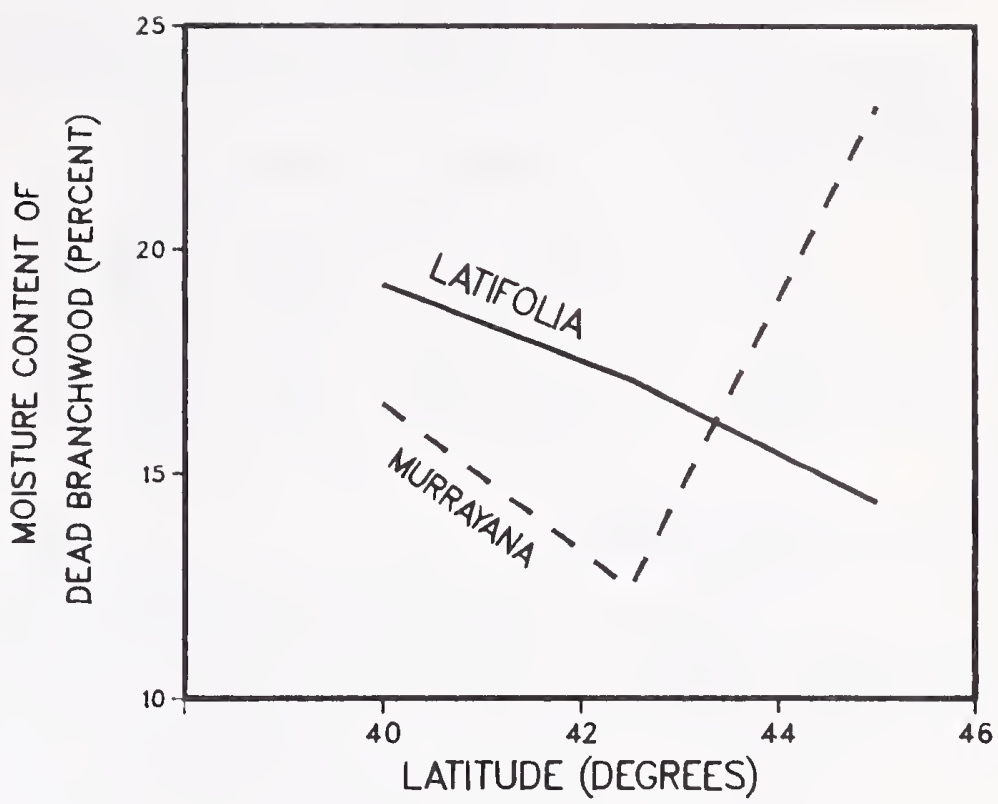

Figure 2-47-Moisture content of dead branchwood of latifolia trees of three diameters (diameter data pooled) compared with that of murrayana related to latitude.

\begin{tabular}{|c|c|c|c|c|}
\hline Latitude & \multicolumn{2}{|c|}{ Latifolia } & \multicolumn{2}{|c|}{ Murrayana } \\
\hline Degrees & $\ldots$ & $\cdots P$ & $n t-\cdots$ & $\cdots$ \\
\hline 40 & 120.1 & $(10.5)$ & 103.8 & (10.3) \\
\hline 42.5 & 119.3 & $(16.6)$ & 114.5 & (2.5) \\
\hline 45 & 119.7 & (14.1) & 125.1 & $(9.8)$ \\
\hline Pooled & 119.7 & $(14.1)$ & 114.5 & (11.9) \\
\hline
\end{tabular}

\section{Dead Branchwood}

At 40 and 42.5 degrees latitude, latifolia had higher dead branchwood moisture content than murrayana; the reverse was true at 45 degrees, as follows (fig. 2-47):

\begin{tabular}{|c|c|c|c|c|}
\hline Latitude & \multicolumn{2}{|c|}{ Latifolia } & \multicolumn{2}{|c|}{ Murrayana } \\
\hline Degrees & $\ldots$ & $\cdots I$ & $t=$ & . \\
\hline 40 & 19.2 & (5.3) & 16.5 & $(3.2)$ \\
\hline 42.5 & 17.1 & (3.1) & 12.4 & $(1.2)$ \\
\hline 45 & 14.4 & (1.6) & 23.2 & $(8.7)$ \\
\hline Pooled & 16.9 & $(4.1)$ & 17.4 & $(6.9)$ \\
\hline
\end{tabular}




\section{Live Branches, Wood Plus Bark}

The moisture content of wood plus bark of live branches was significantly higher in latifolia than in murrayana, as follows:

\begin{tabular}{|c|c|c|c|c|}
\hline D.b.h. & \multicolumn{2}{|c|}{ Latifolia } & \multicolumn{2}{|c|}{ Murrayana } \\
\hline $\mathrm{mm}$ & $\cdots$ & $\cdots P$ & $t$ t. & $\ldots$ \\
\hline 76 & 100.3 & (13.7) & 88.6 & $(11.0)$ \\
\hline 152 & 106.1 & (6.8) & 97.7 & $(11.0)$ \\
\hline 228 & 107.7 & $(20.3)$ & 101.2 & (8.0) \\
\hline Pooled & 104.7 & (14.5) & 95.8 & (11.1) \\
\hline
\end{tabular}

\section{Live Branchbark}

Moisture content of the bark of live branches was also significantly higher in latifolia than in murrayana trees, as follows (fig. 2-48):

\begin{tabular}{crrrr} 
D.b.h. & \multicolumn{2}{c}{ Latifolia } & \multicolumn{2}{c}{ Murrayana } \\
$m m$ & $\ldots \ldots$ & $\ldots$ & - & Percent $\ldots \ldots . .$. \\
76 & 115.3 & $(21.6)$ & 91.6 & $(16.0)$ \\
152 & 120.0 & $(32.6)$ & 92.6 & $(15.6)$ \\
228 & 121.3 & $(22.9)$ & 105.2 & $(20.0)$ \\
Pooled & 118.9 & $(25.2)$ & 96.5 & $(17.8)$
\end{tabular}

\section{Stump-Root System, Wood Plus Bark}

Moisture content of wood plus bark of the stump-root system averaged higher in latifolia (110.8 percent, with standard deviation of 21.6 percentage points) than in murrayana (107.3 percent, with standard deviation of 22.6 percentage points), but this was due only to a large difference at 42.5 degrees latitude; at 40 degrees and 45 degrees the reverse was true (fig. 2-49).
COMPARISON

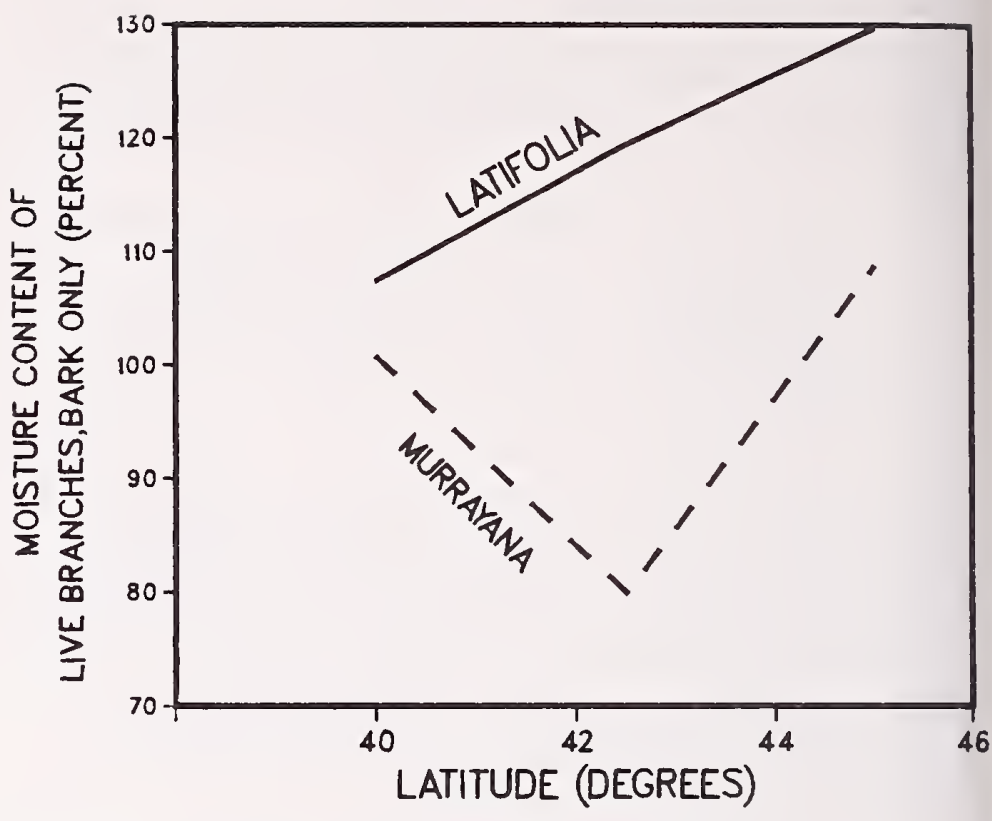

Figure 2-48-Comparative moisture content of live branchbark of latifolia and murrayana trees of three diameters (diameter data pooled) related to latitude.

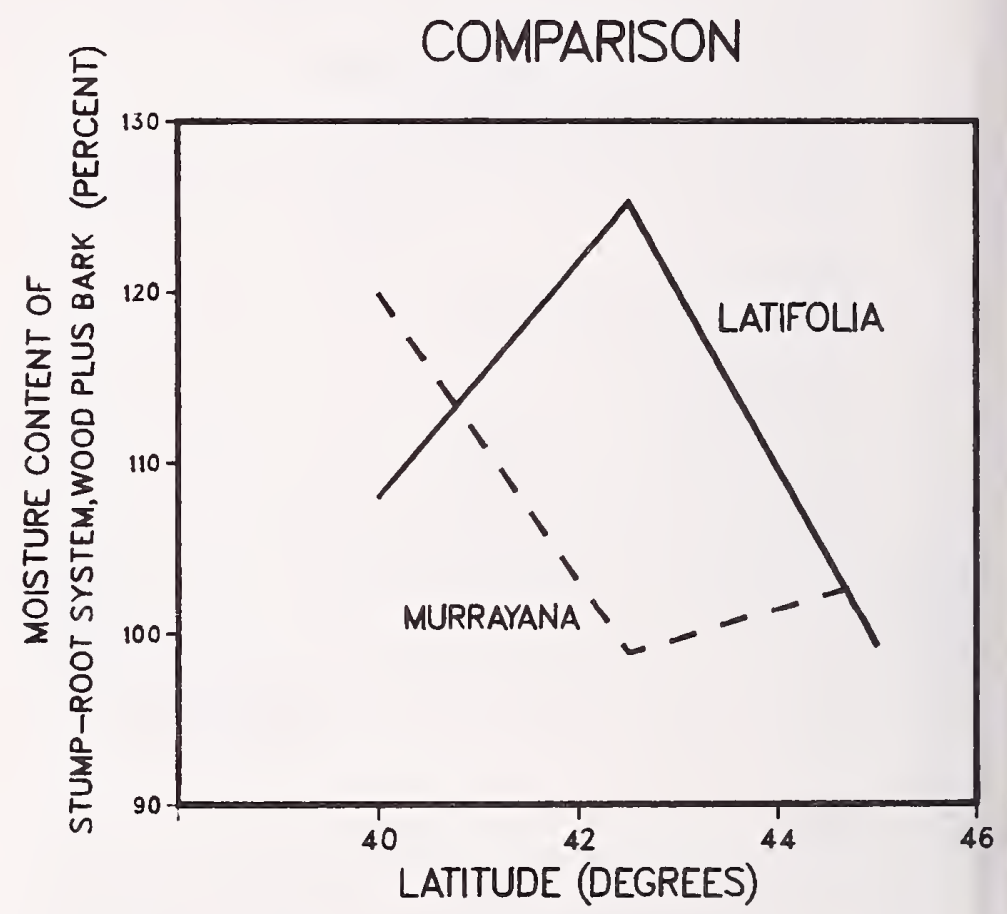

Figure 2-49-Comparative moisture content of stump-root system, wood plus bark, of latifolia and murrayana trees of three diameters (diameter data pooled) related to latitude. 


\section{Stump-Root System, Bark Only}

Moisture content of bark of the stump-root system of latifolia averaged 128.3 (27.8) percent, while that of murrayana was less at 117.2 (23.3) percent, but this relationship reversed at 40 degrees latitude in trees of the two larger diameter classes (fig. 2-50).

\section{COMPARISON}
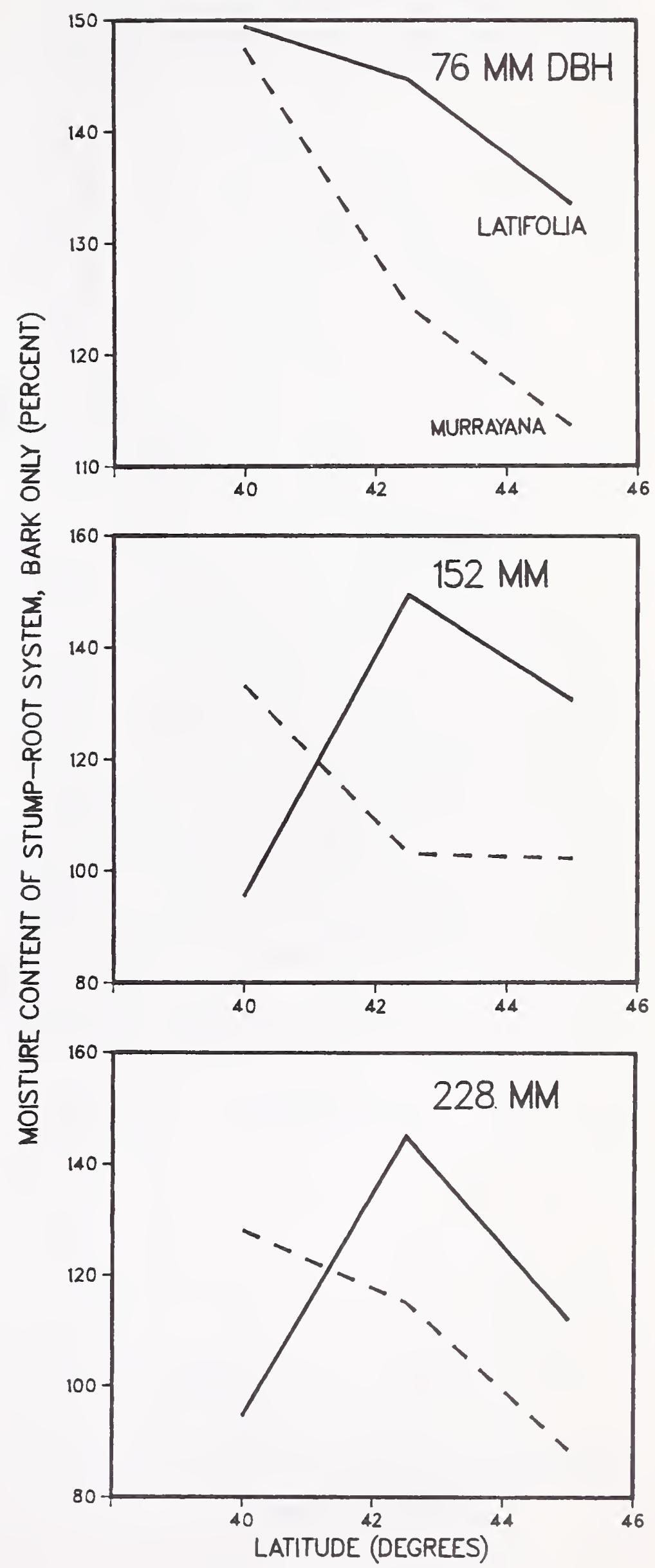

Figure 2-50-Comparative moisture content of stump-root system bark of latifolia and murrayana trees of three diameters related to latitude. 


\section{Stumpbark}

The stumpbark of both latifolia and murrayana had average moisture content of 87 percent, but variety moisture contents differed significantly with various combinations of latitude and diameter class (fig. 2-51).

\section{COMPARISON}

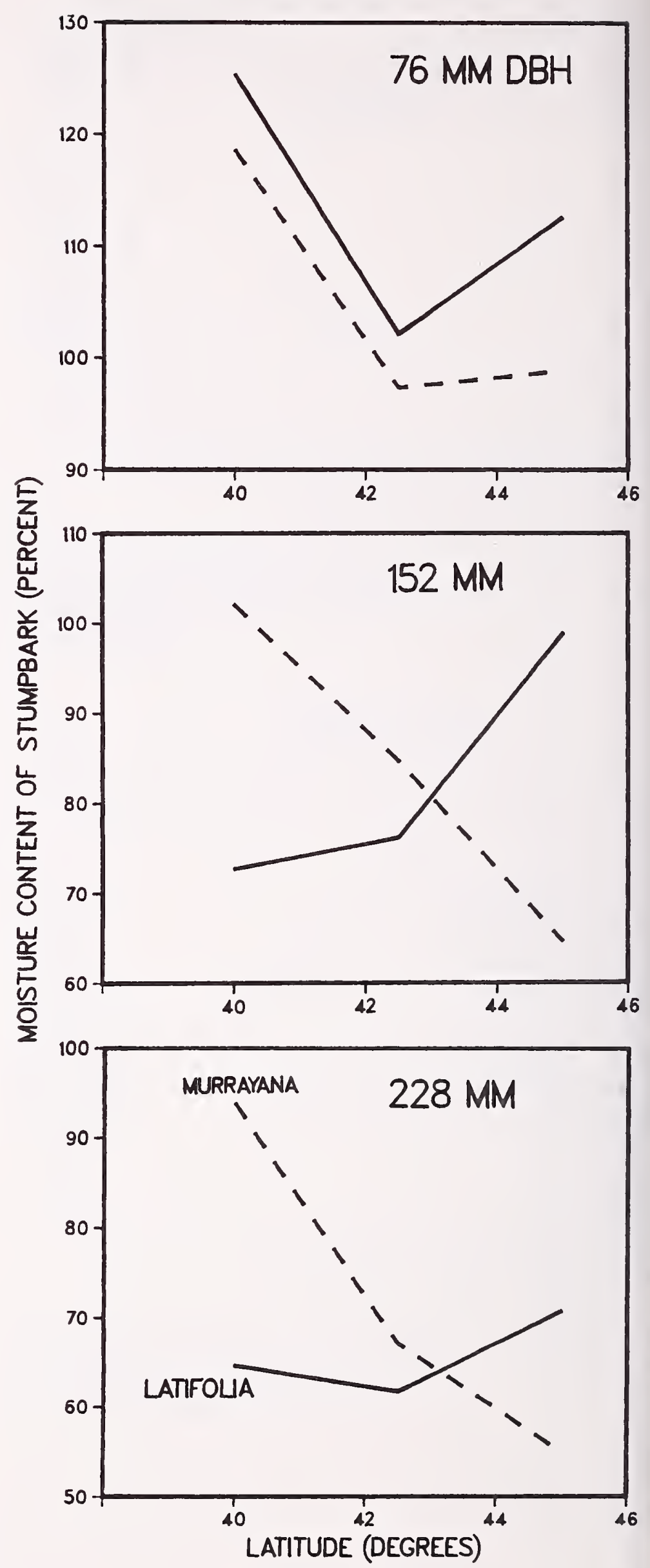

Figure 2-51-Comparative moisture content of stumpbark of latifolia and murrayana trees of three diameters related to latitude. 


\section{Lateral Roots, Bark Only}

Bark of the lateral roots of latifolia had average moisture content of 104.7 (27.3) percent-less than the average for murrayana, which was 108.5 (28.7) percent; but this relationship changed depending on latitude and diameter class (fig. 2-52).

\section{COMPARISON}
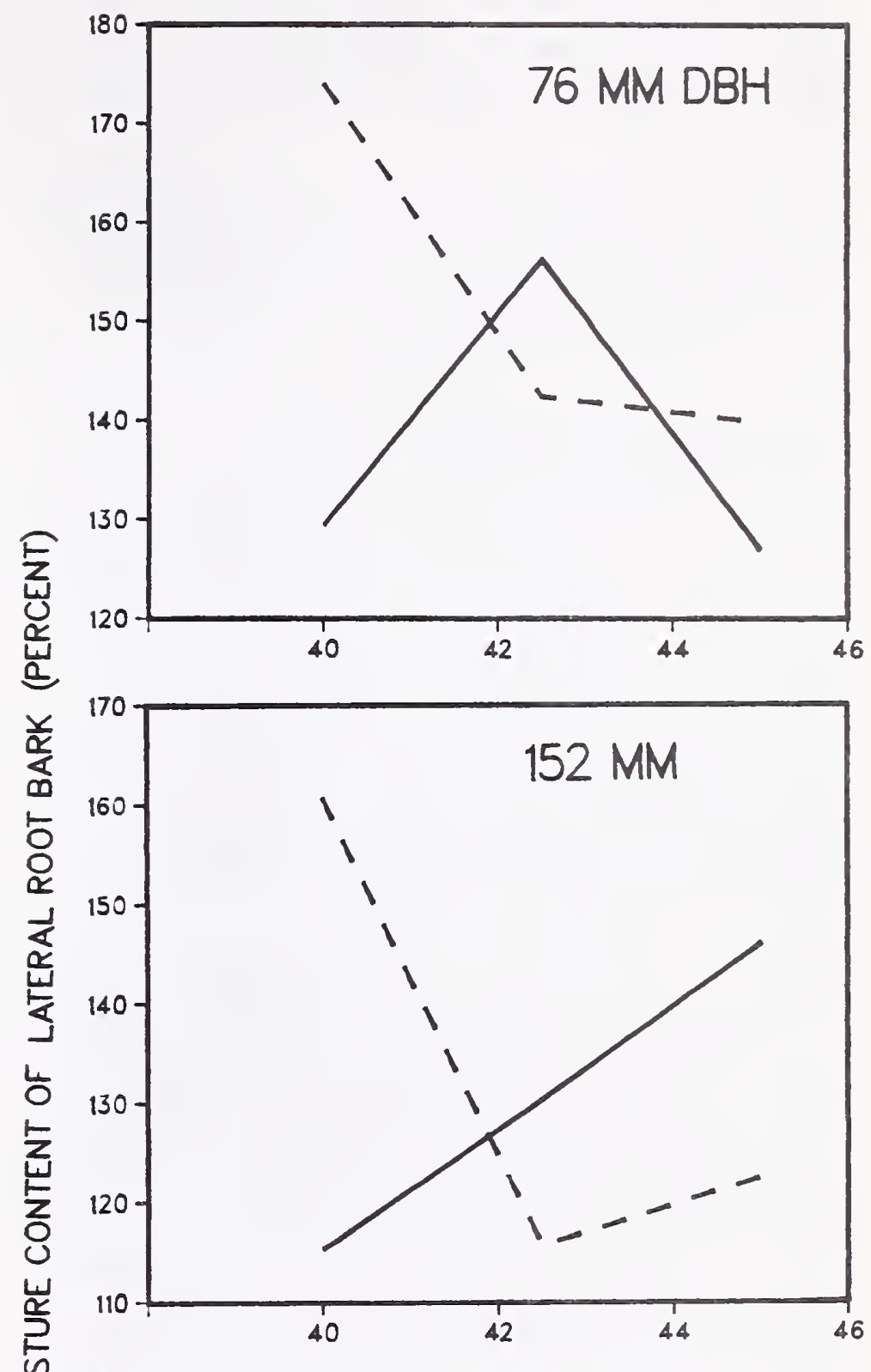

$\frac{\bar{n}}{\frac{0}{2}}$

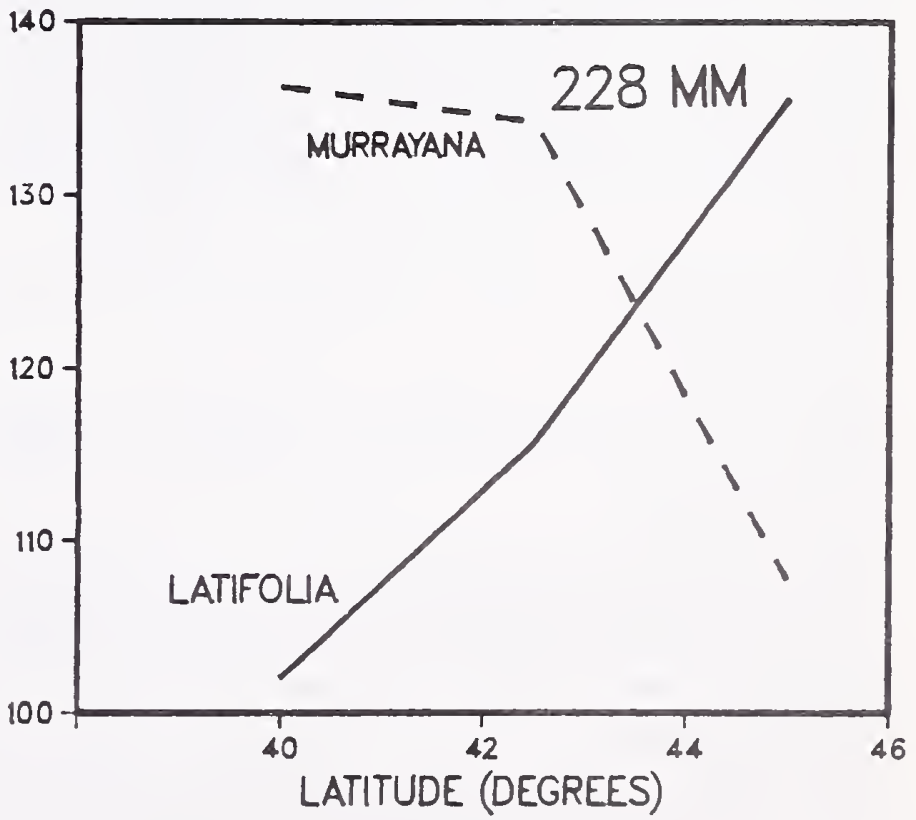

Figure 2-52-Comparative moisture content of lateral root bark of latifolia and murrayana trees of three diameters related to latitude. 


\section{Central Root Mass-Taproot, Bark Only}

Bark of the central root mass-taproot of latifolia had average moisture content of 123.4 (25.7) percent-more than the average for murrayana which was 113.9 (28.7); but this relationship reversed at 40 degrees latitude (fig. 2-53).

For those bark components where significant differences in moisture content were observed, moisture of latifolia bark tended to be positively correlated with latitude, whereas bark moisture of murrayana tended to be negatively correlated with latitude.

\section{2-8 SUMMARY OF RESULTS}

The moisture contents of components of lodgepole pine trees of varieties latifolia and murrayana are strongly related to latitude and diameter, but less related to elevational zone. Longitudinal zone was studied only for latifolia, but no effects were discernible.

Differences between the moisture contents of tree components of latifolia and murrayana were minor-most related to bark moisture contents; in latitudes $40,42.5$, and 45 degrees latifolia bark moisture content tended to be positively correlated with latitude, whereas bark moisture of murrayana was negatively correlated with latitude.

Throughout the full range of latitude (40 to 60 degrees) in which latifolia moisture contents were studied, however, there was a pronounced decrease in latifolia treecomponent moisture content from south to north. Maximum moisture contents usually occurred at latitude 42.5 or 45 degrees, and minimums were observed between 52.5 and 60 degrees. For example, stemwood moisture content (diameter data pooled) averaged 124 percent at 42.5 degrees and only 83 percent at 60 degrees. Similarly, stembark moisture content averaged 131 percent at 45 degrees but only 80 percent at 52.5 degrees.

Moisture contents of the following components were inversely correlated with d.b.h., that is, moisture contents were higher in trees $76 \mathrm{~mm}$ in d.b.h. than in trees of larger diameter: complete trees (with or without foliage), foliage, stembark, heartwood, and wood and bark of the stump-root system. Sapwood, however, had higher moisture content in trees of large diameter than in those of small diameter.

The moisture content of both wood and bark increased sharply from stump height to upper stem; the increase was greater in bark (72 to 165 percent) than in wood (90 to 130 percent).

Moisture contents of tree components were most closely and most frequently correlated with specific gravity of wood and bark of components, heartwood percentage of stemwood volume, sapwood thickness at stump height, and with crown ratio.

Tree-average moisture contents (all latifolia data pooled) for tree components were generally in the range from 90 to 110 percent of ovendry weight, with exceptions as follows: cones (26 percent), dead branchwood (18 percent),

\section{COMPARISON}
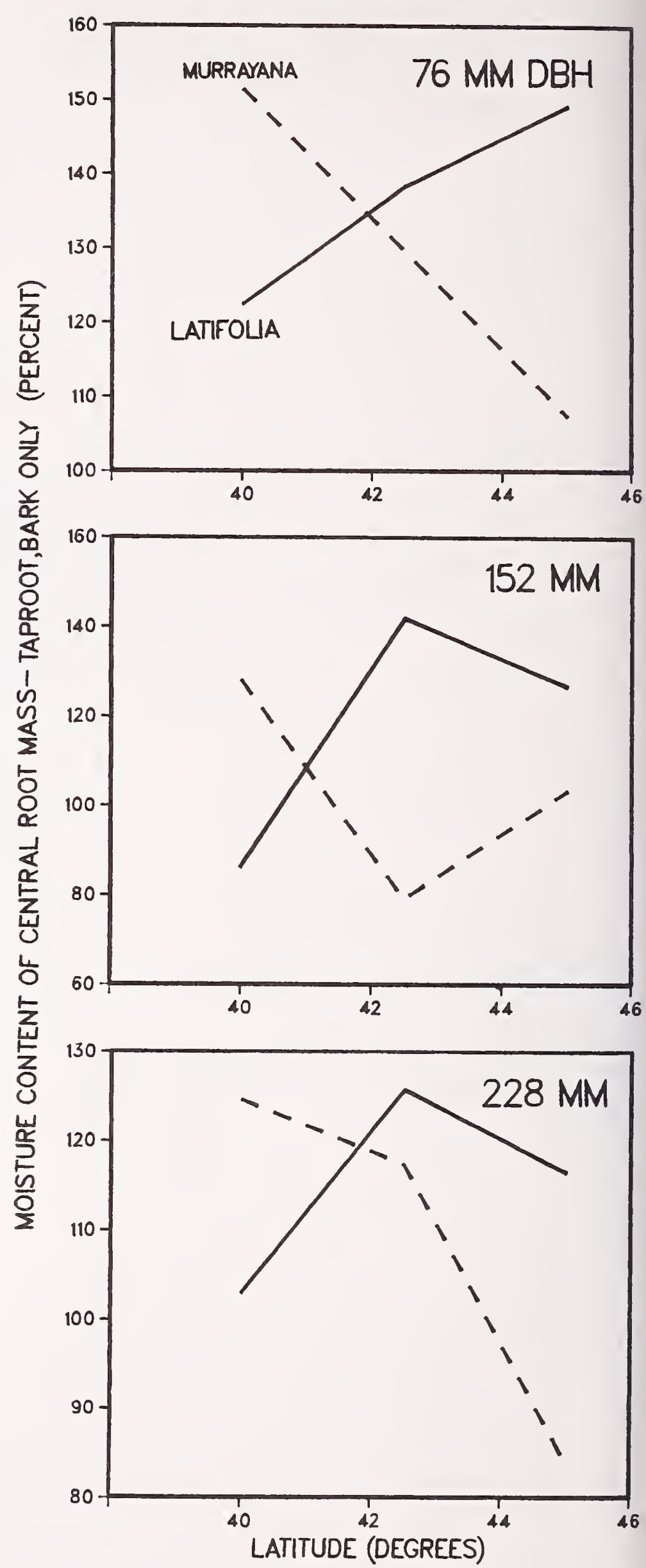

Figure 2-53-Comparative moisture content of bark from the central root mass-taproot of latifolia and murrayana trees of three diameters related to latitude. 
sapwood (119 percent), heartwood (43 percent), and bark of lateral roots (121 percent).

Significant variations related to latitude, d.b.h., elevational zone, and height in tree are so large, however, that variety-wide generalizations about average moisture contents of tree components should be made with caution.

\section{2-9 REFERENCES}

Brown, James K. Weight and density of crowns of Rocky Mountain conifers. Research Paper INT-197. Ogden, UT: U.S. Department of Agriculture, Forest Service, Intermountain Forest and Range Experiment Station; 1978. $56 \mathrm{p}$.

Dixon, Hobart Norris. The growth of lodgepole pine in the Colorado front range as related to environment. Dissertation Abstracts International. 30(6): 2561-B; 1969. Abstract.

Dobie, J.; McIntosh, J. A. Spruce foliage yields more than triple that of pine. Pulp and Paper of Canada. 77(10): $71-72 ; 1976$.

Fahey, Thomas D. Evaluating dead lodgepole pine for products. Forest Products Journal. 30(12): 34-39; 1980.

Fahey, Thomas D. Value ranking for utilizing lodgepole pine residues. In: Harvesting and utilization opportunities for forest residues in the Northern Rocky Mountains: symposium proceedings; 1979 November 28-30; Missoula, MT. General Technical Report INT-110. Ogden, UT: U.S. Department of Agriculture, Forest Service, Intermountain Forest and Range Experiment Station; 1981: 239-250.

Fahnestock, George R. Logging slash flammability. Research Paper 58. Ogden, UT: U.S. Department of Agriculture, Forest Service, Intermountain Forest and Range Experiment Station; 1960. 67 p.

Ince, Peter J. Economic perspective on harvesting and physical constraints on utilizing small, dead lodgepole pine. Forest Products Journal. 32(11/12): 61-66; 1982.

Johnstone, W. D. Some variations in specific gravity and moisture content of 100-year-old lodgepole pine trees. Information Report A-X-29. Calgary, AB: Department of Fisheries and Forestry, Canadian Forestry Service, Forest Research Laboratory; 1970. 19 p.
Lieu, Peter J.; Kelsey, Rick G.; Shafizadeh, Fred. Some chemical characteristics of green and dead lodgepole pine and western white pine. Research Note INT-256. Ogden, UT: U.S. Department of Agriculture, Forest Service, Intermountain Forest and Range Experiment Station; 1979. 8 p.

Lowery, David P. Using dead softwood timber: kiln-drying procedures for lumber and preservative treatments for fenceposts. In: The dead softwood timber resource: Proceedings; 1978 May 22-24; Spokane, WA. Pullman, WA: Washington State University; 1978: 127-146.

Lowery, David P.; Hearst, Allen L., Jr. Moisture content of lumber produced from dead western white pine and lodgepole pine trees. Research Paper INT-212. Ogden, UT: U.S. Department of Agriculture, Forest Service, Intermountain Forest and Range Experiment Station; 1978. $11 \mathrm{p}$.

Lowery, David P.; Hillstrom, William A.; Elert, Erwin E. Chipping and pulping dead trees of four Rocky Mountain timber species. Research Paper INT-193. Ogden, UT: U.S. Department of Agriculture, Forest Service, Intermountain Forest and Range Experiment Station; 1977. $11 \mathrm{p}$.

Markstrom, Donald C.; Hann, Robert A. Seasonal variation in wood permeability and stem moisture content of three Rocky Mountain softwoods. Research Note RM-212. Fort Collins, CO: U.S. Department of Agriculture, Forest Service, Rocky Mountain Forest and Range Experiment Station; 1972. 7 p.

Reid, R. W. Moisture changes in lodgepole pine before and after attack by the mountain pine beetle. Forestry Chronicle. 37(4): 368-375, 403; 1961.

Smith, J. H. G.; Kozak, A. Thickness, moisture content, and specific gravity of inner and outer bark of some Pacific Northwest trees. Forest Products Journal. 21(2): $38-40 ; 1971$.

U.S. Department of Agriculture, Forest Service. Commercial and laboratory pulping tests were made on insectkilled and green-cut lodgepole pine. In: Thirty-seventh annual report for the calendar year 1947. Missoula, MT: U.S. Department of Agriculture, Forest Service, Northern Rocky Mountain Forest and Range Experiment Station; 1948: 22-23. 


\section{CHAPTER 3: STEM TAPER}

\section{CONTENTS}

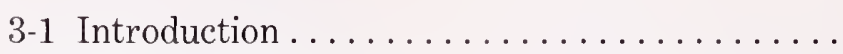

3-2 Objective and Scope ..............

3-3 Literature Review . . . . . . . . . . . . . . .

117

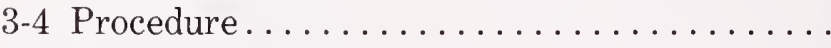

3-5 Results-Latifolia .................

119

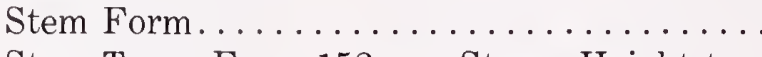

Stem Taper From 152-mm Stump Height to

Base of Live Crown, Inside Bark .........

Stem Taper From Base of Live Crown to Apical Tip, Inside Bark ..............

Stem Diameter at base of Live Crown, Inside

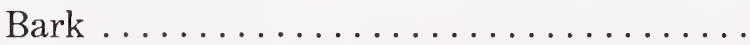

Stemwood Volume Within the Live Crown, as a Proportion of Total Stemwood Volume

From 152-mm Stump Height to Apical Tip. .

3-6 Results-Murrayana................

Stem Taper From 152-mm Stump Height to

Base of Live Crown, Inside Bark .........

Stem Taper From Base of Live Crown to

Apical Tip, Inside Bark . . . . . . . . . . . .

Stem Diameter at Base of Live Crown, Inside Bark

Stemwood Volume Within the Live Crown, as a Proportion of Total Stemwood Volume

From 152-mm Stump Height to Apical Tip. . 


\section{3-1 INTRODUCTION}

Taper of trees strongly affects their utility. Stems with little taper are preferred in roundwood products, yield more lumber when sawn, and contain more cubic volume when chipped for fiber than those of the same butt diameter but with a high degree of taper. Among coniferous species lodgepole pine is noted for its minimal taper; it does, however, display significant variation in this characteristic.

\section{3-2 OBJECTIVE AND SCOPE}

Only those taper parameters most important to processors of lodgepole pine stems are scrutinized in this chapter, and no attempt is made to construct equations predicting stem form; instead, graphs are presented of data aggregated in various significant ways that permit reading of taper information directly from the observed study data. Emphasis is given to stem dimensions inside bark below the live crown as distinct from stemwood within the live crown. Because processors frequently leave whole crowns in the forest, it is useful to know the percentage of total stemwood such crown stemwood represents, and the diameter of stemwood at the base of the live crown. Also, stem forms are plotted to illustrate their curvilinearity with height in tree.

As previously noted, the characterization effort is confined to two varieties of lodgepole pine: Pinus contorta var. latifolia Engelm. and Pinus contorta var. murrayana (Grev. \& Balf.) Engelm., with emphasis on the former. The primary objective during tree collection was to obtain three replications of disease- and insect-free specimens of var. latifolia measuring 76,152 , and $228 \mathrm{~mm}$ in diameter at breast height (d.b.h.) at low, medium, and high elevations from nine equally spaced north latitudinal zones ( 40 to 60 degrees) across 10 degrees of longitude in such a way as to encompass the major range of this variety (fig. 1-1).

A secondary objective was to sample three replications of these same three diameter classes of var. murrayana at midelevation at four north latitudes $(37.5,40,42.5$, and 45 degrees) in California and Oregon at a single longitude per latitude (fig. 1-1).

The trees of both varieties were sampled in such a way that between-variety comparisons could be made for midelevation trees at latitudes $40,42.5$, and 45 degrees. The sampling plan does not permit computation of speciesaverage values. The collection totaled 243 latifolia and 36 murrayana trees.

Explanations of statistical analyses procedures and a table of analyses of variance formats, with degrees of freedom indicated, are shown in table 1-2. In the results portion of this chapter standard deviations are noted in the text in parentheses following average values. Correlations of interest observed in latifolia between taper data and tree characteristics are also noted in the results section of the chapter.

\section{3-3 LITERATURE REVIEW}

In his treatise on latifolia in Alberta, Smithers (1961) commented on its variability in form of bole. He noted that boles of open-grown trees taper noticeably in an almost conical form. In extremely dense stands the stem is whiplike and hardly thicker at ground level than at the top; he also found this stem form in muskeg and other high-water-table conditions where growing conditions are submarginal. Smithers further observed that in more mature stands density affects appearance, so that in very dense stands (for example, 25,000 stems per ha at 90 years) trees have very little taper and are rarely over $6 \mathrm{~m}$ in height and $76 \mathrm{~mm}$ in d.b.h. At medium densities $(2,500$ to 7,500 stems per ha), form class is usually high, averaging 70 to 75 percent. In low-density stands ( 250 to 1,500 mature trees per ha) the bole has considerably more taper and form class is usually 65 to 70 percent. (Form class is the ratio between d.b.h. outside bark and the diameter inside bark at the top of the first 16 -ft log.)

Baranyay and Safranyik (1970) found that stem taper is also related to growth modification caused by dwarf mistletoe attack; heavily infected trees had greater taper than those of uninfected Alberta stands of latifolia.

Plank and Cahill (1984) observed that coniferous trees have a stem comprised of many different shapes (fig. 3-1), and selection of an accurate and unbiased formula to estimate the cubic volume of tree-length logs is therefore difficult. To evaluate the performance of three commonly used formulas for estimating cubic volume, they sampled 509 lodgepole pine tree-length logs (inside bark) from Wyoming and Oregon. They found that Smalian's formula overestimated volume by 19 percent, Bruce's formula

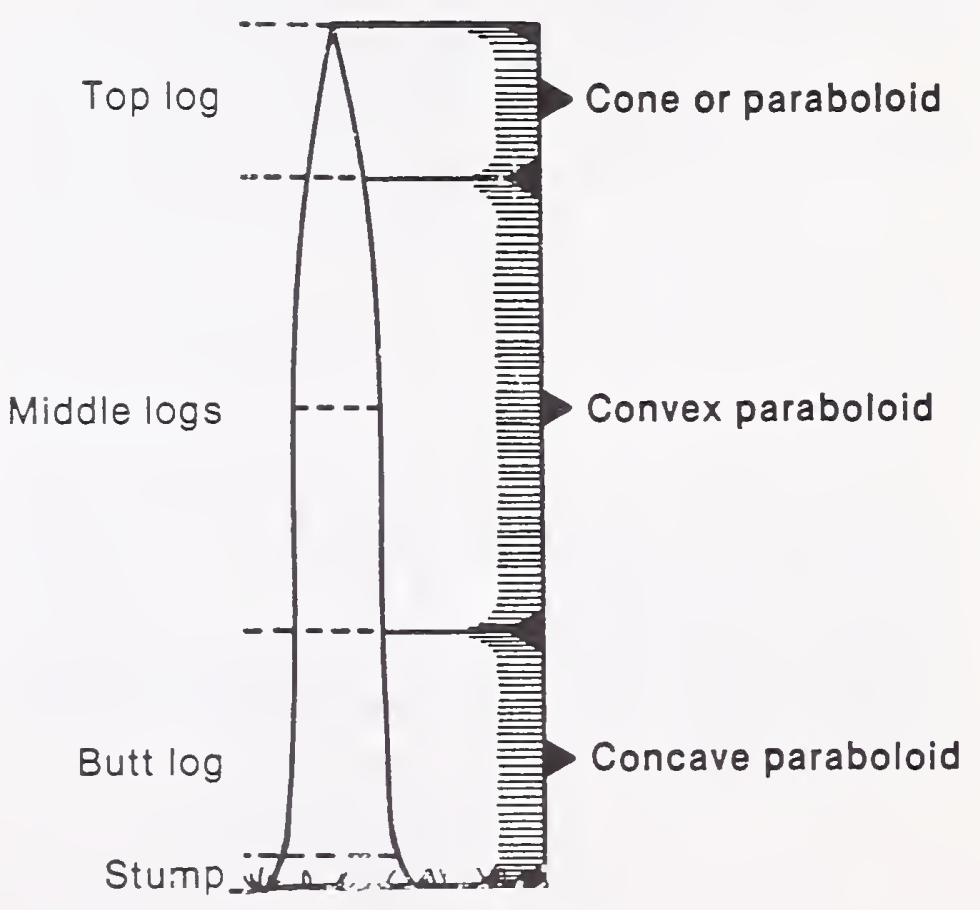

Figure 3-1-Geometric shapes in a coniferous tree stem. (Drawing from Plank and Cahill 1984.) 
underestimated by 16 percent, and Huber's formula underestimated by 2 percent. They recommended Huber's formula, which follows:

Volume in cubic feet $=0.005454\left(D^{2}\right) L$ where:

$D=$ diameter at midlength of $\log$, inches

$L=\log$ length, feet.

It is beyond the scope of this paper to delve deeply into the mathematical formulation of stem curves; those interested in the subject will find useful the review by Sterba (1980).

Following are a few abstracts of additional North American literature specific to taper in lodgepole pine.

In 1973 Adamovich (1975a) sampled latifolia $113 \mathrm{~km}$ north of Prince George, BC, from relatively open, mixed stands on optimum growing sites at low elevation where tree crowns had high green weight. In 1974 he also sampled latifolia on poor sites in British Columbia at elevations from $730 \mathrm{~m}$ to $1,460 \mathrm{~m}$ in the vicinities of Cranbrook, Penticton, Kamloops, Prince George, and Burns Lake (Adamovich 1975b). He expressed the taper in stems studied as the ratio of section butt diameters outside bark to breast height diameter outside bark. In the following tabulation, the values opposite decile 1 mean the ratio of stump diameter to d.b.h.; the values opposite decile 5 mean the ratio of the butt diameter of a $l o g$, with length of one-tenth of tree height and small end at 50 percent of tree height, to d.b.h. Values in parentheses in the "poor site" column are standard deviations, as follows:

\begin{tabular}{rcrr} 
Decile & Good site & \multicolumn{2}{c}{ Poor site } \\
& $\ldots \ldots \ldots$ Ratio $\ldots \ldots .$. \\
1 & 1.46 & 1.18 & $(0.07)$ \\
2 & .96 & .98 & $(.03)$ \\
3 & .88 & .92 & $(.03)$ \\
4 & .82 & .87 & $(.04)$ \\
5 & .77 & .79 & $(.04)$ \\
6 & .71 & .73 & $(.05)$ \\
7 & .65 & .65 & $(.05)$ \\
8 & .57 & .55 & $(.07)$ \\
9 & .44 & .44 & $(.07)$ \\
10 & .23 & .28 & $(.08)$
\end{tabular}

These data indicate that taper within the first tenth of tree height (including butt swell just above the stump) is greater on good sites than on poor sites.

Alemdag and Honer (1977) tabulated the relationship between breast height and stump diameters-both measured outside bark-for latifolia in central and eastern Canada; their data are abstracted as follows:

\begin{tabular}{ccccc} 
& \multicolumn{4}{c}{$\begin{array}{c}\text { Diameter of stump at } \\
\text { four stump heights }\end{array}$} \\
D.b.h. & $\mathbf{1 0} \mathbf{c m}$ & $\mathbf{2 0} \mathbf{c m}$ & $\mathbf{3 0} \mathbf{~ c m ~}$ & $\mathbf{6 0} \mathbf{c m}$ \\
$m m$ & $\ldots \ldots$ & - Millimeters & $\ldots$ \\
100 & 118 & 115 & 113 & 107 \\
140 & 165 & 161 & 158 & 150 \\
180 & 212 & 207 & 203 & 193 \\
220 & 259 & 253 & 248 & 236 \\
260 & 306 & 299 & 293 & 279
\end{tabular}

Ziegler (1907) tabulated similar data, but in feet and inches, for latifolia from the Medicine Bow National Forest in Wyoming, as follows:

\begin{tabular}{|c|c|c|c|}
\hline \multirow{3}{*}{$\begin{array}{l}\text { D.b.h. } \\
\text { Inches }\end{array}$} & \multicolumn{3}{|c|}{$\begin{array}{l}\text { Diameter of stump } \\
\text { (outside bark) } \\
\text { at three stump heights }\end{array}$} \\
\hline & 1 foot & 2 feet & 3 feet \\
\hline & & Inches & $\ldots$ \\
\hline 5 & 5.5 & 5.4 & 5.2 \\
\hline 6 & 6.6 & 6.4 & 6.2 \\
\hline 7 & 7.8 & 7.4 & 7.2 \\
\hline 8 & 8.9 & 8.4 & 8.2 \\
\hline 9 & 10.0 & 9.4 & 9.2 \\
\hline 10 & 11.1 & 10.4 & 10.2 \\
\hline
\end{tabular}

Gideon and Faurot (1977) developed a model for latifolia predicting merchantable length; that is, length of bole from stump top to a predetermined inside-bark top diameter, excluding trimming allowance. Their formula requires knowledge only of d.b.h. and tree height, as follows:

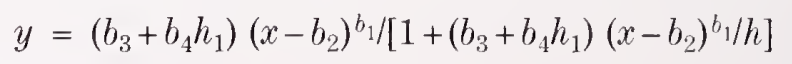

where:

$$
\begin{aligned}
& y=\text { merchantable length, feet } \\
& h=\text { total tree height, feet } \\
& h_{1}=\left(h-h_{m}\right) / h \\
& x=\text { d.b.h., inches } \\
& b_{2}=\text { top diameter limit, inches }
\end{aligned}
$$

Other constants, related to the top diameter limit, as follows:

Top diameter
limit
Inches
2
3
4
5
6
7
8

$\begin{array}{cccc}\boldsymbol{b}_{1} & \boldsymbol{b}_{3} & \boldsymbol{b}_{1} & \begin{array}{c}\boldsymbol{h}_{m} \\ \text { Feet }\end{array} \\ 0.97 & 6.82 & 87.02 & 21.0 \\ .95 & 3.84 & 71.14 & 24.0 \\ .86 & 2.26 & 70.83 & 28.0 \\ .77 & 1.65 & 78.06 & 36.0 \\ .80 & 5.41 & 62.96 & 44.0 \\ .86 & 8.95 & 42.40 & 51.0 \\ .93 & 5.98 & 33.71 & 51.0\end{array}$

In this equation, $h_{m}$ is the total height of the shortest tree within a species for a particular top diameter. When evaluated against measurements of western Montana latifolia trees, $R^{2}$ values ranged from 0.88 to 0.99 , with standard error of estimates from 2.0 to 4.7 feet; predictions of merchantable length were most accurate with small top diameter limits.

Hanzlik (1916) provided taper tables for latifolia trees in the Ochoco National Forest on a western spur of the Blue Mountains of eastern Oregon. He tabulated inside bark diameters at various heights above ground for trees 7 through 20 inches in d.b.h., stratified by tree heights; that is, less than 60 feet, 61 to 80 feet, and more than 80 feet.

For Colorado and Wyoming latifolia trees, Myers (1964) related inside bark diameters at various heights above ground for trees 3.5 to 25.5 inches d.b.h. outside bark, stratified by tree height classes of $30,40,50,60,70,80$, and 90 feet. 
Heger (1965) used Hohenadl's method on 37 dominant and codominant latifolia trees grown on various sites in the Clearwater District of Alberta. He concluded that the method efficiently and accurately estimated stem form and stem volume. He also concluded that for 80 percent of the lower bole of latifolia, stem form (over bark) in Alberta does not differ appreciably from stem form (bark-free) in British Columbia.

MacLean and Berger (1976) determined the form factor-the ratio of tree cubic volume to that of a cylinder with the same diameter and length-for murrayana in California, as follows:

$$
F=0.422709-0.0000612236\left(H^{2} / D\right)
$$

where:

$$
\begin{aligned}
& F=\text { form factor as defined above } \\
& H=\text { tree height, feet } \\
& D=\text { d.b.h., feet. }
\end{aligned}
$$

\section{3-4 PROCEDURE}

Procedural details of the study are given in chapter 1 , and will not be repeated here except to note that the diameters of the larger stem disks taken at 10 percent height intervals were measured in the laboratory with a diameter tape-both inside and outside bark. The smaller disks were measured with a scale on major and minor diameters and values averaged.

Average inside bark stem taper below crown, expressed as millimeters taper per meter of stem length below crown, was calculated by considering the below-crown stem section as a truncated cone with bottom diameter equal to diameter at $152-\mathrm{mm}$ stump height and top diameter equal to the diameter of the stem at the base of the live crown. Within-crown taper was calculated by considering this stem portion as a cone with bottom diameter equal to inside bark stem diameter at the base of the live crown and top diameter of zero at the apical tip.

The elevational zones of low, medium, and high are relative. Medium refers to an elevation that is medium for the variety at the latitude at which sampled; similarly, low and high refer to lower and upper elevational zones in which the variety occurs at the latitude sampled. Latifolia elevational zones were highest in the south $(2,481,2,711$, and $3,144 \mathrm{~m}$ at 40 degrees) and progressively lower with each more northerly latitude (604, 739, and $879 \mathrm{~m}$ at 60 degrees). Murrayana was sampled at elevations in the range from 1,148 to $2,402 \mathrm{~m}$.

Trees were taken from within natural unthinned stands on level benches in National or Provincial Forests. The sampling scheme resulted in selection of 76-, 152-, and 228-mm trees averaging 71, 91, and 107 years of age, respectively, for latifolia, and 67, 84, and 91 years for murrayana. Most of the small-diameter trees were suppressed, while the larger trees were the fast growers.

\section{3-5 RESULTS-LATIFOLIA}

Average taper data are summarized in table 3-1, but interpretation of these averages requires reference to the main effects and interactions related to d.b.h., latitude, and elevational zone-as discussed in the following paragraphs.

In the following paragraphs summarizing results, only those main effects and interactions shown statistically significant ( 0.05 level) by analyses of variance are discussed, tabulated, and graphed. All reported conclusions are statistically significant (0.05 level).

As noted previously (fig. 1-1), latitudinal sampling spanned 10 degrees of longitude. The only significant taper-related variation associated with longitudinal zone was that of within-crown taper; the correlation was weak $(r=-0.189)$, indicating that within each latitudinal zone, trees on the western end had slightly less within-crown taper than those on the eastern end.

\begin{tabular}{|c|c|c|}
\hline \multirow[b]{2}{*}{ Statistic } & \multicolumn{2}{|c|}{ Variety } \\
\hline & Latifolia & Murrayana \\
\hline $\begin{array}{l}\text { Average stem taper from } 152-\mathrm{mm} \\
\text { stump height to base of live } \\
\text { crown, inside bark }(\mathrm{mm} / \mathrm{m})\end{array}$ & 8.2 (3.6) & $9.5 \quad(4.7)$ \\
\hline $\begin{array}{l}\text { Average stem taper from base of } \\
\text { live crown to apical tip, inside } \\
\text { bark }(\mathrm{mm} / \mathrm{m})\end{array}$ & $15.8 \quad(4.1)$ & $15.7 \quad(4.8)$ \\
\hline $\begin{array}{l}\text { Stem diameter at base of live } \\
\text { crown, inside bark }(\mathrm{mm})\end{array}$ & $100.1(43.5)$ & $111.8(48.8)$ \\
\hline $\begin{array}{l}\text { Stemwood volume within live } \\
\text { crown, proportion of total stem- } \\
\text { wood volume from } 152-\mathrm{mm} \\
\text { stump height to apical tip } \\
\text { (percent) }\end{array}$ & $16.0(12.1)$ & 26.5 (13.8) \\
\hline
\end{tabular}

Table 3-1-Average values (and standard deviations) of taperrelated data for 243 latifolia and 36 murrayana trees aggregated by variety ${ }^{1}$

'Because of significant variations related to d.b.h., latitude, and elevational zone, reference to appropriate figures and test discussion is required for interpretation of these data. 


\section{Stem Form}

As previously noted, coniferous trees typically display three different geometric shapes from stump top to apical tip (fig. 3-1). For simplicity, inside bark stem forms of 76-, 152-, and 228-mm latifolia trees from low-, medium-, and high-elevation zones are shown (figs. 3-2, 3-3, and 3-4) divided into only two segments-that between stump top and base of the live crown, and that within the live crown. It is evident that average stemwood taper is significantly greater within the crown than below the crown.
LATIFOLIA

LOW ELEVATION
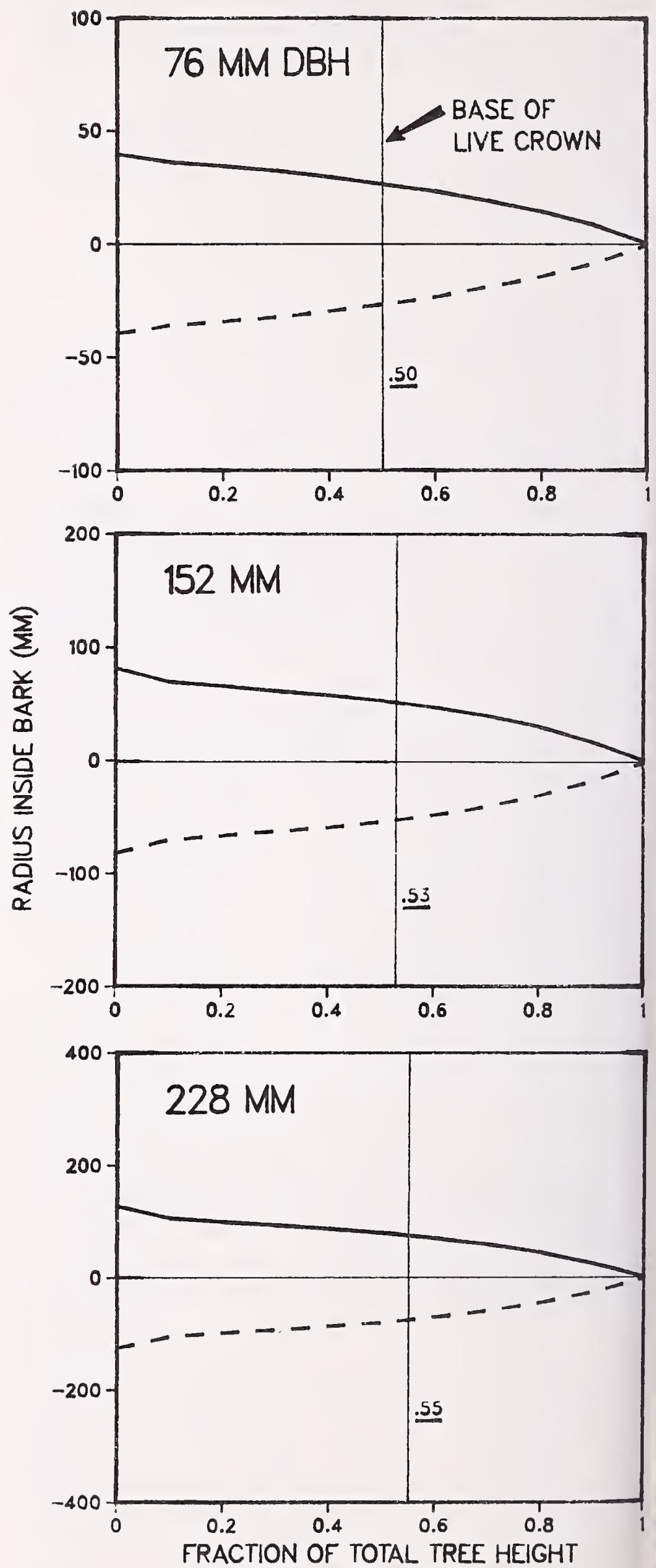

Figure 3-2-Crown base position related to stemwood form in latifolia trees of three diameters from low-elevation zones. The dashed lines are mirror images of the solid lines. 

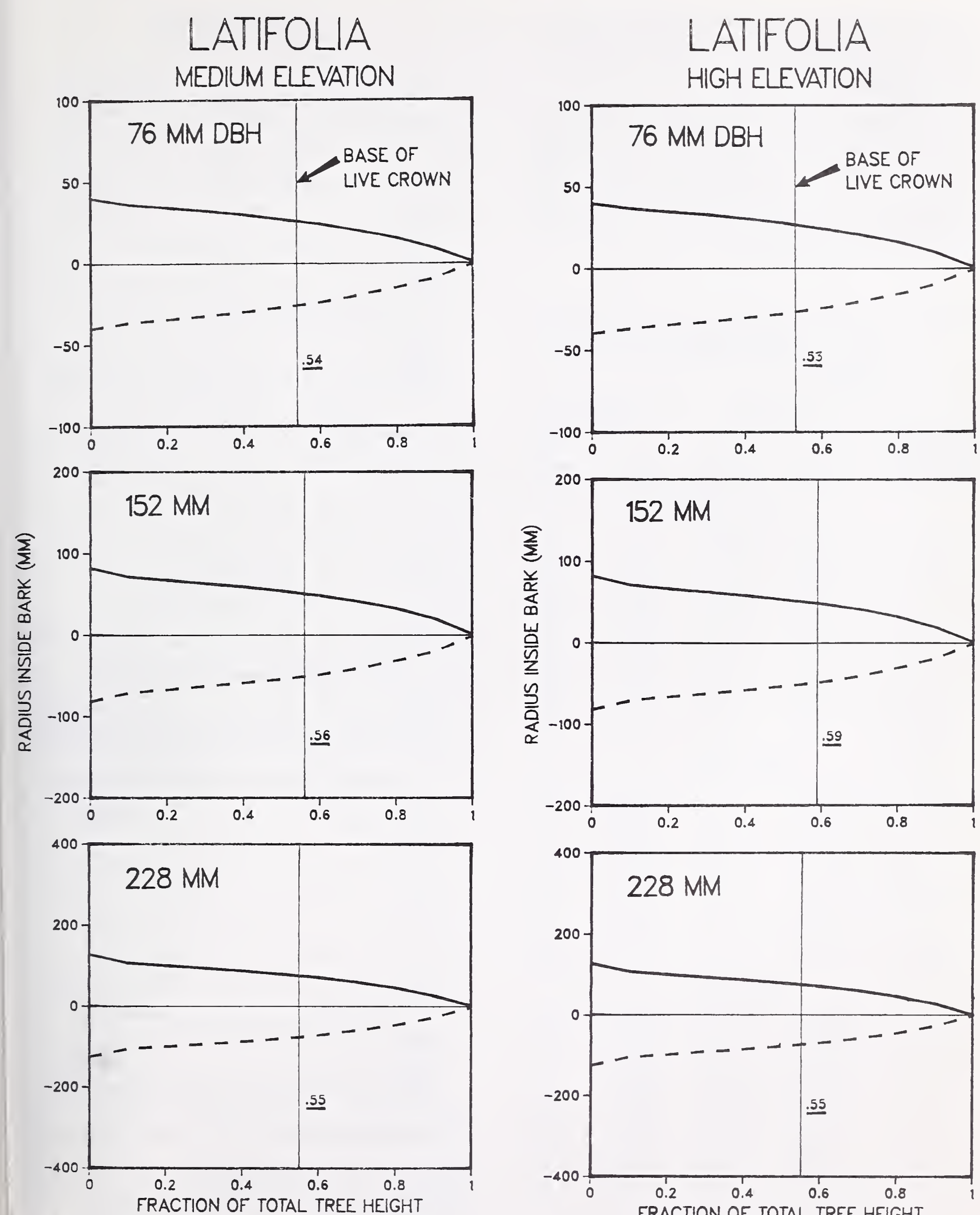

Figure 3-3-Crown base position related to stemwood form in latifolia trees of three diameters from medium-elevation zones. The dashed lines are mirror images of the solid lines.

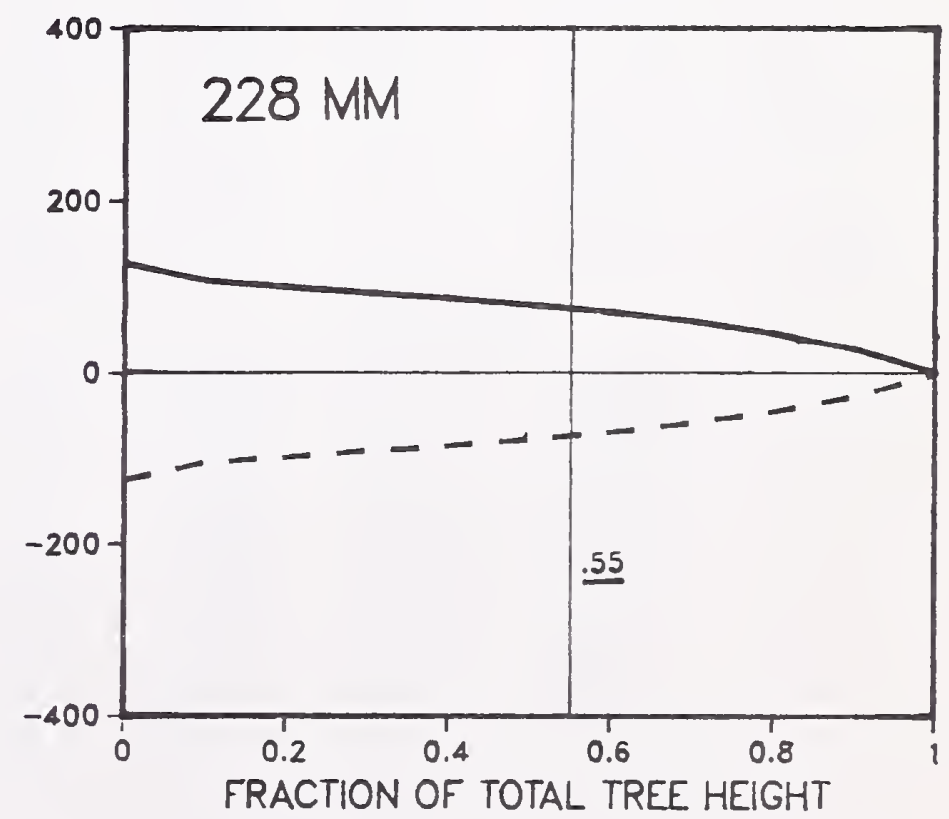

Figure 3-4-Crown base position related to stemwood form in latifolia trees of three diameters from high-elevation zones. The dashed lines are mirror images of the solid lines. 
Stems of large-diameter latifolia flared more at the butt than those of small diameter-both inside bark (fig. 3-5) and outside bark (fig. 3-6); in other respects, stems of the three diameters had similar forms.

Stem diameters at various levels in trees of the three diameters, inside and outside bark, are given in table 3-2. In constructing this table latitudinal and elevational data were pooled. Standard deviations were greatest at stumptop level. Trees $76 \mathrm{~mm}$ in d.b.h. had $25 \mathrm{~mm}$ diameter inside bark at a level between 0.8 and 0.9 , while for the two larger diameter classes, this diameter was reached above the 0.9 level. (See also fig. 1-7.)

Table 3-2-Latifolia stem diameters inside and outside bark from 152-mm stump height to apical tip at 11 levels in trees of three diameters; latitudinal and elevational data pooled

\begin{tabular}{|c|c|c|c|c|}
\hline \multirow{2}{*}{$\begin{array}{l}\text { Fraction of } \\
\text { stem height } \\
\text { above stump }\end{array}$} & \multicolumn{2}{|c|}{ Inside bark } & \multicolumn{2}{|c|}{ Outside bark } \\
\hline & Average & $\begin{array}{c}\text { Std. } \\
\text { deviation }\end{array}$ & Average & $\begin{array}{c}\text { Std. } \\
\text { deviation }\end{array}$ \\
\hline
\end{tabular}

0

0.1

.2

.3

.4

.5

.6

.7

.8

.9

1.0

ก

0.1

.2

.3

.4

.5

.6

.7

.8

.9

1.0

0

0.1

.2

.3

.4

.5

.6

.7

.8

.9

1.0
. . . . . . . - Millimeters

\section{$76 \mathrm{~mm}$ d.b.h.}

79.4
72.5
68.8
65.0
60.0
54.
47.7
39.
30.
18.0
1.7

4.5

2.8

3.8

3.8

4.0

60.0

54.3

47.7

39.6

30.2

18.0

1.7

$152 \mathrm{~mm}$ d.b.h.

163.3
140.9
132.9
124.7
117.2
107.3
96.1
81.4
62.8
37.7
1.7

\section{0}

3.6

4.3

4.8

5.4

6.0

6.6

7.8

7.7

8.5

2.4

228 mm d.b.h.

253.1
210.9
197.7
186.1
173.3
158.1
141.1
118.5
89.9
51.7
1.7

15.1

5.1

6.8

7.4

8.5

9.5

10.6

11.4

10.9

9.1

2.5
87.4

78.1

74.0

69.9

5.3

3.3

3.0

3.6

4.0

4.4

5.0

5.4

6.2

175.5

149.1

140.4

131.8

124.1

114.1

102.9

87.9

68.7

42.1

7.4

270.4

221.3

207.4

195.3

182.2

167.0

150.3

126.7

97.3

57.6

7.4

10.2

4.0

4.7

5.0

5.8

6.3

6.9

8.0

8.0

8.0

1.9

18.5

5.1

6.9

7.7

8.8

9.9

11.2

12.0

11.4

9.8

2.1
LATIFOLIA
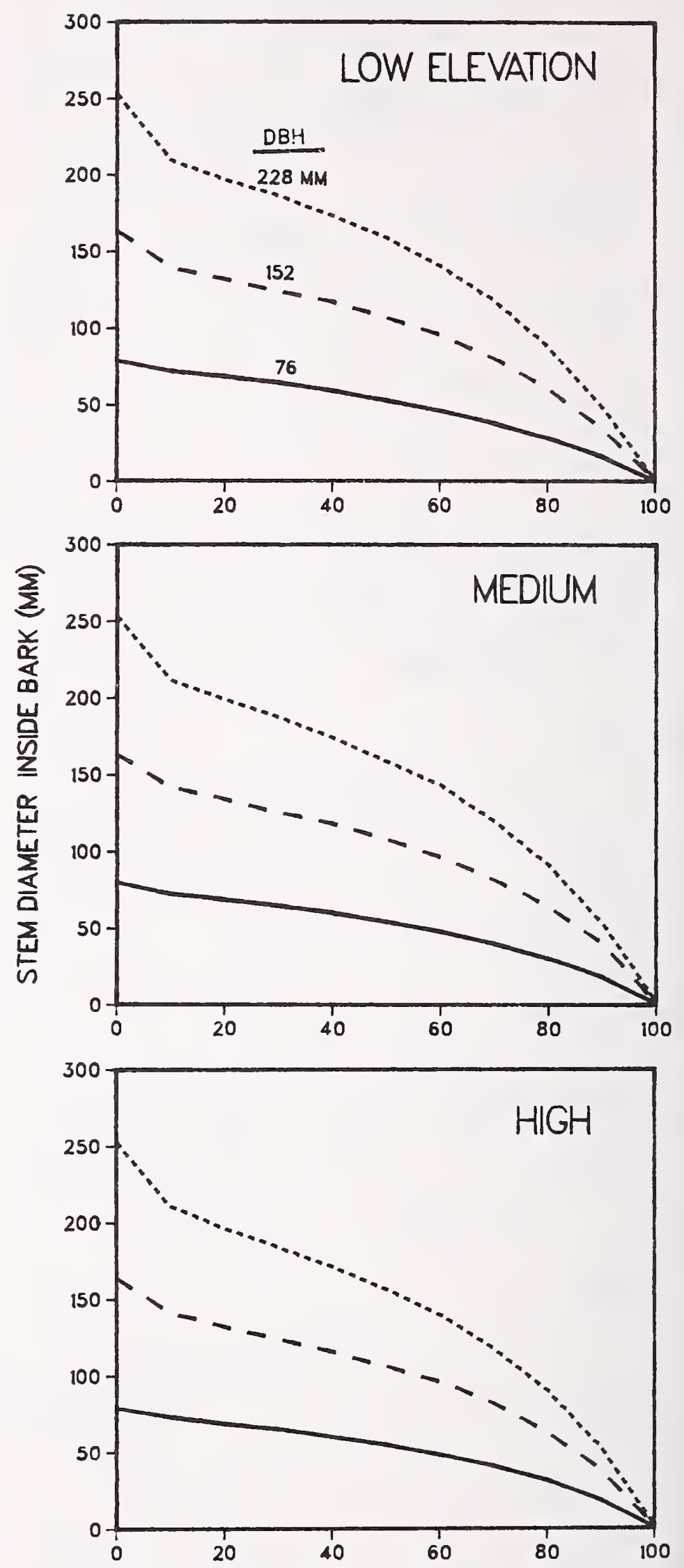

HEIGHT IN TREE,STUMP TOP TO APICAL TIP (PERCENT)

Figure 3-5-Inside bark stem diameters of latifolia trees 76, 152, and $228 \mathrm{~mm}$ in d.b.h. related to height in tree and elevational zone; latitudinal data pooied. 
LATIFOLIA
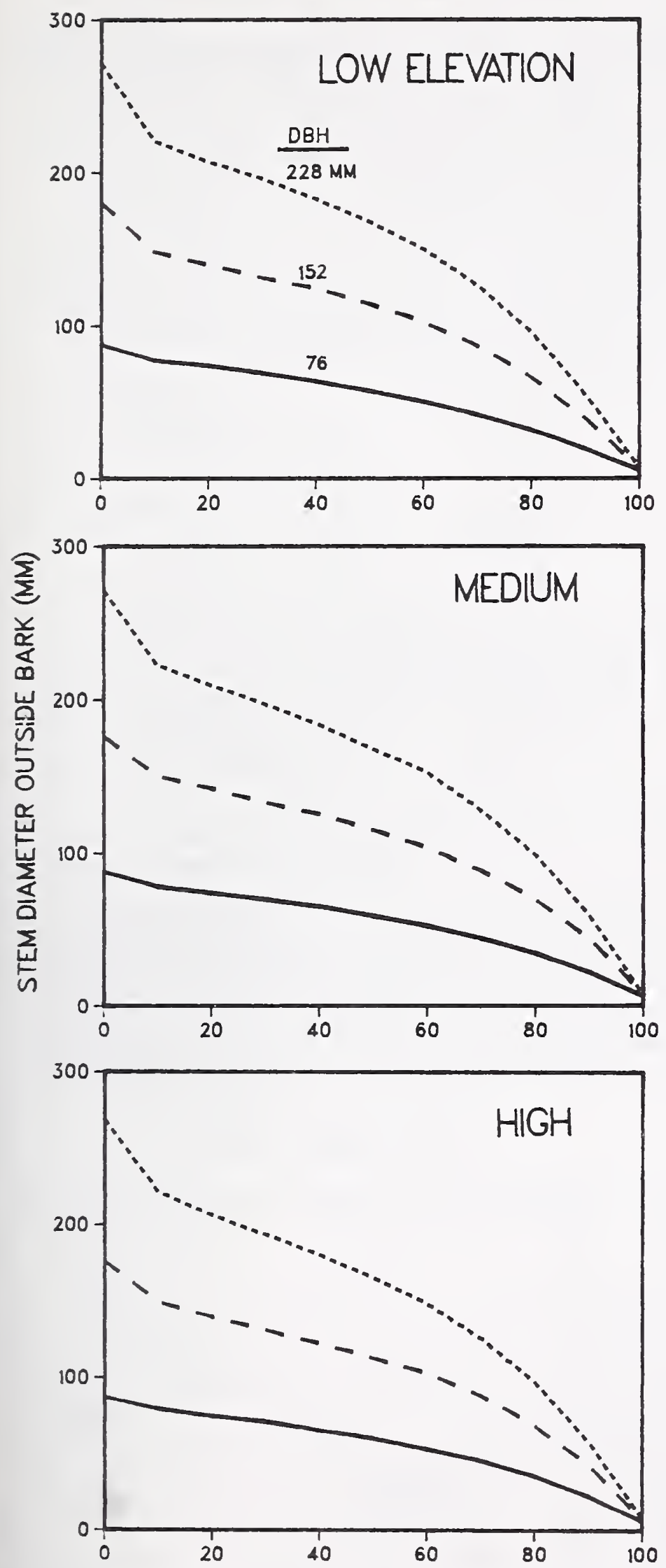

HEIGHT IN TREE,STUMP TOP TO APICAL TIP (PERCENT)

Figure 3-6-Outside bark stem diameters of latifolia trees 76,152 , and $228 \mathrm{~mm}$ in d.b.h. related to height in tree and elevational zone; latitudinal data pooled. 


\section{LATIFOLIA}
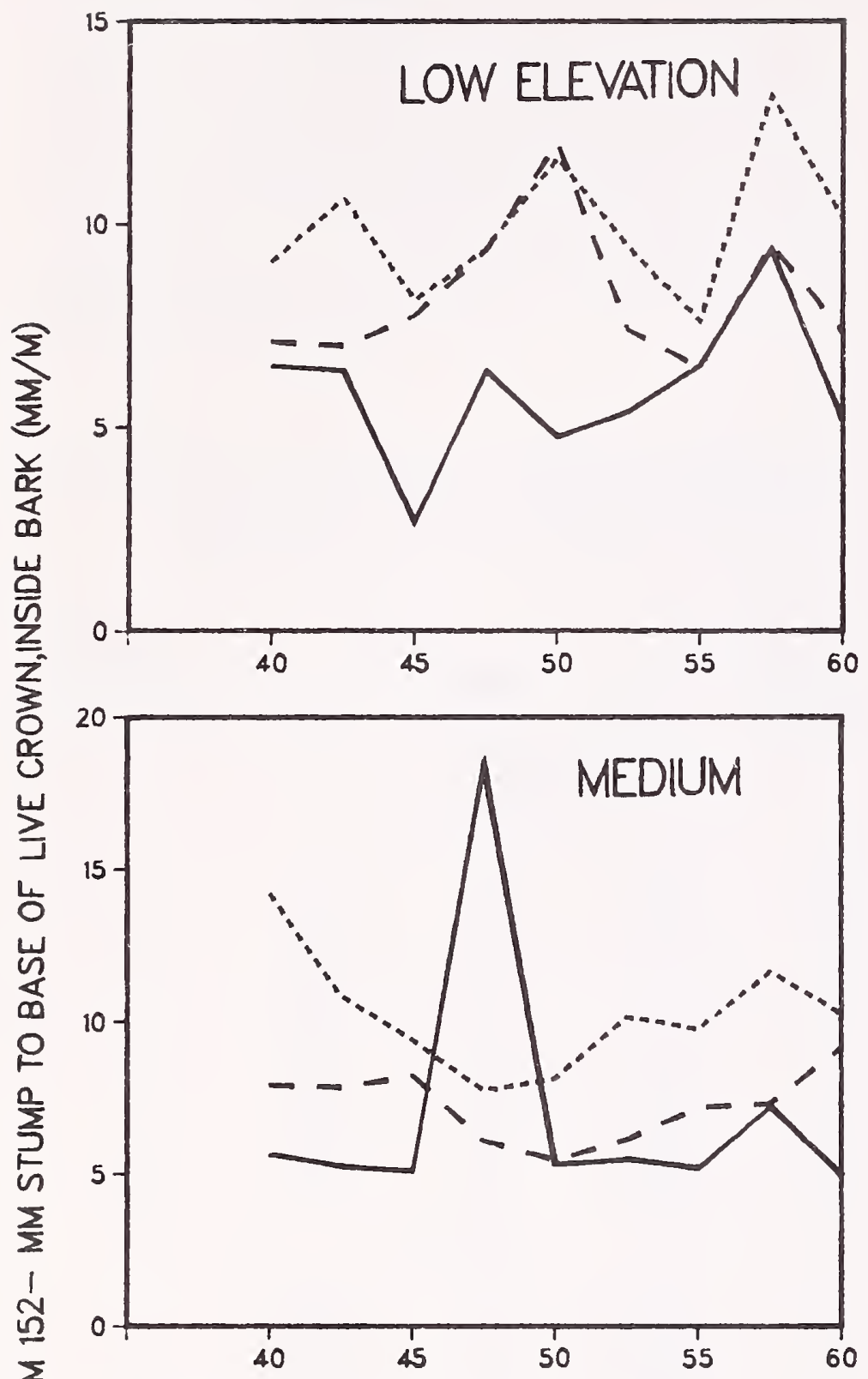

눈

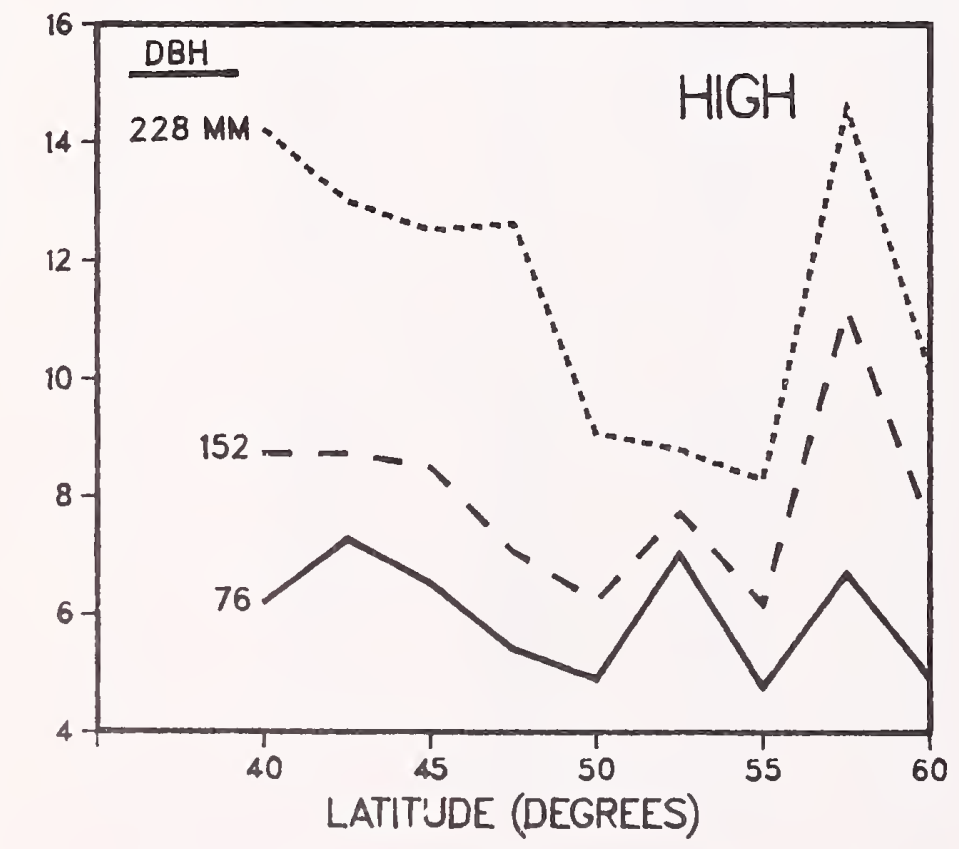

Figure 3-7-Below-crown, inside bark, average stem taper in latifolia trees of three diameters related to latitude and elevational zone.

\section{Stem Taper From 152-mm Stump Height to Base of Live Crown, Inside Bark}

Below-crown stem taper inside bark averaged $8.2 \mathrm{~mm} / \mathrm{m}$, with standard deviation of $3.6 \mathrm{~mm} / \mathrm{m}$. Analysis for significant differences was difficult because of unequal variances-mainly occurring with $76-\mathrm{mm}$ trees at 47.5 degrees latitude-particularly at medium elevation (fig. 3-7). The data (figs. 3-7 and 3-8) show that below-crown taper is positively correlated with d.b.h. $(r=0.487)$, and that 228-mm trees from high-elevation zones tend to have more below-crown stem taper than those from low- or mediumelevation zones (fig. 3-8). By elevational zone, below-crown stemwood taper averaged as follows (diameter and latitudinal data pooled):

$\begin{array}{ccc}\begin{array}{c}\text { Elevational } \\ \text { zone }\end{array} & \text { Average } & \begin{array}{r}\text { Standard } \\ \text { deviation }\end{array} \\ \text { Low } & \ldots \ldots-m m / m & \ldots . \\ \text { Medium } & 8.0 & 3.3 \\ \text { High } & 8.1 & 4.0 \\ & 8.5 & 3.5\end{array}$

Below-crown stem taper inside bark for the three diameters averaged as follows:

$\begin{array}{rcr}\text { D.b.h. } & \text { Average } & \begin{array}{r}\text { Standard } \\ \text { deviation }\end{array} \\ m m & \ldots \ldots-m m / m & \ldots \\ 76 & 6.3 & 3.6 \\ 152 & 7.8 & 2.6 \\ 228 & 10.5 & 3.3\end{array}$

Latitudinal differences varied with diameter (fig. 3-7), but the averages-with elevational and diameter data pooled-all fell within the range of $8 \mathrm{~mm} / \mathrm{m} \pm 1 \mathrm{~mm} / \mathrm{m}$, except for latitudes $47.5,55$, and 57.5 degrees, where taper averaged 9.2, 6.9, and 10.1, respectively. With the exception of 57.5 degrees, trees in Canadian latitudes

\section{LATIFOLIA}

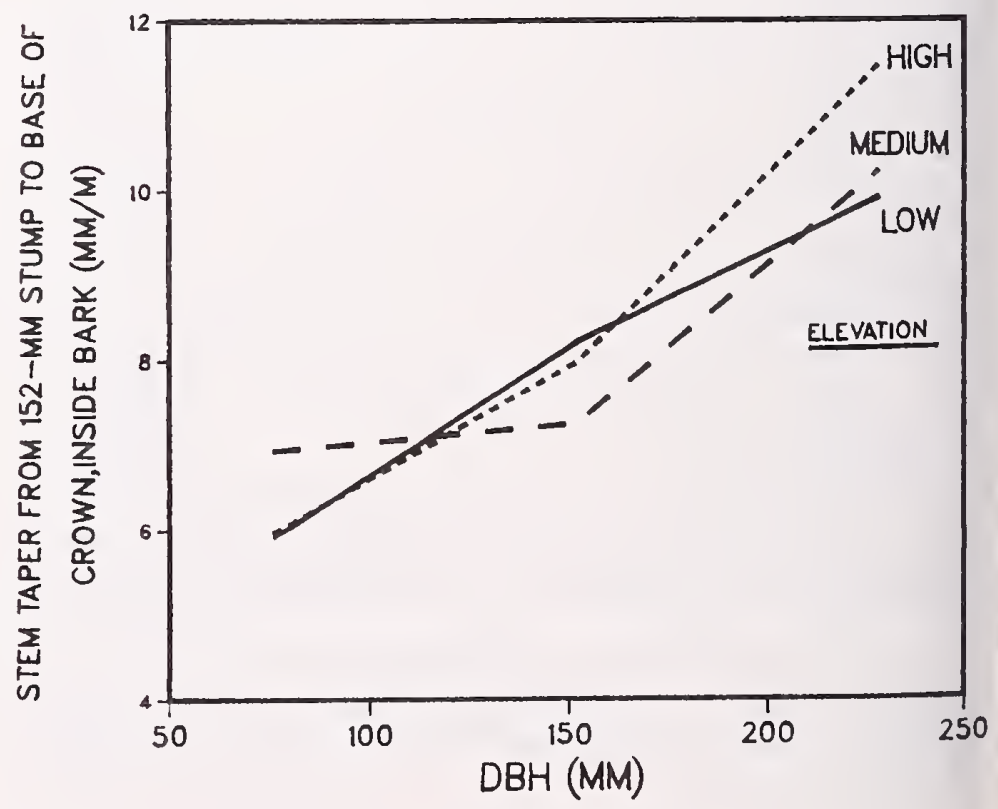

Figure 3-8-Below-crown, inside bark, average stem taper in latifolia trees related to d.b.h. and elevational zone; latitudinal data pooled. 
averaged less than $8 \mathrm{~mm} / \mathrm{m}$; those within the United States, with the exception of 45 degrees, averaged more than $8 \mathrm{~mm} / \mathrm{m}$.

Correlations between below-crown stemwood taper and the following measured properties are of interest:

$$
\text { Property }
$$

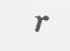

Stem diameter at base of live crown, inside

$$
\text { bark }
$$

Stem diameter at $152 \mathrm{~mm}$ stump height, inside bark

Foliage weight, ovendry basis

Average annual ring width at stump height

Volume of live branches, wood plus bark

Weight of live branches, wood plus bark,

$$
\text { ovendry }
$$

D.b.h.

Crown width

Average diameter of live branches

Volume of complete-tree bark (stump-root, stem, branches)

Weight of central stump-root system, wood plus bark, ovendry

These data indicate that below-crown stemwood tapers least in small-diameter, slow-grown trees with little foliage, small branches, narrow crowns, thin bark, and small central stump-root systems.

\section{Stem Taper From Base of Live Crown to Apical Tip, Inside Bark}

Within-crown inside bark stem taper averaged $15.8 \mathrm{~mm} / \mathrm{m}$, with standard deviation of $4.1 \mathrm{~mm} / \mathrm{m}$-nearly double that of below-crown stem taper. Within-crown stem taper was positively correlated with d.b.h. $(r=0.535)$ and with elevational zone (fig. 3-9), but these relationships were complicated by interactions with latitude (fig. 3-10).

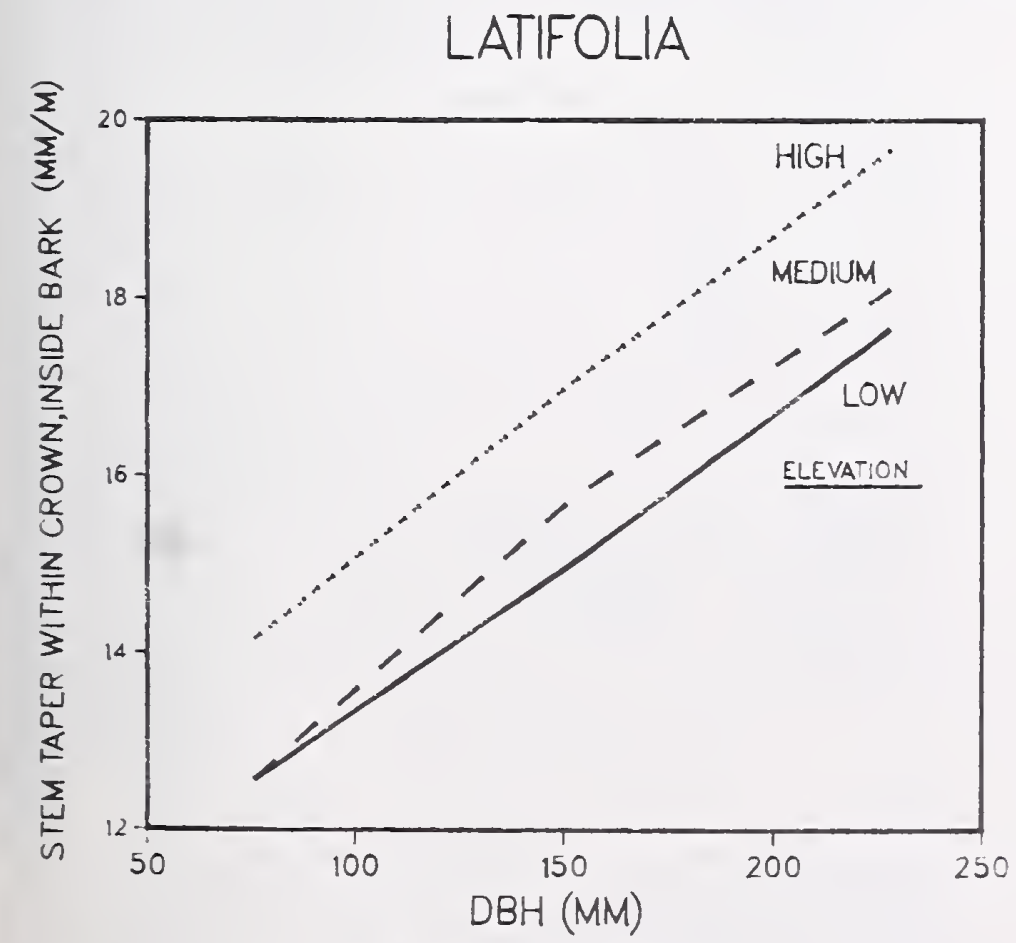

Figure 3-9-Within-crown, inside bark, average stem taper in latifolia trees (latitudinal data pooled) related to d.b.h. and elevational zone.
LATIFOLIA
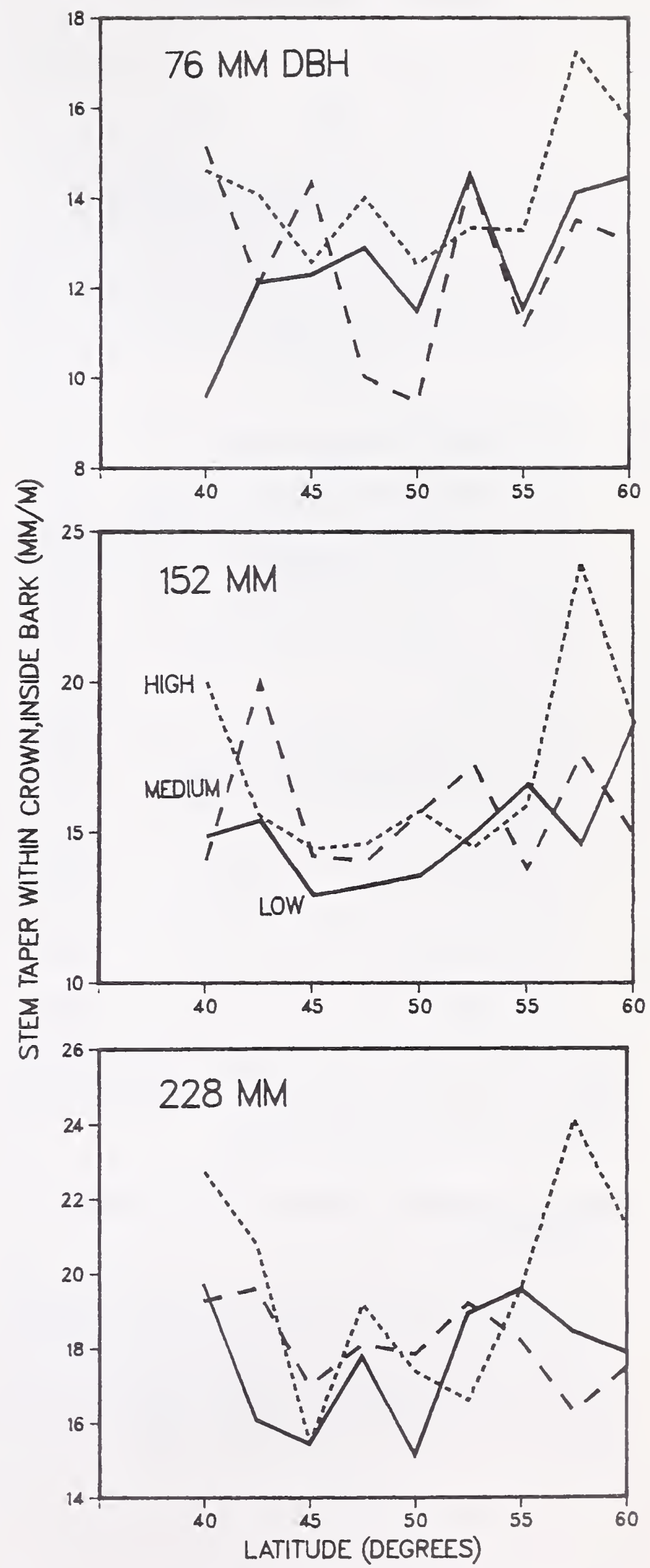

Figure 3-10-Within-crown, inside bark, average stem taper in latifolia trees of three diameters related to latitude and elevational zone. 
Averages by diameter were as follows:

$\begin{array}{rcc}\text { D.b.h. } & \text { Average } & \begin{array}{r}\text { Standard } \\ \text { deviation }\end{array} \\ m m & -\ldots . . & m m / m \\ 76 & 13.1 & 3.1 \\ 152 & 15.9 & 3.8 \\ 228 & 18.5 & 3.5\end{array}$

Unequal variances made analysis for significant differences difficult, but with diameter and elevational data pooled, latifolia trees from midlatitudes (45 through 55 degrees) had less within-crown taper than those from the southern and northern extremities of the range (fig. 3-11).

Correlations between within-crown stemwood taper and the following measured properties are of interest:

\begin{tabular}{lc}
\multicolumn{1}{c}{ Property } & $\boldsymbol{r}$ \\
Live branch diameter & 0.595 \\
Heartwood diameter at $152 \mathrm{~mm}$ stump & .583 \\
height & .536 \\
Stemwood diameter at $152 \mathrm{~mm}$ stump height & .535 \\
D.b.h. (outside bark) & .533 \\
Tree age at $152 \mathrm{~mm}$ stump height & .506 \\
Weight of central stump-root system, wood & \\
plus bark, ovendry & .477 \\
Volume of complete-tree bark (stump-root, & .466 \\
stem, branch) & .459 \\
Crown width & .457 \\
Stem gross volume, wood plus bark & \\
Weight of stem, wood plus bark, ovendry & .449 \\
Weight of live branches, wood plus bark, & .443 \\
ovendry & -.443 \\
Volume of live branches, wood plus bark & \\
Crown ratio & \\
Number of cones on the tip 305 mm of the & \\
top 25 branches & \\
Heartwood volume as percentage of stem- & \\
wood volume &
\end{tabular}

These data suggest that within-crown stemwood taper is least in small trees with small branches, narrow crowns with few cones, high crown ratios, low heartwood content, and small central stump-root systems.

\section{Stem Diameter at Base of Live Crown, Inside Bark}

Stem diameter inside bark at the base of the live crown was proportional to d.b.h., averaging 52 (11.4), 100 (18.5), and $148(23.1) \mathrm{mm}$ for the three diameter classes. This below-crown diameter tended to be larger in southern latitudes than northern (fig. 1-16), probably because crowns in the south were longer than in the north (figs. 1-9 and 1-17).

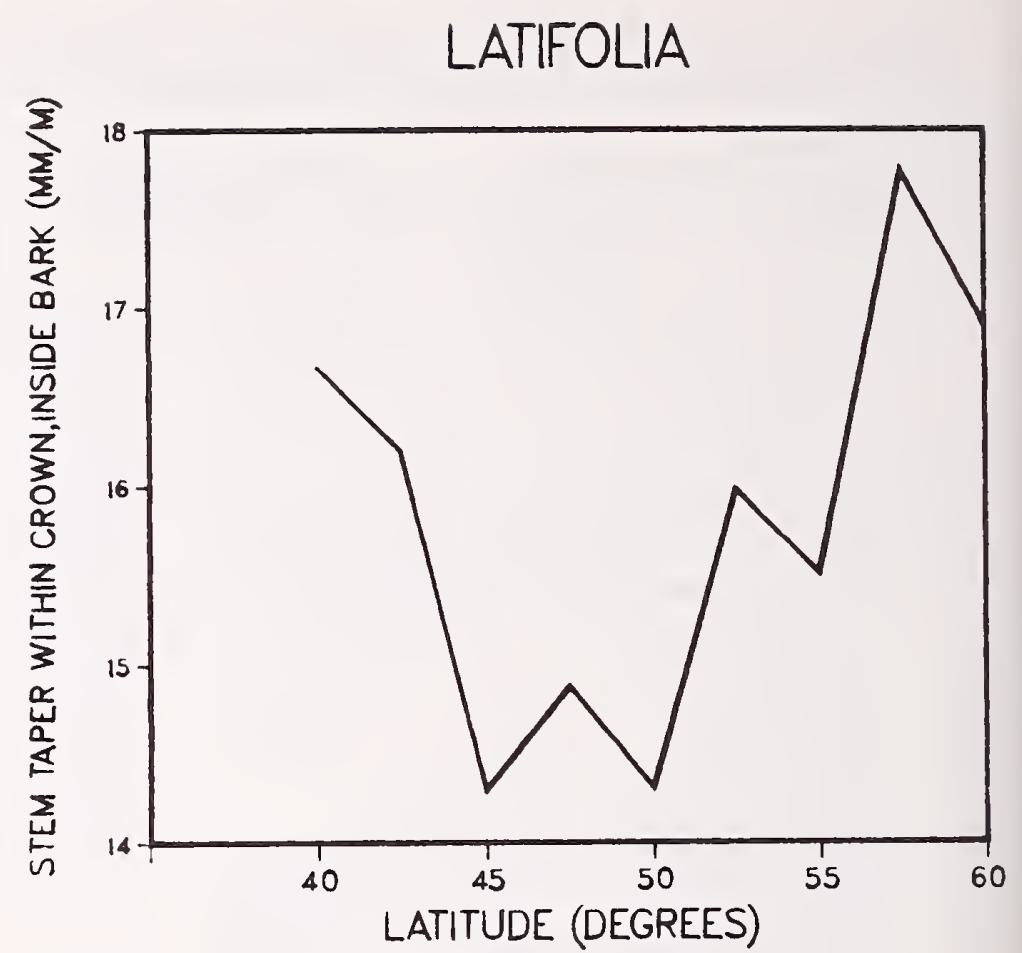

Figure 3-11-Within-crown, inside bark, average stem taper (diameter and elevational data pooled) in latifolia trees related to latitude.

Correlations between stemwood diameter inside bark at the base of the live crown and the following measured properties are of interest:

\section{Property}

D.b.h., outside bark

Diameter at 152-mm stump height, outside bark

Volume of complete-tree bark

Foliage weight, ovendry

Weight of central stump-root system, wood plus bark, ovendry

Weight of live branches, wood plus bark, ovendry

Volume of live branches, wood plus bark

Volume of stem, wood plus bark

Weight of stem, wood plus bark, ovendry

Crown length

Crown width

Average diameter of live branches

Heartwood diameter at $152 \mathrm{~mm}$ stump height

Sapwood thickness at $152 \mathrm{~mm}$ stump height

Height of tree to apical tip

Stembark as percentage of gross stem volume

Bark thickness at $152 \mathrm{~mm}$ stump height 
To avoid excessive taper and the expense of delimbing, users of lodgepole pine prefer that the crowns be limited to that portion of the tree stem with smaller-thanmerchantable diameter. The foregoing data suggest that stem diameter inside bark at the base of the live crown is least in small, thin-barked trees with little heartwood, small stump-root systems, and short and narrow crowns with small branches.

Silviculturists note that unfortunately these characteristics typically occur where merchantable volumes per hectare are considerably below the site potential for merchantable volume production-usually because of overstocking and advanced age to reach merchantable size.

\section{Stemwood Volume Within the Live Crown, as a Proportion of Total Stemwood Volume From 152-mm Stump Height to Apical Tip}

Stemwood volume within the live crown, as a proportion of total stemwood volume, averaged 16.0 percent, with standard deviation of 12.1 percentage points. It was unrelated to elevational zone but was significantly related to latitude. Canadian latitudes averaged 12.2 percent for 50 through 60 degrees-considerably less than in U.S. latitudes where the average was 20.8 percent for 40 through 47.5 degrees (fig. 3-12).

Percentages did not differ significantly $(0.05$ level) by diameter; averages were as follows:

$\begin{array}{ccc}\text { D.b.h. } & \text { Average } & \begin{array}{r}\text { Standard } \\ \text { deviation }\end{array} \\ m m & \ldots \ldots \text {. Percent } \ldots . . . \\ 76 & 17.8 & 13.2 \\ 152 & 15.6 & 13.0 \\ 228 & 14.7 & 9.5\end{array}$

Correlations between within-crown stemwood proportion of total stemwood volume and the following measured properties are of interest:

\section{Property}

Crown ratio

0.861

Crown length

Percentage moisture content of complete tree

Heartwood volume as proportion of stemwood volume

Stembark specific gravity

Within-crown taper

Complete-tree specific gravity

$-.352$

Age of tree at 152-mm stump height

$-.344$

$-.318$

$-.318$

Sapwood specific gravity

$-.305$

Tree height to apical tip

$$
.300
$$

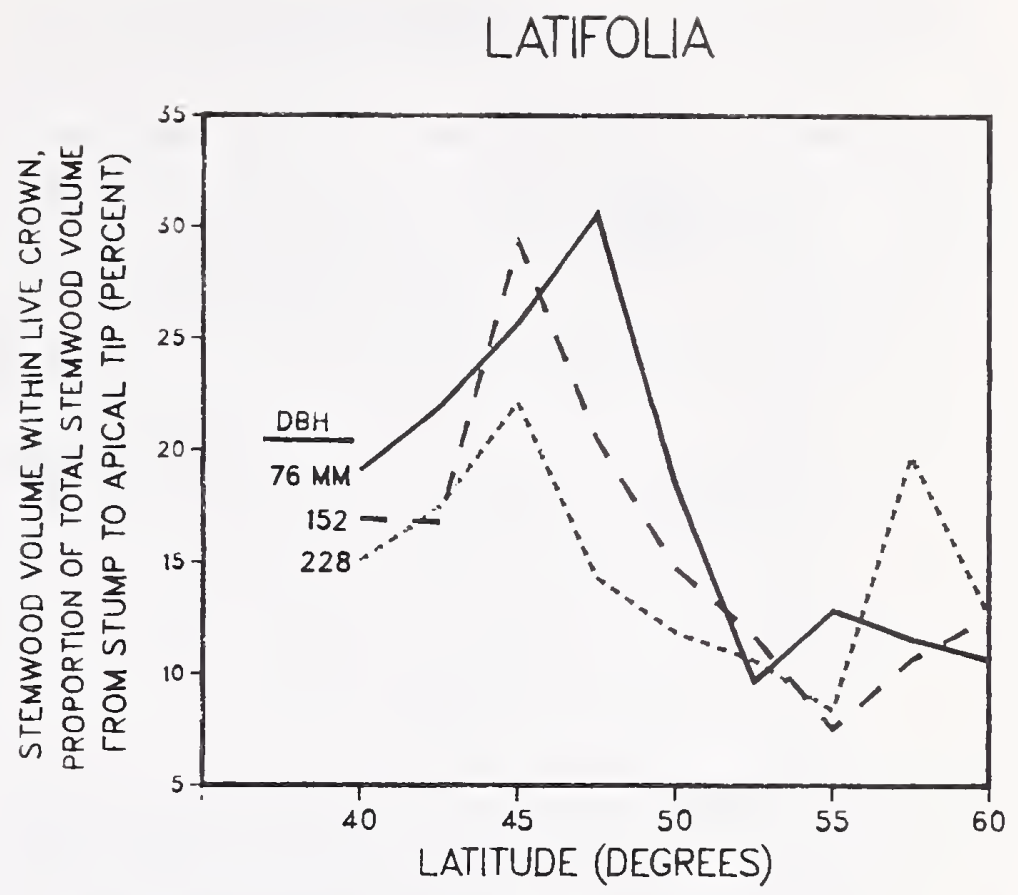

Figure 3-12-Stemwood volume in crown as a percentage of total stemwood volume in latifolia trees related to d.b.h. and latitude.

These data suggest that within-crown stemwood has the least proportion of total stemwood volume in tall but short-crowned older trees having low moisture content, high heartwood content, high specific gravity of bark and sapwood, and thin stembark. 


\section{MURRAYANA}
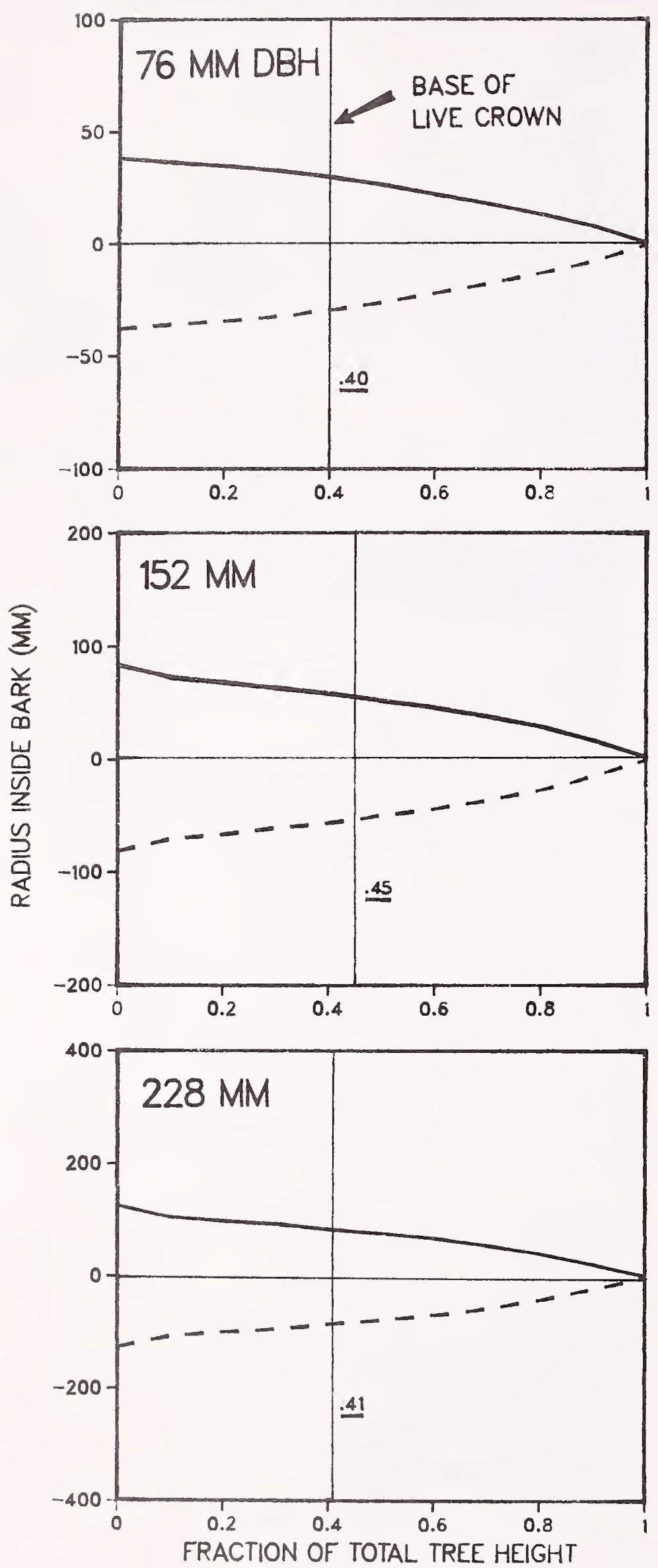

Figure 3-13-Crown base position related to sternwood form of murrayana trees of three diameters. The dashed lines are mirror images of the solid lines.

\section{3-6 RESULTS-MURRAYANA}

Because the entire murrayana sample totaled but 36 trees, correlations among tree characteristics are not noted in the detail provided for the 243 latifolia trees. Standard deviations for diameter-class data are noted in parentheses following their average values, as they were in the latifolia results section.

Even with this small sample (nine trees per latitude), some latitudinal differences were observed. Only those statistically significant (5-percent level) are graphed or tabulated.

\section{Stem Form}

As with latifolia, murrayana stem form, inside bark, is comprised of three geometric shapes; the section within the crown has significantly greater taper than that below the crown (fig. 3-13). Trees $76 \mathrm{~mm}$ in d.b.h. have little butt flare in the first 10 percent of tree height, but this flare becomes distinct in trees 152 and $228 \mathrm{~mm}$ in d.b.h. (figs. 3-13 and 3-14).

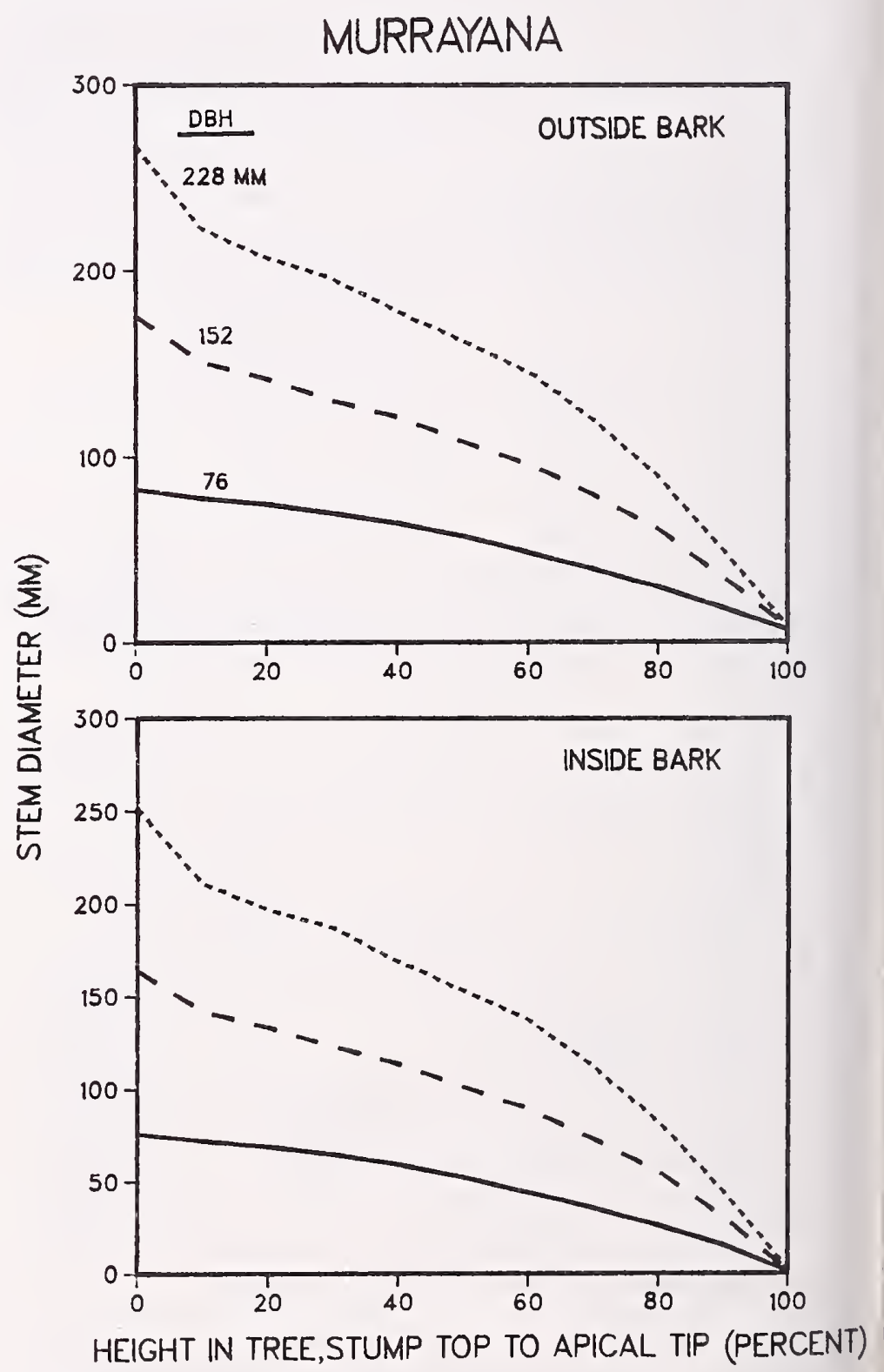

Figure 3-14-Outside bark and inside bark stem diameters of murrayana trees 76,152 , and $228 \mathrm{~mm}$ in d.b.h. related to height in tree; latitudinal data pooled. 
Stem diameters at 10 percent height intervals in trees of the three diameters, inside and outside bark, are given in table 3-3. In constructing this table, latitudinal data were pooled. Standard deviations were generally greatest at stump top and at about 80 percent of tree height. Trees $76 \mathrm{~mm}$ in d.b.h. had a $25-\mathrm{mm}$ top diameter inside bark at the 0.8 level; for $152-$ and $228-\mathrm{mm}$ trees, however, this top diameter fell above the 0.9 level. (See also fig. 1-56.)

Table 3-3-Murrayana stem diameters inside and outside bark from 152-mm stump height to apical tip at 11 levels in trees of three diameters; latitudinal and elevational data pooled

\begin{tabular}{cccccc}
\hline & \multicolumn{2}{c}{ Inside bark } & & \multicolumn{2}{c}{ Outside bark } \\
\cline { 2 - 2 } \cline { 5 - 6 } $\begin{array}{c}\text { Fraction of } \\
\text { stem height } \\
\text { above stump }\end{array}$ & Average & $\begin{array}{c}\text { Std. } \\
\text { deviation }\end{array}$ & & Average & $\begin{array}{c}\text { Std. } \\
\text { deviation }\end{array}$ \\
\hline
\end{tabular}
......... . Millimeters . . . . . . . . .

$76 \mathrm{~mm}$ d.b.h.

0

0.1

.2

.3

.4

.5

.6

.7

.8

.9

1.0

0

0.1

.2

.3

.4

.5
.6

.6
.7
.8

.7
.8

.9

1.0

0

0.1

.2

.3

.4

.5

.6

.7

.8

.9

1.0

$\begin{array}{lr}6.4 & 82.5 \\ 4.1 & 77.7 \\ 3.1 & 74.4 \\ 3.6 & 69.6 \\ 3.8 & 64.2 \\ 3.6 & 57.0 \\ 3.2 & 48.3 \\ 2.8 & 39.3 \\ 3.1 & 29.5 \\ 3.0 & 18.4 \\ 1.6 & 6.6\end{array}$

152 mm d.b.h.

163.9
142.0
133.5
123.1
113.8
101.3
89.1
72.9
55.4
30.6
1.6

$228 \mathrm{~mm}$ d.b.h.

251.3

211.3

196.9

186.8

168.9

153.3

137.3

112.2

82.2

44.4

2.3

$\begin{array}{rr}9.2 & 175.7 \\ 2.9 & 151.0 \\ 4.7 & 141.8 \\ 5.0 & 130.5 \\ 6.6 & 121.3 \\ 7.8 & 108.5 \\ 9.6 & 95.9 \\ 11.4 & 79.5 \\ 11.3 & 60.8 \\ 8.7 & 35.1 \\ 2.4 & 8.0 \\ \text { d.b.h. } & \end{array}$

13.9

5.9

8.7

9.2

7.6

8.2

7.6

12.6

12.0

12.0

3.0
266.8

222.7

206.8

196.0

178.2

162.3

145.7

119.8

89.3

49.5

8.4
7.1

4.9

3.4

4.3

4.9

4.4

3.6

2.9

3.0

3.2

1.4

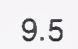

3.4

5.0

4.9

6.2

7.5

9.5

11.5

11.6

8.9

1.4

15.1

6.6

10.2

9.8

8.1

8.9

8.1

12.8

11.9

12.1

2.0

\section{Stem Taper From 152-mm Stump Height to Base of Live Crown, Inside Bark}

Stemwood taper from stump top to base of live crown averaged $9.5 \mathrm{~mm} / \mathrm{m}$, with standard deviation of $4.7 \mathrm{~mm} / \mathrm{m}$. Trees in the two northern latitudes had less below-crown stemwood taper than those from the two southern latitudes (fig. 3-15). Small trees averaged less below-crown stemwood taper than large trees, as follows (see also fig. 3-15):

$\begin{array}{rcc}\text { D.b.h. } & \text { Average } & \begin{array}{r}\text { Standard } \\ \text { deviation }\end{array} \\ m m & \ldots \ldots-m m / m \ldots . . \\ 76 & 5.8 & 2.3 \\ 152 & 10.8 & 5.1 \\ 228 & 11.9 & 4.2\end{array}$

\section{Stem Taper From Base of Live Crown to Apical Tip, Inside Bark}

Within-crown stemwood taper was two-thirds larger than below-crown taper. It averaged $15.7 \mathrm{~mm} / \mathrm{m}$, with standard deviation of $4.8 \mathrm{~mm} / \mathrm{m}$, and was unrelated to either d.b.h. or latitude.

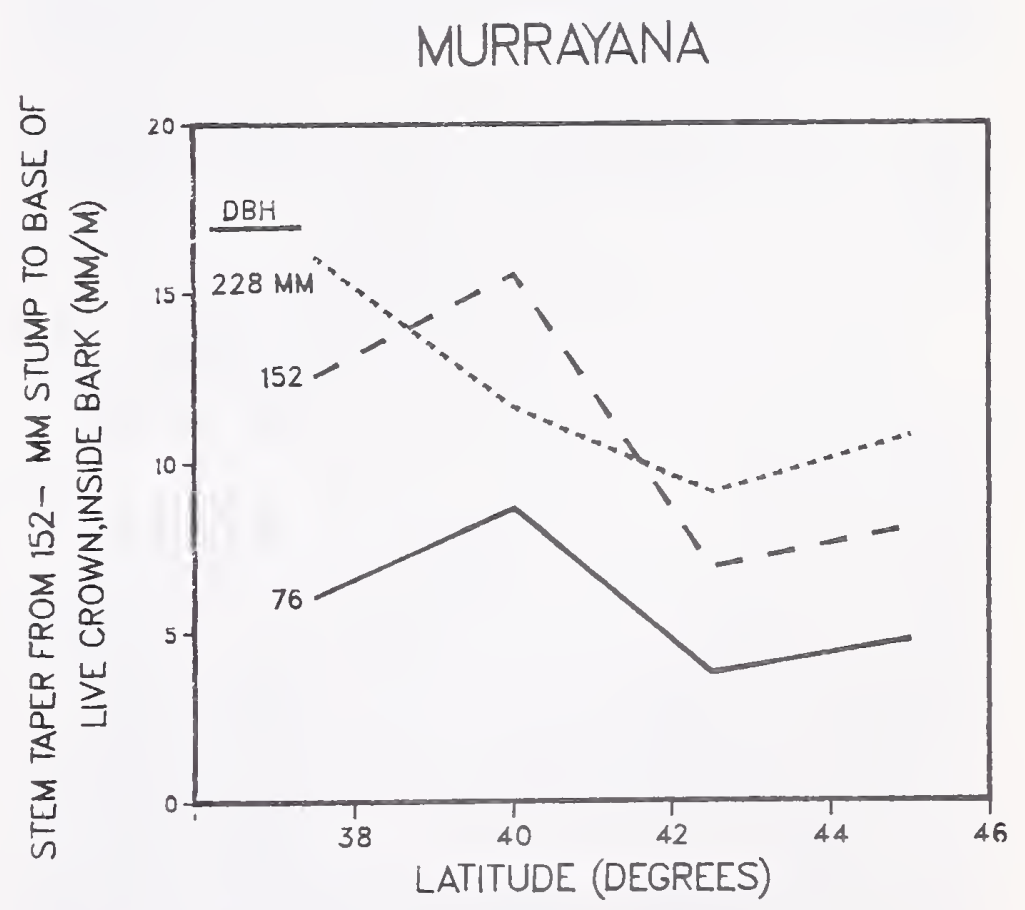

Figure 3-15-Below-crown, inside bark, average stem taper in murrayana trees of three diameters related to latitude. 


\section{Stem Diameter at Base of Live Crown, Inside Bark}

Stem diameter at the base of the live crown was not significantly related to latitude, but was positively correlated with d.b.h., averaging 58 (12), 108 (17), and 169 (21) $\mathrm{mm}$ for the three diameter classes.

\section{Stemwood Volume Within Live Crown, as a Proportion of Total Stemwood Volume From 152-mm Stump Height to Apical Tip}

Stemwood volume within the live crown, as a percentage of total stemwood volume, averaged 26.5 percent, with standard deviation of 13.8 percentage points. It was unrelated to d.b.h., but trees in the two southern latitudes had a greater percentage of crown stemwood than those in the two northern latitudes, as follows:

\begin{tabular}{|c|c|c|}
\hline Latitude & Average & $\begin{array}{l}\text { Standard } \\
\text { deviation }\end{array}$ \\
\hline Degrees & \multicolumn{2}{|c|}{..... Percent -.... } \\
\hline 37.5 & 33.9 & 12.7 \\
\hline 40 & 28.3 & 17.8 \\
\hline 42.5 & 20.4 & 11.9 \\
\hline 45 & 23.4 & 9.7 \\
\hline
\end{tabular}

\section{3-7 RESULTS-LATIFOLIA COMPARED TO MURRAYANA}

The experimental design permitted an orthogonal comparison between the two varieties at three latitudes as follows:
Varieties:
(2) latifolia and murrayana
D.b.h. classes:
(3) 76,152 , and $228 \mathrm{~mm}$
Latitudinal zones:
(3) $40,42.5$, and 45 degrees
Elevational zones:
(1) medium $(1,148 \mathrm{~m}$ to $2,711 \mathrm{~m})$
Replications:

Sample size for this comparison therefore totaled 54 trees, 27 of each variety. In the discussion that follows, only significant relationships associated with varietal differences are explained; the other effects are more completely described in the preceding two results sections. No statistically significant varietal differences were observed in within-crown stem taper, diameter inside bark at the base of the live crown, or percentage of total stemwood volume found in the live crown. At 42.5 degrees latitude in all three diameters, latifolia had more below-crown stemwood taper than murrayana; at 45 degrees, the latifolia trees of 76 and $152 \mathrm{~mm} \mathrm{d.b.h.} \mathrm{also} \mathrm{had} \mathrm{more}$ below-crown taper than murrayana. In trees 76 and $152 \mathrm{~mm}$ in d.b.h. at 40 degrees, however, murrayana had more below-crown stemwood taper than latifolia (fig. 3-16).
COMPARISON
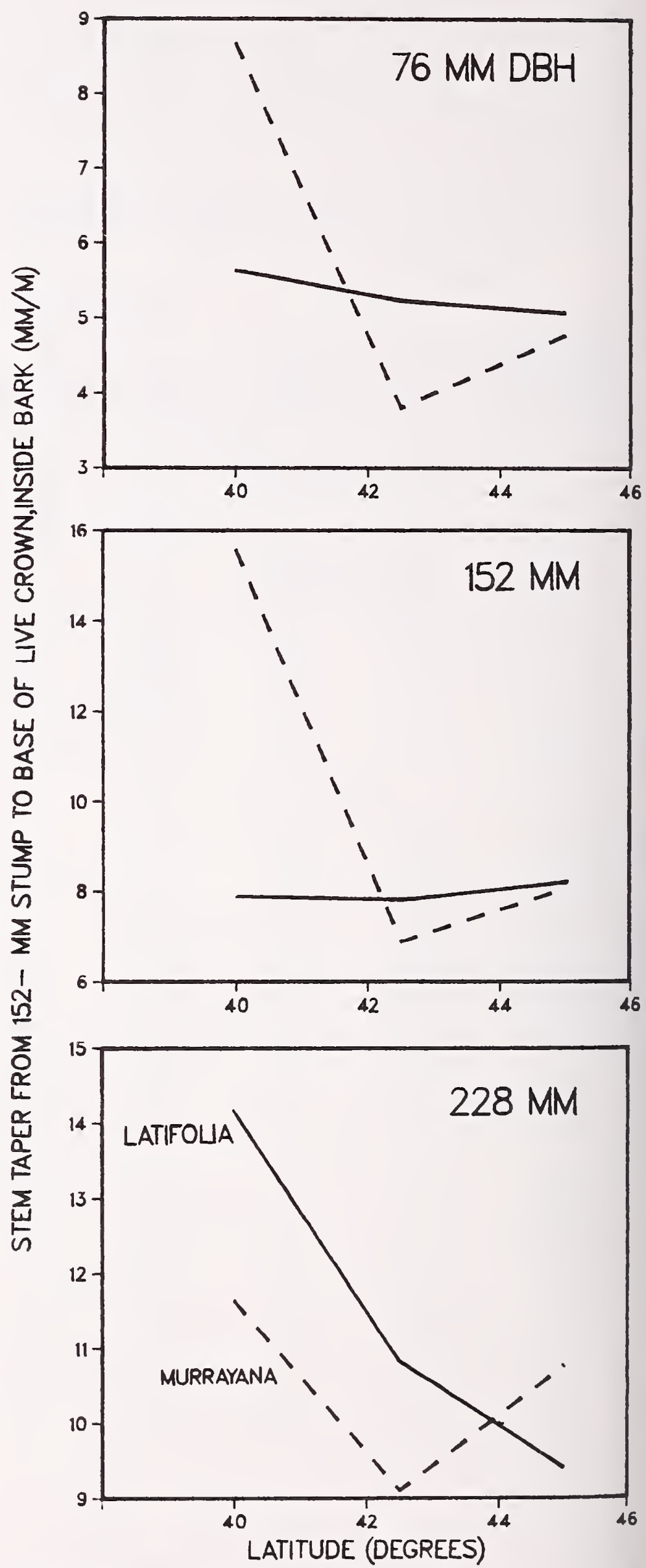

Figure 3-16-Below-crown, inside bark, average stem taper of latifolia trees compared to murrayana related to latitude. 


\section{3-8 SUMMARY OF RESULTS}

Stems of large-diameter latifolia and murrayana trees flared more in the butt section than those of smaller diameter-both inside and outside bark. Below-crown average stemwood taper averaged $8.2 \mathrm{~mm} / \mathrm{m}$ (3.6 standard deviation) for latifolia and $9.5 \mathrm{~mm} / \mathrm{m}$ (4.7) for murrayana; in both, this taper was positively correlated with d.b.h. Latifolia trees $228 \mathrm{~mm}$ in d.b.h. from high-elevation zones usually had more below-crown stemwood taper than those from medium or low zones. Latifolia trees in Canada had less below-crown stemwood taper than those in the United States. Least below-crown taper was found in smalldiameter, slow-grown trees with little foliage, small branches, narrow crowns, thin bark, and small central stump-root systems.

Within-crown stemwood taper was also positively correlated with d.b.h., but was much greater than belowcrown taper; it averaged $15.8 \mathrm{~mm} / \mathrm{m}$ (4.1) for latifolia and 15.7 (4.8) for murrayana. Trees from high-elevation zones had more within-crown stemwood taper than those from low and medium zones. Within-crown stemwood taper in latifolia averaged least in the middle latitudes (45 to 50 degrees). For all latifolia it was least in small trees with small branches, narrow crowns with few cones, high crown ratios, low heartwood content, and small central stump-root systems.

For both varieties stem diameter inside bark at the base of the live crown was proportional to d.b.h.; it averaged 52 (11), 100 (18), and 148 (23) $\mathrm{mm}$ for latifolia and 58 (12), 108 (17), and 169 (21) mm for murrayana in trees 76, 152, and $228 \mathrm{~mm}$ in d.b.h. Stem diameter inside bark at the base of the live crown was least in small, thin-barked trees with little heartwood, small stump-root systems, and short, narrow crowns with small branches. In latifolia trees, stem diameter at the base of the live crown tended to be larger in southern latitudes than in northern.

Stemwood volume within crown, as a percentage of total stemwood volume, averaged 16.0 (12.1) percent for latifolia and 26.5 (13.8) percent for murrayana. This proportion was unrelated to elevational zone or d.b.h. Latifolia in Canadian latitudes had only 12.2 percent within-crown stemwood, whereas trees of this variety in the United States averaged 20.8 percent. Within-crown stemwood had the least proportion of total stemwood volume in tall but short-crowned older trees having low moisture content, high heartwood content, high specific gravity of bark and sapwood, and thin stembark.

Longitudinal effects on taper characteristics were absent or minor.

\section{3-9 REFERENCES}

Adamovich, L. L. Engineering characteristics of Canadian trees-centre of gravity and green weight of components of four species in interior British Columbia. Information Report FMR-X-74. Ottawa, ON: Department of the Environment, Canadian Forestry Service, Forest Management Institute; 1975a. $55 \mathrm{p}$.

Adamovich, L. L. Engineering characteristics of Canadian trees-centre of gravity and green weight of components of three conifers in interior British Columbia on poor growing sites. Information Report FMR-X-82. Ottawa, ON: Environment Canada, Environmental Management Service, Forest Management Institute; 1975b. 67 p.

Alemdag, I. S.; Honer, T. G. Metric relationships between breast-height and stump diameters for eleven tree species from eastern and central Canada. Information Report FMR-X-49M. Ottawa, ON: Department of the Environment, Canadian Forestry Service, Forest Management Institute; 1977.62 p.

Baranyay, J. A.; Safranyik, L. Effect of dwarf mistletoe on growth and mortality of lodgepole pine in Alberta. Publication 1285. Ottawa, ON: Department of Fisheries and Forestry, Canadian Forestry Service; 1970. 19 p.

Gideon, Rudy A.; Faurot, James L. A model relating merchantable length to tree diameter and height. Forest Science. 23(2): 143-150; 1977.

Hanzlik, Edward J. A growth and volume study of lodgepole pine in the Ochoco Mountains. University of Washington Forestry Club Annual. 4: 27-33; 1916.

Heger, L. A trial of Hohenadl's method of stem form and stem volume estimation. Forestry Chronicle. 41(4): 466-475; 1965.

MacLean, Colin; Berger, John M. Softwood tree volume equations for major California species. Research Note PNW-266. Portland, OR: U.S. Department of Agriculture, Forest Service, Pacific Northwest Forest and Range Experiment Station; 1976. 34 p.

Myers, Clifford A. Taper tables, bark thickness, and diameter relationships for lodgepole pines in Colorado and Wyoming. Research Note RM-31. Fort Collins, CO: U.S. Department of Agriculture, Forest Service, Rocky Mountain Forest and Range Experiment Station; 1964. $6 \mathrm{p}$.

Plank, Marlin E.; Cahill, James M. Estimating cubic volume of small diameter tree-length logs from ponderosa and lodgepole pine. Research Note PNW-417. Portland, OR: U.S. Department of Agriculture, Forest Service, Pacific Northwest Forest and Range Experiment Station; 1984. 7 p.

Smithers, L. A. Lodgepole pine in Alberta. Bulletin 127. Ottawa, ON: Canada Department of Northern Affairs and National Resources, Department of Forestry; 1961. $153 \mathrm{p}$.

Sterba, Hubert. Stem curves-a review of the literature. Forestry Abstracts. 41(4): 141-145; 1980.

Ziegler, E. A., compiler. Forest tables-lodgepole pine. Circular 126. Washington, DC: U.S. Department of Agriculture, Forest Service; 1907. 24 p. 


\section{CHAPTER 4: SPECIFIC GRAVITIES AND WEIGHTS OF TREE COMPONENTS}

\section{CONTENTS}

4-1 Introduction . .

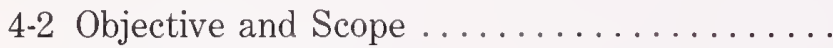

4-3 Literature Review. . . . . . . . . . . . . . . .

Weight of Tree Components ............

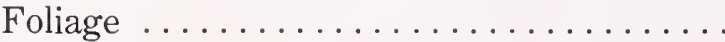

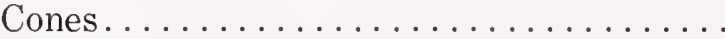

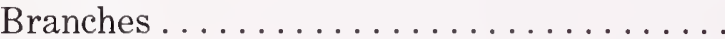

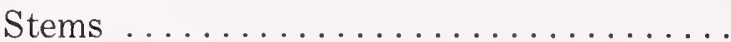

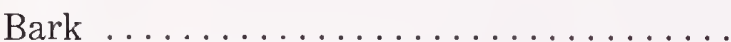

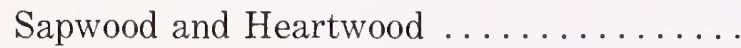

Stump-Root system ................

Specific Gravity and Bulk Density of Tree

Components ....................

Stemwood Bulk Density .............

Stemwood Tree Average Specific Gravity . .

Within-Stem Variation in Wood Specific

Gravity ......................

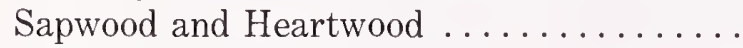

Early Wood and Late Wood ...........

Branches ......................

Bark .......................

Stump-Root System ................

Weight of Tree Components per Hectare ... .

4-4 Procedure.......................

4-5 Results-Latifolia .................

Correlations Between Moisture Content and

Specific Gravity of Tree Components ......

Stemwood Specific Gravity Correlations ..... .

Stembark Specific Gravity Correlations...... .

Correlations of the Six Major Tree Compo-

nent Weight Percentages of Complete-Tree

Ovendry Weight (Including Foliage) With

Other Tree Properties ................

Stem, Wood Plus Bark ..............

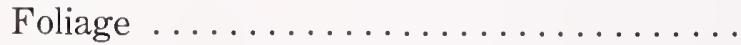

Cones............................

Live Branches, Wood Plus Bark .........

Dead Branches ....................

Stump-Root System, Wood Plus Bark .....

Complete Tree With Cones and Foliage .....

Weight, Green ....................

Weight, Ovendry ................

Complete Tree Without Cones or Foliage $\therefore$. .

Specific Gravity ..................

Weight, Green ... . . . . . . . . . . . . .

Weight, Ovendry ................

Complete Tree, Wood Only .............

Specific Gravity ..................

Weight, Green .................

Weight, Ovendry ...............

Complete Tree, Bark Only . . . . . . . . . . .

Specific Gravity . . . . . . . . . . . . . . . . . . . . .

Weight, Green
Page

136

136

136

137

138

138

138

139

139

139

139

139

139

140

141

141

141

141

141

141

142

142

146

147

147
Weight, Ovendry ................

Percentage of Weight of Gross Foliage-Free Complete Tree, Green and Ovendry ......

Foliage ......................

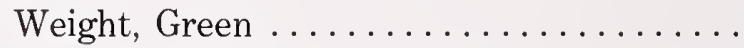

Weight, Ovendry ................

Tree Component Proportion, Green-Weight

Basis

Tree Component Proportion, Ovendry-

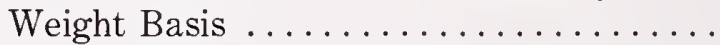

Cones, Individual. . . . . . . . . . . .

Weight, Green ..................

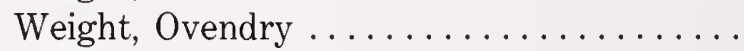

All Cones on Tree ..................

Weight, Green ..................

Weight, Ovendry ................

Tree Component Proportion, Green-Weight

Basis ....................

Tree Component Proportion, Ovendry-

Weight Basis ..................

Dead Branchwood .................

Weight, Green ..................

Weight, Ovendry ...............

Tree Component Proportion, Green-Weight

Basis .....................

Tree Component Proportion, Ovendry-

Weight Basis .................

Live Branches, Wood Plus Bark ..........

Specific Gravity .................

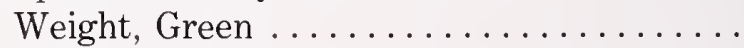

Weight, Ovendry .................

Green Weight to Yield $1 \mathrm{~m}^{3}$ of Wood......

Tree Component Proportion, Green-Weight

Basis .....................

Tree Component Proportion, Ovendry-

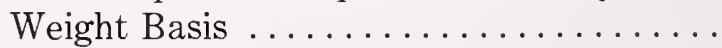

Live Branchwood .................

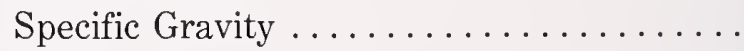

Weight, Green ................

Weight, Ovendry ................

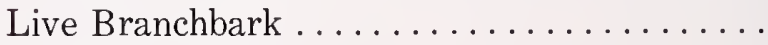

Specific Gravity . . . . . . . . . . . . . .

Weight, Green .................

Weight, Ovendry ................

Live Branchbark as Percentage of Gross

Live Branch Weight, Green and

Ovendry ...................

Stem, Wood Plus Bark-Tree Average ......

Specific Gravity ..................

Weight, Green ..................

Weight, Ovendry ................

Green Weight to Yield $1 \mathrm{~m}^{3}$ of Wood......

Tree Component Proportion, Green-Weight

Basis ...................... 
Tree Component Proportion, Ovendry-

Weight Basis ....................

Stem, Wood Plus Bark-Variation With

Height. . . . . . . . . . . . . . . .

Specific Gravity .................

Stemwood-Tree Average . . . . . . . . . . .

Specific Gravity ..................

Weight, Green ..................

Weight, Ovendry ................

Stemwood-Variation With Height........

Specific Gravity .................

Stembark-Tree Average ..............

Specific Gravity .................

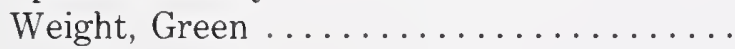

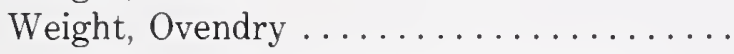

Stembark as Percentage of Gross Stem

Weight, Green and Ovendry ..........

Stembark-Variation With Height ........

Specific Gravity .................

Weight Percentage, Green ............

Weight Percentage, Ovendry ..........

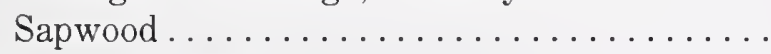

Specific Gravity .................

Weight, Green .................

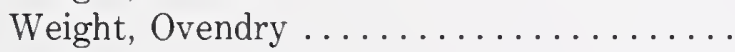

Heartwood ....................

Specific Gravity .................

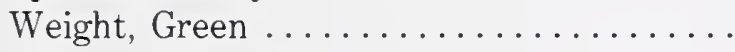

Weight, Ovendry ...............

Ovendry Weight as Percentage of

Stemwood ...................

Stump-Root System, Wood Plus Bark ......

Specific Gravity .................

Weight, Green ..................

Weight, Ovendry ................

Green Weight to Yield $1 \mathrm{~m}^{3}$ of Wood.....

Tree Component Proportion, Green-Weight

Basis ......................

Tree Component Proportion, Ovendry-

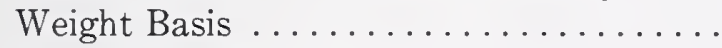

Stump-Root System, Wood Only..........

Specific Gravity .................

Weight, Green ..................

Weight, Ovendry ...............

Stump-Root System, Bark Only ..........

Specific Gravity .................

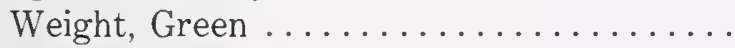

Weight, Ovendry .................

Stump-Root Bark as Percentage of Gross

Stump-Root Weight, Green and Ovendry..

Stump, Wood Plus Bark ..............

Specific Gravity .................

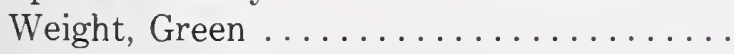

Weight, Ovendry ...............

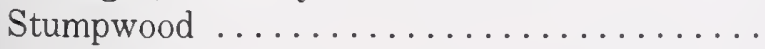

Specific Gravity .................

Weight, Green .................

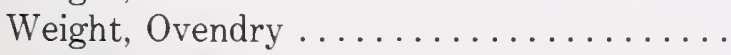

Stumpbark .....................

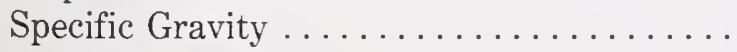

Weight, Green
Page
Lateral Roots, Wood Plus Bark ........... 208

Specific Gravity ... . . . . . . . . . . . 208

Weight, Green ................... 208

Weight, Ovendry ................. 208

Lateral Roots, Wood Only ... . . . . . . . . 209

Specific Gravity . . . . . . . . . . . . . . . . 209

Weight, Green .................... 209

Weight, Ovendry ................ 209

Lateral Roots, Bark Only .............. 210

Specific Gravity ................... 210

Weight, Green .................... 211

Weight, Ovendry ................. 212

Central Root Mass-Taproot, Wood Plus

Bark ....................... 213

Specific Gravity ................... 213

Weight, Green ... . . . . . . . . . . . . . . 214

Weight, Ovendry ................. 215

Central Root Mass-Taproot, Wood Only ..... 216

Specific Gravity ................ 216

Weight, Green .................. 216

Weight, Ovendry ................ 216

Central Root Mass-Taproot, Bark Only ...... 218

Specific Gravity ................... 218

Weight, Green .................. 218

Weight, Ovendry ................. 218

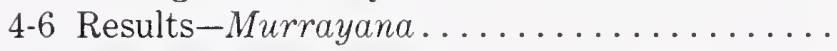

Complete Tree With Cones and Foliage ..... 220

Weight, Green ................. 220

Weight, Ovendry ................ 220

Complete Tree Without Cones or Foliage .... 220

Specific Gravity .................. 220

Weight, Green ... . . . . . . . . . . . . . . 220

Weight, Ovendry .................. 220

Complete Tree, Wood Only ............. 220

Specific Gravity ................. 220

Weight, Green .................. 220

Weight, Ovendry ................. 220

Complete Tree, Bark Only . . . . . . . . . . . . 220

Specific Gravity .................. 220

Weight, Green .................. 220

Weight, Ovendry ................ 220

Percentage of Weight of Gross Foliage-Free Complete Tree, Green and Ovendry ...... 221

Foliage . . . . . . . . . . . . . . . . . . . . 222

Weight, Green .................. 222

Weight, Ovendry ................. 222

Tree Component Proportion, Green-Weight

Basis ...................... 222

Tree Component Proportion, Ovendry-

Weight Basis .................. 222

Cones, Individual. . . . . . . . . . . . . . . . 222

Weight, Green ... . . . . . . . . . . . . 222

Weight, Ovendry ................. 222

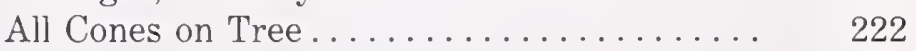

Weight, Green ................... 222

Weight, Ovendry ................. 222

Tree Component Proportion, Green-Weight

Basis ....................... 222

Tree Component Proportion, Ovendry-

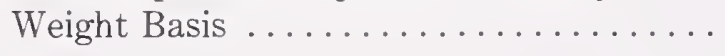


Dead Branchwood ..................................................

Weight, Green .................................. 222

Weight, Ovendry .................. 222

Tree Component Proportion, Green-Weight

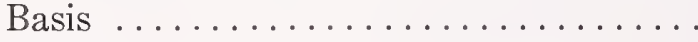

Tree Component Proportion, Ovendry-

Weight Basis ................

Live Branches, Wood Plus Bark..........

Specific Gravity ................

Weight, Green ................

Weight, Ovendry ...............

Green Weight to Yield $1 \mathrm{~m}^{3}$ of Wood......

Tree Component Proportion, Green-Weight

Basis ......................

Tree Component Proportion, Ovendry-

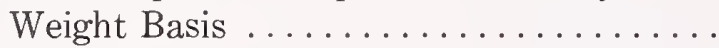

Live Branchwood .................

Specific Gravity .................

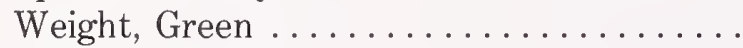

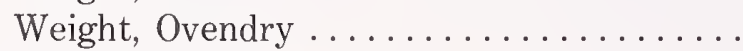

Live Branchbark .................

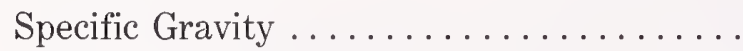

Weight, Green .................

Weight, Ovendry ................

Live Branchbark as Percentage of Gross

Live Branch Weight, Green and

Ovendry ....................

Stem, Wood Plus Bark-Tree Average ..... .

Specific Gravity ..................

Weight, Green .................

Weight, Ovendry ................

Green Weight to Yield $1 \mathrm{~m}^{3}$ of Wood.....

Tree Component Proportion, Green-Weight

Basis ......................

Tree Component Proportion, Ovendry-

Weight Basis ................

Stem, Wood Plus Bark-Variation With

Height ....................

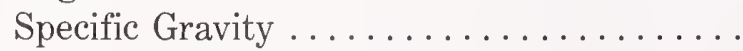

Stemwood-Tree Average .............

Specific Gravity ................

Weight, Green .................

Weight, Ovendry ...............

Stemwood-Variation With Height.........

Specific Gravity ..................

Stembark-Tree Average . . . . . . . . . . . .

Specific Gravity ..................

Weight, Green ..................

Weight, Ovendry ................

Stembark as Percentage of Gross Stem

Weight, Green and Ovendry ..........

Stembark-Variation With Height ........

Specific Gravity .................

Weight Percentage, Green ............

Weight Percentage, Ovendry ..........

Sapwood ......................

Specific Gravity .................

Weight, Green ..................

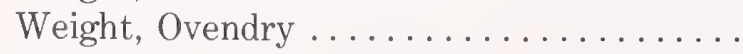

Heartwood .....................

Specific Gravity
Weight, Green

Weight, Ovendry

Ovendry Weight as Percentage of

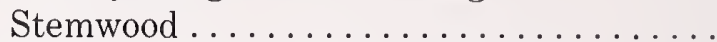

Stump-Root System, Wood Plus Bark ......

Specific Gravity ..................

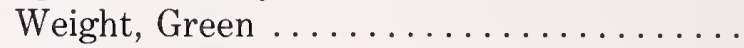

Weight, Ovendry ................

Green Weight to Yield $1 \mathrm{~m}^{3}$ of Wood......

Tree Component Proportion, Green-Weight

Basis

Tree Component Proportion, Ovendry-

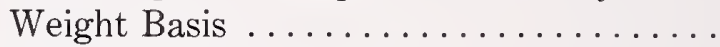

Stump-Root System, Wood Only..........

Specific Gravity ..................

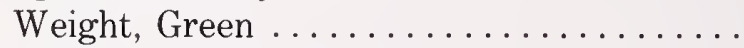

Weight, Ovendry ...............

Stump-Root System, Bark Only .........

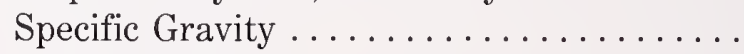

Weight, Green .................

Weight, Ovendry ................

Stump-Root Bark as Percentage of Gross

Stump-Root Weight, Green and

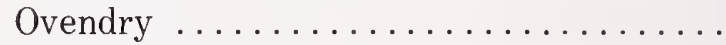

Stump, Wood Plus Bark .............

Specific Gravity .................

Weight, Green .................

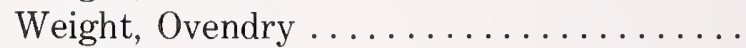

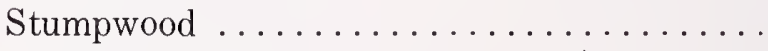

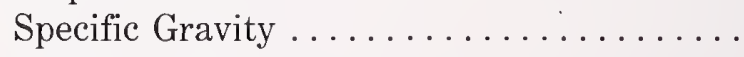

Weight, Green ..................

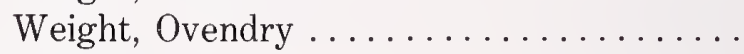

Stumpbark .....................

Specific Gravity ..................

Weight, Green .................

Weight, Ovendry ................

Lateral Roots, Wood Plus Bark ..........

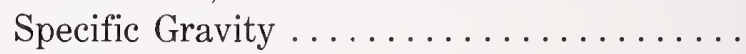

Weight, Green .................

Weight, Ovendry .................

Lateral Roots, Wood Only .............

Specific Gravity .................

Weight, Green .................

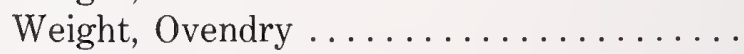

Lateral Roots, Bark Only . . . . . . . . . . .

Specific Gravity ..................

Weight, Green .................

Weight, Ovendry .................

Central Root Mass-Taproot, Wood Plus Bark .

Specific Gravity .

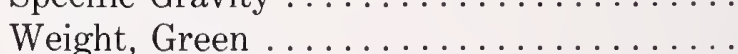

Weight, Ovendry .................

Central Root Mass-Taproot, Wood Only .....

Specific Gravity ..................

Weight, Green ..................

Weight, Ovendry ................

Central Root Mass-Taproot, Bark Only ..... .

Specific Gravity ..................

Weight, Green .

Weight, Ovendry 
4-7 Results-Latifolia Compared to Murrayana. . Complete Tree Without Cones or Foliage ....

Foliage ..........................

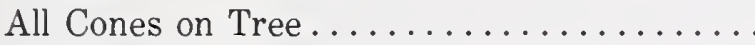

Live Branches ....................

Stem Specific Gravity.................

Wood Plus Bark..................

Wood ..........................

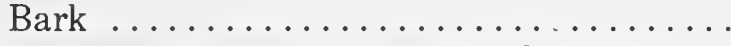

Stem Green Weight to Yield $1 \mathrm{~m}^{3}$ of Wood ..

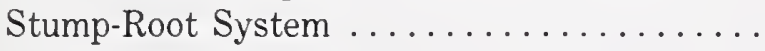

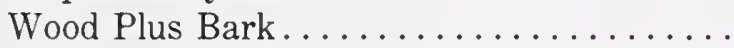

Bark

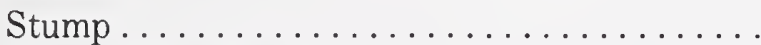

Wood Plus Bark.

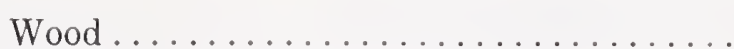

Bark ...................... 244

Central Root Mass-Taproot ............. 247

4-8 Summary of Results ................. 248

Specific Gravity.................. 248

Complete-Tree Weight, Including Foliage .... 248

Tree Component Proportions of Complete-

Tree Ovendry Weight............... 248

Weight of Green Components for $1 \mathrm{~m}^{3}$ of

Wood ....................... 248

Proportion of Bark in Each Component, Ovendry-Weight Basis ................ 248

Longitudinal Effects................ 248

Latifolia Compared to Murrayana......... $\quad 248$

$4-9$ References ..................... 248 


\section{4-1 INTRODUCTION}

Statistical information on weight of tree components when green is needed to plan harvesting activities and green-wood transport. Ovendry weights are needed to develop process material balances in wood conversion plants.

Specific gravity, a unitless measure of density relating wood or bark weight to the weight of water, is a simple and useful index to the suitability of wood and bark for many important uses. It is closely correlated with the mechanical properties of wood and is therefore a primary factor in the segregation of wood for high-strength lumber, posts, poles, and crossties. Density, frequently expressed as specific gravity, largely determines pulp yield from a given volume of wood; that is, a cord of highdensity lodgepole pine will yield significantly more pounds of pulp than an equal volume of low-density wood of the same species. Similarly, a cord of high-density wood and bark will yield more heat when burned for energy than a cord of low-density wood.

\section{4-2 OBJECTIVE AND SCOPE}

Only those weight and specific gravity parameters most important to processors of lodgepole pine are discussed in this chapter. No attempt is made to construct equations predicting weights, and only two specific gravity prediction equations are developed-one for wood and one for bark based on average growth-ring width at 152-mm stump height. Graphs are presented of data aggregated in various significant ways, however, that permit reading of weight and specific gravity information directly from observed study data.

As previously noted, the characterization effort is confined to two varieties of lodgepole pine: Pinus contorta var. latifolia Engelm. and Pinus contorta var. murrayana (Grev. \& Balf.) Engelm., with emphasis on the former. The primary objective during tree collection was to obtain three replications of disease- and insect-free specimens of var. latifolia measuring 76, 152, and $228 \mathrm{~mm}$ in diameter at breast height (d.b.h.) at low, medium, and high elevations from nine equally spaced north latitudinal zones (40 to 60 degrees) across 10 degrees of longitude in such a way as to encompass the major range of this variety (fig. 1-1).

A secondary objective was to sample three replications of these same three diameter classes of var. murrayana at midelevation at four north latitudes $(37.5,40,42.5$, and 45 degrees) in California and Oregon at a single longitude per latitude (fig. 1-1).

The trees of both varieties were sampled in such a way that between-variety comparisons could be made for midelevation trees at latitudes $40,42.5$, and 45 degrees. The sampling plan does not permit computation of speciesaverage values. The collection totaled 243 latifolia and 36 murrayana trees.

Explanations of statistical analyses procedures and a table of analyses of variance formats, with degrees of freedom indicated, are shown in table 1-2. In the results portion of this report standard deviations are noted in the text in parentheses following average values. Correlations of interest observed in latifolia between component

weights (and specific gravities) and tree characteristics are also noted in the results section of this chapter.

\section{4-3 LITERATURE REVIEW}

There is a substantial body of literature on the weight of lodgepole pine components-much of it related to fire research, and a smaller literature related to specific gravity of tree components. Following is an abstract of this information, with emphasis on North American data.

\section{Weight of Tree Components}

Complete Trees-Adamovich (1975) sampled lodgepole pine from good sites about 70 miles north of Prince George, BC, to determine aboveground tree component proportions and green weights. Proportions determined were as follows:

\section{Component}

Stemwood
Stembark
Branches with foliage
Total

Proportion of green weight and standard deviation - . . . . Percent - . . . . .

86.8

6.6

6.6

100.0

(1.43)
His equation $\left(R^{2}=0.992\right)$ for green whole-tree weight, including all aboveground portions, follows (logarithmic, base 10$)$ :

$\log$ of whole-tree weight, pounds $=$ $-0.946+1.608 \log D+1.257 \log H$

where:

$$
\begin{aligned}
& D=\text { d.b.h., inches } \\
& H=\text { tree height, feet. }
\end{aligned}
$$

In Crater Lake National Park, Agee (1983) sampled understory murrayana of small diameter $(0.86$ to $5.88 \mathrm{~cm}$ groundline diameter). He found that aboveground tree biomass, ovendry-weight basis, was best expressed as a natural logarithmic function of tree height, as follows:

$$
\begin{aligned}
& \text { in dense stands }\left(R^{2}=0.95\right) \\
& \ln Y=-1.0415+2.4574 \ln X \\
& \text { in open stands }\left(R^{2}=0.96\right) \\
& \ln Y=-0.2727+2.4567 \ln X
\end{aligned}
$$

where:

$Y=$ aboveground biomass per tree, grams

$X=$ tree height from ground to apical tip, meters.

Chapman and others (1982) sampled trees 12 inches in d.b.h. and smaller in northeastern Washington (Stevens, Ferry, and Pend Oreille Counties). They found that total aboveground weight, green basis, could be predicted $\left(R^{2}=0.90\right)$ as follows:

$$
Y=5.540+13.2964 D^{2} H
$$

where:

$Y=$ total aboveground biomass green weight, pounds

$D=$ d.b.h., inches

$H=$ tree height, feet. 
Johnstone (1971) studied three stands of 100-year-old trees in southwestern Alberta and observed the following average proportions for tree components (ovendry-weight basis) (two of the stands averaged 7.1 inches d.b.h., and the third was only 2.2 inches):

\section{Component}

$\begin{aligned} & \text { 7.1-inch } \\ & \text { stands }\end{aligned} \begin{gathered}\text { 2.inch } \\ \text { stand }\end{gathered}$
... - - Percent - . . . -

Needles

Branches

5

Stem, wood plus bark

7

Root plus stump

Total

73
15
100

7

13

61

19

100

His equations (logarithmic to the base 10) for tree component weights follow and are based on data pooled from two of the three stands in which d.b.h. averaged 7.1 inches, height 60.4 feet, and crown length 21.6 feet; $D=$ d.b.h., inches; $H=$ tree height, feet:

$\log$ dry needle weight, pounds $=-0.996+1.148 \log D^{2} H$

$\log$ dry branch weight, pounds $=-4.126+1.509 \log D^{2} H$

$\log$ dry stem weight, wood plus bark, pounds $=$

$-0.889+0.938 \log D^{2} H$

$\log$ dry stump-root weight, pounds $=-1.879+1.022 \log D^{2} H$

$\log$ dry complete-tree weight, pounds $=$

$-0.996+0.997 \log D^{2} H$

$R^{2}$ values for the foregoing equations were $0.849,0.894$, $0.978,0.949$, and 0.987 , respectively. The equations were based on 72 or 85 trees.

Pearson (1982) found from a study in the Medicine Bow Mountains of southeastern Wyoming that trees grown in very open stands ( $<1,000$ trees/ha) had 28 percent more biomass than trees of the same diameter in very dense stands (>5,000 stems/ha). Biomass of foliage, branches, boles, and woody lateral roots of individual trees decreased by $73,25,25$, and 80 percent, respectively, across this density gradient, but root crown biomass increased by 25 percent. Sapwood area was a more precise predictor of foliage biomass than basal area, except in very dense stands. For stands of various densities, the biomass distribution varied as follows:

\begin{tabular}{|c|c|c|c|c|}
\hline \multirow{3}{*}{ Component } & \multicolumn{4}{|c|}{ Stand density (trees/ha) } \\
\hline & $<1,000$ & $1,000-1,500$ & $1,500-5,000$ & $>5,000$ \\
\hline & \multicolumn{4}{|c|}{ Percent of complete-tree weight, ovendry } \\
\hline Foliage & 13 & 12 & 7 & 5 \\
\hline Branches & 8 & 8 & 8 & 8 \\
\hline Bole, wood plus & & & & \\
\hline bark & 61 & 63 & 60 & 62 \\
\hline Root crown & 13 & 14 & 22 & 23 \\
\hline Lateral roots & 5 & 3 & 3 & 2 \\
\hline
\end{tabular}

Based on a sample of 60 trees from Alberta, Canada, Singh (1982b) tabulated aboveground weights, ovendry basis and foliage-free, of lodgepole pine related to d.b.h. and height; his table is abstracted as follows:

\begin{tabular}{|c|c|c|c|c|c|c|}
\hline \multirow{2}{*}{ D.b.h. } & \multicolumn{6}{|c|}{ Tree height, meters } \\
\hline & 8 & 12 & 16 & 20 & 24 & 28 \\
\hline $\mathrm{cm}$ & $\cdots$ & $\ldots$ & $-K i$ & ams & $\ldots$ & $\cdots$ \\
\hline 8 & 8 & 19 & & & & \\
\hline 12 & 26 & 38 & 51 & & & \\
\hline 16 & & 61 & 80 & 99 & & \\
\hline 20 & & 89 & 116 & 143 & 169 & \\
\hline 24 & & & 160 & 196 & 232 & 269 \\
\hline 28 & & & 212 & 260 & 308 & 356 \\
\hline 32 & & & & 336 & 397 & 459 \\
\hline
\end{tabular}

Based on the same sample of 60 trees, Singh (1982a) gives equations for predicting ovendry weights of stump, stem, and live branches-all based on d.b.h. and height.

From the literature, Smith and DeBell (1973) estimated biomass distribution (ovendry basis) in aboveground portions of lodgepole pine, as follows: stemwood, 65 percent; stembark, 10 percent; branches, 16 percent; and foliage, 9 percent.

Weaver and Forcella (1977), from reviews of the literature and data from a 39-tree sample in Montana, concluded that functions of the logarithm (base 10) of $D^{2} H$ are good predictors of logarithms of lodgepole pine component weight. They noted that predictions of weight from such relationships become poorer for environments increasingly different from those for which the relationships were developed.

Foliage-In Crater Lake National Park, Agee (1983) sampled understory murrayana of small diameter ( 0.86 to $5.88 \mathrm{~cm}$ groundline diameter). He found that foliage weight, ovendry, was best expressed as a natural logarithmic function of diameter, as follows:

in dense stands $\left(R^{2}=0.70\right)$

$\ln Y=-1.1430+1.5001 \ln X$

in open stands $\left(R^{2}=0.95\right)$

$\ln Y=-1.8756+1.9529 \ln X$

where:

$Y=$ foliar biomass dry weight, grams

$X=$ groundline diameter, centimeters .

Brown (1978) found that in lodgepole pines 1-inch d.b.h. or less, foliage averages about 52 percent of the weight of live branches including foliage, ovendry basis; for larger trees the decimal fraction represented by foliage equals $0.493-0.0117$ (d.b.h), with d.b.h. expressed in inches.

Dobie and McIntosh (1976) found that foliage on 8-inch d.b.h. whole lodgepole pine trees summer-harvested in Alberta averaged only 2.4 percent of their ovendry weight as delivered to a mill. The proportion was small because some trees had broken tops and others no foliage at time of mill delivery.

Based on 12 lodgepole pines 10 to 60 years old destructively sampled in the Central Colorado Mountains at an elevation of 2,700 m, Running (1980) developed the following equation for predicting foliage ovendry weight from sapwood basal area at breast height $\left(R^{2}=0.94\right)$ :

$Y=-0.76+0.051 X$

where:

$Y$ = foliage ovendry weight, kilograms

$X=$ sapwood basal area, square centimeters. 
Kaufmann and Troendle (1981) also found that ovendry foliage weight of lodgepole pine is linearly related to sapwood cross-sectional area at breast height in the stem, as follows $\left(R^{2}=0.95\right)$ :

Dry foliage weight, grams $=$

46.2 (sapwood cross-sectional area, $\mathrm{cm}^{2}$ )

This equation is based on 11 trees sampled in August and September at about $915 \mathrm{~m}$ elevation near Fraser, CO.

Moir and Francis (1972) measured the foliage weight of 15 trees 3.6 to $19.3 \mathrm{~cm}$ d.b.h. sampled from three stands in the Colorado Front Range, partitioned into current year's foliage and previous year's foliage; because it is information peripheral to this paper, their results are not abstracted.

Moore (1981), in a study of lodgepole pine from Colorado, Wyoming, and Montana, found that the average weight of a fascicle of needles (ovendry basis) was $3.5 \mathrm{mg}$, with range from 2.0 to $6.1 \mathrm{mg}$; strong latitudinal or elevational trends in fascicle weight were not found.

Cones-In a survey including lodgepole pine from Colorado, Wyoming, and Montana, Moore (1981) found that ovendry weights of individual cones varied significantly with location, but not in an easily identified latitudinal or longitudinal pattern; mean weights for the 13 areas studied varied from 3.82 to $7.18 \mathrm{~g}$ per cone. The overall average ovendry weight per cone was $5.6 \mathrm{~g}$.

Branches-Adamovich (1975) developed the following equation for green branch weights, including wood, bark, and foliage $\left(R^{2}=0.951\right)$; the equation is based on trees sampled about 70 miles north of Prince George, BC:

$\log$ (base 10) green branch weight, pounds $=$

$$
-2.53+2.272 \log D+0.553 \log (L / H)
$$

where:

$$
\begin{aligned}
& D=\text { d.b.h., inches } \\
& H=\text { tree height, feet } \\
& L=\text { crown length, feet. }
\end{aligned}
$$

Brown and others (1977) developed predictive relationships between slash weight and tree d.b.h. from trees sampled in Montana and Idaho, expressed as weight per tree of crowns (including foliage) and nonmerchantable stem tips to various stem top diameters, as follows:

\begin{tabular}{cccc} 
& \multicolumn{3}{c}{ Crown above a } \\
\cline { 2 - 4 } D.b.h. & $\begin{array}{c}\text { 3-inch } \\
\text { top }\end{array}$ & $\begin{array}{c}\text { 4-inch } \\
\text { top }\end{array}$ & $\begin{array}{c}\text { 6-inch } \\
\text { top }\end{array}$ \\
Inches & - - Pounds, ovendry & basis - - \\
4 & 29 & & \\
6 & 46 & 62 & \\
8 & 74 & 86 & 158 \\
10 & 112 & 122 & 177 \\
12 & 155 & 164 & 207 \\
14 & 205 & 213 & 249 \\
16 & 262 & 269 & 299
\end{tabular}

Brown (1978) developed an equation $\left(R^{2}=0.88\right)$ to predict live branch weight of lodgepole larger than 1-inch d.b.h., as follows (ovendry basis):

branch weight with foliage, pounds $=$

$0.02238 D^{3}+0.1233 D^{2} R-2.00$

where:

$D=$ d.b.h., inches

$R=$ crown ratio.

He concluded that the dead-branch weight (ovendry) was as follows:

for trees 10 inches or less in d.b.h.

weight, pounds $=0.026 D-0.025$ (live branch weight)

for trees larger than 10 inches d.b.h.

weight, pounds $=0.235$ (live branch weight)

Snell and Brown (1980) estimated the ovendry weight of entire crowns (wood plus bark and foliage) above that portion of the stem that has a top diameter of 6 inches outside bark, as follows:

$\begin{array}{cc}\text { D.b.h. } & \text { Ovendry weight } \\ \text { Inches } & \text { Pounds } \\ 8 & 177 \\ 10 & 201 \\ 12 & 224 \\ 14 & 258 \\ 16 & 301\end{array}$

Stems-Adamovich (1975) developed the following equations for green stem weights, wood plus bark $\left(R^{2}=0.993\right)$, and wood only $\left(R^{2}=0.994\right)$; the equations are based on trees sampled about 70 miles north of Prince George, BC:

$\log$ (base 10 ) stem weight, wood plus bark, pounds = $-1.259+1.507 \log D+1.453 \log H$

$\log$ (base 10) stemwood weight, pounds = $-1.374+1.534 \log D+1.487 \log H$ where:

$D=$ d.b.h., inches

$H=$ tree height, feet.

From lodgepole 4 inches in d.b.h. and less in the Rocky Mountain region of the United States, Brown (1978) developed the following equation for estimating bole weights, wood plus bark, ovendry basis $\left(R^{2}=0.97\right)$ :

bole weight, pounds $=1.49-2.388 D+2.297 D^{2}$ where:

$D=$ d.b.h., inches.

Chapman and others (1982) sampled trees 12 inches d.b.h. and smaller in northeastern Washington and found that entire green stem weights, wood plus bark, above 0.34 -foot stump height could be predicted $\left(R^{2}=0.89\right)$, as follows:

stem weight, pounds $=4.17605+0.14225 D^{2} H$ where:

$D=$ d.b.h., inches

$H=$ tree height, feet. 
Bark-Adamovich (1975) developed the following equation for the green weight of stembark $\left(R^{2}=0.974\right)$; the equation is based on trees sampled about 70 miles north of Prince George, BC:

$\log$ (base 10 ) of stembark weight, pounds =

$$
0.841+1.877 \log D+0.410 \log H
$$

where:

$$
\begin{aligned}
D & =\text { d.b.h., inches } \\
H & =\text { tree height, feet. }
\end{aligned}
$$

Snell and Max (1982) analyzed data from Oregon, Washington, and Idaho, and concluded that lodgepole logging residue sufficient to yield $100 \mathrm{~kg}$ of bark-free wood will also yield $8 \mathrm{~kg}$ of bark-ovendry-weight basis.

Sapwood and Heartwood-No data on the weight per tree of sapwood and heartwood were found in the literature.

Stump-Root System-See abstracts of Johnstone (1971) and Pearson (1982) previously discussed under the paragraph heading "Complete Trees."

Further to these previous comments, Moir (1972) estimated that the biomass of lodgepole roots larger than $5 \mathrm{~mm}$ in diameter constitutes about 25 percent of complete-tree biomass, ovendry basis. When reading the results section of this paper, readers should be aware that workers carefully excavating the full extent of the root system will recover a much greater weight of roots than workers who pull the central root mass-taproot with laterals intact to a radius of only $305 \mathrm{~mm}$ from tree pithas was the procedure for the work reported here.

\section{Specific Gravity and Bulk Density of Tree Components}

Stemwood Bulk Density-According to the American Lumberman (1910), seasoned wood of lodgepole pine weighs $25.53 \mathrm{lb} / \mathrm{ft}^{3}$. Bramhall and Wellwood (1976) reported the average specific gravity of Canadian lodgepole pine lumber as 0.408 based on ovendry weight and green volume, and further noted that the average ovendry weight of a cubic foot of such green wood is $25.50 \mathrm{lb}$. Brown and others (1977), in predicting weight of upper stem portions of lodgepole pine in the western part of the United States, used bulk densities of $25.6 \mathrm{lb} / \mathrm{ft}^{3}$ of wood (based on the ovendry weight of a cubic foot of wood at 12 percent moisture content) and $26.5 \mathrm{lb} / \mathrm{ft}^{3}$ of bark (based on the ovendry weight of a cubic foot of green in-place bark). In his studies of dead lodgepole pine in the Intermountain West of the United States, Fahey $(1980,1981)$ used a bulk density for wood and stembark of $24 \mathrm{lb} / \mathrm{ft}^{3}$, ovendry, of green material. In a major study of the specific gravity of lodgepole pine in the United States, Maeglin and Wahlgren (1972) concluded that the average bulk density of lodgepole pine stemwood in trees larger than 5 inches d.b.h. in the western part of the United States (murrayana as well as latifolia) was $23.7 \mathrm{lb} / \mathrm{ft}^{3}$, ovendry, of green wood; data by State are shown in table 4-1.

Stemwood Tree Average Specific Gravity-Brazier (1980), reporting on the properties of lodgepole pine grown in Britain, found that average stemwood specific
Table 4-1-Bulk density and specific gravity of lodgepole pine

\begin{tabular}{|c|c|c|c|c|}
\hline \multirow[b]{2}{*}{ State } & \multirow[b]{2}{*}{ Density } & \multicolumn{2}{|c|}{ Specific gravity } & \multirow{2}{*}{$\begin{array}{c}\text { Standarc } \\
\text { error }\end{array}$} \\
\hline & & Average & Range & \\
\hline & $L b / f t^{3}$ & & & \\
\hline $\begin{array}{l}\text { California } \\
(1) \\
(2)\end{array}$ & $\begin{array}{l}25.03 \\
23.29\end{array}$ & $\begin{array}{r}0.401 \\
.373\end{array}$ & $\begin{array}{r}0.292-0.505 \\
.328-.430\end{array}$ & $\begin{array}{r}0.0088 \\
.0047\end{array}$ \\
\hline Colorado & 21.66 & .347 & $.264-.401$ & .0048 \\
\hline $\begin{array}{l}\text { Idaho } \\
\text { (north) } \\
\text { (south) }\end{array}$ & $\begin{array}{l}23.91 \\
23.54\end{array}$ & $\begin{array}{l}.383 \\
.377\end{array}$ & $\begin{array}{ll}.303-.512 \\
.285-.498\end{array}$ & $\begin{array}{l}.0045 \\
.0022\end{array}$ \\
\hline $\begin{array}{c}\text { Montana } \\
\text { (west) } \\
\text { (east) }\end{array}$ & $\begin{array}{l}24.22 \\
22.66\end{array}$ & $\begin{array}{l}.388 \\
.363\end{array}$ & $\begin{array}{l}.305-.509 \\
.319-.405\end{array}$ & $\begin{array}{l}.0019 \\
.0051\end{array}$ \\
\hline $\begin{array}{l}\text { Oregon } \\
\text { (west) } \\
\text { (east) }\end{array}$ & $\begin{array}{l}26.34 \\
24.10\end{array}$ & $\begin{array}{l}.422 \\
.386\end{array}$ & $\begin{array}{ll}.328- & .554 \\
.319- & .493\end{array}$ & $\begin{array}{l}.0137 \\
.0026\end{array}$ \\
\hline $\begin{array}{l}\text { Utah } \\
\text { Washington } \\
\text { (west) } \\
\text { (east) }\end{array}$ & $\begin{array}{l}22.79 \\
26.97 \\
24.28\end{array}$ & $\begin{array}{l}.432 \\
.389\end{array}$ & $\begin{array}{l}.284-.425 \\
.388-.512 \\
.319-.499\end{array}$ & $\begin{array}{l}.0025 \\
.0393 \\
.0040\end{array}$ \\
\hline Wyoming & 23.16 & .371 & $.298-.482$ & .0023 \\
\hline
\end{tabular}
stemwood based on ovendry weight and green volumes (Maeglin and Wahlgren 1972) ${ }^{1}$

${ }^{1}$ Computed from data taken from breast-height increment cores.

gravity (based on ovendry weight and green volume) was 0.375 , but that trees from seed sources in the Prince George, BC, area had significantly lower stemwood specific gravity than those from seed sources of the southcoastal region of British Columbia.

Cannell and others (1983), reporting on studies of plantations in Scotland, found that mean stemwood specific gravity at age 8 years differed by 21 percent among lodgepole pine clones originating in Alaska and British Columbia, and that there was a 22 percent drop in specific gravity between the innermost and outermost annual rings of the 8-year-old trees. For all clones, stemwood specific gravity decreased as a linear function of the logarithm (base $e$ ) of the annual stemwood volume production; that is, fast-grown wood had lower density than slow-grown wood. In Finland, Bjorklund (1982) also concluded that stemwood specific gravity in lodgepole pine is inversely correlated with growth-ring width; moreover, he noted that specific gravity of small lodgepole pine removed in thinnings was greater than that of sawtimber trees left to grow. Sylvander and Smith (1973) reported a similar trend for lodgepole stemwood in interior British Columbia.

Carlson and Nimlos (1966) found that stemwood increment cores taken at breast height from lodgepole pine in Montana's Clark Fork Valley west of Thompson Falls had higher specific gravity $(0.409)$ than those found by Tackle (1962) in Wyoming and southern Idaho (0.386).

In a study of lodgepole pine, ponderosa pine, and Douglas-fir from the west slope of the Sierra Nevada in California, Echols (1973) found that stemwood of lodgepole pine (murrayana) had not only the least intra-incremental variation in wood density, but also the least variation among trees. 
In two southeastern Wyoming stands, Fahey (1983) found that standing dead lodgepole pine had stemwood specific gravities of 0.53 and 0.48 (probably based on ovendry weight and air-dry volume, although not stated).

Hakkila and Panhelainen (1970) studied lodgepole pine 29 to 43 years old grown in Finland from seed originally obtained in Alberta and British Columbia. They found that an unbiased estimate of average stemwood density can be obtained from a knot-free sample taken at 20 percent of tree height, with the following equation $\left(R^{2}=0.828\right.$; standard error of estimate $11.9 \mathrm{~kg} / \mathrm{m}^{3}$ ):

$$
Y=117.6+0.723 X
$$

where:

$$
\begin{aligned}
Y= & \text { stemwood density based on ovendry volume and } \\
& \text { weight, } \mathrm{kg} / \mathrm{m}^{3} \\
X= & \text { stemwood density at } 20 \text { percent of tree height. }
\end{aligned}
$$

Average stemwood specific gravity was 0.433 . Standard deviation between stands in southern Finland was 3.1 percent of the mean. Specific gravity of stemwood in northern Finland at about 66.5 degrees latitude was 11.6 percent less than that in southern Finland at 60 to 62 degrees.

In a major study of specific gravity of lodgepole pine 5 inches and larger d.b.h. in the United States, Maeglin and Wahlgren (1972) took 3,516 breast-height increment cores throughout the Western States (murrayana as well as latifolia, but without distinguishing between varieties). From these cores they estimated tree stemwood specific gravities based on correlations determined from 213 trees, as follows $\left(R^{2}=0.749\right.$; standard error of the estimate $=$ $0.025)$ :

Tree stemwood specific gravity $=$ $0.06464+0.7617$ (core specific gravity)

The overall average for tree stemwood specific gravity on the basis of green volume and ovendry weight was 0.379 . Statistics for tree stemwood specific gravity and bulk density are given, by State, in table 4-1.

The Wood Handbook (USDA-FS 1974) gives 0.38 as the species average for lodgepole pine based on ovendry weight and green volume.

Singh (1984) sampled 60 lodgepole pine trees, measuring 10 to more than $30 \mathrm{~cm}$ d.b.h., along a north-south gradient in Alberta. He found that average stemwood specific gravity was 0.444 , with range from 0.376 to 0.539 . Stemwood specific gravity was maximum at stump height $(0.48)$, decreased to 0.44 at breast height and 0.43 in the upper merchantable stem, and then increased to 0.47 in the nonmerchantable stem top. Large branchwood of these trees had average specific gravity of 0.53 . All data were based on ovendry weights and ovendry volumes.

Tackle (1962) concluded from a study of 44 dominant lodgepole pines in Idaho, Utah, and Wyoming, that treeaverage stemwood specific gravity was 0.392 and ranged from 0.317 to 0.487 based on ovendry weight and green volume. Stemwood specific gravity decreased significantly from stump height up to about 20 feet, but changed little above that. Tackle found that the relation of tree stemwood specific gravity to increment core specific gravity at breast height was as follows $(r=0.754$; standard error of estimate $=0.021$ ):

$$
\begin{aligned}
& \text { Stemwood specific gravity }= \\
& 0.143+0.661 \text { (core specific gravity) }
\end{aligned}
$$

Taylor and others (1982) studied two stands, one at high and one at low elevation, in each of three western Alberta Provincial Forests-one in the north, one in the south, and one midway between. Within each stand he sampled at breast height 10 dominant or codominant trees. Additionally, he sampled a total of six trees for variations within stems. All trees were 77 to 110 years old and 28 to $30 \mathrm{~cm}$ d.b.h. His determinations were made on an extractive-free basis, ovendry weight and green volume. Trees from the three forests did not differ significantly in stemwood specific gravity at breast height; but differences between stands were significant, with range of means from 0.33 to 0.42 for rings 1 to bark. Within-stand variation between trees was also large. No differences between elevational zones were reported. Stemwood specific gravity decreased linearly with height above ground. Radial variation was different at different heights in the trees.

Diseases also affect stemwood specific gravity. In three even-aged stands-65, 67, and 95 years-of lodgepole pine in Alberta, Baranyay and others (1973) found that stemwood unaffected by Atropellis canker averaged 0.443 specific gravity based on ovendry weight and green volume; wood portions infected by the canker disease had specific gravity of 0.715 . Pitch and extractives content of the infected wood (38 percent of ovendry weight) was largely responsible for the increased specific gravity noted. Also, stemwood of lodgepole pine parasitized by dwarf mistletoe has been found by Smythe (1967) to have significantly higher specific gravity than that of uninfected healthy wood.

Within-Stem Variation in Wood Specific GravityBjorklund (1982) found that lodgepole pine trees growing in Finland had stemwood specific gravity averaging 0.432 based on ovendry weight and green volume. Stemwood specific gravity diminished with height in stems to 60 to 80 percent of tree height and then rose slightly in the uppermost stem section. Radially from the pith, density diminished initially and then increased. Intrastand variation was considerable and was inversely correlated with growth-ring width; that is, trees with wide rings had lower specific gravity than those with narrow rings.

The variation of stemwood specific gravity with height in 36 lodgepole pine trees averaging 4.3 inches in d.b.h. sampled near Prince George, BC, was studied by Heger (1974). He found a curvilinear variation with highest specific gravity at 10 percent height $(0.428)$ and lowest at 70 percent height (0.395); at 90 percent height specific gravity increased slightly from the minimum to about 0.400 .

Johnstone (1970a, 1970b) found from a study of 85-yearold lodgepole pine growing near Hinton, AB, that specific gravity decreased linearly from the base to the top of the trees if plotted against feet above ground $(H)$, as follows $\left(R^{2}=0.137 ;\right.$ standard error of the estimate $\left.=0.039\right)$ :

$$
\text { specific gravity }=0.497-0.000854 H
$$


The relationship between tree stemwood specific gravity and that at breast height was as follows $\left(R^{2}=0.576\right.$; standard error of estimate $=0.022$ ):

tree stemwood specific gravity =

$0.166+0.642$ (breast height specific gravity)

Mean stemwood specific gravity was 0.476 , with standard deviation of 0.042 and range from 0.345 to 0.637 .

From an analysis of three height classes of lodgepole pine broadly distributed in the Western United States (35-foot class, 10.6 inches d.b.h.; 50-foot class, 12.0 inches d.b.h.; and 65-foot class, 15.7 inches d.b.h.), Okkonen and others (1972) concluded that stemwood specific gravity declined more or less linearly with height above ground. In the two taller classes, the decline was less rapid above 20 feet than below 20 feet.

Additional findings related to within-tree variations in stemwood specific gravity are abstracted from Singh (1984), Tackle (1962), and Taylor and others (1982) under the preceding paragraph heading.

Sapwood and Heartwood-No data comparing heartwood to sapwood specific gravity were found in the literature.

Early Wood and Late Wood-From a study of 28-yearold lodgepole pine in Ireland, the Forest Products Laboratory, Princes Risborough (1960) found that there was no significant change in the specific gravity of late wood with height in stem, but early wood density decreased with increasing height in tree. Stem-average values for the two stands studied were:

$\begin{array}{lcc}\text { Stemwood } & & \\ \text { component } & \text { Stand A } & \text { Stand B } \\ \text { Late wood } & 0.51 & 0.54 \\ \text { Early wood } & .30 & .31 \\ \text { Entire ring } & .36 & .37\end{array}$

From 16 sites in New Zealand, Harris (1973) took increment cores at breast height from lodgepole pine trees 203 to $376 \mathrm{~mm} \mathrm{d.b.h.} \mathrm{He} \mathrm{found} \mathrm{that} \mathrm{the} \mathrm{specific} \mathrm{gravity} \mathrm{of} \mathrm{late}$ wood increased more or less abruptly from the pith outward, but soon tended to settle at some nearly constant value between 0.5 and 0.7 depending on site. Early wood densities usually decreased over the first two to four growth increments and thereafter remained more or less constant between 0.30 and 0.35 depending on site. Weighted mean densities of the cores ranged from 0.362 to 0.453 depending on site (basis of ovendry weight and green volume).

Henderson and Petty (1972) found significant differences in stemwood specific gravity between American coastal provenance material and Canadian inland provenance (Prince George) material grown in Scotland, as follows (data are from increment cores taken at 10 percent of tree height and are based on ovendry weight and green volume):

$\begin{array}{lccc}\text { Provenance } & \begin{array}{c}\text { Early } \\ \text { wood }\end{array} & \begin{array}{c}\text { Late } \\ \text { wood }\end{array} & \begin{array}{c}\text { Entire } \\ \text { increments }\end{array} \\ \text { Prince George } & 0.30 & 0.56 & 0.39 \\ \text { Coastal U.S. } & .33 & .65 & .47\end{array}$

Sylvander and Smith (1973), from an analysis of lodgepole pine throughout most of the interior of British Columbia-including that area adjacent to the Yukon
Territory-concluded that the specific gravity of stem early wood ranges from 0.36 to 0.43 while that of late wood is in the range from 0.57 to 0.70 based on ovendry weight and green volume. They found a generally negative correlation between early wood increment width and early wood specific gravity, but did not find this trend uniformly in late wood. Specific gravity of entire annual rings tended to be negatively correlated with ring width.

Branches-In a western Wyoming study of lodgepole residues remaining after clearcut harvesting to a 6 -inch merchantable top, Foulger and Harris (1973) found that bark of the residues had a specific gravity of 0.350 (basis of green weight and ovendry volume) and that this value did not vary with diameter of the residues. Wood density, however, decreased from about 0.48 for material less than 0.6 -inch diameter to about 0.38 for that larger than 3 inches.

As noted previously, Singh (1984) found that large branchwood from Alberta lodgepole had average specific gravity of 0.53 , ovendry weight and volume basis.

Bark-Smith and Kozak (1971) concluded from a study of lodgepole pine in British Columbia that the specific gravity of inner and outer stembark was little influenced by tree d.b.h. Specific gravity of inner bark averaged 0.335 and that of outer bark 0.508 -both based on ovendry weight and green volume. These values were derived from specimens taken at 30 - and $137-\mathrm{mm}$ heights in 22 trees measuring $280 \mathrm{~mm}$ in d.b.h.

See comments under the preceding paragraph heading regarding the specific gravity of branchbark.

Stump-Root System-No data were found in the literature related to specific gravity of lodgepole pine stump-root systems.

\section{Weight of Tree Components per Hectare}

Not within the scope of this paper, but of peripheral interest, are weights per hectare of lodgepole pine biomass. Following is a listing of pertinent references with an indication of content.

Benson (1982) evaluated ground fuels in Wyoming, by component weight, before and after logging. Brown and others (1977) decribed procedures to predict slash weights per hectare on the basis of basal area or number of trees per hectare. Fahnestock and Dieterich (1962) tabulated the reduction in fuel weight on the forest floor 1 and 5 years after harvest. Kiil (1968) studied the weight per hectare of the fuel complex in a 70-year-old stand in Alberta.

Moir (1972) tabulated-per unit area-stand biomass of bole, live branches, roots, green needles, cones, dead branches, standing dead timber, forest floor humus, and ground flora on the east slopes of the Colorado Front Range.

Muraro (1971) tabulated the number of live and dead trees per acre and tons per acre of fuel on the ground based on 160 sampling points in a variety of lodgepole pine associations 20 miles south of Merritt, BC. In an earlier publication describing the same area Muraro (1966) tabulated per-acre tonnage of slash, foliage, branchwood, and tops.

Pearson (1982) found in a study of stands 70 years old or older in southeastern Wyoming that biomass ranged 
from 116 to 175 tons per hectare, ovendry basis; of this total, woody roots accounted for 20 to 46 t/ha.

Peterson and others (1982) studied the upper limits of density, expressed as kilograms per cubic meter of a standing crop of lodgepole pine. Reynolds and Knight (1973) found that litter in lodgepole pine forests in Wyoming weighed $12,113 \mathrm{~kg} / \mathrm{ha}$, ovendry basis.

Roydhouse and others (1985), from data on 20-year-old fire-originated stands near Williams Lake, BC, related biomass per hectare to number of stems per hectare, as follows:

$\begin{array}{rc}\text { Stems/ha } & \begin{array}{c}\text { Aboveground } \\ \text { biomass, ovendry } \\ k g / h a\end{array} \\ 150,000 & 27,500 \\ 50,000 & 53,000 \\ 20,000 & 52,000 \\ 5,000 & 45,000\end{array}$

These references, and conversations with experienced technologists, suggest that a typical well-stocked stand of lodgepole pine 80 to 150 years old on a typical site has stemwood volume (stump top to apical tip) in standing live trees of about $104 \mathrm{t} / \mathrm{ha}$, and perhaps $26 \mathrm{t} / \mathrm{ha}$ of standing dead stemwood for a total of 130 t/ha of stemwoodovendry basis. Total aboveground biomass-live and standing dead, including foliage-typically totals about $166 \mathrm{t} / \mathrm{ha}$, ovendry basis.

\section{4-4 PROCEDURE}

Procedural details of the experiment are given in chapter 1 , and will not be repeated here except to note that the elevational zones of low, medium, and high are relative. Medium refers to an elevation that is medium for the variety at the latitude at which sampled; similarly, low and high refer to lower and upper elevational zones in which the variety occurs at the latitude sampled. Latifolia elevational zones were highest in the south $(2,481,2,711$, and $3,144 \mathrm{~m}$ at 40 degrees) and progressively lower with each more northerly latitude $(604,739$, and $879 \mathrm{~m}$ at 60 degrees). Murrayana was sampled at elevations in the range from 1,148 to $2,404 \mathrm{~m}$.

Trees were uprooted (with central taproot intact and with lateral roots severed at a radius of $305 \mathrm{~mm}$ from tree pith) from level benches in natural, unthinned stands within National or Provincial Forests. The sampling scheme resulted in selection of 76-, 152-, and 228-mm trees averaging 71,91 , and 107 years of age, respectively, for latifolia, and 67, 84, and 91 years for murrayana. Most of the small-diameter trees were suppressed, while the larger trees were the fast growers. Stump tops were $152 \mathrm{~mm}$ above ground level.

\section{4-5 RESULTS-LATIFOLIA}

In the following paragraphs summarizing results, only those main effects and interactions shown statistically significant ( 0.05 level) by analyses of variance are discussed, tabulated, and graphed. All reported correlations are statistically significant ( 0.05 level).

Average specific gravities of tree components are summarized in table 4-2, weights in table 4-3, major tree com-
Table 4-2-Average specific gravities (basis of ovendry weight and green volume), with standard deviations shown in parentheses, of lodgepole pine tree components; data are from 243 latifolia and 36 murrayana trees ${ }^{1}$

\begin{tabular}{|c|c|c|c|c|}
\hline \multirow[b]{2}{*}{ Tree component } & \multicolumn{4}{|c|}{ Variety } \\
\hline & \multicolumn{2}{|c|}{ Latifolia } & \multicolumn{2}{|c|}{ Murrayana } \\
\hline \multicolumn{5}{|c|}{$\begin{array}{l}\text { Complete tree without cones } \\
\text { and foliage }\end{array}$} \\
\hline Wood plus bark & 0.421 & $(0.028)$ & 0.438 & $(0.037)$ \\
\hline Wood & .428 & $(.030)$ & .449 & $(.043)$ \\
\hline Bark & .381 & $(.040)$ & .379 & $(.033)$ \\
\hline \multicolumn{5}{|l|}{ Live branches } \\
\hline Wood plus bark & .457 & $.031)$ & .458 & $(.024)$ \\
\hline Branchwood & .487 & $(.036)$ & .494 & $(.022)$ \\
\hline Branchbark & .411 & $(.051)$ & .414 & $(.048)$ \\
\hline \multicolumn{5}{|l|}{ Stem } \\
\hline Wood plus bark & .412 & $(.030)$ & .433 & $(.041)$ \\
\hline Stemwood & .418 & $(.032)$ & .433 & $(.048)$ \\
\hline Stembark & .369 & $(.042)$ & .361 & $(.029)$ \\
\hline Sapwood & .414 & $(.034)$ & .437 & $(.048)$ \\
\hline Heartwood & .434 & $(.034)$ & .502 & $(.067)$ \\
\hline \multicolumn{5}{|l|}{ Stump-root system } \\
\hline Wood plus bark & .461 & $(.043)$ & .461 & $(.045)$ \\
\hline Wood & .469 & $(.045)$ & .467 & $(.050)$ \\
\hline Bark & .415 & $(.056)$ & .412 & $(.043)$ \\
\hline \multicolumn{5}{|l|}{ Stump } \\
\hline Wood plus bark & .471 & $(.046)$ & .496 & $(.054)$ \\
\hline Wood & .476 & $(.051)$ & .506 & $(.063)$ \\
\hline Bark & .445 & $(.064)$ & .431 & $(.055)$ \\
\hline \multicolumn{5}{|l|}{ Lateral roots } \\
\hline Wood plus bark & .442 & $(.047)$ & .432 & $(.066)$ \\
\hline Wood & .453 & $(.048)$ & .443 & $(.072)$ \\
\hline Bark & .399 & $(.082)$ & .388 & $(.059)$ \\
\hline \multicolumn{5}{|l|}{ Central root mass-taproot } \\
\hline Wood plus bark & .468 & $(.052)$ & .457 & $(.051)$ \\
\hline Wood & .475 & $(.055)$ & .460 & $(.055)$ \\
\hline Bark & .425 & $(.066)$ & .426 & $(.057)$ \\
\hline
\end{tabular}

1Because of the effects and interactions of d.b.h., latitude, and elevational zone, reference to appropriate figures and text discussion is required for interpretation of these data.

ponent proportions of weight in table 4-4, bark weight proportions of tree components in table 4-5, and green weights of the three major tree components required to yield $1 \mathrm{~m}^{3}$ of wood in table 4-6. Interpretation of these averages requires reference to the main effects and interaction attributable to d.b.h., latitude, and elevational zone-as discussed in the following paragraphs.

Longitudinal effects on latifolia were confounded with latitudinal effects (the northern latitudinal zones were farther west than the southern latitudinal zones). When each latitudinal zone was divided into 10 longitudinal zones, each a degree of longitude wide and expressed by a number from 1 to 10 going from east to west, only two significant relationships were observed in which the correlation coefficients exceeded 0.20 . Average weights, green and ovendry, of cones taken from the tip $305 \mathrm{~mm}$ of the top 25 branches of each tree were negatively correlated with longitudinal zone $(r=-0.394$ and -0.428 , respectively); that is, individual cone weights from trees on the east end of the latitudinal zones averaged more than those on the west end. 
Table 4-3-Average weights-green and ovendry-of lodgepole pine tree components, with data from the 243 latifolia and the 36 murrayana trees by d.b.h. classes of 76,152 , and $228 \mathrm{~mm}^{\prime}$

\begin{tabular}{|c|c|c|c|c|c|c|}
\hline \multirow[b]{2}{*}{ Tree component } & \multicolumn{3}{|c|}{ Green } & \multicolumn{3}{|c|}{ Ovendry } \\
\hline & 76 & 152 & 228 & 76 & 152 & 228 \\
\hline & \multicolumn{6}{|c|}{$\begin{array}{c}\text { Latifolia } \\
\text { Kilograms } \ldots \ldots \ldots \\
\end{array}$} \\
\hline Complete tree with foliage & 28.40 & 170.46 & 440.19 & 14.51 & 87.30 & 227.73 \\
\hline Tree wood & 21.88 & 141.11 & 370.58 & 11.42 & 72.55 & 191.17 \\
\hline Tree bark & 3.91 & 17.34 & 39.17 & 1.84 & 8.69 & 20.57 \\
\hline Foliage & 2.47 & 11.05 & 26.71 & 1.14 & 5.28 & 12.90 \\
\hline Cones, tree total ${ }^{2}$ & .14 & .96 & 3.74 & .11 & .78 & 3.09 \\
\hline Cones, individual ${ }^{3}$ & 0.0052 & 0.0060 & 0.0068 & 0.0042 & 0.0048 & 0.0056 \\
\hline Dead branchwood & .32 & 2.03 & 5.76 & .26 & 1.65 & 4.87 \\
\hline \multicolumn{7}{|l|}{ Live branches } \\
\hline Wood plus bark & 1.31 & 9.07 & 31.92 & .67 & 4.62 & 16.32 \\
\hline Wood & .74 & 5.93 & 23.14 & .39 & 3.11 & 12.09 \\
\hline Bark & .57 & 3.14 & 8.80 & .28 & 1.51 & 4.23 \\
\hline \multicolumn{7}{|l|}{ Stem } \\
\hline Wood plus bark & 20.34 & 128.49 & 328.84 & 10.35 & 65.15 & 168.12 \\
\hline Stemwood & 17.63 & 116.62 & 303.01 & 9.14 & 59.13 & 154.08 \\
\hline Stembark & 2.71 & 11.87 & 25.83 & 1.27 & 6.02 & 14.04 \\
\hline Sapwood & 14.37 & 91.34 & 226.16 & 6.89 & 41.45 & 99.81 \\
\hline Heartwood & 3.26 & 25.28 & 76.85 & 2.25 & 17.86 & 54.27 \\
\hline \multicolumn{7}{|l|}{ Stump-root system } \\
\hline Wood plus bark & 3.82 & 18.86 & 43.22 & 1.91 & 9.82 & 22.43 \\
\hline Wood & 3.19 & 16.53 & 38.67 & 1.61 & 8.66 & 20.13 \\
\hline Bark & .63 & 2.33 & 4.54 & .30 & 1.16 & 2.30 \\
\hline \multicolumn{7}{|l|}{ Stump } \\
\hline Wood plus bark & 1.15 & 3.67 & 7.18 & .59 & 2.01 & 3.89 \\
\hline Wood & .98 & 3.28 & 6.51 & .50 & 1.76 & 3.45 \\
\hline Bark & .17 & .43 & .72 & .09 & .25 & .44 \\
\hline \multicolumn{7}{|l|}{ Lateral roots } \\
\hline Wood plus bark & 1.05 & 6.75 & 15.53 & .51 & 3.37 & 7.80 \\
\hline Wood & .81 & 5.72 & 13.45 & .40 & 2.88 & 6.82 \\
\hline Bark & .24 & 1.03 & 2.08 & .11 & .49 & .98 \\
\hline \multicolumn{7}{|l|}{ Central root mass-taproot } \\
\hline Wood plus bark & 1.62 & 8.40 & 20.47 & .81 & 4.45 & 10.74 \\
\hline Wood & 1.40 & 7.54 & 18.72 & .71 & 4.02 & 9.86 \\
\hline Bark & .22 & .86 & 1.75 & .10 & .43 & $\begin{array}{r}.88 \\
\text { (con.) }\end{array}$ \\
\hline
\end{tabular}


Table 4-3 (Con.)

\begin{tabular}{|c|c|c|c|c|c|c|}
\hline \multirow[b]{2}{*}{ Tree component } & \multicolumn{3}{|c|}{ Green } & \multicolumn{3}{|c|}{ Ovendry } \\
\hline & 76 & 152 & 228 & 76 & 152 & 228 \\
\hline & \multicolumn{6}{|c|}{$\ldots \ldots \ldots$ Kilograms . . . . . . . . . . . . . . . . . } \\
\hline Complete tree with foliage & 24.25 & 151.57 & 419.37 & 12.11 & 72.95 & 197.65 \\
\hline Tree wood & 19.01 & 127.59 & 362.34 & 9.74 & 61.44 & 161.91 \\
\hline Tree bark & 3.39 & 15.54 & 36.37 & 1.51 & 7.36 & 17.77 \\
\hline Foliage & 1.81 & 8.19 & 19.83 & .83 & 3.94 & 9.28 \\
\hline Cones, tree total ${ }^{2}$ & .04 & .25 & .83 & .03 & .21 & .69 \\
\hline Cones, individual ${ }^{3}$ & 0.0037 & 0.0052 & 0.0049 & 0.0031 & 0.0044 & 0.0041 \\
\hline Dead branchwood & .26 & 1.08 & 4.91 & .21 & .89 & 4.34 \\
\hline \multicolumn{7}{|l|}{ Live branches } \\
\hline Wood plus bark & 1.25 & 7.85 & 28.15 & .65 & 4.34 & 13.82 \\
\hline Wood & .63 & 4.82 & 18.58 & .35 & 2.69 & 9.37 \\
\hline Bark & .62 & 3.03 & 9.57 & .30 & 1.65 & 4.45 \\
\hline \multicolumn{7}{|l|}{ Stem } \\
\hline Wood plus bark & 17.16 & 113.41 & 321.69 & 8.59 & 54.17 & 149.05 \\
\hline Stemwood & 14.98 & 103.41 & 298.80 & 7.63 & 49.46 & 137.55 \\
\hline Stembark & 2.18 & 10.00 & 22.89 & .96 & 4.71 & 11.50 \\
\hline Sapwood & 13.60 & 88.54 & 253.53 & 6.74 & 39.00 & 105.30 \\
\hline Heartwood & 1.38 & 14.87 & 45.27 & .95 & 10.46 & 32.25 \\
\hline \multicolumn{7}{|l|}{ Stump-root system } \\
\hline Wood plus bark & 3.75 & 20.53 & 43.87 & 1.80 & 9.70 & 20.56 \\
\hline Wood & 3.16 & 18.14 & 39.96 & 1.55 & 8.59 & 18.73 \\
\hline Bark & .59 & 2.39 & 3.91 & .25 & 1.11 & 1.83 \\
\hline \multicolumn{7}{|l|}{ Stump } \\
\hline Wood plus bark & 1.25 & 4.57 & 6.80 & .65 & 2.30 & 3.28 \\
\hline Wood & 1.09 & 4.15 & 6.27 & .58 & 2.08 & 2.98 \\
\hline Bark & .16 & .42 & .53 & .07 & .22 & .30 \\
\hline \multicolumn{7}{|l|}{ Lateral roots } \\
\hline Wood plus bark & .63 & 6.25 & 15.65 & .28 & 2.80 & 7.11 \\
\hline Wood & .47 & 5.25 & 13.79 & .22 & 2.38 & 6.31 \\
\hline Bark & .16 & 1.00 & 1.86 & .06 & .42 & .80 \\
\hline \multicolumn{7}{|l|}{ Central root mass-taproot } \\
\hline Wood plus bark & 1.87 & 9.72 & 21.42 & .87 & 4.60 & 10.18 \\
\hline Wood & 1.60 & 8.74 & 19.90 & .76 & 4.13 & 9.45 \\
\hline Bark & .27 & .98 & 1.52 & .11 & .47 & .73 \\
\hline
\end{tabular}

1Because of the effects of latitudinal and elevational zones, reference to appropriate figures and text discussion is required for interpretation of these data. Components may not total exactly because of computational and rounding procedures.

${ }^{2}$ Calculated.

3From tip $305 \mathrm{~mm}$ of top 25 branches. 
Table 4-4-Tree component proportions of complete-tree weight, green and ovendry, with data from the 243 latifolia and 36 murrayana trees by d.b.h. classes of 76, 152, and 228 $\mathrm{mm}^{1}$

\begin{tabular}{|c|c|c|c|c|c|c|}
\hline \multirow{2}{*}{$\begin{array}{l}\text { Tree component } \\
\text { and moisture content }\end{array}$} & \multicolumn{3}{|c|}{ Latifolia } & \multicolumn{3}{|c|}{ Murrayana } \\
\hline & 76 & 152 & 228 & 76 & 152 & 228 \\
\hline
\end{tabular}

Foliage (including branches to

6-mm diameter)

\begin{tabular}{|c|c|c|c|c|c|c|}
\hline Green & 8.7 & 6.6 & 6.1 & 7.6 & 5.8 & 5.0 \\
\hline Ovendry & 8.2 & 6.3 & 5.8 & 7.1 & 6.0 & 5.0 \\
\hline \multicolumn{7}{|l|}{ Cones } \\
\hline Green & .5 & 6 & .9 & .1 & .2 & .2 \\
\hline Ovendry & .7 & .9 & 1.4 & .2 & .3 & .4 \\
\hline \multicolumn{7}{|c|}{ Live branches (wood plus bark) } \\
\hline Green & 4.6 & 5.4 & 7.4 & 5.2 & 5.6 & 7.3 \\
\hline Ovendry & 4.8 & 5.5 & 7.3 & 5.6 & 6.8 & 7.8 \\
\hline \multicolumn{7}{|c|}{ Dead branches } \\
\hline Green & 1.2 & 1.2 & 1.3 & 1.1 & .8 & 1.2 \\
\hline Ovendry & 1.9 & 1.9 & 2.2 & 1.8 & 1.3 & 2.2 \\
\hline \multicolumn{7}{|c|}{$\begin{array}{l}\text { Stem (wood plus bark) from } 152-\mathrm{mm} \\
\text { stump height to apical tip }\end{array}$} \\
\hline Green & 71.5 & 75.1 & 74.4 & 70.4 & 73.4 & 75.6 \\
\hline Ovendry & 71.0 & 74.0 & 73.4 & 70.3 & 72.3 & 73.9 \\
\hline \multicolumn{7}{|c|}{$\begin{array}{l}\text { Stump-root system (wood plus bark) } \\
\text { with laterals to a radius of } 305 \mathrm{~mm} \\
\text { from stump pith }\end{array}$} \\
\hline Green & 13.5 & 11.2 & 9.9 & 15.6 & 14.0 & 10.7 \\
\hline Ovendry & 13.3 & 11.4 & 10.0 & 15.0 & 13.8 & 10.7 \\
\hline \multicolumn{7}{|l|}{ Total $^{2}$} \\
\hline Green & 100.0 & 100.1 & 100.0 & 100.0 & 99.8 & 100.0 \\
\hline Ovendry & 99.9 & 100.0 & 100.1 & 100.0 & 100.5 & 100.0 \\
\hline
\end{tabular}

${ }^{1}$ Because of the interactions of d.b.h., latitude, and elevational zone on these properties, reference to appropriate figures and text discussion is needed for interpretation of these data. For weight proportions of sapwood and heartwood see chapter 5 .

${ }^{2 T}$ Totals may not sum to exactly 100.0 due to rounding errors.

Table 4-5-Bark weight proportions, green and ovendry, of major lodgepole pine tree components, with data from 243 latifolia and 36 murrayana trees by d.b.h. classes of 76 , 152 , and $228 \mathrm{~mm}$

\begin{tabular}{|c|c|c|c|c|c|c|}
\hline \multirow{2}{*}{$\begin{array}{l}\text { Tree component } \\
\text { and moisture content }\end{array}$} & \multicolumn{3}{|c|}{ Latifolia } & \multicolumn{3}{|c|}{ Murrayana } \\
\hline & 76 & 152 & 228 & 76 & 152 & 228 \\
\hline
\end{tabular}

Bark of foliage-free complete tree, percent of gross foliage-free complete-tree weight

Green
Ovendry

Stembark percent of gross stem weight,

stump top to apical tip

\section{Green \\ Ovendry}

Live branchbark percent of gross live branch weight

\section{Green}

Ovendry

Stump-root bark percent of gross stumproot weight

Green
Ovendry

$\begin{array}{rrrrrr}15.3 & 11.1 & 9.7 & 15.3 & 11.3 & 9.4 \\ 14.1 & 10.9 & 9.8 & 13.7 & 11.3 & 10.0 \\ & & & & & \\ 13.5 & 9.3 & 7.9 & 12.9 & 9.1 & 7.3 \\ 12.4 & 9.4 & 8.4 & 11.4 & 9.2 & 8.0 \\ & & & & & \\ 44.1 & 35.0 & 28.0 & 49.5 & 38.4 & 32.2 \\ 41.8 & 33.2 & 26.4 & 47.4 & 37.8 & 30.7 \\ & & & & & \\ & & & & & \\ 16.5 & 12.3 & 10.6 & 15.7 & 11.5 & 8.9 \\ 15.5 & 11.9 & 10.2 & 13.8 & 11.5 & 9.0\end{array}$


Table 4-6-Green weights of the three major tree components required to yield $1 \mathrm{~m}^{3}$ of wood for latifolia and murrayana of three diameters'

\begin{tabular}{ccc}
\hline \multirow{2}{*}{$\begin{array}{c}\text { Tree component } \\
\text { (wood plus bark), } \\
\text { and d.b.h., mm }\end{array}$} & \multicolumn{2}{c}{ Weight } \\
\cline { 2 - 3 } & Latifolia & Murrayana \\
\hline Foliage-free branches & $\ldots \ldots$ Kilograms & $\ldots$ \\
76 & 1,649 & 1,854 \\
152 & 1,427 & 1,584 \\
228 & 1,267 & 1,416 \\
Stems & & \\
76 & 968 & 1,093 \\
152 & 920 & 1,030 \\
228 & 872 & 968 \\
Stump-root systems & & \\
76 & 1,109 & 1,156 \\
152 & 1,044 & 1,110 \\
228 & 984 & 1,061 \\
\hline
\end{tabular}

1 Because of the interactions of d.b.h., latitude, and elevational zone on these yields, reference to appropriate figures and text discussion is needed for interpretation of these data. Data are based on 243 latifolia and 36 murrayana trees.

2Based on stumps to a $152-\mathrm{mm}$ height, lateral roots to a radius of $305 \mathrm{~mm}$ from stump pith, and as much of the taproots as the field crews were able to extract; see figure 1-4.

With data from each longitudinal zone averaged, mean ovendry weights per cone varied as follows (zone 1 is the easternmost zone and zone 12 is westernmost):

\begin{tabular}{ccc}
$\begin{array}{c}\text { Longitudinal } \\
\text { zone }\end{array}$ & $\begin{array}{c}\text { Average weight } \\
\text { per cone, ovendry } \\
\text { Grams }\end{array}$ & $\begin{array}{c}\text { Number of trees with } \\
\text { cones per zone }\end{array}$ \\
1 & 6.90 & \\
2 & 9.13 & 10 \\
3 & 6.31 & 4 \\
4 & 4.55 & 21 \\
5 & 5.89 & 22 \\
6 & 4.64 & 12 \\
7 & 5.60 & 26 \\
8 & 4.04 & 27 \\
9 & 4.17 & 13 \\
10 & 4.40 & 25 \\
11 & 3.45 & 15 \\
12 & 2.97 & 13 \\
\hline
\end{tabular}

The 16 cone-bearing trees in longitudinal zones 11 and 12 were slightly to the west of intended sampling areas because of scarce roads in northern Canada. As previously noted, each longitudinal zone was 1 degree wide; northern zones therefore spanned less distance than southern zones.

The foregoing data, if used to predict weight of individual cones on the tip $305 \mathrm{~mm}$ of the top 25 branches, yields the following equation $\left(R^{2}=0.713\right.$; standard error of estimate $=0.96 \mathrm{~g}$ ):

Ovendry weight/cone $=$

$7.76508-0.39918$ (longitudinal zone number)

\section{Correlations Between Moisture Content and Specific Gravity of Tree Components}

As described in chapter 2, throughout the full range of latitude (40 to 60 degrees) in which moisture contents were studied, there was a pronounced decrease in latifolia tree-component moisture content from south to north. Maximum moisture contents usually occurred at latitude 42.5 or 45 degrees, and minimums were observed between 52.5 and 60 degrees. For example, stemwood moisture content (diameter data pooled) averaged 124 percent at 42.5 degrees and only 83 percent at 60 degrees. Similarly, stembark moisture content averaged 131 percent at 45 degrees, but only 80 percent at 52.5 degrees.

This variation in tree component moisture content is explained to a significant degree by the inverse relationship between moisture content and specific gravity; that is, wood or bark of high specific gravity tends to have low moisture content. The correlation coefficients were found to be between -0.6 and -0.9 , with generally higher correlations for bark than for wood (table 4-7).

With data from all wood components of latifolia pooled, the following regression equation applies $\left(R^{2}=0.367\right.$; standard error of the estimate $=18.421$ ):

Wood moisture content, percent of ovendry weight $=$ 295.90 - 467.52 (wood specific gravity, ovendry weight and green volume)

For all bark components pooled, the following equation applies $\left(R^{2}=0.693 ;\right.$ standard error of the estimate $=$ 14.055):

Bark moisture content, percent $=$

305.43 - 530.80 (bark specific gravity)

Table 4-7-Correlations between moisture content and specific gravity of components of 243 latifolia trees (all diameter, latitudinal, and elevational data pooled)

\begin{tabular}{|c|c|c|c|}
\hline Tree component & $\begin{array}{l}\text { Wood plus } \\
\text { bark }\end{array}$ & Wood & Bark \\
\hline & \multicolumn{3}{|c|}{...- Correlation coefficient, $r . .}$. \\
\hline $\begin{array}{l}\text { Complete tree (without } \\
\text { foliage and cones) }\end{array}$ & -0.665 & -0.606 & -0.832 \\
\hline $\begin{array}{l}\text { Stem from } 152-\mathrm{mm} \text { stump } \\
\text { height to apical tip }\end{array}$ & -.641 & -.600 & -.820 \\
\hline Live branches & -.753 & -.629 & -.858 \\
\hline $\begin{array}{l}\text { Stump-root system, entire, } \\
\text { to a radius of } 305 \mathrm{~mm} \\
\text { from stump pith }\end{array}$ & -.632 & -.613 & -.701 \\
\hline $\begin{array}{l}\text { Stump, groundline to } \\
152-\mathrm{mm} \text { height }\end{array}$ & -.674 & -.659 & -.699 \\
\hline $\begin{array}{l}\text { Lateral roots, root collar to } \\
152-\mathrm{mm} \text { radius from stump } \\
\text { pith }\end{array}$ & -.776 & -.725 & -.579 \\
\hline $\begin{array}{l}\text { Central root mass in- } \\
\text { cluding taproot }\end{array}$ & -.779 & -.738 & -.685 \\
\hline
\end{tabular}




\section{Stemwood Specific Gravity Correlations}

In addition to the correlation with stemwood moisture content, the following significant correlations of entire stemwood specific gravity (basis of ovendry weight and green volume) with other tree statistics are of interest:

\section{Statistic}

$r$

Moisture content of complete tree with foliage

Live-branch weight (wood plus bark) as percentage of gross complete-tree weight including foliage-ovendry basis

Stem (wood plus bark) as percentage of gross complete-tree weight including foliage-ovendry basis

Sapwood thickness at 152-mm stump height

Foliage as percentage of complete-tree

weight-ovendry basis

Crown ratio

Elevation, $m$

Stem diameter at base of live crown, inside bark

Average stem taper below live crown, inside bark, $\mathrm{mm} / \mathrm{m}$

Stembark specific gravity

Average growth-ring width at $152-\mathrm{mm}$ stump height

Average live branch angle

Foliage weight, ovendry

Heartwood volume as percentage of stemwood volume

Average diameter of live branches

Length of live crown

$-.272$

Live-branch weight, wood plus barkovendry basis

$-.255$

D.b.h.

$-.254$

$-.238$

$-.225$

Width of live crown

$-.167$

In the foregoing tabulation, 17 of the 21 are negative corrolations. These negative correlations suggest that low stemwood specific gravity will be found at high elevation in vigorously growing large trees with thick sapwood, high moisture content, long and wide crowns with large branches and heavy foliage, highly tapered stems below crown, and wide growth rings.

Conversely, higher stemwood gravities will be found at lower elevations in smaller, slower growing trees with large branch angles, stembark of high specific gravity, and stems that constitute a high proportion of complete-tree weight, and in which heartwood percentage of stemwood volume is high.

Because growth-ring width is an easily measured parameter, it is useful to have a predictive equation relating stemwood specific gravity to average growth-ring width, as follows $\left(R^{2}=0.074\right.$; standard error of the estimate $=$ 0.038):

$$
G=0.4780-0.0228 \mathrm{~W}
$$

where:

$G=$ stemwood specific gravity at $152-\mathrm{mm}$ stump height, basis of ovendry weight and green volume

$W=$ average growth-ring width at $152-\mathrm{mm}$ stump height, $\mathrm{mm}$.

Readers are cautioned that this relationship is weak, and that it pertains only to stemwood at $152-\mathrm{mm}$ stump height-where, with all data pooled, stemwood specific gravity averaged 0.455 and average growth-ring width averaged $1.00 \mathrm{~mm}$; it is not applicable to higher stem positions.

\section{Stembark Specific Gravity Correlations}

In addition to the correlation with stembark moisture content, the following significant correlations of entire stembark specific gravity (basis of ovendry weight and green volume) with other tree characteristics are of interest:

\section{Statistic}

Moisture content of complete tree with foliage

Heartwood volume as percentage of stemwood volume

Foliage weight as percentage of completetree weight-ovendry basis

Crown ratio

Heartwood diameter at $152-\mathrm{mm}$ stump height

Stem (wood plus bark) as percentage of complete-tree weight including foliageovendry basis

Tree age at $152 \mathrm{~mm}$ stump height $\quad 364$

Tree height to apical tip $\quad .358$

Bark thickness at $152 \mathrm{~mm}$ stump height $\quad 343$

Stem weight, wood plus bark, ovendry $\quad .329$

Stemwood specific gravity

Stump-root system weight, wood plus bark, ovendry

Average taper within crown, inside bark, $\mathrm{mm} / \mathrm{m}$

Complete-tree weight, including foliage, ovendry

Diameter outside bark at 152-mm stump height

D.b.h.

Average diameter of live branches

Number of cones on the tip $305 \mathrm{~mm}$ of the top 25 branches

Width of live crown

Live-branch weight (wood plus bark) as percentage of complete-tree weight including foliage-ovendry basis

Live-branch weight, wood plus bark, ovendry

Elevation, $\mathrm{m}$

These data suggest that stembark of high specific gravity is likely to be found at lower elevations in taller, 
older, and larger thick-barked trees of low moisture content, with short and narrow crowns, little foliage but many cones on the top 25 branches, large stump-root systems, large branches, stemwood of high specific gravity and a high percentage of heartwood volume, and with stems constituting a high percentage of complete-tree weight.

\section{Correlations of the Six Major Tree Component Weight Percentages of Complete-Tree Ovendry Weight (Including Foliage) With Other Tree Properties}

Stem, Wood Plus Bark-The following significant correlations with stem weight as a percentage of completetree ovendry weight are of interest:

\section{Statistic}

Foliage weight as percentage of completetree weight-ovendry basis

Live-branch weight (wood plus bark) as percentage of complete-tree weight including foliage-ovendry basis

Crown ratio

$-.609$

Tree height to apical tip

Heartwood volume as percentage of stemwood volume

Moisture content of complete tree with foliage

Stump-root system weight (wood plus bark) as percentage of complete-tree weight including foliage-ovendry basis

Stembark specific gravity

Stemwood specific gravity

Average stem taper, inside bark, to base of

live crown, $\mathrm{mm} / \mathrm{m}$

Heartwood diameter at 152-mm stump height

Dead-branch weight as percentage of complete-tree weight with foliageovendry basis

Weight of stem, wood plus bark, ovendry

Tree age at 152-mm stump height

Cone weight as percentage of complete-tree weight with foliage-ovendry basis

Complete-tree weight including foliage, ovendry

Sapwood thickness at 152-mm stump height

Live-branch weight, wood plus bark, ovendry

Thus, aside from the obvious correlation with weight percentages of the other tree components, stem weight percentage is highest in older and taller trees with high stemwood and stembark specific gravities, low crown ratios, low moisture content, little stem taper below the crown, a high percentage of heartwood volume in the stem, and thin sapwood.
Foliage-The following significant correlations with foliage weight as a percentage of complete-tree weight are of interest:

\section{Statistic}

$r$

Stem (wood plus bark) as percentage of complete-tree weight with foliageovendry basis

$-0.792$

Crown ratio

Heartwood volume as percentage of stemwood volume

Moisture content of complete tree with foliage

Stembark specific gravity

Tree height to apical tip

Live-branch (wood plus bark) weight as percentage of complete-tree weight with foliage-ovendry basis

Heartwood diameter at 152-mm stump height

$-.458$

Stemwood specific gravity

Weight of stem, wood plus bark, ovendry

Complete-tree weight with foliage, ovendry

Weight of stump-root system, wood plus bark, ovendry

$-.285$

Tree age at $152-\mathrm{mm}$ stump height

D.b.h.

$-.272$

Stump-root system (wood plus bark) as percentage of complete-tree weight with foliage-ovendry basis

Diameter outside bark at 152 -mm stump height

Average stem taper within crown, inside bark, $\mathrm{mm} / \mathrm{m}$

Elevation, $m$

Average stem taper below crown, inside bark, $\mathrm{mm} / \mathrm{m}$

Taproot length (portion recovered)

Number of cones on tip $305 \mathrm{~mm}$ of top 25 branches

Dead-branch weight, ovendry

Average diameter of live branches

$-.167$

These data suggest that foliage comprises the highest percentage of complete-tree ovendry weight in young, small trees growing at higher elevations with high crown ratios, high complete-tree moisture content, low heartwood volume percentage of stemwood volume, low stemwood and stembark specific gravities, little stem taper within crown but high taper below crown, small average branch diameter, few cones on the top 25 branches, and a low percentage of stem weight but a high percentage of livebranch weight. Trees with a high proportion of their weight in the central stump-root system also tend to have a high proportion of foliage weight.

Cones-The following significant correlations with cone weight percentage of complete-tree ovendry weight are of interest. The cone weights per tree were calculated from data on cones found on the tip $305 \mathrm{~mm}$ of the top 25 branches, as described in the procedure section of chapter 1. 


\section{Statistic}

Stem (wood plus bark) as percentage of complete-tree weight with foliageovendry basis

Foliage weight, ovendry

Average diameter of live branches

Average stem taper within crown, inside bark, $\mathrm{mm} / \mathrm{m}$

Diameter outside bark at $152-\mathrm{mm}$ stump height

D.b.h.

Stem diameter at base of live crown, inside bark

Complete-tree weight with foliage, ovendry

Heartwood diameter at $152-\mathrm{mm}$ stump height

Stump-root system weight, wood plus bark, ovendry

Live-branch weight, wood plus bark, ovendry

These correlations should be interpreted with caution, because they were based on a computed ovendry weight of cones per tree, rather than on direct measurement.

The data suggest, however, that cones attain highest proportion of complete-tree ovendry weight on largediameter trees with heavy stump-root systems, highly tapered stems within crowns, heavy foliage, large-diameter branches, large heartwood diameter at stump height, and a low proportion of complete-tree weight in the stem.

Live Branches, Wood Plus Bark-The following significant correlations with foliage-free live-branch weight percentage of complete-tree ovendry weight are of interest:

\section{Statistic}

$r$

Stem (wood plus bark) as percentage of complete-tree weight with foliageovendry basis

Live-branch weight, wood plus bark, ovendry

Width of live crown

Foliage weight, ovendry

Average stem taper, inside bark, to base of live crown, $\mathrm{mm} / \mathrm{m}$

Stem diameter at base of live crown, inside bark

Crown ratio

Foliage weight as percentage of complete-

tree weight-ovendry basis

Sapwood thickness at $152-\mathrm{mm}$ stump height

Average diameter of live branches

Stemwood specific gravity

$-.416$

Average growth-ring width at $152-\mathrm{mm}$

stump height

Diameter outside bark at 152 -mm stump height

\section{Statistic}

Moisture content of complete tree with foliage

Length of live crown

Dead-branch weight, ovendry

Weight of stump-root system, wood plus bark, ovendry

Complete-tree weight, ovendry

Bark thickness at 152-mm stump height

Heartwood volume as percentage of stemwood volume

Number of live branches

Average live-branch angle

Taproot length (portion recovered)

Dead-branch weight as percentage of complete-tree weight with foliage, ovendry basis

Stembark specific gravity

Weight of stem, wood plus bark, ovendry

Aside from the obvious increase in live-branch weight as a percentage of complete-tree weight caused by numerous large, heavy branches in big crowns, other correlations suggest that live branches comprise the highest weight proportion of complete trees in large-diameter, heavy, fast-growing trees with high moisture content, heavy foliage, heavy dead branches, large stem diameter at the base of the live crown, highly tapered stems, thick sapwood, thick bark, and heavy stump-root systems with long taproots. Live-branch weight proportion was negatively correlated with stemwood and stembark specific gravities, heartwood volume as percentage of stemwood volume, average branch angle, and with proportion of completetree weight in the stem.

Dead Branches-The following significant correlations with dead-branch weight as percentage of complete-tree weight are weak, but of interest:

\begin{tabular}{lc}
\multicolumn{1}{c}{ Statistic } & $r$ \\
Dead-branch weight, ovendry & 0.697 \\
Stem (wood plus bark) weight as percentage & \\
of complete-tree weight, ovendry basis & -.292 \\
Average growth-ring width at 152-mm & \\
stump height & .230 \\
Live-branch (wood plus bark) weight as & \\
percentage of complete-tree weight, oven- & .199 \\
dry basis & \\
Average stem taper to base of live crown, & .195 \\
inside bark, mm/m & -.182 \\
Elevation, m & -.168
\end{tabular}

These data suggest that dead-branch weight as a percentage of complete-tree weight is highest in lowelevation, fast-growing trees with a high percentage of live-branch weight, small average live-branch angle, highly tapered stems below crown, and a low proportion of complete-tree weight in the stem. 
Stump-Root System, Wood Plus Bark-The following significant correlations with stump-root system weight percent of complete-tree ovendry weight are of interest:

\section{Statistic}

Tree height from 152-mm stump height to apical tip

Complete-tree weight, including foliage, ovendry

Weight of stem, wood plus bark, ovendry

$-.522$

D.b.h.

$-.537$

$-.506$

Diameter outside bark at $152-\mathrm{mm}$ stump height

$-.480$

Number of live branches

Stem (wood plus bark) as percentage of complete-tree weight with foliageovendry basis

Heartwood diameter at 152-mm stump height

Stem diameter at base of live crown, inside bark

Foliage weight

$-.403$

Stump-root weight, wood plus bark, ovendry

Live-branch weight, wood plus bark, ovendry

Width of live crown

Length of live crown

$-.344$

Average diameter of live branches

$-.338$

Sapwood thickness at 152-mm stump height

$-.321$

Dead-branch weight, ovendry

$-.287$

Foliage as percentage of complete-tree weight-ovendry basis

Number of cones on the tip $305 \mathrm{~mm}$ of the top 25 branches

Bark thickness at stump height

Average growth-ring width at $152-\mathrm{mm}$ stump height

$-.244$

Tree age at 152-mm stump height

$-.221$

Taproot length (portion recovered)

$-.217$

Average live-branch angle

$-.199$

All of these correlation coefficients are negative, with the exception of that for foliage as a percentage of complete-tree weight; even taproot length and weight of the stump-root system are negatively correlated with the weight percentage of the stump-root system.

If a high percentage of complete-tree weight in the stump-root system was desired (perhaps for naval stores manufacture from paraquat-enriched oleoresin content), such percentage would likely be highest in young, slowgrown, small trees with small crowns, few branches, little foliage, little dead-branch wejght, and thin stembark.

\section{Complete Tree With Cones and Foliage}

Weight, Green-Green weight of complete trees with stump-root system and foliage was positively correlated with d.b.h., averaging 28.40 (4.99), 170.46 (27.61), and $440.19(65.31) \mathrm{kg}$ for trees 76,152 , and $228 \mathrm{~mm}$ in d.b.h. In general, trees in high-elevation zones weighed less than those in low-elevation zones; for example, complete trees $228 \mathrm{~mm}$ in d.b.h. weighed $468.32,439.63$, and $412.62 \mathrm{~kg}$ in low-, medium-, and high-elevation zones, respectively.

With diameter and elevation data pooled, complete trees averaged least weight $(195.11 \mathrm{~kg})$ in the southernmost latitudinal zone and were heaviest in latitudes 50 to 55 degrees-where they averaged $227.09 \mathrm{~kg}$, but relationships varied with diameter and elevational zone (fig. 4-1).

Weight, Ovendry-Ovendry weight of complete trees with stump-root system and foliage was positively correlated with d.b.h., averaging 14.51 (2.90), 87.30 (15.96), and $227.72(34.71) \mathrm{kg}$ for the three diameter classes.

Complete-tree weight was negatively correlated with elevational zone (fig. 4-2), as summarized by the following tabulation of average tree weights by d.b.h.:

\begin{tabular}{lccc}
\multirow{2}{*}{$\begin{array}{c}\text { Elevational } \\
\text { zone }\end{array}$} & \multicolumn{3}{c}{ Diameter class } \\
\cline { 2 - 4 } & $\mathbf{7 6} \mathbf{~ m m}$ & $\mathbf{1 5 2} \mathbf{~ m m}$ & $\mathbf{2 2 8} \mathbf{~ m m}$ \\
Low and medium & 14.62 & 89.66 & 235.46 \\
High & 14.29 & 82.57 & 212.26
\end{tabular}

With diameter and elevational data pooled, average tree weight was lowest $(99.49 \mathrm{~kg})$ in the three southernmost latitudinal zones -40 through 45 degrees, and highest $(119.41 \mathrm{~kg})$ from 47.5 through 55 degrees; in the northernmost latitudes of 57.5 and 60 degrees, average tree weight was intermediate $(106.25 \mathrm{~kg})$. (See figure 4-2.) 


\section{LATIFOLIA}

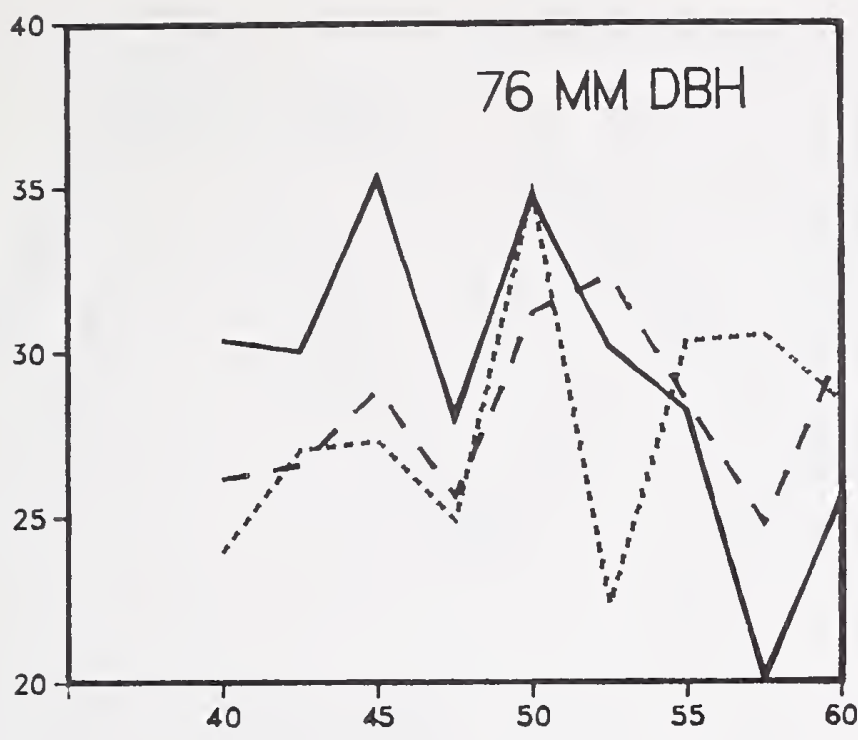

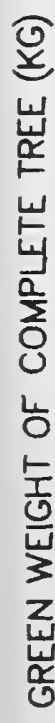
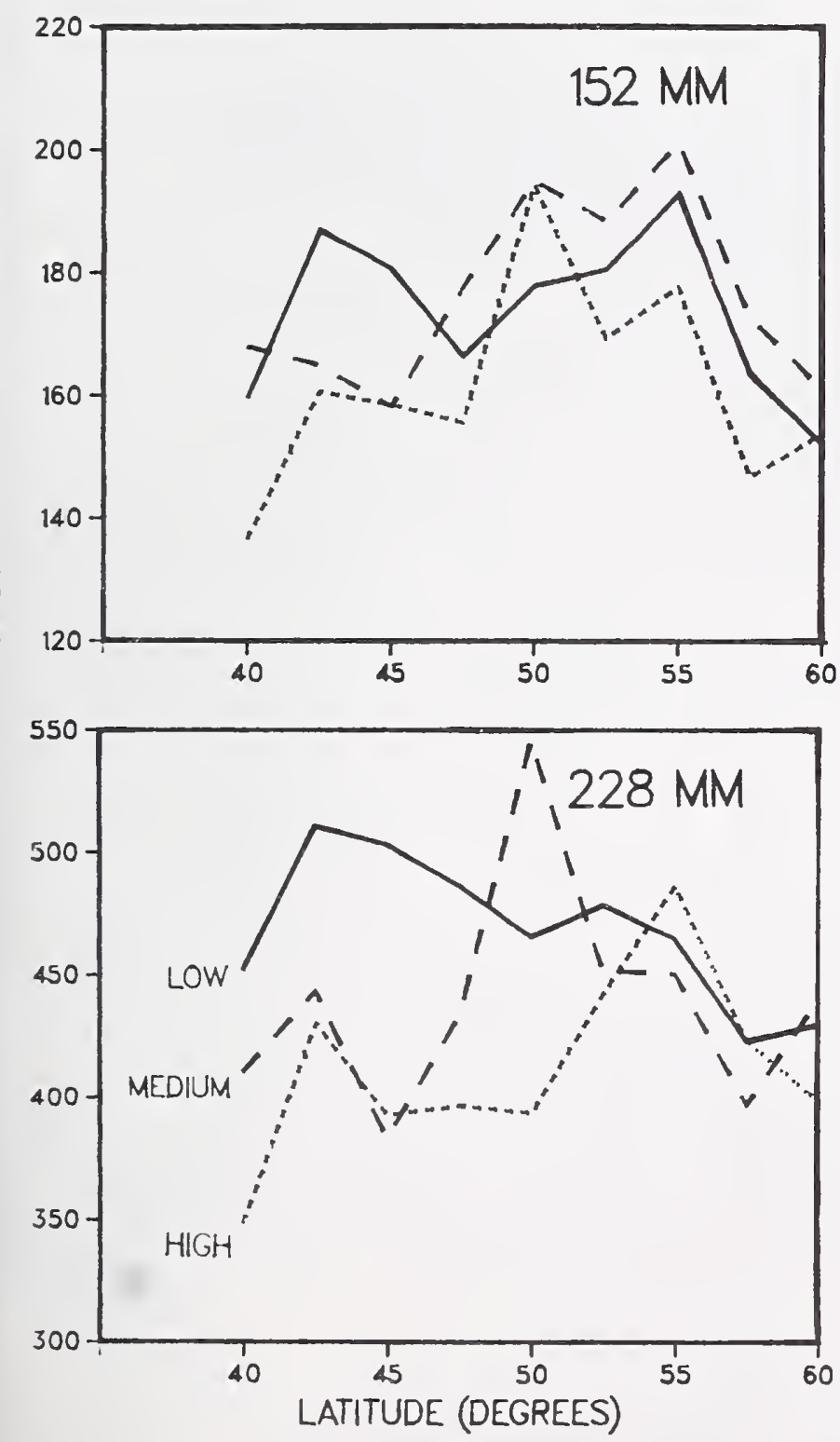

Figure 4-1-Green weight of complete latifolia trees of three diameters (including foliage and stump-root system) related to latitude and elevational zone.
LATIFOLIA
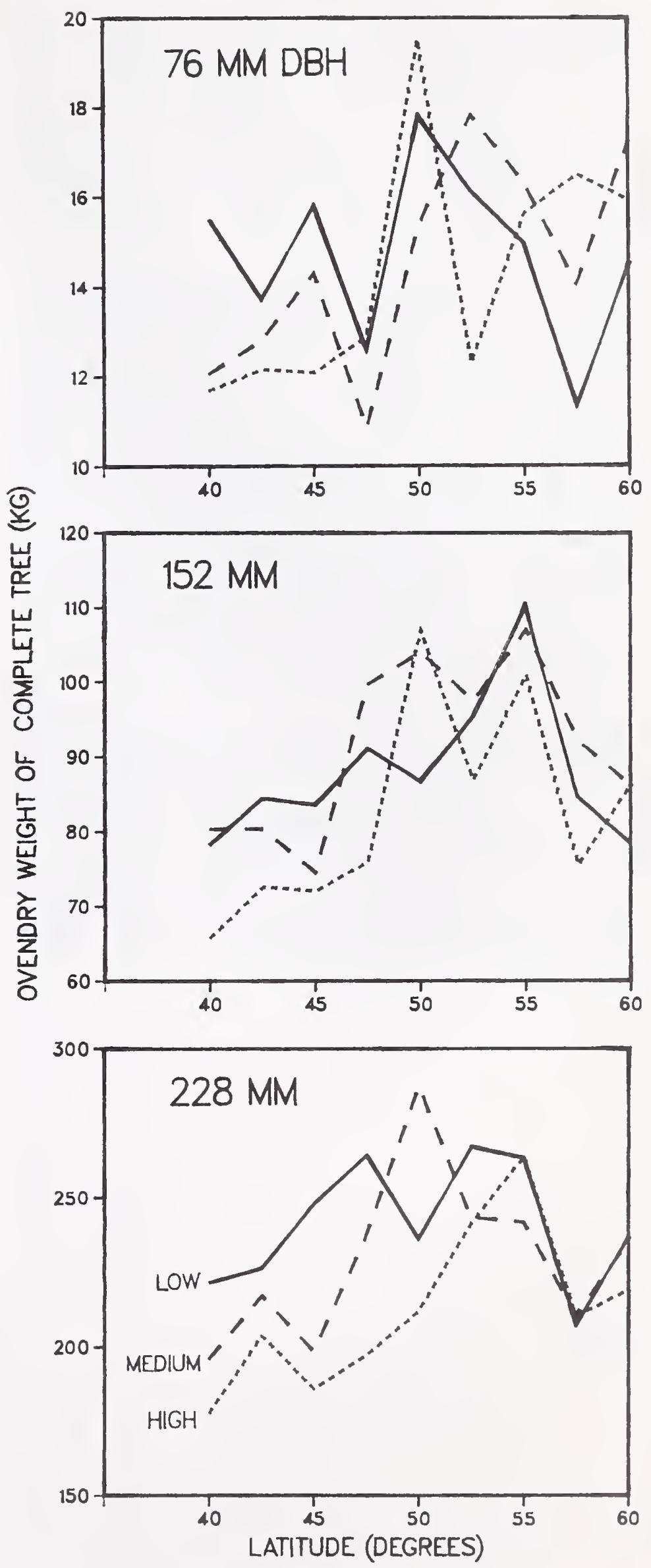

Figure 4-2-Ovendry weight of complete latifolia trees of three diameters (including foliage and stump-root system) related to latitude and elevational zone. 


\section{Complete Tree Without Cones or Foliage}

Specific Gravity-Wood plus bark of the complete trees (foliage-free branches, stem, and stump-root system) had average specific gravity, based on ovendry weight and green volume, of 0.421 with standard deviation of 0.028 . It was unrelated to elevational zone, but was-in northern latitudes-negatively correlated with d.b.h.; overall averages were $0.425(0.034), 0.423(0.026)$, and $0.416(0.024)$ for trees 76,152 , and $228 \mathrm{~mm}$ in d.b.h. - a relationship unusual in conifers.

Variation with latitude (fig. 4-3) was inverse to that of moisture content (fig. 2-3). Average specific gravity was lowest (0.397) at 42.5 degrees latitude, and increased with increasing latitude to maximums ( 0.430 or more) in latitudes 47.5 through 55 degrees and at 60 degrees (fig. 4-3).

Weight, Green-Without foliage, green weights of complete trees 76,152 , and $228 \mathrm{~mm}$ in d.b.h. averaged 25.93 (4.71), 159.41 (27.31), and 413.48 (64.42) kg. Green-weight variation with latitude was not pronounced (fig. 4-4); evidently the lower moisture content of trees in northern latitudes (fig. 2-3) offsets the greater ovendry weight of the northern trees (fig. 4-5). Green weight was negatively correlated with elevational zone, however, averaging 209.88, 201.76, and 187.17 kg in low, medium, and high zones, respectively (diameter data pooled).

Weight, Ovendry-Without foliage, weights of ovendry trees of the three diameter classes averaged 13.37 (3.00), 82.02 (16.41), and $214.82(35.44) \mathrm{kg}$. With diameter data pooled, trees in low- and medium-elevation zones averaged heavier $(106.82 \mathrm{~kg})$ than those in high zones $(96.57 \mathrm{~kg})$. In contrast with green-basis weights, weights of ovendry trees increased significantly from south to north (fig. 4-5); weights averaged maximum at 55 degrees $(119.74 \mathrm{~kg})$ and minimum at 40 degrees $(88.85 \mathrm{~kg})$.

\section{LATIFOLIA}

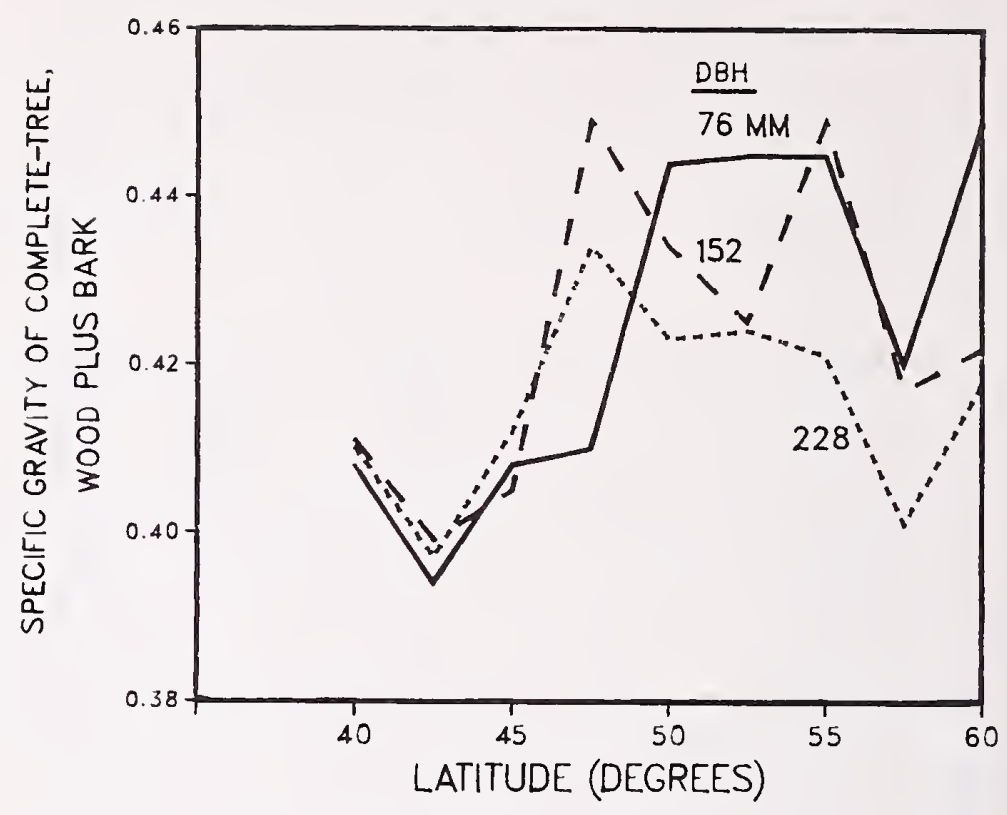

Figure 4-3-Specific gravity based on ovendry weight and green volume of foliage-free complete latifolia trees of three diameters, including wood plus bark of branches, stem, and stumproot system related to latitude. 


\section{LATIFOLIA}

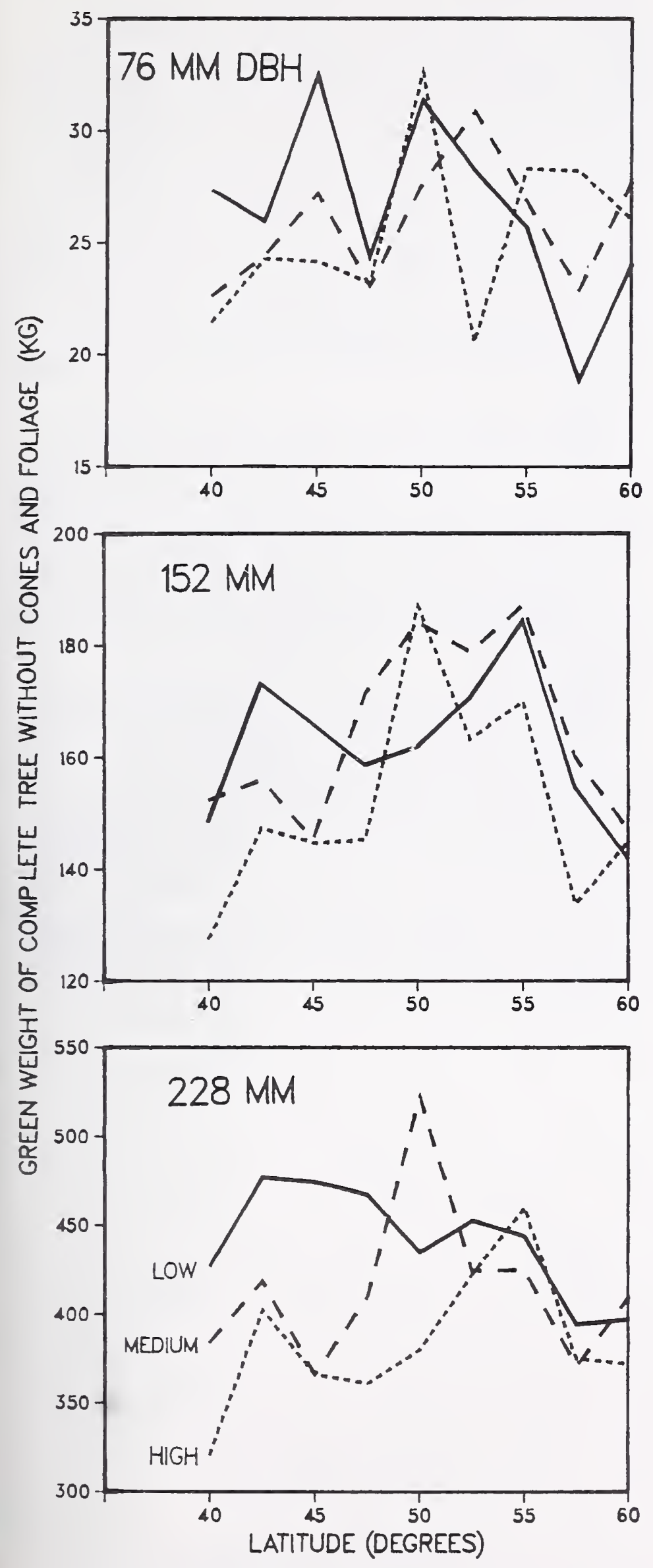

Figure 4-4-Green weight of foliage-free complete latifolia trees of three diameters related to latitude and elevational zone.
LATIFOLIA
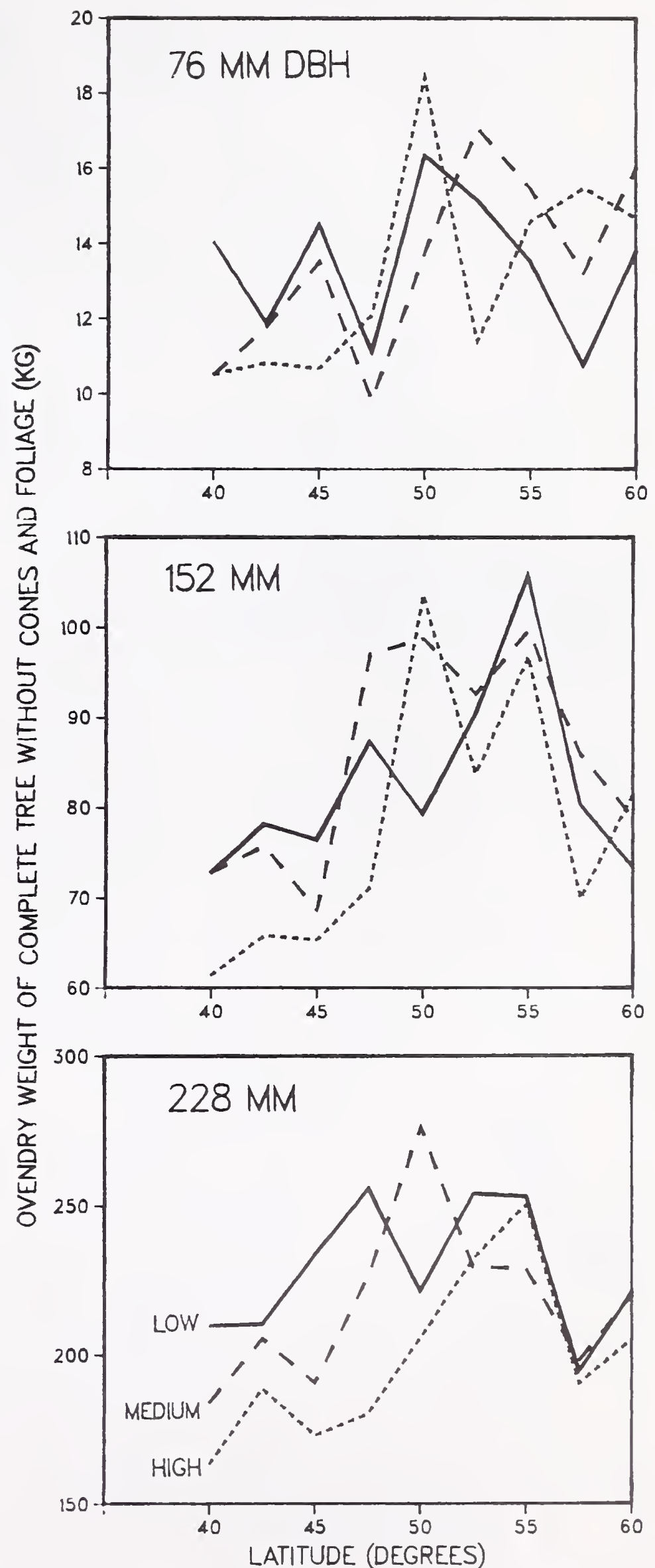

Figure 4-5-Ovendry weight of foliage-free complete latifolia trees of three diameters related to latitude and elevational zone. 


\section{LATIFOLIA}

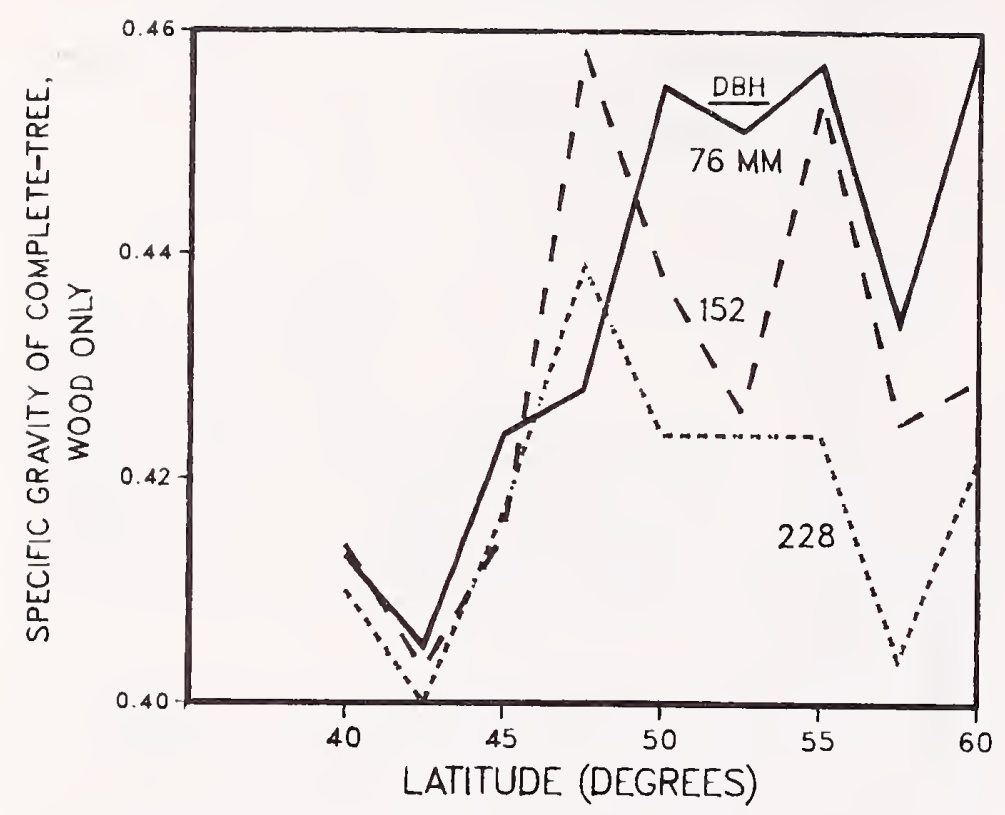

Figure 4-6-Specific gravity based on ovendry weight and green volume of wood of complete latifolia trees of three diameters (including branches, stem, and stump-root system) related to latitude.

\section{Complete Tree, Wood Only}

Specific Gravity-Specific gravity of wood of the complete trees (branchwood, stemwood, and wood of the stump-root system) averaged 0.428 , with standard deviation of 0.030 , based on ovendry weight and green volume. It was unrelated to elevational zone but was negatively correlated with d.b.h. (fig. 4-6), averaging $0.436(0.035)$, $0.429(0.027)$, and $0.418(0.025)$ for trees 76,152 , and $228 \mathrm{~mm}$ in d.b.h.-a relationship unusual for conifers.

The relationship of treewood specific gravity to latitude (fig. 4-6) was the reverse of its moisture content (fig. 2-4). Treewood specific gravity averages were lowest $(0.403)$ at 42.5 degrees latitude and increased with increasing latitude, reaching their highest levels in latitudes from 47.5 through 55 degrees $(0.434$ to 0.445$)$ and at 60 degrees (0.436).

Weight, Green-On a green-weight basis, wood of branches, stem, and stump-root system of trees 76,152 , and $228 \mathrm{~mm}$ in d.b.h. averaged 21.88 (4.20), 141.11 (25.39), and $370.59(60.15) \mathrm{kg}$. At most latitudes treewood weight was inversely correlated with elevational zone (fig. 4-7). Because of the interactions of treewood moisture content (fig. 2-4) and ovendry weight (fig. 4-8) with latitude, strong latitudinal trends in treewood green weights were not evident.

Weight, Ovendry-On an ovendry-weight basis, however, treewood weight is positively correlated with latitude (fig. 4-8); with diameter data pooled it averaged minimum at 40 degrees $(79.04 \mathrm{~kg})$ and maximum at 55 degrees $(107.56 \mathrm{~kg})$. Trees in high-elevation zones-particularly those $228 \mathrm{~mm}$ in d.b.h.-tended to have less weight (ovendry) of treewood than those in low or medium zones (fig. 4-8).

Treewood weights, ovendry, for the three diameter classes averaged $11.41(2.70), 72.55(15.24)$, and 191.17 (32.93) kg. 


\section{LATIFOLIA}
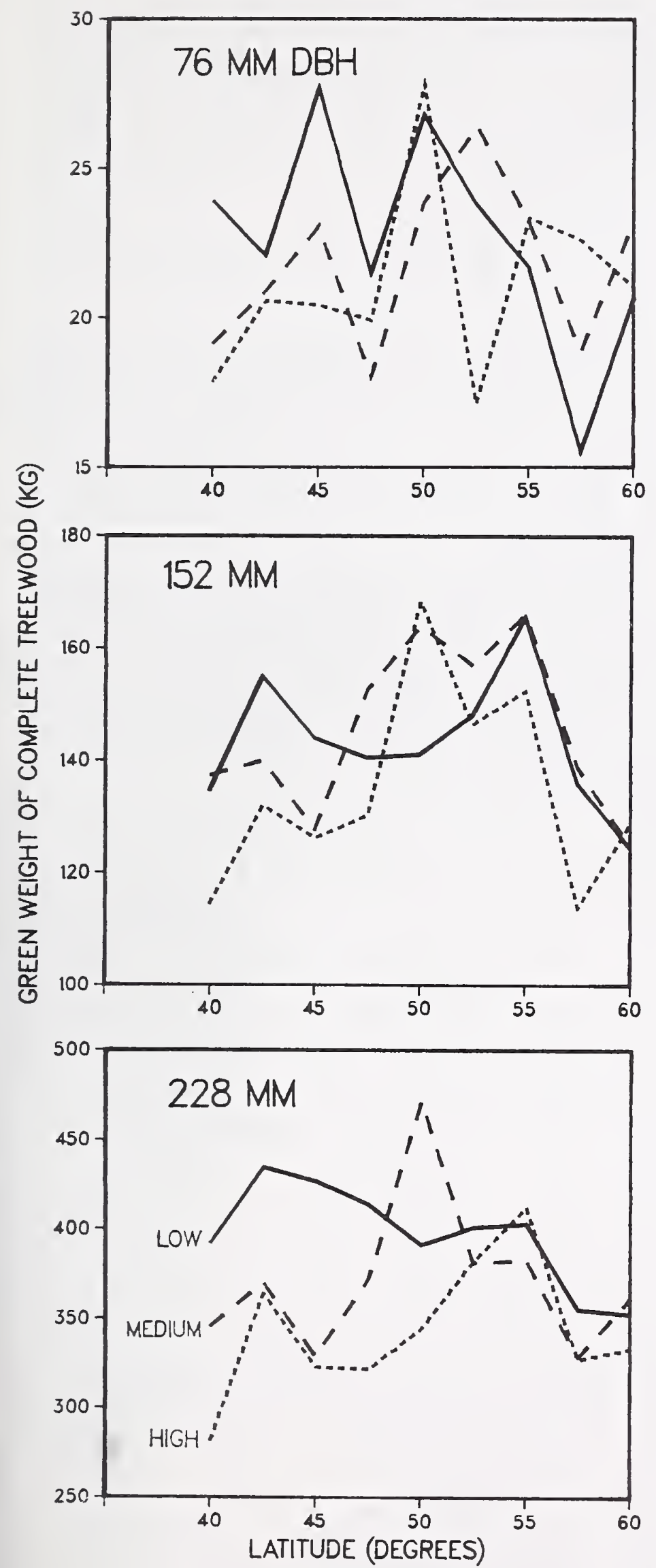

Figure 4-7-Green weight of wood of complete latifolia trees of three diameters related to latitude and elevational zone.
LATIFOLIA

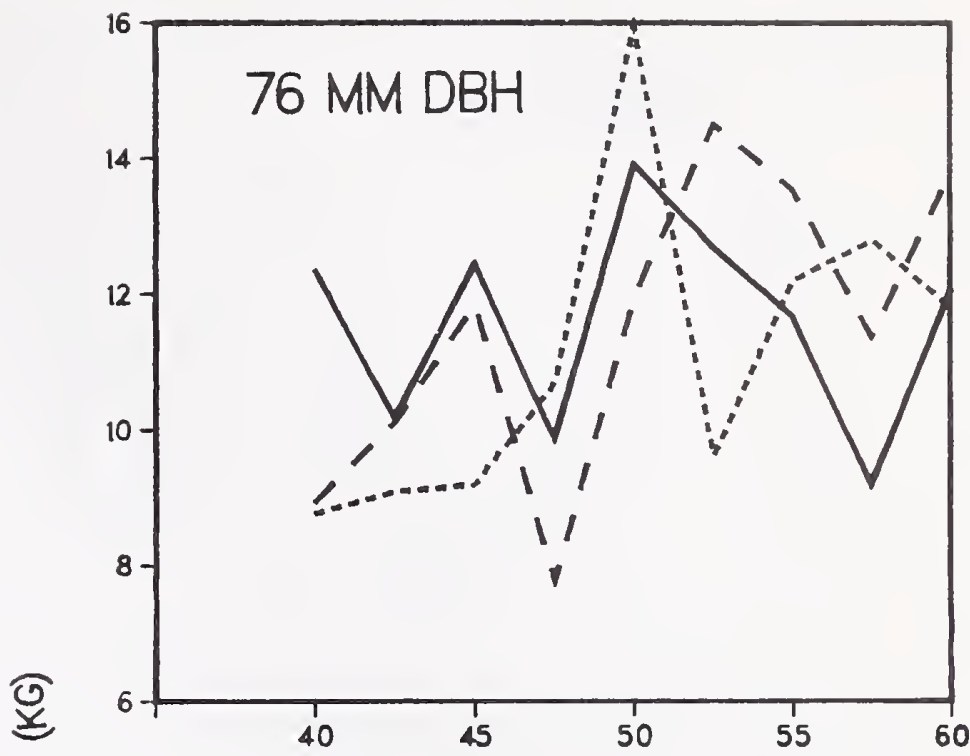

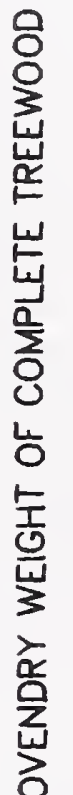
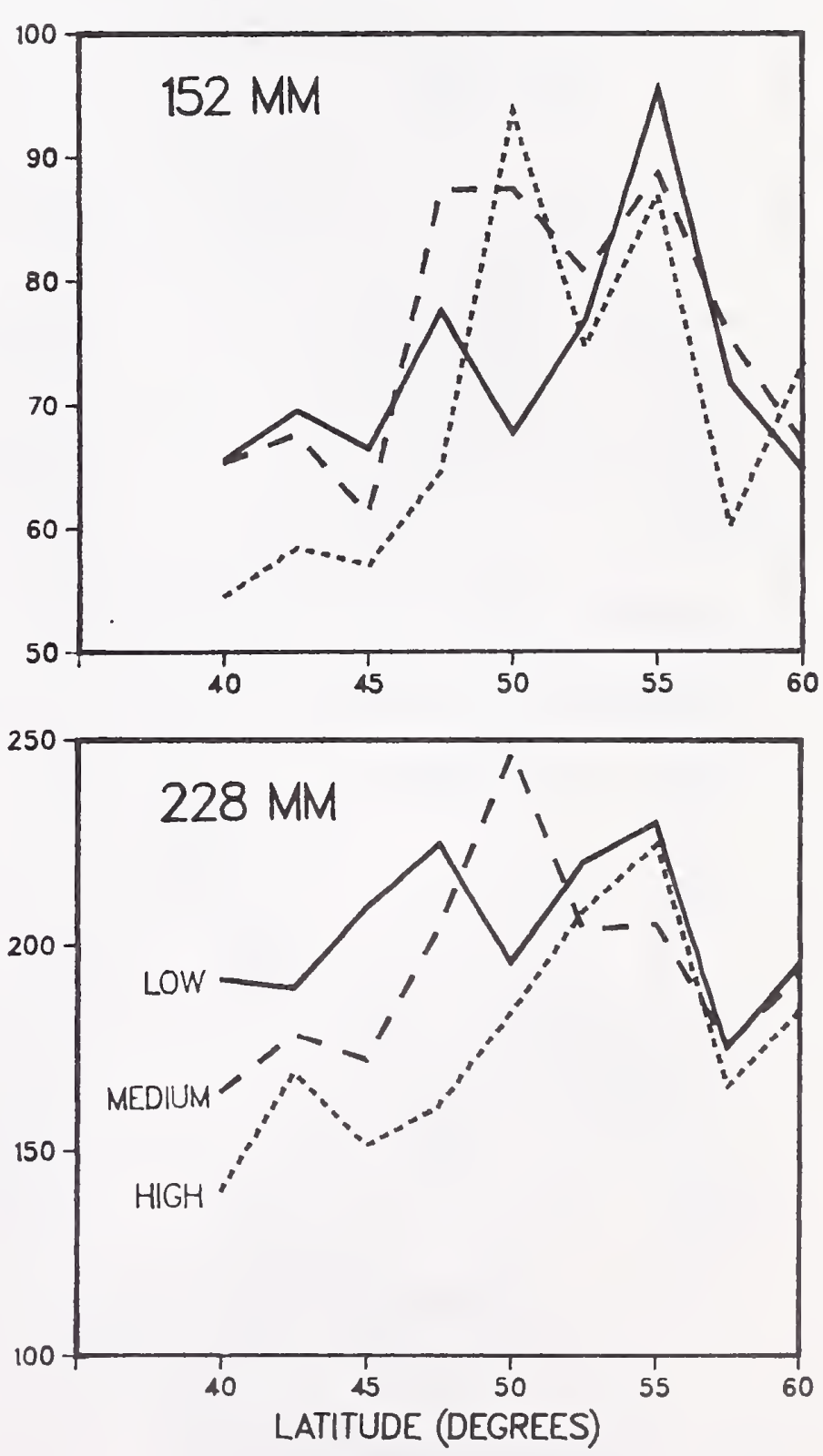

Figure 4-8-Ovendry weight of wood of complete latifolia trees of three diameters related to latitude and elevational zone. 
LATIFOLIA
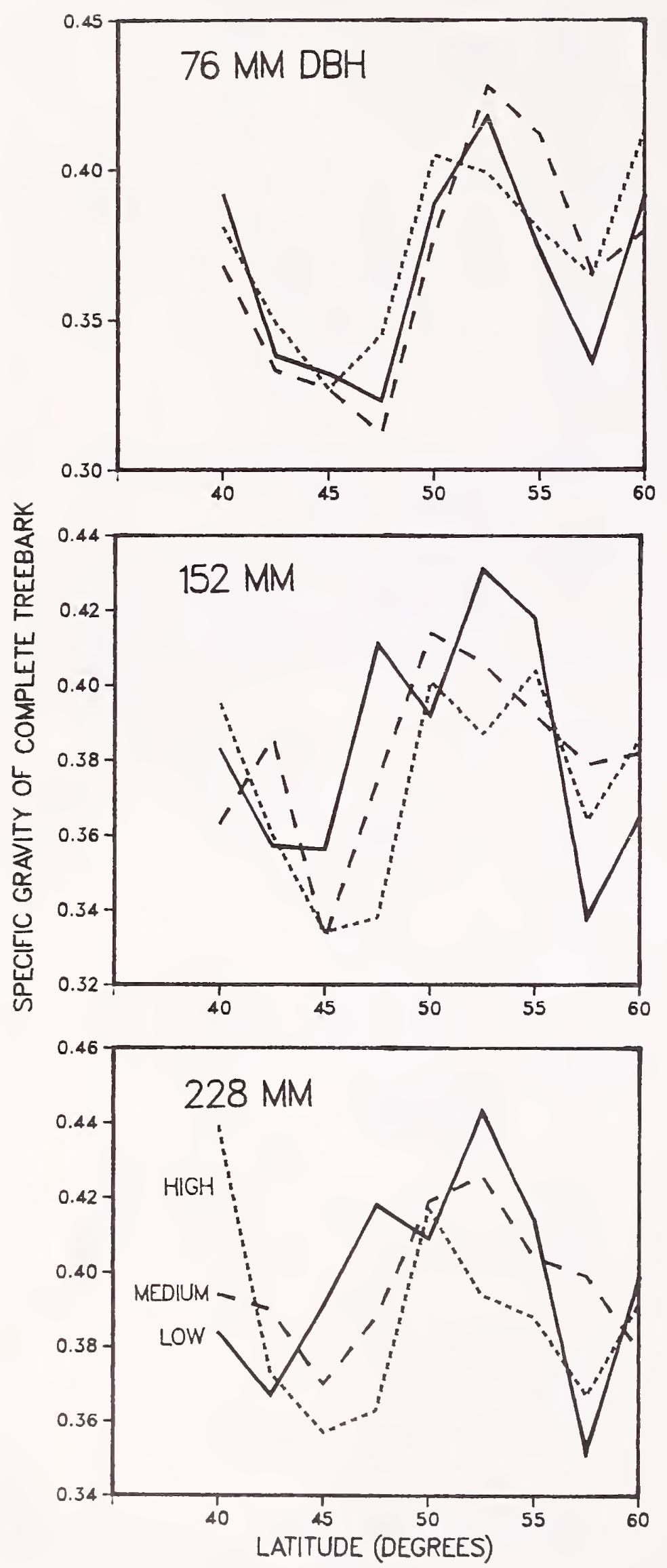

Figure 4-9-Specific gravity based on ovendry weight and green volume of bark of complete latifolia trees of three diameters (including branches, stem, and stump-root system) related to latitude and elevational zone.

\section{Complete Tree, Bark Only}

Specific Gravity-Weighted-average specific gravity of bark from branches, stem, and stump-root system was positively correlated with d.b.h., averaging 0.369 (0.043), $0.380(0.037)$, and $0.394(0.035)$ for trees 76,152 , and $228 \mathrm{~mm}$ in d.b.h. Treebark specific gravity averaged least $(0.347)$ at 45 degrees and most at 52.5 degrees latitude $(0.415)$. Interactions between elevation and latitude were complex (fig. 4-9).

Overall average with diameter, latitudinal, and elevational data pooled was 0.381 , with standard deviation of 0.040 .

Weight, Green-Treebark green weight was positively correlated with d.b.h., averaging 3.91 (0.76), 17.34 (3.41), and $39.18(6.78) \mathrm{kg}$ for trees of the three diameter classes. Treebark weight was inversely correlated with elevational zone for trees 152 and $228 \mathrm{~mm}$ in d.b.h. (fig. 4-10), but pronounced latitudinal trends were not evident, except at 40 degrees, where treebark weight averaged less than at other latitudes.

Weight, Ovendry-Similarly, ovendry treebark weight averaged $1.84(0.40), 8.69(2.01)$, and 20.57 (4.14) $\mathrm{kg}$ for trees of the three diameter classes. For trees 152 and $228 \mathrm{~mm}$ in d.b.h., these weights were negatively correlated with elevational zone (fig. 4-11). Treebark weights, ovendry, were lowest at 40 degrees latitude and highest at 52.5 degrees (fig. 4-11). 


\section{LATIFOLIA}
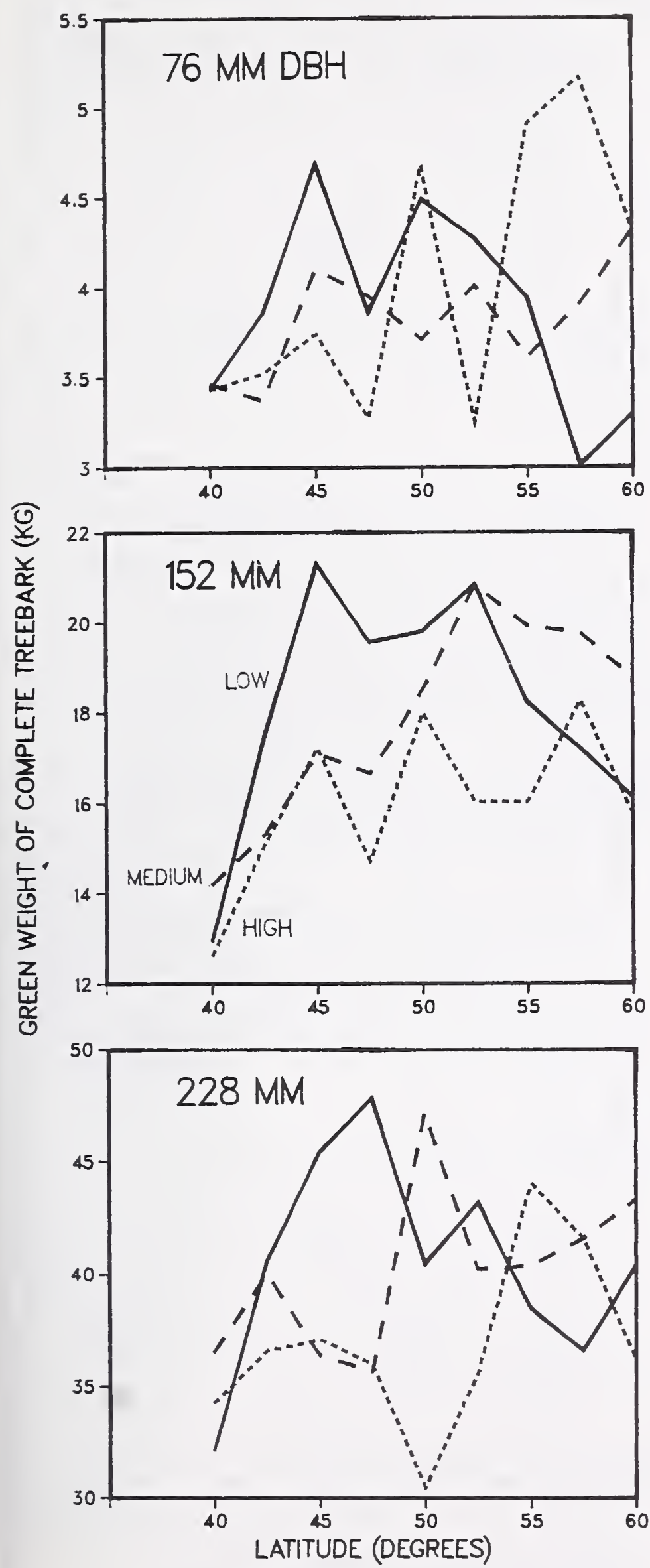

Figure 4-10-Green weight of bark of complete latifolia trees of three diameters related to latitude and elevational zone.
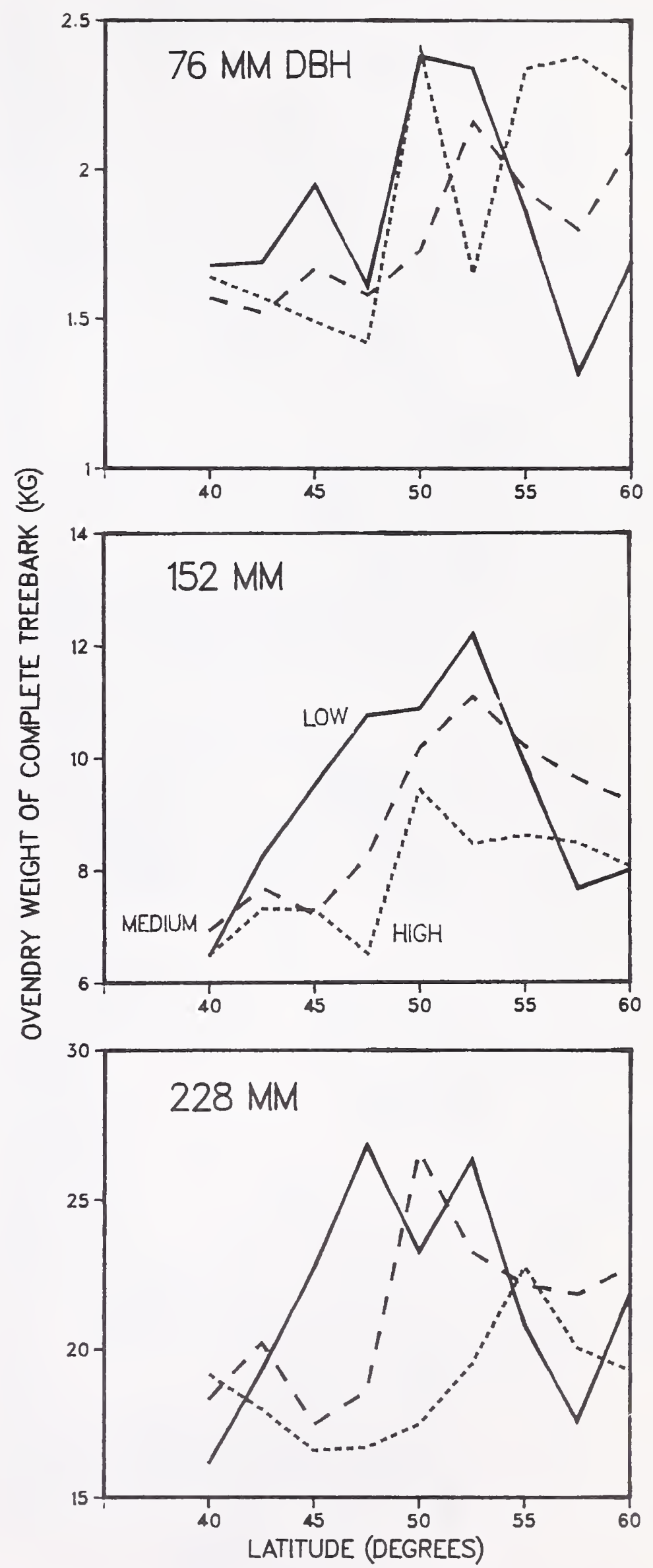

Figure 4-11-Ovendry weight of bark of complete latifolia trees of three diameters related to latitude and elevational zone. 
LATIFOLIA
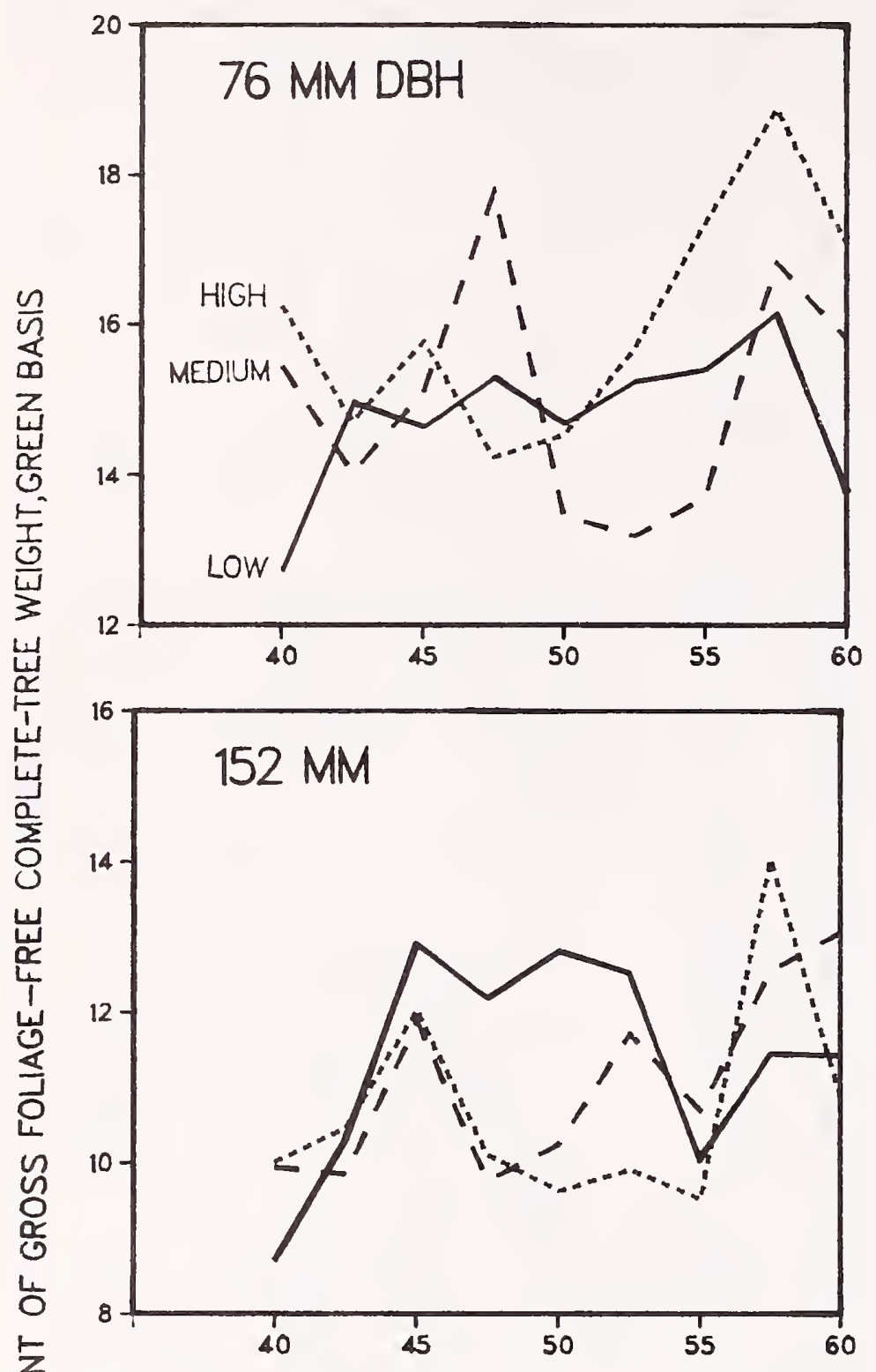

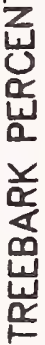

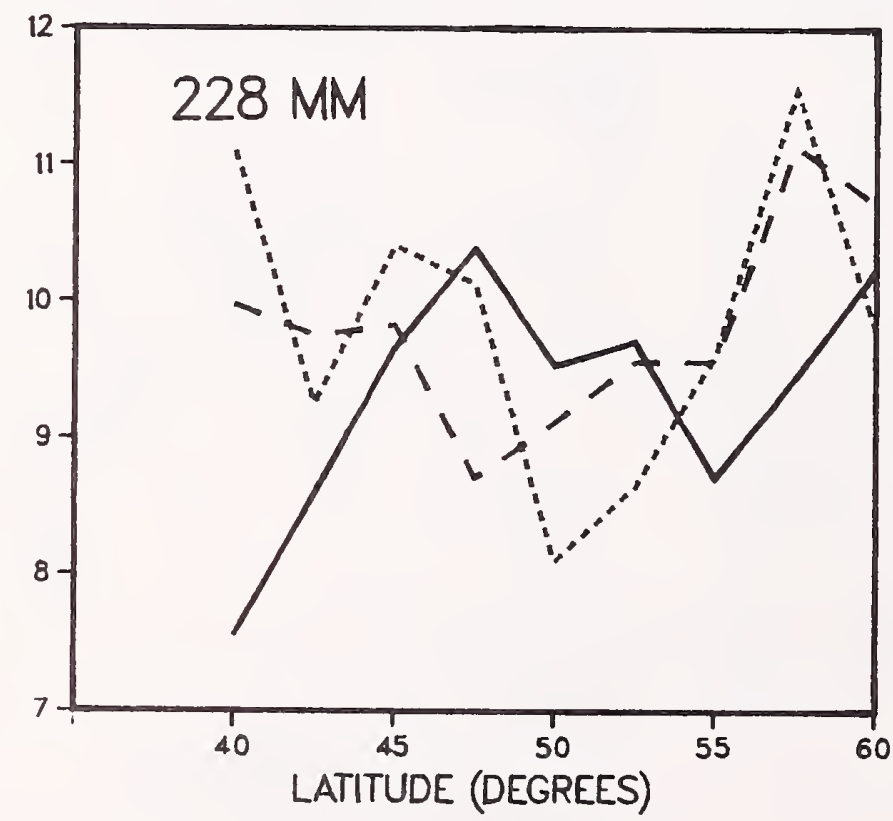

Figure 4-12-Treebark as percentage of gross foliage-free complete-tree weight (green basis) for latifolia trees of three diameters related to latitude and elevational zone.
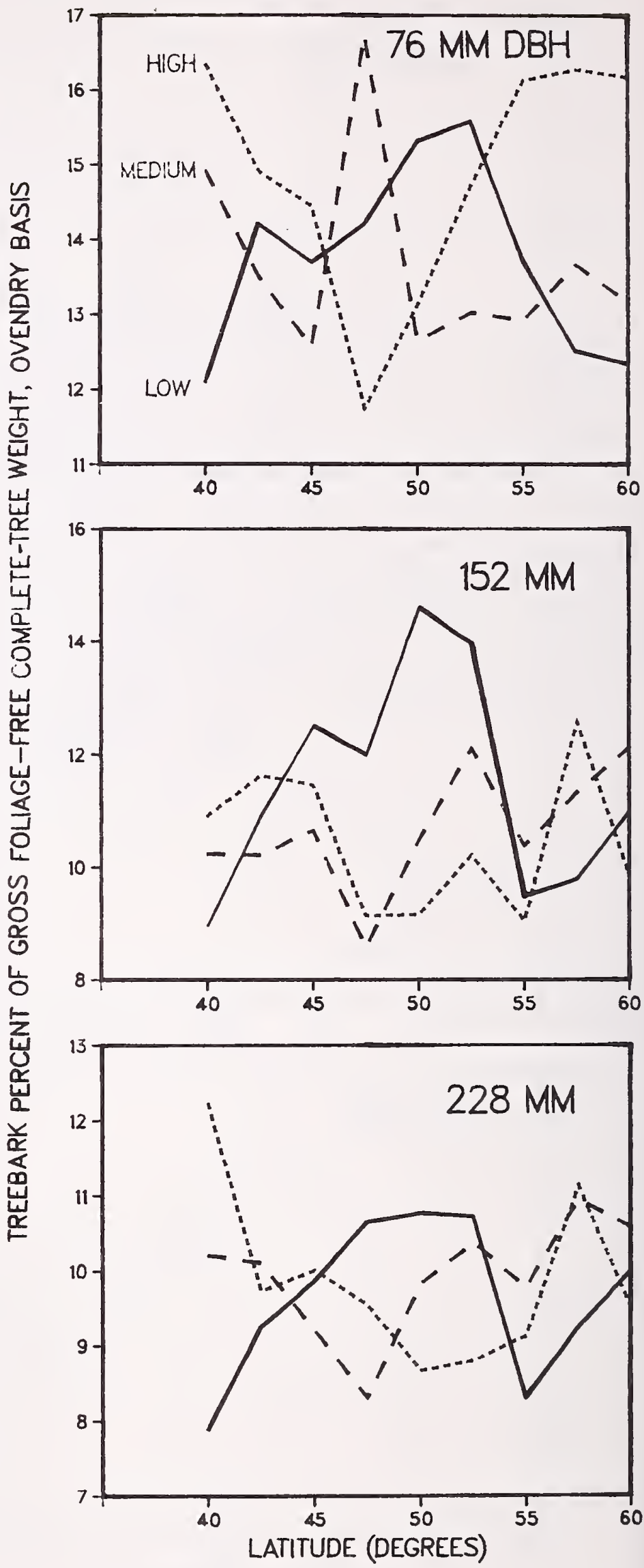

Figure 4-13-Treebark as percentage of gross foliage-free complete-tree weight (ovendry basis) for latifolia trees of three diameters related to latitude and elevational zone. 
Percentage of Weight of Gross Foliage-Free Complete Tree, Green and Ovendry - With all diameter, latitudinal, and elevational data pooled, treebark averaged 12.00 (3.08) percent of foliage-free complete-tree green weight, and $11.59(2.80)$ percent on an ovendry weight basis. The percentages were negatively correlated with d.b.h., as follows:

$\begin{array}{rcr}\text { D.b.h. } & \text { Green } & \text { Ovendry } \\ m m & \ldots \ldots \text { - . Percent } \ldots \ldots \\ 76 & 15.28(2.23) & 14.10(2.32) \\ 152 & 11.06(1.99) & 10.86(2.29) \\ 228 & 9.66(1.54) & 9.81(1.72)\end{array}$

Elevational and latitudinal trends in treebark weight percent were not pronounced, and interactions were complex (figs. 4-12 and 4-13).

\section{Foliage}

Here and elsewhere in this text the term "foliage" means "technical foliage"; that is, all needles and needlebearing twigs up to 6 -mm diameter outside bark.

Weight, Green-Green foliage weight was unrelated to latitude and elevational zone, but was positively correlated with d.b.h., averaging 2.47 (1.33), 11.05 (4.74), and 26.71 (10.27) $\mathrm{kg}$ for trees 76,152 , and $228 \mathrm{~mm}$ in d.b.h.-a relationship approximately linear with d.b.h. ${ }^{2}$.

Weight, Ovendry-Similarly, ovendry foliage weight was not significantly related to latitude or elevational zone, but was positively correlated with d.b.h., averaging $1.14(0.59)$, $5.28(2.22)$, and $12.90(4.58) \mathrm{kg}$ for trees of the three diameter classes.

Tree Component Proportion, Green-Weight BasisFoliage green weight averaged 7.13 percent of green complete-tree weight, with standard deviation of 3.52 percentage points. It was unrelated to elevational zone, but was negatively correlated with d.b.h., averaging 8.68 (4.40), $6.58(2.96)$, and 6.14 (2.40) percent for trees 76 , 152 , and $228 \mathrm{~mm}$ in d.b.h.

Foliage as a percentage of green weight was negatively correlated with latitude (fig. 4-14); averages were highest at the southernmost latitude of 40 degrees (8.57 percent) and were lowest at 52.5 degrees (5.40 percent).

Tree Component Proportion, Ovendry-Weight BasisSimilarly, foliage ovendry weight averaged 6.80 percent of ovendry complete-tree weight, with standard deviation of 3.66 percentage points. It was unrelated to elevational zone, but was negatively correlated with d.b.h., averaging $8.25(4.70), 6.32(3.13)$, and 5.82 (2.33) percent for trees 76,152 , and $228 \mathrm{~mm}$ in d.b.h.

Foliage as a percentage of ovendry weight was negatively correlated with latitude (fig. 4-15); averages were highest (8.37 percent) in the two southernmost latitudes and lowest (5.06 percent) at 52.5 degrees.

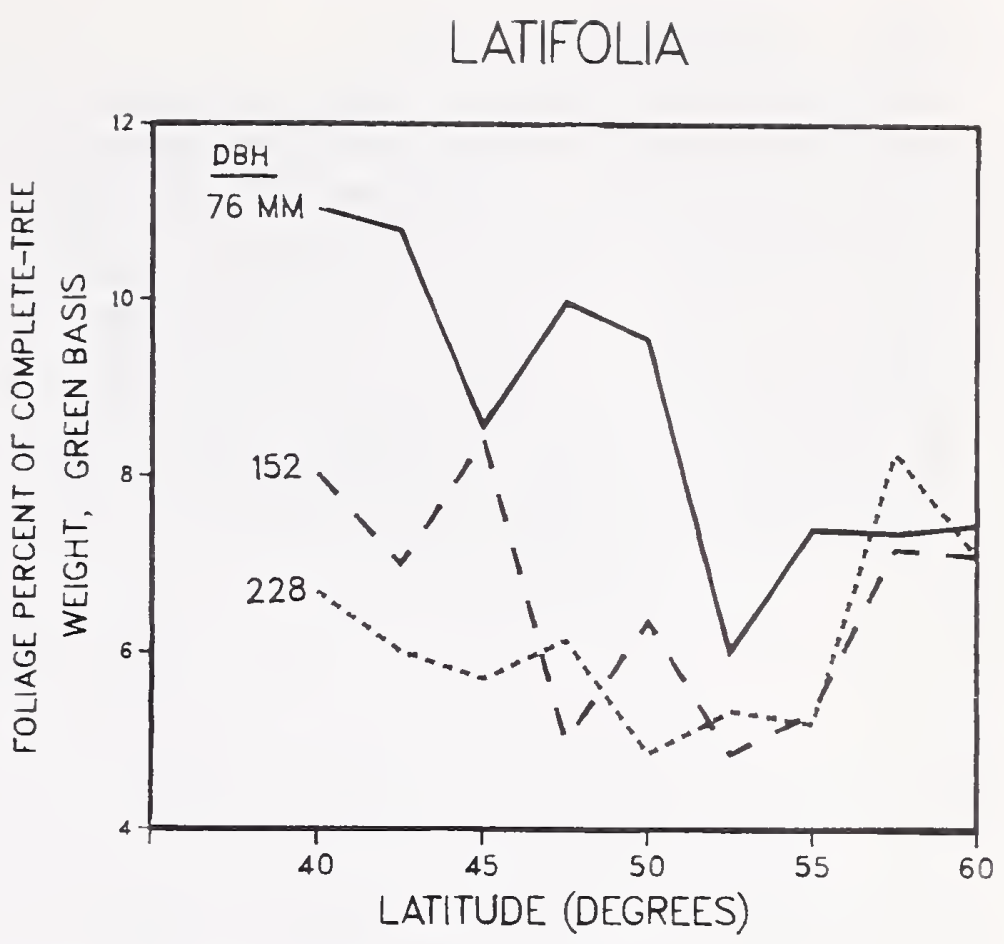

Figure 4-14-Foliage as percentage of complete-tree weight (green basis) for latifolia trees of three diameters related to latitude.

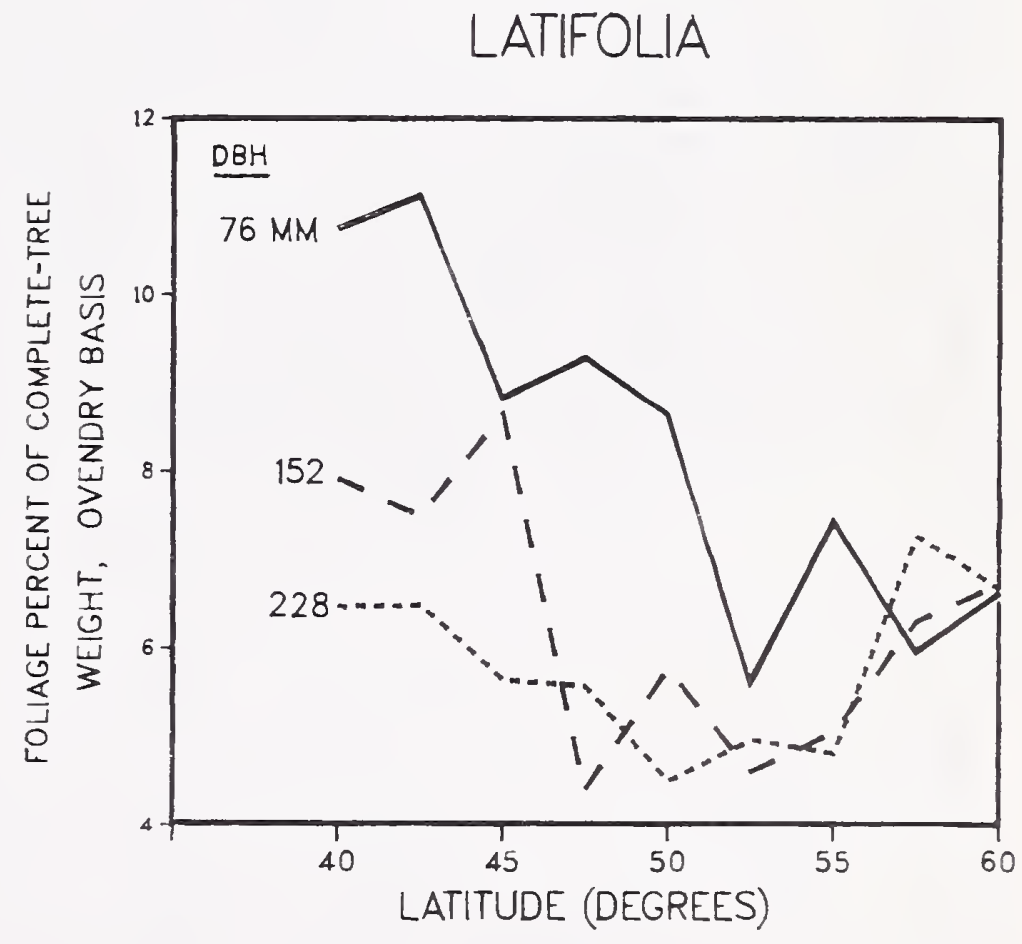

Figure 4-15-Foliage as percentage of complete-tree weight (ovendry basis) for latifolia trees of three diameters related to latitude. 


\section{Cones, Individual}

Weight, Green-With all data pooled, green cones sampled from the tip $305 \mathrm{~mm}$ of the top 25 branches had average weight of $6.2 \mathrm{~g}$, with standard deviation of $2.6 \mathrm{~g}$. Green-cone weight was positively correlated with d.b.h., averaging $5.2(2.4), 6.0(2.2)$, and $6.8(2.8) \mathrm{g}$ for trees 76 , 152 , and $228 \mathrm{~mm}$ in d.b.h. Elevational trends varied with latitude (fig. 4-16); cones weighed least at 45 degrees latitude $(4.3 \mathrm{~g})$ and most at latitudes 52.5 and 60 degrees $(7.8 \mathrm{~g})$. In some of the southern latitudes, none of the $76-\mathrm{mm}$ trees had cones on the top 25 branches, so cone weights could not be determined (fig. 4-16).
LATIFOLIA
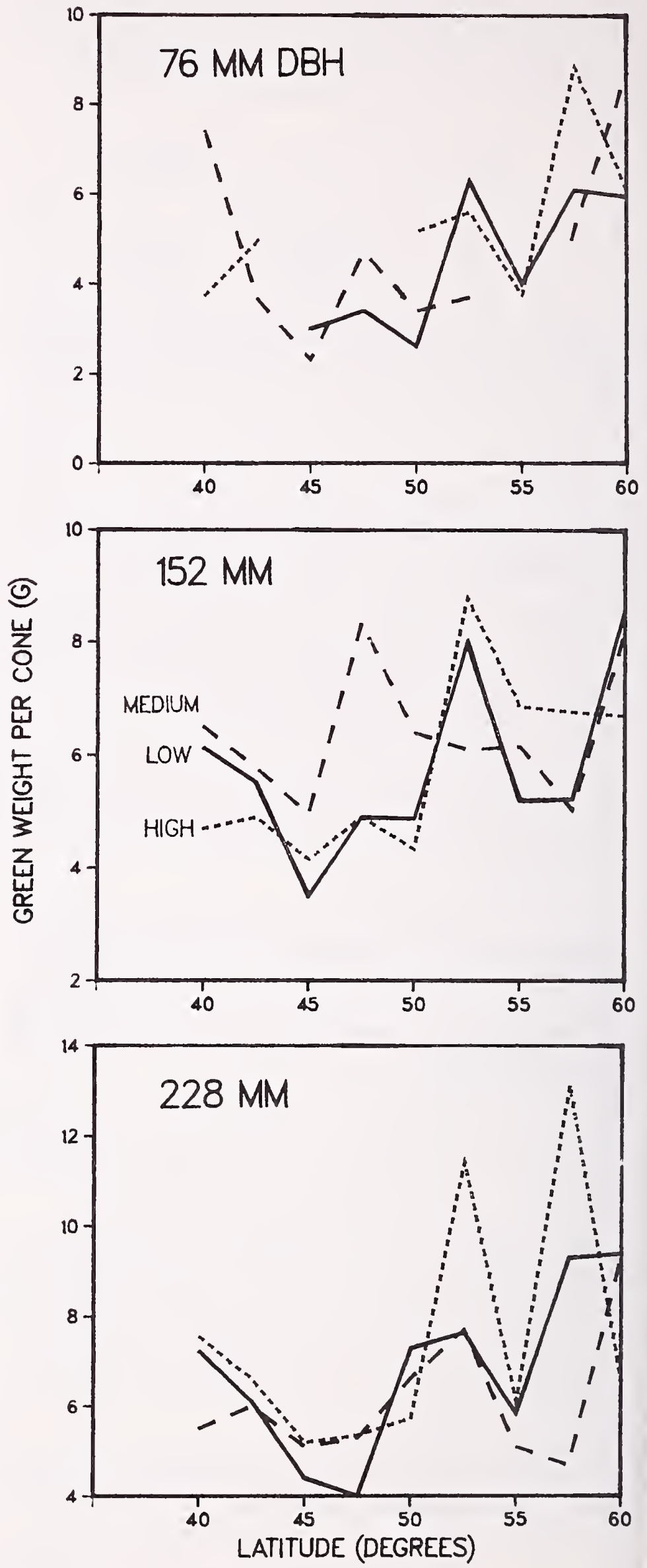

Figure 4-16-Green weight of individual cones from the tip $305 \mathrm{~mm}$ of the top 25 branches of latifolia trees of three diameters related to latitude and elevational zone. 
Weight, Ovendry-On an ovendry-weight basis, cone weight was positively correlated with latitude (fig. 4-17); interactions of latitude and elevation were complex.

With all data pooled, cones had an average ovendry weight of $5.0 \mathrm{~g}$, with standard deviation of $2.1 \mathrm{~g}$. Cone weight, ovendry, was positively correlated with d.b.h., averaging $4.2(2.0), 4.8(1.8)$, and $5.6(2.2) \mathrm{g}$ for trees of the three diameter classes.
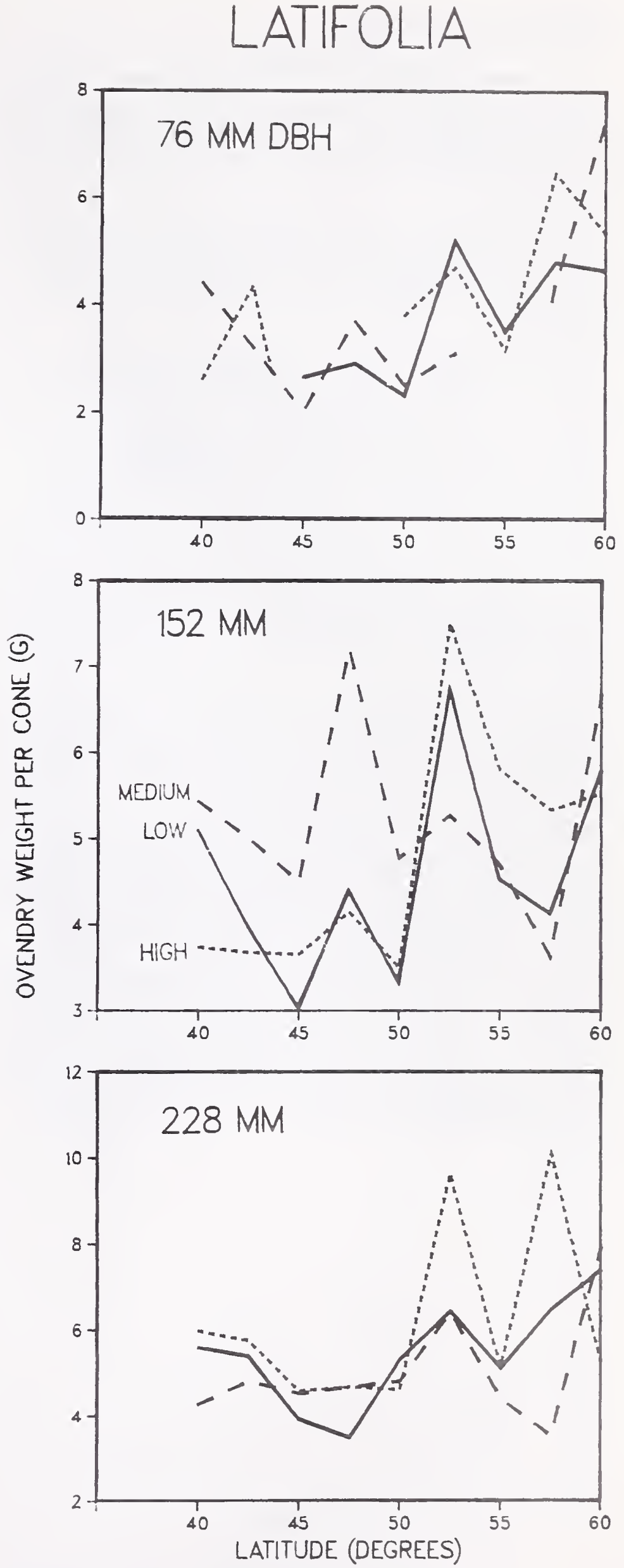

Figure 4-17-Ovendry weight of individual cones from the tip $305 \mathrm{~mm}$ of the top 25 branches of latifolia trees of three diameters related to latitude and elevational zone. 


\section{All Cones on Tree}

As explained in chapter 1, weight of all cones on each tree was computed (based on the number of cones counted on the tip $305 \mathrm{~mm}$ of the top 25 branches), not measured directly, and therefore results should be interpreted with caution.

Weight, Green-Green weight of all cones on each tree was unrelated to latitude and elevational zone, but was positively correlated with d.b.h., averaging $0.14(0.32)$, $0.96(1.02)$, and $3.74(3.62) \mathrm{kg}$ for trees of the three diameter classes.

Weight, Ovendry-Similarly, ovendry weight of all cones per tree averaged $0.11(0.27), 0.78(0.83)$, and 3.09 (3.09) $\mathrm{kg}$ for trees of the three diameter classes.

Tree Component Proportion, Green-Weight BasisGreen-cone percentage of complete green-tree weight averaged 0.62 percent, with standard deviation of 0.86 percentage points. It was not significantly related to elevational zone but averaged $0.53,0.61$, and 0.75 percent in low, medium, and high zones. Green-cone weight proportion was positively correlated with d.b.h., averaging 0.46 (1.03), $0.57(0.61)$, and $0.86(0.85)$ percent for trees 76 , 152 , and $228 \mathrm{~mm}$ in d.b.h.

Green-cone weight proportion tended to increase slightly with increasing latitude (fig. 4-18, top), with minimum average weight proportion ( 0.37 percent) at 47.5 degrees and maximum of 1.03 percent at 60 degrees.

Tree Component Proportion, Ovendry-Weight BasisOn an ovendry basis, cone weight proportion averaged 1.00 percent of complete-tree weight, with standard deviation of 1.34 percentage points. Although the differences with elevational zone were not significant, the average weight proportions for low, medium, and high zones were $0.82,0.96$, and 1.21 percent.

Ovendry cone-weight proportions did not vary significantly with latitude (fig. 4-18, bottom), but were positively correlated with d.b.h., averaging 0.73 (1.62), 0.90 (0.95), and 1.37 (1.39) percent for trees of the three diameter classes.

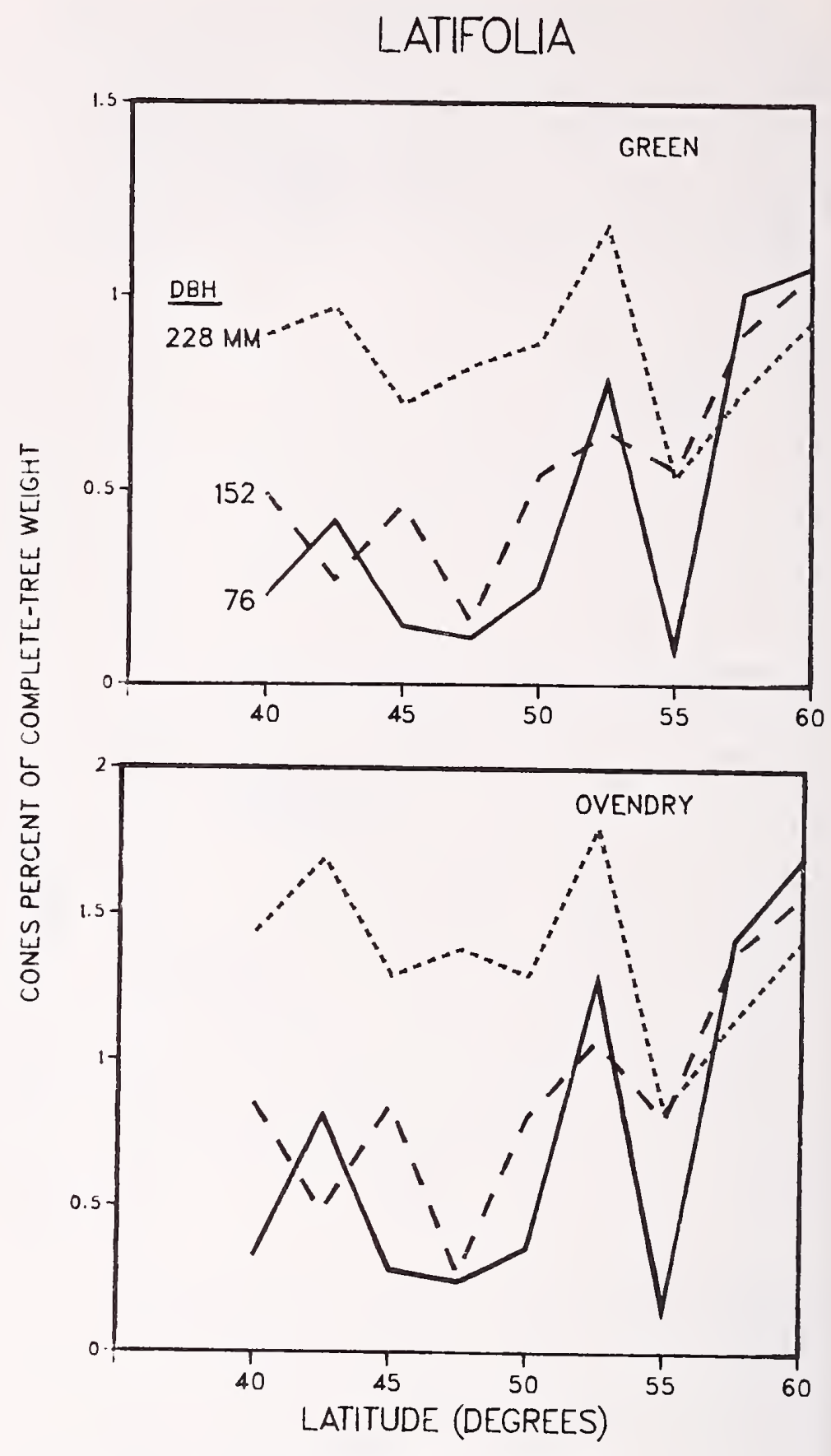

Figure 4-18-Cones as percentage of completetree weight (green and ovendry) of latifolia trees of three diameters related to latitude. 


\section{Dead Branchwood}

Weight, Green-Green weight of dead branches was positively correlated with d.b.h., averaging $0.32(0.25)$, $2.03(2.00)$, and $5.76(5.41) \mathrm{kg}$ for trees 76,152 , and $228 \mathrm{~mm}$ in d.b.h. Trees from high-elevation zones retained less weight of dead branches than those from medium and low zones (fig. 4-19); with diameter and latitudinal data pooled, averages were $1.92,2.77$, and $3.41 \mathrm{~kg}$ from the three zones, respectively. Also, trees in southern latitudes retained less weight of dead branches than those in northern latitudes: this relationship was most pronounced in the smaller trees (fig. 4-19).
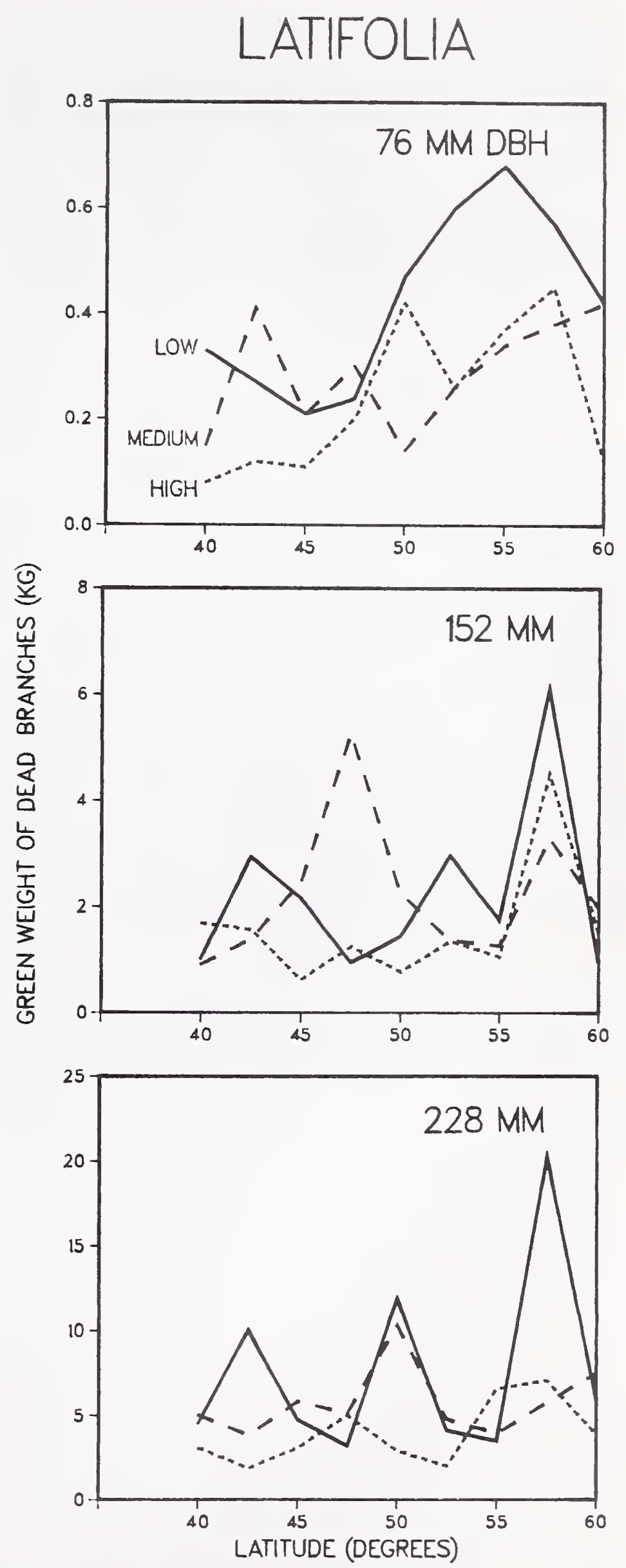

Figure 4-19-Green weight of dead branches from latifolia trees of three diameters related to latitude and elevational zone. 
Weight, Ovendry-On an ovendry basis (fig. 4-20), latitudinal and elevational trends were similar to those for green dead branches. With diameter and latitudinal data pooled, trees from high-, medium-, and low-elevation zones retained $1.58,2.34$, and $2.86 \mathrm{~kg}$ of dead branches, respectively.

Ovendry weight of dead branches was positively correlated with d.b.h., averaging $0.26(0.21), 1.65(1.41)$, and $4.87(4.46) \mathrm{kg}$ for trees of the three diameter classes.

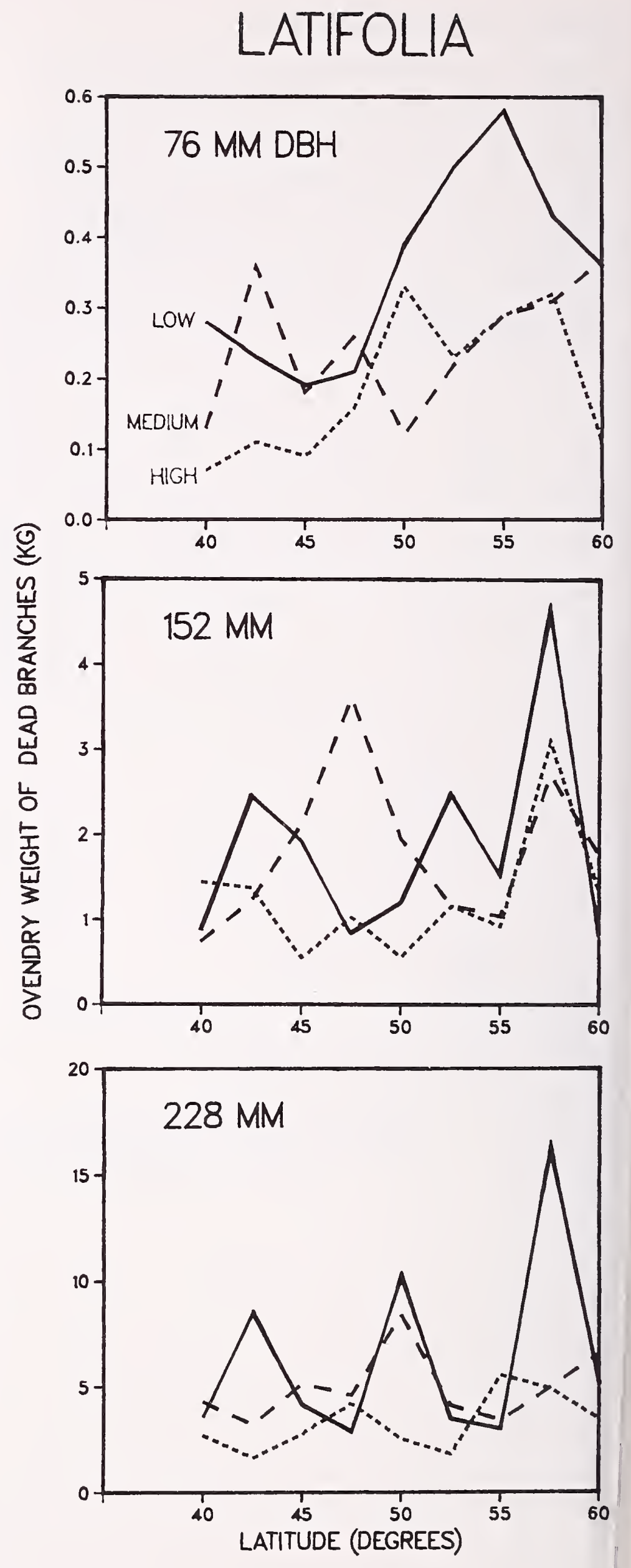

Figure 4-20-Ovendry weight of dead branches of latifolia trees of three diameters related to latitude and elevational zone. 
Tree Component Proportion, Green-Weight Basis-On a green-weight basis, dead branches comprised 1.23 percent of complete-tree weight (including foliage), with standard deviation of 1.13 percentage points. This weight proportion was unrelated to d.b.h., but in most latitudes (fig. 4-21) trees from low-elevation zones had a greater weight proportion of dead branches than those in high zones; averages for low, medium, and high zones were $1.51,1.21$, and 0.97 percent. Trees in northern latitudes tended to have a greater weight proportion of dead branches than those in the south (fig. 4-21).

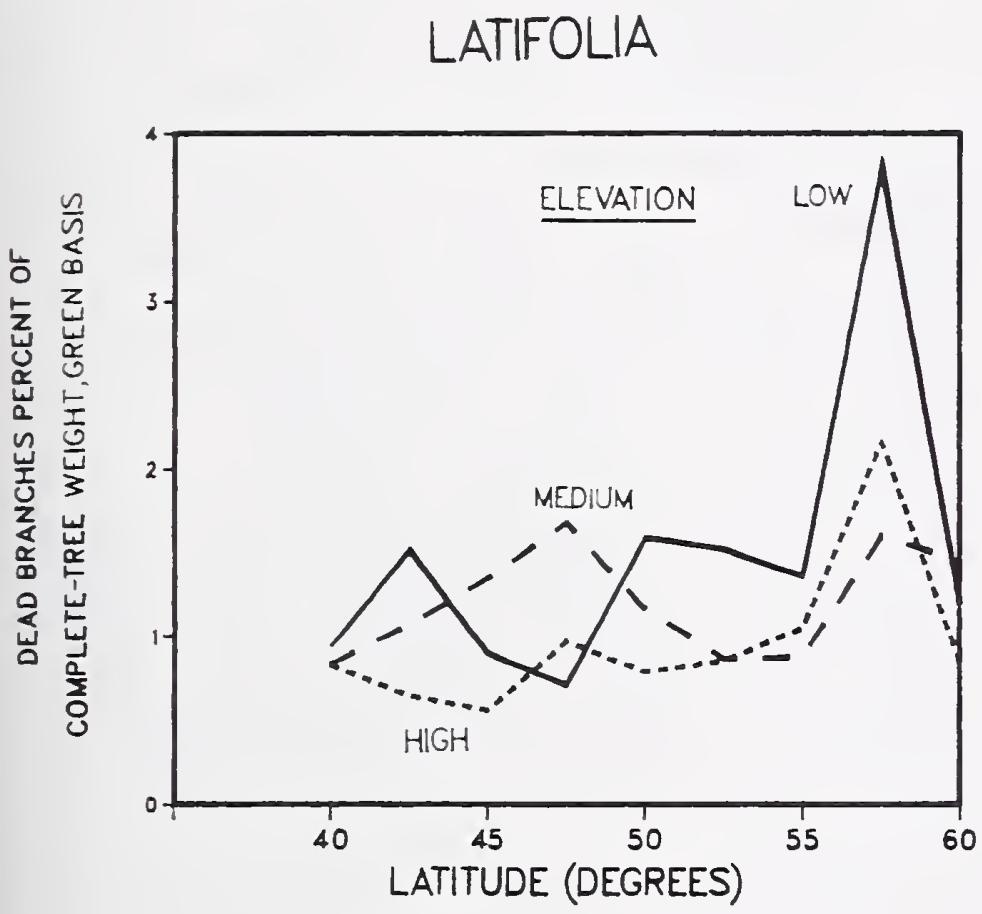

Figure 4-21-Dead branches as percentage of weight of complete latifolia trees with foliage (green basis) related to latitude and elevational zone.
Tree Component Proportion, Ovendry-Weight BasisOn an ovendry-weight basis, dead branches averaged 1.98 percent of complete-tree weight including foliage, with standard deviation of 1.72 percentage points. The proportion was unrelated to d.b.h., but negatively correlated with elevational zone in most latitudes (fig. 4-22), averaging $2.44,1.98$, and 1.53 percent in low-, medium-, and highelevation zones.

Dead branchwood ovendry-weight proportion averaged least (1.47 percent) in the southernmost latitude of 40 degrees and most (3.73 percent) at 57.5 degrees (fig. 4-22).

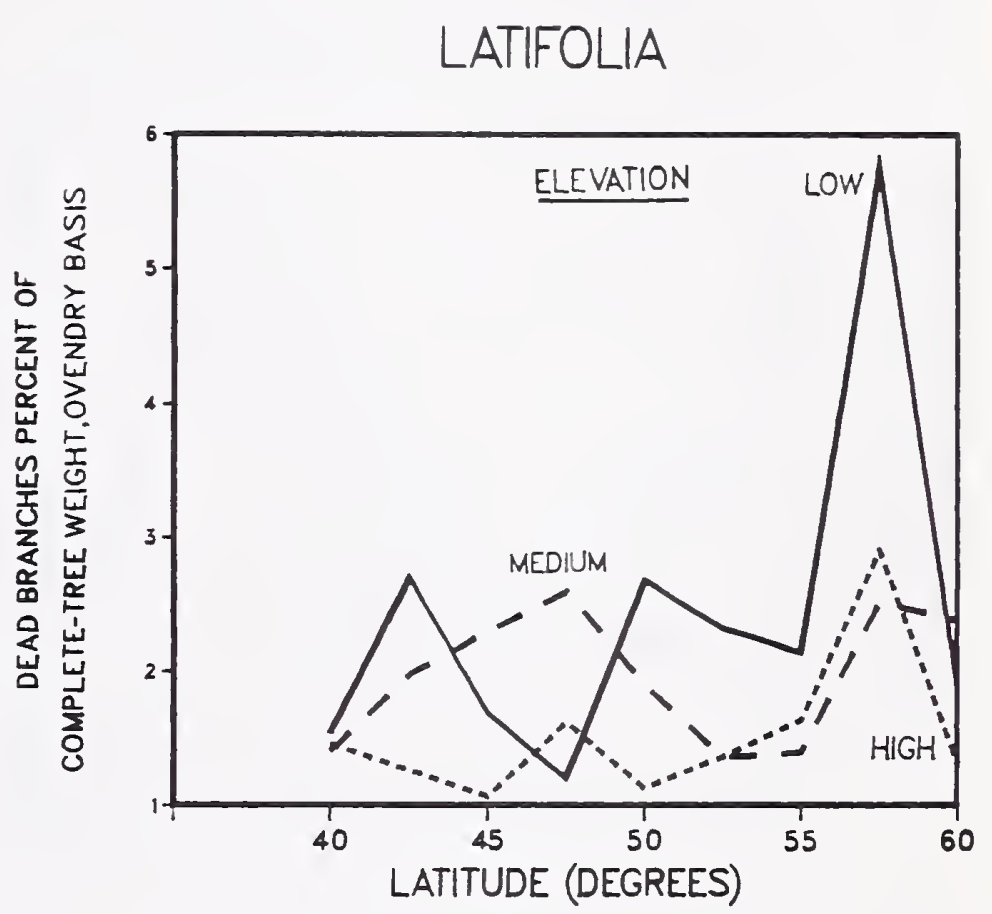

Figure 4-22-Dead branches as percentage of weight of complete latifolia trees with foliage (ovendry basis) related to latitude and elevational zone. 


\section{Live Branches, Wood Plus Bark}

Specific Gravity-Specific gravity of wood plus bark of live branches averaged 0.457 , with standard deviation of 0.031 , based on ovendry weight and green volume. It was unrelated to either d.b.h. or elevational zone.

Its latitudinal variation (fig. 4-23) was inverse to the latitudinal variation of the moisture content of this tree portion (fig. 2-9). Wood-plus-bark specific gravity averaged least $(0.439)$ at 45 degrees latitude and most $(0.477)$ at 52.5 degrees (fig. 4-23).

\section{LATIFOLIA}

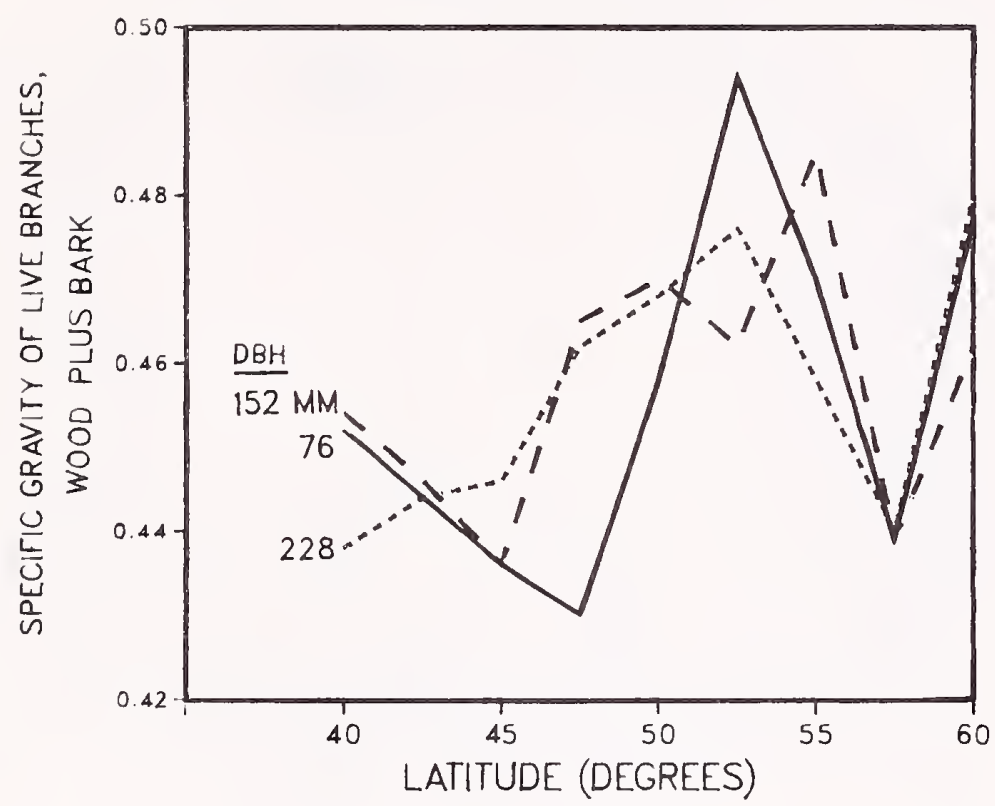

Figure 4-23-Specific gravity of wood plus bark of live branches (based on ovendry weight and green volume) of latifolia trees of three diameters related to latitude.

Weight, Green-Green weight of foliage-free live branches, wood plus bark, was positively correlated with d.b.h., averaging $1.32(0.74), 9.08(4.00)$, and $31.92(13.80)$ $\mathrm{kg}$ for trees 76,152 , and $228 \mathrm{~mm}$ in d.b.h. Trees in highelevation zones tended to have less weight of green branches than those in low zones, but latitudinal trends were not pronounced (fig. 4-24).
LATIFOLIA

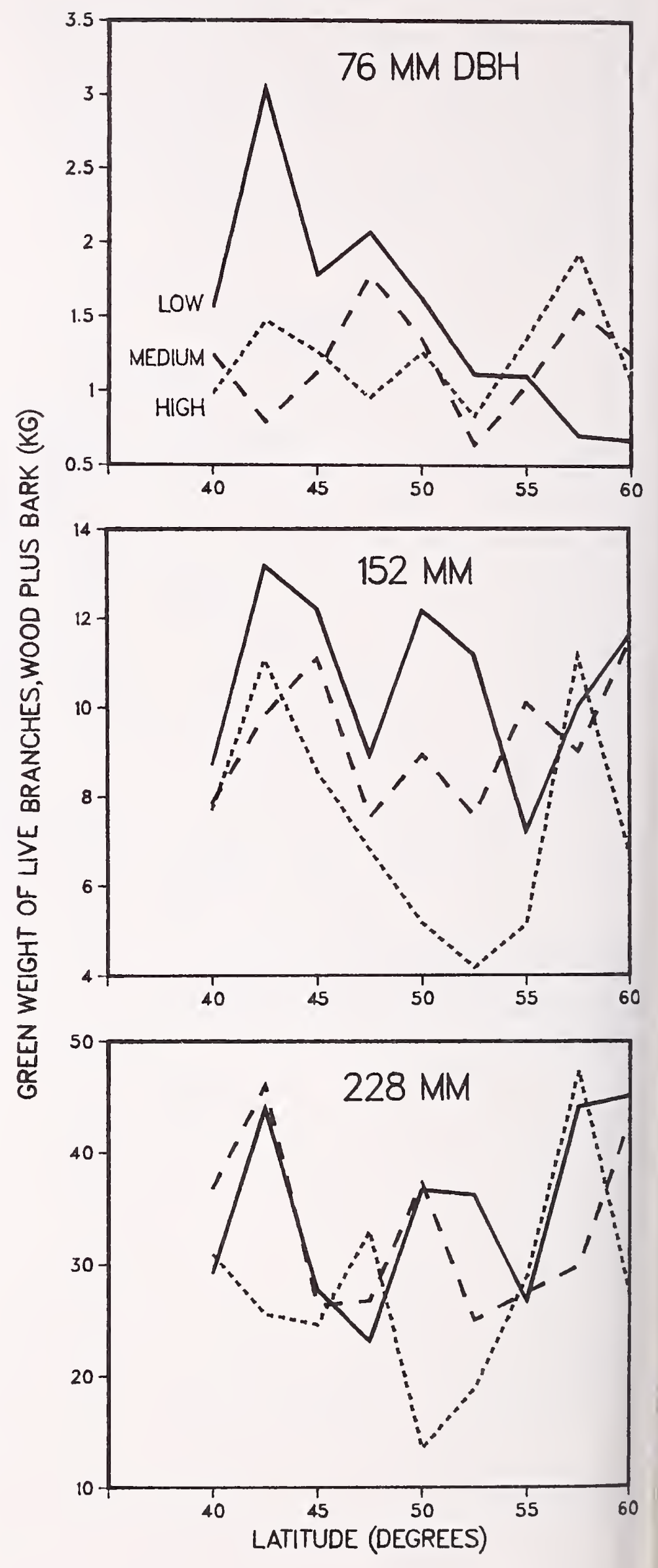

Figure 4-24-Green weight of wood plus bark of live branches of latifolia trees of three diameters related to latitude and elevational zone. 
Weight, Ovendry-Similarly, ovendry weight of live branches averaged $0.67(0.35), 4.62(1.93)$, and $16.32(6.79)$ $\mathrm{kg}$ for trees of the three diameter classes, with no prominent latitudinal trends (fig. 4-25). Branch weights were negatively correlated with elevational zone, averaging (with diameter data pooled) 7.91, 7.46, and $6.23 \mathrm{~kg}$ for trees in low-, medium-, and high-elevation zones, respectively.

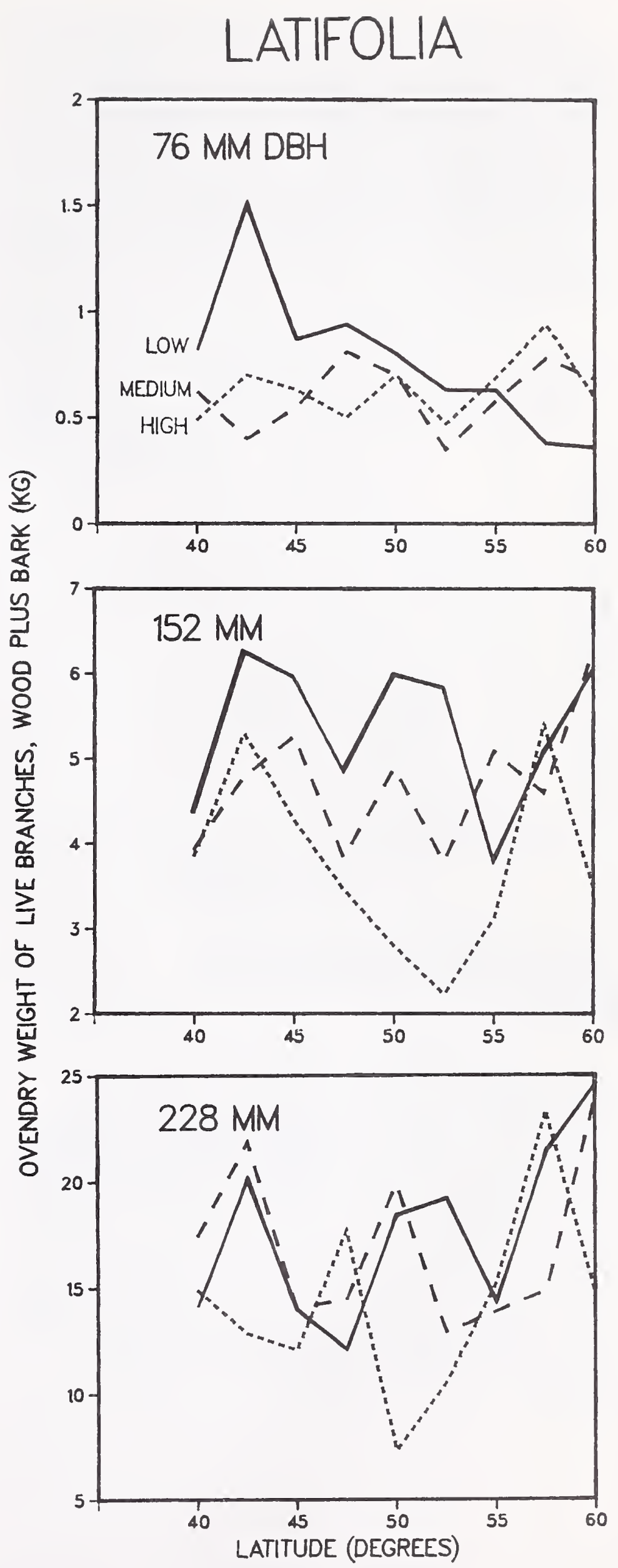

Figure 4-25-Ovendry weight of wood plus bark of live branches of latifolia trees of three diameters related to latitude and elevational zone. 
Green Weight to Yield $1 \mathrm{~m}^{3}$ of Wood-Weight of foliage-free green live branches required to yield $1 \mathrm{~m}^{3}$ of wood averaged $1,448 \mathrm{~kg}$, with standard deviation of $209 \mathrm{~kg}$. This weight requirement was unrelated to elevational zone, but was negatively correlated with d.b.h., averaging 1,649 (162), 1,427 (134), and 1,267 (116) kg for trees 76,152 , and $228 \mathrm{~mm}$ in d.b.h. The requirement varied somewhat with latitude; it averaged maximum $(1,543 \mathrm{~kg})$ at 45 degrees and minimum $(1,411 \mathrm{~kg})$ at 47.5 degrees (fig. 4-26).

\section{LATIFOLIA}

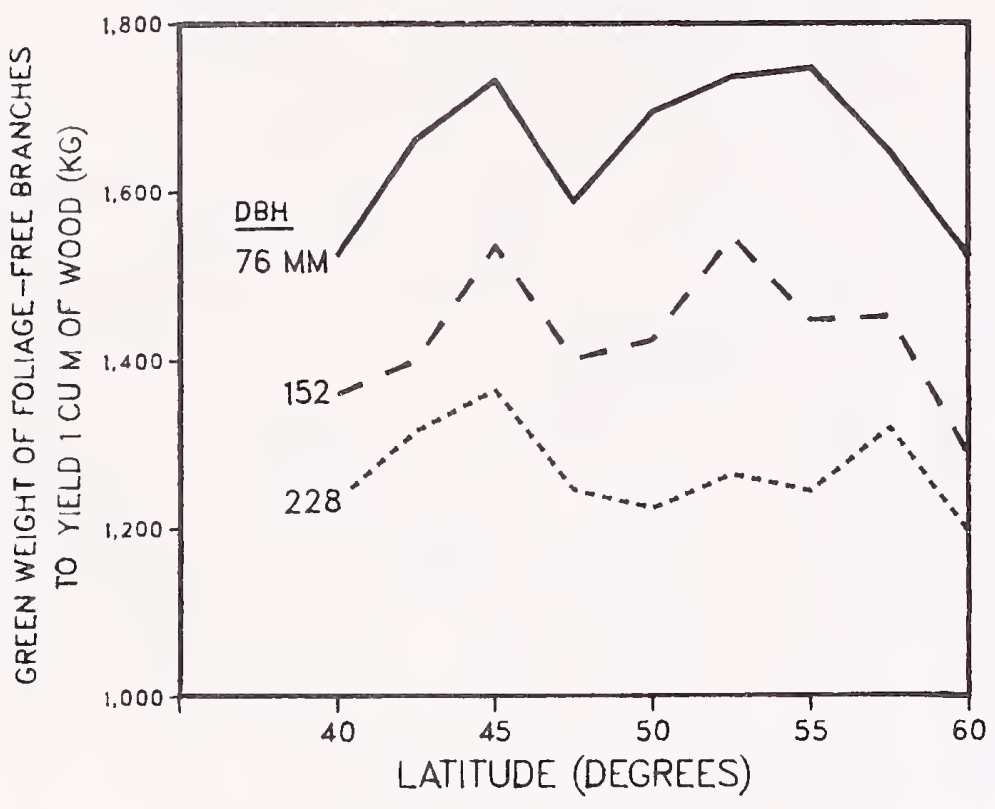

Figure 4-26-Weight of green foliage-free live branches to yield $1 \mathrm{~m}^{3}$ of bark-free wood from latifolia trees of three diameters related to latitude.

Tree Component Proportion, Green-Weight BasisWith all data pooled, green, foliage-free live branches averaged 5.80 percent of complete-tree green weight in. cluding foliage, with standard deviation of 2.95 percentage points. This proportion was positively correlated with d.b.h., averaging 4.64 (2.55), 5.40 (2.43), and 7.35 (3.15) percent for trees 76,152 , and $228 \mathrm{~mm}$ in d.b.h. Latitudinal trends were not pronounced, but trees in high-elevation zones tended to have less percentage of their green weight in live branches than those in low zones (fig. 4-27). With diameter and latitudinal data pooled, trees in high, medium, and low zones averaged 5.31, 5.76, and 6.32 percent.
LATIFOLIA

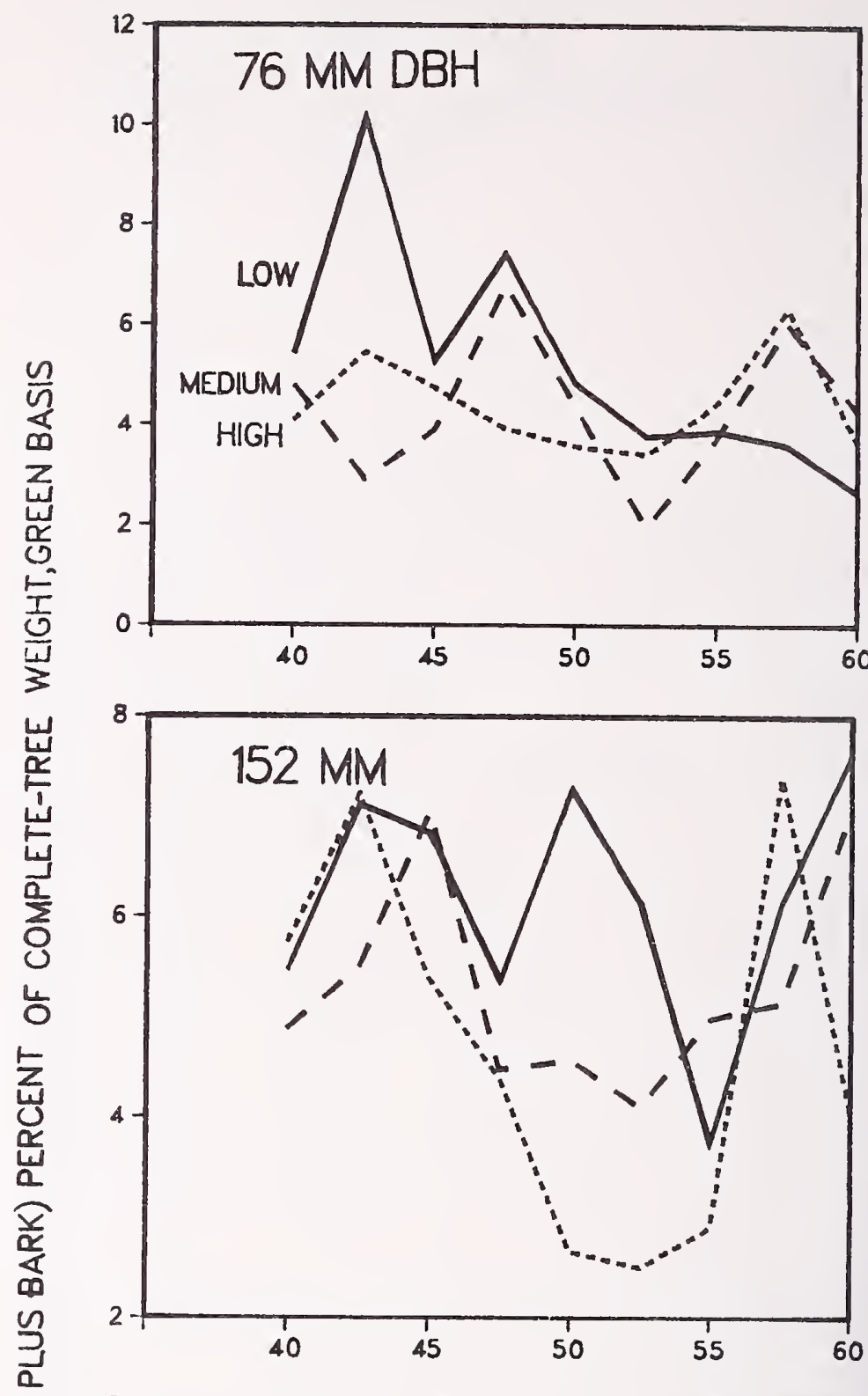

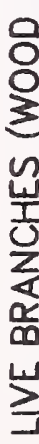

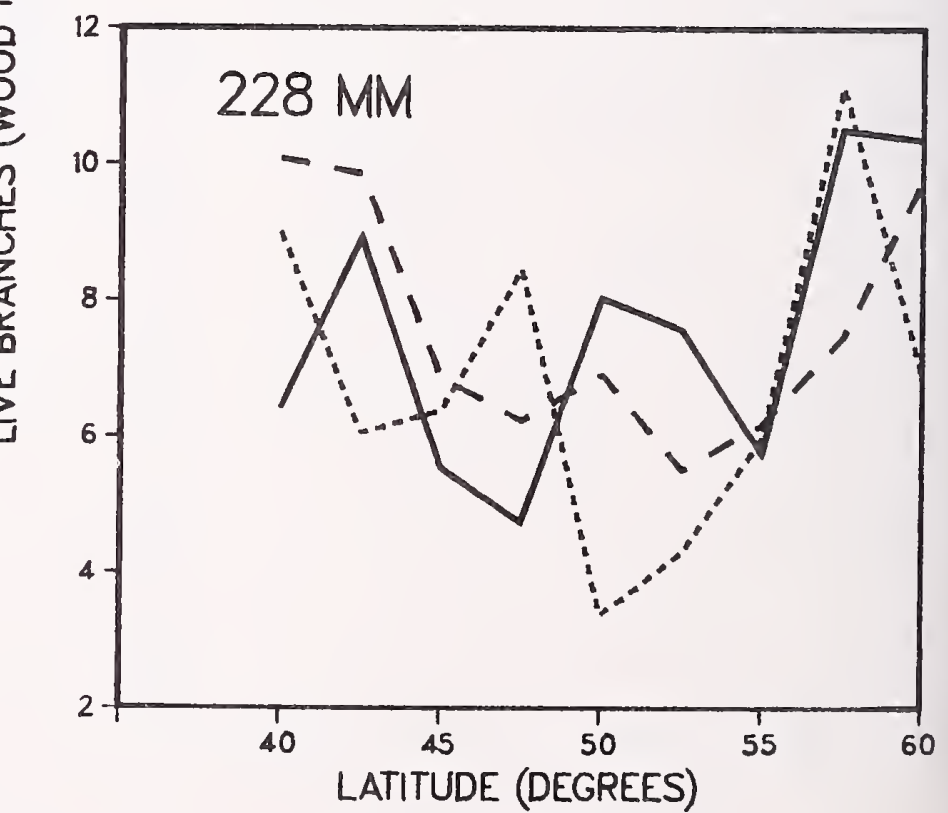

Figure 4-27-Live branches, wood plus bark but not foliage, as percentage of complete-tree green weight-including foliage, for latifolia trees of three diameters related to latitude and elevational zone. 
Tree Component Proportion, Ovendry-Weight BasisOvendry, foliage-free live branches averaged 5.88 percent of ovendry complete-tree weight including foliage, with standard deviation of 3.02 percentage points. This percentage was unrelated to elevational zone, but was positively correlated with d.b.h., averaging 4.81 (2.68), 5.49 (2.61), and $7.32(3.19)$ percent for trees of the three diameter classes. As a percentage of total ovendry tree weight, weight of live branches was lowest in the middle latitudes (4.38 percent at 52.5 degrees) and highest ( 7.37 percent) at 42.5 degrees (fig. 4-28).

\section{LATIFOLIA}

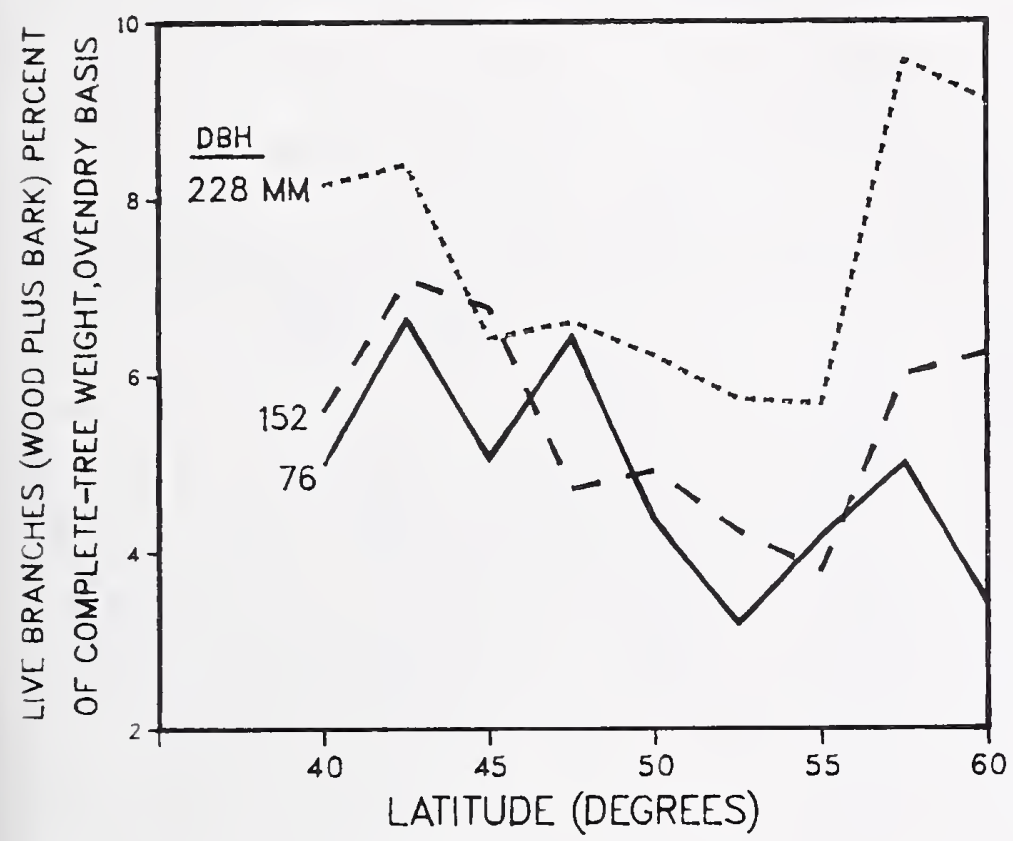

Figure 4-28-Live branches, wood plus bark but not foliage, as percentage of complete-tree ovendry weight-including foliage, for latifolia trees of three diameters related to latitude.

\section{Live Branchwood}

Specific Gravity-Wood of live branches had the highest specific gravity of any tree component (table 4-2), averaging 0.487 , with standard deviation of 0.036 , based on ovendry weight and green volume. It was unrelated to elevational zone, but was negatively correlated with d.b.h., averaging $0.499(0.041), 0.487(0.032)$, and $0.477(0.030)$ for trees 76,152 , and $228 \mathrm{~mm}$ in d.b.h.

Latitudinal relationship to branchwood specific gravity (fig. 4-29) was inverse to that of moisture content (fig. 2-10). Average specific gravity of branchwood was lowest (0.463) in the southernmost latitude of 40 degrees and increased to an average range from 0.484 to 0.502 in latitudes 45 through 60 degrees (fig. 4-29).

\section{LATIFOLIA}

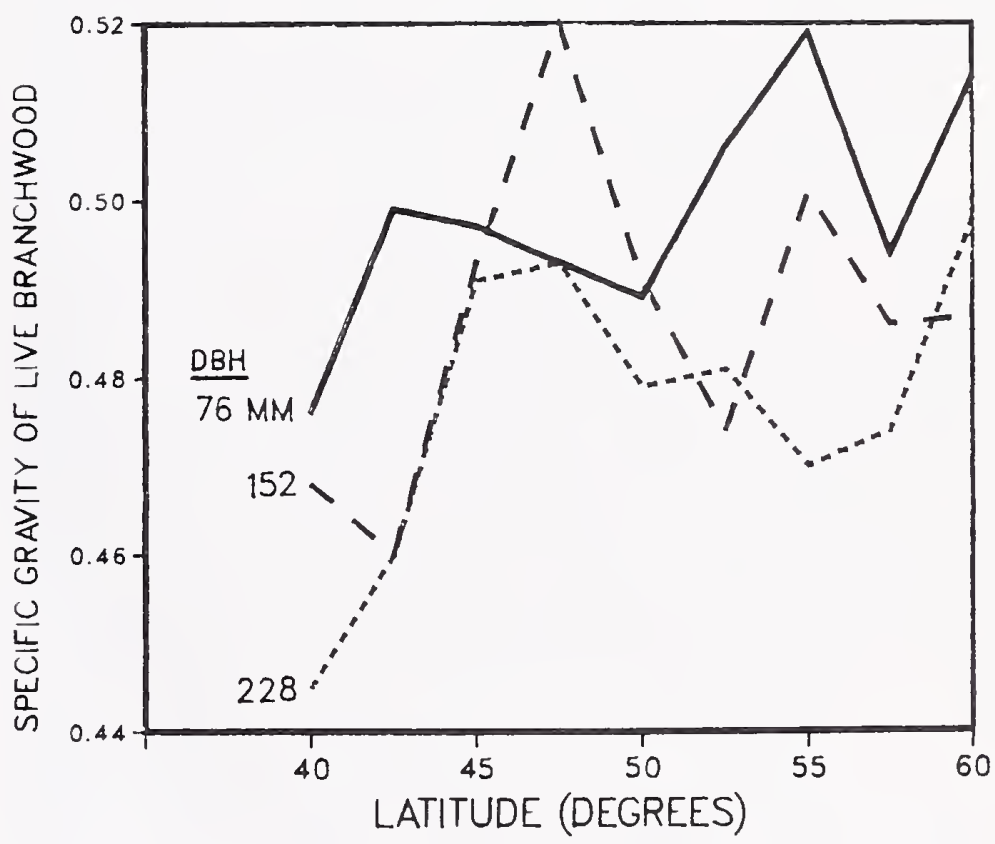

Figure 4-29-Specific gravity of live branchwood (based on ovendry weight and green volume) of latifolia trees of three diameters related to latitude. 
Weight, Green-Weight of green live branchwood was positively correlated with d.b.h., averaging $0.74(0.45)$, 5.93 (2.71), and $23.14(10.55) \mathrm{kg}$ for trees of the three diameter classes. In small-diameter trees, but not in large, branchwood weight was less in northern than in southern latitudes (fig. 4-30). Also, green branchwood weight was inversely correlated with elevational zone, averaging-with diameter data pooled-11.16, 10.27, and 8.39 $\mathrm{kg}$ for trees in low, medium, and high zones.

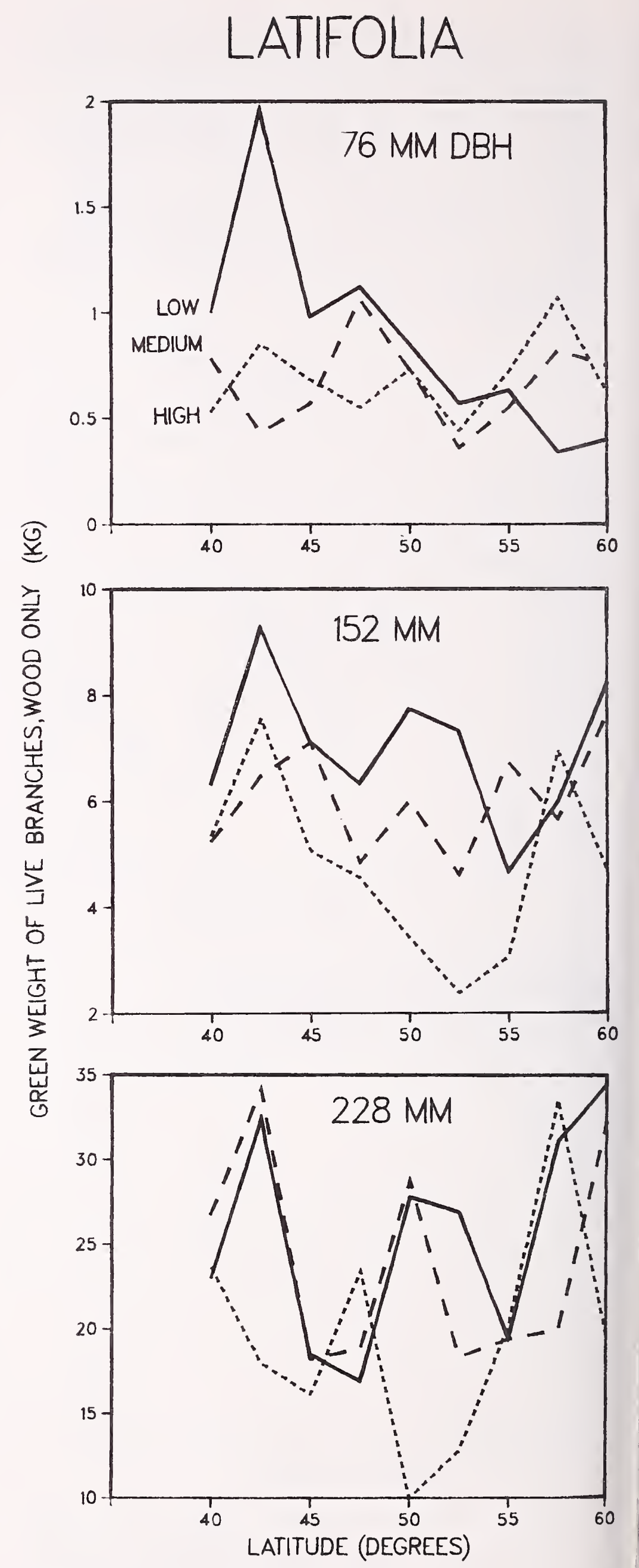

Figure 4-30-Green weight of wood of live branches of latifolia trees of three diameters related to latitude and elevational zone. 
Weight, Ovendry-Ovendry weight of wood of live branches also varied inversely with elevational zone, averaging-with diameter data pooled-5.76, 5.38, and $4.45 \mathrm{~kg}$ in low, medium, and high zones (fig. 4-31). In low elevational zones, $76-\mathrm{mm}$ trees had less branchwood weight in northern latitudes than in southern. All diameters considered, branchwood weight was least at 52.5 degrees $(4.26 \mathrm{~kg})$ and most at 60 degrees $(6.78 \mathrm{~kg})$; but trends were complex (fig. 4-31).

Weight of ovendry branchwood was positively correlated with d.b.h., averaging $0.40(0.22), 3.11$ (1.38), and 12.09 (5.34) $\mathrm{kg}$ for trees 76,152 , and $228 \mathrm{~mm}$ in d.b.h.

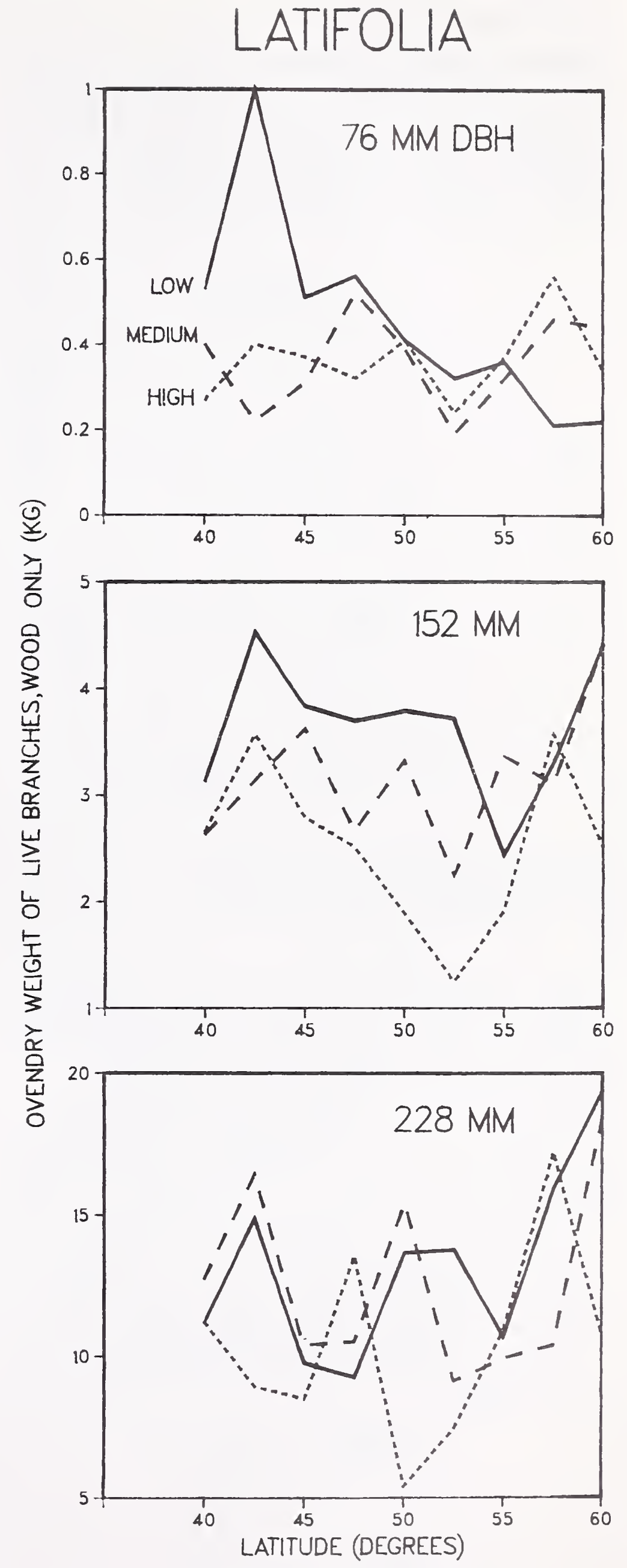

Figure 4-31-Ovendry weight of wood of live branches of latifolia trees of three diameters related to latitude and elevational zone. 


\section{Live Branchbark}

Specific Gravity-The bark of live branches had average specific gravity of 0.410 , with standard deviation of 0.051 . This specific gravity was unrelated to either d.b.h. or elevational zone. It did, however, vary significantly with latitude (fig. 4-32), averaging minimum (0.365) at 45 degrees and maximum (0.466) at 52.5 degrees.

\section{LATIFOLIA}

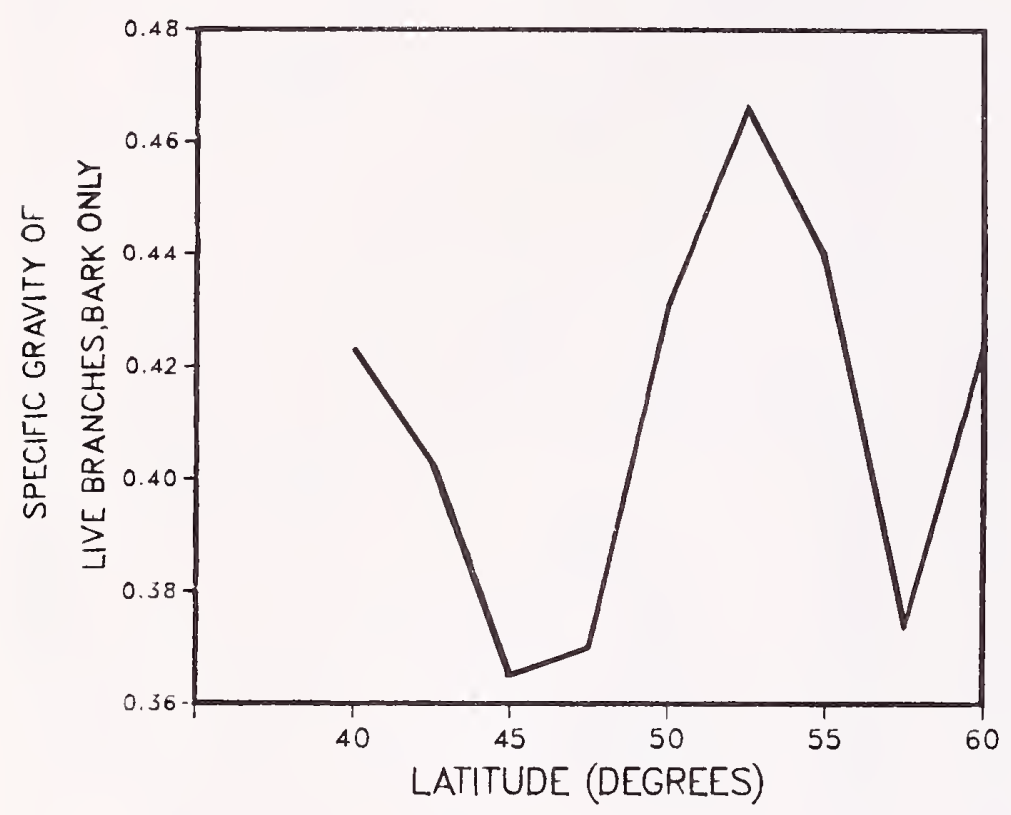

Figure 4-32-Specific gravity of bark of live branches (based on ovendry weight and green volume) of latifolia trees related to latitude.

Weight, Green-Green weight of bark of live branches was positively correlated with d.b.h., averaging $0.57(0.32)$, $3.14(1.44)$, and $8.80(3.66) \mathrm{kg}$ for trees of the three diameter classes. Branchbark weight of low-elevation $76-\mathrm{mm}$ trees was less in the north than in the south, but the reverse was true for $228-\mathrm{mm}$ trees in low-elevation zones (fig. 4-33). Trees of 152-mm d.b.h. in high-elevation zones had less green weight of branchbark than those in lower zones (fig. 4-33).

Weight, Ovendry-Ovendry weight of live branchbark was unrelated to latitude, but was positively correlated with d.b.h., averaging 0.28 (0.14), 1.51 (0.64), and 4.23 (1.65) $\mathrm{kg}$ for trees of the three diameters studied.

For 152-mm trees only, weight of ovendry live branchbark was negatively correlated with elevational zone, as follows:

$\begin{array}{lc}\begin{array}{c}\text { Elevational } \\ \text { zone }\end{array} & \text { Weight } \\ & \mathrm{kg} \\ \text { Low } & 2.15 \\ \text { Medium } & 2.08 \\ \text { High } & 1.78\end{array}$
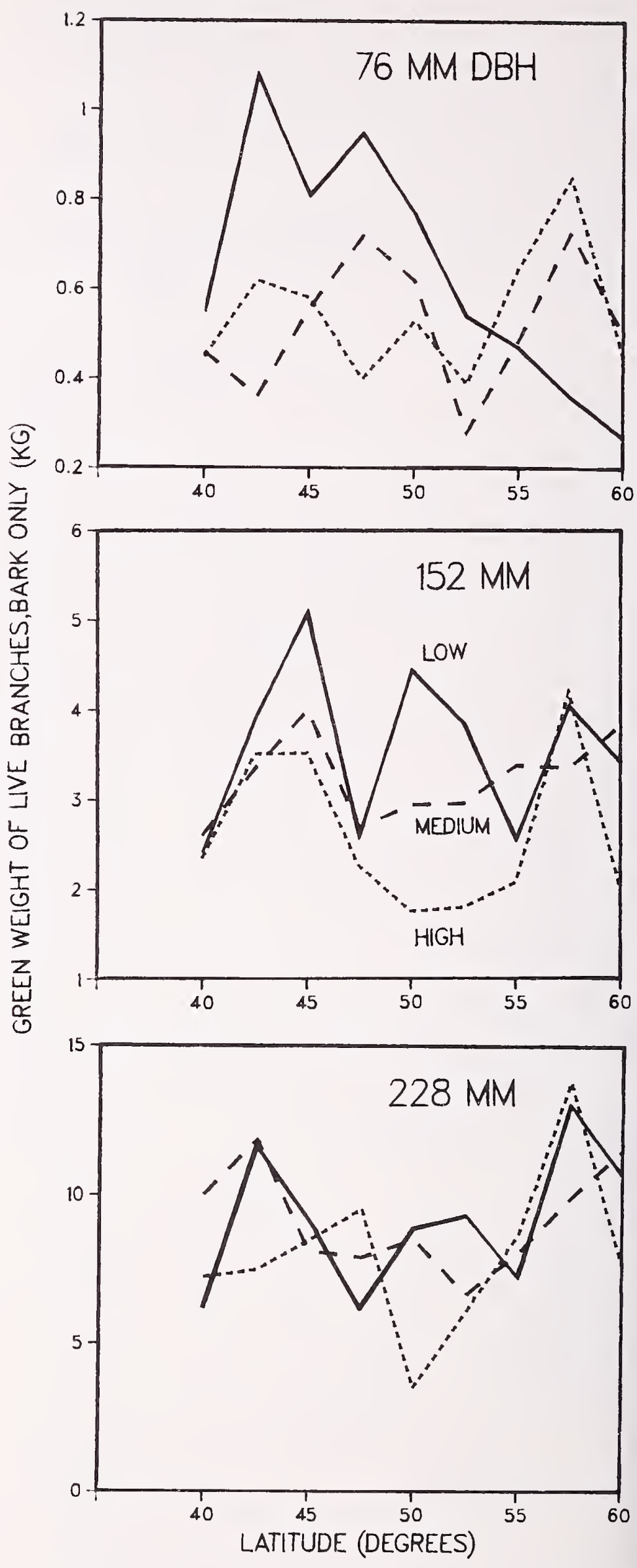

Figure 4-33-Green weight of bark of live branches of latifolia trees of three diameters related to latitude and elevational zone. 
LATIFOLIA

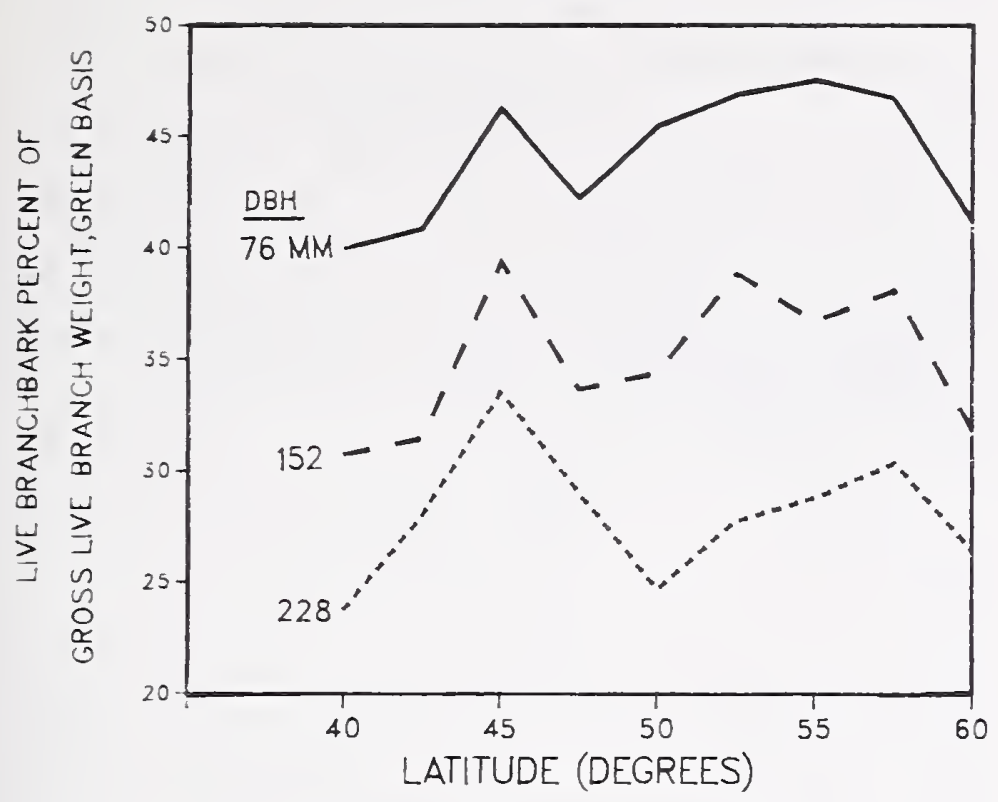

Figure 4-34-Bark as percentage of green weight of foliage-free live branches of latifolia trees of three diameters related to latitude.

Live Branchbark as Percentage of Gross Live Branch Weight, Green and Ovendry-Bark of live branches averaged 35.72 percent of the weight of green foliage-free branches, with standard deviation of 8.62 percentage points; on an ovendry basis, comparable values were 33.79 and 8.41 percent. Both green and ovendry bark weight percentages were negatively correlated with d.b.h., as follows:

$\begin{array}{rcr}\text { D.b.h. } & \text { Green } & \text { Ovendry } \\ m m & \ldots \ldots \ldots \text { Percent } \ldots \ldots . . \\ 76 & 44.13(6.17) & 41.78(6.63) \\ 152 & 35.01(5.37) & 33.19(5.50) \\ 228 & 28.03(5.08) & 26.41(4.43)\end{array}$

On both green (fig. 4-34) and ovendry (fig. 4-35) bases, branchbark weight percentages were minimum or near minimum (31.49 and 31.43 percent, respectively) at the southernmost latitude of 40 degrees. Maximums averaged 39.71 percent at 45 degrees on a green basis and 39.30 percent at 52.5 degrees on an ovendry basis.

\section{Stem, Wood Plus Bark-Tree Average}

Specific Gravity-Wood plus bark of the stems had arerage specific gravity of 0.412 , with standard deviation of 0.030 . It was unrelated to elevational zone but was negatively correlated with d.b.h.-particularly in northern latitudes (fig. 4-36), averaging for all latitudes 0.416 $(0.036), 0.413(0.027)$, and $0.406(0.025)$ for trees 76.152 , and $228 \mathrm{~mm}$ in d.b.h.

Its relationship with latitude was inverse to that of moisture content (fig. 2-12). Specific gravity was positively correlated with latitude, with minimum average $(0.387)$ at 42.5 degrees and maximum (0.421 or more) from 47.5 degrees north-except at 57.5 degrees where it was 0.403 (fig. 4-36).

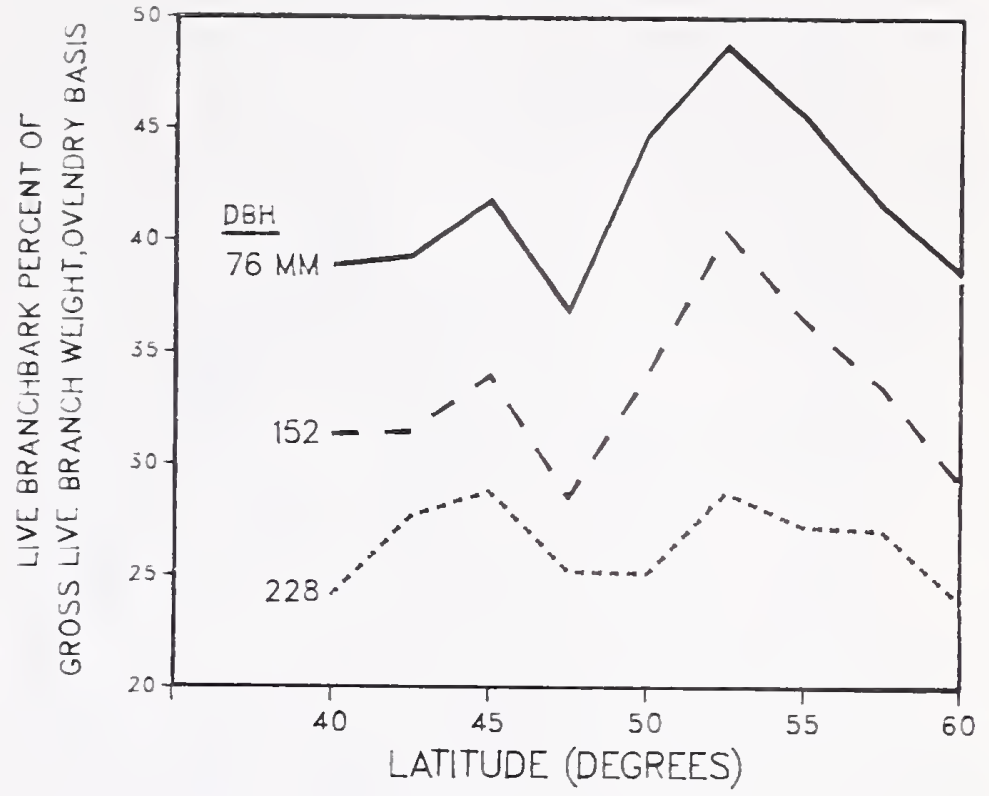

Figure 4-35-Bark as percentage of ovendry weight of foliage-free live branches of latifolia trees of three diameters related to latitude.

\section{LATIFOLIA}

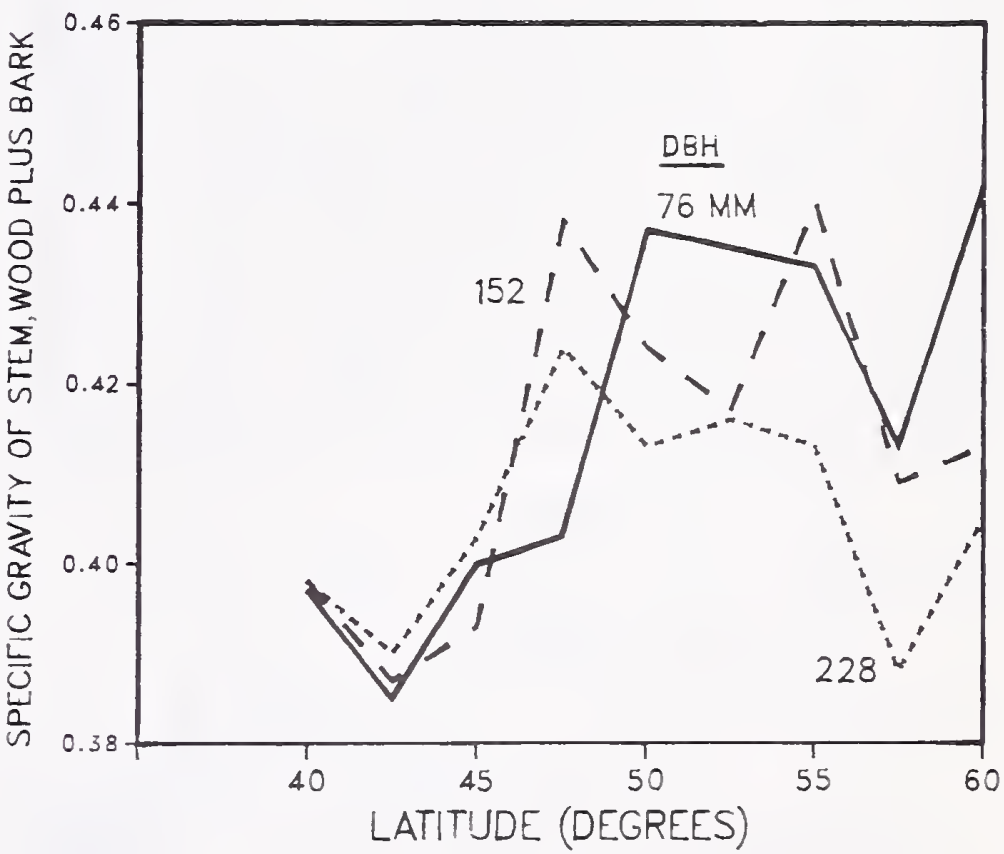

Figure 4-36-Specific gravity (based on ovendry weight and green volume) of stem, wood plus bark, of latifolia trees of three diameters related to latitude. 


\section{LATIFOLIA}
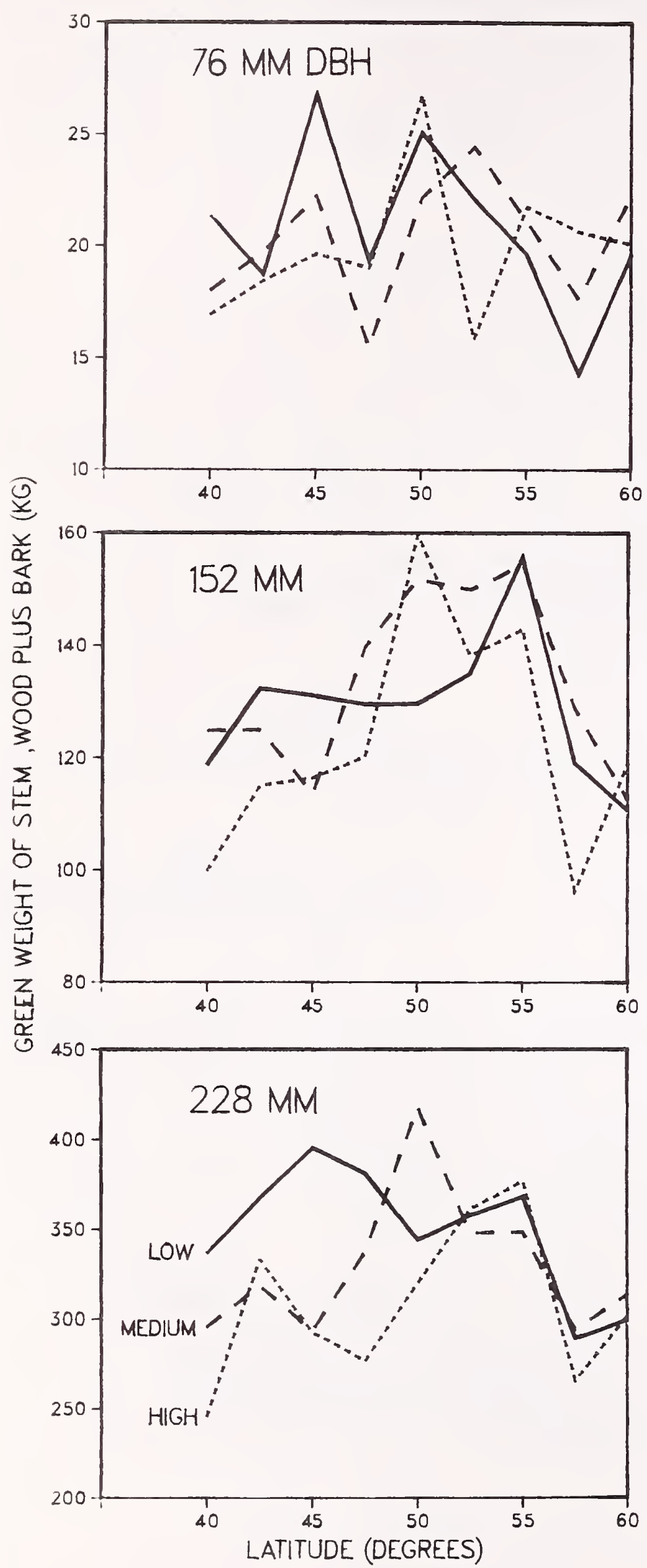

Figure 4-37-Green weight of stem, wood plus bark from $152-\mathrm{mm}$ stump height to apical tip, of latifolia trees of three diameters related to latitude and elevational zone.
Weight, Green-Trees 76, 152, and $228 \mathrm{~mm}$ in d.b.h. had average green stem weights (wood plus bark) of 20.34 (4.37), 128.49 (25.45), and 328.85 (61.81) kg. Green stems from high-elevation zones tended to weigh less than those in low; for example, stems of 228-mm trees from high, medium, and low zones averaged 308.22, 329.59, and $348.73 \mathrm{~kg}$, rospectively (fig. 4-37). Because stems (wood plus bark) from northern latitudes have much lower moisture content than those from southern latitudes (fig. 2-12), green stem weight does not vary as much with latitude as ovendry-weight variation would suggest (figs. 4-37 and 4-38). 
LATIFOLIA

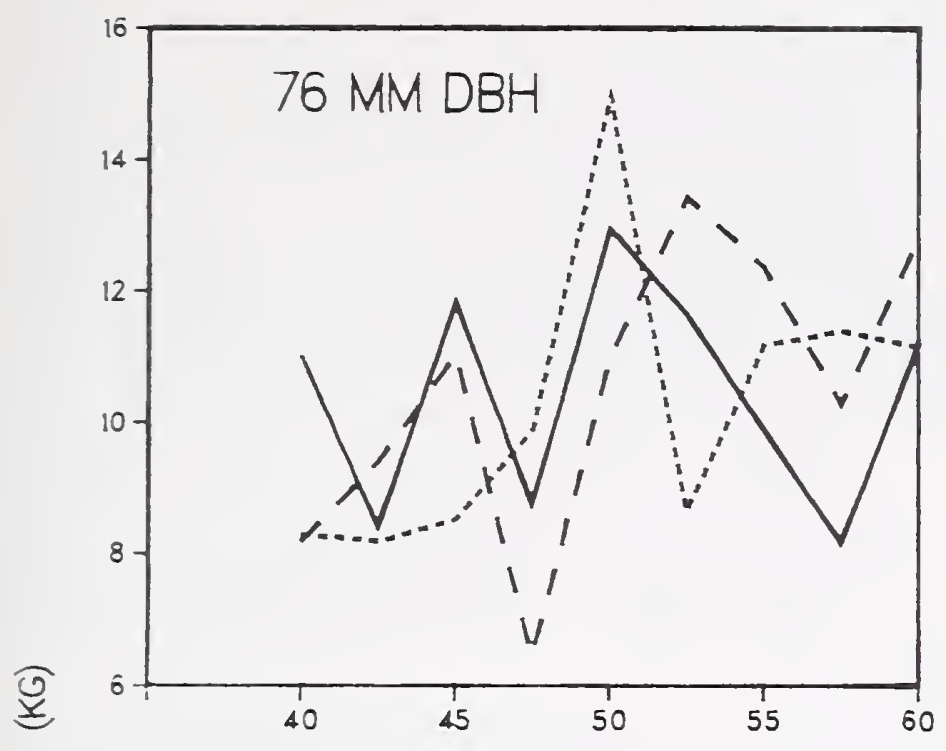

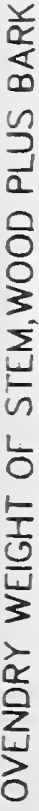
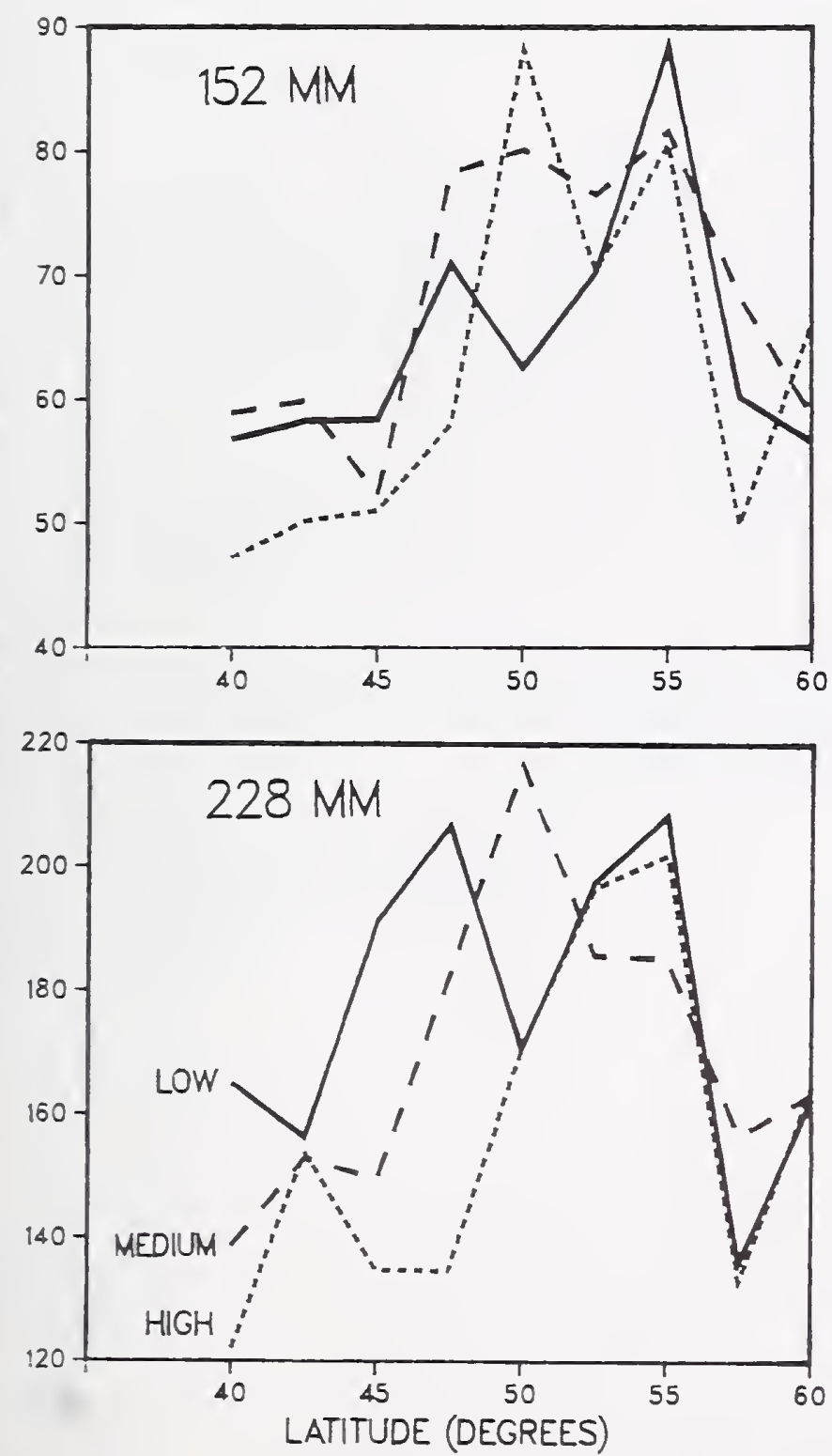

Figure 4-38-Ovendry weight of stem, wood plus bark from $152-\mathrm{mm}$ stump height to apical tip, of latifolia trees of three diameters related to latitude and elevational zone.
Weight, Ovendry-On an ovendry basis, stem weight (wood plus bark) increases sharply from southern latitudes to maximums in latitudes from 50 through 55 degrees and then diminishes in the two northernmost latitudes (fig. 4-38). Stems from trees in high-elevation zones weigh less than those from low; with diameter data pooled, ovendry stem weights from low, medium, and high zones averaged 84.11, 83.02, and $76.48 \mathrm{~kg}$ (fig. 4-38).

Trees 76,152 , and $228 \mathrm{~mm}$ in d.b.h. had average ovendry stem weights (wood plus bark) of 10.35 (2.90), 65.15 (15.49), and $168.12(34.87) \mathrm{kg}$.

Green Weight to Yield $1 \mathrm{~m}^{3}$ of Wood-With diameter data pooled, green weight of wood plus bark of stems required to yield $1 \mathrm{~m}^{3}$ of wood averaged $920 \mathrm{~kg}$, with standard deviation of $93 \mathrm{~kg}$. This requirement was unrelated to elevational zone, but was negatively correlated with d.b.h., averaging 968 (105), 920 (74), and 872 (73) $\mathrm{kg}$ for trees 76,152 , and $228 \mathrm{~mm}$ in d.b.h.

It was negatively correlated with latitude (fig. 4-39), with maximum requirement $(981 \mathrm{~kg}$ ) at 45 degrees and minimum (869 kg) at 57.5 degrees (fig. 4-39).

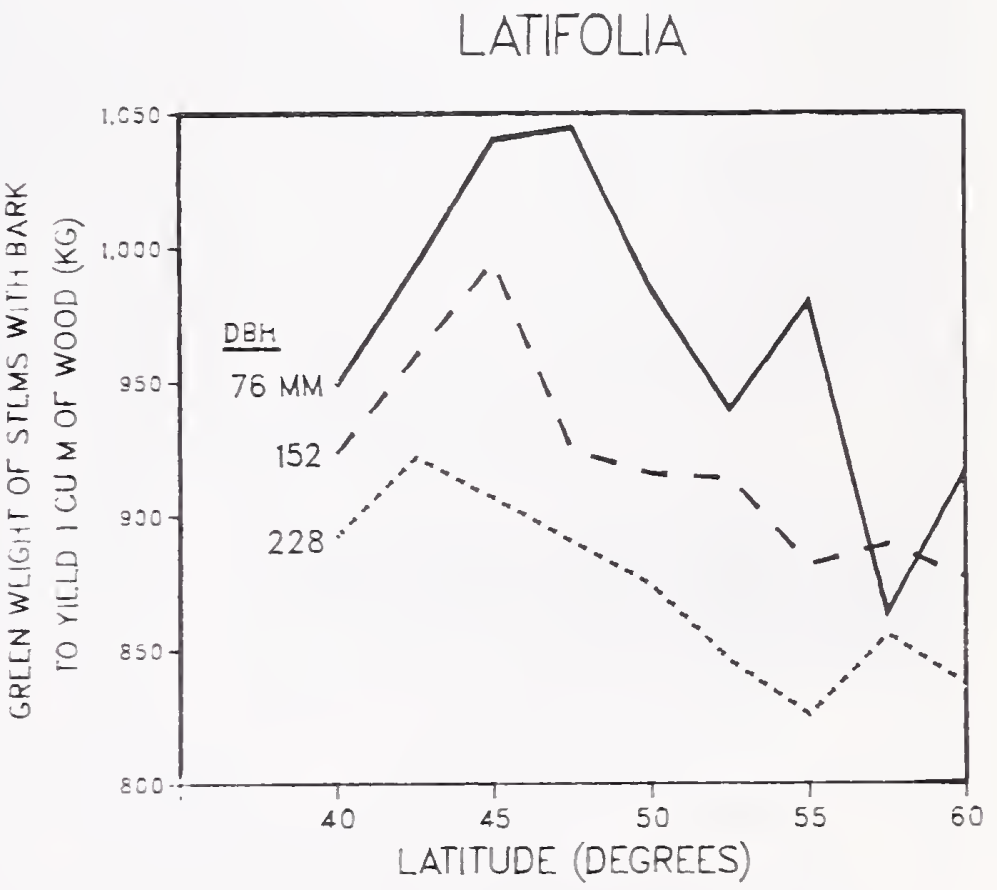

Figure 4-39-Green weight of stems with bark required to yield $1 \mathrm{~m}^{3}$ of bark-free wood from latifolia trees of three diameters related to latitude. 
Tree Component Proportion, Green-Weight BasisWood plus bark of the stem averaged 73.67 percent of green complete-tree weight including foliage, with standard deviation of 6.64 percentage points. This percentage was unrelated to elevational zone, but was less in $76-\mathrm{mm}$ trees than in larger trees, averaging 71.50 (7.38), 75.09 (5.80), and 74.42 (6.17) for trees 76,152 , and $228 \mathrm{~mm}$ in d.b.h.

The percentage was positively correlated with latitude (fig. 4-40); it averaged minimum (71.55 percent) at 42.5 degrees and maximum (75.72 to 76.57 percent) in latitudes 50 through 55 degrees.

\section{LATIFOLIA}

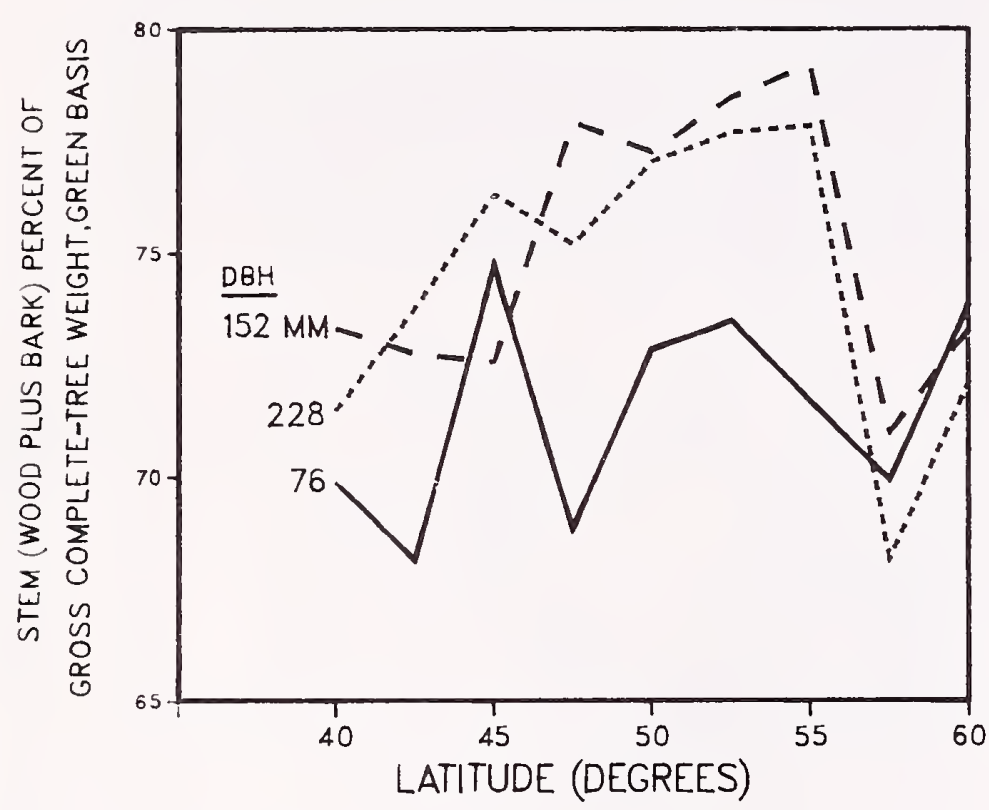

Figure 4-40-Stem (wood plus bark) as percentage of complete-tree green weight, including foliage, of latifolia trees of three diameters related to latitude.
Tree Component Proportion, Ovendry-Weight BasisOn an ovendry-weight basis, wood plus bark of stems averaged 72.79 percent of complete-tree weight including foliage, with standard deviation of 7.13 percentage points. This proportion was unrelated to elevational zone, but was less in 76-mm trees than in larger trees, averaging 71.01 (8.17), 74.00 (6.36), and 73.37 (6.46) percent for trees 76 , 152 , and $228 \mathrm{~mm}$ in d.b.h.

It was positively correlated with latitude (fig. 4-41), with minimum (69.69 percent) at 42.5 degrees and maximums (75.06 to 75.83 ) in latitudes 50 through 55 degrees.

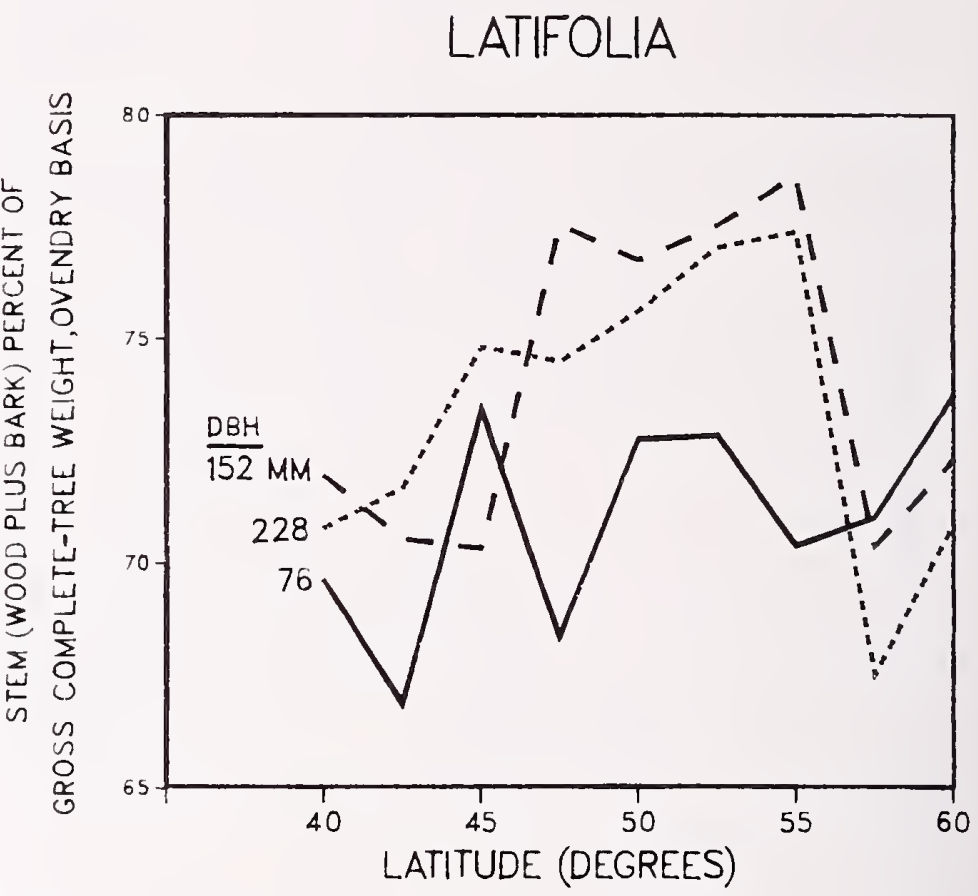

Figure 4-41-Stem (wood plus bark) as percentage of complete-tree ovendry weight, including foliage, of latifolia trees of three diameters related to latitude. 


\section{Stem, Wood Plus Bark-Variation With Height}

Specific Gravity-The specific gravity of stemwood diminishes curvilinearly from stump height up to the base of the live crown and then remains somewhat constant, whereas stembark specific gravity continues to diminish all the way to the apical tip. Stem specific gravity, including both wood and bark, therefore diminishes at an intermediate rate, with a rapid drop near the apical tip where bark proportion is large (fig. 4-42). Levels of the specific gravity patterns differed significantly with diameter. The specific gravity of a disk (wood plus bark) taken at 20 percent of tree height approximates the stem average (fig. 4-42).

Specific gravity-height relationships also varied significantly with latitude (fig. 4-43).

LATIFOLIA

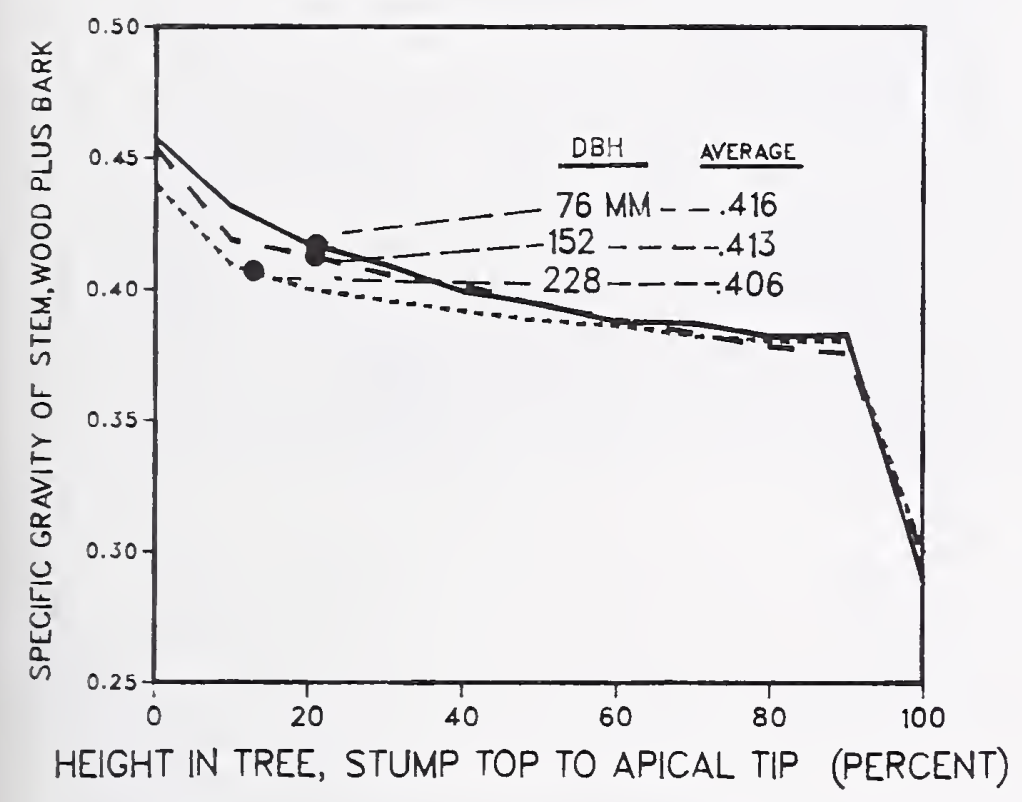

Figure 4-42-Specific gravity of stem (wood plus bark), based on ovendry weight and green volume, of latifolia trees of three diameters related to height in tree.

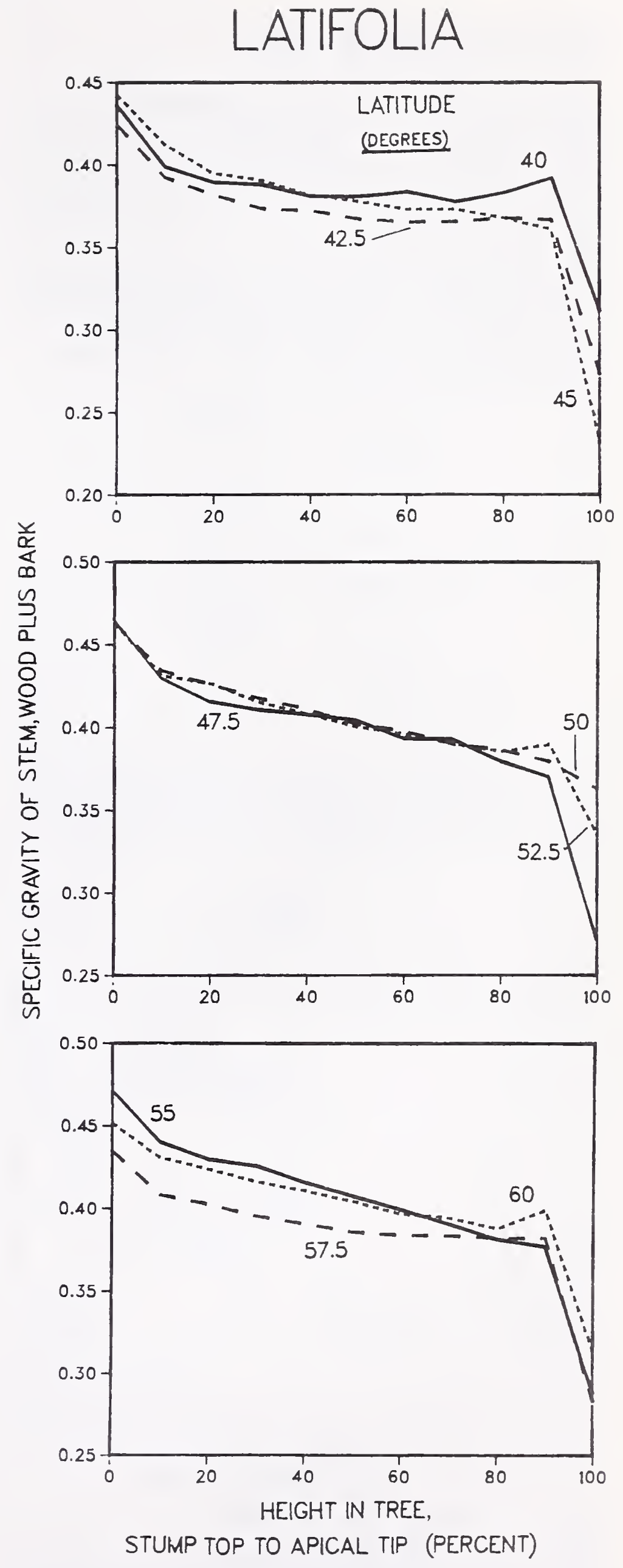

Figure 4-43-Specific gravity of stem (wood plus bark), based on ovendry weight and green volume, of latifolia trees related to height in tree and latitude. 


\section{Stemwood-Tree Average}

Specific Gravity-With all data pooled, stemwood specific gravity based on ovendry weight and green volume averaged 0.418 , with standard deviation of 0.032 . It was unrelated to elevational zone, but negatively correlated with d.b.h., averaging $0.427(0.037), 0.419(0.028)$, and $0.407(0.026)$ for trees 76,152 , and $228 \mathrm{~mm}$ in d.b.h. (fig. 4-44).

The relationship of stemwood specific gravity to latitude (fig. 4-44) was inverse to that of stemwood moisture content (fig. 2-15). That is, stemwood specific gravity was positively correlated with latitude, as follows (diameter and elevational data pooled):

$\begin{array}{lr}\begin{array}{c}\text { Latitude } \\ \text { Degrees }\end{array} & \begin{array}{r}\text { Specific } \\ \text { gravity }\end{array} \\ 40 & 0.401 \\ 42.5 & .390 \\ 45 & .408 \\ 47.5 & .431 \\ 50 & .430 \\ 52.5 & .426 \\ 55 & .435 \\ 57.5 & .410 \\ 60 & .427\end{array}$

Average specific gravity (basis of ovendry weight and green volume) of entire stemwood from 152-mm stump height to apical tip in latifolia trees of the diameters studied can be closely estimated from the specific gravity of a complete stemwood disk taken at 20 percent of tree height, by the following relationship $\left(R^{2}=0.878\right.$; standard error of the estimate $=0.011$ ):

Average stemwood specific gravity $=$ $0.07524+0.82479$ (stemwood specific gravity at 20 percent of tree height)

Weight, Green-Because stemwood moisture content is so much less in northern latitudes than in southern (fig. 2-15), green stemwood weight varies less with latitude than ovendry stemwood weights would suggest (figs. 4-45 and 4-46). Green stemwood from trees in low-elevation zones tends to weigh more than that from high zones; with diameter data pooled, green stemwood weights from low, medium, and high zones averaged 322.12, 303.18, and $283.74 \mathrm{~kg}$, respectively (fig. 4-45).

Trees 76, 152, and $228 \mathrm{~mm}$ in d.b.h., had average green stemwood weights of 17.63 (3.95), 116.62 (23.83), and $303.01(58.13) \mathrm{kg}$, respectively.

Weight, Ovendry-On an ovendry basis, stemwood weights averaged 9.14 (2.56), 59.13 (14.46), and 154.08 (32.58) $\mathrm{kg}$ for the three diameter classes. Ovendry stemwood-diameter data pooled-weighed less in trees from high zones $(144.01 \mathrm{~kg})$ than that from low zones $(162.52 \mathrm{~kg})$, but interactions with diameter and latitude were complex (fig. 4-45). Weight of ovendry stemwood increased sharply from the southernmost latitude to maximums in latitudes from 50 to 55 degrees, and then diminished in the two northernmost latitudes (fig. 4-46).

\section{LATIFOLIA}

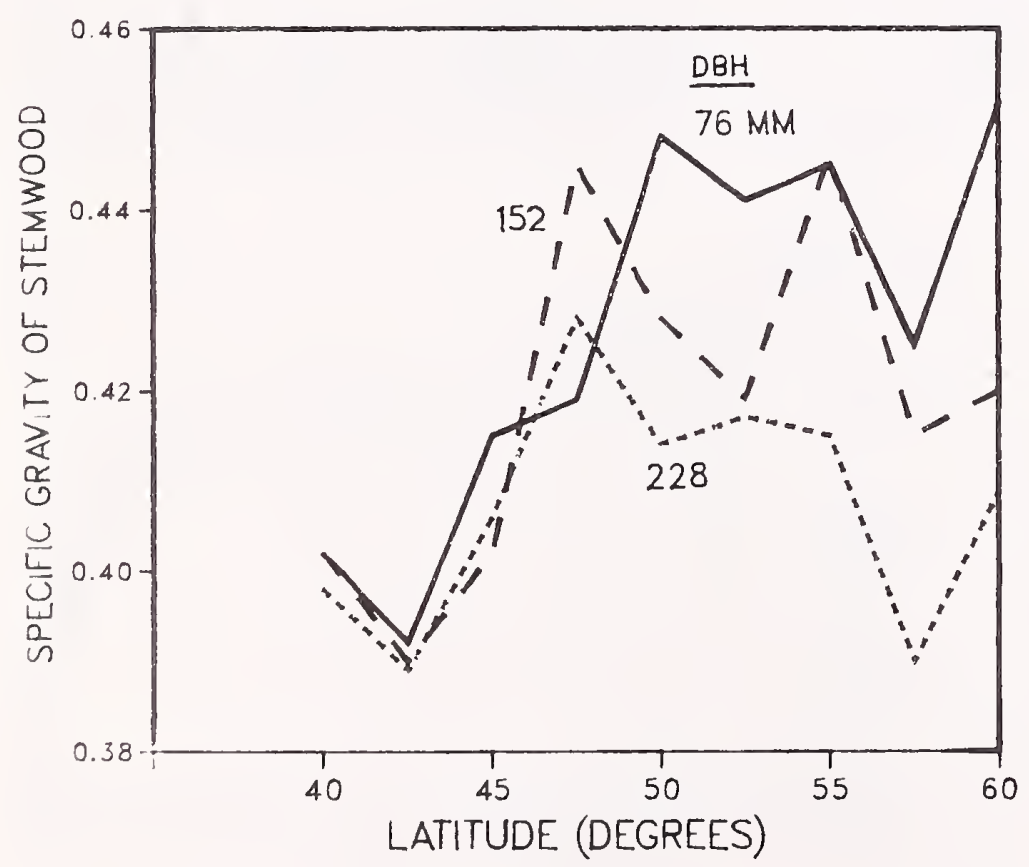

Figure 4-44-Specific gravity of stemwood (152-mm stump height to apical tip), based on ovendry weight and green volume, of latifolia trees of three diameters related to latitude. 


\section{LATIFOLIA}
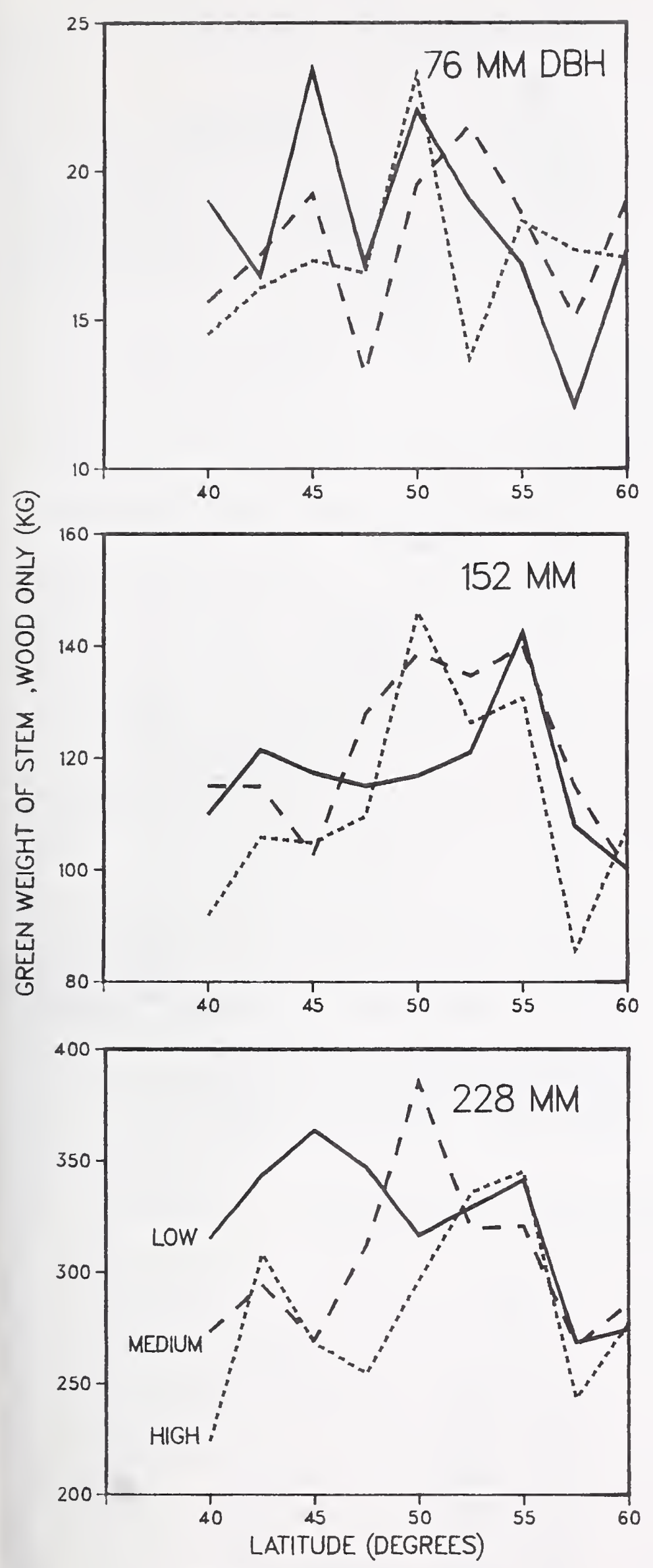

Figure 4-45-Green weight of stemwood from $152-\mathrm{mm}$ stump height to apical tip of latifolia trees of three diameters related to latitude and elevational zone.
LATIFOLIA
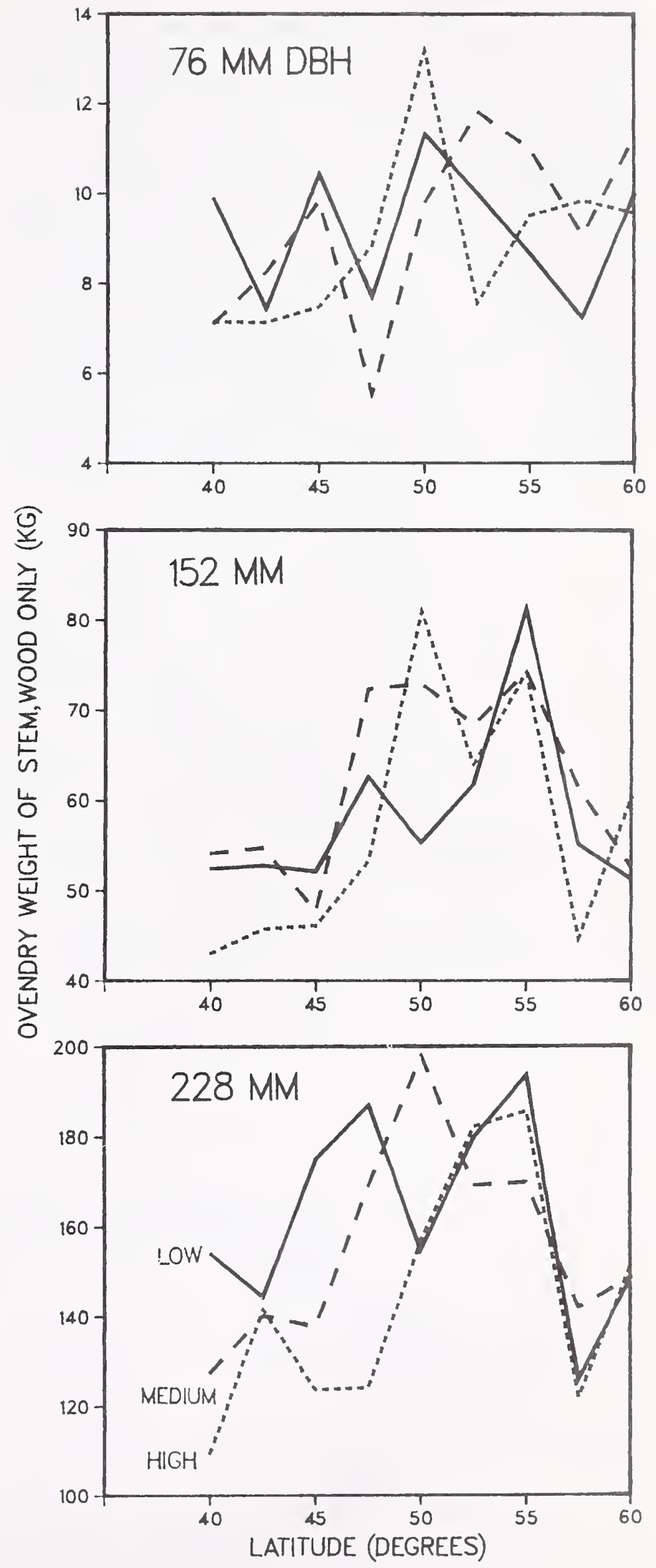

Figure 4-46-Ovendry weight of stemwood from 152-mm stump height to apical tip of latifolia trees of three diameters related to latitude and elevational zone. 


\section{Stemwood-Variation With Height}

Specific Gravity-As previously noted, average stemwood specific gravity can be closely predicted from a stemwood disk taken at 20 percent of tree height. Stemwood specific gravity diminishes curvilinearly from stump top to near the base of the live crown, above which it remains more or less constant-or increases slightly (fig. 4-47, top, and table 4-8). Variation patterns were similar for the three tree diameters studied, but the level of the curves varied significantly with diameter-that is, at all heights small-diameter trees had higher stemwood specific gravity than large trees. At 60 percent of tree height, that is, to just above the base of the live crown, stemwood specific gravity differed little with diameter, however, averaging $0.399,0.395$, and 0.391 for trees 76 , 152, and $228 \mathrm{~mm}$ in d.b.h. (table 4-9).

Stemwood specific gravity relationship to height in tree also differed significantly with latitude (fig. 4-48).
LATIFOLIA

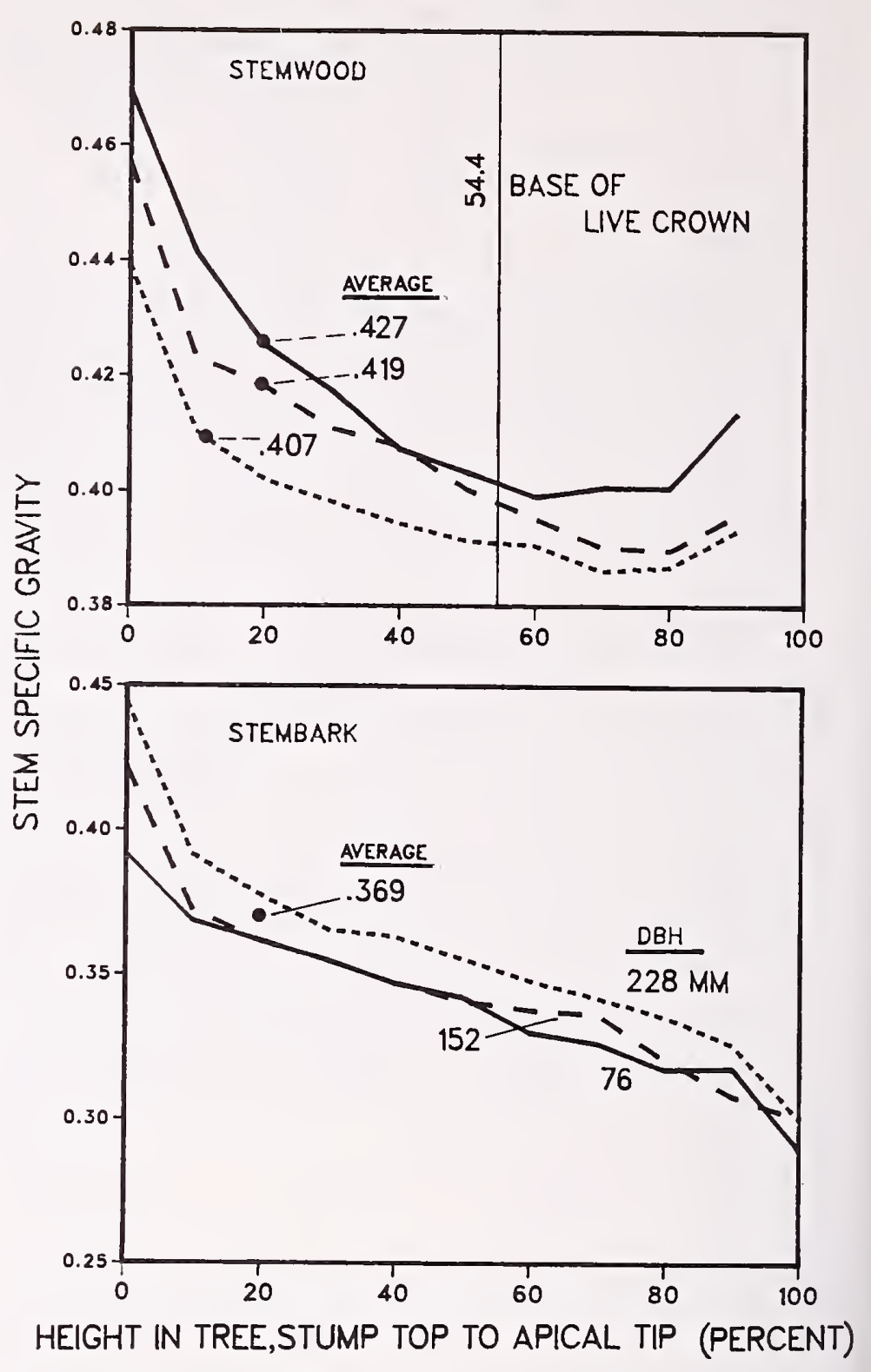

Figure 4-47-Specific gravity of stemwood and stembark (based on ovendry weight and green volume) of latifolia trees of three diameters related to height in tree and base of live crown.

Table 4-8-Latifolia stemwood specific gravities (ovendry weight and green volume) from 152-mm stump height to apical tip at 10 levels in trees of three breast-height diameters $^{1}$

\begin{tabular}{ccccccc}
\hline \multirow{2}{*}{$\begin{array}{c}\text { Percent of stem } \\
\text { height above stump }\end{array}$} & \multicolumn{7}{c}{ Diameter } \\
\cline { 2 - 7 } & $76 \mathrm{~mm}$ & $152 \mathrm{~mm}$ & $228 \mathrm{~mm}$ \\
\hline 0 & 0.469 & $(0.044)$ & 0.457 & $(0.038)$ & $0.439(0.031)$ \\
10 & .441 & $(.041)$ & .423 & $(.032)$ & .410 & $(.031)$ \\
20 & .425 & $(.040)$ & .418 & $(.034)$ & .402 & $(.030)$ \\
30 & .417 & $(.040)$ & .411 & $(.033)$ & .398 & $(.028)$ \\
40 & .407 & $(.041)$ & .408 & $(.033)$ & .394 & $(.029)$ \\
50 & .403 & $(.039)$ & .400 & $(.028)$ & .391 & $(.032)$ \\
60 & .399 & $(.036)$ & .395 & $(.025)$ & .391 & $(.026)$ \\
70 & .401 & $(.040)$ & .390 & $(.026)$ & .386 & $(.027)$ \\
80 & .401 & $(.047)$ & .390 & $(.025)$ & .387 & $(.026)$ \\
90 & .414 & $(.056)$ & .396 & $(.034)$ & .393 & $(.027)$
\end{tabular}

'Latitudinal and elevational data pooled; standard deviations shown in parentheses following average values. Data based on 81 trees of each diameter. 
Table 4-9-Stemwood specific gravities and stemwood diameters at 60 percent of tree height ${ }^{1}$ in latifolia trees of three diameters

\begin{tabular}{rcc}
\hline D.b.h. & Specific gravity & Diameter inside bark \\
\hline$m m$ & & $m m$ \\
76 & $0.399(0.036)$ & $47.7(4.7)$ \\
152 & $.395(.025)$ & $96.1(6.6)$ \\
228 & $.391(.026)$ & $141.4(10.6)$ \\
\hline
\end{tabular}

IIn these latifolia trees, the crown base averages about 55 percent of tree height from 152-mm stump height to apical tip.

2Based on ovendry weight and green volume. The average values are followed by the standard deviation in parentheses.
LATIFOLIA
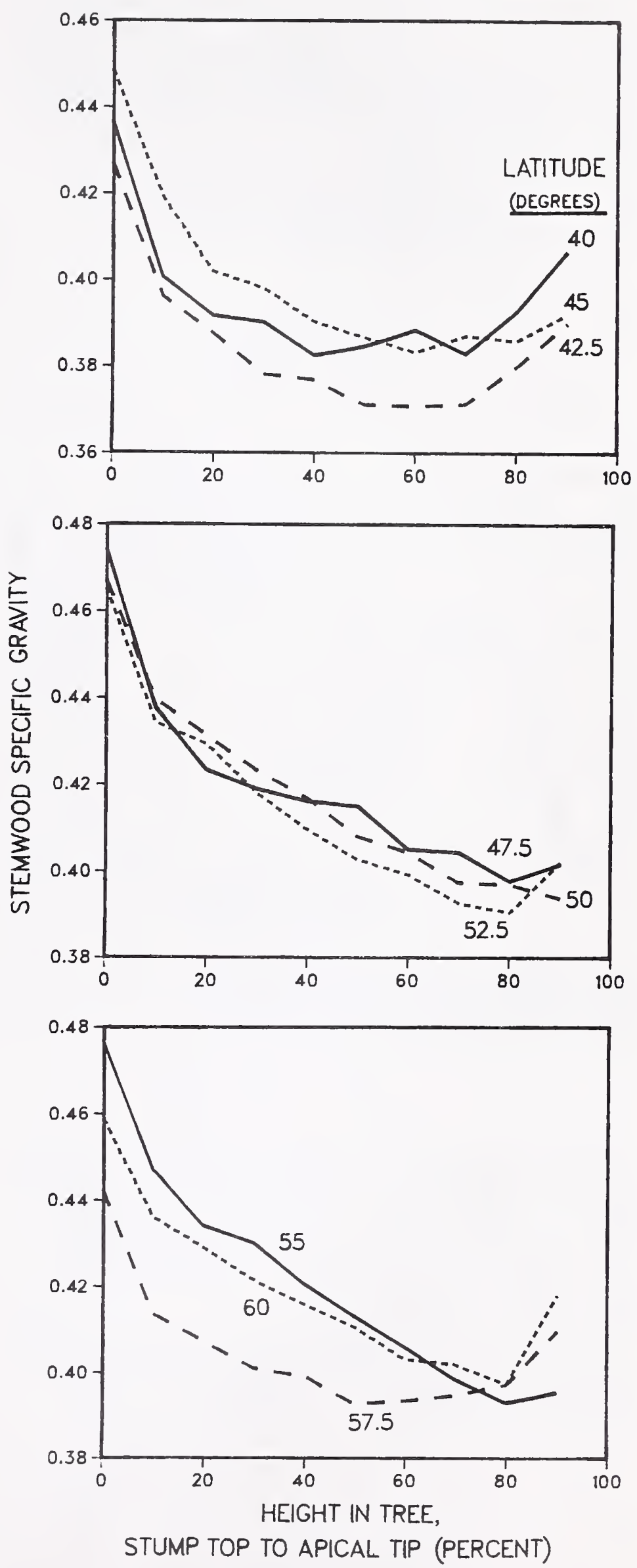

Figure 4-48-Stemwood specific gravity (based on ovendry weight and green volume) of latifolia trees related to height in tree and latitude. 


\section{Stembark-Tree Average}

Specific Gravity-Stembark specific gravity averaged 0.369 , with standard deviation of 0.042 , based on ovendry weight and green volume. It was unrelated to elevational zone, but was positively correlated with d.b.h., averaging $0.356(0.046), 0.367(0.038)$, and $0.383(0.036)$ for trees 76 , 152 , and $228 \mathrm{~mm}$ in d.b.h.

Stembark specific gravity varied significantly with latitude (fig. 4-49); it averaged minimum (0.338) at 45 degrees and maximum (0.403) at 52.5 degrees.

\section{LATIFOLIA}

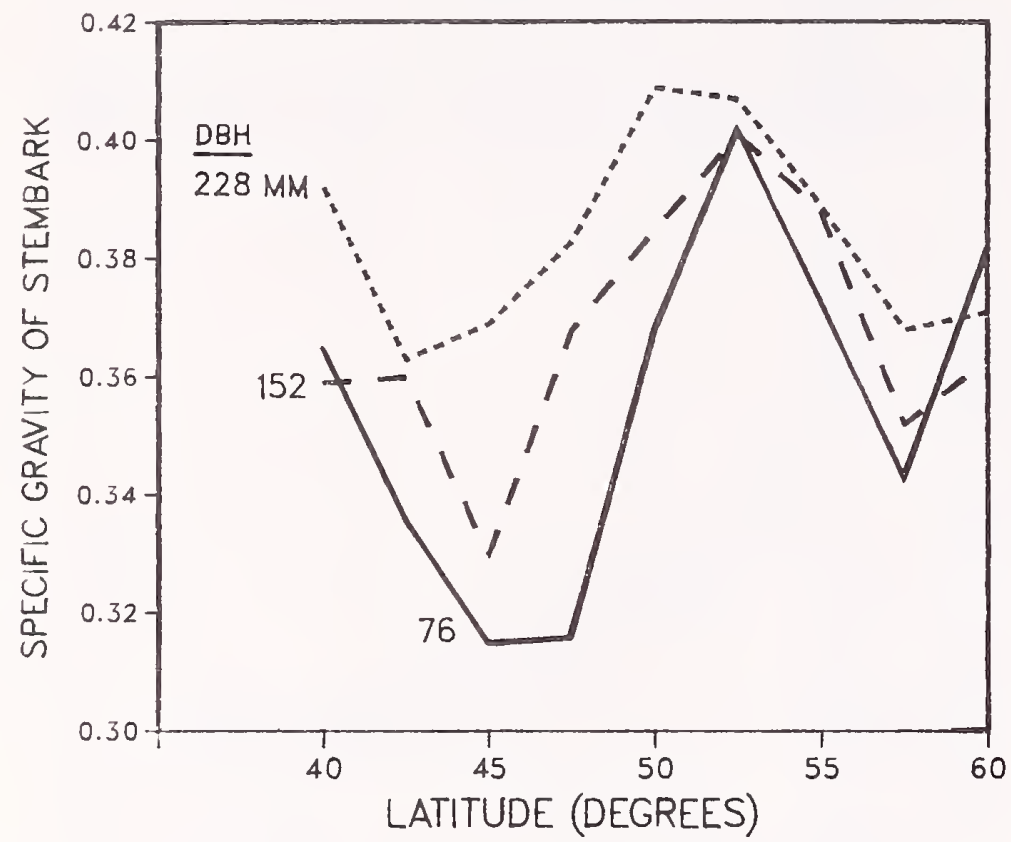

Figure 4-49-Specific gravity of stembark from 152-mm stump height to apical tip (based on ovendry weight and green volume) of latifolia trees of three diameters related to latitude.

Weight, Green-Moisture content of stembark is maximum at about 45 degrees latitude and minimum near 52.5 degrees latitude (fig. 2-18), which yields higher green stembark weights at 45 degrees than ovendry weights would suggest (figs. 4-50 and 4-51). In high-elevation zones, green stembark from larger trees weighed less than that from low zones (fig. 4-50).

Trees 76,152 , and $228 \mathrm{~mm}$ in d.b.h. had green stembark weights averaging $2.71(0.56), 11.87$ (2.62), and 25.83 (5.23) $\mathrm{kg}$, respectively.
LATIFOLIA

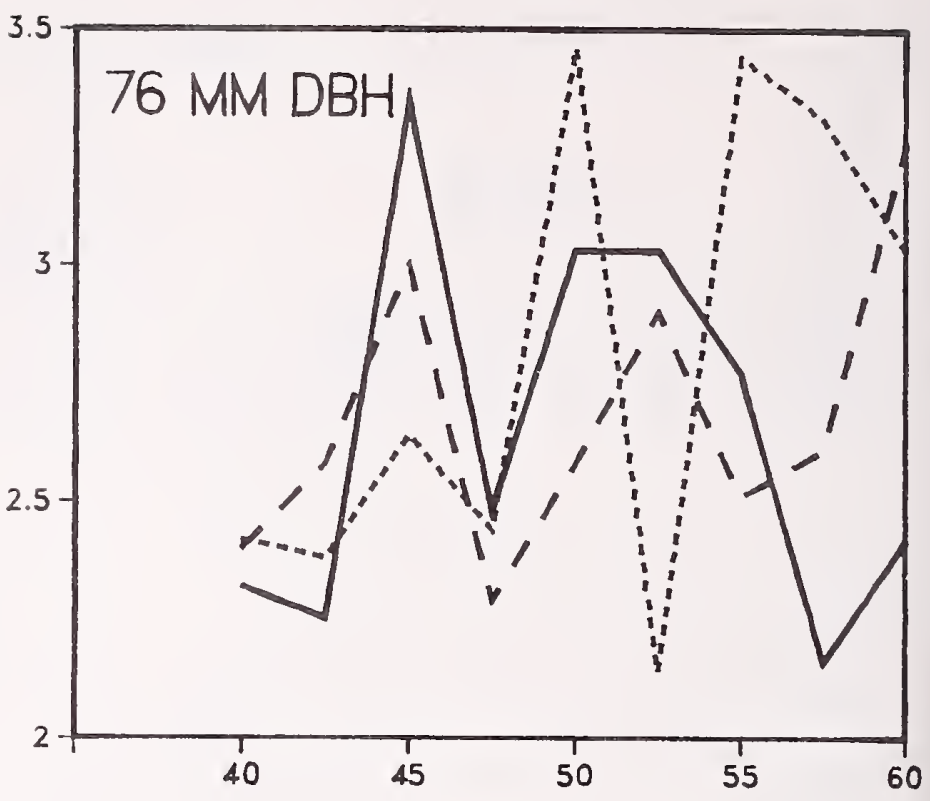

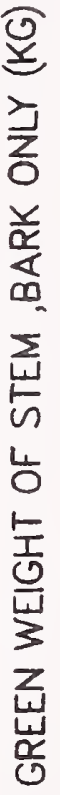
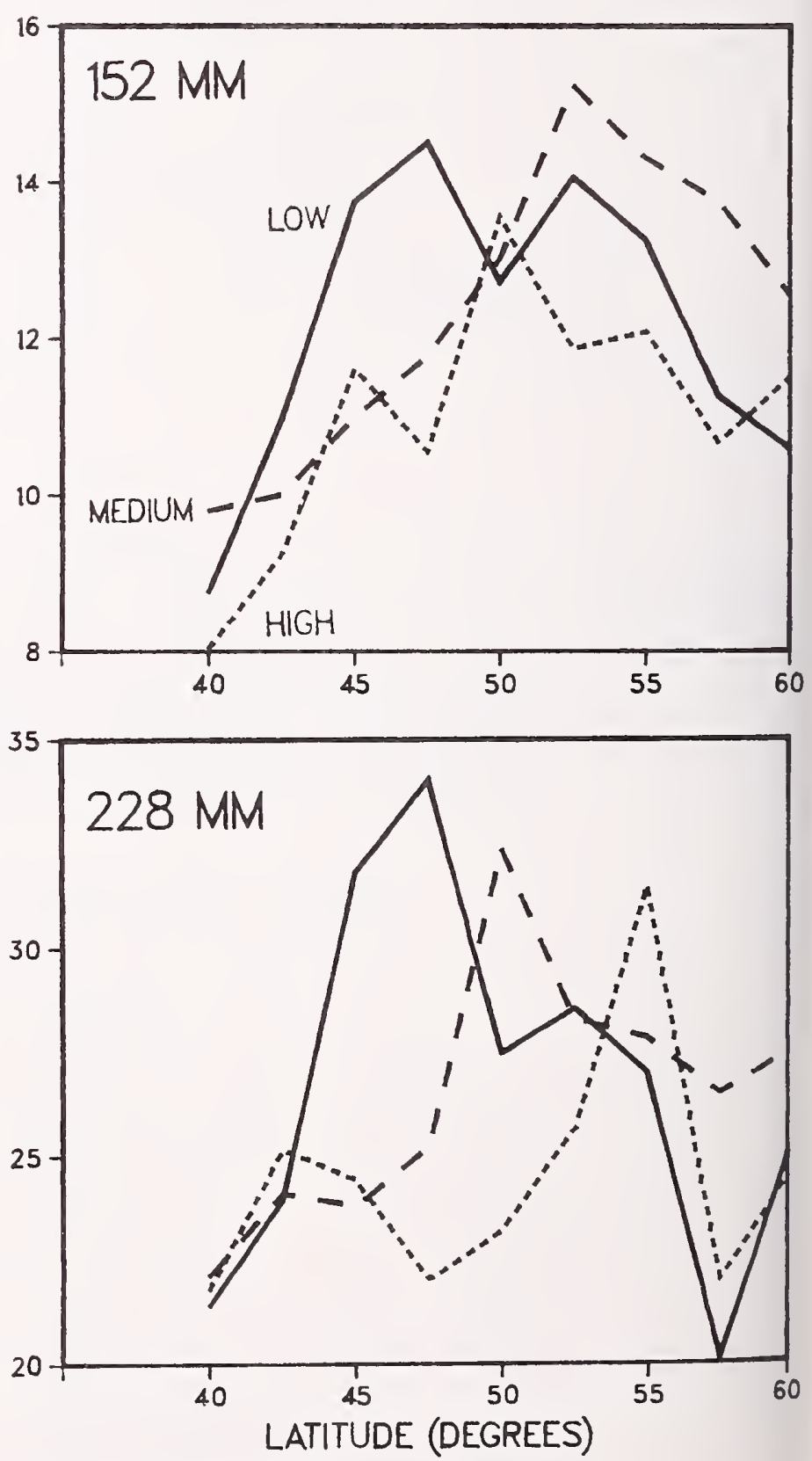

Figure 4-50-Green weight of stembark from 152-mm stump height to apical tip of latifolia trees of three diameters related to latitude and elevational zone. 
Weight, Ovendry-On an ovendry basis, stembark weight averaged $1.27(0.32), 6.02$ (1.66), and 14.03 (3.37) $\mathrm{kg}$ for trees of the three diameter classes. From minimum weights at 40 degrees latitude, ovendry stembark weight increased to maximums in latitudes 47.5 (except for 76-mm trees) through 55 degrees, and then diminished in the two northernmost latitudes (fig. 4-51). In larger trees, stembark from high-elevation zones weighed less than that from low zones (fig. 4-51).

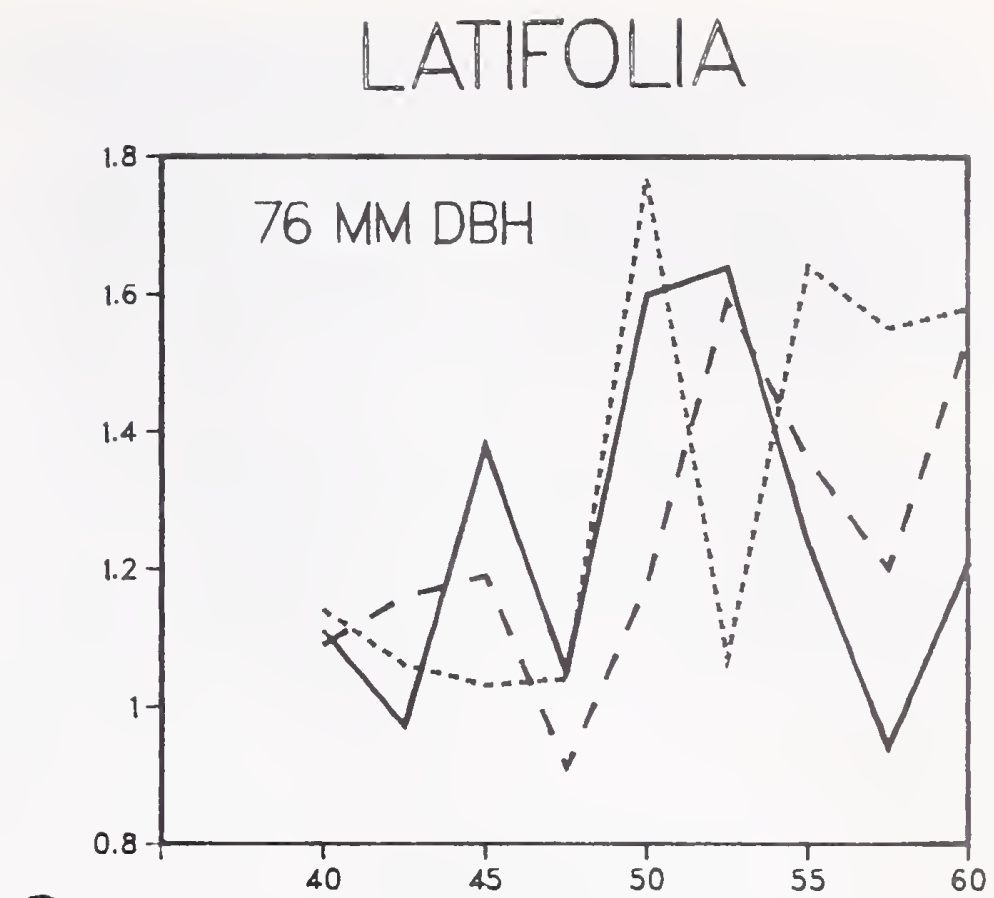

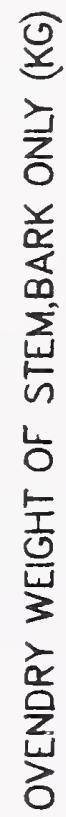
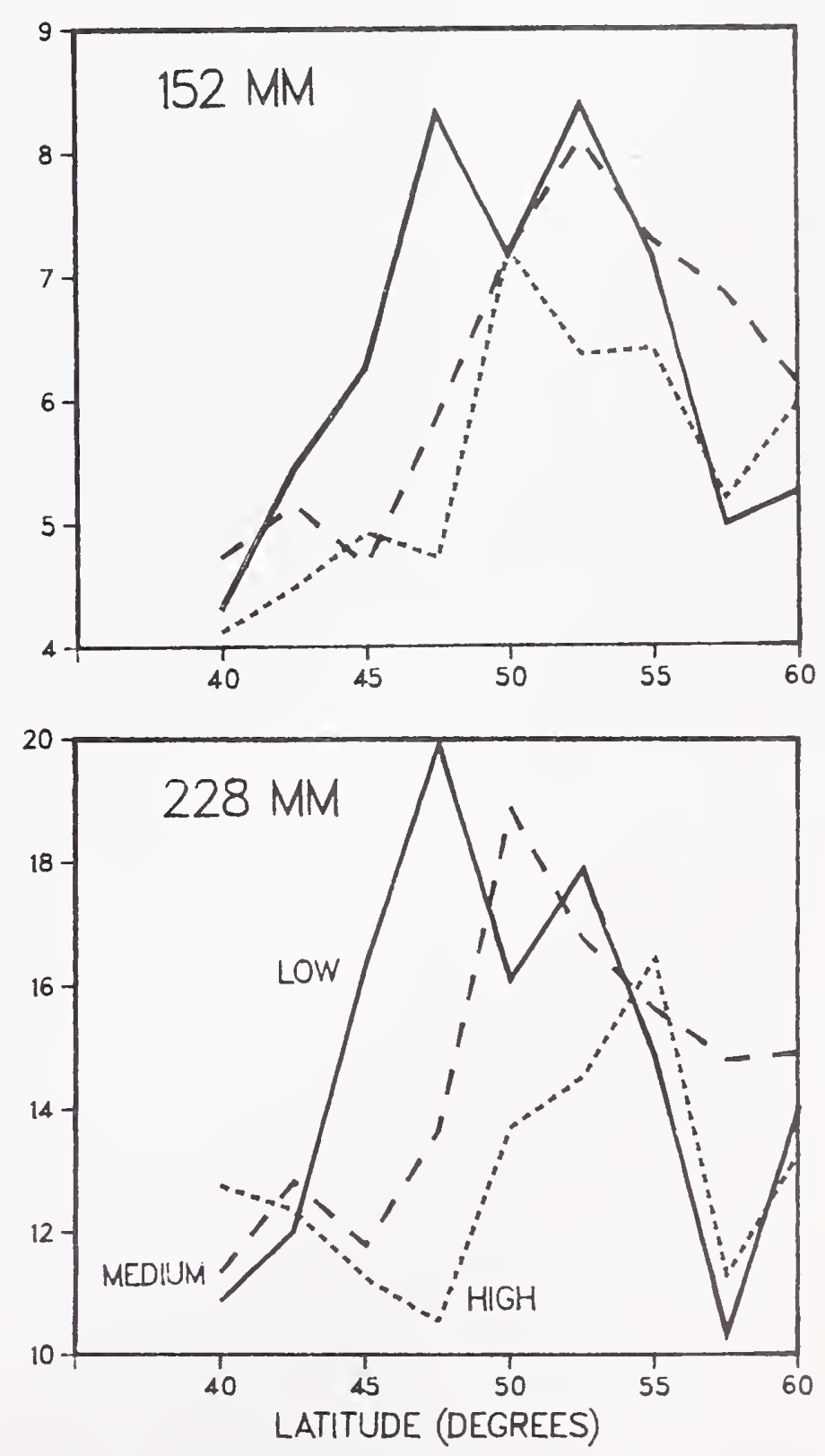

Figure 4-51-Ovendry weight of stembark from 152-mm stump height to apical tip of latifolia trees of three diameters related to latitude and elevational zone. 
Stembark as Percentage of Gross Stem Weight, Green and Ovendry - On green and ovendry bases, stembark averaged 10.25 and 10.06 percent, with standard deviations of 2.85 and 2.49 percentage points, respectively. Stembark percentage had complex relationships with both elevational zones and latitude (figs. 4-52 and 4-53), and was inversely related to d.b.h as follows:

\begin{tabular}{|c|c|c|}
\hline $\begin{array}{l}\text { D.b.h. } \\
\mathrm{mm}\end{array}$ & $\begin{array}{c}\text { Green basis } \\
\ldots \ldots \ldots\end{array}$ & $\begin{array}{l}\text { Ovendry basis } \\
n t \ldots \ldots\end{array}$ \\
\hline 76 & $13.47(1.87)$ & $12.38(1.96)$ \\
\hline 152 & $9.35(1.69)$ & $9.37(2.03)$ \\
\hline 228 & $7.93(1.19)$ & $8.42(1.47)$ \\
\hline
\end{tabular}

LATIFOLIA
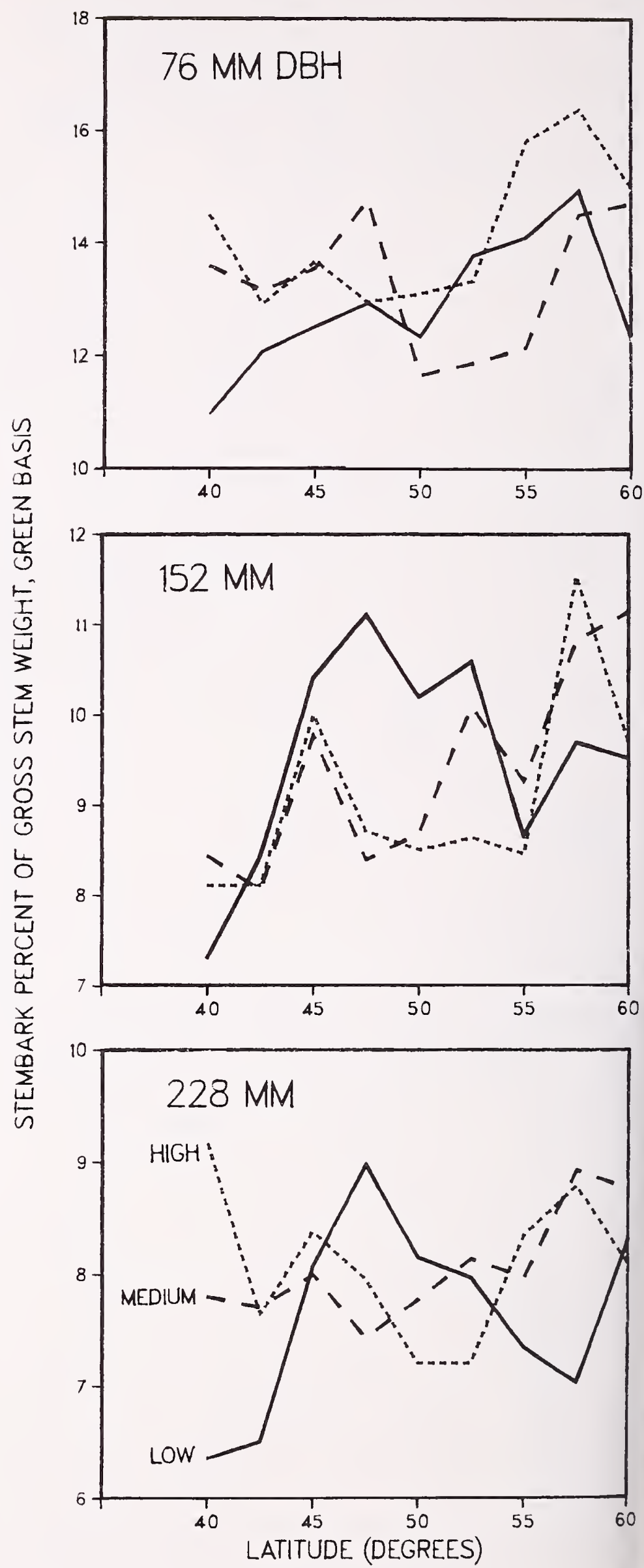

Figure 4-52-Stembark as percentage of gross stem weight (green basis) for latifolia trees of three diameters related to latitude and elevational zone. 
LATIFOLIA
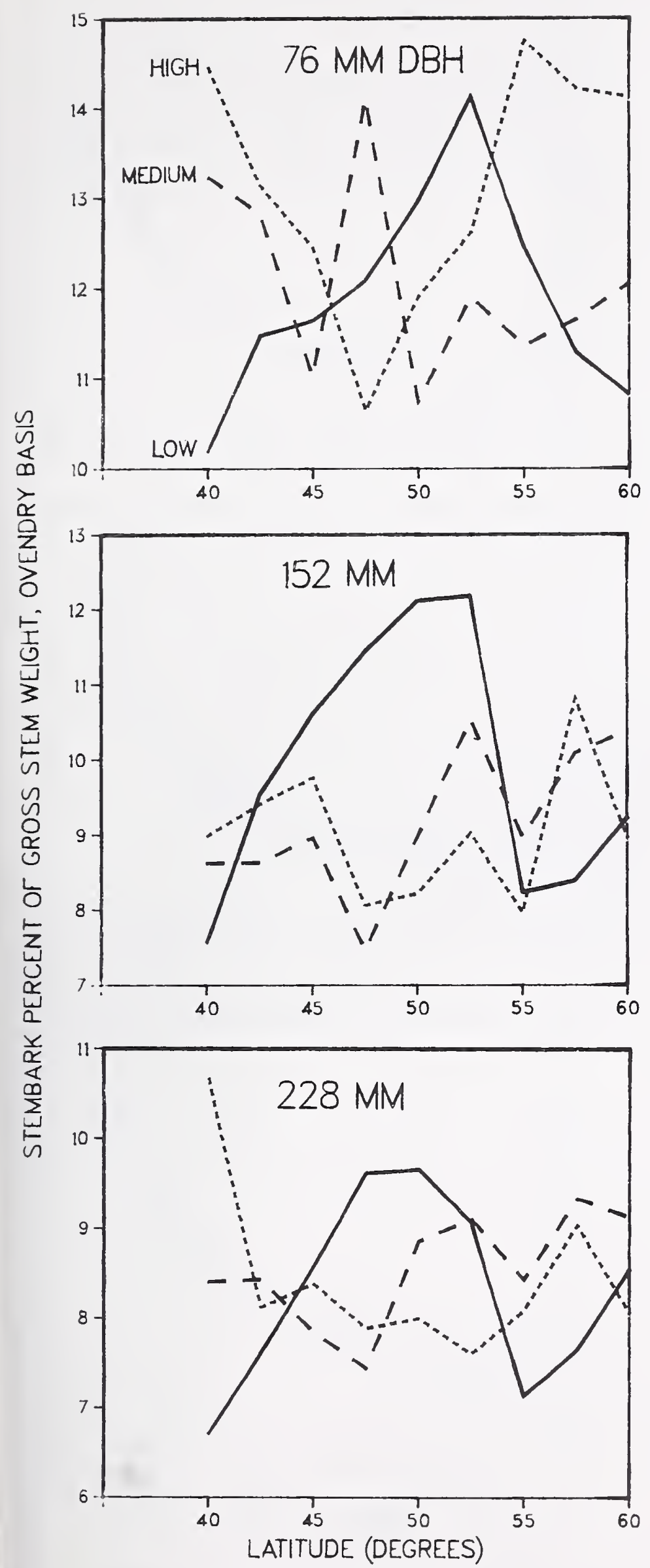

Figure 4-53-Stembark as percentage of gross stem weight (ovendry basis) for latifolia trees of three diameters related to latitude and elevational zone.

\section{Stembark-Variation With Height}

Specific Gravity-Stembark specific gravity diminishes curvilinearly in an ogee pattern from about 0.42 at stump height to about 0.30 near the apical tip (fig. 4-47, bottom). In contrast to stemwood of trees of the three diameters, stembark specific gravity was greater at all heights in $228-\mathrm{mm}$ trees than in trees of the two smaller diameter classes.

Weight Percentage, Green-Stembark weight as a percentage of green stem sections decreases from stump level to a minimum at about 10 percent of tree height and then increases sharply up the stem to a maximum at the apical tip (fig. 4-54, left). At all heights in the stem, stembark weight percentage is inversely correlated with tree d.b.h.
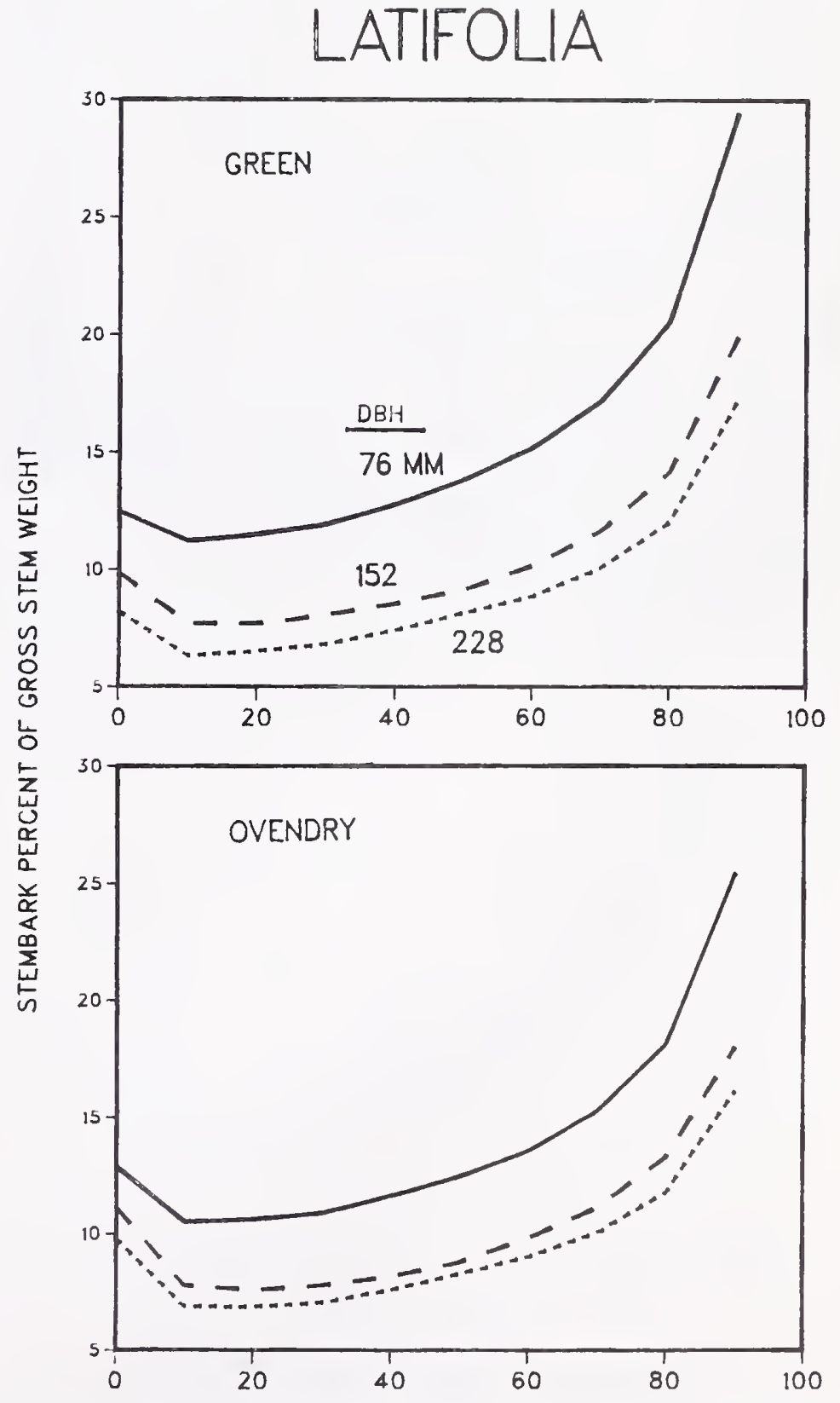

HEIGHT IN TREE,STUMP TOP TO APICAL TIP (PERCENT)

Figure 4-54-Stembark as percentage of gross stem weight, green and ovendry, for latifolia trees of three diameters related to height in tree. 
On a green-weight basis, stembark from trees in lowelevation zones comprised a lower percentage of stem weight at all heights in the tree (except stump height) than stembark from trees in medium- or high-elevation zones (fig. 4-55).

Also, height variation patterns of stembark weight as percentage of gross green stem weight varied with latitude (fig. 4-56).

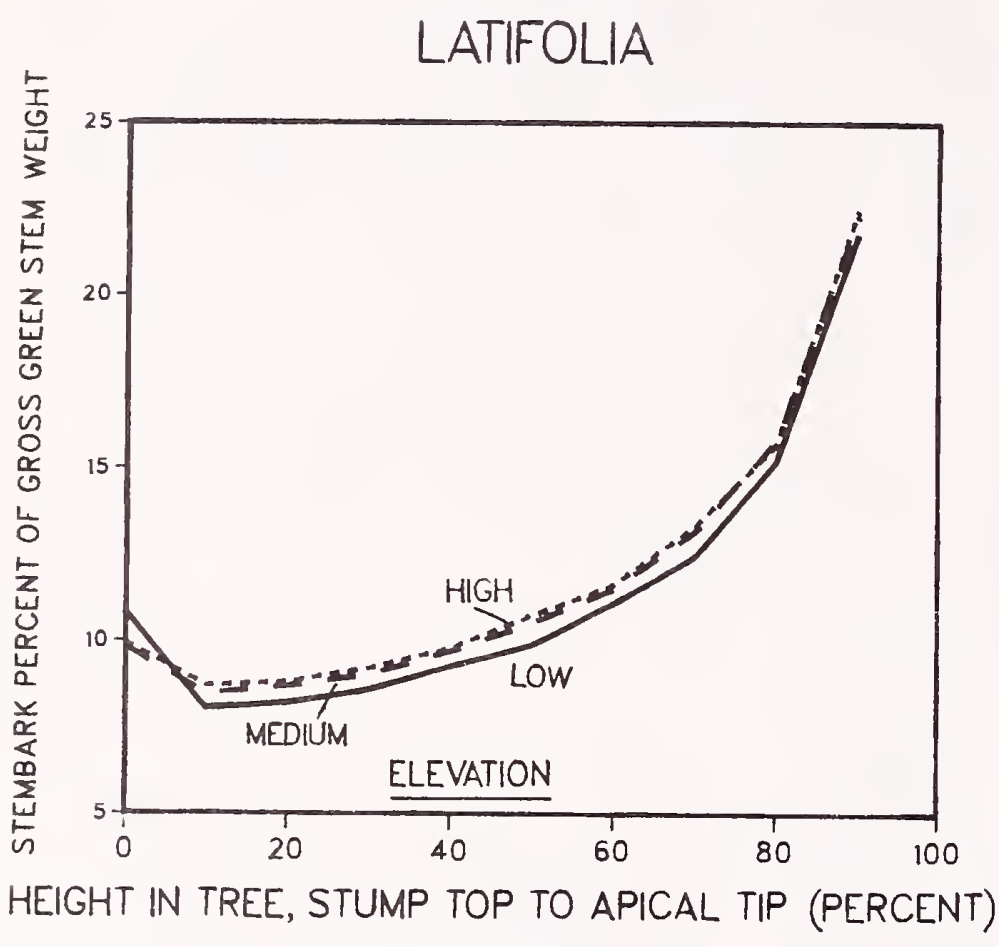

Figure 4-55-Stembark as percentage of gross green stem weight of latifolia trees related to height in tree and elevational zone.
LATIFOLIA
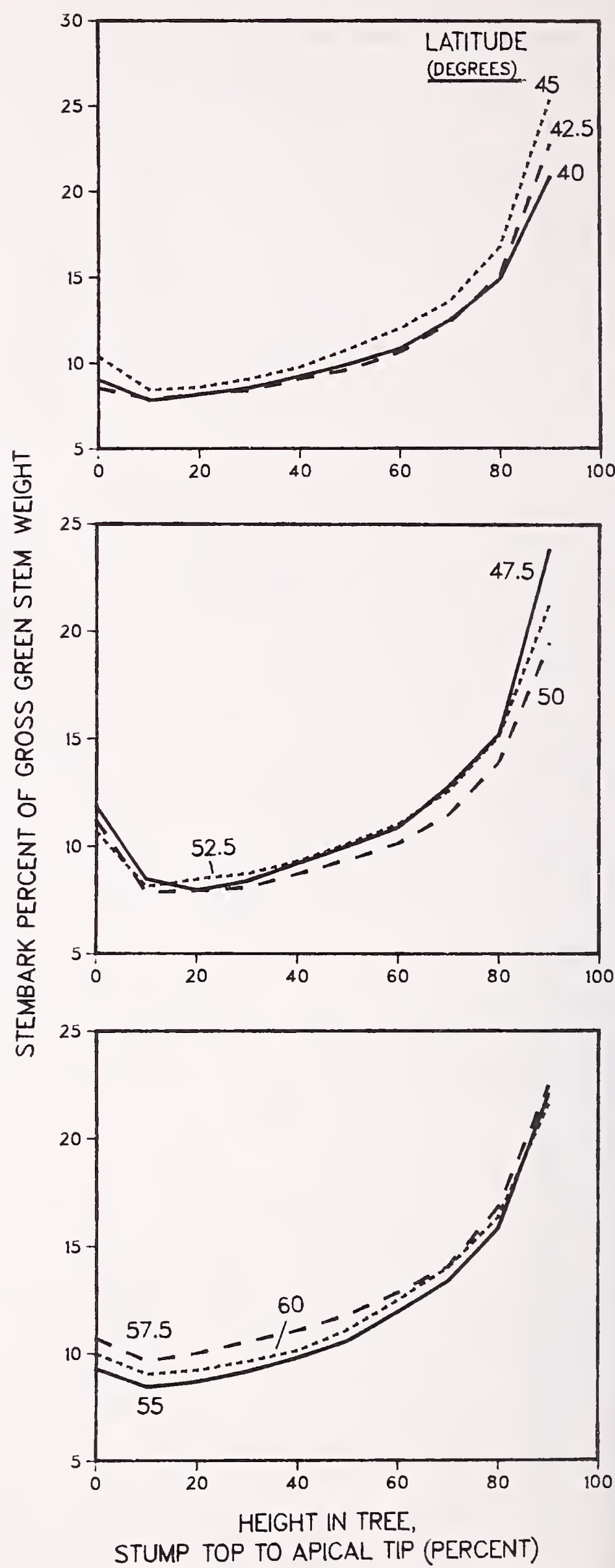

Figure 4-56-Stembark as percentage of gross green stem weight of latifolia trees related to height in tree and latitude. 
Weight Percentage, Ovendry-On an ovendry-weight basis, stembark weight percentage of stem sections also decreases from stump height to a minimum value at 10 or 20 percent of tree height and then increases curvilinearly up the stem to a maximum at the apical tip (fig. 4-54, right). At all heights, small-diameter trees have a higher weight percentage of stembark than large trees.

Height variation patterns of stembark weight as percentage of gross ovendry stem weight varied with latitude (fig. 4-57).

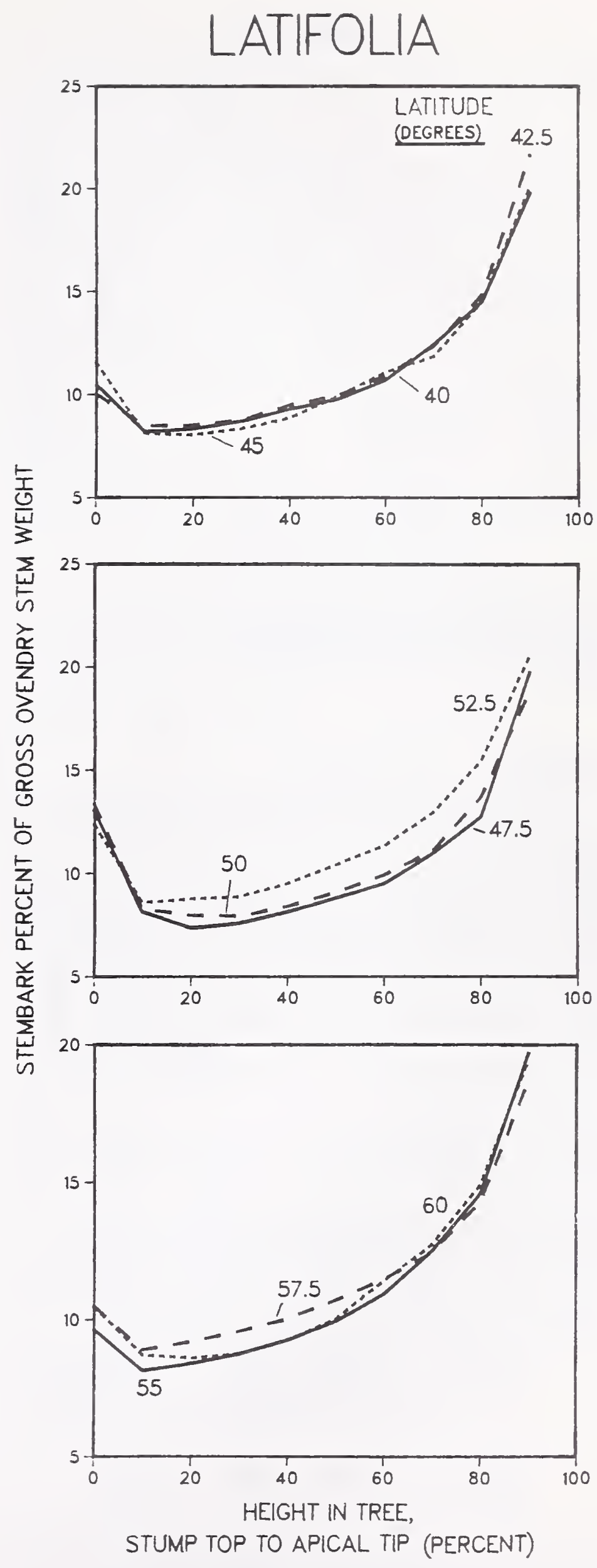

Figure 4-57-Stembark as percentage of gross ovendry stem weight of latifolia trees related to height in tree and latitude. 
LATIFOLIA

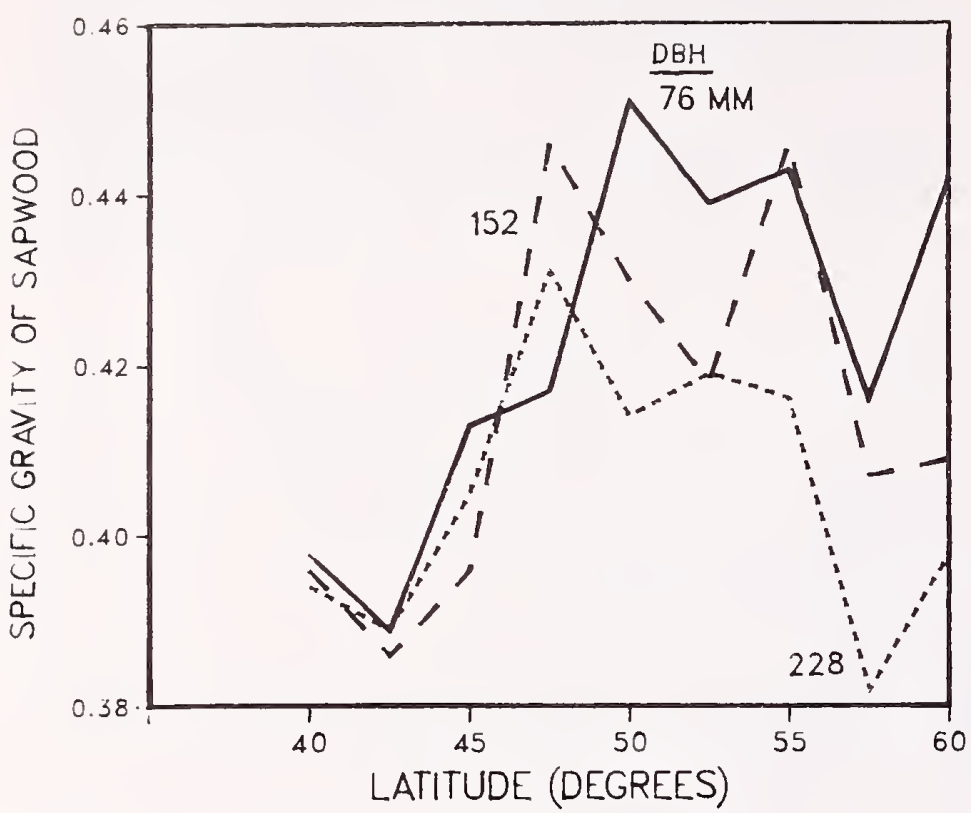

Figure 4-58-Specific gravity of sapwood (based on ovendry weight and green volume) for latifolia trees of three diameters related to latitude.

\section{Sapwood}

For additional information on sapwood characteristics see chapter 5 .

Specific Gravity-Sapwood specific gravity in the entire stem (ovendry weight and green-volume basis) was less than that of heartwood, averaging 0.414 , with standard deviation of 0.034 . Like whole stemwood specific gravity, it was negatively correlated with d.b.h., averaging 0.423 $(0.039), 0.415(0.032)$, and $0.405(0.030)$ for trees 76,152 , and $228 \mathrm{~mm}$ in d.b.h.; diameter-related differences were more pronounced in northern than in southern latitudes (fig. 4-58).

Sapwood specific gravity averaged maximum $(0.425$ to $0.435)$ at middle latitudes of 47.5 through 55 degrees and minimum (0.396) at 40 degrees (fig. 4-58).

Weight, Green-Sapwood green weight was positively correlated with d.b.h. (fig. 4-59), averaging 14.37 (4.27), $91.34(23.70)$, and $226.16(60.87) \mathrm{kg}$ for trees of the three diameter classes. It was negatively correlated with elevational zone, particularly in 228-mm trees, as follows:

\begin{tabular}{|c|c|c|c|}
\hline $\begin{array}{l}\text { Elevational } \\
\text { zone }\end{array}$ & $\begin{array}{l}76 \mathrm{~mm} \\
\text { d.b.h. }\end{array}$ & $\begin{array}{c}152 \mathrm{~mm} \\
\text { d.b.h. }\end{array}$ & $\begin{array}{c}228 \mathrm{~mm} \\
\text { d.b.h. }\end{array}$ \\
\hline & \multicolumn{3}{|c|}{-... Kilograms - } \\
\hline Low & 15.19 & 94.82 & 248.38 \\
\hline Medi & 14.39 & 94.61 & 221.86 \\
\hline High & 13.53 & 84.60 & 208.23 \\
\hline
\end{tabular}

Sapwood green weight was also negatively correlated with latitude, diminishing slightly in northern latitudes (fig. 4-59).

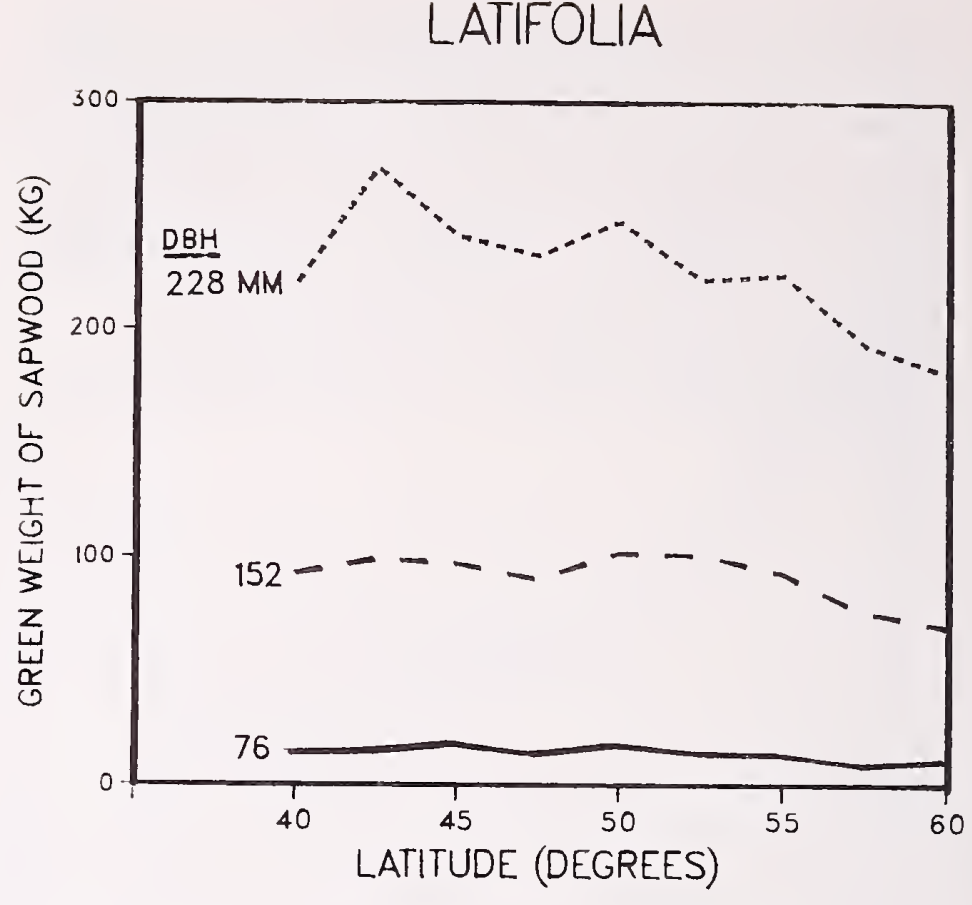

Figure 4-59-Green weight of sapwood in stems from 152-mm stump height to apical tip in latifolia trees of three diameters related to latitude.

Weight, Ovendry-Ovendry sapwood weight was also positively correlated with d.b.h., averaging $6.89(2.00)$, 41.45 (10.78), and 99.81 (24.88) $\mathrm{kg}$ for trees 76,152 , and $228 \mathrm{~mm}$ in d.b.h. In 228-mm trees, ovendry sapwood weight was negatively correlated with elevational zone, averaging $109.91,98.13$, and $91.40 \mathrm{~kg}$ in low, medium, and high zones, respectively.

As with green sapwood weight, ovendry weight had a slight negative correlation with latitude (fig. 4-60).
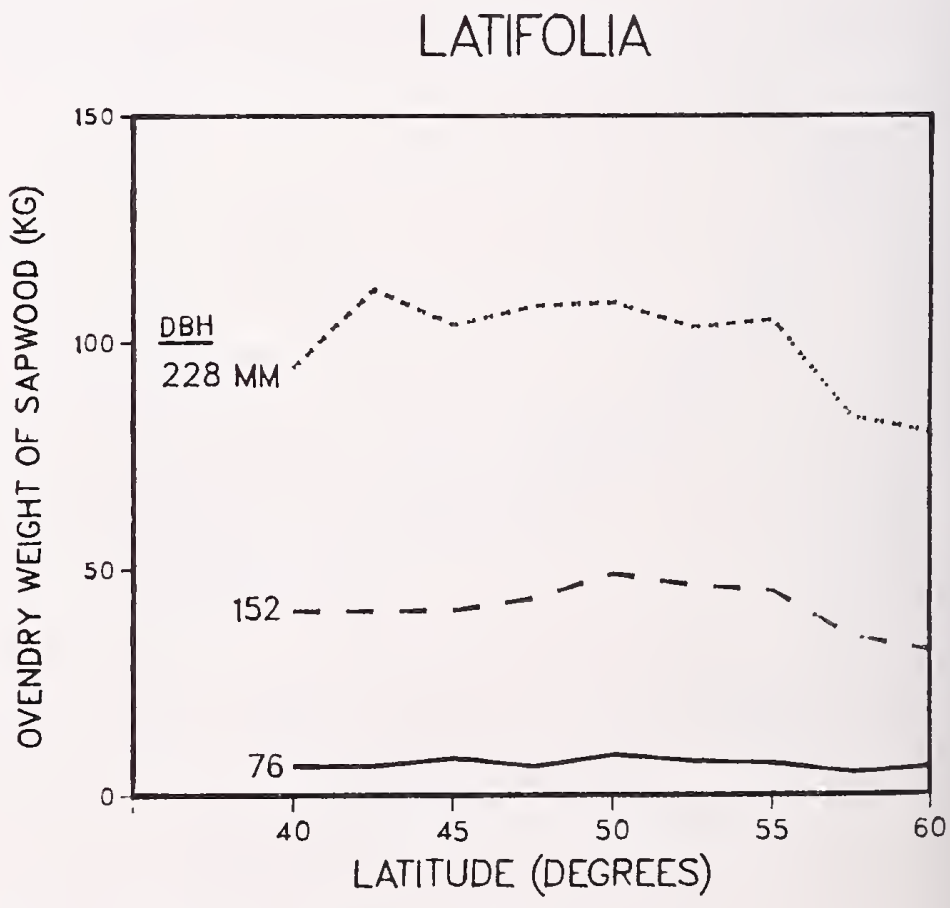

Figure 4-60-Ovendry weight of sapwood in stems from 152-mm stump height to apical tip in latifolia trees of three diameters related to latitude. 


\section{Heartwood}

For heartwood information additional to that in the following paragraphs, see chapter 5.

Specific Gravity-Heartwood specific gravity in the entire stem averaged 0.434 , with standard deviation of 0.034 , based on ovendry weight and green volume. It was unrelated to elevational zone and latitude, but was negatively correlated with d.b.h., averaging 0.459 (0.038), $0.430(0.022)$, and $0.412(0.022)$ for trees 76,152 , and $228 \mathrm{~mm}$ in d.b.h.

Weight, Green-Weight of green heartwood was positively correlated with d.b.h. (fig. 4-61), averaging 3.26 (2.51), 25.28 (16.15), and $76.85(37.92) \mathrm{kg}$ for trees 76 , 152 , and $228 \mathrm{~mm}$ in d.b.h. It was generally also positively correlated with elevational zone, averaging as follows for trees of the three diameters:

$\begin{array}{lccc}\begin{array}{c}\text { Elevational } \\ \text { zone }\end{array} & \mathbf{7 6} \mathbf{~ m m} & \mathbf{1 5 2} \mathbf{~ m m} & \mathbf{2 2 8} \mathbf{~ m m} \\ & \ldots \ldots & \text { Kilograms } & \ldots \ldots \\ \text { Low } & 2.94 & 22.02 & 73.74 \\ \text { Medium } & 3.28 & 26.34 & 81.32 \\ \text { High } & 3.56 & 27.46 & 75.50\end{array}$

Green heartwood weight was also positively correlated with latitude, with the relationship most pronounced in large trees (fig. 4-61).

Weight, Ovendry-As with green weight, ovendry heartwood weight was positively correlated with d.b.h. (fig. 4-62), averaging 2.25 (1.78), 17.86 (11.34), and 54.27 (26.23) $\mathrm{kg}$ for trees of the three diameter classes. It was also generally positively correlated with elevational zone, averaging as follows for trees of the three diameters:

$\begin{array}{lccc}\begin{array}{c}\text { Elevational } \\ \text { zone }\end{array} & \mathbf{7 6} \mathbf{m m} & \mathbf{1 5 2} \mathbf{m m} & \mathbf{2 2 8} \mathbf{~ m m} \\ & \ldots \ldots & \text { Kilograms } & \ldots . . \\ \text { Low } & 2.02 & 15.83 & 52.61 \\ \text { Medium } & 2.29 & 18.65 & 57.59 \\ \text { High } & 2.46 & 19.09 & 52.61\end{array}$

As with green heartwood, weight of ovendry heartwood was positively correlated with latitude; the relationship was most pronounced in trees of large diameter (fig. 4-62).

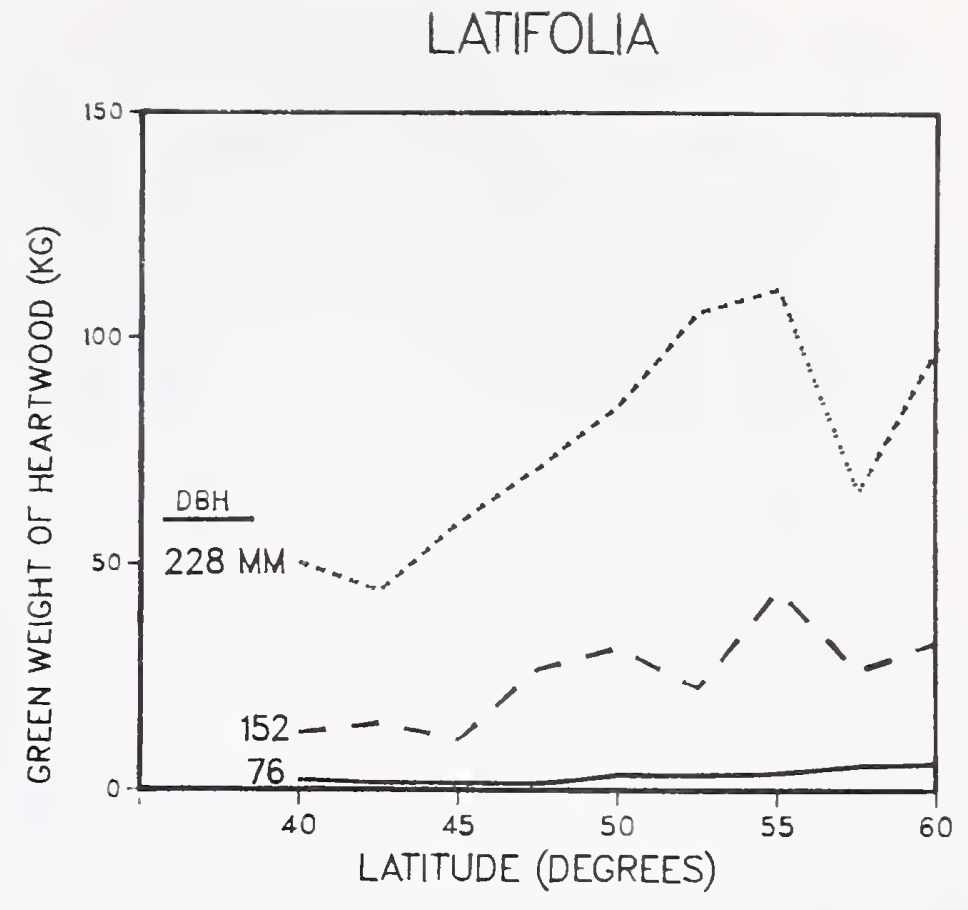

Figure 4-61-Green weight of heartwood in stems from 152-mm stump height to apical tip in latifolia trees of three diameters related to latitude.

\section{LATIFOLIA}

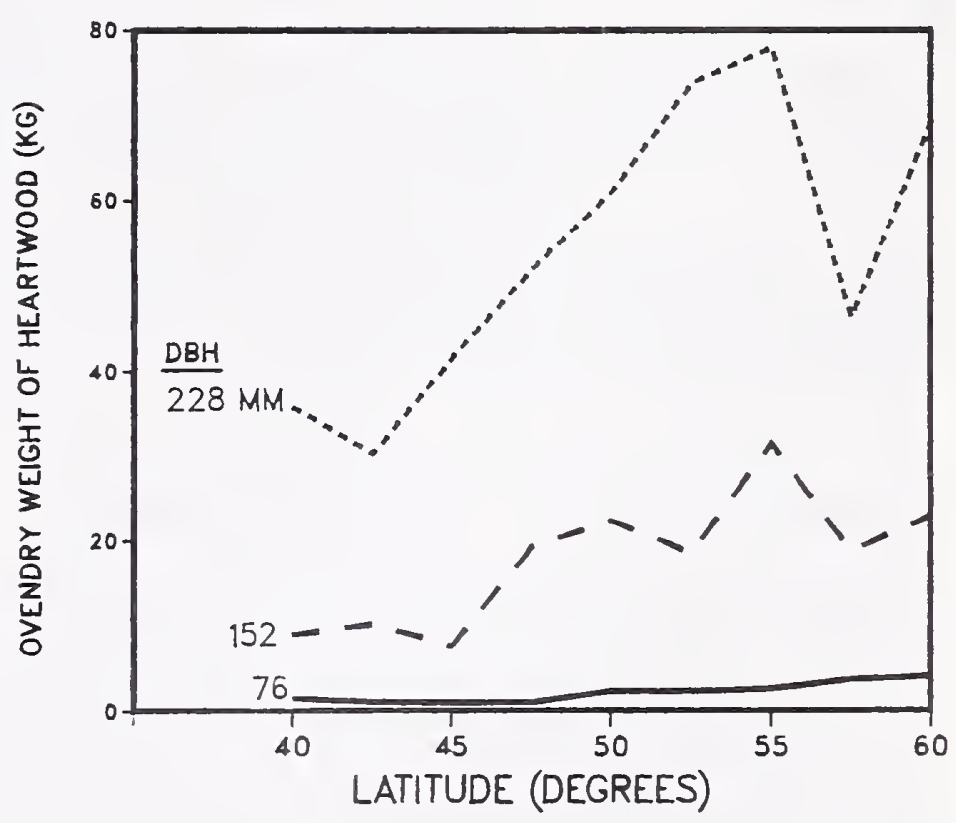

Figure 4-62-Ovendry weight of heartwood in stems from 152-mm stump height to apical tip in latifolia trees of three diameters related to latitude. 
Ovendry Weight as Percentage of StemwoodHeartwood ovendry weight as percentage of stemwood was positively correlated with d.b.h. (fig. 4-63), averaging 22.63 (16.29), 28.78 (15.31), and 34.58 (13.39) percent for trees 76,152 , and $228 \mathrm{~mm}$ in d.b.h. It was also positively correlated with latitude, averaging (with diameter data pooled) minimum (18.01 percent) at 42.5 degrees and maximum (43.00 percent) at 60 degrees (fig. 4-63). For all trees studied, it averaged 28.67 percent, with standard deviation of 15.76 percent.

\section{LATIFOLIA}

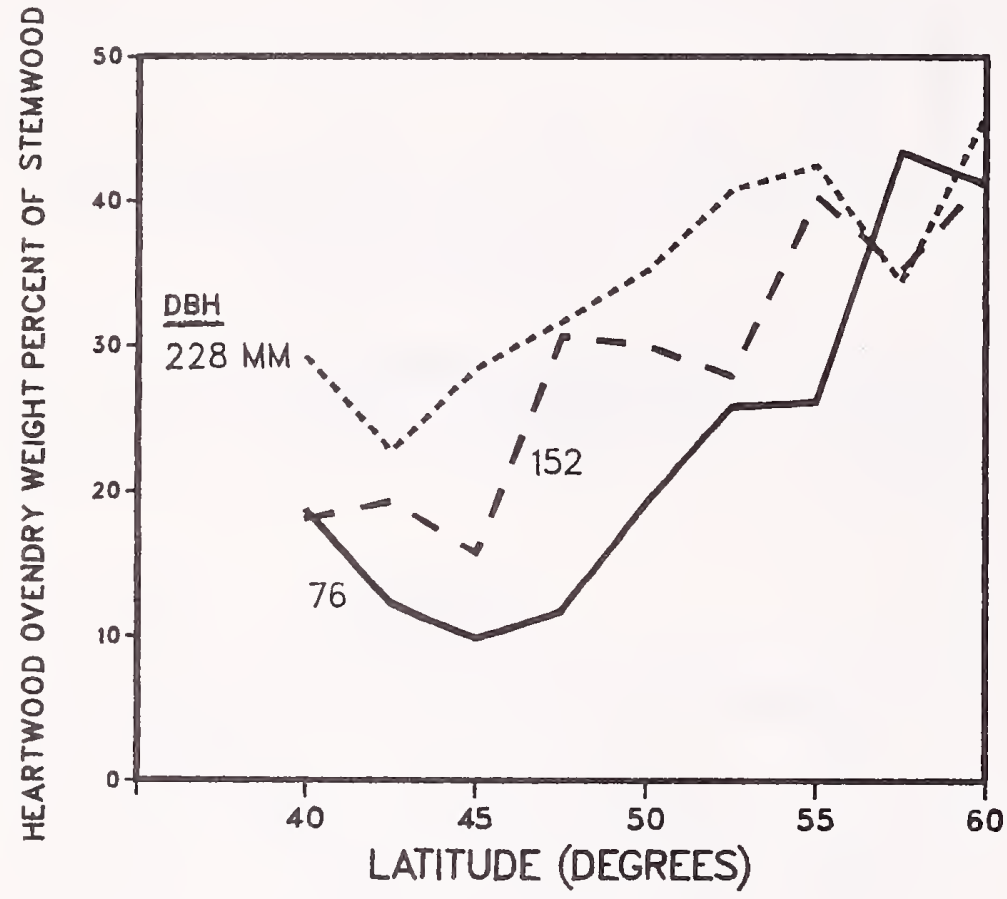

Figure 4-63-Heartwood ovendry weight as percentage of stemwood in latifolia trees of three diameters related to latitude.

\section{Stump-Root System, Wood Plus Bark}

Specific Gravity-Specific gravity-based on ovendry weight and green volume-of the stump-root system (wood plus bark) is higher than that of stem or branches (table 4 -2), averaging 0.461 , with standard deviation of 0.043 . It increases from a minimum (0.43) at 42.5 degrees to maximums ( 0.47 to 0.49 ) from 47.5 through 55 degrees, but is poorly correlated with elevational zone or tree d.b.h. (fig. 4-64).
LATIFOLIA
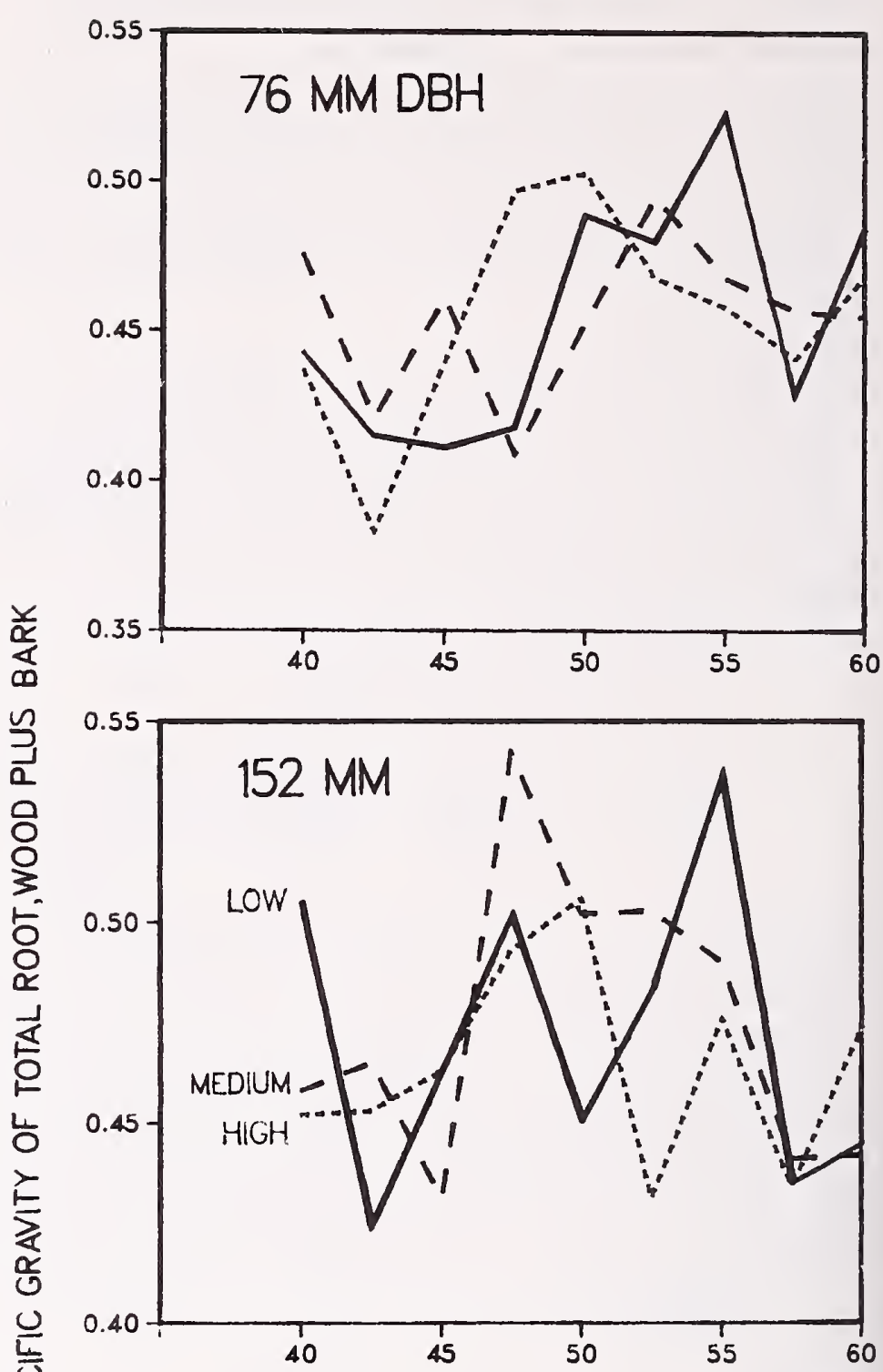

禽

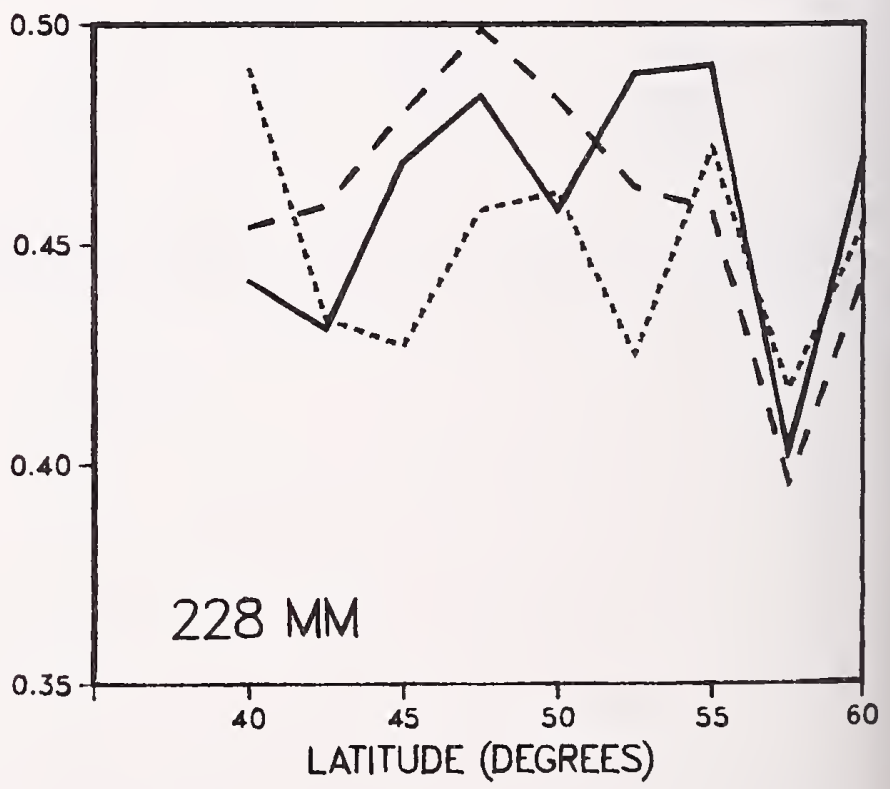

Figure 4-64-Specific gravity of the stump-root system (wood plus bark of stump to $152-\mathrm{mm}$ height, central root mass-taproot, and lateral roots to a radius of $305 \mathrm{~mm}$ from stump pith) based on ovendry weight and green volume of latifolia trees of three diameters related to latitude and elevational zone. 
Weight, Green-Green weight of the stump-root system, wood plus bark, including 152 -mm-high stump, lateral roots to a $305-\mathrm{mm}$ radius from stump pith, and the recovered portion of the taproot was positively correlated with d.b.h., averaging $3.82(0.89), 18.86$ (3.14), and 43.22 (6.84) $\mathrm{kg}$ for trees 76,152 , and $228 \mathrm{~mm}$ in d.b.h. There was no pronounced latitudinal trend in this green weight, but stump-root systems from high-elevation zones tended to weigh less than those from low zones (fig. 4-65), averaging $22.87,22.07$, and $20.95 \mathrm{~kg}$ for low, medium, and high zones (diameter data pooled).
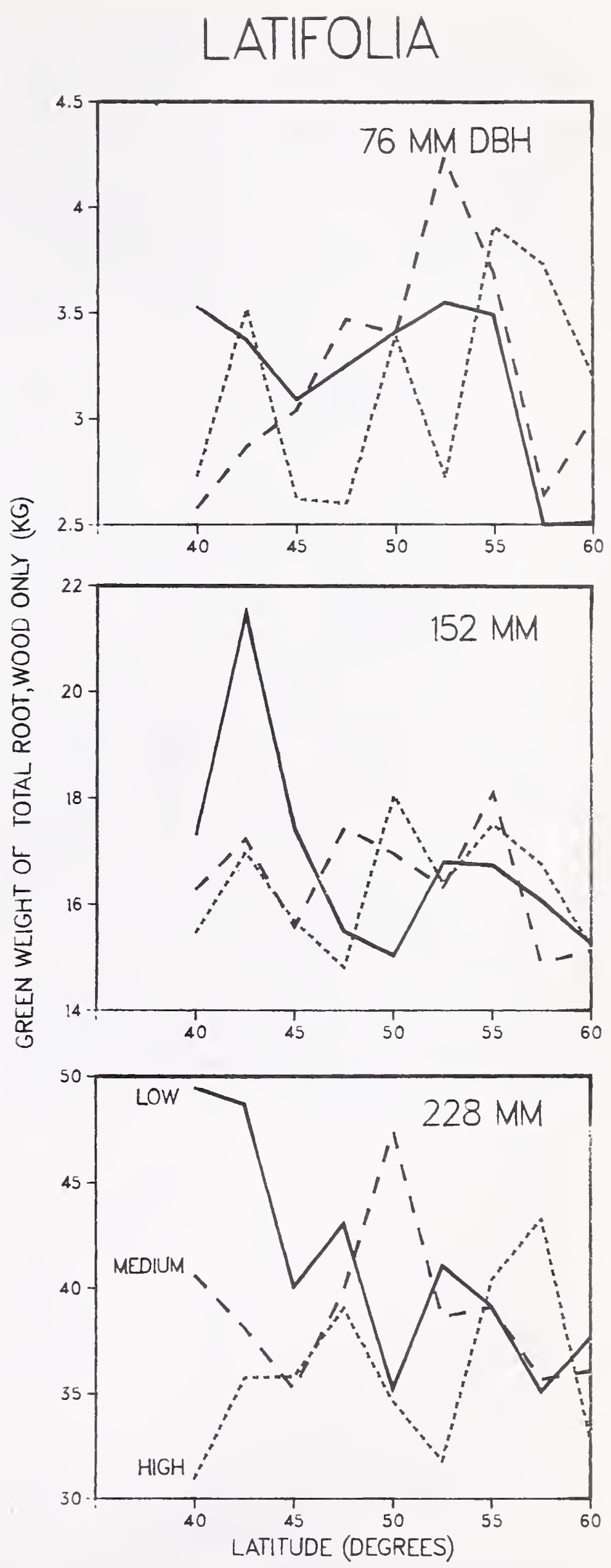

Figure 4-65-Green weight of stump-root systems, wood plus bark, of latifolia trees of three diameters related to latitude and elevational zone. 
LATIFOLIA

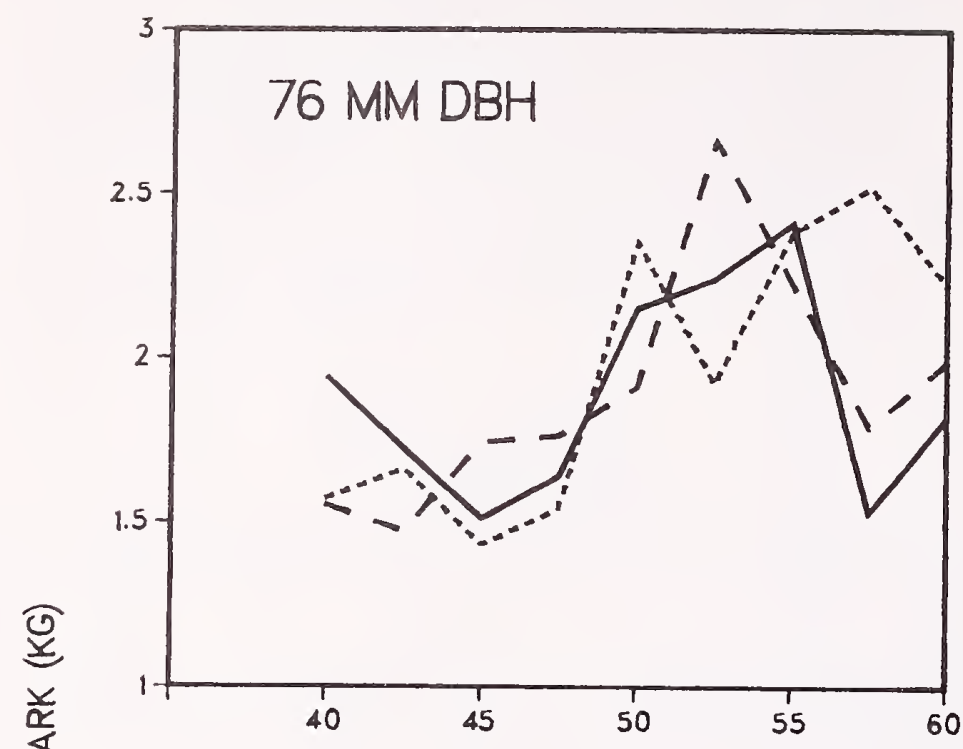

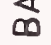

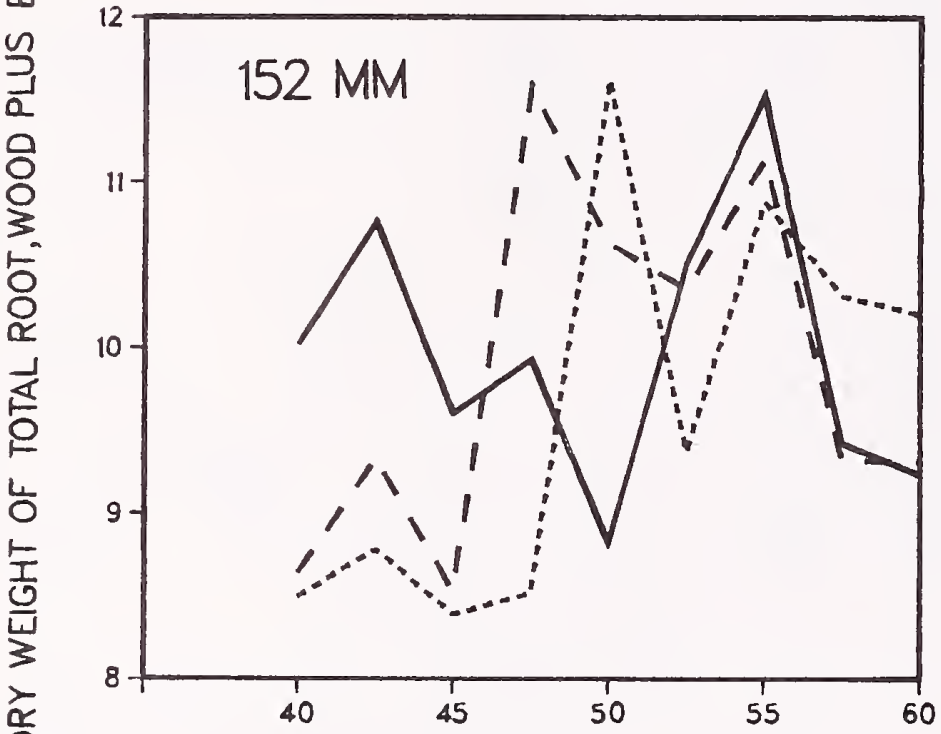

峲

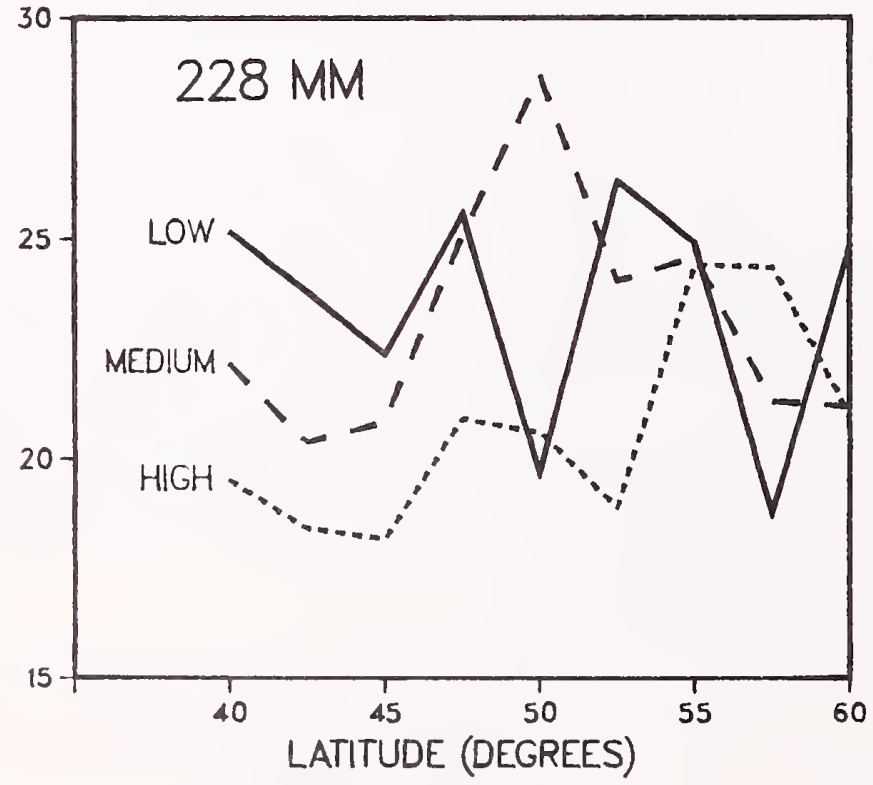

Figure 4-66-Ovendry weight of stump-root systems, wood plus bark, of latifolia trees of three diameters related to latitude and elevational zone.
Weight, Ovendry-Similarly, strong latitudinal trends were not evident in ovendry weights of the stump-root system, wood plus bark (fig. 4-66). In the larger trees there was a tendency for those from high-elevation zones to have about 10 percent less stump-root weight than those from low zones. Ovendry stump-root weights were positively correlated with d.b.h., averaging $1.91(0.46)$, 9.82 (1.17), and 22.43 (3.43) $\mathrm{kg}$ for trees of the three diameter classes.

Green Weight to Yield $1 \mathrm{~m}^{3}$ of Wood-Less green weight of stump-root system is required to yield a cubic meter of bark-free wood than weight of live branches (table 4-6); for stump roots it averages $1,046 \mathrm{~kg}$, with standard deviation of $99 \mathrm{~kg}$. This weight requirement is negatively correlated with d.b.h., averaging 1,109 (89), $1,044(82)$, and $984(82) \mathrm{kg}$ for trees 76,152 , and $228 \mathrm{~mm}$ in d.b.h.

The weight requirement to yield a cubic meter of barkfree wood diminishes from south to north, averaging $1,093 \mathrm{~kg}$ in the four southern latitudinal zones, but only $1,007 \mathrm{~kg}$ in the five northern zones (fig. 4-67). In lowelevation zones slightly more weight $(1,054 \mathrm{~kg})$ is required, on average, than from medium and high zones $(1,041 \mathrm{~kg})$. 
LATIFOLIA

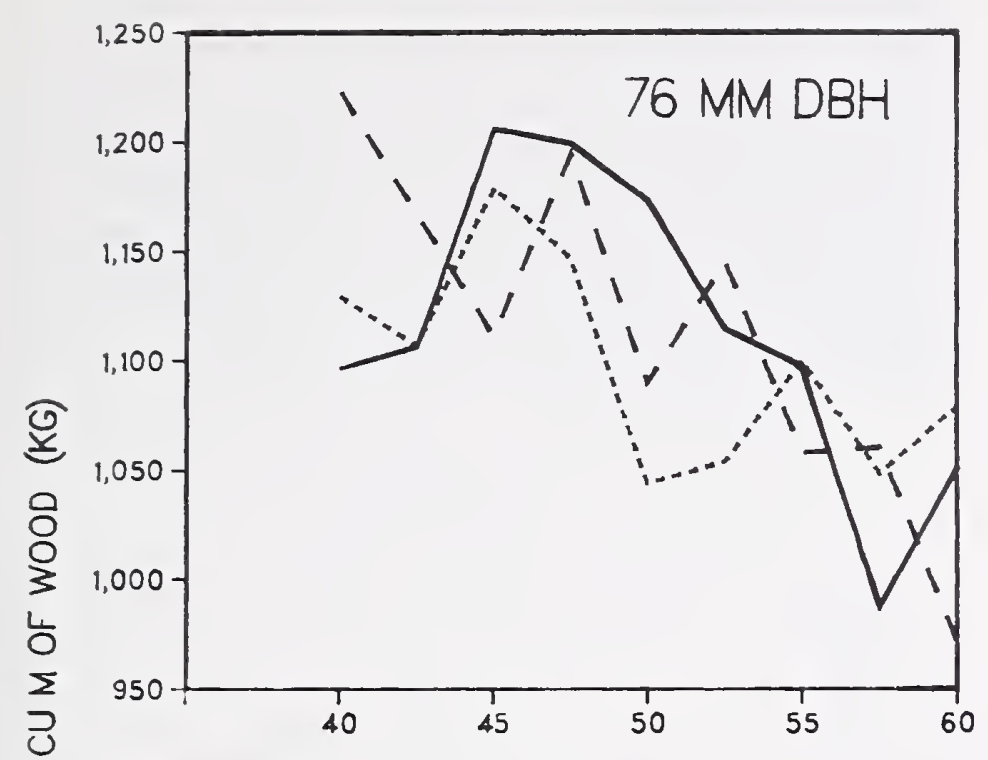

Tree Component Proportion, Green-Weight BasisWith all data pooled, wood plus bark of stump-root systems averaged 11.55 percent of green complete-tree weight including foliage, with standard deviation of 2.53 percentage points. This percentage was unrelated to elevational zone but was negatively correlated with d.b.h. (fig. 4-68), averaging 13.54 (2.67), 11.19 (1.70), and 9.93 (1.60) percent for trees 76,152 , and $228 \mathrm{~mm}$ in d.b.h.

In $76-\mathrm{mm}$ trees the percentage increased in northerly latitudes, but in the two larger diameter classes it declined slightly (fig. 4-68).

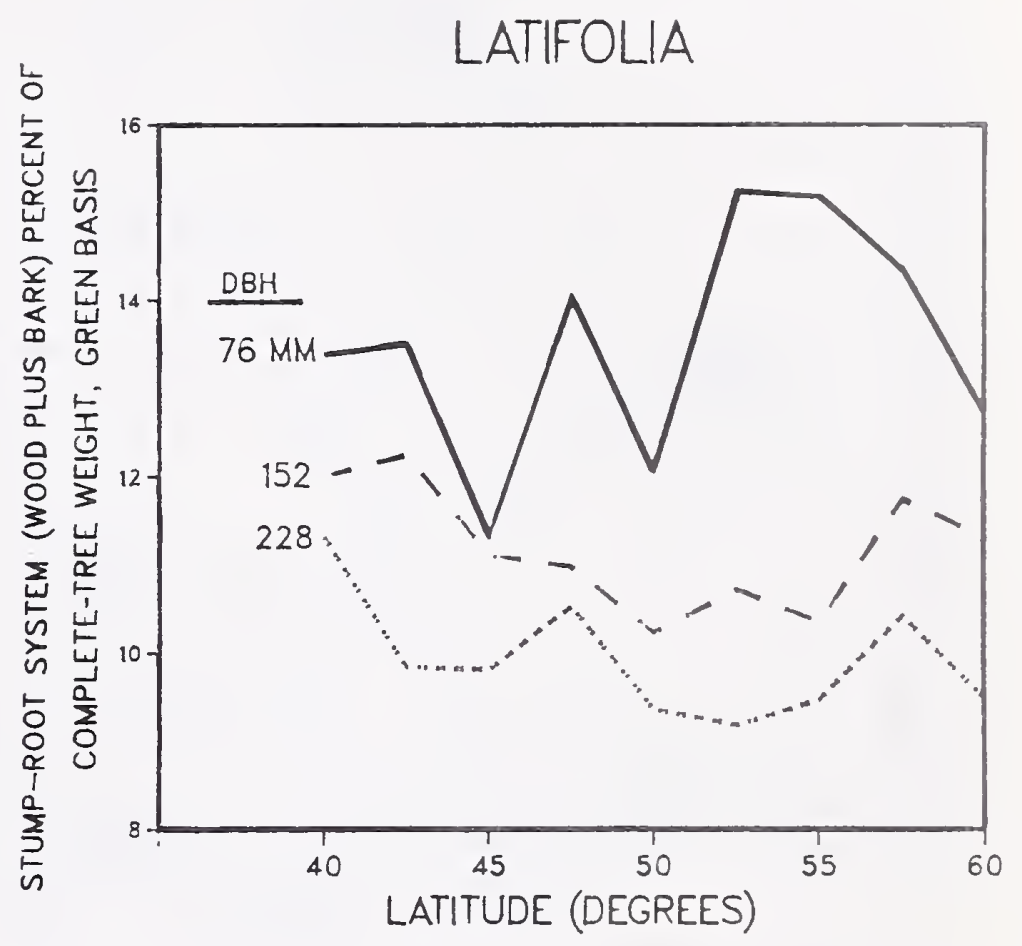

Figure 4-68-Stump-root system (wood plus bark) as percentage of complete-tree weight including foliage-green basis-of latifolia trees of three diameters related to latitude. 
Tree Component Proportion, Ovendry-Weight BasisOn an ovendry basis, wood plus bark of the stump-root system averaged 11.57 percent of complete-tree weight including foliage, with standard deviation of 2.44 percentage points. This percentage was unrelated to elevational zone but was negatively correlated with d.b.h. (fig. 4-69), averaging 13.33 (2.64), 11.39 (1.67), and 9.98 (1.60) for trees 76,152 , and $228 \mathrm{~mm}$ in d.b.h.

Latitudinal trends (fig. 4-69) were similar to those for green-weight percentages.

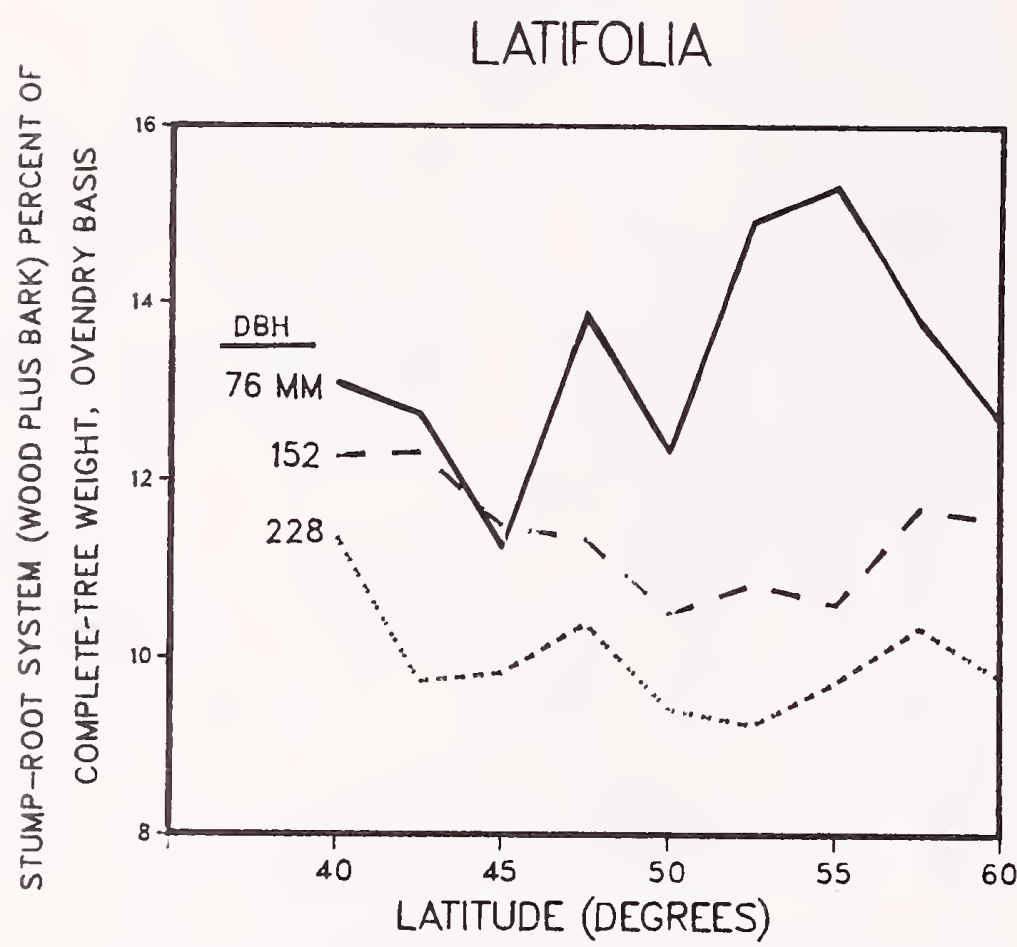

Figure 4-69-Stump-root system (wood plus bark) as percentage of complete-tree weight including foliage-ovendry basis_of latifolia trees of three diameters related to latitude.

\section{Stump-Root System, Wood Only}

Specific Gravity-Wood of the stump-root system had average specific gravity of 0.469 , with standard deviation of 0.045 , based on ovendry weight and green volume. Specific gravity was unrelated to elevational zone, but varied with latitude. Wood specific gravity was least $(0.444)$ at 42.5 degrees and most $(0.476$ to 0.493$)$ in latitudes 47.5 through 55 degrees. In northern latitudes, trees from low-elevation zones had higher specific gravity than those from high zones (fig. 4-70).

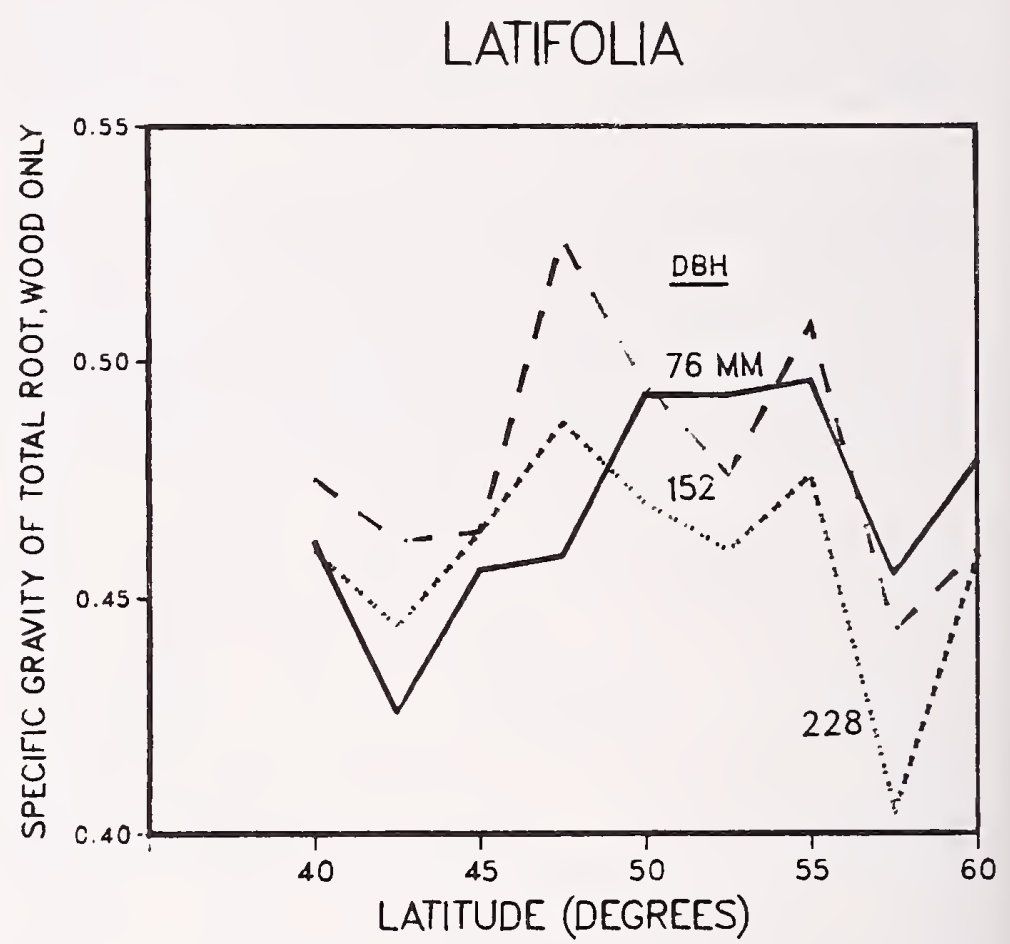

Figure 4-70-Specific gravity (based on ovendry weight and green volume) of wood of stump-root systems of latifolia trees of three diameters related to latitude. 
Weight, Green-Green weight of wood from the stumproot system was positively correlated with d.b.h., averaging $3.19(0.76), 16.53(2.79)$, and $38.67(6.29) \mathrm{kg}$ for trees 76,152 , and $228 \mathrm{~mm}$ in d.b.h. This weight was inversely correlated with elevational zone, averaging-with diameter data pooled-20.35, 19.54, and $18.50 \mathrm{~kg}$ for low-, medium-, and high-elevation zones, respectively; interactions with diameter and latitude were complex, however (fig. 4-71). In low-elevation zones, green weights were greatest in southern latitudes and least in northern latitudes (fig. 4-71)-partly attributable to a similar trend in rootwood moisture content with latitude (fig. 2-24).

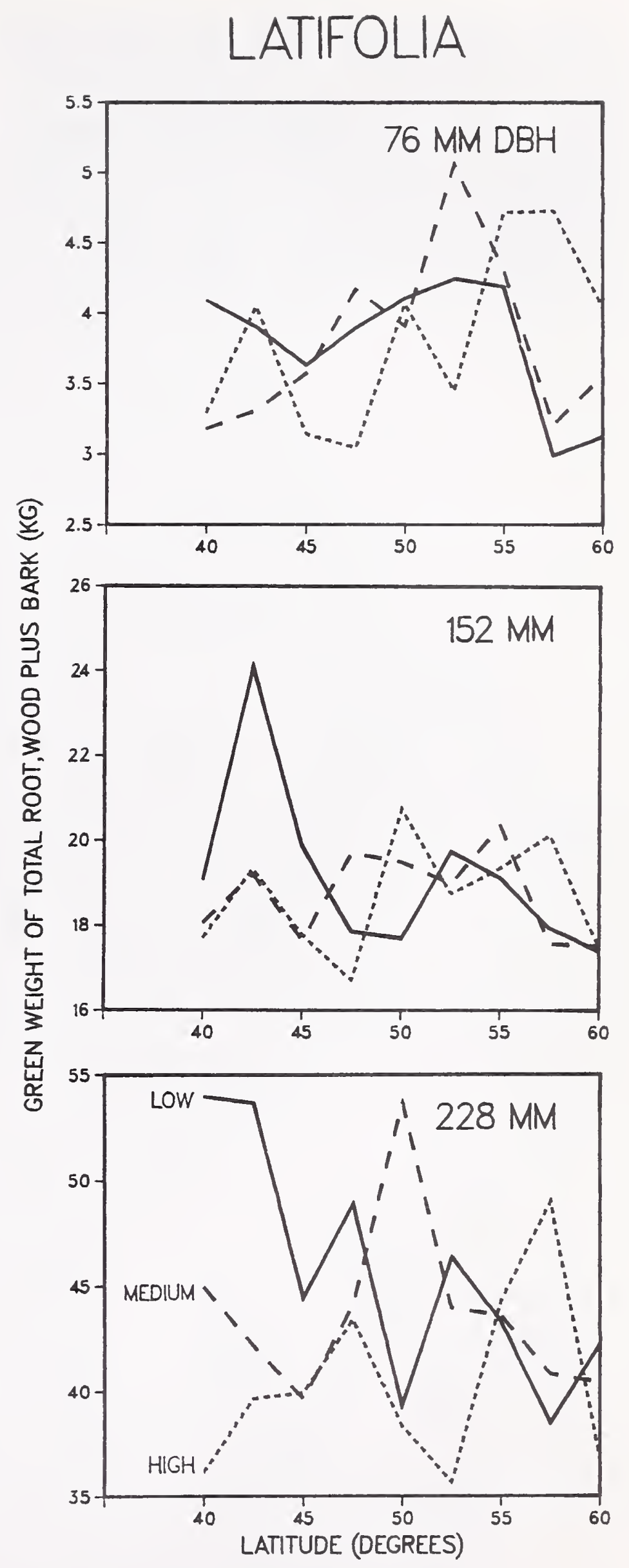

Figure 4-71-Green weight of wood from the stump-root systems of latifolia trees of three diameters related to latitude and elevational zone. 
Weight, Ovendry-On an ovendry basis, weight of wood of the stump-root system tended to be least $(9.2$ to $9.8 \mathrm{~kg}$ with diameter data pooled) in the southern three latitudinal zones, and most in the latitudes from 47.5 through 55 degrees (10.4 to $11.4 \mathrm{~kg}$ with diameter data pooled). In larger trees, rootwood from high-elevation zones weighed slightly less than that from low zones (fig. 4-72).

Ovendry rootwood weight was positively correlated with d.b.h., averaging $1.62(0.39), 8.66$ (1.51), and 20.13

(3.06) $\mathrm{kg}$ for trees of the three diameter classes.
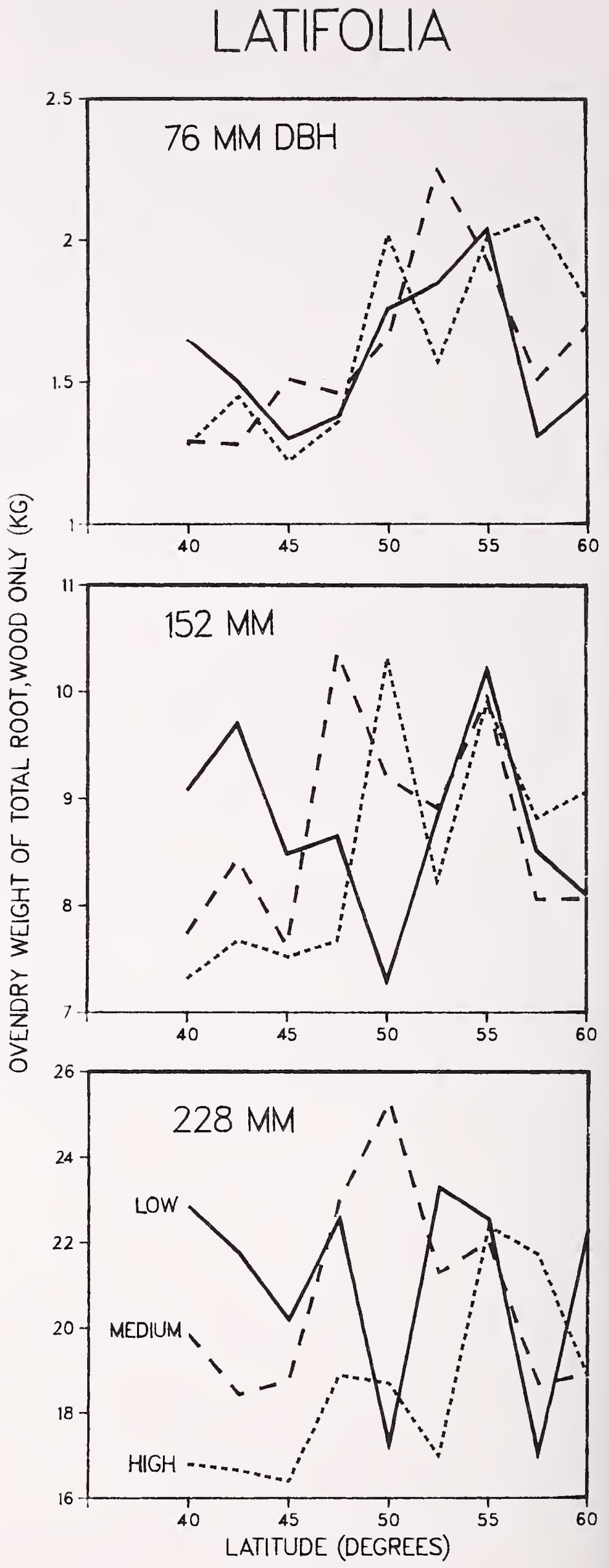

Figure 4-72-Ovendry weight of wood from the stump-root systems of latifolia trees of three diameters related to latitude and elevational zone. 


\section{Stump-Root System, Bark Only}

Specific Gravity-Specific gravity of bark of the stumproot system was higher than that of stembark or branchbark (table 4-2), averaging 0.415 , with standard deviation of 0.056 , based on ovendry weight and green volume. It was positively correlated with d.b.h., averaging 0.393 $(0.054), 0.419(0.057)$, and $0.435(0.051)$ for trees 76,152 , and $228 \mathrm{~mm}$ in d.b.h.

Rootbark specific gravity was negatively correlated with elevational zone, averaging $0.425,0.417$, and 0.403 in low, medium, and high zones (fig. 4-73); this relationship was weakest in small trees. Specific gravity averaged least $(0.358)$ at 42.5 degrees latitude and most (0.442 to 0.450$)$ in latitudinal zones from 50 through 55 degrees (fig. 4-73).

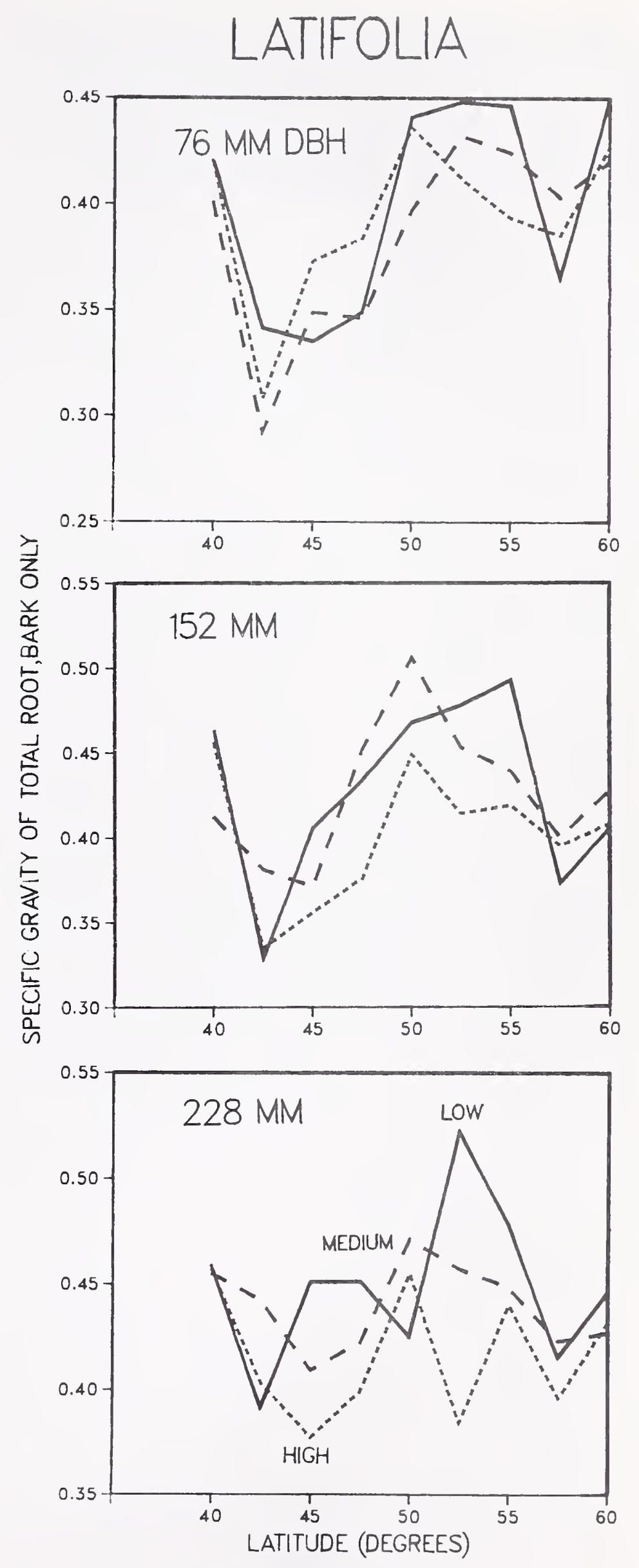

Figure 4-73-Specific gravity (based on ovendry weight and green volume) of bark from the stump-root systems of latifolia trees of three diameters related to latitude and elevational zone. 
Weight, Green-Green weight of bark of the stump-root system was positively correlated with d.b.h., averaging $0.63(0.19), 2.33(0.68)$, and $4.54(1.05) \mathrm{kg}$ for trees of the three diameter classes. It was unrelated to elevational zone. For the smaller trees, root-system green bark weighed more in northern latitudes than southern (fig. 4-74).

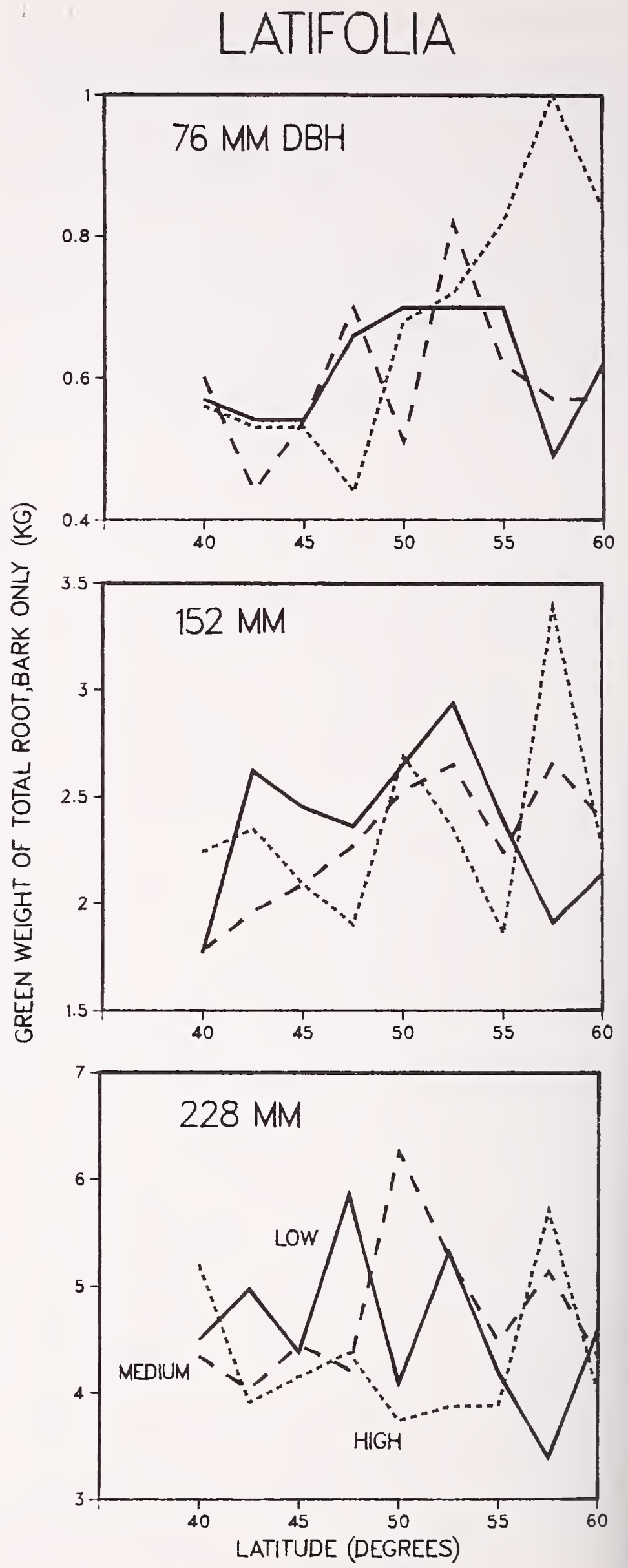

Figure 4-74-Green weight of bark from the stump-root systems of latifolia trees of three diameters related to latitude and elevational zone. 
Weight, Ovendry-On an ovendry basis, average weight of the stump-root system bark was lowest-diameter data pooled-at 42.5 degrees latitude $(1.04 \mathrm{~kg})$ and highest $(1.42$ to $1.45 \mathrm{~kg}$ ) at 50 and 52.5 degrees (fig. $4-75$ ). In the middle latitudes, trees from high-elevation zones had less weight of root-system bark than those from low zones (fig. 4-75).

Weight of ovendry bark of the stump-root system was positively correlated with d.b.h., averaging $0.30(0.10)$, $1.17(0.35)$, and $2.30(0.60) \mathrm{kg}$ for trees 76,152 , and $228 \mathrm{~mm}$ in d.b.h.

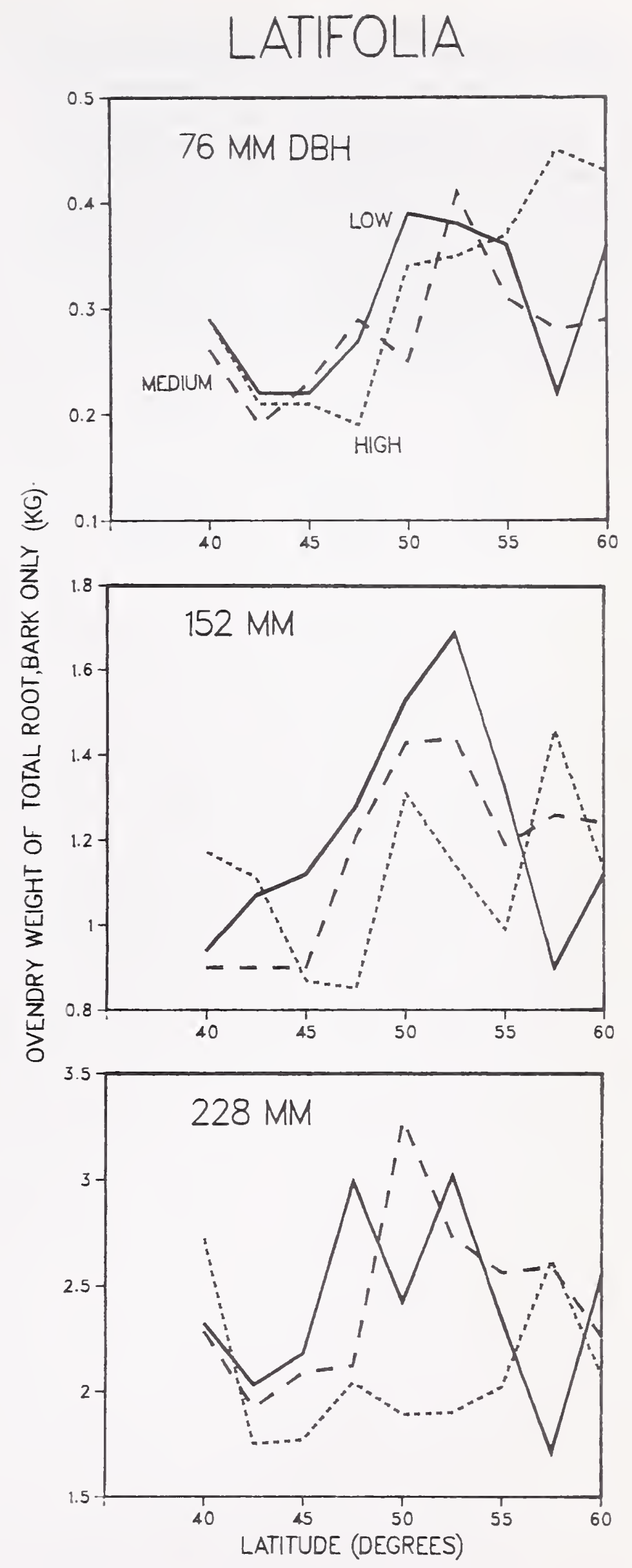

Figure 4-75-Ovendry weight of bark from the stump-root systems of latifolia trees of three diameters related to latitude and elevational zone. 
Stump-Root Bark as Percentage of Gross Stump-Root Weight, Green and Ovendry-On a green-weight basis, bark of stump-root systems averaged 13.13 percent of gross stump-root system weight, with standard deviation of 3.72 percentage points. On an ovendry-weight basis, comparable values were 12.52 (3.52) percent. Average percentage of bark by weight, both green and ovendry, was lowest at 42.5 degrees latitude (11.35 and 10.88 percent, respectively) and highest at 52.5 degrees (14.37 and 14.01 percent); elevational trends were complex, and varied with latitude and d.b.h. (figs. 4-76 and 4-77).

Bark weight percentages were negatively correlated with d.b.h., as follows:

$\begin{array}{rlr}\text { D.b.h. } & \text { Green } & \text { Ovendry } \\ m m & \ldots \ldots \text {. } & \text { Percent } \ldots . . . \\ 76 & 16.51(3.32) & 15.46(3.21) \\ 152 & 12.32(2.83) & 11.85(2.96) \\ 228 & 10.55(1.99) & 10.25(2.02)\end{array}$

LATIFOLIA
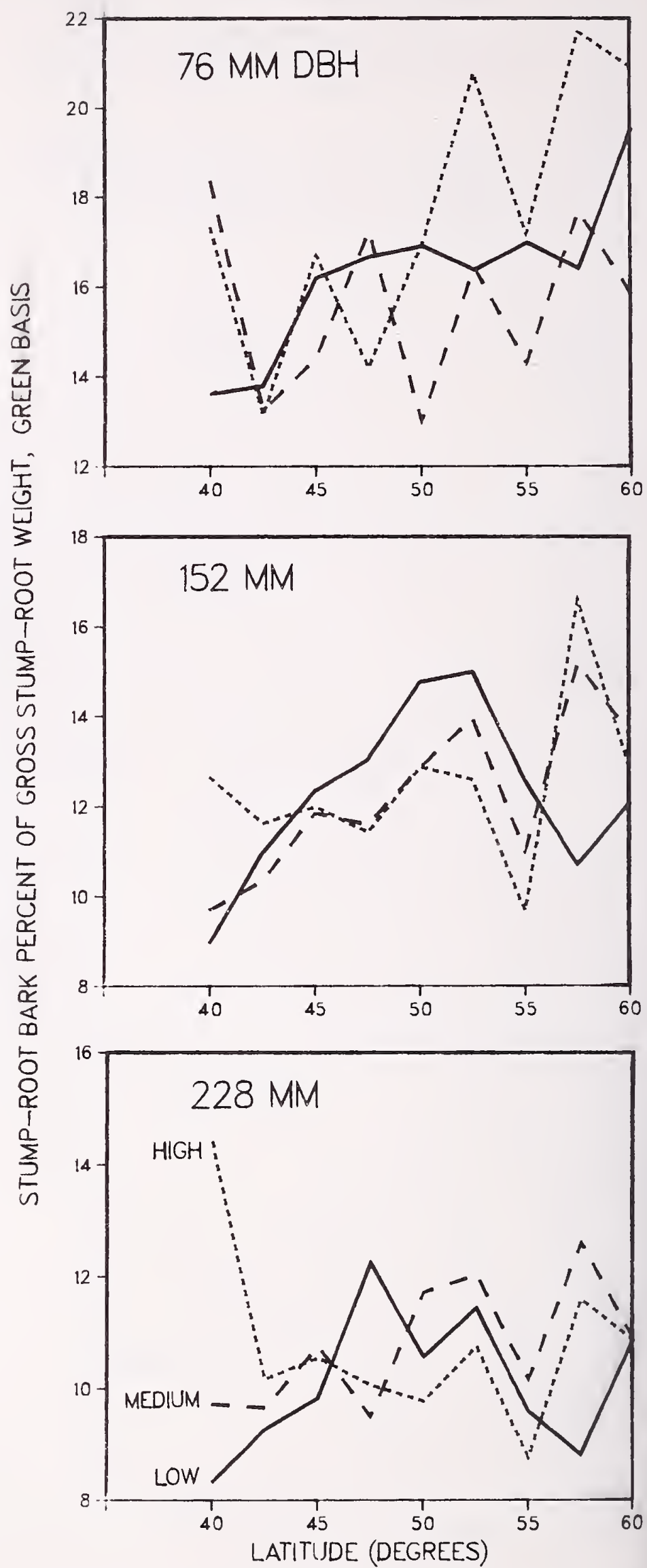

Figure 4-76-Weight of stump-root system bark as a percentage of gross stump-root systems (green basis) of latifolia trees of three diameters related to latitude and elevational zone. 


\section{LATIFOLIA}

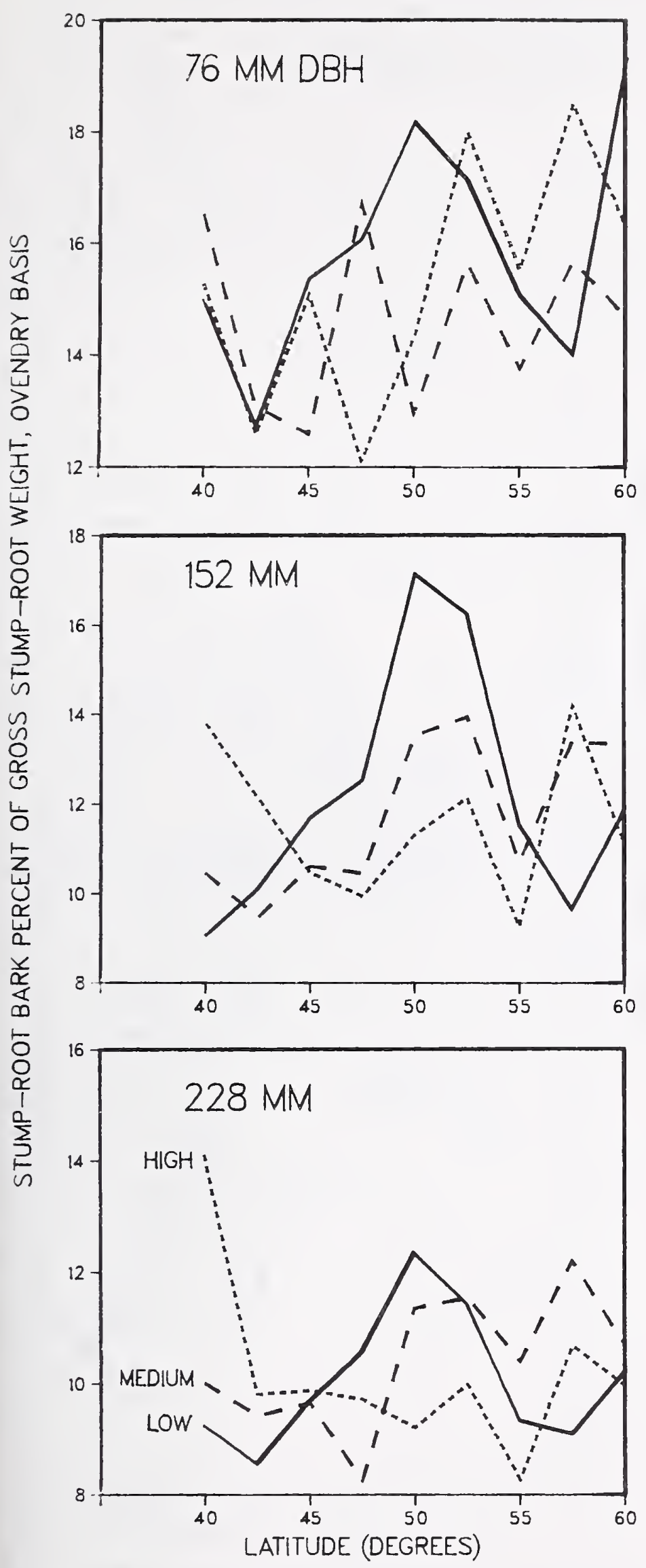

Figure 4-77-Weight of stump-root system bark

as a percentage of gross stump-root systems (ovendry basis) of latifolia trees of three diameters related to latitude and elevational zone. 


\section{Stump, Wood Plus Bark}

Specific Gravity-Wood plus bark of the stumps had higher specific gravity than wood plus bark of any other tree component (table 4-2), averaging 0.471 , with standard deviation of 0.046 , based on ovendry weight and green volume. Specific gravities were highest in the smaller trees, averaging $0.475(0.047), 0.480(0.048)$, and 0.459 $(0.041)$ in trees 76,152 , and $228 \mathrm{~mm}$ in d.b.h.

Specific gravities averaged least $(0.443)$ at 42.5 degrees latitude and most at 52.5 and 55 degrees (0.494 and 0.492 , respectively); variations with elevation were complex and differed with latitude (fig. 4-78).
LATIFOLIA

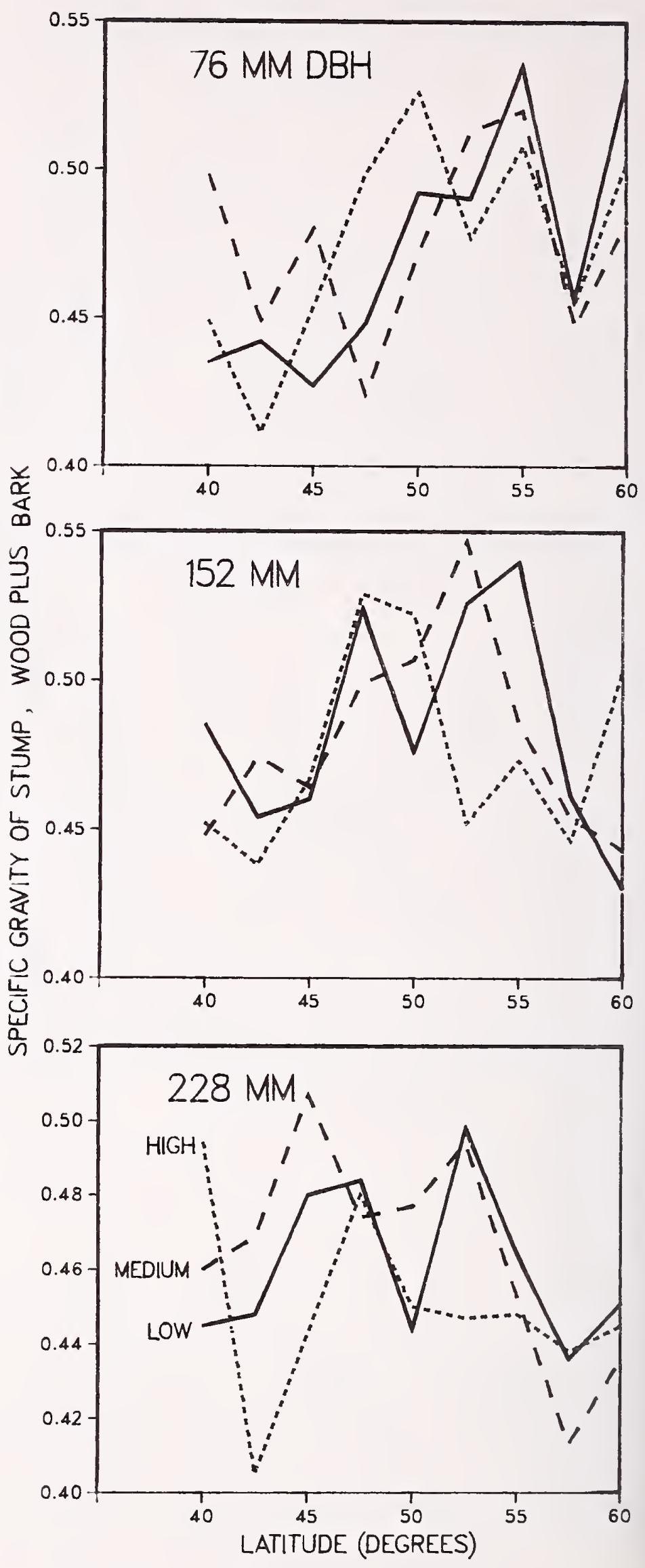

Figure 4-78-Specific gravity (based on ovendry weight and green volume) of wood plus bark of stumps from ground level to $152-\mathrm{mm}$ height from latifolia trees of three diameters related to latitude and elevational zone. 
Weight, Green-Weight of green wood plus bark of stumps was positively correlated with d.b.h. (fig. 4-79), averaging $1.15(0.32), 3.67(1.24)$, and $7.18(2.54) \mathrm{kg}$ for trees 76,152 , and $228 \mathrm{~mm}$ in d.b.h. Weight was unrelated to elevational zone, but was negatively correlated with latitude, particularly in smaller trees (fig. 4-79).

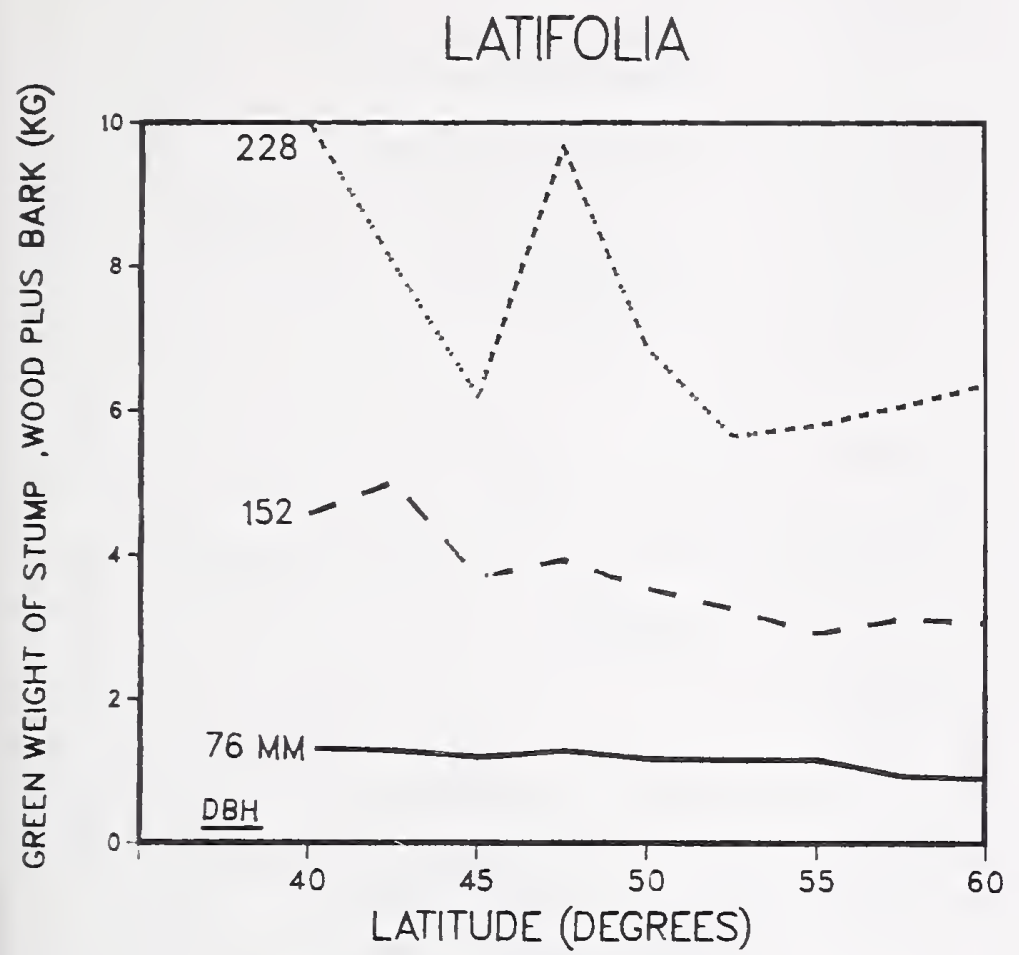

Figure 4-79-Green weight of wood plus bark of stumps (ground level to $152-\mathrm{mm}$ stump height) from latifolia trees of three diameters related to latitude.
Weight, Ovendry-Ovendry weights of wood plus bark of stumps were also unrelated to elevational zone but positively correlated with d.b.h. (fig. 4-80), averaging 0.59 $(0.14), 2.01(0.61)$, and $3.89(1.31) \mathrm{kg}$ for trees of the three diameter classes. Weights, ovendry, in northern latitudes were slightly less than those in southern (fig. 4-80).

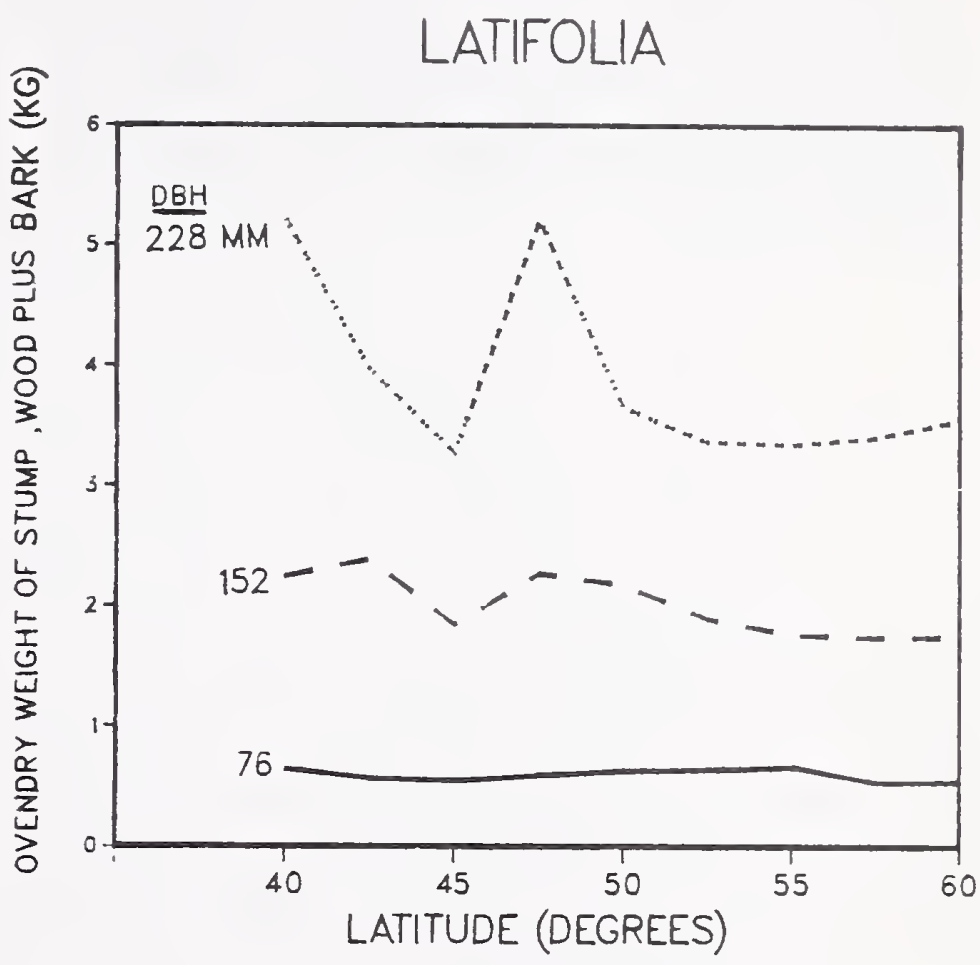

Figure 4-80-Ovendry weight of wood plus bark of stumps (ground level to 152-mm stump height) from latifolia trees of three diameters related to latitude. 


\section{Stumpwood}

Specific Gravity-Stumpwood had specific gravity averaging 0.476 , with standard deviation of 0.051 , based on ovendry weight and green volume. It was highest in smaller trees, averaging $0.486(0.051), 0.485(0.052)$, and $0.457(0.044)$ in trees 76,152 , and $228 \mathrm{~mm}$ in d.b.h. This inverse relationship to d.b.h. is unusual in conifers.

Stumpwood specific gravity averaged minimum (0.447) at 42.5 degrees latitude and was maximum $(0.486$ to 0.498 ) from 47.5 degrees through 55 degrees; its relationship to elevation was not pronounced and varied with latitude (fig. 4-81).
LATIFOLIA
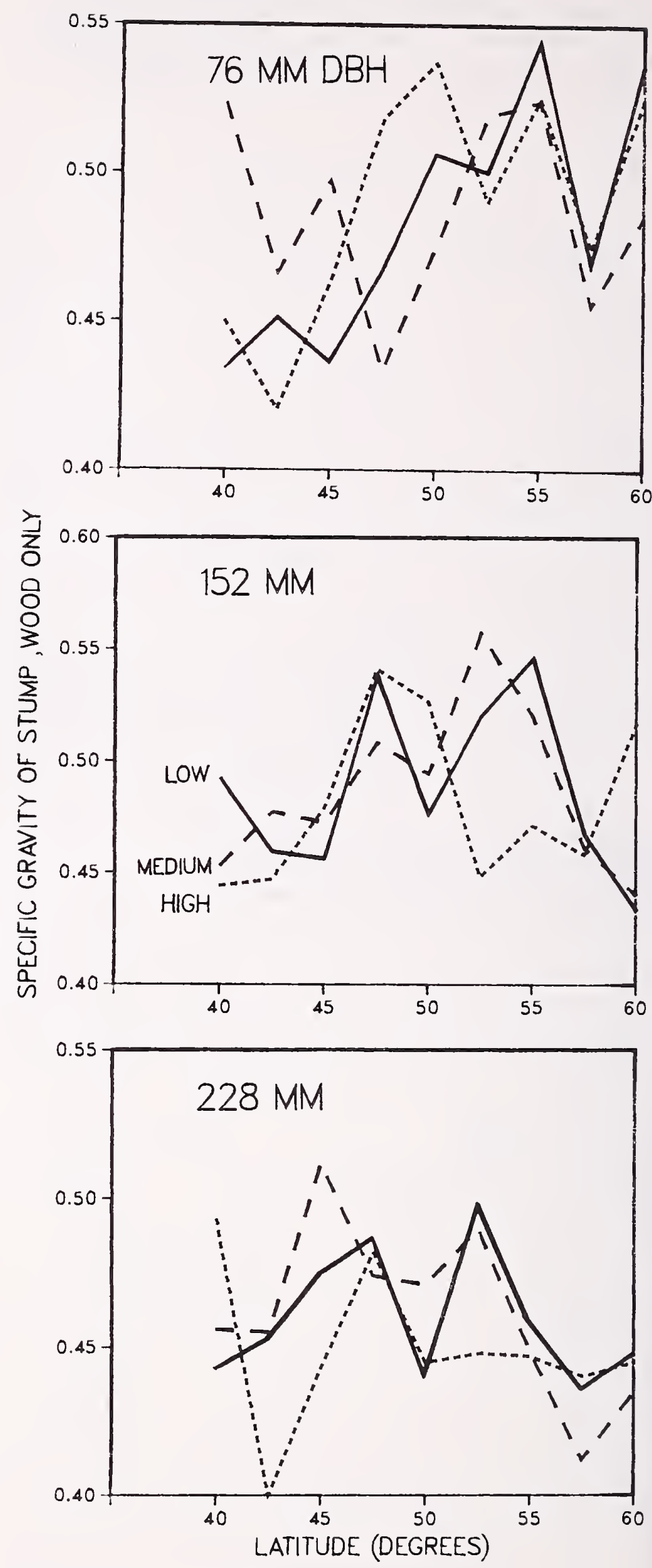

Figure 4-81-Specific gravity of stumpwood (based on ovendry weight and green volume) from latifolia trees of three diameters related to latitude and elevational zone. 
Weight, Green-Stumpwood green weight was unrelated to elevational zone, but positively correlated with d.b.h. (fig. 4-82), averaging $0.98(0.28), 3.28$ (1.06), and $6.51(2.25) \mathrm{kg}$ for trees 76,152 , and $228 \mathrm{~mm}$ in d.b.h. Trees in northern latitudes, particularly small trees, had less weight of green stumpwood than trees in southern latitudes (fig. 4-82).
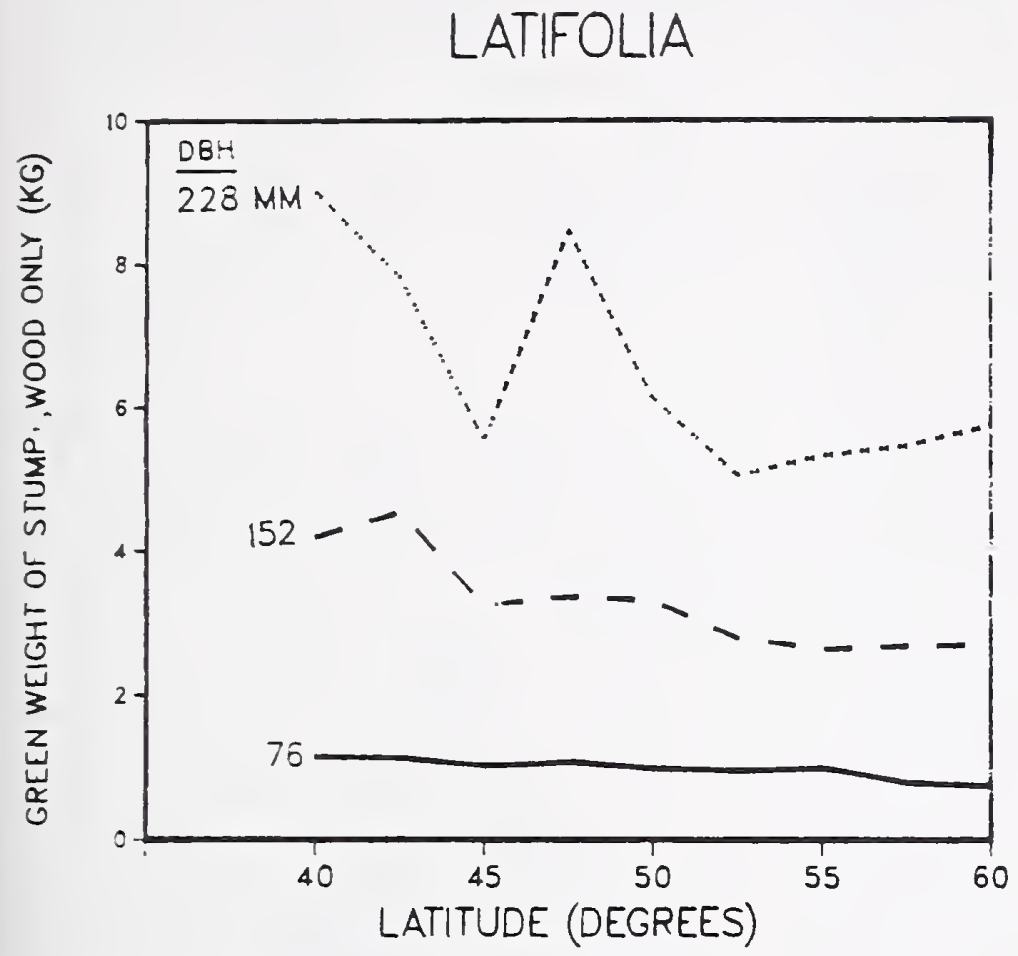

Figure 4-82-Green weight of stumpwood, from groundline to $152-\mathrm{mm}$ stump height, of latifolia trees of three diameters related to latitude.
Weight, Ovendry-Weight of ovendry stumpwood was also unrelated to elevational zone, but positively correlated with d.b.h. (fig. 4-83), averaging 0.50 (0.12), 1.76 (0.54), and $3.45(1.15) \mathrm{kg}$ for trees of the three diameter classes. As with green stumpwood, ovendry weights in northern latitudes were slightly less than those in southern (fig. 4-83).

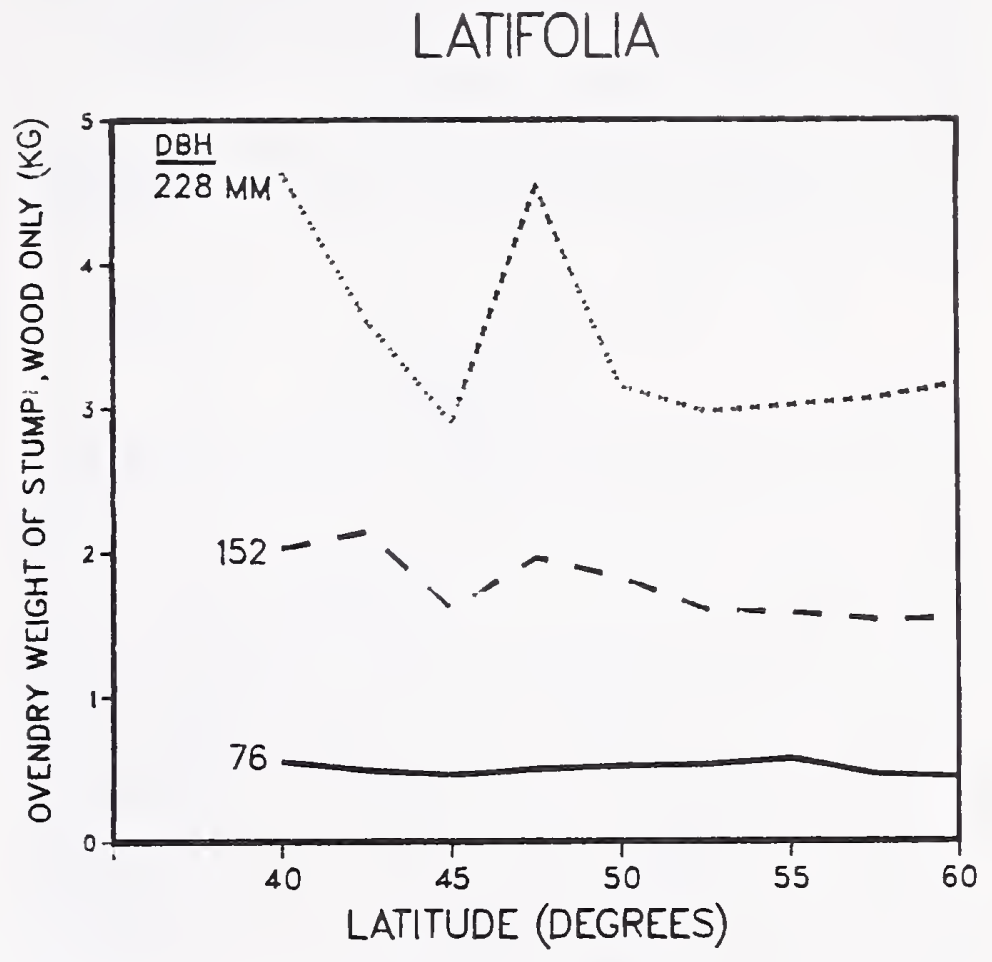

Figure 4-83-Ovendry weight of stumpwood, from groundline to $152-\mathrm{mm}$ stump height, of latifolia trees of three diameters related to latitude. 


\section{Stumpbark}

Specific Gravity-Stumpbark specific gravity was greater than that of the bark of any other tree component (table 4-2), averaging 0.445 , with standard deviation of 0.064 , based on ovendry weight and green volume. Stumpbark specific gravity was unrelated to elevational zone. Unlike wood of stem and stump, specific gravity of stumpbark was positively correlated with d.b.h. (fig. 4-84), averaging $0.418(0.063), 0.446(0.068)$, and $0.470(0.051)$ for trees 76,152 , and $228 \mathrm{~mm}$ in d.b.h.

It was also positively correlated with latitude, averaging minimum (0.401) at 42.5 degrees and maximum (0.486) at 50 degrees (fig. 4-84).

\section{LATIFOLIA}

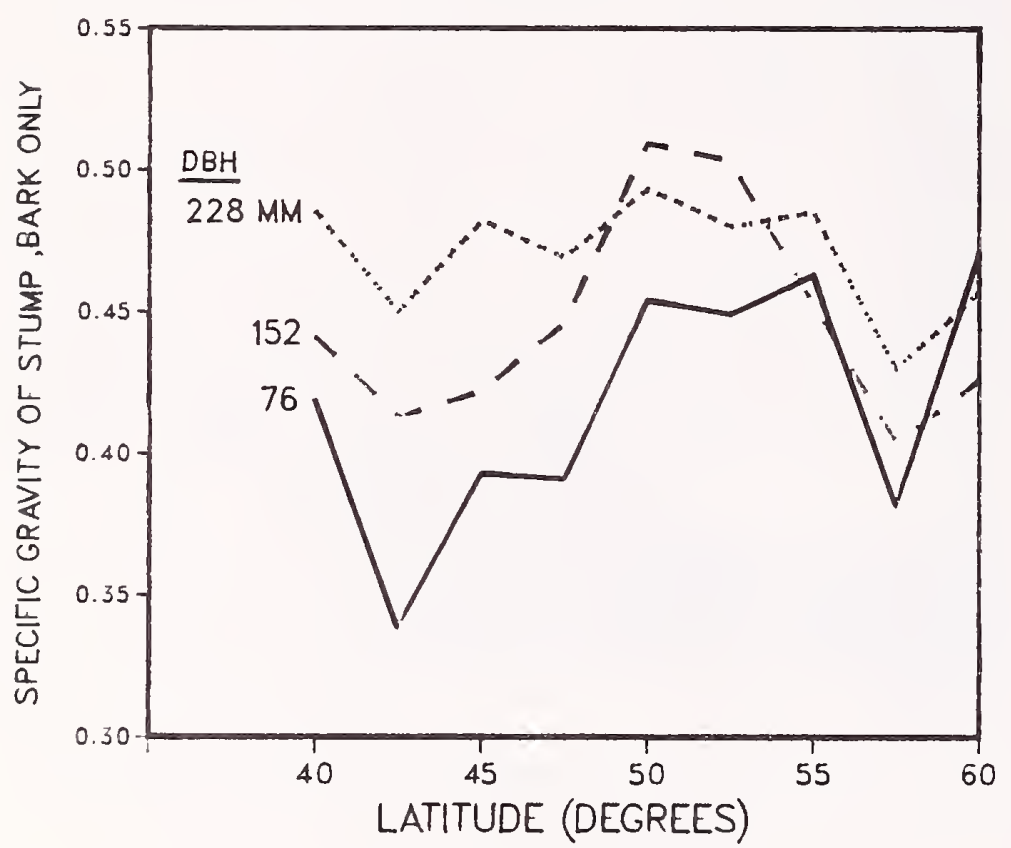

Figure 4-84-Specific gravity of stumpbark (based on ovendry weight and green volume) from latifolia trees of three diameters related to latitude.

Weight, Green-Stumpbark green weight was positively correlated with d.b.h., averaging 0.17 (0.06), $0.43(0.23)$, and $0.72(0.36) \mathrm{kg}$ for trees of the three diameter classes. Stumpbark tended to weigh most in low-elevation zones (fig. 4-85) and weight was minimum $(0.31 \mathrm{~kg})$ at 55 degrees latitude and maximum $(0.65 \mathrm{~kg})$ at 47.5 degrees (fig. 4-85).
LATIFOLIA
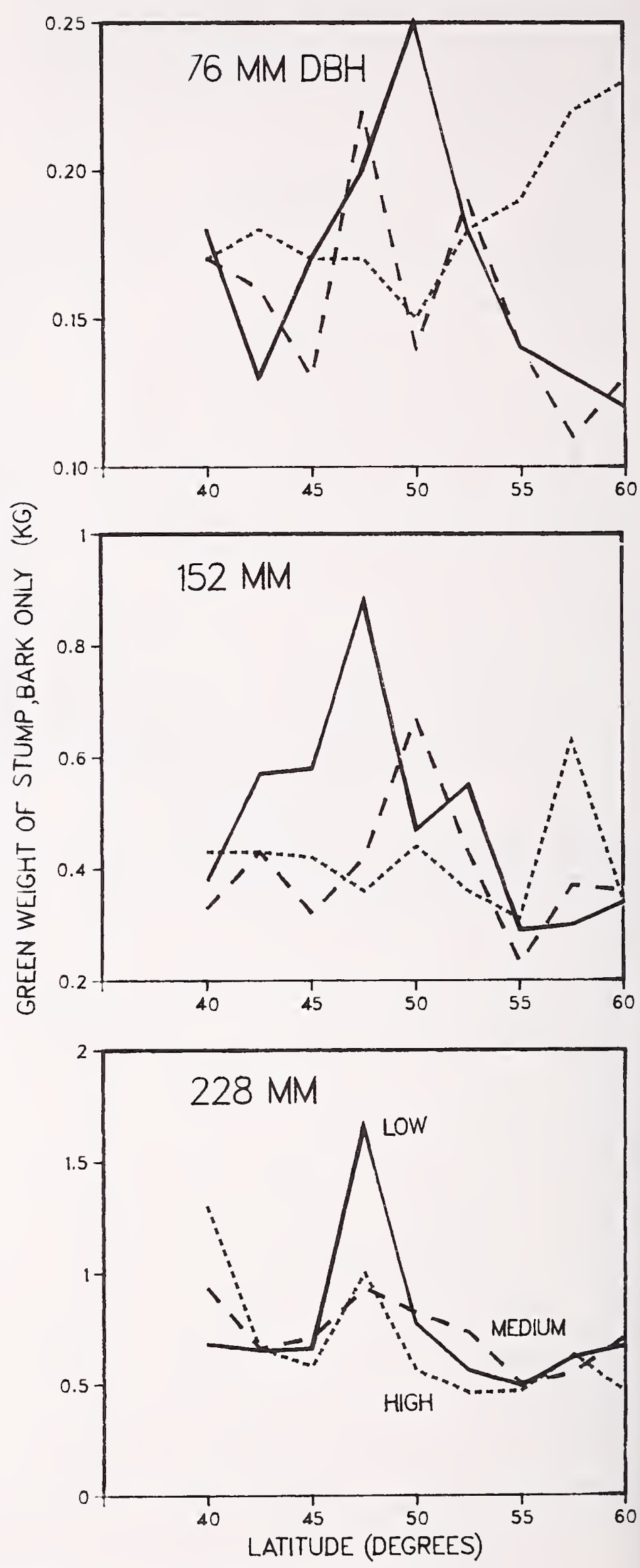

Figure 4-85-Green weight of stumpbark from groundline to $152-\mathrm{mm}$ stump height of latifolia trees of three diameters, related to latitude and elevational zone. 
Weight, Ovendry-On an ovendry basis, stumpbark weight was also positively correlated with d.b.h., averaging $0.09(0.03), 0.25(0.13)$, and $0.44(0.22) \mathrm{kg}$ for trees 76 , 152 , and $228 \mathrm{~mm}$ in d.b.h. Ovendry stumpbark weight varied inversely with elevational zone (fig. 4-86), averaging $0.28,0.26$, and $0.24 \mathrm{~kg}$ in low, medium, and high zones. As with green stumpbark, ovendry weight of stumpbark averaged minimum $(0.19 \mathrm{~kg})$ at 55 degrees latitude and was maximum $(0.37 \mathrm{~kg})$ at 47.5 degrees.

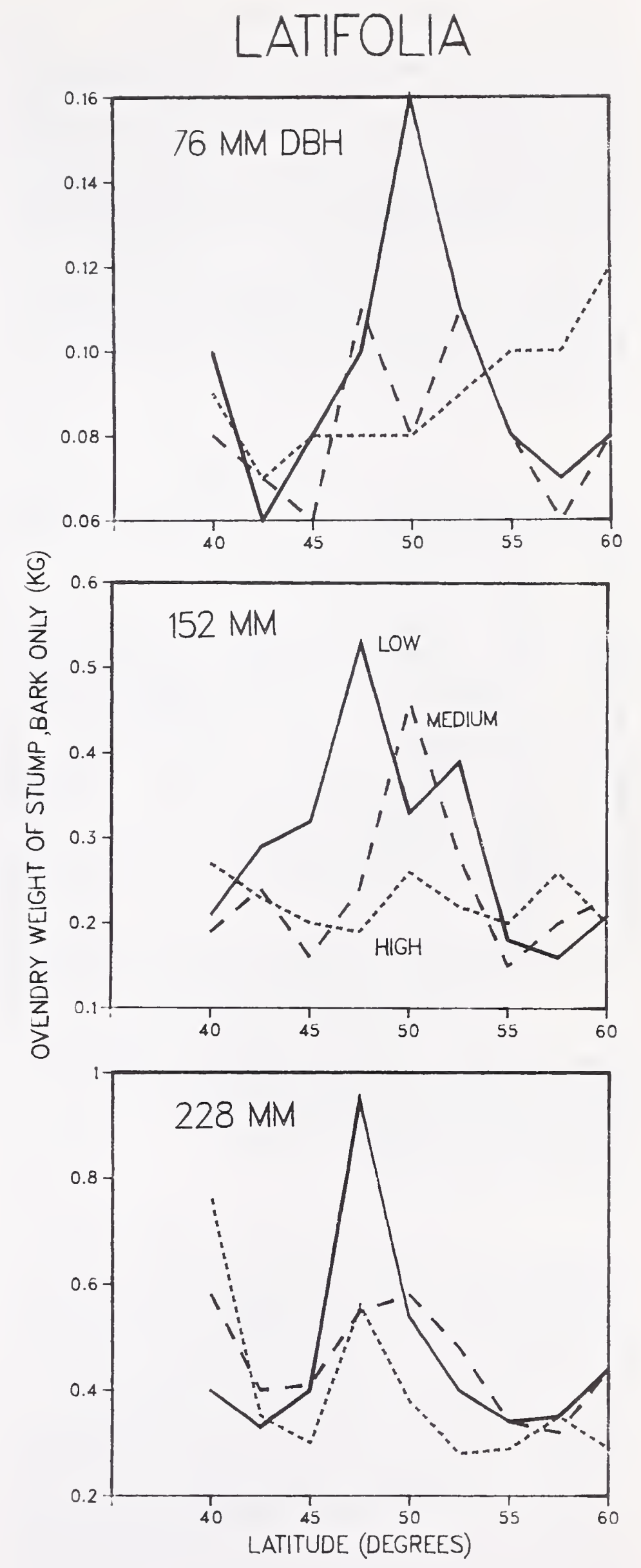

Figure 4-86-Ovendry weight of stumpbark from groundline to $152-\mathrm{mm}$ stump height of latifolia trees of three diameters, related to latitude and elevational zone. 


\section{Lateral Roots, Wood Plus Bark}

Specific Gravity-Specific gravity of wood plus bark of lateral roots averaged 0.442 , with standard deviation of 0.047 , based on ovendry weight and green volume. It was unrelated to elevational zone, but in southern latitudes was positively correlated with d.b.h. (fig. 4-87); with data from all latitudes pooled, it averaged $0.424(0.046), 0.452$ $(0.050)$, and $0.449(0.039)$ for trees 76,152 , and $228 \mathrm{~mm}$ in d.b.h.

Specific gravity of wood plus bark from lateral roots was positively correlated with latitude, averaging minimum $(0.410)$ at 42.5 degrees and maximum (0.479) at 55 degrees (fig. 4-87).

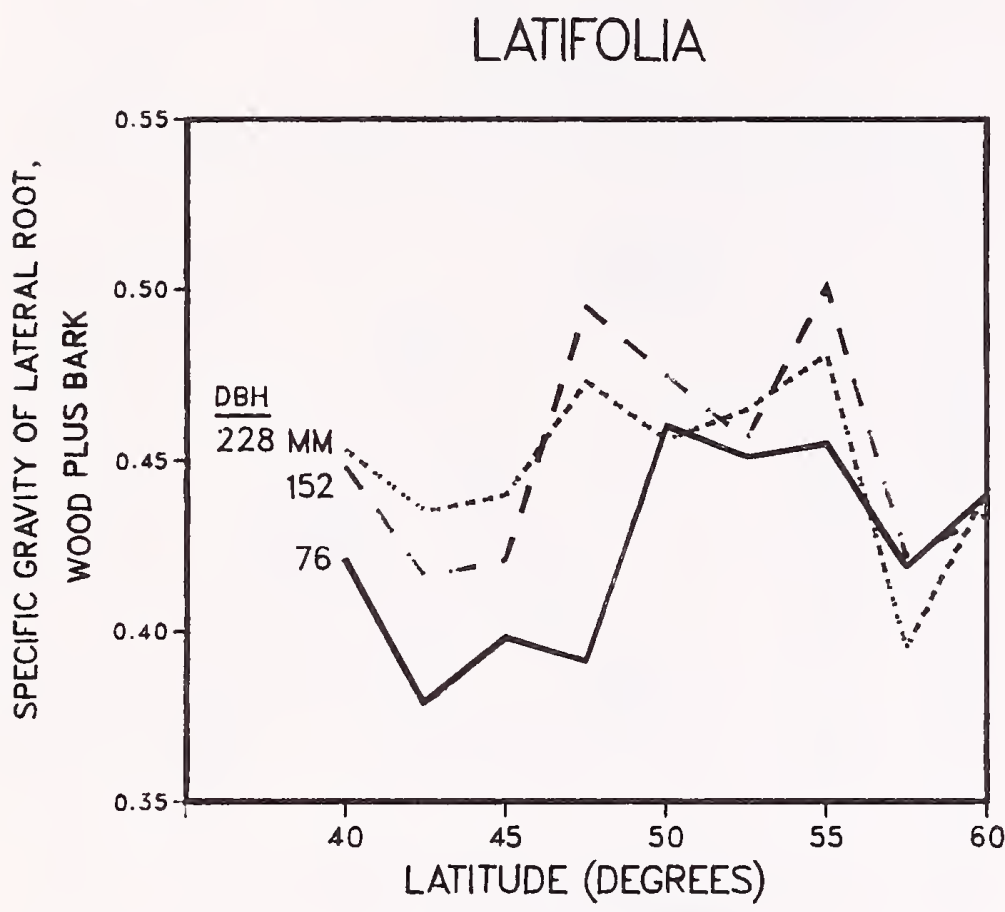

Figure 4-87-Specific gravity of wood plus bark (based on ovendry weight and green volume) of lateral roots from root collar to $305-\mathrm{mm}$ radius, from stump pith from latifolia trees of three diameters, related to latitude.

Weight, Green-Weight of green wood plus bark of lateral roots was unrelated to elevational zone, but positively correlated with d.b.h. (fig. 4-88), averaging 1.05 (0.52), $6.75(1.70)$, and $15.52(3.97) \mathrm{kg}$ for trees of the three diameter classes. Unlike the stump, green weight of wood plus bark of the lateral roots was positively correlated with latitude, averaging near minimum $(6.65 \mathrm{~kg})$ at 40 degrees, minimum $(6.19 \mathrm{~kg})$ at 47.5 degrees, and maximum $(9.24 \mathrm{~kg})$ at 57.5 degrees (fig. 4-88).

Weight, Ovendry-Weight of ovendry wood plus bark of lateral roots was also unrelated to elevational zone, and positively correlated with d.b.h. (fig. 4-89), averaging 0.52 $(0.28), 3.37(0.96)$, and $7.80(2.25) \mathrm{kg}$ for trees of the three diameter classes. Ovendry weight was positively correlated with latitude, averaging minimum $(3.10 \mathrm{~kg})$ at 40 degrees and maximum (4.84 kg) at 55 degrees (fig. 4-89).

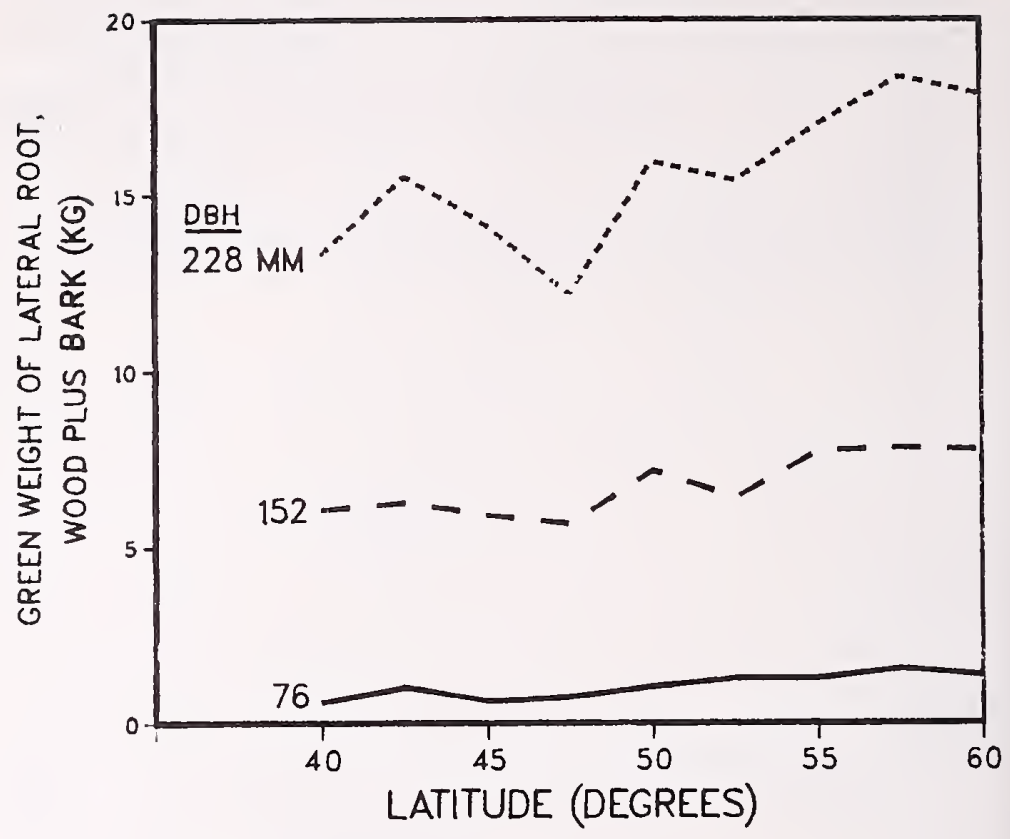

Figure 4-88-Green weight of wood plus bark from lateral roots (root collar to $305-\mathrm{mm}$ radius from stump pith) of latifolia trees of three diameters, related to latitude.

\section{LATIFOLIA}

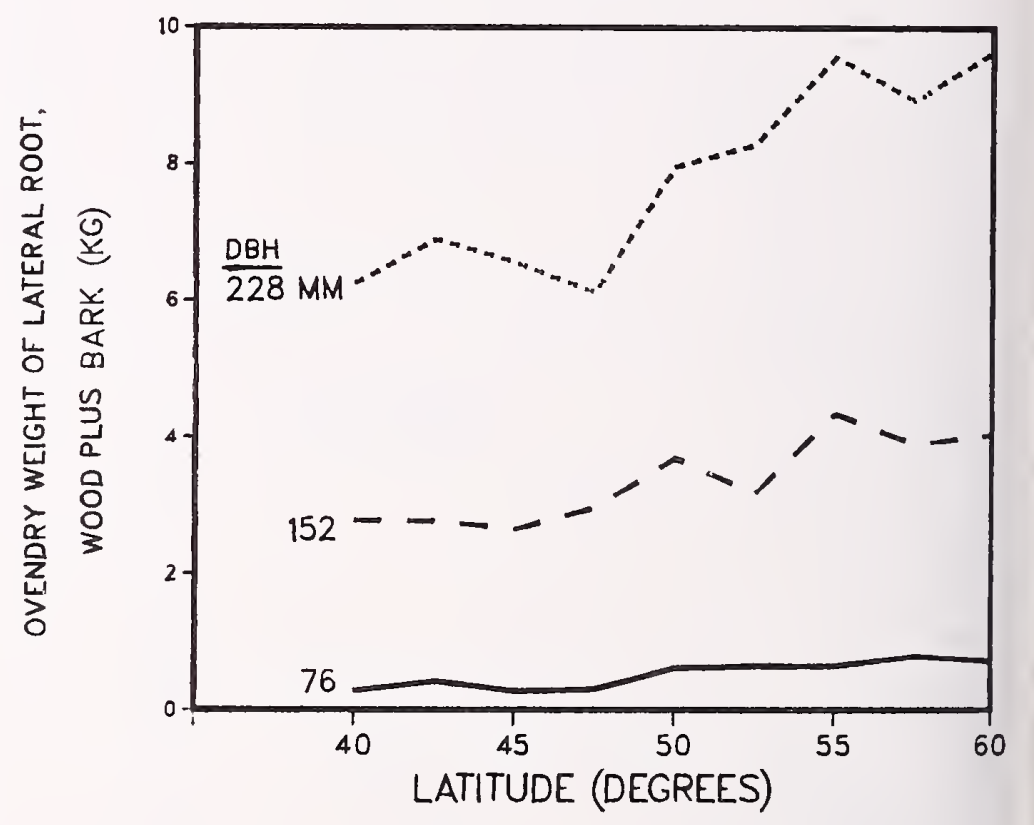

Figure 4-89-Ovendry weight of wood plus bark from lateral roots (root collar to $305-\mathrm{mm}$ radius from stump pith) of latifolia trees of three diameters, related to latitude. 


\section{Lateral Roots, Wood Only}

Specific Gravity-Wood of the lateral roots had average specific gravity of 0.453 , with standard deviation of 0.048 , based on ovendry weight and green volume. It was unrelated to elevational zone and only in southern latitudes was positively correlated with d.b.h. (fig. 4-90). Specific gravity was lowest $(0.427$ and 0.421$)$ at latitudes 42.5 and 57.5 degrees and highest (0.472) at middle latitudes of 47.5 and 50 degrees (fig. 4-90).

\section{LATIFOLIA}

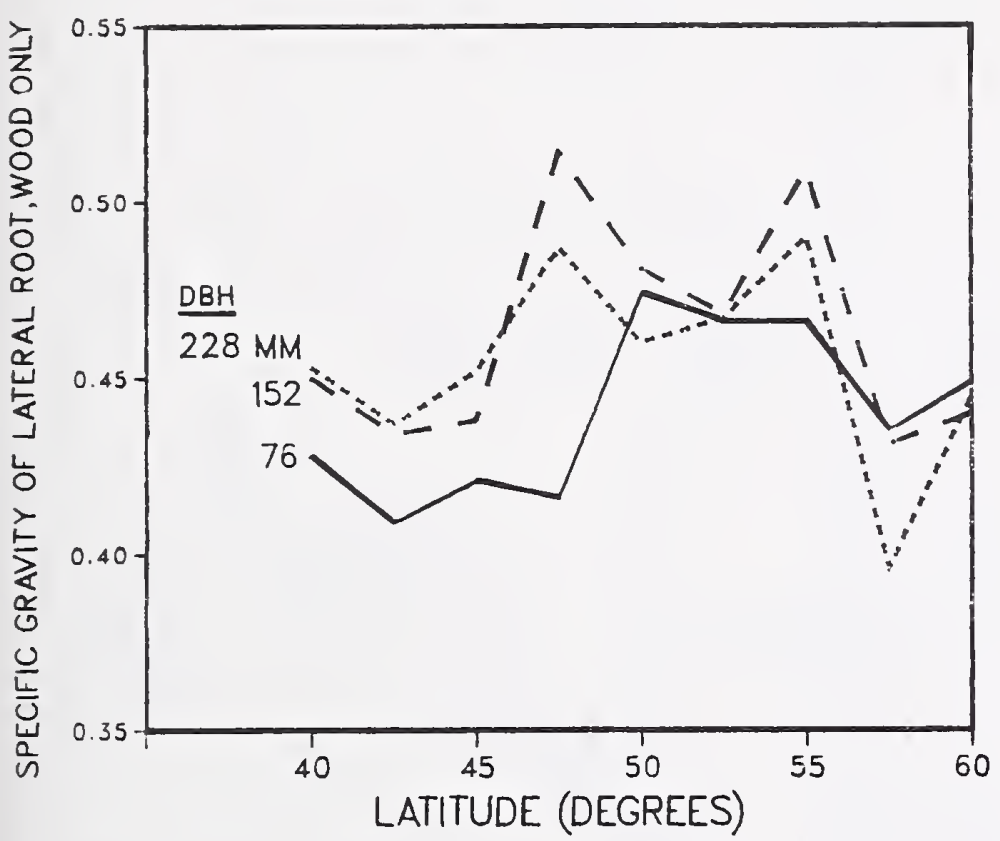

Figure 4-90-Specific gravity of wood of lateral roots (based on ovendry weight and green volume) of latifolia trees of three diameters, related to latitude.

Weight, Green-Weight of green wood from lateral roots was unrelated to elevational zone, but was positively correlated with d.b.h. (fig. 4-91), averaging 0.81 (0.43), $5.72(1.46)$, and 13.45 (3.46) $\mathrm{kg}$ for trees 76,152 , and $228 \mathrm{~mm}$ in d.b.h. Weight of wood from lateral roots increased slightly from south to north, particularly in smaller trees (fig. 4-91).

Weight, Ovendry-On an ovendry basis the latitudinal trend was accentuated (fig. 4-92); with diameter data pooled, ovendry wood weight was minimum $(2.66 \mathrm{~kg})$ in the southernmost latitude of 40 degrees and maximum $(4.25$ and $4.15 \mathrm{~kg})$ at 55 and 60 degrees.

As when green, ovendry weight was unrelated to elevational zone but positively correlated with d.b.h., averaging $0.40(0.23), 2.88(0.85)$, and $6.82(1.97) \mathrm{kg}$ for trees of the three diameter classes.

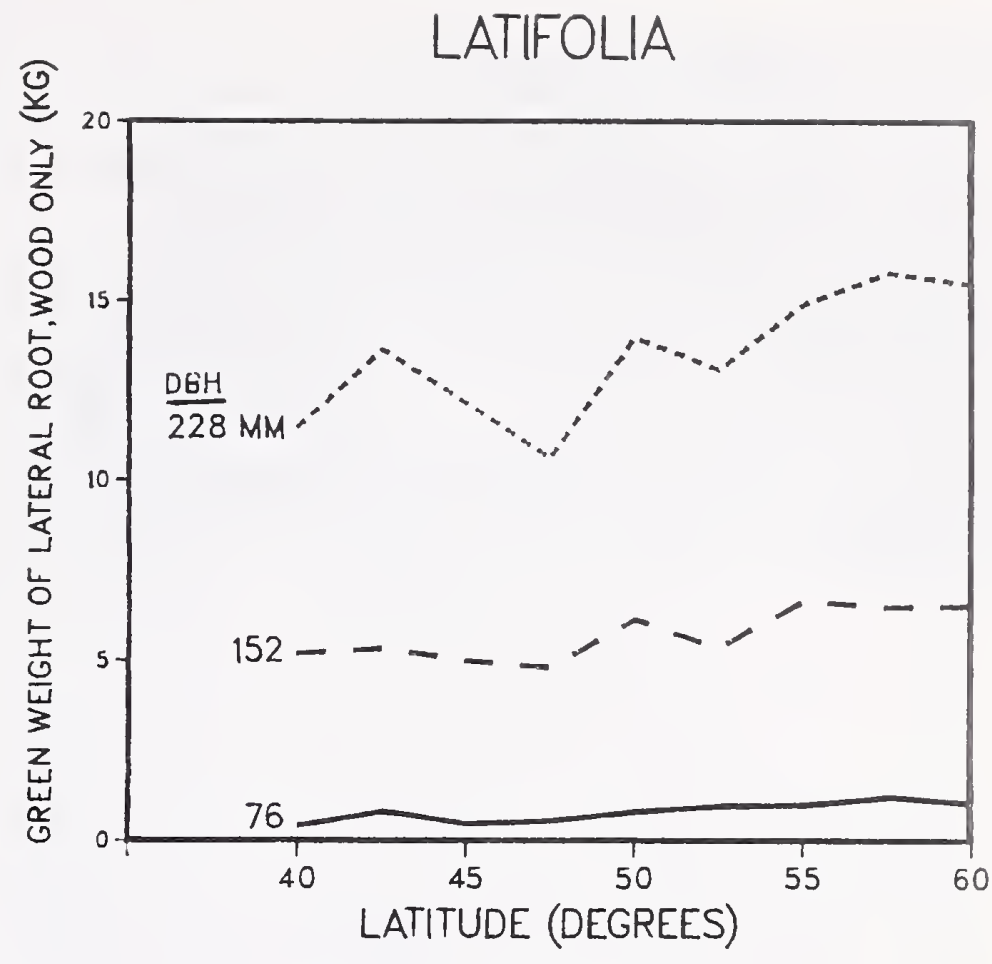

Figure 4-91-Green weight of wood of lateral roots (from root collar to $305-\mathrm{mm}$ radius from stump pith) of latifolia trees of three diameters, related to latitude.

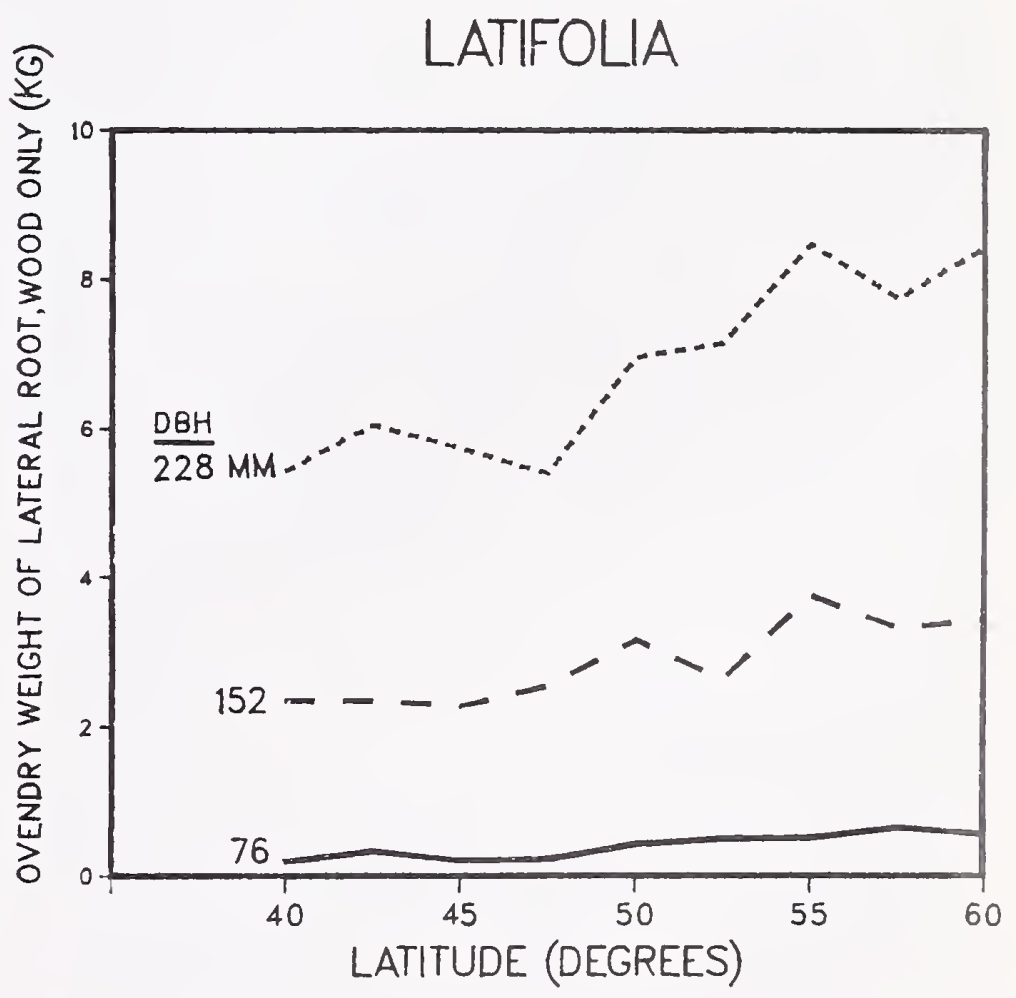

Figure 4-92-Ovendry weight of wood of lateral roots (from root collar to $305-\mathrm{mm}$ radius from stump pith) of latifolia trees of three diameters, related to latitude. 


\section{Lateral Roots, Bark Only}

Specific Gravity-Specific gravity of bark of lateral roots averaged 0.399 , with standard deviation of 0.082 , based on ovendry weight and green volume. Specific gravity was unrelated to elevational zone, but in most latitudes it was positively correlated with d.b.h. (fig. 4-93), averaging $0.375(0.070), 0.400(0.076)$, and $0.421(0.093)$ for trees 76, 152, and $228 \mathrm{~mm}$ in d.b.h. Except for latitude 40 degrees, where specific gravity averaged 0.440 , it was positively correlated with latitude with minimum $(0.346)$ at 45 degrees and a second maximum (0.435) at 55 degrees (fig. 4-93).
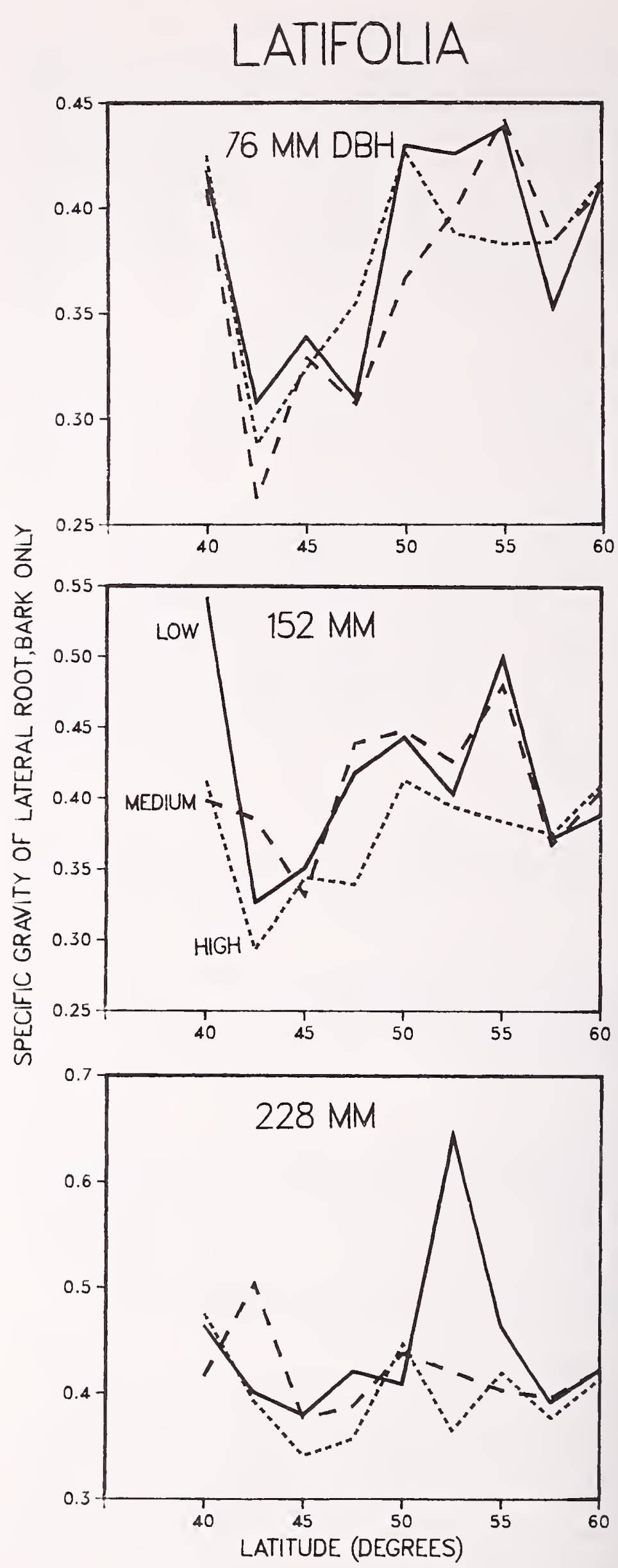

Figure 4-93-Specific gravity of bark of lateral roots (based on ovendry weight and green volume) from latifolia trees of three diameters, related to latitude and elevational zone. 
Weight, Green-With some variations (notably a minimum at 47.5 degrees), green weight of bark of lateral roots was positively correlated with latitude (fig. 4-94).

Trees in low-elevation zones averaged less weight of such bark $(1.08 \mathrm{~kg})$ than those in high zones $(1.16 \mathrm{~kg})$.

Green weight of bark of lateral roots was positively correlated with d.b.h., averaging $0.24(0.11), 1.03(0.34)$, and $2.08(0.65) \mathrm{kg}$ for trees 76,152 , and $228 \mathrm{~mm}$ in d.b.h.

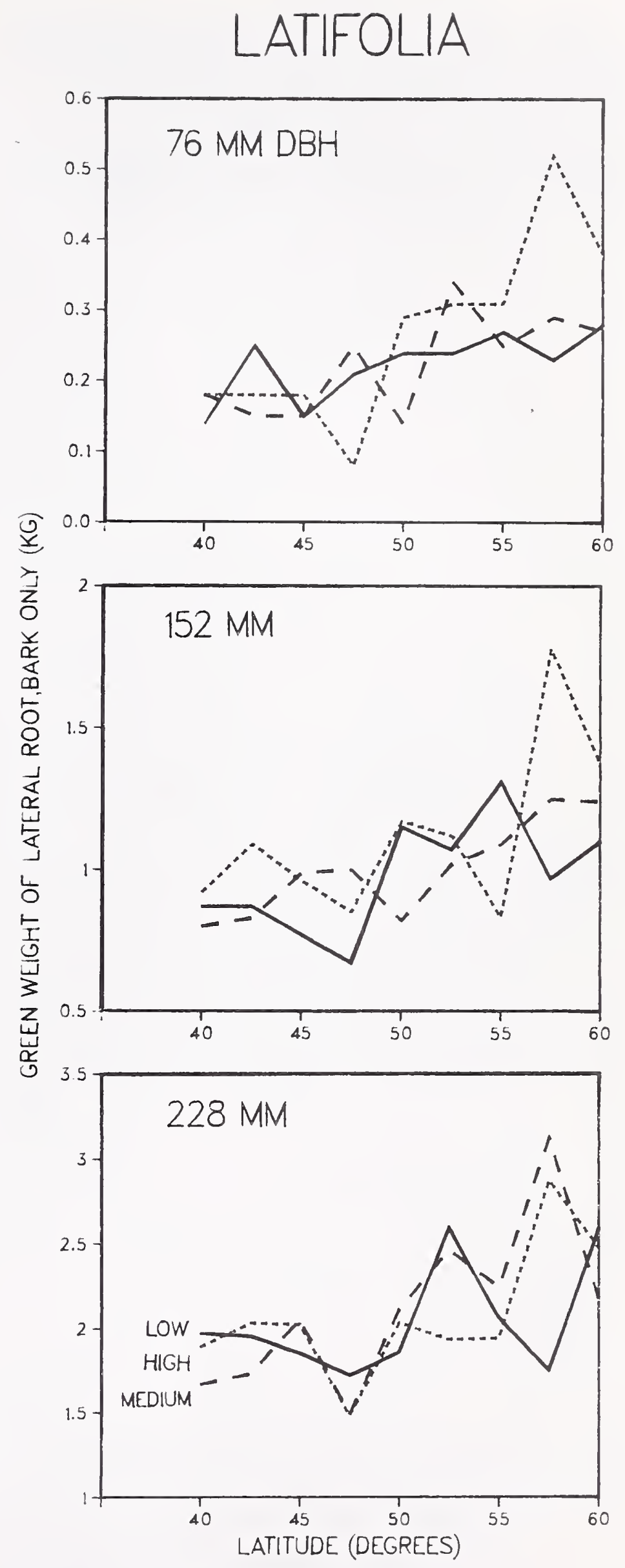

Figure 4-94-Green weight of bark of lateral roots from latifolia trees of three diameters, related to latitude and elevational zone. 
Weight, Ovendry-On an ovendry basis, weight of bark of lateral roots decreased from 40 through 47.5 degrees latitude, and then increased with increasing latitude (fig. 4-95). It was unrelated to elevational zone.

Ovendry weight of lateral rootbark was positively correlated with d.b.h., averaging $0.11(0.05), 0.49(0.17)$, and $0.99(0.33) \mathrm{kg}$ for trees of the three diameter classes.
LATIFOLIA

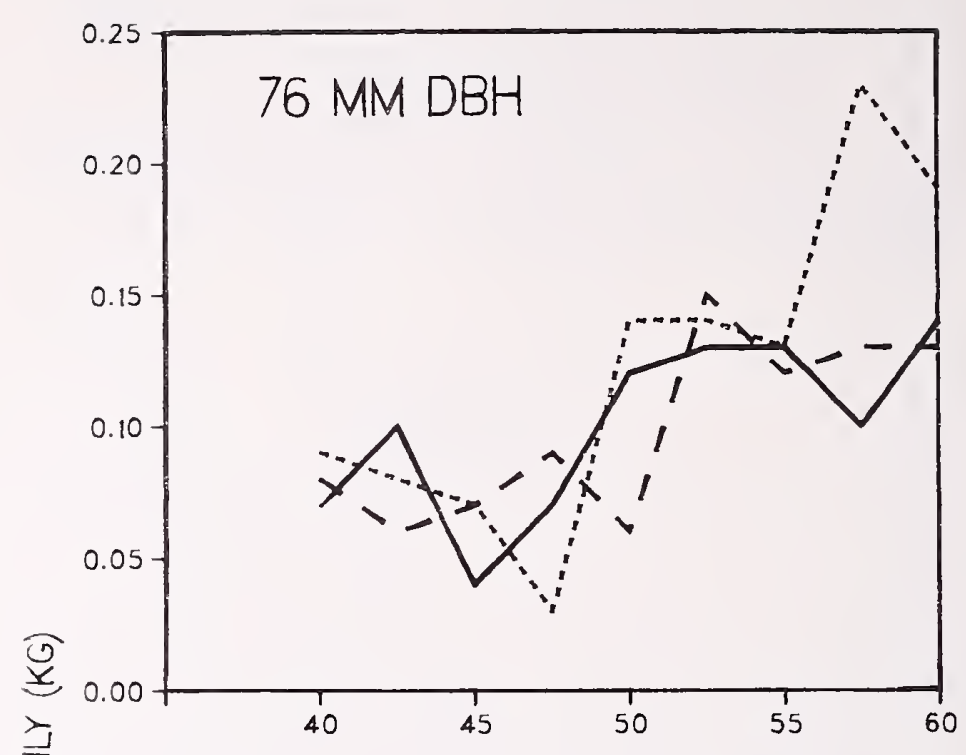

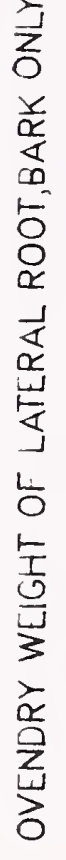
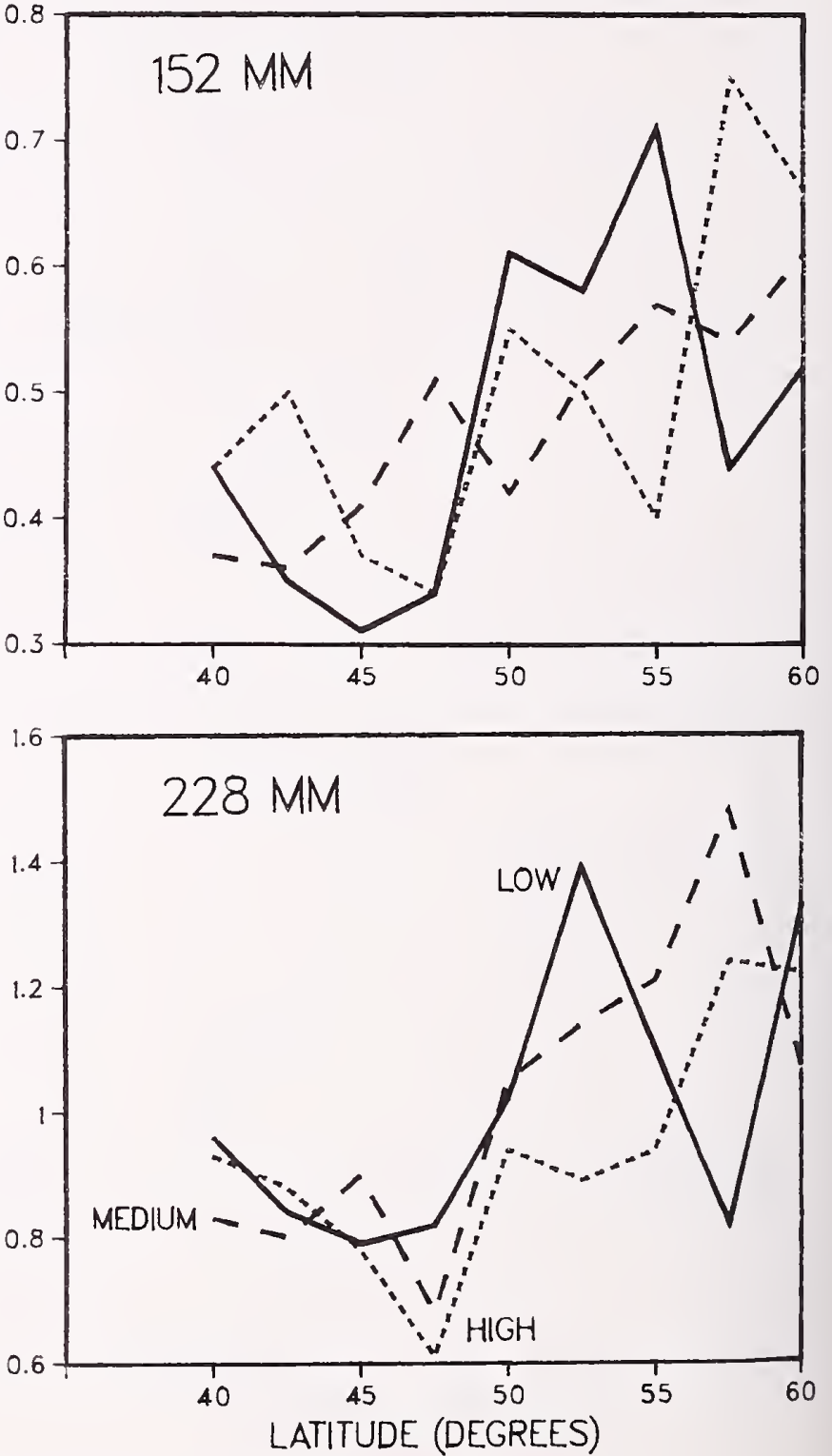

Figure 4-95-Ovendry weight of bark of lateral roots from latifolia trees of three diameters, related to latitude and elevational zone. 


\section{Central Root Mass-Taproot, Wood Plus Bark}

Specific Gravity-Specific gravity of the central root mass-taproot is second only to the stump (table 4-2), averaging 0.468 , with standard deviation of 0.052 , based on ovendry weight and green volume. In $76-\mathrm{mm}$ trees, specific gravity of wood plus bark of the central root mass-taproot is positively correlated with latitude, but in larger trees there is little latitudinal trend (fig. 4-96); neither is there a strong trend related to elevational zone.

Trees 76, 152, and $228 \mathrm{~mm}$ in d.b.h. averaged 0.462 $(0.050), 0.482(0.057)$, and $0.460(0.048)$.

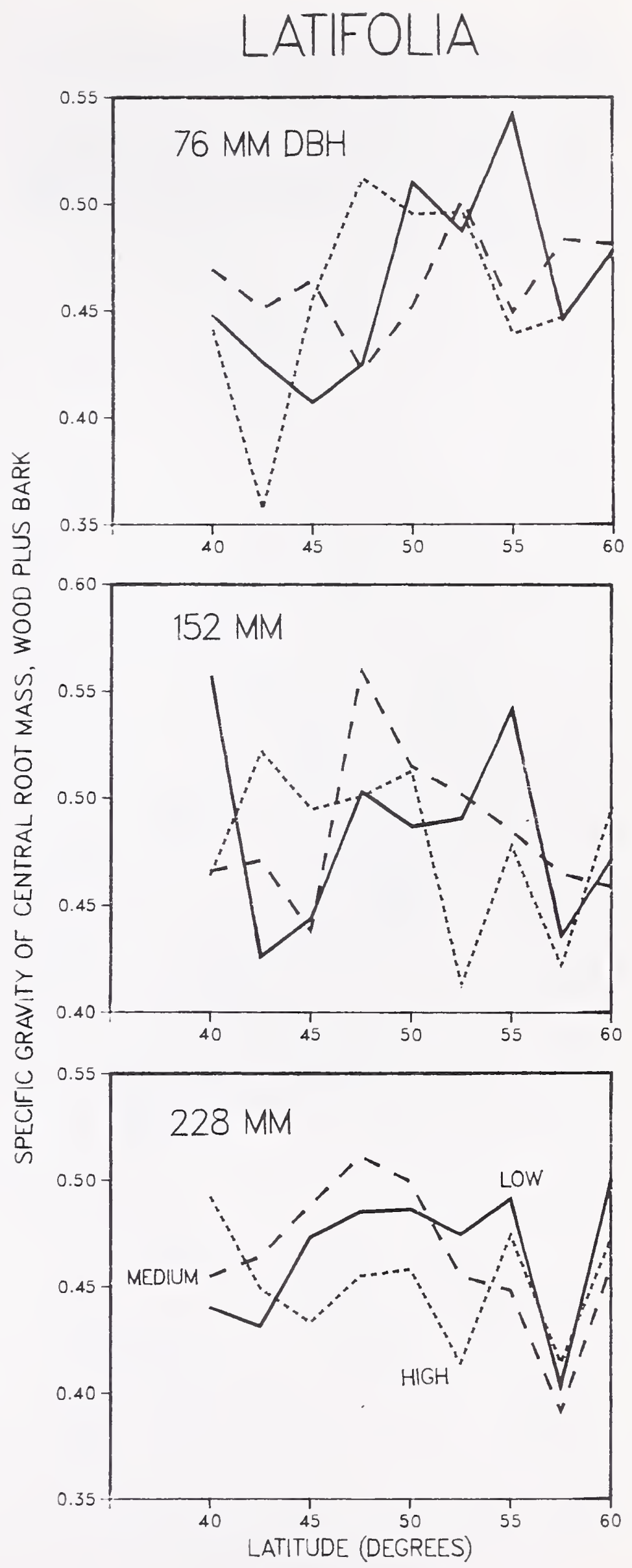

Figure 4-96-Specific gravity of wood plus bark from the central root mass-taproot (based on ovendry weight and green volume) of latifolia trees of three diameters, related to latitude and elevational zone. 
Weight, Green-In southern latitudes trees from lowelevation zones had heavier central root mass-taproots than those from high zones (fig. 4-97); on average, other latitudinal effects were minor.

Green weight of wood plus bark of this tree component was positively correlated with d.b.h., however, averaging $1.62(0.53), 8.40(2.51)$, and $20.46(5.76)$ for trees 76,152 , and $228 \mathrm{~mm}$ in d.b.h.

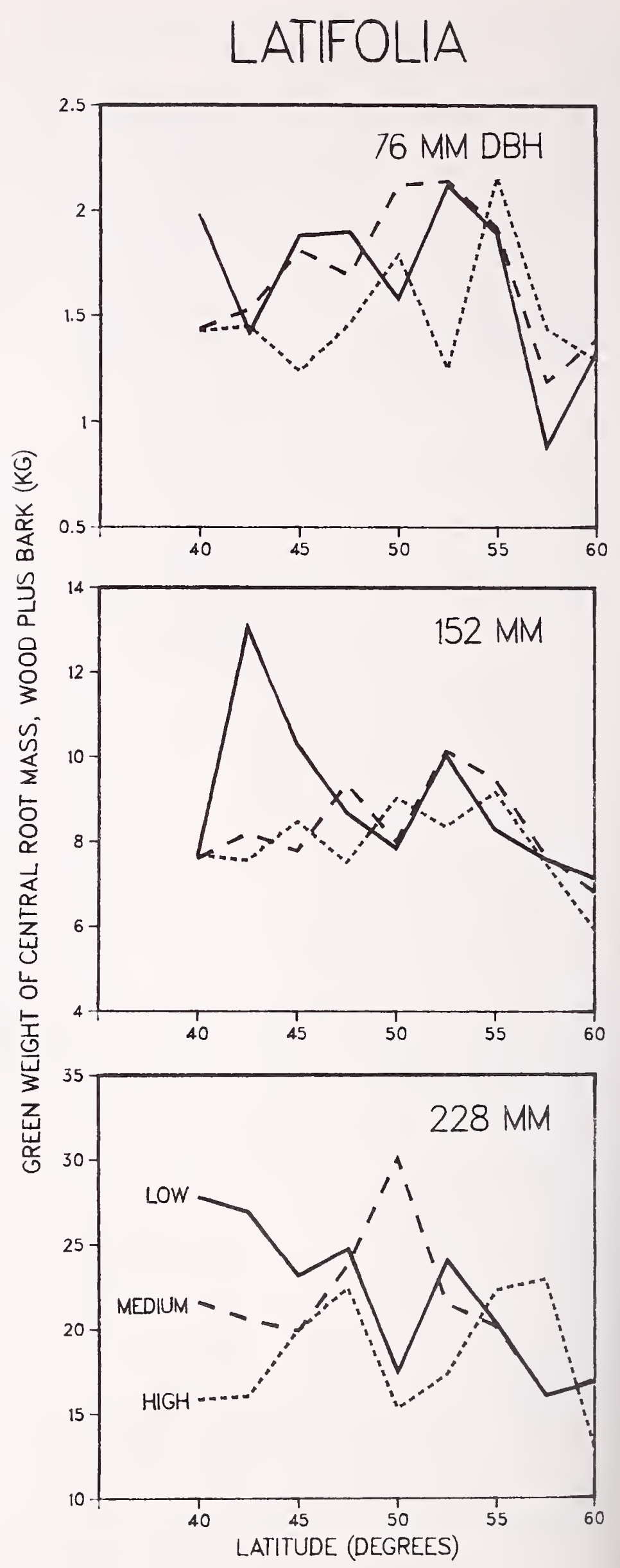

Figure 4-97-Green weight of wood plus bark of the central root mass-taproot of latifolia trees of three diameters, related to latitude and elevational zone. 
Weight, Ovendry - When ovendried, southern-latitude trees from low-elevation zones also had heavier central root mass-taproots than those from high zones (fig. 4-98). Average ovendry weights were highest $(6.02 \mathrm{~kg})$ at 47.5 degrees latitude and lowest $(4.56 \mathrm{~kg})$ at 60 degrees.

Ovendry weights, wood plus bark, were positively correlated with d.b.h., averaging $0.81(0.27), 4.45(1.28)$, and $10.74(2.81) \mathrm{kg}$ for trees of the three diameter classes.
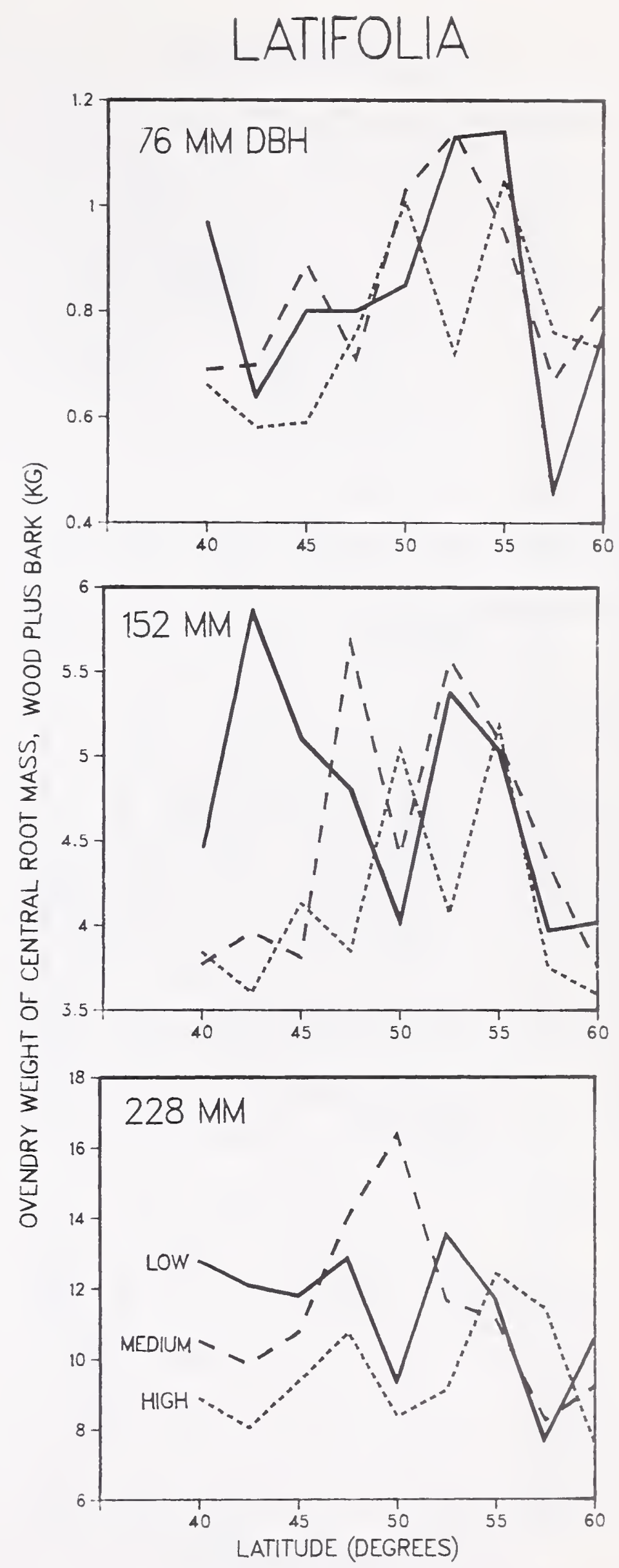

Figure 4-98-Ovendry weight of wood plus bark of the central root mass-taproot of latifolia trees of three diameters, related to latitude and elevational zone. 


\section{LATIFOLIA}
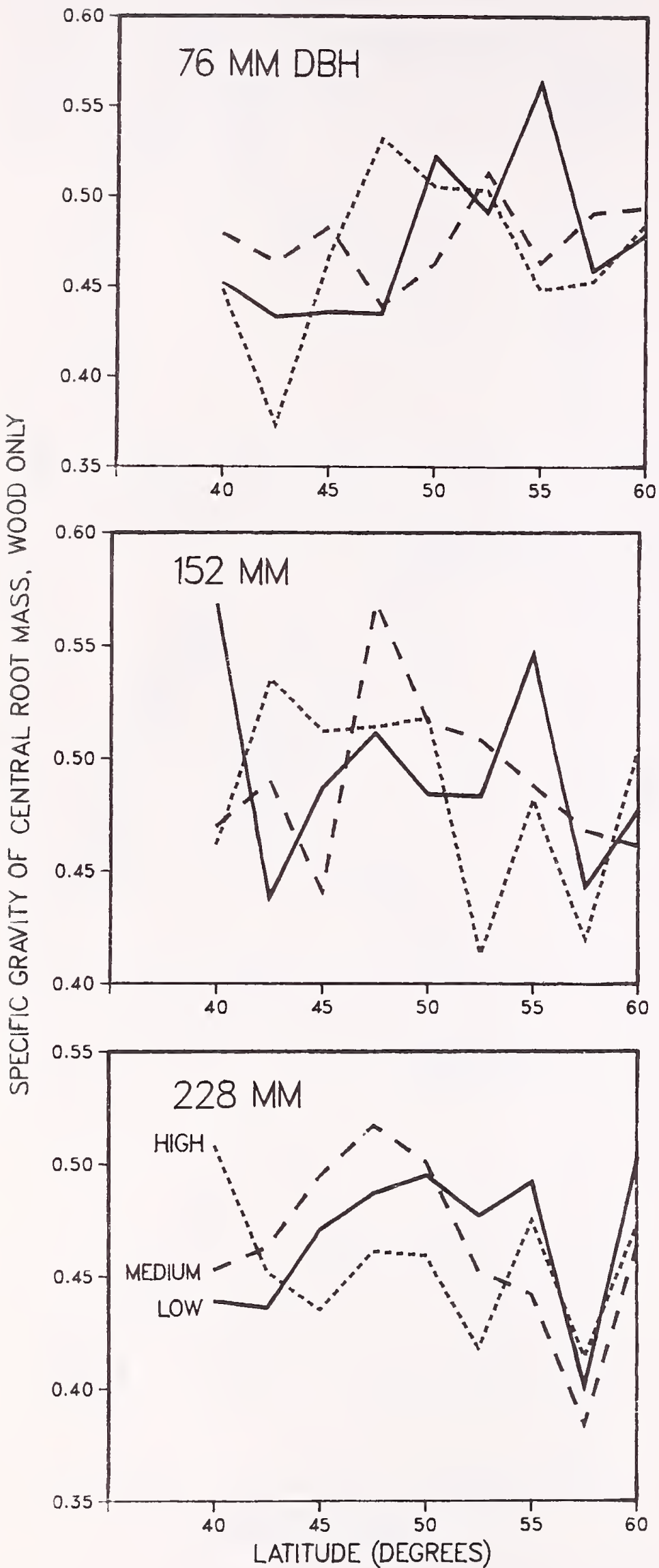

Central Root Mass-Taproot, Wood Only

Specific Gravity-Specific gravity of the wood of the central root mass-taproot was second only to stumpwood, averaging 0.475 , with standard deviation of 0.055 , based on ovendry weight and green volume. Trees from lowelevation zones tended to have specific gravities in this root portion greater than those from high zones ( 0.478 vs. 0.469 , with diameter data pooled). Except in $76-\mathrm{mm}$ trees, where specific gravity was positively correlated with latitude, latitudinal trends were not pronounced-average values ranging from a minimum of 0.437 at 57.5 degrees to a maximum of 0.496 at 50 degrees (fig. 4-99).

Specific gravity of wood of this root portion in trees 76 , 152 , and $228 \mathrm{~mm}$ in d.b.h. averaged $0.473(0.052), 0.489$ $(0.060)$, and $0.462(0.051)$.

Weight, Green-In most latitudes south of 55 degrees, trees from low-elevation zones had more weight of green wood in the central root mass-taproot than those from high zones (fig. 4-100). Green weights averaged least at the two extremes of latitude -40 and 60 degrees.

Weights of green wood from this root portion were positively correlated with d.b.h., averaging $1.40(0.46)$, $7.54(2.22)$, and $18.72(5.24) \mathrm{kg}$ for trees 76,152 , and $228 \mathrm{~mm}$ in d.b.h.

Weight, Ovendry-Weights of ovendry wood of this root portion averaged maximum at middle latitudes and minimum in the two southern and two northern latitudes (fig. 4-101). As with green wood of this root portion, south of 55 degrees latitude most trees from low-elevation zones had more weight of ovendry wood in the central root mass-taproot than trees from high zones.

Weight of ovendry wood from this root portion was positively correlated with d.b.h., averaging $0.71(0.24)$, $4.02(1.15)$, and $9.86(2.56) \mathrm{kg}$ for trees of the three diameter classes.

Figure 4-99-Specific gravity of wood of the central root mass-taproot (based on ovendry weight and green volume) from latifolia trees of three diameters, related to latitude and elevational zone. 
LATIFOLIA
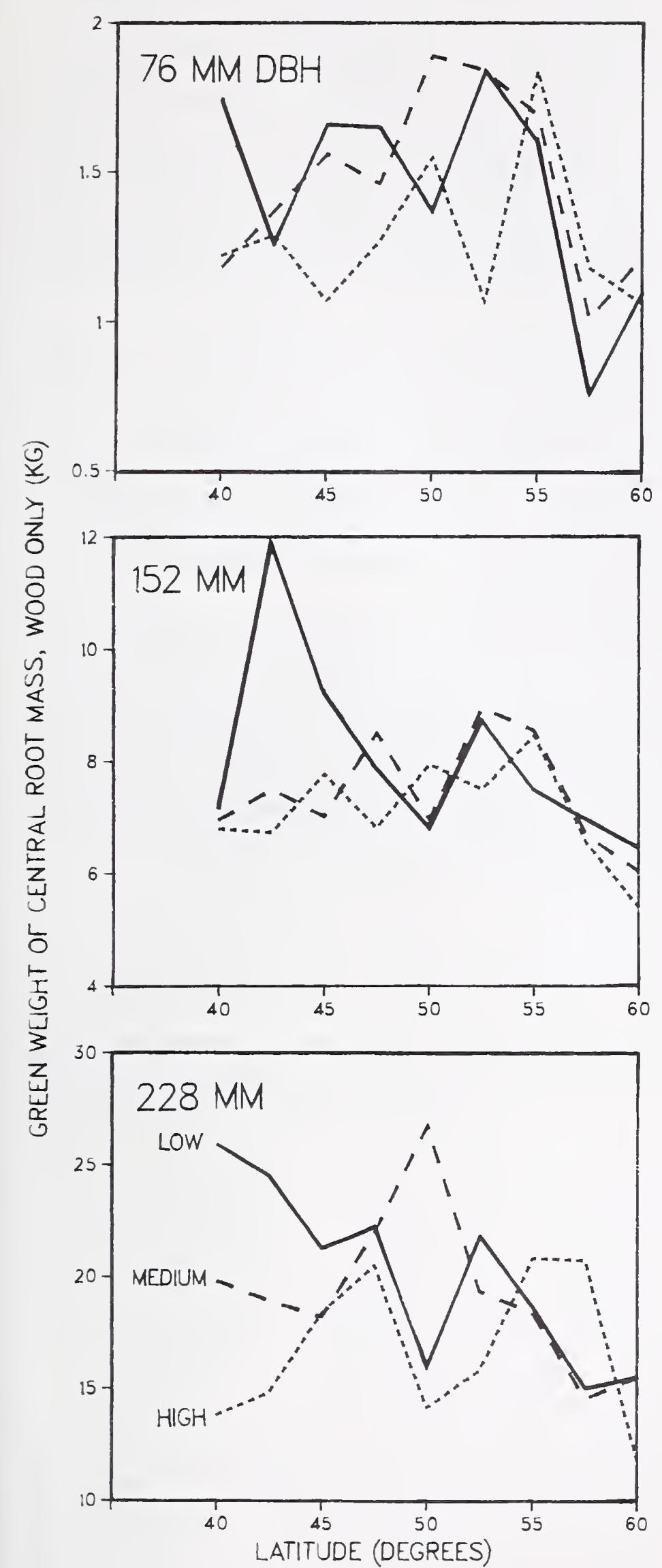

Figure 4-100-Green weight of wood from the central root mass-taproot of latifolia trees of three diameters, related to latitude and elevational zone.
LATIFOLIA
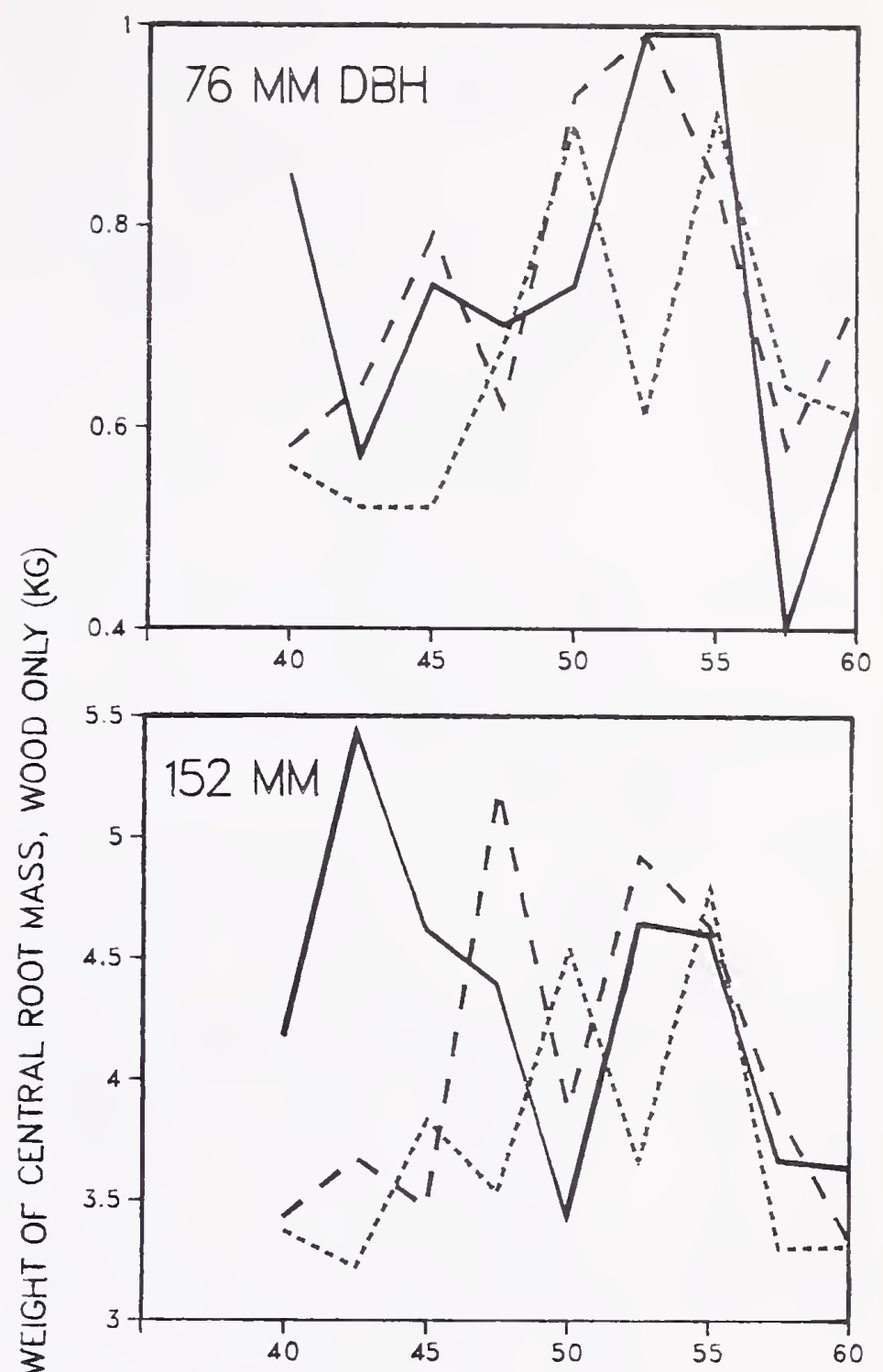

文

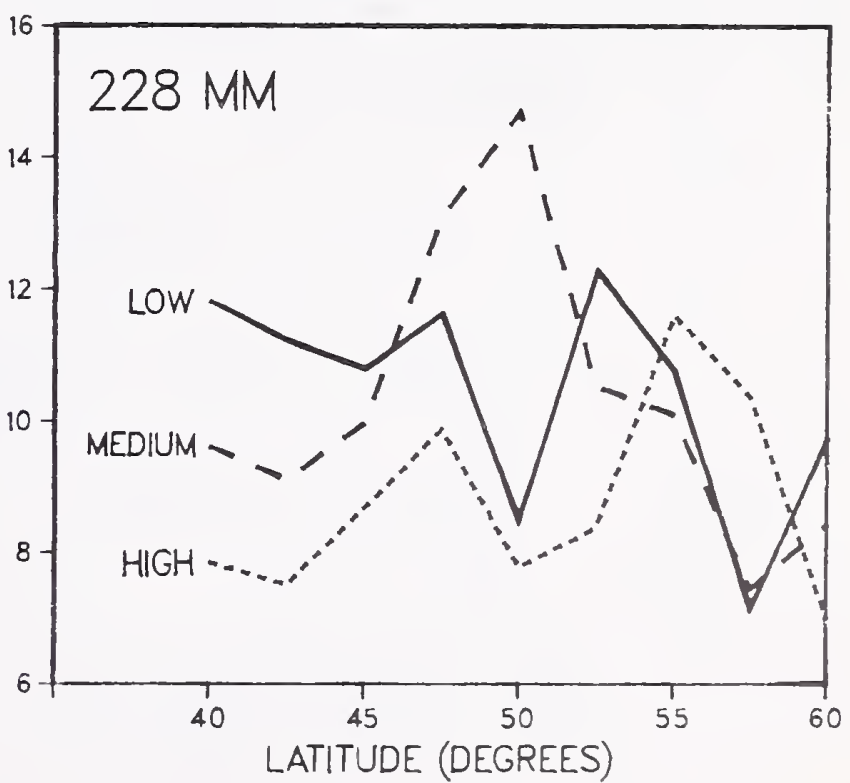

Figure 4-101-Ovendry weight of wood from the central root mass-taproot of latifolia of three diameters, related to latitude and elevational zone. 


\section{LATIFOLIA}
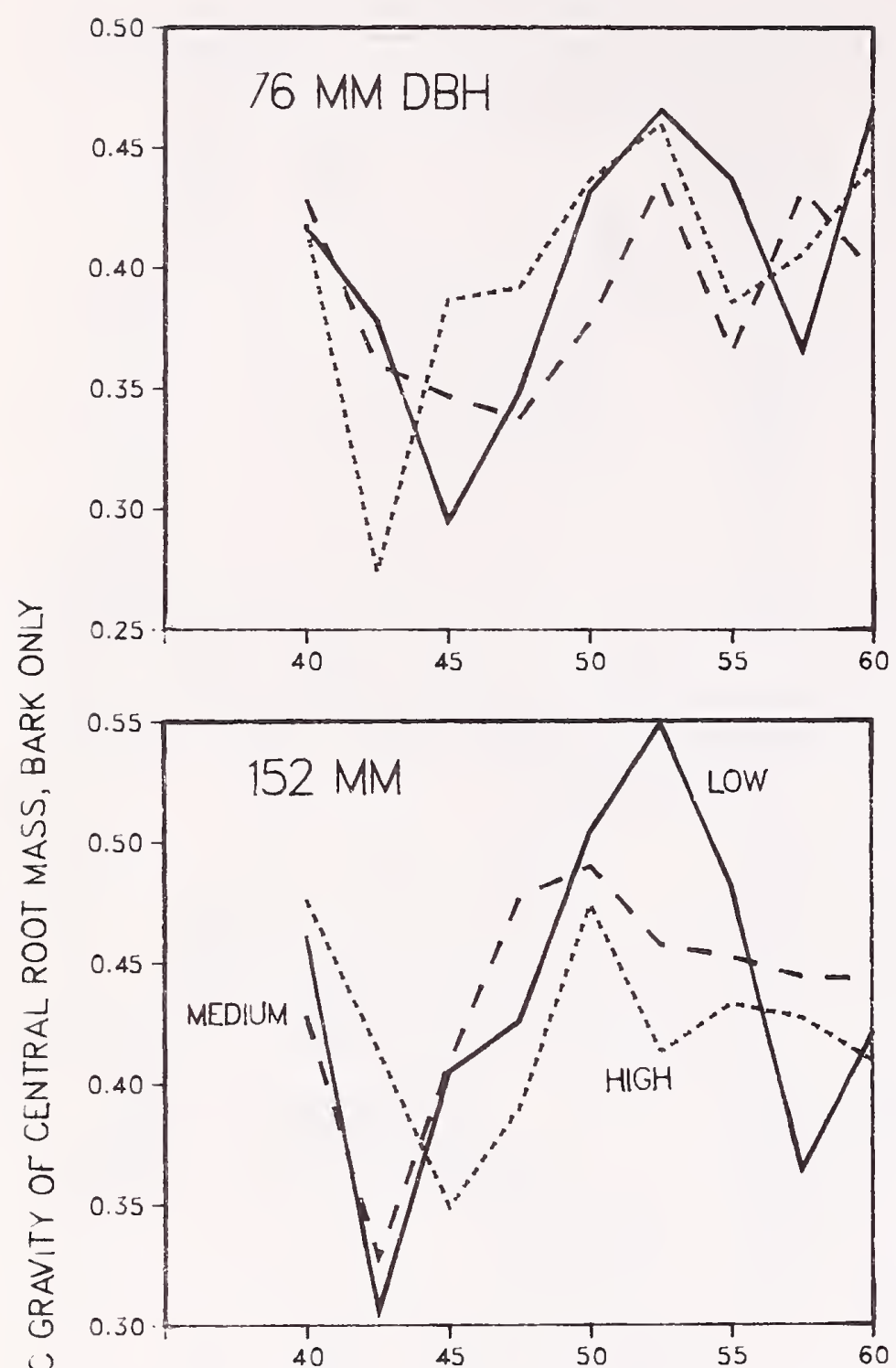

这

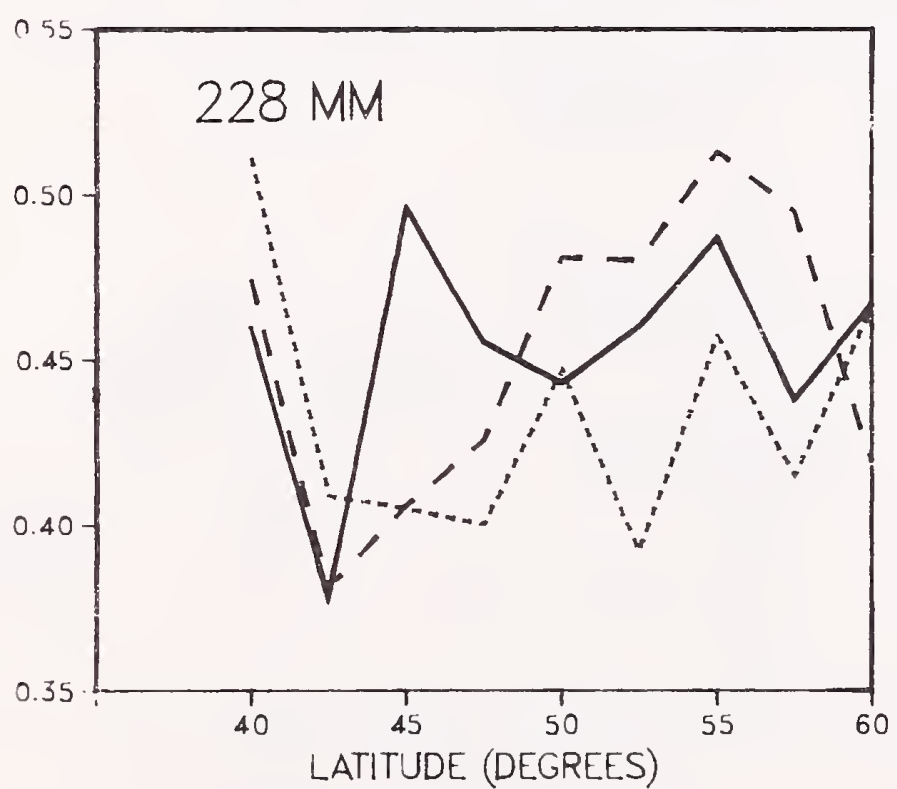

\section{Central Root Mass-Taproot, Bark Only}

Specific Gravity-Specific gravity of the bark of the central root mass-taproot was second only to that of stumpbark (table 4-2), averaging 0.425 , with standard deviation of 0.066 . At most latitudes it was inversely correlated with elevational zone, averaging $0.430,0.425$, and 0.418 in low, medium, and high zones. It averaged minimum (0.359 to 0.406 ) from 42.5 to 47.5 degrees latitude; in other latitudes it exceeded 0.420 (fig. 4-102).

Specific gravity of bark of this root portion was positively correlated with d.b.h., averaging $0.396(0.064), 0.431$ $(0.065)$, and $0.447(0.060)$ for trees 76,152 , and $228 \mathrm{~mm}$ in d.b.h.

Weight, Green-In most latitudes weight of green bark of the central root mass-taproot was greater in lowelevation zones than in high (fig. 4-103). It averaged least $(0.72$ to $0.90 \mathrm{~kg})$ in the three northernmost latitudes and maximum $(1.02$ to $1.08 \mathrm{~kg})$ in the three middle latitudes.

Weights of green bark from this root portion were positively correlated with d.b.h., averaging $0.23(0.09)$, $0.87(0.39)$, and $1.75(0.68) \mathrm{kg}$ for trees of the three diameter classes.

Weight, Ovendry-Also when ovendry, weight of bark from the central root mass-taproot was usually greater in low-elevation zones than in high (fig. 4-104). It averaged least $(0.38$ and $0.39 \mathrm{~kg})$ at 42.5 and 60 degrees latitude and most $(0.56$ and $0.59 \mathrm{~kg})$ at 50 and 52.5 degrees.

Weights of ovendry bark from this root portion were positively correlated with d.b.h., averaging $0.10(0.04)$, $0.43(0.19)$, and $0.88(0.34) \mathrm{kg}$ for trees 76,152 , and $228 \mathrm{~mm}$ in d.b.h.

Figure 4-102-Specific gravity of bark (based on ovendry weight and green volume) from the central root mass-taproot of latifolia trees of three diameters, related to latitude and elevational zone. 
LATIFOLIA
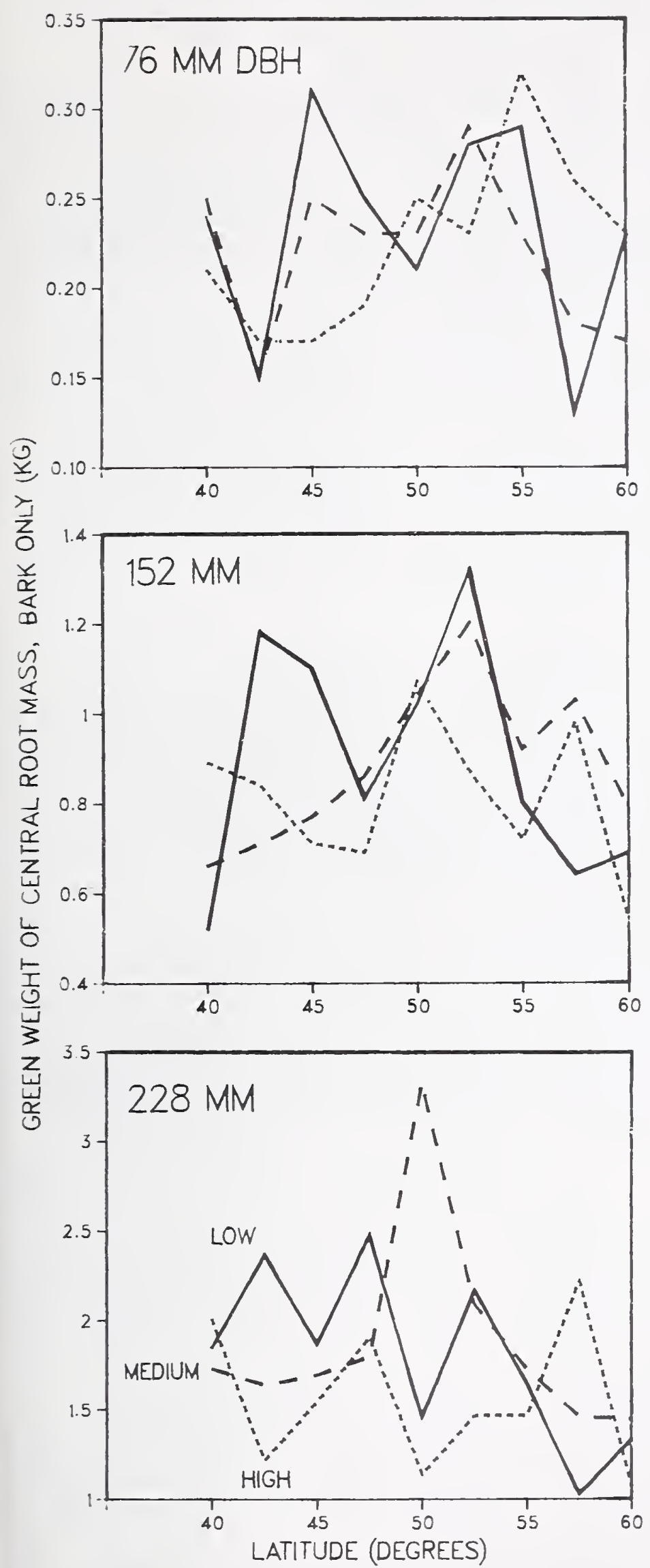

Figure 4-103-Green weight of bark from the central root mass-taproot of latifolia trees of three diameters, related to latitude and elevational zone.
LATIFOLIA
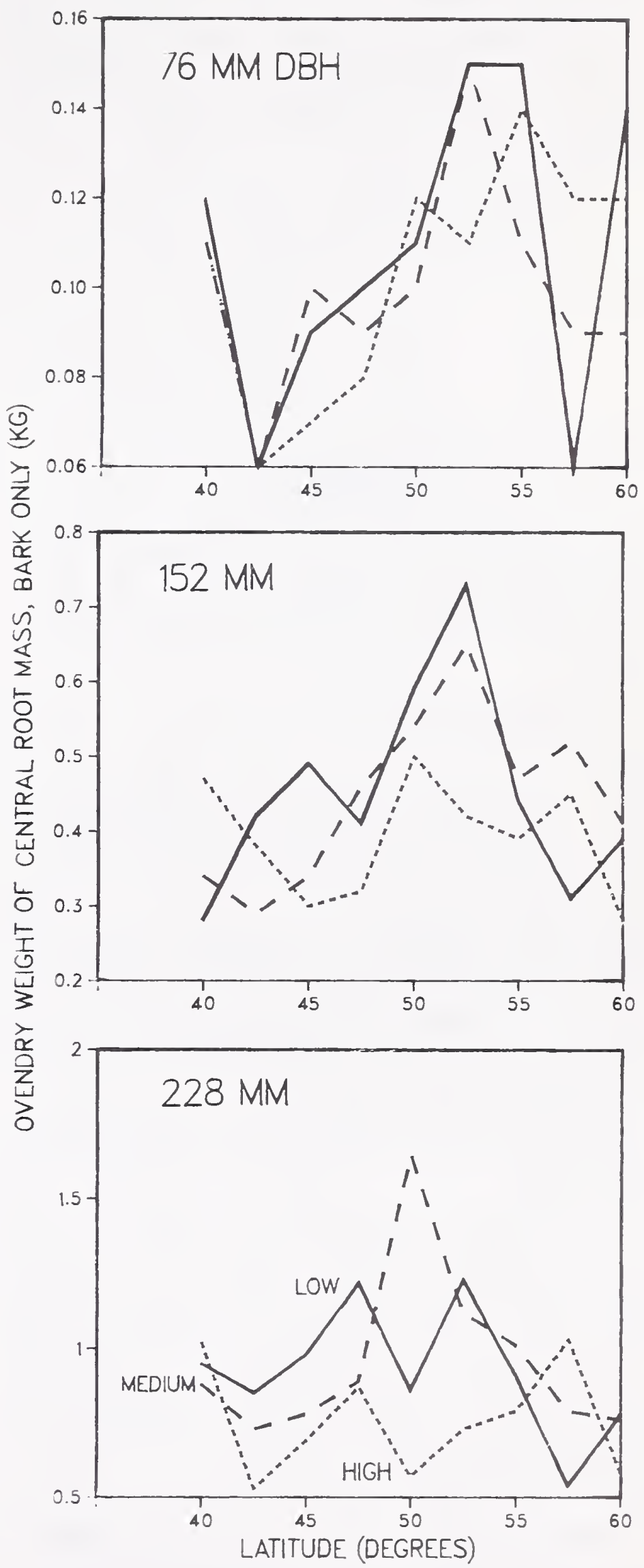

Figure 4-104-Ovendry weight of bark from the central root mass-taproot of latifolia trees of three diameters, related to latitude and elevational zone. 


\section{4-6 RESULTS-MURRAYANA}

For trees of variety murrayana, the three d.b.h. classes averaged $76 \mathrm{~mm}$ with standard deviation of $1.8 \mathrm{~mm}$, $151 \mathrm{~mm}$ with standard deviation of $2.9 \mathrm{~mm}$, and $229 \mathrm{~mm}$ with standard deviation of $3.9 \mathrm{~mm}$. All were selected at medium elevation, which for the four latitudes averaged as follows (fig. 1-1):

\begin{tabular}{|c|c|c|}
\hline Latitude & Elevation & General location \\
\hline Degrees & Meters & \\
\hline 37.5 & 2,402 & $\begin{array}{l}\text { Just east of Yosemite } \\
\text { National Park }\end{array}$ \\
\hline 40 & 1,676 & Vicinity of Quincy, CA \\
\hline 42.5 & 2,006 & Southwest of Paisley, OR \\
\hline 45 & 1,148 & North of Breitenbush, OR \\
\hline
\end{tabular}

Because the entire murrayana sample totaled but 36 trees, correlations among tree characteristics are not noted in the detail provided for the 243 latifolia trees. It is worth noting, however, that for the 36 murrayana trees, stemwood specific gravity and average growth-ring width at 152 -mm stump height were more closely correlated than in latifolia trees. The murrayana equation follows $\left(R^{2}=0.312\right.$; standard error of the estimate $=$ $0.0449)$ :

$$
G=0.5462-0.0519 W
$$

where:

$$
\begin{aligned}
G= & \text { stemwood specific gravity at } 152-\mathrm{mm} \text { stump } \\
& \text { height, basis of ovendry weight and green volume } \\
W= & \text { average growth-ring width at } 152-\mathrm{mm} \text { stump } \\
& \text { height, mm. }
\end{aligned}
$$

This equation is applicable only at $152-\mathrm{mm}$ stump height, where stemwood specific gravity averaged 0.488 and growth-ring width averaged $1.12 \mathrm{~mm}$.

Standard deviations for diameter-class data are noted in parentheses following their average values, as they were in the latifolia results section.

Even with this small sample (nine trees per latitude), numerous latitudinal differences were observed. Only those statistically significant $(0.05$ level $)$ are graphed or tabulated.

Average specific gravities of tree components are summarized in table 4-2, weights in table 4-3, major tree component proportions of weight in table $4-4$, bark weight proportions of components in table 4-5, and green weights of the three major tree components required to yield $1 \mathrm{~m}^{3}$ of wood in table 4-6; interpretation of these averages requires reference to the main effects and interaction attributable to d.b.h., latitude, and elevational zone-as discussed in the following paragraphs.

\section{Complete Tree With Cones and Foliage}

Weight, Green-Complete-tree green weight was not significantly related to latitude, but was positively correlated with tree d.b.h., averaging 24.25 (4.48), 151.57 (34.30), and 419.37 (76.70) $\mathrm{kg}$ for the three diameter classes.
Weight, Ovendry-Similarly, complete-tree ovendry weight was unrelated to latitude, but was positively correlated with d.b.h., averaging 12.11 (2.43), 72.95 (19.03), and $197.65(43.03) \mathrm{kg}$ for the three diameter classes.

\section{Complete Tree Without Cones or Foliage}

Specific Gravity-Complete-tree specific gravity (wood plus bark-but not foliage-of all components) significantly increased from south to north (fig. 4-105, top), and was negatively correlated with d.b.h., averaging $0.464(0.033)$, $0.438(0.036)$, and $0.413(0.025)$ for $76-, 152-$, and $228-\mathrm{mm}$ trees, respectively (fig. 4-105, top).

Weight, Green-Without foliage, complete-tree green weight was unrelated to latitude, but was positively correlated with d.b.h., averaging 22.45 (4.35), 143.38 (34.83), and $399.54(78.32) \mathrm{kg}$ for the three diameter classes.

Weight, Ovendry-Similarly, foliage-free complete-tree ovendry weight was unrelated to latitude, but averaged 11.28 (2.44), 69.02 (19.43), and 188.37 (44.07) $\mathrm{kg}$ for the three diameter classes.

\section{Complete Tree, Wood Only}

Specific Gravity-Treewood specific gravity (data from stem, branches, and stump-root system included) generally increased from south to north in the two larger diameter classes (fig. 4-105, center), and was negatively correlated with d.b.h., averaging $0.482(0.039), 0.440(0.042)$, and $0.407(0.031)$ for trees 76,152 , and $228 \mathrm{~mm}$ in d.b.h., respectively.

Weight, Green-Treewood green weight was not significantly related to latitude, but was positively correlated with d.b.h., averaging 19.02 (3.88), 127.59 (33.27), and $362.34(77.26) \mathrm{kg}$ for the three diameter classes.

Weight, Ovendry-Correspondingly, ovendry weight of complete-tree wood averaged 9.74 (2.26), 61.44 (18.66), and $169.91(43.38) \mathrm{kg}$ for the three diameter classes.

\section{Complete Tree, Bark Only}

Specific Gravity-Specific gravity of treebark (data from stem, branches, and stump-root system included) did not vary with tree d.b.h., and averaged 0.379 , with standard deviation of 0.033 . It did, however, vary with latitude, with maximum of 0.404 at 42.5 degrees and minimum of 0.355 at 37.5 degrees (fig. $4-105$, bottom).

Weight, Green-Green bark weight of the complete tree was unrelated to latitude, but was positively correlated with d.b.h., averaging 3.39 (0.69), 15.54 (2.51), and 36.37 $(5.51) \mathrm{kg}$ for the three diameter classes, respectively.

Weight, Ovendry-Correspondingly, ovendry weight of complete-tree bark averaged $1.51(0.29), 7.36(1.05)$, and $17.77(2.91) \mathrm{kg}$ for the three diameter classes. 


\section{MURRAYANA}
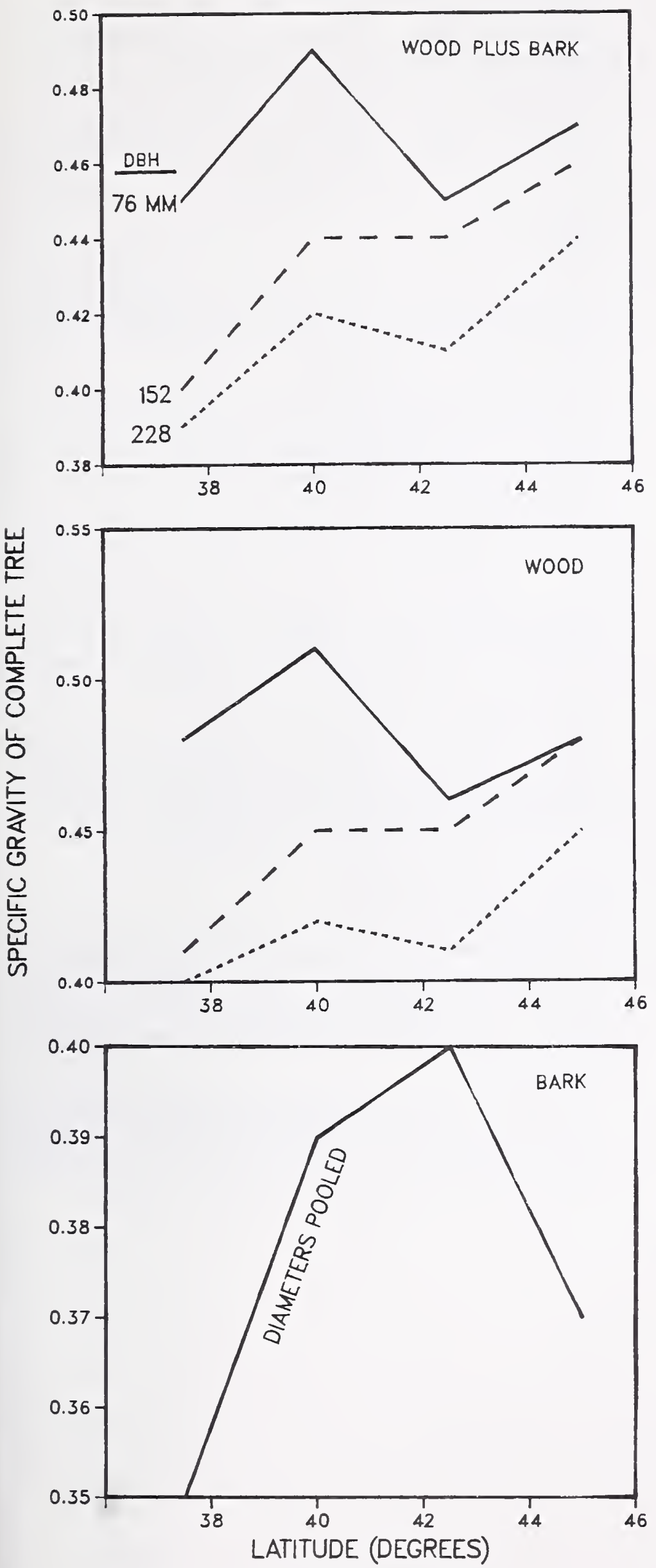

Figure 4-105-Specific gravity (based on ovendry weight and green volume) of wood plus bark, wood only, and bark only of complete murrayana trees of three diameters, related to latitude.
Percentage of Weight of Gross Foliage-Free Complete Tree, Green and Ovendry-Treebark percentage of gross foliage-free complete-tree weight was inversely correlated with latitude (fig. 4-106) and with d.b.h., as follows:

\begin{tabular}{|c|c|c|}
\hline \multirow[b]{2}{*}{ D.b.h. } & \multicolumn{2}{|c|}{ Moisture condition } \\
\hline & Green & Ovendry \\
\hline$m m$ & \multicolumn{2}{|c|}{$\ldots$. Percent ..... } \\
\hline 76 & $15.25(2.55)$ & $13.67(2.26)$ \\
\hline 152 & $11.31(2.41)$ & $11.31(2.54)$ \\
\hline 228 & $9.45(2.58)$ & $9.56(3.12)$ \\
\hline
\end{tabular}

MURRAYANA
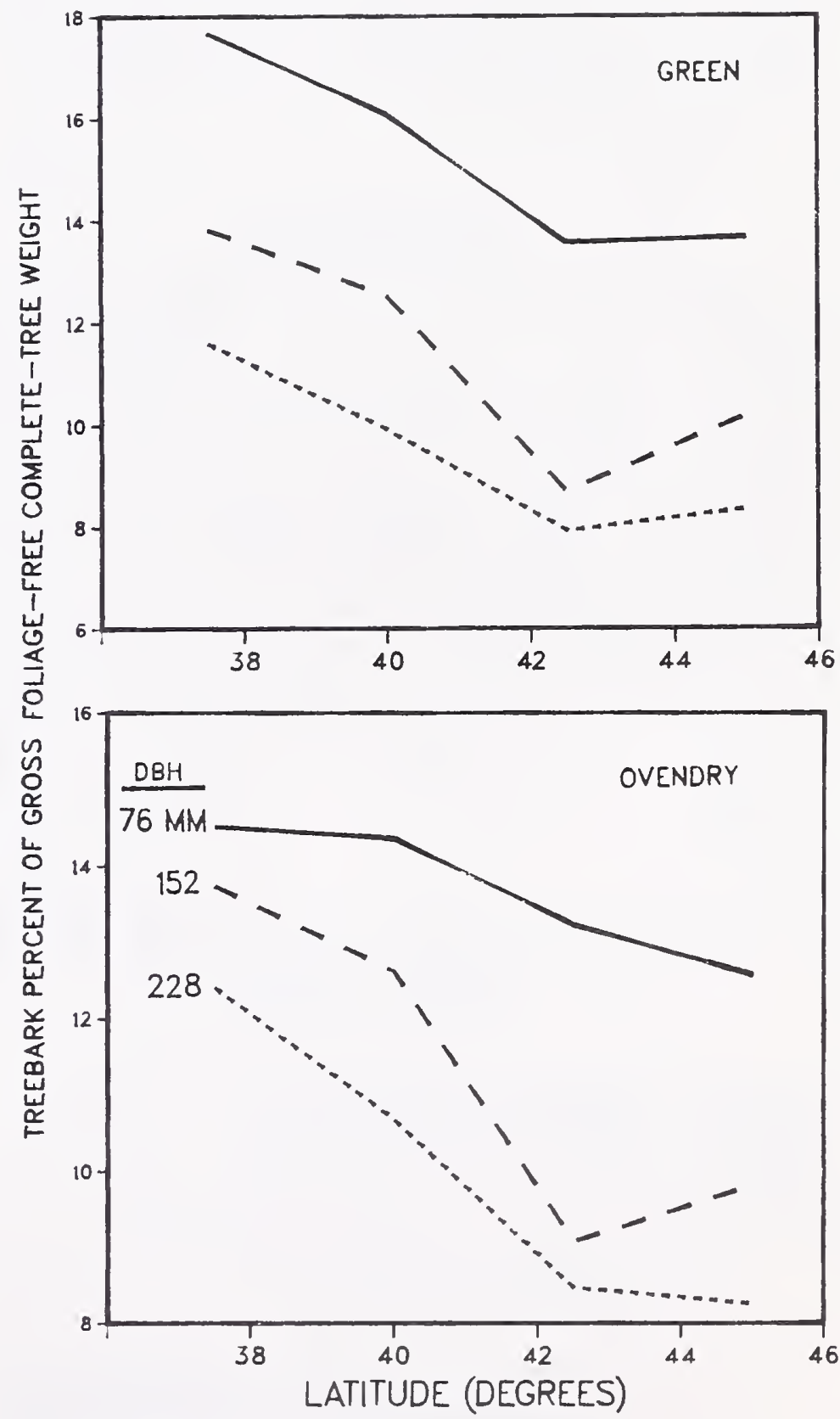

Figure 4-106-Treebark (from branches, stem, and stump-root system) as percentage of gross foliage-free complete-tree weight-green and ovendry, for murrayana trees of three diameters, related to latitude. 


\section{Foliage}

Weight, Green-Technical-foliage green weight per tree was unrelated to latitude, but was positively correlated with d.b.h., averaging 1.81 (0.81), 8.19 (3.52), and 19.83 (5.39) $\mathrm{kg}$ for the three diameter classes.

Weight, Ovendry-Correspondingly, ovendry foliage weight averaged $0.83(0.38), 3.94(1.79)$, and $9.28(2.50)$ for the three diameter classes.

Tree Component Proportion, Green-Weight Basis-On a green-weight basis foliage as a percentage of completetree weight was unrelated to either latitude or d.b.h., with overall average of 6.12 percent and standard deviation of 3.19 percentage points.

Tree Component Proportion, Ovendry-Weight BasisOn an ovendry-weight basis, however, foliage as a percentage of complete tree weight was negatively correlated with latitude (fig. 4-107); average foliage weights were highest at 37.5 degrees (8.44 percent) and lowest at 45 degrees (4.09 percent). Overall dry-weight foliage proportion averaged 6.05 percent, with standard deviation of 3.43 percentage points.

\section{MURRAYANA}

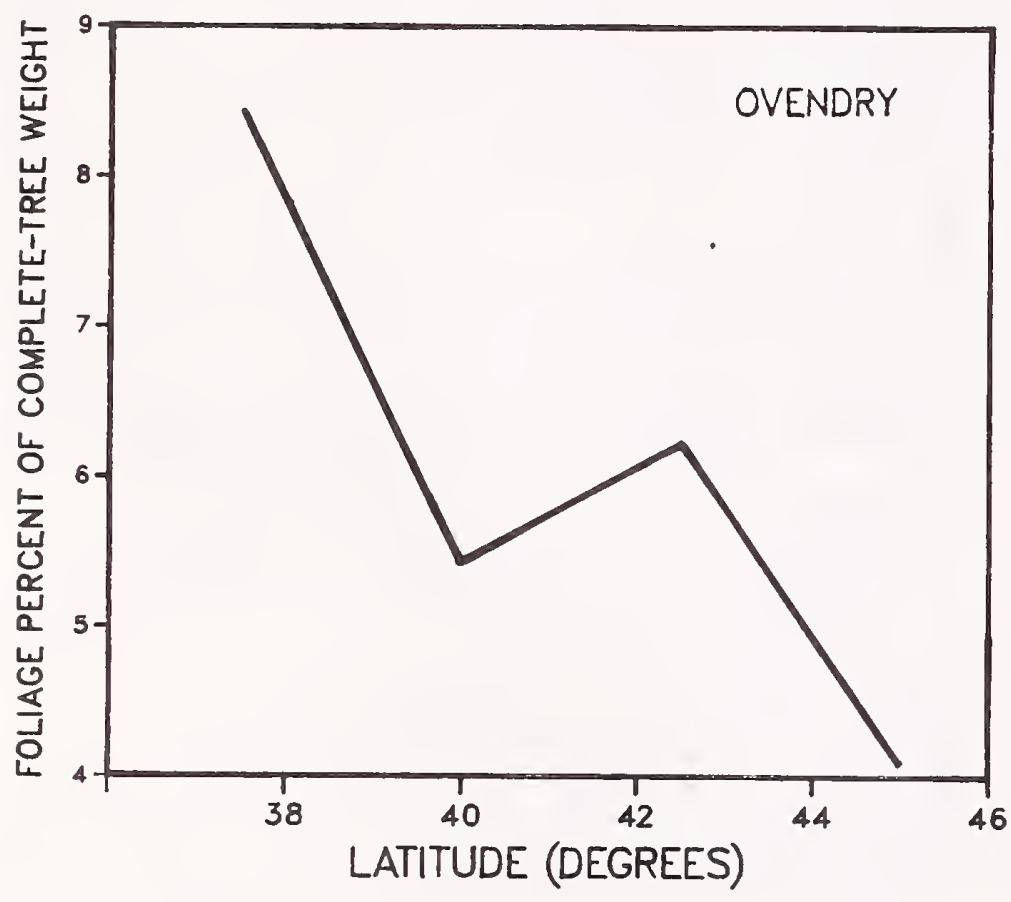

Figure 4-107-Foliage as percentage of complete-tree weight (ovendry basis) for murrayana trees, related to latitude; diameter data pooled.

\section{Cones, Individual}

Weight, Green-Individual green cone weight, as sampled from the tip $305 \mathrm{~mm}$ of the top 25 branches, was unrelated to latitude or d.b.h., with overall average of $4.90 \mathrm{~g}$ per cone and standard deviation of $0.92 \mathrm{~g}$.

Weight, Ovendry-Similarly, dry cone weight was unrelated to either latitude or d.b.h., and averaged $4.11 \mathrm{~g}$, with standard deviation of $0.99 \mathrm{~g}$.

\section{All Cones on Tree}

As explained in chapter 1, weight of all cones on each tree was computed, not measured directly, and therefore results should be interpreted with caution.

Weight, Green-Green weight of all cones on each tree was unrelated to latitude but was positively correlated with d.b.h., averaging 38 (105), 246 (221), and 833 (572) g for the three diameter classes.

Weight, Ovendry-Similarly, ovendry weight averaged 31 (86), 209 (190), and 691 (513) $\mathrm{g}$ for the three diameter classes.

Tree Component Proportion, Green-Weight BasisWeight of green cones averaged $0.14(0.36), 0.17(0.17)$, and $0.21(0.17)$ percentage of green complete-tree weight for trees 76,152 , and $228 \mathrm{~mm}$ in d.b.h.; these percentages were unrelated to latitude.

Tree Component Proportion, Ovendry-Weight BasisSimilarly, weight of ovendry cones averaged $0.22(0.61)$, $0.30(0.31)$, and $0.37(0.32)$ percent of ovendry weight of complete trees of the three diameter classes.

\section{Dead Branchwood}

Weight, Green-Green weight of dead branches was greater in northern than in southern latitudes (fig. 4-108, top), and was positively correlated with d.b.h., averaging $0.26(0.18), 1.08(0.69)$, and $4.91(4.50) \mathrm{kg}$ for the three diameter classes.

Weight, Ovendry-Latitudinal trends were similar on an ovendry-weight basis (fig. 4-108, bottom); ovendry deadbranch weights per tree averaged $0.21(0.15), 0.89(0.57)$, and $4.34(3.64) \mathrm{kg}$ for the three diameter classes. 
MURRAYANA

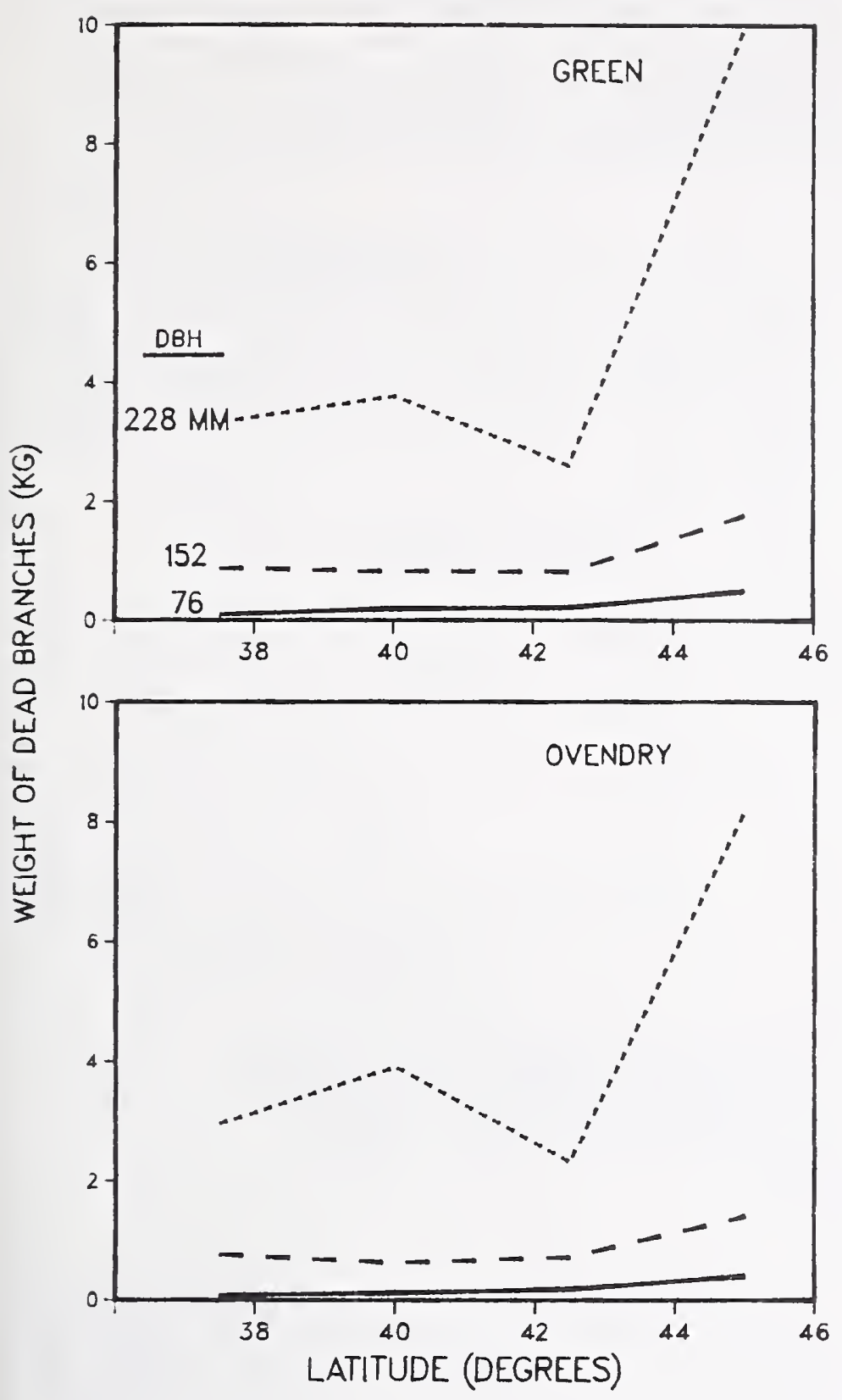

Tree Component Proportion, Green-Weight BasisDead branches, green-weight basis, totaled 1.02 percent of complete-tree weight, with standard deviation of 0.84 percent; this proportion did not vary significantly with d.b.h., but was significantly higher at 45 degrees latitude than in the three southerly latitudes (fig. 4-109, top).

Tree Component Proportion, Ovendry-Weight BasisOn an ovendry-weight basis, dead branches comprised 1.77 percent of complete-tree weight, with standard deviation of 1.39 percent. Trees in southern latitudes had a smaller proportion of dead-branch weight than those at the northernmost latitude (fig. 4-109, bottom).

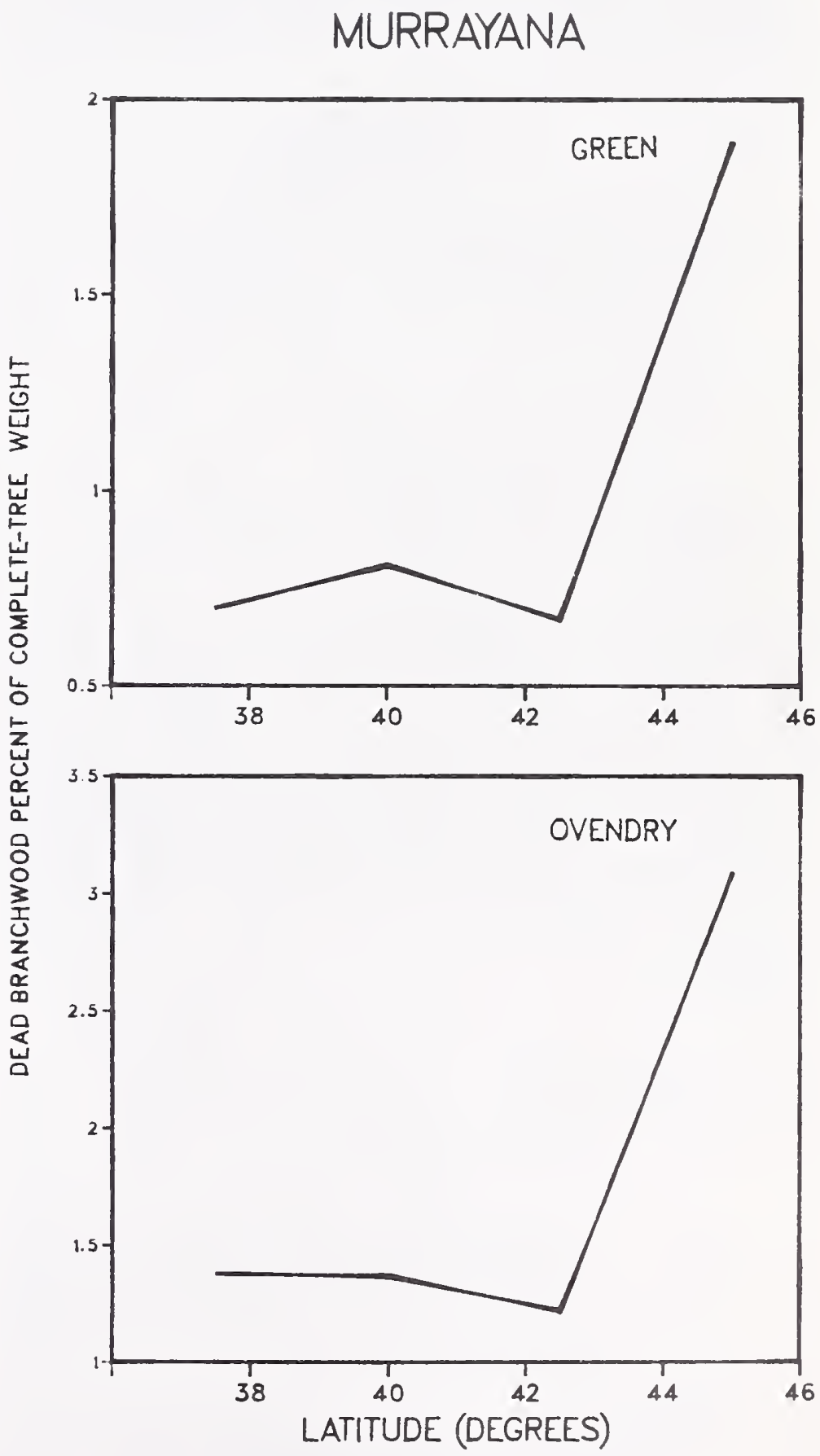

Figure 4-109-Dead branchwood as percentage of the weight of complete trees with foliage (green and ovendry) for murrayana trees related to latitude; diameter data pooled. 


\section{Live Branches, Wood Plus Bark}

Specific Gravity-Specific gravity of live branches (wood plus bark) was unrelated to tree d.b.h., but varied with latitude (fig. 4-110, top); it was minimum (0.437) at 37.5 degrees and maximum at 42.5 degrees (0.477). Overall average was 0.458 , with standard deviation of 0.024 .

Weight, Green-The green weight of wood plus bark of foliage-free live branches was unrelated to latitude, but was positively correlated with d.b.h., averaging $1.25(0.52)$, 7.85 (3.18), and 28.15 (13.05) $\mathrm{kg}$ for the three diameter classes.

Weight, Ovendry-The ovendry weight of wood plus bark of live branches was also unrelated to latitude and averaged $0.65(0.26), 4.35(1.60)$, and $13.82(6.30) \mathrm{kg}$ for the three diameter classes.

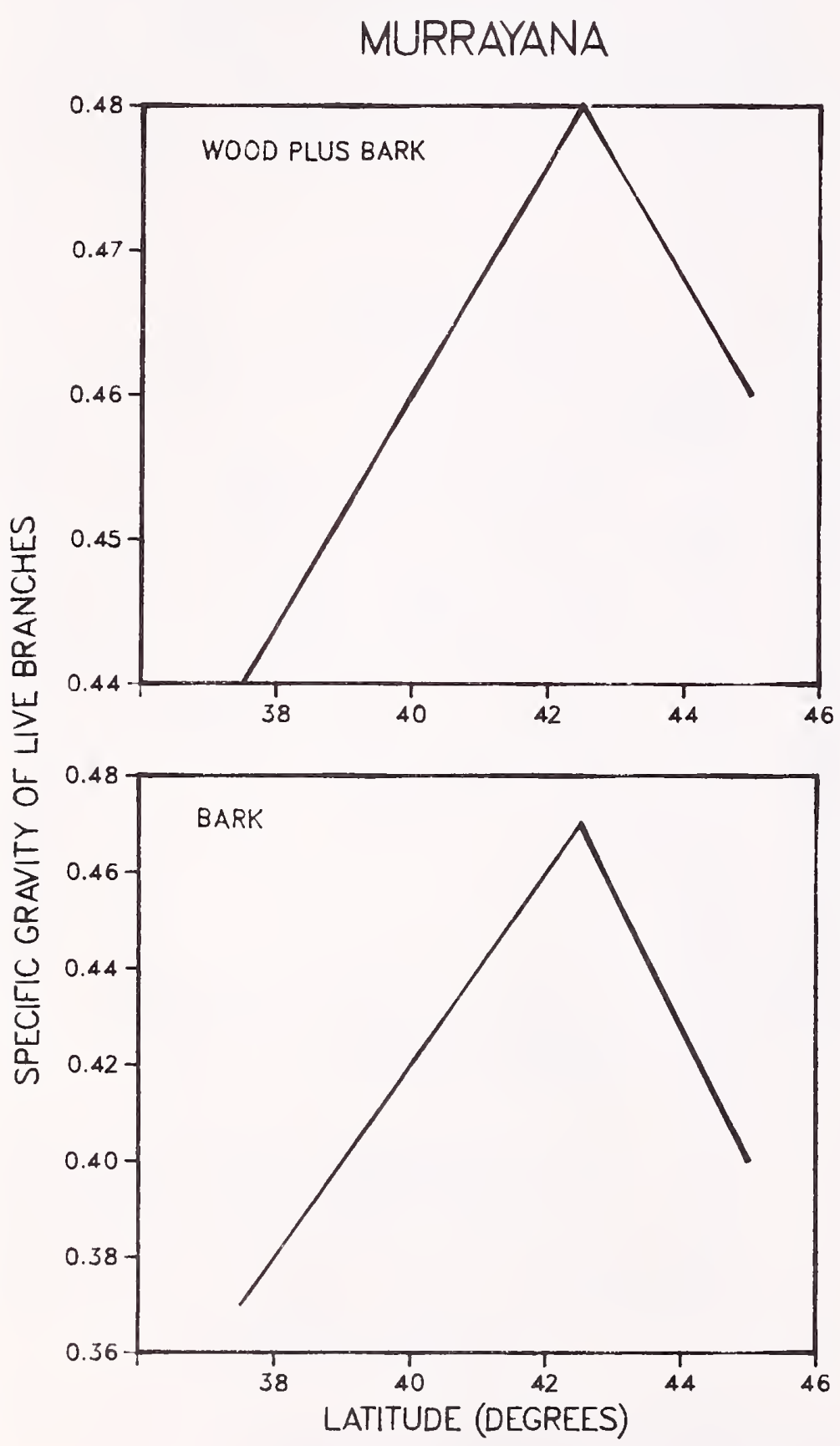

Green Weight to Yield $1 \mathrm{~m}^{3}$ of Wood-Green weight of foliage-free branches required to yield $1 \mathrm{~m}^{3}$ of wood varied significantly with latitude (fig. 4 -111); average requirement was highest at 40 degrees $(1,735 \mathrm{~kg})$ and lowest at 42.5 degrees $(1,562 \mathrm{~kg})$. It also was negatively correlated with d.b.h., averaging 1,854 (169), 1,584 (139), and 1,416 (147) $\mathrm{kg}$ for trees 76,152 , and $228 \mathrm{~mm}$ in d.b.h.

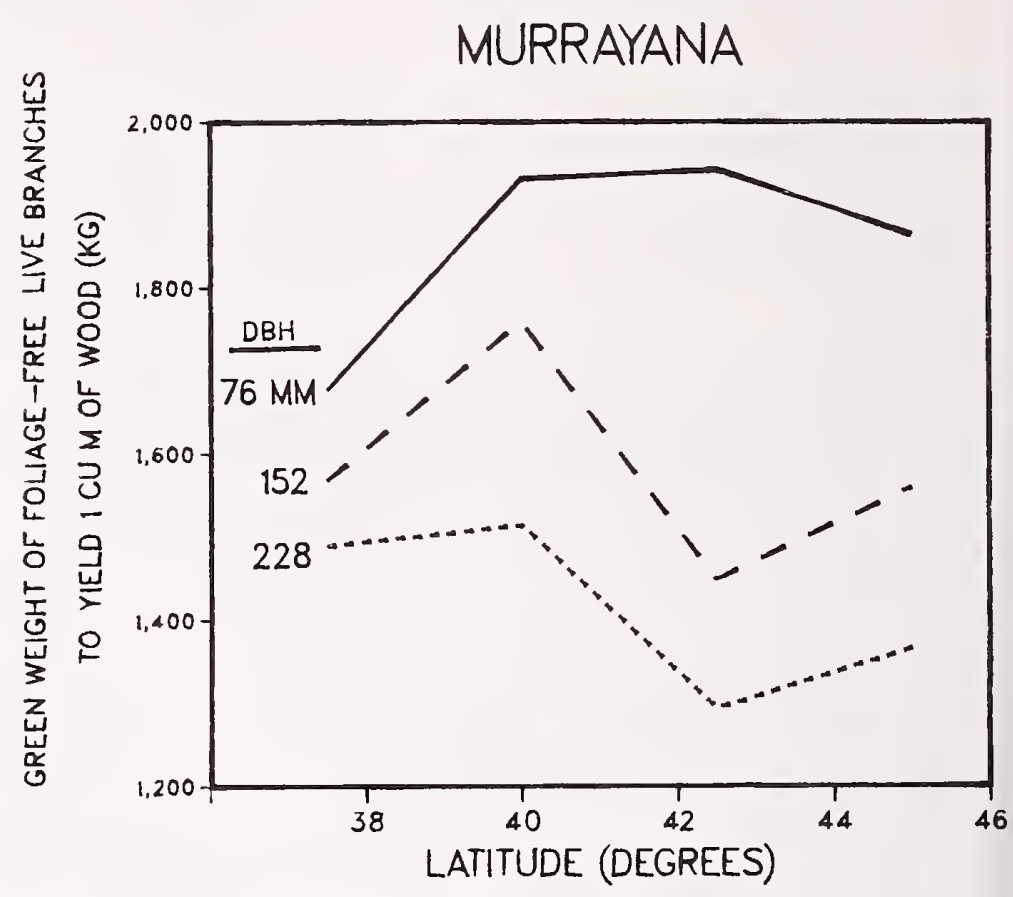

Figure 4-111-Green weight of live branches with bark (but after removal of technical foliage) required to yield $1 \mathrm{~m}^{3}$ of branchwood from murrayana trees of three diameters, related to latitude.

Tree Component Proportion, Green-Weight BasisLive branch (wood plus bark) percentage of complete-tree green weight varied significantly with latitude (fig. 4-112, top); it was maximum at 37.5 degrees (8.95 percent) and minimum at 42.5 degrees (5.03 percent). The proportion was unrelated to d.b.h., with overall average of 6.04 percent and standard deviation of 3.59 percentage points.

Tree Component Proportion, Ovendry-Weight BasisOn an ovendry-weight basis the trend was similar (fig. 4-112, bottom), with maximum of 9.75 percent at 37.5 degrees and minimum of 4.22 percent at 42.5 degrees. The proportion was unrelated to d.b.h., with overall average of 6.71 percent and standard deviation of 4.08 percentage points.

Figure 4-110-Specific gravity of live branches (wood plus bark and bark only) of murrayana trees, related to latitude; diameter data pooled. 


\section{Live Branchwood}

Latitude was unrelated to specific gravity, or to green or ovendry weights of branchwood.

Specific Gravity-Branchwood specific gravity was inversely correlated with tree d.b.h., averaging 0.509 (0.015), $0.495(0.023)$, and $0.479(0.018)$ for trees 76,152 , and $228 \mathrm{~mm}$ in d.b.h.

Weight, Green-Green branchwood weight was positively correlated with tree d.b.h., averaging $0.63(0.28), 4.82$ (1.88), and $18.58(7.42) \mathrm{kg}$ for the three diameter classes.

Weight, Ovendry-Similarly, ovendry branchwood weight averaged $0.35(0.16), 2.69(0.96)$, and $9.37(3.68) \mathrm{kg}$ for trees 76,152 , and $228 \mathrm{~mm}$ in d.b.h.

\section{MURRAYANA}

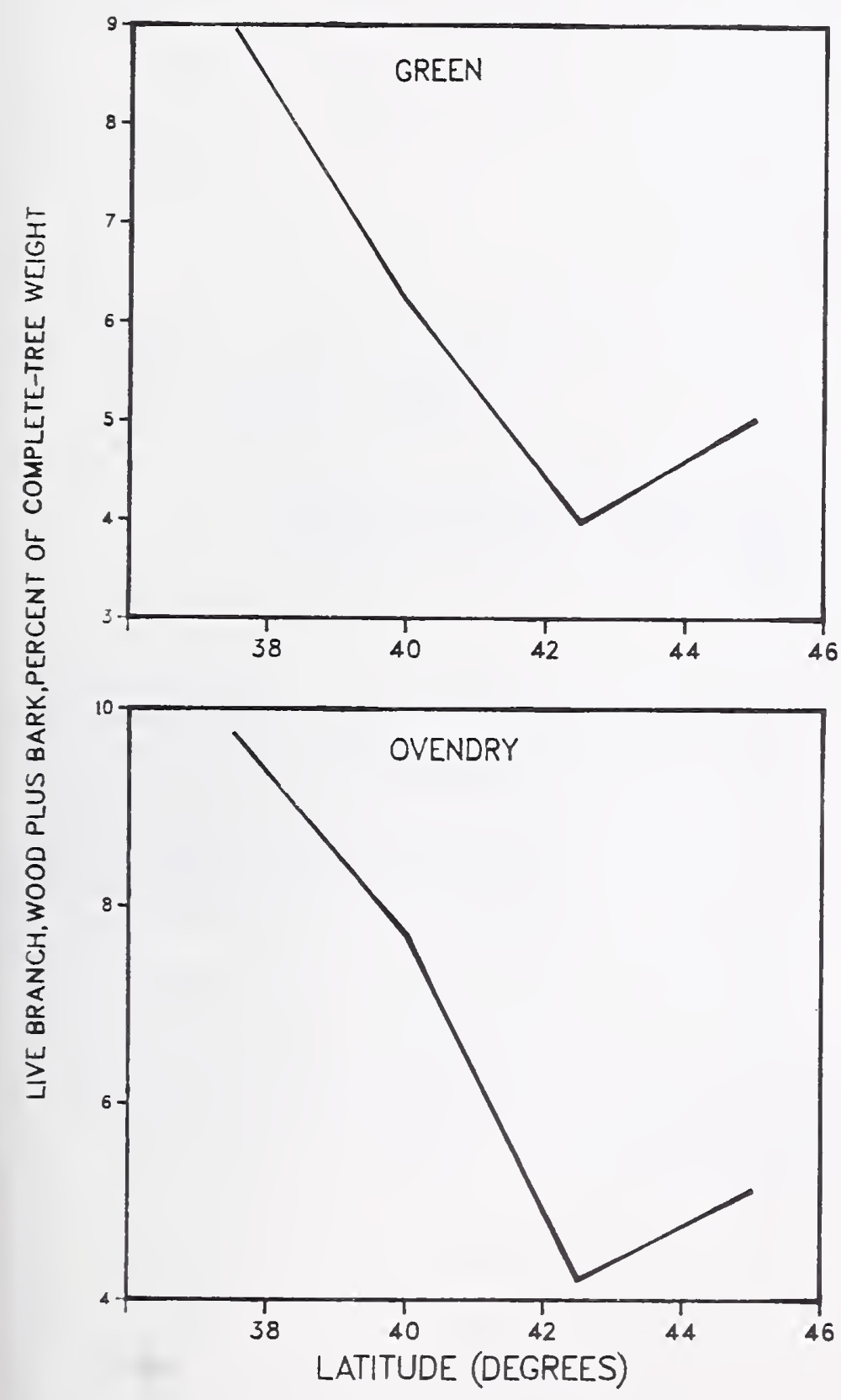

\section{Live Branchbark}

Specific Gravity-Specific gravity of branchbark was unrelated to tree d.b.h., but was significantly related to latitude (fig. 4-110, bottom); it was minimum at 37.5 degrees (0.367) and maximum at 42.5 degrees (0.468).

Weight, Green-Green weight of branchbark was unrelated to latitude but was positively correlated with tree d.b.h., averaging $0.62(0.26), 3.04(1.40)$, and 9.56 (5.89) $\mathrm{kg}$ for trees of the three diameter classes.

Weight, Ovendry-Similarly, ovendry weight of branchbark averaged $0.31(0.12), 1.65(0.67)$, and $4.44(2.77) \mathrm{kg}$ for trees 76,152 , and $228 \mathrm{~mm}$ in d.b.h.

Live Branchbark as Percentage of Gross Live Branch Weight, Green and Ovendry-On a green-weight basis, bark of live branches averaged 40.05 percent of total foliage-free weight, but this proportion varied significantly with latitude (fig. 4-113) and with d.b.h., averaging 49.55 (5.12), 38.42 (4.78), and 32.20 (6.39) for trees 76,152 , and $228 \mathrm{~mm}$ in d.b.h.

On an ovendry basis, only d.b.h. was significant; the bark proportions averaged 47.44 (6.46), 37.82 (3.19), and 30.67 (5.78) percent for trees 76,152 , and $228 \mathrm{~mm}$ in d.b.h.

\section{MURRAYANA}

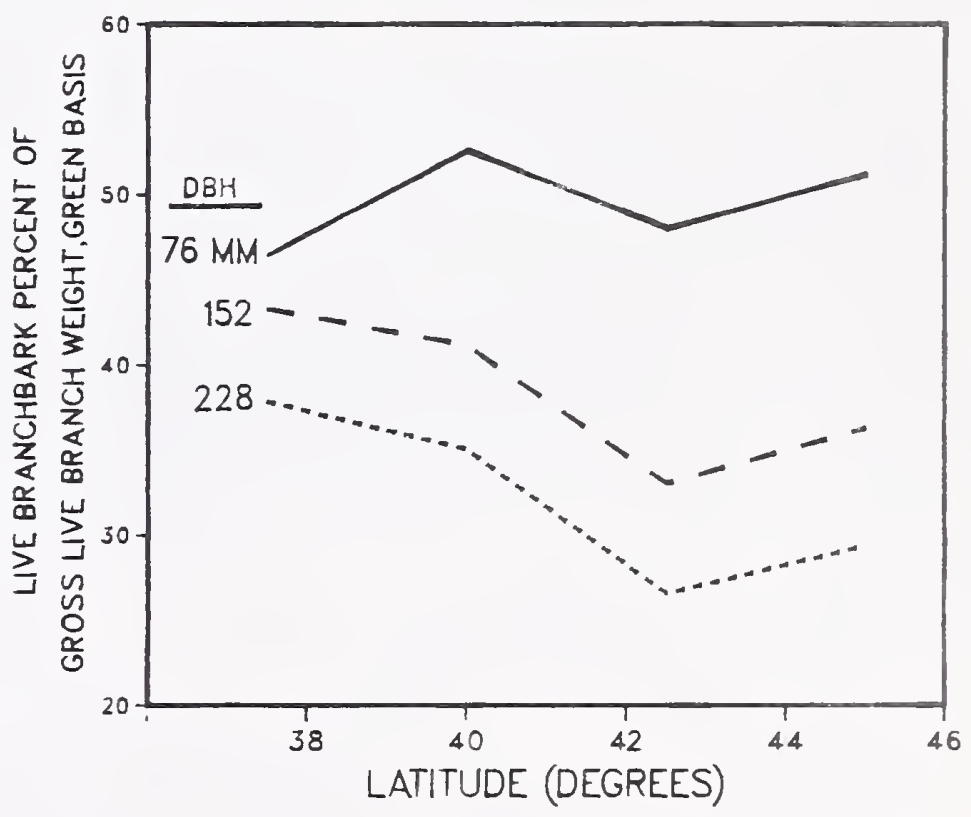

Figure 4-113-Live branchbark as percentage of gross live branch weight for murrayana trees of three diameters, related to latitude; green-weight basis.

Figure 4-112-Live branches (wood plus bark) as percentage of the weight of complete murrayana trees with foliage-green and ovendryrelated to latitude; diameter data pooled. 


\section{Stem, Wood Plus Bark-Tree Average}

Specific Gravity-Stem specific gravity (wood plus bark, from 152-mm stump height to apical tip) in smaller trees was positively correlated with latitude (fig. 4-114, top); it was negatively correlated with diameter, averaging 0.463 $(0.035), 0.431(0.038)$, and $0.404(0.028)$ for trees 76,152 , and $228 \mathrm{~mm}$ in d.b.h.

Weight, Green-Wood plus bark of green stems was unrelated to latitude, but was positively correlated with d.b.h., averaging 17.16 (4.07), 113.41 (34.63), and 321.69 $(83.64) \mathrm{kg}$ for trees of the three diameter classes.

Weight, Ovendry-Similarly, ovendry weights averaged 8.59 (2.25), 54.17 (19.11), and 149.05 (45.76) $\mathrm{kg}$ for trees of the three diameter classes.

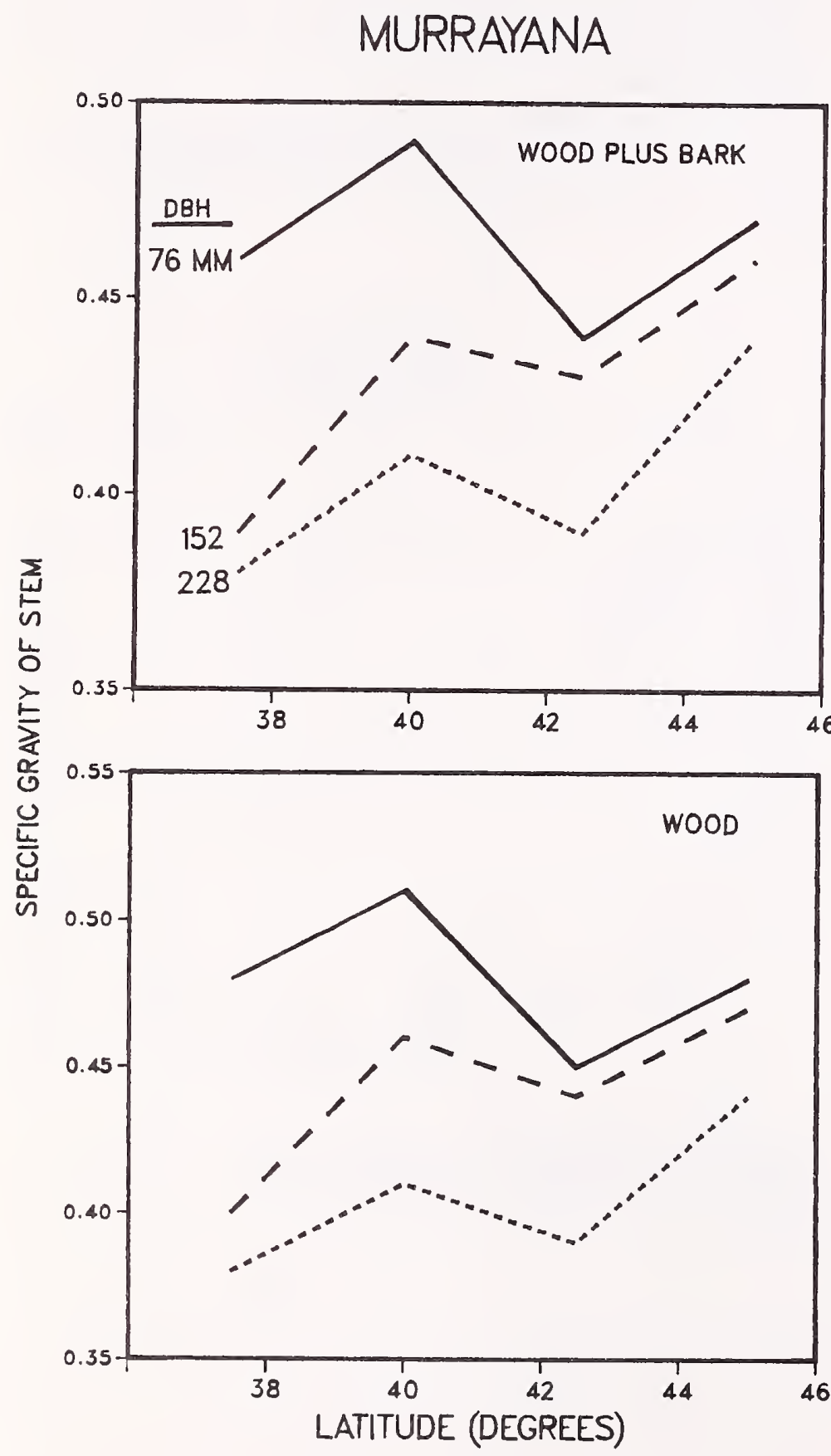

Figure 4-114-Average specific gravity (based on ovendry weight and green volume) for stems (wood plus bark and wood only) of murrayana trees of three diameters, related to latitude.
Green Weight to Yield $1 \mathrm{~m}^{3}$ of Wood-Green weight of stems with bark required to yield $1 \mathrm{~m}^{3}$ of wood was least at 42.5 degrees latitude for all three tree diameters (fig. 4-115). Although varying with latitude, the statistic was generally negatively correlated with d.b.h., averaging 1,093 (74), 1,030 (76), and 968 (67) $\mathrm{kg}$ for trees 76, 152, and $228 \mathrm{~mm}$ in d.b.h.

\section{MURRAYANA}

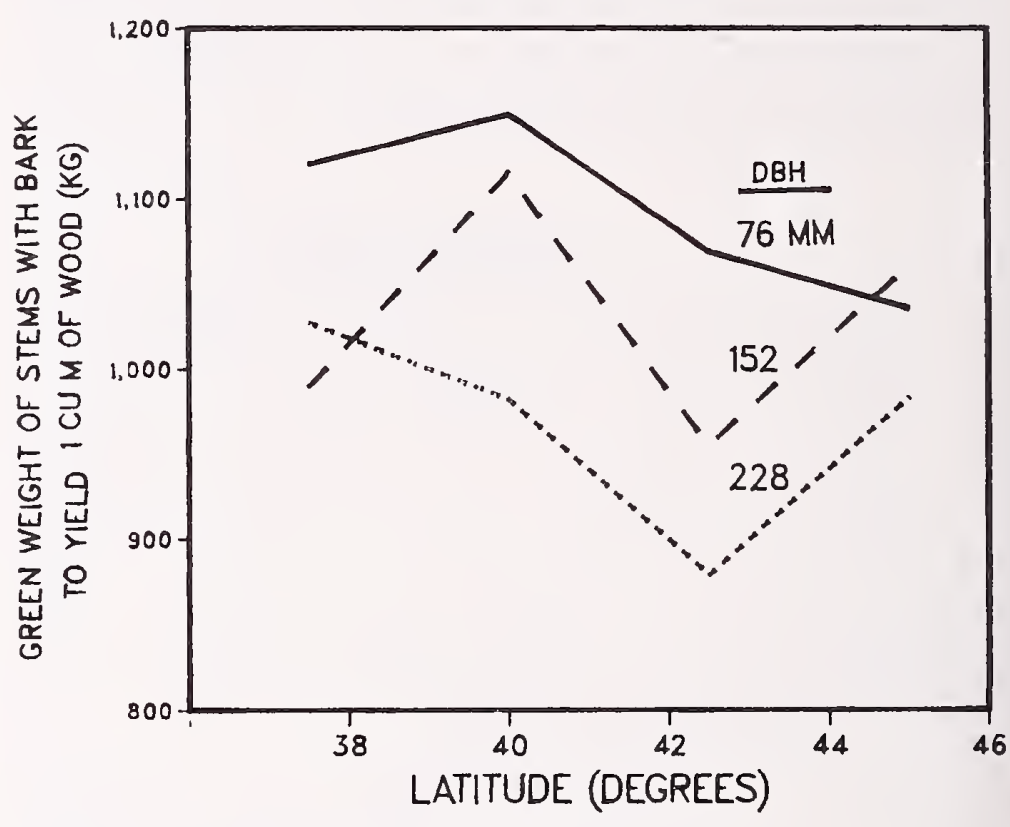

Figure 4-115-Green weight of stems with bark required to yield $1 \mathrm{~m}^{3}$ of stemwood from murrayana trees of three diameters, related to latitude.

Tree Component Proportion, Green-Weight Basis-The stems with bark averaged 73.1 percent of the green weight of complete trees with foliage; standard deviation was 8.6 percent. This percentage was not significantly related to d.b.h., but did vary significantly with latitude. It was least at 37.5 degrees (66.7 percent) and most at 45 degrees (fig. 4-116, top).

Tree Component Proportion, Ovendry-Weight BasisOn an ovendry-weight basis the overall average was 72.2 percent, with standard deviation of 8.8 percentage points. The percentage was least at 37.5 degrees latitude (65.4 percent) and most at 45 degrees (76.9 percent); see figure 4-116, bottom. 
MURRAYANA
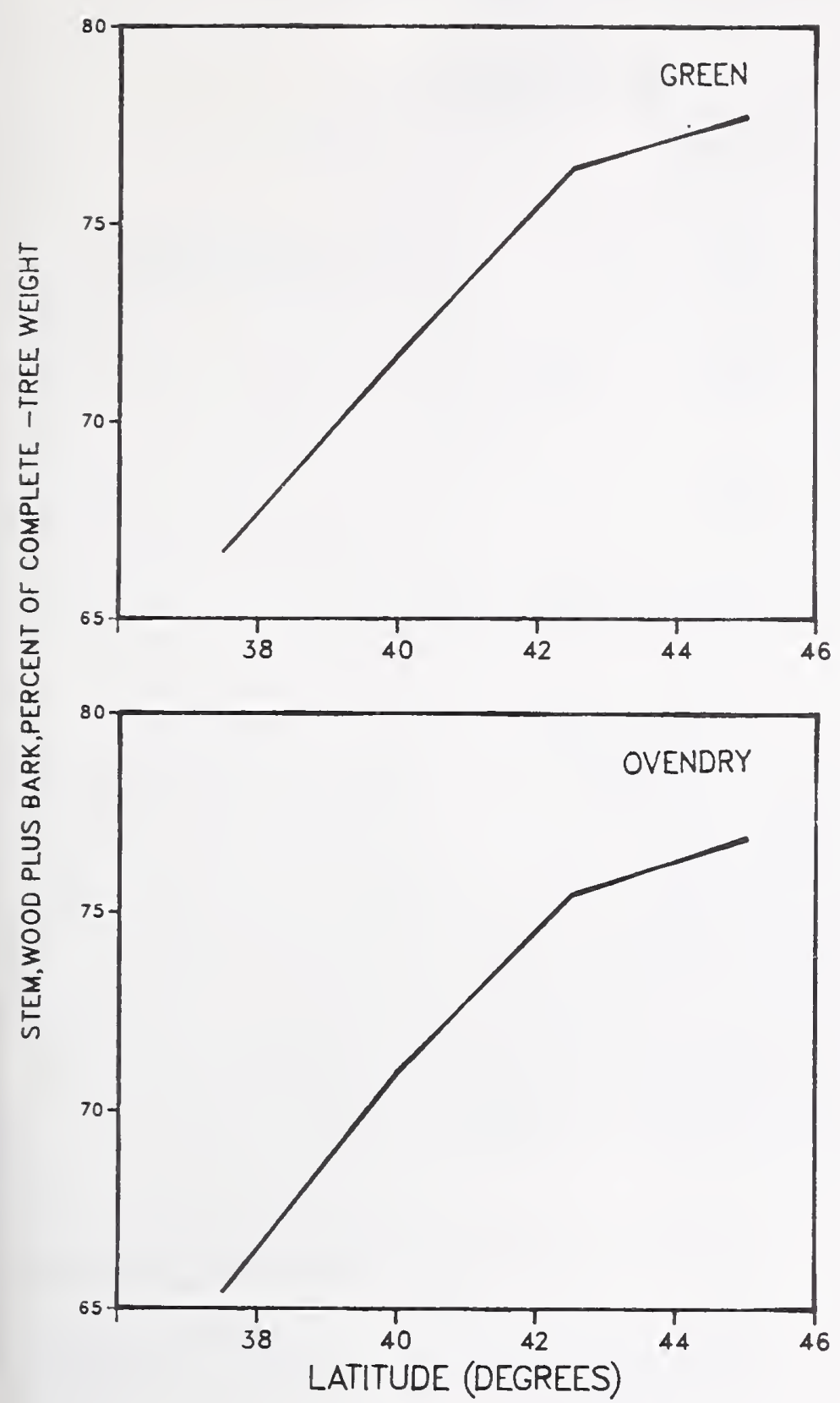

Stem, Wood Plus Bark-Variation With Height

Specific Gravity-The specific gravities of stems with bark diminish curvilinearly with height above stump (fig. 4-117). Curve forms are similar for the three d.b.h. classes studied, with small trees having consistently higher specific gravity than large trees at all levels below 90 percent of tree height. Specific gravity at 20 percent of tree height is near average for stems of these diameters (fig. 4-117).

\section{MURRAYANA}

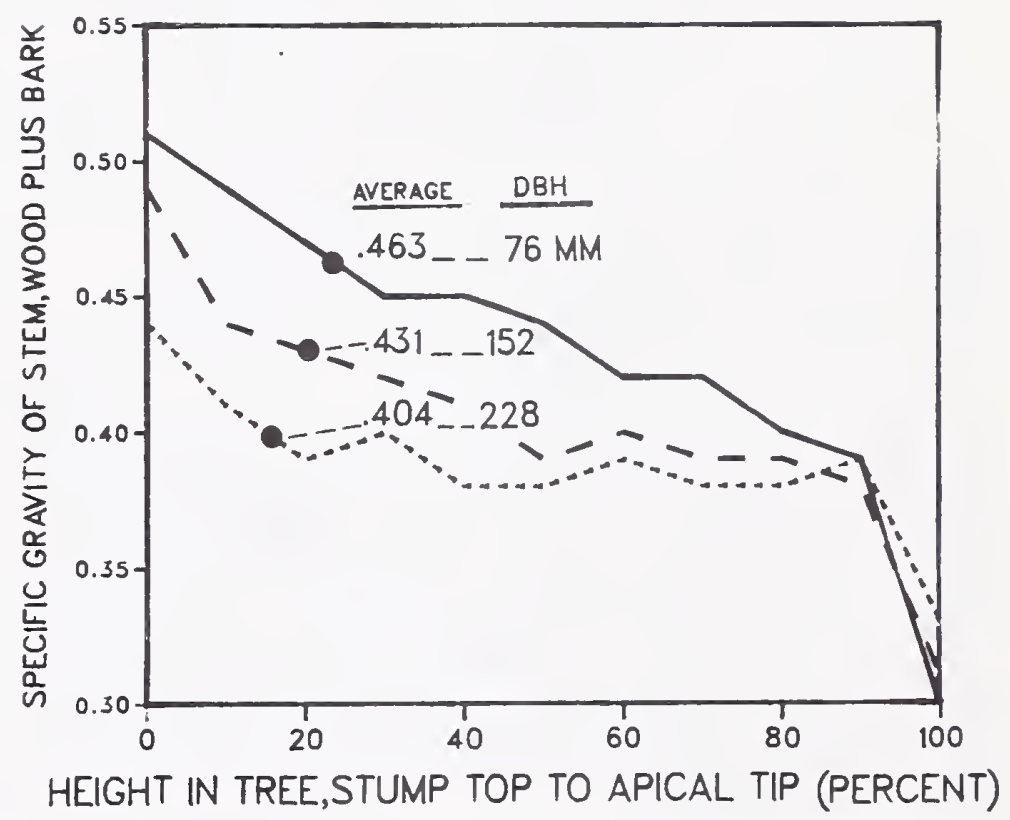

Figure 4-117-Stem, wood plus bark, specific gravity (based on ovendry weight and green volume) of murrayana trees of three diameters, related to height in tree. Stem average values are listed below each diameter designation.

Figure 4-116-Stem (wood plus bark) as percentage by weight of complete murrayana trees with foliage-green and ovendry-related to latitude. 


\section{Stemwood-Tree Average}

Specific Gravity-Average entire stemwood specific gravity was inversely correlated with average growth-ring width at 152 -mm stump height $\left(R^{2}=-0.490\right)$; that is, fast-grown trees had lower stemwood specific gravity than slow growers.

Average specific gravity of entire stemwood from 152-mm stump height to apical tip in murrayana trees of the diameters studied can be closely estimated from the specific gravity of a stemwood disk taken at 20 percent of tree height (figs. 4-118 and 4-119) by the following relationship $\left(R^{2}=0.937\right.$; standard error of the estimate $=$ 0.012):

Average stemwood specific gravity, ovendry weight and green volume basis $=$

$0.0917+0.8014$ (stemwood specific gravity at 20 percent of tree height)

For trees 152 and $228 \mathrm{~mm}$ in d.b.h., average stemwood specific gravity was least at the southernmost latitude (fig. 4-114, bottom). Surprisingly, average stemwood specific gravity was inversely correlated with d.b.h., averaging $0.482(0.039), 0.40(0.042)$, and $0.407(0.031)$ for trees 76,152 , and $228 \mathrm{~mm}$ in d.b.h.

Weight, Green-Stemwood weight, green basis-from 152-mm stump height to apical tip-was not significantly related to latitude, but was positively correlated with d.b.h., averaging 17.16 (4.07). 113.41 (34.63), and 321.69 (83.64) $\mathrm{kg}$ for the three diameter classes.

Weight, Ovendry - On an ovendry-weight basis, stemwood weight was only correlated with d.b.h., averaging 7.63 (2.09), 49.46 (18.04), and 137.55 (43.36) $\mathrm{kg}$ for the three diameter classes.

\section{MURRAYANA}

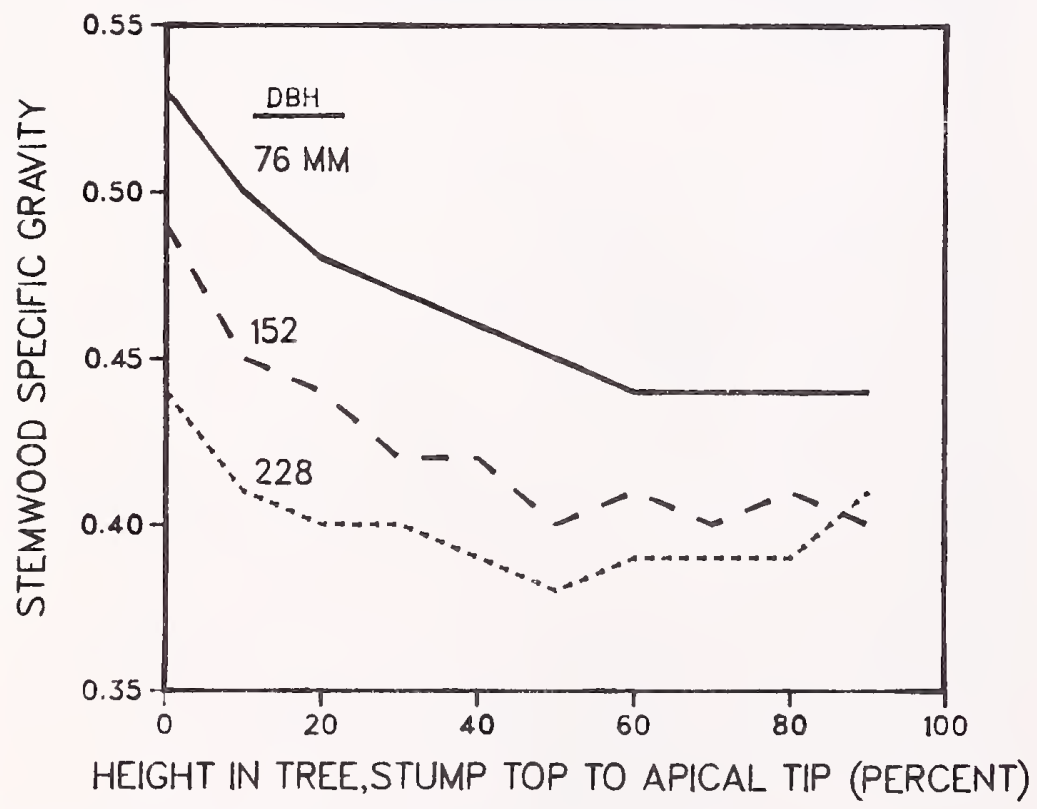

Figure 4-118-Stemwood specific gravity (based on ovendry weight and green volume) for murrayana trees of three diameters, related to height in tree.
MURRAYANA
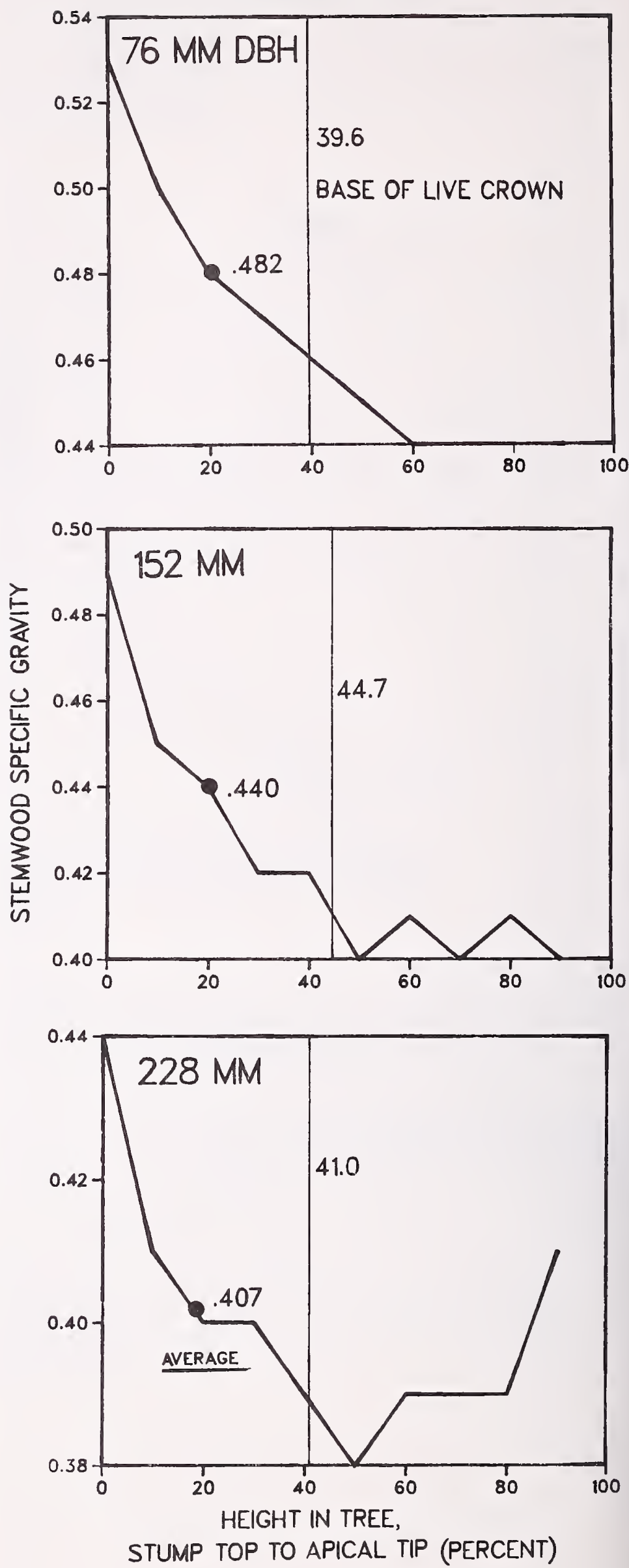

Figure 4-119-Stemwood specific gravity (based on ovendry weight and green volume) for murrayana trees of three diameters, related to height in tree, position of crown base, and position and value of stem average value of stemwood specific gravity. 
Table 4-10-Murrayana stemwood specific gravities (basis of ovendry weight and green volume) from 152-mm stump height to apical tip at 10 levels in trees of three breast-height diameters'

\begin{tabular}{|c|c|c|c|c|}
\hline \multirow{2}{*}{$\begin{array}{l}\text { Percent of stem } \\
\text { height above stump }\end{array}$} & \multicolumn{4}{|c|}{ Diameter } \\
\hline & $76 \mathrm{~mm}$ & $152 \mathrm{~mm}$ & 228 & $\mathrm{~mm}$ \\
\hline 0 & $0.529(0.051)$ & $0.494(0.037)$ & 0.442 & $(0.030)$ \\
\hline 10 & $.504 \quad(.041)$ & $.448 \quad(.042)$ & .441 & $(.042)$ \\
\hline 20 & $.480 \quad(.048)$ & $.440 \quad(.052)$ & .395 & $(.042)$ \\
\hline 30 & $.466 \quad(.044)$ & $.424 \quad(.050)$ & .401 & $(.039)$ \\
\hline 40 & $.462 \quad(.043)$ & $.416 \quad(.053)$ & .386 & $(.035)$ \\
\hline 50 & $.455 \quad(.031)$ & $.403 \quad(.048)$ & .384 & $(.031)$ \\
\hline 60 & $.443 \quad(.029)$ & $.407 \quad(.041)$ & .393 & $(.029)$ \\
\hline 70 & $.444 \quad(.025)$ & $.399 \quad(.043)$ & .387 & $(.037)$ \\
\hline 80 & $.439 \quad(.030)$ & $.409 \quad(.039)$ & .387 & $(.024)$ \\
\hline 90 & $.440 \quad(.034)$ & $.404 \quad(.033)$ & .408 & $(.036)$ \\
\hline
\end{tabular}

\footnotetext{
${ }^{1}$ Latitudinal data pooled; standard deviations shown in parentheses following average values. Data based on
} 12 trees of each diameter.

\section{Stemwood-Variation With Height}

Specific Gravity-Stemwood specific gravity curvilinearly diminishes above stump height to near the base of the live crown, but then remains more or less constant within the live crown (table 4-10 and figs. 4-118 and 4-119). At all percentages of tree height below 90 percent, stemwood specific gravity is negatively correlated with tree d.b.h. (fig. 4-118). Stemwood specific gravity at 20 percent of tree height approximates stemwood-average specific gravity (fig. 4-119); see predictive equation under the preceding heading.

\section{Stembark-Tree Average}

Specific Gravity-Tree average stembark specific gravity was unrelated to either latitude or d.b.h.; it averaged 0.361 , with standard deviation of 0.029 .

Weight, Green-Green stembark weight was unrelated to latitude, but was positively correlated with d.b.h., averaging $2.18(0.42), 10.00(2.43)$, and $22.89(4.65) \mathrm{kg}$ for the three diameter classes.

Weight, Ovendry-Similarly, stembark ovendry weights for the three tree diameters averaged 8.59 (2.25), 54.17 (19.11), and $149.05(45.76) \mathrm{kg}$.

Stembark as Percentage of Gross Stem Weight, Green and Ovendry-Stembark percentage of the weight of stem with bark, green basis, averaged 9.77 percent, but averaged less in northern latitudes and more in southern latitudes (fig. 4-120). It also was negatively correlated with d.b.h., averaging 12.91 (1.83), 9.13 (1.49), and $7.26(0.73)$ percent for trees 76,152 , and $228 \mathrm{~mm}$ in d.b.h.

On an ovendry basis, stembark percentage by weight averaged 9.53 percent and was not significantly related to latitude (although averaging nearly two percentage points less in the two northern latitudes than in the two southern). It was negatively correlated with d.b.h., averaging 11.42 (1.75), 9.15 (1.56), and 8.01 (1.32) percent for the three diameter classes.

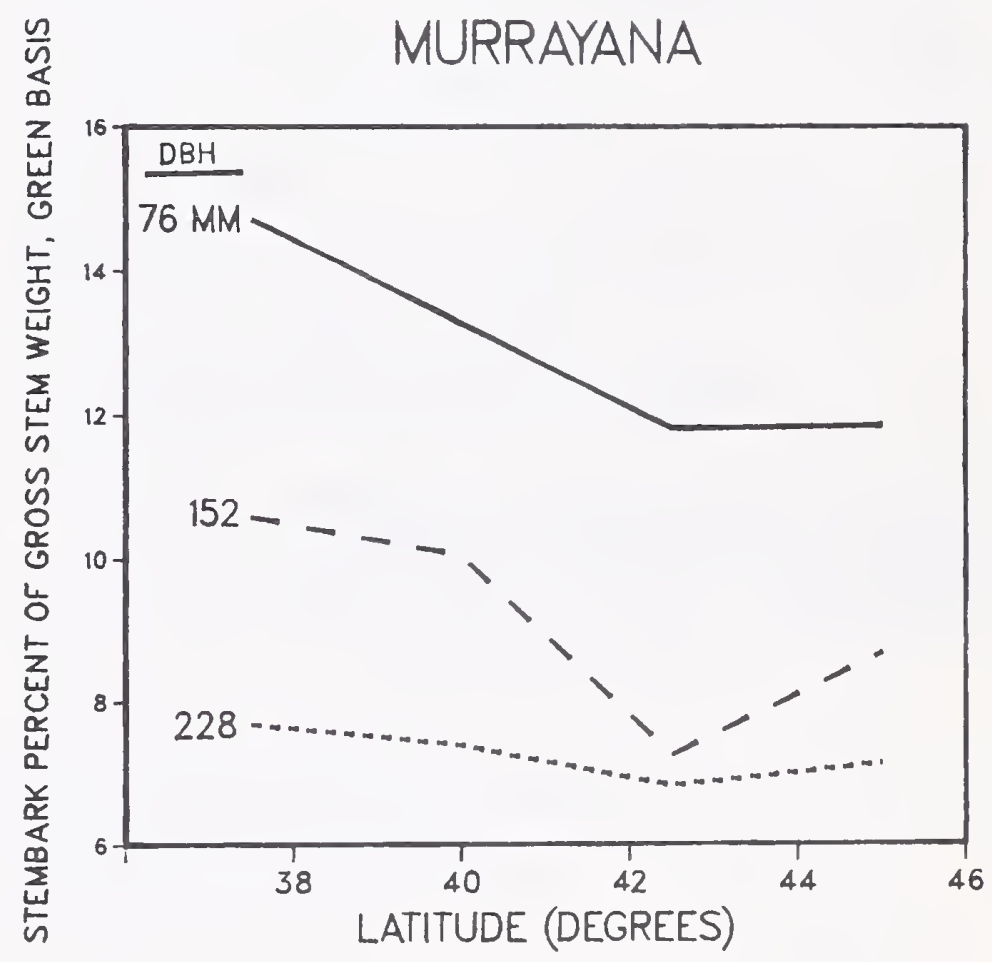

Figure 4-120-Stembark as percentage of gross stem weight in murrayana trees of three diameters, related to latitude. 


\section{Stembark-Variation With Height}

Specific Gravity-Stembark specific gravity decreased curvilinearly with height in tree from a maximum at stump height of about 0.40 to a minimum of about 0.30 near the apical tip (fig. 4-121); shape and position of the curves did not vary significantly with tree d.b.h. Bark specific gravity at 20 percent of tree height approximates the tree average value (fig. 4-121).

\section{MURRAYANA}

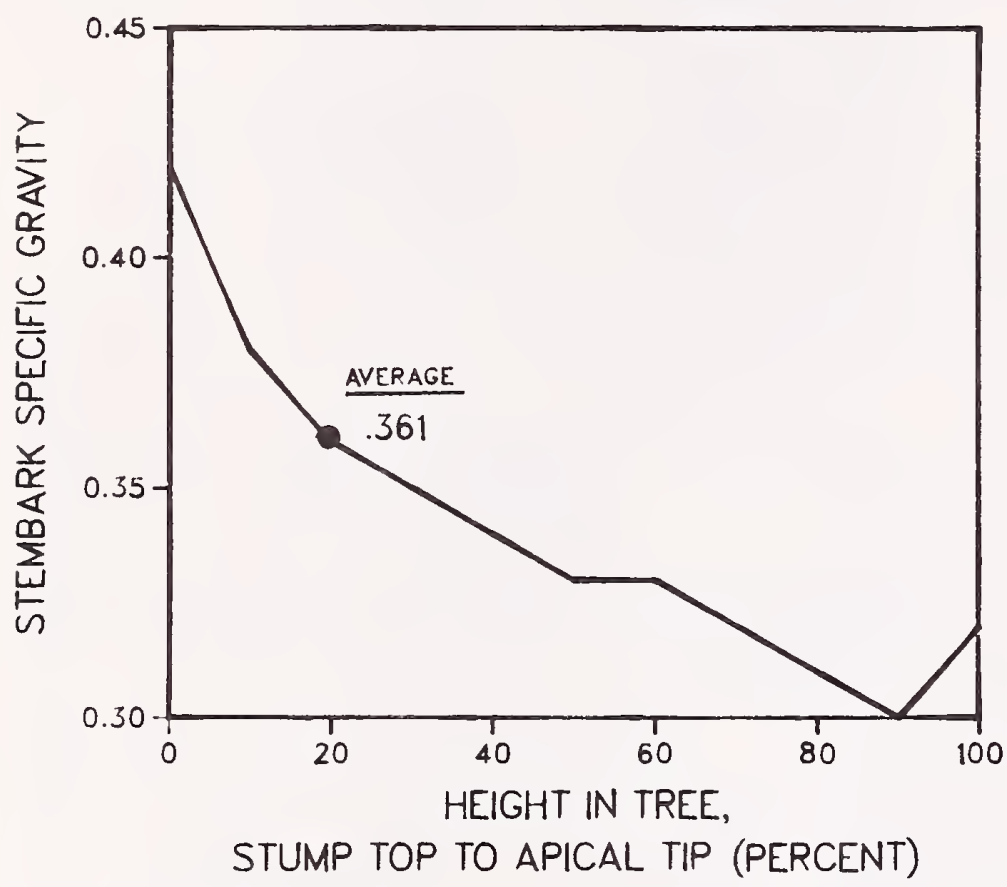

Figure 4-121-Stembark specific gravity (based on ovendry weight and green volume) of murrayana trees, related to height in trees; diameter data pooled.
Weight Percentage, Green-Stembark as a percentage of green stem weight is positively correlated with height in tree, varying from about 10 percent at stump height to over 20 percent at 90 percent of tree height, but is negatively correlated with tree d.b.h. (fig. 4-122, top); that is, small-diameter trees have a higher percentage of stembark at all heights in the stem than do large trees.

Weight Percentage, Ovendry-On an ovendry-weight basis (fig. 4-122, bottom), the weight-percentage relationship and values are similar to those on a green basis.
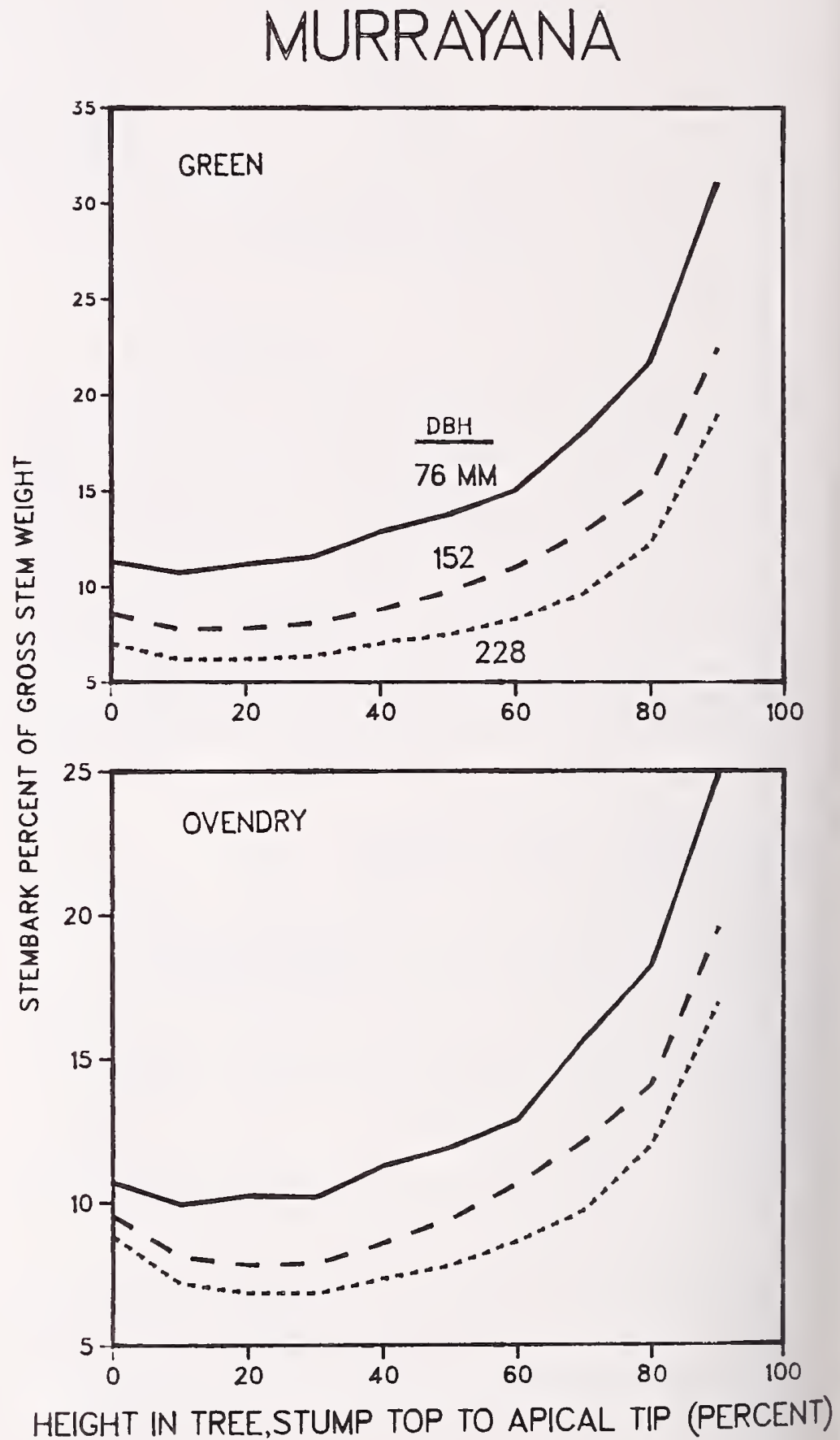

Figure 4-122-Stembark as percentage of gross stem weight, green and ovendry, in murrayana trees of three diameters, related to height in trees. 


\section{Sapwood}

Specific Gravity-Sapwood specific gravity of the 152and 228-mm trees averaged significantly less in the south than in the north (fig. 4-123, top). Also, sapwood specific gravity was negatively correlated with d.b.h., averaging $0.476(0.038), 0.433(0.044)$, and $0.401(0.032)$ for trees 76 , 152 , and $228 \mathrm{~mm}$ in d.b.h. Overall average was 0.437 , with standard deviation of 0.048 .

Weight, Green-Sapwood weight, green basis, was not significantly related to latitude but was positively correlated with d.b.h., averaging 13.60 (3.48), 88.54 (25.48), and $253.53(60.56) \mathrm{kg}$ for trees of the three diameter classes.

Weight, Ovendry-Dry sapwood weight was also unrelated to latitude and positively correlated with d.b.h., averaging 6.74 (1.75), 39.00 (11.72), and $105.30(26.76) \mathrm{kg}$ for trees of the three diameter classes.

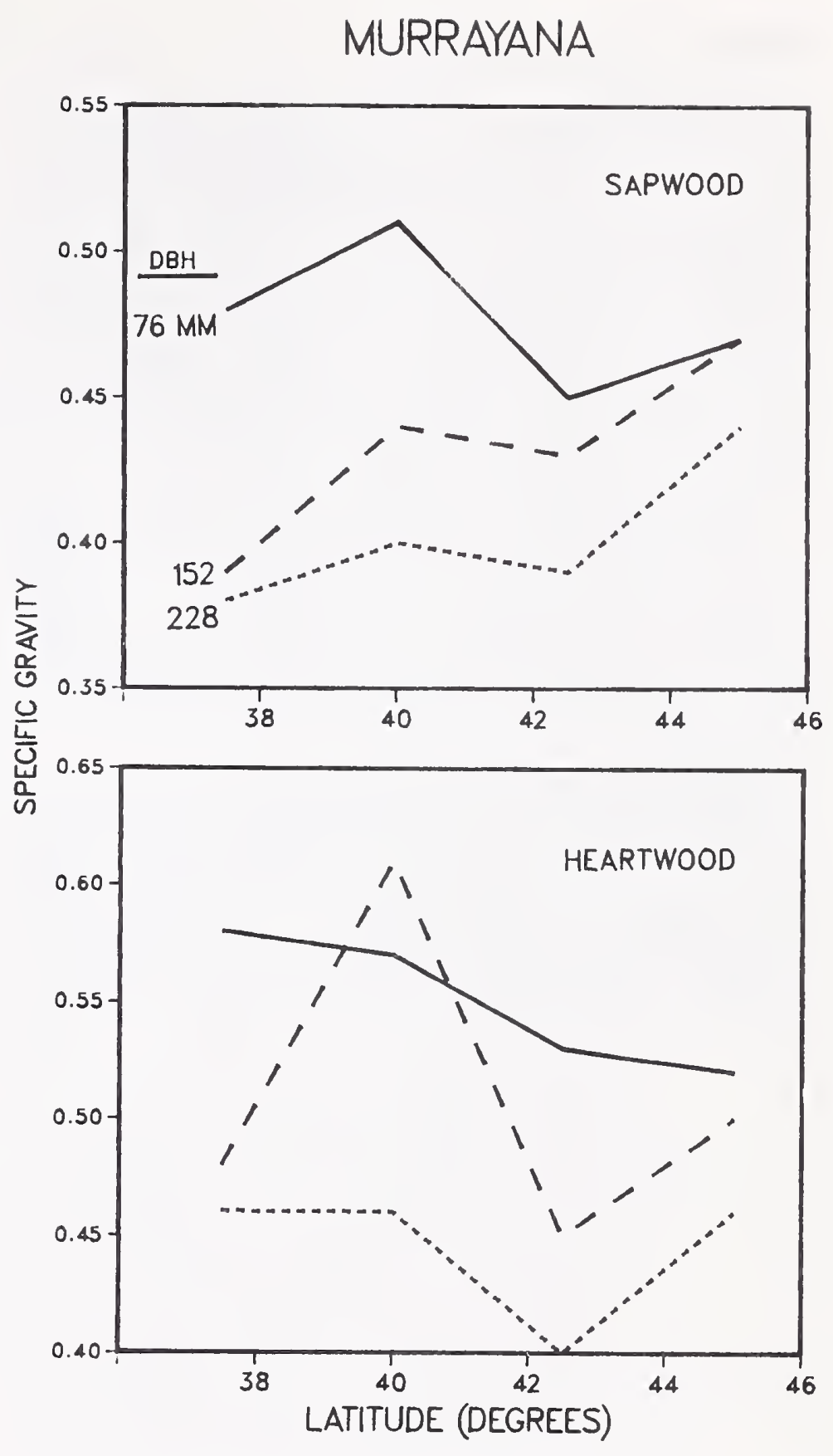

Figure 4-123-Average specific gravity (based on ovendry weight and green volume) of sapwood and heartwood of murrayana trees of three diameters, related to latitude. 


\section{Heartwood}

Specific Gravity-Average heartwood specific gravity was highest (0.547) at 40 degrees and lowest (0.461) at 42.5 degrees (fig. 4-123, bottom). It was negatively correlated with d.b.h., averaging $0.550(0.046), 0.508(0.071)$, and $0.446(0.037)$ for trees 76,152 , and $228 \mathrm{~mm}$ in d.b.h. Overall, heartwood specific gravity was greater than that of sapwood-probably because of a higher content of extractives, averaging 0.502 , with standard deviation of 0.067 . Information on the variation of heartwood and sapwood specific gravity with height in tree is given in figures 5-49 and 5-50 (see next chapter).

Weight, Green-Although heartwood specific gravity averaged least at 42.5 degrees latitude, green weight of heartwood was greatest at this latitude (fig. 4-124, top). Heartwood green weight was positively correlated with d.b.h. at all latitudes, averaging 1.38 (1.42), 14.88 (12.87), and $45.28(29.60) \mathrm{kg}$ for trees of the three diameter classes.

Weight, Ovendry-On an ovendry basis, latitudinal and diameter trends were similar (fig. 4-124, bottom), with heartwood weights for trees of the three diameter classes averaging $0.96(0.99), 10.46(9.10)$, and $32.25(21.55) \mathrm{kg}$. From the large standard deviations in dry heartwood weight, it is evident that trees varied greatly in their heartwood content.

\section{MURRAYANA}

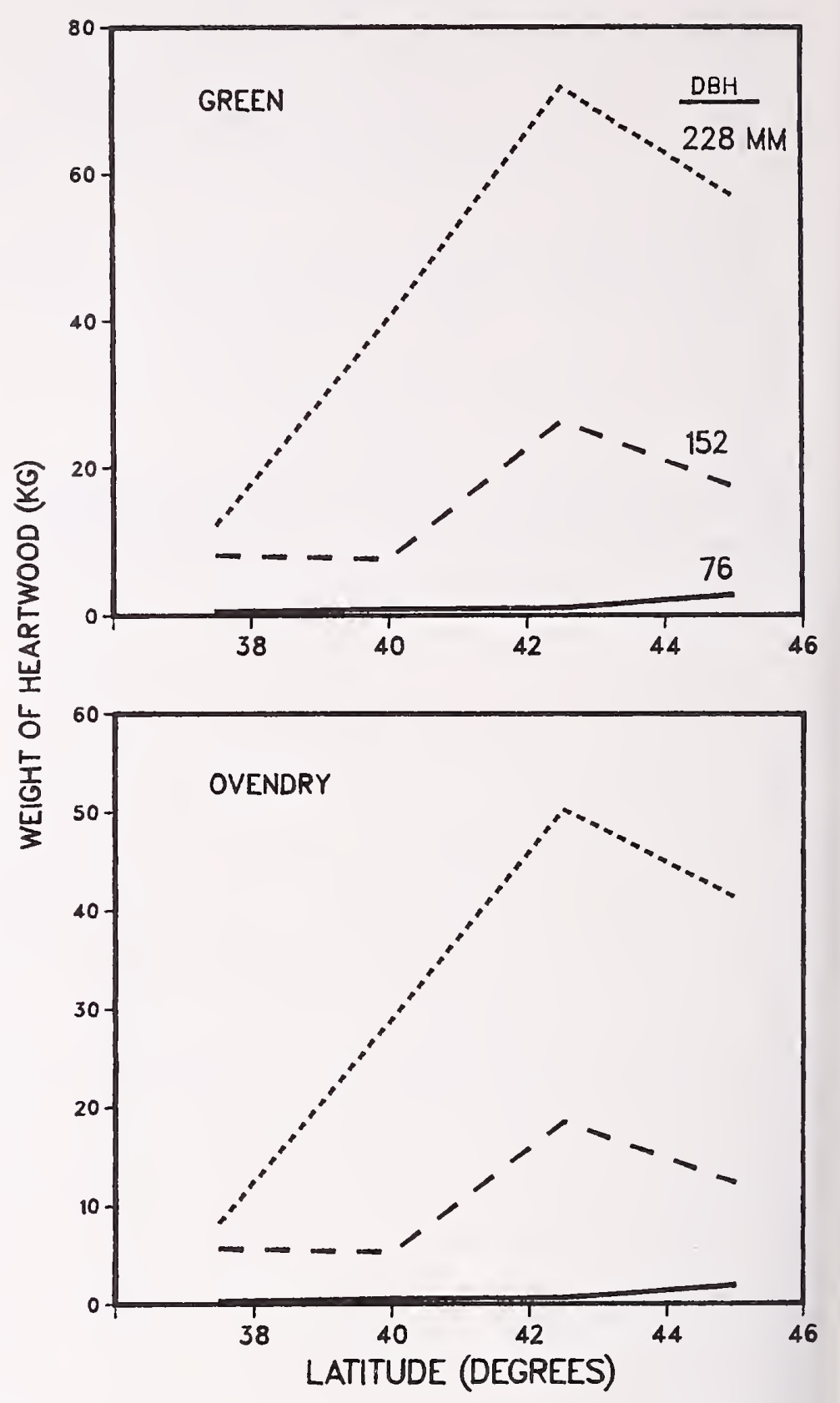

Figure 4-124-Weight of heartwood (green and ovendry) in murrayana trees of three diameters, related to latitude. 
Ovendry Weight as Percentage of Stemwood-

Ovendried heartwood weight as a percentage of stemwood averaged lowest (9.16 percent) at 37.5 degrees and highest (23.16 percent) at 42.5 degrees latitude (fig. $4-125)$. The percentage was positively correlated with d.b.h., averaging 11.39 (11.05), 18.26 (11.91), and 21.52 (10.02) percent for trees of the three diameter classes.

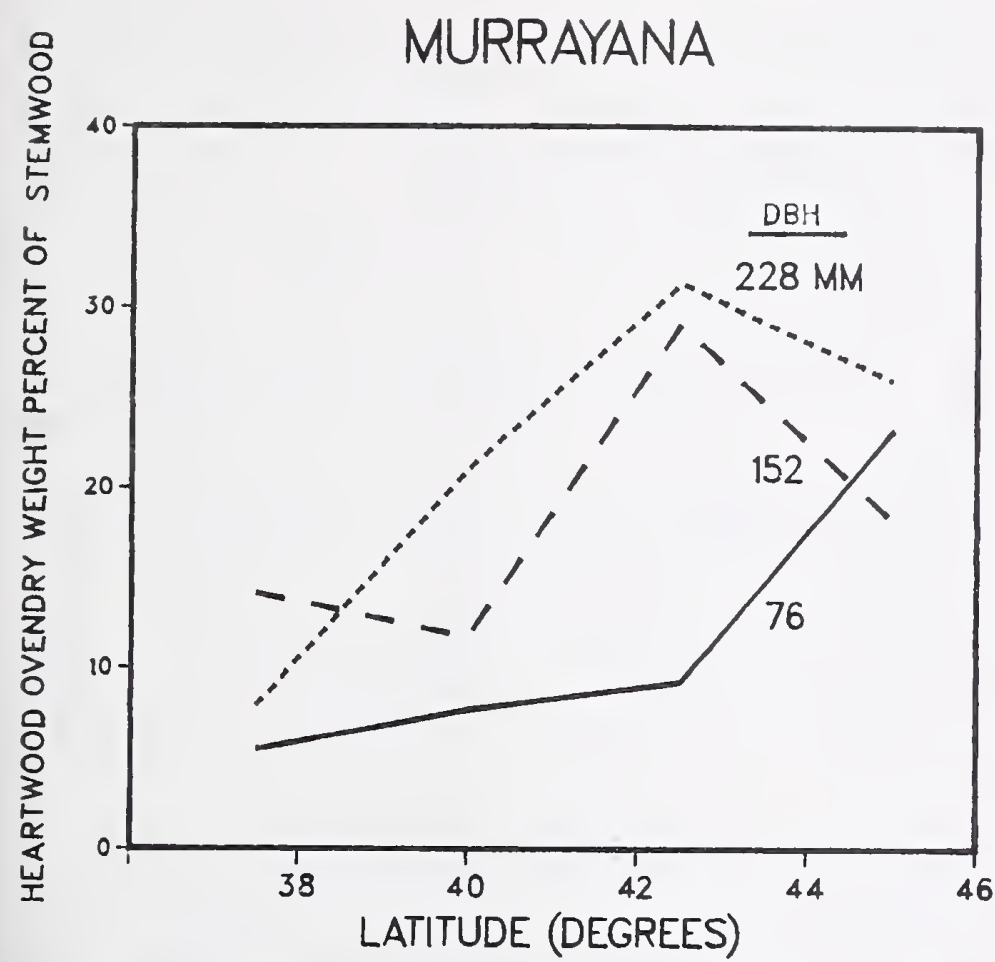

Figure 4-125- Heartwood as percentage of stemwood weight (ovendry basis) of murrayana trees of three diameters, related to latitude.

\section{Stump-Root System, Wood Plus Bark}

Specific Gravity-Specific gravity of wood plus bark of the stump-root system averaged 0.461 , with standard deviation of 0.045 . Average specific gravity was lowest $(0.429)$ at 37.5 degrees latitude and highest $(0.487)$ at 42.5 degrees, but was not significantly related to tree d.b.h. (fig. 4-126).

Weight, Green-Weight of wood plus bark of the green stump-root system was unrelated to latitude but was positively correlated with d.b.h., averaging 3.75 (1.07), $20.53(5.36)$, and $43.87(6.85) \mathrm{kg}$ for trees of the three diameter classes.

Weight, Ovendry-On an ovendry basis trends were similar, with stump-root systems of trees of the three diameters averaging $1.80(0.48), 9.70(2.28)$, and 20.56 (3.82) $\mathrm{kg}$.

Green Weight to Yield $1 \mathrm{~m}^{3}$ of Wood-The overall average of green weight of stump-root systems, wood plus bark, required to yield $1 \mathrm{~m}^{3}$ of wood was $1,109 \mathrm{~kg}$, with standard deviation of $59 \mathrm{~kg}$. This statistic varied inversely with d.b.h., averaging 1,156 (48), 1,110 (35), and 1,061 (50) $\mathrm{kg}$ for trees 76,152 , and $228 \mathrm{~mm}$ in d.b.h. It was not significantly related to latitude.

\section{MURRAYANA}

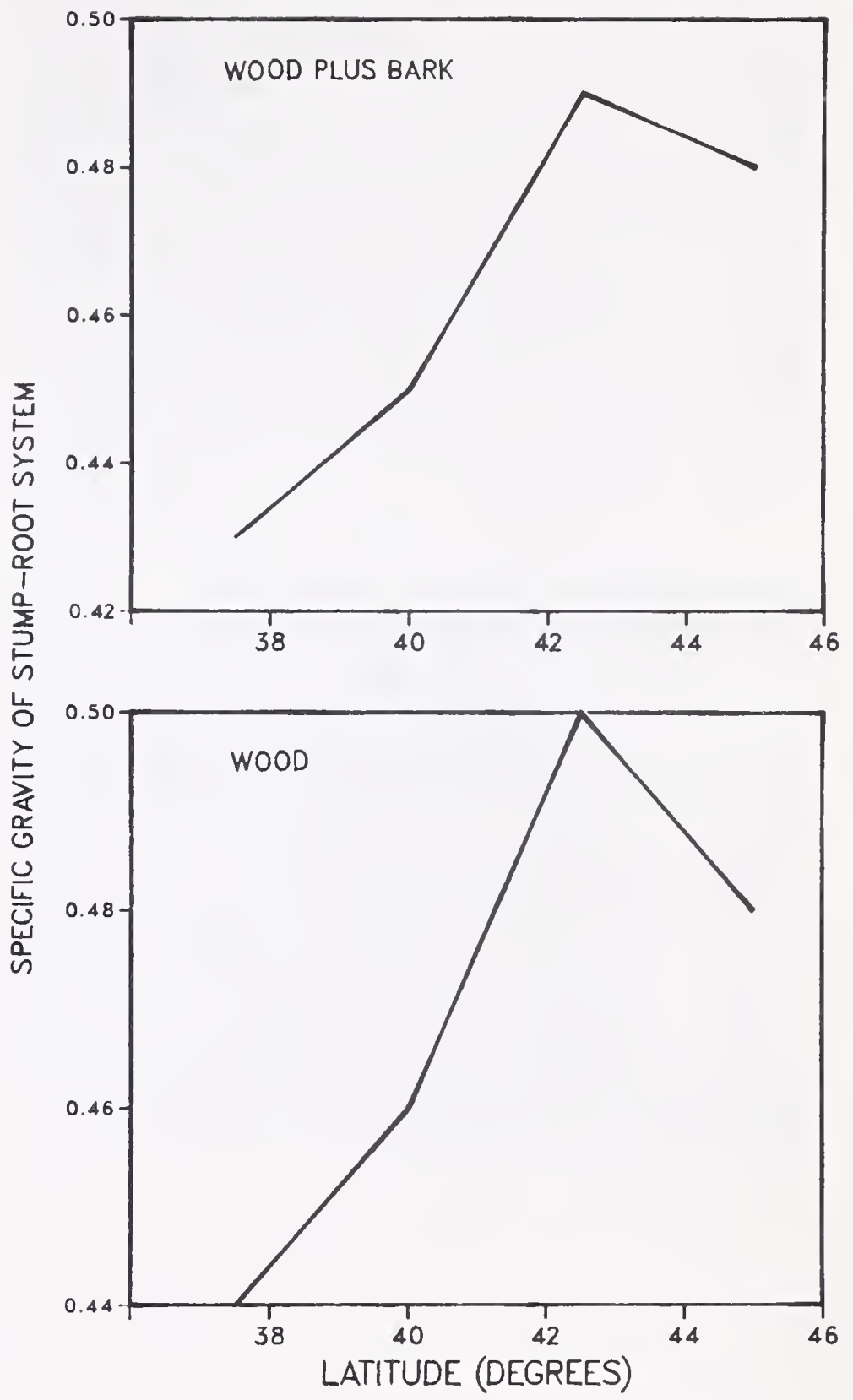

Figure 4-126-Specific gravity, based on ovendry weight and green volume, of the stump-root system (wood plus bark and wood only) of murrayana trees, related to latitude; diameter data pooled. 
Tree Component Proportion, Green-Weight Basis-The stump-root system (wood plus bark) percentage of green weight of complete trees with foliage was smallest (10.39 percent) at 45 degrees and largest (15.76 percent) at 40 degrees latitude (fig. 4-127, top). This percentage was negatively correlated with d.b.h., averaging 15.63 (4.26), $14.02(4.14)$, and $10.72(2.19)$ percent for trees 76,152 , and $228 \mathrm{~mm}$ in d.b.h. The overall average was 13.18 percent, with standard deviation of 3.66 percentage points.

Tree Component Proportion, Ovendry-Weight BasisOn an ovendry-weight basis, latitudinal trends were similar (fig. 4-127, bottom), and trees of 76, 152, and $228 \mathrm{~mm}$ in d.b.h. averaged 15.05 (3.81), 13.82 (3.49), and 10.68 (2.21) percent of complete-tree ovendry weight. The overall average was 13.18 percent, with standard deviation of 3.66 percentage points.

\section{Stump-Root System, Wood Only}

Specific Gravity-Specific gravity of wood of the stumproot system averaged 0.467 , with standard deviation of 0.050 . It was not significantly related to tree d.b.h., but did vary with latitude (fig. 4-126, bottom); specific gravity was minimum at 37.5 degrees $(0.436)$ and maximum at 42.5 degrees (0.497).

Weight, Green-Weight of green wood of the stumproot system was unrelated to latitude but was positively correlated with d.b.h., averaging $3.16(0.90), 18.14$ (4.55), and $39.96(6.16) \mathrm{kg}$ for trees of the three diameter classes.

Weight, Ovendry-On an ovendry basis, d.b.h. was the only significant variable, with wood weight averaging 1.55 (0.42), 8.59 (2.03), and 18.73 (3.61) for trees $76 \mathrm{~mm}$, $152 \mathrm{~mm}$, and $228 \mathrm{~mm}$ in d.b.h.
MURRAYANA
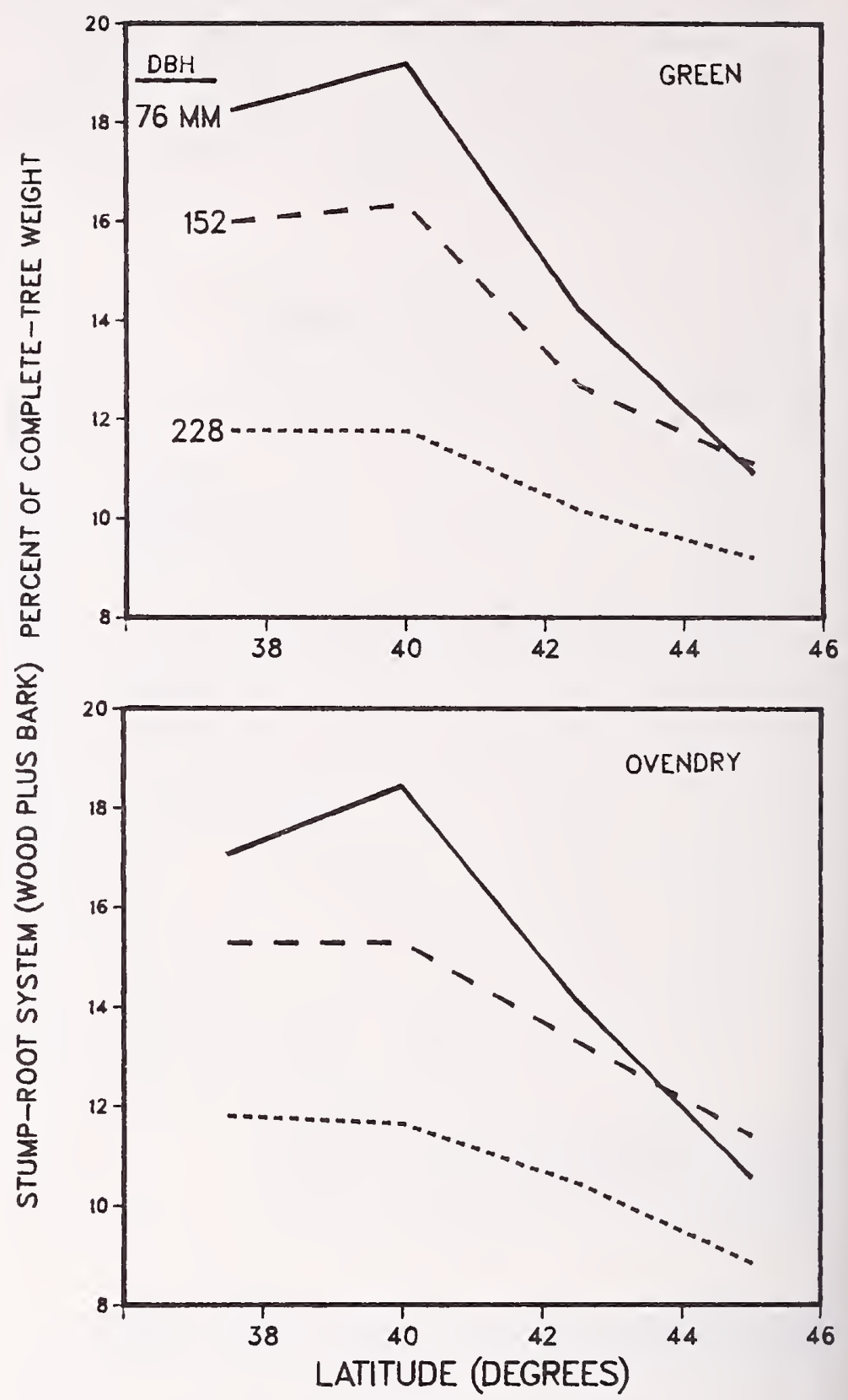

Figure 4-127-Stump-root system (wood plus bark) as percentage of the weight of complete trees with foliage-green and ovendry-for murrayana trees of three diameters, related to latitude. 


\section{Stump-Root System, Bark Only}

Specific Gravity-Specific gravity of bark of the stumproot system averaged 0.412 , with standard deviation of 0.043 . It did not vary significantly with latitude, but the larger trees had denser root-system bark than the smaller; that is, for trees 76,152 , and $228 \mathrm{~mm}$ in d.b.h., bark specific gravity averaged $0.386(0.047), 0.429(0.022)$, and $0.422(0.046)$.

Weight, Green-Green weight of bark of the stump-root system averaged maximum at 40 degrees latitude and minimum at 45 degrees (fig. 4-128), and was positively correlated with d.b.h., averaging $0.59(0.20), 2.39(1.01)$, and $3.91(1.05) \mathrm{kg}$ for trees of the three diameter classes.

Weight, Ovendry-On an ovendry-weight basis, bark weight was not significantly related to latitude, but was positively correlated with d.b.h., averaging $0.25(0.07)$, $1.12(0.39)$, and $1.83(0.46) \mathrm{kg}$ for trees of the three diameter classes.

Stump-Root Bark as Percentage of Gross Stump-Root Weight, Green and Ovendry-Bark averaged 12.03 percent of the green weight of wood plus bark of the stumproot systems, with standard deviation of 3.56 percentage points. This percentage was unrelated to latitude, but was negatively correlated with d.b.h., averaging 15.72 (2.32), 11.47 (2.44), and 8.89 (1.71) percent for trees 76, 152, and $228 \mathrm{~mm}$ in d.b.h.

On an ovendry basis, bark weight proportion had overall average of 11.46 percent, with standard deviation of 2.96 percentage points. Trees 76,152 , and $228 \mathrm{~mm}$ in d.b.h. had 13.85 (1.85), 11.53 (2.77), and 9.00 (1.98) percent bark weight in stump-root systems.

\section{MURRAYANA}

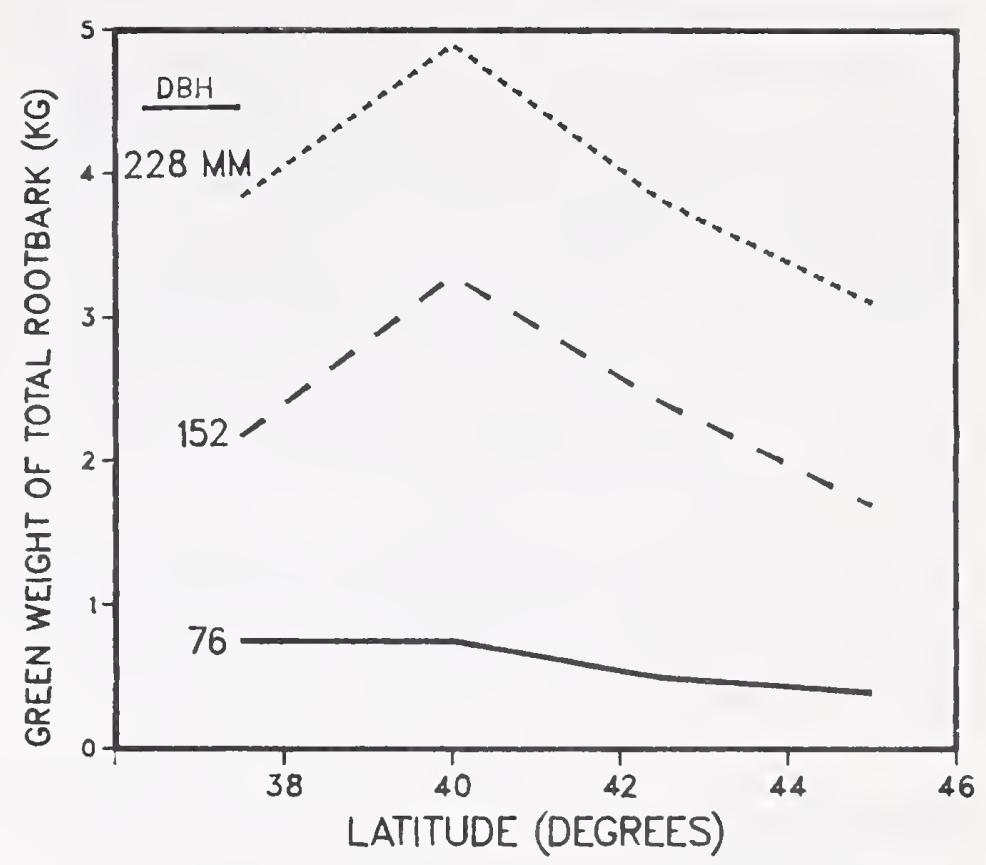

Figure 4-128-Weight of green bark from the stump-root system of murrayana trees of three diameters, related to latitude. 


\section{Stump, Wood Plus Bark}

Specific Gravity-Specific gravity of stumps, wood plus bark, from groundline to 152-mm stump height averaged 0.496 , with standard deviation of 0.054 . It was unrelated to latitude but negatively correlated with d.b.h., averaging $0.520(0.056), 0.506(0.054)$, and $0.462(0.033)$ for trees 76 , 152 , and $228 \mathrm{~mm}$ in d.b.h.

Weight, Green-Green weight of wood plus bark of stumps averaged maximum at 40 degrees latitude and minimum at 45 degrees (fig. 4-129, top). This weight was positively correlated with d.b.h., averaging $1.25(0.38)$, $4.57(1.68)$, and $6.80(1.82) \mathrm{kg}$ for trees of the three diameter classes.

Weight, Ovendry-Ovendry weight of wood plus bark of the stumps varied significantly only with d.b.h., averaging $0.65(0.19), 2.30(0.72)$, and $3.28(0.83) \mathrm{kg}$ for trees 76 , 152 , and $228 \mathrm{~mm}$ in d.b.h.

\section{Stumpwood}

Specific Gravity-Stumpwood had average specific gravity of 0.506 , with standard deviation of 0.063 . This specific gravity was unrelated to latitude, but was negatively correlated with d.b.h., averaging $0.541(0.062), 0.512$ (0.059), and $0.463(0.042)$ for trees 76,152 , and $228 \mathrm{~mm}$ in d.b.h.

Weight, Green-Weight of green stumpwood was unrelated to latitude, but positively correlated with tree d.b.h., averaging 1.09 (0.32), $4.15(1.54)$, and $6.27(1.65) \mathrm{kg}$ for the three diameter classes.

Weight, Ovendry-Similarly, ovendry stumpwood weight averaged $0.57(0.17), 2.08(0.67)$, and $2.98(0.76) \mathrm{kg}$ for trees of the three diameter classes.

\section{Stumpbark}

Specific Gravity-Specific gravity of stumpbark averaged 0.431 , with standard deviation of 0.055 . It was unrelated to latitude but positively correlated with d.b.h., averaging $0.398(0.041), 0.445(0.055)$, and $0.450(0.057)$ for trees of the three diameter classes.

Weight, Green-Weight of green stumpbark averaged greatest at the southernmost latitude and least at the northernmost (fig. 4-129, bottom). Green stumpbark weight was positively correlated with d.b.h., averaging 160 (63), 415 (153), and 531 (201) $\mathrm{g}$ for trees of the three diameter classes.

Weight, Ovendry-When ovendry, stumpbark weight was not significantly related to latitude (although it averaged only $165 \mathrm{~g}$ at 40 degrees compared to an average of $234 \mathrm{~g}$ at 37.5 degrees). Dry stumpbark weight was positively correlated with d.b.h., averaging 72 (23), 222 (71), and 304 (111) $g$ for trees of the three diameter classes.

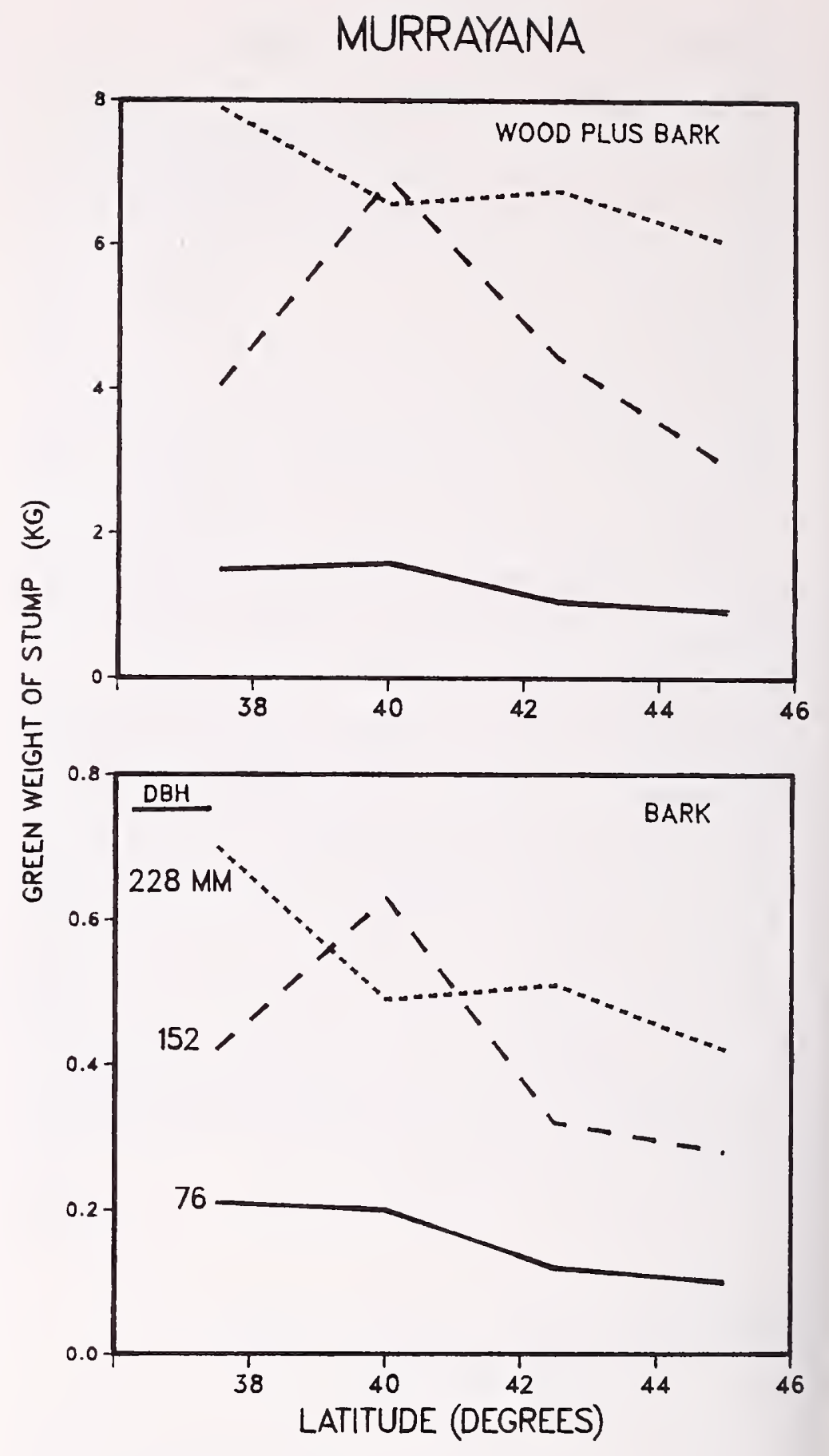

Figure 4-129-Weight of green stumps from groundline to $152-\mathrm{mm}$ stump height (wood plus bark and bark only) of murrayana trees of three diameters, related to latitude. 


\section{Lateral Roots, Wood Plus Bark}

Specific Gravity-Specific gravity of lateral roots, wood plus bark, was not significantly related to d.b.h. (although the average for $76-\mathrm{mm}$ trees was 0.415 and that for $228 \mathrm{~mm}$ was 0.445 , with $152-\mathrm{mm}$ trees intermediate), and averaged 0.432 , with standard deviation of 0.066 . With diameter data pooled, specific gravity averaged lowest at 37.5 degrees $(0.390)$ and highest $(0.463)$ at 45 degrees (fig. 4-130).

\section{MURRAYANA}

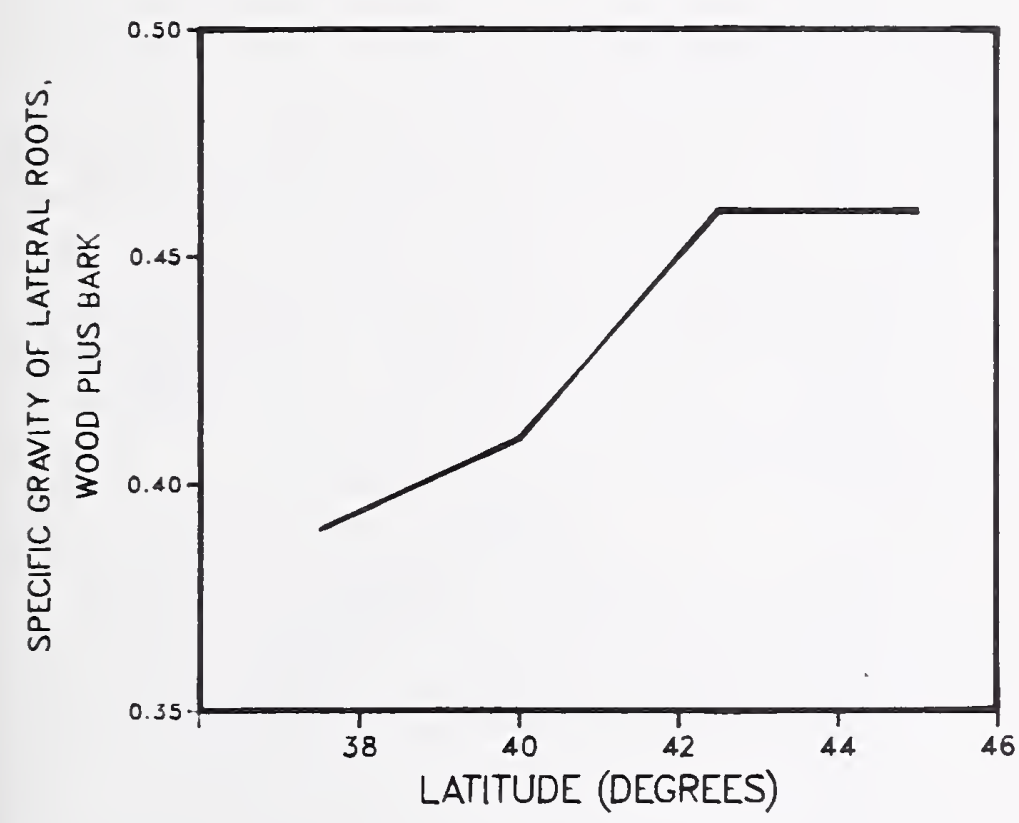

Figure 4-130-Specific gravity of wood plus bark of lateral roots (based on ovendry weight and green volume) of murrayana trees, related to latitude; diameter data pooled.
Weight, Green-Weight of wood plus bark of green lateral roots was highest at the two intermediate latitudes (fig. 4-131, top), and positively correlated with d.b.h., averaging $0.63(0.27), 6.25(2.45)$, and $15.66(3.95) \mathrm{kg}$ for trees of the three diameter classes.

Weight, Ovendry-Ovendry weight of wood plus bark of lateral roots varied similarly with latitude (fig. 4-131, bottom), and with d.b.h., averaging 0.28 (0.12), 2.80 (1.08), and $7.11(1.80) \mathrm{kg}$ for trees 76,152 , and $228 \mathrm{~mm}$ in d.b.h.

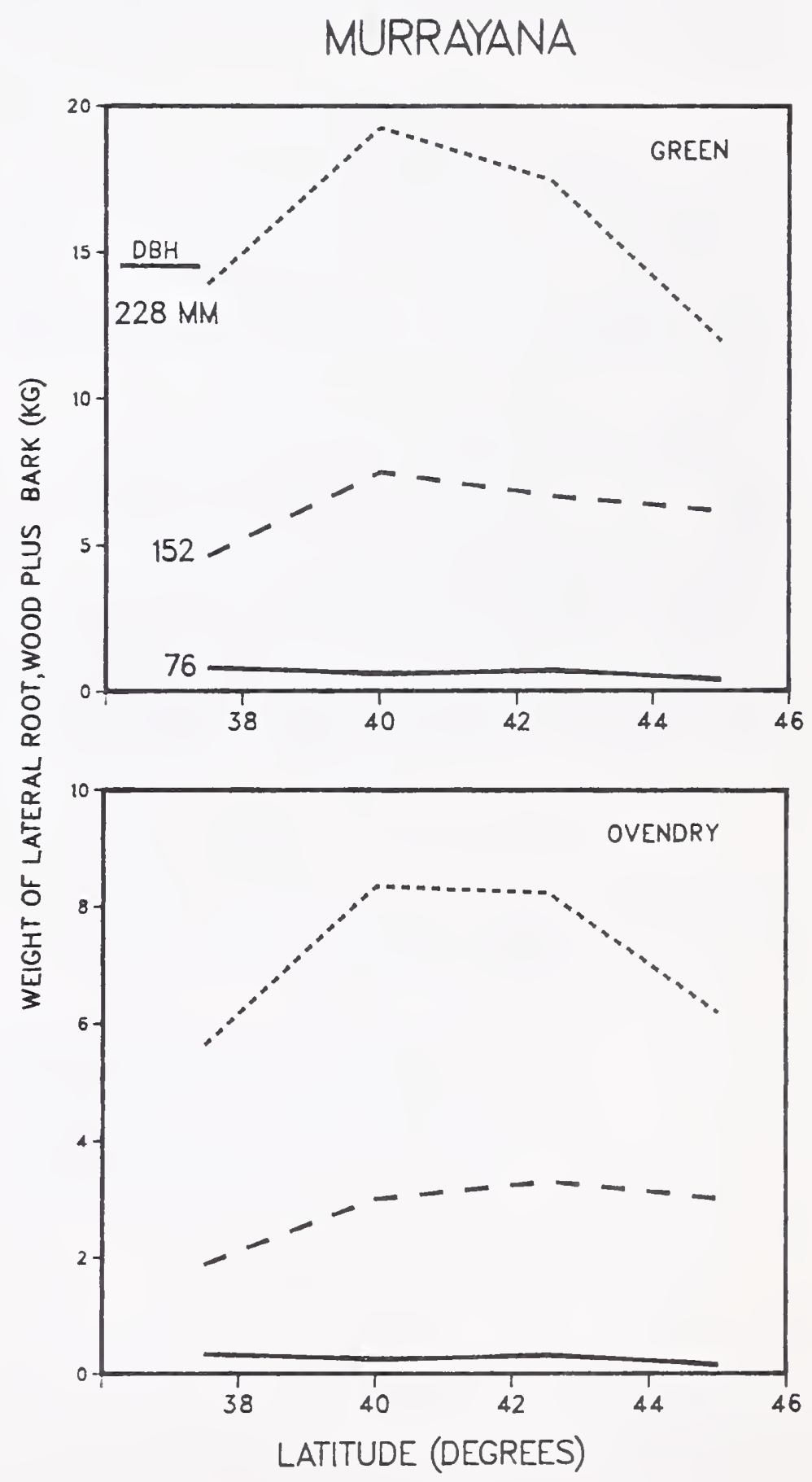

Figure 4-131-Weight of wood plus bark of lateral roots (green and ovendry) to a radius of $305 \mathrm{~mm}$ from stump pith from murrayana trees of three diameters, related to latitude. 


\section{Lateral Roots, Wood Only}

Specific Gravity-Specific gravity of wood of lateral roots did not vary significantly with latitude or tree d.b.h.; the overall average was 0.443 , with standard deviation of 0.072 .

Weight, Green-Weight of green wood in lateral roots was unrelated to latitude, but was positively correlated with d.b.h., averaging $0.47(0.21), 5.25$ (1.94), and 13.79 (3.52) $\mathrm{kg}$ for trees of the three diameter classes.

Weight, Ovendry-Exhibiting similar trends, weight of ovendry wood of lateral roots averaged $0.21(0.10), 2.38$ (0.93), and $6.31(1.72) \mathrm{kg}$ for trees 76,152 , and $228 \mathrm{~mm}$ in d.b.h.

\section{Lateral Roots, Bark Only}

Specific Gravity-Specific gravity of bark of lateral roots was not significantly related to latitude or d.b.h.; the overall average was 0.388 , with standard deviation of 0.059. Judging from the averages, however, a larger sample would likely have shown a positive correlation with d.b.h.

Weight, Green-Weight of green bark of lateral ronts was highest at 40 degrees latitude and lowest at 45 degrees (fig. 4-132, top). It was positively correlated with d.b.h., averaging 164 (66), 998 (609), and 1,862 (707) $\mathrm{g}$ for trees 76,152 , and $228 \mathrm{~mm}$ in d.b.h.

Weight, Ovendry-On an ovendry-weight basis, the latitudinal trend was similar (fig. 4-132, bottom). Trees 76 , 152 , and $228 \mathrm{~mm}$ in d.b.h. had average weight of dry bark from lateral roots of 63 (22), 422 (204), and 801 (275) g.

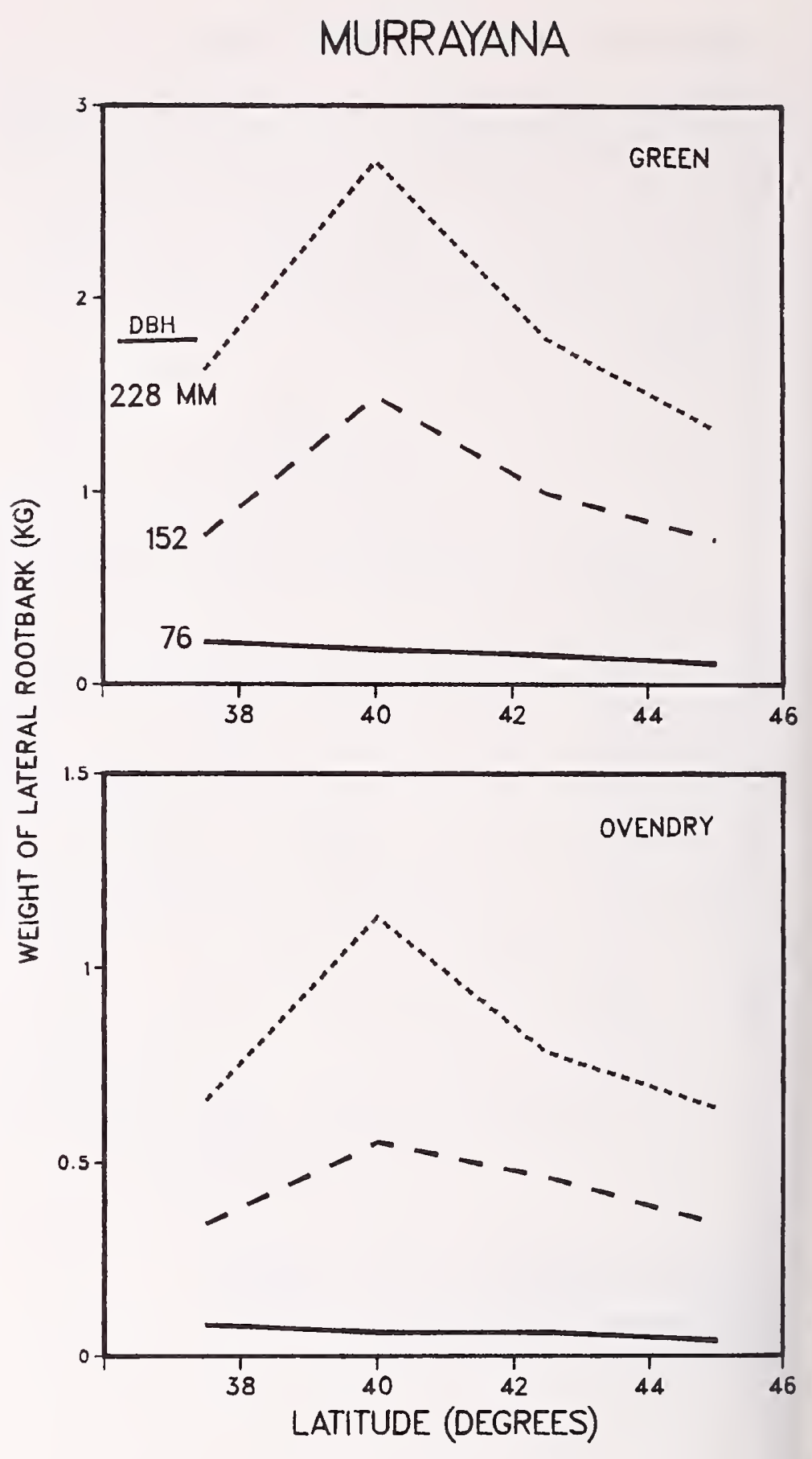

Figure 4-132-Weight of green and ovendry bark from lateral roots of murrayana trees of three diameters, related to latitude. 


\section{Central Root Mass-Taproot, Wood Plus Bark}

Specific Gravity-Overall average specific gravity of wood plus bark of the central root mass-taproot was 0.457 , with standard deviation of 0.051 . It was unrelated to d.b.h., but varied with latitude-highest at 42.5 degrees and lowest at 37.5 degrees (fig. 4-133, top).

Weight, Green-Green weight of wood plus bark of the central root mass-taproot did not vary significantly with latitude, but was positively correlated with d.b.h., averaging $1.87(0.68), 9.72(2.65)$, and $21.40(5.12) \mathrm{kg}$ for trees of the three diameter classes.

Weight, Ovendry-Ovendry weights did not vary significantly with latitude, but were positively correlated with d.b.h., averaging $0.87(0.30), 4.60(1.24)$, and 10.17 (2.25) for trees 76,152 , and $228 \mathrm{~mm}$ in d.b.h.

\section{Central Root Mass-Taproot, Wood Only}

Specific Gravity-Overall average specific gravity of wood of the central root mass-taproot was 0.460 , with standard deviation of 0.055 . It did not vary significantly with d.b.h., but, with diameter data pooled, was maximum $(0.502)$ at 42.5 degrees latitude and minimum (0.429) at 37.5 degrees (fig. 4-133, bottom).

Weight, Green-Weight of wood from the central root mass-taproot did not vary significantly with latitude, but was positively correlated with d.b.h., averaging $1.60(0.58)$, $8.74(2.36)$, and $19.90(4.68) \mathrm{kg}$ for trees of the three diameter classes.

Weight, Ovendry-On an ovendry-weight basis trends were similar, with wood weight averaging $0.76(0.26), 4.13$ (1.13), and $9.45(2.03) \mathrm{kg}$ for trees 76,152 , and $228 \mathrm{~mm}$ in d.b.h.

\section{Central Root Mass-Taproot, Bark Only}

Specific Gravity-Overall average specific gravity of bark of the central root mass-taproot was 0.426 , with standard deviation of 0.057 ; it was not significantly related to latitude or to tree d.b.h. The latitudinal averages suggest a trend of increasing specific gravity from south (0.401) to north $(0.464)$, however.

Weight, Green-Weight of green bark from the central root mass-taproot was unrelated to latitude but was positively correlated with d.b.h., averaging 271 (119), 975 (382), and 1,520 (549) $\mathrm{g}$ for trees 76,152 , and $228 \mathrm{~mm}$ in d.b.h.

Weight, Ovendry-On an ovendry-weight basis trends were similar, with bark weight averaging 113 (45), 471 (196), and 729 (296) $\mathrm{g}$ for trees of the three diameter classes.

\section{MURRAYANA}

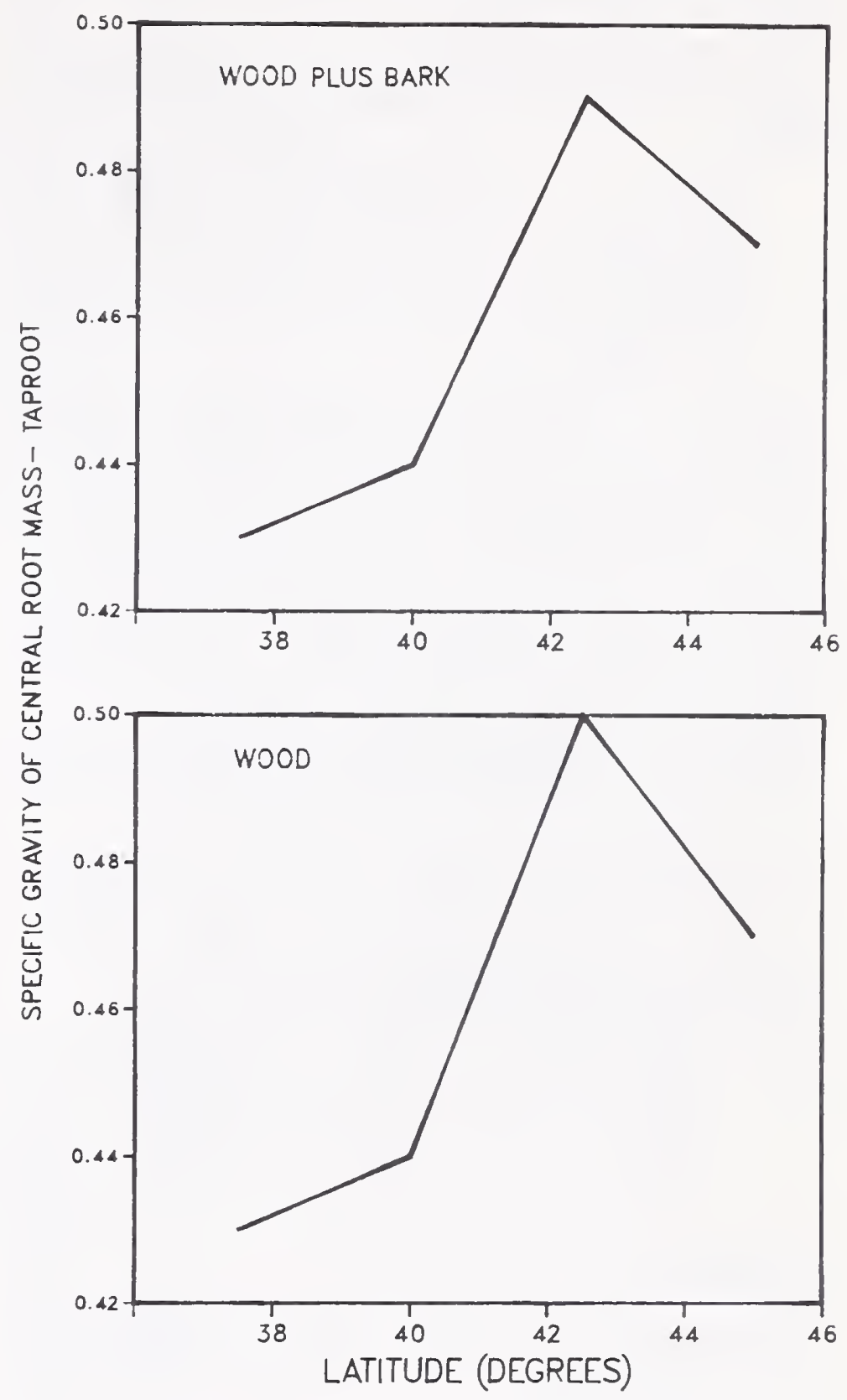

Figure 4-133-Specific gravity (based on ovendry weight and green volume) of wood plus bark and wood only of the central root mass-taproot of murrayana trees, as related to latitude; diameter data pooled. 


\section{4-7 RESULTS-LATIFOLIA COMPARED TO MURRAYANA}

The experimental design permitted an orthogonal comparison between the two varieties at three latitudes as follows:

$\begin{array}{lll}\text { Varieties: } & \text { (2) } & \text { latifolia and murrayana } \\ \text { D.b.h. classes: } & \text { (3) } 76,152 \text {, and } 228 \mathrm{~mm} \\ \text { Latitudinal zones: } & \text { (3) } 40,42.5 \text {, and } 45 \text { degrees } \\ \text { Elevational zones: } & \text { (1) medium (1,148 to } 2,711 \mathrm{~m}) \\ \text { Replications: } & \text { (3) }\end{array}$

Sample size for this comparison therefore totaled 54 trees, 27 of each variety. In the discussion that follows, only significant relationships associated with varietal differences are graphed and tabulated; the other effects are more completely described in the preceding two sections.

Because specific gravity is a particularly useful statistic, table 4-11 lists component values that differ significantly at the three sample latitudes common to the two varieties. Throughout this table, murrayana components have higher specific gravities than those of latifolia.

Discussions of significant varietal differences in component weights, as well as specific gravities, follow.

\section{Complete Tree Without Cones or Foliage}

Complete-tree specific gravity of murrayana was higher than that of latifolia as follows (from table 4-11):

$\begin{array}{lcc}\text { Component } & \text { Latifolia } & \text { Murrayana } \\ \text { Wood plus bark } & 0.406 & 0.446 \\ \text { Wood } & .413 & .456 \\ \text { Bark } & .363 & .387\end{array}$

\section{Foliage}

Latifolia had more weight of foliage, and a higher foliage-weight percentage, than murrayana, as follows:

D.b.h. and

$\begin{array}{ccc}\text { foliage moisture } & \text { Latifolia } & \text { Murrayana } \\ & \ldots \ldots & \text { kg/tree } \\ 76 \mathrm{~mm} \text { Green } & 2.48 & 1.71 \\ \text { Ovendry } & 1.12 & .79 \\ 152 \mathrm{~mm} \text { Green } & 12.53 & 7.93 \\ \text { Ovendry } & 5.96 & 3.79 \\ 228 \mathrm{~mm} \text { Green } & 22.56 & 18.25 \\ \text { Ovendry } & 10.41 & 8.52\end{array}$

When green, foliage proportion of complete-tree weight averaged 7.4 percent for latifolia and 5.4 percent for mur. rayana, but at 42.5 degrees latitude the two varieties had about the same foliage proportion (fig. 4-134).

When ovendry, all three diameters of latifolia averaged higher in weight proportion of foliage (7.27 percent, with diameter data pooled) than murrayana (5.25 percent).
Table 4-11-Tree component specific gravities that differ significantly between latifolia and murrayana trees (at medium elevation and latitudes of $40,42.5$, and 45 degrees) ${ }^{4}$

\begin{tabular}{|c|c|c|}
\hline \multirow[b]{2}{*}{ Tree component } & \multicolumn{2}{|c|}{ Variety } \\
\hline & Latifolia & Murrayana \\
\hline \multicolumn{3}{|c|}{$\begin{array}{l}\text { Complete tree without cones or } \\
\text { foliage }\end{array}$} \\
\hline Wood plus bark & $0.406(0.023)$ & $0.446(0.036)$ \\
\hline Wood & $.413 \quad(.026)$ & $.456 \quad(.042)$ \\
\hline Bark & $.363(.038)$ & $.387 \quad(.033)$ \\
\hline \multicolumn{3}{|l|}{ Live branches } \\
\hline Wood plus bark & $.441 \quad(.026)$ & $.466 \quad(.020)$ \\
\hline Wood $^{2}$ & $.477 \quad(.045)$ & $.495 \quad(.020)$ \\
\hline Bark & $.393 \quad(.046)$ & $.429 \quad(.042)$ \\
\hline \multicolumn{3}{|l|}{ Stem, tree average } \\
\hline Wood plus bark ${ }^{2}$ & $.395 \quad(.024)$ & $.441 \quad(.039)$ \\
\hline Wood $^{2}$ & $.401 \quad(.027)$ & $.451 \quad(.046)$ \\
\hline Heartwood $^{2}$ & $.427 \quad(.035)$ & $.500 \quad(.072)$ \\
\hline \multicolumn{3}{|l|}{ Stump-root system } \\
\hline Bark & $.390 \quad(.064)$ & $.418 \quad(.041)$ \\
\hline \multicolumn{3}{|c|}{$\begin{array}{l}\text { Stump, groundline to } 152-\mathrm{mm} \\
\text { height }\end{array}$} \\
\hline Wood plus bark & $.472 \quad(.048)$ & $.505 \quad(.052)$ \\
\hline Wood & $.479 \quad(.056)$ & $.516 \quad(.060)$ \\
\hline Bark $^{2}$ & $.417 \quad(.079)$ & $.433 \quad(.056)$ \\
\hline \multicolumn{3}{|l|}{ Central root mass-taproot } \\
\hline Bark $^{2}$ & $.396 \quad(.063)$ & $.434 \quad(.059)$ \\
\hline
\end{tabular}

'Each value is based on ovendry weight and green volume data for 27 trees (that is, diameter data were pooled), and is followed by the standard deviation in parentheses.

2These component values are involved in significant interactions with d.b.h. or latitude; see text discussion.

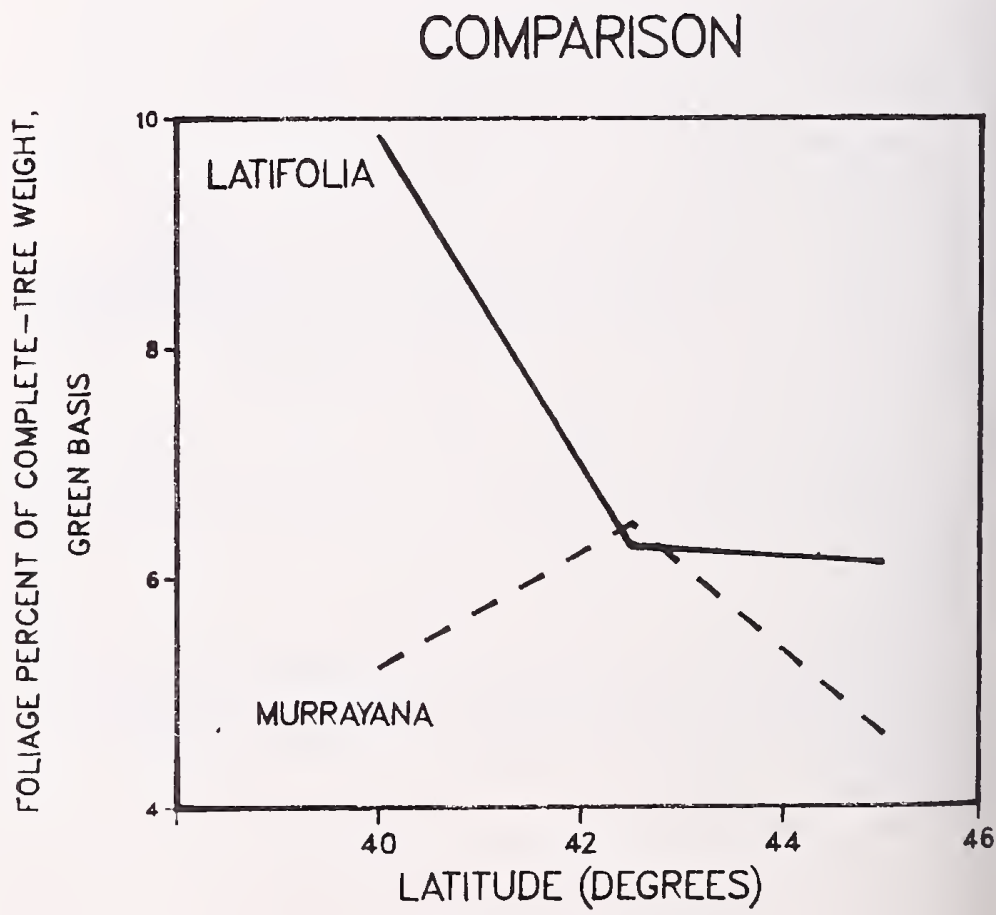

Figure 4-134-Foliage as percentage of complete-tree green weight; latifolia compared to murrayana, as related to latitude. 
COMPARISON

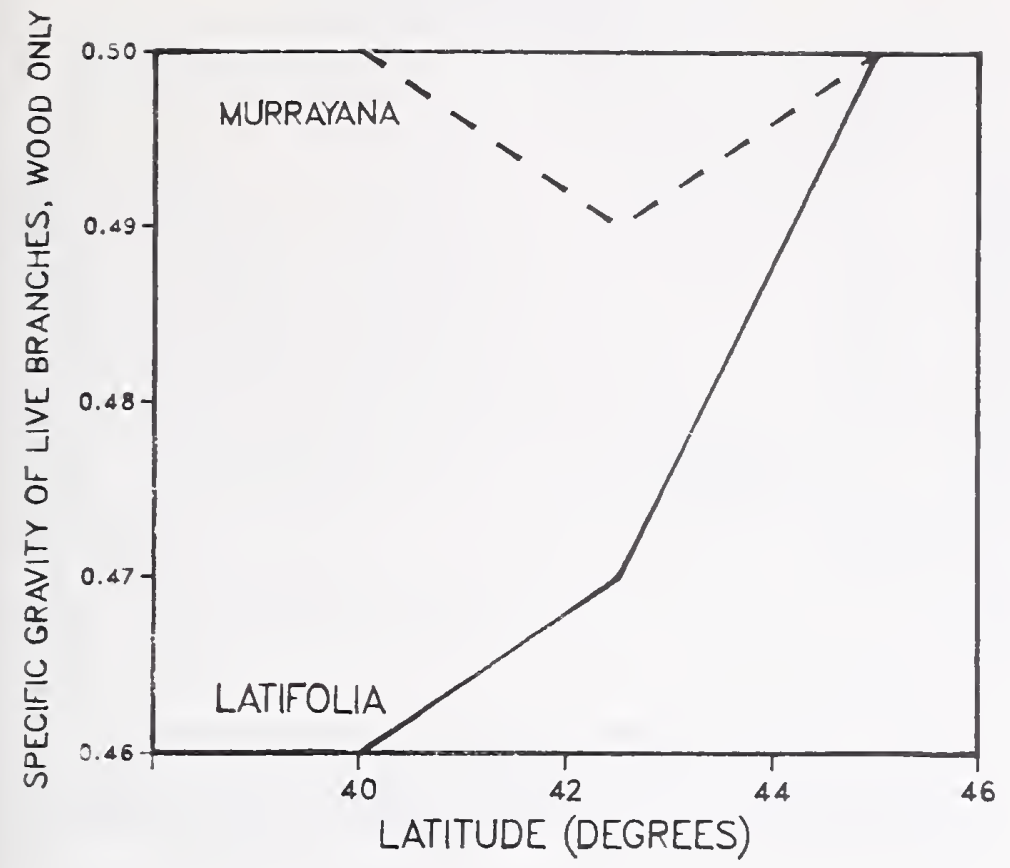

Figure 4-135-Specific gravity of live branch wood; latifolia compared to murrayana, as related to latitude.

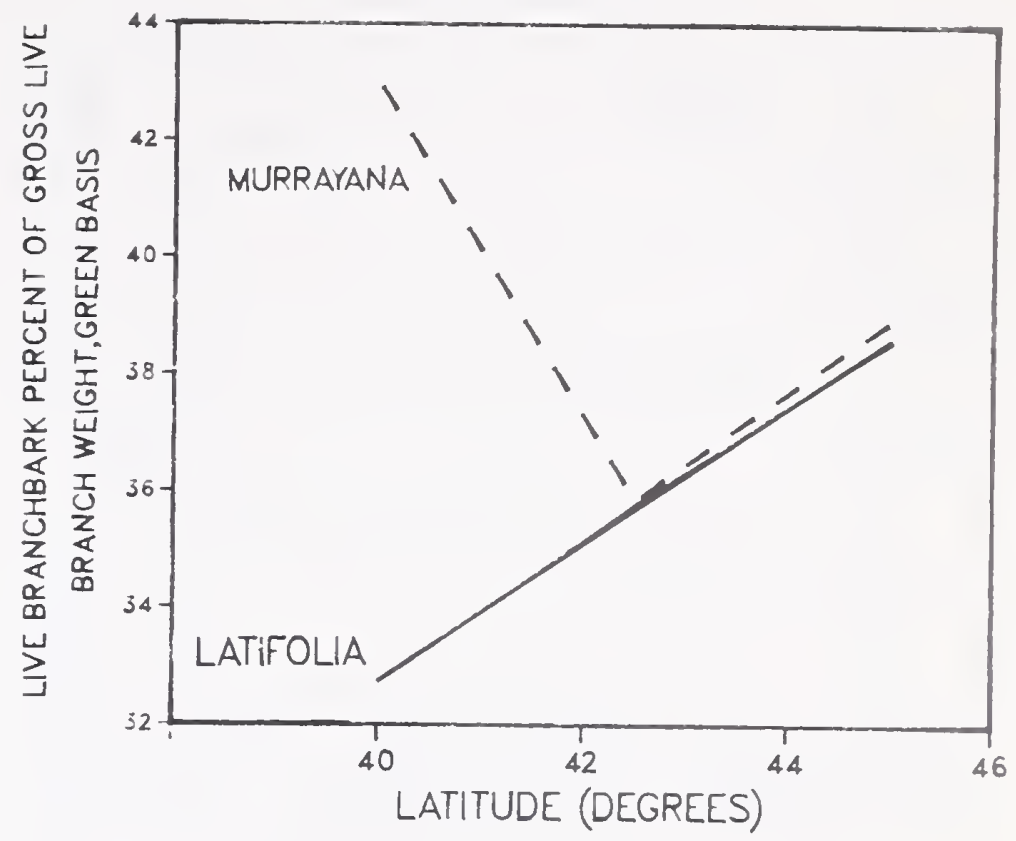

Figure 4-136-Live branchbark as percentage of green, foliage-free, live-branch weight; latifolia compared to murrayana, as related to latitude.

\section{COMPARISON}

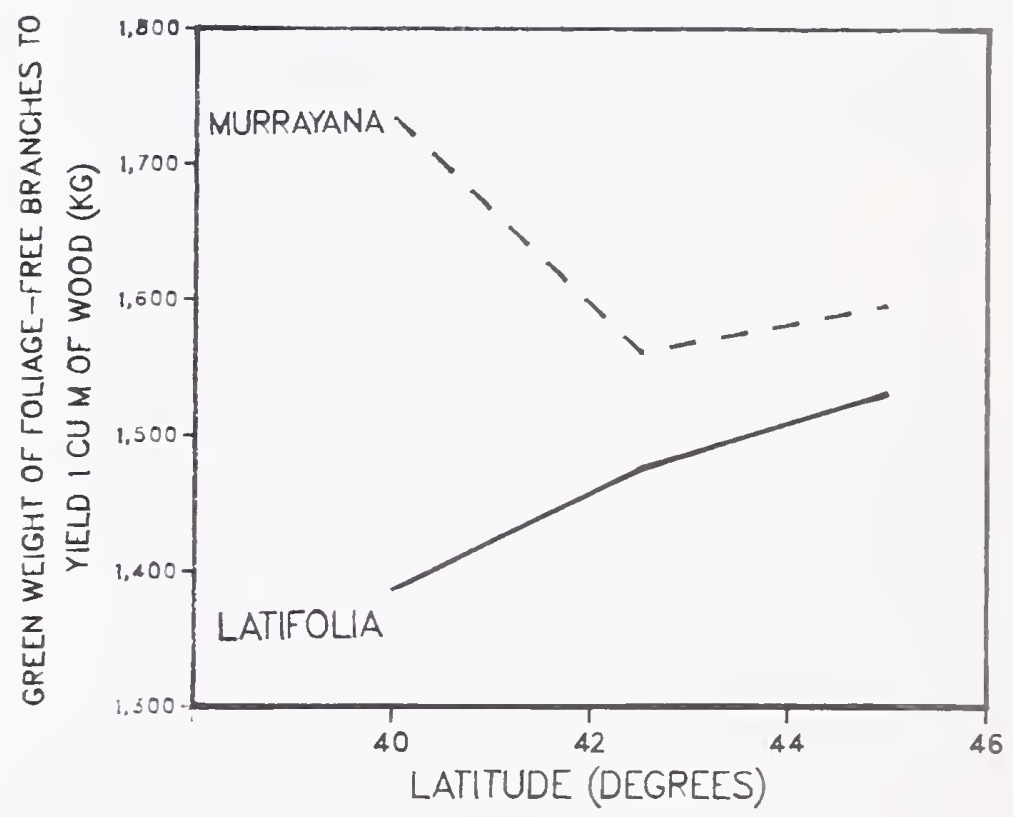

Figure 4-137-Green weight of foliage-free live branches to yield $1 \mathrm{~m}^{3}$ of wood; latifolia compared to murrayana, as related to latitude.

Specific gravity of live-branch wood was about equal for the two varieties only at 45 degrees latitude (fig. 4-135).

For all three tree diameters, live branches of murrayana had a higher percentage of bark (39.2 percent) than latifolia (33.5 percent); the difference was greatest at 40 degrees latitude (fig. 4-136).

To yield $1 \mathrm{~m}^{3}$ of bark-free wood from live branches, a greater weight of green murrayana branches $(1,631 \mathrm{~kg})$ than latifolia branches $(1,465 \mathrm{~kg})$ is therefore required (fig. 4-137). 
COMPARISON

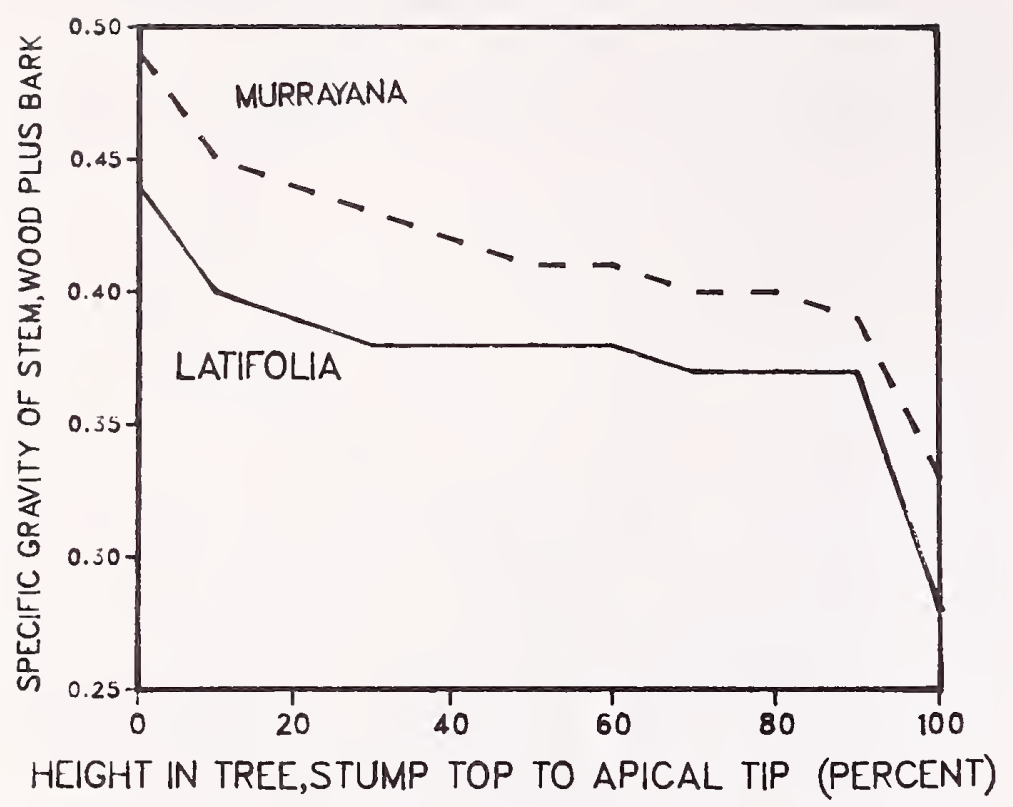

Figure 4-138-Specific gravity of stem (wood plus bark), ovendry weight and green volume basis; latifolia compared to murrayana, as related to height in tree.

\section{Stem Specific Gravity}

Wood Plus Bark-Specific gravity of wood plus bark of entire stems of murrayana averaged greater in trees of all three diameters than that of latifolia, as follows:

$\begin{array}{ccc}\text { D.b.h. } & \text { Latifolia } & \text { Murrayana } \\ m m & & \\ 76 & 0.398 & 0.466 \\ 152 & .392 & .444 \\ 228 & .396 & .412 \\ \text { Average } & .395 & .441\end{array}$

With diameter data pooled, the difference was observable at all percentages of tree heights (fig. 4-138).

Wood-Specific gravity of entire stemwood of murrayana was greater than that of latifolia, as follows:

$\begin{array}{ccc}\begin{array}{c}\text { D.b.h. } \\ m m\end{array} & \text { Latifolia } & \text { Murrayana } \\ 76 & & \\ 152 & 0.409 & 0.482 \\ 228 & .396 & .454 \\ \text { Average } & .398 & .416 \\ .401 & .451\end{array}$

With diameter data pooled, the difference was nearly constant at all percentages of tree height (fig. 4-139).

Heartwood of murrayana had average specific gravity greater than that of latifolia; the difference was less in large trees than in small, as follows:

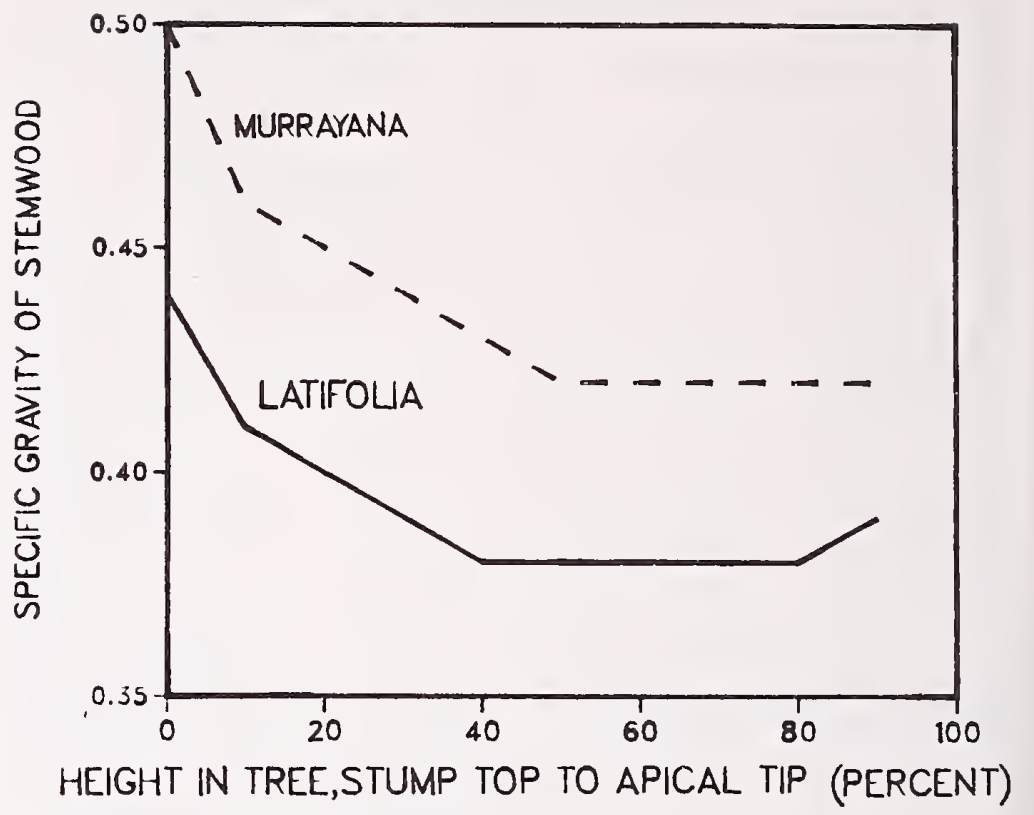

Figure 4-139-Specific gravity of stemwood, ovendry weight and green volume basis; latifolia compared to murrayana, as related to height in tree.

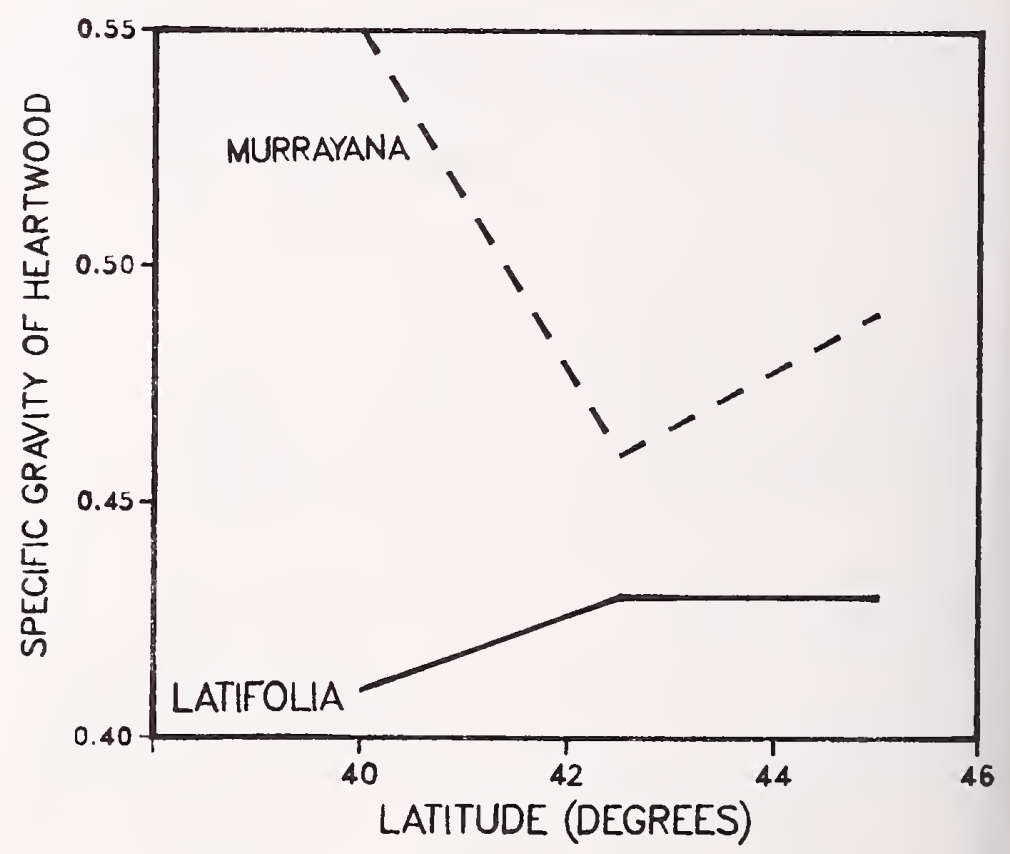

Figure 4-140-Specific gravity of heartwood, ovendry weight and green volume basis; latifolia compared to murrayana, as related to latitude.

$\begin{array}{ccc}\text { D.b.h. } & \text { Latifolia } & \text { Murrayana } \\ m m & & \\ 76 & 0.457 & 0.542 \\ 152 & .419 & .517 \\ 228 & .404 & .500 \\ \text { Average } & .427 & .500\end{array}$

The difference was greatest at 40 degrees latitude (fig. 4-140). 
COMPARISON

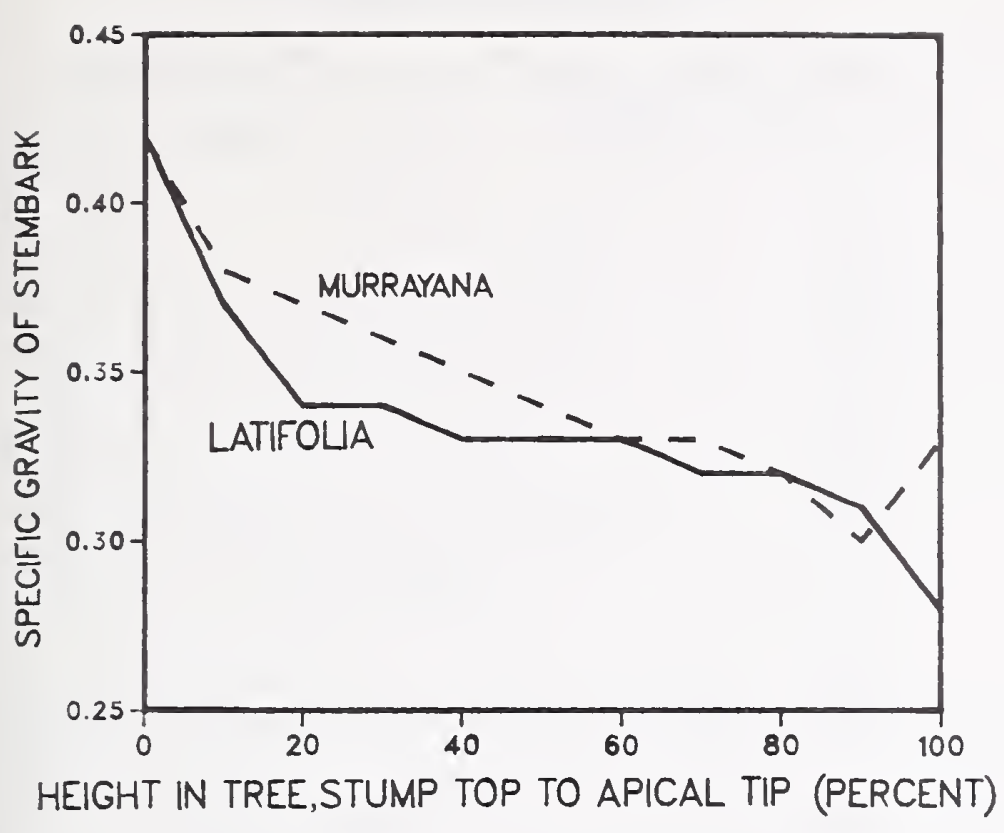

Figure 4-141-Specific gravity of stembark, ovendry weight and green volume basis; latifolia compared to murrayana, as related to height in tree.

Bark-With diameter data pooled, stembark specific gravity of murrayana was greater than that of latifolia at most heights in stems (fig. 4-141).

\section{Stem Green Weight to Yield $1 \mathrm{~m}^{3}$ of Wood}

With diameter data pooled, $1,025 \mathrm{~kg}$ of murrayana stems (wood plus bark, green) is required to yield $1 \mathrm{~m}^{3}$ of wood, whereas only $926 \mathrm{~kg}$ of latifolia will yield this volume of wood.

\section{Stump-Root System}

Wood Plus Bark-On both a green-weight and an ovendry-weight basis, murrayana trees averaged slightly higher in their percentage of complete-tree weight in the stump-root system than latifolia, as follows:

$\begin{array}{lcc}\begin{array}{l}\text { Moisture } \\ \text { condition }\end{array} & \text { Latifolia } & \text { Murrayana } \\ & \ldots \ldots & \text { Percent } \\ \text { Green } & 11.5 & 12.8 \\ \text { Ovendry } & 11.4 & 12.7\end{array}$

But the difference was reversed at 45 degrees latitude (figs. 4-142 and 4-143).

Bark-Bark of murrayana stump-root systems had average specific gravity of 0.418 , that of latifolia only 0.390 .

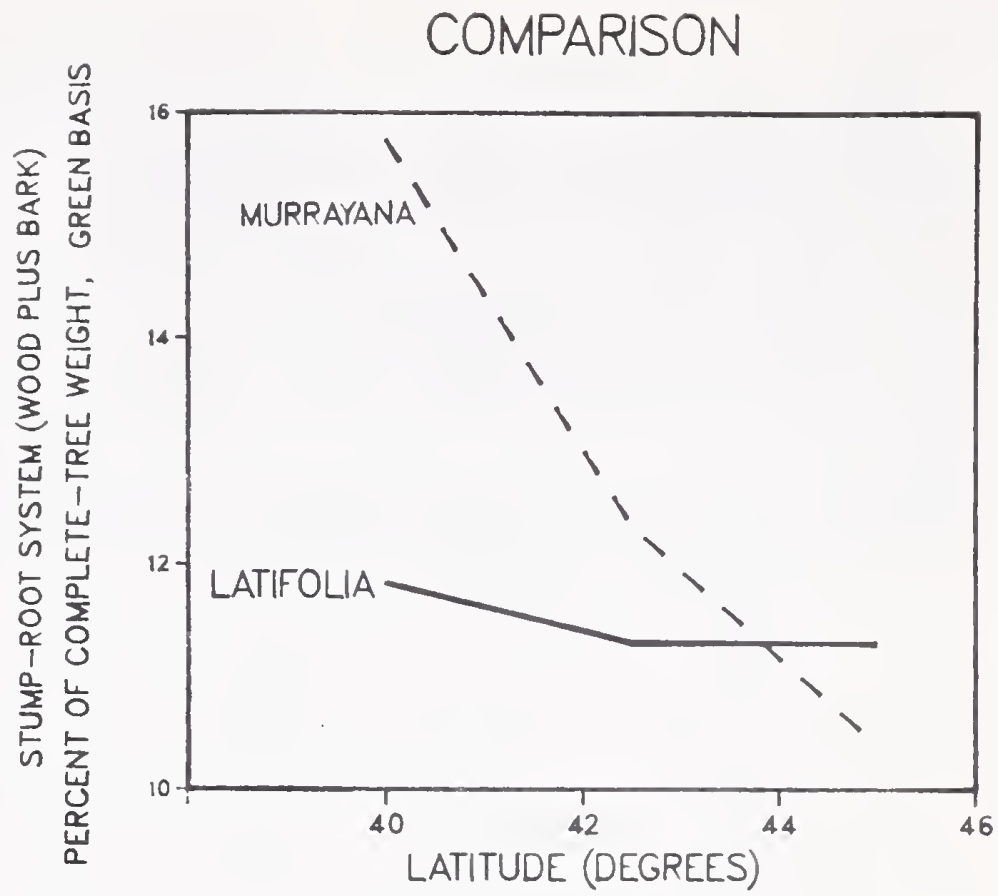

Figure 4-142-Stump-root system (wood plus bark) as percentage of green complete tree including foliage; latifolia compared to murrayana, as related to latitude.
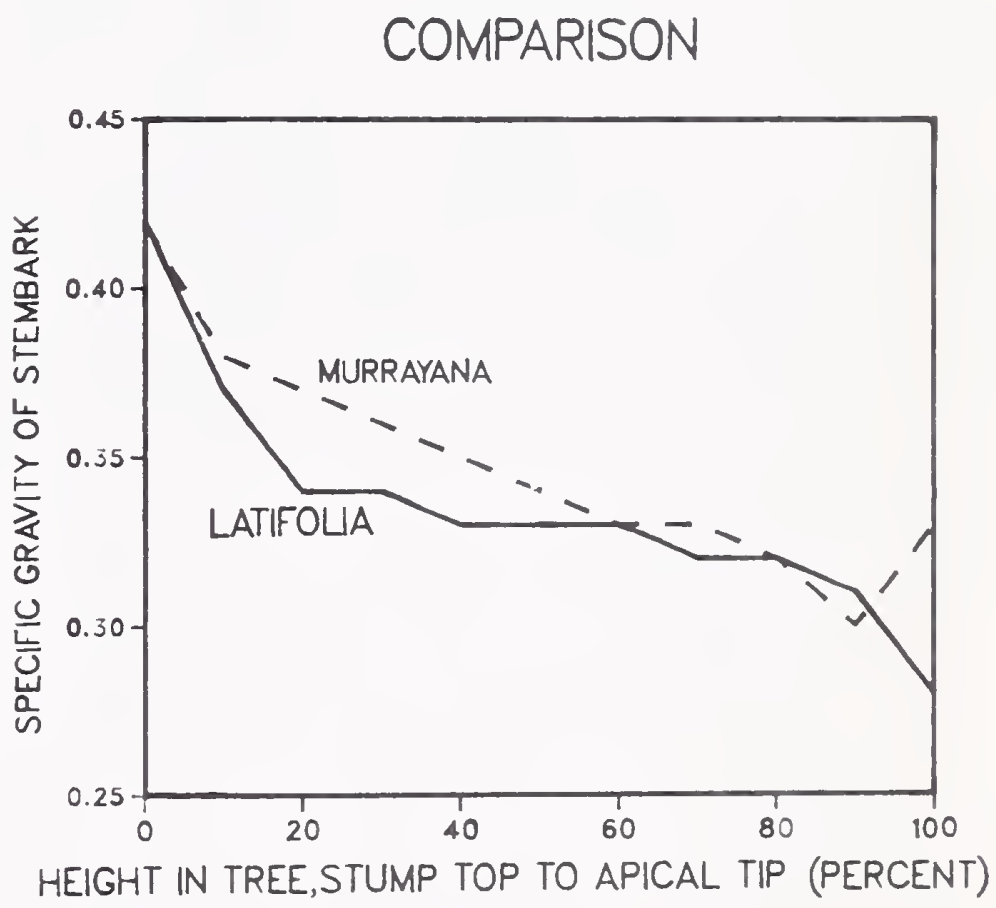

Figure 4-143-Stump-root system (wood plus bark) as percentage of ovendry complete tree including foliage; latifolia compared to murrayana, as related to latitude. 


\section{Stump}

Wood Plus Bark-Specific gravity of wood plus bark of murrayana stumps from groundline to $152-\mathrm{mm}$ top averaged 0.505 , while that of latifolia was only 0.472 .

Wood-Murrayana stumpwood specific gravity (0.516) was also higher than that of latifolia (0.479).

Relative green and dry weights of stumpwood of the two varieties varied with latitude and tree d.b.h. (figs. 4-144 and 4-145).

Bark-In smaller trees, stumpbark specific gravity was less in latifolia than in murrayana, as follows:

$\begin{array}{ccc}\text { D.b.h. } & \text { Latifolia } & \text { Murrayana } \\ m m & & \\ 76 & 0.346 & 0.412 \\ 152 & .419 & .440 \\ 228 & .486 & .448 \\ \text { Average } & .417 & .433\end{array}$

\section{COMPARISON}
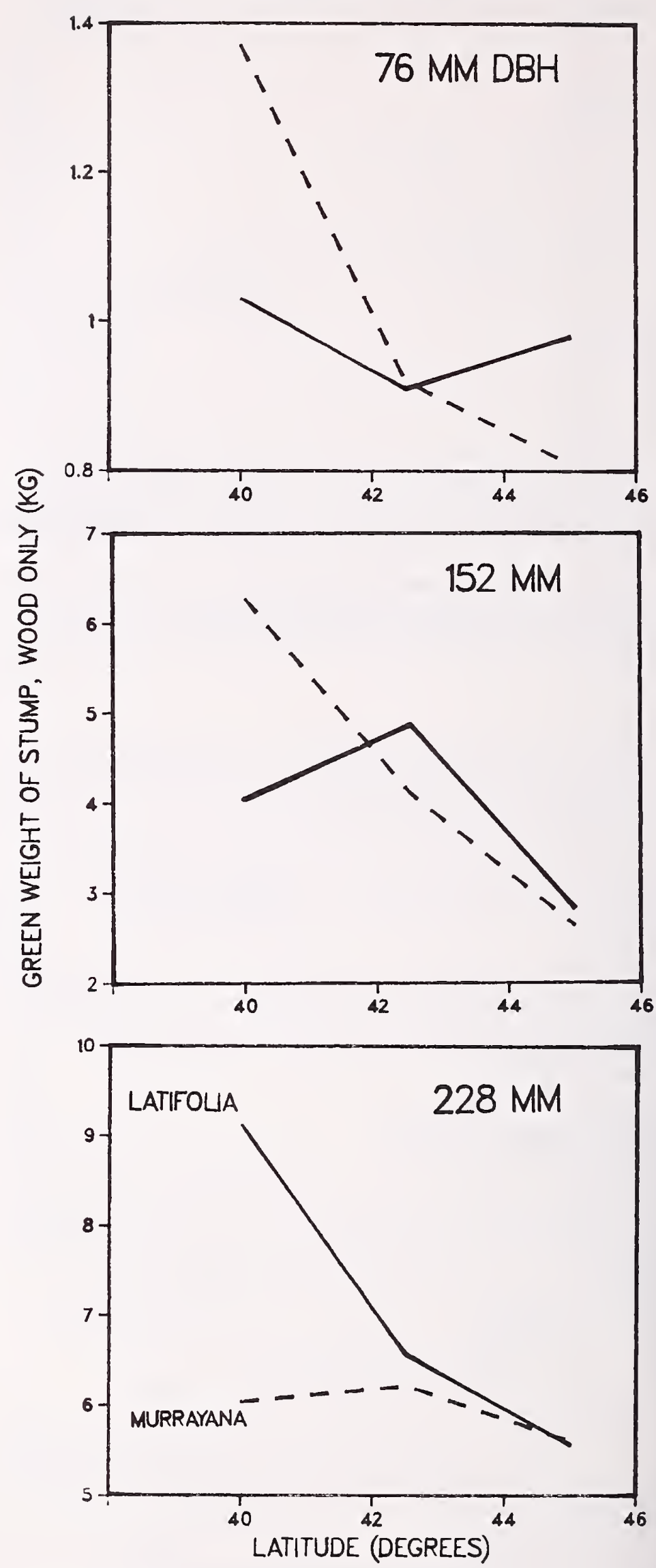

Figure 4-144-Green weight of stumpwood; latifolia compared to murrayana, as related to latitude. 


\section{COMPARISON}
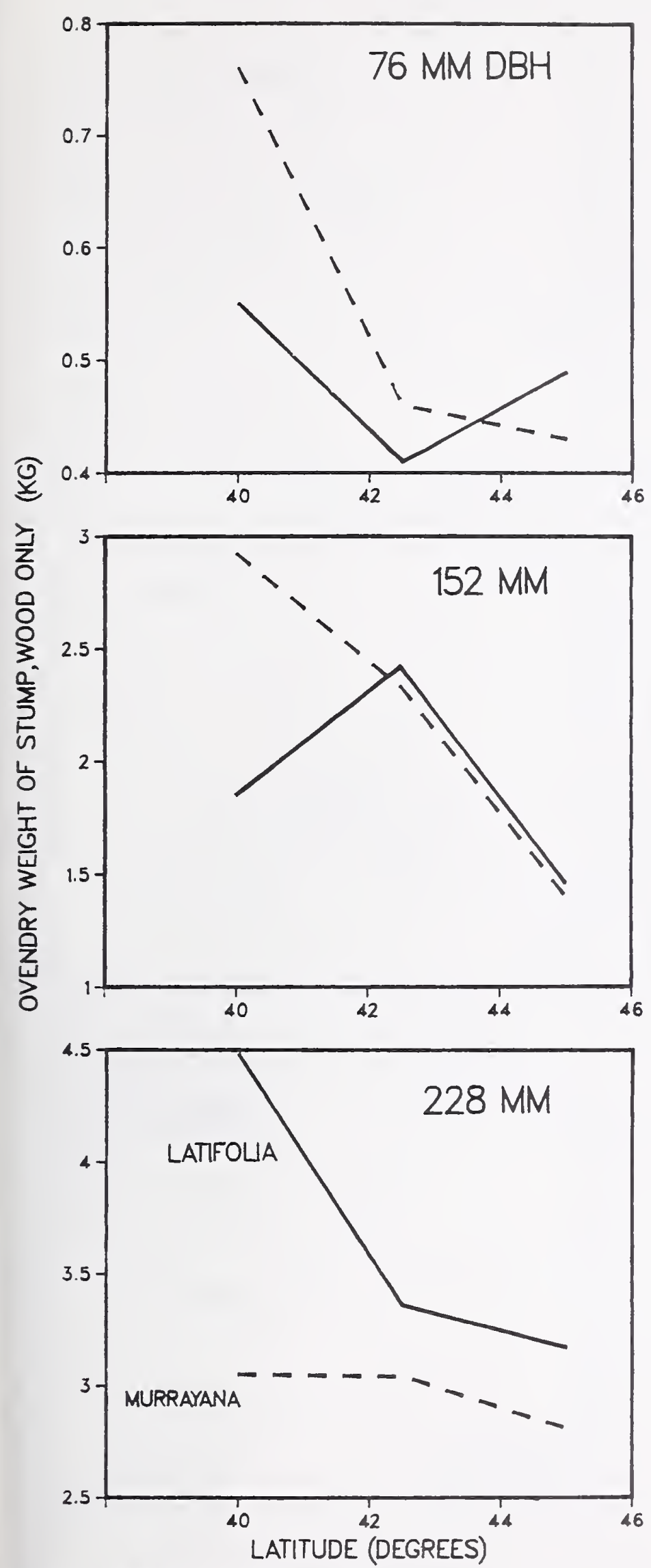

Figure 4-145-Ovendry weight of stumpwood;

latifolia compared to murrayana, as related to latitude. 
But bark of latifolia stumps generally weighed more than that of murrayana; not, however, in smaller trees at 40 degrees latitude (figs. 4-146 and 4-147).

\section{COMPARISON}
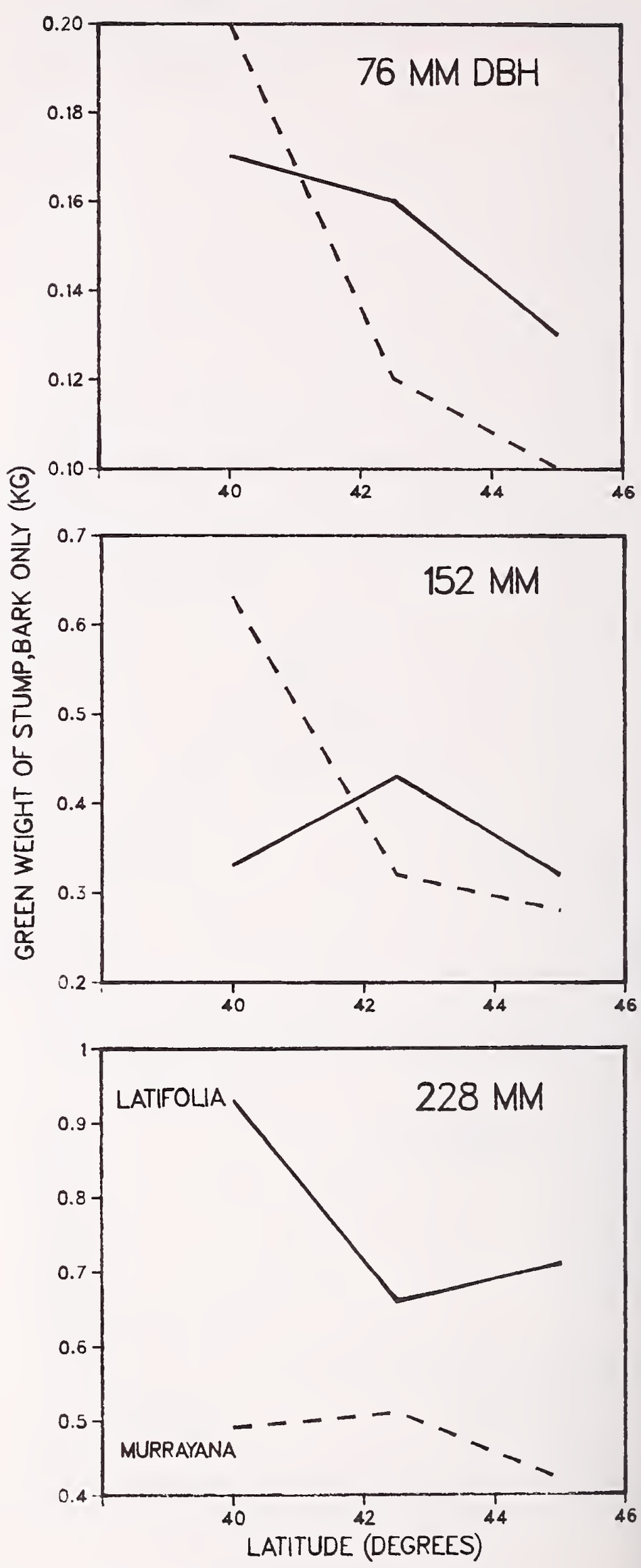

Figure 4-146-Green weight of stumpbark; latifolia compared to murrayana, as related to latitude. 


\section{COMPARISON}
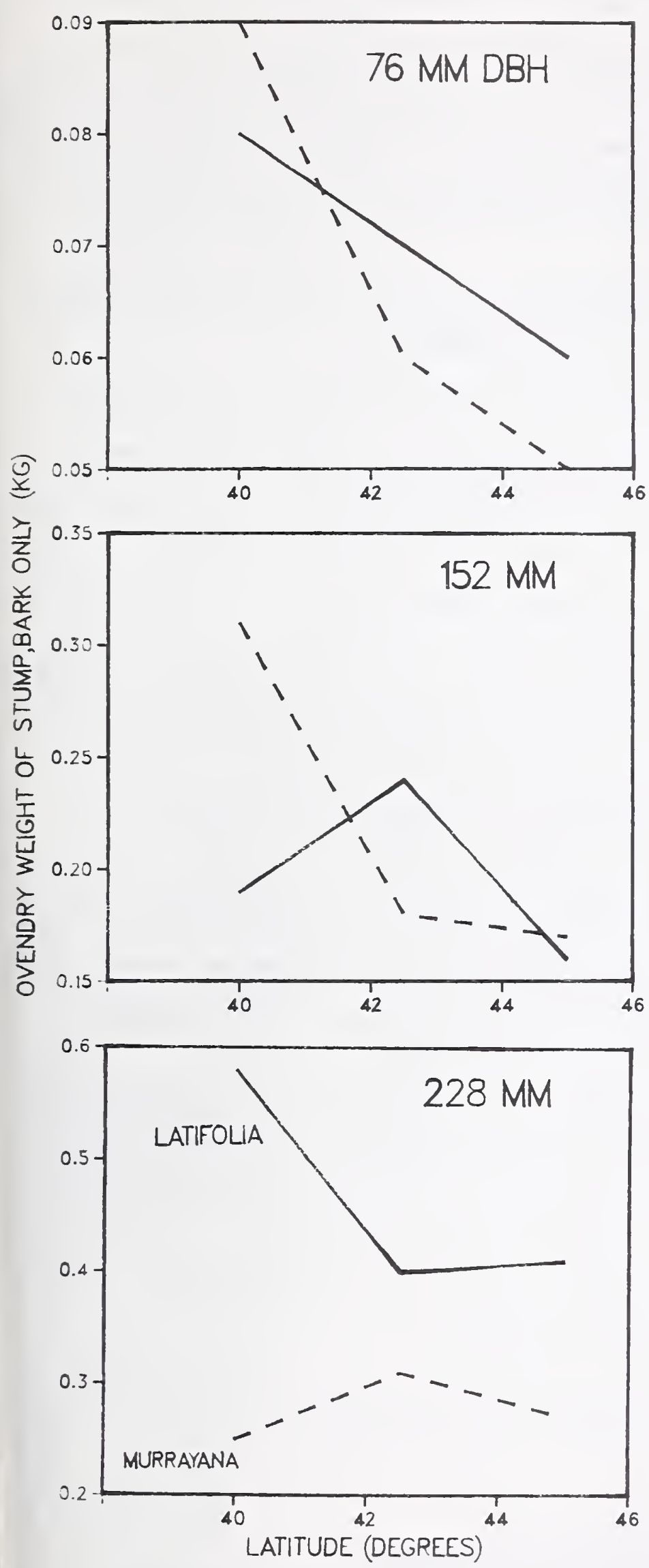

Figure 4-147-Ovendry weight of stumpbark; latifolia compared to murrayana, as related to latitude.

\section{Central Root Mass-Taproot}

Specific gravity of bark of the central root mass-taproot averaged higher in murrayana trees (0.434) than in latifolia (0.3967), but the relationship varied with latitude (fig. 4-148).

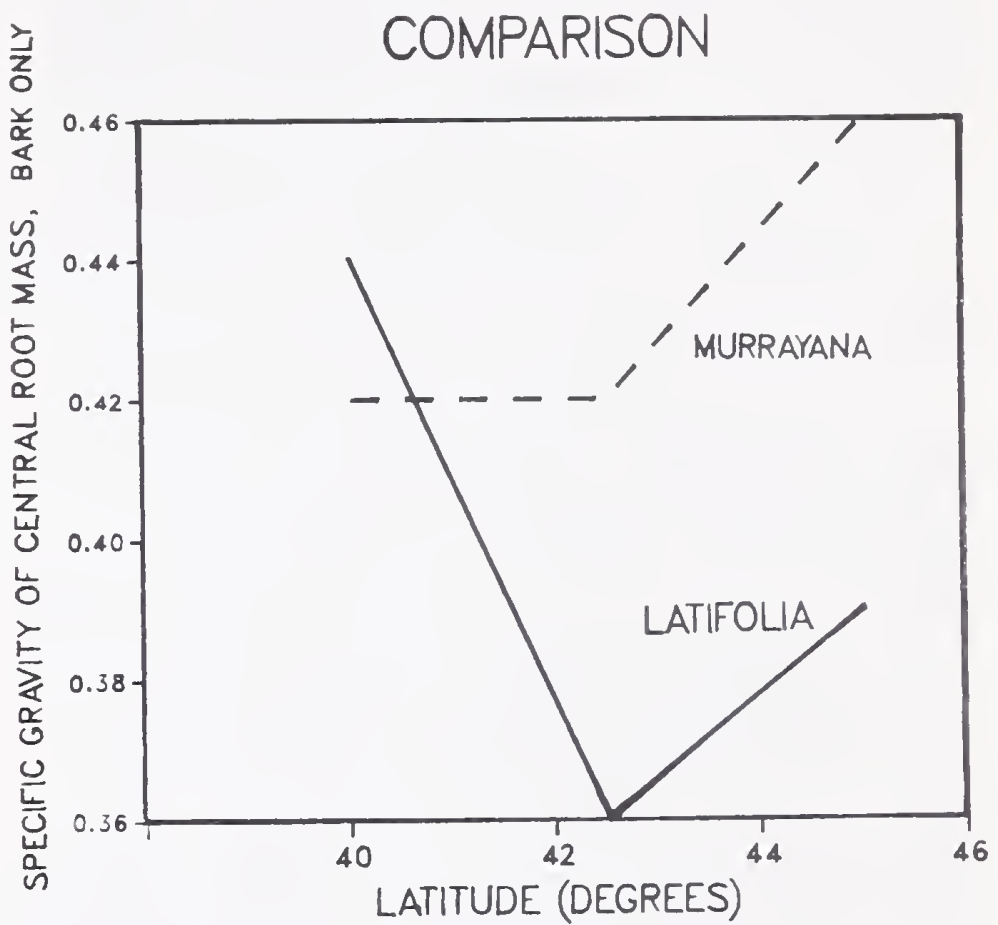

Figure 4-148-Specific gravity of bark of the central root mass-taproot, ovendry weight and green volume basis; latifolia compared to murrayana, as related to latitude. 


\section{4-8 SUMMARY OF RESULTS}

\section{Specific Gravity}

The most important finding of this research is that stemwood specific gravity of latifolia trees 76, 152, and $228 \mathrm{~mm}$ in d.b.h.-in a spectrum of ages-decreased with increasing d.b.h. and increased with increasing latitude. With diameter, latitudinal, and elevational data pooled, latifolia stemwood specific gravity averaged 0.418 (sapwood averaged 0.414 and heartwood 0.434 ), based on ovendry weight and green volume. As noted above, latifolia stemwood specific gravity was negatively correlated with d.b.h., averaging $0.427,0.419$, and 0.407 for trees 76,152 , and $228 \mathrm{~mm}$ in d.b.h. Trees in the three diameter classes averaged 71, 91, and 107 years old, respectively, with growth-ring width at a stump height of $152 \mathrm{~mm}$ averaging $0.67,1.01$, and $1.33 \mathrm{~mm}$.

Stemwood specific gravity diminished with increasing height in tree up to the base of the live crown, above which it remained constant or increased slightly at values between 0.39 and 0.40 . At all percentages of height in the stems, small-diameter trees had higher stemwood specific gravity than large trees. For all diameters, entire stemwood specific gravity could be closely estimated from stemwood specific gravity at 20 percent of tree height. Stemwood specific gravity was unrelated to elevational zone, but was positively correlated with latitude, averaging minimum (0.390) at 42.5 degrees and maximum $(0.435)$ at 55 degrees. The specific gravity trend was inverse to stemwood moisture content trend with latitude, and aligned with the trend of heartwood as a percentage of stemwood weight.

Wood of latifolia live branches had higher average specific gravity $(0.487)$ than that of the stump-root system $(0.469)$ or stem $(0.418)$. Specific gravity of bark of live branches, stump-root system, and stem averaged 0.411 , 0.415 , and 0.369 , respectively.

\section{Complete-Tree Weight, Including Foliage}

Complete latifolia trees 76,152 , and $228 \mathrm{~mm}$ in d.b.h. had average ovendry weights of 28,170 , and $440 \mathrm{~kg}$, including foliage and stump-root systems to a lateral-root radius of $305 \mathrm{~mm}$ from stump pith. Trees from highelevation zones weighed less than those from low. With diameter and elevational data pooled, trees weighed least in the three southernmost latitudes (40 through 45 degrees) and most in latitudes 47.5 through 55 degrees.

\section{Tree Component Proportions of Complete- Tree Ovendry Weight}

Latifolia tree component proportions varied significantly with d.b.h., latitude, and elevation; but with all data pooled, component weight percentages (ovendry) averaged $6.8,1.0,5.9,2.0,72.8$, and 11.5 percent for technical foliage, cones, live branches, dead branches, stem, and stump-root system. Small trees had a greater proportion of foliage and stump-root system, and a lesser proportion of cones, live branches, and stem weight than large trees.

\section{Weight of Green Components for $1 \mathrm{~m}^{3}$ of Wood}

The weight of latifolia green wood plus bark of the three major tree components required to provide $1 \mathrm{~m}^{3}$ of bark-free wood was greater for small trees than large, and varied with latitude and elevation. With all data pooled, average requirements for foliage-free branches, stem (152-mm stump height to apical tip), and stump-root system were $1,448,920$, and $1,046 \mathrm{~kg}$, respectively.

\section{Proportion of Bark in Each Component, Ovendry-Weight Basis}

Bark ovendry-weight proportions of tree components were greater in small trees than large, and varied with latitude and elevational zone. With all latifolia data pooled, however, averages were 11.6, 10.1, 33.8, and 12.5 percent for complete foliage-free tree, stem, live branches, and stump-root system, respectively.

\section{Longitudinal Effects}

Variations related to longitudinal zones across latitudinal sampling zones were minor, except that individual latifolia cones from trees on the east end of sampling zones weighed more than those on trees from the west end.

\section{Latifolia Compared to Murrayana}

The text reports specific gravity and weight data for murrayana at medium elevation from four latitudes -37.5 , $40,42.5$, and 45 degrees. Of these latitudes, latifolia was sampled from 40, 42.5, and 45 degrees, so a comparison at medium elevation at these three latitudes was possible based on 27 trees of each variety-nine trees $76 \mathrm{~mm}$, nine $152 \mathrm{~mm}$, and nine $228 \mathrm{~mm}$ in d.b.h.

At these three latitudes murrayana had higher specific gravity for most tree components than latifolia; for example, stemwood of murrayana averaged 0.451 vs. 0.401 for latifolia, and specific gravity of bark of complete trees averaged 0.387 for murrayana vs. 0.363 for latifolia (basis of ovendry weight and green volume).

Latifolia had more weight of foliage per tree, and a higher foliage-weight proportion (7.3 percent vs. 5.3 percent, ovendry basis).

With diameter data pooled, $1,025 \mathrm{~kg}$ of murrayana stems (wood plus bark, green) is required to yield $1 \mathrm{~m}^{3}$ of bark-free wood; whereas only $926 \mathrm{~kg}$ of latifolia will yield this volume of wood.

\section{4-9 REFERENCES}

Adamovich, L. L. Engineering characteristics of Canadian trees-centre of gravity and green weight of components of four species in interior British Columbia. Information Report FMR-X-74. Ottawa, ON: Department of the Environment, Canadian Forestry Service, Forest Management Institute; 1975.55 p. 
Agee, James K. Fuel weights of understory-grown conifers in southern Oregon. Canadian Journal of Forest

Research. 13(4): 648-656; 1983.

American Lumberman. Properties, preparation and increasing utilization of lodgepole pine. American Lumberman. 1851: 39; 1910 November 12.

Baranyay, J. A.; Szabo, T.; Hunt, K. Effect of Atropellis canker on growth and utilization of lodgepole pine. Information Report BC-X-86. Victoria, BC: Department of the Environment, Canadian Forestry Service, Pacific Forest Research Centre; 1973. 22 p.

Benson, Robert E. Management consequences of alternative harvesting and residue treatment practiceslodgepole pine. General Technical Report INT-132. Ogden, UT: U.S. Department of Agriculture, Forest Service, Intermountain Forest and Range Experiment Station; 1982.58 p.

Bjorklund, Tarja. Kontortamännyn puutekniset ominaisuudet: Technical properties of lodgepole pine wood. Folia Forestalia. 522: 1-25; 1982.

Bramhall, G.; Wellwood, R. W. Kiln drying of western Canadian lumber. Information Report VP-X-159. Vancouver, BC: Department of Fisheries and the Environment, Canadian Forestry Service, Western Forest Products Laboratory; 1976. 112 p. Available from: FORINTEK CANADA CORP., Vancouver, BC.

Brazier, J. D. A report on the effects of provenance on the timber properties of lodgepole pine. In: Pinus contorta as an exotic species: Proceedings, IUFRO working party meeting on Pinus contorta provenances (S2-02-06) in Norway and Sweden; 1980. Research Note 30. Garpenberg, Sweden: Swedish University of Agricultural Sciences, Department of Forest Genetics; 1980: 181-207.

Brown, James K. Weight and density of crowns of Rocky Mountain conifers. Research Paper INT-197. Ogden, UT: U.S. Department of Agriculture, Forest Service, Intermountain Forest and Range Experiment Station; 1978. $56 \mathrm{p}$.

Brown, James K.; Snell, J. A. Kendall; Bunnell, David L. Handbook for predicting slash weight of western conifers. General Technical Report INT-37. Ogden, UT: U.S. Department of Agriculture, Forest Service, Intermountain Forest and Range Experiment Station; 1977. 35 p.

Cannell, M. G. R.; Sheppard, L. J.; Ford, E. D.; Wilson, R. H. F. Clonal differences in dry matter distribution, wood specific gravity and foliage "efficiency" in Pinea sitchensis and Pinus contorta. Silvae Genetica. 32(5-6): 195-202; 1983.

Carlson, T. C.; Nimlos, T. J. Using soil series to predict site index and wood specific gravity in western Montana. Northwest Science. 40(2): 56-67; 1966.

Chapman, R. C.; Baldwin, V. C.; Clausnitzer, R. R. Cubic foot volume, bole green weight and total above ground green weight of small diameter lodgepole pine, larch and ponderosa pine. Research Bulletin XB 0914. Pullman, WA: Washington State University, Agricultural Research Center; 1982. 7 p.

Dobie, J.; McIntosh, J. A. Spruce foliage yields more than triple that of pine. Pulp \& Paper of Canada. 77(10):

$71-72 ; 1976$.
Echols, R. M. Uniformity of wood density assessed from $\mathrm{x}$-rays of increment cores. Wood Science Technology. 7(1): 34-44; 1973.

Fahey, Thomas D. Evaluating dead lodgepole pine for products. Forest Products Journal. 30(12): 34-39; 1980.

Fahey, Thomas D. Value ranking for utilizing lodgepole pine residues. In: Harvesting and utilization opportunities for forest residues in the Northern Rocky Mountains: symposium proceedings; 1979 November 28-30; Missoula, MT. General Technical Report INT-110. Ogden, UT: U.S. Department of Agriculture, Forest Service, Intermountain Forest and Range Experiment Station; 1981: 239-250.

Fahey, Timothy J. Nutrient dynamics of aboveground detritus in lodgepole pine (Pinus contorta ssp. latifolia) ecosystems, southeastern Wyoming. Ecological Monographs. 53(1): 51-72; 1983.

Fahnestock, George R.; Dieterich, John H. Logging slash flammability after five years. Research Paper 70. Ogden, UT: U.S. Department of Agriculture, Forest Service, Intermountain Forest and Range Experiment Station; 1962. $15 \mathrm{p}$.

Forest Products Research Laboratory, Princes Risborough. Properties of thinnings of home-grown lodgepole pine (Pinus contorta): progress report 2-consignment 1027; 1960. 34 p.

Foulger, A. N.; Harris, Johnny. Volume of wood, bark and needles after clearcutting a lodgepole pine stand. Journal of Forestry. 71(2): 93-95; 1973.

Hakkila, Pentti; Panhelainen, Arja. On the wood properties of Pinus contorta in Finland. Communicationes Instituti Forestalis Fenniae. 73(1); 1970. 43 p.

Harris, J. Maddern. Physical properties, resin content, and tracheid length of lodgepole pine grown in New Zealand. New Zealand Journal of Forest Science. 3(1): 91-109; 1973.

Heger, L. Longitudinal variation of specific gravity in stems of black spruce, balsam fir, and lodgepole pine. Canadian Journal of Forest Research. 4(3): 321-326; 1974.

Henderson, J.; Petty, J. A. A comparison of wood properties of coastal and interior provenances of lodgepole pine. Forestry (Great Britain). 45(1): 49-57; 1972.

Johnstone, W. D. Some variations in specific gravity and moisture content of 100-year-old lodgepole pine trees. Information Report A-X-29. Calgary, AB: Department of Fisheries and Forestry, Canadian Forestry Service, Forest Research Laboratory; 1970a. 19 p.

Johnstone, W. D. Component dry weights of 100-year-old lodgepole pine trees. Information Report A-X-31. Calgary, AB: Department of Fisheries and Forestry, Canadian Forestry Service, Forest Research Laboratory; 1970b. $14 \mathrm{p}$.

Johnstone, W. D. Total standing crop and tree component distributions in three stands of 100-year-old lodgepole pine. In: Forest biomass studies: proceedings of working group on forest biomass studies: section 25, growth and yield; 15th IUFRO Congress; 1971 March 15-20; Gainesville, FL. Miscellaneous Report 132. Orono, ME: University of Maine, Life Sciences and Agriculture Experiment Station; 1971: 81-89. 
Kaufmann, Merrill R.; Troendle, Charles A. The relationship of leaf area and foliage biomass to sapwood conducting area in four subalpine forest tree species. Forest Science. 27(3): 477-482; 1981.

Kiil, A. D. Weight of the fuel complex in 70-year-old lodgepole pine stands of different densities. Department Publication 1228. Ottawa, ON: Canada Department of Forestry and Rural Development, Forestry Branch; 1968. 9 p.

Maeglin, Robert R.; Wahlgren, Harold E. Western wood density survey: report No, 2. Research Paper FPL 183. Madison, WI: U.S. Department of Agriculture, Forest Service, Forest Products Laboratory; 1972. 24 p.

Moir, W. H.; Francis, R. Foliage biomass and surface area in three Pinus contorta plots in Colorado. Forest Science. 18(1): 41-45; 1972.

Moir, William H. Litter, foliage, branch, and stem production in contrasting lodgepole pine habitats of the Colorado Front Range. In: Franklin, Jerry F.; Dempster, L. J.; Waring, Richard H., eds. Proceedings-research on coniferous forest ecosystems-a symposium; 1972 March 23-24; Bellingham, WA. Portland, OR: U.S. Department of Agriculture, Forest Service, Pacific Northwest Forest and Range Experiment Station; 1972: 189-198.

Moore, Musser Beighley. Geographic variation in lodgepole pine in the Central Rocky Mountains. Fort Collins, CO: Colorado State University; 1981. 188 p. Ph.D. dissertation. Available from: University Microfilms International, Ann Arbor, MI.

Muraro, S. J. Lodgepole pine logging slash. Department of Forestry Publication 1153. Ottawa, ON: Department of Forestry Canada; 1966. 14 p.

Muraro, S. J. The lodgepole pine fuel complex. Information Report BC-X-53. Victoria, BC: Department of the Environment, Canadian Forestry Service, Pacific Forest Research Centre; 1971. 50 p.

Okkonen, E. A.; Wahlgren, H. E.; Maeglin, R. R. Relationships of specific gravity to tree height in commercially important species. Forest Products Journal. 22(7): 37-42; 1972.

Pearson, John Alan. Biomass distribution and ecosystem development in lodgepole pine forests of the Medicine Bow Mountains, Wyoming. Laramie, WY: University of Wyoming; 1982. 113 p. Ph.D. dissertation.

Peterson, E. B.; Levson, V. M.; Kabzems, R. D. Upper limits of standing crop density for woody species in the prairie provinces. Information Report NOR-X-243. Edmonton, AB: Environment Canada, Canadian Forestry Service, Northern Forest Research Centre; 1982.55 p.

Reynolds, James F.; Knight, Dennis H. The magnitude of snowmelt and rainfall interception by litter in lodgepole pine and spruce-fir forests in Wyoming. Northwest Science. 47(1): 50-60; 1973.

Roydhouse, F. M.; Crane, J. L.; Bassman, J. H. Biomass distribution in young stands of stagnant and nonstagnant lodgepole pine. In: Baumgartner, David M.; Krebill, Richard G.; Arnott, James T.; Weetman, Gordon F., eds. Lodgepole pine: the species and its management: symposium proceedings; 1984 May 8-10; Spokane, WA; 1984 May 14-16; Vancouver, BC. Pullman, WA: Washington State University, Office of
Conferences and Institutes, Cooperative Extension; 1985: 379. Abstract.

Running, Steven W. Relating plant capacitance to the water relations of Pinus contorta. Forest Ecology and Management. 2(4): 237-252; 1980.

Singh, T. Biomass equations for ten major tree species of the prairie provinces. Information Report NOR-X-242; ENFOR Project P-92. Edmonton, AB: Environment Canada, Canadian Forestry Service, Northern Forest Research Centre; 1982a. 34 p.

Singh, T. Weight tables for important tree species in the prairie provinces. Forest Management Note 14. Edmonton, AB: Environment Canada, Canadian Forestry Service, Northern Forest Research Centre; 1982b. 4 p.

Singh, T. Variation in the ovendry wood density of ten prairie tree species. Forestry Chronicle. 60(4): 217-221; 1984.

Smith, J. H. G.; DeBell, D. S. Opportunities for short rotation culture and complete utilization of seven northwestern tree species. Forestry Chronicle. 49(1): 31-34; 1973.

Smith, J. H. G.; Kozak, A. Thickness, moisture content, and specific gravity of inner and outer bark of some Pacific Northwest trees. Forest Products Journal. 21(2): 38-40; 1971.

Smythe, Stuart L. Comparative characteristics of lodgepole pine (Pinus contorta) wood parasitized by dwarfmistletoe (Arceuthobium americanum). Journal of the Colorado-Wyoming Academy of Science. 5(8): 66-67; 1967. Abstract.

Snell, J. A. Kendall; Brown, James K. Handbook for predicting residue weights of Pacific Northwest conifers. General Technical Report PNW-103. Portland, OR: U.S. Department of Agriculture, Forest Service, Pacific Northwest Forest and Range Experiment Station; 1980. 44 p.

Snell, J. A. Kendall; Max, Timothy A. Bark-to-wood ratios for logging residue in Oregon, Washington, and Idaho. Portland, OR: U.S. Department of Agriculture, Forest Service, Pacific Northwest Forest and Range Experiment Station; 1982.9 p. Administrative report.

Sylvander, Robert B.; Smith, J. Harry G. Widths and specific gravity of earlywood and latewood components of annual rings from interior British Columbia lodgepole pine. Vancouver, BC: University of British Columbia, Faculty of Forestry; 1973. 61 p.

Tackle, David. Specific gravity of lodgepole pine in the Intermountain Region. Research Note 100 (rev.). Ogden, UT: U.S. Department of Agriculture, Forest Service, Intermountain Forest and Range Experiment Station; 1962. 4 p.

Taylor, Fred W.; Wang, Eugene I. C.; Micko, Michael M. Differences in the wood of lodgepole pine in Alberta. Wood and Fiber. 14(4): 296-309; 1982.

U.S. Department of Agriculture, Forest Service. Wood handbook: wood as an engineering material. Agriculture Handbook 72, rev. Madison, WI: U.S. Department of Agriculture, Forest Service, Forest Products Laboratory; 1974. $415 \mathrm{p}$.

Weaver, T.; Forcella, F. Biomass of fifty conifer forests and nutrient exports associated with their harvests. Great Basin Naturalist. 37(3): 395-401; 1977. 


\section{CHAPTER 5: DISTRIBUTION, MOISTURE CONTENT, WEIGHT, AND SPECIFIC GRAVITY OF HEARTWOOD AND SAPWOOD}

\section{CONTENTS}

5-1 Introduction . . . . . . . . . . . . . . . . 253

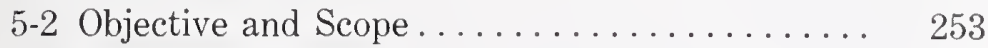

5-3 Literature Review ................. 253

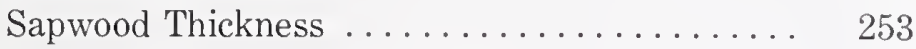

Within-Tree Variation .............. 253

At Breast Height ................. 253

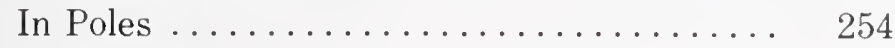

In Posts . . . . . . . . . . . . . . . 254

Heartwood Proportion of Stem Volume ....... 254

Sapwood Area Related to Foliage Weight .... . 254

Moisture Content ................... 255

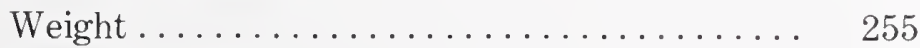

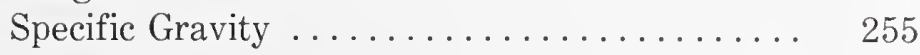

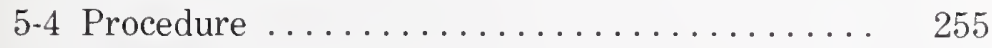

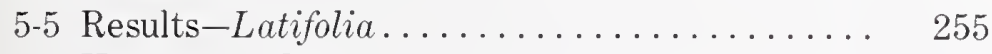

Heartwood Occurrence ............... 259

Age of Lowest Tree Disk Where Heartwood

Does Not Occur.................

Height in the Tree at Which Heartwood No

Longer Occurs, Percent.............

Height in the Tree at Which Heartwood No

Longer Occurs, Meters...............

Heartwood Maximum Diameter and Location ..

Heartwood Maximum Diameter ..........

Height at Which Maximum Heartwood

Diameter Occurs, Percent ............

Height at Which Maximum Heartwood

Diameter Occurs, Meters ...............

Heartwood as Percentage of Stem Diameter,

at Height of Maximum Heartwood

Diameter ....................

Heartwood Diameter by Level ............

Minimum Sapwood Thickness and Location

Where Heartwood Is Present............

Minimum Thickness ...............

Height at Which Minimum Sapwood

Thickness Occurs, Percent...........

Height at Which Minimum Sapwood

Thickness Occurs, Meters ............

Sapwood Thickness by Level .............

Heartwood Volume as Percentage of Entire

Stemwood Volume ..................

Heartwood as Percentage of Stemwood Volume

by Level. . . . . . . . . . . . . . . . . .

Moisture Content of Entire Stemwood

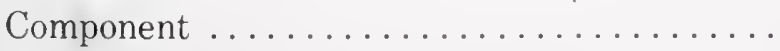

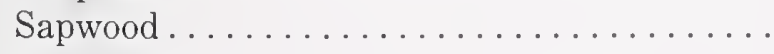

Heartwood ....................

Moisture Content of Sapwood by Level .......

Moisture Content of Heartwood by Level......

Weight of Sapwood in Entire Stem.........

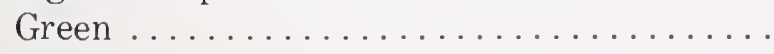

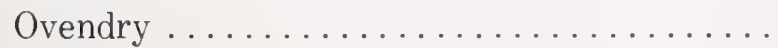

Weight of Heartwood in Entire Stem ........

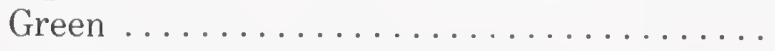

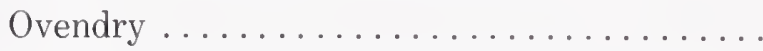

Heartwood as Percentage of Weight of Entire

Stemwood ......................

Green .......................

Ovendry

Heartwood as Percentage of Stemwood Weight by Level. .

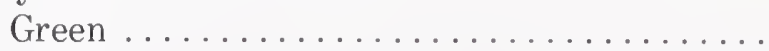

Ovendry

Specific Gravity of Sapwood in Entire Stem ...

Specific Gravity of Sapwood by Level.........

Specific Gravity of Heartwood in Entire Stem .

Specific Gravity of Heartwood by Level.......

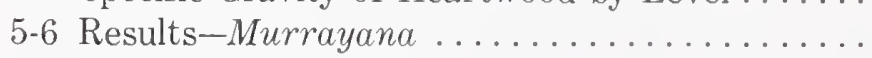

Heartwood Occurrence ................

Age of Lowest Tree Disk Where Heartwood

Does Not Occur...................

Height in the Tree at Which Heartwood No

Longer Occurs, Percent.............

Height in the Tree at Which Heartwood No

Longer Occurs, Meters...............

Heartwood Maximum Diameter and Location ..

Heartwood Maximum Diameter ..........

Height at Which Maximum Heartwood

Diameter Occurs, Percent ............

Height at Which Maximum Heartwood

Diameter Occurs, Meters .

Heartwood as Percentage of Stem Diameter,

at Height of Maximum Heartwood

Diameter

Heartwood Diameter by Level . . . . . . . . . . .

Minimum Sapwood Thickness and Location

Where Heartwood is Present .............

Minimum Thickness ...............

Height at Which Minimum Sapwood

Thickness Occurs, Percent........

Height at Which Minimum Sapwood

Thickness Occurs, Meters

Sapwood Thickness by Level

Heartwood Volume as a Percentage of Entire

Stemwood Volume .

Heartwood as Percentage of Stemwood Volume

by Level.

Moisture Content of Entire Stemwood

Component

Sapwood. .

Heartwood

Moisture Content of Sapwood by Level ....... . .

Moisture Content of Heartwood by Level......

Weight of Sapwood in Entire Stem .........

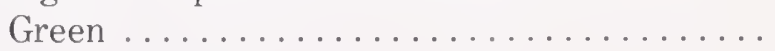

Page

282

282

283

284

284

285

285

285

288

290

291

293

294

294

294

294

294

294

295

295

295

296

296

296

296

296

296

296

298

299

299

300

300

300

300

301

302

302 
Ovendry ...................... 302

Weight of Heartwood in Entire Stem . . . . . . 302

Green ....................... 302

Ovendry .................... 302

Heartwood as Percentage of Weight of Entire

Stemwood ........................ 302

Green ............................ 302

Ovendry .................... 302

Heartwood as Percentage of Stemwood Weight by Level......................... 303

Green ........................ 303

Ovendry .................... 303

Specific Gravity of Sapwood in Entire Stem ... 304

Specific Gravity of Sapwood by Level........ 304

Specific Gravity of Heartwood in Entire

Stem............................
Specific Gravity of Heartwood by Level .......

5-7 Results-Latifolia Compared to Murrayana

Within Latitudinal Sampling Zones of 40 ,

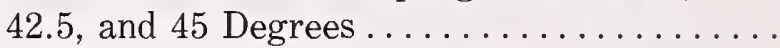

305

Height Where Maximum Heartwood Diameter

Occurs ........................ 305

Proportion ....................... 305

Meters .................... 306

Heartwood Volume as Percentage of Stemwood

Volume ......................... 306

Specific Gravity of Sapwood ............ 307

Specific Gravity of Heartwood ........... 308

5-8 Summary of Results.................... 309

$5-9$ References.................... 310 


\section{5-1 INTRODUCTION}

The sapwood of stem and branches changes abruptly after a particular, but variable, age. The resulting interior core is heartwood; that is, the inner zone of wood which, in the growing tree, has ceased to contain living cells and in which the reserve materials (for example, starch) have been removed or converted into heartwood substances. Heartwood in lodgepole pine is usually darker than sapwood.

In lodgepole pine, sapwood and heartwood differ not only in color, but in extractive content, moisture content, specific gravity, and permeability. Processors of lodgepole pine stemwood therefore should find it useful to know something of the gross dimensions, moisture contents, weights, and specific gravities of these two stem components.

\section{5-2 OBJECTIVE AND SCOPE}

Parameters describing heartwood and sapwood distribution, moisture content, weight, and specific gravity are discussed in this chapter, but no attempt is made to construct equations predicting these parameters. Instead, graphs are presented of data aggregated in various significant ways that permit reading of the parameters directly from observed study data.

As previously noted, the entire characterization effort is confined to two varieties of lodgepole pine: Pinus contorta var. latifolia Engelm. and Pinus contorta var. murrayana (Grev. \& Balf.) Engelm., with emphasis on the former. The primary objective during tree collection was to obtain three replications of disease- and insect-free specimens of var. latifolia measuring 76,152 , and $228 \mathrm{~mm}$ in diameter at breast height (d.b.h.) at low, medium, and high elevations from nine equally spaced north latitudinal zones ( 40 to 60 degrees) across 10 degrees of longitude in such a way as to encompass the major range of this variety (fig. 1-1).

A secondary objective was to sample three replications of these same three diameter classes of var. murrayana at midelevation at four north latitudes $(37.5,40,42.5$, and 45 degrees) in California and Oregon at a single longitude per latitude (fig. 1-1).

The trees of both varieties were sampled in such a way that between-variety comparisons could be made for midelevation trees at latitudes $40,42.5$, and 45 degrees. The sampling plan does not permit computation of speciesaverage values. The collection totaled 243 latifolia and 36 murrayana trees.

Explanations of statistical analyses procedures and a table of analyses of variance formats, with degrees of freedom indicated, are shown in table 1-2. In the results portion of this chapter standard deviations are noted in the text in parentheses following average values. Correlations of interest observed in latifolia between heartwood and sapwood characteristics and tree characteristics are also noted in the results section.

\section{5-3 LITERATURE REVIEW}

There is a considerable body of literature on heartwood and sapwood of lodgepole pine-much of it related to extractives, fungal attack, and to permeability and treatability. There is also a body of literature relating lodgepole pine sapwood amount to leaf area. These subjects are not within the scope of this paper, but for the benefit of readers wishing to study these subjects, following are pertinent references:

Extractives content and chemistry Anderson and others (1969), Erdtman (1949), Harris (1969), Lieu and others (1979), Lindstedt (1949), Loman (1970a,1970b), Rickey and Hergert (1974), Shrimpton $(1972,1973)$

Fungi in sapwood

Ballard and others (1984)

Fungi in heartwood

Bourchier (1961a,1961b), Denyer (1952), Eades and Roff (1957,1959), Englerth and Scheffer (1955), Eslyn (1979),

Loman (1970a,1970b), Loman and Paul (1963)

Permeability and treatability

Alexander (1934), Cooper (1973), Cooper and others

(1974), Fosberg (1970), Graham (1956), Harris (1969),

Lowery and Rasmussen (1965), Markstrom and others

(1970), Markstrom and Hann (1972), Meyer (1974),

Owston and others (1972), Ruddick (1980)

Sapwood amount related to leaf area

Kaufmann and Troendle (1981), Lopushinsky (1975),

Pearson (1982), Running (1980), Thompson (1985),

Waring and others (1982)

Following is a summary of the literature on heartwoodsapwood distribution within stems, moisture content, weight, and specific gravity.

\section{Sapwood Thickness}

Within-Tree Variation-From study of 19 Pinus contorta Dougl. ex Loud. from the east shore of Vancouver Island, Yang (1985) concluded that lodgepole pine sapwood thickness ranges from 20 to $30 \mathrm{~mm}$ for both north and south aspects, except at stump height $(0.15 \mathrm{~m}$ above ground level), where it is $50 \mathrm{~mm}$ wide. He found that the number of growth rings in sapwood ranges from 25 to 50 , and decreases from ground level upward into the tree crown. He also observed that the lineal width of sapwood is consistent at various positions along the tree trunk and is independent of tree age, tree diameter, radial growth rate of the sapwood, and the radial growth rate of the whole tree. The number of growth rings in sapwood, however, he found to be strongly correlated with tree age, tree diameter, radial growth rate of the sapwood, and the radial growth rate of the whole tree. Yang found no statistically significant relationship between sapwood width and number of sapwood growth rings.

At Breast Height-Lassen and Okkonen (1969) measured sapwood thickness at breast height on 3,290 
lodgepole pines sampled throughout the species range in the United States; both latifolia and murrayana were included in the sample. They found a more or less linear relationship between sapwood thickness and tree diameter, with trees measuring $150 \mathrm{~mm}$ d.b.h. inside bark having a sapwood thickness of about $38 \mathrm{~mm}$ and those $530 \mathrm{~mm}$ in d.b.h. inside bark having twice this thickness of sapwood.

In interior British Columbia-including areas adjacent to the Yukon Territory-Sylvander and Smith (1973) measured sapwood thickness at breast height in 803 lodgepole pines averaging $254 \mathrm{~mm}$ d.b.h. and 67 years of age. They found that sapwood thickness averaged $45 \mathrm{~mm}$ or 18 percent of d.b.h., with standard deviation of 6.7 percentage points. Sapwood thickness increased with increasing d.b.h. and also with longitude; it was negatively correlated with tree age and also decreased at higher elevations and in the more northerly latitudes. They developed a regression equation including these five variables that accounted for 42 percent of the observed variation in sapwood thickness at breast height. Rapidly growing trees had wider sapwood than the slow growers.

Brazier (1980) studied lodgepole pine grown in Wales, England, and Scotland from coastal and interior North American provenances. When sampled 0.75 to $1.40 \mathrm{~m}$ from stump height, trees averaged 18 growth rings, and all trees contained heartwood. Width of sapwood varied with provenance ( 29 to $53 \mathrm{~mm}$ and 10 to 15 growth rings), but averaged $41 \mathrm{~mm}$ and 13 growth rings. Heartwood radius varied from 14 to $28 \mathrm{~mm}$ (3 to 10 growth rings) and averaged $17 \mathrm{~mm}$ (5 growth rings) in radius.

In Poles-Alexander (1934) studied 100 Class A, 7.6-mlong telephone poles with average top diameter of $203 \mathrm{~mm}$-all cut in British Columbia and Alberta. From disks cut from butt, top, and an intermediate point, he found that sapwood thickness averaged $44 \mathrm{~mm}$ and that sapwood accounted for 53 percent of the cross-sectional area.

In a study of lodgepole pine 9.1-m-long Class 6 and 7 poles sampled near Libby, MT, Lowery and Rasmussen (1965) found that average sapwood thickness ranged from 11 to $38 \mathrm{~mm}$ and averaged $18 \mathrm{~mm}$.

In Posts-From study of 107-mm-diameter posts averaging 1.6 annual rings/mm sampled near Fort Collins, CO, Markstrom and others (1970) found that sapwood thickness varied from 18 to $33 \mathrm{~mm}$, with average of $25 \mathrm{~mm}$.

\section{Heartwood Proportion of Stem Volume}

Hakkila and Panhelainen (1970) sampled lodgepole pine grown in northern (66.5 degrees latitude) and southern (60 to 62 degrees latitude) Finland from seed derived from Alberta and British Columbia sources; mean age of the trees was 40 years, d.b.h. averaged $128 \mathrm{~mm}$, and height averaged $13.4 \mathrm{~m}$. Average heartwood proportion of entire stemwood volume was 17.5 percent, with standard deviation of 9.1 percentage points. Of external tree characteristics, tree height best explained variation in percentage heartwood, as follows $\left(R^{2}=0.35\right.$; standard error of the estimate $=7.31$ percent):

$$
Y=4.50+0.0653 X
$$

where:

$$
\begin{aligned}
& Y=\text { heartwood percentage of entire stem volume } \\
& X=\text { tree height, } \mathrm{m} \text {. }
\end{aligned}
$$

Stands in the north of Finland did not differ significantly in heartwood content from those in the south. In southern stands, a three-component equation for prediction for heartwood content was developed, as follows $\left(R^{2}=0.75\right.$; standard error of the estimate $=3.66$ percent):

$$
Y=-48.03+1.336 X-0.303 C R+0.145 G
$$

where:

$$
\begin{aligned}
X= & \text { tree height, } \mathrm{m} \\
C R= & \text { crown ratio } \\
G= & \text { stemwood specific gravity, basis of green weight } \\
& \text { and ovendry volume. }
\end{aligned}
$$

Hakkila and Panhelainen also found that the percentage of heartwood increases about 5 percentage points from stump height to a maximum at 10 to 20 percent of tree height, and then declines toward the crown. They concluded that heartwood volume percentage $(Y)$ of stemwood volume was best estimated from a disk at 40 percent of tree height, as follows $\left(R^{2}=0.875\right.$; standard error of the estimate $=3.4$ percentage points):

$$
\begin{aligned}
& Y=3.03+0.874 \text { (heartwood percentage } \\
& \text { at } 40 \text { percent of tree height) }
\end{aligned}
$$

It can also be estimated from heartwood percentage at breast height $\left(R^{2}=0.841\right.$; standard error of the estimate $=4.4$ percentage points):

$$
\begin{aligned}
& Y=0.48+0.780 \text { (heartwood percentage } \\
& \text { at breast height) }
\end{aligned}
$$

In a sample of lodgepole pine grown in New Zealand from seed originally obtained from the northwestern part of the United States (murrayana as well as latifolia), Harris (1973) found that heartwood percentage of stemwood volume was positively correlated with stem volume, ranging from 18 percent to 41 percent, as follows:

$\begin{array}{cc}\begin{array}{c}\text { Stem volume } \\ m^{s}\end{array} & \begin{array}{c}\text { Heartwood volume } \\ \text { Percent of } \\ \text { stemwood volume }\end{array} \\ 0.91 & 41 \\ .91 & 23 \\ .77 & 38 \\ .62 & 32 \\ .59 & 20 \\ .46 & 29 \\ .22 & 27 \\ .19 & 18\end{array}$

\section{Sapwood Area Related to Foliage Weight}

Based on 12 lodgepole pines 10 to 60 years old destructively sampled in the Central Colorado Mountains at an elevation of $2,700 \mathrm{~m}$, Running (1980) developed the follow- 
ing equation for predicting foliage ovendry weight from sapwood basal area at breast height $\left(R^{2}=0.94\right)$ :

$$
Y=-0.76+0.051 X
$$

where:

$$
Y=\text { foliage ovendry weight, } \mathrm{kg}
$$

$X=$ sapwood basal area, $\mathrm{cm}^{2}$.

Kaufmann and Troendle (1981) also found that ovendry foliage weight of lodgepole pine was linearly related to sapwood cross-sectional area at breast height in the stem, as follows $\left(R^{2}=0.95\right)$ :

Dry foliage weight, $\mathrm{g}=$

46.2 (sapwood cross-sectional area, $\mathrm{cm}^{2}$ )

This equation is based on 11 trees sampled in August and September at about $915 \mathrm{~m}$ elevation near Fraser, CO.

\section{Moisture Content}

In British Columbia, Reid (1961) observed that the moisture content of latifolia sapwood normally averages in the range from 85 to 165 percent of ovendry weight; he found heartwood averaged about 30 percent moisture content. He also found that the moisture content of outer sapwood and inner bark was about 10 percentage points greater at 4 a.m. than from 4 to 8 p.m.; noontime moisture content was intermediate. His data indicated an outer sapwood moisture content of about 150 percent of ovendry weight, with inner sapwood having a much lower moisture content-about 50 percent. He noted that outer heartwood had about 25 percent moisture content and innermost heartwood about 40 percent (fig. 2-1).

Because snow prevented access to upper elevations from early November to early June, tree collections for the study here reported were made during the months of June through October in 1983 and 1984. Interpretation of data reported in the results section of this chapter should be tempered with knowledge that some variation in tree component moisture content occurs with both year and season sampled. For example, Markstrom and Hann (1972) found that in five trees sampled each season near Fort Collins, $\mathrm{CO}$, sapwood of 156- to 242-year-old latifolia had higher moisture content in 1967 than in 1968, and that moisture content was least in spring and most in fall and winter, as

\begin{tabular}{|c|c|c|c|c|}
\hline \multirow{3}{*}{ Year and season } & \multicolumn{2}{|c|}{ Sapwood } & \multicolumn{2}{|c|}{ Heartwood } \\
\hline & Outer & Inner & Outer & Inner \\
\hline & \multicolumn{4}{|c|}{ - . - Percent of ovendry weight .... } \\
\hline \multicolumn{5}{|l|}{1967} \\
\hline Spring growing & 138 & 138 & 35 & 43 \\
\hline Summer & 145 & 144 & 42 & 48 \\
\hline Fall dormancy & 161 & 147 & 39 & 47 \\
\hline Winter & 173 & 164 & 43 & 68 \\
\hline \multicolumn{5}{|l|}{1968} \\
\hline Spring growing & 127 & 131 & 36 & 47 \\
\hline Summer & 150 & 150 & 42 & 55 \\
\hline
\end{tabular}
follows:

The foregoing data are based on increment cores removed at 0.91 and $1.22 \mathrm{~m}$ above ground level.

\section{Weight}

No data relating heartwood and sapwood weights to tree characteristics were found in the literature.

\section{Specific Gravity}

No data comparing the specific gravities of heartwood and sapwood were found in the literature, but Englerth and Scheffer (1955)-in a study of natural decay resistance of 10 lodgepole pines 9.4 to 14.3 inches in diameter and 58 to 220 years old-found that specific gravity of outer heartwood 4 to 6 feet above stump ranged from 0.42 to 0.57 , with average of 0.48 (based on volume and weight when ovendry).

\section{5-4 PROCEDURE}

Procedural details of the experiment are given in chapter 1 , and will not be repeated here except to note that the elevational zones of low, medium, and high are relative. Medium refers to an elevation that is medium for the variety at the latitude at which sampled; similarly, low and high refer to lower and upper elevational zones in which the variety occurs at the latitude sampled. Latifolia elevational zones were highest in the south $(2,481,2,711$, and $3,144 \mathrm{~m}$ at 40 degrees) and progressively lower with each more northerly latitude $(604,739$, and $879 \mathrm{~m}$ at 60 degrees). Murrayana was sampled at elevations in the range from 1,148 to $2,402 \mathrm{~m}$.

Trees were uprooted (with central taproot intact and with lateral roots severed at a radius of $305 \mathrm{~mm}$ from tree pith) from level benches in natural unthinned stands within National or Provincial Forests. The sampling scheme resulted in selection of $76-, 152-$, and $228-\mathrm{mm}$ trees averaging 71,91 , and 107 years of age (at stump height of $152 \mathrm{~mm}$ ), respectively, for latifolia, and 67, 84, and 91 years for murrayana. Most of the small-diameter trees were suppressed, while the larger trees were the fast growers.

At levels of $0,10,20,30,40,50,60,70,80$, and 90 percent of tree height above a $152-\mathrm{mm}$-high stump, disks were removed in the field for laboratory analyses. In the laboratory, after determination of green diskwood volume and weight, heartwood was indicated by application of ferric chloride solution ( $10 \mathrm{~g} \mathrm{FeCl}$ in $90 \mathrm{~g}$ of water) and split away from the sapwood; average heartwood diameter was then measured and weight and volume of the green heartwood recorded. Ovendry weights of sapwood and heartwood were then determined and recorded. From these data stem-component specific gravities, weights, and volumes could be computed.

\section{5-5 RESULTS-LATIFOLIA}

In the following paragraphs summarizing results, only those main effects and interactions shown statistically significant ( 0.05 level) by analyses of variance are discussed, tabulated, and graphed. All reported correlations are statistically significant ( 0.05 level). 
Stemwood average heartwood and sapwood characteristics are summarized in table 5-1. Variations of these characteristics with height in stems are summarized in table 5-2. Interpretation of these averages requires reference to the main effects and interactions related to d.b.h., latitude, and elevational zone-as discussed in the remainder of this chapter.

None of the heartwood or sapwood characteristics studied were correlated with longitudinal zone; that is, with east-west location within a particular latitudinal sampling zone.

Table 5-1-Characteristics of heartwood and sapwood from latifolia and murrayana trees according to d.b.h. classes of 76,152 , and $228 \mathrm{~mm}^{\top}$

\begin{tabular}{|c|c|c|c|c|c|c|}
\hline \multirow[b]{2}{*}{ Statistic } & \multicolumn{3}{|c|}{ Latifolia } & \multicolumn{3}{|c|}{ Murrayana } \\
\hline & 76 & 152 & 228 & 76 & 152 & 228 \\
\hline \multicolumn{7}{|c|}{ Moisture content of entire stemwood component, percent of ovendry weight } \\
\hline Sapwood ${ }^{2}$ & 110 & 122 & 126 & 104 & 128 & 142 \\
\hline Heartwood $^{2}$ & 47 & 42 & 41 & 47 & 44 & 43 \\
\hline \multicolumn{7}{|l|}{$\begin{array}{l}\text { Specific gravity, basis of green volume and ovendry weight-entire } \\
\text { component }\end{array}$} \\
\hline Sapwood ${ }^{3}$ & 0.423 & 0.415 & 0.405 & 0.476 & 0.433 & 0.401 \\
\hline Heartwood $^{3}$ & 0.459 & 0.430 & 0.412 & 0.550 & 0.508 & 0.446 \\
\hline Heartwood percentage of stemwood volume & 22.0 & 28.3 & 34.2 & 10.3 & 16.9 & 20.3 \\
\hline \multicolumn{7}{|l|}{ Heartwood percentage of stemwood weight } \\
\hline Green-weight basis ${ }^{3}$ & 18.4 & 21.6 & 25.7 & 8.8 & 12.9 & 14.3 \\
\hline Ovendry-weight basis ${ }^{3}$ & 22.6 & 28.8 & 34.6 & 11.4 & 18.3 & 21.5 \\
\hline \multicolumn{7}{|l|}{ Weight of sapwood in entire stem, ${ }^{3} \mathrm{~kg}$} \\
\hline Green & 14 & 91 & 226 & 14 & 89 & 254 \\
\hline Ovendry & 7 & 41 & 100 & 7 & 39 & 105 \\
\hline \multicolumn{7}{|l|}{ Weight of heartwood in entire stem, ${ }^{3} \mathrm{~kg}$} \\
\hline Green & 3.3 & 25.3 & 76.9 & 1.4 & 14.9 & 45.3 \\
\hline Ovendry & 2.3 & 17.9 & 54.3 & 1.0 & 10.5 & 32.2 \\
\hline \multicolumn{7}{|l|}{ Heartwood occurrence } \\
\hline Age of lowest tree disk where heartwood does not occur, years & 21 & 11 & 10 & 20 & 14 & 11 \\
\hline Height in tree at which heartwood no longer occurs, percent & 76.1 & 89.5 & 93.6 & 60.8 & 80.0 & 88.3 \\
\hline Height in tree at which heartwood no longer occurs, m & 7.2 & 14.0 & 17.9 & 4.7 & 11.3 & 16.6 \\
\hline \multicolumn{7}{|l|}{ Heartwood maximum diameter and location } \\
\hline Heartwood maximum diameter, $\mathrm{mm}$ & 36 & 85 & 147 & 27 & 67 & 108 \\
\hline Height of maximum diameter, percent & 8.6 & 3.5 & 2.2 & 8.3 & 5.8 & 8.3 \\
\hline Height of this maximum diameter, $m$ & 0.80 & 0.53 & 0.44 & 0.60 & 0.78 & 1.33 \\
\hline \multicolumn{5}{|c|}{ At height of maximum heartwood diameter, heartwood percent stemwood } & 44.1 & 48.0 \\
\hline \multicolumn{7}{|l|}{ Minimum sapwood thickness (where heartwood is present) and location } \\
\hline Minimum thickness, mm & 16 & 24 & 29 & 21 & 31 & 36 \\
\hline Height of this minimum, percent & 51.3 & 60.5 & 70.5 & 43.3 & 54.2 & 77.5 \\
\hline Height of this minimum, $m$ & 4.8 & 9.3 & 13.3 & 3.2 & 7.4 & 14.6 \\
\hline
\end{tabular}

1 Because of the main effects and interactions of d.b.h., latitude, and elevational zone, reference to appropriate figures and text discussion is required for interpretation of these data. Data are based on 243 latifolia trees ( 81 of each diameter), and 36 murrayana trees (12 of each diameter).

2From chapter 2

${ }^{3}$ From chapter 4. 
Table 5-2-Variations in heartwood and sapwood characteristics with height in stems of latifolia and murrayana trees of three diameters'

Characteristic Height (percent)

and $d . b$.

$\begin{array}{lllll}0 & 10 & 20 & 30 & 40\end{array}$

60

70

80

90

Latifolia

Heartwood diameter, mm

$76 \mathrm{~mm}$

$152 \mathrm{~mm}$

$228 \mathrm{~mm}$

Sapwood thickness, $\mathrm{mm}$

$76 \mathrm{~mm}$
$152 \mathrm{~mm}$

$228 \mathrm{~mm}$

Heartwood percent of

stemwood volume

$76 \mathrm{~mm}$
$152 \mathrm{~mm}$

$228 \mathrm{~mm}$

Sapwood M.C. (percent) ${ }^{2}$

$$
76 \mathrm{~mm}
$$

$152 \mathrm{~mm}$

$228 \mathrm{~mm}$

Heartwood M.C. (percent) ${ }^{2}$

$76 \mathrm{~mm}$

$152 \mathrm{~mm}$

$228 \mathrm{~mm}$

Heartwood percent of

stemwood, green weight

$76 \mathrm{~mm}$

$152 \mathrm{~mm}$

$228 \mathrm{~mm}$

$\begin{array}{rrr}34 & 34 & 32 \\ 83 & 79 & 74 \\ 146 & 132 & 122\end{array}$

29
66
111

24

58

58
97

20

48

14

111

$24 \quad 19$

$40 \quad 31$

54

$$
39
$$

18

30

18

29

18

30

38

38

$22 \quad 28$

$30 \quad 35$

37

35
42

27
34

24

33

40

$103 \quad 101 \quad 104$

110

117

114

118

115

122

38

$46 \quad 46$

41

40

46
43
42

47

42

42

108

120

125

38

48
42
41

22
29

34

19
24
30

$$
112
$$

124

130

$$
\begin{aligned}
& 117 \\
& 129
\end{aligned}
$$

136

$\begin{array}{ll}48 & 51 \\ 42 & 43 \\ 42 & 41\end{array}$

$\begin{array}{lll}19 & 24 & 23 \\ 24 & 27 & 27\end{array}$

21

$$
\begin{aligned}
& 21 \\
& 25
\end{aligned}
$$

18
22

28

Heartwood percent of

stemwood, ovendry weight

$76 \mathrm{~mm}$

$152 \mathrm{~mm}$

$228 \mathrm{~mm}$

Sapwood specific gravity ${ }^{3}$

$$
76 \mathrm{~mm}
$$

$152 \mathrm{~mm}$

$228 \mathrm{~mm}$

Heartwood specific gravity ${ }^{3}$

$76 \mathrm{~mm}$

$152 \mathrm{~mm}$

$228 \mathrm{~mm}$

29

32

30

22
25

16
18

21

11
14

14
17

$\begin{array}{lll}23 & 28 & 28\end{array}$

$\begin{array}{lll}30 & 34 & 34\end{array}$

$\begin{array}{lll}37 & 41 & 39\end{array}$

$\begin{array}{ll}25 & 22 \\ 31 & 28 \\ 37 & 34\end{array}$

19

19
24

24
30

15
20
25

\section{$0.406 \quad 0.399$}

.405

.398

0.394

0.394
.391

.384

0.397
.385

.380

$\begin{array}{rr}0.398 & 0.413 \\ .385 & .393\end{array}$

.450
.435

$.414 \quad .406$

.401

.395

$\begin{array}{lll}.512 & .462 \quad .443\end{array}$

$\begin{array}{lll}.432 & .429 \quad .430\end{array}$

$\begin{array}{lll}.411 & .416 \quad .419\end{array}$

$\begin{array}{lll}.411 & .416 & .419 \\ .395 & .396 & .403\end{array}$

.437
.423
.416

$\begin{array}{llr}.450 & .462 & .454 \\ .435 & .451 & .481 \\ .421 & .445 & .480 \\ & & \text { (con.) }\end{array}$

$\begin{array}{llr}.450 & .462 & .454 \\ .435 & .451 & .481 \\ .421 & .445 & .480 \\ & & \text { (con.) }\end{array}$

$\begin{array}{llr}.450 & .462 & .454 \\ .435 & .451 & .481 \\ .421 & .445 & .480 \\ & & \text { (con.) }\end{array}$

.445

.414
.395

.452

.419
.404

.395

(con.) 
Table 5-2 (Con.)

\begin{tabular}{|c|c|c|c|c|c|c|c|c|c|c|}
\hline \multirow{2}{*}{$\begin{array}{l}\text { Characteristic } \\
\text { and d.b.h. }\end{array}$} & \multicolumn{10}{|c|}{ Height (percent) } \\
\hline & 0 & 10 & 20 & 30 & 40 & 50 & 60 & 70 & 80 & 90 \\
\hline \multicolumn{11}{|c|}{ Murrayana } \\
\hline \multicolumn{11}{|c|}{ Heartwood diameter, $\mathrm{mm}$} \\
\hline $76 \mathrm{~mm}$ & 23 & 25 & 22 & 17 & 12 & 8 & 4 & 1 & 0 & 0 \\
\hline $152 \mathrm{~mm}$ & 64 & 62 & 55 & 45 & 36 & 28 & 20 & 11 & 4 & 0 \\
\hline 228 mm & 105 & 106 & 96 & 86 & 70 & 55 & 40 & 24 & 12 & 1 \\
\hline \multicolumn{11}{|c|}{ Sapwood thickness, $\mathrm{mm}$} \\
\hline $76 \mathrm{~mm}$ & 26 & 24 & 24 & 24 & 24 & 22 & 20 & 17 & 13 & 8 \\
\hline 152 mm & 50 & 40 & 39 & 39 & 39 & 37 & 35 & 31 & 26 & 15 \\
\hline $228 \mathrm{~mm}$ & 73 & 53 & 50 & 50 & 50 & 49 & 49 & 44 & 35 & 22 \\
\hline \multicolumn{11}{|l|}{$\begin{array}{l}\text { Heartwood percent of } \\
\text { stemwood volume }\end{array}$} \\
\hline 76 mm & 13 & 15 & 14 & 11 & 7 & 5 & 3 & 1 & 0 & 0 \\
\hline $152 \mathrm{~mm}$ & 19 & 24 & 22 & 18 & 15 & 12 & 8 & 4 & 1 & 0 \\
\hline $228 \mathrm{~mm}$ & 20 & 28 & 26 & 24 & 19 & 15 & 11 & 6 & 4 & 1 \\
\hline \multicolumn{11}{|c|}{ Sapwood M.C. (percent) ${ }^{2}$} \\
\hline 76 mm & 93 & 99 & 103 & 106 & 106 & 112 & 120 & 121 & 123 & 119 \\
\hline $152 \mathrm{~mm}$ & 111 & 126 & 125 & 131 & 136 & 143 & 142 & 146 & 142 & 140 \\
\hline $228 \mathrm{~mm}$ & 133 & 140 & 144 & 138 & 148 & 153 & 150 & 154 & 157 & 139 \\
\hline \multicolumn{11}{|c|}{ Heartwood M.C. (percent) ${ }^{2}$} \\
\hline $76 \mathrm{~mm}$ & 46 & 45 & 50 & 47 & 47 & 53 & 57 & 50 & 40 & - \\
\hline $152 \mathrm{~mm}$ & 43 & 43 & 44 & 47 & 45 & 48 & 51 & 51 & 54 & - \\
\hline 228 mm & 45 & 42 & 41 & 42 & 43 & 43 & 44 & 49 & 52 & 46 \\
\hline \multicolumn{11}{|c|}{$\begin{array}{l}\text { Heartwood percent of } \\
\text { stemwood, green weight }\end{array}$} \\
\hline $76 \mathrm{~mm}$ & 12 & 13 & 12 & 9 & 10 & 4 & 2 & 1 & 0 & 0 \\
\hline $152 \mathrm{~mm}$ & 16 & 18 & 17 & 14 & 11 & 8 & 6 & 3 & 1 & 0 \\
\hline $228 \mathrm{~mm}$ & 15 & 20 & 18 & 17 & 13 & 10 & 7 & 4 & 3 & 0 \\
\hline \multicolumn{11}{|c|}{$\begin{array}{l}\text { Heartwood percent of } \\
\text { stemwood, ovendry weight }\end{array}$} \\
\hline 76 mm & 14 & 17 & 15 & 12 & 8 & 5 & 3 & 1 & 0 & 0 \\
\hline $152 \mathrm{~mm}$ & 21 & 25 & 23 & 19 & 16 & 12 & 9 & 6 & 2 & 0 \\
\hline $228 \mathrm{~mm}$ & 22 & 29 & 26 & 24 & 20 & 16 & 12 & 7 & 4 & 1 \\
\hline \multicolumn{11}{|c|}{ Sapwood specific gravity ${ }^{3}$} \\
\hline $76 \mathrm{~mm}$ & 0.523 & 0.495 & 0.474 & 0.462 & 0.460 & 0.453 & 0.443 & 0.443 & 0.439 & 0.440 \\
\hline $152 \mathrm{~mm}$ & .484 & .442 & .437 & .423 & .415 & .401 & .403 & .397 & .407 & .404 \\
\hline $228 \mathrm{~mm}$ & .431 & .405 & .394 & .399 & .386 & .380 & .385 & .384 & .383 & .408 \\
\hline \multicolumn{11}{|c|}{ Heartwood specific gravity ${ }^{3}$} \\
\hline $76 \mathrm{~mm}$ & .590 & .571 & .513 & .532 & .508 & .508 & .459 & .558 & .385 & - \\
\hline 152 mm & .565 & .499 & .486 & .458 & .462 & .455 & .464 & .470 & .499 & - \\
\hline 228 mm & .509 & .443 & .417 & .424 & .420 & .442 & .456 & .458 & .472 & .502 \\
\hline
\end{tabular}

1 Because of the main effects and interactions of d.b.h., latitude, and elevational zone, reference to the appropriate figures and text discussion is required for interpretation of these data. Data are based on 243 latifolia trees (81 of each diameter) and 36 murrayana trees (12 of each diameter).

2Percent of ovendry weight.

${ }^{3}$ Based on ovendry weight and green volume. 


\section{Heartwood Occurrence}

Age of Lowest Tree Disk Where Heartwood Does Not Occur-The age of the lowest tree disk where heartwood did not occur averaged 14.20 years, with standard deviation of 11.43 years. It was unrelated to elevational zone, but was negatively correlated with d.b.h., averaging 20.87 (11.47 standard deviation), 11.49 (9.50), and 10.23 (10.24) years for trees 76, 152, and $228 \mathrm{~mm}$ in diameter (fig. 5-1). This age was also negatively correlated with latitude; for example, it averaged 27 years at 40 degrees latitude and only 8 years at 57.5 degrees (fig. $5-1$ ).

The following significant correlations (arbitrarily truncated at $r=0.300$ ) of the age of the lowest tree disk where heartwood does not occur with other tree statistics are of interest:

\begin{tabular}{|c|c|}
\hline Statistic & $\boldsymbol{r}$ \\
\hline $\begin{array}{l}\text { Percentage of stem height where heart- } \\
\text { wood no longer occurs }\end{array}$ & -0.531 \\
\hline $\begin{array}{l}\text { Height }(\mathrm{m}) \text { where heartwood no longer } \\
\text { occurs }\end{array}$ & -.515 \\
\hline $\begin{array}{l}\text { Height }(\mathrm{m}) \text { where sapwood thickness is } \\
\text { minimum }\end{array}$ & -.455 \\
\hline Heartwood maximum diameter & -.442 \\
\hline Green weight of heartwood & -.423 \\
\hline Ovendry weight of heartwood & -.418 \\
\hline Tree height & .403 \\
\hline Elevation & .394 \\
\hline D.b.h. & -.384 \\
\hline $\begin{array}{l}\text { Heartwood volume as percentage of bark- } \\
\text { free stem volume }\end{array}$ & -.370 \\
\hline $\begin{array}{l}\text { Heartwood as percentage of bark-free } \\
\text { ovendry stem weight }\end{array}$ & -.364 \\
\hline $\begin{array}{l}\text { Ovendry weight of stump-root system } \\
\text { (wood plus bark) }\end{array}$ & -.364 \\
\hline Ovendry weight of stem (wood plus bark) & -.356 \\
\hline $\begin{array}{l}\text { Stemwood d.i.b. (diameter inside bark) at } \\
\text { base of live crown }\end{array}$ & -.345 \\
\hline $\begin{array}{l}\text { Heartwood as percentage of bark-free stem } \\
\text { weight, green }\end{array}$ & -.344 \\
\hline $\begin{array}{l}\text { Percentage of stem height where sapwood } \\
\text { is thinnest }\end{array}$ & -.321 \\
\hline $\begin{array}{l}\text { Heartwood as percentage of stem diameter } \\
\text { at height of maximum heartwood diameter }\end{array}$ & -.307 \\
\hline Average branch diameter & -.304 \\
\hline
\end{tabular}

In the foregoing tabulation, 16 of the 18 are negative correlations. The two positive correlations suggest that age of the lowest tree disk free of heartwood is greatest in tall trees growing at high elevation. The negative correlations suggest that this age tends to be greatest in trees in which heartwood does not extend far up the tree, sapwood has minimum thickness low in the tree, heartwood maximum diameter is small, weight of heartwood is small, d.b.h. is small, heartwood weight and volume as percentage of stemwood is small, stump-root weight is small, and stemwood d.i.b. at the base of the live crown is small.

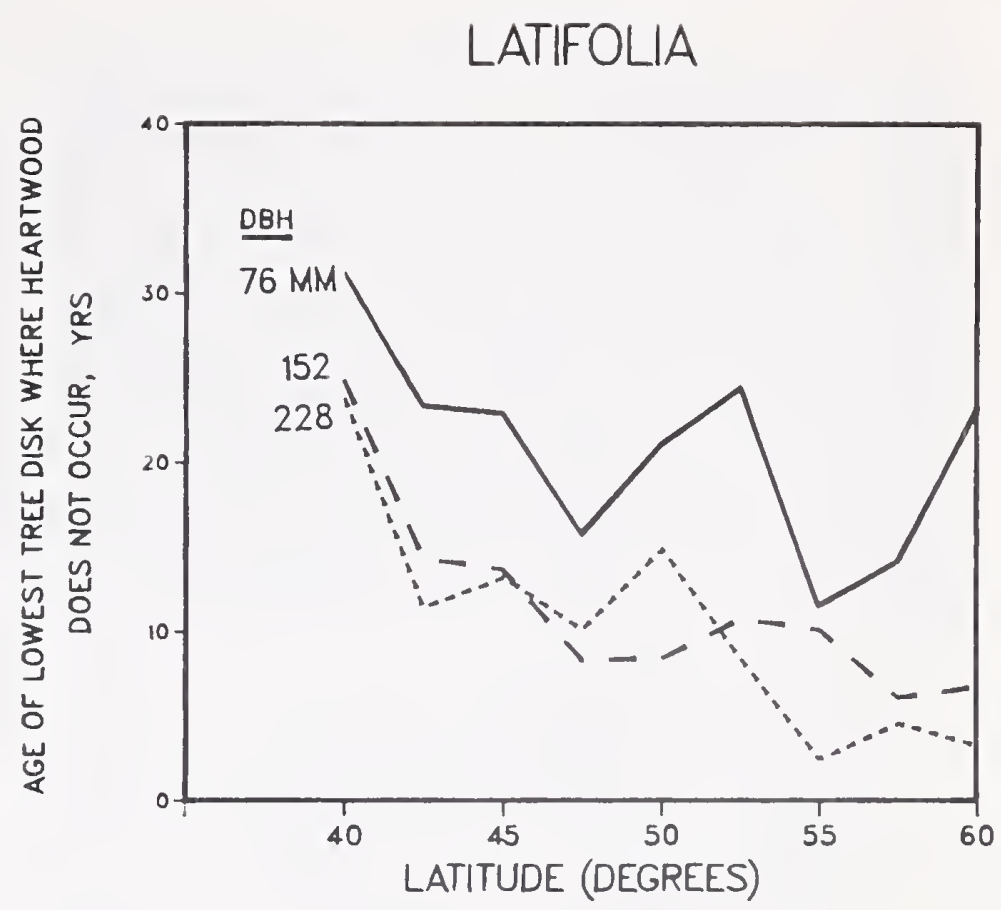

Figure 5-1-Age of lowest tree disk where heartwood does not occur in latifolia trees of three diameters, related to latitude. 
Height in the Tree at Which Heartwood No Longer Occurs, Percent-Percentage height in the tree above which heartwood did not occur averaged 86.38 percent, with standard deviation of 14.86 percent. This percentage was unrelated to elevational zone, but was positively correlated with d.b.h., averaging 76.05 (18.82), 89.51 (9.99), and $93.58(6.58)$ for trees of the three diameter classes (fig. 5-2). It also was positively correlated with latitude; for example, the percentage averaged 79 percent at 40 degrees and 96 percent at 60 degrees (fig. 5-2).

The following significant correlations (arbitrarily truncated at $r=0.500$ ) of the percentage height in the tree at which heartwood no longer occurred with other tree statistics are of interest:

\section{Statistic}

Heartwood as percentage of stemwood diameter at height of maximum heartwood diameter

Heartwood volume as percentage of entire stemwood volume

Heartwood percentage of entire stemwood weight, ovendry

Height in tree at which heartwood no longer occurs, $m$

Heartwood percentage of entire stemwood weight, green

Foliage percentage of complete-tree weight, ovendry

Heartwood maximum diameter

Percentage moisture content of complete tree with foliage and cones

Percentage moisture content of complete tree without foliage and cones

Percentage moisture content of stem, wood plus bark

Percentage moisture content of complete tree, wood only

Percentage moisture content of stemwood, tree average

Percentage moisture content of stump-root system, wood plus bark

Percentage moisture content of wood of the stump-root system

Moisture content of stembark, tree average

Height in tree where minimum sapwood thickness occurs

Tree height

Within-crown stemwood as percentage of stemwood volume

Stembark specific gravity

Tree age at $152-\mathrm{mm}$ stump height

Percentage moisture content of completetree bark

Age of lowest tree disk where heartwood does not occur

Green weight of heartwood of entire stem

Ovendry weight of heartwood of entire stem Crown ratio

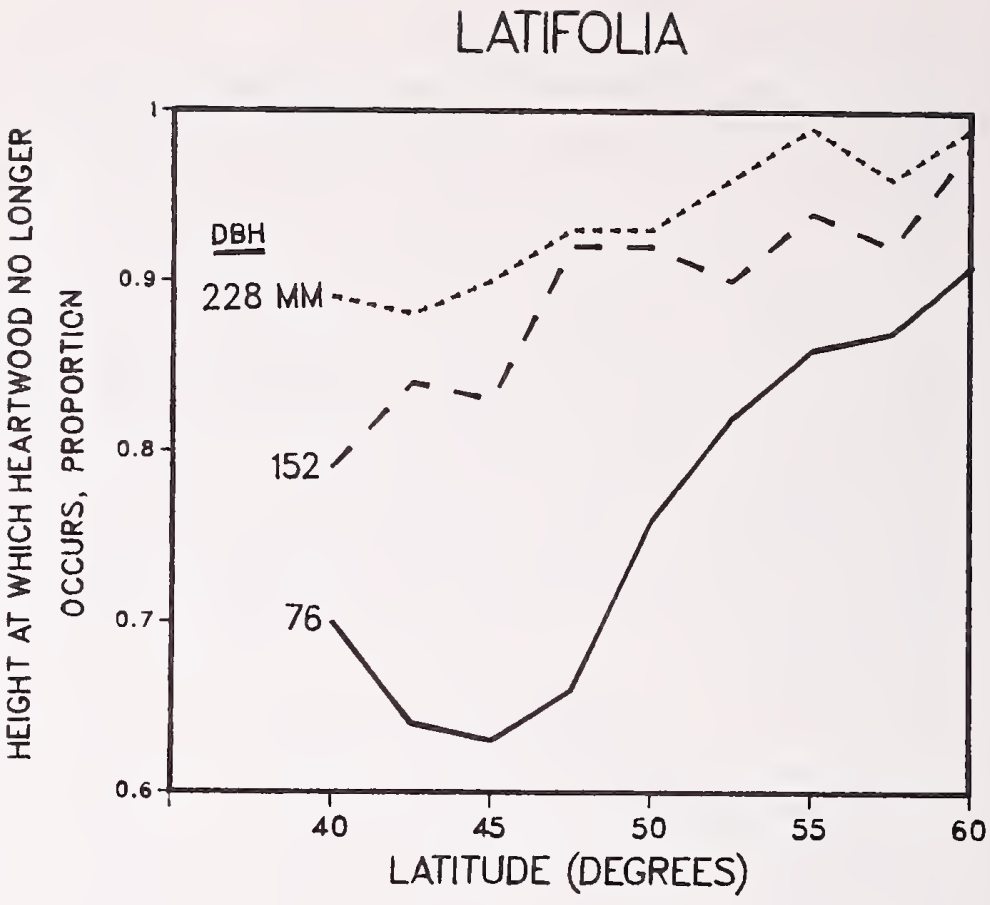

Figure 5-2- Height in tree (proportion) at which heartwood does not occur in latifolia trees of three diameters, related to latitude.

These correlation coefficients suggest that heartwood extends upward the greatest percentage of tree height in taller and older trees in which maximum heartwood diameter (as a percentage of tree diameter) is large, heartwood weight and volume (as percentages of stemwood weight and volume) are large, foliage ovendry weight (as a percentage of complete-tree weight) is small, percentage moisture content of complete tree and stem and root are low, minimum sapwood thickness occurs high in the stem, within-crown stemwood percentage of total stemwood volume is low, stembark specific gravity is high and moisture content low, age of the lowest disk in which heartwood does not occur is low, and crown ratio is low. 
Height in the Tree at Which Heartwood No Longer Occurs, Meters-The height (meters) in the trees at which heartwood no longer occurred was unrelated to elevational zone, but was positively correlated with d.b.h., averaging 7.19 (2.65), $14.00(3.10)$, and 17.87 (3.12) $\mathrm{m}$ for trees of the three diameter classes (fig. 5-3). This height was also positively correlated with latitude; for example, it averaged $10.9 \mathrm{~m}$ at 40 degrees and $15.4 \mathrm{~m}$ at 55 degrees latitude (fig. 5-3).

The following significant correlations (arbitrarily truncated at $r=0.50$ ) of height in tree (meters) at which heartwood no longer occurs, with other tree statistics are of interest:

\section{Statistic}

Tree height

Ovendry weight of stem, wood plus bark

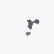

Heartwood maximum diameter

D.b.h.

Ovendry weight of entire heartwood

Ovendry weight of stump-root system, wood plus bark

Green weight of entire heartwood

Ovendry weight of entire sapwood

Green weight of entire sapwood

Height in tree at which heartwood no longer occurs, percent

Height in tree where minimum sapwood thickness occurs, $m$

Stump-root system percentage of ovendry complete-tree weight

Stemwood d.i.b. at base of live crown

Average branch diameter

Foliage as percentage of ovendry weight of complete tree

Percentage moisture content of bark of complete tree

Weight of ovendry foliage

Weight of ovendry branches, wood plus bark

Number of live branches

Stem (wood plus bark) as percentage of ovendry weight of complete tree

Percentage moisture content of entire heartwood

Heartwood as percentage of stemwood

diameter at height of maximum heartwood diameter

Heartwood as percentage of stemwood volume

Taproot length

Percentage moisture content of completetree bark

Heartwood as percentage of ovendry stemwood weight

Age of lowest stem disk above which heartwood does not occur
$-.544$

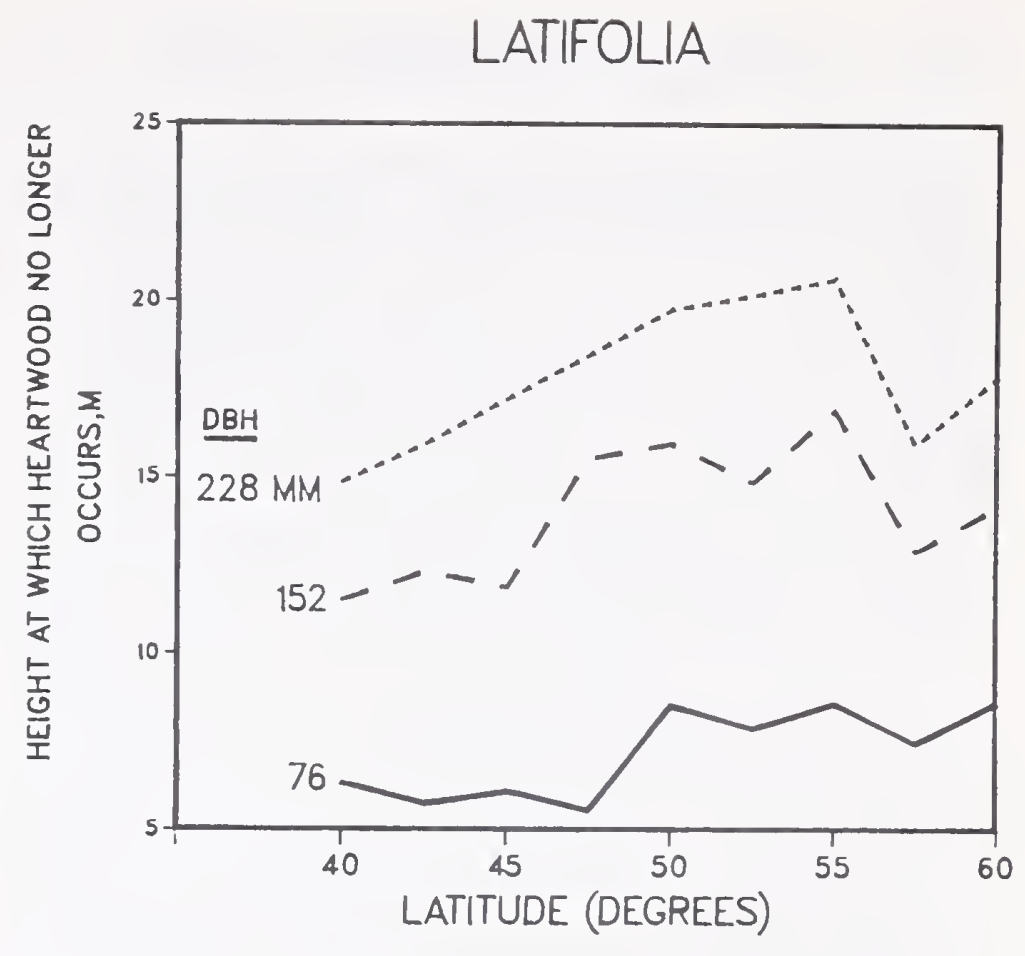

Figure 5-3-Height in tree (meters) at which heartwood does not occur in latifolia trees, related to latitude.

These data suggest that heartwood extends upward in stems the greatest distance (meters) in large-diameter, tall trees, with numerous large, heavy branches, heavy foliage, and heavy stems comprising a high percentage of complete-tree weight, and in which heartwood diameter and weight are large, stump-root weight is large (but stump-root percentage of complete-tree weight is small), sapwood weight is large, minimum sapwood thickness occurs high in the tree, stemwood d.i.b. at the base of the live crown is large, foliage as percentage of ovendry weight of complete tree is small, percentage moisture content of complete-tree bark and of heartwood are both low, heartwood as percentage of stemwood diameter and volume are high, taproots are long, and age of lowest stem disk above which heartwood does not occur is low. 


\section{Heartwood Maximum Diameter and Location}

Heartwood Maximum Diameter-Heartwood maximum diameter was unrelated to elevational zone but was positively correlated to d.b.h., averaging 36.1 (15.1), 85.3 (25.6), and $146.9(32.2) \mathrm{mm}$ for trees of the three diameter classes (fig. 5-4). It was also positively correlated with latitude; with diameter data pooled, maximum heartwood diameter averaged $71 \mathrm{~mm}$ at 42.5 degrees and $104 \mathrm{~mm}$ at 60 degrees (fig. 5-4).

The following significant correlations (arbitrarily truncated at $r=0.500$ ) of heartwood maximum diameter with other tree statistics are of interest:

\section{Statistic}

Ovendry weight of entire heartwood $r$

Green weight of entire heartwood

0.913

.911

.875

Ovendry weight of stump-root system, wood plus bark

Ovendry weight of stem, wood plus bark

Height in tree $(\mathrm{m})$ above which heartwood does not occur

Tree height

Average branch diameter

Ovendry weight of entire sapwood

Green weight of sapwood

Ovendry weight of live branches

Heartwood as percentage of ovendry weight of stemwood

Heartwood as percentage of stemwood diameter at height of maximum heartwood diameter

Percentage height in tree above which heartwood does not occur

Ovendry foliage weight

Percentage moisture content of stembark, tree average

Heartwood as percentage of green stemwood weight

Within-crown stemwood taper, $\mathrm{mm} / \mathrm{m}$

Number of cones on the tip $305 \mathrm{~mm}$ of the top 25 branches

Percentage moisture content of completetree bark

Height in tree where minimum sapwood thickness occurs, $m$

Tree age at $152-\mathrm{mm}$ stump height

Ovendry weight of dead branches

Stump-root system (wood plus bark) as percentage of ovendry weight of complete tree

\section{LATIFOLIA}

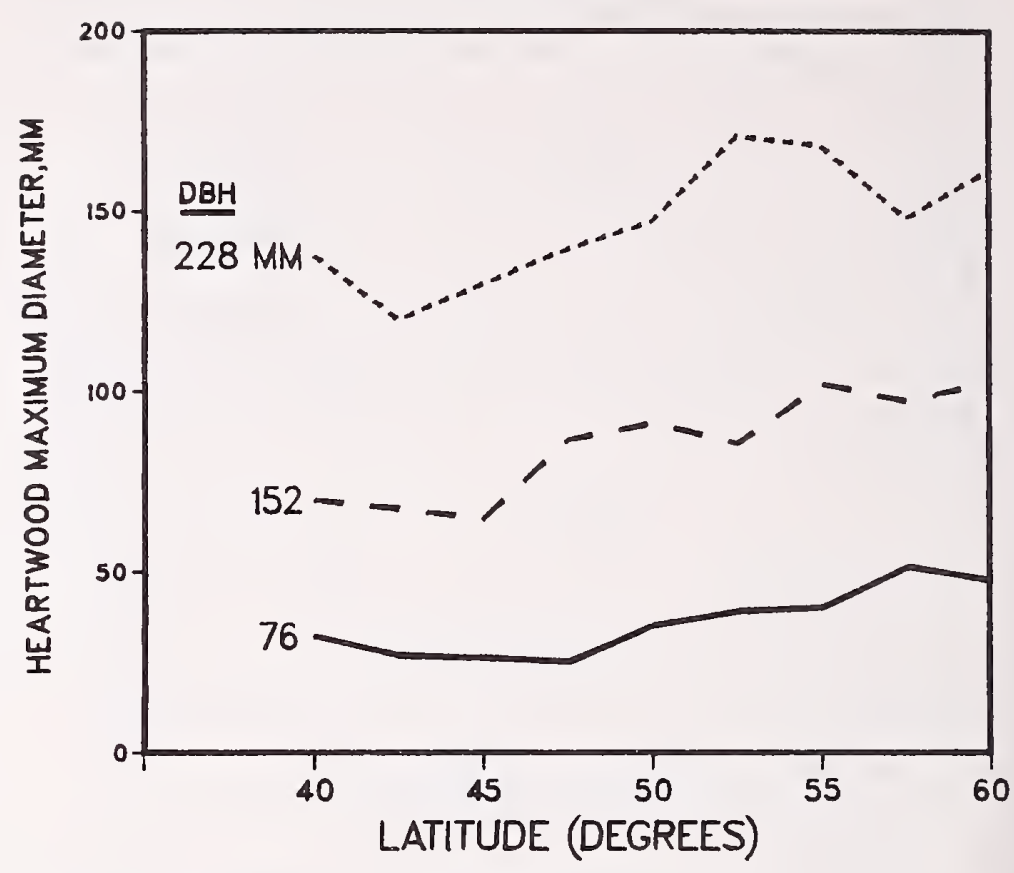

Figure 5-4-Heartwood maximum diameter in latifolia trees of three diameters, related to latitude.

These data suggest that largest heartwood diameter is found in large-diameter tall, old trees with large-diameter branches, many cones on the top 25 branches, large within-crown stem taper, heavy foliage, and a large ovendry weight of dead branches. In addition to the obvious correlations with heartwood volume and weight, largest heartwood diameter tends to occur in trees with heavy stump-root systems (but comprising a low percentage of complete-tree weight), large stemwood d.i.b. at base of live crown, heavy crowns, and stembark and treebark of low percentage moisture content. 
Height at Which Maximum Heartwood Diameter Occurs, Percent-The percentage of tree height at which maximum heartwood diameter occurred was generally not far above stump height, but this percentage was negatively correlated with d.b.h., averaging 8.64 (8.02), 3.46 (5.95), and $2.22(4.18)$ percent for trees 76,152 , and $228 \mathrm{~mm}$ in d.b.h. The percentage height at which the maximum occurred was generally also negatively correlated with latitude (averaging 7.4 percent at 40 degrees and 1.5 percent at 57.5 degrees), but interactions of latitude, elevational zone, and d.b.h. were complex (fig. 5-5).

The following significant correlations (arbitrarily truncated at $r=0.250$ ) of the percentage of total height in trees at which maximum heartwood diameter occurred with other tree statistics are of interest:

\section{Statistic}

Height in trees $(\mathrm{m})$ of maximum heartwood diameter

0.906

Heartwood maximum diameter

$-.481$

D.b.h.

Ovendry weight of entire heartwood

Green weight of entire heartwood

Ovendry weight of stump-root system, wood plus bark

Height in tree $(\mathrm{m})$ above which heartwood does not occur

Heartwood as percentage of volume of entire stemwood

Heartwood as percentage of weight, ovendry, of entire stemwood

Tree height

Ovendry stem weight, wood plus bark

Heartwood as percentage of weight, green, of entire stemwood

Average branch diameter

Stemwood d.i.b. at base of live crown

Percentage moisture content of stump-root system, wood plus bark

Age of the lowest stem disk in which heartwood does not occur

Ovendry weight of live branches, wood plus bark

Ovendry foliage weight

Percentage moisture content of entire stembark

Percentage moisture content of bark of stump-root system

Below-crown stemwood taper, $\mathrm{mm} / \mathrm{m}$

Bark thickness at 152-mm stump height

Percentage moisture content of wood of stump-root system

Ovendry weight of entire sapwood

Percentage moisture content of bark of complete tree

Percentage moisture content of complete tree with foliage and cones

Percentage moisture content of complete tree without foliage or cones

$-.379$

$-.358$

$-.352$

$-.340$

$-.339$

Percentage height in tree above which heartwood does not occur
LATIFOLIA
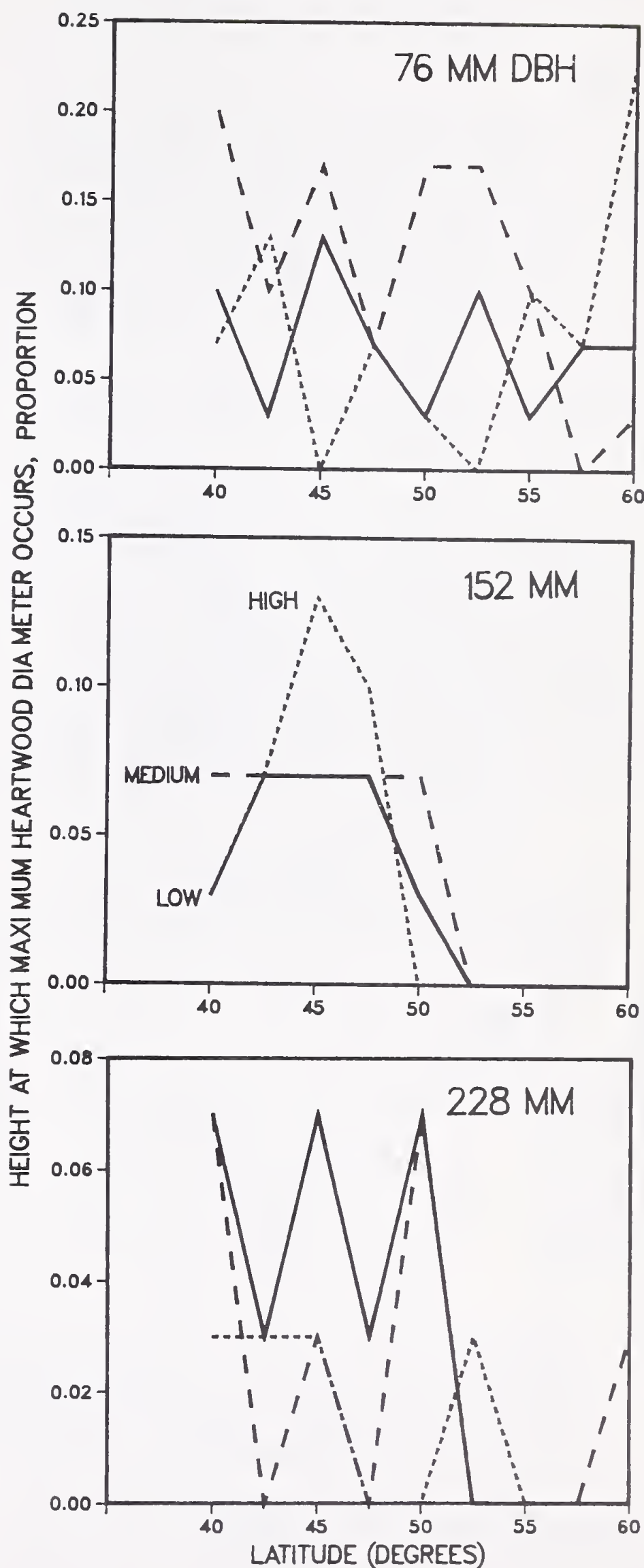

Figure 5-5-Proportion of height at which maximum heartwood diameter occurs in latifolia trees of three diameters, related to latitude and elevational zone. 
These data suggest that maximum heartwood diameter occurs at greatest percentage of tree height in smalldiameter, short, light-weight trees with small branches, and low weight of branches, foliage, and stump-root systems.

Of the 28 characteristics listed in the foregoing tabulation, only nine are positively correlated. Thus, maximum heartwood diameter occurs at greatest percentage of tree height in trees in which percentage moisture content of the stump-root system is high, percentage moisture content of stembark and treebark is high, percentage moisture content of the complete tree is high, and the age of the lowest tree disk in which heartwood does not occur is high.

The negative correlations further indicate that maximum heartwood diameter occurs at the greatest percentage of tree height in trees in which maximum heartwood diameter is small, heartwood weight is small, heartwood comprises a small percentage of stemwood weight, stemwood d.i.b. at the base of the live crown is small, below-crown stemwood taper is small, bark at stump height is thin, sapwood weight is small, and percentage of tree height above which heartwood does not occur is small.

Height at Which Maximum Heartwood Diameter Occurs, Meters-The height (meters) at which maximum heartwood diameter occurred was unrelated to elevational zone but was negatively correlated with d.b.h., averaging $0.80(0.74), 0.53(0.92)$, and $0.44(0.84) \mathrm{m}$ for trees 76,152 ,

\section{LATIFOLIA}

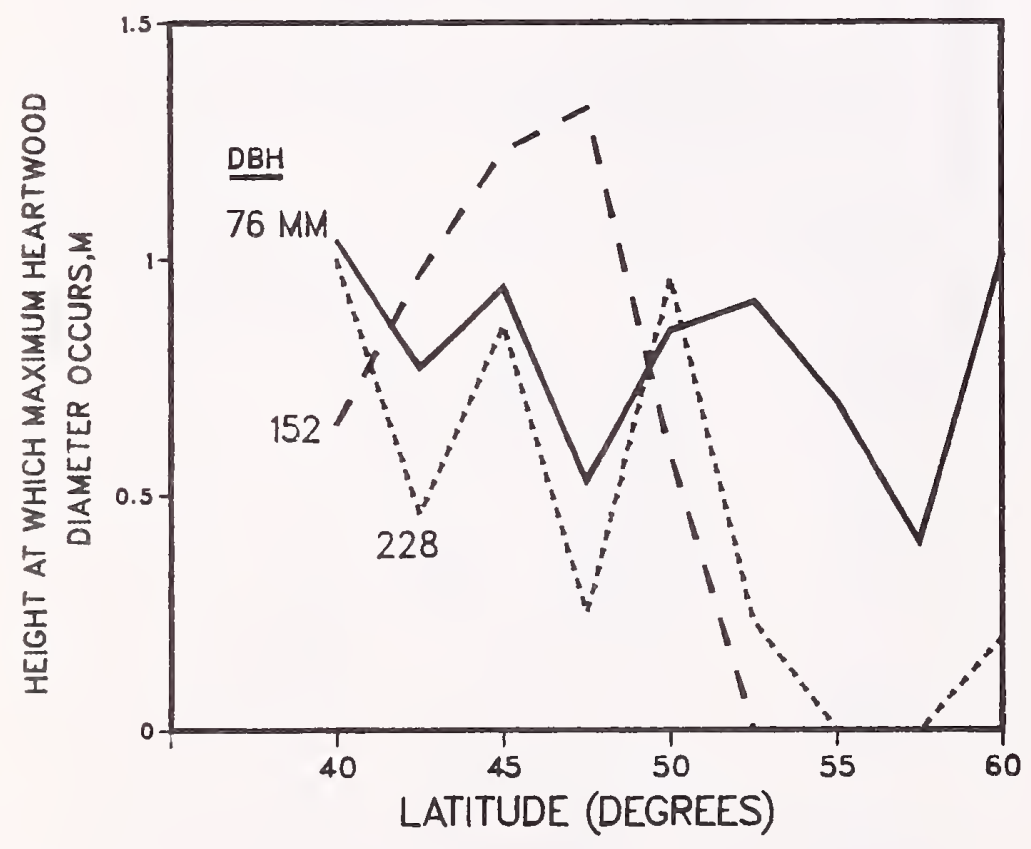

and $228 \mathrm{~mm}$ in d.b.h. This height was generally negatively correlated with latitude-averaging $0.89 \mathrm{~m}$ at 40 degrees and only $0.13 \mathrm{~m}$ at 57.5 degrees, but the relationship varied with d.b.h. (fig. 5-6).

The following significant correlations (arbitrarily truncated at $r=0.200$ ) of the height (meters) at which maximum heartwood diameter occurred with other tree statistics are of interest:

\section{Statistic}

$r$

Height (percent) where maximum heartwood diameter occurs

Heartwood maximum diameter

Heartwood as percentage of weight of barkfree stem, ovendry

Heartwood as percentage of stemwood volume

Heartwood as percentage of weight of barkfree stem, green

Percentage moisture content of stump-root system (wood plus bark)

Percentage moisture content of wood of stump-root system

Green weight of heartwood

Ovendry weight of heartwood

Percentage moisture content of complete tree with foliage and cones

Percentage moisture content of complete tree without foliage or cones

Percentage moisture content of complete tree (wood only)

Percentage moisture content of stem (wood plus bark)

Below-crown average stemwood taper, $\mathrm{mm} / \mathrm{m}$

Percentage moisture content of stemwood, tree average

Within-crown stemwood taper, $\mathrm{mm} / \mathrm{m}$

Age of the lowest tree disk in which heart-

wood does not occur

.207

Elevation, $m$

The foregoing data suggest that the height (meters) at which maximum heartwood diameter occurs is greatest in trees growing at high elevation with high moisture content, little stem taper, and low heartwood content-and in those trees in which the age of the lowest tree disk in which heartwood does not occur is large.

Figure 5-6-Height (meters) at which maximum heartwood diameter occurs in latifolia trees of three diameters, related to latitude. 
Heartwood as Percentage of Stem Diameter, at Height of Maximum Heartwood Diameter-Heartwood as percentage of stem diameter at height of maximum heartwood diameter was unrelated to elevational zone, but was positively correlated with d.b.h., averaging 48.15 (19.14), 53.80 (14.47), and 59.94 (11.36) percent for the three diameter classes. Differences between diameter classes were most pronounced at 40 to 50 degrees of latitude; also, heartwood as percentage of diameter was positively correlated with latitude, averaging minimum (43.13 percent) at 42.5 degrees and maximum (64.64 percent) at 60 degrees (fig. 5-7).

The following significant correlations (arbitrarily truncated at $r=0.450$ ) of heartwood as percentage of stem diameter at height of maximum heartwood diameter with other tree statistics are of interest:

\section{LATIFOLIA}

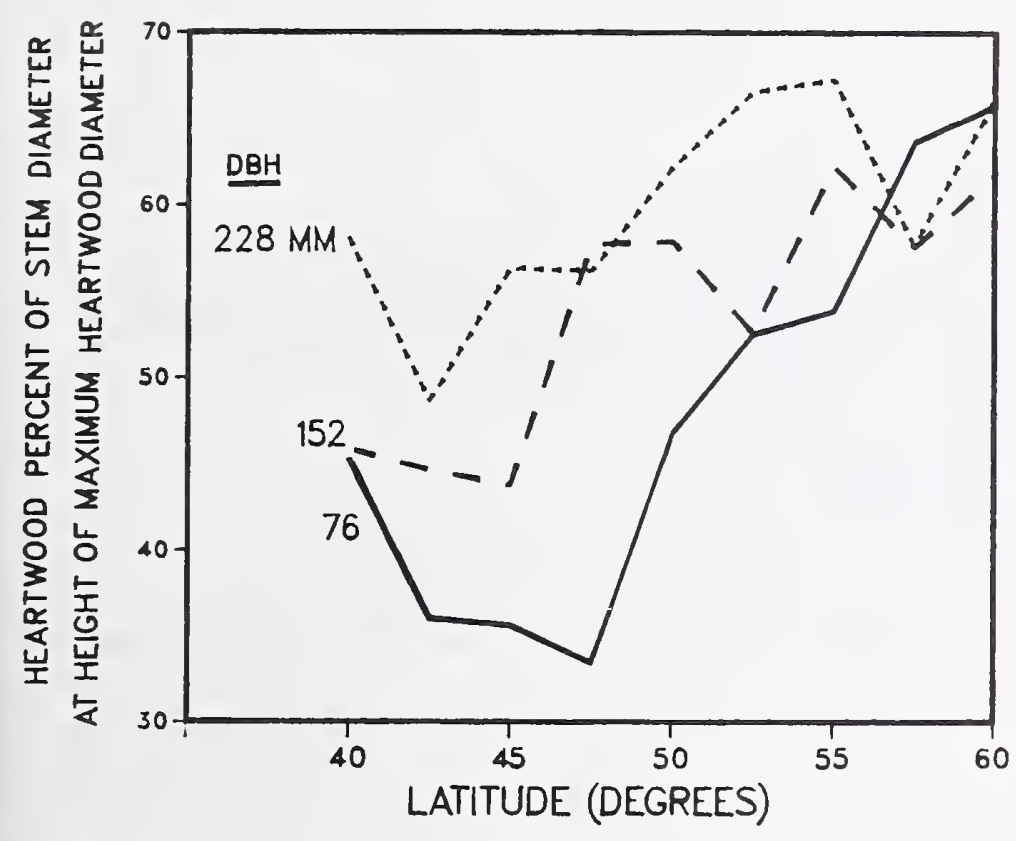

Figure 5-7-Heartwood as percentage of stem diameter at height of maximum heartwood diameter in latifolia trees of three diameters, related to latitude.

\section{Statistic}

Heartwood as percentage of stemwood volume

Heartwood as percentage of stemwood weight, ovendry

Heartwood as percentage of stemwood weight, green

Height (percent) of lowest tree disk in which

heartwood does not occur

Percentage moisture content of complete tree with foliage and cones

Percentage moisture content of complete tree without foliage or cones

Percentage moisture content of complete tree, wood only

Percentage moisture content of stem, wood plus bark

Percentage moisture content of stemwood, tree average

Foliage as percentage of complete-tree weight, ovendry

Percentage moisture content of wood of stump-root system

Percentage moisture content of stump-root system, wood plus bark

Heartwood maximum diameter

Percentage moisture content of complete tree, bark only

Percentage moisture content of stembark. tree average

Within-crown stemwood percentage of entire stemwood volume

Stembark specific gravity

Crown ratio

Height $(m)$ of lowest tree disk in which heartwood does not occur

Percentage moisture content of foliage-free branches, wood plus bark

Stem (wood plus bark) as percentage of complete-tree weight, ovendry

Tree age at $152-\mathrm{mm}$ stump height

$-.474$

Percentage moisture content of sapwood

$-.452$

The foregoing tabulation suggests that heartwood percentage of stemwood diameter at height of maximum heartwood diameter is maximum in older trees with low moisture content, low crown ratio, and with foliage comprising a low percentage of complete-tree weight. It also tends to be maximum in trees with high stembark specific gravity, a low percentage of within-crown stemwood, and-obviously - a high weight and volume content of heartwood and thin sapwood. 


\section{Heartwood Diameter by Level}

Heartwood diameters at various proportions of tree height are positively correlated with d.b.h. (table 5-2 and figs. 5-8 and 5-9). They are also positively correlated with latitude (fig. 5-10).

\section{LATIFOLIA}

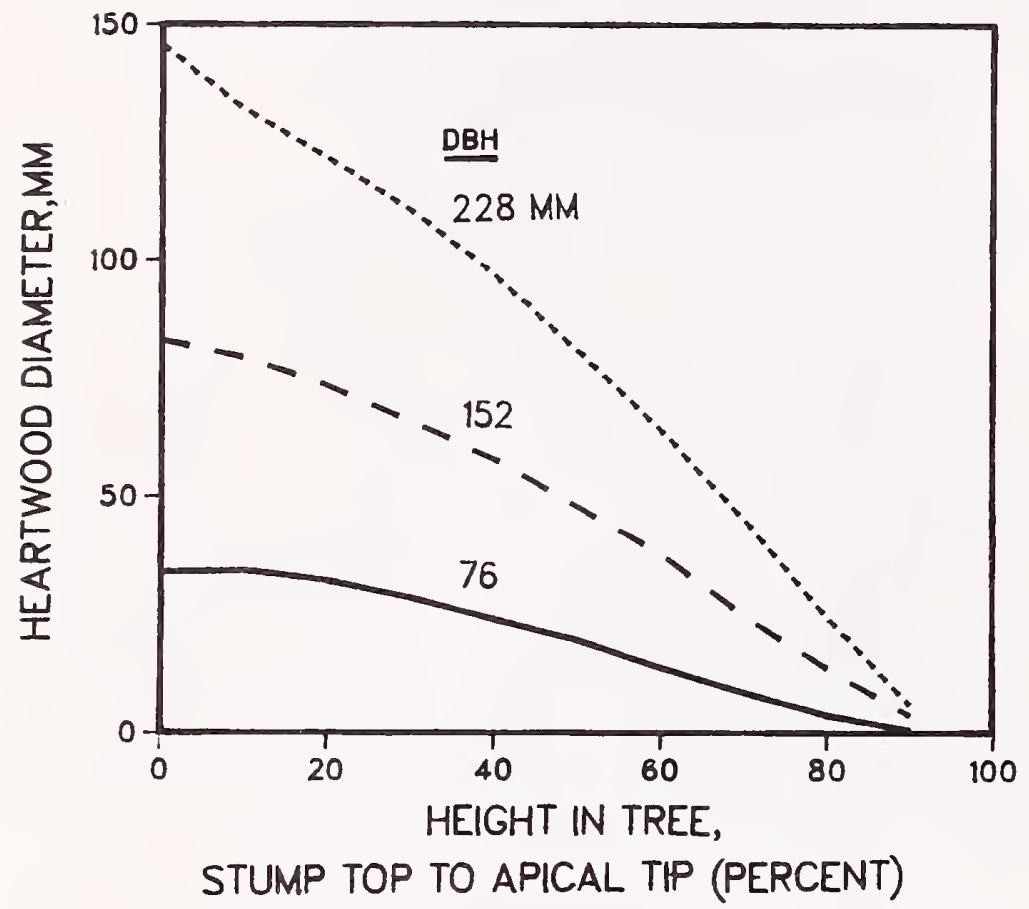

Figure 5-8-Heartwood diameter in latifolia trees of three diameters, related to height in tree.
LATIFOLIA
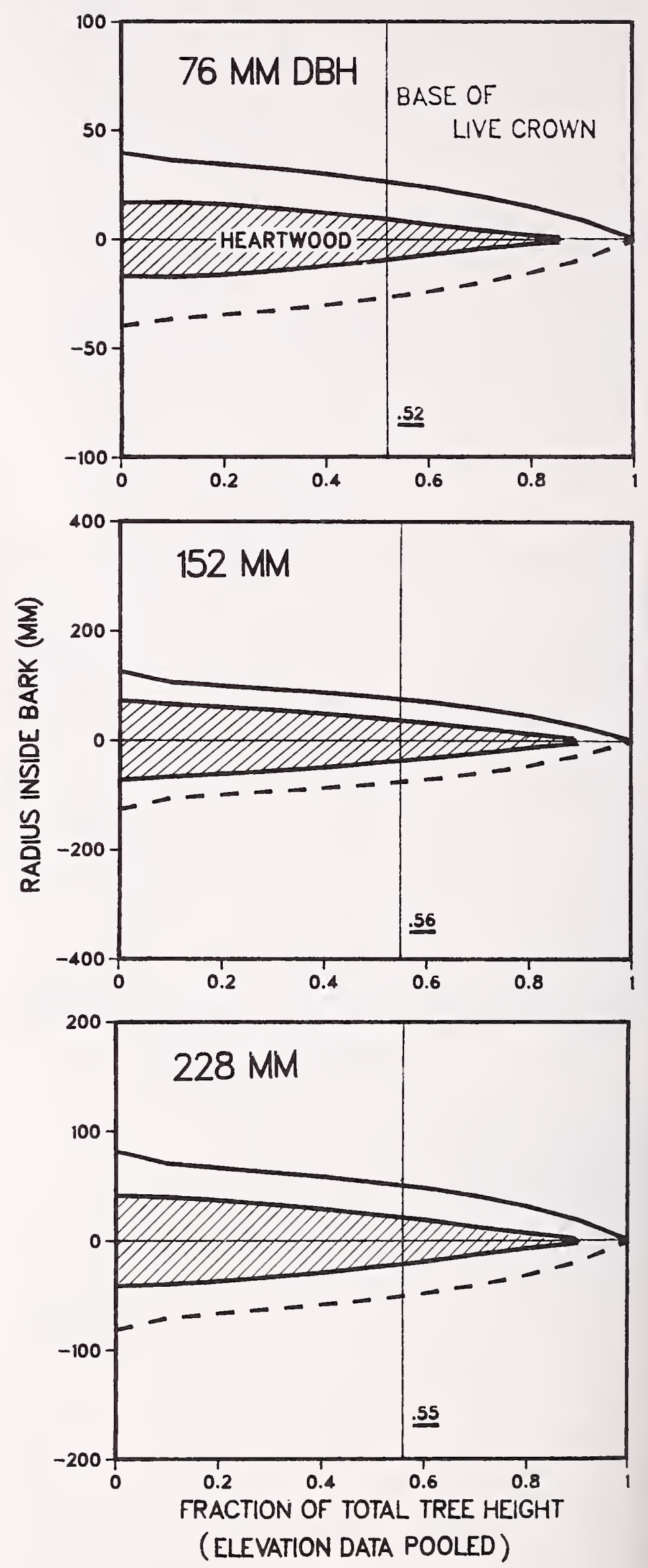

Figure 5-9-Heartwood and stemwood radius in latifolia trees of three diameters, related to height in tree and base of live crown. 


\section{LATIFOLIA}
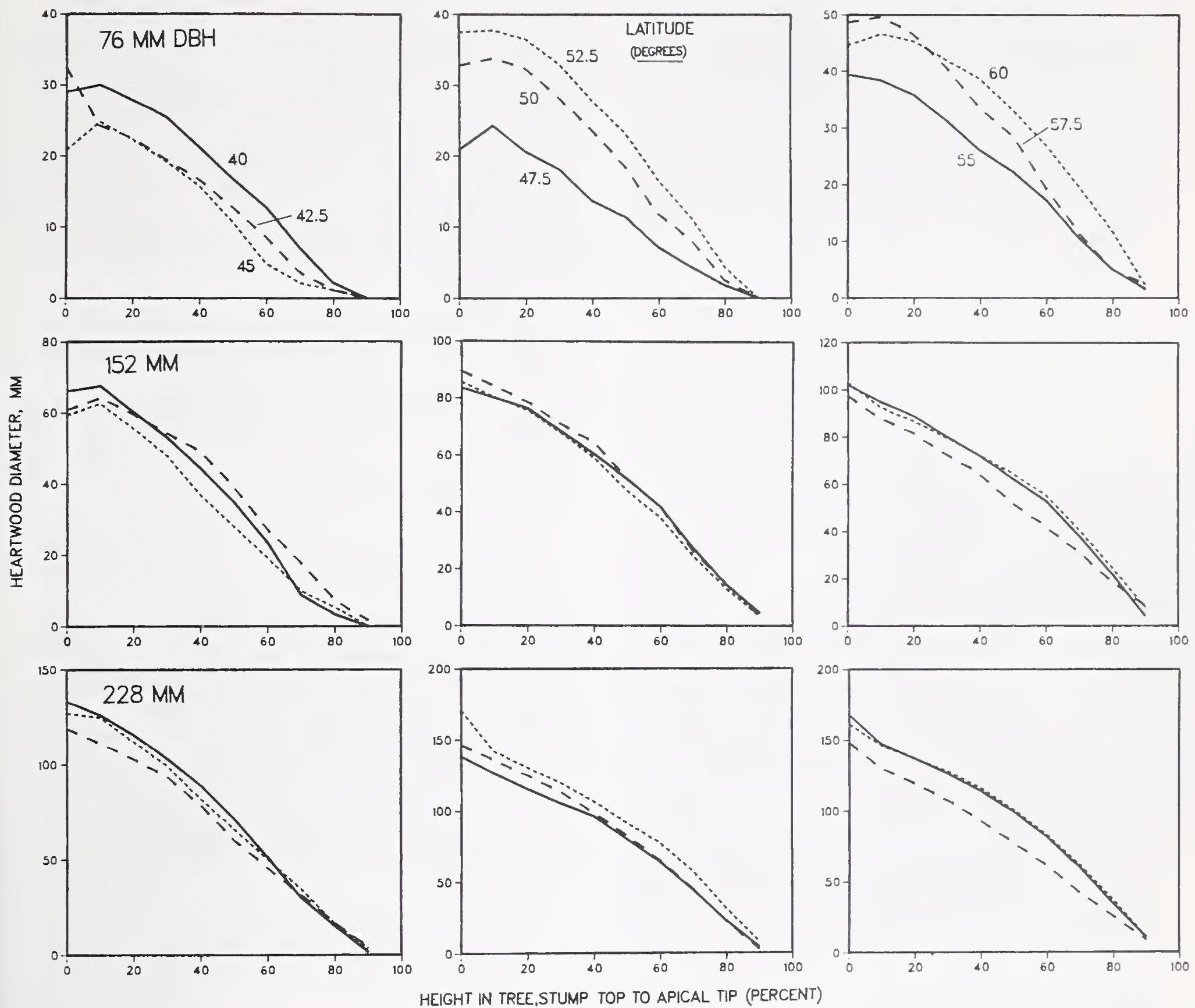

Figure 5-10-Heartwood diameter in latifolia trees of three diameters, related to height in tree and latitude. 


\section{LATIFOLIA}
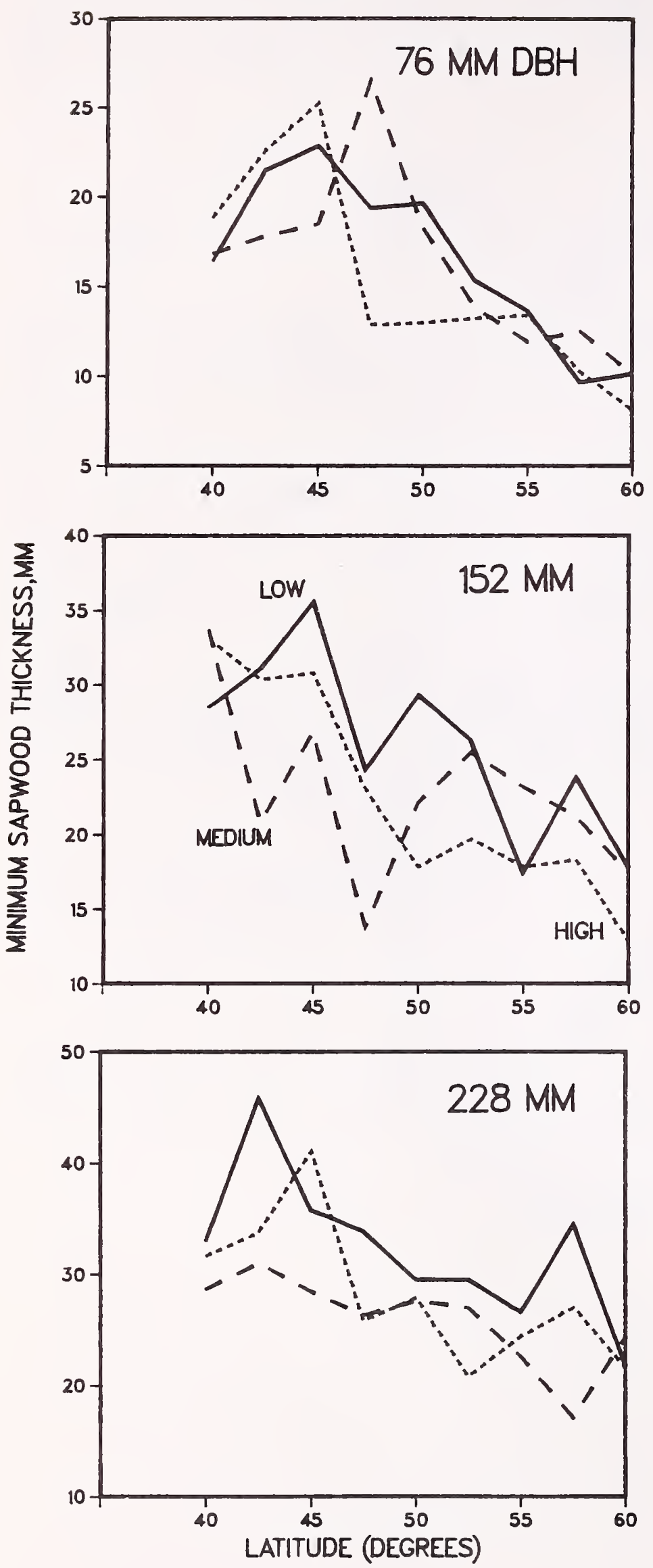

Figure 5-11-Minimum sapwood thickness in latifolia trees of three diameters, related to latitude and elevational zone.

\section{Minimum Sapwood Thickness and Location Where Heartwood Is Present}

Minimum Thickness-Minimum sapwood thickness was positively correlated with d.b.h., averaging 16.03 (6.85), 23.81 (8.43), and $28.80(8.76) \mathrm{mm}$ for trees of the three diameter classes. It was negatively correlated with latitude; that is, trees in northern latitudes had thinner sapwood than those in the south (fig. 5-11). Minimum sapwood thickness was also significantly related to elevational zone; for all three d.b.h. classes, sapwood averaged thickest in trees from low-elevation zones; that is, 24.94, 21.64 , and $22.06 \mathrm{~mm}$ for low-, medium-, and high-elevation zones (fig. 5-11).

Because woods with thin sapwood are difficult to treat with preservatives, significant correlations of minimum sapwood thickness (where heartwood is present) with other tree statistics are listed in considerable detail, as follows (list arbitrarily truncated at $r=0.300$ ):

\section{Statistic}

Average growth-ring width at $152-\mathrm{mm}$ stump height

0.680

Green weight of sapwood

Ovendry weight of sapwood

Stemwood d.i.b. at base of live crown

Number of live branches

Ovendry foliage weight

D.b.h.

Heartwood as percentage of weight of bark-

free stem, green

Percentage moisture content of sapwood

Percentage moisture content of complete tree, wood only

Percentage moisture content of stemwood, tree average

Taproot length

Percentage moisture content of complete tree without foliage or cones

Percentage moisture content of stem, wood plus bark

Ovendry weight of stump-root system, wood plus bark

Heartwood as percentage of weight of barkfree stem, ovendry

Percentage moisture content of complete tree with foliage and cones

Heartwood as percentage of stemwood volume

Ovendry weight of live branches, wood plus bark

Percentage moisture content of foliage-free live branches, wood plus bark

Ovendry weight of stem, wood plus bark

Heartwood as percentage of stem diameter at height of maximum heartwood diameter

Percentage moisture content of live branchwood
$-.452$ 


\section{Statistic}

Stemwood specific gravity

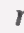

Tree height

Live branch (wood plus bark) as percentage

of complete-tree weight, ovendry

Percentage moisture content of stump-root system

Average branch angle

Average branch diameter

Bark thickness at $152-\mathrm{mm}$ stump height

Percentage moisture content of stump-root system, wood plus bark

Specific gravity of entire sapwood

Ovendry weight of dead branches

Crown ratio

Specific gravity of entire heartwood

$-.313$

Within-crown stemwood as percentage of entire stemwood volume

Below-crown average stemwood taper, $\mathrm{mm} / \mathrm{m}$

Elevation, $m$

Percentage moisture content of live branchbark

.308

The foregoing tabulation suggests that sapwood tends to be thinnest in slow-grown, small-diameter, short, lightweight trees having a low crown ratio, little foliage, few branches of small diameter and low weight with large branch angles, and a lightweight stump-root system with short taproot.

Sapwood also tends to be thinnest in trees with thin bark at stump height, low moisture content in most components, little below-crown stemwood taper, and a small percentage of total stemwood volume within the crown.

\section{Height at Which Minimum Sapwood Thickness}

Occurs, Percent-The percentage of tree height at which sapwood is thinnest was unrelated to elevational zone, but was positively correlated with d.b.h., averaging 51.36 (25.19), 60.49 (28.50), and 70.49 (25.73) percent of tree height for the three diameter classes. Also, this percentage of height tended to increase with increasing latitude; for example, it averaged smallest (52.59 percent) at 45 degrees and largest (75.56 percent) at 60 degrees, but the relationship varied with diameter (fig. 5-12).

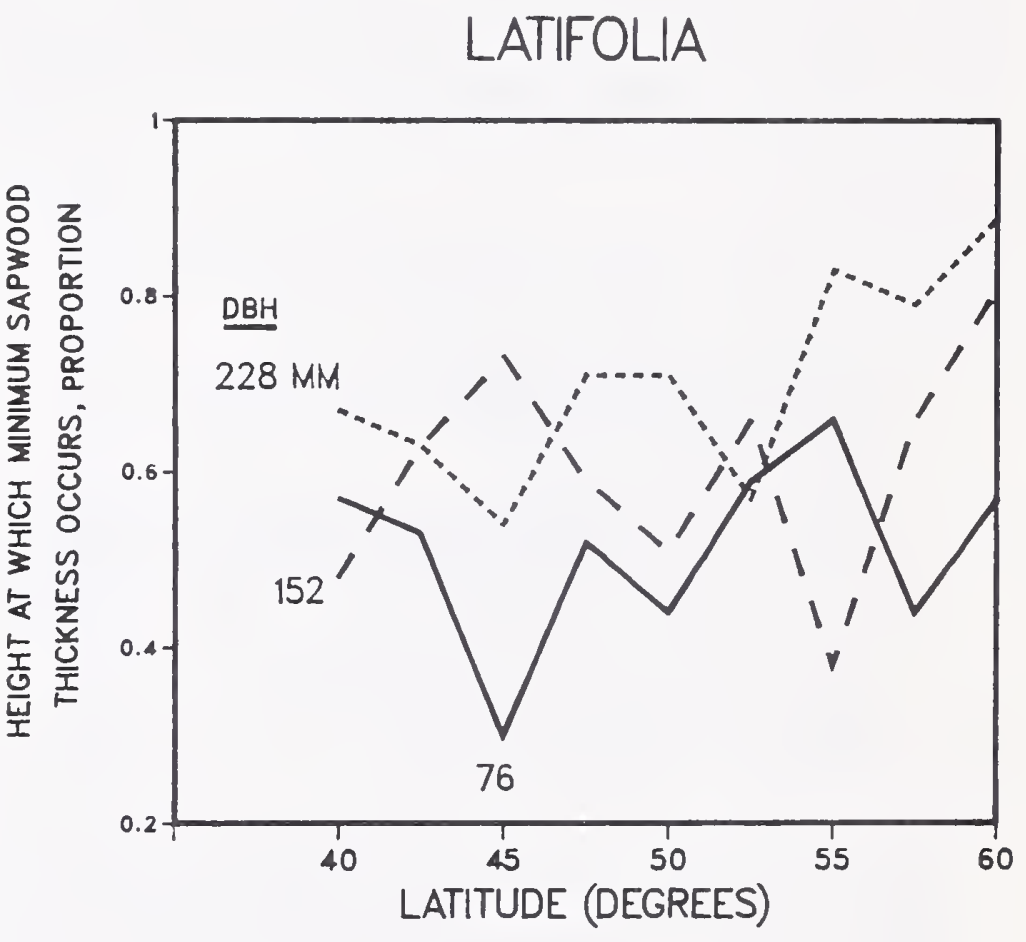

Figure 5-12-Proportion of tree height at which minimum sapwood thickness occurs in latifolia trees of three diameters, related to latitude. 
The following significant correlations (arbitrarily truncated at $r=0.200$ ) of the height of minimum sapwood thickness-where heartwood is present-expressed as percentage of tree height, with other tree statistics are of interest:

\section{Statistic}

Height in tree $(\mathrm{m})$ where sapwood thickness is minimum

Height (percent) of lowest tree disk in which heartwood does not occur

Ovendry foliage weight

Age of the lowest tree disk in which heartwood does not occur

Stemwood d.i.b. at base of live crown

Ovendry weight of live branches, wood plus bark

D.b.h.

Ovendry weight of stump-root system, wood plus bark

Height $(m)$ of lowest tree disk in which heartwood does not occur

Average branch diameter

Green weight of sapwood

Bark thickness at 152-mm stump height

Ovendry weight of sapwood

Percentage moisture content of heartwood

Ovendry weight of stem, wood plus bark

Heartwood maximum diameter

Tree age at 152-mm stump height

The foregoing tabulation suggests that the minimum sapwood thickness occurs at the highest percentage of tree height in older and larger trees having heavy stems and foliage, heavy stump-root systems, large-diameter branches, thick bark at stump height, and heavy sapwood content.

Also, percentage of tree height where minimum sapwood thickness occurs tends to be maximum in trees in which heartwood extends high in the stem, and in which heartwood has large maximum diameter and low moisture content.

\section{Height at Which Minimum Sapwood Thickness}

Occurs, Meters-The height (meters) at which minimum sapwood thickness occurred (where heartwood was present) was unrelated to elevational zone or to latitude. It was, however, positively correlated to d.b.h., as follows:

$\begin{array}{ccc}\text { D.b.h. } & \text { Height } & \begin{array}{r}\text { Standard } \\ \text { deviation }\end{array} \\ m m & \ldots \ldots \text {. . . Meters } \ldots . . . \\ 76 & 4.80 & 2.68 \\ 152 & 9.25 & 4.59 \\ 228 & 13.27 & 5.14\end{array}$

The following significant correlations (arbitrarily truncated at $r=0.300$ ) of the height (meters) at which minimum sapwood thickness occurs with other tree statistics are of interest:

\section{Statistic}

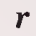

Height in tree (percent) where minimum sapwood thickness occurs

Height $(\mathrm{m})$ of lowest tree disk in which heartwood does not occur

D.b.h.

.633

Ovendry weight of sapwood

.622

Ovendry weight of stump-root system, wood plus bark

Ovendry weight of stem, wood plus bark

Green weight of sapwood

.613

Tree height

Stemwood d.i.b. at base of live crown $\quad .579$

Ovendry foliage weight

Height (percent) of lowest tree disk in which heartwood does not occur

Heartwood maximum diameter

Ovendry weight of live branches, wood plus bark

Ovendry weight of heartwood $\quad .476$

Average branch diameter $\quad .473$

Green weight of heartwood $\quad .468$

Number of live branches $\quad .464$

Age of lowest tree disk in which heartwood does not occur

Bark thickness at 152-mm stump height

Stump-root system (wood plus bark) as percentage of complete-tree weight, ovendry

Percentage moisture content of heartwood

Specific gravity of entire heartwood

Taproot length

Number of cones on tip $305 \mathrm{~mm}$ of top 25 branches

Percentage moisture content of stembark, tree average

Tree age at 152-mm stump height

The foregoing tabulation suggests that the height (meters) of minimum sapwood thickness is highest in large-diameter, tall trees with heavy stems and foliage, heavy stump-root systems with long taproots (but comprising a small percentage of complete-tree weight), numerous large and heavy branches bearing numerous cones, large stemwood diameter at the base of the live crown, and thick bark at stump height.

Also, this height is greatest in trees having heartwood that extends high up in the stem, and which have low moisture content, low specific gravity, and large maximum diameter. 


\section{Sapwood Thickness by Level}

Sapwood thickness is maximum near ground level, diminishes rapidly up to about 10 percent of tree height, then remains more or less constant up to about 70 percent of tree height, and finally diminishes with approach to the apical tip (fig. 5-13).

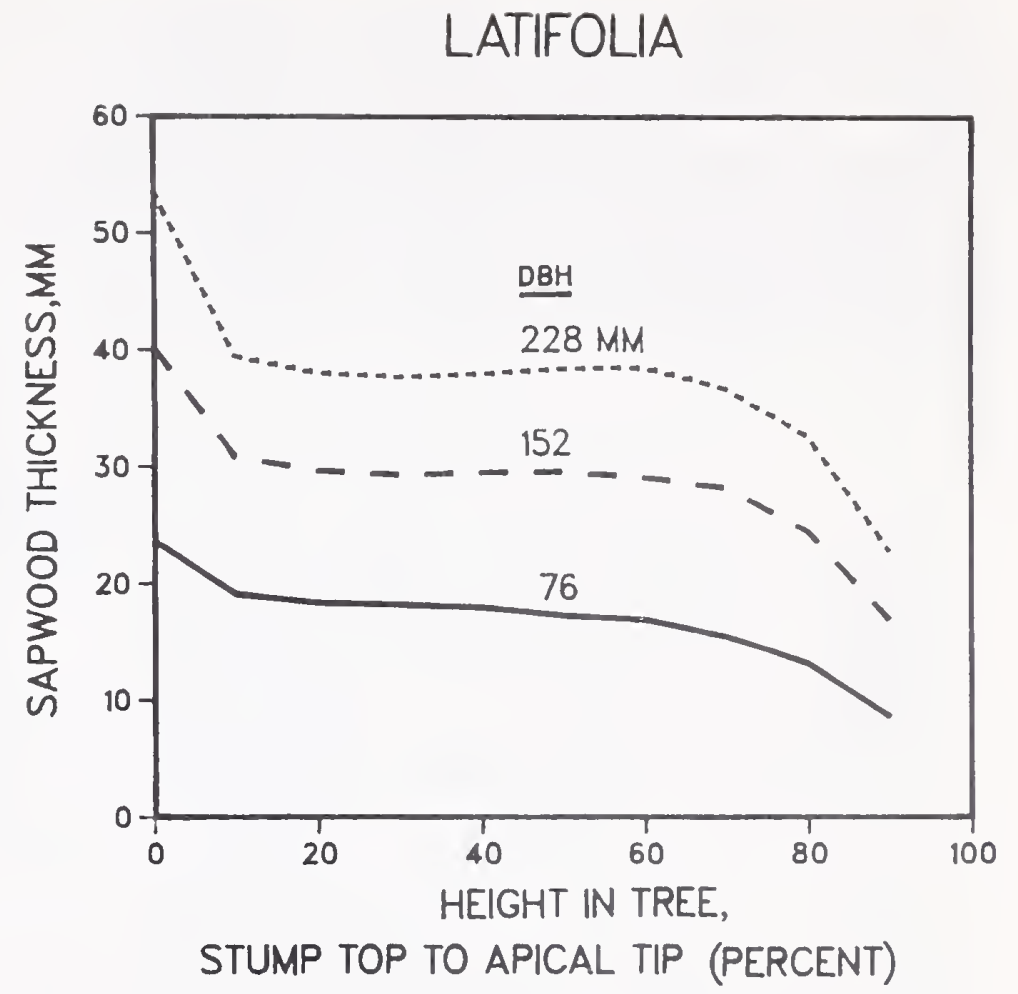

Figure 5-13-Sapwood thickness in latifolia trees of three diameters, related to height in tree. 
It was unrelated to elevational zone, but positively correlated with d.b.h., averaging-at 40 percent of tree height-17.98 (6.11), 29.59 (9.94), and 38.00 (10.91) $\mathrm{mm}$ for trees of the three diameter classes (fig. 5-13). Sapwood was thickest in the three southernmost latitudes (32 to $36 \mathrm{~mm}$ at 40 percent of tree height), and thinnest in northern latitudes (21 $\mathrm{mm}$ at 40 percent of tree height at 60 degrees latitude); see figure 5-14.

LATIFOLIA
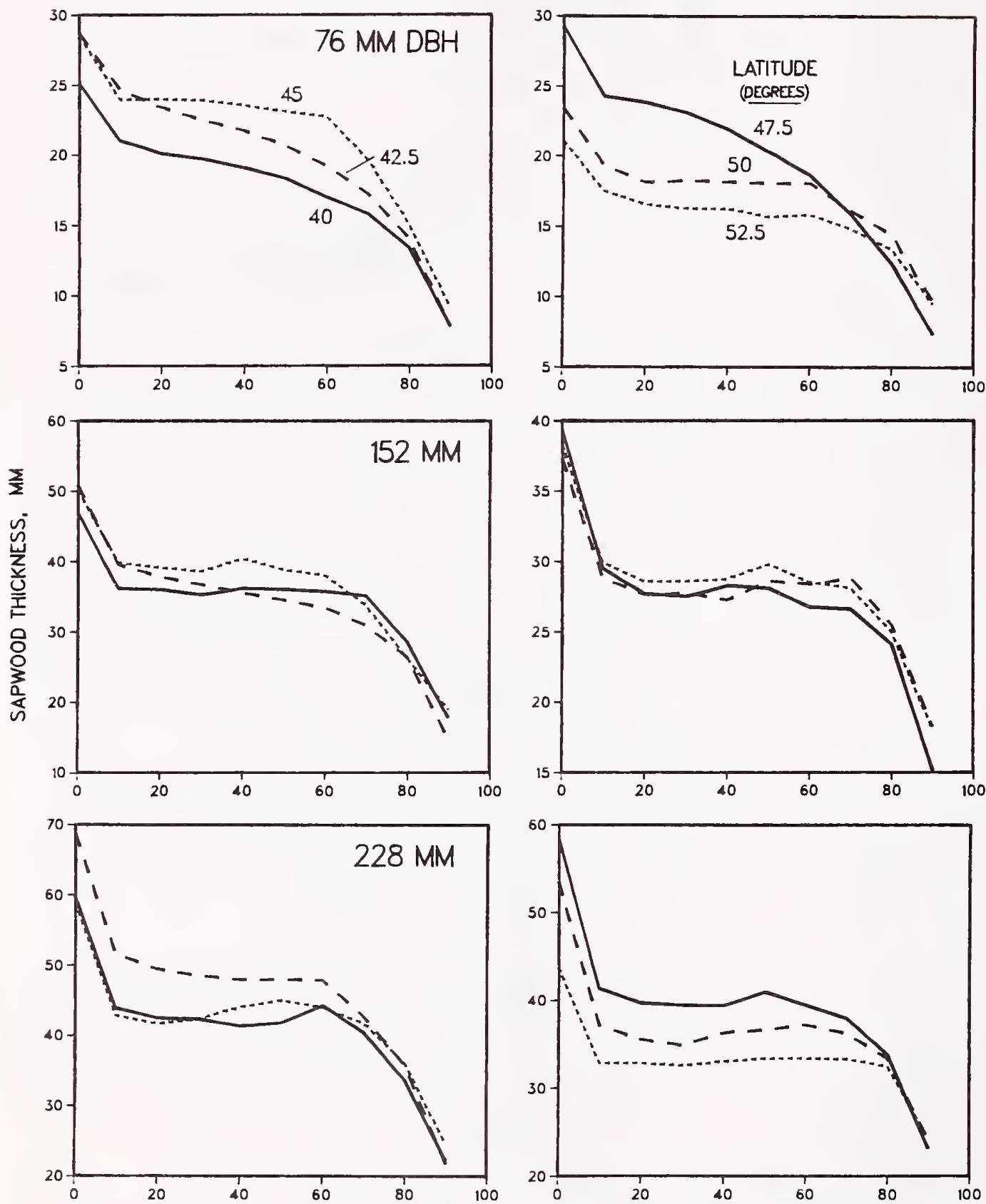

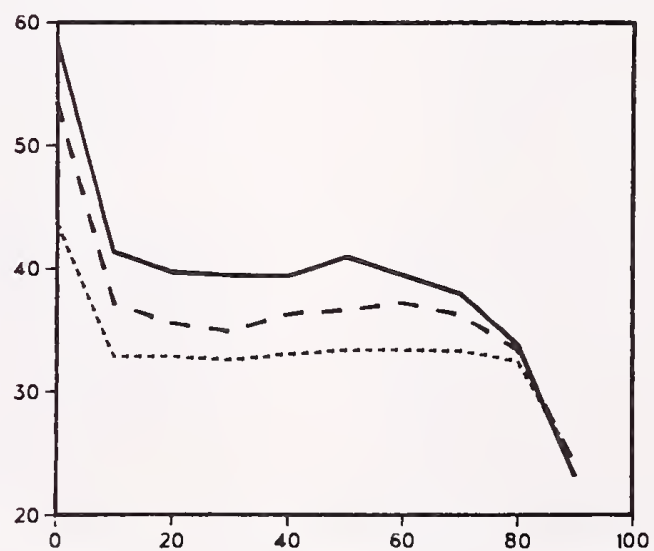

HEIGHT IN TREE,STUMP TOP TO APICAL TIP (PERCENT)
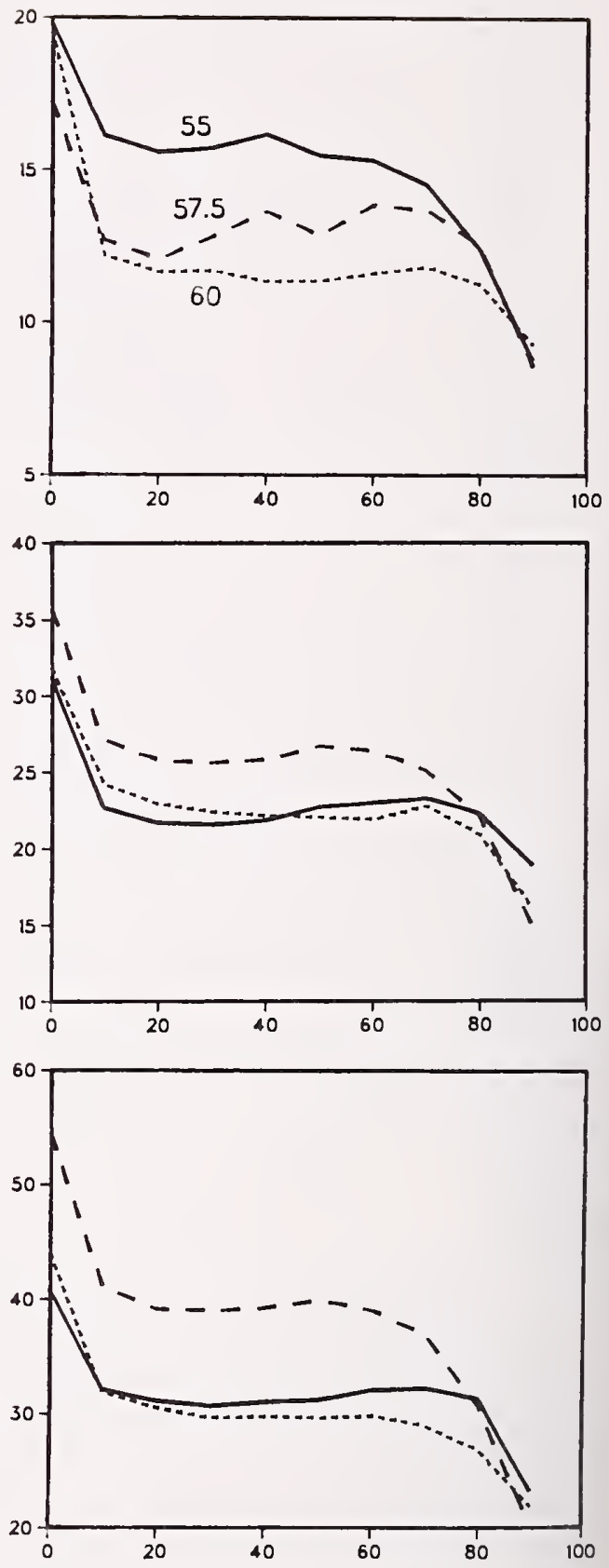

Figure 5-14-Sapwood thickness in latifolia trees of three diameters, related to height in tree and latitude. 


\section{Heartwood Volume as Percentage of Entire Stemwood Volume}

Heartwood volume as a percentage of stemwood volume was unrelated to elevational zone, but was positively correlated with d.b.h., averaging 21.96 (16.22), 28.27 (15.28), and 34.20 (13.36) percent for trees of the three diameter classes (fig. 5-15).

Percentage of heartwood volume was also positively correlated with latitude, averaging least (17.4 percent) at 45 degrees and most (41.6 percent) at 60 degrees-with diameter data pooled; see figure 5-15.

\section{LATIFOLIA}

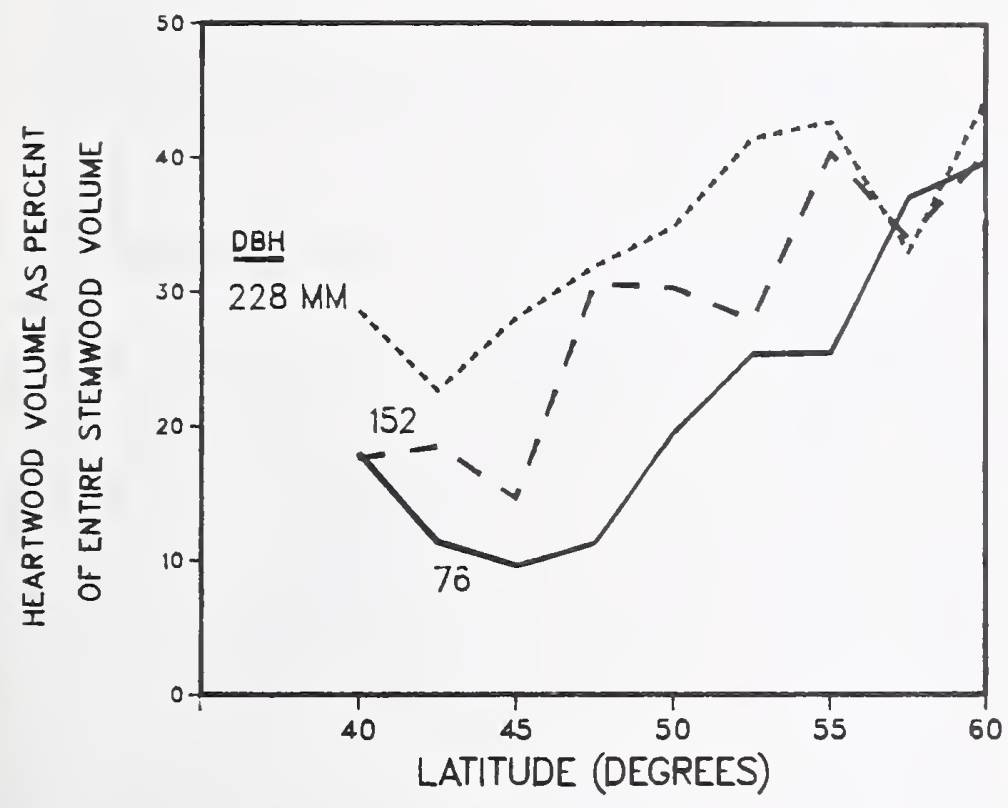

Figure 5-15-Heartwood as percentage of entire stemwood volume in latifolia trees of three diameters, related to latitude.

The following significant correlations (arbitrarily truncated at $r=0.300$ to show the numerous factors involved) of heartwood volume as percentage of stemwood volume with other tree statistics are of interest:

\section{Statistic}

$r$

Heartwood as percentage of weight of barkfree stem, ovendry

Heartwood as percentage of weight of barkfree stem, green

Heartwood as percentage of stem diameter at height of maximum heartwood diameter

Percentage moisture content of complete tree with foliage and cones

Percentage moisture content of complete tree without foliage or cones

Percentage moisture content of complete tree, wood only

Height (percent) of lowest tree disk in which heartwood does not occur

Percentage moisture content of stem, wood plus bark
Statistic

Percentage moisture content of stemwood, tree average

Heartwood maximum diameter

Percentage moisture content of wood of stump-root system

Percentage moisture content of stump-root system, wood plus bark.

Green weight of heartwood

Ovendry weight of heartwood

Foliage as percentage of complete-tree weight, ovendry

Percentage moisture content of complete tree, bark only

Percentage moisture content of stembark tree average

Stembark specific gravity

Tree age at 152 -mm stump height

Percentage moisture content of foliage-free live branches

Height $(\mathrm{m})$ of lowest tree disk in which

heartwood does not occur

Within-crown stemwood as percentage of entire stemwood volume

Crown ratio

Minimum sapwood thickness

Stem (wood plus bark) as percentage of complete-tree weight, ovendry

Percentage moisture content of bark of stump-root system

Percentage moisture content of sapwood

Within-crown average stemwood taper, $\mathrm{mm} / \mathrm{m}$

Percentage moisture content of live branchwood

Percentage moisture content of live branchbark

Tree height

Ovendry weight of stem, wood plus bark

Age of the lowest tree disk in which heartwood does not occur

Elevation, $m$

Height (percent) where maximum heartwood diameter occurs

Ovendry weight of stump-root system, wood plus bark

Average branch diameter

Height $(\mathrm{m})$ where maximum heartwood diameter occurs

D.b.h.
The foregoing tabulation suggests that percentage of heartwood volume tends to be largest in large-diameter, tall, heavy, old trees growing at low elevation (in meters as opposed to elevational zone within a latitudinal zone) with low crown ratios, large branches, and large withincrown stemwood taper.

Also, heartwood volume percentage tends to be greatest in trees of low moisture content having stembark of high specific gravity, a small percentage of complete-tree weight in foliage, but a large percentage in stemwood. 


\section{Heartwood as Percentage of Stemwood Volume by Level}

Heartwood as percentage of stemwood volume varied with height in tree; from 22 to 37 percent at $152-\mathrm{mm}$ stump height it increased to a maximum (28 to 42 percent) at about 10 percent of tree height, and then diminished more or less linearly toward the apical tip (fig. 5-16). At all levels in the tree, heartwood as percentage of stemwood volume was positively correlated with d.b.h. (fig. 5-16).

In low-elevation zones within latitudinal zones heartwood as percentage of stemwood volume was less-at all levels in the trees-than that found in medium- and highelevation zones of that latitude (fig. 5-17).

\section{LATIFOLIA}

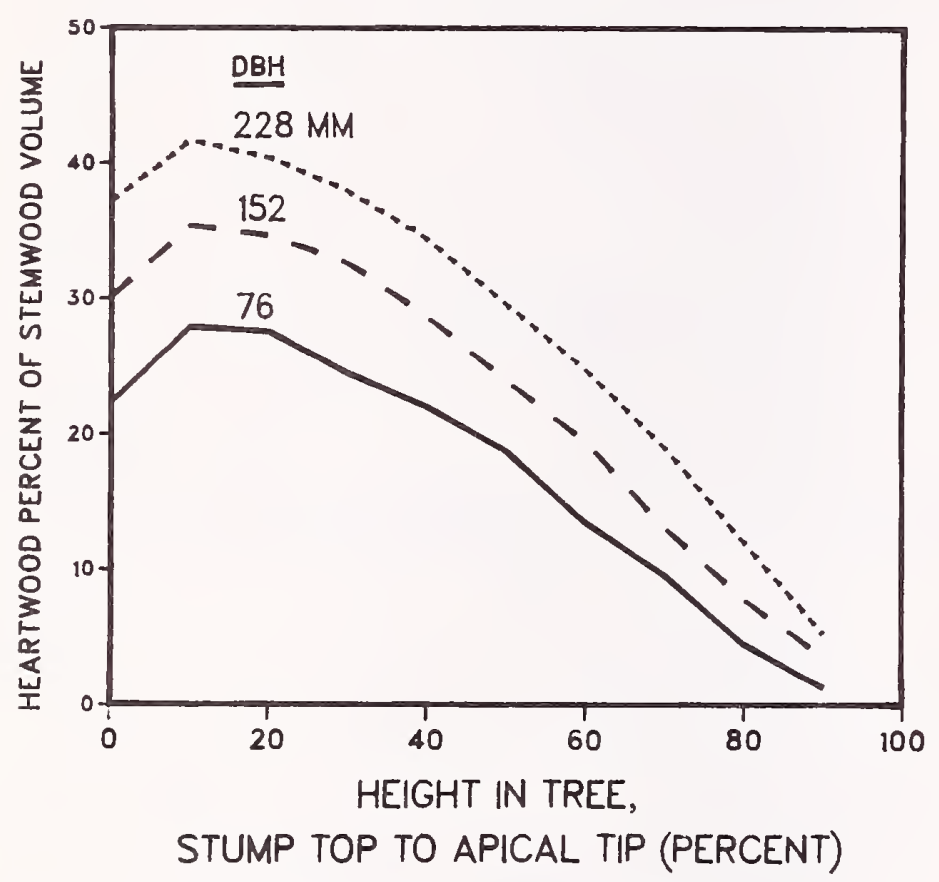

Figure 5-16- Heartwood as percentage of stemwood volume in latifolia trees of three diameters, related to height in tree.

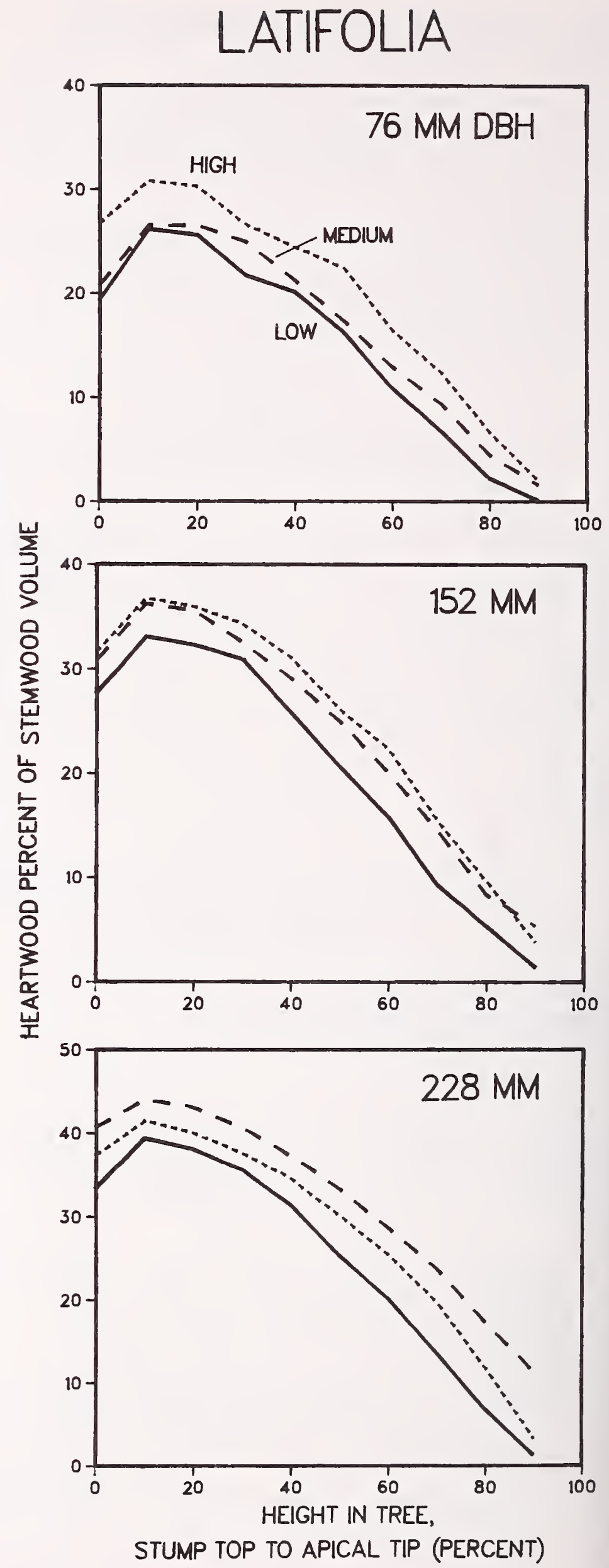

Figure 5-17-Heartwood as percentage of stemwood volume in latifolia trees of three diameters, related to height in tree and elevational zone. 
Heartwood as percentage of stemwood volume was positively correlated with latitude; for example, at 10 percent of tree height-with diameter data pooled-the percentage averaged minimum (22.6 percent) at 42.5 degrees and maximum (48.3 percent) at 60 degrees (fig. 5-18).

LATIFOLIA
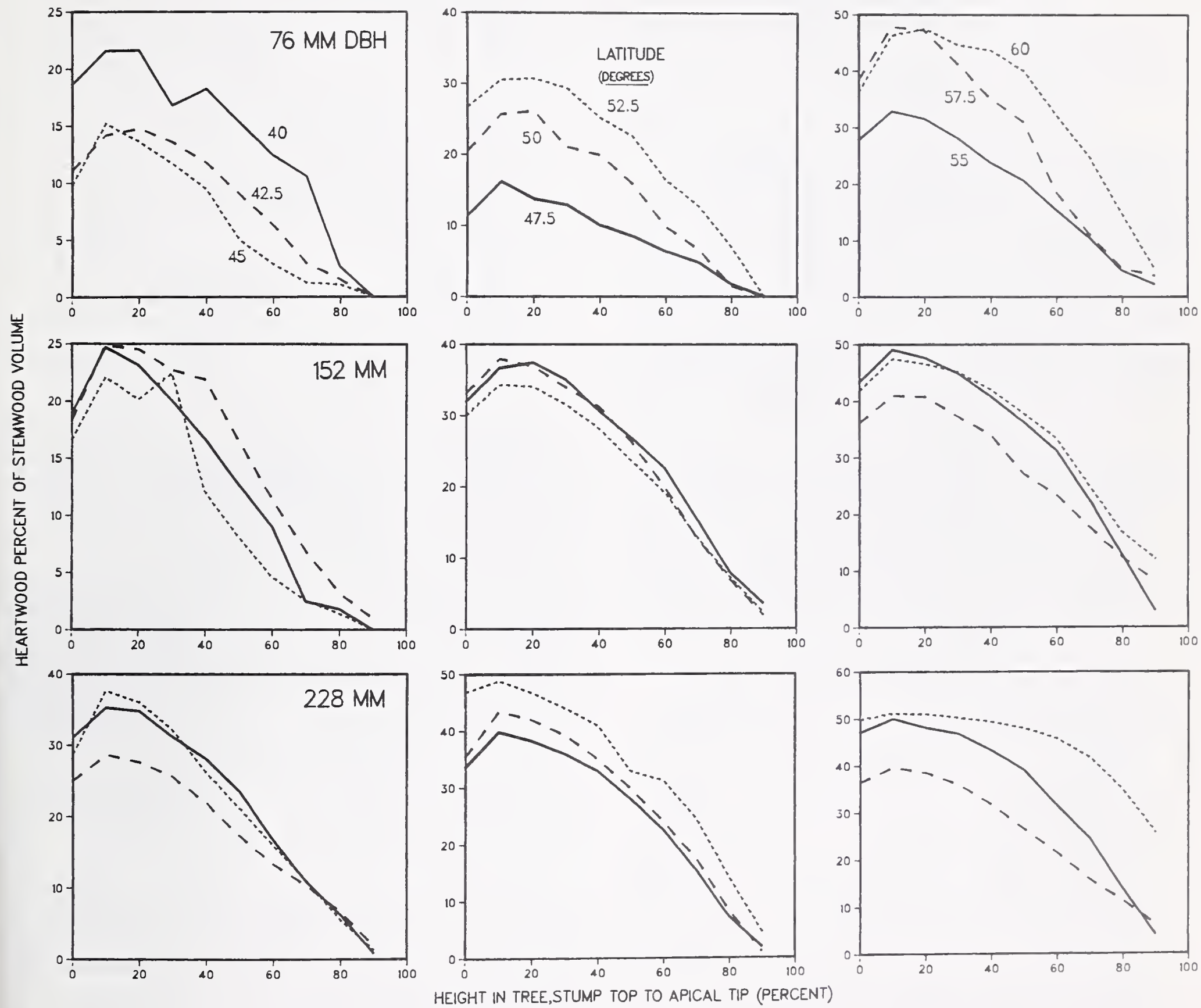

Figure 5-18-Heartwood as percentage of stem wood volume in latifolia trees of three diameters, related to height in tree and latitude. 


\section{Moisture Content of Entire Stemwood Component}

Sapwood-Sapwood moisture content was not strongly related to elevational zone within a latitudinal zone. As noted in chapter 2 , it averaged 119.3 percent, with standard deviation of 23.1 percent. The smallest trees had lowest sapwood moisture content, as follows:

\begin{tabular}{rrr} 
D.b.h. & \multicolumn{2}{c}{$\begin{array}{c}\text { Moisture content } \\
\text { and standard deviation }\end{array}$} \\
$m m$ & $\ldots \ldots$ - Percent - . - . \\
76 & 110.1 & $(28.5)$ \\
152 & 121.7 & $(18.6)$ \\
228 & 126.1 & $(17.7)$
\end{tabular}

This relationship changed at 45 degrees latitude, where trees of all three diameters had sapwood with the same moisture content, and at 47.5 degrees where sapwood moisture content was higher in $76-\mathrm{mm}$ trees than in 228-mm trees (fig. 2-21). Sapwood moisture content averaged highest at latitude 42.5 degrees (139 percent), and lowest at 55 degrees (108 percent).

The following significant correlations (arbitrarily truncated at $r=0.300$ ) of the moisture content of entire sapwood with other tree statistics are of interest:

\section{Statistic}

Percentage moisture content of stemwood, tree average

0.886

Percentage moisture content of complete tree, wood only

Percentage moisture content of stem, wood plus bark

Percentage moisture content of complete tree without foliage or cones

Percentage moisture content of complete tree with foliage and cones

Stemwood specific gravity

Specific gravity of entire sapwood

Percentage moisture content of foliage-free live branches

Percentage moisture content of wood of stump-root system

Percentage moisture content of stump-root system, wood plus bark

Percentage moisture content of live branchwood

Minimum sapwood thickness

Heartwood as percentage of weight of barkfree stem, green

Heartwood as percentage of stem diameter at height of maximum heartwood diameter

Foliage as percentage of complete-tree weight, ovendry

Percentage moisture content of live branchbark

\section{Statistic}

Heartwood as percentage of stemwood volume

Live branch (wood plus bark) as percentage of complete-tree weight, ovendry

Heartwood as percentage of weight of bark-

free stem, ovendry

$-.408$

Stem (wood plus bark) as percentage of complete-tree weight, ovendry

Percentage moisture content of complete tree, bark only

Stemwood d.i.b. at base of live crown

Elevation, $m$

.371

Crown ratio

Within-crown stemwood as percentage of entire stemwood volume

Stembark specific gravity

Percentage moisture content of bark of stump-root system

Ovendry foliage weight

Percentage moisture content of stembark, tree average

Height (percent) of lowest disk in which heartwood does not occur

Green weight of sapwood

These data suggest that sapwood moisture content tends to be greatest in trees growing at high elevation (meters) with large crown ratios, heavy foliage, and a high percentage of complete-tree weight in foliage and branches, but a low percentage in stem (wood plus bark).

Also, sapwood moisture content is maximum in trees with wide sapwood, a low volume and weight percentage of heartwood, bark of high moisture content, and low specific gravity of stemwood, sapwood, and stembark.

The moisture content of sapwood has significant positive correlation with the moisture content of the complete tree without foliage and cones $(r=0.845)$, branches including bark (0.430), and stump-root system (0.601).

Moisture content of sapwood, while significantly correlated with that of heartwood, is not closely correlated $(r=$ 0.287 ); it is not significantly correlated with foliage moisture content.

Heartwood-Moisture content of heartwood was not significantly related to elevational zone within a latitudinal zone. As noted in chapter 2, heartwood moisture content was much less than that of sapwood; it averaged 43.4 percent, with standard deviation of 5.7 percent. Heartwood moisture content was inversely correlated with d.b.h., averaging 47.2 (6.9), 41.9 (3.8), and 40.9 (3.8) percent in trees 76,152 , and $228 \mathrm{~mm}$ in d.b.h.

In contrast with sapwood, the smallest trees had highest heartwood moisture content at all latitudes; variation with latitude was less pronounced in heartwood than in sapwood-especially in larger trees (fig. 2-22). 
The following significant correlations (arbitrarily truncated at $r=0.300$ ) of the moisture content of entire heartwood with other tree statistics are of interest:

\section{Statistic}

$r$

Percentage moisture content of stembark, tree average

Percentage moisture content of complete tree (bark only)

Height (m) of lowest disk in which heartwood does not occur

Tree height

Height (percent) of lowest disk in which heartwood does not occur

Percentage moisture content of complete tree with foliage and cones

Percentage moisture content of complete tree without foliage or cones

Ovendry weight of sapwood

Percentage moisture content of stem, wood plus bark

D.b.h.

Stembark specific gravity

Ovendry weight of stem, wood plus bark

Foliage as percentage of complete-tree weight, ovendry

Ovendry weight of stump-root system, wood plus bark

Green weight of sapwood

Heartwood maximum diameter

Percentage moisture content of complete tree, wood only

Percentage moisture content of stemwood, tree average

Percentage moisture content of bark of stump-root system

Percentage moisture content of stump-root system, wood plus bark

Height in tree $(\mathrm{m})$ where minimum sapwood thickness occurs

Percentage moisture content of wood of stump-root system

Heartwood as percentage of stem diameter at height of maximum heartwood diameter

Stem (wood plus bark) as percentage of complete-tree weight, ovendry

Stump-root system (wood plus bark) as percentage of complete-tree weight, ovendry

Stemwood d.i.b. at base of live crown

Specific gravity of entire sapwood

Bark thickness at 152-mm stump height

Within-crown stemwood as percentage of entire stemwood rolume

Ovendry foliage weight

Ovendry weight of heartwood

Number of live branches

Stemwood specific gravity

Ovendry weight of live branches, wood plus bark
$-.441$

$-.440$

$-.435$
Statistic $r$

Heartwood as percentage of stemwood volume

Green weight of heartwood

$-.304$

Taproot length

The foregoing data suggest that heartwood moisture content tends to be greatest in short, small-diameter trees with few branches of light weight, and stump-root systems (with short taproots) and foliage that comprise a large percentage of complete-tree weight.

As noted previously, heartwood moisture content is not significantly correlated with sapwood moisture content. It is, however, significantly and positively correlated with the moisture content of stembark $(r=0.560)$, complete tree (0.469), and wood of the stump-root system (0.383).

It is negatively correlated with sapwood ovendry weight $(r=-0.468)$, stembark specific gravity $(-0.448)$, heartwood maximum diameter $(-0.435)$, ovendry weight of heartwood $(-0.324)$, stemwood specific gravity $(-0.322)$, and both ovendry weight of heartwood and heartwood as percentage of stemwood volume $(-0.323$ and -0.311 , respectively).

Surprisingly, heartwood moisture content is not significantly correlated with heartwood specific gravity.

\section{Moisture Content of Sapwood by Level}

Sapwood moisture content was least (averaging 110 percent) in the lowest 10 percent of the tree stems, increased more or less linearly to a maximum (averaging 136 percent) at about 80 percent of tree height, and then diminished slightly toward the apical tip (fig. 5-19).

Sapwood moisture content was positively correlated with d.b.h. at all heights in the trees (fig. 5-19).

\section{LATIFOLIA}

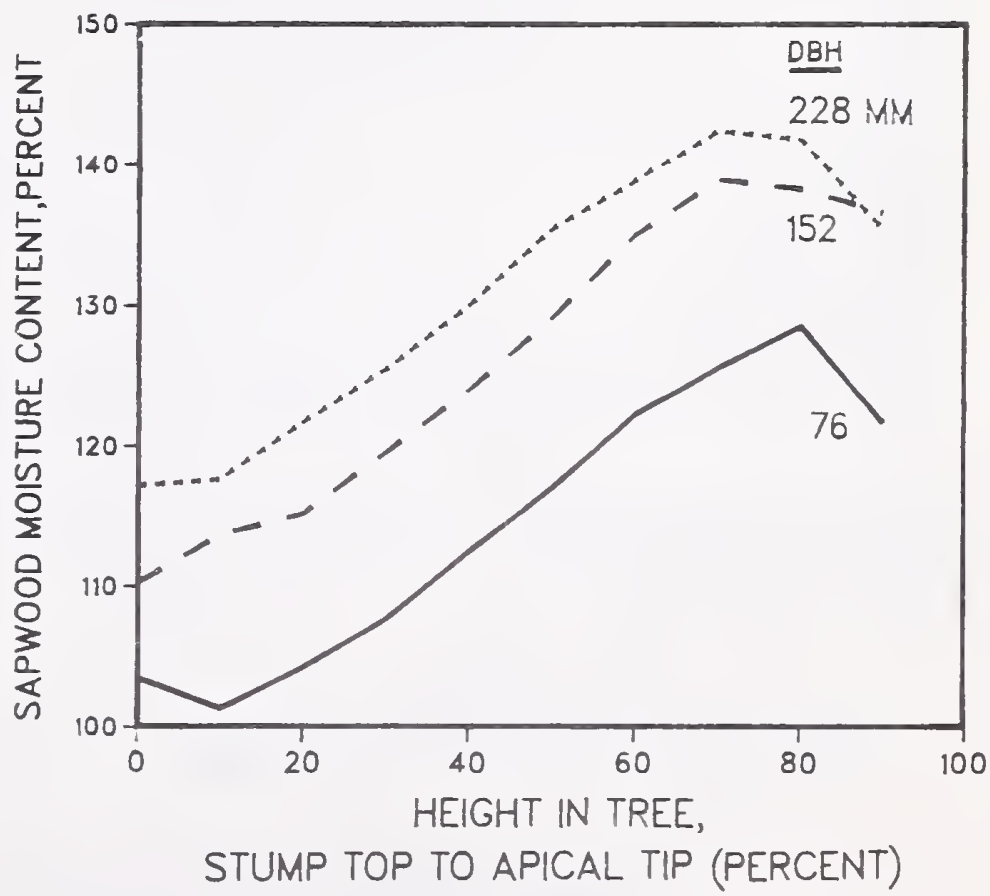

Figure 5-19-Sapwood moisture content in latifolia trees of three diameters, related to height in tree. 
Sapwood moisture content at most levels was negatively correlated with latitude. For example, at 40 percent of tree height sapwood moisture content averaged 146 percent at 42.5 degrees latitude (diameter data pooled), but averaged only 115 percent at 60 degrees (fig. 5-20).

\section{LATIFOLIA}
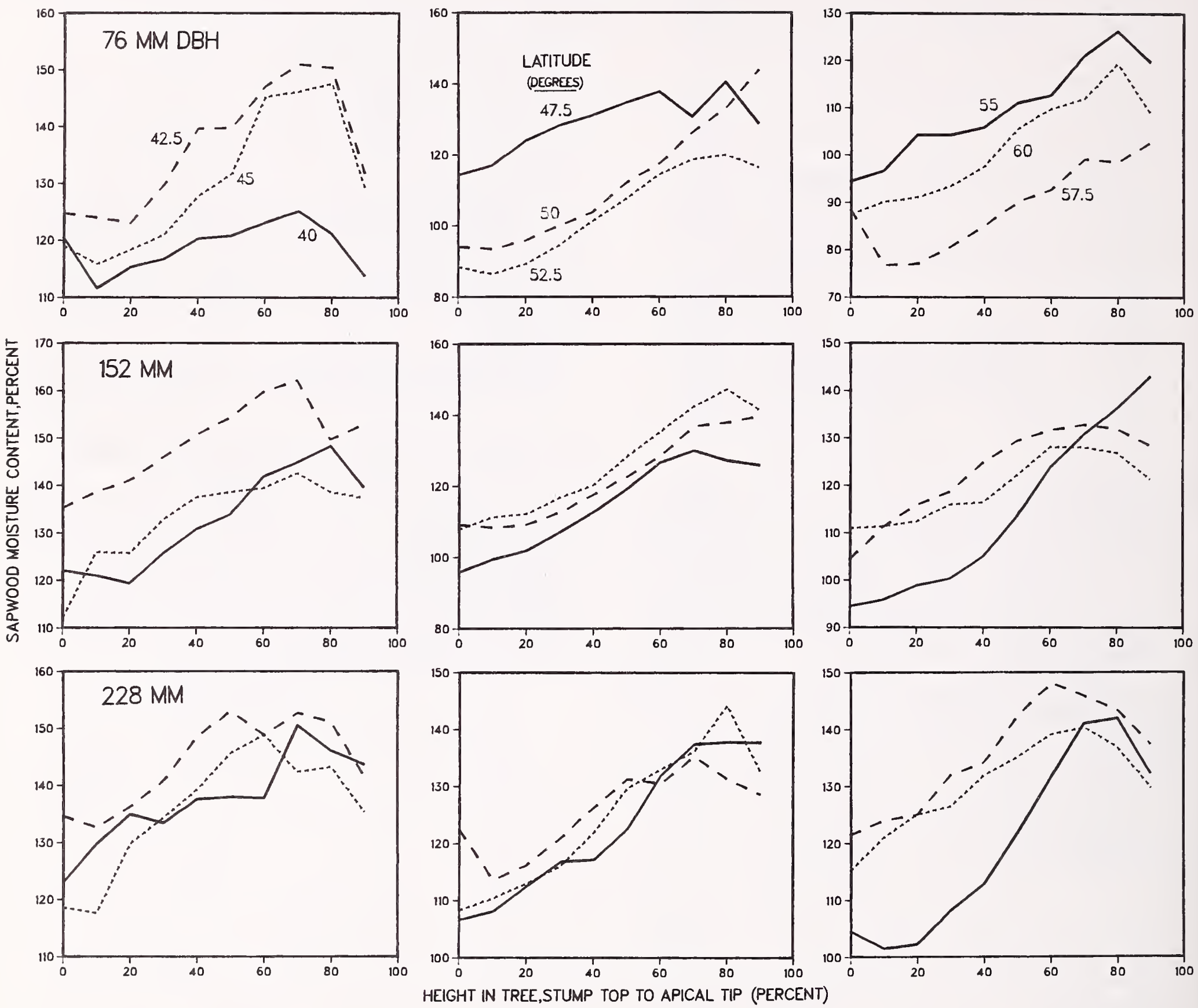

Figure 5-20-Sapwood moisture content in latifolia trees of three diameters, related to height in tree and latitude. 


\section{Moisture Content of Heartwood by Level}

Heartwood moisture content was minimum (averaging 42 percent with diameter data pooled) at 152-mm stump height, and increased curvilinearly to a maximum (averag. ing 52 percent) at 90 percent of tree height (fig. 5-21).

Below about 70 percent of tree height, heartwood in 152- and 228-mm trees had moisture content positively correlated with elevational zone (fig. 5-22).

\section{LATIFOLIA}

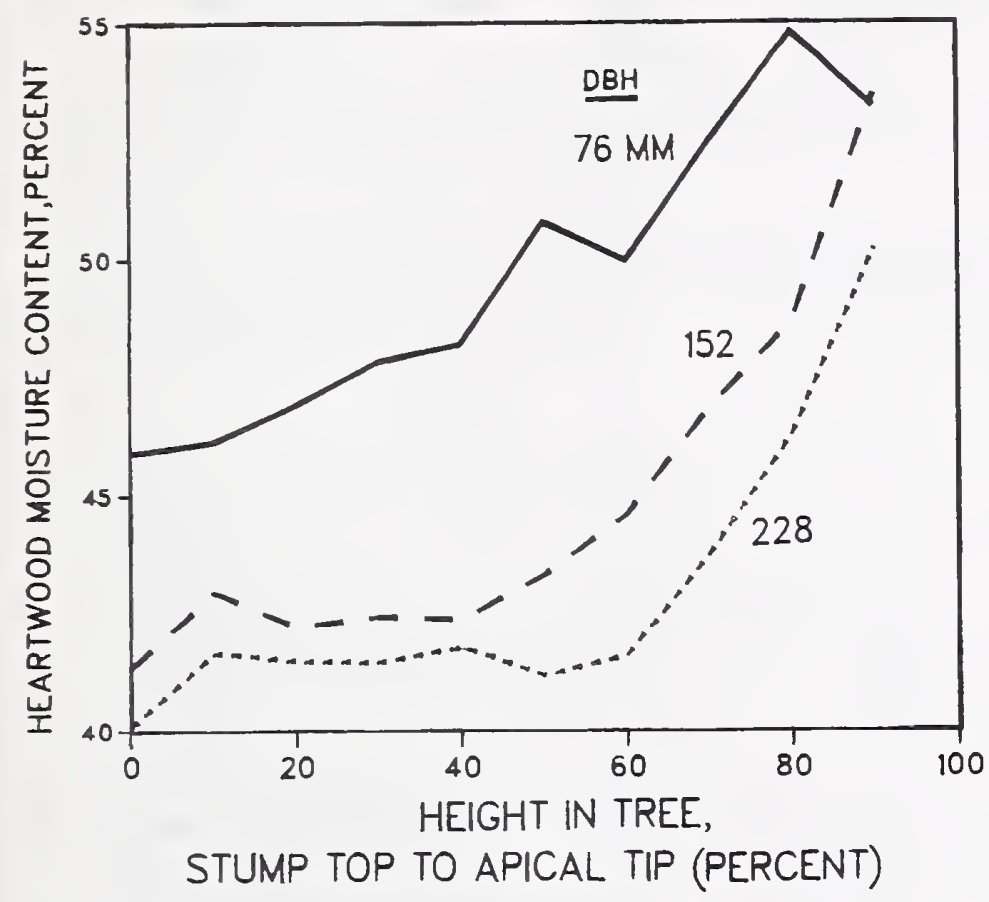

Figure 5-21-Heartwood moisture content in latifolia trees of three diameters, related to height in tree.
LATIFOLIA
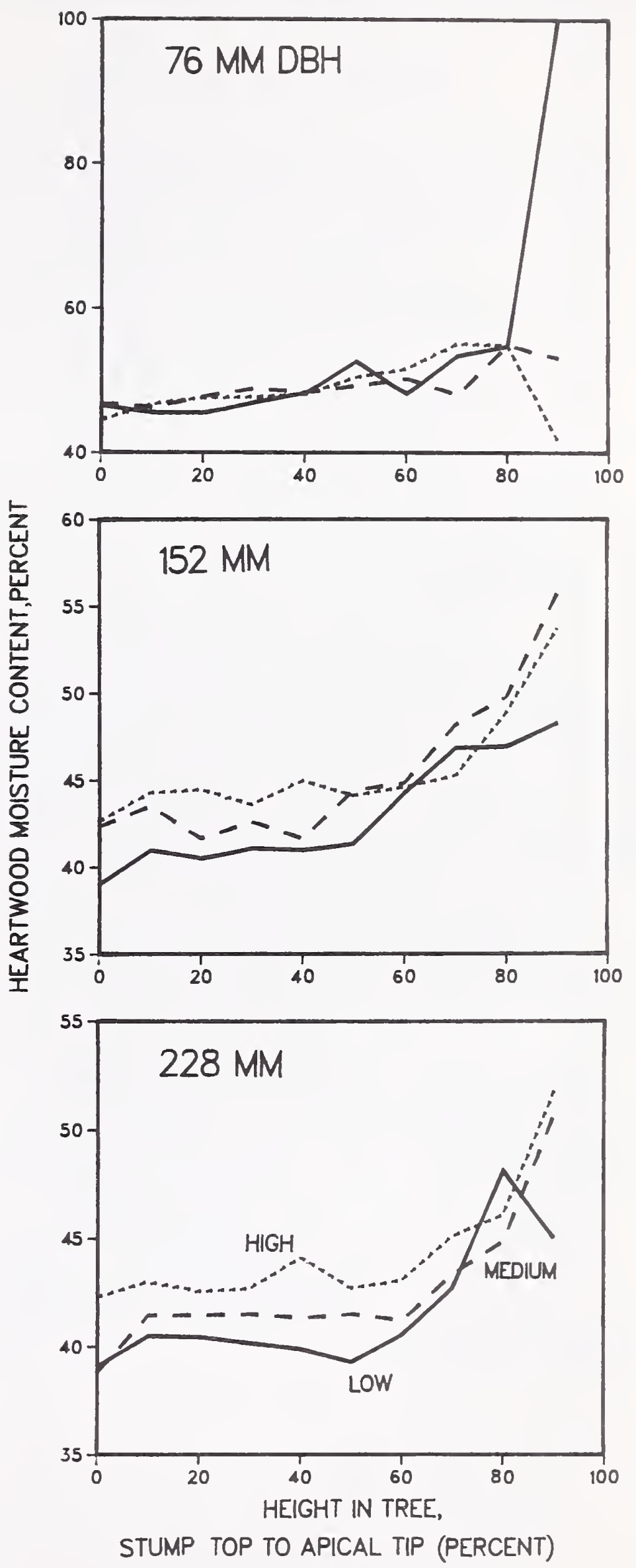

Figure 5-22-Heartwood moisture content in latifolia trees of three diameters, related to height in tree and elevational zone. 
The relationships between latitude and heartwood moisture content at various heights in the trees were complex, and differed with d.b.h. (fig. 5-23).

LATIFOLIA
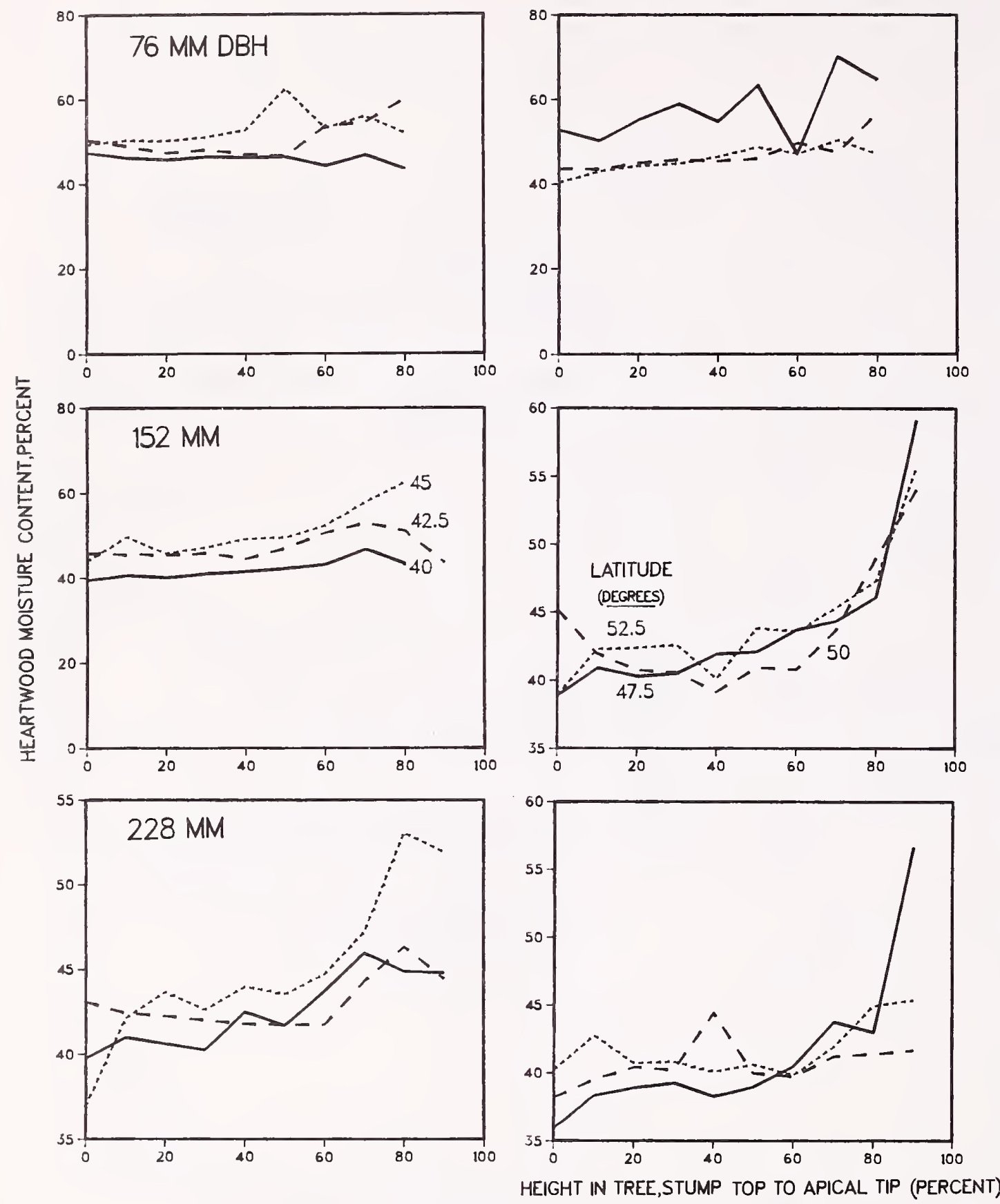
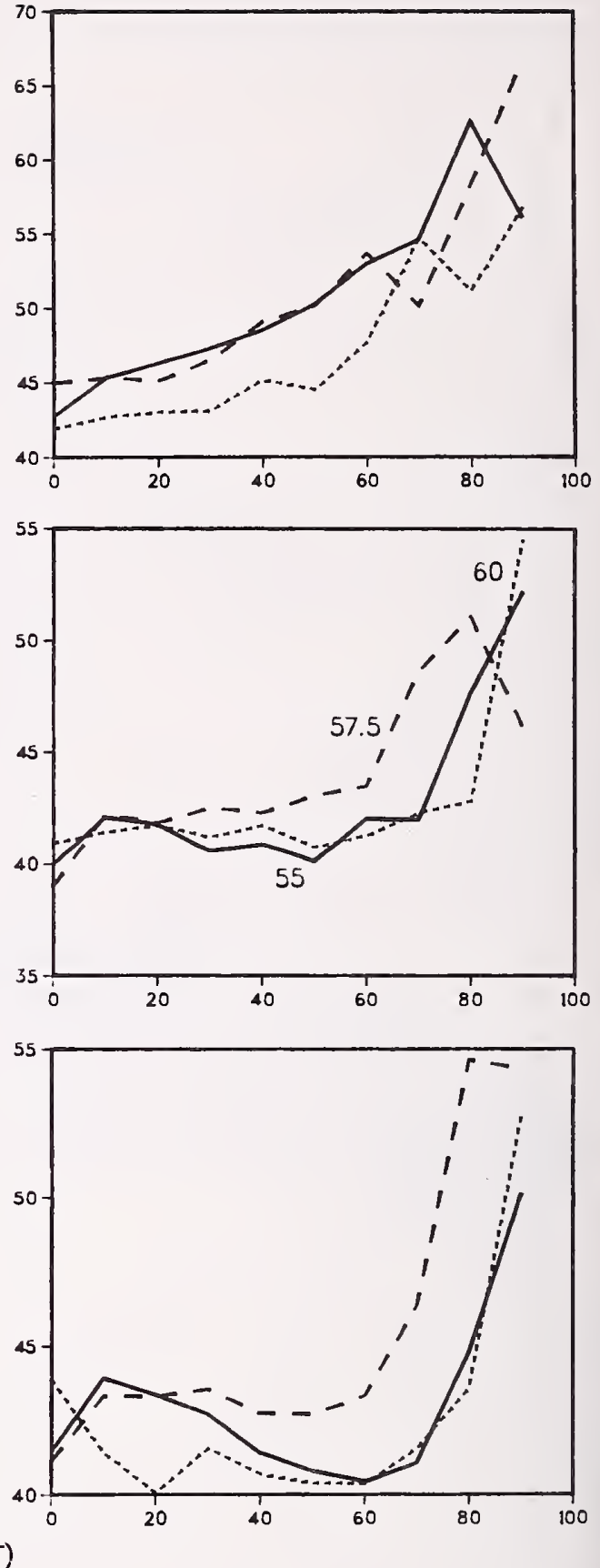

Figure 5-23-Heartwood moisture content in latifolia trees of three diameters, related to height in tree and latitude. 


\section{Weight of Sapwood in Entire Stem}

Green-As noted in chapter 4, sapwood green weight was positively correlated with d.b.h. (fig. 4-59), averaging 14.37 (4.27), 91.34 (23.70), and $226.16(60.87) \mathrm{kg}$ for trees of the three diameter classes. It was negatively correlated with elevational zone, particularly in $228-\mathrm{mm}$ trees, as follows:

$\begin{array}{lccc}\begin{array}{c}\text { Elevational } \\ \text { zone }\end{array} & \begin{array}{c}\mathbf{7 6} \mathbf{~ m m} \\ \text { d.b.h. }\end{array} & \begin{array}{c}\text { 152 } \mathbf{~ m m} \\ \text { d.b.h. }\end{array} & \begin{array}{c}\text { 228 } \mathbf{~ m m} \\ \text { d.b.h. }\end{array} \\ & -\ldots \ldots & - \text { Kilograms } & -\ldots .- \\ \text { Low } & 15.19 & 94.82 & 248.38 \\ \text { Medium } & 14.39 & 94.61 & 221.86 \\ \text { High } & 13.53 & 84.60 & 208.23\end{array}$

Sapwood green weight was also negatively correlated with latitude, diminishing slightly in northern latitudes

(fig. 4-59).

The following significant correlations (arbitrarily truncated at $r=0.300$ ) of the green weight of sapwood with other tree statistics are of interest:

\begin{tabular}{lc}
\multicolumn{1}{c}{ Statistic } & $r$ \\
Ovendry weight of sapwood & 0.992 \\
Ovendry weight of stem, wood plus bark & .926 \\
D.b.h. & .907 \\
Ovendry weight of stump-root system, wood & \\
plus bark & .899 \\
Stemwood d.i.b. at base of live crown & .843 \\
Tree height & .835 \\
Ovendry foliage weight & .823 \\
Ovendry weight of live branches, wood plus & \\
bark & .776 \\
Height (m) of lowest tree disk in which & .770 \\
heartwood does not occur & .694 \\
Number of live branches & .680 \\
Heartwood maximum diameter & .685 \\
Average branch diameter & .652 \\
Taproot length & .652 \\
Minimum sapwood thickness & .648 \\
Ovendry weight of heartwood & .637 \\
Green weight of heartwood & \\
Average growth-ring width at 152-mm & .618 \\
stump height & \\
Height in tree (m) where minimum sapwood & \\
thickness occurs & .613
\end{tabular}

\section{Statistic}

Stump-root system (wood plus bark) as percentage of complete-tree weight, ovendry $\quad-.588$

Bark thickness at 152-mm stump height

Number of cones on tip $305 \mathrm{~mm}$ of top 25 branches

Ovendry weight of dead branches

Specific gravity of entire heartwood

Percentage moisture content of heartwood $\quad-.440$

Within-crown average stemwood taper, $\mathrm{mm} / \mathrm{m}$

Percentage moisture content of stembark, tree average

Height (percent) of lowest tree disk in which heartwood does not occur

Below-crown average stemwood taper, $\mathrm{mm} / \mathrm{m}$

Percentage moisture content of sapwood

Sapwood green weights are obviously positively correlated with d.b.h. $(r=0.907)$, with tree height $(0.835)$, and with sapwood moisture content $(0.305)$.

Also, sapwood green weights are maximum in fastgrowing trees with heavy foliage and numerous large, heavy live branches bearing numerous cones, heavy dead branches, and thick bark at stump height-all of which are attributes of many large, tall trees. Additionally, sapwood green weights tend to be greatest in trees with long taproots, large stemwood diameter at the base of the live crown, and large stemwood taper-both within and below crown.

Sapwood green weights are negatively correlated with stump-root as percentage of complete-tree weight $(r=$ $-0.588)$, heartwood specific gravity $(-0.522)$, heartwood moisture content $(-0.440)$, and stembark moisture content $(-0.366)$.

Ovendry-As noted in chapter 4, ovendry sapwood weight was positively correlated with d.b.h., averaging $6.89(2.00), 41.45(10.78)$, and $99.81(24.88) \mathrm{kg}$ for trees of the three diameter classes. In $228-\mathrm{mm}$ trees, ovendry sapwood weight was negatively correlated with elevational zone, averaging 109.91, 98.13, and $91.40 \mathrm{~kg}$ in low, medium, and high zones, respectively.

As with green sapwood weight, ovendry weight had a slight negative correlation with latitude (fig. 4-60). 
The following significant correlations (arbitrarily truncated at $r=0.300$ ) of the ovendry weight of sapwood with other tree statistics are of interest:

\section{Statistic}

$r$

Green weight of sapwood

Ovendry weight of stem, wood plus bark

D.b.h.

Ovendry weight of stump-root system, wood plus bark

0.992

.952

.916

Tree height

.916

.867

Stemwood d.i.b. at base of live crown

Height $(\mathrm{m})$ of lowest tree disk in which

heartwood does not occur

Ovendry foliage weight

Ovendry weight of live branches, wood plus bark

Heartwood maximum diameter

Ovendry weight of heartwood

Number of live branches

Average branch diameter

Green weight of heartwood

Taproot length

Height in tree $(\mathrm{m})$ where minimum sapwood thickness occurs

Minimum sapwood thickness

Average growth-ring width at $152-\mathrm{mm}$ stump height

Stump-root system (wood plus bark) as percentage of complete-tree weight, ovendry

Bark thickness at $152-\mathrm{mm}$ stump height

Number of cones on tip $305 \mathrm{~mm}$ of top 25 branches

Ovendry weight of dead branches

Specific gravity of entire heartwood

Percentage moisture content of heartwood

Percentage moisture content of stembark, tree average

Height (percent) of lowest tree disk in which heartwood does not occur

Within-crown average stemwood taper, $\mathrm{mm} / \mathrm{m}$

Below-crown average stemwood taper, $\mathrm{mm} / \mathrm{m}$

Percentage moisture content of complete tree, bark only

Sapwood ovendry weights, like sapwood green weights, are positively correlated with d.b.h. $(r=0.916)$, and with tree height (0.867). Also, sapwood ovendry weights are maximum in fast-growing trees with heavy foliage and numerous large, heavy live branches bearing numerous cones, heavy dead branches, and thick bark at stump height-all of which are frequently attributes of large, tall trees.

As with green weights, sapwood ovendry weights are also greatest in trees with long taproots, large stemwood diameter at the base of the live crown, and large stemwood taper-both within and below crown.
Sapwood ovendry weights are negatively correlated with stump-root system percentage of complete-tree weight $(r=-0.602)$, specific gravity of entire heartwood $(-0.502)$, percentage moisture content of heartwood $(-0.468)$, and percentage moisture content of bark of complete tree $(-0.320)$.

\section{Weight of Heartwood in Entire Stem}

Green-As noted in chapter 4, weight of green heartwood was positively correlated with d.b.h. (fig. 4-61), averaging 3.26 (2.51), 25.28 (16.15), and $76.85(37.92) \mathrm{kg}$ for trees 76, 152, and $228 \mathrm{~mm}$ in d.b.h. Generally it was also positively correlated with elevational zone, averaging as follows for trees of the three diameters:

$\begin{array}{lccc}\begin{array}{c}\text { Elevational } \\ \text { zone }\end{array} & \mathbf{7 6} \mathbf{~ m m} & \mathbf{1 5 2} \mathbf{~ m m} & \mathbf{2 2 8} \mathbf{~ m m} \\ & \ldots \ldots & \text { Kilograms } & \ldots . \\ \text { Low } & 2.94 & 22.02 & 73.74 \\ \text { Medium } & 3.28 & 26.34 & 81.32 \\ \text { High } & 3.56 & 27.46 & 75.50\end{array}$

Green heartwood weight was also positively correlated with latitude; the relationship was most pronounced in large trees (fig. 4-61).

The following significant relationships (arbitrarily truncated at $r=0.400$ ) of the green weight of heartwood with other tree statistics are of interest:

\begin{tabular}{lr}
\multicolumn{1}{c}{ Statistic } & $r$ \\
Ovendry weight of heartwood & 0.999 \\
Heartwood maximum diameter & .911 \\
Ovendry weight of stem, wood plus bark & .874 \\
Height (m) of lowest tree disk in which & \\
heartwood does not occur & .809 \\
Ovendry weight of stump-root system, wood & \\
plus bark & .804 \\
D.b.h. & .773 \\
Tree height & .767 \\
Average branch diameter & .708 \\
Ovendry weight of sapwood & .686 \\
Green weight of sapwood & .637 \\
Heartwood as percentage of stemwood & .635 \\
volume &
\end{tabular}

Heartwood as percentage of stemwood weight, ovendry

Ovendry weight of live branches, wood plus bark

Stemwood d.i.b. at base of live crown

Heartwood as percentage of bark-free stem, green

Heartwood as percentage of stem diameter at height of maximum heartwood diameter

Ovendry foliage weight

Percentage moisture content of stembark, tree average

Height (percent) of lowest tree disk in which heartwood does not occur

Tree age at 152-mm stump height

Number of cones on tip $305 \mathrm{~mm}$ of top 25 branches 


\section{Statistic}

Stump-root system (wood plus bark) as percentage of complete-tree weight, ovendry

$-.504$

Within-crown average stem taper, $\mathrm{mm} / \mathrm{m}$

Percentage moisture content of complete tree, bark only

Height in tree $(\mathrm{m})$ where minimum sapwood thickness occurs

Ovendry weight of dead branches

.443

Taproot length

Age of the lowest tree disk in which heartwood does not occur

Foliage as percentage of complete-tree weight, ovendry

Stembark specific gravity

Number of live branches

Heartwood green weights, in addition to being positively correlated with d.b.h. $(r=0.773)$, tree height $(0.767)$, heartwood maximum diameter (0.911), and heartwood height in tree (0.809), are also positively correlated with the ovendry weight of the stump-root system (0.804), live branch weight (0.590), stemwood diameter at the base of the live crown (0.582), and foliage weight (0.523).

Heartwood green weight is negatively correlated with foliage percent of complete-tree ovendry weight, however.

Additionally, heartwood green weight tends to be greatest in trees with numerous cones, large within-crown taper, heavy dead branches, long taproots, dense stembark, and numerous large live branches.

Heartwood green weight is negatively correlated with stembark percentage moisture content $(r=-0.520)$, stump-root system percent of complete-tree weight $(-0.504)$, and age of lowest tree disk in which heartwood does not occur $(-0.423)$.

Ovendry-As noted in chapter 4 , ovendry heartwood weight was also positively correlated with d.b.h. (fig. 4-62), averaging 2.25 (1.78), 17.86 (11.34), and $54.27(26.23) \mathrm{kg}$ for trees of the three diameter classes. It was also generally positively correlated with elevational zone, averaging as follows for trees of the three diameters:

$\begin{array}{lccc}\begin{array}{c}\text { Elevational } \\ \text { zone }\end{array} & \mathbf{7 6} \mathrm{mm} & \text { 152 } \mathrm{mm} & \mathbf{2 2 8} \mathrm{mm} \\ & \ldots \ldots & \text { Kilograms } & \ldots . . \\ \text { Low } & 2.02 & 15.83 & 52.61 \\ \text { Medium } & 2.29 & 18.65 & 57.59 \\ \text { High } & 2.46 & 19.09 & 52.61\end{array}$

As with green heartwood, weight of ovendry heartwood was positively correlated with latitude; the relationship was most pronounced in trees of large diameter (fig. 4-62).

The following significant correlations (arbitrarily truncated at $r=0.400$ ) of the ovendry weight of entire heartwood with other tree characteristics are of interest:
Statistic

Green weight of heartwood

Heartwood maximum diameter

Ovendry weight of stem, wood plus bark

Height $(\mathrm{m})$ of lowest tree disk in which

heartwood does not occur

Ovendry weight of stump-root system, wood plus bark

D.b.h.

Tree height

Average branch diameter $\quad .706$

Ovendry weight of sapwood $\quad .697$

Green weight of sapwood

Heartwood as percentage of stemwood volume

Heartwood as percentage of stemwood weight, ovendry

Ovendry weight of live branches, wood plus bark

Stemwood d.i.b. at base of live crown

Heartwood as percentage of stemwood weight, green

Heartwood as percentage of stem diameter at point of maximum heartwood diameter

Ovendry foliage weight

Percentage moisture content of stembark, tree average

Height (percent) of lowest tree disk in which heartwood does not occur

Number of cones on tip $305 \mathrm{~mm}$ of top 25

branches

Stump-root system as percentage of complete-tree weight, ovendry

Tree age at $152-\mathrm{mm}$ stump height

Within-crown average stemwood taper, $\mathrm{mm} / \mathrm{m}$

Percentage moisture content of complete tree, bark only

Height in tree $(\mathrm{m})$ where minimum sapwood thickness occurs

Ovendry weight of dead branches

Taproot length

Foliage as percentage of complete-tree weight, ovendry

Age of the lowest tree disk in which heartwood does not occur

Number of live branches

Stembark specific gravity

These correlations vary only slightly from the tabulation for green heartwood weights, so the comments made about green heartwood weight relationships apply equally to ovendry weight of heartwood. 


\section{Heartwood as Percentage of Weight of Entire Stemwood}

Green-Heartwood as percentage of green stemwood was positively correlated with d.b.h., averaging 18.4 (14.6), 21.6 (13.4), and 25.7 (11.9) percent for trees 76, 152, and $228 \mathrm{~mm}$ in diameter (fig. 5-24). Generally it was also positively correlated with elevational zone within a latitudinal zone, averaging as follows for trees of the three diameters (see also fig. 5-26):

$\begin{array}{lccc}\begin{array}{c}\text { Elevational } \\ \text { zone }\end{array} & \mathbf{7 6} \mathbf{~} \mathbf{m m} & \begin{array}{c}152 \mathbf{~ m m} \\ \text { Low }\end{array} & \mathbf{2 2 8} \mathbf{~ m m} \\ \text { Medium } & 16.5 & 18.9 & 23.2 \\ \text { High } & 17.7 & 22.2 & 27.6 \\ & 21.0 & 23.8 & 26.4\end{array}$

In all three diameter classes heartwood as percentage of green stemwood weight was positively correlated with latitude (fig. 5-24). With diameter data pooled, heartwood content was minimum at 42.5 degrees (13.0 percent) and maximum at 60 degrees (33.9 percent).

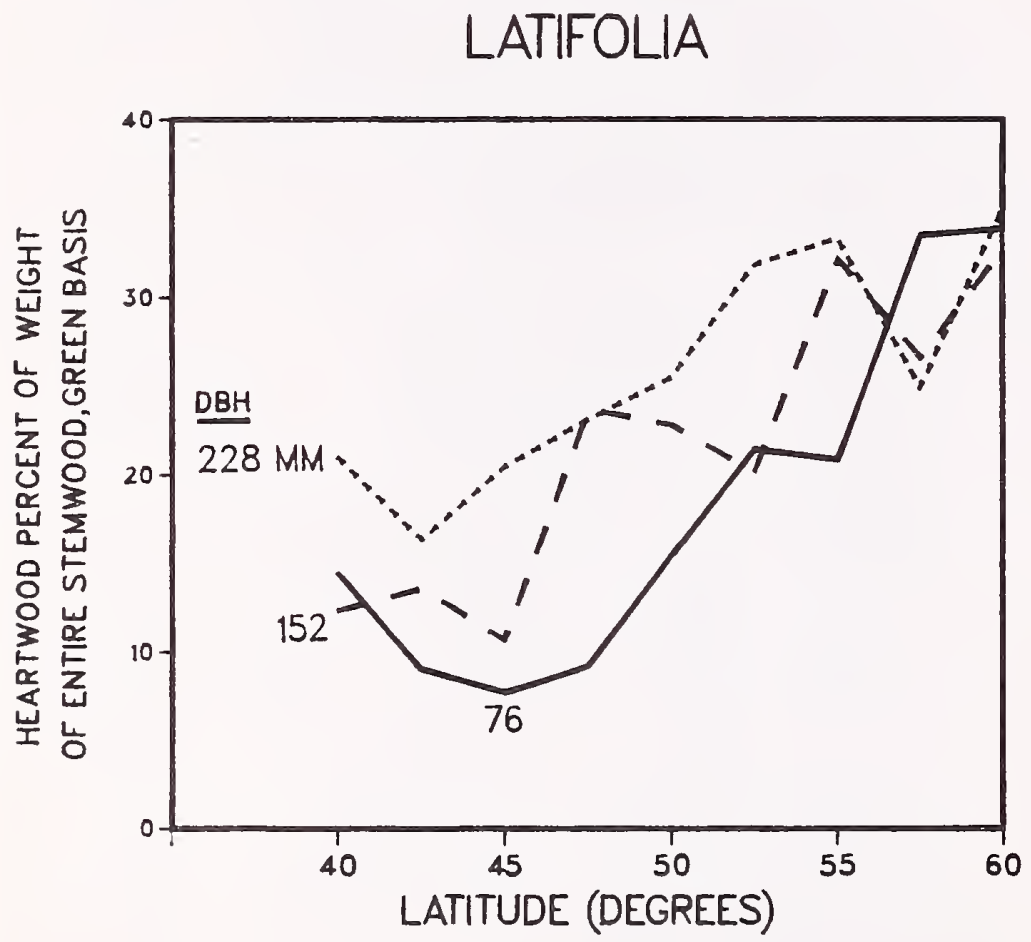

Figure 5-24-Green heartwood as percentage of entire green stemwood weight in latifolia trees of three diameters, related to latitude.
The following significant correlations (arbitrarily truncated at $r=0.300$ ) of the heartwood percent of the green and ovendry weights of entire stemwood with other tree characteristics are of interest:

\section{Statistic}

Heartwood as percentage of stemwood volume

\begin{tabular}{|c|c|}
\hline \multicolumn{2}{|c|}{$r$} \\
\hline Ovendry & Green \\
\hline 0.997 & 0.987 \\
\hline .988 & 1.000 \\
\hline 1.000 & .988 \\
\hline .937 & .917 \\
\hline-.747 & -.761 \\
\hline-.733 & -.749 \\
\hline .730 & .681 \\
\hline-.727 & -.748 \\
\hline-.720 & -.738 \\
\hline-.711 & -.733 \\
\hline-.675 & -.675 \\
\hline .673 & -.600 \\
\hline-.663 & -.657 \\
\hline .624 & .569 \\
\hline .619 & .562 \\
\hline-.604 & -.590 \\
\hline .560 & .516 \\
\hline-.546 & -.519 \\
\hline-.545 & -.509 \\
\hline .537 & .525 \\
\hline-.531 & -.569 \\
\hline-.526 & -.508 \\
\hline
\end{tabular}




\section{Statistic}

Height ( $m$ ) of lowest tree disk in

which heartwood does not occur

Crown ratio

Minimum sapwood thickness

Stem (wood plus bark) as percent-

age of dry complete-tree weight

Within-crown average stemwood

taper, $\mathrm{mm} / \mathrm{m}$

Percentage moisture content of

bark of stump-root system

Percentage moisture content of

live branchwood

Percentage moisture content of sapwood

Percentage moisture content of live branchbark

Age of lowest tree disk in which

heartwood does not occur

Elevation, $m$

Ovendry weight of stem, wood plus bark

Height (percent) where maximum

heartwood diameter occurs

Tree height

Average branch diameter

Ovendry weight of stump-root

system, wood plus bark

Height $(\mathrm{m})$ where maximum heart-

wood diameter occurs

D.b.h.

Heartwood as a percentage of green weight of entire stemwood, in addition to the obvious positive correlation with heartwood as a percentage of stem volume and heartwood as a percentage of stem diameter at height of maximum heartwood diameter, is also positively correlated with stembark specific gravity $(r=0.525)$, tree age at stump height (0.516), stem (wood plus bark) as a percentage of complete-tree ovendry weight $(0.449)$, and withincrown stem taper $(0.387)$.

The negative correlations in the foregoing tabulation suggest that heartwood as a percentage of green weight of entire stemwood is maximum at low elevation (elevation in meters, as opposed to elevational zone within a latitudinal zone) in trees with low moisture content, foliage comprising a small percentage of complete-tree weight, thin sapwood, and low crown ratio. Heartwood as a percentage of green weight of entire stemwood is also negatively correlated with the age of the lowest tree disk in which heartwood does not occur $(r=-0.344)$.

Ovendry-As noted in chapter 4 , heartwood ovendry weight as a percentage of stemwood was positively correlated with d.b.h. (fig. 4-63), averaging 22.6 (16.3), 28.8 (15.3), and 34.6 (13.4) percent for trees 76, 152, and $228 \mathrm{~mm}$ in diameter. It was also positively correlated with latitude, averaging-with diameter data pooled-minimum (18.0 percent) at 42.5 degrees and maximum (43.0 percent) at 60 degrees (fig. 4-63).

Within latitudinal zones there was a tendency for trees in low-elevation zones to have a smaller percentage of heartwood by ovendry weight than those in medium or high zones, as follows:

$\begin{array}{lccc}\begin{array}{c}\text { Elevational } \\ \text { zone }\end{array} & 76 \mathbf{m m} & \mathbf{1 5 2} \mathbf{m m} & \mathbf{2 2 8} \mathbf{~ m m} \\ & \ldots \ldots & \text { Percent } & \ldots \\ \text { Low } & 20.7 & 26.0 & 31.5 \\ \text { Medium } & 21.4 & 29.4 & 36.9 \\ \text { High } & 25.8 & 30.9 & 35.5\end{array}$

Significant correlations (arbitrarily truncated at $r=$ 0.300 ) of heartwood as a percentage of ovendry weight of entire stemwood with other tree characteristics are shown in the tabulation of similar data on a green basis. These correlations vary only slightly from those applicable to green weight percentages; the comments made about green heartwood weight percentages therefore apply equally to ovendry weight percentages.

Additionally, heartwood as percentage of ovendry weight of entire stemwood is positively correlated with ovendry weight of stem, including both wood and bark $(r=0.357)$; ovendry weight of stump-root system, including wood and bark (0.330); tree height (0.352); average branch diameter (0.355); and d.b.h. (0.312).

\section{Heartwood as Percentage of Stemwood Weight by Level}

Green-With diameter data pooled, heartwood as percentage of green stemwood weight averaged about 24 percent at stump height of $152 \mathrm{~mm}$, increased to about 28 percent at 10 percent of tree height, and then decreased curvilinearly toward the apical tip (fig. 5-25). At all levels in the tree, heartwood green weight proportion of stemwood was positively correlated with d.b.h.

\section{LATIFOLIA}

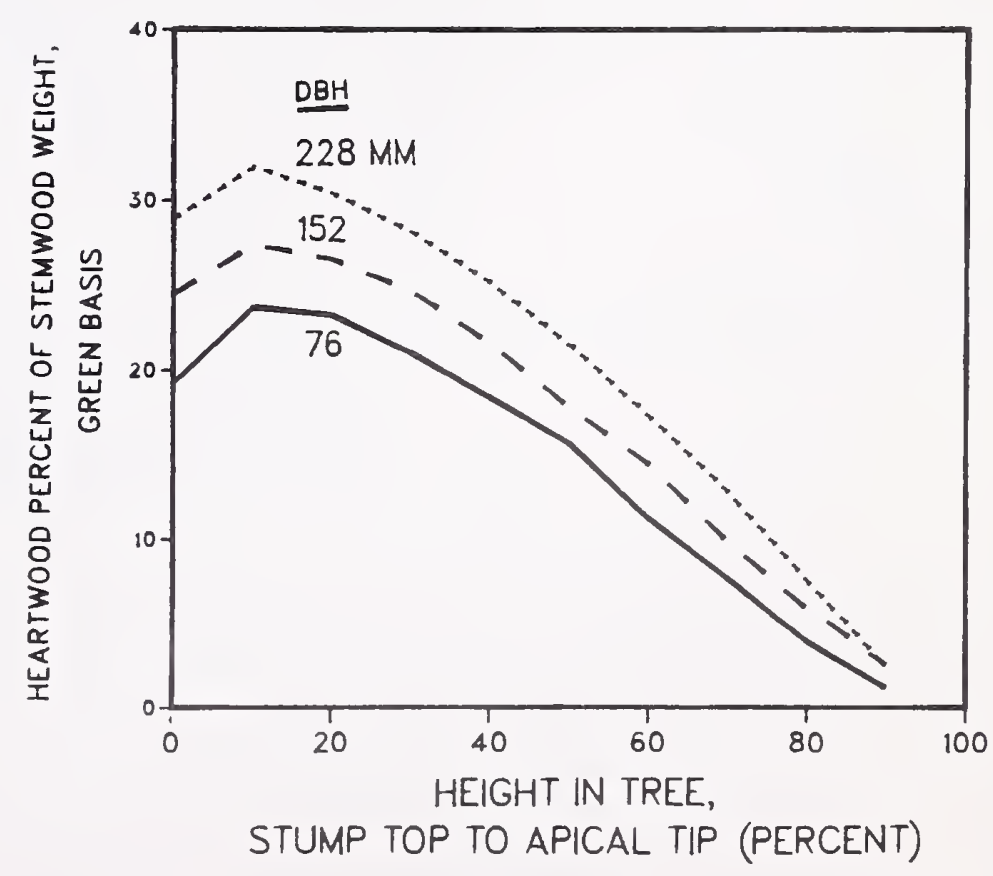

Figure 5-25-Green heartwood as percentage of green stemwood weight in latifolia trees of three diameters, related to height in tree. 
Within latitudinal zones, trees from low-elevation zones had less heartwood as a percentage of green stemwood weight at all stem levels than those from medium and high zones (fig. 5-26).
LATIFOLIA
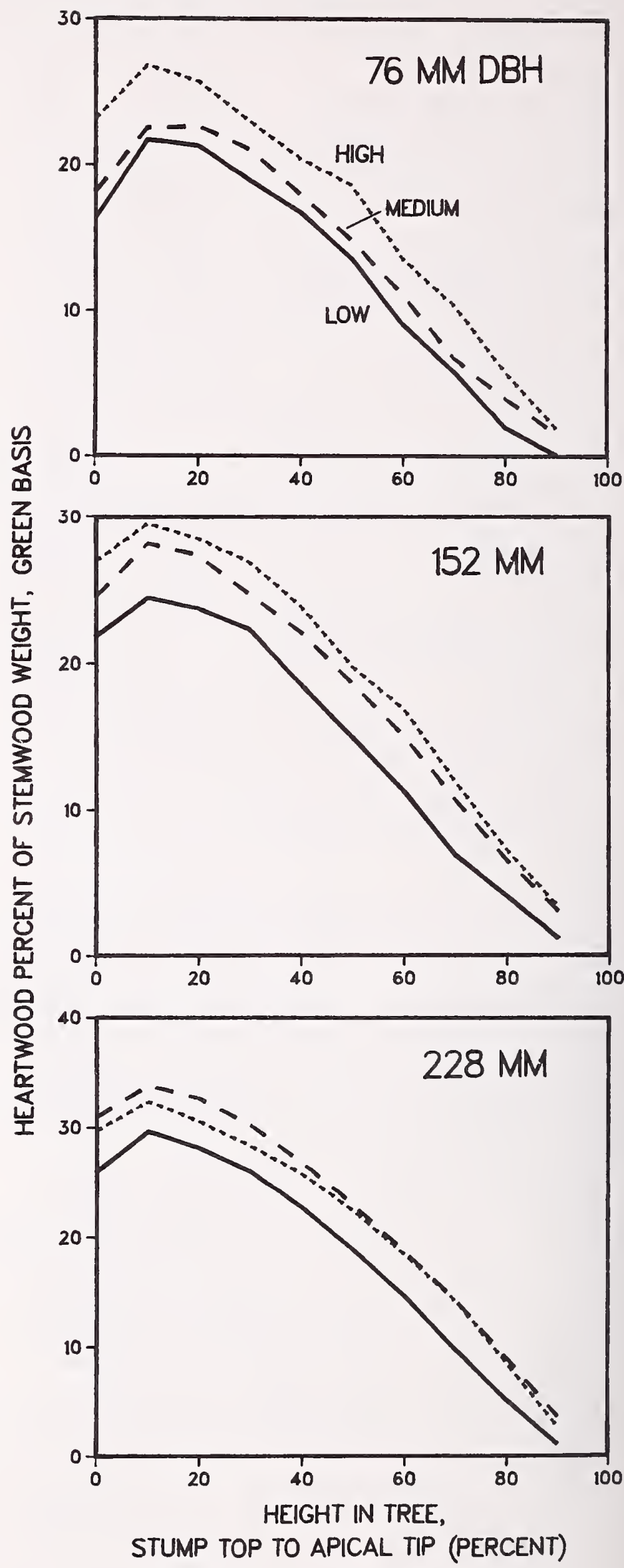

Figure 5-26-Green heartwood as percentage of green stemwood weight in latifolia trees of three diameters, related to height in tree and elevational zone. 
In general, heartwood as a percentage of green stemwood weight was greatest in northern latitudes and least in southern, but relationships varied with d.b.h. and height in tree (fig. 5-27).
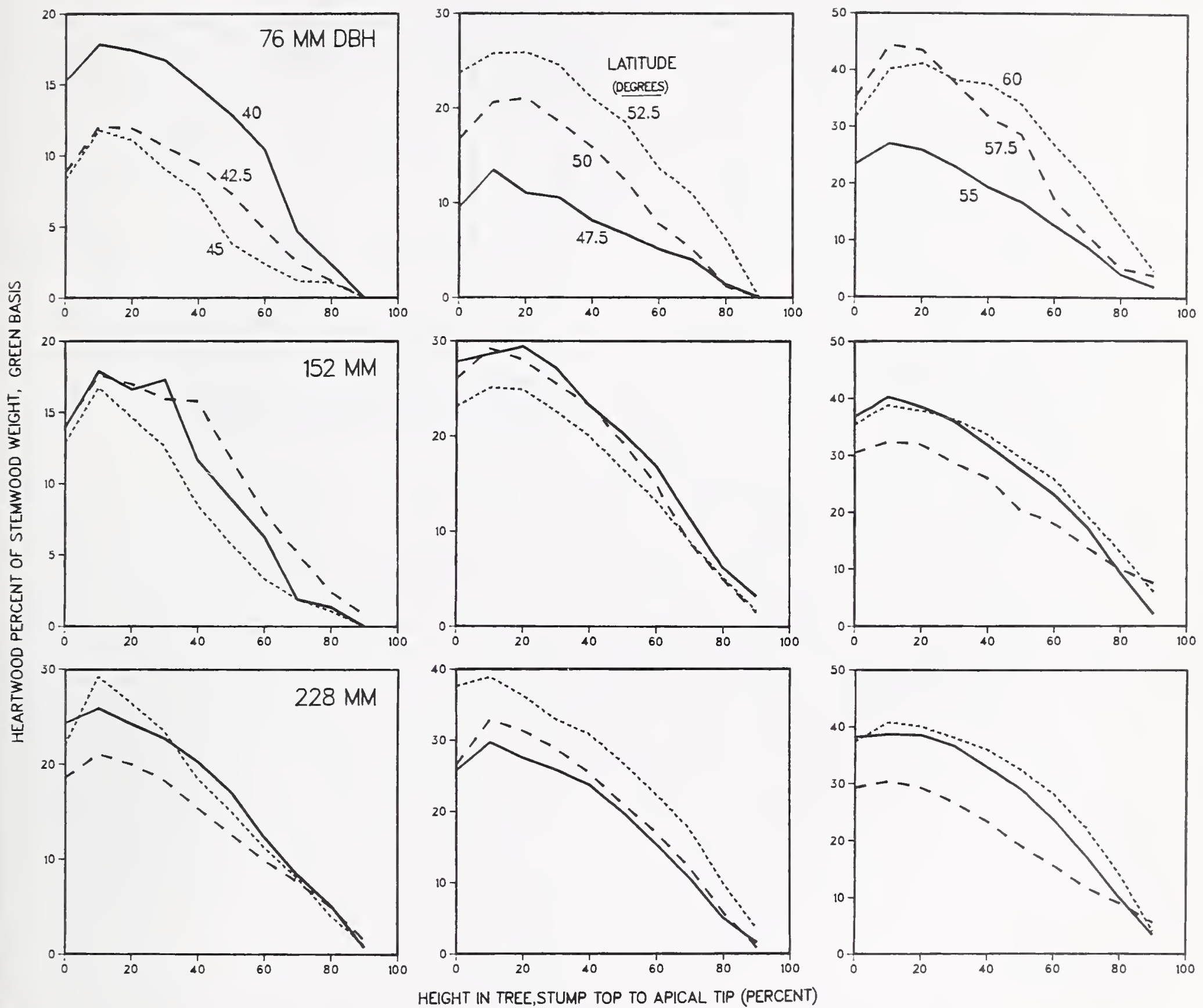

Figure 5-27-Green heartwood as percentage of green stemwood weight in latifolia trees of three diameters, related to height in tree and latitude. 
Ovendry-With diameter data pooled, heartwood as a percentage of ovendry stemwood weight averaged about 30 percent at stump height of $152 \mathrm{~mm}$, increased to about 34 percent at 10 percent of tree height, and then decreased curvilinearly toward the apical tip (fig. 5-28). As with green weight proportion, at all levels in the tree heartwood ovendry weight proportion of stemwood weight was positively correlated with d.b.h. (fig. 5-28).
LATIFOLIA

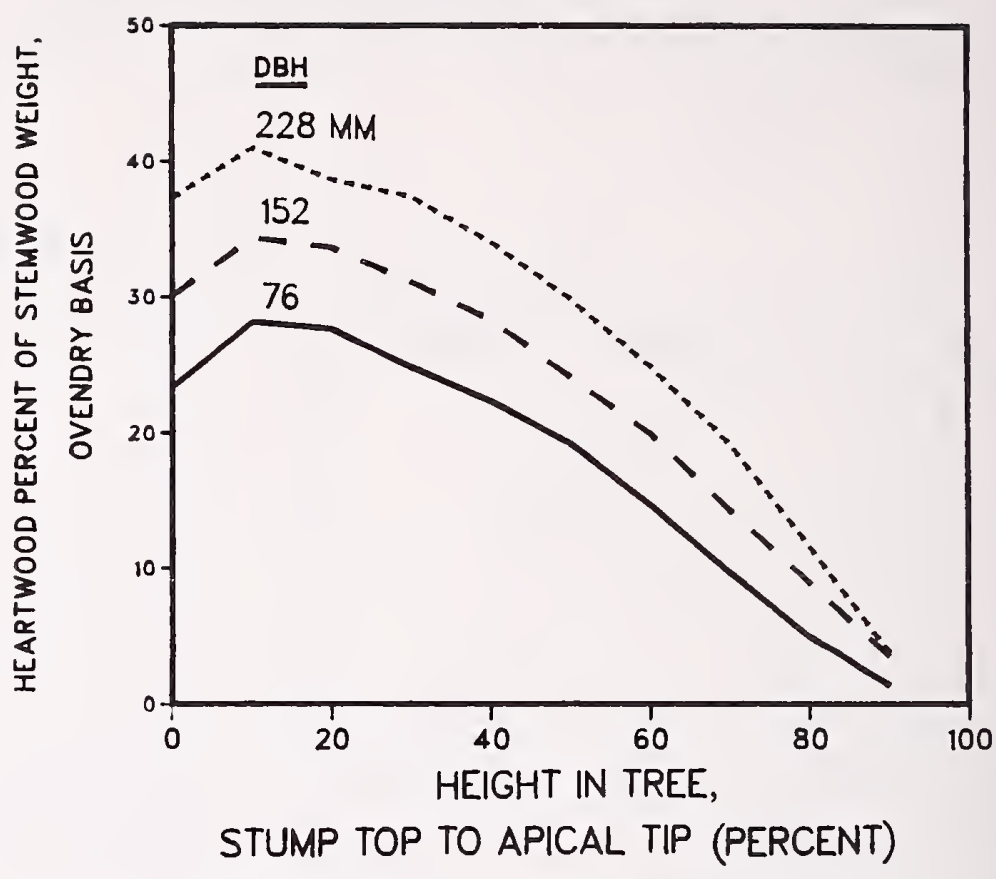

Figure 5-28-Ovendry heartwood as percentage of ovendry stemwood weight in latifolia trees of three diameters, related to height in tree. 
As with green weight proportion, heartwood as a percentage of ovendry stemwood weight tended to be greatest in northern latitudes and least in southern, but relationships varied with d.b.h. and height in tree

(fig. 5-29).
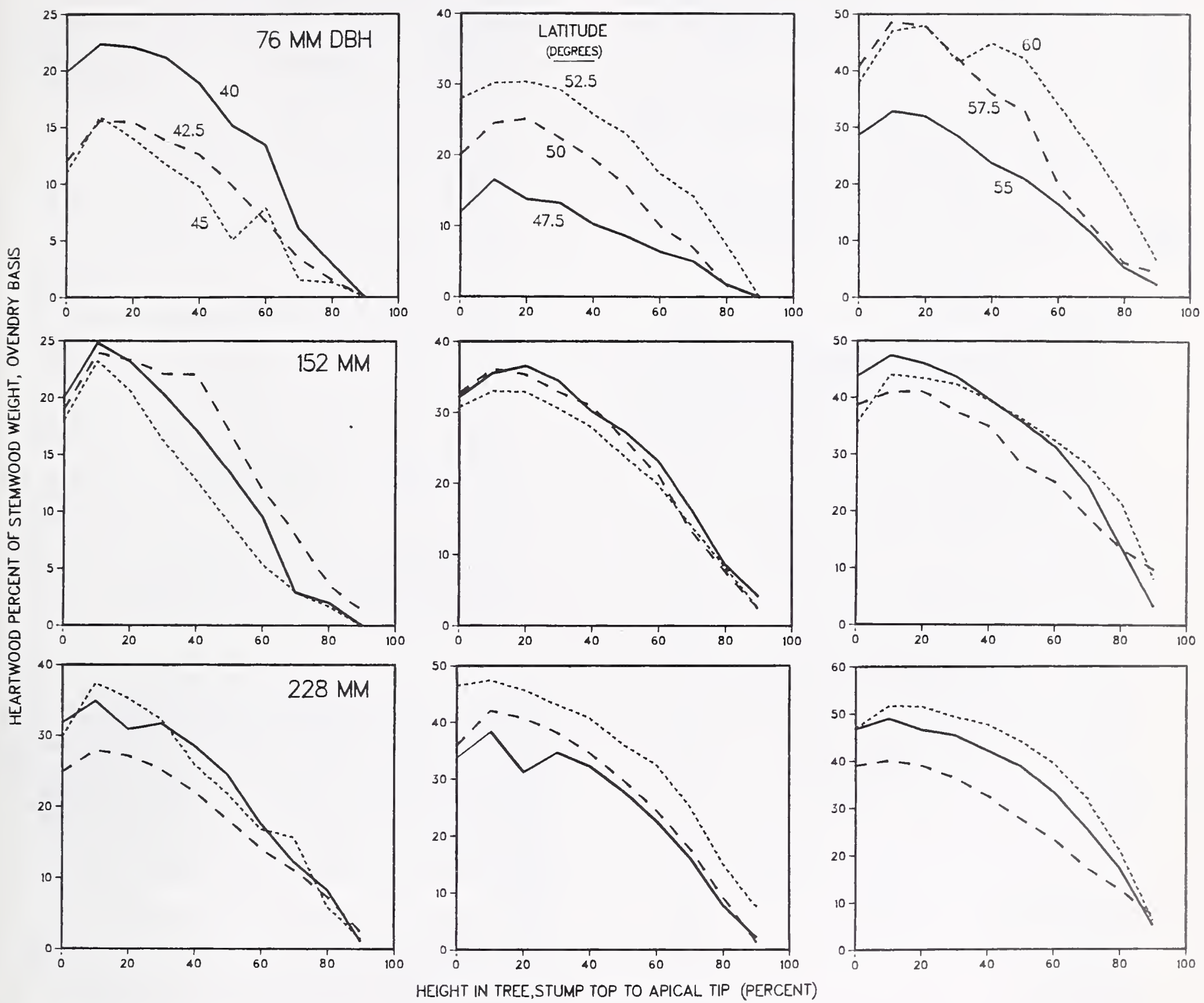

Figure 5-29-Ovendry heartwood as percentage of ovendry stemwood weight in latifolia trees of three diameters, related to height in tree and latitude. 


\section{Specific Gravity of Sapwood in Entire Stem}

As noted in chapter 4, sapwood specific gravity in the entire stem (ovendry weight and green volume basis) was less than that of heartwood, averaging 0.414 , with standard deviation of 0.034 . Like whole-stemwood specific gravity it was negatively correlated with d.b.h., averaging $0.423(0.039), 0.415(0.032)$, and $0.405(0.030)$ for trees 76 , 152 , and $228 \mathrm{~mm}$ in d.b.h.; diameter-related differences were more pronounced in northern than in southern latitudes (fig. 4-58).

Sapwood specific gravity averaged maximum $(0.425$ to 0.435 ) at middle latitudes of 47.5 through 55 degrees, and minimum (0.396) at 40 degrees (fig. 4-58).

The following significant correlations (arbitrarily truncated at $r=0.200$ to show most relationships involved) of sapwood specific gravity with other tree statistics are of interest:

\section{Statistic}

Stemwood specific gravity

0.967

Percentage moisture content of sapwood

$-.678$

Percentage moisture content of complete tree (wood only)

$-.566$

Percentage moisture content of stemwood, tree average

Percentage moisture content of complete tree without foliage or cones

Percentage moisture content of stem (wood plus bark)

Percentage moisture content of complete tree with foliage and cones

Percentage moisture content of wood of stump-root system

Percentage moisture content of stump-root system (wood plus bark)

Stem (wood plus bark) as percentage of complete-tree weight, ovendry

Specific gravity of entire heartwood

Percentage moisture content of foliage-free live branches (wood plus bark)

Live branch (wood plus bark) as percentage of complete-tree weight, ovendry

Foliage as percentage of complete-tree weight, ovendry

Percentage moisture content of live branchwood

Crown ratio

Below-crown average stemwood taper, $\mathrm{mm} / \mathrm{m}$

Minimum sapwood thickness

Percentage moisture content of heartwood

\section{Statistic}

Stembark specific gravity

Elevation, $m$

Percentage moisture content of live branchbark

$-.326$

Stemwood d.i.b. at base of live crown

Within-crown stemwood percentage of entire stemwood volume

Percentage moisture content of bark of stump-root system

$-.287$

Average branch diameter $\quad-.287$

Ovendry foliage weight

Percentage moisture content of complete tree (bark only)

Heartwood as percentage of stemwood diameter at height of maximum heartwood diameter

Height (percent) of lowest tree disk in which heartwood does not occur

Average branch angle

Heartwood as percentage of weight of stemwood, green

Heartwood as percentage of stemwood volume

Ovendry weight of live branches (wood plus bark)

Average growth-ring width at $152-\mathrm{mm}$ stump height

D.b.h.

Percentage moisture content of stembark, tree average

Heartwood as percentage of weight of stemwood, ovendry
These data suggest that sapwood specific gravity tends to be highest at low elevation in small-diameter, slowgrowing trees with a high percentage of complete-tree weight in the stem, low crown ratio, a small percentage of complete-tree weight in foliage, a low weight of foliage, little stemwood taper below crown, thin sapwood, small stemwood diameter at the base of the live crown, and small-diameter lightweight branches having high branch angles.

Sapwood specific gravity is positively correlated with heartwood specific gravity $(r=0.449)$, stembark specific gravity (0.333), heartwood as a percentage of stemwood diameter at height of maximum heartwood diameter $(0.273)$, height of heartwood in tree (0.261), and heartwood as a percentage of stemwood weight and volume $(0.238)$.

It is negatively correlated with sapwood moisture content $(-0.678)$ and moisture content of most other tree components. 


\section{Specific Gravity of Sapwood by Level}

With diameter data pooled, sapwood specific gravity based on ovendry weight and green volume averaged 0.449 at stump height of $152 \mathrm{~mm}$, decreased to a minimum of 0.387 at 70 percent of tree height, and then increased to 0.399 at 90 percent of tree height. At all levels, it was negatively correlated with d.b.h. (fig. 5-30).

As noted previously, sapwood specific gravity averaged maximum at latitudes from 47.5 through 55 degrees, and minimum at 40 degrees; figure 5-31 relates latitude to sapwood specific gravity at various heights in trees of the three diameters.

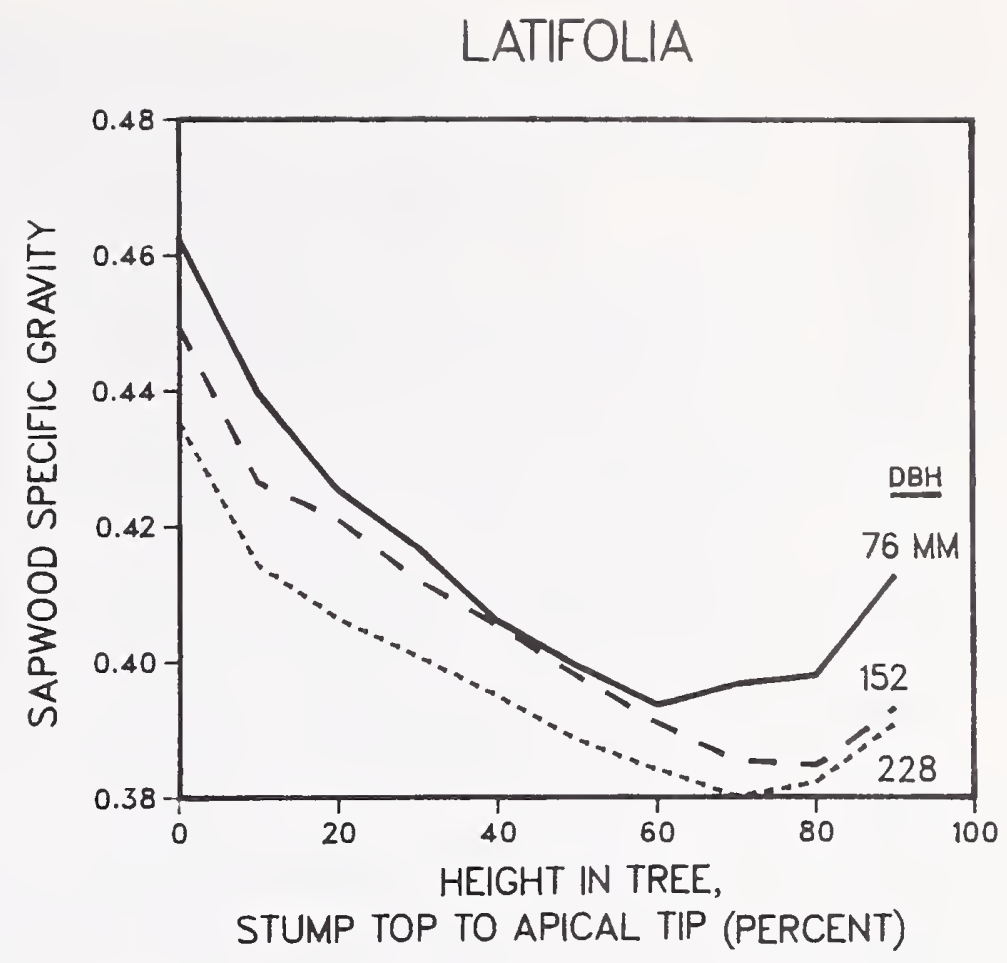

Figure 5-30-Sapwood specific gravity (based on green volume and unextracted ovendry weight) in latifolia trees of three diameters, related to height in tree. 
LATIFOLIA
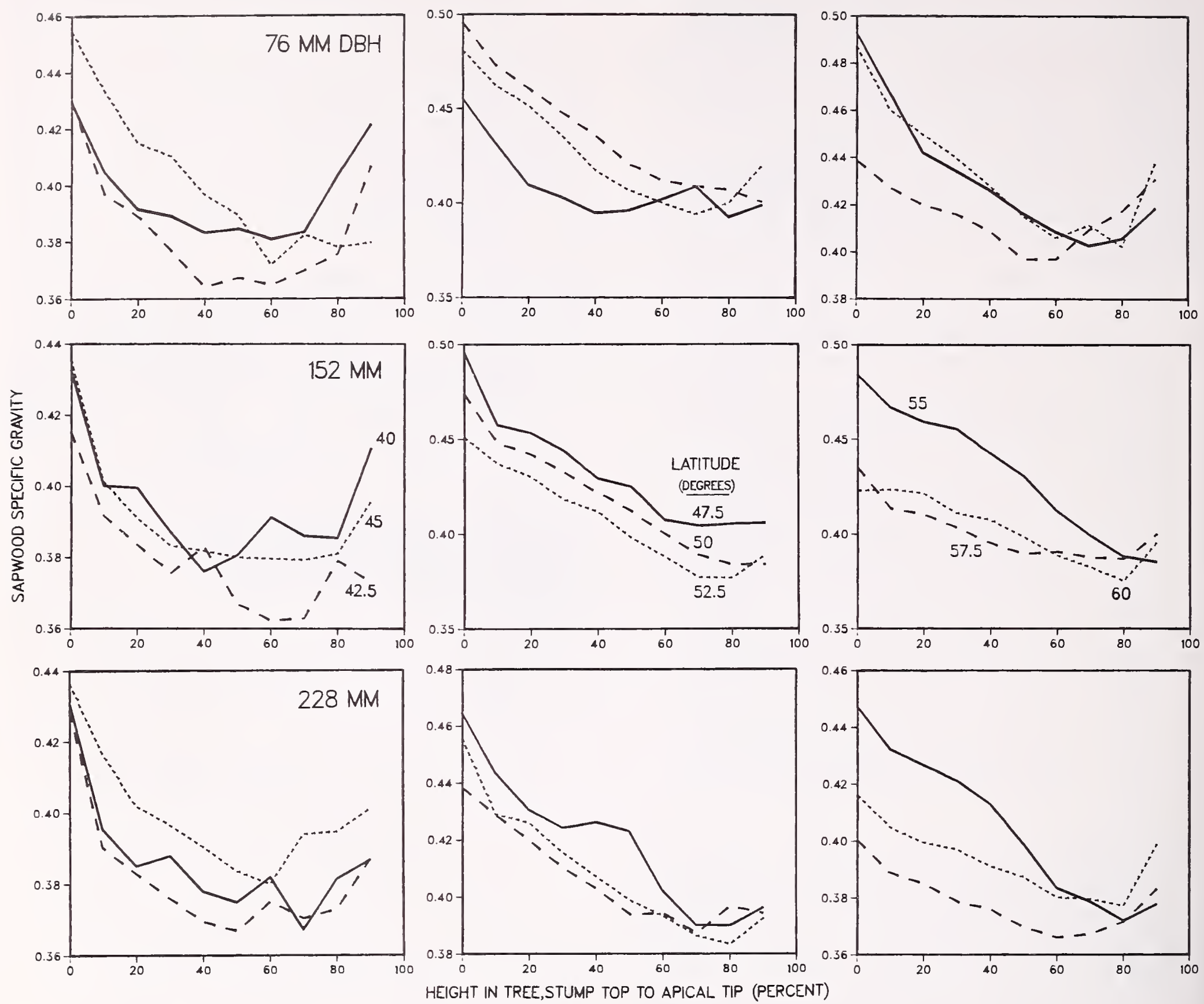

Figure 5-31-Sapwood specific gravity (based on green volume and unextracted ovendry weight) in latifolia trees of three diameters, related to latitude. 


\section{Specific Gravity of Heartwood in Entire Stem}

As noted in chapter 4, heartwood specific gravity in entire stems averaged 0.434 , with standard deviation of 0.034 , based on unextracted ovendry weight and green volume. It was unrelated to elevational zone and latitude, but was negatively correlated with d.b.h., as follows:

\begin{tabular}{rrr} 
D.b.h. & \multicolumn{2}{c}{$\begin{array}{c}\text { Specific gravity and } \\
\text { standard deviation }\end{array}$} \\
$\mathrm{mm}$ & & \\
76 & 0.459 & $(0.038)$ \\
152 & .430 & $(.022)$ \\
228 & .412 & $(.022)$
\end{tabular}

The following significant correlations (arbitrarily truncated at $r=0.200$ to show most relationships involved) of heartwood specific gravity with other tree statistics are of interest. In addition to the tree statistics listed, content of extractives likely has a significant effect on heartwood specific gravity, but such determinations-although scheduled-had not been made at the time this paper was written.

\section{Statistic}

D.b.h.

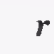

Stemwood specific gravity

$-0.560$

.548

Green weight of sapwood

$-.522$

Stemwood d.i.b. at base of live crown

$-.514$

Tree height

$-.502$

$-.502$

Ovendry weight of sapwood

$-.495$

heartwood does not occur

$-.489$

(wood plus bark)

$-.489$

Heartwood maximum diameter

$-.480$

$-.478$

$-.454$

Ovendry foliage weight

Specific gravity of entire sapwood

Average branch diameter

.449

$-.446$

Ovendry weight of live branches (wood plus bark)

$-.432$

Average growth-ring width at $152-\mathrm{mm}$

stump height

$-.432$

Stump-root system (wood plus bark) as percentage of complete-tree weight, ovendry

Height in tree $(\mathrm{m})$ where minimum sapwood thickness occurs

Number of live branches

$-.359$

Green weight of heartwood

$-.349$

Taproot length

$-.348$

Height (percent) of lowest tree disk in which heartwood does not occur

Ovendry weight of heartwood
Statistic

Ovendry weight of dead branches

Number of cones on tip $305 \mathrm{~mm}$ of top 25 branches

Minimum sapwood thickness

$-313$

Average branch angle

Bark thickness at 152-mm stump height

Percentage moisture content of stembark, tree average

Within-crown average stemwood taper, $\mathrm{mm} / \mathrm{m}$

Age of the lowest tree disk in which heartwood does not occur

Percentage moisture content of sapwood

Foliage as percentage of complete-tree weight, ovendry

Below-crown average stemwood taper, $\mathrm{mm} / \mathrm{m}$

Heartwood as percentage of stemwood diameter at height of maximum heartwood diameter

Percentage moisture content of complete tree (bark only)

Heartwood as percentage of stemwood volume

The foregoing tabulation suggests that heartwood has highest specific gravity in small-diameter, short, slowgrowing trees with thin sapwood and with thinnest sapwood occurring close to ground level, thin bark at stump height, small-diameter branches with large branch angles in lightweight crowns having few branches and few cones, few dead branches, short taproots, little stemwood taper within or below crown, and with foliage comprising a large percentage of complete-tree weight.

Unlike sapwood, the specific gravity of heartwood is not significantly correlated with its moisture content, as follows:

\begin{tabular}{ccc} 
& \multicolumn{2}{c}{ Moisture content of } \\
\cline { 2 - 3 } Statistic & Sapwood & Heartwood \\
& $\boldsymbol{r}$ & $\boldsymbol{r}$ \\
Specific gravity of sapwood & -0.678 & -0.340 \\
Specific gravity of heartwood & -.271 & N.S.
\end{tabular}

Heartwood specific gravity is, however, positively correlated with stump-root system (wood plus bark) as percentage of complete-tree ovendry weight $(r=0.394)$, percentage moisture content of stembark (0.289), and age of lowest tree disk in which heartwood does not occur $(0.279)$.

Also, heartwood has highest specific gravity in trees with small heartwood maximum diameter in which heartwood does not extend far up the stem; that is, heartwood specific gravity is negatively correlated with both weight and volume of heartwood in a tree. 


\section{Specific Gravity of Heartwood by Level}

The pattern of variation in heartwood specific gravity with height in tree is significantly different than that of sapwood (compare figs. 5-30 and 5-32). With diameter data pooled, heartwood had average specific gravity of 0.482 at a stump height of $152 \mathrm{~mm}$, sharply decreased to a minimum of 0.412 at 30 percent of tree height, and then increased to a near maximum $(0.478)$ at 90 percent of tree height.

The specific gravity of heartwood at all levels except 90 percent was lowest in trees of $228 \mathrm{~mm}$ d.b.h., and highest in $76-\mathrm{mm}$ trees (fig. 5-32).

\section{LATIFOLIA}

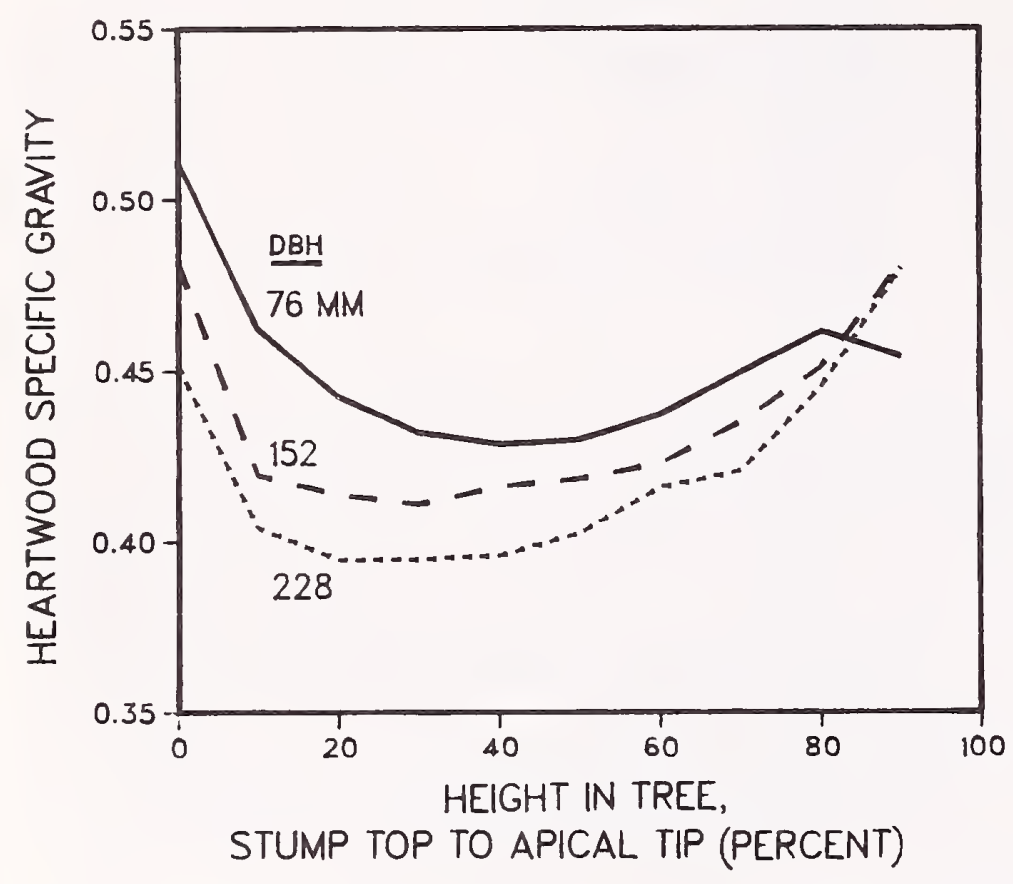

Figure 5-32-Heartwood specific gravity (based on green volume and unextracted ovendry weight) in latifolia trees of three diameters, related to height in tree.

\section{5-6 RESULTS-MURRAYANA}

As noted in previous chapters, the three d.b.h. classes of murrayana trees averaged $76 \mathrm{~mm}$ with standard deviation of $1.8 \mathrm{~mm}, 151 \mathrm{~mm}$ with standard deviation of $2.9 \mathrm{~mm}$, and $229 \mathrm{~mm}$ with standard deviation of $3.9 \mathrm{~mm}$. All were selected at medium elevation, which for the four latitudes averaged as follows (fig. 1-1):

\begin{tabular}{ccl} 
Latitude & Elevation & \multicolumn{1}{c}{ General location } \\
Degrees & Meters & \\
37.5 & 2,402 & $\begin{array}{l}\text { Just east of Yosemite } \\
\text { National Park }\end{array}$ \\
40 & 1,676 & $\begin{array}{l}\text { Vicinity of Quincy, CA } \\
42.5\end{array}$ \\
45 & 2,006 & $\begin{array}{l}\text { Southwest of Paisley, OR } \\
\text { North of Breitenbush, OR }\end{array}$
\end{tabular}

Because the entire murrayana sample totaled but 36 trees, correlations between tree characteristics are not noted as they were for latifolia trees.

\section{Heartwood Occurrence}

Age of Lowest Tree Disk Where Heartwood Does Not Occur-With data on all trees pooled, the age of the lowest tree disk in which heartwood did not appear averaged 14.78 years, with standard deviation of 7.77 years. This age was unrelated to latitude but was inversely correlated with d.b.h., averaging 20.17 (7.99), 13.67 (5.26), and 10.5 (6.90) years for trees 76,152 , and $228 \mathrm{~mm}$ in diameter.

Height in the Tree at Which Heartwood No Longer Occurs, Percent-For all 36 murrayana trees, height in tree at which heartwood did not occur averaged 76.4 percent, with standard deviation of 17.8 percent. This percentage was unrelated to latitude, but was positively correlated with d.b.h., averaging 60.8 (16.2), 80.0 (15.4), and $88.3(8.4)$ percent for trees of the three diameters.

Height in the Tree at Which Heartwood No Longer Occurs, Meters-The lowest height (meters) in trees at which heartwood did not occur was positively correlated with d.b.h., averaging 4.65 (2.08), 11.26 (4.38), and 16.60 (4.75) $\mathrm{m}$ for trees of the three diameter classes. This height was also positively correlated with latitude (fig. 5-33), averaging 3 to $6 \mathrm{~m}$ higher at 45 degrees than at 37.5 degrees.

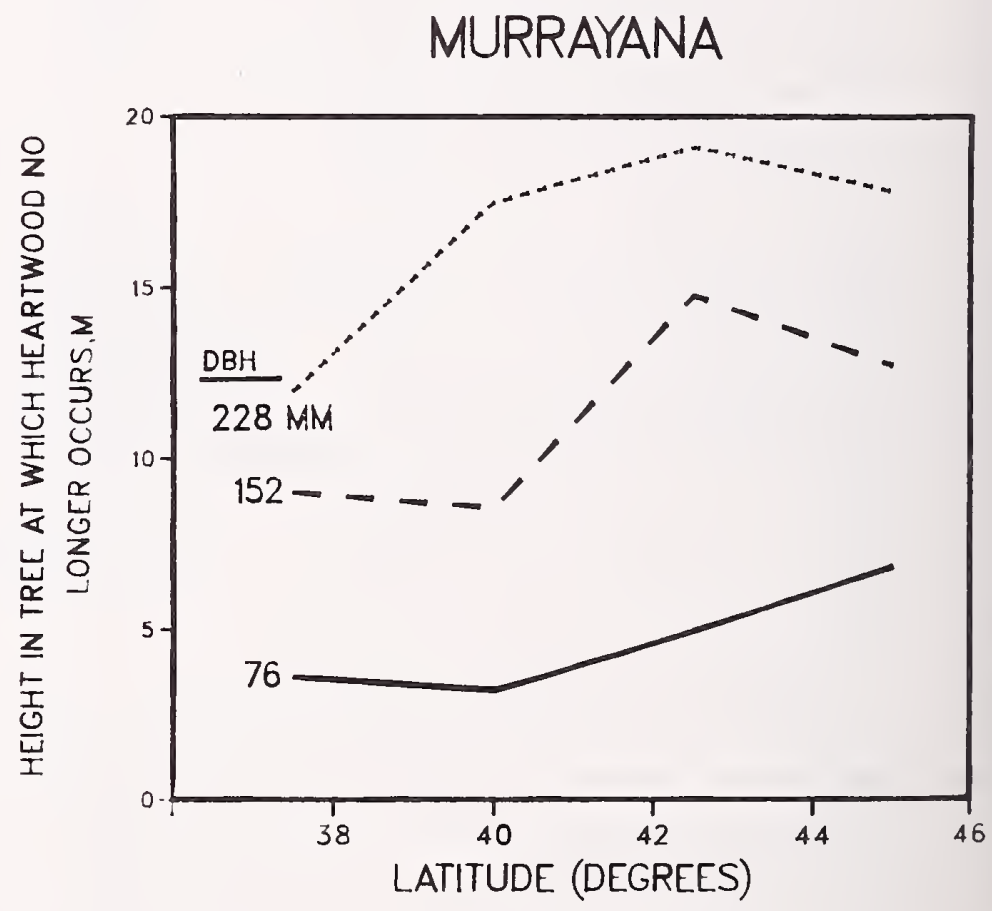

Figure 5-33-Height in tree at which heartwood does not occur in murrayana trees of three diameters, related to latitude. 


\section{Heartwood Maximum Diameter and Location}

Heartwood Maximum Diameter-Heartwood maximum diameter was positively correlated with d.b.h., averaging 26.7 (11.1), 66.8 (22.6), and $108.3(30.0) \mathrm{mm}$ for trees of the three diameter classes. This maximum diameter was also positively correlated with latitude, particularly in 228-mm trees where the smallest was $64.3 \mathrm{~mm}$ at 37.5 degrees and the largest 134.7 at 42.5 degrees (fig. 5-34).

\section{MURRAYANA}

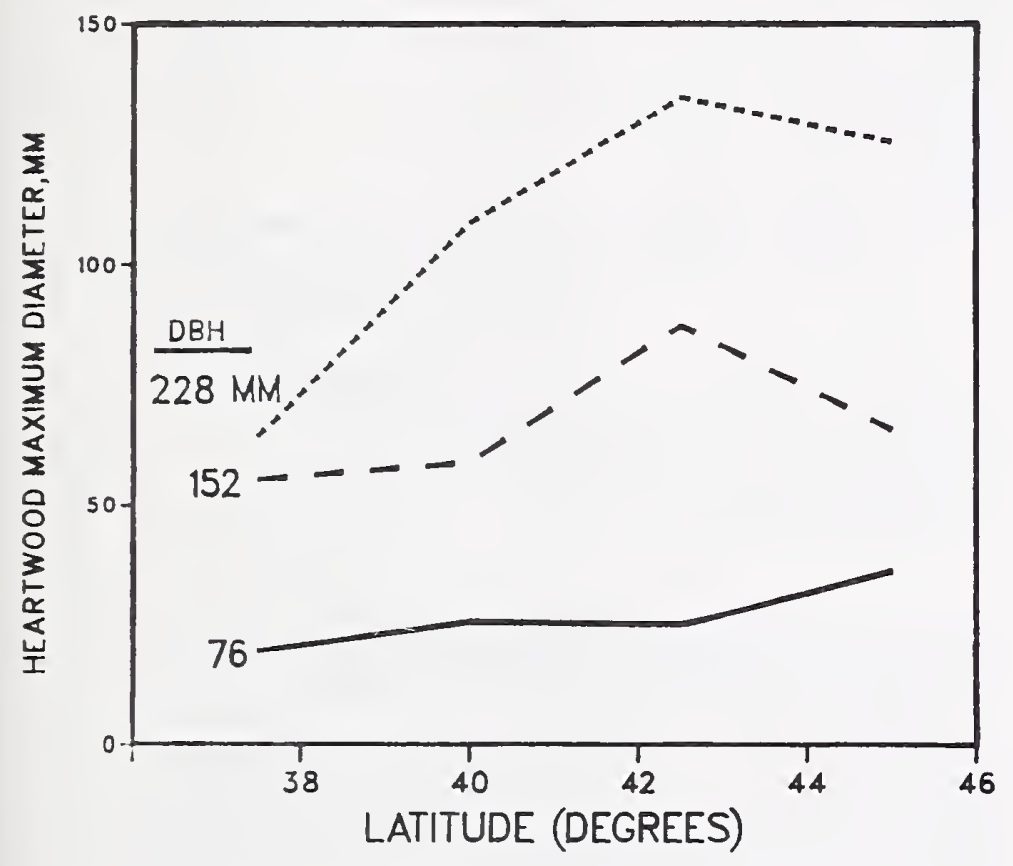

Figure 5-34-Heartwood maximum diameter in murrayana trees of three diameters, related to latitude.
Height at Which Maximum Heartwood Diameter Occurs, Percent-The proportion of tree height at which heartwood diameter was maximum was unrelated to d.b.h., averaging 7.5 percent, with standard deviation of 6.9 percent for all 36 trees. This height proportion did, however, vary significantly with latitude; it was greatest (11.1 percent) at 37.5 degrees and least (2.2 percent) at 40 degrees (fig. 5-35).

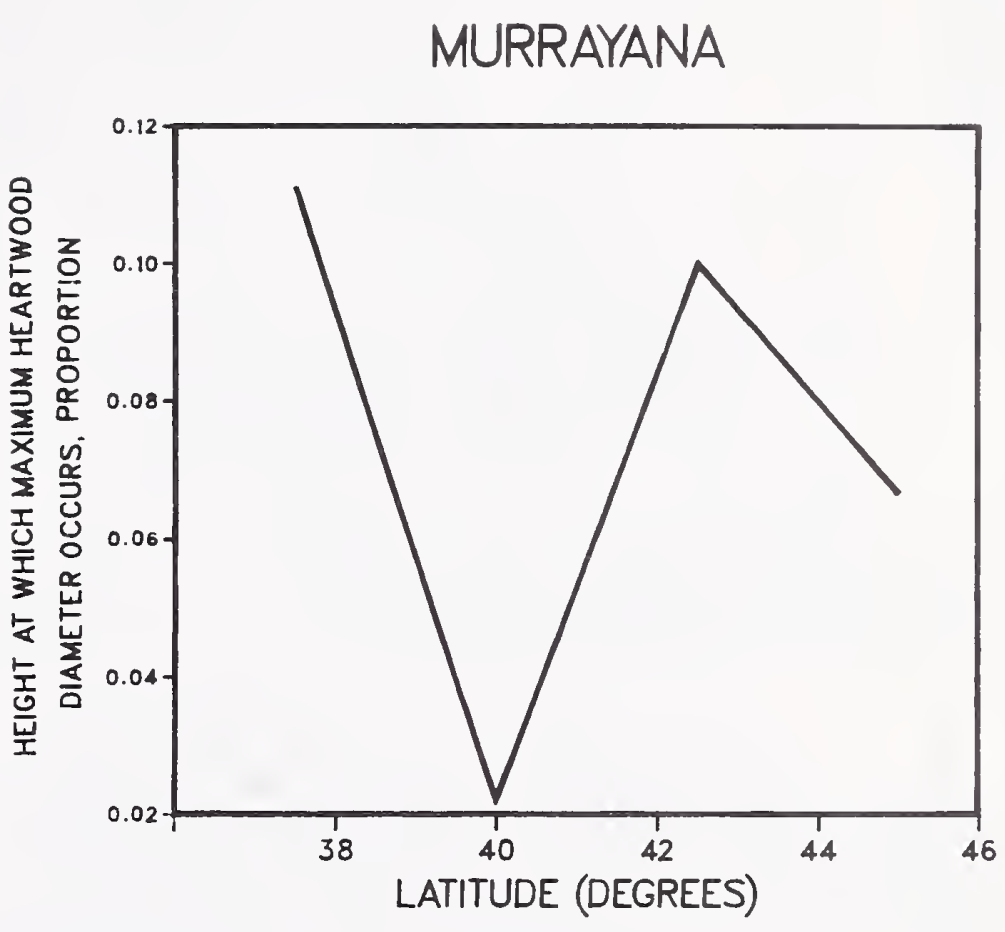

Figure 5-35-Proportion of tree height at which maximum heartwood diameter occurs in murrayana trees, related to latitude (diameter data pooled). 
MURRAYANA

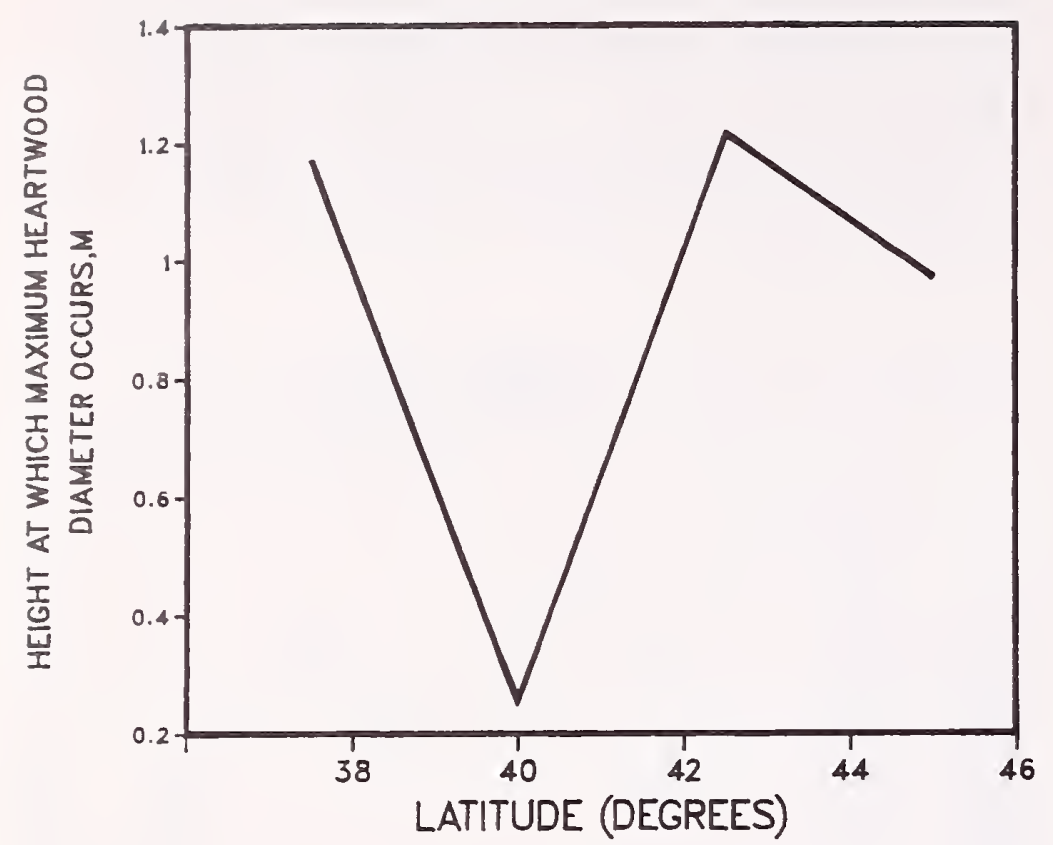

Figure 5-36- Height (meters) at which maximum heartwood diameter occurs in murrayana trees, related to latitude (diameter data pooled).

Height at Which Maximum Heartwood Diameter Occurs, Meters-Similarly, the height (meters) at which maximum heartwood diameter occurred did not vary significantly with d.b.h., averaging $0.90 \mathrm{~m}$, with standard deviation of $0.83 \mathrm{~m}$ for all 36 trees. It was highest in trees sampled at 37.5 and 42.5 degrees $(1.2 \mathrm{~m})$ and lowest in those from 40 degrees $(0.3 \mathrm{~m})$; see figure 5-36.

Heartwood as Percentage of Stem Diameter, at Height of Maximum Heartwood Diameter-Heartwood as a percentage of stemwood diameter at height of maximum heartwood diameter averaged 42.8 percent, with standard deviation of 15.1 percent. Differences related to diameter were not statistically significant; averages were as follows:

$\begin{array}{rcc}\text { D.b.h. } & \text { Average } & \begin{array}{r}\text { Standard } \\ \text { deviation }\end{array} \\ m m & \ldots \ldots \text { - }- \text { Percent } \ldots \ldots .- \\ 76 & 36.3 & 15.6 \\ 152 & 44.1 & 15.1 \\ 228 & 48.0 & 13.3\end{array}$

This percentage did, however, have significant positive correlation with latitude, averaging minimum (32.3 percent) at 37.5 degrees and maximum (51.1 percent) at 42.5 degrees (fig. 5-37).

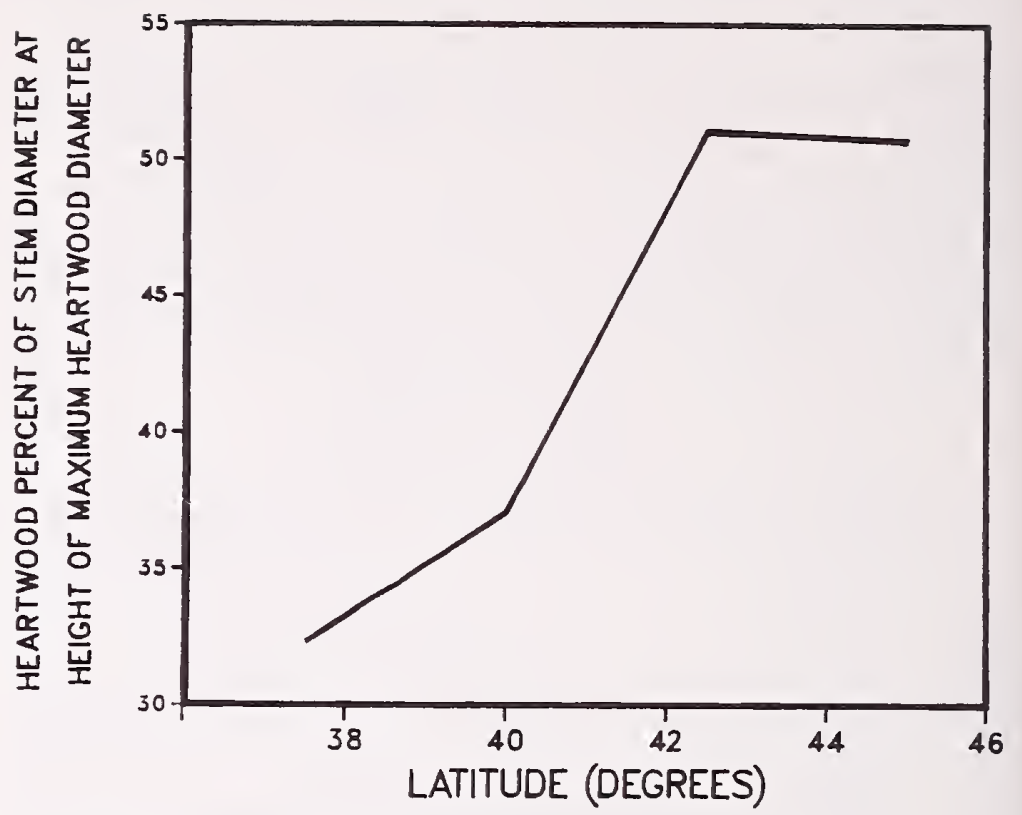

Figure 5-37-Heartwood as percentage of stem diameter at height of maximum heartwood diameter in murrayana trees, related to latitude (diameter data pooled).

\section{Heartwood Diameter by Level}

Heartwood diameters are negatively correlated with height in tree, but positively correlated with d.b.h. (table 5-2 and figs. 5-38 and 5-39). They are also positively correlated with latitude (fig. 5-39).

\section{Minimum Sapwood Thickness and Location Where Heartwood is Present}

Minimum Thickness-Minimum sapwood thickness averaged $29.4 \mathrm{~mm}$, with standard deviation of $10.4 \mathrm{~mm}$. This minimum thickness was positively correlated with d.b.h., averaging 21.5 (6.5), 30.7 (10.2), and $36.1(9.0) \mathrm{mm}$ for trees of the three diameter classes.

Height at Which Minimum Sapwood Thickness Occurs, Percent-The percentage of tree height where minimum sapwood thickness occurred was positively correlated with d.b.h., averaging $43.3(18.8), 54.2(27.1)$, and 77.5 (10.6) percent for trees 76, 152, and $228 \mathrm{~mm}$ in d.b.h.

Height at Which Minimum Sapwood Thickness Occurs, Meters-Tree height (meters) at this minimum sapwood thickness was also positively correlated with d.b.h., averaging $3.23(1.85), 7.41$ (4.48), and $14.56(4.47)$ $\mathrm{m}$ for trees of the three diameter classes. 


\section{MURRAYANA}
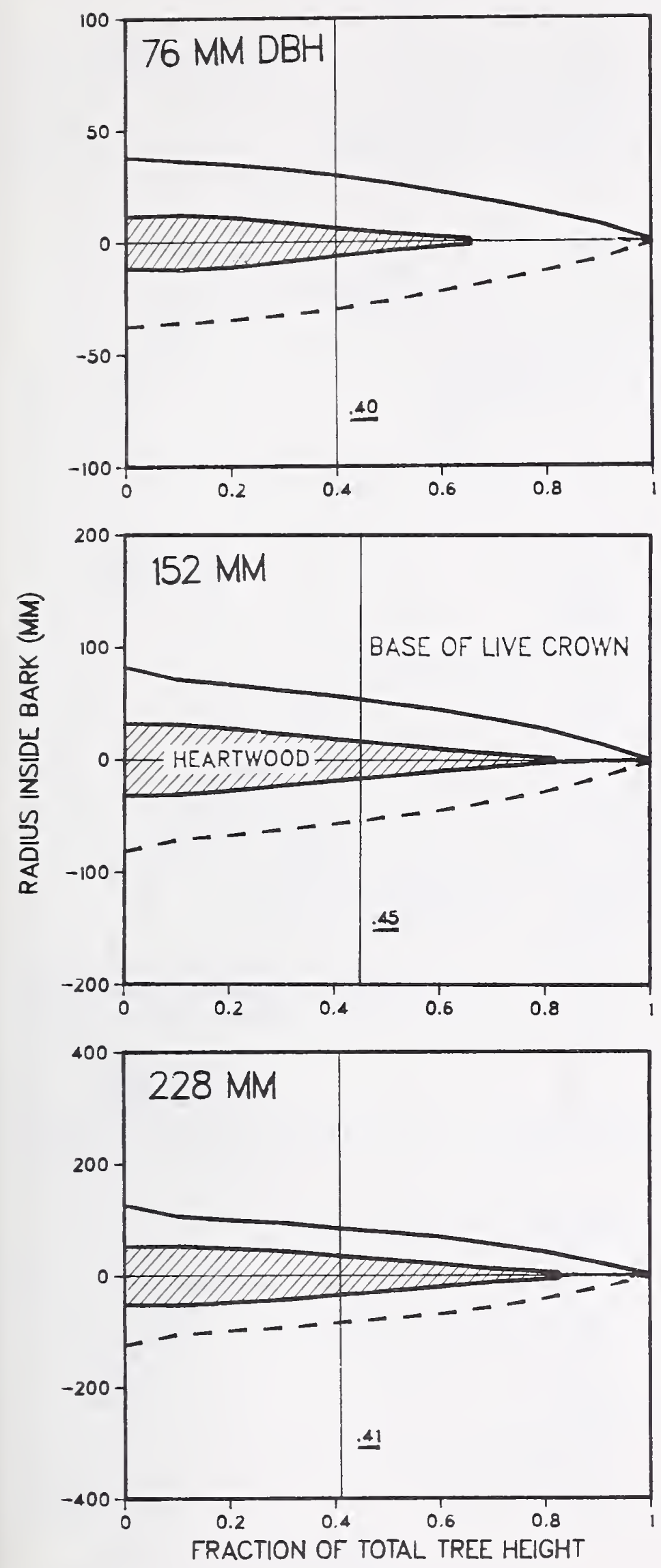

Figure 5-38-Heartwood and stemwood radius in murrayana trees of three diameters, related to height in tree and base of live crown.
MURRAYANA
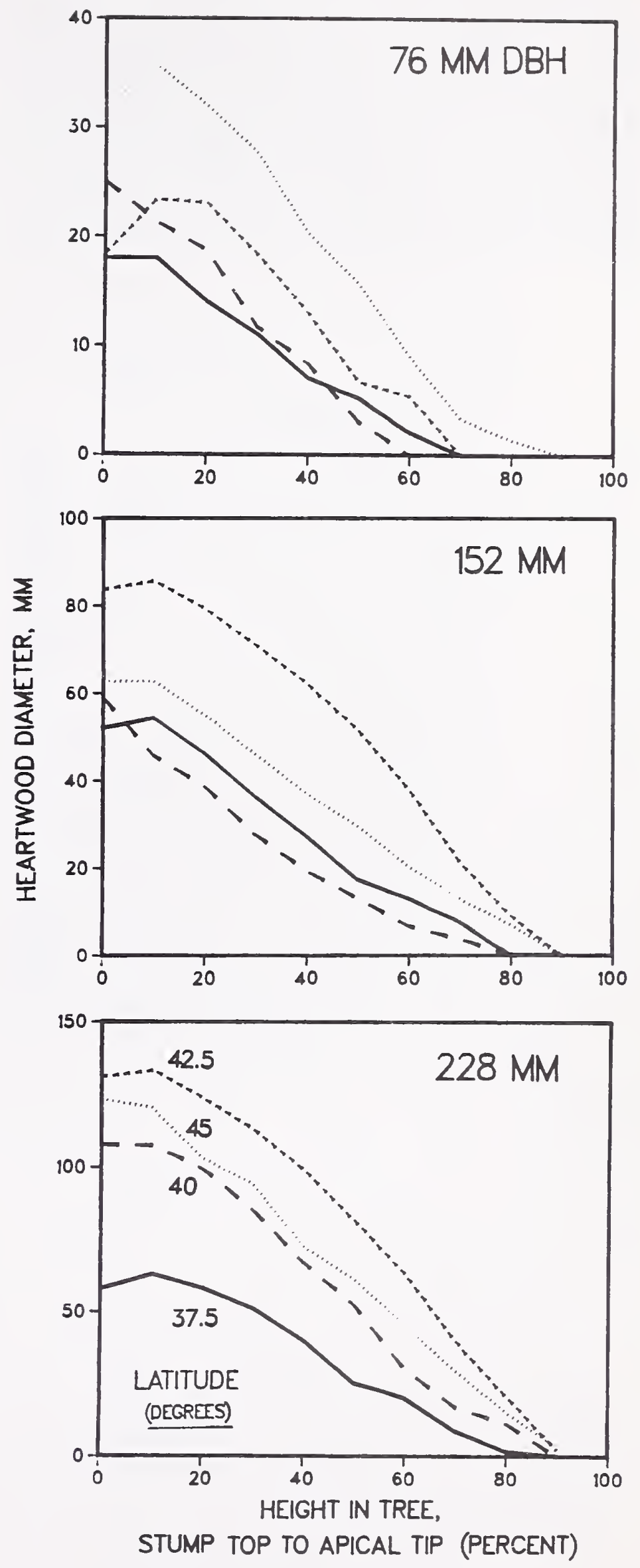

Figure 5-39-Heartwood diameter in murrayana trees of three diameters, related to height in tree and latitude. 


\section{Sapwood Thickness by Level}

Sapwood was thickest at stump height of $152 \mathrm{~mm}$, averaging 26, 50, and $73 \mathrm{~mm}$ for trees 76,152 , and $228 \mathrm{~mm}$ in d.b.h. It diminished sharply between stump height and 10 percent of tree height, remained more or less constant up to 50 percent of tree height, and then diminished more or less linearly toward the apical tip. Sapwood thickness was positively correlated with d.b.h. at all heights in the tree, but was generally negatively correlated with latitude at levels up to about 70 percent of tree height (fig. 5-40 and table 5-2).
MURRAYANA
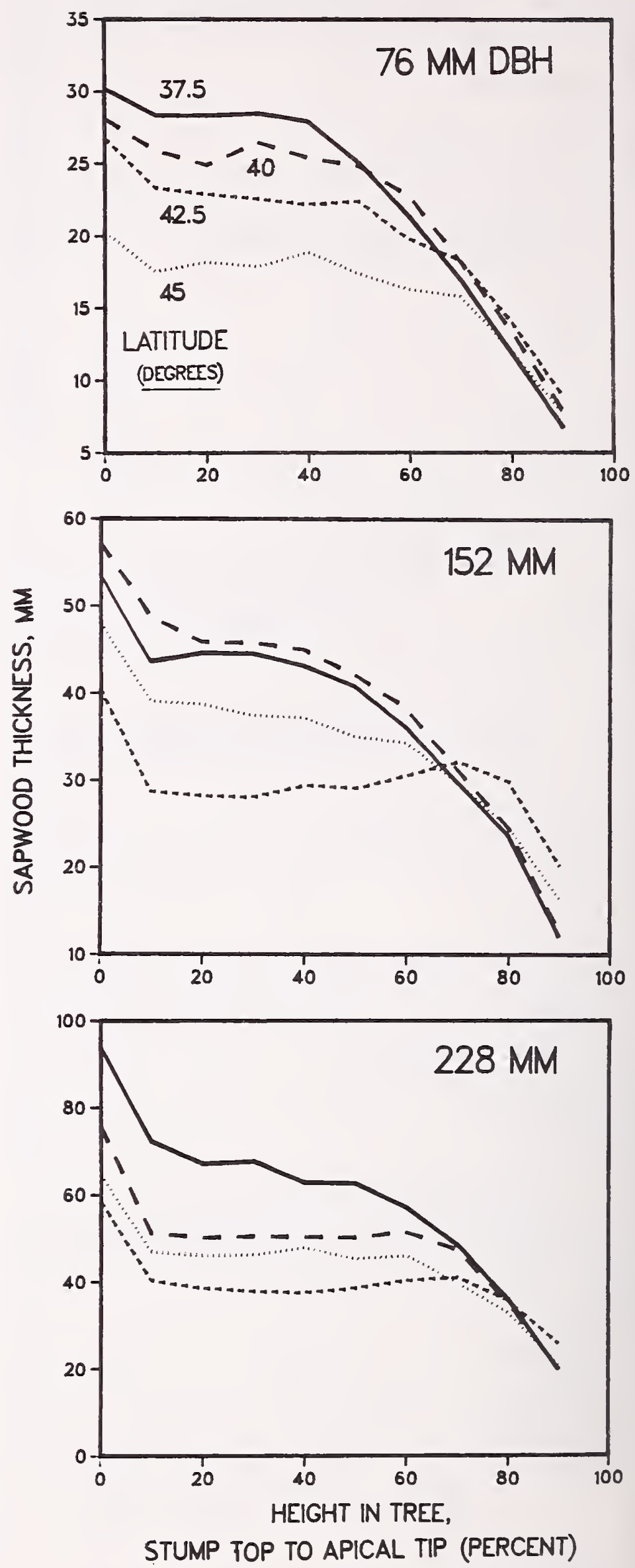

Figure 5-40-Sapwood thickness in murrayana trees of three diameters, related to height in tree and latitude. 


\section{Heartwood Volume as a Percentage of Entire Stemwood Volume}

Heartwood as percentage of stemwood volume was positively correlated with d.b.h., averaging 10.3 (10.7), 16.9 (12.1), and $20.3(10.5)$ percent for trees of the three diameter classes. This percentage was also positively correlated with latitude, the average nearly tripling from 37.5 to 45 degrees (fig. 5-41).

\section{MURRAYANA}

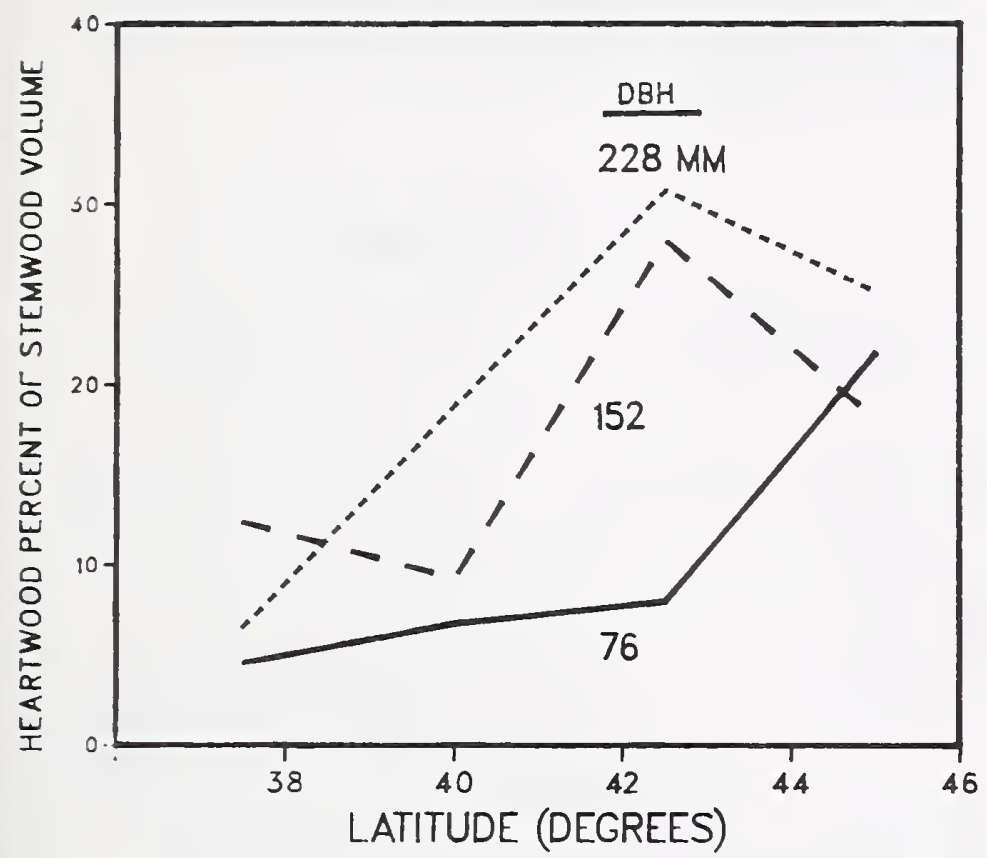

Figure 5-41-Heartwood as percentage of stemwood volume in murrayana trees of three diameters, related to latitude.

\section{Heartwood as Percentage of Stemwood Volume by Level}

Heartwood as a percentage of stemwood volume averaged about 13, 19, and 20 percent at a stump height of $152 \mathrm{~mm}$ for trees 76,152 , and $228 \mathrm{~mm}$ in d.b.h.; heartwood percentages were highest $(15,24$, and 28 percent, respectively) at 10 percent of tree height, and then decreased more or less linearly toward the apical tip (table 5-2 and fig. 5-42). At all levels in the tree heartwood as percentage of stemwood volume was positively correlated with d.b.h., and was also generally positively correlated with latitude-with large differences among latitudes (fig. 5-42).
MURRAYANA
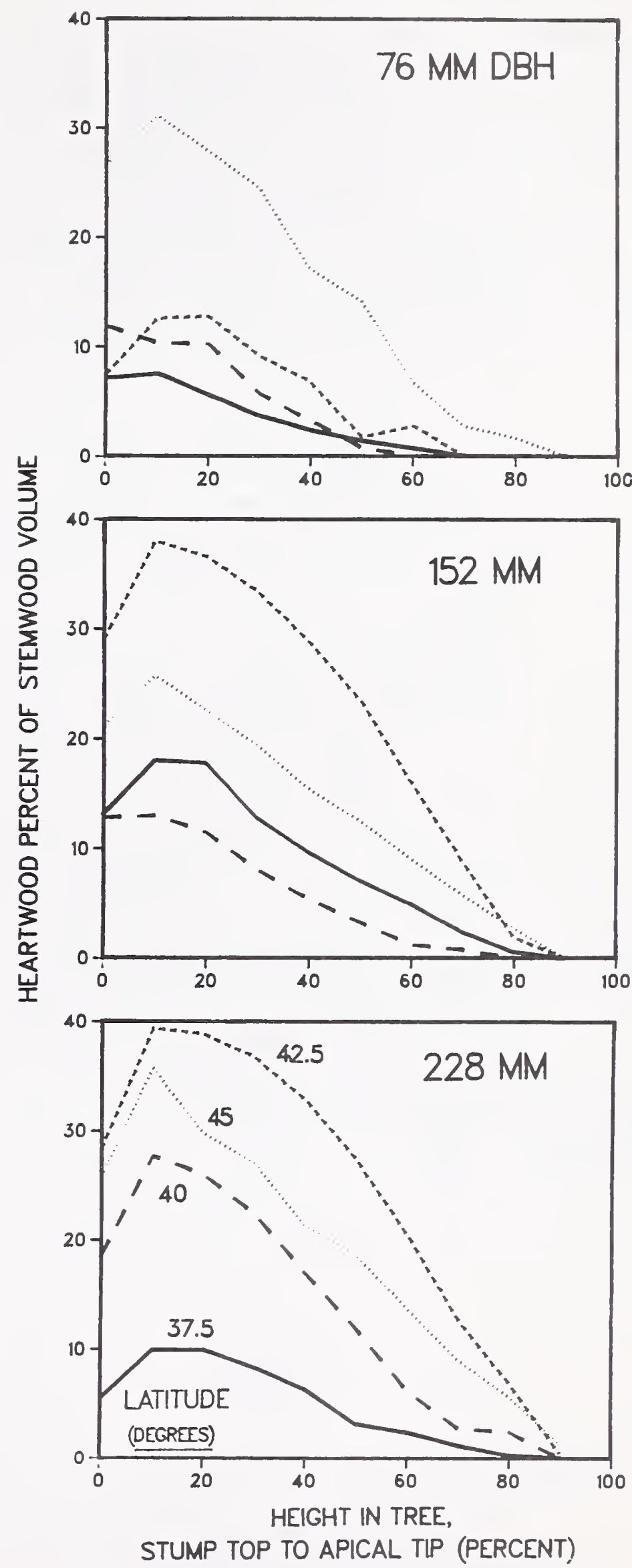

Figure 5-42-Heartwood as percentage of stemwood volume in murrayana trees of three diameters, related to height in tree and latitude. 


\section{Moisture Content of Entire Stemwood Component}

Sapwood-Sapwood moisture content averaged 125.1 percent, with standard deviation of 21.2 percent. Sapwood moisture content was not significantly related to latitude, but had positive significant correlation with diameter, averaging 104.5 (15.5), 128.5 (14.4), and 142.3 (13.3) percent for trees 76,152 , and $228 \mathrm{~mm}$ in d.b.h.

Heartwood-The moisture content of entire heartwood averaged 44.4 percent, with standard deviation of 5.8 percent. Moisture content of heartwood was negatively correlated with latitude, averaging 49.0 percent at 37.5 degrees and only 41.1 percent at 45 degrees (fig. 5-43).

\section{MURRAYANA}

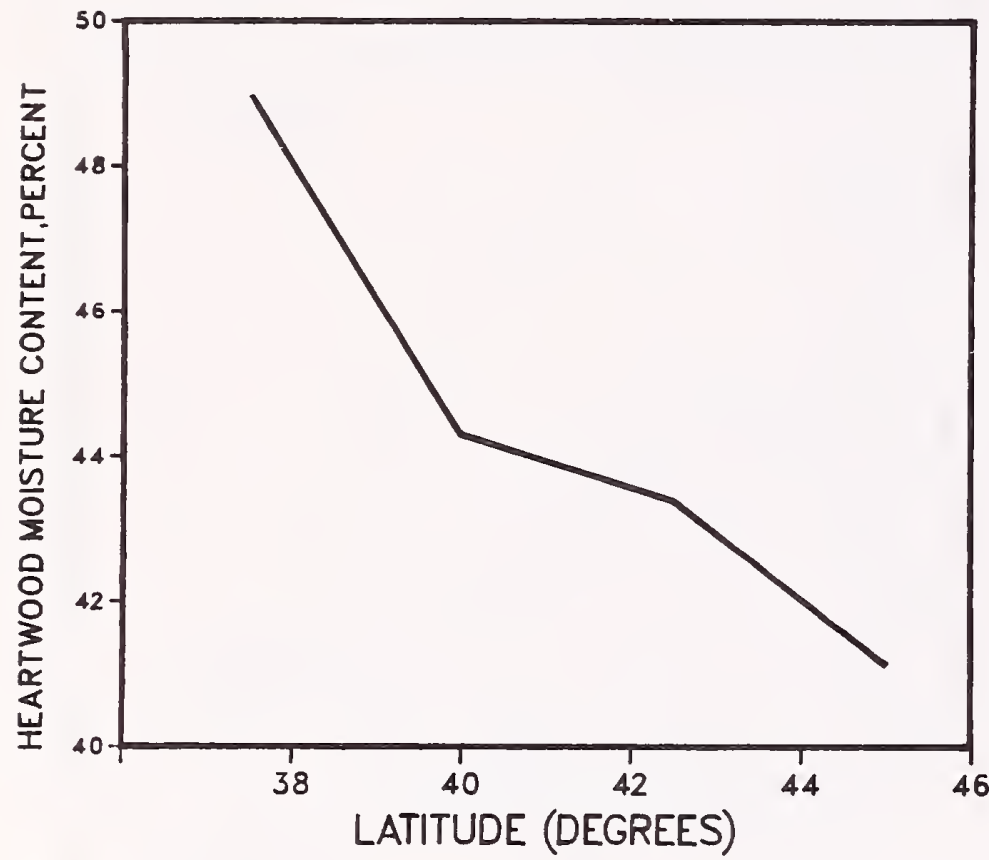

Figure 5-43-Heartwood moisture content in murrayana trees, related to latitude (diameter data pooled)
Although not significantly correlated with diameter, the following tabulation is of interest:

$\begin{array}{rcc}\text { D.b.h. } & \begin{array}{c}\text { Average } \\ \text { moisture content }\end{array} & \begin{array}{c}\text { Standard } \\ \text { deviation }\end{array} \\ m m & \ldots \ldots \text { - . Percent } & \ldots \ldots \\ 76 & 47.1 & 6.5 \\ 152 & 43.7 & 3.0 \\ 228 & 42.6 & 6.7\end{array}$

\section{Moisture Content of Sapwood by Level}

Moisture content of sapwood increased more or less linearly from stump height to about 80 percent of tree height and was positively correlated with d.b.h. at all heights (table 5-2 and fig. 5-44).

\section{MURRAYANA}

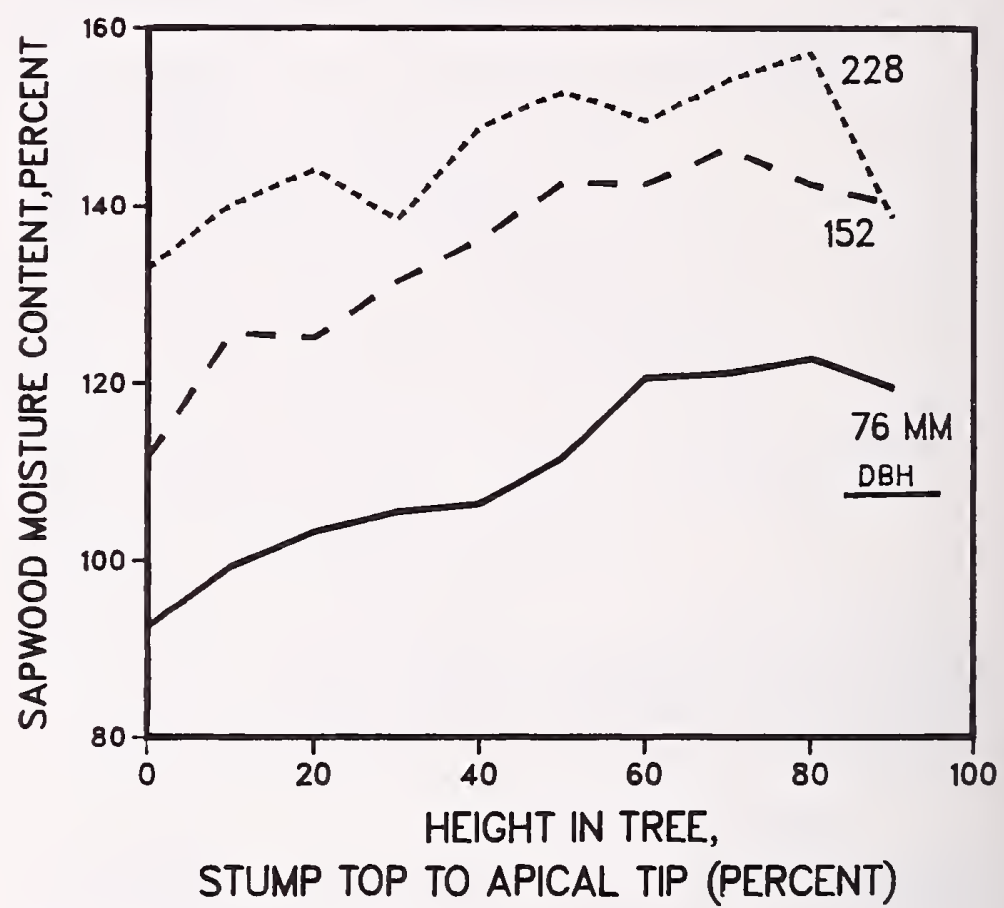

Figure 5-44-Sapwood moisture content in murrayana trees of three diameters, related to height in tree. 


\section{Moisture Content of Heartwood by Level}

Moisture content of heartwood, although positively correlated with height in stem, varied much less with height than moisture content of sapwood (table 5-2 and fig. 5-45). Heartwood moisture content was inversely correlated with latitude at most heights (fig. 5-45).
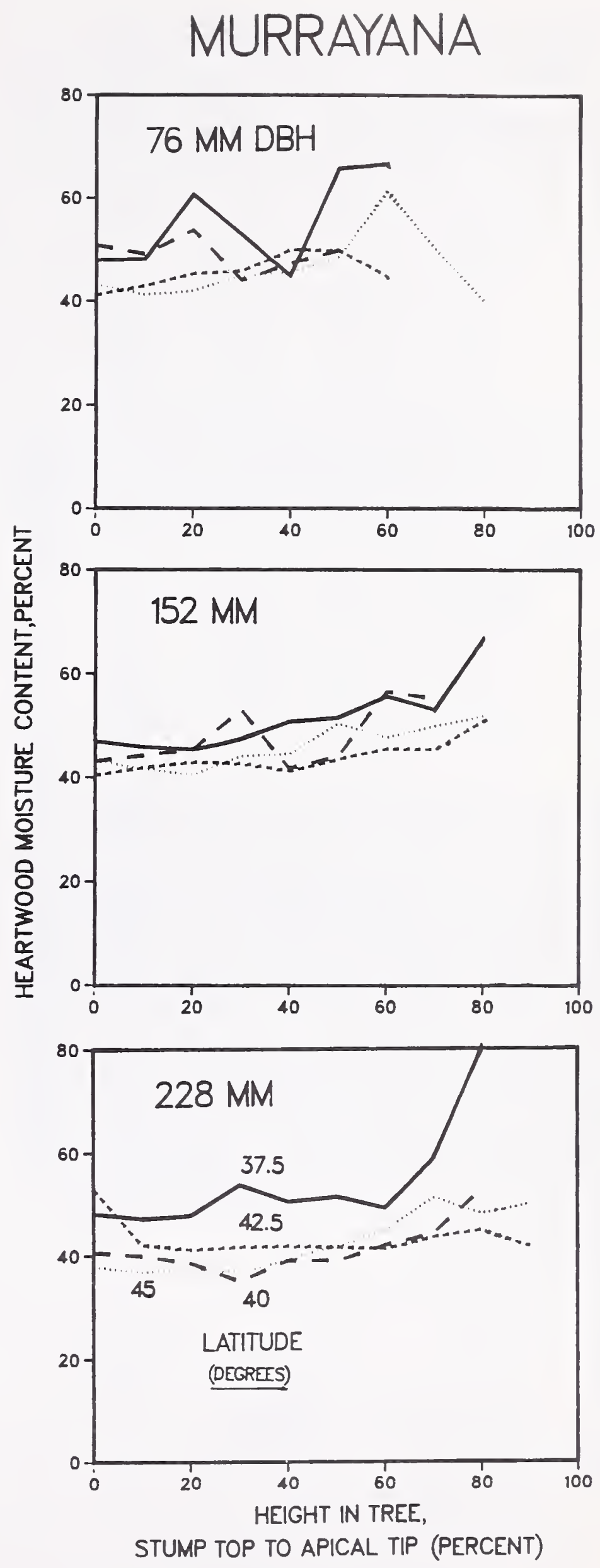

Figure 5-45-Heartwood moisture content in murrayana trees of three diameters, related to height in tree and latitude. 


\section{Weight of Sapwood in Entire Stem}

Green-Green sapwood weight was positively correlated with d.b.h., averaging 13.60 (3.48), 88.54 (25.48), and $253.53(60.56) \mathrm{kg}$ for trees of the three diameter classes. Green sapwood weight was not significantly correlated to latitude; values were as follows:

$\begin{array}{cccc}\text { Latitude } & \mathbf{7 6} \mathbf{~ m m} & \mathbf{1 5 2} \mathbf{~ m m} & \mathbf{2 2 8} \mathbf{~ m m} \\ \text { Degrees } & \ldots \ldots & \text { Kilograms } & \ldots . . \\ 37.5 & 12.74 & 61.18 & 238.41 \\ 40 & 13.85 & 89.66 & 256.80 \\ 42.5 & 13.97 & 103.02 & 260.12 \\ 45 & 13.83 & 100.29 & 258.78\end{array}$

Ovendry-Similarly, sapwood ovendry weight was positively correlated with diameter, averaging 6.74 (1.75), $39.00(11.72)$, and 105.30 (26.76) $\mathrm{kg}$ for trees 76,152 , and $228 \mathrm{~mm}$ in d.b.h. Ovendry weights of sapwood were not significantly correlated with latitude; values were as follows:

\begin{tabular}{|c|c|c|c|}
\hline Latitude & $76 \mathrm{~mm}$ & $152 \mathrm{~mm}$ & $228 \mathrm{~mm}$ \\
\hline Degrees & \multicolumn{3}{|c|}{$\ldots \ldots$ Kilograms ........ } \\
\hline 37.5 & 6.32 & 26.29 & 92.71 \\
\hline 40 & 7.12 & 38.74 & 105.80 \\
\hline 42.5 & 6.51 & 45.06 & 109.69 \\
\hline 45 & 7.01 & 45.91 & 113.01 \\
\hline
\end{tabular}

\section{Weight of Heartwood in Entire Stem}

Green-It was noted in chapter 4 that although heartwood specific gravity averaged least at 42.5 degrees latitude, weight of green heartwood was greatest at this latitude (fig. 4-124, top). Heartwood green weight was positively correlated with d.b.h. at all latitudes, averaging 1.38 (1.42), 14.88 (12.87), and $45.28(29.60) \mathrm{kg}$ for trees of the three diameter classes.

Ovendry-On an ovendry-weight basis, latitudinal and diameter trends were similar (fig. 4-124, bottom), with heartwood weights for trees of the three diameter classes averaging $0.95(0.99), 10.46(9.10)$, and $32.25(21.55) \mathrm{kg}$. From the large standard deviations in dry heartwood weight it is evident that trees varied greatly in their heartwood content.

\section{Heartwood as Percentage of Weight of Entire Stemwood}

Green-Green heartwood weight as percentage of entire green stemwood averaged $6.2,9.0,16.2$, and 16.6 percent at latitudes $37.5,40,42.5$, and 45 degrees (diameter data pooled), and was generally positively correlated with diameter, averaging $8.8(9.6), 12.9(9.2)$, and $14.3(7.3)$ percent for trees 76, 152, and $228 \mathrm{~mm}$ in d.b.h. (fig. 5-46).

Ovendry-Heartwood ovendry weight percent of stemwood averaged least (9.2 percent) at 37.5 degrees and most (23.2 percent) at 42.5 degrees latitude (fig. 4-125). The percentage was positively correlated with d.b.h., averaging 11.4 (11.1), 18.3 (11.9), and 21.5 (10.0) percent for trees of the three diameter classes.

\section{MURRAYANA}

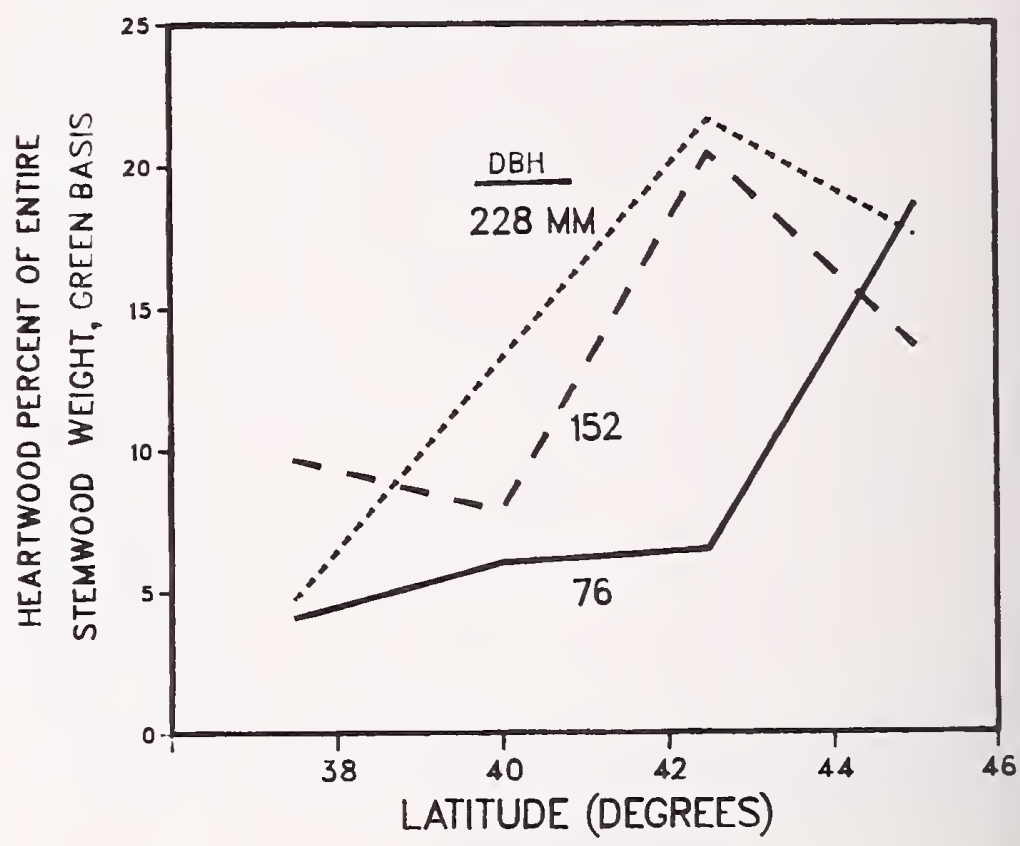

Figure 5-46-Green heartwood as percentage of entire green stemwood weight of murrayana trees of three diameters, related to latitude. 


\section{Heartwood as Percentage of Stemwood Weight by Level}

Green-At most heights in the tree, heartwood as percentage of green stemwood weight was unrelated to d.b.h., but was positively correlated with latitude; at 10 percent of tree height, heartwood as percentage of green weight averaged 9.4 percent at 37.5 degrees and 24.2 percent at 45 degrees. With diameter and latitudinal data pooled, it averaged 14.1 percent at stump height of $152 \mathrm{~mm}$, increased to 17.4 percent at 10 percent of tree height, and then decreased toward the apical tip (fig. 5-47 and table 5-2).

\section{MURRAYANA}

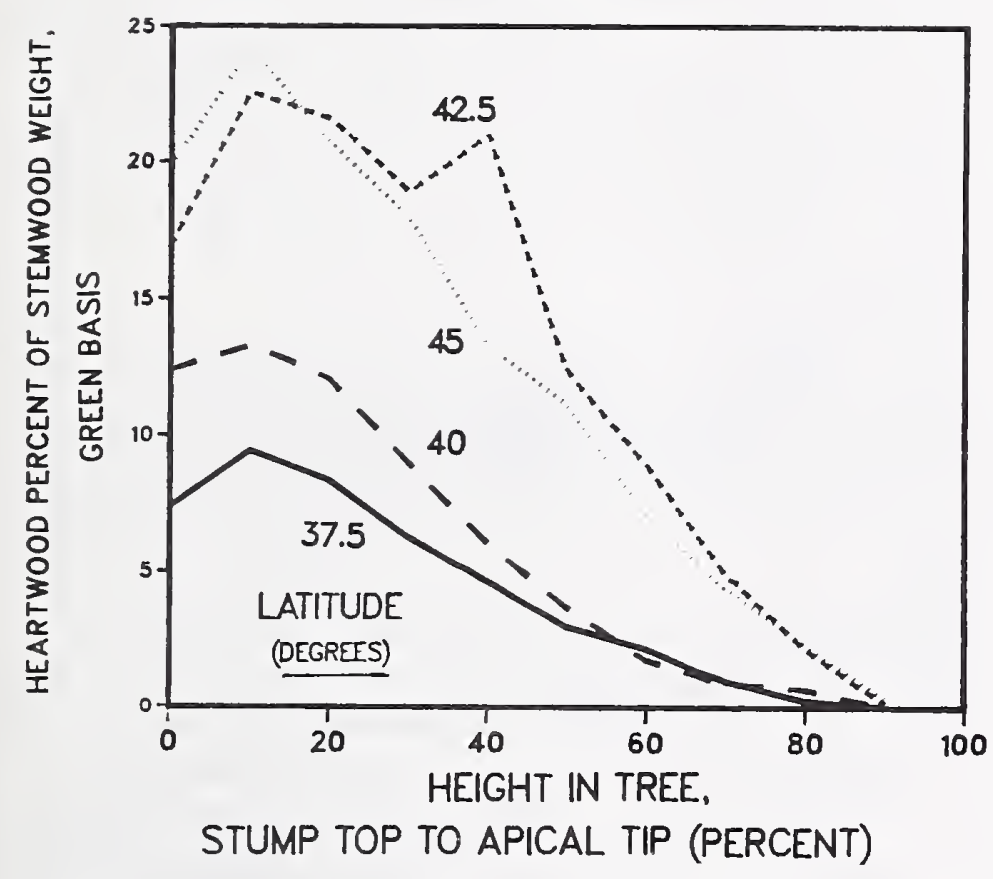

Figure 5-47-Green heartwood as percentage of green stemwood weight of murrayana trees of three diameters, related to height in tree and latitude.

Ovendry-On an ovendry weight basis, both d.b.h. and latitude were significant factors related to variation with height of heartwood as a percentage of stemwood weight (fig. 5-48). At all heights in the trees, heartwood ovendry weight as a percentage of stemwood was positively correlated with d.b.h., and at all levels, trees from latitudes 37.5 and 40 degrees had a lower percentage of heartwood in terms of ovendry-weight than those from latitudes 42.5 and 45 degrees. With latitudinal data pooled, heartwood ovendry weight as a percentage of stemwood averaged as follows (fig. 5-48 and table 5-2):

\begin{tabular}{|c|c|c|c|}
\hline D.b.h. & $\begin{array}{c}\text { Stump height } \\
\text { of } 152 \mathrm{~mm}\end{array}$ & $\begin{array}{l}10 \text { percent } \\
\text { height }\end{array}$ & $\begin{array}{l}80 \text { percent } \\
\text { height }\end{array}$ \\
\hline $\mathrm{mm}$ & $\cdots$ & Percent - - & - . . . . \\
\hline 76 & 14.3 & 16.8 & 0.4 \\
\hline 152 & 20.7 & 25.0 & 1.5 \\
\hline 228 & 21.6 & 29.4 & 4.4 \\
\hline
\end{tabular}

MURRAYANA
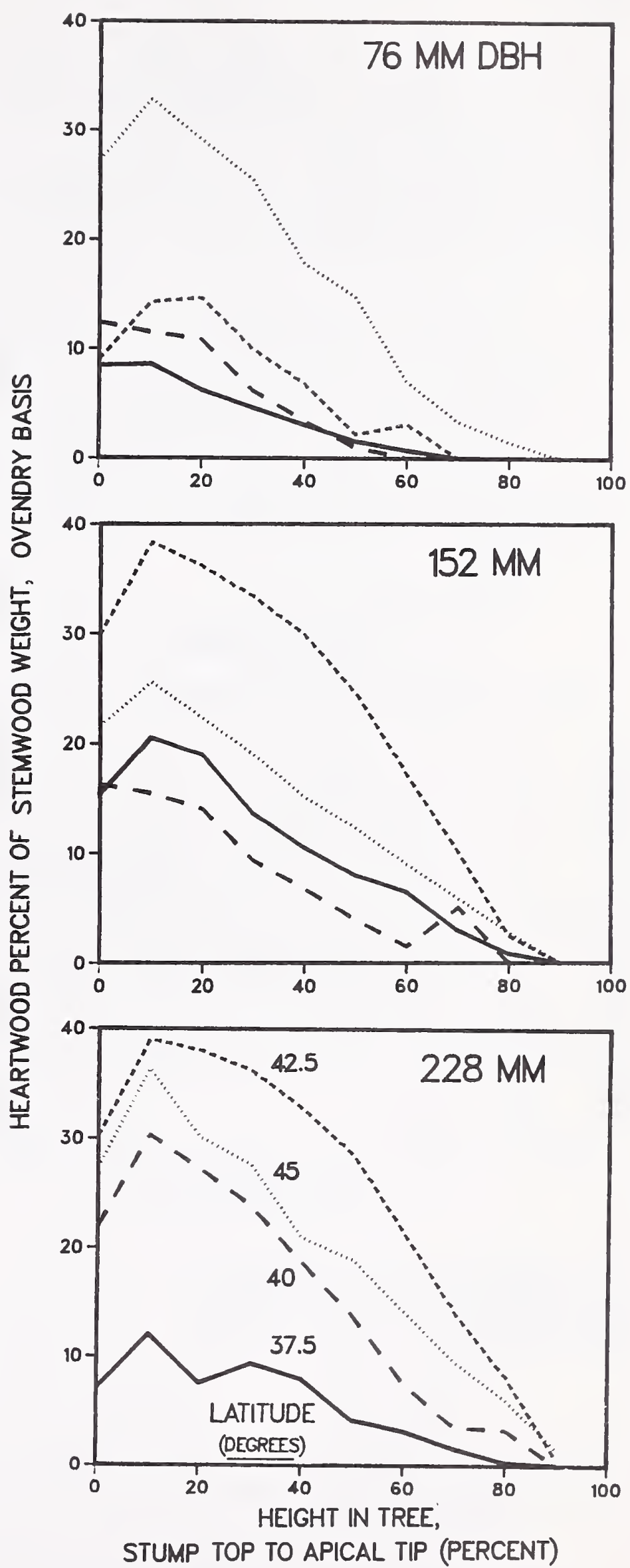

Figure 5-48-Ovendry heartwood as percentage of ovendry stemwood weight of murrayana trees of three diameters, related to height in tree and latitude. 


\section{Specific Gravity of Sapwood in Entire Stem}

As noted in chapter 4, sapwood specific gravity of the 152- and 228-mm trees (based on green volume and unextracted ovendry weight) averaged significantly less in the south than in the north (fig. 4-123, top). Also, sapwood specific gravity was negatively correlated with d.b.h., averaging $0.476(0.038), 0.433(0.044)$, and $0.401(0.032)$ for trees 76,152 , and $228 \mathrm{~mm}$ in d.b.h. Overall average was 0.437 with standard deviation of 0.048 .

\section{Specific Gravity of Sapwood by Level}

At all heights in the trees, specific gravity of sapwood was inversely correlated with d.b.h. (fig. 5-49 and table 5-2). With all data pooled, specific gravity averaged greatest at stump height of $152 \mathrm{~mm}(0.479)$, and least at about 70 percent of tree height $(0.408)$. In general, sapwood specific gravity variation with height was unrelated to latitude.

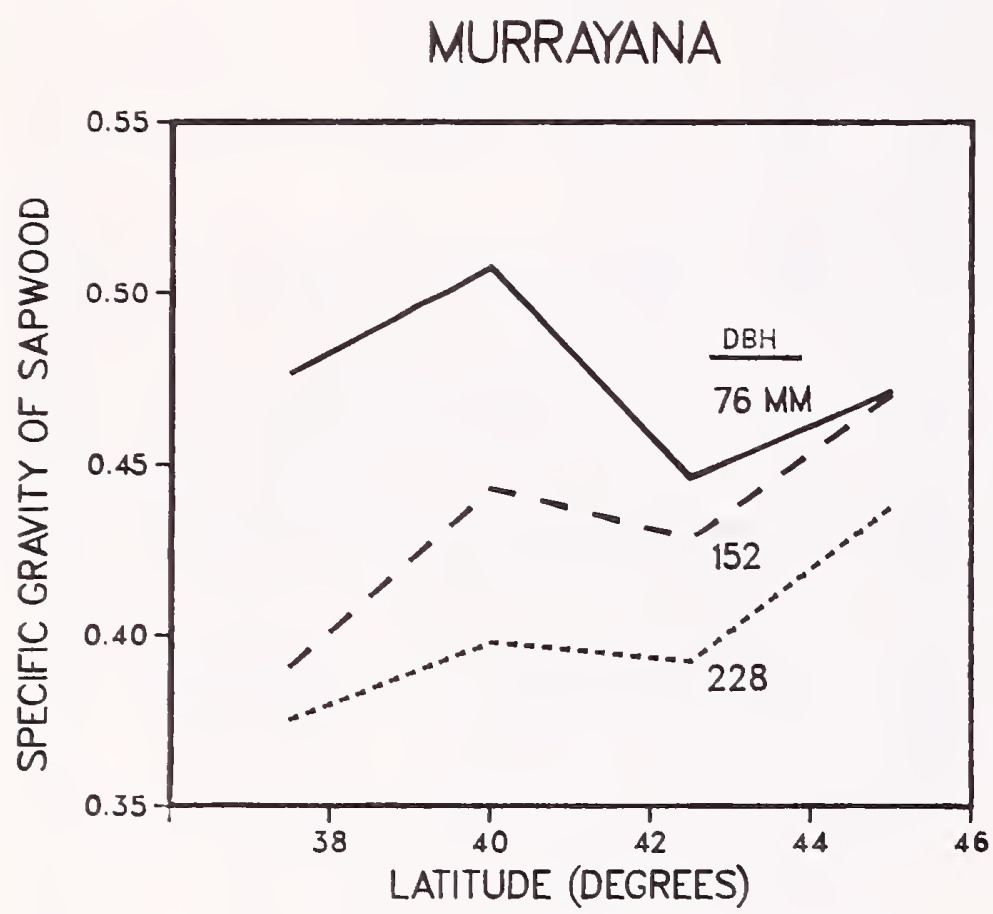

Figure 5-49-Specific gravity of sapwood (based on green volume and unextracted ovendry weight) of murrayana trees of three diameters, related to height in tree.
MURRAYANA
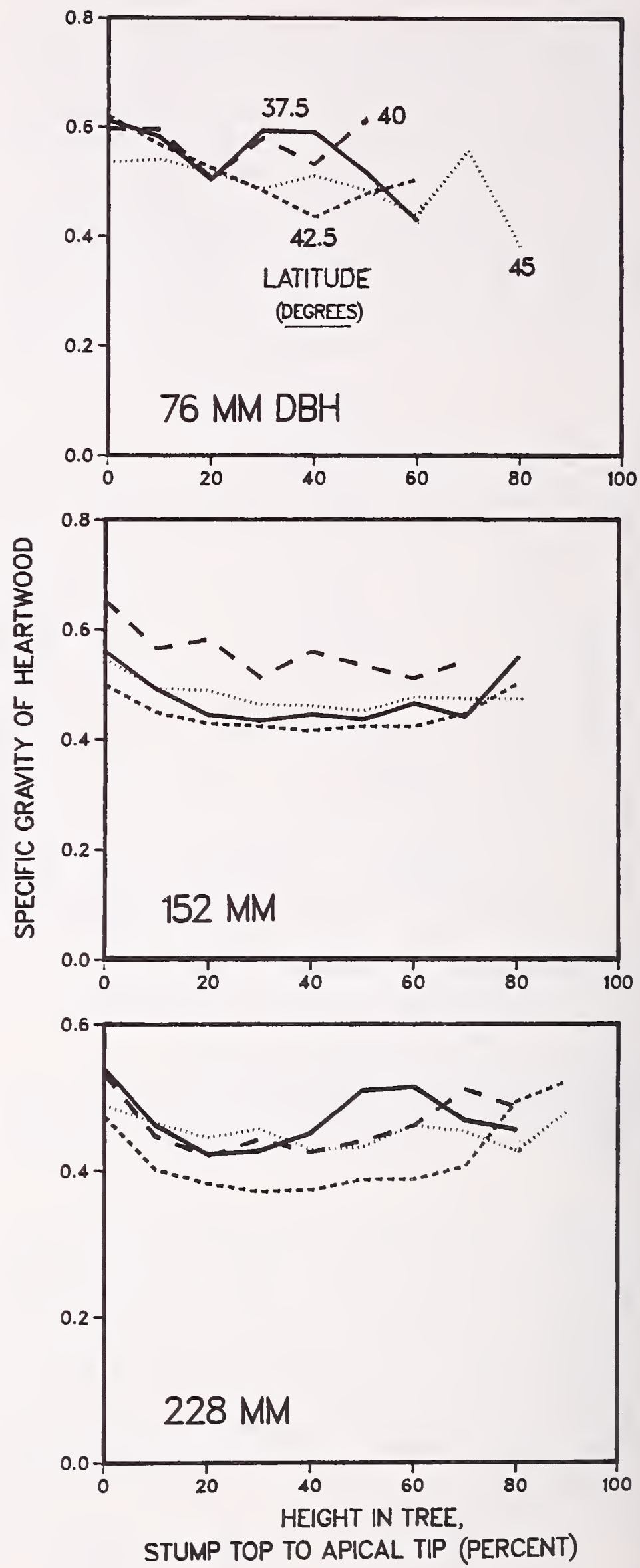

Figure 5-50-Specific gravity of heartwood (based on green volume and unextracted ovendry weight) of murrayana trees of three diameters, related to height in tree and latitude. 


\section{Specific Gravity of Heartwood in Entire Stem}

As noted in chapter 4, heartwood specific gravity, based on green volume and unextracted ovendry weight, averaged maximum (0.547) at 40 degrees and minimum (0.461) at 42.5 degrees (fig. $4-123$, bottom). It was negatively correlated with diameter, averaging $0.550(0.046), 0.508$ $(0.071)$, and $0.446(0.037)$ for trees 76,152 , and $228 \mathrm{~mm}$ in d.b.h. With all data pooled, heartwood specific gravity was greater than that of sapwood (probably because of a higher content of extractives), and averaged 0.502 , with standard deviation of 0.067 .

\section{Specific Gravity of Heartwood by Level}

Heartwood specific gravity varied less than that of sapwood with height in tree (figs. 5-49 and 5-50); it was maximum at stump height of $152 \mathrm{~mm}$ where it averaged 0.555 , and averaged minimum at 40 percent of tree height (0.461). In general, heartwood specific gravity at all heights was minimum at 42.5 degrees latitude (fig. 5-50). At all heights except 60 and 80 percent, heartwood specific gravity was inversely correlated with d.b.h. (table 5-2).

\section{5-7 RESULTS-LATIFOLIA COMPARED TO MURRAYANA WITHIN LATITUDINAL SAMPLING ZONES OF 40, 42.5, AND 45 DEGREES}

The following comparisons between varieties are limited to the three latitudinal sampling zones they have in common, namely $40,42.5$, and 45 degrees.

\section{Height Where Maximum Heartwood Diameter Occurs}

Proportion-In latifolia, maximum heartwood diameter occurred at an average of 8.5 percent of tree height; it averaged lower in murrayana (6.3 percent), but the relationship varied with both d.b.h. and latitude (fig. 5-51).
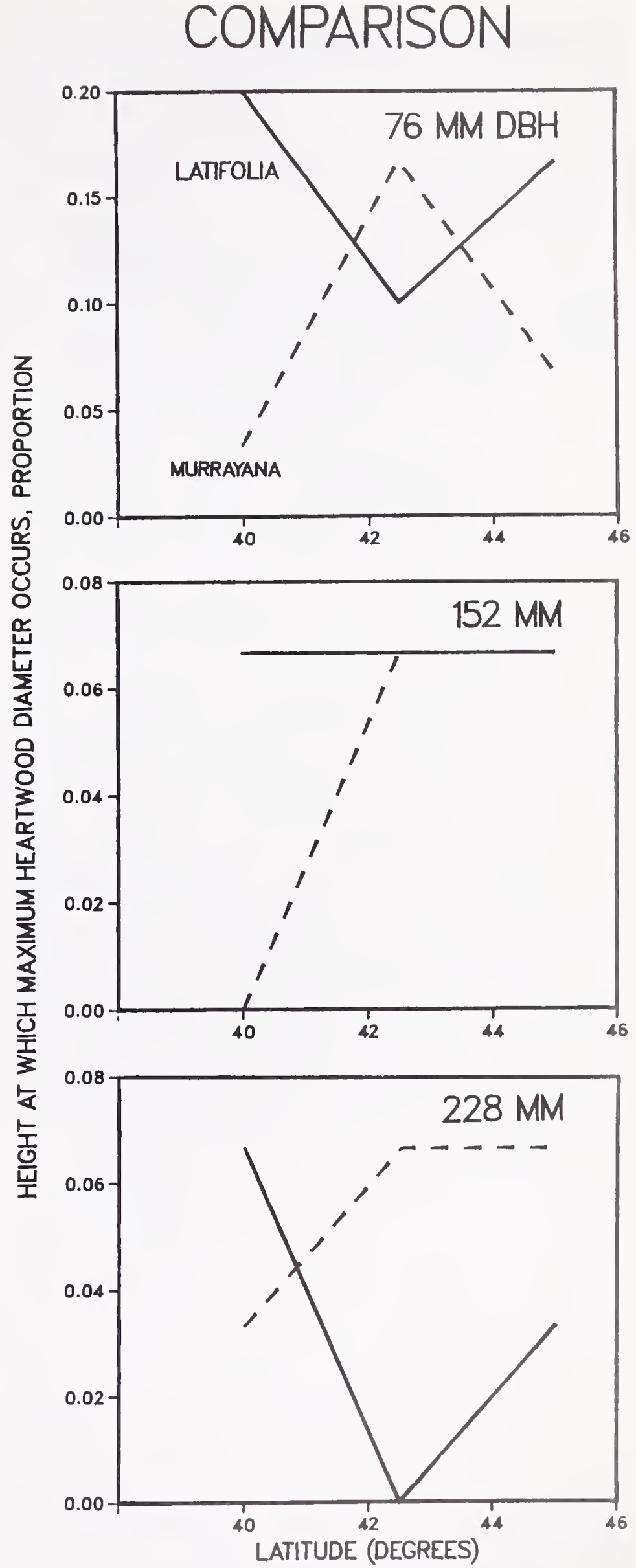

Figure 5-51_-Proportion of height at which maximum heartwood diameter occurs in latifolia and murrayana trees of three diameters, related to latitude. 
Meters-In latifolia, maximum heartwood diameter occurred at an average height of $1.01 \mathrm{~m}$ above stump top, while in murrayana, the average was $0.81 \mathrm{~m}$, but the relationship varied with d.b.h. and latitude (fig. 5-52).

\section{Heartwood Volume as Percentage of Stemwood Volume}

Although varietal differences were not statistically significant, the following heartwood volumes as percentages of stemwood volumes (averaged for the three latitudinal zones they have in common) are of interest:

$\begin{array}{rcc}\text { D.b.h. } & \text { Latifolia } & \text { Murrayana } \\ m m & \ldots \ldots \text {. . Percent } \ldots . . . \\ 76 & 14.8 & 12.2 \\ 152 & 21.4 & 18.4 \\ 228 & 30.1 & 24.9\end{array}$

COMPARISON

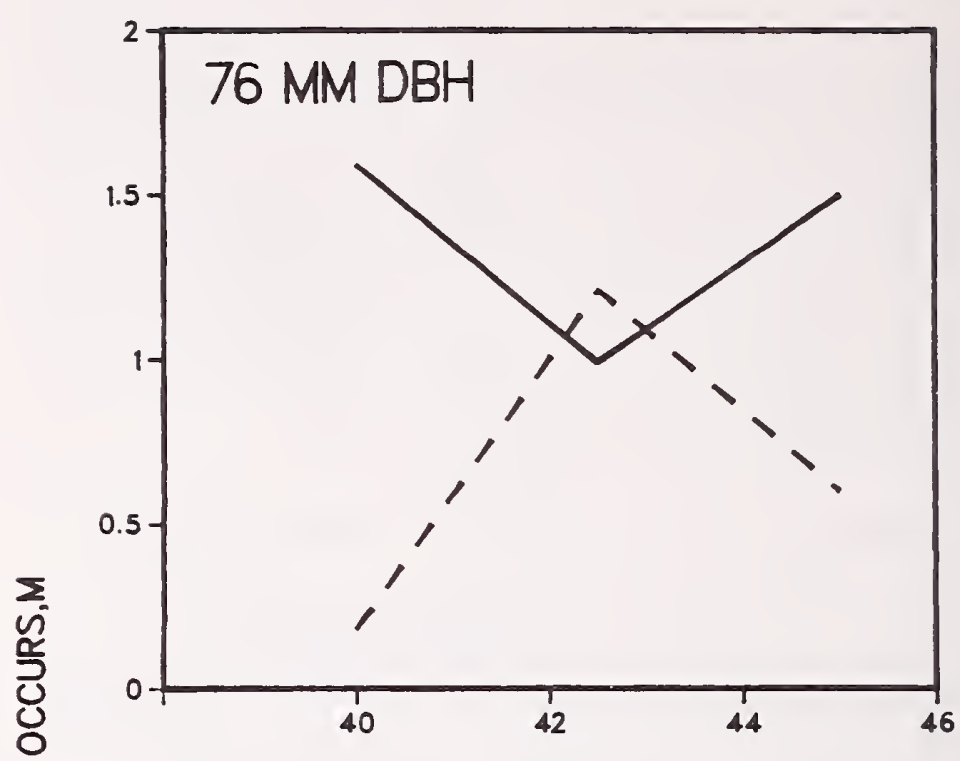

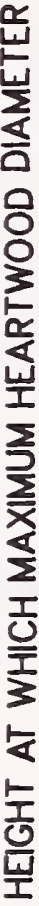
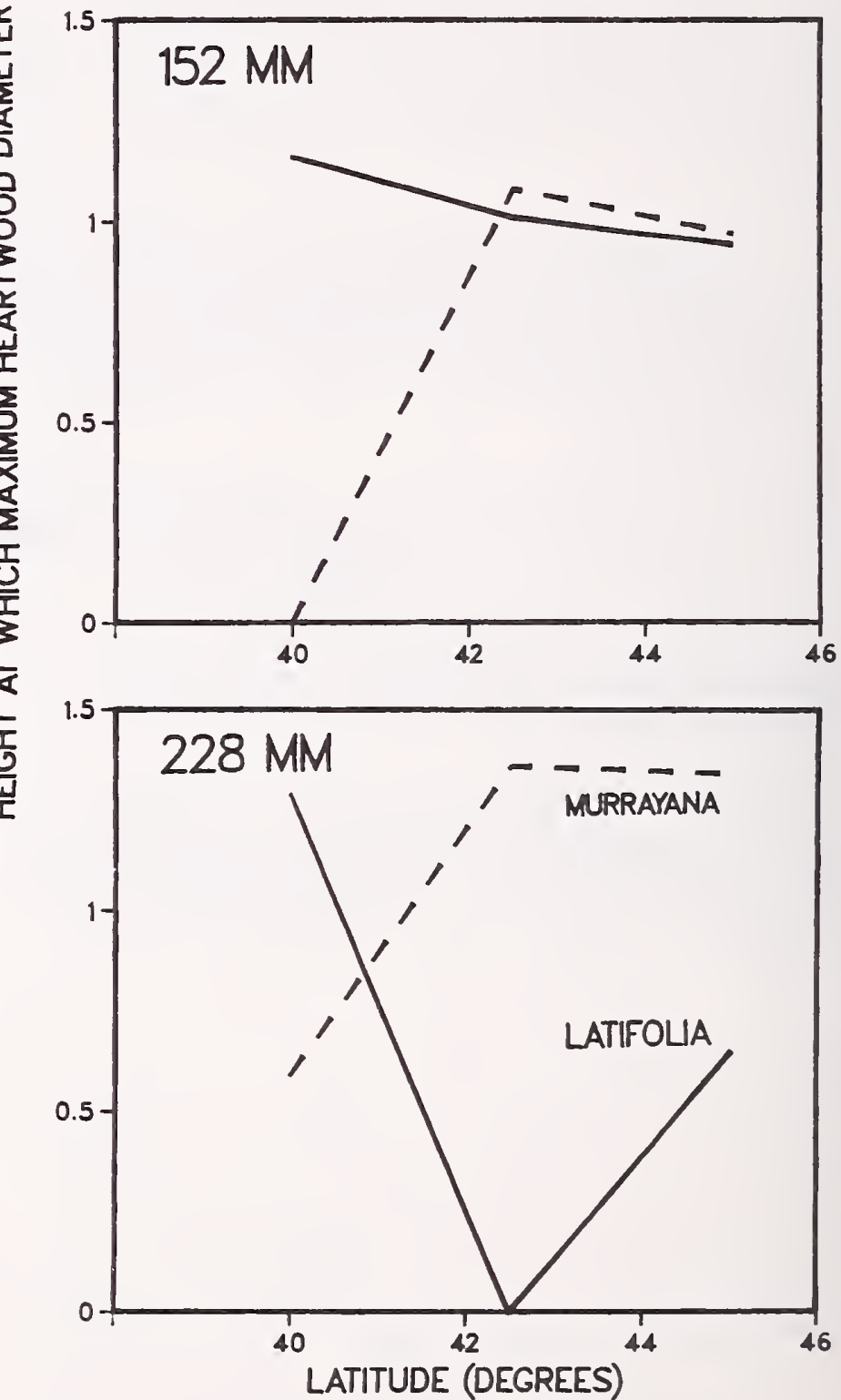

Figure 5-52-Height (meters) at which maximum heartwood diameter occurs in latifolia and murrayana trees of three diameters, related to latitude. 


\section{Specific Gravity of Sapwood}

Specific gravity of entire sapwood, based on green volume and unextracted ovendry weight, averaged significantly greater in murrayana $(0.444)$ than in latifolia (0.397); this relationship occurred in all three diameter classes (fig. 5-53).

At all heights in the trees murrayana had greater sapwood specific gravity than latifolia (fig. 5-54).

\section{COMPARISON}

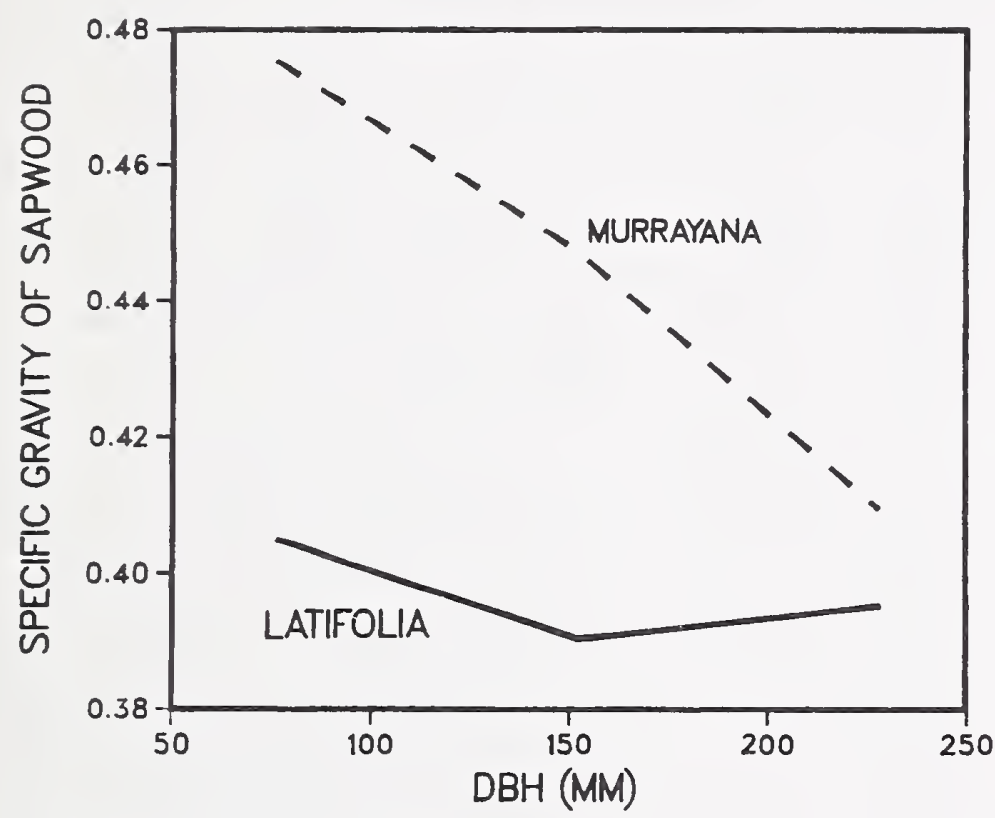

Figure 5-53-Specific gravity of sapwood of latifolia and murrayana trees related to d.b.h.; data from latitudes $40,42.5$, and 45 degrees pooled.
COMPARISON
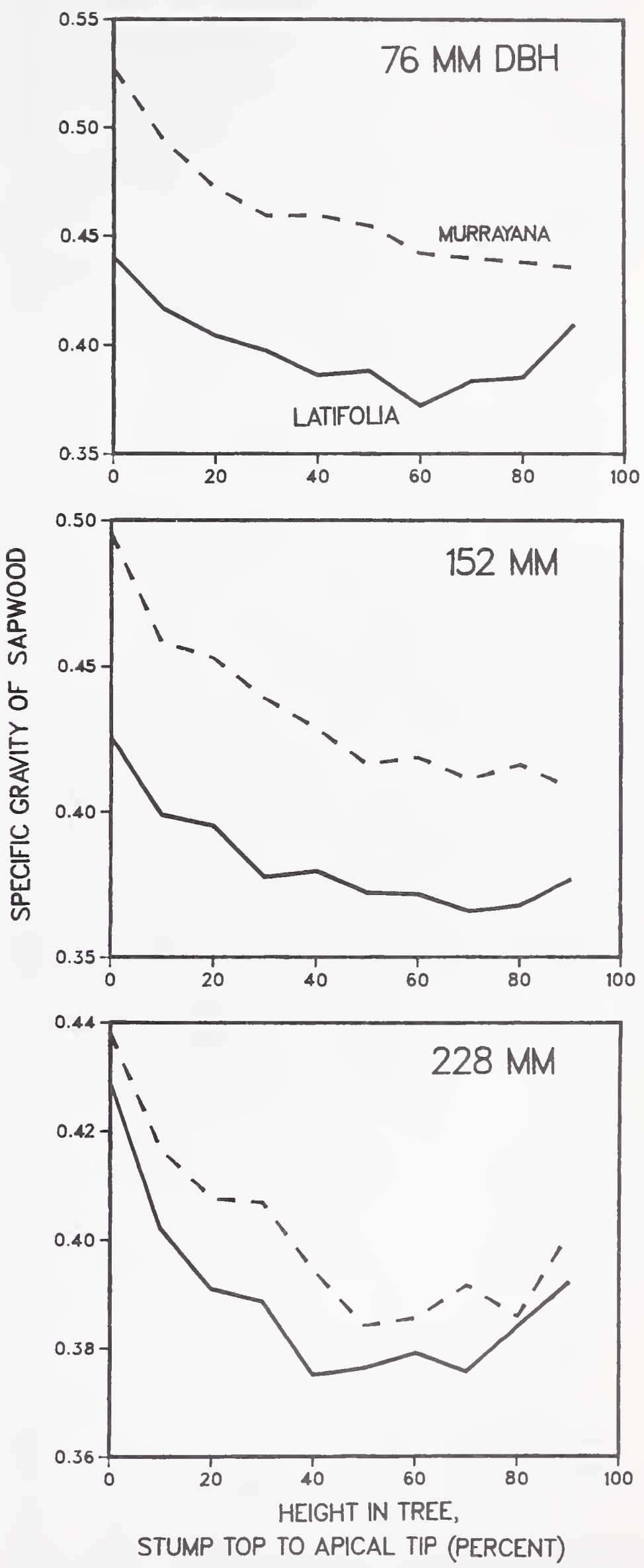

Figure 5-54-Specific gravity of sapwood of latifolia and murrayana trees of three diameters related to height in tree; data from latitudes 40 , 42.5 , and 45 degrees pooled. 


\section{COMPARISON}
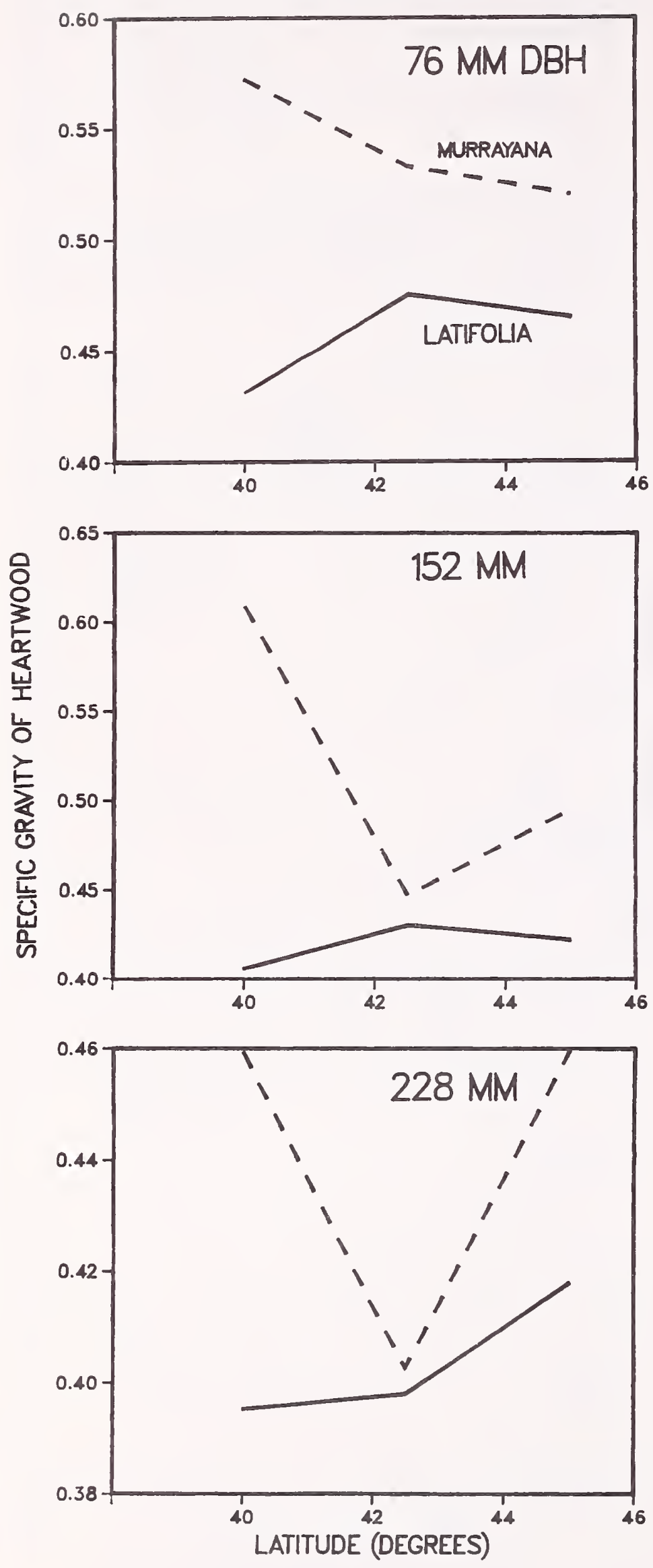

\section{Specific Gravity of Heartwood}

Specific gravity of entire heartwood, based on green volume and unextracted ovendry weight, also averaged significantly higher in murrayana (0.500) than in latifolia (0.427); this relationship occurred at all three latitudes and in all three diameter classes (fig. 5-55).

At all heights in the trees (except 80 percent in $76-\mathrm{mm}$ trees), heartwood specific gravity of murrayana significantly exceeded that of latifolia (fig. 5-56).

Figure 5-55-Specific gravity of heartwood of latifolia and murrayana trees of three diameters, related to latitude. 


\section{COMPARISON}
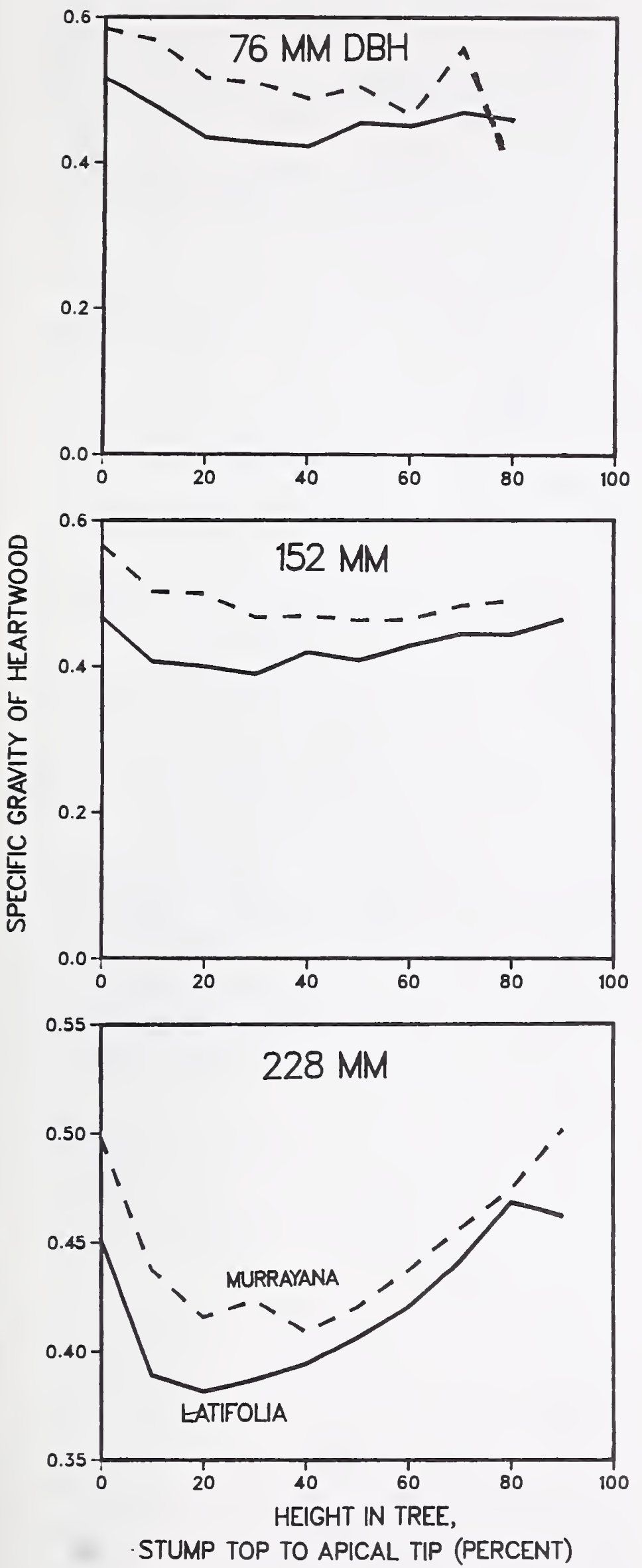

Figure 5-56-Specific gravity of heartwood of latifolia and murrayana trees of three diameters related to height in tree; data from latitudes 40 , 42.5 , and 45 degrees pooled.

\section{5-8 SUMMARY OF RESULTS}

In latifolia, the age of the lowest tree disk where heartwood did not occur averaged 21, 11, and 10 years in trees 76,152 , and $228 \mathrm{~mm}$ in d.b.h.; this age was also negatively correlated with latitude. The height of this lowest heartwood-free disk averaged 76,90 , and 94 percent in trees of the three diameters, and was positively correlated with latitude.

The height (above a stump height of $152 \mathrm{~mm}$ ) in latifolia at which maximum heartwood diameter occurred averaged $0.80,0.53$, and $0.44 \mathrm{~m}$ for trees 76,152 , and $228 \mathrm{~mm}$ in d.b.h.; this height was also negatively correlated with latitude. Heartwood as percentage of stem diameter at height of maximum heartwood diameter was positively correlated with latitude, and averaged 48, 54, and 60 percent for trees of the three diameter classes.

In latifolia, minimum sapwood thickness where heartwood was present averaged 16,24 , and $29 \mathrm{~mm}$ for trees 76,152 , and $228 \mathrm{~mm}$ in d.b.h.; trees in northern latitudes and middle- to upper-elevation zones (within latitudinal zones) had thinnest sapwood. This minimum sapwood thickness occurred at 51,60, and 70 percent of height in trees of the three diameter classes; the percent height was positively correlated with latitude. Sapwood thickness was maximum near ground level, diminished rapidly up to about 10 percent of tree height, remained more or less constant to about 70 percent of tree height, and finally diminished with approach to the apical tip. Sapwood was thinnest in northern latitudes.

Heartwood volume as a percentage of entire stemwood volume in latifolia averaged 22, 28, and 34 percent in trees 76,152 , and $228 \mathrm{~mm}$ in d.b.h.; heartwood volume percentages were positively correlated with latitude.

Sapwood moisture content in latifolia averaged 119 percent, with moisture contents of 110,122 , and 126 percent in trees 76,152 , and $228 \mathrm{~mm}$ in d.b.h.; it was negatively correlated with latitude. Sapwood moisture content was minimum in the lowest 10 percent of the stems (110 percent), increased more or less linearly to a maximum (136 percent) at about 80 percent of tree height, and then diminished slightly toward the apical tip.

Heartwood moisture content in latifolia averaged 43 percent, with moisture contents of 47,42 , and 41 percent in trees 76,152 , and $228 \mathrm{~mm}$ in d.b.h. Average heartwood moisture content was lowest (42 percent) at stump height of $152 \mathrm{~mm}$ and increased curvilinearly to a maximum (52 percent) at 90 percent of tree height.

Heartwood as a percentage of ovendry weight of entire latifolia stemwood averaged 23, 29, and 35 percent for trees 76,152 , and $228 \mathrm{~mm}$ in d.b.h.; these percentages were positively correlated with latitude.

Specific gravity of sapwood in entire stems (based on green volume and unextracted ovendry weight) averaged 0.414 , and was maximum at middle latitudes; it was 0.423 , 0.415 , and 0.405 in trees 76,152 , and $228 \mathrm{~mm}$ in d.b.h. Sapwood specific gravity averaged 0.449 at stump height, decreased to a minimum of 0.387 at 70 percent of tree height, and then increased to 0.399 at 90 percent of tree height.

Specific gravity of heartwood of entire latifolia stemwood averaged 0.434 ; it was $0.459,0.430$, and 0.412 in 
trees 76,152 , and $228 \mathrm{~mm}$ in d.b.h. With diameter data pooled, heartwood had average specific gravity of 0.482 at stump height of $152 \mathrm{~mm}$, decreased sharply to a minimum of 0.412 at 30 percent of tree height, and then increased to a near maximum $(0.478)$ at 90 percent.

In the three latitudinal sampling zones common to the two varieties (40,42.5, and 45 degrees), some significant differences were observed between latifolia and murrayana. In latifolia, maximum heartwood diameter occurred at an average of 8.5 percent of tree height $(1.01 \mathrm{~m}$ above stump top); it averaged lower in murrayana (6.3 percent and $0.81 \mathrm{~m}$ ). Specific gravity of entire sapwood averaged significantly higher in murrayana (0.444) than in latifolia (0.397); at all heights in trees, murrayana had greater sapwood specific gravity than latifolia. Specific gravity of heartwood also averaged significantly higher in murrayana (0.500) than in latifolia $(0.427)$; this relationship applied to all latitudes, diameters, and heights in trees.

\section{5-9 REFERENCES}

Alexander, J. B. The strength of lodgepole pine telephone poles. Forest Service Circular 42. Ottawa, ON: Department of the Interior, Canada, Forest Service, Forest Products Laboratories; 1934. 14 p.

Anderson, Arthur B.; Riffer, Richard; Wong, Addie. Monoterpenes, fatty and resin acids of Pinus contorta and Pinus attenuata. Phytochemistry. 8(12): 2401-2403; 1969.

Ballard, R. G.; Walsh, M. A.; Cole, W. E. The penetration and growth of blue-stain fungi in the sapwood of lodgepole pine attacked by mountain pine beetle. Canadian Journal of Botany. 62(8): 1724-1729; 1984.

Bourchier, R. J. Laboratory studies on microfungi isolated from the stems of living lodgepole pine, Pinus contorta Dougl. Canadian Journal of Botany. 39(6): 1373-1385; 1961a.

Bourchier, R. J. Two new imperfect fungi from the heartwood of living lodgepole pine. Canadian Journal of Botany. 39(7): 1781-1784; 1961 b.

Brazier, J. D. A report on the effects of provenance on the timber properties of lodgepole pine. In: Pinus contorta as an exotic species: proceedings, IUFRO working party meeting on Pinus contorta provenances (S2-02-06) in Norway and Sweden. Research Note 30. Garpenberg, Sweden: Swedish University of Agricultural Sciences, Department of Forest Genetics; 1980: 181-207.

Cooper, P. A. Effect of species, precompression, and seasoning on heartwood preservative treatability of six western conifers. Forest Products Journal. 23(7): 51-59; 1973.

Cooper, P. A.; Bramhall, G.; Ross, N. A. Estimating preservative treatability of wood from its air-flow properties. Forest Products Journal. 24(9): 99-103; 1974.

Denyer, W. B. G. Red stain in lodgepole pine in Alberta. Bi-monthly Progress Report. 8(2): 3-4; 1952.

Eades, H. W.; Roff, J. W. Red heart stain of lodgepole pine logs in the northern interior of British Columbia. V-1023. Vancouver, BC: Department of Northern Affairs and National Resources, Forestry Branch, Forest Prod- ucts Laboratories of Canada, Vancouver Laboratory; 1957. $14 \mathrm{p}$.

Eades, H. W.; Roff, J. W. Red heart stain of lodgepole pine logs in the southern interior of British Columbia. V-1025. Vancouver, BC: Department of Northern Affairs and National Resources, Forestry Branch, Forest Products Laboratories of Canada, Vancouver Laboratory; 1959. $11 \mathrm{p}$.

Englerth, George H.; Scheffer, Theodore S. Tests of decay resistance of four western pole species. Journal of Forestry. 53(8): 556-561; 1955.

Erdtman, Holger. Heartwood extractives of conifers. Tappi. 32(7): 305-310; 1949.

Eslyn, W.E. Utillity pole decay, part 3: detection in pine by color indicators. Wood Science Technology. 13: 117-126; 1979

Fosberg, Michael A. Drying rates of heartwood below fiber saturation. Forest Science. 16(1): 57-63; 1970.

Graham, R. D. The preservative treatment of eight Oregon conifers by pressure processes. Proceedings of the American Wood-Preservation Association. 52: 118-139; 1956.

Hakkila, Pentti; Panhelainen, Arja. On the wood properties of Pinus contorta in Finland. Communicationes Instituti Forestalis Fenniae. 73(1): 1970. 43 p.

Harris, J. Maddern. The use of beta rays in determining wood properties-part 5: measuring resin content. New Zealand Journal of Science. 12(2): 443-451; 1969.

Harris, J. Maddern. Physical properties, resin content, and tracheid length of lodgepole pine grown in New Zealand. New Zealand Journal of Forest Science. 3(1): 91-109; 1973.

Kaufmann, Merrill R.; Troendle, Charles A. The relationship of leaf area and foliage biomass to sapwood conducting area in four subalpine forest tree species. Forest Science. 27(3): 477-482; 1981.

Lassen, L. E.; Okkonen, E. A. Sapwood thickness of Douglas-fir and five other western softwoods. Research Paper FPL 124. Madison, WI: U.S. Department of Agriculture, Forest Service, Forest Products Laboratory; 1969. $16 \mathrm{p}$.

Lieu, Peter J.; Kelsey, Rick G.; Shafizadeh, Fred. Some chemical characteristics of green and dead lodgepole pine and western white pine. Research Note INT-256. Ogden, UT: U.S. Department of Agriculture, Forest Service, Intermountain Forest and Range Experiment Station; 1979. 8 p.

Lindstedt, Gösta. Constituents of pine heartwood: IX. The heartwood of Pinus montana Mill. X. The heartwood of Pinus contorta var. latifolia S. Wats. XI. The heartwood of Pinus radiata D. Don. XII. The heartwood of Pinus ponderosa Dougl. XIII. The heartwood of Pinus jeffreyi Balf. Acta Chem. Scand. 3(7): 755-772; 1949.

Loman, A. A. The effect of heartwood fungi of lodgepole on its phenolic heartwood extractives. In: Shigo, Alex L., chairman. Interaction of organisms in the process of decay of forest trees: symposium. Bulletin 13. Quebec, Canada: Laval University Research Foundation; 1970a: 39-43.

Loman, A. A. The effect of heartwood fungi of Pinus contorta var. latifolia on pinosylvin, pinosylvinmonomethyl 
ether, pinobanksin, and pinocembrin. Canadian Journal of Botany. 48: 737-747; 1970b.

Loman, A. A.; Paul, G. D. Decay of lodgepole pine in two foothills sections of the Boreal Forest in Alberta.

Forestry Chronicle. 39(4): 422-435; 1963.

Lopushinsky, William. Water relations and photosynthesis in lodgepole pine. In: Baumgartner, David M., ed. Management of lodgepole pine ecosystems: symposium proceedings; 1973 October 9-11; Pullman, WA. Pullman, WA: Washington State University, Cooperative Extension Service, College of Agriculture; 1975: 135-153. (vol. 1).

Lowery, David P.; Rasmussen, E. F. Accelerated drying of lodgepole pine and western larch poles. Forest Products Journal. 13(6): 221-226; 1965.

Markstrom, Donald C.; Hann, Robert A. Seasonal variation in wood permeability and stem moisture content of three Rocky Mountain softwoods. Research Note RM-212. Fort Collins, CO: U.S. Department of Agriculture, Forest Service, Rocky Mountain Forest and Range Experiment Station; 1972. 7 p.

Markstrom, Donald C.; Mueller, Lincoln A.; Gjovik, Lee R. Treating resistant Rocky Mountain species by regular and modified double-diffusion methods. Forest Products Journal. 20(12): 17-20; 1970.

Meyer, R. W. Effect of enzyme treatment on bordered-pit ultrastructure, permeability, and toughness of the sapwood of three western conifers. Wood Science. 6(3): 220-230; 1974.

Owston, Peyton W.; Smith, James L.; Halverson, Howard G. Seasonal water movement in tree stems. Forest Science. 18(4): 266-272; 1972.

Pearson, John Allan. Biomass distribution and ecosystem development in lodgepole pine forests of the Medicine Bow Mountains, Wyoming. Laramie, WY: University of Wyoming; 1982. 113 p. Ph.D. dissertation.

Reid, R. W. Moisture changes in lodgepole pine before and after attack by the mountain pine beetle. Forestry Chronicle. 37(4): 368-375, 403; 1961.
Rickey, R. G.; Hergert, H. L. Reactions in pine heartwood during acid bisulfite pulping. Tappi. 57(7): 114-117; 1974.

Ruddick, John N. R. Treatability of lodgepole pine lumber with ACA and CCA. Forest Products Journal. 30(2): 28-32; 1980.

Running, Steven W. Relating plant capacitance to the water relations of Pinus contorta. Forest Ecology and Management. 2(4): 237-252; 1980.

Shrimpton, D. M. Variations in the extractives from lodgepole pine sapwood and heartwood. Information Report NOR-X-18. Edmonton, AB: Department of the Environment, Canadian Forestry Service, Northern Forest Research Centre; 1972. 22 p.

Shrimpton, D. M. Extractives associated with wound response of lodgepole pine attacked by the mountain pine beetle and associated microorganisms. Canadian Journal of Botany. 51(3): 527-534; 1973.

Sylvander, Robert B.; Smith, J. Harry G. Widths and specific gravity of earlywood and latewood components of annual rings from interior British Columbia lodgepole pine. Vancouver, BC: University of British Columbia, Faculty of Forestry; 1973.61 p.

Thompson, Dan C. Sapwood-leaf area relations in lodgepole pine in western Montana. In: Baumgartner, David M.; Krebill, Richard G.; Arnott, James T.; Weetman, Gordon F., eds. Lodgepole pine: the species and its management: symposium proceedings; 1984 May 8-10; Spokane, WA; 1984 May 14-16; Vancouver, BC. Pullman, WA: Office of Conferences and Institutes, Cooperative Extension; 1985: 380. Abstract.

Waring, R. H.; Schroeder, P. E.; Oren, R. Application of the pipe model theory to predict canopy leaf area. Canadian Journal of Forest Research. 12(3): 556-560; 1982.

Yang, Kung-Chi. Sapwood thickness in Pinus contorta Dougl. ex Loud. In: Baumgartner, David M.; Krebill, Richard G.; Arnott, James T.; Weetman, Gordon F., eds. Lodgepole pine: the species and its management: symposium proceedings; 1984 May 8-10; Spokane, WA; 1984 May 14-16; Vancouver, BC. Pullman, WA: Office of Conferences and Institutes, Cooperative Extension; 1985: 380. Abstract. 

Koch, Peter. 1987. Gross characteristics of lodgepole pine trees in North America. Gen. Tech. Rep. INT-227. Ogden. UT: U.S. Department of Agriculture, Forest Service, Intermountain Research Station. 311 p.

Presents gross characteristics of North American lodgepole pine (Pinus contorta) as an industrial raw material, based on analysis of complete-tree specimens collected from the full range of var. latifolia Engelm. in the United States and Canada, and var. murrayana (Grev. \& Balf.) Engelm. collected from Oregon and California. Compares and correlates with latitude, longitude, elevation, and tree diameter: general tree characteristics, dimensions, moisture contents, weights, cubic volumes, and stem taper; and specific gravity, weight, volume and moisture content of tree components, including heartwood and sapwood, foliage, and wood and bark of roots, stem, and branches. Properties of lodgepole pines vary significantly with latitude, elevation, diameter class, and variety.

KEYWORDS: lodgepole pine, Pinus contorta, timber utilization, tree characteristics, wood utilization, timber resource 


\section{INTERMOUNTAIN RESEARCH STATION}

The Intermountain Research Station provides scientific knowledge and technology to improve management, protection, and use of the forests and rangelands of the Intermountain West. Research is designed to meet the needs of National Forest managers, Federal and State agencies, industry, academic institutions, public and private organizations, and individuals. Results of research are made available through publications, symposia, workshops, training sessions, and personal contacts.

The Intermountain Research Station territory includes Montana, Idaho, Utah, Nevada, and western Wyoming. Eighty-five percent of the lands in the Station area, about 231 million acres, are classified as forest or rangeland. They include grasslands, deserts, shrublands, alpine areas, and forests. They provide fiber for forest industries, minerals and fossil fuels for energy and industrial development, water for domestic and industrial consumption, forage for livestock and wildlife, and recreation opportunities for millions of visitors.

Several Station units conduct research in additional western States, or have missions that are national or international in scope.

Station laboratories are located in:

Boise, Idaho

Bozeman, Montana (in cooperation with Montana State University)

Logan, Utah (in cooperation with Utah State University)

Missoula, Montana (in cooperation with the University of Montana)

Moscow, Idaho (in cooperation with the University of Idaho)

Ogden, Utah

Provo, Utah (in cooperation with Brigham Young University)

Reno, Nevada (in cooperation with the University of Nevada)

USDA policy prohibits discrimination because of race, color, national origin, sex, age, religion, or handicapping condition. Any person who believes he or she has been discriminated against in any USDA-related activity should immediately contact the Secretary of Agriculture, Washington, DC 20250.

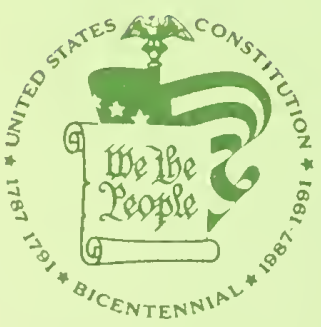

